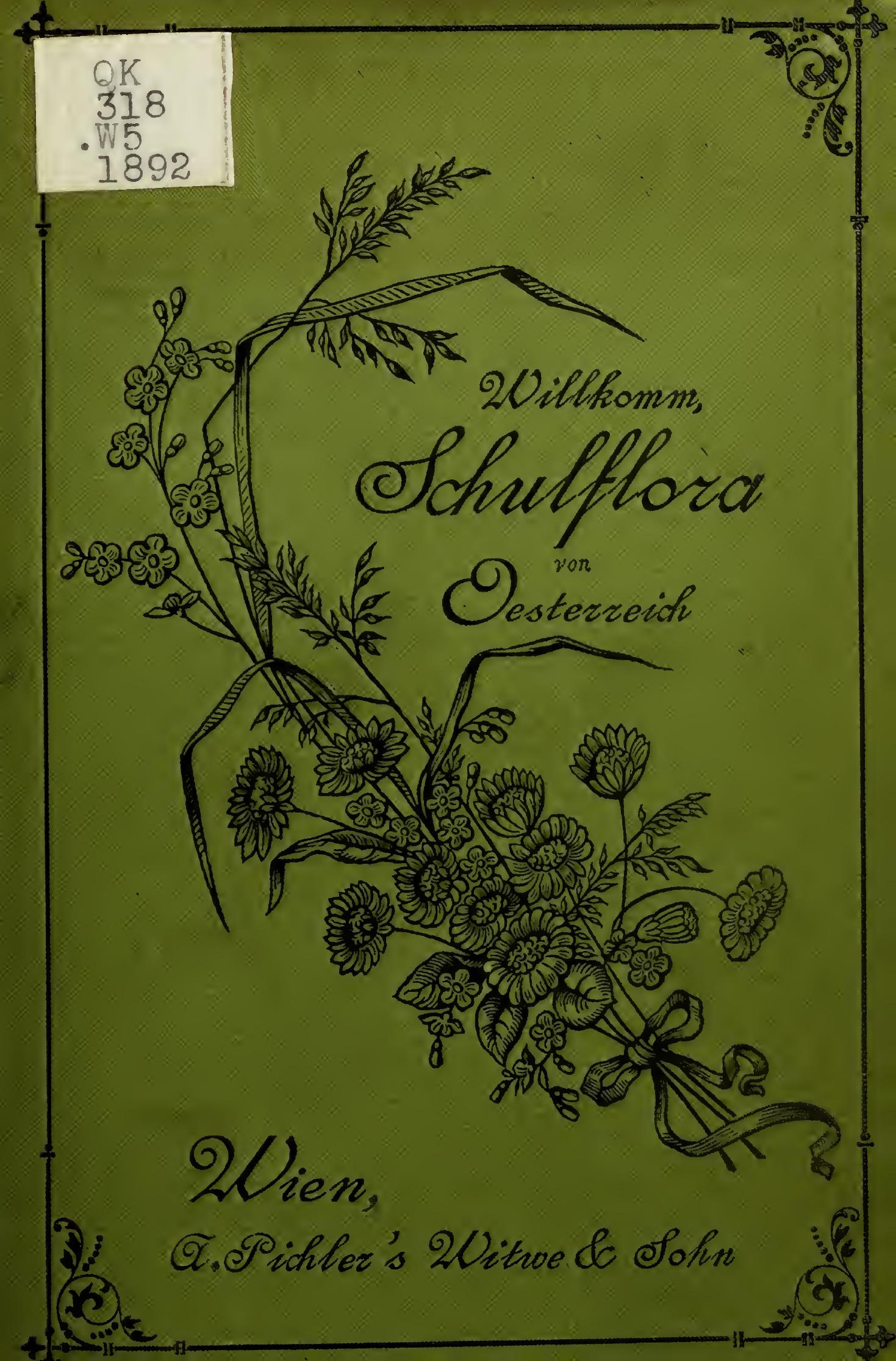


Verlag von A. Pichler's Witwe \& Sohn, Wien und Leipzig.

\section{Illustriertes}

\section{Schmetterlingsbuch.}

Beschreibung der am häufigsten gesammelten

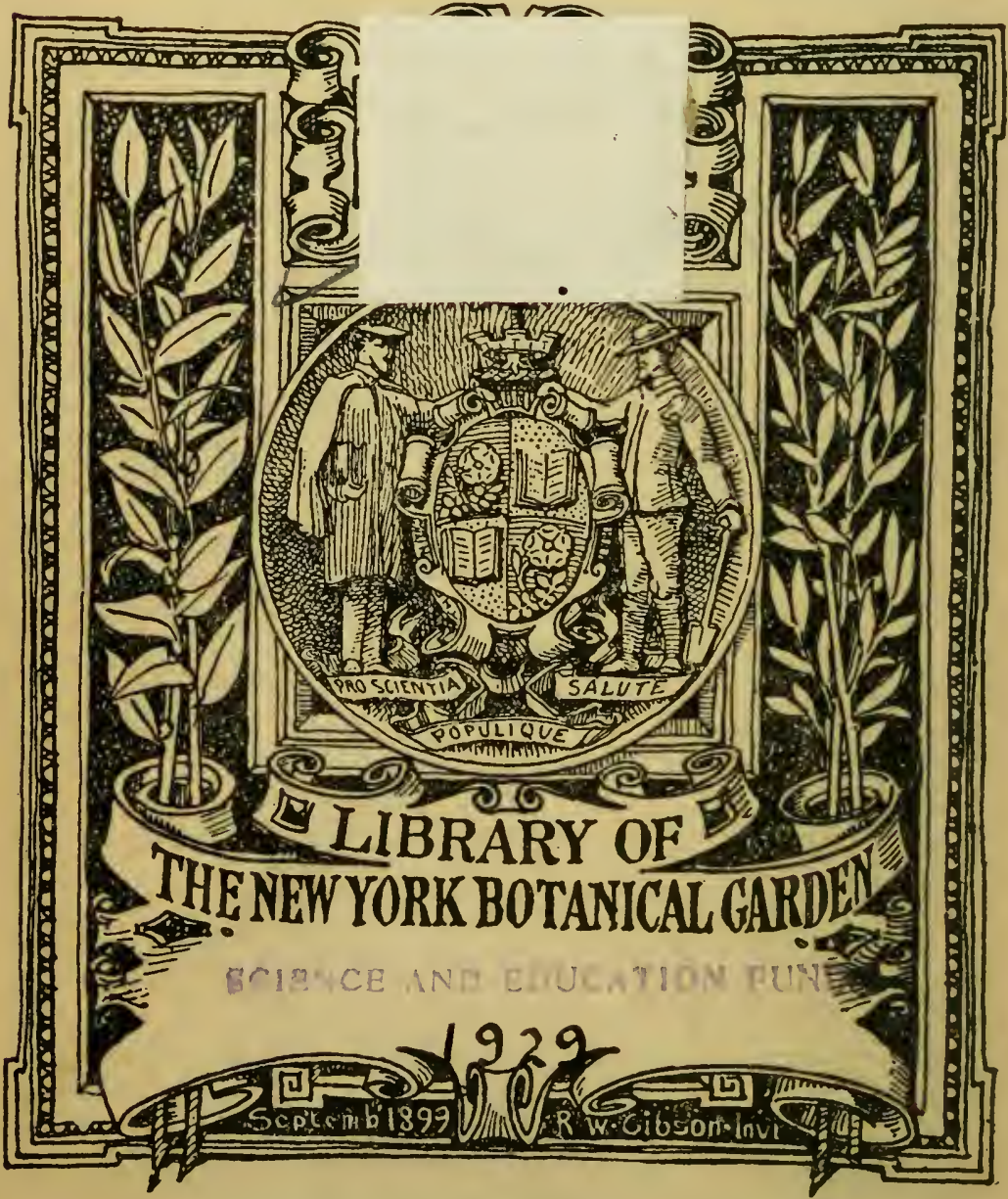

ideln

ln und

größtend ein uch die $r$ angees jedes st nene eser die de dem

ge

Raupen.

nannten le Name

Herausgegeben von Dr. C. Rothe, Realschul-Professor.

12 Blätter mit Einleitung. In Umschlag $40 \mathrm{kr}$. $=80 \mathrm{Pf}$.

Die Etiketten enthalten die Gattungen und Artennamen. Da zwischen den Etiketten einer Seite ein Papierstreifen leer gelassen wird, braucht man nur die gerade nöthigen Nummern auszuschneiden und behält di n nicht gleich verwendbaren in der Reihenfolge des Systems vorräthig. 


\title{
Schulflora von Österreich.
}

\author{
Von
}

\section{Dr. Moritz Willkomm,}

o. ö. Professor der Botanik und Director des botanischen Gartens der k. k. deutschen Universität in Prag.

Zweite, verbesserte und vermehrte Auflage.

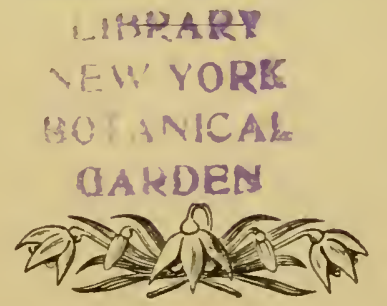

\section{Wien, 1892.}

Verlag von A. Pichler's Witwe \& Sohn, Buchhandlung für pädagogische Literatur und Lehrmittel-Anstalt. จ. Margaretenplatz 2. 
$4 \times 318$

. W5

1892

E. und k. Hofbuchdruckerei Karl Prochaska in Teschen. 


\section{Inhaltsverzeichnis.}

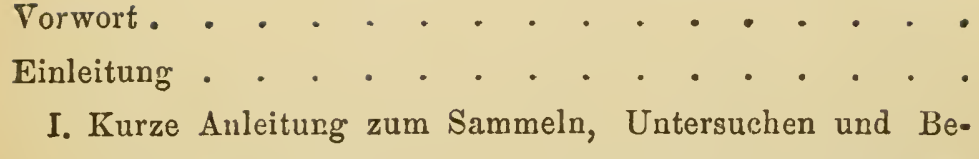
stimmen der Pflanzen und zur Anlegung eines Herbarium

Seite

II. Erklärung der in dieser Flora der Anordnung der Pflanzen zugrunde gelegten Systeme . . . . . . X XVI

III. Erklärung der im Text vorkommenden Abkürzungen $\mathrm{XX}$

Schlüssel zum Bestimmen der Gattungen nach dem Linnéschen Syrstem . . . . . . . . . . . . XXIII -LIII Erste Abtheilung. Gefäßsporenpflanzen . . . . . . 1-7 Zweite Abtheilung. Samenpflanzen.

I. Nacktsamige . . . . . . . . . . . . 7-10

II. Bedecktsamige Pflanzen mit einem Samenlappen . . 10-65

III. Bedecktsamige Pflanzen mit zwei Samenlappen . . 65-356

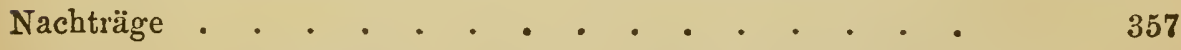

Verzeichnis der lateinischen Gattungs- und Familiennamen 374

Verzeichnis der deutschen Gattungs- und Volksnamen • . 380 



\section{LIBSART \\ TORF \\ Vorwort. \\ Ain $E N$}

Die Herausgabe dieses Buches ist einem dringenden Bedürfnis entsprungen, das wohl alle Hittcl- und Hochschullehrer, welche mit ihren Schülern Excursionen und Übungen im Bestimmen von Pflanzen der üsterreichichen Flora zu veranstalten gewohnt sind, schon seit Jahrzehnten empfunden haben, in noch höherem Grade aber die Schüler und Studenten, welche Pflanzen sammeln und bestimmen, sowie alle Freunde der Pflanzenwelt, die sich eine grïindliche Kenntnis der Flora ihrer Heimat erwerben wollen. Denn die früher und neuerdings veröffentlichten größeren Florenwerke über Mitteleuropa, in denen auch Österreich berücksichtigt wird - eine Flora des österreichischen Kaiserstaates, ist seit $\mathrm{M}$ a ly's lateinisch verfasster "Enumeratio plantarum phanerogamicarum imperii austriaci universi" (Wien 1848) nicht erschienen - sind viel zu umfangreich und auch zu kostspielig, als dass sie sich für Schïler, Studenten und andere angehende Botaniker eigneten. Dasjenige Buch aber, welches bisher von Lehrern und Schiilern zum Bestimmen der Pflanzen Österreichs allein benutzt werden konnte, nämlich Lorinser's „Botanisches Fxcursionsbuch für die deutschösterreichischen Kronländer" ist, da selbst seine nenesten Auflagen bezïglich der Charakterisierung der Gattungen und Arten im Vergleich mit den früheren wenig verändert, beziehungsweise verbessert sind, auch weder die überaus zahlreichen, in neuerer Zeit in Cisleithanien aufgefundenen Arten berücksichtigen, noch den Fortschritten der systematischen Botanik Rechnung tragen, kaum mehr brauchbar, um sich eine genauere Kenntnis der österreichischen Flora zu erwerben. Dazu kommt dass die von Lorinser gewählten Merkmale der Gattungen und Arten sehr häufig so schwer erkennbare oder an den gesammelten Exemplaren, wenn solche nicht gleichzeitig Blïten und Früchte besitzen, gar nicht zu finden sind, dass nur zu oft Lehrer und Schüler es aufgeben müssen, eine ihnen unbekannte Pflanze nach diesem Buche zu bestimmen. Unsere "Schulflora" sucht allen solchen Übelständen $\mathrm{zu}$ begegnen. So weit es nur irgend thunlich war, sind leicht erkennbare und an allen Exemplaren zu findende Merkmale zur Charakterisierung der Gattungen und Arten gewählt und ist die Nomenclatur, sowie die Beschreibung und Umgrenzung der Gattungen und Arten dem gegenwärtigen Standpunkte der systematischen Botanik angepasst worden. Obwohl unser Buch eine weit geringere Bogenzahl besitzt, als die neuesten Auflagen von Lorinsers Werk, enthält dasselbe doch beträchtlich mehr Pflanzenarten als dieses, trotzdem dass alle wirklich seltenen, d. h. nur in einer Gegend oder an einem Standort vorkommenden Arten (mit Ausnahme der besonders auffälligen), sowie sehr viele der in neuester Zeit aus Cisleithanien beschriebenen neuen Arten, nämlich alle zweifelhaften oder in ihrem Vorkommen sehr be- 
schränkten, weggelassen und die zur Karpathenzone gehörenden Länder Cisleithaniens, nämlich Galizien und die Bukowina, desgleichen das Litorale, Istrien, Dalmatien uud Wälschtirol, deren Vegetation eine vorherrschend mediterrane ist, ausgeschlossen worden sind. Denn die Aufnahme der iiberaus zahlreichen Mediterranpflanzen jener siidlichsten Kronländer, sowie der Karpathenflora wiirde den Umfang dieses Buches nahezu verdoppelt haben. Auch musste für die Abgrenzung des Florengebietes maßgebend sein, dass unser Buch lediglich für de utsclse Mittel- und Hochschulen bestimmt, die Zahl solcher aber in den an die Adria und an Russland grenzenden Kronländern eine sehr beschränkte ist. - Aus der Angabe der Kronländer bei nicht allgemein verbreiteten Arten ersieht der Lehrer und Schüler sofort, ob er eine solche Pflanze in seinem Heimatslande zu suchen hat oder nicht, was das Bestimmen der Arten oft gar sehr erleichtert. Wertvolle Fingerzeige fuir die Bestimmung geben auch die bei vielen Alpenpflanzen beigefiigten Höhenangaben. Der systematischen Aufzählung ist eine verbesserte Modification des Pfanzensystems von End licher und Unger zu Grunde gelegt. Eine Charakteristik der Pflanzenfamilien konnte wegen Raummangels nicht gegeben werden und erschien auch deshalb weniger nöthig, weil die wahrhaft natiirlichen Familien (z. B. die Gramineen, Compósiten, Labiaten, Umbelliferen u. s. w.) in dem nach dem Linné'schen System ausgearbeiteten Schlüssel zum Bestimmen der Gattungen charakterisiert sind. Die Gattungen solcher Familien sind in besonderen Schlïsseln gekennzeichnet welche der systematischen Aufzählung der Gattungen und Arten vorgedruckt erscheinen, in den nach Linné's System geordneten Gattungsschlüssel nur solche Gattungen aufgenommen, welche zı minder natürlichen Familien gehören oder einen vom Typus ihrer Familie abweichenden Charakter haben.

Die Synonymen sind, solche ausgenommen, welche bisher als Species-Benennungen gebrä̈uchlich gewesen, weggelassen, und was den Formenkreis der Arten betrifft, nur gut unterschiedene und deshalb leicht erkennbare Varietäten aufgenommen worden, wobei bemerkt sein mag, dass, wenn neben der Benennung einer solchen Varietät der Name des Autors in Klammern steht, dies bedeutet, dass dieselbe von dem betreffenden Autor als selbstständige Art beschrieben worden ist. Bezüglich der deutschen Benennungen der Pflanzenarten ist der Verfasser der Ansicht, dass nur wirkliche Vulgär-, also Volksnamen in eine populäre Flora aufgenommen zu werden verdienen, nicht aber Übersetzungen der lateinischen Speciesnamen. Denn diese sind keine Volksnamen und darf wohl von jedem Mittel- und Hochschïler, geschweige denn Lehrer vorausgesetzt werden, dass er soviel Latein weiß, um die wissenschaftlichen Benennungen der Arten zu verstehen. - Bei den formenreichen Gattungen Hieracium, Rosa und Rubus musste selbstverständlich eine strenge Musterung und Auswahl der Arten platzgreifen, um das Verständnis der Anfänger nicht zu verwirren und ihnen das Bestimmen solcher Pflanzen nicht zu verleiden. Ja, bezïglich der Brombeerformen sah sich der Verf. genöthigt, von jeder Charakterisierung der zahllosen seit Weihe und Nees v. Esenbeck unterschiedenen Arten abzusehen und dieselben unter dem Collectivnamen R. fruticusos L. zusammenzufassen. Die Aufnahme der Cultur-, darunter auch der verbreiteteren Gartenzierpflanzen, welche in Cisleithanien 
im Freien fortkommen, wird wohl jerler Kritiker als in eine "Schulflora $^{*}$ gehörig anerkennen. Sind doch die Culturpflanzen diejenigen Gewächse, welche Jedermann zuerst und am häufigsten sieht und deshalb auch kennen soll. Die Anleitnng ztun Sammeln und Präparieren der Pflanzen, sowie zur Anlegung eines Herbars von wirklichem Werte dürfte den Schülern, vielleicht auch manchem Lehrer willkommen sein. Vou einer Erklärung der in den Pflanzenbeschreibungen vorkommenden Kunstausdriicke und von der Schilderung der Pflanzenorgane und deren Formen musste wegen Mangel an Raum Uingang genommen werden. Auch ist es nach des Verf. Meinung Sache der Lehrer, ihren Schülern die Kenntnis der zur Beniitzung dieses Buches wie jeder Flora erforderlichen Organographie und Terminologie zu vermitteln, wozu das Untersuchen der gesammelten Exemplare die beste Gelegenheit bietet. Und so glaubt der Terf. alles gethan zu haben, um sein Buch möglichst praktisch fuir Lehrer und Schïler einzurichten, wie auch die Verlagshandlung keine Kosten gescheut hat, um demselben ein gefälliges Äußere zu geben. Möge diese ${ }_{n}$ Schulflora " in recht vielen Mittel- und Hochschülern Interesse fiur die Vegetation ihrer schönen Heimatländer erwecken und die Kenntnis der vaterländischen Flora in den weitesten Kreisen fördern! Mit diesem Wunsche empfiehlt sein Buch allen Freunden der Pflanzenwelt

Prag, im Jänner 1888.

\section{der Verfasser.}

\section{Vorwort zur zweiten Auflage.}

Diese zweite gründlich durchgesehene und corrigierte Auflage enthält 10 Gattungen und 93 Arten mehr als die erste. Leider konnten diese neu hinzugekommenen Gattungen und Arten an den betreffendeu Orten nicht in den Verband der Gattungen und Arten eingefügt, sondern mussten dieselben als Nachträge in systematischer Ordnung zusanmengestellt werden, weil die Verlagshandlung den Satz der ersten Auflage hatte stereotypieren lassen. Außer diesen Arten, deren meiste wegen nur stelleuweisen Vorkommens als zu seltene in der ersten Auflage absichtlich weggelassen, jedoch auf das Anrathen namhafter Botaniker Österreichs in die neue aufgenommen worden sind, um die Flora Österreichs vollständiger vorzuführen und dadurch das Buch noch brauchbarer zu machen, hat der Verf. 112, der Mehrzahl nach erst in neuester Zeit in Cisleithanien aufgefundene Arten, theils ganz neue, theils Arten der benachbarten Florengebiete in einem anhangsweise beigegebenen Verzeichnisse in ebenfalls systematischer Reihenfolge nur namentlich und mit Angabe ihres Vorkommens angeführt, um nicht den Vorwurf auf sich zu laden, dass er diese Arten entweder nicht kenne oder sie absichtlich ignoriere. Verfasser hält dieselben der Mehrzahl nach für 
ebenso berechtigte Arten, wie viele der neueren in den Nachträgen charakterisierten Arten, konnte sich aber nicht entschließen, dieselben in die Nachträge aufzunehmen, weil sie entweder bisher wirklich nur an einem Standort gefunden wurden oder - die meisten - bloß in den Grenzgebieten Osterreichs (vorzugsweise an der italienischen und ungarischen Grenze) vereinzelt auftreten. Die Angabe der Standorte dürfte genügen, um Pflanzensammler in jenen Gebieten auf sie aufmerksam zu machen. Auch wiirde eine Charakteristik derselben die Nachträge um mehr als das Doppelte vergrößert und dadurch die Bogenzahl des Buches zu sehr vermehrt haben. Trotz dieser vielen neu hinzugekommenen Arten ist eine große Anzahl neuerdings aus Cisleithanien beschriebener Pflanzenarten unberücksichtigt geblieben, theils weil Verfasser deren Artberechtigung noch in Zweifel zieht, theils weil er es für unmöglich erachtet, dieselben nach der analytischen Methode mit wenigen Worten so zu charakterisieren, dass auch ein.Anfänger sie zu bestimmen vermöchte. Dergleichen Arteu sind z. B. die Unzahl von Rosenarten, welche von H. Braun, E. v. Ha la cs y, V. v. Borbàs, Oborny u. a. aus Österreich und Mähren beschrieben rorden sind. Die zallireichen von $\mathrm{Zimmeter}$ aufgestellten Arten ron Potentilla, viele neuerdings bekannt gewordenen Formen oder angebliche Arten von Hieracium, Gentiana, Thymus, Mentha und Euphrasia u. a. m. Aus denselben Gründen hat sich der Verf. auch diesmal noch nicht entschließen können, die Brombeerarten und Formen in sein Buch aufzunehmen. Eine Auswahl unter diosen nach Hunderten zählenden angeblichen Arten zu treffen, ist sehr schwer und würde eine solche, auch wenn nur etwa die älteren Arten (von Weihe u. a.) aufgenommen worden wären, die ron der Verlagshandlung dem Verfasser zugestandenen Grenzen weit überschritten haben. Bezüglich der Nomenclatur ist der Verfasser bestrebt gewesen, den auf die Priorität begründeten Ansichteu der tonangebenden Wiener Schule nach Möglichkeit Rechnung zu tragen, denn in vielen Fällen vermag er nicht sich mit denselben einverstanden zu erklären. Schließlich spricht er allen Botanikern und Benützern seiner Schulflora, welche ihn auf Mängel und Druckfehler aufmerksam gemacht und berechtigte Wünsche bezüglich der neuen Auflage ausgedrückt haben, seinen aufrichtigsten Dank aus, womit er die Bitte rerbindet, ihm auch fernerhin dergleichen zweckdienliche Mittheilungen zugehen lassen zu wollen.

Prag, im Februar 1892.

Der Verfasser. 


\section{Einleitung.}

I.

\section{Kurze Anleitung zum Sammeln, Untersuchen fund Bestimmen der Pflanzen und zur Anlegung eines Herbarium.}

1. Das Sammeln der Fflanzen. Bezüglich desselben sind folgende, auf langjähriger Erfahrung beruhende Grundsätze wohl zu beachten:

a) Landbewohnende Pflanzen, welche man untersuchen will, sind im trockenen Zustande zu sammeln, da die Blüten, welche stets die Haupterkennungsmerkmale darbieten (besonders bei der Bestimmung der Gattungen), im nassen Zustande sich schwierig untersuchen lassen, zuma! wenn sie klein sind und gedrängt (in Köpfchen, Ähren, Knäueln) beisanmen stehen. Deshalb sollten botanische Excursionen nur bei heiterem oder wenigstens nicht regnerischem Wetter unternommen werden. Ist man dennoch genöthigt, nass gewordene Pflanzen (z. B. am Morgen von bethauten Wiesen oder, wenn plötzlich Regenwetter eintritt) zu sammeln, so müssen dieselben vor der Untersuchung und namentlich vor dem Einlegen (Trocknen) so lange an der Luft (nicht im Sonnenschein!) ausgebreitet liegen gelassen werden, bis sie abgetrocknet sind. Dasselbe gilt selbstverständlich von allen Wasserpflanzen. Nass eingelegte Pflanzen schimmeln gern oder werden schwarz.

b) Man sammle möglich vollständige Exemplare, d. h. mit allen denjenigen Organen begabte, welche zum Bestimmen erforderlich sind. Die vetreffenden Pflanzen müssen demnach mit vollständig entwickelten Blüten versehen sein und wo möglich auch bereits Früchte besitzen. Viele Pflanzen, z. B. sämmtliche Doldengewächse (Umbelliferae), die Rietgräser (Carex), Hasenfußarten (Ranunculus) u. a. m. lassen sich ohne gut entwickelte Früchte gar nicht bestimmen. Ferner genügt es nicht, bloß 
blühende und fruchtende Zweige abzuschneiden oder gar, wie es Anfänger meist $\mathrm{zu}$ thun pflegen, abzureißen, sondern müssen grasartige Pfanzen oder Kräuter wo möglich mit der Wurzel oder dem Wurzelstock ausgehoben werden, da die Gestaltung beider nicht selten ein Haupterkennungsmerkmal solcher Pflanzen ist, Rhizomgewächse (d, h. mit Wurzelstock oder unterirdischer Achse begabte) auch häufig charakteristische unter-oder oberirdische Sprossen nnd Ausläufer treiben, welche in den Bestimmungsbuichern berücksichtigt sind, z. B. viele Rietgrüser, Habichtskräuter (Hieracium), Weidenröschen (Epilobium) u. a. m. Knollen- und Zwiebelgewächse (z. B. die Orchideen, Irideeu, Liliaceen, die Lerchensporne, Corydalis) müssen stets ausgegraben werden. Bei den im Schlamme wurzelnden schwimmenden oder flutenden Wasserpflanzen ist dies nicht nöthig, sondern genügt da ein größeres Stengelstiick, an welchem alle Blattformen vorhanden sind, von solchen zu nehmen. Von Sträuchern und Bäumen sind mit Blättern und Blüten, bez. Frïchten begabte Ziveige abruschneiden; wenn solche vor dem Laubausbruch blühen (z. B. viele Weiden, die Rüstern u. a.), so müssen (und zwar von demselben Strauch oder Baum) zweimal Zweige genommen werden, nämlich im blühenden Zustande und mit völlig entfalteten Blättern begabte.

c) Zum Pflanzensammeln sind folgende Utensilien unentbehrlich: 1. ein starker Stock mit hakenförmig gebogenem Griffe, um damit Baumzweige herab- und Wasserpflanzen vom Ufer (oder vom Kahne aus) aus dem Wasser herausziehen zu können. Derselbe muss eine starke Eisenspitze mit eiserner $Z$ winge haben, um beim Bergsteigen als feste Stütze dienen zu können. Es gibt auch „Botanisierstöcke“, welche anstatt des Griffes eine queraufliegende stählerne, rïckwärts in eine Spitze auslaufende Hackenklinge (wie eine Rodehacke geformt) haben. Mit dergleichen Stöcken kann man Pflanzen leicht mit Wurzeln oder Wurzelstock heranshacken; für tief im Boden steckende Zwiebeln und Knollen reichen sie aber nicht aus und ist für solche ein lang- und starkklingiges Taschenmesser oder 2. ein Pflanzenstecher (Pfanzenspatel, Botanisierspatel) erforderlich. Ein solcher, etwa $1 / 3 m$ l., muss von gutem Stahl (auch der Stiel), damit er sich nicht biegt (was auf steinigem Terrain bei bloß eisernen Spateln sehr leicht geschieht), und, wenn der Griff von Holz ist, dieser mit dem Stiel sehr fest verbunden (der im Holze befindliche Theil des Stieles vierseitig) sein. Die dauerhaftesten und praktischsten Pflanzenstecher sind die gänzlich aus gestähltem Eisen bestehenden mit querem Griff am Stiele. Wer einen guten starken Spatel besitzt, bedarf eines mit Hacke begabten Botanisierstockes nicht. 3. Ein starkklingiges Taschenmesser mit nicht zu kurzer gerader oder gekrümmter Klinge (Gartenhippe). Ein solches leistet sowohl beim Abschneiden von Baum- 
zweigen als beim Durchschneiden von Wurzeln und beim Ausgraben von Wurzeln und Wurzelstöcken treffliche Dienste und kann in den meisten Fällen den Spatel ersetzen. 4. Eine Botanisierbü chse oder Botanisiermappe. Erstere, von lackiertem Blech, darf nicht zu klein sein, namentlich bei größeren Excursionen oder mehrtägigen Reisen in planzen. reichen Gegenden (Alpen u. a. Hochgebirgen). Praktisch ist es, wenn die Büchse eine kleinere Abtheilung für kleine Pfanzen ( 7. B. in Polstern wachsende Alpenkränter, Mooso oder auch Wasserpflanzen, durch welche andere Pflanzen leicht verunreinigt werden können) neben đer größeren enthält, in welchem Falle die Gesammtlänge mindestens $1 / 2 m$ betragen muss. In Botanisierbiuchsen halten sich Pflanzen oft Tage lang frisch, besonders dann, wenn dieselben dicht zusammengedrängt darin liegen, die Büchse also gänzlich mit Pflanzen gefüllt ist. Dagegen bietet die Botanisiermappe den Vortheil, schon während des Sammelns die verschiedenen Pflanzenarten zu sondern, und das Abfallen von Blumen- und Blumenblättern zu verhindern, indem die gesammelte Pflanze sofort zwischen zwei Bogen Papier zu liegen kommt und von denselben fest. gehalten wird. Eine Botanisiermappe besteht aus zwei $35-40 \mathrm{~cm}$ langen und 25-28 cm breiten Pappdeckeln, welche durch zwei Gurtbänder oder Lederriemen so verbunden sind, dass sie sich nach Belieben einander nähern und von einander entfernen lassen, indem die beiden Bänder oder Riemen durch Spaltlücher oder Ösen an den beiden Langseiten gezogen werden. Gefüllt wird die Mappe mit zusammengebrochenen gleichgroßen Bögen starken Papiers, deren Falz nach unten gekehrt sein muss, damit die an der obern klaffenden Seite der Mappe in die Bögen gelegten Planzen nicht herausfallen können. Eine solche Mappe kann entweder an einer Handhabe mit der Hand getragen werden, oder, was bequemer ist und beide Hände frei gibt, gleich der Botanisierbüchse an einem Tragriemen über die Schulter. Legt man, nach Hause gekommen, die gesammelten Pflanzen ordentlich ein (s. unten), und das Papier mit den Pflanzen wieder in die Mappe, so kann diese auch als Presse benütz仑 werden, indem man sie mit einem Stein oder mit schweren Büchern belastet. Doch ist dazu die unter 3 besprochene Drahtmappe viel empfehlenswerter.

2. Das Untersuchen und Bestimmen der gesammelten Pflanzen. Dasselbe muss sofort nथch der Rückkehr von der Excursion geschehen oder wenigstens so lange die Pflanzen noch frisch und ihre Blüten nicht zusammengefallen sind. Die Untersuchung der letzteren ist bei Pflanzen, welche man nicht kennt, namentlich solchen, bei denen man nicht weiß, zu welcher Gattung sie gehören, immer die Hauptsache. Kennt man die Gattung, weif man z. B., dass man eine Potentilla oder ein Hieracium vor sich hat, 
so kann man sofort die betreffende Gattung in der Flora aufsuchen und an die Bestimmung der Art gehen. Dabei spielt auch die Gestaltung der Laubblättel stets eine Rolle. Die Untersuchung der letzteren macht in der Regel keine Schwierigkeit; nur bei Wasserptanzen mit fein zertheilten Blättern (z. B. den Wasserranunkeln, Batrachium), wo die Blattzipfel sich beim Herausnehmen der Pflanze aus dem Wasser häufig an einander legen, muss man Blättel der Pflanze oder ein beblättertes Stück iłıres Stengels in eine Schale mit Wasser legen, damit die Blätter sich wieder ausbreiten und ihre natïrliche Form und Lage wiederbekommen. Zur Untersuchung großer Blüten (z. B. Lilien, Magnolien, unechten Jasmin, großblumiger Enzianen) gentigen das bloße Auge und die Finger; in den meisten Fällen wird unan aber mindestens eine Piacette und eine Präp ariernadel zur Hand lıaben müssen, um die Blütentheile zu trennen, auseinander zu biegen, abzulüsen u. s. w. und bei kleinen Blüten sind diese Instrumente, sowie eine gute Lo u pe ganz unentbelırlich. Zum Zerschneiden der Blïten (um Läugs- oder Querschnitte durch solche, su wie, was namentlich oft sehr nöthig, durch Blütenknospen zu machen) ist zwar ein gutes scharfes Federmesser meist ausreichend, in vielen Fällen aber ein sogenanntes Skalpell, d. h. eine schmale gerade und spitze Klinge mit sehr scharfer Schneide am Ende eines 10-12 cm langen Holzstieles sehr wünschenswert. Auch eine kleine Scheere mit gekrïmmten Schenkeln zum Herausschneiden von Staubgefaßßen, Griffeln, Fruchtknoten u. s. w. leistet unter Umständen gute Dienste*). Zum Bestimmen der Pflanzen nach unserer Flora ist endlich ein Centimetermaß unentbehrlich. Wenn man verlindert gewesen ist, die gesammelten Pflanzen im frischen Zustande zu untersuchen, oder, wenn man bereits getrocknete, aber nicht bestimmte Pflanzen von Anderen zur Bestimmung erhält, so glaube man nicht, dass deshalb, weil die Pflanze getrocknet, beziehentlich gepresst ist, jede Untersuchung ihrer Blïten unmöglich geworden sei. Wenn anders rie Pflanzen gut präpariert worden sind (s. 3), so ist die Untersuchung von deren Blüten ebenso leicht, ja oft noch bequemer als im frischen $\mathrm{Zu}$ stande. Man braucht dann nur die Blüten in kochendes Wasser zu tauchen (am besten in einem Probiergläschen mit Wasser über der Spirituslampe zu kochen), worin sie sicll sofort ausbreiten und alle ihre Theile ihre ursprüngliche Form und Lage wieder annehmen. Freilich verlieren sie gewöhnlich ilıre Farben, indem sich diese in kochendem Wasser auflüsen, doch einestheils kommt es auf die Farben wenig an, anderntheils

*) Alle diese Instrumente, sowie die oben erwähnten Geräthschaften, welche man beim Botanisieren gebraucht, werden in der Verlagsbuchhandlung dieser Schulfora (Wien, V. Margaretenplatz 2) zu möglichst billigen Preisen rorräthig gehalten. 
weiß man ja, wenn man die Pflanzen selbst gesammelt hat, welche Färbung die Blüten besaßen cder ist dieselbe noch zu erkennen, wenn die Pflanzen sorgfältig getrocknet worden waren.

Bei Benutzung des „Schlïssels zum Bestimmen der Gattungen nach dem Linné'schen System", dessen man sich nur dann zu bedienen hat, wenn man nicht weiß, zu welcher natürlichen Familie die zu bestimmenden Pflanzen gehören (den größeren natürlichen Familien sind ja in der eigentlichen Flora besondere Gattungsschliissel vorausgeschickt) hat man vor allen Dingen darauf zu achten, dass die betreffenden Pflanzen noch vollkommen erhaltene Blïten besitzen und wäre dies nicht der Fall, etwa vorlıandene Blütenknospen zu öffnen, um sich genau zu vergewissern, wie viele Staubgefäße und Griffel die Blüten enthalten, ob erstere frei -oder verwachsen sind u. s. w. Denn bei älteren Blüten sind die Staubheutel, selbst ganze Staubgefäße oft schon abgefallen. Besitzt die betreffende Pflanze nur männliche oder weibliche Blüten, so ist sie sicher eine zweihäusige und dann die Gattung, zu der sie gehört, in der XXII. Classe (Dioecia) aufzusuchen; zeigen sich neben eingeschlechtigen Blïten auch Zwitterblüten (zweigeschlechtige), so ist sie vielehig (polygamisch) und dann da die XXIII. Classe (Polygamia) eingezogen worden, nach der Zabl, Einfügungsweise, dem Verwachsen- oder Freisein der Staubgefäße in den ursten 20 Classen des Systems nachzusehen. Sowohl bei Bestimmung der Gattungen als der Arten muss man genau die angegebenen Unterscheidungsmerkmale berücksichtigen, um sich nicht zu verirren; übrigens ist es in einem solchen Falle leicht, sich mit Hilfe der eingeklammerten rückwärts verweisenden Nummern wieder zurecht zu finden. So z. B. zeigt in der artenreichen Gattung Hieracium Nummer 26 (20) auf Nummer 20 zurück (Haare der Blätter drïsentragend oder drüsenlos).

\section{Das Trocknen und Präparieren gesammelter Pflanzen behufs An-} Jegung eines Herbarium. Nichts vermag eine bleibende Kenntnis der Pflanzen irgend einer Gegend mehr zu fördern und die Namen der Pflanzenarten besser einzuprägen als die Anlegung eines Herbars. Damit aber ein solches diesen $\mathbf{Z}$ wecken entspreche und überhaupt einen wirklichen, einen wissenschaftlichen Wert habe, ist es zuvörderst nöthig, dass die Pfanzen, welche in dasselbe aufgenommen werden sollen, nicht nur in möglichst vollständigen Exemplaren gesammelt, sondern auch zweckmäßig präpariert und gut getrocknet werden. Als eine gut präparierte und getrocknete Pflanze ist eine solche $\mathbf{z u}$ bezeichnen, deren Theile (Blätter, Blüten u. s. w.) nicht in einander gequetscht, nicht unregelmäßig zusammengefaltet, niclit runzlig (wenn nicht etwa die Blätter von Natur runzlig waren), sondern möglichst naturgemäß ausgebreitet und glatt erscheinen und ihre natürlichen Farben möglichst bewahrt haben, kurz ein gefälli- 
ges $\mathrm{An}_{\mathrm{S}}$ ehen zeigen. Um trische Ptanzen zu trocknen; presst man sie bekanntlich zwischen Lagen von Papier. Zum Pressen kann man sich zivar einer wirklichen mit Schrauben versehenen Presse nach Art der Buchbinder oder Serviettenpressen bedienen (eine Pllanzenpresse muss immer zivei Schrauben besitzen), unbedingt nöthig ist aber eine solche nicht, denu jedes mit Steinen oder schweren Biichern belastete Brett kann als. Pflanzenpresse dienen. Ja, in vielen Fällen ist einer solchen improvisierten Presse sogar der Vorzug zu geben, weil ein belastetes Brett einen. dauernden gleichartigen Druck auf das darunter liegende Planzenpacket ausiubt, während bei einer durch Schrauben festgestellten Presse der Druck aufhört, sobald die in dem Papier liegenden Pllanzen durch Abgabe ihrer Feuchtigkeit ihr Volumen verringert haben. Für mehrtïgige Excursionen oder größere Reisen (z. B. Ferienreisen in Hochgebirgen). sind die neuerdings erfundenen, leichten und leicht zu trausportierenden Drahtmappen nicht genug zu empfehlen. Dieselben bestehen aus zwei in viereckige Eisenrahmen von der Größe eines zusammengefalteten Papierbogens eingespannten Drahtgittern, welche durch vier geglielerte. Messingkettchen zusammengezwängt werden können und bieten den unschätzbaren Vortheil dar, dass die in den zwischen den Gittern eingezwängten Papier liegenden PAlanzen (abgesehen von sehr saftvollen oder fleischigen) gar nicht umgelegt zu werden brauchen, da die Gitter den. freien Zutritt der Luft gestatten und die aus den gepressten Planzen entweichende Feuchtigkeit durch die Maschen der Gitter hindurch. verdunstet.*) Da diese Drahtmappen eine Handhabe besitzen, so kanı man dieselben sowohl in der Hand, als mittelst eines Umlängriemens tragen. Benutzt man keine Drahtmappen, so müssen die Papierschichten, sobald sie feucht geworden, durch Trocknen ersetzt oder die Pfluzen. müssen umgelegt werden. Gewöhnlich wird vorgeschrieben, die Planzen so lange umzulegen, bis sie vollkommen trocken geworden sind. (d. h. so steif, dass Stengel oder Blätter beim Biegen zerbrechen oder knicken) und das Umlegen alle 24 Stunden zu wiederholen. Verfasser ist: gestützt auf langjährige Erfahrung, die auch von vielen Pflarzensammlern. bestätigt wurde, nicht dieser Ansicht. Zunächst ist es als Irrthum zu bezeichnen, dass sogenauntes Fließ-oder Lisschpapier, d. h. ein ungeleintesweiches Papier, welches jede Feuchtigkeit leicht aufsaugt, das beste zum Pfanzenpressen sei. Wird solches Papier wicht häufig gewechselt, so beginnen die eingelegten Pfanzen sehr bald zu schimmeln oder sich schwarz zu tïrben. Die Schimmelbildung wird veranlasst durch das Keimen der

*) Eine Drahtmappe von $40 \mathrm{~cm}$ Länge und $27 \mathrm{~cm}$ Breite kostet bei der Verlagsbuchlandlung dieses Buches nur 2 fl. $50 \mathrm{kr}$. 
mikroskopischen Schimmelpilzsporen, die fast an allen Gegenständen Laf. ten und in dem feucht geworảenen weichen Papier ein voruügliches Keimbett finden. Warum trocknen denn Blumen und andere Pflanzentheile, welche in alte Bücher mit starkem geleimten Papier gelegt wurden, in der Regel ganz vorzïglich, so dass Blätter und Blumen ihre natürliche Farbe behalten, auch wenn dieselben niemals zwischen andere Blätter des Buches gelegt wurden? - Weil das geleimte Papier die Feuchtigkeit gar nicht oder nur wenig aufsaugt und diese zwischen den Blättern hinaus ins Freie verdunstet. Wendet man geleimtes Schreibpapier an, so wird man nicht nöthig haben, die Pflanzen offter umzulegen, zumal wenn man dabei ein gleich zu besprechendes Verfahren anwendet. Da aber Schreibpapier theuer ist, so nehme man das in neuester Zeit mit Recht zum Pfanzentrocknen empfohlene ungemein billige gelbe Stroh. papier, denn dieses ist (wenigstens auf der einen Seite) ebenso glatt wis Schreibpapier, hinreichend steif und nimmt die Feuchtigkeit ebensowenig an, wie jenes. Verfasser und viele Botaniker der Gegenwart beobachten nun folgendes Verfahren. Sie lassen die frisch zwischen entsprechend dicke Lagen von Schreib- oder Strohpapier gelegten Pflanzen $2 t$ bis 48 Stunden in der Presse liegen, leyen dieselben sodann in frisches dergleichen Papier um und nehmen nach abermals 1 bis 2 Tagen Einpressung das ganze Packet aus der Presse. Es werden dann die Pfianzen in der Regel bereits vollkommen gut gepresst sein. Um dieselben nun völlig zu trocknen, ohne sie weiter umlegen zu dürfen, legt man die Bogen, auf oder in welchen Pfanzen liegen, aber höchstens 3 oder 4 iibereinander und breitet diese dünnen Schichten auf den Dielen eines luftigen Zimmers aus. Liegen die Pfanzen nicht in zusammengefalteten Bogen, sondern anf solchen, so muss die oberste mit einem Bogen Papier zugedeckt werden. Nach Verlauf einiger Tage oder auch erst Wochen, - je nach der Beschaffenheit der Pflanzen, werden diese vollkommen getrocknet sein und ihre natürlichen Farben behalten haben. Sollten die zu oberst gelegenen Pflanzen etwas uneben geworden sein, so braucht man dieselben nur nocl eiumal 24 Stunden lang in die Presse zu legen. Saftarme Pflanzen, wie z. B. die meisten Gräser, brauchen gar nicht amgelegt zu werden, sondern können nach etwa zweitägiger Pressung sofort mit den Papierbögen in oder auf welche sie gelegt wurden, an der Luft ausgebreitet werden. Dieses bequeme Verfahren empfiehlt sich jedoch nicht für sehr saftvolle oder fleischige Pflanzen (z. B. Orchideen, Orobanchen, Crassulaceen). Diese müssen entweder zwischen weichem Flit\}papier, dessen Schichten täglich zweimal zu wechseln sind, so lange gepresst werden, bis sie alle Feuchtigkeit verloren haben oder man muss, was besser, aber freilich noch aufhältlicher ist, nachłen die Pflanzen zwischen Lagen von Fließpapier ge- 
bracht worden, über die obere Schicht mit einem heißen Plattstahl unter Anwendung von Druck und häufigem Wechsel des Papiers so lange hin und herfahren, bis man sich überzengt hat, dass die Pfanzen allen ihren Saft hergegeben haben. Dann werden sie in trockenes Fließpapier gelegt, 12 Stunden lang tuichtig gepresst, hierauf in oder auf geleimtes Papier gebracht und an der Luft ausgebreitet. Anstatt dieses umständlichen und zeitraubenden Verfahrens kann man auch dergleichen saftig-fleischige PGanzen in kochendes Wasser eintauchen (mit Ausnahme der Blüten!), worin sie rasch ihre Säfte hergeben und hierauf zwischen Fiießpapier pressen. Orchideen und Orobancheen, deren Blüten bei aller Sorgfalt gern braun oder schwärzlich werden, kann man die natürliche Blumenfarbe möglichst erhalten, wenn man die gesammelten Pfanzen einen Tag an der Luft (aber nicht im Sonnensclıein!) welken lässt und sie hierauf zwischen Fließ- oder Druckpapier presst, später in Schreib- oder Strohpapier umlegt u. s. w.

Beziiglich des Einlegens sind noch folgende Winke beachtenswert :

a) Man lege $z$ wischen zwei Papierlagen niemals so viele Pflanzen, dass dieselben übereinander zu liegen kommen, weil sonst leicht Zusammenkleben und Verschimmelung eintreten kann. Aus demselben Grunde dürfen auclı bei einzelnen Exemplaren die Blätter und Blïten möglichst wenig übereinander liegen.

b) Die einzulegenden Pflanzenexemplare dürfen nicht über die Ränder der Papierbögen hinausragen. Sind sie länger, z. B. Grashalme, so werden sie entweder eingeknickt oder zerschnitten. Dicke Pflanzen (z. B. Orobanchen, die Schuppenwurz), stärkere Baumzweige kann man der Länge nach spalten, wodurch man zugleich zwei Exemplare erhält.

c) Die eingelegten Pfanzen müssen zwar stark gepresst werden, doch darf der Druck nicht so groß sein, dass zarte Theile, z. B. Blüten zerquetscht werden.

4. Anlegung, Einrichtung und Conservierung des Herbariums. Vor Allem sei das Format des dazu verwendeten Papiers nicht zu klein, da ein solches bei Gräsern und größeren Pflanzen allerhand Verlegenheiten bereitet, denn die Pflanzen dürfen nie über die Blattränder hinausragen. Das Format des gewölnlichen Schreibpapiers ist entschieden zu klein, ein Format (des zusammengefalteten Papierbogens) von $40 \mathrm{~cm}$ Länge und $25 \mathrm{~cm}$ Breite das bequemste und handlichste. Als Papier ist ein geleimtes nicht zu steifes Papier (ob weißes oder graues, ist ganz gleichgiltig) zu verwenden, nicht aber ungeleimtes weiches Papier (weißes Fließ. oder Druckpapier), weil dieses die pflanzenzerstörenden Insecten (siehe unten) arlockt. Beziiglich der Einrichtung ist Folgendes zu beachten: 
a) In einen einzelnen Bogen dürfen nie so viele Pflanzenexemplare gelegt werden, dass sie über einander zu liegen kommen, sondern müssen, wenn davon die betreffende Art an verschiedenen Standorten (in verschiedenen Ländern) gesammelt wurde, die Exemplare nach den Standorten getrennt auf einzelne halbe Bögen in den Umschlagsbogen gelegt werden.

b) Um beim Gebranch des Herbars das Herausfallen der Pflanzen zu verhindern (was übrigens bei gehöriger Vorsicht nicht geschehen kann), empfiehlt es sich, die Pflanzenexemplare nittelst einiger schmaler Streifchen gummierten Schreibpapiers an die Papierblätter, auf denen sie liegen, anzuheften. Gummiertes Papier kann man sich leicht beschaffen, indem man beliebiges Schreibpapier auf der einen Seite mit einer Lösung von Gummi arabicum bestreicht und diesen Übcrzug an der Luft trocknen lässt. Wichtiger als die Anheftung der Exemplare ist die Sicherung der Etiletten (siehe c), indem bei dem Gebrauch der Herbarien gar zu leicht Vertauschungen derselben vorkommen können. Werden die Pflanzen mittelst Gummipapierstreifen angeheftet, so kann man die dazu gelörigen Etiketten ebenfalls anf das betreffende Papierblatt aufkleben oder auch mit einer S'ecknadel befestigen; bei nicht angehefteten Pflanzen empfiehlt es sich, die Etikette an eines der Exemplare selbst zu befestigen.

c) Jede Pfanzenart, so wie jede Varietät oder Form ist mit einer Etikette, d. h. mit eirem Zettel zu versehen, auf welchem der wissenschaftliche (lateinische) Name der Pflanze mit Angabe des Autors (d. b. dem Namen des Botanikers, welcher die Pflanze zuerst beschrieben hat) in Abkürzung (z. B. Anemone Hepatica L. = Linné, Primula officinalis Jcqu. = Jaquin), ferner das Land und der Fundort der Pflanze, die Beschaffenheit des Standorts und endlich das Datum des Tages, wo sie gesammelt wurde, geschrieben steht, z. B.

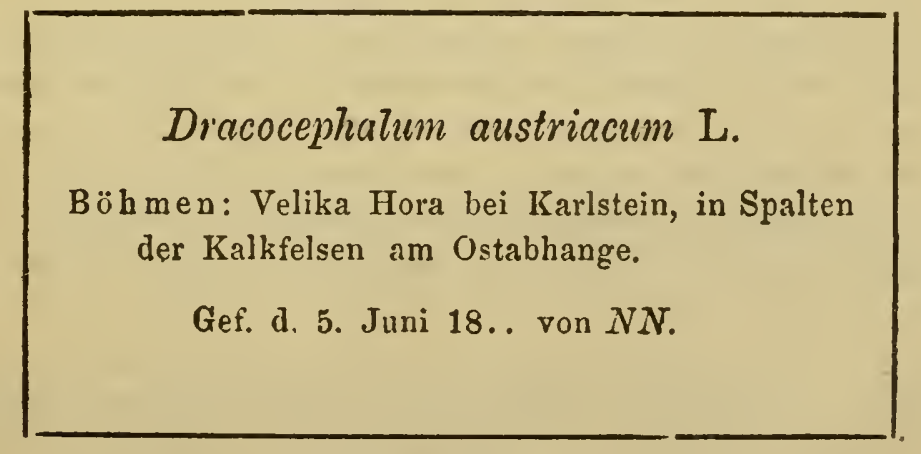

Deshalb dürfen die Etiketten nicht zu klein sein. 
d) Die Bögen, welche die Arten enthalten (in jedem Bogen darf nur eine Art liegen) sind so über einander zu legen, dass sie sich von rechts nach links aufschlagen lassen und empfiehlt es sich, des leichteren Auffindens wegen, den Namen der darinliegenden Art auch auswendig auf den Bogen und zwar in die linke untere Ecke zu schreiben. Die Arten einer Gattung werden mit einem gemeinschaftlichen Umschlagsbogen versehen, welcher in entgegengesetzter Richtung zusammengefaltet wird, so dass er sich von links nach rechts aufschlagen lässt und den Gattungsnamen in der rechten untern Ecke trägt. Bei artenreichen Gattungen können die Arten, um das Aufsuchen oder Nachsehen gewünschter Arten zu erleichtern, in alphabetischer Reihenfolge liegen; dagegen müssen die Gattungen stets in der Reihenfolge des bei der Einrichtung des Herbars gewählten Pflanzensystems angeordnet sein. Legt man eine bestimmte Flora, z. B. die unsrige zu Grunde, so kann man auch die Gattungsnummern dieser Flora auf die Umschlagsbögen der Gattungen schreiben, um jede Herbarpflanze ohne Zeitverlust mit der in der Flora gegebenen Charakterisierung vergleichen zu können.

e) Legt man ein natürliches System zu Grunde, was sehr zu empfehlen ist, so vereinigt man die Gattungen zu Familien, welche wieder in der Reihenfolge des Systems angeordnet und durch besondere, aus den Packeten hervorragende Etiketten kenntlich gemacht werden. Je nach dem Unfange der Familien können mehrere Familien oder bloß eine in ein Packet (Herbariumfaszikel) vereinigt werden; große Familien (z, B. die Compositen, Papilionaceen, Umbelliferen u. a.) werden beim Anwachsen des Herbars mehrere bis viele Faszikel füllen. Letztere dürfen nie zu dick gemacht werden. Jedes Faszikel ist entweder in große Bogen Packpapier einzuschlagen und kreuzweis mit Bindfaden (Spagat) zuzubinden (was die Pflanzen am besten gegen Staub und die Angriffe schädlicher Gliederthiere schützt, aber den Gebrauch des Herbars erschwert), oder, wie iiblicher, in eine Herbariummappe einzuschließen, welche aus zwei starken Pappdeckeln von der Größe des gewählten Papierformates besteht, die durch zwei durchgezogene feste Bänder oder durch darumgelegte Gurtbänder oder Riemen mit Schnallon zusammengeschnürt werden können.

Ein in dieser Weise eingerichtetes Herbar hat wirklichen wissenschaftlichen Wert und ist für seinen Besitzer eine Quelle reicher Freude und Belehrung.*)

*) Man hat neuerdings sogenannte Schülerherbarien für Anfänger im Pflanzensammeln auf den Marlit gebracht, entweder fertige Herbarien mit einigen Hunderten von allgemein verbreiteten und besonders wichtigen Pflanzenarten mit gedruckten Etiketten, und angeklebten Pflanzen oder Herbarienmappen mit dem erforderlichen $\mathrm{Pa}$. pier und gedruckten Etikettenbögen, welche in die einzelnen Etiketten zerschnitten werden können. Mappen letzterer Art mit 100 Blatt starken Papiers und 400 Etiketten sind such in der Verlagsbuchhandlung dieser Flora in eleganter Ausstattung für $1 \mathrm{fl} .80 \mathrm{kr}$. 
Getrocknete Pflanzen sind den Angriffen verschiedener kleiner, iiberall vorkommender Gliederthiere ausgesetzt, so namentlich der Bohrkäfer (Arten von Anobium), deren Maden die Stengel aushühlen und die Blüten, schließlich die ganze Pfanze zerstören, der Blütenkäfer (Anthrenus), verschiedener Milben u. a. m. Das sicherste Mittel, die Pflanzen gegen diese Feinde zu schützen, ist das Eintauchen der getrockneten Exemplare in eine weingeistige Lösung von Sublimat, deren Anwendung aber, abgesehen von der Umständlichkeit dieses Verfahrens, nicht ungefährlich, weil das Sublimat sich zum Theil wieder in fester Form ausscheidet und als weifer Staub die Pflanzen oder Papierbogen bedeckt und so leicht beim Blättern im Herbar eingeathmet werden kann. Besser und ganz ungefährlich ist die Anwendung von Schwefel-Ammonium, einer sehr billigen, rasch verdunstenden Flïssigkeit, deren Dämpfe die Pflanzenpackete durchdringen und alles etwa darin befindliche thierische Leben vernichten. Zur Anwendung dieser Flüssiglkeit bedarf man aber eines inwendig mit Zinkblech ausgesclilagenen Kastens, groß genug, um gleichzeitig mehrere Herbarienpackete hineinlegen zu können (jede Kiste ist dazu verwendbar!), dessen oberer Rand eine fortlaufende Rinne bilden muss, die mit Wasser gefüllt werden kann. Dadurch, dass der mit einer niedrigen senkrechten Leiste zu versehende Deckel des Kastens mit dieser Leiste genau in die Rinne eingreift, wird (durch das Wasser) eine luftdichte Verschließung des Kastens herbeigeführt. Auf den Boden des letztern setzt man ein offenes Gefäß mit Schwefelammonium, schichtet die Pflanzenpackete darum hinein und verschließt hierauf den Kasten, in dem man die Packete 4 bis 5 Tage liegen lässt. Die wieder herausgenommenen Packete (die Faszikel sind aufgebunden in den Kasten zu legen, damit die Planzen locker liegen und von dem Schwefelammoniumdunste gänzlich durchdrungen werden können) müssen einige Tage an die Luft gelegt werden, damit sich der sehr unangenehme Geruch des Schwefelammoniums verliert. Sehr empfehlenswert ist es, neu gesammelte Pflanzen, bevor man solche dem Herbar einverleibt, in einen solchen Giftkasten einige Tage lang zu legen. Wer

\footnotetext{
zu haben. So löblich solche Schulerherbarien genannt zu werden verdienen, so kann Verf. doch nicht umhin, zu bemerken, dass der Anfänger im Pfanzensammeln viel mehr lernen wird, wenn er nicht nur die Pfanzen selbst sammelt und bestimmt, sondern sich sein Herbar nach den angegebenen Regeln selbst anlegt, und die Etiketten selbst schreibt. Enthalten letztere das Datum, so wird deren Anblick ihn noch in späteren Jahren an so manche schöne Gegend, an so manchen genussreichen Tag, an so manches Abenteuer erinnern. Die selbstgeschriebenen Etiketten des Herbariums eines Botanikers, welcher sein ganzes Leben hindurch gesammelt hat, enthalten eine ganze Biographie und ist ein solches Herbar, wenn dessen Besitzer, wie es wohl immer der Fall gewesen sein wird, mit vielen andern Botanikern im Tauschverkehr gestanden hat, zugleich eine wertrolle Autographensammlung.
} 
sein Herbar alle 3-4 Jahre dieser Procedur unterwirft, wird keines Insectenschaden $\mathrm{zu}$ beklagen haben. $\mathrm{Zu}$ warnen ist vor der Anwendung. des persischen Insectempulvers, weil dieses die Pfanzeneremplare, besonders die Blüten selır verunreinigt.

II.

\section{Erklärung der in dieser Flora der Anordnung der Yflanzen zugrunde gelegten Systeme.}

\section{Das Linnè'sche System.}

Dieses von dem berühmten schwedischen Naturforscher Karl v. Linné (geb. zu Råshult d. 13 Mai 1707, gest. zu Upsala d. 10. Januar 1778) herrührende System, welches auch das Sexualsystem genannt wird, weil seine Classen und Ordnungen fast lediglich auf die Verhältnisse der Geschlechtsorgane der Pflanzen gegründet sind, ist ein sogenanntes künst. liches, weil bei der Anordnung der Planzen die natürliche Verwandtschaft: (Zusammengehörigkeit) der Pflanzengattungen fast gar nicht berïcksich. tigt worden ist, sondern die Gattungen nur nach leicht erkennbaren, an und für sich unwesentlichen Merkmalen (z. B. Anzahl der Staubgefäße und Griffel einer Blïte) classificiert werden. Ebendeshalb aber eignet sich dieses System in vorzüglicher Weise zur Auffindung (Bestirimung) der Gattungen für Anfänger, welche erst wenige oder gar keine Pflanzen kennen, weshalb auch in dieser Schulflora der nach dem natürlichen System angeordneten Aufzählung und Charakterisierung der Arten der zu natürlichen Familien vereinigten Gattungen ein Schliissel zur Bestimmung der Gattungen (beziehentlich Familien) nach dem Linné'schen System vorausgeschickt worden ist.

Die 24 Classen des Linné'schen Systems beruhen auf folgenden Principien: 1. auf der bloßen Anzahl der Staubgefäße in einer Blüte (Cl. 1-11), 2. auf der Zahl und Einfügungsweise der Staubgefäße (Cl. 12 und 13), 3. anf verschiedener Länge derselben (Cl. 14 und 15), 4. auf dem Verwachsensein der Staubfäden (Cl. 16-18), 5. auf dem Verwachsensein der Staubbeutel (Cl. 19), 6. auf der Verwachsung der Staubbeutel mit dem Griffel (einer Griffelsäule, Cl. 20), 7. auf dem Vorkommen bloß eingeschlechtiger (männlicher und weiblicher) Blïten (Cl. 21 und 22) und 8. auf dem gleichzeitigen Vorkommen ein- oder zweigeschlechtiger Blüten (Zwitterblüten) auf einem und demselben Pflanzenexemplar (Cl. 23). Die Pflanzen der zwanzig ersten Classen besitzen nämlich lauter Zwitterblïten. Die 24. Cl. enthält alle jene Pflanzen, welche sich nicht durch keimhaltige Samen, sondern durch keimlose, mikroskopische Zellen (Sporen) 
fortpflanzen, d. h. die Pilze, Flechten, Algen, Moose, Farne, Schachtelhalme, Bärlappe u. a. m. Diese nannte Linné kryptoga mische (plantao cryptogamae, wörtlich: „verborgenzeugende“, gewöhnlich ,verborgenblütige" oder, ,blütenlose“" genannt), im Gegensatz zu den phanerogamischen (pl. phanerogamae, wörtlich: "sichtbarzeugende", gewöhnlich als „sichtbarblühende" oder kurzweg als „Blütenpflanzen" bezeichnet), unter denen er sämmtliche Samenpflanzen verstand. Umstehend geben wir eine Übersicht der Classen des Linné'schen Systems. Jede Classe zerfällt in Ordnungen, welche der Mehrzahl nach ebenso künstliche sind, ais wie die 23 ersten Classen, zum Theil aber ganze natürliche Familien umfassen, so z. B. die 1. Ordnung der 14. Classe die Familie der Lippenblätter (Labiatae). Die Ordnungen der ersten 13 Classen beruhen auf der Zahl der Griffel oder Narben in einer Blume, die der 14. und 15. Classe auf der Beschaffenheit der Frucht. In der 16., 17., 18. und 20. Cl. sind die Ordnungen wieder auf die Zahl der Stauhgefäße begründet, in der 21. und 22. theils auch auf die bloße Zahl, theils auf das Verwachsensein der Staubgefäße. Es kehren in diesen Classen (16-22) die Namen der 19 ersten Classen als Benennungen der Ordnungen wieder. Die 23. Classe zerfiel in 2 Ordnungen; da aber das gemischte Vorkommen von einund zweigeschlechtigen Blüten ein sehr unbeständiges ist, so ist diese ganze Classe bei Zeiten aufgegeben worden. Die Ordnungen der „4. Classe umfassen ziemlich natürliche Gruppen.

\section{Übersicht der Classen des Linné'schen Systems.}

Classen und Benennung derselben.

I. Monandria. Einmänniglkeit. Zwitterblïten mit 1 Staubgefii $\int$.

II. Diandria. Zweimännigkeit.

III. Triandria. Dreimännigkeit.

IV. Tetrandria. Viermännigkeit.

V. Pentandria. Fünfmännigkeit.

VI. Hexandria. Sechsmännigkeit.

VII. Heptandria. Siebenmännigkeit.

VIII. Octaudria. Achtmännigkeit.

IX. Enneandria, Neunmännigkeit

$\mathrm{X}$. Decandria. Zehnmännigkeit.

XI. Dodecandria. Zwölfmännigkeit. " $\quad$ " $11-12$ "Staubgef.

XII. Icosandria. Zwanzigmännigkeit. Zwitterblüten mit 20 und mehr Staubgefäßen, welche im Kelchschlunde eingefügt sind.

XIII. Polyandria. Vielmännigkeit. Zwitterblïten mit 20 und mehr auf dem Blütenboden eingefügten Staubgefäßen. 
XIV. Didyuania. Zweimächtigkeit. Zwitterblüten mit 2 langen und 2 kurzen Staubgefäßen.

XV. Tetradynamia. Viermächtigkcit. Zwitterblüten mit 4 langen und 2 kurzen Staubgefäßen.

XVI. Monadelphia. Einbrüdrigkeit. Zwitterblüten mit in einen Cylinder oder nur am Grunde unter sich verwachsenen Staubfäden.

XVII. Diadelphia. Zweibrüdrigkeit. Zwitterblüten mit in 2 gesonderte Partieen (Bündel) verwachsenen Staubfäden oder mit 10 Staubfäden, von denen 9 unter sich verwachsen sind, der 10. (obere) frei ist (viele Schmetterlingsblütler).

XVIII. Polyadelphia. Vielbrüdrigkeit. Zwitterblïten mit in 3 oder mehr Bündel verwachsenen Staubfäden.

XIX. Syngenesia. Staubbeutelverwachsung. Zwitterblüten mit 5 Staubgefäßen, deren Beutel in eine Röhre verwachsen sind.

XX. Gynandria. Mannweibigkeit. Zwitterblüten, deren Staubbeutel mit dem Griffel (mit einer Griffelsäule) verwachsen sind.

XXI. Monoecia. Einhäusigkeit. Männliche und weibliche Blüten auf e in em Pflanzen-Exemplar.

XXII. Dioecia. Zweihäusigkeit. Männliche Blüten auf dern einen, weibliche auf dem ardern Exemplar derselben Pflanzenart.

XXIII. Polygamia. Vielhäusigkeit. Eingeschlechtige und Zwitterblüten unter einander gemengt auf demselben Pflanzenexemplar.

XXIV. Cryptogamia. Verborgenzeugung. S. oben.

Die Benennungen der Ordnungen endigen in den 13 ersten Classen auf gynia (von ruvh, das Weib, ebenso wie die Endungen der Benennungen dieser Classen von ávrip, der Mann, herrühren), folglich Monogynia, Digynia, Trigynia, Tetragynia, Pentagynia u. s. f. bis Polygynia, d. h. mit 1, 2, 3, 4, 5, vielen Griffeln oder Narben oder ganzen Stempeln. Es sind in keiner Classe alle Ordnungen vorhanden. Die beiden Ordnungen der 14. Classe heißen Gymnospermia, Nacktsamigkeit und Angiospermia, Bedecktsamigkeit, indem Linné die 4 Nüsschen, in welche die Frucht der Lippenblütler zerspringt, irrigerweise für nackte Samen hielt, während die Pflanzen der 2. Ordnung eine mehrsamige Kapselfrucht besitzen. Die beiden Ordnungen der 15. Clisse führen die Namen Siliquosae, Schotenfrüchtige, und Siliculosae, Schötchenfrüchtige, weil die Früchte dieser Pflanzen (sämmtlich der Familie der Kreuzblütler angehörig) Schoten oder Schötchen sind. In der 16., 17. und 18. Classe kehren die Classennamen als Ordnungsbenennungen wieder, als: Triandria, Pentandria, Hexandria, Octandria, Decandria, Polyandria. Die 19., sämmtliche Compositen und einige andere Pflanzen umfassende Classe, zerfällt in folgende 6 Ordnungen, von denen 5 den gemeinschaftlichen 
Namen Polygamia führen: 1. P. a equalis, mit iauter gleichgeformten Zwitterbliiten im Blütenkürbchen, 2. P. superflua, mit weiblichen fiuchtbaren Blüten im Strahl und fruchtbaren Zwitterblüten in der Scheibe, 3. P. frustranea, mit geschlechtslosen Blüten im Strahl und fruchtbaren Zwitterblüten in der Scheibe; 4. P. necessaria, mit fruchtbaren weiblichen Strahlblüten und männlichen (verkiimmerten Zwitterblüten) in der Scheibe; 5. P. segregata, mit getrennten, von besonderen Hüllen umgebenen Zwitterblüten in einem kugelrunden Köpfchen. Die 6. Ordnung, Monogamia enthäit syngenesische Pfanzen mit nicht in Körbchen gestellten Blüten, welche nicht zu den Compositen gehören. Die Ordnungen der 21. und 22. Classe sind wieder nach der Zahl n. s. w. der Staubgefäße (der männlichen Blüten) benannt, als: Monandria, Polyandria, Monadelphia u. Syngenesia. Die 24. Classe theilte Linné selbst in 4 Ord. nungen: Filices, Farne, M usci, Moose, Algae, Algen, Fungi, Pilze. Später wurde deren Zahl vermehrt, indem man von den Farnen die Schachtelhalme und Wurzelfrüchtler, von den Moosen die Bärlappe, von den Algen die Flechten als eigene natiirliche Ordnungen abtrennte.

Die zah!reichen Ausnahmen (Schwankungen in der Zahl der Staubgefäße u. a. m.), welche einzelne Arten der nach dem Linné'schen System geordneten Gattungen darbieten, sind in dem Schlüssel der Gattungen dieser Flora gebürend berücksichtigt worden.

\section{Das natürliche in dieser Schulflora zugrunde gelegte System.}

Sämmtliche Gewächse zerfallen in Samenpflanzen (Spermato. phyta $=$ den Phanerogamen Linnés) und in Sporengewächse (Sporophyta = den Linné'schen Kryptogamen). Von letzteren sind in unserer Flora bloß die G e fäß-Spore n p flanzen (Schachtelhalme, Bärlappe, Farne und Wurzelfrüchtler) berücksichtigt. Die Samenpflanzen theilen sich in nacktsamige (Gymnospermae), d. h. Pflanzer, deren Samenknospen, folglich auch Samen nicht in einen Fruchtknoten eingeschlossen, sondern offen an Schuppen oder anders geformten Trägern befestigt sind, (z. B. die Samen der Nadelhölzer) und in Bedecktsamige (Angiospermae), d. h. Pflanzen mit einem den oder die Samen umschließenden Fruclitlnoten. Letztere zerfallen in ein s a m e $\mathrm{l}$ a p pige (A. monocotyledoneae) und z we isamenlappige (A. dicotyledoneae). Bei ersteren ist der Keim (embryo) von einem mantelförmigen Samenlappen (Keimblatt, cotyledon) umhüllt, welcher bei der Keimung in der Samenschale zurïckbleibt, folglich nie über den Boden hervortritt, bei letzteren mit 2 gegenständigen mehr weniger blattartigen Samenlappen (Keimblättern), die in der Regel durch die Streckung des hypokotylen Gliedes (Stengelchen des Keimes) über den Boden emporgehoben werden, sich hier ausbreiten, grün färben und als 
die ersten Blätter functionieren. Die Dikotyledonen werden eingetheilt in Kronenlose (Apetalae), deren Blüten keine Blumenkrone, sondern nur einen Kelch oder Perigon besitzen oder ganz lüillenlos sind, in diesem Falle also nur aus den Geschlechtsorganen bestehen, in verwachsenblumige (Gamopetalae), mit Kelch und ganz- oder verwachsenblättriger Blumenkrone, und in getrenntblumige (Dialypetalae), mit Kelch und mehrblättriger Blumenkrone. Letztere fehlt häufig. Demnach gliedert sicb das System wie folgt:

Erste Reihe: Sporophyta.

Zweite Reihe: Spermatophyta.

I. Abtheilung und I. Classe: Gymnospermae.

II. Abtheilung: Angiospermae.

II. Classe: Monocotyledoneae.

III. " Dicotyledoneae.

1. Unterclasse: Apetalae.

2. $"$ "Gamopetalae.

3. " " Dialypetalae.

Diesen Classen und Unterclassen sind die natürlichen Familien nach ihrer Verwandtschaft subordiniert.*)

III.

\section{Erklärung der im Text rorkommenden Abkürzungen. 1. Abkürzungen in den Beschreibungen.}

b. bei.

Bl. Blatt, Blätter.

Blbl. Blumenkronenblätter.

Blt. Bliute.

Bltstand. Blütenstand.

Bltstiel. Blütenstiel.

br. breit.

Fr. Frucht.

Frkn. Fruchtknoten.

gr. groß.

Gr. Griffel.

Kch. Kelch.

Kchbl. Kelchblätter.

h. hoch.

1. lang.

kl. klein.

Perig. Perigon.

Pf. Pflanze.

St. Stengel.

Stbl. Stengelblätter.

Stbg. Staubgefäße.

Stbb. Staubbeutel.

Stbf. Staubfäden.

Stpl. Stempel.

Var. Varietät.

Wz. Wurzel.

Wzst. Wurzelstock.

Zwb. Zwiebel.

\section{Zeichen für die Lebensdauer.}

$\odot$ einjährig. $\odot$ zweijährig. 4 ausdauernd. † Holzgewăcbs.

Die hinter diesen Zeichen stehenden Ziffern bedeuten die Monate des Blühens, z. B. 5. 6. = Mai, Juni ; $7-9=$ Juli bis September.

*) Eine Charakterisierung der in der österreichischen Flora repräsentierten Familien zu geben, verbietet die Beschränktheit des Raumes. Viele sind in dem Schlüssel zur Bestimmung der Gattungen kurz charakterisiert. 


\section{Abgekürzte Ländernamen (fettgedruckt).}

B. = Böbmen. $-K_{.}=$Kärnthen. $-K_{\text {r. }}=$ Krain. - Mh. $=$ Mïhren. - Noe. $_{0}=$ Niederösterreich. -0 e. $=$ Österreich. -0 oe. $=$ Oberösterreich. - Sch. = Schlesien (österreichisch). - St. $=$ Steiermark. $\mathbf{S} \mathbf{z}_{0}=$ Salzburg. $-\mathbf{T} .=$ Tirol. $-\mathbf{V} .=$ Vorarlberg.

\section{Abgekürzte Autorennamen.}

Ad. Adans. Adanson.

Ait. Aiton.

A. Br. Alexander Braun.

All. Allione.

Andrz. Andrzejowski.

Ard. Arduino.

Asch. Ascherson.

Bab. Babington.

Balb. Balbis.

Bartl. Bartling.

Bast. Bastard.

C. Bauh. Caspar Bauhin.

J. Bauh. Johann Bauhin.

Bàumg. Baumgarten.

P. B. Palisot de Beauvois.

Bechst. Bechstein.

Beck. Beck.

Bth. Beuth. Bentham.

Brnh. Bernhardi.

Bert. Bertoloni.

Bess. Besser.

Biv. Bivona.

Boengh. Boenninghausen.

Boerh. Boerhaave.

Borkh. Borkhausen.

Brot. Brotero.

C. A. M. Carl Anton Meyer.

Casp. Caspary.

Cass. Cassini.

Cav. Cavanilles.

Clairv. Clairville.

Coss. Germ. Cosson und Germain.

Coult. Coulter.

Crtz. Crantz.

Curt. Curtis.

Cuss. Cusson.

Čelak. Čelakowsky.

DC. De Candolle.

Delarb. Delarbre.

Desf. Desfontaines.

Desr. Desrousseaux.

Desv. Desvaux.

Dill. Dillen.

Döll. Döll.

Don. Don.

Dougl. Douglas.
Drej. Drejer.

Dub. Duby.

Dum. Dumortier.

Ehrh. Ehrhart.

Fl. Wett. Flora der Wettcrau.

Forsk. Forskål.

Fr. Fries.

Freyn. Freyn.

Froel. Froelich.

Gaertn. Gaertner.

Gaud. Gaudin.

Gilib. Gilibert.

Grke. Garcke.

Gmel. Gmelin.

Gochn. Gochnat.

Godr. Gren. Godron und Grenier.

Good. Goodenough.

Gren. Grenier.

Gris. Grisebach.

Hack. Hackel.

Hal. Halacksy.

Hall. Haller.

Hartm. Hartmann.

Haw. Haworth.

Hayn. Hayne.

Hegetsch. Hegetschweiler.

Hke. Haenke.

Hoffm. Hoffmann.

Horn. Hornemann.

Host. Host.

Hppe. Hoppe.

Huds. Hudson.

Jeq. Jacq. Jacquin.

Juss. Jussieu.

Kern. Kerner.

Kit. Kitaibel.

Koel. Koeler.

Kth. Kunth.

Kütz. Kützing.

Lag. Lagasca.

Lap. Lapeyrouse.

Lamk. Lamarck.

L'Hér. L'Héritier.

Lehm. Lehmann.

Lej. Lejeune.

Less. Lessing. 
Leyss. Leysser.

Lightf. Lightfoot.

Lilj. Liljeblad.

Lk. Link.

L. Linné.

Lois. Loiseleur.

Lumn. Lumnitzer.

M. B. oder M. Bieb. Marchall von Bieberstein.

Med. Medicus.

Mér. Mérat.

M. K. Mertens und Koch.

E. Mey. Ernst Meyer.

Mchx. Michaux.

Mett. Mettenius.

Mich. Micheli.

Mik. Mikan.

Mill. Miller.

Moehr. Moehring.

Mnch. Moench.

Mol. Molina.

Moq. T. Moquin Tandon.

Murr. Murray.

Naeg. Naegeli.

N. v. E. Nees von Esenbeck.

Nest. Nestler.

Nutt. Nuttall.

Pall. Pallas.

P. Persoon.

Peterm. Petermann.

Pfr. Pfeiffer.

Poir. Poiret.

Poll. Pollich.

Presl. Presl.

R. Br. Robert Brown.

Rchb. Reichenbach.

Rchb. fil. Reichenbach filius.

Rebent. Rebentisch.

Retz. Retzius.

Rich. Richard.

R. Sch. Roemer u. Schultes.

Rth. Roth.

Roz. Rozier.

R. P. Ruiz u. Pavon.

Salisb. Salisbury.

Schle. Scheele.

Schied. Schiede.

Schimp. Schimper.

Schk. Schkuhr.

Schott. Schott.

Schtdl. Schlechtendal.
Schleich. Schleicher.

Schrd. Schrader.

Sobrk. Schrank.

Schreb. Schreber.

Schutt. Schutter.

Schum. Schumacher.

Scop. Scopoli.

Seb. Maur. Sebastiani u. Mauri.

Ser. Seringe.

Sibth. Sibthorp.

Sm. Smith.

Soy. Will. Soyer-Willemet.

Spr. Sprengel.

St. Sturm.

St. Hil. Saint-Hilaire.

Sternb. Sternberg.

Stev. Steven.

Sutt. Sutton.

Sw. Swartz.

Ten. Tenore.

Thuill. Thuillier.

Tourn. Tournefort.

Tratt. Trattinik.

Trev. Treviranus,

Trin. Trinius.

Tsch. Tausch.

Uechtr. v. Uechtritz.

Vaill. Vaillant.

Vent. Ventenat.

Vill, Villars.

Vis. Visiani.

Weiss. Weiss.

Whlbg. Wahlberg.

Wahlenb. Wahlenberg.

W. Kit. Waldstein u. Kitaibel.

Whe. N. Weihe u. Nees.

Wallr. Wallroth.

Web. Weber.

Weig. Weigel.

Wender. Wenderoth.

Wib. Wibel.

Wigg. Wiggers.

Wickstr. Wickström.

Wiesb. Wiesbaur.

Wimm. Grab.Wimmer u. Grabowski

Willd. od. W. Willdenow.

Wirtg. Wirtgen.

With. Withering.

Wk. Willkomm.

WVulf. Wulfen.

Zimm. Zimmeter. 


\section{Schlüssel zum Bestimmen der Gattungen nach dem Linnéschen System.}

\section{Classe. Monandria.}

Erste Ordnung (I, 1). Monogynia.

1. Wasser- od. Sumpfgewächse.

Landpflanzen.

2.

3.

2. Kl. Wasserpt, mit schwimmendem Laub; Blt. sehr kl., in rand. ständigem Spalt, zwitterlich od. 1 geschlechtig-2 häusig, mit zartem Perigon. Lemna (32).*)

Im Schlamme wurzelnde Sumpfpf.; Blt. mit undeulichem oberständ. Kelchsaum, 1 samiges Nüsschen.

Hippuvis (164).

3. Blkr. oberständig langröhrig, am Grunde gespornt, Saum ausgebreitet, ungleich 5̆lappig; Kelch undeutlich, 2 samige kl. Schließfr.

Centranthus (303).

Blkr. fehlend, Kelch unterständig, 4spaltig. Sehr kl. Pfänzchen. Alchemilla Aphanes (695).

\section{Zweite Orduung (I, 2). Digynia.}

1. Wasserpt.; Blt. kl. mit 2 häutigen Deckblättchen.

Callitriche (165). Vgl, Cl. XXI, 1.

2. Grïser: Vulpia Myurus und V. bromoides (51).

3. Landbewohnende Kräuter.

4. St. bllos, gegliedert. Salicornia (184). Vgl. II, 1.

St. beblättert.

5. Blt. mit 3 spaltig., später fleischig-saftig werdendem und sich roth färbendem Kelch. Blitum (185). Vgl. V, 2.

Kelch trockenbleibend od. fehlend.

6. Kelch aus $2 \mathrm{kl}$. Schüppchen bestehend od. fehlend.

Kelch 5 blättrig, von 2 Derkblättchen gestützt.

$$
\text { Corispermum (190). Vgl. V, } 2 .
$$$$
\text { Polycnemum (194). Vgl. III, } 1 .
$$

*) Die hinter den Gattungsnamen eingeklammerten Ziffern sind die Nummeru der Gattungen in der systematischen Aufzählung der Pfanzen der Flora 


\section{I. Classe. Diandria.}

\section{Erste Ordnung (II, 1). Monogynia.}

1. Schwimmende oder flutende Wasserpfl.

2.

b) Landbewohnende Kräuter.

3.

c) Bäume od. Sträucher mit gegenständigen Bl. (Oleaceen). 11.

2. Schwimmendes Laub (s. I, 1).

Lemna (32).

St. fadenförmig, mit feinzertheilten Bl.; Kelch 2 blättrig, Blkr. maskiert. 2 lippig; 1 fächrige Kapsel.

Utricularia (415).

3. St. gegliedert, bllos; Blt. sehr kl., zu 3 in den Aushöhlungen d. Stglieder stehend, Perigon ganz, fleischig.

Salicornia (184).

Beblätterte Pf.

4. Frkn. unterständ., Kelchsaum 2 lappig, Blkr. 2 blättrig; Nüsschen.

Frkn. oberständig.

Circaea (673).

5. Frkn. 4 theilig, Spaltfr. in 4 Nüssch. zerfallend (Lippenblïtler). 6.

Frkn. ganz, mehrsamige Kapsel.

6. Kelch 5 zähnig, Blkr. trichterförm. 4 spaltig, undeutlich 2 lippig; Stbg. vorstehend (neben d. 2 fruchtbaren oft 2 beutellose Filamente).

Lycopus (329).

Kelch 2 lippig, Blkr. rachenförmig-2 lippig mit helmförm. Oberlippe; Stfïden mit quer aufliegendem Mittelband, dessen eines Ende ein pollenhıltiges, dessen anderes Ende ein verkümmertes Staubbeutelfach trägt.

7. Blkr. radförmig, mit ungleich 4lappigem Saum; Kaps. zusammen. gedrückt, ausgerandet od. 2 lappig.

Blkr. röhrig-2 lippig.

8. Blkr. gespornt, Kelch 5 spalt., Kaps. 1 fächr. Pinguicula (414).

Blkr. nicht gespornt.

Veronica (403).

9. Blt. achselständig; Blkr. mit 4 kantiger Röhre u. undeutlich 2 lipp, 4 lappigem Saum; außer d. 2 fruchtbaren Stbg. 2 Filamente; Kaps. 2 fächr., 2klappig.

Gratiola (395).

Blt. in endständ. Trauben, Blkr. deutlich 2 lippig, Kapsel 2 fächr. 10.

10. Kelch 5 theilig, Stbg. in den Buchten $z$ wischen den Lippen der Blkr. eingefügt, Stbb. nierenförmig, Schlund d. Blkr. nackt.

Wulfenia (397).

Kelch 5 spaltig, Stbg. im Grunde d. Blkrrröhre einem Haarringe eingefügt, Stbb. herzförmig.

11. (1, c.) Blt. vollständig.

Paederota (398).

Blt. unvollständ., hüllenlos od. mit 4 zähnig. Kelch, oft 1 geschlecht. Zungenförmige 1 samige Flügelfrucht.

22. Blkr. 4 blättrig, mit gedrehtem $\mathrm{Bl}$; zungenförnige Flügelfr.

Blkr. ganz, 4 spaltig.

Ornus (316).

13. Blkr. trichterförmig. Beere.

13.

Bl Blly. trichterformig. Beere. Ligustrum (313).

Ligustrum (313).
hrige 2 klapp. Kaps. Syringa (314).

\section{Zweite 0rdnung (II, 2). Digynia.}

1. Gräser: Authoxanthum, Hierochloa, Bromus (z. Th.). Vgl. Gramineen S. 13.

2. Bäume u. Sträucher mit Kätzchen. Salix (166). Vgl. XXII, 2. 


\section{Classe. Triandria.}

Erste Ordnnng (III, 1). Monogynia.

1. Blt. vollständig, mit Kelch und Blkr.

2.

Blt. unvollständig, mit einfacher od. gar keiner Hülle. 4.

2. Frkn. oberständ., Kelch 2 blättrig, bleibend, Blkr. trichterförmig, mit gespaltener Röhre und 5 theiligem Saum. Kapsel 1 fächrig, 3 klappig. Montia (600).

Frkn. nnterständig, Kelch u. Blkr. oberständig. (Valerianaceen). 3.

3. Kelch ein umgerollter gezähnter Saum, der sich nach dem Blühen in eine aus Federborsten bestehende Frkrone (pappus) verwandelt; Blkr. trichterförmig, mit ungleich 5lappigem Saum; 1 samige Schließfr.

Valeriana (302).

Kelch ein gezähnter od. undeutlicher Saum, nicht in Federborsten auswachsend, aber sich nach d. Blühen vergrößernd u. verändernd; Blkr. kl. trichterförm, Schließfr. 3 fächr., v. Kelch gekrönt. Valerianella (301).

4. Blumenartiges Perigon, Narben (3) blumenblattartig, Frkn. unterständig, Kaps. 3 fächrig, 3 klappig, vielsamig: I r i d e en.

b) Kelchartige kl. 5 blättrige Blthülle, von 2 Deckblättch. gestützt, Frkn. oberständig, Stbg. einem Ringe eingefügt. Einsamige Schlauchfr. Polycnemium (194).

c) Blt. hüllenlos, in Ährchen od. Ähren unter einer spelzenartigen Schuppe, od. von Borsten, Haaren, Schüppchen umgeben, ebenfalls unter Schuppen in Ährchen geordnet. Einsamige Schließfr. (Karyops.). Grasartige Pflanze: Familie d. Scheingräser (Cyperaceae). S. 35.

d) Ährengras mit 1 bltigen Ährchen; Frkn. mit einer fedrigen Narbe.

5. Perigon regelmäßig 6 theilig. Nardus (41).

Perigon röhrig-trichterförmig, 6 theilig, mit ungleichgroßen fast zweilippig gruppierten Theilstücken; Stbg. vorstehend, aufsteigend, Gr. fadenförmig.

6. Perigon kurz- od. langröhrig, äußere Theilstücke zurückgebogen, innere (meist schmäler) aufrecht od. zusammengeneigt; Gr. kurz, Narben groß, nach außen umgebogen, gekielt, mit 2 lappigem Saum; Stbg. unter den Narben liegend.

Perigon langröhrig mit glockigem Saume; Gr. sehr l., Narben schmal, nach oben verbreitert. Crocus (106).

\section{Zweite Orduung (III, 2), Digynia.}

Blt. hüllenlos, zwischen 2 Spelzen eingeschlossen, selten unter einer Spelze liegend; Stbfäd. haarfein, Stbb hängend lineal, Frkn. oberständig, 2 fedrige od. pinselförmige Gr. od. Narben tragend; Fr. eine 1 samige Karyopse. Blt. zı 2 bis vielen in am Grunde von 2 Spelzen (Kelchspelzen) umschlossenen Ährchen, oder einzeln innerhalb zweier Kelchspelzen (einblütiges Ährchen): Familie der Gräs er (Gramineae). S. 13.

\section{Dritte Ordnung (III, 3). Trigynia.}

Mit 3 Stbg. kommen bisweilen vor: Holosteum umbellatum $(\mathrm{X}, 3)$, Stellaria media (X, 3), Elatiue (VIII, 3), A marantus (XXI, 5), mit 3 Griffeln Montia (III, 1). 


\section{Classe. Tetrandria.}

\section{Erste Ordnung (IV, 1). Monogynia.}

1. Blt. vollständig (mit Kelch und Blkr.).

2.

Blt. unvollständig (mit Kelch od. Perigon).

2. Blkr. verwachsenblättrig.

Blkr. getrenntblättrig.

3. Frkn. unterständig.

Frkn. oberständig.

4. Frkn. nackt (ohnt besondere Hülle), Kelch rudimentär, gezähnt, Blkr. rad-od. trichterförmig: in 2 einsamige Hälften zerfallende Spaltfr.: Familie der $\mathrm{Rubiaceen.}$ S. 142.

Frkn. u. Fr. von einer besonderen kelchartigen Hülle mit verscbiedenartig gebildetem Saume (Hüllehen, involucellum) umschlossen; Kelch schüssel- od. beckenförmig, gezähnt od. borstig: einsamige Schließfrucht: Familie d. Dipsaceen. S. 138.

5. Blkr. fast 2 lippig, mit $4-5$ spaltigem Saume; 1 samiges, nicht aufspringendes Schlauchfrüchtchen; Blt. in dichten Köpfchen.

Blkr. regelmäßig, mit 4 theiligem Saume. Globularia (359).

6. Blkr. röhrig, mit zurückgeschlagenem Saume, trockenhäutig, Narben 2, fađenförmig; 2 fächrige, vielsamige, ringsherum aufspring. Kapsel. Plantago (412).

Bikr. kuglig mit abstehendem Saume, Narbe kopfförmig; 1 fächrige, vielsamige, ringsherum aufspringende Kapsel

Centunculus (426).

7. (2) Frkn. oberständ., Kelch u. Blkr. 4 blättrig, Blt. kreuzförm. 8.

Frkn. unterständig, Kelch 4 spaltig, Blkr. 4 blättrig. 10.

8. Kelch-, Blbl. u. Stbg. vor einander stehend, Blbl. kappenförmig, in d. kahnförmigen Kelchbl. eingeschlossen; vielsamige Balgkapsel.

Kelch-, Blbl. u. Stbg. abwechselnd gestellt. Epimedium (537).

9. Stbg. am Rande einer d. Frkn. umgebenden Scheibe eingefügt; 4 knopfige, 4 samige, barettförmige Kapsel; Samen von einem orangerothen Mantel umhüllt. Sträucher.

Evonymus (644).

Keine Scheibe unter d. Frkn., häutige, 1 samige ovale Flügelfrucht. Ptelea (658).

Anmerk. Mit 4 Stb. kommen auch vor: Rhamnus cathartica $(V, 1)$, Lythrum Hyssopifolia (XI, 1) und Cardamine hirsuta $(\mathrm{XV}, 2)$.

10. Blt. in endständ. Köpfchen od. Trugdolden, pflaumen- od. beerenförmige Steinfr. mit 2 fächrigem, 2 samigem Steinkern. Sträucher.

Cornus (441).

Blt. einzeln, blwinkelständig; Fr. eine durch die vergrößerten und verhärteten Kelchzipfel mit 4 Dornen begabte 1 samige Nuss. Schwimmende Wasserplanze. Trapa (675).

11. (1) Bäume od. Sträucher. Blt. zwitterlich u. männlich, mit außen silberglänzendem, innen gelbem. röhrig-trichterförmigem, 4 spaltig. Perigon.

Kräuter. Elaeagnus (205). 
12. Blt. in dichten walzigen Köpfchen ohne Blkr., Kelch mit vier. theiligem ausgebreitetem Saume und 4 kantiger, den Frlkn. einschließender Röhre; Narbe kopifg. Nüsschen von d. verhärteten Kelchröhre umschlossen.

Blt. anders angeordnet.

Sanguisorba (699).

13. Frkn. unterständig, Kelchsaum 4 theilig, Blbl. fehlend (selten 4), Kaps. 4 füchrig, 4 klappig, vielsamig.

Frkn. oberständig.

Isnardia (672).

14. Blt. alle zwitterlich.

Blt. vielehig (zwitterl. und 1 geschlechtige vermengt), mit glockenförnnigem, meist 4 spaltigem Kelch; Stbg. in d. Knospe einwärts gelknickt, beim Aufblühen elastisch zurücksprirgend. Einsamiges Nüsschen.

Parietaria (183).

15. Blt. kl., ohne Blbl, mit grünem 4 theilig. ausgebreitetem Kelch and meist noch 4 theiligem Außenkelch (dann Kelch 8 spaltig erscheinend); Stbg. 1, 2, 4 auf einem d. Schlund verengendem Ringe. Einsam. Nüsschen.

Blt. mit 4 theiligem weißem Perigon. Beere. Majanthemum (146).

Alchemilla (695).

Vierte Ordnung (IV, 4). Tetragynia.

1. Immergrüner B. od. Str.; Kelch 4-5 zähnig. Blkr. 4-5 theilig, Irkn. oberständig mit 4-5 fast sitzenden Narben. Beerenförmige Steinfrucht.

Kräuter.

Ilex $(645)$.

2. Schwimmende od. flutende Wasserpfl.; Blt. hüllenlos, Mittelbänder der 4 sitzenden Stbb. in gr. blattartige Schuppen umgestaltet, scheinbar ein 4 blättriges Perigon darstellend; je 4 sitzende Steinfrüchtchen.

Landpflanzen; Frkn. oberständig.

Potamogeton (35).

3. Kelch 4 spaltig mit 2-3 spaltigen Zipfeln, Blkr. 4 blättrig; Kaps.

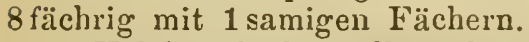

Radiola (664).

Kelch 4 theilig, Blkr. 4 blättrig; je 4 vielsamige Balgkapseln.

Vgl. auch Sagina und Moenchia (X, 3).

Builiarda (505).

\section{Classe. Pentandria.}

\section{Erste Orduung $(V, 1)$. Monogynia.}

1. Blüten vollständig. gefärbt.

Blt. unvollständig, ohne Blbl. (selten mit kl, verkümmerten). Kelch

2. Blkr. verwachsenblättrig.

25.

Blkr. getrenntblättrig.

3. Frkn. unterständig.

Frkn. oberständig.

4.

4. Blkr. trichter- oder röhrenförmig mit 5 lappigem, mehr weniger 2 lippigem Salme; Gr. fadenförmig; beerenförmige Steinfr. Holzgewächse. Lonicera (311).

Blkr. regelmäßig, mit 5 spaltigem od. 5 theiligem Saume. 
5. Blkr. kl., trichterförmig, zwischen d. eingeschlossenen Stbg. mit Haarbüscheln; Beere. Strauch.

Symphoricarpus (312).

Blkr. verschieden geformt, zwischen den Stbg. keine Haarbüschel; Kapsel. Kräuter.

6. Frkn. u. Kapsel halb-unterständig, letztere bis zur Hälfte 5 klapp., 1 fächrig; Blkr. kurz-glockig, außer d. 5 vollkommenen, im Grunde eingefügten Stbg. noch 5 beutellose zwischen d. Zipfeln d. Blkr. stehende Stbf.

Samolus (427).

Frkn. u. Kapsel ganz-unterständig, letztere 3-5 fächrig, mit ebenso vielen Löchern aufspringend, vielsamig; Blkr. glocken-, trichter-, rad-od. röhrenförmig, Gr. fadenförmig, meist mit 3 Narben: Familie d. Campanulaceen. S. 86.

7. (3) Frkn. 4- od. 2 getheilt, auf einer Scheibe stehend, in 4 ein. od. 2 zweisamige Nusschen zerfallend, selten (b. Heliotropium) e in Frkn. mit 4 Nähten, bei der Reife ebenfalls in 4 Nüsschen spaltend; Blkr. trichter-, röhren-, radförmig, selten fast 2 lippig (b. Echium), Schlund oft durch einwärts vorspringende hohle Schuppen od. Schwielen, Falten, Haarleisten mehr weniger verschlossen: Familie d. As perifolien. S. 165.

Frkn. ganz, in eine Kaps, od. Beere sich umgestaltend. 8.

8. Stbg. vor den Zipfeln d. Blkr. stehend, Gr. fadenförm. mit einfacher Narbe; Frkn. u. Kaps. 1 fächrig, mit freiem mittelständ. Samenträger. Fam. der Primula ceen. S. 19:.

Stbg. mit d. Zipfeln d. Blkr. abwechselnd, Frkn. 1-5 fächrig, im ersten Falle nie mit mittelständ. Sameuträger.

9. Frkn. auf einer Scheibe stehend; Kelch 5 theilig, bleibend, Blkr. trichterförm., 5 faltig, Gr. mit 2 Narben, Kaps. 2-4 fächrig.

Convolvulus (379).

Keine Scheibe unter d. Frkn., Gr. faden- od. stielförmig. 10.

10. Narben 3 am Ende d. Gr., Kaps, 3 fächrig: P ol em o nia c e en.

Narben 1 od. 2.

12.

11. Blkr. radförmig, Stbf. am Grunde verbreitert, Kapselfächer melır . samig.

Polemonium (377).

Blkr. präsentiertellerförm. mit 1. dünner Röhre; Stbf. am Grunde nicht verbreitert, Kapselfächer 1 samig.

Collomia (378).

12. Blkr. im Schlunde od. am Saume bärtig, Narbe einfach od. getheilt, Kaps. 1 fächrig mit randständ. Samenträgern. Sumpf- u. Wasserpfl. Gentianea e. S. 149.

Blkr. weder im Schlunde, noch am Saume bärtig, Kaps. 2-5 fächrig od. Beere, vielsamig.

13. Stbb. nach d. Verblühen schraubenförmig gedreht, Blkr. trichterod. tellerförmig, Kapsel.

Erythraea (326).

Stbb. nach $d$. Verblülen nicht schraubenförmig gedreht.

14.

14. Stbf. mit weißer od. violetter Wolle bekleidet, Blkr. radförmig, ungleich 5 lappig; Kaps. 2 fächrig, 2 klappig, vielsamig. Verbascum (391).

Stbf. kahl, Stbb. nie nierenförmig.

15.

15. Narbe gr., doppelt, nämlich scheibenförmig u. drunter mit einer manschettenförmigen zurückgeschlagenen Membran an der Spitze des säulenförm. Gr.; Frkn. 2, durch d. Gr. zusammengehalten, in 2 Balgkaps. sich umwandelnd; Kelch 5 spaltig, kl, Blkr. gr., langröhrig-tellerförmig.

Vinca (317). 
Narbe einfach, Gr. faden- od. stielförmig; ein einziger Frkn. 16.

16. Narbe scheibenförm., ungetheilt; Kelch 5 theilig, Blkr. glockig od. trichterförm., 5 lappig; Kaps. 2-3 fächrig, mit 2-3 Klappen aufspringend. Azalea (432).

Narbe meist kopfig, oft getheilt; Kelch 5 theilig, sich meist nach $d$. Blïhen vergrößend und meist stehenbleibend; Blkr. verschieden, mit 5 lappigem Saume, Fr. eine 2 (selten 4-) fächrige Kapsel oder Beere: Fam. der Solanaceen. S. 172.

17. (2). Frkn. oberständig.

Frkn. unterständig. Beere. Holzgewächse.

18.

18. Blkr. unregelmäßig.

24.

Blkr. regelmässig. Holzgewächse.

19.

20.

19. Hinteres Kelchbl. sehr gr., blumenblattartig gefärbt, gespornt, die ïbrigen (2. 4.) Kelchbl. sehr kl., meist fehlend; Blbl. 5, die seitenständigen paarweis verwachsen; Stbb. zusammenklebend. Elastisch aufspringende Kapsel. Impatiens (667).

Kelch krautig, 5 blättrig, am Grunde mit Anhängseln; Blbl. 5, das untere größer, rückwärts gespornt; Stbbl. an einander geschmiegt mit 3 eckigem Mittelbandanhang, die beiden unteren am Grunde gespornt; 3 klappige Kapsel.

Viola (598).

20. Mit Ranken begabte Klettersträucher; Fr. eine Beere. 21.

Aufrechte Sträucher u. Bäume.

22.

21. Blbl. 5, an d. Spitze zusammenhängend, am Grunde sich beim Aufblïhen ablösend; Kelch rudimentär. Frkn. mit drüsiger Scheibe.

Vitis (646).

Blbl. 5 an d. Spitze nicht zusammenhängend, sonst wie vorige. Ampelopsis (6+7).

22. Blt. alle zwitterlich. 23.

Blt. unvollständig 2 häusig od. vielehig, männl. oft mit 4 Stbg.; Kelch trichterförm. 4-5 spaltig, Blbl. meist fehlend od. sehr kl.; Beerenförmige Steinfr. Kapsel.

23. Stbg. u. Frkn, einer Scheibe eingefügt; barettförmige, 5 knopfige Rhamnus (648). Evongmus (644).

Keine untenweibige Scheibe, Kelch trichterförm. 5 spaltig, Blbl. kl., aufrecht; beerenförmige Steinfr. Rhamnus Frangula u. rupestris (648).

24. (17). Aufrechte sommergrüne Str.; Kelch corollinisch mit 5 lappigem Saume. Blbl. 5, sehr kl., aufrecht; Gr. 2-4 theilig. Ribes (504).

Immergrïner Kletterstrauch; Kelch rudimentär, Blbl. und Stbg. 5 bis 10, einer oberständ. Scheibe eingefügt, Gr. kurz, ungetheilt. Hedera (442).

25. (1). Frkn. unterständig u. Kelch trichterförm., 4-5 spaltig, Stbg. von einem Haarbüschel umschlossen. Einsamiges, vom Kelch gekröntes Nüsschen.

Frkn. oberständig.

Thesium (200).

26. Nur die 5 vollkommenen Stbg. vorhanden, Kelch glockig, 5 spaltig, innen gekielt; Kaps. kuglig, 5 klappig. Glaux (424). Außer den 5 vollkomm. Stbg. 5 beutellose Stbf.; Blt. sehr kl. 27. 27. Kelch 5 theilig, Zipf. flach, grün od. wenig gefärbt; 1 samiges, vom Kelch umschlossenes Nüsschen.

Herniaria (602)

Kelch 5 theilig, Zipf. seitlich zusammengedrïckt, stachelspitzig, weiß ; vom Kelch urnschlossene, 1 samige, in 5-10 Klapp. aufspringende Kapsel. Illecebrum (603). 


\section{Zweite Ordnung $(V, 2)$. Digynia.}

1. Blt. unvollständig (olme Blkr.).

Blt. vollständig.

2. Bäume; Kelch glockig, 4-6 zähnig, Frkn. 2 fächrig, Gr. 2; einsamige, breithäutige, oben 2 lappige Flïgelfrucht.

Ulmus (176).

Kräuter; Kelch meist 5 theilig u. krautig, selten aus 2 durchsich. tigen Schüppchen bestehend oder fehlend (b. Corispermum); einsamige Schlauch-, selten geflügelte Nussfr., Keim ring- od. schraubenförmig; BIt. kl., unscheinbar: Fam. d. Chen op odi a ceen. S. 75 .

3. Blkr. verwachsenblättrig, Frkn. oberständig.

Blkr. getrenntblättrig.

4. Zwei getrennte Stempel, von einer gr., den Griffeln aufliegenden 5 eckigen scheibenförm. Narbe zusammengehalten; außer dem 5 spaltigen Kelch und dem 5 theiligen Blkr. eine Nebenkrone; Stbbfächer offen mit hineinhängenden, an d. Ecken d. Narbe befestigten Pollinarien; gedoppelte vielsamige Balgkapsel. Asclepiadeen.

Ein einziger Stempel, keine Nebenkrone, Stbb. u. Pollen von gewöhnlicher Form.

5. Blkr. radförmig, Nebenkrone gefaltet, Blt. in Trugdolden, Vincetoxicum (318).

Blkr. präsentiertellerförm., kurzröhrig, zurückgeschlagen; Nebenkr. gr., ein aufrechter Stern; Blt. in hängenden kugligen Dolden.

Asclepias (319).

6. Blkr. 4-5 spaltig, fleischig, mit gezäluten Schuppen unterhalb d. Stbg., Narbe lineal od. keulenförmig; ringsum aufspringende Kapsel.

$$
\text { Cuscuta (380). }
$$

Blkr. nicht Aleischig, ohne Schuppen in d. Röhre; Kaps. vielsamig, mit 2 Klap. an d. Spitze aufspring.: Fam. d. Gentianaceen. S. 149.

7. Frkn. unterständig, 2 fäcllrig, mit oberständiger quergefurchter, die Gr. tragender Scheibe (Griffelpolster); Kelch meist rudimentär am oberen Rande d. Frkn., Blbl. 5; Spaltfrucht, in 2 einsamig. Hälften (Theilfrüchte) zerfallend: Fam. d. Doldengewä chse (Umbelliferae.) S. 202.

Frkn. oberständ., Kelch radförm. 5 theilig, rundherum abspringend, Blbl. (5) u. Stbg. einer Aleischigen Scheibe eingefügt. Saftige Steinfrucht. Strauch.

Zizyphus (649).

\section{Dritte Ordnung (V, 3). Trigynia.}

1. Bäume u. Str.

Kräuter od. Stauden.

2. Frkn. oberständig, Blkr. getrenntblättrig.

Frkn. unterständig, Blkr. verwachsenblättrig, Kelch rudimentär, Narben 3, sitzend.

3. Kelch scheibenförmig, ringsherum abspringend, die bleibende Basis von einem holzig., die trockene knopfförmige Fr. umgebenden Flügel umringt; Blbl. 5, dorniger Strauch. Paliurus (649).

Kelch bleibend, Blbl. 5. Wehrlose Str. u. B. 4.

4. Kelch 5 theilig, mit einer unterweibigen Scheibe verwachsen; Blbl. kl., am Rande der Scheibe, Stbg. auf dieser eingefügt. Kleine 1 samige, nüsschenförm., trockene Steinfr.; Blt. kl., oft vielehig-2 häusig. Rhus (656). 
Kelch 5 blättrig, corollinisch; Blbl. u. Stbg. einem den Frkn. umgebenden Ringe eingefügt; Frkn. 2-3 fächrig; gr., häutige, 2-3 fächrige, am Scheitel klaffende Kaps., Samen gr, hart; Bit. stets zwitterlich.

$$
\text { Staphylea (643). }
$$

5. Blkr. radförmig od. röhrig-trichterförmig, im ersten Falle geschlechtslos; Frkn. 3 fächrig Fr. eine 1 samige beerenförm., saftige Steinfr.; Bl. einfach.

Vi̋urnum (310).

Blkr. rałförmig, Frkn. $3-5$ fächrig, Fr. eine 3 samige, saftige, heerenförm. Steinfr.; Bl. unpaarig gefiedert.

6. Frkn. unterständig, Blkr. radförmig. Wie vorige Gattung.

Sambucus Ebulus.

Frkn. oberständig; Kelch 5 zipflig, Blbl. 5, so l. als d. Kelchzipf.; einsamige nicht aufspringende Schließfr., Blt. kl. Corrigiola (604).

Anmerkung. Mit 5 Stbg. kommen auch vor: Stellaria media und Holosteum umbellatum (X, 3), mit 3 Griff. Drosera (V, 5).

\section{Tierte Ordnung $(V, 4)$. Tetragynia.}

Frkn. oberständ., Kelch- u. Blbl. 5; vor letzteren 5 schmale strahlig zertheilte glänzende Drüsen tragende Nebenkronenbl.; Kaps. 1 fächrig, an der Spitze 4 klappig.

Parnassia (503).

Mit 4 Gr. kommen auch vor manche Arten von $\mathrm{Sagina}(\mathrm{X}, 5)$.

\section{Fiinfte Ordnung $(V, 5)$. Pentagynia.}

1. Untergetaucht schwimmende Wasserpfl.; Kelch- u. Blbl. 5, Frkn. oberständ., mit fädigen Gr.; Kapsel kuglig, 1 fächrig, 5 klappig.

Landbewohnende Kräuter, Frkn. oberständig. Aldrovandia (597).

2. Fünf (bisweil. 10) freie Frknoten, Kelch 5 spaltig mit kleinerem 5 spaltigem Außenkelch, Blbl. 5 ; einsamige Nüsschen. Sibbaldia (692).

Ein einziger Frknoten, kein Außenkelch.

3. Kelch verwachsenblättrig, mit trockenhäutigem Saume, Blbl. 5, am Grunde durch Zotten verbunden; einsamige, unregelmäßig zerreißende Schlauchfr.; Blt. in Köpfcher. Armeria (428).

Kelch 5 spaltig, Blbl. 5, frei, Kapselfr.; Blt. nicht in Köpfchen. 4.

4. Frkn. u. Kaps. 10 fächrig, Gr. einfach. Iinum (665).

Frkn. u. Kaps. 1 fächrig, letztere $3-5$ klappig; Gr. 2 theilig. Drosera (596).

Anmerkung. Fünf Stbg. haben auch einzelne Arten von Cerastium u. Spergula $(X, 5)$.

\section{Sechste Ordnung $(V, 6)$. Polygynia.}

Fünf Stbg. hat bisweilen Myosurus minimus (XIII, 7), mehs als 5 Gr. u. Fr. Sibbaldia (s. oben).

\section{Classe. Hexandria.}

\section{Erste Ordnung (VI, 1). Monogynia.}

1. Kelch u. Blkr.

2.

Einfache Blthïlle (Perigon), 6 spaltig, 6 theilig od. 6 blättrig.

2. Frkn. oberständig. 
Frkn. unterständig, Kelch randförmig, abgestutzt od. gezähnt, Blbl. 4-8; Fr. eine 1 samige Beere. Schmarotzerstr. Loranthus (201).

3. Kelch u. Blkr. 6 blältrig, Kelch-, Blbl. u. Stbg. vor einander stehend, Stbb. mit Klappen aufspringend; Fr. eine 2-3 samige Beere. Sträucher. Berberis (536).

Kelch glockig, 12 zähnig, Blbl. 6, sehr kl. od. fehlend, Gr. sehr kurz mit kugliger Narbe; Kaps. kuglig, 2 fächrig, vielsamig. Kraut.

$$
\text { Peplis (677). }
$$

Anmerkung. Mit 6 Stbg. kommen auch vor Lythrum Hyssopifolia (XI, 1) und Lysimachia thyrsiflora (V, 1; s. Primulaceen).

4. (1). Frkn. unterst., Fr. eine 3 fächrige Kaps.: A maryllid een. 5.

Frkn. oberständig.

5. Perigon mit Röhre und ausgebreitetem 6 theiligem Saume. Im Schlunde ein Honigbecher.

Perigon 6 blättrig, glockig; Blte. hängend.

6. Alle 6 Perigonbl. gleich groß.

Narcissus (109). kleiner, walzig zusammenschließend, ansgerandet.

7. Perigon blumenkronenartig, verwachsen- oder getrenntblättrig, 6 zähnig od. 6 theilig od. 6 blättrig.

8.

Perigon trockenhäutig-durchscheinend, kelchartig, 6 blättrig. 9.

8. Perigon verwachsenblättrig, glockig, röhrig, krugförmig, selten (b. Majanthenum u. Paris) tief 4-8 theilig; Fr. eine Beere: Fam. der Asparageen. S. 58 .

Perigon verwachsen- od. getrenntblättrig, Fr. eine 3 fächrige, vielsamige, 3 klappig aufspringende Kapsel: Fam. d. Liliaceen. S. 59.

9. Blt. an einem seitenständ, nackten Kolben, Perigonbl. kl., bleibend, Narbe sitzend, Fr. eine trockene Beere.

Acorus (38).

Blt. in Trugdold., Ähren, Knäueln; Perigonbl. spelzenartig, Gr. mit 3 fadenförm. Narben; Kapsel (J u n cacee n).

10.

10. Kaps. 3 fächrig, 3 klappig, vielsamig; Klappen in d. Mitte d. Scheidewand tragend; Bl. kabl.

Juncus (138).

Kaps. 1 fächrig, 3 klappig, 3 samig; Klappen ohne Scheidewand; Bl, wimperhaarig.

Luzula (137).

\section{Zweite Ordnung (VI, 2). Digynia.}

Perigon 4 blättrig, aus 2 äußeren (größeren) u. 2 inneren (kleineren) B1. bestehend; Narben 2, kurz gestielt, pinselförmig. Zusammengedrücktes br. geflügeltes Nüsschen.

Oxyria (198).

\section{Dritte Ordnung (VI, 3). Trigynia.}

1. Perigon verwachsenblättrig, langröhrig, mit 6 theiligem glockigtrichterigem Saume; Stlog. dem oberen Theile d. Röhre eingefügt, Frkn. oberständ., Gr. sehr 1.; Kapsel aufgeblasen 3 fächrig, vielsamig.

Perigon getrennt (6-) blättrig; Frkn. oberständig. Colchicum (141).

2. Perigonbl rleichförm sich nach d. Blühen nicht veräudernd.

Die 3 äußeren Perigonbl. viel kleiner als d. 3 inneren, letztere nach d. Blühen sich vergrößernd, oft auch anders gestaltend und das 3 kantige Nitsschen umbüllend (Fruchtklappen); Gr. mit faden- od. pinselförm. Narben; Blt. oft vielehig- od. 2 häusig. Rumex (197). 
3. Frkn. 3, in d. Gr. verschmälert, mehr weniger untereinander verwachsen.

Frkn. 3, frei od, ein einziger, aus 3-6 Karpellen zusammengesetzter; Blt. kl., unscheinbar.

5.

4. Frkn. am Grunde verwachsen, Stbb. quer in ein Schüsselchen aufspringend, Perigon sternförnig ausgebreitet. Veratrum (140).

Frkn. bis zur Mitte verwachsen, Gr. sehr kurz, Stbb. der Lünge nach aufspringend; Blt. kl. mit abstehendem Perigon. Tofieldia (139).

5. Frkn. frei, mit sitzender, auswärts schief angehefteter Narbe, aus einander stehend; Perigonbl. zurückgeschlagen; einsamige Balgkaps. mit einem Längsspalt sich öffnend.

Scheuchzeria (115).

Ein aus 3-6 Karpellen bestehender Frkn. mit 3-6 pinselfürmigen Narben; Karpellen zur Reifezeit sich vom Grunde aus lösend und mit den Spitzen an der Mittelsäule hängen bleibend; Perigonbl. aufrecht.

Trigloclin (116).

Anmerk. Sechs Stbg. und 3 Gr. besitzen Elatine hexandra (VIII, 4) und manche Arten von Polygonum (VIII, 1).

\section{Fünfte ordnung (VI, 5). Polygynia.}

Kelch u. Blkr. 3 blättrig, Frrkn. oberständig, aus 6 od. vielen quirlständigen Karpellen zusammengesetzt, aus denen 1 samige Schließfrüchtchen entstehen. Alisma (112).

\section{Classe. Heptandria.}

\section{Erste Orduung (VII, 1). Monogynia.}

1. Blt. regelmäßig, Kelch 6-9॰, meist 7 spaltig. Blkr. sternförmig, 7-(6-9) theilig; Kapsel 1 fächrig, 7 klappig, mehrsamig. Kraut.

Trientalis (42:).

2. Blt. unregelmäßig, Kelch glockig, 5 zähnig, Blbl. 4 sammt d. aufsteigenden Stbg. dem Rande einer untenweibigen Scheibe eingefügt, die 2 oberen Blbl. größer mit umgebogener Platte. Krautstachlige 1-3 samige Kapsel. Bäume. Aesculus (641).

Anmerk. Sieben Stbg. hat bisweilen Lysimachia thyrs iflora..

\section{V1II. Classe. Octandria.}

\section{Erste Ordnung (VIII, 1). Monogynia.}

1. Blt. vollständig.

2.

Bit. unvollständig, mit einem kelchartigen Perigon begabt; Frkn. oberständig.

2. Blkr. verwachsenblättrig.

Blkr. getrenntblättrig, Frkn. oberständig.

3. Frkn. oberständig; Fr. eine Kapsel. 12.

Frkn. unterständig, Fr. eine 4-5 fächrige vielsamige Beere. 6.

4. Kelch 8 spaltig, Blkr. tellerförmig, mit 6 spaltigem Saume, Stbg. der Blkröhre eingefügt; Gr. in 2 zweilappige Narben gespalten, 1 fächrige Kapsel.

Chlora (322).

Will k om m, Schuleora. 
Kelch 4 blättrig od. 4 spaltig, Blkr. 4 spaltig, Kaps. 4 fächrig, vierklappig.

5. Kelch 4 spaltig, viel kürzer als d. krugförmige, mit kurzem 4 zähnigem Saume versehene Blkr.; Stbb. mit einem Loch sich öffnend, Scheidewände d. Kaps. mit d. Klappen abfallend.

Erica (430).

Kelch 4 blättr., blumenartig, viel größer als d. tief 4 theilige Blkr.; Stbb. mit Längsritzen aufspringend; Scheidewände d. Kaps. an d. Mittelsäule stehen bleibend.

Calluna (429). geschlossen.

6. Blkr. glockig od. krugförmig, mit 5 lappigem Saume, Stbg. ein-

B!kr. tief, 4 theilig, krugförmig, Stbg. vorstehend, mit aneinander geschmiegten Beuteln.

Oxycoccus (438).

7. (2). Bäume u. Sträuch.; Blt. meist vielehig, bisweil. 2 lıäusig. 8 .

Kräuter.

8. Dorniger B. mit 1-2 fach gefiederten Bl., Kelch $3-5$ theilig, Blbl. 3-5, Stbg. 8-10; Fr. eine 1. u. br., flach zusammengedrückte vielsamige Hülse.

Gleditschia (705).

Wehrlose B. u. Str. mit einfachen Bl.; Kelch 5 theilig, Blbl. 5, sammt d. Stbg. $(8,5,10)$ dem Rande einer fleischigen unterweibigen Scheibe eingefügt; Frkn. zusammengedrückt, Gr. in 2 Narben getheilt; gedoppelte Flügelfrucht.

9. Frkn. oberständig. Acer (639).

Frkn. unterständig; Kelchsaum 4 theilig, Blbl. 4, Kaps. 4 klappig, vielsamig.

10. Bleiche bllose, beschuppte Schmarotzerpt. (s. X, 1). Monotropa (439).

Beblättert. Halbstr.; Kelch $4-5$ theilig, bleibend; Blbl. kahnförmig, genagelt, ausgebreitet, bei d. endständ. Blt. 5, b. d. übrigen 4 Stbg. u. Kapselfächer demgemäß 10 od. 8; unterweibige, drüsige Scheibe.

Ruta (660).

11. Kelchröhre sehr kurz, Kaps. lineal, 4 kantig, Samen mit Haarschopf. Epilobium (671).

Kelchröhre verlängert, Kaps. länglich, Samen ohne Haarschopf.

Oenothera (670).

12. (1). Perigon röhrig, mit 4 lappigem Saume; Stbg. in der Röhre eingefïgt.

13.

Perigon trichterförmig, mit 5 lappigem Saume, verwelkend, das 2 bis 3 kantige 1 samige Nüsschen ganz od. nur am Grunde umliullend; Stbg. $5-8$, Narbe $1-3$.

Polygonum (199).

13. Perigon bunt gefärbt, abfallend; Fr. eine 1 samige Beere. Daphne (204).

Perigon grün, verwelkend $\mathbf{u}$. d. 1 samige Nüsschen umin̈̈llend̆. Thymelaea (203).

\section{Zweite Ordung (VIII, 2). Digynia.}

1. Blt. unvollständig, Kelch 4 spaltig, innen gelb gefärbt, Blbl. fehlend, Stbg. (eigentlich nur 4 zweigetheilte) einer drüsigen, den halb unterständ. Frku. umgebenden Scheibe eingefügt; Fr. eine 1 fächrige vielsamige Kapsel (MittelbJten oft mit 5 spalt. Kelch und 10 Stbg.).

Frkn. oberståndig. 
2. Blt. unvollständig, mit glockigem Kelch od. kelchartig. Perigon: Ulmus effusa $(V, 2)$, Arten von Polygonum (VIII, 1) u. Scleranthus $(X, 2)$.

Blt. vollständig, Kelch- u. Blbl. 4, Kapsel: Moehringia muscos a $(\mathrm{X}, 3)$.

\section{Dritte Ordnung (VIII, 3). Trigynia.}

1. Blt. mit kelchartigem Perigon: Polygonum (VIII, 1).

2. Kelch- u. Blbl. 4 (letztere bisweilen fehlend), Frkn. oberständig, Kapsel 3 klappig. Siebera (610).

\section{Vierte Ordunng (VIII, 4). Tetragynia.}

1. Blt. mit 8 theiligem wagerecht abstehendem bleibendem Perigon, die 4 äußeren Theilstïcke breiter als d. inneren; Stbb. mit fadenförmig verlängertem Mittelband, Fr. eine 4 fächrige Beere (bisweilen 10 Perigonzipfel, 10 Stbg., 5 Gr.).

Kelch u. Blkr.

Paris (142).

2. Frkn. halb unterständig, Kelch d. endständigen Blt. 2-, d. seiten. ständigen 3 lappig: Blkr. d. endständigen Blt. 4-, d. seitenständ. 5 theilig, Stbg. 8 od. 10, Fr. eine 4-5 fächrige, am Scheitel d. Kelchlappen tragende Beere.

Adoxa (308).

Frkn. oberständig, Kelch 3-4 theilig, Blbl. 3-4, Sthg. 3, 4, 6, 8, Gr. 3-4; Fr. eine 3-4 fächrige vielsamige Kapsel. Elatine (637).

\section{Classe. Enneandria.}

\section{Zweite Ordnung (IX, 2). Trigyuia.}

Blt. mit 6 blättr. weißem Perigon, Frkn. oberständig, Gr. mit kopfig. Narbe, Fr. ein 3 seitiges, an den Kanten geflügeltes, 1 samiges $N$ üsschen. Rheum (196).

\section{Dritte Ordnung (IX, 3). Hexagynia.}

Blt. mit 6 blättrigem gefärbtem Perigon, Frkn. Ba, oberständig, in 6 unten verwachsene einwärts aufspringende Balgkapseln sich umgestaltend. Butomus (114).

\section{Classe. Decandria.}

\section{Erste Ordnung $(\mathrm{X}, 1)$. Monogynia.}

1. Blt. vollständig.

Blt. unvollständig (ohne Blkr.).

2. Kelch u. Blkr. verwachsenblättrig.

11.

Blkr. getrenntblättrig, Frkn. oberständig. ceen).

3. Frkn. oberständig, Kelch u. Blkr. mit 5 theiligem Saume (Erica-

Frkn. unterständig od. halb unterständig.

4. Blkr. trichterförmig, bisweilen fast 2 lippig, selten radförmig, Stbg. eingeschlossen oder wenig vorstehend, Gr. fadenförmig; Kapsel 4 fächrig, klappig aufspringend, vielsamig. Rhododendron (433). 
Blkr. glockig, eiförmig, kuglig, mit kurzem 5 lappigem Saum; Stbg. eingeschlossen.

5. Fr. eine 5 fächrige, 5 klappige, vielsamige Kaps.

Fr. eine beerenförmige, saftige, 5 kernige Steinfrucht. Andromeda (431). Arctostaphylos (435).

Fr. eine erdbeerartige, äußerlich spitzwarzige Beere. Großstr. od. B. Arbutus (436).

6. Frkn. ganz unterständig; Beere (s. VIII, 1). Vaccinium (437).

Frkn. halb unterständig; Kapsel (s. V, 1). Samolus (427).

7. (2) Bllose beschuppte bleiche Schmarotzerpt.; Kelch $4-5$ blättrig, Blbl. glockig od. wa'ziğ zusammengeneigt, am Grunde höckerig; 4- bis 5 fächrige Kapsel.

Beblätterte, nicht schmarotzende $\mathrm{PA}$. Monotropa (439).

8. Bäume und Sträucher.

Kräuter od. kl. Halbstr.

9. Dorniger B. mit $1-2$ fach gefiederten Bl.; Kelch $3-5$ theilig, Blkr. $3-5$ blättrig; Hülse (s. VIII, 1 ). Gleditschia (705). Hülse.

Wehrloser B. mit ganzen Bl.; Bllkr. 5 blättrig, schmetterlingsförmig,

Immergrüner Str.; Kelch 5 zähnig, Blkr. 5 blättrig, regelmäßig; Blbl. und Stbg. am Rande einer unterweibigen Scheibe eingefügt; Kaps. 5 fächrig, 5 klappig.

Tedum (434).

10. Immergrüne Kr. od. Halbstr.; Kelch 5spaltig, bleibend; Frkn. oft von einem drüsigen Ringe am Grunde umgeben, Gr. fadenförm. mit scheibenförmiger Narbe; 5 fächrige, mit Klappen od. Längsspalten sich üfruende Kapsel. Pirola (438).

Sommergrüne Staude; Kelch 5 blättrig, abfallend, Blbl. ungleichgroß, eine gr. 2lippige Blkr. bildend; Stbf. l., aufsteigend; Frkn. 5 theilig, auf driisiger Scheibe sitzend; 5 am Grunde verbundene Balgkapseln.

11. (1) Kelch blumenartig, gelb, 4 spaltig (s. VIII, 2). Dictamnus (661). Chrysosplenium (502).

Kelch grün od. weiß, 5 theilig: Herniaria u. Illecebrum (s. V, 1).

\section{Zweite Ordnung $(X, 2)$. Digynia.}

1. Blkr. fehlend. Kelch 5 zähnig, knorplig; Fr. ein 1 samiges, im Grunde des verhärteten Kelchs sitzendes Nüsschen. Scleranthus (601).

Kelch und Blkr.

2. Zwei bis 5 getrennte Frknoten, aus denen sich längliche netzadrige Flügelfr. entwickeln; Blt. kl., regelmäßig, vielehig, $Z$ witterblt. oft nur mit 2-3 Stbg. Baum.

Ailanthus (657).

Ein einziger Frkn,; Kräuter.

3. Kelch 5 zähnig od. 5 theilig, Blkr. 5 blättrig; Stbg. und Blbl. am Grunde der Kelchabschnitte eingefügt; Frkn. 2 fächrig, ober- od. halb unterständig, mit 2 getrennten $\mathrm{Gr}$; 2 fächrige, von d. ausgespreizten $\mathrm{Gr}$. geschnäbelte Kapsel, am Scheitel zwischen d. Gr. aufspringend, Samen an der Scheidewand sitzend. Saxifraga (500).

Kelch röhrig, glockig, pyramidal, 5 zähnig; Blbl. 5, genagelt, sammt d. Stbg. u. d. oberständ. Frkn. auf einem kurzen Träger stehend; Fr. eine 
einfächrige, selten (b. Vaccaria) am Grunde unvollständig 4 fächrige Kaps. mit freiem mittelständig. Samenträger, mit Zähnen od. Klappen aufspringend: Fam. d. Sileneen (z. Th.). S. 285.

\section{Dritte 0rdnung $(\mathrm{X}, 3)$. Trigynia.}

1. Kelch verwachsenblättrig, Frkn. oberständig, sammt den 5 Blbl. und Stbg. auf einem Träger (Sileneen).

2.

Kelch getrennt. $(4-7)$ blättrig, Blbl. 5 (selten 4), sammt d. Stbg. auf d. Bltboden stehend; Frkn. oberständim.

3.

2. Kelch kurz glockig, mit 3 gr. Zähnen, zuletzt bauchig; Blt. lang genagelt; Fr. eine 1 fächrige mehrsamige Beere. Cucubalus (624).

Kelch röhrig, keulenförmig, glcckig, 5 zähnig od. 5 spaltig; Blbl. lang genagelt, Fr. eine am Grunde unvollständig 3•, selten eine 1 fächr. Kapsel mit freiem centralen Samenträger, mit 6 Zähnen aufspringd. Silene (625).

3. Trockenhäıtige Nebenblätter.

Keine Nebenblätter: Fam. d. Alsineen (z. Th.). S. 277.

Spergularia (606).

\section{Vierte Ordung $(X, 4)$. Tetragynia.}

Kelch u. Blkr. 4-5 blättrig, Stbg. 3-10, Frkn. oberständ., Gr. 4-5, Kapsel 1 fächrig, mit 8 od. 10 Zähnen aufspringend. Moenchia (615).

Anmerk. Mit 10 Stbg. u. 4 Gr. kommt anch Adoxa vor (VIII, 4).

\section{Finfte Ordnung $(X, 5)$. Pentagynia.}

1. Stbf, am Grunde verwachsen, Kelch 5 theilig od. 5 blättrig, Blbl. 5, Frkn. oberständ., Gr. am Grunde verwachsen; Kaps. länglich, 5 kantig, 5 füchrig, an d. Kanten aufschlitzend.

Stbf. u. Gr. frei, Frkn. oberständig.

Oxalis (666).

2. Fünf einzelne, am Grunde verwachsene Frkn., aus denen ein. fächrige mehrsamige, sternförmig ausgebreitete Balgkaps, entstehen; Kelch 5 theilig, nebst d. 5 Blbl. Aleischig; Stbg. mit 5 schuppenförmigen Drüsen.

Sedum (507).

Ein einziger Frkn. mit 5 Gr., einfächrige, meist vielsamige Kapsel mit freiem centralem Samenträger.

3.

3. Bl. mit häutigen Nebenbl; Kelch 5 blättrig, Blbl. 5, ungetheilt, Stbg. 5-10; Kaps. 5 klappig, Samen kreisrund, geflügelt. Spergula (605).

Bl. ohne Nebenbl.

4. Kelch 4-5 blättrig, Blbl. 4-5, sammt d. Stbg. (10, selten 4, 5) u. d. Frkn. auf dem Bltboden stehend; Kaps. verschieden aufspringend: Alsineen (z. Th.). S. 277.

Kelch verwachsenblättrig, 5 zähnig od. 5 spaltig, Elbl. 5, genagelt, sammt d. Stbg. u. d. Frkn. auf einem Träger; Kaps. mit Zähnen anfspringend: Silen een (z. Th.). S. 285 .

Anmerk. Mit 5 Gr., beziehentlich 5 getrenuten Stempeln kommt auch Ailanthus vor $(\mathrm{X}, 1)$.

\section{Classe. Dodecandria.}

\section{Erste Ordunng (XI, 1). Monogynia.}

1. Blt. mit glockigem 3 lappigem fleischigem Perigon, Lappen einwärts geschlagen; Frkn, unterständig, Narbe sitzend, 6 strahlig; vielsamige 6 fächrige Kapsel.

Asarum (208). 
Blt. mit Kelch u. Blkr., Frkn. oberständig, Kapsel,

2. Kelch 2 spaltig, zuletzt von seinem bleibenden Grunde rundherum abspringend, Blkr. regelmäßig, 3-5 blättrig, Gr. 3-6 theilig; Kaps. ringsherum aufspringend, 1 fächrig.

Portulaca (599).

Kelch röhrig, 8-12zähnig, mit abwechselnden aufrechten und abstehenden Zähnen; Blbl. 4-6, unter d. Kelchsaum eingefügt, Stbg. meist 12 (bisweilen 6, 3, 2); Kaps. 2 fächrig.

Lythrum (676).

\section{Zweite Ord̉nung (XI, 2). Digynia.}

1. Kelch kreiselförmig, Röhre mit hakenförmig., sich später vergirüBernden Krautstacheln dicht besetzt, Saum 5 spaltig, nach dem Verblühen nach aufwärts zusammengeneigt; Blbl. 5 sammt d. Stbg. (bisweilen 6 od. 15) dem Rande eines den Kelchschlund auskleidenden Ringes eingefügt; einsamiges im verhärteten Kelch eingeschlossenes Nüsschen.

Agrimonia (697).

2. Kelch länglich, unter d. Saum mit $5 \mathrm{kl}$. Zähnen, welche zu langen pfriemenförmigen Krautstacheln auswachsen. Sonst wie v. G.

Aremonia (696).

\section{Dritte 0rdnung (XI, 3). Trigynia.}

Kelch 4-6 theilig, Blbl. 4-6, ganz od. unregelmäßig zerschlitzt; Frkn. oberständig, Gr. od. Narben $3-6 ;$ Fr. eine 1 fächrige, vielsamige, 3-6 kantige, oben offene, 3-6 zähnige Kapsel.

Reseda (594).

\section{Vierte Orduung (XI, 4). Dodecagynia.}

Kelch 6-12 theilig, Blbl. 6-12, mit d. Grunde d. Stbg. unten zusammengewachsen; Stempel u. Balgkaps. oberständig, am Grunde verwachsen.

Sempervivum (508).

\section{X11. Classe. Icosandria.}

\section{Erste Orduung (XII, 1). Monogynia.} mäßjg.

1. Frkn. unterständig, Kelch gezähnt, Blkr. getrenntblättrig, regel-

Frkn. oberständig, Kelch röhrig mit 5 theiligem Saum, Blbl. 5, sammt d. Stbg. in der Kelchröhre einem drüsigen Ringe eingefügt, Frkn. frei: 1 fächrig; einkernige meist 1 samige Steinfr.: Familie d. Amygdala ceen.

3.

2. Kelchzähne u. Blbl. 4-5, Fr. eine 4-5 klappige mehrsam, Kaps. Sommergrüe Str.

Philadelphus (668).

Kelchsaum 4-5lappig, Blbl. 4-5, Fr. eine vom Kelchsaum ge. krönte mehrsamige Beere. Immergrüner Str.

Hierher gehört auch Crataegus monogyna (XII, 2).

3. Steinkern dickschalig, unregelmäßig gefurcht und mit Löchern.

Steinkern glatt, gefurcht, netzgrubig, stets ohne Löcher. Myrtus (669). 


\section{Zweite Ordnung (XII, 2). Di-Pentagynia.}

1. Frkn. ober- od. halboberständig, sich in 2-od. mehrsamige Balgkapseln umgestaltend, Kelch 5 spaltig, Blkr. 5 blättrig: Fam.d. Spiraeac e a e.

Frkn. scheinbar einer und unterständig, nämlich ein hohler Bltenboden, in welchem die 2-5 (selten 1) Frkn. eingeschlossen und mit demselben sowie unter sich verwachsen sind. Kelch 5 zipflig, mit dem oberen Raude dieses Scheinfruchtkn. verwachsen, an dessen innerem Rande die Stbg. und Blbl. (5) angeheftet erscheinen; Gr. frei oder am Grunde verwachsen, Fr. eine durch fleischige Verdickung des die Frkn. meist gänzlich umschließenden Bltenbodens entstehende, vom Kelch gekrönte Scheinfr., welche entweder $2-5$ ein- bis mehrsamige Kapselfächer (Kernapfel) oder 1 bis 5 Steinkerne (Steinapfel) enthält: Fam. d. Pomaceae. S. 315.

2. Bltboden flach, Kelch 5 lappig, Blbl. goldgelb, Frkn. frei, 2-3. Strauch.

Kerria (701).

Bltboden schüssel-, kreisel- oder becherförmig, mit dem 5 spaltigen Kelch verwachsen, inwendig mit einem d. Blbl. u. Stbg. tragenden Ringe, Blbl. weiß, rosa, roth, Frkn. 2-5 (selten mehr). Kräuter und Str.

Spiraea (700).

\section{Dritte Ordnung (XII, 3). Polyggnia.}

1. Bltboden scheiben-, schüssel-, becher- od. krugförmig (dann einen unterständigen Scheinfrkn. darstellend), mit den 5 Kelchbl. verwachsen, ohne Ring; Blbl. 5 sammt d. Stbg. innen unter d. Rande d. Kelchzipfel eingefügt; Eirzelfrkn. (Karpellen) frei, Gr. bisweilen (nur bei manclien Rosen) verwachsen; einsamige Nüsschen: Fam. d. Rosaceae. S. 319.

2. Bltboden becherförmig, innen mit wulstigem Ringe, aut dem $d$. Blbl. (5) und d. Stbg. stehen; Kelchbl. zahlreich, mit d. Blbl. gleichfarbig, dachziegelig, in d. Blbl. übergehend; Stempel im Grunde des Bltbodens, frei. Einsamige Nüsschen.

Calycanthus (678).

\section{Classe. Polyandria.}

\section{Erste Ordnung (XIII, 1). Monogynia.}

1. Blt. regelmäßig.

Blt. unregelmäßig, Kelch blumenartig, oberes Kelchbl, gespornt; Frkn. oberständig: Arten von Delphinium (529).

2. Blkr. 4 blättrig, Frkn. oberständig.

b) Blkr. 5 blättrig, Frkn. oberständig.

3.

c) Blkr. vielblättrig, Wasserpfl.: Fam. d. N y m pha e ace ae. 6 .

3. Kelchbl. 2, beim Aufblühen abfallend; kuglige oder schotenförm. Kapsel: Fam. d. Papaveraceen. S. 246.

Kelchbl. 4.

4. Kelchbl. hinfällig, mit d. Blbl. gleichfarbig; Stbb. an die verbreiterte Spitze der Stbf, angewachsen; Fr. eine mehrsamige Beere. Actaea (531).

Kelchbl. bleibend, krautig; Frkn, und Fr. gestielt, letztere länglich, Aleischig, vielsamig.

Capparis (545). 
5. Kelch 5 blättrig, den Blbl. ähnlich; Frkn. 5 fächrig, Gr. säulenförmig mit 5 zähniger Narbe; Fr. eine $1-2$ samige nussartige, erst beim Keimen mit 5 Klappen aufspringende Kapsel. Bäume. Tilia (635).

Kelch 3 blättrig mit 2 kleinen außen angewachsenen Blättchen (Außenkelch); Frkn. und Kapsel 1 fächrig oder unvollkommen 3 fächrig, letztere $3 \mathrm{klappig,} \mathrm{vielsamig;} \mathrm{Gr}$. fadenförm. mit kopfiger oder scheibenförmiger Narbe.

Helianthemum (595).

6. Kelchbl. 4, außen grün, Blbl. ohne Honiggrube, allmählich in d. Stbg. übergehend, äußere länger als d. Kelch; Frkn. in eine fleischige halblkuglige Scheibe eingesenkt, an deren Außenfläche d. Blbl, und Stbg. hoch oben eingefügt sind; Narbe sitzend, vielstrahlig, Fr. Aleischig, vielsamig, nicht aufspringend. Nymphaea (538).

Kelchbl. 5-6, bedeutend größer als die äußeren Blbl.; Frlın. rielfächrig, oberständig auf tleischiger Scheibe, Narbe scheibenförmig, vielstrahlig, sitzend; Fr. wie b. v. G.

Nuphar (539).

\section{Zweite Ordunng (XIII, 2). Di-Pentagynia.}

Kelch und Blkr. melurblättrig, oder bloß ein blumenartiger mehr. blättriger Kelch; Frkn. (Karpellen) oberständig, frei od. (wie bei Nigella) verwachsen; Fr. einsamige Nïsschen oder mehrsamige Balgkapseln; Fam. d. Ranunculaceen (z. Th.) S. 230.

Vgl. auch Hypericum (XVIII, 1).

\section{Dritte Ordnung (XIII, 3). Polygynia.}

1. Wie d. vor. Ordnung: Fam. d. Ranunculaceen (z. Th.) S. 230.

2. Einzelfruchtknoten (Karpellen) mit einer centralen Verlängerung des Bltbodens und unter sich verwachsen, im Frzustande einen Zapfen darstellend; Kelch meist 3 blättrig, abfallend. Bäume: Fam. d. M a g noliaceen.

3. Blbl. 6, Frzapfen aus ziegeldachig über einander liegenden $1-2$ samigen Flügelfr. gebildet.

Liriodendron (535).

Blbl. 6-9, Frzapfen holzig, aus verwachsenen, mit einem Spalt sich nach außen öffnenden Balgkapseln bestehend, aus denen zuletzt d. Samen an langen Fäden heraushä̉ngen.

Magnolia (534).

\section{Classe. Didynamia.}

\section{Erste Orduung (XIV, 1). Gymnospermia.}

Frkn. ober'ständig, 4 lappig mit mittelständigem fadenförmigem Gr., ler sich in 2 ungleiche Narben spaltet, auf einer Scheibe stehend; Kelch 5 spaltig, oft 2 lippig, Blkr. 2-, selten 1 lippig, Stbg. unter d. Oberlippe, in d. Blkronenröhre eingefügt; Spaltfrucht in 4 einsamige Nüsschen zerfallend; Bit. meist in Scheinquirlen, St. 4 kantig, Bl. kreuzweis-gegenständ.: Fam. d. La biaten. S. 153 .

\section{Zweite Ordnung (XIV, 2). Angiospermia.}

Frkn. ganz, sich in eine mehrsamige Kapsel verwandelnd, selten (b. Verbena) in 4 Nüsschen zerfallend.

1. Stbbfächer ain Grunde ohne Spitzchen. 
Stbbfächer am Grunde mit einem Spitzchen oder Dörnchen begabt, Frkn. oberständig.

2. Frkn. oberständig.

3.

Frkn. unterständig, Kelch 5 zähnig, Blkr. gluckenförmig, 5 lappig; Fr. eine trockene Beere.

Linnaea (312b).

3. Frkn. 4 fächrig, zuletzt in 4 einsamige Nüsschen spaltend; Kelch 5 zähnig, Blkr. röhrig-tellerförmig, mit ungleich 5 lappigem Saume.

Verbena (358).

Frkn. 2-, selten 1 fächrig, Gr. fadenförmig; Kelch 5 zähnig bis 5 theilig, Blkr. mehr weniger 2 lippig; vieisamige Kapsel: Fam.d. Scrophulariaceen. S. 174.

4. (1). Frkn. 1 fächrig mit wandständigen Samenträgern, Kapsel mit Klappen aufspringend. Bleiche od. buntgefärbte bllose Wurzelschmarotzer mit fleischigem beschupptem St.

5.

Frkn. 2 fächrig, reif 1-vieisamig; Kelch röhrig od. glockig, 4-5 zähnig, Blkr. 2 lippig. Beblätterte Pfl.: Fam. d. Rhinanthaceen. S. 182.

5. Kelch glockig, 4 spaltig, Blkr. 2 lippig, nach dem Verbliihen sich ganz ablösend.

Lathraea (410).

Kelch 2 spaltig, mit einem Deckblättchen begabt; Blkr. rachenförmig-2 lippig, nach d. Verblïhen bis auf den bleibenden Grund ringsum sich ablösend; Klappen d. Kapsel oben und unten verbunden bleibend.

Orobanche (411).

Kelch röhrig, 3-6 zähnig, mit 3 Deckblättchen; Blkr. trichterförm.2 lippig, Kapsel halb 2 klappig.

Phelipaea (411).

\section{Classe. Tetradynamia.}

Kelch- und Blbl. 4, alternierend, erstere aufrecht od. abstehend, abfallend, letztere genagelt mit abstehender Platte, ein Kreuz bildend; bodenständige Drüsen am Grunde der Stbg.; Blt. meist in Doldentrauben, welche sich später zu Trauben ausdehnen, Bl. wechselständig, obne Nebenbl.: Fam. d. Cruciferen. S. 249.

\section{Erste 0rdnung ( $X V, 1)$. Siliculosa.}

Fr, ein meist aufspringendes, selten geschlossen bleibendes Schötchen.

\section{Zweite Ordnung ( $X V, 2)$. Siliquosa.}

Fr. eine meist anfspringende, selten geschlossen bleibende Schote.

\section{Classe. Monadelphia.}

\section{Erste 0rdnung (XVI, 1). Pentandria.}

Hierber gehören Arten von Erodium (XVI, 2), Linum (V, 5). Lysimachia $(V, 1)$, auch Vincetoxicum $(V, 2)$ u. Radiola $(I V, 4)$.

\section{Zweite Ordunng (XVI, 2). Decandria.}

1. Blt. regelmäßig, Frkn. oberständig.

Blkr. schmetterlingsförm.; s. Fam. d. P a pilion a ceen. S. 334. Vgl. auch Polygala (XVII, 3). 
2. Kelch 5 theilig, Blkr. 5 blättrig, Stbf. abwechselnd kürzer, Gr. 2-4 (meist 3); Fr. eine fast schotenförmige, einfüichrige, vielsamige, mit 3 (2-4) Klappen aufspringende Kaps., Samen mit gestieltem Haarschopf. Strauch. Myricaria (638).

Kelch und Blkr. 5 blättrig.

3. Frkn. einfach mit $5 \mathrm{Gr}$., sich in eine 5 kantige, an den Kanten aufspaltende Kapsel verwandelnd. (s. X, 5).

Oxalis (666).

Frkn. aus 5 Karpellen, die um eine Mittelsäule stehen, zusammengesetzt, mit 5 zusammengewachsenen, nur gegen d. Spitze hin freien Gr., welche in einen 1. Schnabel auswachsen und zur Reifezeit sammt den 1 samigen Karpellen sich von einander und von der Mittelsäule ablösen: Fam. d. Gerani a ce en.

4. Alle 10 Stbg. mit Beutel, am Grunde der 5 längeren Stbg. eine Honigdrüse, Gr. bei der Reife sich bogenförmig nach unten biegend.

\section{Geranium (662).}

Nur 5 Stbg. mit Beutel, keine Honigdrüse, Gr. zur Reifezeit sich ablösend und schraubenförmig zusammendrehend.

Erodium (663).

\section{Dritte 0rdnung (XVI, 3). Polyandria.}

Blt. regelmäßig, Kelch verwachsenblïttrig, stehen bleibend, mit einem aus 3 oder mehr freien oder verwachsenen Blättchen bestehenden Außenkelch; Blbl. 5, mit dem Stbgrefäßcylinder verwachsen und mit diesem abfallend, Stbf. am Grunde meist kuppelförmig verbreitert, d. Frkn. verdeckend, oben ästig; Frkn. oberstäudig, meist aus vielen kreisförmig um eine Mittelsäule angeordneten Karpellen bestehend, selten ganz, 5 fächrig; Fr. eine in 1 samige Karpellen zerfallende Spaltfrucht oder (selten) eine 5 fächrige Kapsel : Fam. d. Malvaceen. S. 292.

\section{XV1I. Classe. Diadelphia.}

\section{Zweite 0rdnung (XVII, 2). Hexandria.}

1. Kelch 2 blättrig, zart, meist hinf:̈lllig; Blbl. 4, eine 2 lippige Blume bildend, oberes Bl. nach rückwärts in einen abwärts gebogenen Sporn verlängert, unteres spornlos, die beiden seitlichen gleichgestaltet, an der Spitze gebunden, löffelförmig, in der Anschwellung d. Stbl. und d. Narbe bergend; Stbf. in 2 Bündel verwachsen; Frkn. oberständig, Gr. mit scheibenförmiger Narbe: Fam. d. Fum a riaceen.

2.

2. Fr. ein kugliges 1 samiges nicht aufspringendes Nüsschen.

Fr. eine längliche mehrsamige Balgkapsel.

Corydalis (543).

\section{Dritte Ordnung (XVII, 3). Octandria.}

Blt. unregelmäßig, 2 lippig, Kelch 5 blättrig, die 2 inneren Bl. sehr gr., blumenartig, die Blkr. und später die Fr. seitlich einschließend (Flügel), die 3 äußeren kl.; Blbl. 3-5, die untersten sehr kl. mit den Stbg. mehr weniger verwachsen; das vordere gr., am Scheitel oft einen vieltheiligen Kamm tragend; Stbg. in 2 unten verwachsene Gruppen zu 4 Stlk. geordnet, Stbb. mit einem Loch sich öffnend; Frkn. oberständig, zusammengedrückt, Gr. fadenförmig mit trompetenförmiger hohler Narbe; Kapsel 2 fächrig, 2 samig, an den Rändern aufspaltend. Polygala (642). 


\section{Vierte Ordnung (XVII, 4). Decandria.}

Stbf. entweder alle in eine Röhre (monadelphisch), oder 9 in eine röhrige Rinne verwachsen, in deren Spalt der 10. (obere) hineinpasst, an der Spitze frei; Frkn. oberständig, gestreckt, in d. fädigen Gr. verschmälert; Fr. eine Hülse oder Gliederhülse, selten nüsschenförmig, nicht aufspringend.

1. Kelch röhrig, 5 zähnig; bloß 1 Blbl., welches die vorstehenden Stbg. umhïllt. Amorpha (717).

2. Kelch meist verwachsenblättrig, 5 zähnig oder 2 lippig; Blkr. schmetterlingsförmig: Fam. d. Papili on a ce en. S. 334 .

\section{XV1II. Classe. Polyadelphia.}

\section{Erste Ordinung (XVIII, 1). Polyandria.}

1. Ein Griffel. Bäume (s. XIII, 1).

Tilia (635).

2. Drei Gr., Frkn. und Kapsel oberständig, 3 fächrig, letztere viel. samig, 3 klappig; Kelch und Blkr. 5 blättrig, regelmäßig.

\section{Hypericum (636).}

\section{Classe. Syngenesia.}

Sthg. 5, ihre Beutel in eine Röhre verwachsen oder verklebt, dursh welche bei $Z$ witterblten $d$. Gr. hindurchgeht.

1. Blt. einzeln stehend, ohne gemeinschaftliche Hülle, jede besonders gestielt, mit Kelch u. Blkr., zweigeschlechtig; Frkn. oberständig: Gattungen Solanum $(V, 1)$, Viola $(V, 1)$, Impatiens $(V, 1)$.

Blt. in ein Köpfchen oder Körbshen dicht zusammengestellt; Frkn. unterständio.

2. Blt. in einem von einer Deckblhïlle umgebenen Körbchen, 2 geschlechtig, regelmäßig; B!kr. trichterig, 5 theilig, Gr. fadenförmig mit 2 lappiger Narbe; Fr. eine mehrsamige Kapsel (s. V, 1). Jasione (216).

Fr. ein 1 samiges Schließfüchtchen (Akene), Kelch aus Schuppen, Haaren, Borsten bestehend, nach d. Blühen zu einer auf d. Fr. meist stehen bleibenden Schuppen-, Haar-, Borsten- oder Federkrone (Pappus) auswachsend, seltner ganz fehlend, Blkr. verschieden geformt; Blt. gewöhnlich auf dem scheiben-, halbkugel-, kugel-, ei- oder kegelförmigen Ende d. St. oder d. Äste (dem Blüten- oder Fruchtboden, receptaculum) dicht beisammen stehend, von einer gemeinsamen Deckllatthülle (Korbhülle) umgeben, ein Blütenkörbchen bildend: Fam. d. Compositen. S. 92.

\section{Erste Ordnung (XIX, 1). Polygamia aequalis.}

Alle Blt. des Körhchens 2 geschlechtig, gleichgestaltet mit zungenoder röhren- oder trichterförmiger Blkr.: sämmtliche Ligulifloren (S. 92), einige Radiaten u.d. meisten Cynarocephalen (S. 130).

\section{Zreite Ordnung (XIX, 2). Polygamia superflua.}

Randständige Blt. d. Körbchens weiblich, fruchtbare zungen- oder röhren- oder fadenförmig (im ersten Falle einen Strahl, radius) bildend, mittlere Blt. (die Scheibe, discus) röhrenförmig, 2 geschlechtig, fruchtbar: die meisten Radiaten, (S. 111). 


\section{Dritte Orduung (XIX, 3). Polygamia frutranea.}

Randblt. geschlechtslos, Scheibenblt. 2 geschlechtig, fruchtbar. Gattungen Rudbeckia (260), Helianthus (259), Bidens (258), Cen. taurea (286).

\section{Vierte Ordnung (XIX, 4). Polygamia necessaria.}

Randblt. weiblich, fruchtbar, Scheibenblt. verkümmert 2 geschlechtig: nur als männliche functionierend.

Calendula (280).

\section{Fiinfte Ordnung (XIX, 5). Polygamia segregata.}

Lauter gleichgestaltete Zwitterblt. in einen kugelrunden Kopf gestellt, jede einzelne mit einer besonderen Schuppenhülle, aber keine gemeinsame Hülle (kein Bltenkorb).

Echinops (295).

\section{$X X$. Classe. Gynandria.}

\section{Erste Ordnung (XX, 1). Monandria.}

Frkn. unterständig, Blume aus einem 6 blättrigen unregelmäßigen Perigon bestehend, dessen 3 äußeren $\mathrm{Bl}$. gleichgeformt, bald kreuzweis ausgebreitet, bald aufrecht auseinanderstehend, bald helmförmig zusammengeneigt sind; von den 3 inneren Perigonbl. die 2 oberen gleichgeformt, d. untere (d. Honiglippe, labellum) ganz anders u. sehr verschieden gestaltet: im Mittelpunkt der Blume eine fleischige Griffelsäule mit grundständiger Narbenfläcủe, an deren Vorderseite od. Ende ein zweifächriger Stbb. ganz od. nur mit seinem Grunde angewachsen ist; Bltstaub in keulige Körper (Pollinarien) vereinigt; Fr. eine 1 fächrige, 3 klappige, vielsamige Kapsel, Samen sehr kl.: Fam. d. Orchideen. S. 49.

\section{Zweite Orduung (XX, 2). Diandria.}

Zwei getrennte Stbb., nur 2 äußere Perigonbl,, mit den 2 oberen inneren ein Kreuz bildend; sonst wie b. d. vor. Ordn. Cypripedium (136).

\section{Dritte 0rdnung ( $\mathrm{XX}, 3)$. Hexandria.}

Frkn. unterständig, Blume aus einem röhrigen, am Grunde kuglig aufgetriebenen, an der erweiterten Mündung in einen zungenförm. Lappen auslaufenden Perigon bestehend; innerhalb d. kugligen Erweiterung eine fleischige Griffelsäule mit 6 strahliger Narbe, unter welcher dio 6 Stbb. an d. Säule angewachsen sind; Fr. eine 6 fächrige, vielsamige Kapsel. Aristolochia (207).

\section{Classe. Monoëcia.}

\section{Erste Orduung (XXI, 1). Monandria.}

1. Holzgewächse. Männliche Blt. (nackte Schuppen mit 2 Staubbeutel. fächern) in Kätzchen, weibl. (Schuppen mit 2 hängenden Eichen) in den Achseln von um eine Spindel spiralig angeordneten Schuppen (Deckschupp.) mit diesen ein Zäpfchen bildend, aus denen ein holziger Samenzapfen hervorgeht: Familie d. Coniferen (z. Th.).

Kräuter. 
2. Bl. als lange Nadeln ausgebildet (Nadellıölzer). wickelt.

Bl. als kl. 4 reihig angeordnete, gedrängtstehende Schuppen ent-

3. Nadeln stets einzeln stehend, melırjährig; Zapfenschuppen (samentragende) gegen den äußeren Rand verdünnt.

Nadeln zu $2-5$ in Scheiden od. gebüschelt.

4. Zapfen aufrecht, zuletzt zerfallend.

Zapfen hängend, ganz abfallend.

5. Nadeln von mehrjähriger Dauer, zu 2, 3-5; Zapfenschuppen schmal, gegen die Spitze verdickt.

Nadeln der im Frühling austreibenden Knospen gebuischelt, an den im Juni sich entwickelnden Langtrieben einzeln; Zapfen kl, ganz abfallend. Sommergrüner $B$. Larix (26).

6. Zweige 4 kantig, Zapfen wallnussgroß, Schuppen dick, schildförm. Cupressus (28).

Zweige zusammengedrückt-2 flächig, an den breiten Seiten flache, an den Kanten zusammengefalzte Schuppenbl.; Zapfen sehr kl., mit länglichen Schuppen.

Thuija (29).
7. (1) Flutende Wasserpt.
Land- u. Sumpfpfl.
10.

8. Je 1 Blte in einblättriger krugförm., an d. Spitze $2-3$ züliniger Scheide, welche d. Stbb. einschließt, Frkn. mit 2-3 Narben; Einsamige Niisschen.

Blt. nicht in eine Scheide eingeschlossen.

Najas (33).

9. Blt. hüllenlos (1 Stbg. od. 1 Frkn.), einzeln, achselständig, von 2 oft halbınondförmigen Deckblättchen gestützt; kl., in 4 Theile zerfallende Steinfrucht.

Callitriche (165).

Blt. blwinkelständig, männl. nackt (1 Stbg.), weibl. mit kl. glockig. Perigon u. 4. Stempeln mit fädigem Gr. und schiefer scheibenförmiger Narbe; aus denen gestielte Nüsschen hervorgehen. Zanichellia (34).

10. (7) Blt. nackt, 1 l. gestielter Frkn. mit 3 getheilten Gr. (weibl. Blt.) u. 10-15 Stbg. (männl. Blt.) auf sich nach einander verlängernden, mit dem Filament durch Gliederung verbundenen Stielen, von einer kelchartigen, am Rande mit $4 \mathrm{gr}$. quer gestellten Drüsen besetzten Hülle umgcben; Fr. eine 3 knöpfige, 3 samige, zerspring. Kaps. Euphorbia (653).

Blt. nackt, an fleischigen, von einem gr. Hüllbl. umgebenen Kolben; Fr. eine Beere: Aroideen.

11.

11. Kolben am Grunde sitzende Frkn. (weibl. Blt.), darüber sitzende Stbb. (männl. Blt.) tragend, nach oben in eine nackte Keule auslaufend. Arum (36). Frkn.

Kolben gänzlich bedeckt mit durcheinander gemengten Stbb. und Calla (37).

\section{Dritte 0rdnung (XXI, 3). Triandria.}

1. B. od. Str.; Blt. an d. Innenwandung eines hohlen keulenförmig. fleischigen Behälters geđrängt stehend, kl., mit 3-5theiligem Perigon, männl. 3 Stbg, weibl. 1 oberständ. Frkn. enthaltend, aus dem ein $1 \mathrm{sam}$. Nüsschen entsteht. Behälter wird durch Verdickung zu einer Scheinfrucht (Feige). Ficus (179).

Kräuter od. Gräser.

2. Beiderlei Blt. od. nur die weibl. in Kolben. 
Blt. in Ähren od. Ährchen, unter spelzenartigen Deckschuppen: Cyperaceen.

3. Beiderlei Blt. in Kolben. Sumpf-u. Wasserkr.: Ty p haceen. 4.

Weibl. Blt. in walzigen, von vielen Hüllbl. umwickelten Kolben, mit 1. fadenförmig. Gr., männl. in 2 bltigen rispig gruppierten Ährchen. Gras. Zea (94).

4. Männl. u. weibl. Kolben walzig, über einander an der Spitze des einfachen St. stehend, erstere nackt, Frkn. von Borsten umgeben; 1samige Schließfrucht.

Typha (39).

Männl. u. weibl. Kolben knglig, traubig angeordnet; Blt. mit mehrschuppiger Hülle, Fr. ein 1 samiges Nüsschen.

Sparganium (40).

5. Frkn, u. Fr. von einem kelchartigen, in einen 2 zähnigen Hals ansgezogenen Schlauch (Frschlauch) locker umschlossen; Narben 2 od. 3, einsamige Karyopse.

Kein Frschlauch.

Carex (95).

6. Eine einzige, aus 2 bltigen Ährchen zusammengesetzte Ähre, jedes Ährehen in einer scheidenartigen gespaltenen Hülle, 1 sitzenden Frkn. u. 1 gestielte männl. Blte enthaltend; Narb. 3, Nüssch. 3 kantig. Elyna (96).

Gelappte, straußförmige, aus mehrbltigen Ährchen zusammengesetzte Ähre; unterste Blt. d. Ährchen weiblich, Frkn. umringt von einer scheidigen gespaltenen Hülle, obere Blt. männlich, zwischen 2 Spelzen; Narben 3 , Nüsschen lanzettlich 2 seitig.

Kobresia (97).

\section{Vierte Ordnung (XXI, 4). Tetrandria.}

1. Bäume od. Sträucher.

2.

Kräuter.

3.

2. Männliche Blt. in Kätzchen, weibl. in Ährchen, die sich in holzige Frzapfen umgestalten, ron ersteren je 3 , von 4 Perigonblättch. umringte Blt. unter jeder Kätzchenschuppe; weibl. Blt. nackt, ein Frkn. mit 2 Gr.; 1 samige Nüsschen.

Alnus (168).

b) Beiderlei Blt. in Kätzchen, männl. mit 4 theiligem, weibliche mit 4 blättrigem Kelch. Frkn. oberständ., mit 2 fadenförm. Narben; weibliche Kätzchen durch Fleischigwerden u. Verschmelzen d. Kelchbl. sich in eine beerenartige Scheinfr. (Maulbeere) umgestaltend. Morus (178).

c) Blt. einzeln in d. Blwinkeln, männl. mit 3 theiligem Kelch und 2 blättr. Blkr., weibl. mit $2-3$ blättr. Kelch und oberständig. Frkn. mit 3 Gr, F Fr. eine 3 fächrige 3 schnäblige Kapsel mit 2 samigen Fächern,

Buxus (652).

3. Männl. Blt. mit 4 theiligem Kelch und elastisch aufspringenden Stbf., weibl. mit 2 theiligem Kelch und oberständig. Frkn., Narbe sitzend, pinselförm.; 1 samiges Nüsschen. Brennhaare.

Urtica (182).

Männl. Blt. gestielt mit 4 spaltigem Kelch u. röhriger 4 theilig. Blkr., weibl. sitzend mit 3 spalt. Kelch und oberständ. Frkn.; 1 samiges Nüssch. Litorella (413).

\section{Fiufte 0rdnung (XXI, 5). Pentandria-Polyandria.}

1. Bäume od. Sträucher.

Kräuter. 2.

2. Beiderlei Blt, od, wenigstens d. männl, in Kätzchen. 
Beiderlei Blt. blwinkelständig, 1. gestielt, einzeln od. in Büscheln, mit 5 blättr. hinfälligem Kelch, männl. mit 5 Stbg., weibl, mit oberständ, Frkn.; Narb. 2, dick, behaart; Fr. eine beerenförmige Steinfr. Celtis (177).

3. Beiderlei Blt. in Kätzchen.

Männl. Blt. in Kätzchen, weibl, verschieden angeordnet.

4. Kätzchen kuglig, zu 2-4 an einem hängenden Stiel, Blt. nackt, zwischen keilförmigen Deckbl. sitzend, Frkn. mit pfriemlichem Gr.; lederartige, 1 samige Niusschen, von Haaren umringt; Frkätzchen zuletzt zerfallend.

Platanus (175).

Männl. Kätzchen walzig mit eiförmig. Schuppen, unter denen 6 bis 12 Stbg. sitzen, weibl. sehr schıächtig u. kl. mit länglichen Schuppen, unter jeder 2-3 Frkn. mit eng anliegendem, in einen oberständ. gezähnten Saum ausgebreitetem Perigon, am Grunde od. gänzlich von einer später sich vergrößernden Schuppe umhüllt; 1 samige Nussfr. Carpin een. 5.

5. Hiillschuppe der weibl. Blt. den Frkn. am Grunde umgebend, flach, 3 theilig, sich sehr vergrößernd.

Carpinus $(1 ; 0)$.

Hüllschuppe als hohler, d. weibl. Blt. gänzlich umschließend. Schlauch ausgebildet; Frkätzchen einem Hopfenzapfen gleichend. Ostrya (171).

6. (3) Bl. einfach, Blt. vor od. mit d. Laubausbruch erscheinend. 7.

Bl. unpaarig gefiedert, Blt. mit dem Laubausbruch erscheinend, männl. in dicken walzigen Kätzchen aus Knospen vorjähriger Sprossen, mit 4 theiligem Kelch u. 10-12 Stbg., weibl. zu 1-3 an der Spitze der diesjährigen Sprossen, von Deckbl. gestïtzt, mit unterständ. Frkn., 4 the iligem Kelchsaum u. 2 gr. gelappten Narben. Aufspringende Steinfrucht mit 2 klappigem Steinkern. Juglans (659).

7. Männl. Kätzchen walzig od. länglich mit gestielten schildförmigen Schuppen, unter jeder 8-12 Stbg. von kl. Schuppenbl. umgeben; weibl. Blt. in kl. schmächtigen Ähren, welche sich in walzige od. längliche, zuletzt zerfallende Frzapfen umgestalten, mit zuletzt 3 lappigen Schuppen, unter denen jeder $2-3$ nackte Frln. mit 2 Gr.; Fr. ein 1 samiges, br. gefliigeltes Nïsschen.

Betula (169).

Weibl. Blt. nicht in Ähren, jede einzelne od. $2-3$ von einer Deckblätterhiille umgeben, welclıe sich vergrößernd die Fr. (Nuss) von unten her od. ganz umhüllt (Fruchtbecher, cupula): Fam. d. Cupuliferen. 8.

8. Männl. Kätzchen walzig, unter jeder Schuppe 8 nackte Stbg.; weibl. Blt. in Kuospen eingeschlossen, aus deren Spitze d. rothen Gr. hervorragen; Frbecher blattartig, zerschlitzt, je eine Nuss von unten her einschließend.

Weibl. Blt. nicht in Knospen eingeschlossen. Corylus (172).

9. Männl. Kätzchen schlaff, l., hängend, Blt. mit 5-9 theilig. Kelch und ebenso vielen Stbg.; weibl. Blt. in d. Blivinkeln d. jungen Sprossen mit unterständ. Frkn. u. gezähntem Kelchsaume, von zahlreichen Schuppen umringt, welche sich zu einer becherförmigen, die Nuss (Eichel) von unten umgebenden Cupula entwickeln.

Quercus (173).

b) Männl. Blt. in langen ährenförmigen Kätzchen, geknäuelt, sitzend, mit 6 theiligem Kelch u. 10-20 Stbg.; weibl. am Grunde d. männlichen Kätzchen mit 4 spaltigem oberständigem Kelch, je 1-3 mit gemeinsamer Deckblhülle, woraus eine d. Früchte (Kastanien) gänzlich umhüllende, l., stachlige, zuletzt klappig aufspringende Cupula entsteht. Castanea (174).

c) Männl. Blt. in seitenständ., gestielten, hängenden, kuglig. Kätzchen, mit 5-6 spaltigem Kelch und. vielen Stbg; weibl, in endständigen 
Büscheln, je 2 auf gemeinschaftl. Stiele, von Deckschuppen umgeben, woraus eine die Früchte (Bucheln) gïnzlich umschließende, kurz krautstachlige, zuletzt kreuzförmig mit 4 Klappon aufspringende Cupula entsteht.

10. (1) Flutende Wasserpflanzen.

Fagus (174 b.).

Landpfl. od. aufrechte, über d. Wasserspiegel hervorragende Wasserod. Sumpfkräuter.

12.

11. Blt. bloss mit vielblättrigem Kelch, männl. mit vielen, siłzenden, bedornten Stbb., weibl. mit 1 Frkn.; 1 samiges in einen Dorn endigendes Nüsschen.

Ceratophyllum (163).

Männl. Blt mit 4 lappigem Kelch u. 4 hinfälligen Blbl. u. 8 Stbg., weibl. mit oberständ. 4 zähnigem Kelchsaum u. 4 Narb.; Spaltfrucht in 4 Steinkerne zerfallend. Myriophyllum (674).

12. Blt. ansehnlich, mit 3 theiligem Kelch und 3 blättr. Blkr., Stlog. viele, Frkn. viele auf kugligem Bltenboden oberständig; 1 samige Nüsschen.

Sagittaria (113).

Blt. bloss mit Kelch. 13.

13. Männl. u. (wenn vielehig) Zwitterblt. mit 5 blättr. Kelch und 5 (auch nur 3) Stbg., weibl. mit 2 theiligem od. 2 spaltigem Kelch, dessen Stücke zu Fruchtklappen auswachsen, zwischen denen die zusammengedrückte Schlauchfr. liegt.

Alle Blt. gleichgeformt. Atriplex (189).

14. Blt. geknäuelt in rispigen Ähren, Kelch $3-5$ theilig, Stbg. $3-5$, Fr. 2-3; 1 samige Schlauchtr., ringsum aufspringend od. geschlosseu bleibend.

Amarantus (195).

Blt. in endständigen Köpfchen, Kelch 4lappig, Stbg. viele, Narben pinselförmig; aus d. verhärteten Kelchröhre gebildete Scheinfrucht, ein 1 samiges Nïsschen einschließend.

Poterium (698).

\section{Neunte Ordnung (XX, 9). Monadelphia.}

1. Blt. einzeln od. gebiischclt, blwinkelständig, Kelch mit d. Blkr. verwachsen, Stbg. 5, Frkn. unterständ., Gr. 3; Fr. fleischig, vielsamig: $\mathrm{Cucurbitaceen}$.

Männl. Blt. in mit Korbhülle begabten Köpfchen, mit röhriger, fünfzähniger Blkr, ohne Kelch, weibl. zu 2 in einer krautstachligen u. zweischnäbligen Hülle eingeschlossen u. mit dieser verwachsen, mit fadenförm. Blkr. u. 2 spaltigem Gr.; 2 samige Scheinfr. aus d. verhärteten Hülle gebildet.

2. Kelch 6 zähnig, auch d. Stbb. röhrig verwachsen; Samen der sehr verschieden geformten Fr. mit wulstigem Rande. Cucurbita (209).

Kelch 5 zähnig, Stbb. nicht verwachsen; Fr. l. gestreckt, Samen scharfkantig.

Cucumis (210). stumpfrandig.

Kelch 5 zähnig, Stbb. frei; kuglige, 3-6 samige Beere. Samen Bryonia (211).

\section{Classe. Dioëcia.}

\section{Erste Orduung (XXII, 1). Monandria.}

Hierher gehören Najus major (33) u. Salix purpurea (166). 


\section{Zweite Ordnung (XXII, 2). Diandria.}

Beiderlei Blt. in Kätzchen, hüllenlos, je 2 (selten 3-5) Stbg. oder ein Stempel mit $1 \mathrm{Gr}$. und 2 Narben unter jeder Kätzchenschuppe; Fr. eine 2 klappige, vielsamige Kaps., Samen mit Haarbüschel. Holzgewächse. Salix (166).

Vgl. auch L e mna und Fraxinus (II, 1).

\section{Dritte Ordnung (XXII, 3). Triandria.}

Kelch 3 theilig, Blbl. 3 blättrig, Frkn. unterständig, mit 6-9 strah. liger Narbe; Fr. eine beerenförmige, 5-9 kernige Steinfr. Holzgewächs. Empetrum (651).

Anmerk. Zweihäusig sind auch Valeriana dioica und tripteris (IJI, 1), Salix amygdalina und undulata, Carex dioica und D avalliana (XXI, 3).

\section{Vierte Ordnung (XXII, 4). Tetrandria.}

\section{Holzgewächse.}

Krautpfl,; Kelch der männl. Blt. 4 theilig, der weibl. 2-3 spaltig, Blkr. fehlend, Frkn. oberständı mit 4 Gr., Fr. ein 1 samiges mit d. verhärteten Kelch verwachsenes Niisschen.

Spinacia (188).

2. Immergrüner, auf Bäumen schmarotzender Str.; rnännl. Blt. ohne Kelch mit 4 theiliger Blkr., weibl. mit 4 blättr. Blkr. und unterständigem Frkn.; Fr. eine 1-3 samige Beere.

Viscum (202).

Sommergrüner Str. oder B.; Perigon der männl. Blt. 2 theilig, der weibl. röhrig, an d. Spitze a spaltig; Frkn. uberständig mit 1 hakenförmigen Narbe; Scheinbeere, durch Fleischigwerden des d. Nüsschen einhüllenden Perigons gebildet.

Hippophaё (205).

Anmerk. Zweihäusig sind auch Urtica dioica und häufig Morus nigra (XXI, 4).

\section{Fünfte Ordnung (XXII, 5). Pentandria.}

1. Bäume und Sträucher, Blt. kl. ohne Blkr.

Kräuter.

2.

3.

2. Kelch 5 theilig, Stbg. 4-5, 1. gestielt, Frkn. oberständig mit tief getheiltem Gr.; gedoppelte Flügelfrucht, in 2 einsamige Hälften spaltend. Negundo (640).

Kelch der männl. Blt. 5-, der weibl. $3-4$ spaltig, Stbb. 5 sitzend, gr., Frkn. oberständig, mit 3 dicken Narben; kl. 1 samige trockene Steinfrucht.

Pistacia (655).

3. Männl. Blt. mit 5 theiligem, weibl. mit seitlich gespaltenem Kelch, Blkr. fehlend; Frkn. oberständig, mit $2 \mathrm{Gr}$.; einsamiges vom Kelch umuülltes Nüsschen.

Cannabis (180).

Männl. Blt. mit 5 theiligem Kelch, in Rispen, weibl. (Frkn.) mit einem krugförmigen Deckblättchen in d. Achsel gr. Deckschuppen in Ähren, aus denen zapfenförmige Fruchtstände entstehen; Blkr. fehlend, 1 samiges Nüsschen.

Humulus (181).

Anmerk. Zweihäusig sind Ribes alpinum $(V, 1)$, Trinia ( $V$, 2), und häufig Rhamnus cathartica $(V, 1)$, Rhus $(V, 3)$, und Atriplex (XXI, 5), ferner Salix pentandra; 5 Stbg. hat häufig Spinacia.

Will komm, Schulfiara. 


\section{Sechste Ordnung (XXII, 6). Hexandria.}

Perigon 6 theilig, Frkn. unterständig, Beere.

Tamus (148).

Anmerk. Zweihäusig sind oft Asparagus, Loranthus (VI, 2) und Rumex (VI, 3).

\section{Siebente Ordnung (XXII, 7). Octandria.}

1. Beiderlei Blt. in Kätzchen, hüllenlos, unter gezähnten oder zerschlitzten Schuppen, auf einer becherförmigen Scheibe sitzend; Frkn. mit 2 getheilten Gr., 2 klappige Kapsel, Samen mit Haarschopf.

Populus (167).

2. Kelch 4 theilig, männl. Blt. mit 4 blättriger, weibl. meist ohne Blkr.; Stempel 4, oberständig, sich in Balgkapseln umgestaltend.

Rhodiola (506).

Anmerk. Zweihäusig sind nicht selten Arten von Acer (VIII, 1).

\section{Achte Ordnung (XXII. 8). Enneandria.}

1. Landpflanzen: Kelch 3 theilig, Stbg. 9-12, Frkn. oberständig, mit 2 Narben; 2 knopfige Kapsel mit 1 samigen Fächern.

Mercurialis (654).

2. Schwimmende Wasserpt.; Kelch 3 theilig, Blkr. 3 blättrig, männl. Blt. mit 9 vollkommenen Stbg. in 3 Kreisen und 3 inneren beutellosen Filamenten, weibl. mit 3-6 beutellosen Filamenten, 3 Honigschuppene Frkn. unterständig, mit 6 Gr. und 2 lappigen Narben; trockene 6 fächrig; Fr.

Hydrocharis (117);

\section{Neunte Ordnung (XXI, 9). Decandria.}

Hierher gehören: Silene inflata und Otites $(X, 3)$ u. Melandryum $(X, 5)$.

\section{Zehnte Ordinung (XXII, 10). Dodecandria.}

Kelch 3 theilig, Blkr. 3 blättrig, Stbg. 12 oder mehr: Gr. 6, zweispaltig; Fr. eine 1 fächrige 6 seitige Beere, vielsamig. Stratiotes (118).

Hierher gehört auch Spiraea Aruncus (XII, 3).

\section{Elfte Ordnung (XXII, 11). Polyandria.}

Vgl. Stratiotes und Populus nigra.

\section{Zwölite Ordnung (XXII, 12). Monadelphia.}

Immergrüne B. und Str. mit Nadel- oder Schuppenbl. und nacktea Samen. Männl, Blt. in kl. Kätzchen.

1. Stbg. schildförmig ausgebreitet mit 3-7 Stbbfächern, weibl. (Eichen) an schuppenförm. zu einem knospenförmigen Gebilde vereinigtea Frbl.; Scheinbeere, aus d. Verschmelzung d. Frbl. entstanden.

\section{Juniperus (30).}

2. Stbb. 1 fächrig unter schildförmigen Schuppen, 5-6; weibl. Blt (Eichen) einzeln stehend, von Deckschuppen umschlossen; Scheinbeere, oben offen, aus einem fleischigen Samenmantel bestehend. Taxus (31). 


\title{
Drcizehnte Orduung (XXII, 13). Syngenesia.
}

\author{
Fierier gehören: Ginapablium dioicum und carpathicam \\ (264), sowie Petasites (244).
}

\section{Classe. Polygamia.}

Die von Linné hierher gestellten Pa. sind nach àer Beschaffenheir ihrer Zwitterblt. in den vorhergehenden Classen untergebraslt und dort zu suchen.

\section{Classe. Cryptogamia.}

Es sind hier nur die Gefäßkryptogamen (Cryptogamae vascilares) aufgenommen und werden deren Gattungen nicht nach den sehr unnatïrlich begrenzten Ordnungen Linnés, sondern nach natürlichen classificiert.

\section{Erste Familie (XXIV, 1). Equisetaceae, Schachtelhalme.}

Sporenbehälter (Sporangien) sackförmig, aufreißend, an der Unterseite kurz gestielter eckiger Schildschuppen, welche wirtelförmig in eine endständige zapfenförmige Ähre geordnet sind.

Equisetum (1).

\section{Zweite Familie (XXIV, 2). Lycopodiaceae, Bärlappe.} blätter.

Sporangien einzeln in d. Achseln flacher gedrängt stehender Schuppen-

1. Sporangien von einer Form, sitzend od. sehr kurz gestielt, rundlich, nierenförmig oder quer eiförmig, mit einem Querritz aufspringend, unter d. oberen Bl. d. St. oder in endständ. Äiren. Lycopodium (2).

2. Sporangien in 1. Ähren, von zweierlei Form, die einen (Makrosporangien) 3-4 knöpfig, 3-4 größere Sporen enthaltend, die anderen (Mikrosporangien) nierenförmig oder rundlich, mit sehr vielen, sehr kl. feinstachligen Sporen erfüllt.*) Selaginella (3).

\section{Dritte Familie (XXIV, 3). Polypodiaceae, Laubfarne.}

Sporangien sehr zartwandig, zusammengedrückt, mit gegliedertem Stiel $\mathrm{n}$. von einem unvollstïndigen gegliederten Ringe umgeben, an einer Kante klaffend aufreißend, eckige Sporen enthaltend, in Häufchen (Fruchthäufchen, sori), welche bald mit einer zarten, später verschwindenden Membran (Schleier, indusium) bedeckt, bald vom Anfange an nackt sind, an der untern Fläche oder am Rande sänmtlicher oder besonderer Bl. gruppiert. Blätter in der Jugend uhrteāerartig zusammengerollt.

1. Frbäufchen nackt.

Frhäufchen beschleiert.

2.

8.

2. Frhäufchen gänzlich unbedeckt.

*) In die Nähe $\nabla$. Selaginella gehört auch d. Brachsenkraut (Isoëtes lacustris L.), eine auf dem Grunde von Seen wachsende stammlose Pfl. mit gebüschelten pfriemenförmigen $\mathrm{Bl}$, in deren grundständiger Scheide zweierlei Sporenfrüchte gehäuft stehen, nämlich größere und äußerlich holprige, Makrosporen enthaltende, u. kleinero glatte mit Mikrosporen. - Kornmt nur im Schwarzen See des Böhmerwaldes vor und ist daselbst sc! twer $z u$ erlangen. 
Frhäufehen vom umgeschlagenen Blrande mehr weniger bedeckt. 6 .

3. Frhäufchen ohne grundständige Hälle.

Unter d. rundlichen Frhäufchen eine tellerförmige, am Rande 4 spaltig in wimperartige. Franzeu aufgelöste Hülle.

Woodsia (6).

4. Frhäufchen kreisrund, zu beiden Seiten des Mittelnervs der Blabschnitte, 2 zeilig.

Frhäufchen länglich oder lineal.

Polypodium (7).

5. Frhäufchen lineal, an der der Mittelrippe der bl. zugekelorten Seite d. Nerven stehend, schief od. gabelig gelagert, meist von d. Spreuschuppen verdeckt.

Ceterach (4).

Frhäufchen länglich oder lineal, auf dem Rücken des Nerven d. Blzipfel zwischen d. Spreuschuppen sitzend.

Gymnogramme (5).

6. (2), Alle Bl. gleichgeformt: Frhäufchen länglich, auf den in den zurückgebogenen Randlappen d. Blabschnitte endigenden Nerven sitzend. Adiantum (14).

Frtragende Bl. zusammengezogen, schmäler als dio ausgebreiteten sterilen $\mathrm{BI}$.

7. Alle Bl, 3 fach fiederschnittig, Frhäufchen rundlich, neben unı unter dem zurüclrgeschlagener: Blrande verborgen, bald zusammentießend. Allosurus (17).

Unfrbare Bl. fiederschnittig-fiederspaltig, frbare 1 fach fiederschnittig, Abschnitte lineal, zusammengezogen, fast stielrund; Frhäufchen rundlich, zusammenfließend, beiderseits d. Mittelrippe d. Abschnitte.

8. (1) Alle Bl. gleichgeformt.

Struthiopteris (18).

Bl. 1 fach fiederschnitt., sterile ausgebreitet, Frbl. zusammengezoren mit linealen stielrundlichen Abschnitten; Frhäufchen lineal, zu beiden Seiten mit linealem Schleier.

Blechnum (15).

9. Frhäufchen und Schleier rund oder ruudlich bis eiförmig. 10 .

b) Frhäufchen länglich rund oder gebogen, fast hakenförmig, auf. d. Fläche oder an d. Winkeln d. Blzipfel, zuletzt zusammenfließend; Schleier entlang d. einen Seite $d$. Frhäufchens befestigt, gefranzt, bald verschwindend.

c) Frhäufchen und Schleier lineal oder länglich.

Athyrium (11).

10. Schleier im Umriss rund, in d. Mitte des Frhäufchens befestigt, mit ringsherum freiem Rande; Frhäufchen zu beiden Seiten des Mittelnervs und der Blabschnitte.

11.

Schleier rundlich, nur an einer Stelle des Randes des Frhäufchens befestigt, uber denselben herübergreifend, sehr zart, bald verschwindend; Frhäufchen auf d. Fläche d. Blzipfel, zerstreut, zuletzt zusammenfließend.

11. Schleier kreisrund-schildförmig. Cystopteris (10).

Schleier nierenförmig 2 lappig, oben rund. Aspidium (9). Polystichum (8).

12. $(9$, c). Frhäufchen auf dem Mittelfelde der Bl. oder der Blabschnitte.

Frlıäufchen lineal, längs des umgebogenen Randes der Blabschnitte, denselben endlich umsäumend; Schleier lineal, aus d. Blrande selbst od. vor d. Blrande aus der Blfläche entspringend.

Pteris (16).

13. Frhäufchen lineal oder länglich, Schleier ebenso, längs d. äußoren Seite d. Frhäufchen angeheftet; Bl. 1-3 fach fiederschnittig. 
Frhäufchen lineal, schräg gegen die Mittelrippe des stets einfachen und ganzen Bl. gestellt; Schleier lineal, gegen das Frhäufchen offen.

Scolopendrium (13).

\section{Vierte Familie (XXIV, 4). Osmundaceae, Traubenfarne.}

Sporangien gestielt, netzadrig, mit einem Längspalte aufspringend, büschelig auf den zusammengezogenen Fiedern der oberen Blabschnitte stehend, ästige Trauben od. Rispen bildend. Einzige Gattung: Osmunda (19).

Fiinfte Familie (XXIV, 5). Ophioglosseae, Ährenfarne.

Sporangien gr., kuglig, derbwandig, mit einem Querspalt anfspringend, in einfache oder verzweigte Ähren gestellt, sitzend.

1. Eine einzige, endständige, 2 reihige Ähre; Sporangien verwachsen. Ophioglossum (21).

2. Verzweigte rispige Ähren; Sporangien einseitswendig, getrennt. Botrychium (20).

\section{Sechste Familie (XXIV, 6). Rhizocarpeae, Wurzelfruichtler.}

Sporenfrüchte am Grunde d. St. oder Bl. stehend; Sporen zweierlei: große (Makrosporen) und kleine (Mikrosporen).

1. Schwimmende Wasserpfl.; Sporenfr. Kuglig, zwischen den WVzl. zu 4-8 gehäuft einem kurzen, abwärts gerichteten Zweiglein angeheftet, Makro- und Mikrosporangien enthaltend. Salvinia (24).

Sumpfkr., im Boden wurzelnd; Sporenfr. knglig od. eiförmig, lederartig, Makro. und Mikrosporangien enthaltend, zuletzt am Scheitel in 2-4 Lappen aufspringend.

2. Sporenfr. am Grunde der Bl, einzeln aus den kriechenden St. entspringend, liurz gestielt, 4 lappig aufspringend; Bl. pfriemenförmig.

Pilularia (22).

Sporenfr. am untern Theile $d$. Bltstiele, einzeln oder zu $2-3$ auf einem 2-3 spaltigen Stielchen oder fast sitzend, 2 lappig aufspringend; Bl. l. gestielt mit 4 theiliger Spreite.

Marsilea (23). 



\section{Erste Abtheilung.}

\section{Gefä B. Sporenpflanzen.}

(Plantae vasculares sporophorae s. cryptogamae.)

Fam. I. Equisetaceae. Schachtelhalme.

\section{Equisétum L. Schachtellıalm (XXIV, 1*).}

Zarte Kr. mit kriechendem Wzst. u. bllosen einfachen od. quirlästigen St., welche sammt d $\ddot{A} s t e n$ gegliedert $u$, an $d$. Gliederungen mit gezähnten od. zerschlitzten Scheiden begabt sind.

1. Frtragende St. stets od. anfangs röthlichweif, einfach od. nachträglich Quirläste treibend, unfrbare quirlästig, grün.

St. alle gleich, meist quirlästig, selten einfach.

2.

4.

2. Frtragende St. früher als die unfrbaren erscheinend und vor der Entwicklung der letzteren vergehend.

Frbare u. unfrbare gleichzeitig, erstere $15-30 \mathrm{~cm}$ h., anfangs einfach, später quirlästig, letztere $30-60 \mathrm{~cm}$ h., überhängend, quirlförmig sehr stark verzweigt; Äste hängend, 4 kantig Ringscheiden mit $4-5 \mathrm{ab}$ stehenden braunen Zähnen. - Feuchte Wälder. 4. 4. 5.

$\mathrm{Sch}$ eu erkraut, $E$. silváticum L.

3. Frbare St. $8-27 \mathrm{~cm}$ h., röthlichweiß, Scheiden aufgeblasen, 8-12 zipflig; unfrbr. St. grün, gefurcht, bis $30 \mathrm{~cm}$ h., mit 12-18zipflig. Ringscheiden und ebenso vielen 4 kantigen Ästen. - Feuchte Äcker. 4. 4. 5 . Katzenzahl, E. arvense L.

Frbr. St. bis $32 \mathrm{~cm}$ h., rötblichweiß, dick, einfach, Glieder länger als d. gr., nach oben übereinandergeschobenen 20-30 zipfligen Scheiden, eine 1. dicke Ähre tragend; unfrbare St. elfenbeinweiß, bis $1: 3 \mathrm{~m}$ h., quirlästig, Ringscheiden mit 20-40 schwarzbraunen Zipfeln; Äste zahlreich, hängend, 8 kantig. - Waldsümpfe, Schluchten, Bachufer; stellenweis (E. Telmateja Ehrh.). 4. 4. 5.

E. maximum Orth.

4. Ähre stumpf; St. im 1. Jahre fruchtend, dann verwelkend, weich...glatt, grasgrün.

5.

Ähre bespitzt; St. überwinternd, im 1. Jahre nicht fruchtend, hart, rauh, graugrün.

5. St. flach gefurcht, meist einfach, $16-80 \mathrm{~cm}$ h., Scheiden anliegend, mit 15-20 braunen Zähnen. - Stehende Wässer. 4. 6. 7. E. limosum L.

St. tief gefurcht, stets quirlästig, $30-60 \mathrm{~cm}$ h., Scheiden locker, mit 5-8 schwarzbraunen weißhäutig gerandeten Zähnen. - Sumpfwiesen. 7. $5-10$. E. palustre L. Systems.

*) Die eingeklammerten Ziffern bedeuten Classe und Ordnung des Linnéschen W'illkomm, Schulfiora. 
6. St. wenigstens bis zur Mitte quirlästig, unfrbare in eine lange einfache Spitze auslaufend, $0.3-1 \mathrm{~m}$ h., Scheiden kantig gefurcht, am Rande schwarzbraun, mit 8-20 weißhäut. Zähnen (E. elongatum Willd.). Feuchter Sandboden, an Gräben; zerstreut. 4. 6. 7.

E. ramosissimum Desf.

St. einfach gebüschelt, am Grunde oft stengelförm. einfache Äste treibend.

7. St. $16-30 \mathrm{~cm}$ h., fadenförmig, rasig-büschelig, Scheiden fast becherförm, schwarz od. grïn u. schwarz gerandet, mit 5-8 weißhäutig. Zähnen. - Nasser Sandboden, Sümpfe in B., T., Sz., St. ; sehr zerstreut. 4. $5-7$.

E. variegaitum Schleich.

St. $0 \cdot 6-1 \cdot 3 m \mathrm{~h}$. , stark, starr, einzeln oder zu wenigen; Scheiden walzig, anliegend, mit 15-20 Kerbzähnen. - Feuchter Sand- u. Lenmboden, hier u. da. 4. $4-8$.

Polier-Sch., $E$. hiemále L.

\section{Fam. II. Lycopodiáceae. Bärlappgewächse.}

\section{Lycopódium L. Bärlapp (XXIV, 2).}

Immergrüne Pfl. mit oft holzigem St., Bl. gedrängt stehend, nadel-, pfriemen- od. schuppenförmig.

1. St. и. Äste stielrund, ringsherum abstehend beblättert.

St: rund, Äste 2 schneidig-zusammengedrückt mit anliegenden 4 reiligen Schuppenbl.; Sporangien in Ähren, diese zu 2-3 auf 1. kleiuschuppigem Stiel.

2. Sporangien in walzigen Ähren.

3.

Sporangien einzeln in d. Achseln d. oberen Bl. sitzend; St. $5-15 \mathrm{~cm}$ 1., aufsteigend, ästig, häufig niedrig, aufrecht handförmig ver'zweigt; Bl. lineal-lanzettl., spitz, dachziegelig. - Gerölle, Felsspalten, Nadelwïlder höherer Gebirge. 7. 7. 8.

Te uf els hand, $L$. Selágo $L$.

3. Ähren zu 1-3 auf 1. beschupptem Stiele; St. kiiechend, ästig, bis $1 \mathrm{~m}$ l., Bl. dachziegelig, pfriemenförm., haarspitzig. - Heiden, Bergtriften, Waldwiesen. 4. 7.8.

Gem ei ner B., L. clavatum L.

Ähren sitzend.

4. Deckbl. d. Ähre von d. Stbl wenig verschieden, nur kürzer, alle Bl. pfriemenförm., weich; St. kriechend, 5-8 cm l., Fräste straff aufwärts. - Moosige Heiden, nasser Torfboden; sehr zertreut. 4. S. 9.

\section{L. inundatum L.}

Deckbl. d. Ähre br. eiförmig, zugespitzt, Stbl. nadelförmig. 5.

5. Bl. wagerecht abstehend od. zurückgebogen, steif, stachelspitzig; St. weit umherkriechend, Äste aufrecht 5-16 cm l., gabeltheilig. - Gebirgsnadelwälder. 4. 7. 8 .

L. annótinum $\mathrm{L}$.

Bl. angedrückt, 4 reihig, kurz, stumpf; St. kriechend u. aufsteigend, Äste 8-10 cm l., gebüschelt. - Moorige Hochgebirgstriften; zerstreut, 4. 7. 8 .

L. alpinum L.

6. (I). Bl. verschieden, die der unteren und oberen Reihe kleiner als die der seitenständigen Reihen; St. weit umherkriechend, bis $1 m 1$, Äste aufsteigend, fächerförm., gabeltheilig. -- Gebirgswälder. 4. 7. 8. 
B1. aller Reihen gleichgestaltet, Äste aufrecht, schmäler, gleichhohe fächerförmige Büschel bildend. - Sandige Nadelwälder und Heiden; zerstreut und selten. 24. 7. 8.

L. Chamaecyparissus A. Br.

3. Selaginella Spring. Moosfarn (XXIV, 2).

Kriechende Zwergbärlappe mit 1. aufrechten Frähren.

1. Bl. allseitig abstehend, eilanzettförm., dornig gezähnt; Ähre sitzend, bis $3 \mathrm{~cm}$ l. - Auf bemoostem Boden in den Alpen (häufig) u. im Riesengebirge (selten). 7. 7. 8 .

S. spinulosa A. Br.

2. Bl. 4 reihig, ganzrandig; Ähren kiirzer auf kl. schuppigem Stiele. - Morastige Stellen der Alpen. 4. 5-7.

S. helvética Sprg.

\section{Fam. III. Folypodiáceae. Laubfarne.}

\section{4. Céterach. Bruh. Schuppenfaru (XXIV, 3).}

Bl. gebiischelt, kurz gestielt, 6-16 cm l., buchtig-fiedertheilig; oberseits kahl, grün, unterseits dicht rostroth spreuschuppig. - An Mauern u. Felsen d. südlichen Länder, auch in B. (an der Elbe, selten!) 4. 6-10. (Grammitis Ceterach L.)

C. officinarum Willd.

\section{Grmnográmme Desr. Nacktfarn (XXIV, 3).}

B1. gebüschelt, 1. gestielt, $2-10 \mathrm{~cm}$ l., doppelt-fiederschnittig, lederartig, oberseits kabl, griin, unterseits dicht $m$. anfangs silbergrauen, spät. hellbraunen Spreuschuppen bedeckt. - Felsspalten in IIh., Noe., T.; sehr zerstreut. 4. 6.7.

G. Marantae Mett.

\section{6. Wóodsia R. Br. Wimperfarn (XXIV, 3).}

Bl. dicht gebüschelt, $8-12 \mathrm{~cm}$ l., l. gestielt, fiederschnittig m. fiedertheiligen Abschnitten u. gekerbten Zipfeln, oberseits kahl, unterseits mit 1. franzenartigen Spreuschuppen u. Haaren bedeckt; Wzst. viel- nnd langfasrig. - Felsspalten u. Gerölle nackter Basalt- und Phonolithberge in B. u. T. 4.7 .8 .

W. ilvensis R. Br.

\section{Polypódium L. Tiipfelfarn (XXIV, 3).}

Farnkr. m. 1. kriechendem Wzst. u. einzeln stehend., 1. gestielten Bi.

1. Bl. 1 fach fiedertheilig, $15-20 \mathrm{~cm}$ l.; Frhäufchen gr., 2 reihig, rostgelb. - Fels. und Mauerspalten. 4. 5-8.

Engels ü $\beta, P$. vulgare L.

Bl. 2-3 fach fiederschnittig, Frhäufchen kl. (Phegopteris Fèe). 2.

2. Bl. im Umriss 3 eckig, 3 theilig, 2 fach gefiedert; Mittelrippe ohne Spreuschuppen.

Bl. im Umriss 3 eckig-eiförmig, 1. zugespitzt, $15-30 \mathrm{~cm}$ l., fiederschnittig mit fiederspalt. Abschnitten, an der Mittelrippe dicht spreuschuppig. 4. 7. 8 .

Bu chenfarn, P. Phegópteris L.

3. Bl. kahl, zart, 15-30 cm l., selir l. gestielt. - Laub-, besonders Buchenwälder. 4. $6-8$. Eichenfarn, P. Dryópteris L.

Bl. fein drüsig-weichlıarig, derber, $30-50 \mathrm{~cm} \mathrm{l.} \mathrm{-} \mathrm{Felsen,} \mathrm{Mau-}$ ern, Gerölle der Kalkalpen, sonst sehr zerstreut. 4. 7. 8.

P. calcáreum Sw. 


\section{Polýstichum Rth, Punktfaru (XXIV. 3).}

Bl. gr., in (oft trichterförmigen) Büscheln, im Umriss lanzettförmig, Wzst. dick, kurz.

1. Bl. 1 fach-fiederschnittig, Abschnitte kammförm. fiedertheilig bis fiederschnittig, alle einander genähert.

Bl. 2-3 fach fiederschn., unt. Abschn. von einander entfernt, 4.

2. Zipfel gekerbt-gesägt, mit 2 Reihen gr., zuletzt zusammenfließen. der Frhäufchen, untere Abschnitte stets unfruchtbar, Bl. bis $1 \mathrm{ml}$. Wälder, an Bächen, feuchten Stellen. 4. 8.9.

Wurmfarn, P. Filix mas Rth.

Zipf. ganzrandig, an den Rändern umgebogen.

3. Zipf. abgerundet, unterseits drüsig punktiert; Frhäufch. randständ., kl.; Bl. bis $1 m$ l. (Aspid. Oreópteris L.) - Gebirgswälder. 4. 7. 8.

P. montanum Rth.

Zipf. spitz, drüsenlos, mit 2 Reihen Frhäufch. auf der Fläche; Bl. 30-60 cm l. - Torfige, sumpfige Waldwiesen, zerstreut. 4. 7. S.

P. Thelýpteris Rth.

4. Bl. am Grunde 3 fach-, sonst 2 fach-fiederschnittig, $30-50 \mathrm{~cm} \mathrm{l.,}$ Zipf. grobgesägt mit stachelspitzigen Zähnen, am Rande oft umgebogen; alle Abschn. frtragend. - Gebirgswälder. 4. 7. 8.

P. spinulosum DC.

Bl. 2 fach fiederschnittig, ebenso 1., Zipf. gegen die Spitze stachelspitzig gesägt, flach, unterseits drüsig punktiert; nur die obersten Abschn. frtragend. - Gerölle und Felsen d. Kalkalp. $(1250-1900 \mathrm{~m})$. 4. 6-8. P. rigidum $\mathrm{DC}$.

\section{Aspidium R. Br. Schildfarn (XXIV, 3).}

Bl. gr., gebüsch., steif, fast lederartig, kurz gestielt, sehr spreuschupp.

1. Bl. 1 fach fiederschnittig, $15-60 \mathrm{~cm} \mathrm{l}$., Abschnitte aufwärts gekrümmt, dornig gezähnt. - Felsen und Gerölle d. Alpen, d. Riesengeb. und Gesenkes. 4. 7. 8. A. Lonchítis L.

B1. 2 fach gefiedert od. 2 fach fiederschnittig, $0.3-1 \mathrm{ml}$.

2. Bl. lederartig, starr, Fiederchen sitzend und herablaufend, stachelspitzig gesägt. - Schattige Hocbgebirgshänge, sehr zerstreut. 4. 7. S. A. lobatum Sw.

Bl. fast häutig, Fiederchen kurz gestielt, mit sebr kl. Frbäufchen, ab. gr. Schleiern, od. fast sitzend, mit gr. Frhäufchen u, kl. Schleier (A. angulare Kit.). - Schattige Gebirgswälder, selten. 4. 7. 8.

A. aculeatum Sw.

\section{Cystopteris Beruh. Blasenfarn (XXIV, 3).}

Kl. zierliche Farne mit sehr zerbrechlichen zarten 1. gestielten Bl.; Frhäufch. zerstreut.

1. Bl. einzeln, $8-25 \mathrm{~cm} 1 ., 2-3$ fach fiederschnittig, im Umriss dreieckig. - Felsen d. Alp. bis 1270 m. 4. 7. 8.

C. montana Lk.

Bl. gebüscbelt, 2 fach fiederschnittig, länglich oder lanzettlich. 2.

2. Blspindel geflügelt, d. meisten Nerven der Zipf. in deren Zähnen auslaufend; Bl. 10-25 cm l. Sehr variabel. - Felsen, Manern. 4. 7. 8. C. frógilis Bernh. 
Blspindel ungeflügelt, die meisten Nerven in den Buchten zwischen den Zähnen auslaufend; Bl. $10-15 \mathrm{~cm} \mathrm{l}$. - Gerölle und Felsen à. Alp. 4. 7. 8 .

C. alpina Lk.

\section{11. Athýrium Döll. Waldfarn ( $\mathrm{XXiV}, 3)$.}

B. in trichterförn. Büscheln, 0.3-1 $m$ l., kurz gestielt, 2 fach fiederschnittig; Abschn. kammförm. fiedertheilig od. fiederschnittig, alle Fruchthäufchen tragend.

1. Frhäufchen auf d. Fläche d. Zipf., fast hakenförm., zuletzt zusammenfließend. - Wälder, Bäche, gemein. 4. 7. 8.

\section{A. Filix femina Döll.}

2. Frhäufch. an den Winkeln d. Zipf., rund, niemals zusammenfließend (Polypod. alpestre Hppe.). - Hochgebirgswälder n. Bachufer auf moosigem Gerölle. 4. 7-9. A. rhaeticum Döll.

\section{$6 \quad$ 12. Asplénium L. Streifenfarn (XXIV; 3).}

Bl. gebuischelt, meist kl., sammt d. Stiel ohne Spreuschuppen.

1. Bl. aus 2-4 gestielten lineal-lanzettlichen, vorn ungleich gezähuten Abschnitten zusammengesetzt, 1. gestielt, $8-15 \mathrm{~cm}$ l. - Felsspalten gebirgiger Gegenden. 2. 7. 8.

A. septentrionale Hoffm.

Bl. 1-3 fach gefiedert od. fiederschnittig.

2. Bl. 1 fach gefiedert, im Umriss länglich od. lineal.

Bl. 2-3 fach gefiedert oder fiederschnittig, im Umriss 3 eckig oder lanzettförmig.

3. Fiedern gedrängt, rundlich, eirautenförmig, gekerbt oder eingeschnitten, jederseits bis $30 ; \mathrm{Bl} .8-12 \mathrm{~cm} \mathrm{l}$.

Fiedern entfernt, keilförm., an d. Spitze eingeschnitten.gesägt, die untersten fiederspaltig; BI. $8-15 \mathrm{~cm} \mathrm{l}$. - Felsspalt. gebirg. Gegenden. 4. 7. 8 .

A. germanicum Weiß.

4. Stiel glänzend-schwarzbraun, Fiedern sitzend. - Felsen, Mauern. 4. 7. 8 . Frauenhaar, Widertod, $\boldsymbol{A}$. Trichómanes L.

Stiel grïn, Fiedern gestielt. - Felsen und Gerölle der Alpen, auch im Riesengeb. u. Gesenke. 4. 7. 8.

A. viride Huds.

Var. adulterínum Milde. Stiel glänzend-schwarzbraun, nur Mittelrippe grïn. - An Serpentinfelsen.

5. Bl. im Umriss 3 eckig-eiförm., 3-15 $\mathrm{cm}$ l., Fiederchen verkehrtei- od. rautenförm., vorn eingeschnitten.gezähnt od. gelappt. Sehr variabel. - Fels-u. Mauerspalten. 4.7.8. Mauerraute, A. Ruta muraria L.

Bl. im Umriss 3 eckig-lanzettförm., 1. zugespitzt, 16-40 cm 1., Stiel glänzend-schwarz. - Alpenländer, auf Gerölle und in Felsspalten; zerstreut. 4. 7.8. Schwarzes Frauenha ar, A. Adiantum nigrum L.

Var. Serpentini (Presl.) Kleiner, Stiel grün, glänzend, - An Serpentinfelsen.

\section{Scolopéndrium L. Hirschzunge (XXIV, 3).}

Bl. länglich-lanzettförm., ganzrandig, am Grunde herzförm., kurz gestielt, $15-30 \mathrm{~cm} \mathrm{1}$. - Schattige Felsen, Brunnenmauern d. Alpenländer. 4. 7. 8

S. officinarum $\mathrm{Sw}$. 


\section{Adiantum L. Lappenfarn (XXIV, 3).}

Wrst. kriechend, Bl. 10-30 cm l., 2-3 fach gefiedert; Stiel glänzend-schwarzroth, sehr zerbrechlich; Fiedern gestielt, rauten- od: fächerförmig, - Schattige Mauern und Felsen in den sïdlichen Alpenländern. 4. $6-9$.

Venushaar, A. Capillus Véneris L. ${ }^{5}$

\section{Blechnum L. Rippenfarn (XXIV, 3).}

Bl. gebüschelt, 1 fach fiederschnittig, unfruchtbare mit gedrängt stehenden länglichen spitzen Abschnitten, im Umfang des Büschels, viel kürzer als die mittelständigen bis $50 \mathrm{~cm}$ l. Frbl., deren Abschn. schmal-lineal u. entfernt stehend sind. - Gebirgswälder. 4. 7-9. B. Spicant Rth. 4。

\section{Ptelis L. Saumfarn (XXIV, 3).}

Bl. einzeln, $0.6-1.50$ l., stengelförm., 2-3 fach gefiedert; Fiedern kammförm. fiedertheilig, Zipf. am Rande umgebogen; Wzst. kriechend. Wälder, Heiden mit Moor- od. Sandboden. 7. 7-9.

Adlerfarn, $P$. aquilina L. 4 7

\section{Allosúrus Bruh. Rollfarn (XXIV, 3).}

Bl. gebüschelt, 5-20 cm 1., eiförm.-länglich, fruchtbare 3 fach gefiedert, mit länglich-linealen, ganzrandigen, zurückgerollten Fiedern, unfruchtbare 3 fach fiederschnittig mit keilförm. tief gesägten Abschnitten. - Gerölle und Felsspalten d. Alpen $(1600-1900 \mathrm{~m}$ ), auch im Riesengeb. 4. $7-9$.

A. crispus Bernh.

\section{Struthiopteris W. Straußfarn (XXIV, 3).}

Unfruchtbare Bl. 06-1 $m$ h., einfach gefiedert mit kammförmigfiederschnittigen Fiedern, hellgrün, einen großen Trichter bildend, aus dessen Grunde später die fruchtbaren hervorwachsen. Diese straff, bis $30 \mathrm{~cm}$ h., braun; Fiedern einwärts gekrümmt, walzig, perlschnurförmig gekerbt. - Feuchte Waldschluchten; sehr zerstreut, häufig in Gärten cult. 4. 7. 8 .

St. germanica W.

\section{Fam. IV. Osmundáceae R. Br. Traubenfarn.}

\section{Osmúnda L. Traubenfarn (XXIV, 4).}

Bl. stengelförm., aufrecht, bis $1.6 m$ h., doppelt gefiedert; Fiedern gegenständig, untere unfruchtbar mit lanzettförm., fein gekerbten Fiederchen, obere zusammengezogen, in ästige braune Fruchttrauben verwandelt. - An sumpfigen Waldstellen, sehr zerstreut. 7.6. 7.

$\mathrm{K}$ önigsfarn, O. regalis $L$. so

\section{Fam. V. Ophioglósseae R. Br. Ährenfarn.}

\section{Botrýchium Sw. Mondraute (XXIV, 5).}

Kahle hellgrünt Kräuter mit knollig verkürztem Stengel und einem Laubblatte, das mit dem rispig verzweigten Fruchtstande verwacbsen ist.

1. Laubbl. einfach fiederschnittig, im Umriss länglich. 
Laubbl. 3 zählig fiederschnittig, im Umriss dreieckig, Abschn. fieder. lappig. Pf. $7 \cdot 5-15 \mathrm{~cm}$ h. - Steinige Bergabhänge, zerstreut (in B., 0e., St., T.). 7. 7.8.

B. rutaefolium A. Br.

2. Blabschn. nieren- od. fast halbmondförm., ganze Pf. $8-25 \mathrm{~cm} \mathrm{~h}$. - Grasige Abhänge, trockne Bergwiesen. 4. 6. 7.

If o ndra ute, $B$. Lunaria L.

Blabschn. eiförm. od. länglich, fiederlappig. Pfl. $8-25 \mathrm{~cm} \mathrm{~h} .-$ Trockene Wiesen und Triften, sehr zerstreut. 7. 6. 7.

B. matricáriaefólium A. Br.

\section{Ophioglóssum L. Natterzunge (XXIV, 5).}

Wzst. knollig, St. 7·5-25 $\mathrm{cm}$ h., Bl, eilänglich, g'auzrandig. Feuchte Wiesen, sehr zerstreut. 4. 6.7.

$$
\text { Gemeine N., O. vulgatum L. }
$$

\section{Fam. VI. Rhizocärpeae. Wurzelfrüchtler.}

22. Pilularia Vaill. Pillenkraut (xXIV, 6).

Wzst. kriechend, fadenförm., Bl. einzeln, borstenförm., jung eingerollt; Sporenfriichte wie kleine Erbsen. - Sumpfboden, an Teichen und Gräben, zerstreut (in B., Mh.). 4. 8. 9.

P. globulifera $\mathrm{S}$ :

\section{Marsílea L. Kleefurn (XXIV, 6).}

Wzst. kriechend, fadenförmig; Bl. einzeln, langgestielt, mit 4 keilförmig-dreieckigen Blättchen; Fr. kuglig, kurz gestielt, in d. Blwinkeln. - Stehende seichte Wïsser, Sümpfe, zerstreut (in K., St., Kr.). 4. 8-10. II. quadrifolia $\mathrm{L}$.

\section{Salvinia Mich. Schwimmblatt (XXIV, 6).}

St. freischwimmend, Bl. zweireihig, elliptisch-eiförm., oberseits reihenweis punktiert, 8-13 mm l.; Fr. kuglig, unter den Bl. gebüschelt. Teiche in Mh. u. Süd-T., selten. 4. 6-8.

\section{Zweite Abtheilung.}

\section{Sa m e n f I a nze n.}

(Plantae vasculares seminiferae, shanerogamae.)

I.

\section{Nacktsamige. Gymnospermae.}

Fam. VII. Coniferae. Zapfentragende Nadelhölzer.

25. Abies DC. Tanne, Fichte (XXI, 1).

Immergrüne Holzarten mit einzeln stehenden Nadeln. Zapfenschuppen breit, dünn, nach der Samenreife klaffend. Samen geflügelt, im ersten Herbst reifend. 
1. Nadeln zweiflächig, unterseits mit 2 weißlichen Streifen, kamm. förmig-zweizeilig. Zapfen aufrecht, nach der Samenreife zerfallend (Tannen).

Nadeln vierfächig, gleichfarbig, meist mehrzeilig spiralig. Zapfen hängend, nach dem Austliegen der Samen ganz abfallend (Fichten). 3.

2. Knospen ohne Harz. Zapfen walzig. $13-16 \mathrm{~cm} \mathrm{l}$ - - Wälder. 5. 5. 6 . Weibtanne, Edeltanne, $A$. pectinata DC.

Knospen mit dickem Harzüberzug. Zapfen 5-8 $\mathrm{cm}$ l. - Aus Nordamerilka, häufig in Parken. ち. 5. 6.

Bals amtanne, $A$. balsamifera Michx.

3. Nadeln grün. Zapfen spindlig, $13-16 \mathrm{~cm}$ l. - Wälder. 5.5 .6 . Fichte, Rothtanne, $A$. excelsa DC.

Nadeln bläulich beduftet, Zapfen walzig, 4-8 cm 1. - Aus Nordamerika, häufig in Parken. ち. 5. 6.

We iffichte, $A$. alba Poir.

\section{Larix DC. Lärche (XXI, 1).}

Sommergrüne Bäume mit dünnen gebüschelten (nur an den Junitrieben einzeln stehenden) Nadeln. Zapfen aufrecht, $2 \cdot 7-4 \mathrm{~cm}$ l. mit dünnen, zuletzt klaffenden Schuppen. - Alpenwälder, häufig auch angepflanzt. Ђ. 4. 5 . $\mathrm{L}$ ärchenbaum, $L$. europaea DC.

\section{Pinus L. Kiefer, Föhre (XXI, 1).}

Immergrüne Holzarten mit zu $2-5$ in Scheiden stehenden Nadeln. Zapfenschuppen schmal, gegen die Spitze verdickt, hier (an der Außenfläche des Zapfens) mit einem Schilde endigend. Samen im 2. Herbste reifend, Samen geflügelt, selten ungeflügelt.

1. Nadeln paarweis, halbrund. Zapfenschuppen sehr holzig, mit rhombischem quergekieltem Schilde u. ein. Nabelfleck in d. Mitte des Kiels. 2.

Nadeln zu 5, dreikantig. Zapfenschuppen lederartig, wenig verdickt, mit halbem Schilde.

5.

2. Nadeln oberseits bläulichweiß, unterseits hellgrün. Zapfen gestielt, hängend, $4-5 \mathrm{~cm}$ l, grünlich- od. bräunlich-grau. - Wälder. $\hbar .5$. Gemeine Kiefer, Weißföhre, $P$. silvestris L.

Nadeln einfarbig, grün, Zapfen sitzend.

3. Nadeln 8-16 $\mathrm{cm}$ l, hellgrün. Zapfen eiförmig od. kuglig, bis $15 \mathrm{~cm}$ l., zimmtbraun, Schilder convex oder zizenförm.; Samen groß, fast ungeflügelt, essbar (Pignolen). - In Süd-T., häufig cult. \$. 4. 5.

$$
\text { Pinie, P. Pinea L. }
$$

Nadeln kürzer, dunkelgrün, Samen klein, geflügelt.

4. Nadeln $2 \cdot 7-8 \mathrm{~cm}$ l. stumpf. Weibl. Kätzchen violett. Zapfen kegelförm. bis kuglig; Nabel des Schildes aschgrau mit schwärzlichem Hofe. - Hochgebirge. Ђ. 6. 7.

P. montana Mill.

Varietäten: $\alpha$. Zapfen wagereclit od. schief abwärts, Schilder der Lichtseite stärker vorspringend, oft hakenförmig abwärts gebogen. Aufrechter Baum oder Knieholz. - Alpen, Böhmerwald, Südböhmen, Erzgeb. Sumpfkiefer, L a tsche, $P$. uncinata Ramd.

ß. Zapfen aufrecht-abstehend, eiförm. bis fast kuglig, Schilder ringsherum gleichförmig. Knieholzfarn. - Riesengeb., Alpen, Böhmerwald. Knieholz, P. Pumílio Hke. 
$\%$ Zapfen wagerecht od. schief abwärts, kegel-od. eikegelförm., zinmtbraun; Schilder ringsherum gleichförm. Knieholzform. - Alpen von Kth. und Kr.

Krummholz, Krïmpen, $P$. Mughus Scop.

Nadeln 8-i3 cm 1., spitz. Weibl. Kätrchen röthlich. Zapfen kegelförmig, of gekrümmt, scherbengelb, wagerecht.: Nabel röthlich, ohne Hof. - Wrenerwald, auch in st., Mli., Is. und in Küstenlande (P. nígricans Host.) Ђ. 5. 6. Schwarzliefer, $P$. nigra Arnold.

5. (1) Junge Triebe feinfilzig. Nadeln $4-8 \mathrm{~cm}$ l. Zapfen aufrecht, eiförm., 3-S cm 1.; Samen flïgellos, essbar (Zirbelnuisse). - Alpen. Ђ.6. Zirbe, $P$. Cembra L.

Junge Triebe kahl. Nadeln 10-16 cm l., Zapfen hängend, spindelförmig, $10-13 \mathrm{~cm}$ l., Samen gefügelt. - Nordamerika, häufig angepflanzt. 5. 5. 6 .

IV e y mou thskiefer, $P$. Strobus L.

\section{Cupressus L. Cypresse (XXI, 1).}

Immergrïner Baum mit schmal kegelförmiger Krone und vierreihig. schuppenblättrigen vicrkantigen Zweigen. Zapfen klein, eifürmig-kuglig, Schuppen dick schildförmig, Samen ungeflügelt. - In Süd-T., häufig angepflanzt. Ђ. 3. 4 .

C. sempervirens L.

\section{Thuja L. Lebensbaum (XXI, 1).}

Immergrüne Bäume mit zweischneidig zusammengedrückten, schuppen. blättrigen Zweigen. Zapfen sehr klein, Schuppen länglich, convex, Samen gefligelt.

1. Äste in wagerechter Ebene verzweigt. Zapfen 7-12 $\mathrm{mm} \mathrm{1.,} \mathrm{hell-}$ braun. - Nordamerika, häufig in Parken. \$. 4.

\section{T. occidentalis $\mathrm{L}$.}

2. Äste in senkrechter Ebene verzweigt, Zapfen bis $18 \mathrm{~mm}$ l., bläulich beduftet. - Orient, noch häufiger cult., besonders auf Kirchhöfen. Ђ. 4.5 .

T. orientalis $\mathrm{L}$.

\section{Juníperus L. Wachholder (XXII, 1, 12).}

Immergrüne Sträucher und Bäume mit Nadeln und Schuppenbl., deren knospenförmige weibl. Blüten sich in Beerenzapfen umgestalten, die im zweiten Herbst reifen. Samen unge日ügelt.

1. Bl. nadelförmig, oberseits flach und bläulichweiß, dreiquirlig. 2.

Bl. schuppenförm. (wenigstens an den jungen Trieben).

2. Nadeln gerade, steif, stechend-spitz. Beeren erbsengroß, reif schwarz. hechtblau bereift. Strauch od. kl. B. - Lichte Nadelwälder, sandige Heiden und Triften. 5. 4. 5.

Gem einer W., Kronawett, J. communis L.

Nadeln gekrummt, stumpf. Beerenz. reif sammtschwarz, bläulich bereift. Niederliegender Kleinstrauch. - Alpen $(900-2000 \mathrm{~m})$; im Erzgeb., Riesengeb., Gesenke, selten. Ђ. 7. 8.

$\mathrm{Z}$ w erg - W., J. nana $\mathrm{W}$.

3. Alle Bl. kreuzweis gegenständig, 4 reihig. Beerenz. nickend, schwarz. Str. (oft knieholzförm.) od. kleine B. - Alpen (974-2343 m), auch cult. 5. 4. 5. Sadebaum, J. Sabina L.

Bl. theils kreuzweis gegen-, theils zu 3 quirlständ. Beerenz. aufrecht, schwarzroth. Baum. - Nordamerika, häufig in Parken cult. $\hbar .5$.

Virginische Ceder, J. virginiana L. 
Fam.VIII. Taxineae. Eibenartige.

31. Taxus L. Eibenbaum (XXII, 12).

Immergrüne Str. od. B. mit zweizeiligen flachen, spitzen, unterseits gelblichgrünen (giftigen!) Nadeln. Scheinbeeren einzeln, an der unteren Seite der Zweige, mit rother Hïlle. - Gebirgswälder, sehr zerstreut; bäufig in Parken. ち. 3. 4.

T. baccata L.

II.

Bedecktsamige Pflanzen mit einem Samenlappen.

(Plantae angiospermae monocotyledoneae)

Fam. IX். Lemnáceae. Wasserlinsen.

32. Lemna L. Wasserlinse (I, 1 n. II, 1).

Wasserpfänzchen mit schwimmendern Laub, aus dessen Rande netue P\&änzchen hervorsprossen, sowie (selten!) die sehr kleinen Blütchen.

1. Laub linsenförmig rundlich.

Laub elliptisch od. lanzettförmig, oft gestielt. Pflänzchen kreuzweis verbunden. - In stehenden Wässern, wie die folgenden Arten. $\odot .5$.

L. trisulca L.

2. Untere Seite des Laubes flach.

Untere Seite des Laubes polsterartig gewölbt, mit $1 \mathrm{Wz} .-\odot 5$. L. gibba Is.

3. Nur 1 haarfeine $W z l$, an der Unterseite des 2-5 $m m$ br. Laubes. - Gemeinste Art. $\odot .5$.

L. minor L.

Mehrere $(6-7)$ haarfeine $W z \ln$. an $\mathrm{d}$. Unterseite des $6-9 \mathrm{~mm}$ breiten Laubes. $-\odot .5$.

L. polýrhiza L. 84

Fam. X. Najuideae. Najaden.

33. Najas L. Nixkrant (XXI, 1 od. XXII, 1).

Untergeta!chte festgewurzelte Wasserplanzen mit flutendem, gabeltheiligem $30-60 \mathrm{~cm}$ l. St. und dornig-gezälnten, am Grunde scheidigen $\mathrm{Bl}$, in deren Winkeln die knospenförmigen Bllt. sitzen.

1. Bl. breit lineal. Zweihäusig. (N. major All.) - In stehenden und langsam fliefenden Wässern, sehr zerstreut. $\odot$. S. 9. $N$. marina L.

2. Bl. schmal lineal, borstenförmig. Einhäusig. - Wie vorhergehende. N. minor All.

\section{Zanichéllia L. (XXI, 1).}

Im Schlamme wurzelnde Gewächse mit niedergestrecktem od. flutendem, fadenförm., ästigem St., deren linealen Bl. zu 3 stehen und in den Winkeln Büschel von nackten Blt. tragen.

1. Früchtchen sitzend, Schnabel halb so lang. - In stehenden und langsam fließenden Wässern, zerstreut. 4. 7-9. Z. palustris L. 
2. Frehtch, lang gestielt, ihr Schnabel ebenso lang. $\approx$ iseichtes Meerwasser, in Grälen um Salinen; sehr zerstreut. 7. 7-9.

Z. pedicellata Fr.

\section{Fam. XI. Potamogetóneae. Laichkrëuter.}

\section{Potamógeton L. Laichkrant (IV, 2).}

Im Schlamme stehender od. fliefender Gewächse wurzelnde, schleimbedeckte Kränter. St. fadenförm, mit häutigen Nebenbl.; Blt. in meist langgestielten, stets über dem Wasserspiegel emporragenden Ähren oder Köpfchen.

1. Alle Bl. von gleicher Gestaltung, durchscheinend-häutig. Ganze Pflanze untergetaucht flutend.

Bl. zweigestaltig, oberste auf dem Wasser schwimmend, derb, untergetauchte zart, durchscheinend, bisweilen auch anders geformt. 12.

2. Alle Bl. gegenständig, zweizeilig, an den Zweigenden geschinaeıtgedrängt, eilanzettförm., wellig. - In Seen n. Teichen, zerstreut. 4.7.8. $P$. densus $\mathrm{L}$.

Bloß die obersten, den Àhrenstiel stützenden Bl. gegenständig, alle übrigen abwechselnd.

3. Bl. breit, breit-lineal bis oval od. herzförmig.

Bl. schmal, lineal bis faden- od. borstenförmig. 3.

4. BI. am Grunde herzförm., oval od. länglich, stengelumfassendsitzend. Ähren vielblütig, walzig, auf 1. dickem Stiel. - Stehende und fließende Gewässer. 4. 7. 8.

$P$. perfoliatus $\mathrm{L}$.

Bl. am Grunde nicht herzförm, sondern hier abgerundet od. verschmälert, sitzend od, kurz gestielt. Ähre walzig, dicht.

5.

5. Bl. gestielt, glänzend grün, groß, länglich-bis lineal-lanzettförm., zugespitzt. - Stehende und fließende Gewässer. 4. 7. 8.

\section{P. lucens s.}

Bl. sitzend, bisweilen halb stengelumfassend.

6.

6. Bl. am Rande wellig.kraus, breit lineal od. länglich. Ähre armblütig, locker. - Wie vorige Art. 4. 7. 8.

P. crispus L.

Bl. flach, nicht kraus, mit zusammengezogenem Grunde halb stengelumfassend, länglich bis lineal-lanzettförm., an der Spitze kappenförmig hohl, bis $13 \mathrm{~cm}$ l. - In Seen und langsam fließenden Gewässern in B., 0e., Kr., zerstreut. 4. 7. 8.

P. praelongus Wulf.

7. (3) Bl. am Grunde in eine stengelumfassende und mit den Nebenblättern verwachsene Scheide erweitert, lineal, rinnig. Ähren aus getrennten Bltquirlen bestehend, lang u. dünn gestielt. - Stehende u. fließende Wässer. 4. 6. 7.

$P$. pectinatus L.

Bl. nicht scheidig noch mit d. Nebenbl. verwachsen. Ähren kopfig, mit langem, fadenförmigem Stiel.

8. Bl. fast borstenförm., einnervig. - In stehenden Wässern in B., Mh., Oe.g sehr zerstreut. 4. 7. 8. $P$. trichoides Cham. Schtd.

Bl. lineal, vielnervig.

9. St. zusammengedrückí, an den Kanten schmal ge日ügelt. 10 . St. nicht geflügelt, an den Kanten abgerundet, sehr ästig. 11. 
10. Ähren walzig, 10-15- und mehrblütig, kürzer als d. Stiel. Stehende und langsam fließende Wässer in Mh., 0e., sehr zerstreut. 4. 7. 8 .

$P$. compressus L.

Ähren kopfförm., 4-6 blütig, kurz gestielt. - In Teichen u. Seen, sehr zerstreut.

$P$. acutifolius $\mathrm{M}$. $\mathrm{K}$.

11. Ähre kurz, nicht unterbrochen, 6-20 bliitig, so lang wie ihr Stiel. Bl. stumpf, stachelspitzig. - Ebenso. 4. 7. 8.

P. obtusifolius M. K.

Ähre lockerblütig, unterbrochen, 4-8 blütig, sehr lang gestielt. Bl. spitz, fadenförm. - Stehende und fließende Gewässer. 4. 7. 8.

P. pusillus L. gestielt.

12. (1) Alle Bl. deutlich gestielt. Ähren gedrungen walzig, lang-

Schwimmblätter gestielt, untergetauchte sitzend.

13.

13. Schwimmbl. lederartig glänzend, oval bis länglich, bis $10 \mathrm{~cm} \mathrm{l}$. und bis $5 \mathrm{~cm}$ br., untergetauchte lineal- od. lineal-lanzettförm. (fehlen zur Blütezeit). - In stehenden Gewässern, iiberall. Sehr variabel. 4. 6. 7. $P$. natans $\mathrm{L}$.

Schwimmbl. sehr groß, elliptisch, länglich od. oval, bis $16 \mathrm{~cm} \mathrm{l.,}$ untergetauchte lanzettlich bis lineal, alle sehr lang gestielt. - Fließende Wässer, verbreitet. 4. 6. 7.

$P$. fliitans Roth.

14. Bl. 10-16 cm l., schwimmende länglich, untergetauchte lanzettlich, beide bald grün, bald rothbraun bis roth. Äbrenstiel länger als die Bl. - In stehenden und langsam fließenden Wässern, zerstreut. (P. rufes. cens Schrad.) 7. 7. 8.

P. alpinus Balb.

Bl. höchstens $8 \mathrm{~cm}$ l., schwimmende elliptisch od̄. eiförm. (fehlen bäufig, var. graminifolius Koch), untergetauchte lineal-lanzettlich. Ährenstiele länger als d. Bl. - Wie vorige Art, sehr zerstreut.

P. gramineus L. 102

\section{Fam. XII. Aroideae. Arumgeicüchse.}

\section{Arum L. Aronsstab (XXI, 1).}

Knollengewächs. Bl. grundständig, langgestielt, spieß-pfeilförmig (bisweilen schwarz gefleckt); Kolbenscheide äußerlich hellgrün, innen weiß, mit d. Scheide bis fußhoch. Keule oben nackt, violettbraun, Beeren roth. - Schattige Lanbwälder, zerstreut in B., Mh., Oe., St., Ḱr. 4. 5. A. maculatum L.

\section{Calla L. Schlangenkraut (XXI, 1).}

Sumpfpfl. mit im Schlamme kriechendem, walzigem, gegliedertem, geringeltem Wzst. Bl. lang gestielt, herzförmig-oval. Kolbenstiel bis $25 \mathrm{~cm}$ l., Scheide weiß, weit geöffnet; Kolben ganz mit grünlichen BIt. bedeckt, Beeren roth. - An Teichufern, in Torf- und Waldsümpfen in B., Mh., Oe., St., K., Kr.; zerstreut. 4. 6. 7.

\section{8. Ácorus L. Kalmus (VI, I).}

Wassergewächs mit kriechendem, walzigem, geringeltem, stark aromatischem Wzst. Bl. u. St. 1,25 $\mathrm{m}$ h., breit-lineal. grundständ., St. blattlos, 
in eine blattartige Sprtze auslaufend, mit seitenständ., nacktem, grünlichem Kolben. - Aus dem Orient, in stehenden Wässern verwildert. 2, 6. 7. A. Cálamus L.

\section{Fam. XIII. Typháceae. Rohrliolbenartige.}

\section{Typha L. Rohrkolben, Teichkolben (XXI. 3).}

Sumpf- u. Wassergewächse. Wzst. kriechend, dick, steif aufrechto zweizeilig beblätterte $\mathrm{St}$. treibend, Bl. lineal.

1. $\sigma^{7}$ u. + Kolben an einander stoßend, walzig. St. $1-2 m$ h., Bl. 12-18 $\mathrm{mm}$ br. - In Teichen, Siimpfen. 4. 7. 8. T. latifolia L.

$\sigma^{\top}$ und $q$ Kolben durch einen Zwischenraum getrennt.

2. Beide Kolben walzenförm., jeder $3-26 \mathrm{~cm}$ l., St. $1-2 m \mathrm{~h}$,, bis oben beblättert, Bl. höchst. $8 m m$ br. - Wie vorige, verbreiteter. 4. 7. 8. $T$. angustifolia $\mathrm{L}$.

Kolben klein, kurz, anfangs walzig, später die $q$ bis kuglig, jeder 1.5-5 cm 1.; St. 40-60 cm h., bis zur Mitte mit pfriemenförmigen Bl. - In Siimpfen, an Ufern in 0e., Sz., St., K., sehr zerstreut. 2. 5. 6. T. minima Hppe.

\section{Spargánium L. Igelkolben (XXI, 1).}

Sumpf- und im Schlamme wurzelnde Wasserptanzen mit fasrigem Wzst. St. beblättert; Bl. lineal, Kolben lruglig, die Q stets, die $\sigma^{\top}$ meist von einander getrennt.

1. St, aufrecht, iber das WVasser emporragend.

St. untergetaucht $\mathbf{u}$. flutend od. schwimmend.

2. St. einfach, $30-50 \mathrm{~cm}$ h. - In Sümpfen, Wassergräben. Variiert mit schlafferem futendem St. und schwimmenden Bl.: flúitans Gren. 4. 7. 8 . S. simplex L.

St. nach oben ästig, bis $60 \mathrm{~cm}$ h. - Wie vorige Art.

S. ramosum L.

3. St. 15-20 cm ]., $\sigma^{\lambda}$ Kolben 1-2, 우 meist 2; Bl. kurz. - In Sümpfen, Wassergräben, Torfmooren (in nassem Torfmoos bisweilen aufrecht!) in B., Mh., 0e., zerstreut. 4. 7. 8.

S. minimum Fr.

St. u. Bl. sehr lang (bis $90 \mathrm{~cm}$ ) u. schlaff; beiderlei Kolben meist mehrere, die unteren $q$ gestielt. - In Seen u. Teichen in B. (Schwarzer See im Böhmerwalde) u. 00e., selten. 4. 7. 8 .

S. affine Schnizl.

\section{Fam. XIV. Gramineae. Süßgräser.}

\section{Schliussel der Gattungen.}

1. Blt. eingeschlechtig, $\sigma^{\top}$ in großer endständiger Rispe, $q$ in blattwinkelständigen Kolben.

Blt. meist $z w i t t e r l i c h$ (etwaige eingeschlechtige mit Zwitterblt. in e ine $m$ Ährchen od. wenigstens in einem Blütenstande).

2. Ährchen od. nackte Blt. (b. Nardus !) in eine Ähre gruppiert (d. h. in Ausschnitten der die Ähre durchziehenden Spindel sitzend oder gestielt): $\ddot{A}$ hrengräser. 
b) Ährchen von kurzen einfachen od. verästelten Stielchen d. Spindel getragen, eine walzige, längliche oder eiförmige Scheinähre bildend : Rispenährengräser.

c) Ährchen od. nackte Blt. (b. Leersia) in eine Rispe gestellt, deren $\ddot{A}$ ste meist quirlig od. halbquirlig, selten einzeln aus d. Spindel entspringen. $R$ ispengräser.

30.

3. Nackte Blt. (ohne Kelchspelzen) in eine einseitswendige Ähre gestelit. Gr. lang, blos e in e lange zottige Narbe tragend. Nardus (40).

Wirkliche Ährchen; stets 2 Narben auf dem meist kurzen Gr. 4.

4. Halm nur eine Ähre tragend. 1 blütig.

Halm 2 oder mehr Ähren tragend (Fingerährengräs er). Ährchen

5. In jedem Spindelausschnitt nur 1 Ährchen.

In jedem Spindelausschnitt 2-3 Ährchen.

6. Ährchen vielblütig, mit der schmalen Seite (Kante) der Spindel zugekehrt.

Lolium (42).

Ährchen 2-vielblütig, mit der br. Seite d. Spindel zugekehrt. 7 .

7. Ährchen sitzend.

8.

Ährchen sehr kurz gestielt, anfangs walzenförmig, dann breit, vielblütig; Blt. kurz begrannt.

Brachypodium (43). förmig.

8. Ährchen 2 blïtig, in zweizeiliger Ähre; Kelchspelzen pfriemen-

Ährchen 3-vielblütig.

Secale (46).

9. Kelchspelzen schief abgestutzt, am Rücken gekielt; Ährchen dreiblütig, Blt. grannenlos od. lang begrannt.

Triticum (45).

Kechspelzen länglich, spitz, am Rücken abgerundet. Ährchen vielblütig, Blt. grannenlos od. kurz begrannt.

Agropyrum (44).

10. (5) Ährchen zu 3, 1 blütig, entweder alle od. nur das mittelste fruchtbar und dann die beiden seitlichen geschlechtslos; Kelchspelzen sehr schmal.

Hordeum (48).

Ährchen zu 2-3, alle fruchtbar, 2-3 blitig. Elymus (47).

11. (4) $\ddot{A} h r c h e n$ einzeln stehend, eine einseitswendige Ähre bildend.

Cynodon (77).

Ährchen paarweis, 1 sitzend, 1 gestielt.

12.

12. Beide Ährchen grannenlos, einseitswendige Ähren bildend.

Digitaria (78).

Das sitzende Ährchen (mit Zwitterblt.) begrannt, das gestielte (männl. Blt.) unbegrannt, Ähren seidig behaart. Andropogon (76).

13. (2 b.) Ährchen 1 blütig (wenigst. nur 1 Zwitterblt. enthalt.). 14 .

Ährchen 2- bis mehrblütig.

14. Blt. mit nur 2 Stbg.

Blt. mit 3 Stbg.

15. Rispenähre länglich-lanzettförmig, am Grunde oft unterbrochen. Kelchspelzen sehr ungleich, länger als die zwischen 2 begrannten Nebenspelzerı stehende Blt. Anthoxanthum (88).

Rispenähre halbkuglig, klein, von den bauchigen Blscheiden d. obersten Bl. halb eingehüllt. Kelchspelzen gleich, kürzer als die Blt. 
16. Ährchen paarweis, das eine mit kurzbegrannter Zwitterblt., das audere mit grannenloser männl. Blt. Rispenäbre dicht länglich. Großes schilfartiges Gras.

Sorghum vulgare (75).

Äbrchen nicht paarweis, gleichgeformt, mit Zwitterblte.

17.

17. Rispenähre locker, traubig. Obere (größere) Kelchspelze am Rücken mit hakig gekrümmten Stacheln.

Tragus (82).

Rispenähre dicht, walzig, länglich od. eiförmig; Kelchspelzen stets stachellos.

18.

18. Ährchen von grannenartigen Borsten umgebeu. Setaria (81).

Ährchen nicht von Borsten umgeben

19.

19. Kelchspelzen ungleich groß, spitz, kürzer als die unbegrannten Blt. Rispenähre länglich, gleich über dem obersten Halmblatt.

Crypsis (87).

Kelchspelzen gleichgroß und gleichgeformt.

20. Kelchspelzen am Grunde verwachsen. Bltspelze.

Nur e in e grannenlose Alopecurus (85).

Kelchspelzen nicht verwachsen; 2 Bltspelzen.

21. Kelchspelzen zusammengedrückt, stark gekielt, Blt.granmenlos. 22.

Kelchspelzen kahnförmig, spitz; Blt. von Haaren umgeben, die sich nach dem Blühen verlängern, äußere Bltspelze mit rückenständig'er, kurzer Granne.

Calamagrostis (7:3).

22. Kelchsp. abgestutzt, weißhäutig gerandet, am Kiel gewimpert; Rispenähre walzenförmig, dicht.

Phleum (86).

Kelchsp. bauchig aufgetrieben, spitz, am Kiel häutig gefiügelt; Rispenähre eiförmig, dicht.

23. (13) Neben dem 2-5blütigen Ährchen ein kammartig fiederschnittiges Deckblatt; Rispenähre walzig od, oval.

Kein derartiges Deckbl. neben dem Ährchen. Cynosurus (52).

24. Bltspelzen von langen, seidenglänzenden Haaren gewimpert, grannenlos; Rispenähre walzig, dicht.

Melica z. Th. (56).

Bltspelzen kahl od. nur am Rücken kurz u. fein behaart. 25.

25. Äußere Bltspelze 3 zackig od. 5 zackig mit 5 kurzen geraden Grannen; Rispenähre eiförmig-kuglig bis walzig.

Sessleria (83).

Äußere Bltspelz. nichtgezackt, ganz, grannenlos od. m. 1 Granne. 26.

26. ஷ̈ußere Bltspelze unbegrannt.

27.

Äußere Bltspelze mit 1 geraden, ziemlich langen Granne. 29.

27. Rispenähre länglich od. walzig, dicht od. unterbrochen-gelappt (dann oft pyramidal). Ährchen 2-3blütig, sehr klein. Koeleria (63).

Rispenähre eiförm., dicht, fast 2 zeilig; Ährchen 5-od.mehrbluitig. 28.

28. Rispenähre von der obersten Blscheide am Grunde umhüllt, hart, griin; Äbrchen vielblütig.

Sclerochloa $(60)$.

Rispenähre vom obersten Bl. entfernt, bläulich, Ährchen 5 blütig. Oreochloa (84).

29. (26) Granne am Rücken der Spelze eingefügt. Ährchen 2 blütig. Avena praecox (65).

Granne auf d. Spitze d. Spelze; Ährchen 5. od. mehrblütig.

Vulpia Myurus (51). 
30. (2c.) Ährchen 1 blïtig od. wenigstens nur 1 fruchtbare (Zwitterbluite) enthaltend.

Ährchen 2-vielbliitig.

31. Ährchen ohne Kelchspelzen (Blt. nackt).

Ärrehen mit 2 Kelchspelzen.

33.

32. Rispe klein, traubig lappig; Blt. sehr klein, mit sehr ungleichen Spelzen und 2 Stbg. Sehr kl. Gras.

Coleanthus (93).

Rispe lang, flattrig, aus d. oberen Bltscheide hervorragend; Bltspelzen gleichgroß, 3 Stbg. Großes Gras.

Leersia (92),

33. Am Ende der verzweigten Rispenäste je 2 Ährchen (selten je 3), das eine mit grannenloser Zwitterblt., das andere bloß aus einer kurz begrannten männl. Blt. bestehend, dieses ohne Kelchspelzen. Sorghum (75).

Ährchen einzeln od. in Knäuel od. Ảhren gruppiert, von gleicher Gestaltung, stets mit Zwitterblt.

34.

34. Rispe aus traubig gestellten kurzen Ähren od. großen u. Kleinen ährchenknäueln bestehend.

35 .

Rispe nie knäulig-gelappt, Äste derselben meist quirlständig. 37.

35. Rispe aus traubigen Ähren bestehend. Kelchspelzen sehr ungleich. Neben der grannenlosen Zwitterblte eine begrannte männliche od. geschlechtslose.

Echinochloa (79).

Rispe aus Ährchenknäueln bestehend, gelappt; Kelchspelzen gleichlang.

36. Blt. wenig kürzer als die Kelchspelzen, von Haaren unringt; äußere Bltspelze mit ruickenständiger Granne. Calamagrostis ( $73 \mathrm{z} . \mathrm{Th}$.).

Blt. viel kürzer als die Kelchspelzen, ohne Haare, grannenlos.

Baldingera (90).

37. (34) Äußere Bltspelze mit endständiger langer Granne, welche oft geschlängelt od. knieförmig gebogen und am Grunde seilförmig gedreht ist.

Äußere Bltspelze grannenlos od. mit kurzer gerader Granne. 39.

38. Granne bis fußlang, gewunden u. gesch]ängelt, bisweilen federartig behaart.

Stipa (70).

Granne gekuiet, länger als die langgewimperte Bltspelze.

Lasiagrostis (69).

39. Blt. von nach der Bltzeit sich verlängernden Haaren umringt, åuĐere Spelze mit kurzer rücken- od. endständiger Granne.

Calamagrostis (73).

Blt. nicht von Haaren umgeben.

40. Rispe von Anfang an einseitig überhängend. Neben d. Zwitterblt. jedes Ährchens noch eine Spelze (taube Blt.).

Panicum (80).

Rispe nicht überhängend, keine taube Blt. neben d. frbaren. 41.

41. Kelchspelzen bauchig, am Rücken abgerundet; Blt. grannenlos. Milium (71).

Kelchspelzen zusammengedrückt-gekielt; Blt. grannenlos od, mit kurzer, rückenständiger Granne.

42. (30) Spindel des $3-6$ bltigen Ährchens lang behaart. Agrostis (72). Phragmites (74).

Ährchenspindel nicht behaart. 
43. Ährchen ( $3-5$ blütig) zu Knäueln vereinigt, Rispe armästig. Dactylis (55)

Ährchen nicht knäuelförmig, meist einzeln.

44. Blt. (alle od. einzelne) desselben Ährchens begrannt.

Alle Blt. unbegrannt.

56.

45. Nur einzelne Blt. begrannt (meist in jedem Ährchen Zwitter-od. männl. Blt.). Granne rückenständig.

Alle Blt. begrannt, zwitterblütig.

46 .

50 .

46. Ährchen 2-3 blütig, nur 1 , selten 2 Blt. begrannt.

Ährchen 3-4 blütig, zwei Blt. begrannt.

47.

47. Eine Blt. männlich, die andere zwitterlich, erstere begrannt. 48.

Zwei bis drei Blt. zwitterlieh, die untere begrannt, Granne geliniet. Ährchen groß.

Avena (65 z. Th.)

48. Beide Blt. fast sitzend; Granne der männl. rückenständig, gekniet, am Grunde gedreht.

Arrhenatherum (66).

Männl. Blt. gestielt, Zwitterblt. sitzend; Granne d. männl. rückenständig, schwach gekniet, meist kurz.

Holcus (64).

49. Ährchen glockenförmig, 3 bltig, mittelste Blt, zwitterlich, zwischen 2 kurz begrannten männlichen; Granne rückenständig, gerade.

Hierochloa (89).

Ährchen keilförmig, sehr groß; die 2 untersten Blt. mit langer starker, geknieter Rückengranne. Avena sterilis (65).

50. (45) Granne rückenständig, meist gekniet.

51.

Granne endständig, gerade.

51. Ährchen 2 blütig, klein.

54.

Ährchen $3-5$ blütig.

52.

52. Bltspelzen abgestutzt u. gezähnelt, äußere mit geknieter od. gerader, spitzer Granne.

Aira (67).

Bltspelzen nicht gezähnelt, äußere mit geknieter, im Knie bärtiger, in der oberen Hälfte keulenförmiger Granne. Corynephorus (68).

53. Äußere Bltspelze ganz od. 2 spaltig od. in 2 Borsten auslaufend, mit geknieter, rückenständiger Granne. Avena (65 z. Th.)

Äußere Bltspelze ganz od. 2 spitzig, mit endständ. gerader Granne. 54.

54. Granne aus dem Winkel zwischen døn 2 Endzähnen d. äußeren Bltspelze entspringend oder (bei ganzer Spelze) etwas unter der Spitze Ährchen vielblütig, 2 reihig, groß. Narben an den Seiten d. Frkn. sitzend.

Bromus (49).

Granne aus d. Spitze der nicht gezähnten Spelze entspringend. 55.

55. Äußere Bltspelze am Rücken gekielt, spindelförmig, lang begrannt.

Vulpia (51).

Äußere Bltspelze am Rücken abgerundet, lanzettförmig, kurz begrannt. Narben an der Spitze des Frkn.

Festuca (50).

56. (44) Ährchen glockig-eiförmig od. herzförmig, langgestielt, meist hängend.

Ährchen länglich lanzettförmig od. lineal.

57.

57. Ährchen glockig-eiförmig, aufrecht od. hängend, $2-3$ blütig.

58.

Ährchen herzförmig, hängend, vielblütig. Melica (56 z. Th.)

Willkomm, Schulflora.

Briza (5i). 
58. Äußere Bltspelze 3 zähnig, kürzer als die innere. Ährchen elliptisch, 3-4blütig, Rispe traubig.

Triodia (53).

Äußere Bltspelze nicht gezähnt, ganzrandig.

59.

59. Ährchen stark zusammengedrückt, Kelchspelzen u. äußere Blütenspelze ..gekielt.

Ährchen nicht od. wenig zusammengedrückt, Kelchsppelzen u. äußere Bltspelze am Rücken abgerundet, nicht gekielt.

61.

60. Ährchen lanzett- od. eiförmig, 2-vielblïtig, Kelchspelzen fast gleich. Poa (59).

Ährchen lineal, vielblütig, Kelchsp. zarthäutig. Eragrostis (58).

61. Äußere Bltspelze an der Spitze durchsichtig-trockenhäutig, stumpf oder abgestutzt, mit 3 od. mehr erhabenen parallelen Nerven. 62.

Äußere Bltspelze an der Spitze nicht auffallend trockenhäutig, mit wenigen, nicht erhabenen Längsnerven.

63.

62. Ährchen 2 blütig, äußere Bltspelze 3 nervig; Blscheiden halb geschlossen.

Catabrosa (62).

Älirchen 4-11 blütig, äußere Bltspelze vielnervig; Blscheiden ganz geschlossen.

Glyceria (61).

63. Ährchen $2-3$ blütig, nit 1 keulenförmigen Rudiment einer 3. Blt., Halm knoten- u. blätterlos.

Ährchen 2-vielblütig, ohne Rudiment, Halm beblättert.

Molinia (54).

Festuca (50 z. Th.).

\section{Nardus L. Borstengras (III, 1).}

Bl. borstig, dichte starre Rasen bildend. Halme $8-26 \mathrm{~cm}$ h. Ähre schmutzig-violett. - Mooriger WTald- und Heideboden, besond. in Gebirgen. 4. 5. 6 .

N. stricta $\mathcal{L}$.

\section{Lolium L. Lolch (III, 2).}

Ähren gerade, lineal, breitgedrückt; Ährchen 2 zeilig, mit einer einzigen Kelchspelze

1. Ausdauernde Arten, deren Grundblätter dichte Rasen birlden. Kelchspelze halb so lang als das Ährchen.

Einjährige Arten, nur beblätterte Halme besitzend.

2.

2. Ảhrchen $3-9$ blütig, Blt. grannenlos. Halm $0.30-0.60 m$ h. Variiert mit ästiger Ähre (L. ramosum). - Grasplätze, Ackerraine. 4. 6. bis Herbst.

Englisches Raigras, $L$. perenne L.

Ährchen 5-12 blütig, Blt. meist begrannt. Halme $0 \cdot 60-1 \mathrm{~m} \mathrm{~h}$. Auf Wiesen im Süden, auch augebaut (L. italicum A. Br.). 4. 7. 8.

It alien isches $\mathrm{R}$ a igras, L. multiflórum Lam.

3. Kelchspelze so lang od. länger als d. 5-8 blütige Ährchen; Blt. meist begrannt, Halme $0.30-1 \mathrm{~m} \mathrm{~h}$, sammt den Blscheiden rauh. - Unter d. Saat, besonders Hafer- u. Gerstensaat (giftig!). ๑. 6. 7.

T a umellol ch, Taunielkorn, L. temulentum L.

Var. $\beta$. speciosum (Stev.): Granne schwach geschlängelt od. fellend. Halme u. Scheiden glatt. - $\gamma$. arvense (With.). Ähre und Ährchen zart. Granne kurz, gekrümmt.

Kelchspelze kürzer als d. $3-8$ blütige Ährchen; Blt. unbegrannt, Halme dünn, 14-4j $\mathrm{cm}$ h. - Auf Flachsfeldern. ๑. 6. 7. L. linicolum A. Br. 


\section{Brachypódium P. B. Zwenke (III. 2.).}

Iusdauernde Gräser mit 1-1.25 $m$ hoh. Halmen, flachen Bl. u, zwtizeiliger $8-16 \mathrm{~cm} \mathrm{l}$. Ähre.

$\therefore$ Älıre ïberhängend, meist kahl. Ährchen 5-12 blütig, Wzst. fasrig. - Laubwälder, Gebüsche, Waldwiesen. 7. 7. 8.

B. silváticum P. B.

2. Ähre aufrecht, meist zottig behaart. Ährchen 5-20 bliitig, Wzst. kriechend. - Steinige, sonnige Hïgel mit Kalkboden. 7. 6. 7.

B. pinnatum P. B.

\section{Agrópyrum P. B. Quecke (III, ?.).}

Ausdauernde Gräser mit meist kriechendem Wzst., aufrechten Halınen u. zweizeiliger Ähre.

1. Blt. begrannt, Granne länger od. so lang wie die Ährchen. Ähre zuletzt überhängend. Halm $0.50-1.50 \mathrm{~m}$ h. Wzst. fasrig. - Unter Gebüsch, an Waldrändern. 7.6. 7.

Hundsquecke, A. caninum R. Sch.

Blt. nicht od. kurz begrannt, Granne viel kïrzer als d. Ährchen. Wzst. kriechend. 2.

2. Ganze PA. blaugrün, Bl. (wenigstens d. älteren) eingerollt, steif: untere Blscheiden an den Rändern gewimpert. Kelchspelzen stumpf, äußere Bltspelze stumpf, stachelspitzig od. begrannt, beiderlei kahl oder rauhharig. Halme $30-90 \mathrm{~cm}$ h. (A. intermediun Host.) An sonnigen Berghängen, Hügeln, Wegen, auf Kies- und Kalkboden. 4. 6. 7.

\section{A. glaucum Desf.}

Ganze PA. grasgriin, Bl. flach, breitlineal, Scheiden nicht gewimpert. Kelchspelzen spitz, äußere Bltsp. grannenlos oder kurz begrannt. Halme $0.50-1.25 \mathrm{~m}$ h. Variiert mit hechtblau bereiften Halmen, Bl. u. Ähren (A. caesium Presl.) - An Wegren und auf Äckern. 7. 6. 7.

Gemeine $Q$ u., A. repens P. B.

\section{Tríticum L. Weizen (III, 2.).}

Ein-od. zweijährige Culturgräser (Getreidearten) von meist unbekannter Herkunft. Ähre 2 zeilig, Bl. breitlineal. Halme hoch, Ähren bis $16 \mathrm{~cm} \mathrm{l}$.

1. Körner zur Reifezeit aus den Spelzen herausfallend, Ährenspindel zäh. licl.

Körner vou d. Spelzen umschalt bleibend, Ährenspindel zerbrech-

2. Ähre walzig, sehr 1., Ährchen $2.5 \mathrm{~cm} \mathrm{1,} \mathrm{Kelchpelzen} \mathrm{häutig,} \mathrm{auf-}$ getrieben; BIt. grannenlos. - Selten angebaut. $\odot$. 6. 7. (wie folgende). Polnischer. W., T. pulónicum L.

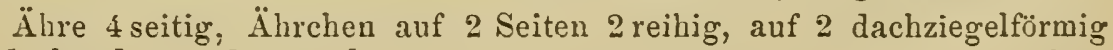
sich deckend, $12-20 \mathrm{~mm} 1$.

3. Ährchen auf d. breiten Seiten d. Ähre dachziegelig, auf d. schmalen 2 reihig, Kelchpelzen stumps gekielt, stachelspitzig; Blt. unbegrannt (Kolben- od. Winterweizen, T. hibernum L.) oder lang begrannt (B art- od. Sommerweizen, T. aestivum L.). - Ueberall gebaut. $\odot$ od. $:$. 
Ährchen auf d. breiten Seiten '2 reihig, auf deu schmalen dachziegelig. Kelchspelzen scharf gekielt, Blt. lang begrannt.

4. Kelchspelzen bauchig, Granne weit abstehend. Variiert m. ästiger Ähre (T. compositum L., W underweizen). - Wenig gebaut. $\odot$ od. $\odot$. Englischer. W., T. turgidum L.

Kelchsp. länglich, niclıt bauchig, Grammen sehr lang u. steif, Körner glasig. - Wenig gebaut. $\odot$,

Glasweizen, Gerstenweizen, T. durum Desf.

5. (1) Ähre 4 seitig.

Ähre zusammengedrückt, Ährchen 2 zeilig, schmächtig, geben nur ein Korn. - Wenig gebant, vorherrscliend anf Kalkboden. $\odot$.

Einkorn, T. monocóccum L.

6. Ährchen auf den breiten Seiten 2 zeilig, an d. schmalen dach. ziegelig, 2 Körner liefernd. - In den Alpenläindern gebaut. $\odot$ od. $\odot$. Emmer, Gerstenspelz, Reisdinkel, T. dicoccum Schrk.

Ährchen auf den breiten Seiten dachziegelig, auf d. schmalen 2 zeilig, liefern 2-3 Körner. Blt. grannenlos (Kolbenspelz) od. begrannt (Grannenspelz). - In den Alpenländern häufig gebaut. $\odot$ od. $\odot$. Spelt, Spelz, Dinkel, T. Spelta L. inq

\section{Secále L. Roggen (III, 2).}

Blt. stets lang begrannt, Gramnen ziemlich parallel. Halme bis $2 m \mathrm{~h}$. - Überall geb. als Winter- $(\odot)$ und Sommerroggen $(\odot)$. Soll aus Asien stammen. 6.7. $S$. cereále L.

\section{7. Élymus L. Haargras (III, 2).}

Halme $0.60-1.25 m$ h., Bl. schmal lineal mit behaarten Scheiden; Ahre schmächtig, $5-8 \mathrm{~cm}$ l., Ährchen 2 blütig, Kelch- und äußere Blittenspelzen begrannt. - Wälder. 4. 6. 7.

$E$. europaeus L.

\section{Hordeum L. Gerste (III, 2).}

Gräser mit 2-, 4- od. 6 zeiligen $\ddot{A}$ hren. Körner meist von d. Spelzen beschalt bleibend.

1. Blt. lang begrannt: Einjährige Culturgersten von unbekaunter Herkunft.

Blt. kurz begrannt, seitliche Ährchen unfruchtbar, Ähre 2zeilig. Wilde Gersten.

2. Alle Ährchen fruchtbar u. gleichgeformt, Ähre 3- od. 6 zeilig. 3.

Nur das mittelste $\ddot{h}$ hrchen fruchtbar und begrannt, die seitlichen männl., grannenlos; Ähre 2 zeilig. gebaut.

3. Ähre 6 zeilig, Grannen nach allen Seiten abstehend. - Wenig

Ähre 4 zeilig. Variiert mit herausfallenden Körnern (n a ckte G., $\mathrm{H}$ immelsgerste). - Häufig gebaut. 7. (Wie folgende.) H. vulgare L.

4. Ährchen d. Spindel angedrückt, Grannen ziemlich parallel. Variiert auch mit herausfallenden Körnern' (Kaffeegerste). - Allgemein gebaut.

H. distichum L.

Ährchen abstehend, Grannen fächerförmig. - Wenig gebaut. P fa u engerste, H. Zeócriton L. 
5. (1) Kelchspelzen der mittleren Ährehen federartig gewimpert, die d. seitlichen borstenfürmig, kahl od. einseitig gewimpert, Halm $15-45 \mathrm{~cm}$ hoch. - An Wegen, Mauern, auf Schutt. ๑ 7.8.

Mäusegerste, II. murinum L.

Kelchspelzen aller Ährchen borstenförmig, ranh. Halm $0.50-1 \mathrm{~m}$ h. - Auf salzhaltigen Wiesen, mm Salinen in Szb., O0e. 4. 6. 7.

Wi es engerste, $H$. secálinum Schreb.

\section{Bromus L. Trespe (III, 2).}

Rispengräser. Rispe aufrecht, ausgebreitet od. einseitig iiberhäugend,

1. Ährehen oval bis lanzettlich, in od. unter d. Mitte am breitesten, nach d. Spitze hin sich verschmälernd, begrannt od, grannenlos. 2.

Ährchen verkehrt-keilfürmig, mit langen, auseinander stehenden Granuen; Bl. und Scheiden weichflaumig behaart. 10.

2. Untere Kelchspel\% 3-5, obere 5-vielnervig, iußere Bltspelze am Rücken abgerundet, mit stunpfer, meist 2 spaltiger Spitze. 3.

Untero Kelchspelze 1-3-, obere 3 nervig; äußere Bltsp. gekielt, spindelförmig, 2 spaltig.

3. Blscheiden kahl, Blt. im Fruchtzustande walzig zusammengezogen und von einander stehend, grannenlos od. begrannt. Frtragende Rispe uberhängend. Halme $0 \cdot 30-1 \mathrm{~m}$ l. - Unter d. Saat. $\odot$. 6. 7.

Korntr., A ckertr., B. secáliuus L.

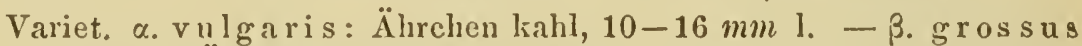

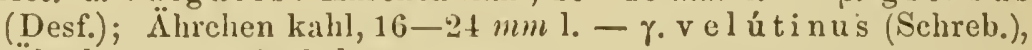
Ärchen sammtig behaart.

Blscheiden (wenigstens die unteren) weich behaart, zottig od. zerstreut behaart. Blt. im Fruchtzustande sich deckend.

4. Ganze Pf. weich grau behaart, Rispe aufrecht, $̈$ hrehen $5-10$ blüt. begrannt, Grannen von d. Länge ihrer Spelze. Halme $30-60 \mathrm{~cm} \mathrm{h.} \mathrm{-}$ Trockne Wiesen, an Weger.. -. 5. 6.

B. mollis L.

Variet. $\beta$. le i o stachys (Tsch). Ährchen kahl. - - . nan u s (Weigl.) Halme 3-16 cm l., Rispe traubig. - Auf magerem Sand- und Lehmboden lier und da.

Ährehen kahl, gruin oł. violett; Halme $0.30-1 \mathrm{~m}$ h.

5 .

5. Rispe traubig, aufrecht od. zuletzt nickend. Ährchen griin, 5 bis 10 bliitig, Grannen kaum so lang, wie ihre Spelze. Bl. u. Scheiden weichhaarig. - Wiesen, zerstreut. $\odot$ od. $\odot$. 5. 6.

B. racemosus $\mathrm{L}$.

Rispe ästig, ausgebreitet, fruchttragende nickend; Grannen von der Länge der Spelze.

6.

6. Gramnen schief nach außen stehend, Ährchen grün od. violett überlaufen, 8-11 blütig. - Unter d. Saat, an Rainen, Wegen; zerstrent. 6. 7.

B. pritulus M. K.

Grannen gerad ausgestreekt.

7. Rispe zuletzt nickend $u$. flattrig, Ährchen länglich od. lanzettlich, 7-11 bliitig, $12-30 \mathrm{~mm}$ l., bleichgrün. - Viesen, Triften, $\ddot{A}$ cker, Brachen; zerstreut. $\odot$. 5. 6 .

$B$. commutatus Sehrad.

Rispe stets aufrecht, flattrig, zierlich; ̈̈hrchen schmächtiger, lang-

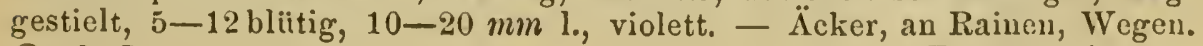
๑. 6. 7.

$B$. arvensis $\mathrm{L}$. 
8. (2) Äußere Bltspelze ziemlich lang begrannt.

Äußere Bltsp. ausgerandet stachelspitzig od. ganz kurz begramnt; Ährchen 5-10 blütig, lineal-lanzettlich, Stbl. goldgelb. Rispe ausgebreitet. Halm bis $1 m$ h., Bl. breit. - Trockne Wiesen, an Rainen, Dämmen. 7. 6. 7.

$B$. inermis Leyss.

9. Rispe groß, locker, schlaff üherhängend, Ährchen lineal-lanzettlich, 7-15 blütig, Bl. breitlineal, sammt d. Scheiden rïckwärts rauhhaarig. Halme 0.60-1.50 $m$ h. - Schattige Bergwälder. 4. 6. 7. B. asper Murr.

Rispe aufrecht, Ährchen 5-10blütig. Scheiden und obere Blätter zerstreut behaart od. kahl, untere (sehr schmal) lang gewimpert. Halme $0.30-1 \mathrm{~m}$ h. - Trockne Wiesen und Hügel, zerstreut. 4. 5-7.

$B$. erectus Huds.

10. (1) Ährchen kahl, 7-11 blütig, langgestielt, hängend; Rispe flattrig ausgebreitet; Halm $0.30-1 \mathrm{~m}$ h. - Auf Schutt, an Wegen, Manern. $\odot .5-7$.

$B$. stéritis $\mathrm{L}$.

Ährchen weich flaumig, 5-9blütig; Rispe schlaff, ïberhängend. Halme $0.20-0.45 \mathrm{~m}$ h. - Auf Sandboden, Schutt, Dächern, Mauern. ๑. 5. 6 .

$B$. tectórum $\mathbf{L}$.

\section{Festúca L. Schwingel (III, 2).}

Rispengräser mit lockerer, ausgebreiteter od. zusammengezogener Rispe, 3 seitiger Spindel. Ährchenstiele nicht verdickt.

1. a) Alle Bl. schmal, zusammengefalzt, daher borsten-, faden- od. pfriemenförmig.

b) Grundständige Bl. zusarnmengefalzt, borstlich, Stbl. flach oder rinnenförmig, breiter. Blt. begrannt.

c) Alle Bl. flach (grofe Arten), Blt. meist grannenlos.

2. Blhälitchen sehr kurz, beiderseits geöhrelt (in ein abgerundetes, häutiges Läppchen verlängert).

Blinäutchen länglich, vorstehend, nicht geöhrelt.

3. Rispe stets zusammengezogen, traubig od. ährig, kaum $2.5 \mathrm{cml} \mathrm{l}$, Älrchen $4-5$ blütig, meist violettbunt, äußere Bltspelze mit 5 vorspringenden Nerven, begrannt (Granne von d. Länge d. Spelze). Halme fingerhoch. - Alpen, auf Gerölle $(1900-2300 \mathrm{~m})$. 4. 7. 8. F alpina Hut.

Rispe zur Blütezeit ausgebreitet, stets zusammengezogen. 4.

4. Rispenäste zur. Blütezeit fast rechtwinklig abstehend; Ährchen lineal-länglich, $3-7$ blütig, grün od. violettbunt; äußere Bltspelze mit 5 erhabenen Nerven, wehrlos od. begrannt, Halme $60-80 \mathrm{~cm}$ h., Rispe 11 bis $22 \mathrm{~cm}$ l., meist nickend. - $0 \ddot{0}$. und Nö., in lichten Nadel- und Mischwäldern, 4 . 5. 6.

$F$. amethystina $\mathrm{L}$.

Rispenäste zur Bltezeit schief abstehend; Ahrchen länglich, 3- bis 10 blütig; grün od. bunt; äußere Bltsp. schwachnervig, stachelspitzig oder kurz begrannt. Dichte glatte Rasenpolster $r$ is Jend. - Auf trocknem, sandigem, felsigem, sonnigem Boden. 7. 5. 6

$$
\text { S: } n \text { af schwingel } F \text {. ovina L. }
$$

Varietäten: $\alpha$. vulgaris Koch Rispe $2 \cdot 5-5 \mathrm{~cm} \mathrm{l.,} \mathrm{schmal,} \mathrm{fast}$ ährenförmig, grün; Ährche' 3-5 blütig, Granne 3-4 mal kürzer als d. Spelze. Halme 7--30 $\mathrm{cm}$ h., sammt d. fädlichen, schwachen Bl. grasgrün. Gemein. - $\beta$. alpina (Sut., Gaud.) Rispe 
wie bei $a$. Ährchen glänzend violettbunt, Grannen länger als ihre Spelze - Kalkalpen, auf Gerölle (1900-2250 m). \%. duriúscula (L.). Rispe $5-7 \mathrm{~cm}$ l., Ährchen 3-iblüig, grün od. mattviolett, Grannen etwas liurzer als d. Spelze. Halme $30-60 \mathrm{~cm}$ l., sammt d. Bl. steif, grün. Verbreitet. - ò. gla uca (Lamk.j. Wie vorige, aber ganze Ffl. blaugrün od. bläulicl bereift. - An Felsen, verbreitet. - $\varepsilon_{\text {. }}$ vaginat a (W. K.). Rispe schlaff, pyramidal, $5-10 \mathrm{~cm}$ l.; Ährchen 5 blütig, oft violett, Blt. kurz begrannt; Halmbl. mit auffallend langen Scheiden, alle Bl. bliulichgriin. Zerstreut..- $\eta$. sulc at a Flack. (T. valesíaca Gand.). Rispe wie bei $\alpha$., Ährchen größer, vielblitig, kahl oder behaart, Blt. begrannt; Bl. sehr laug, fiddlig, gras- od. blaugrün, rïckwärts rauh, getrocknet 2 furchig. In Mh., Xoe., Alpenländer.

5. (2) Bl. zart, borstenförmig, grün; Ährchen 3-5blütig, glänżend violett-gescheckt, Blt. sehr kurz hegrannt; Rispe kl., zusammengezogen; Ialme 10-20 cm h. - Gerölle und Felsen d. Kalkalpen (bis $2500 \mathrm{~m}$ ). 7. 7. 8 .

F. primila Vill.

Bl. dicklicl, starr, hart, borsten- od. pfriemenförmig; Ährchen eiförmig-länglich.

6. Spindel d. 3-5blütigen, glänzend röthlich-bunten đ̈h'chen unter jeder Blt. mit einem Haarbüschel; Blt. grannenlos, Frkn. kahl. Halme $15-45 \mathrm{~cm}$ h., Bl. borstlich-fadenförmig. - Höchste Alpenjoche auf Gerölle, verbreitet. 7. 6. 7. F. pilosa Hall.

Spindel der 5-10 bliit., glänzend bunten Ährchen ohne IIaarbiischel, I3lt. kurz begrannt od. wehrlos, Frkn. an der Spitze belıart. Halme 15 bis $30 \mathrm{~cm}$ h., Bl. steif, starr. - Hochgebirge, auf Weiden und Gerölle. 7. 7. 8 .

F. vária Hke.

Variet. $\alpha$. genuina, Bl. 1., fadenförmig, Ährchen grün, gelb und violett gescheckt. - Riesengeb., Gesenke, Babia Gora, Alpen. - 3. flavescens (Gaud,). Bl. fadenförmig, Ährchen grünlichod. bräunlichgelb. - Alpen. - . Eskia (Ramd.). Bl. dick, pfriemenförmig, stechend. - Alpen v. Kr.

7. (1, b.) Wzst. kriechend, Ausläufer treibend; Grundbl. faden-od. borstenförmig, Halmbl. rinnenfármig, schmal; Rispe zusammengezogen aufrecht, Äbrchen $3-7$ blütig, meist röthlich-od. violettbunt. Halme 30 bis $60 \mathrm{~cm}$ h. - Trockne Wiesen. 4. 6. 7.

F. rubra L.

Wzst. fasrig, ohne Ausläufer; Gruudbl. sehr lang, schlaff, Halmbl. brlineal. Rispe ausgebreitet, überhängend; Ährchen 5-8blütig, grün. Wälder, Hecken. 4. 6. 7.

F. heterophyilla Lam.

8. (1, c.) Ährchen stark zusammengedrückt, ei- od. eilanzettfürm, 9.

Ährchen fast stielrund, lineal-lanzettlich od. fast walzig. 12.

9. Bl. schmal lineal, lang, spitz.

10.

Bl. schilfartig, br., oberseits blau-, unterseits hellgrün, Rispe ausgebreitet, überhüngend.

11.

10. Blscheide d. unfruchtb. Blbüschel knorplig verdickt, die 0.60 bis $1 . m$ l. Halme fast zwieblich umgebend, Bl. stechend spitz, blaugrün; Ährchen 3-5bliitig, glänzend braungelb, in langer, zusammengezogener Rispe. - Alpentriften. 4. 7. 8.

$F$. aurea Lamk. 
Blscheiden nicht knorplig verdickt, Bl. stumpf, griu. Ährchen ebenso. Rispe tlattrig, uberhängend; Halme $0.60-1 \mathrm{~m} \mathrm{~h}$. - Suidseite d. Alpen (in T., Kr.). 7. 6 .

$F$. spectábilis Jan.

11. Wzst. kriechend, beschuppte Ausläufer treibend; Halme 0.60 bis $1 m \mathrm{~h}$. Rispe 50-60 cm l., Ährehen meist 5 blütig, bläulichgriin. - Gebirgswälder, zerstreut. 7. 6. 7. (F. drymeja M. K.) F. montana M. Bieb.

W.zst. fasrig, ohne Ausl., Halme 0.60-1.25 $m$ h., mit bllosen Scheiden am Grunde. Rispe 7-15 cm 1., Ährchen wie b. vorigen. - Schattige Bergwälder. 4. 7. 8 . F. silvaitica Vill.

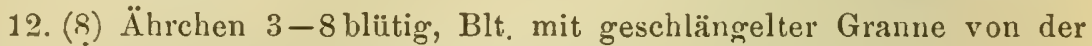
Länge d. Ahrchen. Rispe flattrig, überhängend. Halme $0 \cdot 60-1.50 \mathrm{~m}$ h. Schattige Wälder und Gebïsche. 7. 7. 8.

F. gigantéa Vill.

Ährchen ohne Grannen.

13.

13. Rispe traubenförmig zusammengezogen, ns: beim Blïhen ausge. breitet, untere Äste paarweis, die einen lang mit 3--5, die anderen kurz, mit 1-3 Ährchen, diese 5-10bliitig. Halme 0.30-1 $m \mathrm{~h}$. - Wiesen, gemein. 4.6. 7 .

yy iesense hwinge $1, F$. clatior $\mathrm{L}$.

Rispe flattrig ausgebreitet, überhängend, bis $15 . \mathrm{cm} \mathrm{l,} \mathrm{Aste} \mathrm{paurig,}$ verzweigt, 5 bis viele Ährchen tragend, diese $4-5$ blütig. Halme schilfartig, 0.60-1.50 m 1., Bl. breit. - Fruchtbare Auenwiesen, Moorgründe. 4. 6. 7 .

Rohrsehwingel, $F$. arundinácea Schreb.

\section{Vúlpia Gmel. Federschwingel (III, 2).}

Zarthalmige, lang- und schmalblättrige Gräser nit zusammengezogener dichter Rispe, vielblït. Ährchen $u$. lang und grad begrannten Blt. Halme $8-30 \mathrm{~cm}$ h., Wz. fasrig.

1. Rispe bis $15 \mathrm{~cm}$ 1., überhängend, nahe dem obersten IIalmbl. Auf Sandboden, zerstreut. $\odot$. 5. 6.

V. Myúrus Gmel.

2. Rispe $5-8 \mathrm{~cm}$ 1., aufrecht, vom obersten Halmbl. entfernt. Sandboden, seltner. $\odot$. 5. 6 .

V. bromoides Koch.

\section{Cynosúrus L. Káammgras (III, 2).}

Rispenähren mit flachen, grünen Bl. und schlankem, nach oben blattlosem Halm.

1. Ausdauernd, rasenbildend. Rispenähre lineal, 2 zeilig, Blt. grannenlos. Halm $30-60 \mathrm{~cm} \mathrm{h.} \mathrm{-} \mathrm{Trockne} \mathrm{Wiesen.} \mathrm{4.6.} \mathrm{7.} \mathrm{C.} \mathrm{cristatus} \mathrm{L.}$

2. Einjährig, keine Rasen bildend. Rispenähre oval, Blt. lang begrànnt. Halm 15-45 cm h. - Unter d. Saat, in 00̈., St., T., eingeschleppt. $\odot$. 6. 7 . C. echinatus L.

\section{Triodia R Br. Dreizahn (III, 2).}

Halme niedergestreckt od. aufsteigend, $15-45 \mathrm{~cm} \mathrm{1.,} \mathrm{bis} \mathrm{an} \mathrm{die}$ Rispe beblättert. (Festuca decumbens L.) - Auf Sandboden, besonders in lichten Kiefernwäldern. 4. 6. 7.

T. decumbens P. B.

\section{Molínia Schr. Pfeifengras (III, 3).}

Rispenäste zur Bltezeit rechtwinklig abstehend, sonst zusammengezogen. Stbh. schwarzvinlett. 
1. Halme $30-60 \mathrm{~cm} \mathrm{~h}$. Rispe $7-20 \mathrm{~cm}$ l, sehr schmal. - Torfwiesen. 4. 8. 9 . II. coerúled Mnch.

2. Halne 1-1.30 $m$ h., Rispe 15-30 cm 1., lockerer. - Auf sandigem und sumpfigem Moorboden in Wäldern. 4. S. 9.

M. altissima Host.

55. Dátylis L. Knaulgras (III, 3).

Halme $8.30-1.25 \mathrm{~m}$ h., oben nackt; Bl. brlineal, Rispe nur beim Blühen ausgebreitet, Ährchenknäuel grün od. rothbunt, Stbb. gelblich. Wiesen. 4. 6. 7.

D. glomerata L.

\section{Mélica L. Perlgras (III, 2).}

Rasenbildende Gräser mit einseitiger, armästiger Rispe od. dichter Rispenähre.

1. Rispenähre walzig, wegen der dicht wimperhaarigen äußeren Kronenspelzen weißhaarig-seidenglänzend; Halme $0.60-1.25 \mathrm{~m}$ h. 2.

Lockere Rispe, Ïhrchen kahl, groß, grün-bunt.

2. Rispenähre schmal, nicht unterbrochen; Bl. grün, oben brlineal, Blhäutchen sehr verkürzt, ein zerrissener Rınd. - Auf Kalkboden, in den Alpenländern (?). 7. 5- 7.

M. ciliata $\mathrm{L}$

Rispenähre locker, unterbrochen, lappig; Bl. graugrün, schmal lineal, Blläutchen $2 \mathrm{~mm} \mathrm{1.,}$ abgestutzt, zerrissen. - Dürre Kalkhïgel in B., Mll., Noe. 4. 5. 6.

11. transilvanica Schur.

3. Ährchen überhängend, mit 2 Zwitterblt.; Rispe in eine einfache Traube zusammengezogen; Halme $30-60 \mathrm{~cm} \mathrm{~h}$.

Ährchen aufrecht, mit nur 1 Zwitterblt., rothbunt. Halme $30 \mathrm{~cm}$ h Laubwälder, zerstreut. 4. 6. 7.

4. Blhäutchen, sehr kurz, gestutzt, Ährchen eiförmig, ihre Stiele kahl. - In Laubwäldern, zerstrent. 7. 5.. 6.

M. nutans L.

Blhäutchen deutlich, eiförmig, gestutzt; Ährchen ebenso lang als breit, sehr bunt, auf zottigen Stielen. - In schattigen Laubwäldern in B., Ill., Oe., häufiger als vorige. 4. 5. 6.

M. picta C. Koch.

\section{Briza L. Zittergras (III, 2).}

Halme $30-50 \mathrm{~cm}$ l., Rispe eiförmig, locker, Ährchen grün u. violett gescheclit. Rasenbildend. - Wiesen. 4.6.7.

B. media L.

\section{Eragróstis P. R. Liebesgras (III, 2).}

Zie:liche Rispengräser mit aufsteigenden, am Grunde oft ästigen Halmen und ausgebreiteter Rispe; Blt. 2 reihig.

1. Rispenäste einzeln od. paarig. Ährchen langgestielt, S-20 bltig. schmutzig-violett. - Auf Sanchoden in B. (um Prag u.'a. O.) und Nö. $\odot$ ๑. 8 .

E. minor Host.

2. Rispenäste zu 4-5 in Halbquirlen, Ährchen 4-12 bltig, schwärzlich. - Auf trocknen Grasplätzen, an Straßenrändern in K. und $\mathbf{T} \ddot{0}$. ○. $8-10$.

\section{Poa L. Rispengras (III, 2).}

Rispengräser mit ausgebreiteter, flattriger oder zusammengezogener dichter Rispe.

1. Blscheiden und Halme zusammengedrückt-2 schneidig.

Blscheiden und Halme stielrund. 


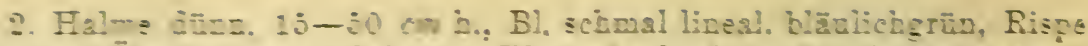

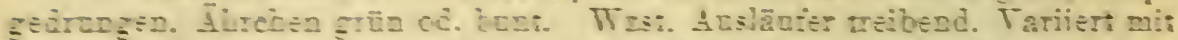

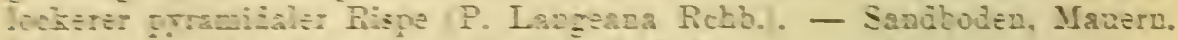

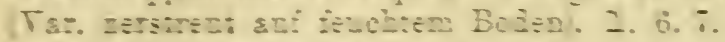

P. compressa L.

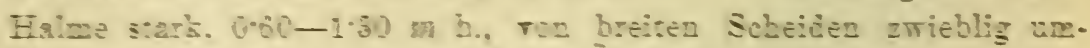

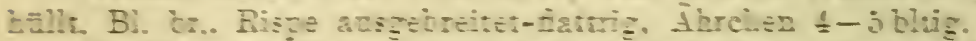

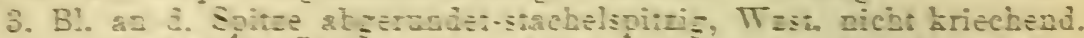

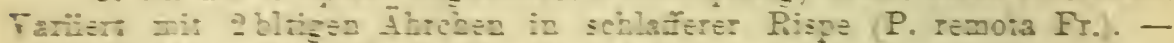

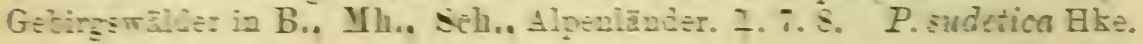

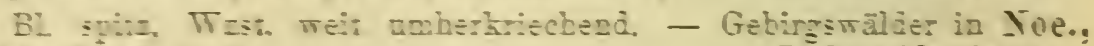
Sz. I.. K. Z. . .

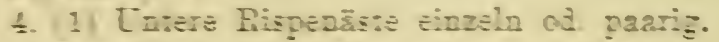

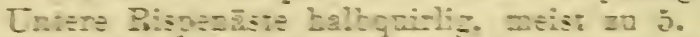

P. hứrida Gaud.

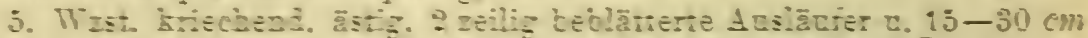
hoһ = Halme :

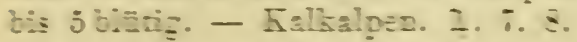

P. envisia All.

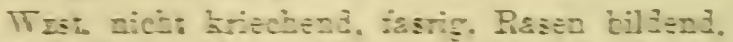
¿ci=mollez

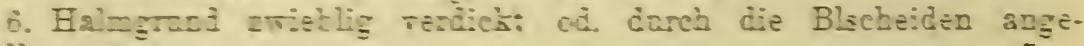

Halrzand aici- re-jick:

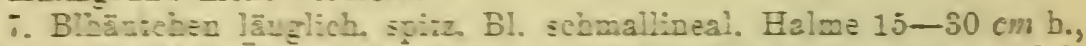

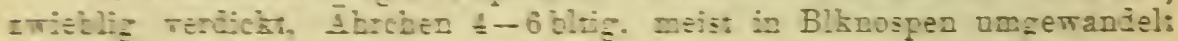

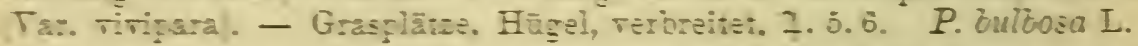

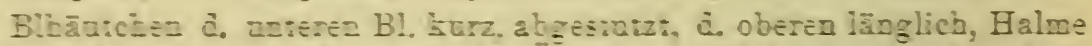

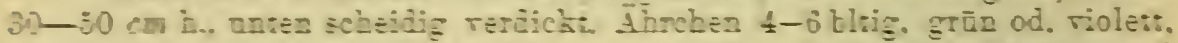

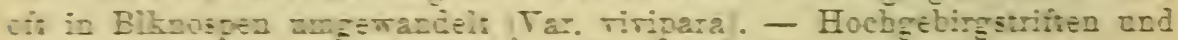

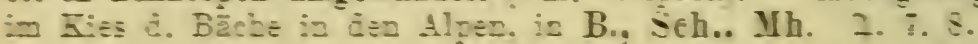

\section{P. alpina L.}

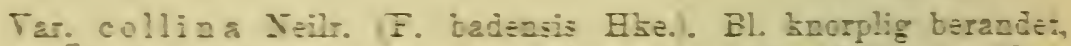

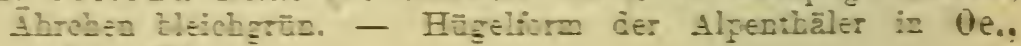
arcil is Ih.

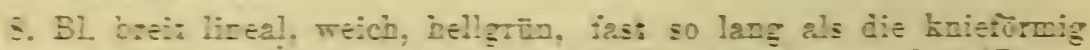

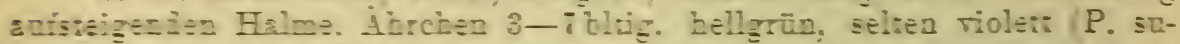

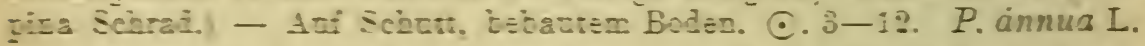

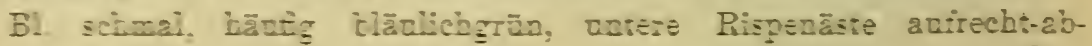
SIE:

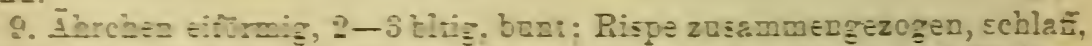

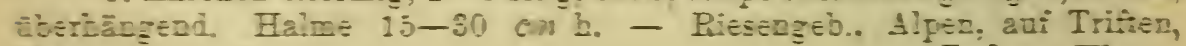
FE: $\Sigma=0.2 . \overline{0}$.

P. laxa Hke.

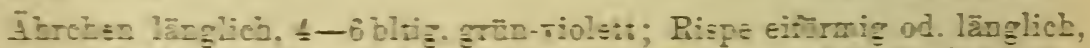

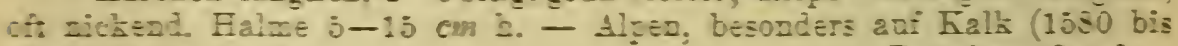
$2000=1.7-9$.

P. minor Gauj.

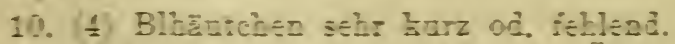

11.

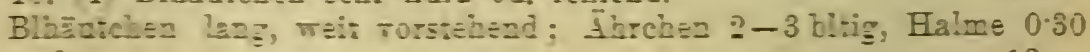
is $12 \pi$.

13.

11. Ganze PE. Lechiblar. Halze $50-j) \mathrm{cm}$ h.. Blscbeiden länger als jis Halmgliejst. Iurcien 2-jtitig. - Riesengeb. Gesená. Alpen,

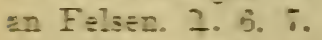
P. caesia Sro.

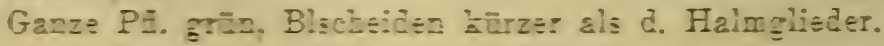




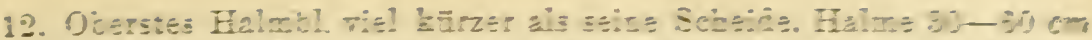

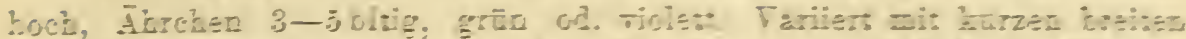

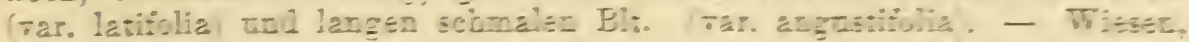

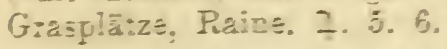

P. pratents L.

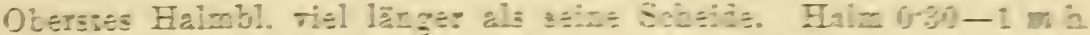

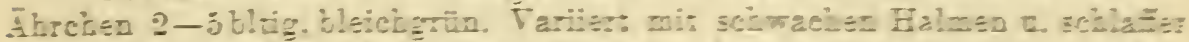

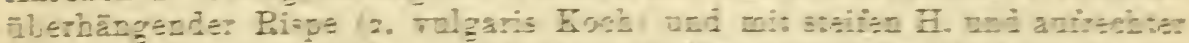

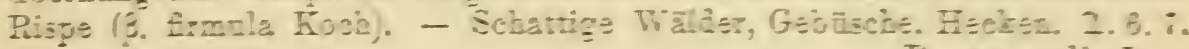

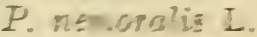

13. Bischeiden crd Haire zarin. Piaye 10-

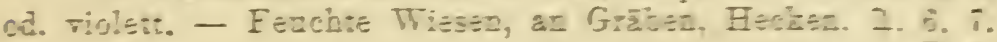

P. tritialis $I$.

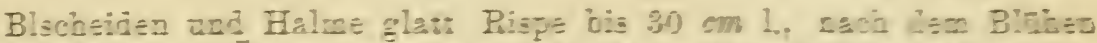

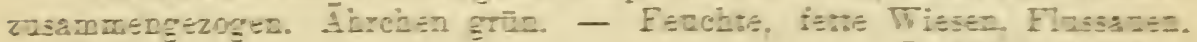
2. $6 . \overline{\text {. }}$

P. fítilis EOs:

Bj. Selerúchloa P. B. Hartgras III, 2.

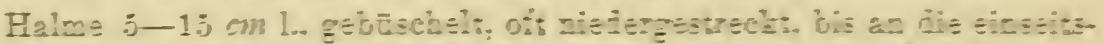

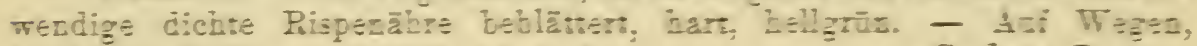
irockenez Iriten. zerstreut. ¿. j.

S. dura P. Z.

\section{Glịcéria R. Br. Süfgras MI. ‥}

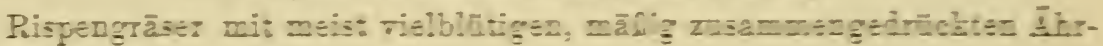
$\mathrm{cb}=2$. B1. Zacis.

1. Un:ere Blispelze juerriz.

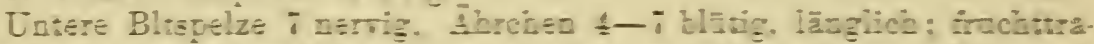

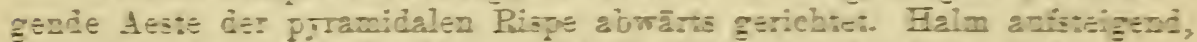

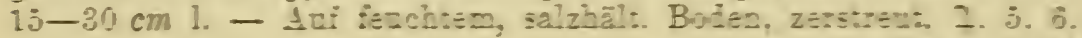

\section{G. dis:ars Tiatenb.}

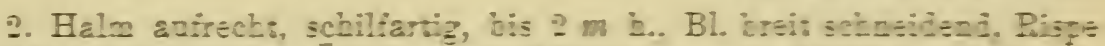

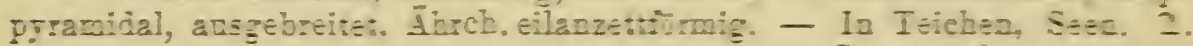
$\because 8$. G. specisili: M. $\mathrm{n}$.

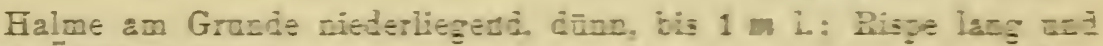
scinal. Ärrchen lineal.

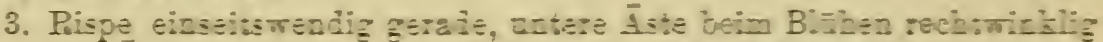

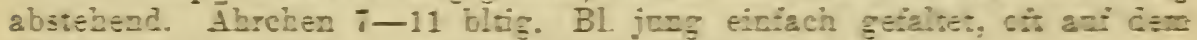

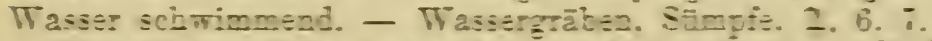

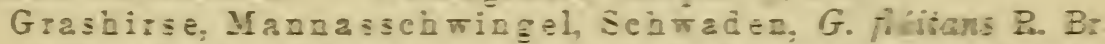

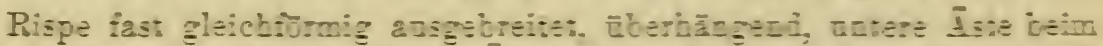

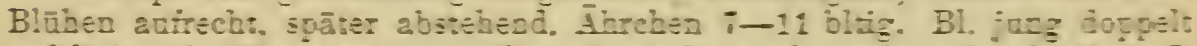

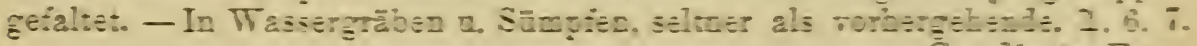

$$
\text { G. Flicats Er. }
$$

\subsection{Catabrusa P. Br. Quellgras III, 2.}

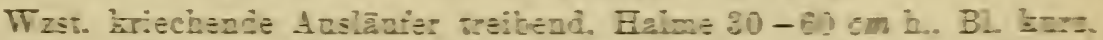

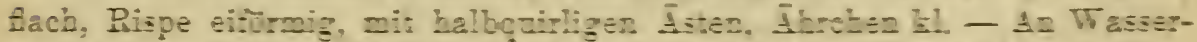

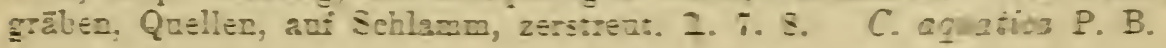

\section{Koeléria P. Kölerie III, ?.}

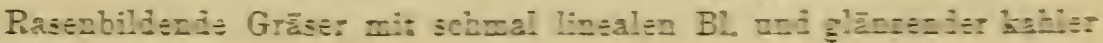
Risp̧ะnābre. 
1. Bl. blaugruin, kahl, Halme $20-30 \mathrm{~cm}$ h., Rispenähre schmal, lang: unterbrochen. - Auf Sandboden in B., Mh., d. Alpenländern; zerstreut. 4. 6. 7.

K. glauca D. C.

2. Bl. grün, behaart. Halme $15-60 \mathrm{~cm}$ h. Rispenähre länglich od. pyramidal, ganz od. gelappt. - Trockene Wiesen, sonnige Hügel, Felsen. 4. 6. 7.

K a m m s chmiele, $K$. cristata P.

Variet. $\beta$. grácilis Koch. Ähre schmal, nicht unterbrochen. El. sehr schmal. Verbreitet. - $\gamma$. montana Hansm. Bl. fast kahl, bläulichgrün, Rispe violett. - o. pubescens Hausm. Spelzen dicht zottig. $\%$ u. o. in d. Alpenlïndem auf Bergwiesen bis $1900 \mathrm{~m}$.

\section{Holcus L. Honiggras (III, 2).}

Rasenbildende Rispengräser mit, $0 \cdot 30-1 m$ h. Halmen $u$. flachen Bl.

1. Rispe eiförmig, Ährchen flaumig, Grannen eingeschlossen; Blt. n. Blscheiden dicht weichbehaart. - Wiesen. 4.6. 7.

H. lanatus $\mathrm{L}$.

2. Rispe pyramidal, Ährchen fast kahl, Granne vorstehend, gekniet; Blt. u. Blscheiden fast kahl. - Waldränder, Gebüsche, Ufer; zerstreut. 4. 7. 8 .

H. mollis $\mathrm{L}$.

\section{Aréna L. Hafer (III, 2).}

Rispen- u. Rispenährengräser. Grannen stets deutlich gekniet u. am Grunde gedreht.

1. Äußere Bltspelze d. oberen Blt. in 2 1. Borsten auslaufend, eine lange Rückengranne tragend, Ährchen meist 3 blütig, in l. lockeren RispenHalme zart, $30-60 \mathrm{~cm}$ h. - Auf Sandboden in B., Ml., Noe.; zerstreut. ๑. ๑. 6. 7 .

A. tenuis Mnch.

Äußere Spelze aller Blt. mit 2 kurzen Borsten, 2 spaltig, 2zähnig od. ganz.

2. Kelchspelzen $1-3$ nervig, Ährchen aufrecht, alle Blt. begrannt. 3 .

Kelchsp. 5-9 nervig, Ährchen hängend (groß), nur d. untern Blt., selten die 2 untersten begrannt.

12.

3. a) Äußere Bltspelze in 2 feine Borsten endigend. Granne stark gekniet (Trisetum P.)

4.

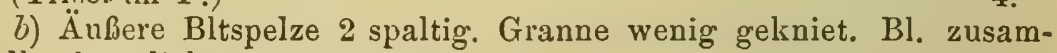
mengerollt, borstlich.

7.

c) Áßßere Bltsp. 2 zähnig. Granne stark gekniet, lang. Bl. flach od. zusammengefalzt.

8.

4. Wzst kriechend, 2 zeilig beblätterter Ausläufer treibend, Bl. blaugrün, kahl, Ährchen meist 3 bltig.

5.

Wzst. faserig, ohne Ausl., Bl. grïn, behaart.

6.

5 Kelchspelzen violett $u$. weiß gerandet; $3-4$ Ährchen an d. längeren Rispenästen. Halme $10-15 \mathrm{~cm}$ h., Bl. flach, starr. - Felsige Abläinge d. Alpen. 7. 7. 8 .

A. distichophýlla Vill.

Kelchsp. violett; 4-8 Ährchen an d. längeren Rispenästen. Halme $30 \mathrm{~cm}$ h., Bl. rinnig, borstlich. - Felsen u. Gerölle d. Alpen. 4. 7. 8.

A. argéntea W.

6. Ährchen $5 \mathrm{~mm}$ l., gelblichgrün; Grannen nicht geschlängelt. Halme $30-60 \mathrm{~cm}$ h. - Trockene Wiesen. 7. 6.-8. 
Ahrchen 7-9 $\mathrm{mm}$ 1., violett u. grünlichgelb gescheckt, Grannen geschlängelt. Halme $15-30 \mathrm{~cm} \mathrm{h.} \mathrm{-} \mathrm{Auf} \mathrm{Alpentriften.} \mathrm{4.} \mathrm{7.} \mathrm{S.}$

A. alpestris Host.

7. (3, b.) Ährchen kurz gestielt, Rispe zusammengezogen, ährenförmig, 13-25 $\mathrm{mm}$ l., Grannen fast gerade. Halme zart, $5-15 \mathrm{~cm} \mathrm{~h}$. Sand- und Heideboden, zerstreut. $\odot .5 . \quad$ A. praecox P. B.

Äbrchen langgestielt, Rispe flattrig, 2.5-7.5 $\mathrm{cm}$ l., dreigablig, Grannen deutlich gekniet. Halme $15-30 \mathrm{~cm}$ h. - Sand- u. Heideboden, zerstreut. $\odot$. 6. 7 .

Nelkenhafer, A. caryophýllea L.

8. (3, c.) Halme u. Blscheiden breit 2 schneidig zusanmengedrückt, erstere steif, $0.60-1.50 \mathrm{~m}$ h.; Bl. breit, flach. Rispe 15-30 cm l. zusammengezogen, Ährchen $6-8$ bltig, bunt. - Gebirgswiesen im Gesenke. u. in d. Alpen. 4. 7. 8 . A. planiculmis Schrd.

Halme u. Blscheiden nicht zusammengedrückt, stielrund.

9. Rispe ähren- od. traubenförmig, Ährchen $4-5$ bltig.

Rispe ästig, locker; Ährchen 2-4 bltig.

11.

10. Bl. glatt, Ährchen glänzend, violett, bräunlich u. weiß gescheckt, 5 bltig. Halme $25-40 \mathrm{~cm}$ h. - Hochalpentriften $(1600-2500 \mathrm{~m})$. 4. 7. 8.

A. versicolor Vill.

Bl, oberseits rauh, schneidend scharf. Ährchen grün u. violett, gescheckt, 4-5 bltig. Halme $30-60 \mathrm{~cm} \mathrm{~h}$. - Trockene Wiesen, steinige Hügel; zerstreut. 7. 6. 7 .

A. pratensis $\mathrm{L}$.

11. Bl. u. untere Scheiden zottig, weich behaart, Ährchen $2-4$ bltig; Blt. violett $u$. weif gerandet. Halme bis $1 \mathrm{~m}$ h. - Trockene Wiesen. \%. 6. 7 .

A. pubescens L.

Bl. u. Scheiden kahl. Ährchen 3-4 bltig, violett u. gelblich gescheckt. Halme $30-60 \mathrm{~cm}$ h. Bl. steif, zusammengesaltet. - Felsige Abhänge d. Alpen. 4. 7. 8.

A. sempervirens Neilr.

12. (2). Ährchenspindel u. Blt. kahl, Ährchen 3 ultig, 17-22 $\mathrm{mm} 1$. - In 0e. hier u. da gebaut. $\odot .7$.

Nackter H., Spinnenhafer, $A$. nuda L.

Ährchenspindel rauh od. biischelig behaart.

13.

13. Ährchenspindel rauhlıarig. Ährchen 3 bltig, $19 \mathrm{~mm}$ l. Rispe gleichmäßig ausgebreitet. Blt. bis zur Mitte behaart. - Unkrant unter d. Saat. $\odot .7 .8$.

W indh., A. fátua $\mathrm{L}$.

Ährchenspindel am Grunde d. Blt. büschelig behaart. 14.

14. Ährchen $3-5$ bltig, $28 \mathrm{~mm}$ l. Untere Blt. lang, zottig behaart, die 2 unteren lang begrannt. - Unter d. Saat im sïdl. Kr. $\odot$. 7. S. A. stérilis L.

Ährchen 2 bltig, Blt. kahl.

15.

15. Beide Blt. begrannt, Ährchen $10 \mathrm{~mm} \mathrm{l}$. - Unter d. Saat, in Oe.g. auch gebaut. $\odot$. 7. 8 . Sperlingsschnabel, $A$. brevis Roth.

Nur 1 Blt. begrannt od. beide unbegrannt. 16.

16. Untere Blt. stets begrannt, Kelchspelzen so lang wie d. Blten. Ährchen (ohne Grannen) bis $15 \mathrm{~mm}$ l., Rispe sehr flattrig. - Unter d. Saat, auch gebaut. $\odot$. 7.8. Ra a hafer, Wildhafer, A. strigosa Schreb.

Untere Blt. begrannt od, graunenlos. Kelchsp. länger als d. Blten, Ährchen bis $21 \mathrm{~mm} l$. 
17. Rispe ausgebreitet, sehr flatterig. - Allgemein gebaut $\odot .7$. Rispe einseitswendig, zusammengezogen. - Hier u. da geb. $\odot .7$. Stangenhafer, $A$. orientalis L. $\quad \geq 22$

66. Arrhenátherum P. B. Glatthafer (III, 2).

Halme $0.60-1.25 \mathrm{~m}$ h., Bl. lineal, flach; Rispe ausgebreitet, überhängend, Ällrchen zahlreicl, glänzend, $6 \mathrm{~mm}$ 1. (Avena elatior L.) - Wiesen. 4. 6. 7 .

Glattluafer, französ. Raigras, $A$. clatius Presl.

\section{Aira L. Schmiele (III, 2).}

Gräser mit ausgebreiteter flattriger, sehr verzweigter, eleganter Rispe u. kl. glänzenden Ährchen.

1. Bl. borstlich, kurz, Halme zart, $30-60 \mathrm{~cm}$ h., Granne vorstehend, deutlich gekniet. - Waldschläge u. Blößen. 4. 7. S.

Haferschmiele, $A$. flexuosa L.

2. Bl. sehr lang, dunkelgrün, dichtrasig; Halme bis $1 m \mathrm{~h}$.; Grannen lsaum vortretend, gerade. - Feuchte Wiesen u. Grasplätze, bis auf das Hochgeb. 4. 6. 7 . $\mathrm{R}$ asenschmiele, $A$. caespitosa L.

\section{Coryuéphorus P. B. Keulengras (III, 2).}

Rasenbüschel, Halme u. Rispen weißlich blaugrïn, Halme $15-45 \mathrm{~cm}$ h., Rispe länglich, diclrt; Bl. borstlig. - Auf Flugsand. 4. 7. 8.

$\mathrm{S}$ and schmiele, C. canescens $\mathrm{P} . \mathrm{B}$.

\section{Lasiagróstis Lr. Rauhgras (II, 2).}

Halme $0.60-1 m$ h., Bl. schmal, dicht rasig. Rispe $7-15 \mathrm{~cm} \mathrm{l}$, dicht, Ährchen $6 \mathrm{~mm}$ l. behaart, Grannen vorstehend. - Steinige Blößen d. Alpen v. K., T., Kr. 4. 7. 8.

L. Calamagróstis Lik.

\section{Stipa L. Pfriemengras (III. 2).}

Rispengräser mit steifen, meist zusammengerollten 1. Bl. und armblütiger schmaler Rispe. Halme $0 \cdot 30-1 \mathrm{~m}$ h.

1. Granne 10-15 cm i., geschlängelt, kahl. - Dürre Kalk-u. Basalthiigel. 4 . 6. 7 .

St. capillata L.

2. Grannen 20-30 cm 1., fedrig behaart, (St. Grafiana Stev u. St. Joannis Č́lalk), - Dürre Kalk-, Gyps- u. Basalthügel, häufig in B. 4. 5. 6. Mariengras, Steinflachs, St. Ivansbart, St. pennata L.

\section{Mílium L. Hirsegras (III, 2).}

Halm 0.60-1.30 $m$ h., Bl. breit, flach, Rispe pyramidal, quirlästig, $15-30 \mathrm{~cm} \mathrm{1.,} \mathrm{Äbrchen} \mathrm{2-3} \mathrm{mm}$ 1. hellgrïn. - Sclıattige Wälder. 4. 5. 6. Waldhirse, TI. effusum L.

\section{Agróstis L. Straußgras (חI, 2).}

kl. Ährchen.

Gräser mit quirlästigen, fein und vielfach verzweigten Rispen $u$, sehr

1. Untere Kelchspelze kleiner als d. obere, Blt mit $5 \mathrm{~mm}$ l. Grame. Rispe bis $30 \mathrm{~cm}$ l., Rispenäste ausgebreitet, erst gegen die Spitze Ährchen tragend. Halm bis $1 m \mathrm{~h}$. - Unter d. Saat, gemein. $\odot$. 6. 7 . 
Untere Kelchsp. größer als d. obere, Blt. meist grannenlos. 2.

2. Eine einzige Bltspelze mit riickenständiger, geknieter Granne. 3.

Zwei Bltsp, keine Granne; Bl. flach.

3. Bl. zusammengerollt, borstenförmig, blassgrün. Rispe eiförmig. 4. Grundbl zusammengerollt, Halmbl. Hach, Rispe lang eiförmig, Ährchen bunt. Halıne $14-45 \mathrm{~cm}$ h. - Wiesen, Triften, Raine 4. 6. 7.

A. canina $\mathrm{L}$.

4 Granne mittelständig, Rispenäste glatt, Ährchen röthlich od. violett. Halme 10-15 $\mathrm{cm}$ h. - Steinige Triften d. Riesengeb. u. d. Alpen. 24. 7. 8. A. rupestris All.

Granne grundständig, Rispenäste rauh, Älırchen dunkelroth, Halme 10-15 cm h. - Auf Weidetriften, Gerölle, an Felsen d. Alpen. 4. 7. 8. A. alpina Scop.

5. (2). Blhäutchen sehr kurz, Rispe länglich-eiförmig, ausgebreitet, Ährchen meist bunt; Halme $0.15-1 m \mathrm{~h}$. Häufig mit Ausläufer (var. stolonifera), bisweilen mit in Blknospen verwandelten Ährchen (vivipara). Wiesen, Triften, IVälder. 4. 6. 7.

A. vulgaris With.

Blhäutchen lang, vorstehend. Rispe länglich-kegelförmig, nach dem Blühen zusammengezogen, Äbrchen meist bleich, Halm $030-1 m$ b. Treibt Ausläufer. (A. alba L.) - Feuchte Wiesen, Fluss- u. Teichufer. 4. 6-9. $\mathrm{F}$ i or ingras, $A$. stolonifera $\mathrm{L}$.

\section{Calamagróstis Roth. Reit., Rohrgras (III, 2).}

Steifhalmige, oft schilfartige Rispen- und Rispenährengräser. Wzst. kriechend, Bl. flach.

1. BIt. mit kurzer gerader Granne oder grannenlos. Spelzen durchscheinend weiß.

2.

Blt. mit geknieter Gr., Spelzen nur am Rücken weißhäutig. 6.

2. Hüllhaare so 1. wie die Kelchspelzen, Granne nicht vorstehend. 3.

Hüllh. halb so l. wie die Kelchsp., Blt. meist unbegrannt, Rispe lang, schlaft, violett. Haime $30-60 \mathrm{~cm} \mathrm{h.} \mathrm{-} \mathrm{Auf} \mathrm{Alpentriften.} \mathrm{7.} \mathrm{7.} \mathrm{8.}$

C. tenella Host.

3. Granne rïckenständig, bisweilen fehlend. Bl. schilfig.

4. Rispe sehr dicht, gelappt, bis $30 \mathrm{~cm}$ 1., bläulichgriin od. violett. Halme $0.60-1.50 \mathrm{~m}$ h. - Auf Sandboden in Wäldern und an Ufern. 4. 7. 8 .

C. Epigéjos Roth.

Rispe locker, ausgebreitet, bis $15 \mathrm{~cm}$ 1., glänzend dunkelviolett. Halme bis $1 \mathrm{~m}$ h. - Auf moorigen Bergwiesen (Erzgeb.. Riesengeb., Gesenke, Alpen), 4. 7.8.

C. Halleriana Gaud.

5. Halme und Bl. grasgrün. Rispe bleich od. violett, Kelchspelzen spitz, äußere Bltspelze stachelspitzig. - Feuchte Wiesen u. Gebüsche, zerstreut. 2. 7. 8.

C. lanceolata Roth.

Halme und $\mathrm{Bl}$. blaugrün. Rispe grün $u$. braunroth, Kelchspelzen pfriemenförmig, Bltsp. begrannt. - Sandige Flussufer, zerstreut. 4. 7. 8.

C. litórea DC.

6. Granne kanm üb. d. Kelchspelzen hinausragend. Hüllhaare so lang od. kürzer als die Kelchspelzen; Rispe ausgebreitet, schlaff; Halme bis $1 \mathrm{~m}$ h. - Alpenwälder, zerstreut. 4. 6. 7.

C. montana DC. 
Gramne weit vorragend. Hüllh, viel kürzer als die Kelchspelzen, Rispe anfangs dicht; Halme bis $1 \mathrm{~m}$ h. (C. silvatica DC.). - In WVäldern, gemein. 7. 7. 8 .

$C$. arundinacea Roth.

\section{Phragmites L. Schilf (III, 2).}

Halme bis $2.5 \mathrm{~m} \mathrm{~h}, \mathrm{Bl}$. bis $25 \mathrm{~mm}$ br. Rispe $15-30 \mathrm{cml}$, rothbraun od. gelblich (var. flavescens). - In Teichen, Seen, an Flüssen. 7. 8. 9. Ph. communis Trin.

75. Sorghum P. Moorhirse (III, 2).

Asiatische rolrrartige Getreidegräser mit brlinealen od.lanzettförmigen Bl. Kelchspelzen weichbehaart. Halme bis $2 \mathrm{~m} \mathrm{~h}$.

1. Rispe straufartig zusammengezogen, länglich-elliptisch. - Ange-

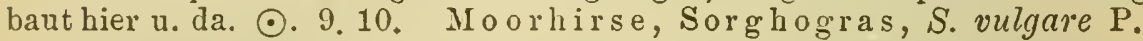

2. Rispe schlaff, flattrig ausgebreitet. - In Gärten geb. ๑. 9. 10 Zuckerhirse, S. saccharatum P.

\section{Andropógon L. Bartgras (III, 2).}

Wzst. kriechend, Halme schlank, $30-60 \mathrm{~cm}$ h., Ähren rötblich od. bunt, seidenglänzend. - Auf dürren Kalk- und Gypshügeln, zerstreut. 4. 6.7 .

A. Ischaemum L.

77. Cýnodon L. Hundszahn (III, 2).

Wzst. kriechend, Halme ästig, aufsteigend, bis $50 \mathrm{~cm}$ 1., 3-6 einseitswendige braune Ähren tragend. - Auf Sand, Schutt, an Wegen in 0e. und den Alpenländern. 4. 7-9.

C. Dictylon L.

\section{Digitária Scop. Fingergras (III, 2).}

Halme aufsteigend, meist ästig, Bl. flach. Neben der $\%$ witterblte eine leere Spelze.

1. Bl. und Scheiden weich behaart. Ähren zu 2-12, meist violettpurpurn. Halme $15-50 \mathrm{~cm}$ h. Variiert mit lang gewimperter leerer Spelze (D. ciliaris Koel.) - Auf bebautem Boden, d. Var. viel seltener ๑. 7 -9. Bluthirse, $D$. sanguinalis scop.

2. Bl. und Scheiden kahl, Ähren zu 2-5, schmächtiger. Halme 8 bis $50 \mathrm{~cm}$ 1. - Wie vorige, seltner. $\odot . ~ 7-9$. D. filiformis Koch.

\section{Eehinóchloa P. B. Stachelhirse (III, 2).}

Halme ästig, aufsteigend, .. sammt den Scheiden zusammengedrückt, bis $1 \mathrm{ml}$, Bl. breit, wellig; Ährchen grün oder violett, mit oder ohne

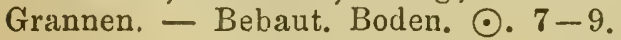

$$
\text { K a mmhirse, E. crus galli P. B. }
$$

\section{Pánicum L. Hirse (III, 2).}

Aus dem Orient stammendes Getreidegras. Bl. breit, Scheiden zottig Rispe lang überhängend, Ährchen kl., bleichgriin. - Häufig gebaut. $\odot$ 7. 8 .

Rispenhirse, $P$. miliácerm L.

\section{Setária P. B. Borstengras (III, 2).}

Halme meist ästig, Bl. lineal-lanzettlich, flach, scharfrandig.

1. Rispenähre dick, gelappt, nickend, sammt den Borsten grün, gelb-

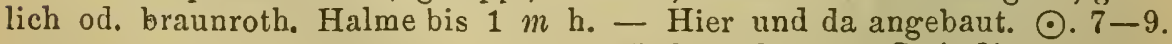


Rispenähre walzig od. länglich, nicht gelappt. Halme höchstens $60 . \mathrm{cm} \mathrm{h}$.

2. Borsten läng. als d. Ährchen, paarweis. Ähre griin, Ährchen scheinbar quirlständig. - Auf Schutt und bebautem Boden. ๑. 7. 8.

S. verticillata $\mathrm{P}$. B.

Borsten viel läng. als die Ährchen, zu mehreren neben einander. 3.

3. Bltspelzen glatt, Borsten und Ähre grün, gelblich, röthlichbraun.

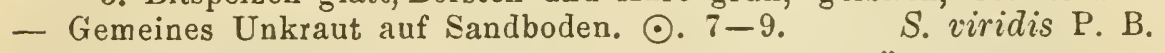

Bltsp. querrunzlig, Borsten zuletzt fuchsroth, Ähre bleichgrün. Unkraut, weniger häufig. ๑. 7. 8.

S. glauca P. B.

\section{Tragus Hall. Klettengras (UI, 2).}

Ähre 2-6 cm 1., zuletzt grün-violett. Halme aufsteigend, $6-20 \mathrm{~cm}$ 1., Bl. flach. - Auf Sandboden in Mll., Noe., T., Kr., eingeschleppt. ๑. $7-9$.

\section{Sessléria Scop. Kammgras (III, 2).}

Felsen-u. Steingräser mit schmallinealen Bl.u.gedrungener Rispenähre. $15 \mathrm{~cm} \mathrm{~h}$.

1. Rispenähre eiförmig bis kugelig, Bl, stumpf, flach, Halme 10 bis

Rispenähre länglich bis walzig, lavendelblau, Halme $5-30 \mathrm{~cm}$ l., bllos, meist nicht länger als d. dichtrasigen Bl. - Auf Kalkboden. 7 . 3. 4.

S. coerílei Ard.

2. Ähre eiförmig, dunkelblau, sehr kl. - Kalkalpen (1900-2800 m) 4. 6. 7. (S. microcephala Koch)

$\therefore$ ovata Hopne.

Anre kuglig, sehr kl., bleichgrïn od. bläulich. - Kalkalpen. 4. 7. 8.

S. sphaerocéphala Ard.

\section{Oreóchloa Lk. Berggras (III, 2).}

Dichtrasig. Halme $8-20 \mathrm{~cm}$ h., Bl. schmallineal, Rispenähre eiförmig, 2 zeilig, violett. - Felsspalten d. höchsten Kalkalpen. 4. 6. 7.

O. disticha Lk.

\section{Alopecúrus L. Fuchsschwanzgras (III, 2).} Bl. Hach.

Ährchen d. walzigen od. länglichen Rispenähre lassen sich abstreifen.

1. Halme aufrecht, Kelchspelzen bis zur Mitte verwachsen. 2.

Halme knieförmig aufsteigend, Kelchspelzen nur am Grunde verwachsen.

2. Ähre spitz, $5-7.5 \mathrm{~cm}$ 1, bleichgrün; Kelchsp. am Kiel geflügelt, Halme $30-50 \mathrm{~cm}$ h. - Unter d. Saat, eingeschleppt u. zerstreut. $\odot$. 6. 7 . A. agrestis L.

Ähre stumpf, $2 \cdot 5-7.5 \mathrm{~cm}$ 1., bleichgrün oder schwärzlich; Kelchsp. am Rücken gewimpert. - Überall auf Wiesen. 4. 5.6. A. pratensis L.

3. Halme u. Bl. blassgrün, Grannen doppelt so lang als d. Spelzen; Stbb. bleichgelb, später hellbraun. Halme $0.30-1 \mathrm{~m}$ l. - An Gräben, Siimpfen, feuchten Orten. 4. 5-8.

A. geniculatus L.

Halme u. Bl. bläulich beduftet, Grannen halb so 1. als d. Spelzen; Stbb. rostgelb. - Wie voriger. $\odot .6-8$.

Willk omm, Schule ora.

A. fulvus Sin. 


\section{Phleum L. Lieschgras (III, 2).}

Ährchen lassen sich von der Spindel nicht abstreifen.

1. Kelchspelzen am Kiele rauh, 1 nervig, länglich, schief abgestutzt, stachelspitzig. Halme $30-60 \mathrm{~cm}$ h., Ähre walzig, hellgriin oder violett überlaufen. (Phalaris phleoides L) - Trockene Wiesen, düre Hügel in Nö. 4. 6.7 . Pl. phlalaroídes Koel.

Kelchsp. am Kiel gewimpert, 1 od. 3 nervig. 2.

2. Kelchsp. lanzettlich spitz, 1 nervig; Ähre walzig, grün-röthlich od. violett; Halme $15-45 \mathrm{~cm} \mathrm{~h}$. - Steinige Triften d. Alpen bis $1900 \mathrm{~m}$ 7. 7. 8 .

P. Michelii Alt.

Kelchsp. breit abgestutzt, bespitzt od. begrannt, 3 nervig. 3.

3. Kelchsp. mit gerader Spitze, Ähre walzig, $2 \cdot 5-15 \mathrm{~cm} 1 .$, bleichgrün bis violett. Halme $0.30-1 \mathrm{~m}$ 1. Hahmbasis häufig zwieblig verdickt (P. nodosum L., P. Bochmeri Vib.) Tleibt bisweilen Ausläufer ( $\beta$. stoloníferum Host.). - Wiesen, häufig auch angeb. ( $\beta$. nu in den Alpen) 24. 7 . \&. Timot he gras, $P$. pratense $\mathrm{L}$.

Kelchsp. mit gebog*ner Granne, Ähre länglich-walzig, schwärzlich, 1.3-5 cm 1., Halme $15-30 \mathrm{~cm}$ h. - Bergwiesen d. Riesengeb., Gesenkes u. d. Alpen. 24. $6-8$.

$P$. alpinum $\mathrm{L}$.

\section{Crypsis Ait. Dorngras (III, 2).}

Kleine Gräser. Halme niedergestreckt od. aufsteigend; Bl. starr, spitz.

1. Oberste Halmbl. als kahnförmige, spitze, die halbluglige Rispenähre am Grunde umhiillende Scheiden ausgebildet.

Oberste Halmbl. von d. übrigen nicht verschieden. Halme gekniet, Ähre walzig, schwärzlich. - Auf Sand, an Gräben in Mh. u. Noe., zerstreut. $\odot . ~ 7-9$.

C. alopecuroides Schrd

2. Halme ästiğ, Bl. stechend. - Auf Salzboden, an Gräben in Mh. u. Noe., zerstreut. $\odot .7-9$.

C. aculeata Ait.

Halme einfach, Bl. weich. - Auf Salzboden, iru südl. MI. ○. 7. S. C. schoenoides Lam.

\section{Anthoxánthum L. Ruchgras (II, 2).}

Halme $30-60 \mathrm{~cm}$ l., Bl. kahl oder behaart, Rispenähre locker, oft unterbrochen, glänzend gelblichgrün. Wohlriechend. - Wiesen, Waldblößen. 2. 5. 6 .

A. odoratum $\mathbf{L}$.

\section{Hieróchloa Gmel. Darrgras (III, 2).}

Halme 30-60 cm h., Bl. flach, Rispe eilänglich, dicht, $2.5-5 \mathrm{~cm}$ l., Ährchen glänzend grünlichbraun; Wzst. faserig. - Wälder u. Waldwiesen, auf Kalkboden in Nö., B. u. MH., zerstreut. 4. 4. 5. H. australis R. Sch.

\section{Baldingéra Fl. Wett. Glanzgras (III, 2).}

Schilfartiges Gras, Halme $0.60-2 m$ h., Bl. breitlineal, schneidend scharfrandig; Rispe pyramidal, bis $20 \mathrm{~cm} \mathrm{l.,} \mathrm{dicht,} \mathrm{rothbunt,} \mathrm{seltener} \mathrm{bleich,}$ vor u. nach d. Blithen zusammengezogen u. kuaulförmig gelappt. (Phalaris arumdinacea L.) - An Flussufern. 4.6.7. B. arundinácea. Dum.

Var. ß. vittata: Bl. weißgestreift, das "Bandgras" d. Gärtez.

\section{Phálaris L. Canariengras (III, 2).}

Halme 0.15-1.50 $\mathrm{m}$ 1. Rispenähre eiförmig, $5 \mathrm{~cm}$ l., grün u. weiß gescheckt. - Hier u. da angebaut u. verwildert. ๑. 7. 8. $P h$. canariensis L. 


\section{Léersia Sw. Reisquecke (III, 2).}

Halme 0.30-1.50 m l., aufsteigeud, Bl. lineal-lanzettlich, flach; Rispe meist in d. obersten Blscheide steckend, flattrig, überhängend, bleichgrün. - In Wassergräben, an Ufern, zerstreut (Oryza clandestina A. Br.) 4 . 8. 9 .

\section{Coleanthus Seid. Scheidengras (III, 2).}

Kleinstes aller Gräser; Halme zart $2 \cdot 5-7.5 \mathrm{~cm}$ h., Bl. bauchig aufgeblasen, zurückgebogen; Ährchen geknäuelt in gelappter Rispe. - Auf Teichschlamm, an sandigen Ufern im siidl. B. u. Wh., in Oe.g stellenweis. $\odot .7-9$. (Schmidtia subtilis l'ratt.) C'. síbilitis Seid.

\section{Zea L. Mais (XXI, 3).}

Bekanntes, aus Siidamerika stammendes Getreidegras, häufig in vielen

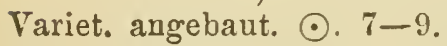

Kukuruz, Z. Mais L.

\section{Fam. XV. Cyperáceae, Scheingräser. \\ Schliissel der Gattungen.}

1. Blt, eingeschlechtig, mäınl. od. weibl.

Blt. zwitterlich.

2.

4.

2. Weibl. Blt. (Frchtkn.) u Früchte (Nüsschen) von einem Schlauch umgeben, aus dessen Mündung d. Griff. hervorragt.

Kein Schlauch, 3 Narben. Blt. in endständigen, aus Ährchen bestebenden Ähren.

3.

3. Ähre einfach, Ährchen 2 bltig, untere Blt. weibl,, obere ınännlich

Elyna (96).

Ähre gelappt, Ährchen mehrbltig. seitliche unten weibl., oben männl.

4. (1). Blt. in ziegeldachigen Ährchen.

Kobresia (97).

Blt. in 2 zeiligen Ährchen.

5. Blt. von Borsten umgeben, die nachher in lange glänzendweiße Haare sich verlängern (Ährchen dann einem weißen Wollflocken gleichend). Eriophorum (102).

Bltborsten fehlen od, wenn vorhanden (dann wenige), sich nicht verlängernd.

6. beblätterten.

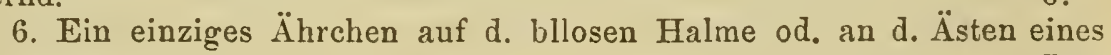

Mehrere bis viele Ährchen in Büscheln, Köpfchen, Spirren, Rispen. 8.

7. Griffel gegliedert, oberes Stück abfallend, unteres auf d. Nüsschen stehen bleibend; Halm einfach bllos.

Heleocharis (98).

Gr. nicht gegliedert, ganz abfallend; Halm einfach od. ästig.

$$
\text { Scirpus (99 z. Th.). }
$$

8. Ährchen zu 1-3 unterhalb d. Spitze des Halmes seitlich, od. viele in seitenständigen Büscheln od. Köpfchen.

Scirpus (99 z. Th.)

Ährchen in endständ. od, end- und achselständ. Büscheln od. Spirreu. Halm beblättert.

9. a) Ährchen in end- u. achselständige einfache Büschel gruppiert. Grund d. Gr. als Schnabel auf d. Fr. stehen bleibend; 2 Narben. 
b) Ahrchen in end- u. achselständige, zusammengesetzte Spirren gestellt, welche eine 1. traubige Rispe bilden.

Cladium (103). Spirren.

c) Ährchen in endständigen sehr verzweigten, weit ausgebreiteten Ähre.

10. (4). a) Ährchen in endständ,, 2 zeilig zusammengesetzter, lappiger Scirpus (99 z. Th.).
mmengesetzter, lappige
Blysmus (100).

b) Ährchen wenigblütig in einem endständ. Köpfchen; 3 Narben. Schoenus (104).

c) Ährchen vielbltig, in eine endständ. bïschlige Spirre od. in trugdoldig gruppierte Büschel gestellt. Narben 2 od. 3. Cyperus (105).

\section{Carex L. Rietgras, Segge (XXI, 3).}

Gräser mit büscheligen, nach 3 Richtungen abstehenden Bl. u. knotenlosem, oft 3 kantigem Halme.

1. a) Eine einzige Ähre auf d. fast bllosen Halme.

b) Eine aus kl. Ährchen bestehende Ähre, Traube od. Rispe; Halm nur oben nackt.

c) Ein einziges, aus kl. grünen Ährchen bestehendes Köpfchen, von 2-3 Hüllbl. umringt. Halm $15-30 \mathrm{~cm} \mathrm{~h}$. - An Teichrändern, zerstreut. ๑. 7. 8.

C. cyperoides $\mathrm{L}$.

d) Eine od. mehrere männl. Ähren an d. Spitze d. Halmes, darunter 1 bis mehrere weibl.

2. Ähre 1 geschlechtig, männl. od. weibl.; 2 Narben.

Ähre am Grunde weibl., an d. Spitze männl.

3. Wzst. kriechend, Halme rund, bis $20 \mathrm{~cm}$ h., Spelzen u. Fr. eiförmig. - Torfwiesen, zerstreut. 4. 4-6.

20.

Wzst. fasrig, Halme 3 kantig, bis $20 \mathrm{~cm}$ h., rasig; Spelzen u. Fr. lanzettförmig. - Torfwiesen (in Torfmoosen), zerstreut. 4. 4. 5.

C. Davalliana $\mathrm{Sm}$.

4. Halme rund, 5-15 cm h., Narben 2, Spelzen u. Fr. lanzettförmig; letztere endlich zurückgeschlagen. - Torfwiesen, zerstreut. 4. 4. 5.

C. pulicáris L.

Halme 3 kantig, 8-10 $\mathrm{cm}$ h., Narben 3, Spelzen eiförmig, Fr. eilanzettförmig, immer aufrecht. - Kalkfelsen der Alpen $(1900-2250 \mathrm{~m})$, auch im Gesenke. 4. 6. 7.

C. rupestris All.

5. (1, b.) Narben 3, Ährchen an d. Spitze männl., in ein längliches dunkelbraunes Köpfchen zusammengedrängt. Halm rund, 5-19 $\mathrm{cm}$ h. Alpen, an kräuterreichen Stellen $(1900-2560 \mathrm{~m})$. 4. 7. S.

Narben 2.

6. a) Ährchen an d. Spitze männl., am Grunde weibl. C. crirvula All.

b) Ährchen an d. Spitze weibl., am Grunde männl.

c) Obere u. untere Ährchen der $2.5-6.2 \mathrm{~cm}$ l, oft gelappten, rostbraunen Ähre ganz weibl., mittlere ganz mä̈nnl. Halme $0 \cdot 30-1 \mathrm{~m}$ h. Sumpfwiesen in B., Mh., Oe., zerstreut. 4. 6. 7. C. disticha Huds. 286

7. Wrst. kriechend, Auslänfer treibend, Halme rundlich, bis $15 \mathrm{~cm}$ h., am Ende d. Ausl. gebüschelt, Bl. sehr schmal. Ährchen ein längliches 
Köpfchen bildend, - Sandige Triften in B., Mh., Noe., zerstreut. 4. 4.5.

C. stenophýlla Whlbg.

Wrzt. fasrig, ohne Ausl.; Fr. eiförmig, geschnäbelt, Schnabel 2 zähnig, gesägt.

8. Ähre locker, oft unterbrochen, gelappt, aus Ährchen od. Ährchenknäueln bestehend.

Ährchenknäuel in eine zuletzt überbängende, $5-20 \mathrm{~cm}$ l. Rispe gruppiert, $\mathrm{Fr}$. griunlichbraun; Halme 3 kantig mit flachen Seiten, 0.30-1.30 $\mathrm{m}$ h. - Nässe, moosige Sümpfe, zerstreut. 4. 5.

C. paniculata $\mathrm{L}$.

9. Fr. griin, planconvex, meist spærrig (oft morgensternartig) auseinander stehend. Halme scharf, 3 kantig.

10.

Fr. braun, aufrecht, Bl. schmal lineal, Ähre hellbraun. 11.

10. Halme geflügelt kantig mit concaven Flächen, $0 \cdot 30-1 \mathrm{~m} \mathrm{~h} . ; \mathrm{Bl}$. breit, schneidend scharf; Ähre eilänglich, dicht, gelappt, licht- bis dunkelbraun. - An Ufern, in Gräben. 4. 5. 6.

C. vulpina $\mathrm{L}$.

Variet. $\beta$. n e mor ós a (Rebent.), Halme schmäler geflügelt mit fast ebenen Flächen, Bl. schmäler, Ähre lineal-länglich, unterbrochen, gelblich-grïn bis grünlich-braun. - Sumpfige Laubwälder.

Halme nicht geflügelt, mit ebenen Flächen, $0 \cdot 30-1 m$ h., Bl. schmal Aach; Ähre bleichgrïn. - Auf Wiesen, an Wegen, in Wäldern. 4. 5. 6.

C. muricata L.

Variet. $\alpha$. densa Neilr,, Ähre locker, nicht unterbrochen, ohne Hüllbl. Gemein; - $\beta$. int erru pta Neilr. (C. virens Lam.) Ähre verlängert, unterbrochen. Yerbreitet; $-\gamma$. Pairaei F. Schultz, wie vorige aber Spelzen bräunlich, Fr. reif braun bis schwärzlich. In B. bäufig; - ò. divulsa (Good.). Ähre sehr unterbrochen, schlaff, überhängend, mit borstenförmigen Hüllbl. am Grunde. Siidl. Kronländer.

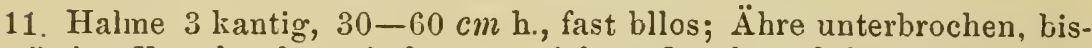
weilen ästig; Fr. glanzlos mit langem nicht geflügeltem Schnabel. - Torfwiesen, zerstreut. 4. 5. 6.

C. parádoxa W.

Halme unten rundlich, nach oben $3 \mathrm{kantig}$, bis $45 \mathrm{~cm}$ h.; Ähre locker od. unterbrochen, bisweilen ästig; Fr. mit kurzem, breit geflügeltem Schnabel. - Sumpfige Wiesen, zerstreut. 4. 5.6. C. tereitiuscula L.

12. (6, b). Wzst. wagerecht umherkriechend, Halme einzeln, Ährchen in eine fast 2 zeilige gelappte $13-25 \mathrm{~mm}$ l. Ähre gruppiert. 13.

Wzst. fasrig, Halme u. Bl. rasig, erstere 3 kantig. 14.

13. Ährchen glänzend weißlichgelb, Bl. sehr lang u. schmal, überhängend, Halme $30-60 \mathrm{~cm}$ h. - In Wäldern auf feuchtem Moosboden. 7. 5. 6.

C. brizoides L.

Ährchen dunkelbraun, Bl. borstenförmig aufrecht, viel kürzer als d. 15-30 cm h. Halme. - Auf Sand- u. Kalkboden, zerstrent. 4. 4. 5.

\section{Schréberi Schrk.}

14. Alle Ährchen weit von einander entfernt, d. untern in d. Achsel eines langen Hiillbl., bleichgrün oder strohgelb; Halme $30-60 \mathrm{~cm} \mathrm{~h}$. Nasse, schattige Wälder, Gebiische, Moore. 4. 5.6. C. remota L.

Ährchen genähert od. wenig entfernt, ohne Hüllbl. 15.

15. Ährchen sehr gen̈̈hert, eine kurze gelappte Ähre bildend. Frschnabel 2 zähnig. 
Ährchen getrennt, in unterbrochener traubiger $\ddot{h} r e$; Fr. grün. 17.

16. Fr. planconvex, schmal geflügelt, mit gezälınten Schnabelrïindern. Ährchen eiförmig, bräunlich, fจ.t 2 zeilig; Halme $15-30 \mathrm{~cm} \mathrm{~h}$. - Feuchte Wiesen u. Triften. 24.6.7.

C. leporina L.

Variet. $\beta$. a rg yroglóchin (Horn.) Ährchen weißlichgrün od. strolhgelb. Zerstreut. $-\gamma$ ovalis (Good.) Ährchen in ein eiförmiges Köpfchen zusammengedrängt. In 0 e.

Fr. planconvex, nicht geflügelt mit plattem Schnabel. Ährchen rundlich, hellbraun, in länglicher Ähre. Halme bis $15 \mathrm{~cm} \mathrm{~h}$. - Granitalpen, auf Grasplätzen $(1580-2600 \mathrm{~m})$. 4. 7. 8. C. lagopina Whlbg.

17. Fr. morgensternförmig von einander stehend, eilanzettförmig, mit 2 zähnigem Schnabel; Ährchen (3-4) grün und braun gescheckt; Halme $15-30 \mathrm{~cm} \mathrm{~h}$. - Sumpfwiesen. 4. 5. 6. C. echinata Murr.

Var. $\beta$. grypos Schk. Fr. wenig abstehend. Schnabel einwärts gebogen. Alpen.

Fr. aufrecht, geschnäbelt.

18. Ährchen länglich nd. lineal, lockerbltig, in eine $4-7.5 \mathrm{~cm} \mathrm{l}$. unterbrochene Ähre gruppiert; Spelzen grïn, am Riicken braun. Halme bis $1 \mathrm{~m}$ h. - Sumpfwiesen, zerstreut. 4. 5. 6. C. elongata L.

Ährchen oval, dichtbltig, in 2 zeiliger unterbrochener Ähre. Spelzen weiß gerandet.

19. Ährchen bleichgrün, meist 6, Frschnabel kurz 2 spaltig, Halme 5-11 cm h. - Nasse Wiesen, Sümpfe, Moore. 4. 5. 6. C. canescens L.

Ïhrchen braun und grïn gescheckt, 5-S, Frschnabel tief 2 spaltig, Halme 15-30 cm h. - Sumpfige Grasplätze d. Alpen (auch Mädel wiese im Riesengeb.) 4. 6. 7.

C. Persoónii Sieb.

20. (1, d.) Narben 2, meist nur 1 (bisweilen an der Spitze weibl.) männliche Ȧhre, seltener mehrere.

Narben 3.

21. Fr. lanzettförmig mit breitem plattem, häufig gerandetem 2 zähnigem Schnabel. Ähre sitzend, dunkelbraun; Bl. fadenförmig, lang, Halme $5-15 \mathrm{~cm}$ h., nackt. - Steinige Triften d. Alpen $(1200-1900 \mathrm{~m})$ 4. 7. 8. C. mucronata All.

Fr. ei- od. verkehrt-eiförmig, mit kurzem stielrundem Schnabel. 22.

22. Scheiden aller od. nur der untersten Blt. in ein Fasernetz anfgelöst.

Sclieiden ganz. Spelzen schwarz- oder rothbraun, grïnnervig. 25.

23. Blos d. untersten Scheiden netzfaserig, Halme $15-30 \mathrm{~cm}$ h., Bl. schmal ; Fr. nervenlos. - Nasse Sumpfwiesen, zerstreut. 4. 4. 5.

C. caespitosa $\mathrm{L}$.

Alle Scheiden netzfasrig, Halme u. Bl. $0 \cdot 30-1 \mathrm{~m}$ h., erstere scharf. kantig; Ähren schwarzbraun.

24.

24. Wzst. ohne Sprossen. Männl. Ähren 1-2, weibl. 2-3, aufrecht, sitzend; Fr. längsnervig. - Sümpfe, Wassergräben. 4. 4. 5.

C. stricta Good.

Wzst. weithin Sprossen treibend. Männl. Ähren 2-3, weibl. 3-5, entfernt, untere oft bogig überhängend; Fr. nervenlos. - An Flussufern in $\mathrm{B}, \mathrm{Mh} . \mathrm{n}$. $\mathbf{N} \ddot{0}$.

C. Briekii Wimm. 
25. Unterstes Hüllbl. länger als der ganze Bltstand, männl. Ähren 2-3, weibl. 3-4, untere gestielt, nickend od hängend; Spelzen schwarzbraun; Iralme 0.30-1 $\mathrm{m} \mathrm{h}$. - An Ufern, in Sumpten. 21. 5. C. acuta L.

Unterstes Hïllbl, kürzer als d. Bltstand; weibl. Ahren aufrecht. 26.

26. Fr. verkehrt-eiförmig, längsnervig; mäunl. Ähren 1-2, walz: weibl. 2-4, länglich; Halme $8-30 \mathrm{~cm}$ l., Bl. schmallineal. - Sumpt wiesen. 7. 4. 5.

C. vulgaris $\mathrm{Fr}^{\mathrm{r}}$.

Fr. elliptisch, nervenlos; eine männliche $̈$ hre, weibl. 2-3; Halme $\mathrm{S}-30 \mathrm{~cm}$ h., Bl. breitlineal, starr. - Steinige Gebirgskämme im Riesengeb., Gesenke, d. Alpen. 4. 6-8. C. rigida Good.

27. (20) Endökre nur unten männlich, sonst weiblich, alle übrigen Ähren weibl.

28.

Endähre od. 2-5 obere Ähren ganz männl., d. untern ganz weibl. 31 .

28. Fr. lanzettförmig mit breitem, spaltigem, gesägtem Schnabel. Ährchen 3-5, länglich, glänzend dunkelbraun, aufrecht, unterstes entfernt. Halm 8-30 cm h. - Gerölle d. Alpen. 7. 7. 8. C. fuliginosa Schk.

Fr. elliptisch oder verkehrt eiförmig, ohne oder mit sehr kurzem Schnabel. 29.

29. Ähren $3-\check{\text { J }}$, in ein endständiges Köpfchen zusammengedrängt, länglich, schwarzviolett; Fr. nervenlos. HaIme $75-15 \mathrm{~cm} \mathrm{~h}$. - Trockene Grasplätze d. Alpen $(1700-2200 \mathrm{~m})$. 7. 7. 8 .

C. nigra All.

Ähren gen:ihert, ähren- od. traubenförmig. 30.

30. Ähren 3-5, gestielt, traubig, d. untern zuletzt längend, Spelzen schwarz, Fr. nervenlos. Halme glatt, 15-60 cm h. - Alpen, Riesengeb., Gesenke auf steinigen Triften. 4. 6-8.

C. atrata L.

Var. a terrima (Hppe): ̈̈hren aufrecht, Fr. schwarzviolett, Halme rauh.

Ähren 4-5, obere sitzend, untere gestielt, entfernt, alle aufrecht. Spelzen schwarıbrann mit grünem Rückenstreif; Fr. längsnervig. Halme $30-45 \mathrm{~cm}$ h. - Torfwiesen in B. u. Mh., zerstreut. 4. 4. 5.

\section{Buxbáumii Whlbg.}

31. (27). Fr. ohne od. mit kurzem stielrundem Schnabel.

32.

Fr. in einen berandeten oder zusammengedrückten Schnabel verlängert.

51.

32. Fr. kahl, Ähren mit Hüllblättern od. Hüllschuppen.

33.

Fr. fein behaart (stets 3 seitig). Eine einzige männl. Ähre. 41.

33. Hüllbl. mit grüner Blspreite, dem Halmbl. ähnlich. 34 .

Hiúllbl. als bäutige Scheiden od. Schuppen ausgebildet. 40. $2-3$.

3t. Hällbl. ohne od. mit ganz kurzer Scheide. Männl. Ähre 1, weibl.

Hüllbl. mit langer krautiger od. häutiger halmumfassender Scheide. 37.

35. Weibl. Ähren länglich-walzig, lang gestielt, hängend; Spelzen rostbraun, Halme $15-30 \mathrm{~cm}$ h. 36.

Weibl. Ähren oval od. länglich, kurz gestielt, aufrecht; Spelzen hellbraun mit grünem Streif; Halme $15-30 \mathrm{~cm}$ h. - Sumpfige Wiesen und Waldblößen. 4. 5. 6.

C. pallescens L. 
36. Hiillbl. wenig schmäler als d, wirklichen Bl, flach. Fr. nervenlos. - Sumpfige Plätze d. Hochgeb. in B. u. Mh., u. d. Alpen. 4. 7.

C. irrigua $\mathrm{Sw}$.

Huillbl. zart, borstenförmig. Fr. deutlich längsnervig. - Sumpfwiesen, Torfmoore, besond. im Hochgeb.; zerstreut. 4. 5. 6.

C. limosa L.

37. Hüllbl..kurz (das unterste niemals d. oberste Ähre erreichend). Bl. grün.

38.

Hüllbl. lang (das unterste d. oberste Ähre überragend od. erreichend). Männl. u. weibl. Ähren 2-3, letztere walzig, langgestielt, hängend; Spelzen braun. Halme 1 כ $-45 \mathrm{~cm}$ h. sammt Bl. blaugruin (C. glauca Scop.). - Sumpfwiesen, quellige Orte. 4. 6. 7.

C. flacca Schreb.

38. Scheiden d. Hüllbl. 10-13 $\mathrm{mm}$ l., weibl. Ähren 2-3, gestielt, aufrecht, entfernt, lockerblütig; Spelzen rothbraun mit grünem Streif, Fr. nervenlos. Halme $15-45 \mathrm{~cm}$ h. - Sumpfwiesen. 4. 5.6. C. panicea L.

Scheiden 2.5-5 cm 1. Weibl. Ähren 2-5, Spelzen braun, Bl. flach. 39.

39. Halme $30-45 \mathrm{~cm} \mathrm{~h}, \mathrm{Bl}$. bis $8 \mathrm{~mm}$ br., gewimpert. Weibl. Ahren lineal. - Laubwälder, zerstreut. 24. 4. 5.

C. pilosa Scop.

Halme $0.60-1.25 \mathrm{~m}$ h., Bl. $8-16 \mathrm{~mm}$ br., kahl. Weibl. Ähren waleenförmig, bis $20 \mathrm{~cm}$ l., hängend. - Wälder, zerstreut. 4. 5. 6.

C. péndula Huds.

40. (33) Hüllbl. sind eilanzettförm., breit häutig gerandete, in eine grüne Spitze auslaufende Schuppen. Weibl. Ảhren 1-2, unter der männl. sitzend, fast kuglig. Halme 5-20 $\mathrm{cm}$ h. Wzst. kriechend. - Heideboden, Kiefernwälder; zerstreut. 4. 4. 5. C. supina Whlbg.

Hiillbl. nur als weißhäutige glänzende Scheiden ausgebildet. Weibl. Ähren 1-2, lockerblütig, lang gestielt; Spelzen glänzendweiß. Halme 30 bis $80 \mathrm{~cm} \mathrm{h.} \mathrm{-} \mathrm{Auf} \mathrm{trocknem} \mathrm{Kalkboden,} \mathrm{zerstreut.} \mathrm{4.} \mathrm{4.} \mathrm{5.}$

C. alba Scop.

41. (32) Hüllbl. ohne od. mit sehr kurzer Scheide.

42.

Unterstes Hüllbl. mit langer Scheide od. alle nur als Scheiden entwickelt.

48.

42. Unterste weibl. Ähre auf langem, grundständ. Stiel, obere $(2-3)$ kurz gestielt, d. männl. Ähre ganz nahe. Hüllbl. sehr kurz, Halme $30 \mathrm{~cm}$ hoch. - Auf Kalkboden in Oe., zerstreut. 7. 5. 7. C. Halleriana Asso.

Alle Ähren nahe bei einander an d. Spitze d. Halmes.

43.

43. Weibl. Ähren 2-4, sitzend, mit d. männl, eine Ahre od. ein Köpfchen bildend. Hüllbl. sehr kurz od. schuppenförmig. Halme $7 \cdot 5-25 \mathrm{~cm}$ hoch.

44.

Weibl. Ähren 2-3, getrennt od. ziemlich entfernt, aufrecht. Hüllbl. deutlich, grün.

46.

44. Wzst. kriechend, mit Ausläufern. Halme am Grunde mit blutrothen Scheiden. Ähren länglich, Spelzen rostbraun, abgerundet. - Trockener Heideboden, zerstreut. 4. 4. 5.

C. ericetórum Poll.

Wzst. fasrig, ohne Ausl, dichte Rasen bildend.

45.

45. Ähren in eine unterbrochene Ähre gruppiert, weibl. eiförmig. kuglig. Spelzen spitz, lichtbraun. Halme zart, meist bogig. - Trockener Sandboden. 2. 4. 5.

C. pilulifera $\mathbf{L}$. 
Ähren in ein gelapptes Köpfchen zusammengedrängt, weibl, eiförm.; Spelzen schwarzbraun. Halme aufrecht. - Trockne, grasige Hügel; zerstreut. 4. 4. 5.

C. montana $\mathrm{L}$.

46. (43) Halme scharf 3 kantig, rauh, $15-30 \mathrm{~cm}$ h., weibl. Ähren kurz walzig, untere entfernt; Spelzen braun, grün gelielt, Fr. dicht filzig. Moor-, Kalk- u. Gypsboden, zerstreut. 4. 5. 6.

C. tomentosa L.

Halme stumpfkantig, glatt. Spelzen rostbraun mit grünem Streif. Fr. zerstreut beharart.

47.

47. Wzst. mit Ausläufern. Halme nackt, erst kürzer als d. Bl., zuletzt $S-30 \mathrm{~cm}$ h.; Ähren kurz, länglich. - Trockne Grasplätze u. Hügel. 4. 3. 4 .

C. praecox $\mathrm{L}$.

Wzst. ohne Ausl., Halme nackt, fadenförmig, anfangs kurz, anfrecht, zuletzt bis $45 \mathrm{~cm} \mathrm{~h}$., niedergebogen; Bl. sehr lang, schmallineal. (C. longifolia Ilost., C. polýrrhiza Wallr.). - In Wäldern, zerstreut. 4. 4. 5.

C. umbrosa Host.

4S. (41) Unterstes Hüllbl. mit langer Scheide und grüner Spreite. C. umbrosa.

Alle Hüllbl. sind häutige, glänzende Scheiden ohne grüne blattförmige Spreite.

49. Scheiden bräunlichweif. Weibl. Ähren 2-3, kl., sehr entfernt; Spelzen groß, weißhäutig; Bl. länger als die $5-10 \mathrm{~cm}$ h. Halme, zurückgekrümmt. - Dürrer Kalkboden. 4. 3. 4.

C. huimitis Leyss.

Scheiden grünlich-rothbraun bis purpurroth. Weibl. Ähren 2-4, gestielt, traubig od. doldig beisammen an d. Spitze d. Halmes. Spelzen mit grünem Streif.

50 .

50. Ähre eine fingerförmige Doldentraube bildend. Spelzen strohgelb od. röthlich, weißrandig. Halıne 5-10 cm h. - Laubwälder. 4. 4. 5.

C. ornithópoda W.

Ähren traubig, lockerblütig; Spelzen rost- od. purpurbraun, weißrandig, Haime 8-15 cm h., seitlich um die mittelständ. Bltrosette. Wälder, zerstreut. 4. 4. 5 .

C. digitata L.

51. (31) Fruchtschnabel planconvex, 2 zähnig, Zähne gerade vorgestreckt. stehend.

Fruchtschnabel zusammengedrüclit, tief 2 spaltig, Zähne auseinander

52. Hüllbl. d. Halmbl. ähnlich, ohne od. (das unterste) mit sehr kurzer Scheide.

Hüllbl. (wenigstens das untere) mit röhriger Scheide.

53.

53. Fr. eiförmig, zusammengedrückt 2 seitig, längsnervig. Spelzen lanzettlich, spitz od. begrannt (C. Kochiana DC.), purpurbraun, weißgerandet; weibl. Ähren 3-4, entfernt, aufrecht; Halme bis $1 \mathrm{~m}$ h., $3 \mathrm{kantig}, \mathrm{Bl}$, breit. - Sümpfe, Ufer. 4. 5. 6.

C. acutiformis Ehrh.

Fr. eikegelförmig aufgedunsen, gerundet-3 seitig. Männl. Ähren 2 bis 5 , kastanienbraun, weibl. 2-5, gestielt, aufrecht, mit hellbräunl. Spelzen. Halme $0.60-1.30 \mathrm{~m}$ h., scharf 3 kantig, Bl. schilfartig. -- Ufer. 4. 5. 6.

$$
\text { C. ripária Curt. }
$$

54. Fr. aufrecht od, aufrecht-abstehend; mit od. ohne Nerven. 55.

Fr. sternförmig auseinander stehend, erhaben gerippt, lang geschnäbelt. 
55. Fr. nervenlos od. undeutlich längsnervig.

Fr. deutlich längsnervig, meist gerippt.

56. streif.

56. Spelzen schwarz- od, rostbraun mit grünem od. hellem Rücken-

Spelzen weiß mit grïnlichem Rückenstreif.

61.

57. Ähren glänzend schwarzbraun, länglich, weibl. 3-4, gestielt nickend, unterste mit langscheidigem Hiillbl. Halme $15-40 \mathrm{~cm} \mathrm{h.}-\mathrm{Ge}-$ rölle d. Alpen, $(1260-1900 \mathrm{~m})$. 2. 7. 8 .

C. frígida Alt. blütig.

Ähren hellrostbraun od. bräunlichweiß, weibl. schmächtig, locker-

58. Bl. zurückgekrümmt, kurz, starr, in dichter Rosette. Halme 5 bis $20 \mathrm{~cm}$ h., weibl. Ähren $2-3$ aufrecht, Hüllbl. fast nur Scheiden. - Kalkalpen (1260-1900 m), an Felsen. 4. 6. 7 .

C. firma Host. Bl. aufrecht, wenig steif, in lockerem Rasen; Hiillbl. mit blartige
Spreite. Bl. aufrecht, wenig steif, in lockerem Rasen; Hüllbl. mit blartiger
Spreite.

59. Halme fast haardiinn, $8-20 \mathrm{~cm}$ l., den Bl. fast gleichlang. Weibl. Ahren 2-3, an haarfeinen stielen hängend. - Alpen, Riesengeb., Gesenke, auf Triften. 4. 6. 7.

C. copillaris $\mathrm{L}$.

Halme 15-45 cm h., viel lïnger als die Bl,; weibl. Ähren 2-3, dünn walzig, lockerblütig, gestielt, unterste entfernt.

60. Spelzen schwarzbraun, Fr. schmutzig-grün, gekrümmt; unterste Ähre stets aufrecht. - Alpen $(1260-1900 \mathrm{~m})$, an grasigen Plätzen. 7. $6-8$.

C. sempervirens Vill.

Spelzen rostbraun, Fr. braun; unterste Ähre oft hängend. - Kalkalpen, an steinigen Plätzen (bis $2000 \mathrm{~m}$ ). 4. 6. 7. C. ferruginea Scop.

61. Weibl. Ähren $2-5$, bis $5 \mathrm{~cm}$ l, sehr lang gestielt, zuletzt hängend, entfernt. Fr. grün. Halme $30-60 \mathrm{~cm}$ h. - Laubwälder. 4. 5. 6. C. silvática Huds.

Weibl. Ähren 3-4, obere genähert, fast sitzend, unterste entfernt, eingeschlossen-gestielt, Fr. braun; Halme $10-30 \mathrm{~cm}$ h. - Sümpfe, an Gräben in M. u. Noe.; zerstreut. 4. 5. 6. C. hordeisichos Vill.

62. (55) Weibl. Ähren lineal, langgestielt, 2-3, entfernt; Spelzen purpur- bis schwarzbraun. Halme $15-30 \mathrm{~cm}$ h., sammt den Bl. zart. Alpen, auf Gerölle. 4. 6. 7. (C. tenuis Host.) C. brachystáchys Schrk.

Weibl. Äbren länglich od. oval, sitzend od. kurz gestielt, aufrecht. 63 .

63. Weibl. Ähren 1-3, eiförmig, wenigblütig, Spelzen grünlich, weiß gerandet; männl. Ähre hellbraun. Halme $15-30 \mathrm{~cm}$ h. - Laubwälder; zerstreut. $4,5.6$.

C. Michélii Host.

Weibl. Ähren 2-3, länglich, gedrungen, entfernt, aufrecht. 64 .

64. Weibl. Ähren sehr entfernt, Spelzen lichtbraun, stachelspitzig. Halme 30-60 cm h. Wzst. ohne Ausläufer. - Torfwiesen. 4. 5. 6.

C. distans L.

Weibl. Ähren wenig entfernt od. die oberen genähert, die unterste entfernt; Spelzen rothbraun, nicht bespitzt. Halme bis $45 \mathrm{~cm} \mathrm{~h}$. Wzst. mit Ausl. - Sumpfwiesen, zerstreut. 4. 5.6. C. Hornschuchiana Hppe。

65. (54.) Frschnabel gerade, halb so lang als d. Fr.; weibl. Ähren $2-3$, fast kuglig, genähert, grünlich-gelb. IIalme $2 \cdot 5-20 \mathrm{~cm} \mathrm{~h}$. Sümpfe, Torfwiesen. 4. 5-9.

C. Oedéri Ehrh. 
Frschnabel abwärts gekrümmt, fast so lang wie d. Fr.; weibl. Aluren ? -3, kuglig-eiförmig, grünlichgelb, traubig; Halme $15-30 \mathrm{~cm}$ h. Sumpfwiesen. 4. 5. 6.

C. flava L.

66. (51) Bl. und Scheiden weichhaarig, männl. und weibl. Ähren 2-4, letztere schr entfernt, gestielt, walzig mit bräunlichen Spelzen. Halme 14-45 $\mathrm{cm}$ h., Bl. breit. Variiert mit fast kahler Bl. und Scheiden (hirtaeformis P.). - Sandboden. 7. 5. 6.

C. hirta L.

Bl. und Scheiden kahl.

67. Fr. filzig behaart, eiförmig; weibl. Ähren 2-3, kurz walzig, sitzend. Spelzen schwarzbraun. Halme $0 \cdot 45-1 m \mathrm{~h}$. Bl. fadenförmig. Sümpfe, Torfmoore. 7.5.6.

C. filiformis $\mathrm{L}$.

Fr. kahl.

68.

68. Männl. Ähre 1, hassgelb, weibl. $3-6$, walzig, grün, lang gestielt und hängend, gen vilej Gräben, Siimpfe. 4. 6. :

C. Pseudocyjérus L.

Männl. u. weibl. $\ddot{B}$ l, $c r$ 2-4, erstere hellbraun, letztere walzig, entfernt. Fr. aufgeblasen-ciförmig, gerippt, gelbgriin. Halme steif, 30 bis $60 \mathrm{~cm} \mathrm{ll}$.

69.

69. Halme scharf 3 kantig, BI. grasgrïn. Unterste weibl. Ähre nickend od. hängend; Spelzen hellbräunlich, Fr. aufrecht-abstehend. - Sümpfe, Ufer. 4. 5. 6.

C. vesicaria $\mathrm{L}$.

Halme stumpfkantig, Bl. bläulichgriin. Weibl. Ähren alle aufrecht, Spelzen gelblichgrün, Fr. horizontal abstehend. - Sümpfe, Gräben, Torfmoore. 4. 5. 6.

C. rostrata With.

\section{Elýna Schrad. (XXI, 3).}

Halme rund, nackt, $15-30 \mathrm{~cm}$ h., Bl. ebenso lang, borstlich; Ähre 13-18 mm l., gelblichbraun. - Grasige Felsabhänge d. Alpen (1900 bis $2500 \mathrm{~m})$. 4. 6. 7.

E. spicata Schrad.

\section{Kobrésia W. (XXI, 3).}

Halme rund, nackt, $20-35 \mathrm{~cm} \mathrm{~h}, \mathrm{Bl}$. viel kürzer, rinnig, Ährchenstrauß rothbraun, bis $18 \mathrm{~mm} \mathrm{l}$. - Wie vorhergehende. 4. 7. 8.

$K$. caricina W.

\section{Heleócharis R. Br. Schlammbinse (III, 1).}

Halme rasig, am Grunde ron röhrigen Scheiden umschlossen.

1. Narben 2, fadenförmig, auf d. ebenfalls fadenförm. Gr.

Narben 3, ebenso, Ahre 2-5 $\mathrm{mm}$ l.. hellbräunlich. Nüsschen gerippt. Halme haarfein, bis $20 \mathrm{~cm}$ h. - An Ufern auf Schlamm, überschwemmten Plätzen. 4. 6-8. $H$. aciculáris $\mathrm{R} . \mathrm{Br}$.

2. Einjährige Faserwurzel, Halme zart, $10-15 \mathrm{~cm}$ h.; Ähre eiförmig, bis $7 \mathrm{~mm}$ l., grijnlichbraun. - Ueberschwemmte Plätze, zerstreut. $7-8$ H. ovata R. Br.

Wagerecht kriechender Wzst. mit Ausläuf. Halme bis $30 \mathrm{~cm}$ h. 3 .

3. Ahre hellrostbraun (selten kastanienbraun), 6-23 $\mathrm{mm}$ l. Halme stark. - Wassergräben, Ufer, Sümpfe. 4. 6-9. H. palustris R. Br.

Ähre schwarz- od. violettbraun, ebenso 1.; Halme schmächtig. Sümpfe, Moorwiesen, zerstreut. 4. 6-8. H. uniglimis Lk. 


\section{Scirpus L. Binse (III, 1 ).}

Ährchen mit mehrreihigen Spelzen. Nüsschen in ein ungegliedertes Schnäbelchen auslaufend.

1. a. Ein Ährchen an d. Spitze des bllosen runden Halmes. 2.

b. Ährchen $1-3$ od. Ährchenbüschel od. Spirre seitlich am meist bllosen Halme.

c. Endständiges Ährchenköpfchen od. Ährchenspirre, stets ron Hüllbl. umringt. Halme beblättert, 3 kantig.

7.

2. Halme starr, dicht rasig, $5-15 \mathrm{~cm}$ h., Ährchen $5 \mathrm{~mm}$ l., wenigblütig, braunroth. - Hochgebirgstorfmoore. 4. 5. 6.

S. caespitosus $\mathrm{L}$.

Halme zart, fadenförmig, nicht rasig, $5-25 \mathrm{~cm} \mathrm{h.,} \mathrm{Ährchen} 3$ bis 5 mm 1., wenigbltig, dunkelbraun. - Nasser Torfboden, zerstreut. 7. 6. 7. S. pauciflórus Lightf.

3. Ährchen länglich od. oval, getrennt von einander. 4.

Ährchen in kuglige Köpfchen zusammengedrängt, diese eiızeln oder in Spirre an d. Seite des bis $1 \mathrm{~m}$ h. Halmes. - Sumpfwiesen in B., Mh., Noe.; zerstreut. 4. 7. 8.

S. Holoschóenus L.

4. Ährchen 1-2, schwarzbraun, 2-7 mm 1., wenig unt. d. Spitze d. zarten, 3-15 cm b. Halmes. - Ueberschwemmte Plätze, Ufer, zerstreut. ๑. 7. 8 .

S. setáceus L.

Ährchen viele, zusammengeknäuelt unter der meist zurückgeschlagenen Spitze des 3 kantigen $0 \cdot 45-1 m \mathrm{~h}$. Halmes. - Stehende Wässer in K., St., Kr.; zerstreut. 4. 7. 8 . S. mucronatus L.

Ährchen gestielt in seitenständiger Spirre.

5. Halme 3 kantig, bllos od. mit 1 Bl., 0.30-1 $m$ h. Ährehen rostbraun. (S. Pollichii Gr. God.) - Überschwemmte Plätze, Wassergräben in Noe. 4. 7. 8.

S. triqueter $\mathrm{L}$.

Halme stielrund, bllos.

6. Halme bis $3 m$ h. und (unten) daumensdick, grasgrün. Ährchen hell rostbraun. Narben 3. - Teiche, Seen. 4. 6-8. Te ichbinse, S. lacustris L.

Halme bis $1.50 m$ h., schmächtig, blaugrün. Ährchen rothbraun. Narben 2. - Sümpfe, an Gräben in B, Mh., Oe.; zerstreut. 4. 6-8. S. Tabernaemontáni Gmel.

7. (1, c.) Ährchen 13-25 mm 1., dunkelbraun, gebüschelt; Büschel langgestielt in einfacher Spirre. Halme $0.30-1 m$ h. - Flussufer, Teichränder. 4. 6. 7.

S. maritimus L.

Variet. compactus (Krock.), ein einziger, endständiger Büschel.

Ährchen 2-8 mm 1., in großer, sehr ästiger Spirre, Halme 0.30 bis $1 m$ b., Bl. br., schilfartig.

8. Ährchen 2-5 $\mathrm{mm}$ 1., bleichgrün od. schwärzlich, gebüsclielt. Waldsïmpfe, Ufer. 4. 6. 7.

S. silváticus L.

Ährchen 3-6 mm 1., schwärzlich, einzeln. Unfruchtbare Halme sich umbiegend, an d. Spitze wurzelnd. - Sumpfwiesen, zerstreut. 4. 6. 7. 
100. Blysmus Fr. Queliriet (II, 1).

Wzst. kriechend, Halme $10-25 \mathrm{~cm}$ h., unten beblättert, stumpfkantig, Bl. gekielt, Ähre rothbraun. - Sumpfwiesen, zerstreut. 4. 7. 8. B. compressus $\mathrm{Pz}$.

101. Rhyuchóspora Vahl. Schnabelbinse (III, 1).

Halme 3 kantig, mit rinnigen, schmallinealen Bl.; Ährchen lanzettlich, $5-7.5 \mathrm{~mm}$ 1. Büschel mit kurzem Hüllbl.

1. Ährchen beim Blühen weißlich, später bräunlich od, röthlich. Halme 15-30 $\mathrm{cm}$ h. Wzst. fasrig. - Sumpfwiesen, Torfmoore. 4. 7. 8 R. alba Vahl.

2. Ährchen beim Blühen rothbraun. Halme $5-25 \mathrm{~cm}$ h. Wzst. kriechend. - Torfwiesen, zerstreut. 4. 6, 7. $\quad R$. fusca R. Sch.

\section{Erióphorum L. Wollgras (III, 1).}

Halme beblättert, Bl. lineal, langscheidig.

1. Eine einzige endständige aufrechte Ähre.

2.

Mehrere gestielte Ähren in endständ. trugdoldiger Spirre.

4.

2. Halme rauh, 3 kantig, beim Blühen $5-8 \mathrm{~cm}$ h., fast nackt. Woll. haare d. 5-8 mm l. Ähre geschlängelt. - Hochgebirgstorfmoore. 4. 4. 5. E. alpinum $\mathrm{L}$.

Halme glatt, nach oben nackt. Wollhaare gerade. 3.

3. Halme 3 kantig, beim Blühen 15, später bis $60 \mathrm{~cm} \mathrm{h.;} \mathrm{bllose}$ Scheiden aufgeblasen, Ähre $13-25 \mathrm{~mm}$ 1. - Gebirgstorfmoore. 4. 4. 5 , E. vaginatum $\mathrm{L}$.

Halme rund, $10-30 \mathrm{~cm}$ h., Scheiden nicht aufgeblasen. Ähre 8 bis $13 \mathrm{~mm} \mathrm{1.} \mathrm{-} \mathrm{Auf} \mathrm{Torfboden} \mathrm{d.} \mathrm{Alpen}(580-1900 \mathrm{~m})$. 4. 6. 7 .

$E$. Scheuchzéri Hppe.

4. (1) Wzst. lang, horizontal kriechend, Halme dünn, bis $45 \mathrm{~cm}$ h., halb nackt, Bl. rinnig, 3 kantig, Ähren 3-4, aufrecht. - Torfmoore, sehr zerstreut. 4. 4. 5 .

E. grácile Koch.

Wzst. nicht kriechend, kurz. Halme $30-60 \mathrm{~cm}$ h., reich beblättert, Ähren $4-7$, zur Frzeit hängend (E. polystáchyum L.). 4. 4. 5 .

5. BI. lineal rinnig; Wollflocken sehr groß, bis $37 \mathrm{~mm} \mathrm{l}$. - Torfwiesen. 4. 5 .

$\boldsymbol{E}$. angustifolium Roth.

Bl. brlineal, flach; Wollflocken nur bis $25 \mathrm{~mm}$ l. - Torfwiesen. 4. E. latifolium Hppe.

\section{Cládium R. Br. Schneidegras (III, 1).}

Wzst. kriechend, Halme steif, 1-2 $m$ h., Bl. rinnig gekielt, an den Rändern und am Kiel fein gesägt. Ährchen rostbraun. - Sumpfwiesen, Ufer in B., Noe., T., Sz.; sehr zerstreut. 4. 7. 8. C. Mariscus R. Br.

\section{Schoenus L. Knopfgras (III, 1).}

Halme dicht rasig, rund, am Grunde bescheidet (oberste Scheide mit linealem Bl.), sonst nackt, $15-30 \mathrm{~cm}$ h. Ährchen undeutlich 2 zeilig.

1. Köpfchen aus 5-10 Ährchen bestehend, glänzend schwarzbraun. Halme nicht gedreht. - Torfwiesen, zerstreut. 2. 5. 6. 
2. Köpfchen nur aus 2-4 Ährchen bestehend, schwarzbraun. Halme am Grunde etwas gedreht. - Torfwiesen in B., 0e. u. d. Alpenländern; sehr zerstreut. 4. 5. 6.

S. ferrugineus L.

\section{Cypérus L. Cyperngras (III, 1).}

Ährchen sehr deutlich 2 zeilig, Halme beblättert.

1. Halme stumpfkantig. Narben 2.

2.

Halme scharf 3 kantig. Narben 3.

2. Wzst. kriechend, Halme $30-60 \mathrm{~cm}$ h.; Ährchen rostbraun, in großer zusammengesetzter Spirre. - Sümpfe im siidl. T. 4. 7. 8.

C. Monti L.

Wzst. fasrig, Haline $2 \cdot 5-30 \mathrm{~cm}$ h. zart; Bl. 1-2, schmal rinnig, am Grunde od. keine.

3.

3. Älurchen grünlichroth, zwischen den Hüllbl. sitzend, einen seitlich gerichteten Büschel bildend. - Salzige Sumpfstellen bei Wien. ๑. 8-10. C. pannonicus Jacqn.

Ährchen gelblich, gestielt, zu 3 bis vielen in einfacher Spirre. Sumpfwiesen, nasser Sand- und Torfboden, zerstreut. ๑. 8. 9.

\section{C. flavescens L.}

4. (1) Faserwurzel. Halme $2 \cdot 5-15 \mathrm{~cm}$ h., oft nackt; Ährchen schwarzbraun (seltener grünlich: var. virescens), in einem Köpfchen od. einer Spirre. - Nasser Sand- u. Moorboden, zerstreut. ๑. 8. 9.

$$
\text { C. fuscus } \mathrm{L} \text {. }
$$

Kriechender Wzst. Halme 15-30 $\mathrm{cm}$ h., unten bebl. 5.

5. Ährchen zahlreich, lineal, rostroth, in kuglige sitzende oder gestielte Büschel vereinigt. - In Gräben, Sümpfen bei Graz und Bozen. 4. 7. 8 .

C. glomeratus L.

Ährchen lineal-lanzettlich, rothbraun, bis $15 \mathrm{~mm}$ l, gebüschelt auf langen und kurzen Stielen in lockerer Spirre. - Sümpfe b. Baden (Wien) und im sïdl. T. 4. 7. 8.

C. longus $\mathrm{L}$.

\section{Fam. XVI. Irídeae. Schwertilienartige.}

\section{Crocus L. Safran (III, 1).}

Zwiebelknollen mit fasriger Schale. Blt. und Bl, grundständig.

1. Blumen violett od, weiß, Narben gelbrotb.

Blumen dottergelb. - Gemeine Zierpflanze aus dem Orient, 4. 3. 4. C. líteus Lam.

2. Narben trichter- od. trompetenförmig.

Narben keulenförmig, Blumen violett. - Aus dem Orient. In Noc. angebaut. 4. 9, 10. Gemeiner.Safran, C. sativus L.

3. Narben länger als die Staubb. Blumen 'violett, selten weiß, 3 bis $4.5 \mathrm{~cm}$ l. (ohne Röhre). - Gebirgswiesen in Mh., Yoe. u. Kr. (massenhaft b. Laibach), häufig in Gärten. 4. 4.

C. vernus Wult.

Narben kürzer als die Staubb. Blumen weiß, $2 \cdot 5-3.5 \mathrm{~cm} \mathrm{l}$. - Gebirgswiesen in den Alpenländern, auch in Gärteu. 2. 4.

C. albiflórus Kit. 


\section{Gladíolus L. Sehwertel (III, 1).}

Zwiebelknollen mit fasriger Haut. St. bebl., Bl. schwertförmig; Blt. in einseitiger Traube, purpurroth. St. $30-60 \mathrm{~cm} \mathrm{~h}$.

1. Blumen $3.7 \mathrm{~cm}$ l., Kapsel oben eingedriickt. - Zierpfl.; auch auf Wiesen in 00e. 4. 5. 6. Siegwurz, G. communis L.

Blumen $25 \mathrm{~mm}$ l.

2. Traube 1 reihig, Narben spatelförmig.

Traube 2 reihig, Narben eiförmig mit linealem Stiel. - Feuchte Wiesen in K. u. Kr.; zerstreut. 4. 5. G. illyricus Koch.

3. Traube lockerbltig, Kapsel oben abgerundet, Faserbülle d. Knollen netzförmig. - Sumpfige IViesen in Mh, Noe., K., Kír.; zerstreut. 4. 5.6. $G$. paluster Gaud.

Traube dichtbltig, Kapsel oben eingedrückt, Faserhiülle parallelfasrig: - Feuchte Wiesen in Sch., Mh., B.; zerstreut. 7.6.

$$
\text { G. imbricatus L. }
$$

\section{Iris L. Schwertlilie (III, 1).}

Wagerechter, gegliederter, knolliger Wzst.; St. bebl., grundständ. Bl. schwertförmig od. lineal, reitend; Blt. von Scheiden umliüll, meist traubig.

1. Äußere Perigonbl. mit Bart, Bl, schwertförmig. 2.

Äußere Perigonbl. bartlos.

2. St. 1-2 bltig, so lang od. kürzer als d. grundständ. Bl. 3.

St. mehrbltig.

3. Bl. sichelförmig, länger als d. 1 bltige $5-10 \mathrm{~cm}$ h. St. Blume violett od. blau, selten gelb od. weiß. - Trockene, grasige Hügel, Mauern in Mh., 0e., K., T. 7. 4. 5.

I. primila L.

Bl. gerade, so lang als d. 2 bltige $5-10 \mathrm{~cm}$ h. St. Blumen gelb, violett geadert. - Sonnige Hügel im südl. Mh. 4.4.

I. arenária W. Kit.

4. Blume gelb, groß, äußere Bl. violett geadert. St. $30-60 \mathrm{~cm}$ h. Grasige Hügel in B., Mh., Oe., K.; zerstreut, auch in Gärten. 4. 5. c.

\section{I. variegata $\mathrm{L}$.}

Blumen (wenigstens äußere $\mathrm{Bl}$.) violett od. blau.

5. Bart gelb, St. stets länger als d. grundst. Bl.

Bart hellviolett, St. $25-50 \mathrm{~cm}$ h., zur Bltezeit so 1., wie d. grundst. BI., später viel kürzer; Bltscheiden krautig (I. bohemica Schm.). - An Kalk- u. Basaltfelsen in B. u. Mh., zerstreut. 4. 5 .

\section{I. nudicaulis Lam.}

6. Bltscheiden ganz trockenbäutig, Blumen groß, hellblau. St. 0.60 bis $1 \mathrm{~m}$ h. - Zierpfl, wild im südl. T. 4. 5. 6.

Bltscheiden halbkrautig, Blumen dunkelviolett.

I. pállida Lam.

7. Blumen sehr groß (bis $12 \mathrm{~cm} \mathrm{l.} \mathrm{u.} \mathrm{br.),} \mathrm{geruchlos.} \mathrm{St.} 30-60 \mathrm{~cm} \mathrm{~h}$. - Auf Felsen u. Manern in Ii.; gemeine Zierpfl. 4. 5.

\section{I. germanica L.}

Blumen bis $7.5 \mathrm{~cm}$ br., nach Flieder duftend, St. $40-60 \mathrm{~cm}$ h. Felsen u. Mauern in Oe. u. B., zerstreut, 4. 6.

I. sambuicina L.

8. (1). Blumen goldgelb, Bl. breit lineal, St. bis $1 \mathrm{~m}$ h. - In Süm. pten, an Ufern. 4. 6. 
Blumen violett od. lila, Bl. schmal lineal.

9. St. 2 schneidig, viel kürzer als d. Bl., 15-30 $\mathrm{cm}$ h. - Wiesen u. kräuterreiche Hügel in B., Hh., Oe., K.; zerstreut, 4. 5. 6.

I. graminea L.

St. rund, länger als d. Bl., 30-60 $\mathrm{cm}$ h. - Sumpfige Wiesen, zerstreut; auch Zierpfl. 4. 5. 6.

I. sibirica $\mathrm{L}$.

\section{Fam. XVII. Amaryllideae, Amaryllisartige.}

\section{Narcissus L. Narzisse (VI, 1).}

Blume langröhrig mit 6 blättr. ausgebreitetem Saum. Honigbecher. Schaft $15-30 \mathrm{~cm}$ h.

1. Honigbecher sehr kurz, napfförmig, Saum weiß.

Honigbecher lang, röhrig od. glockig, Saum gelb.

2. Schaft 1 bltig, Honigb. gelb, roth gerandet. - Wiesen d. Alpen. länder, zerstreut; gemeine Zierpfl.

N. poëticus L.

Schaft 2 bltig, Honigb. gelb, weiß gerandet. - Wiesen in St. u. T., zerstreut; auch in Gärten. $N$. biflórus Curt.

3. Honigb. langröhrig, Perigonröhre weit, gelb. - Bergwiesen d. Alpenländer, anderwärts in Grasgärt. verwildert; gemeine Zierpf. 2. 4. 5. N. Pseudonarcissus L.

Honigb. glockig, Perigonröhre eng, grünlich. - Wiesen u. Grasgärten um Wien u. in T., auch als Zierpfl. cult. 4. 4. 5.

\section{$N$. incomparábilis Curt.}

\section{Leucójum L. Knotenblume (VI, 1).}

Blumen nickend, glockig, ohne Honigbecher, weiß mit grünlichem Fleck vor d. Spitze d. Bl.

1. Schaft 1- (selten 2-) bltig, $10-30 \mathrm{~cm}$ h. - Laubwälder, feuchte Wiesen; verbreitet. 4 . 3. 4 .

Großes Schneeglöckchen, Märzbecher, L. vernum L.

2. Schaft 3-5 bltig, $30-45 \mathrm{~cm}$ h. - Feuchte u. sumpfige Wiesen in Mh., Noe, St., Kr.; zerstreut. 4. 5. 6.

L. aestivum L.

\section{Galánthus L. Schneeglöckchen (VI, 1).}

Blume glockig, weiss, d. 3 äußeren Bl. mit grünem Fleck, d. 3 inneren grün gerandet. Schaft $1 \mathrm{bltig}, 10-30 \mathrm{~cm}$ h. - Feuchte Wiesen und Laubwälder, zerstreut; gemeine Zierpfl, oft verwildert in Grasgärten. 4. $2-4$. $G$. nivalis $\mathrm{L}$.

\section{Fam. XVIII. Alismáceae, Froschlöffelartige.}

\section{Alísma L. Froschlöffel (VI, 4).}

Sumpf- und Wasserpfl. Bl. gestielt, netzadrig. Blt. quirlständig mit bllosem Schaft. Schließrüchtchen.

1. Bl. langgestielt, mit herzeiförmig bis lanzettlicher Spreite.

Blbl. weiß od. röthlich, Schaft $30-60 \mathrm{~cm}$ h. aufrecht. - Wassergräben, Ufer. 4. 6-9. 
Var. aquáticum (A. graminifolium Ehrh.): Bl. untergetaucht, länglich od. lineal. - In Teichen, Bächen; zerstreut.

2. Bl. kürzer gestielt, kl, herzeiförmig, Schaft bis $30 \mathrm{~cm}$ h. - In Teichen und Seen in St. u. K.; zerstreut. 7. 7. 8.

A. parnassifolium $\mathrm{L}$.

\section{Sagittaria L. Pfeilkraut (XXI, 5).}

Bl. langgestielt mit pfeilförm. Spreite. Blt. quirlständig an bllosem 0.30-1 m 1. Schaft, Blbl. weiß mit rothem Nagel. - Gewässer. 4. 6-8. S. sagittaefolia L.

\section{Fam. X1X. Butómeae. Wasserviolen.}

114. Bútomus L. Wasserviole (IX, 3).

Blt. viele in einfacher Dolde auf $0.30-1.25 \mathrm{~m}$ h. Schaft, weiß und rosenroth. Bl. l., lineal-3 kantig. Balgkapseln. - Gewässer. 4. 6. 7.

B. umbellatus L.

\section{Fam. XX. Juncagineae. Blumenbinsen.}

115. Scheuchzeria L. (VI, 3).

Wzst. kriechend, gegliedert, St. $10-20 \mathrm{~cm}$ l., Bl. lineal; Blt. in armblütiger 'Traube, grünlichgelb. Kapseln. - Torfmoore, Torfwiesen; zerstreut. 4. 6. 7 .

Sch. palustris L.

\section{Triglóchin L. Dreizack (VI, 3).}

Wzst. fasrig, Bl. grundständig, lineal, halbstielrund, Schaft bis $60 \mathrm{~cm}$ lang, mit schmächtiger Blttraube, Blt. kl., gelblich. - Sumpfige Wiesen, Moore; zerstreut. 4. 5. 6. Tr. palustre L.

\section{Fam. XXI. Hydrocharideae. Nixkräuter.}

\section{Hydrócharis L. Froschbiss (XXII, 8).}

St. fluthend, Bl. langgestielt mit nierenförmig-runder, schwimmende» Spreite; Blt. langgestielt, weiß. - Stehenàs Gewässer in B. u. Wh.; zerstreut. 4. 7. 8 . H. Morsus ranae $\mathrm{L}$.

\section{Stratiótes I. Wasserscheere (XXII, 10).}

Bl. in schwimmender Rosette, brlineal, $3 \mathrm{kantig}$, dornig gezähnt; Bl. weiß, männl. gestielt, weibl. sitzend. - Stehende Wässer in Uh. und Iӧ ; zerstreut. 4. 7. 8.

\section{Fam. XXII. Orchídeae. Urchisartige.}

\section{Schliissel der Gattungen.}

1. Bllose nicht grüne Pfl., St. beschuppt, Blt. ährig. Pf. mit beblättertem St., Bl. grïn.

2. Eltähre walzig, vielbltig, Lippe verkehrt herzförmig. Neottia (132). 
Bltähre wenig-bltig, Lippe seicht 3 lappig Corallorrliza (135)

3. Lippe aufgeblasen, hohl, schuhförmig; Perigonbl. 4, kreuzweis. Cypripedium (136).

Lippe flach od. rinnig, 3 äußere, 2 innere Perigonbl.

4. Lippe rückwärts in einen hohlen Sporn od. Sack verlängert. 5.

Lippe ohne Sporn od. Sack.

5. Frknoten seilartig gedreht.

Frkn. nicht od. undecitlich gedreht.

6. Lippe ganz, lineal, mit l. dünnem Sporn Platanthera (124).

Lippe getheilt, meist 3 lappig.

7. Lippe mit 1. riemenförnigem, gedrehtem, herabhängendem Míttellappen, viel länger als $d$. Perigon. Hymantoglossum (122).

Lippe anders, nicht od. wenig länger als d. Perigon.

8. Blt. grün, Lippe lineal, 3 zähnig, Sporn kurz. Coeloglossum (123). Blt. purpurn, weiß od. bunt; Lippe 3 lappig.

9. Sporn kürzer als d. Frkn.

Sporn viel länger als d. Frkn, fadenförmig.

10. Sporn kegelförmig od. sackig.

Sporn dünn walzig, Blt.kl., grünlichweiß. Gymnadenia albida 120).

11. Bltähre walzig.

Bltähre pyramidal, kegelförmig bis kuglig.

12. (5) Lippe ziemlich lang gespornt.

Lippe mit kurzem Sack.

13. Lippe ganz.

Lippe 3 lappig, Blt. sehr kl.

14. Lippe fast rhombisch, Blt. ungekehrt.

Lippe kurz, rundlich; Blt. nicht umgekehrt
Gymnadenia (121).

Anacamptis (120).

Orchis (119 z. Th.).

13.

14.

Herminium (128).

Nigritella (125).

Goodyera (133).

15. (4) Lippe 2 gliedrig, hinteres Stiick ausgehöhlt, vord. glatt. 16. Lippe nicht gegliedert. rundlicb.

16. Frkn. nicht gedreht, ab. auf seilförmig gedrehtem Stiel; Lippe

Epipactis (130).

Frkn. gedreht, sitzend; lippe 3 lappig. Cephalanthera (129).

17. Lippe auf $d$. Oberfläche mehr od. weniger sammtig-filzig.

Ophrys (127).

Lippe kahl, platt od. rinnig.

18. Frkn. nach dem Verblühen gedreht, Lippe rundlich, seicht dreilappig; alle Perigonbl. in einen Helm zusammengekrümmt

Chamaeorchis (126).

Frkn. nie gedreht.

19. Lippe lineal, 2 spaltig, platt.

Lippe am Grunde rinnig, mit gekräuseltem Rande, aufgerichtet, von d. Perigonbl. verdeckt.

Spiranthes (134).

119. Orchis L. Knabenkraut, Kuckucksblume (XX, 1).

Kräuter mit 2 Knollen. Blt. in Ähre, jede mit Deckbl.

1. Knollen eiförmig, kuglig od. länglich.

Knollen hand-od. fingerförmig od. in 2 Schenkel getheilt. 
2. Deckbl. 3-5 nervig, Blt. purpurroth, selten weiß in lockerer Ähre. St. $15-30 \mathrm{~cm}$ h., Bl. lineal-lanzettlich (C. palustris Jequ). Sumpfwiesen in B., Mh., 0e., K., zerstreut. 4. 5. 6.

O. laxiflóra Lam.

Deckbl. (wenigstens die oberen) 1 nervig.

3. a) Lippe breit und liurz, 3 lappig.

3.

b) Lippe tief 3 spaltig; Mittelzipfel länglicl.

c) Lippe 3 theilig, Mittelstïck spaltig.

4.

7.

8.

4. Blt. blassgelb in eiförmiger Ähre. St. $15-30 \mathrm{~cm} \mathrm{~h}, \mathrm{Bl}$. elliptischlanzettlich. - Bergwiesen und lichte Wälder auf Kalk in Mh., Oe., St., Ui., Kr.; zerstreut. 4. 4. 5.

O. pallens $\mathbf{L}$.

Blt..purpurn, roth und grün od. weiß und grïn gescheckt.

5. Äußere Perigonbl. helmförmig zusammengeneigt. Blt. purpurn od. weiß und grün, in eiförmiger Ähre. Bl. lanzettlich. - Trockne Wiesen. 4. 4. 5.

O. Mório L.

Äußere Perigonbl. auseinander stehend.

6.

6 Ähre vielbltig, walzig, lang; Sporn wagrecht od. aufsteigend. Blt. hell purpurn, St. bis $45 \mathrm{~cm}$ 1., roth punktiert; Bl. länglich-lanzettf. - Bergwiesen, lichte Gehölze; zerstreut. 4. 5. 6.

O. máscula L.

Var. speciosa (Host.). Perigonzipfel lang zugespitzt. — In Oe.

Ähre wenigbltig; Sporn fast senkrecht, BIt. purpurn; St. bis $30 \mathrm{~cm}$ hoch, ungefleckt, Bl. elliptisch. - Bergwiesen in Noe., Sz., T.; zerstreut. 4. 6. 7 .

O. Spitzelii Saut.

7. $(3, b)$ Blt. grün, braun und purpurn gescheckt, nach Wanzen duftend, in walziger Ähre; St. $15-30 \mathrm{~cm} \mathrm{h.} \mathrm{-} \mathrm{Feuchte} \mathrm{Wieselı,} \mathrm{zer-}$ streut. 4.6 .7 .

0 . corióphora $\mathrm{L}$.

Blt. rosenroth, kl, in kugliger od. länglicher $̈$ hre. St. $30-50 \mathrm{~cm}$ hoch. - Bergwiesen d. Erz- u. Riesengeb., d. Sudeten u. Alpen. 4. 6. 7. O. globosa L.

8. (3, c) Zwischen d. beid. Lappen des Mittelstuicks $1 \mathrm{kl}$. Zahn. 9.

Kein Zahn. Lippe weiß, purpurn gefleckt, ihre Lappen abgestutzt.

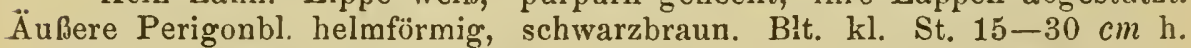
- Trockne Bergwiesen. 4. 5. 6

O. ustulata L.

9. Mittellappen d. rosen- od. purpurrothen, am Grunde dunkler gefleckten Lippe breit verkehrt-herzförmig mit Zahn in der Ausbuchtung, Seitenlappen kurz lineal. Äußere Perigonbl. auseinander stehend, spitz, rosa. St. 25-30 cm h. - Trockne Wiesen auf Kalk, zerstreut. 4. 5. 6.

0 . militaris $\mathrm{L}$.

Mittellappen d. Lippe tief gespalten, seine Zipfel und d. Seitenlappen lineal, parallel, abgestutzt. Äußere Perigonbl. helmförmig.

10.

10. Blt groß, Halm grünlich- od. dunkelroth, Lippe weiß bis rosa, purpurn gefleckt. Ähre eiförmig, St. 30-60 cm h. - Laubwälder, Waldwiesen auf Kalk; zerstreut. 4.6. 7.

O. purpirea Huds.

Blt kl, rosenroth, Lippe purpurn gefleckt, mit brlinealen, am Ende spitzgezähnten Isappen. Ähre kopfig, St. $15-25 \mathrm{~cm}$ h. - Bergwiesen auf Kalk in Mh. und den Alpenländern; zerstreut. 4. 5. 6.

O tridentata Scop. 
11. (1) Knollen 2-od. mehrzackig. Blt. gelblichweif od, purpurn, fiederduftend. - Waldwiesen, Gebüsche; zerstreut. 4. 5. 6.

O. sambuicina L.

Knollen tief getheilt.

12. Der eine Knollen $k l$, handförmig, der andere in 2 lange Schen. kel getheilt. Blt. purpurn, rosa oder weiß, in dichter $\ddot{A}$ hre. St. $30-45 \mathrm{~cm}$. hoch. - Sumpfige Wiesen, Torfmoore; zerstreut. 4. 5. 6.

O. incarnata L.

Beide Knollen lıand- od. fingerförmig. Bl. meist dunkel gefleckt; Lippe dunkelroth gefleckt.

13.

13. St. hohl, $15-30 \mathrm{~cm}$ 1., Bl. oval od. elliptisch, Blt. gr., purpurn, kürzer als d. Deckbl. - Nasse Wiesen, Sümpfe. 4. 5. 6.

O. latifolia L.

St. nicht hohl, 30-60 $\mathrm{cm}$ h., Bl. lanzettlich, Blt. hellroth, lila od: weiß, länger als d. Deckbl. - Waldwiesen, Gebüsche 4. 5. 6.

O maculata L.

\section{Anacamptis Rich. Kammorchis $(\mathrm{XX}, 1)$.}

Blt. rosa, Lippe 3 spaltig, Sporn so lang wie d. Frkn.; St. $30-60 \mathrm{~cm}$ hoch. Bl. lanzettlich, Knollen ganz. - Bergwiesen und Gebüsche, aut Kalk; zerstreut. 6. 7 .

A. pyramidalis Rich.

121. Gymnadénia R. Br. Nacktdruise $(X X, 1)$.

Knollen handförmig, Ähre walzig, Deckbl, 3 nervig, Lippe 3 lappig.

1. Blt. sehr kl, grünlichweiß, Sporn sehr kurz. St. 5-15 cm h. Gebirgswiesen, zerstreut. 2. 6. 7.

G. álbida Rich.

Blt. ansehnlich, purpurn, rosen- bis fleischroth, selten weiß; Sporn: so lang od. länger als d. Frkn.

2.

2. Sporn $1 \frac{1}{2}-2$ mal länger als d. Frkn., Blt. geruchlos oder wenig. duftend, St. $20-60 \mathrm{~cm} \mathrm{h.} \mathrm{-} \mathrm{Trockene} \mathrm{und} \mathrm{feuchte} \mathrm{Moorwiesen.} \mathrm{4.} \mathrm{6.} 7$.

$G$. conopéa $\mathrm{R}$. Br.

Sporn so lang wie d. Frkn., Blt. stark vanilleduftend; St. bis $45 \mathrm{~cm}$ h. - Sumpfwiesen in B., Oe. und den Alpenländern; zerstreut. 4. 6. 7.

G. odoratissima Rich.

\section{Himantoglóssum Spr. Riemenzunge (XX, 1).}

Knollen ganz, St. bis $80 \mathrm{~cm}$ h., dick; Ähre lang, walzig, Blt. gr., grünlich, bockartig stinkend. - Buschige Kalkhügel in Mh., Noe., T.; zerstreut. 4. 6. 7 .

H. hircínum Spr.

\section{Coeloglóssum Hartm. Hohlzunge $(\mathrm{XX}, 1)$.}

Knollen ganz od. gespalten, St. $8-30 \mathrm{~cm}$ h., Bl. elliptisch od. lanzett. lich, Ähre walzig, Blt. kl. - Feuchte Wiesen in Gebirgen, zerstreut 4. 5-7. C. viride Hartm.

124. Platanthéra Rich. Stendelwurz $(X X, 1)$.

Knollen ganz, rübenförmig, St. fäst bllos, 30-60 cm h., Grundbl. elliptisch oder länglich, Ähre walzig.

1. Blt. weiß, sehr wohlriechend, Sporn gleichbreit. - Laubwälder, Waldwiesen. 4. 5-7. Weiße Kuckucksblume, P. bifolia Rich. 
2. Blt. grünlichweiß, geruchlos. Sporn gegen das Ende keulenförmig. - Laubwälder, Waldwiesen; zerstreut.. 4.5-7. P. chlorantha Custer.

\section{Nigritella Rich. Schwarzorche (XX, 1).}

Knollen handförmig, St, 7-21 cm h., Bl. lineal-lanzettlich; Blt. in dichter Ähre, wohlriechend.

1. Blt. schwarzroth, vanilleduftend, Sporn kurz, sackig. - Triften der Alpen, bes. auf Kalk $(800-2000 \mathrm{~m})$ : verbreitet. 4. 6-9. (N. angustifolia Rich., Satyrium nigrum L.) Kohlröschen,.N. nigra Wettst.

2. Blt. hellpurpurn, Sporn walzig. - Grasplätze d. Kalkalpen, selten 4. 7. 8. (N. suaveolens Koch.)

N. fragrans Saut.

\section{Chamaeórchis Rich. Zwergorche (XX, 1$)$.}

Knollen länglich, ganz, St. $2 \cdot 5-13 \mathrm{~cm}$ h., Bl. schmallineal; Blt. kl.y gelblich- od. röthlichgrün, in kurzer Ähre; Helm nickend. - Triften der Kalkalpen $(1500-2200 \mathrm{~m})$, zerstreut. 7. 7. 8 .

Ch. alpina Rich.

\section{Ophrys L. Ragwurz (XX, 1).}

Knollen ganz, St. 15-45 cm h., Bl. länglich oder lanzettlich, Blt. wenige in lockerer Ähre (auch nur 1-2).

1. Lippe ohne Anhängsel, Perigonbl. griinlich.

Lippe mit Anbängsel an d. Spitze, fast 4 eckig, ganz, purpurbraun mit kahlen gelblichen Flecken; Perigonbl. rosenroth. (O. Arachnites Murr.)

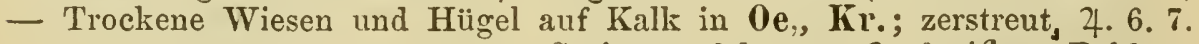
$\mathrm{Sp}$ innenblume, $O$. fuciflora Rchb.

2. Lippe länglich 4 eckig, convex, purpur- od. gelbbraun, grüulich gerandet. - Bebuschte Kalkkügel in 0e.; zerstreut. 4. 5. 6.

Frau enthräne, 0 . araneifera Huds.

Lippe 3 lappig, flach, purpurbraun, grünlich gerandet mit kahlem blïulichem Mittelfleck (O. muscifera Huds.). - Kalkhuigel in B. (Mittelgeb.), 0e., K., Kr., Y.; zerstreut. 4. 5. 6. M ücken blume, O. myódes L.

\section{Hernínium R. Br. $(\mathrm{XX}, 1)$.}

Nur 1 Knollen am blühenden, 10-15 cm l., 2 blättrigen St.; Blt. gelbgrün, in schmächtiger Ähre, Perigonbl. zusammengeschlossen. - Bergtriften d. Alpenländer und im suidl. B. 4. 6. 7. H. Monorchis R. Br.

\section{Cephalanthéra Rich. ( $\mathrm{XX}, 1)$.}

Walziger, kıotiger Wzst., St. $30-45 \mathrm{~cm}$ h., Bl. länglich-lanzettförm., Blt. groß in lockerer Ähre. Kalkliebende Pf.

1. Perigonbl. rosen- bis purpurroth, Lippe zugespitzt, weiß, gelb liniiert. - Wälder, Gebüsche, zerstreut. 4. 6. 7.

Waldvöglein, C. rubra Rich.

Ganze Blume weiß, Lippe abgerundet.

2. Blume gelblichweiß, untere Deckbl. blartig, nur d. obersten kür. zer als d. Frkn. (C. pallens Rich.) - Laubwälder, Gebüsche, zerstreut. 7. 5. 6 .

C. grandiflóra Bab.

Blumen schneeweiß, Lippe mit gelbem Fleck; Deckbl. kürzer als d Erkn. - Laubwälder, zerstreut (selten). 2, 5. 6. C. ensifolia Rich. 


\section{Epipáctis Rich. Sumpfwurz $(\mathrm{XX}, 1)$.}

Blt. in einseitswendiger nickender Traube; Wzst.

1. Wzst. kriechend, Perigonbl. röthlichgrün, Lippe weiß od. rosa, gerundet; St. $30-50 \mathrm{~cm}$ h., Bl. lanzettlich. - Sumpfwiesen, zerstreut. 7 . 6. 7 .

E. palustris Crantz.

Wzst. gebüschelt-fasrig; St. $0 \cdot 30-1 m \mathrm{~h}, \mathrm{Bl}$. ei- od. eilanzettförm., länger als die Stglieder.

2.

2. Blt. dunkelroth, schmutzig violett od. rothbraun, wenig zahlreich, in lockerer Traube. - Laubwälder, Gebüsche, auf Kalk: zerstr. 7. 6. 7.

E. rubiginósa Crantz.

Bit. ganz grün od. grünlichroth bis schmutzig purpurn, zahlreich in dichter Traube. - Wälder. 4. 6. 7. (E. viridans Crtz) E. latifolia All.

\section{Listéra R. Br. Zweiblatt (XX, 1).}

Wzst., St. 2 blättrig; Blt. grünlichgelb in lockerer Traube.

1. Bl. eiförmig od. elliptisch, Traube lang, vielblütig, St. $30-45 \mathrm{~cm}$ hoch. - Sumpfige Waldwiesen. 4. 6. 7.

L. ovata R. Br.

Bl. herzeiförmig, Traube kurz, armbltig, St. 8-15 cm h., schmächtig. - Schattige Gebirgswälder, zerstreut. 4. 7.8 L. cordaț R. Br.

\section{Neóttia Rich. Nestwurz (XX, 1).}

Wzst. vogelnestartig, aus fleischigen, verflochtenen Wzn. bestehend. St. $15-30 \mathrm{~cm}$ h. sammt d. 1. Bltähre braungelb. - Schattige Buchenu. a. Wälder; zerstreut. 4. 6. 7.

N. Nidus avis L.

\section{Goodyéra R. Br. $(\mathrm{XX}, 1)$.}

Wzst. kriechend, beschuppt; St. $15-30 \mathrm{~cm}$ h., Bl. elliptisch, netzadrig; Blt. kl., wei 0 , in einseitiger Traube. — Schattige Nadelwälder, zerstreut. 4. 7. 8.

G. repens R. Br.

\section{Spiranthes Rich. Drehorche (XX, 1).}

Knollengewächse. St. bescheidet, Bl. lanzettlich; Ähre einseitig, schraubig gewunden., Blt. kl., weiß.

1. Knollen 2, dick; Bl. grundständ. neb. d. $10-20 \mathrm{~cm} \mathrm{h.} \mathrm{St.;} \mathrm{Ähre}$ stark gedreht, nickend. - Trockne Bergwiesen, Wälder. 4. 8. 9.

\section{S. autumnalis Rich.}

2. Kuollen mehrere, dünn; St. $15-30 \mathrm{~cm}$ h., am Grunde beblätt.; Ähre wenig gewunden, aufrecht. - Sumpfwiesen in 0e., St., K.; zerstreut. 4. 6. 7 .

$S$. aestivalis Rich.

\section{Corallorihíza Hall. Korallenwurz (XX, I).}

Wzst. horizontal, fleischig, korallenartig-ästig; St. $10-25 \mathrm{~cm}$ hoch, Blt. hängend in lockerer Traube. Ganze Pf. grünlichgelb. - Schattige Bergwälder, zerstreut. 4. 6. 7. C. innata $\mathrm{R}$. Br.

\section{Cypripédium L. Frauenschuh ( $\mathrm{XX}, 2)$.}

Wzst. fasrig, St. $20-30 \mathrm{~cm}$ h., 1 bltig; Bl. groß, elliptisch od. eilanzettlich; Blt. nickend, Perigonbl. purpurbraun, Lippe gelb. - Laubwälder auf Kalk, zerstreut. 4. 5. 6.

C. Calcéolus L. 


\section{Fam. XXIII. Juncáceae. Simsentilien.}

\section{Lúzula DC. Hainsimse (VI, 1).}

Scheingräser mit knotenlosem rundem beblätt. St., Bl. lineal mit röhriger Scheide; Bltstand endständig.

1. a) Blt. einzeln, verschiedenlang gestielt, in doldiger Spirre; Bl. am Rande langgewimpert; St. $15-45 \mathrm{~cm} \mathrm{~h}$.

b) Verschiedenlang gestielte Büschel von 2-4 Blt. in zusammengesetzter Spirre.

c) Ährig od. trugdoldig gruppierte vielbltige Ährchen. 3.

2. Perigonbl. glänzend strohgelb, Wzst. kriechend. - Wälder der Alpen, zerstreut (auch in Mh.). 7. 5. 6.

$L$. flavescens Gaud.

Perigonbl. kastanienbraun, weif gerandet; Spirre vielbltig, Bl. 4-8 $m m$ br., Wzst. fasrig. (L. pilosa W.) - Wälder, Gebüsche. 4. 4. 5.

\section{I. vernalis DC.}

3. $(1$, b.) Bl. am Rande lang gewimpert.

Bl. kahl oder nur am Grunde (an d. Mïndung d. Scheide) gebartet; St. $15-30 \mathrm{~cm} \mathrm{~h}$.

6.

4. Bl. bis $13 \mathrm{~mm}$ br., rinnig; St. hohl, 0.30-1 $m$ h.; Spirre grof, flattrig; Perigonbl. hell- od. grünlichbraun (L. máxima DC.). - Gebirgswïlder. 4. 5. 6.

L. silvática Gaud.

Bl. schmallineal, St. $30-45 \mathrm{~cm}$ b. 5.

5. Perigonbl. weif, d. äufern länger als d. innern. Spirre büschelig. - Alpenwälder in K., T., Kr.; zerstreut. 4.6. 7. . L. nivea DC.

Perigonbl. fast gleichlang, weiflich, hellgelb, röthlich (L. rubella Hppe), selten kupfer- od. schwarzbraun (var. fuliginosa Aschers); Spirre flattrig (L. álbida DC). - Wälder, Gebiische. 7.

L. angustifolia Garke.

6. (3) Bl. am Grunde gebartet, Blt. kl. schwarzbraun, in lockerer Spirre. - Alpentriften $(1500-2200 \mathrm{~m})$. 4. 6. 7. L. spadicea DC.

Bl. kahl, Blt. in flattriger Spirre, Perigonbl.gliinzend schwarzbraun, weißlich gerandet. - Triften der Kalkalpen, zerstreut. 4. 6. 7.

\section{L. glabrata Hppe.}

7. $(1$, c). Ährchen trugdoldig, Bl. stark behaart.

Ïhrchen in gelappter nickender Rispenähre, Blt. purpurbraun, St. $\mathrm{s}-30 \mathrm{~cm} \mathrm{~h}$. - Gerölle und Triften der Alpen $(1580-2350 \mathrm{~m})$, auch im Riesengeb. 4. 6-8.

L. spicata DC.

8. Perigonbl. gleichgeformt, spitz. 9.

Innere Perigonbl. kürzer als d. äußern, lang stachelspitzig. 10.

9. Blt. kastanienbraun, Ährchen zum Theil hängend, St. $10-2 \overline{\mathrm{cm}}$ h., Wzst. mit Ausläufern. - Trockene Wiesen. 4. 3-5.

Hasenbrot, $L$. campestris DC.

Blt. bellbraun, Ährchen aufrecht, St. bis $30 \mathrm{~cm}$ h., Wzst. ohne Ausl. - Wälder. 4. 5. 6.

L. multiflóra Lej.

Variet. congesta (Lcj.). Ährchen in ein Köpfchen zusammengedrängt.

10. Perigonbl. u. Kapseln glänzend schwarzbraun, Ährchen aufrecht, kopfig gehäuft, St. $15-45 \mathrm{~cm}$ h. - Torfige Hochgebirgstriften. $4.3-5$. 
Perigonbl. u. Kapseln bräunlich od. erstere fast weiß, sonst wie vor., doch niedriger. - Sandboden, Kiefernheiden; zerstreut. 4. 3-5.

L. pallescens Bess.

\section{Juncus L. Simse (VI, 1).}

Scheingräser mit knotenlosem St.; Blt. in end- oder seitenständigen Spirren od. Köpfchen, diese mit 1 od. mebreren Hiullbl.

1. a) St. beblättert, außerdem grundständ. Blbïschel.

b) St. bllos, am Grund von d. Scheiden d. Bl. umschlossen. 14.

c) St. bllos, rund, mit Scheiden anı Grunde; Bltst. seitlich. 15.

2. Bl. schmallineal bis borstenförmig.

Bl. stielrund, hohl, gegliedert.

3. Ein- bis 3 endständige Bltköpfchen.

Blt. einzeln od. gebüschelt in endständigen zusammengesetzten flattrigen Spirren.

4. Ein schwarzbraunes Bltköpfchen am Ende d. $8-20 \mathrm{~cm} \mathrm{h.,} \mathrm{bloß}$ 1 pfriemliches Bl. tragenden St. - Gerölle d. Alpen (1580-2200 m). 4. 6. 7 . J. Jacquini L.

Ein- bis 3 wenigbltige Köpfchen über einander. Perigonbl. glänzend kastanienbraun; Stbl. 2-4.

5. Stbl. 2, mit kahler Scheidenmündung, pfriemlich; St. $15 \mathrm{~cm}$ h., Wzst. fasrig. - Kalte Quellsümpfe der Schieferalpeu in St., K., T. 7. 7. 8 . J. castáneus $\mathrm{Sm}$.

Stbl. 3-4, mit langbewimperter Scheidenmündung, borstenförmig; Wzst. kriechend, St. u. Blbüschel in dichten Rasen.

6. St. sehr zart, 7-15 $\mathrm{cm}$ h., unter d. Köpfchen mit 3-4 geuäherten langen Bl., sonst nackt. - Gerölle u. Felsspalten d. Alpen, Sudeten, d. Riesengeb. u. Böhmerwalds. 7. 7. 8.

J. trifidus L.

St. beblättert, $15-30 \mathrm{~cm} \mathrm{h.,} \mathrm{meist} \mathrm{nur} 1 \mathrm{Blt}$. tragend, diese von d. obersten Bl. überragt. (J. Hóstii Tsch) - Felsspalt. d. Kalkalpen, zerstreut. 4. 7. 8 . $J$. monanthus Jacqu.

7. (3). Blt. 3 männig, in traubig od. trugdoldig angeordneten Büscheln, lichtbraun; St. zart. aufrecht $(5-15 \mathrm{~cm}$ b.) od. kriechend und wurzelnd (bis $30 \mathrm{~cm}$ l., J. uliginosus Rth.) od. im Wasser flutend (bis $60 \mathrm{~cm}$ 1.). - Sumpfwiesen, Schlamm, Gewässer. 4. 7. 8. J. supinus Mnch.

Bl. 6 männig, einzeln, in Wickelähren od. gabeltheiligen Spirren. 8.

8. Wzst. kriechend, St. zusammengedruickt, $15-40 \mathrm{~cm}$ h.; Blt. glän. zend hellbraun. - Feuchte Wiesen, Ufer. 4. 7. 8. J. compressus Jequ.

Wz.. fasrig, 1 jährig; St. stielrund.

9. Perigonbl. lanzettförmig, $4-6 \mathrm{~mm}$ I., bleichgrïn, weiß gerandet, länger als die längliche Kapsel; St. $8-30 \mathrm{~cm}$ h. - Feuchte Sand-, Wiesen- u. Ackerboden. $\odot$. 7. 8. J. bufónius L.

Perigonbl. dunkelbraun, weiß gerandet, so lang als d. kuglige Kapsel; St. 6-25 cm b. - Auf feuchtem Sand in B., Mh., Noe.; zerstrent. $\odot$. 7. 8 . J. Tenagéia Ehrh.

10. (2). Bl. u. St. rundlich-zusammengedrückt, Verzweigungen d. Spirre abstehend od, aufgerichtet, St. vom Grund an beblättert. 11. 
Bl. u. St. stielrund, St. am Grunde mit bllosen Scheiden, dann 1 bis $3 \mathrm{Blt}$. tragend, $0 \cdot 50-1 \mathrm{~m} \mathrm{~h}$; äußere Zweige d. Spirre sparrig zurückgebogen. Perigonbl. stumpf, bräunlich. - Sïmpfe, Gräben. 4. 6. 7.

J. obtusiflórus Ehrh.

11. Verzweigungen d. Spirre abstehend, Perigonbl. spitz.

Verzweig. d. Sp. aufrecht, Perigonbl. stumptlich, gleichlang, sammi d. Kapsel glänzend kastanienbraun. St. $30-60 \mathrm{~cm}$ h. - Auf Stumpf-u. Moorboden in d. Alpenländ. 4. 7. 8.

J. alpinus Vill.

12. Perigonbl. stachelspitzig, samm: d. Kapsel glänzend schwarz; St. 0.30-1 m h., Bl. 2-4 zusammengedrückt. - Sümpfe, Lachen; zerstreut. 4. $6-8$.

J. atratus Krock.

Perigonbl. hell- od. dunkelbraun, Kaps. glänzend braun.

13.

13. Die innern Perigonbl. länger als d. äußeren, mit auswärts gekrümmter Spitze, alle braun mit grünem Streif. St. $0 \cdot 30-1 \mathrm{~m}$ h. - Sümpfe, Gräben. 7. 7. 8.

J. acutiflórus Ehrh.

Alle Perigoubl. gleichlang, kurz stachelspitzig, braun, weißlich gerandet; St. 15-60 cm h. (J. lamprocarpus Ehrh.) - Ufer, Gräben, Sumpfwiesen. 4. 7. 8.

.J. articulatus $\mathrm{L}$

Variet. 3. adscendens Neilr. St. rasig, liegend u. aufsteigend. $\gamma$. flútans Neilr. St. verlängert, flutend, an den Gelenken wurzelnd. $\beta$. an überschwemmten Plätzen, $\gamma$. in Bächen; zerstreut.

14. (1, b.). Blt. gebüschelt in Trugdolde, glänzend hellbraun; St. $30-45 \mathrm{~cm}$ h., Bl. schmallineal, steif, zurückgebogen. - Auf Moorboden in B., Mli., Oe., 7. 7. 8 .

J. squarrosus L.

Blt. (meist 3 ) in einem von breiten häutigen Hüllscheiden umringten Köpfchen, rothbraun; St. $7-15 \mathrm{~cm}$ h., Bl. pfriemlich. - Sümpfe, quellige Orte d. Alpen $(1580-1900 \mathrm{~m})$; zerstreut. 4 . 7. 8.

15. (1, c.). St. dicht mit Mark erfüllt, grasgrün. J. triglumis $\mathbf{L}$.

St. liohl, durch Querscheidewände gefächert, blaugrün, $0 \cdot 30-1 \mathrm{~m}$ h. BIt. braun in flattriger Spirre. - Uter. 4. 7. 8.

J. glaucus Ehrh.

16. Blt. 3 männig, grünlich od. braun; St. bis $1 m \mathrm{~h}$.

Blt. 6 männig, bleichgrün od. bräunlich, in einfacher armbltiger Spirre; St. dünn, nickend, 15-60 cm h., rasig. - Sumpfwiesen, zerstreut. 4. 6. 7. J. filiformis L.

17. Zusammengesetzte flattrige Spirre, Kapsel oben eingedriickt. Auf sumpf. u. sandigen Plätzen. 4. 6. 7.

J. effusus L. 6. 7 .

Vielbltiges Köpfchen od. Knäuel, Kapsel stumpf. - Wie vorige. 4. J. conglomeratus $\mathrm{L}$.

\section{Fam. XXIV. Colchicáceae. Zeitlosenartige.}

\section{Tofiéldia Huds. (VI, 3).}

Blt. kl. gelblich in endständ. Traube, unter dem Perigon ein 3 spaltiges kelchartiges Deckbl.; Bl. lineal-schwertförmig, grundständ. reitend; Wzst. fasrig.

1. Am Grunde d. Bltstiels ein lanzettl. Deckbl.; Bl. vielnervig. Moorige Wiesen u. Triften, Gerölle. 4. 6-8. T. calyculata Wahlber. 
a. palustris (Strb. Hppe.). St, $10--45 \mathrm{~cm}$, Traube walzig. - Zerstreut.

३. glacialis (Gaud.). St. $2 \cdot 0-1 j \mathrm{~cm}$. Traube kopfig. - Kalkalpen $(1900-2200 \mathrm{~m})$.

y. rubra (Braun). Kaps, rïthlich. - Hïchste Alpen.

Kein Deckbl. am Grunde d. Bltsticle, Bl. 3 nervig, St. $5-10 \mathrm{~cm} \mathrm{h.,}$ Traube kopfig. - Torfge Stellen, feuchtes Gerülle d hüchsten Alpen. 7. 7. $s$.

$T$. borcalis Wahlbe.

\section{Veratrum I. Germer (VI, 3).}

Gr. Stauden (Giftph.). Wzst. fasrig, St. beblätt,, Bl. d. Länge uacl cefaltet: Blt. in endständ. zusammengesetzter Traube.

1. Blumen purpurbraun; St. $0.00-1.30 \mathrm{~m}$ h. - Gebirgswilder d. Alpenländ., auch in 13. (selten!) u. als Zierjt. in Girten. 7. 7. 8.

\section{I. nigrum L.}

2. Blnm. inwendig weiß, auswend. griin; St. bis 1 ? h. - Torfige Gebirgswiesen, an bïchen d. Alpen. 7. \%. S.

\section{WeiBe $\mathrm{Ni}$ eBwurz, T. album L.}

Var. Lobelianum (Bernhd) Blum. ganz grim. - Alp., Riesengeb., Sudeten.

\section{Cólchicum I. Zeitlose (VI, 3).}

Knolleuæewächs. Rlumen grundständig, nackt, langröhrig, lila od. weiß, Bl. breitlanzettlich, rinnig, d. griine Kapsel unschließend. - Feuclite Wiesen. 7. Blt. im Ilerbst, Bl. n. Fr. im Mai.

C. autumnale L.

\section{Fam. XXY. Asparigeae. Spargelartige.}

\section{Paris L. Einbeere (VIIT, 4).}

Wzst. liriechend, St. einfacl, $15-4 j \mathrm{~cm}$ l., Bl. 4 (j) quirlstïud., oval od. elliptisch: Blt. grünlichgelb, $4-5$ blïtrig, Stbg. $S-10$. Beere schwarzblau, giftig. - Scbattige Wailder. 4. j. P. quadrifolia L.

\section{Stréptopus Mich. Linotenfuß (VI, 1).}

Wzst. knotin, St. bis $1 \mathrm{~m}$ l.. ästig; Bl. wechselstäind., sitzend, herzeifümig. spitz; Blt. achselstïnc., hängend, grünlichweiß; Beeren roth. Gebirgswiilder, zerstrent. 7. 6. 7.

St. amplexifolius DC.

\section{Conrallária I. Maiglöelichen (VI, 1).}

Wzst. fasrig, St. bllos, 15-25 cm l. mit einseitiger, nickender Traube; Blt. hingend, glockig, weib, wohlriechend; Beeren roth. - Laubwiilder. 7. 5. 6 .

\section{4j. Polygonatum Touru. Weifwurz (VI, 1).}

Wzst. wagerecht liriechend, St. einfach, heblättert; Blt. einzeln; parweis od. in lil. Träubchen achselständ, hängend; Perigon rührig, weiß, griin gesäumt; Beeren schwarzblau.

1. Bl. quirlständig (:3--7), lanzettlich, St. $30-60 \mathrm{~cm}$ h. - Gebirgswi̊lder. $\stackrel{y}{+}$. 6.7 .

P. verticillatum All. 
B1. wechselständig. 2 zeilig, oral od. eliptisch; : t. ungebu, ren, ju tris 6n $\mathrm{cm}$ h.; Wzst. mit siegelartigen Eindrüclen.

2. S. kantig, kall; Eltrtiele 1-2 lultig. - Hexwalder u. - eximt buschige Hügel. 2. 5. 6 . Ralcmonsejegel, $Y$. afficinale All

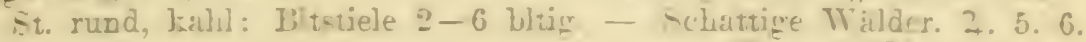
F. multoflorum All.

\section{Majáthemum Wigg. Scbatteublumelien IT, 1).}

Wzst. lriechend, 天t. $\$-15 \mathrm{~cm}$ h., mit \& weclıselständ. herceifirmimen Et.: Blt. Kl., weif, in endetaind. Traube, Beereu roth - Schattige Wialder. 2. 5. 6.

11. Gifolium I)C.

\section{Aspálagus L. Eparyel (VI, 1).}

Wzst. ästig-büschlig, beschuppte flischige siwossen treiluend, die in ästige, $1-1^{1}$, $m$ h. Rt. auswachsen. Bl. geluischelt, nadelformic. Blt. einzelu, hängend, grüulich, Becren roth. - Allgemein cult, an Flussuferu verwildert. 2. 6. 7 .

4 officinalis $\mathrm{L}$.

\section{Fam. XXTI. Dioscóreae. Iamsurétartige.}

\section{1:. Tamus L. Schmeerwurz (XXH, 6)}

Kletteryfl. mit kuolligem Wzst. u. bis 2 m 1. si.: B1. wechselständ., langgestielt, herzeif irmig; Blt. kl. grünlichgelb, in llwinkelständ. Trauben; Beeren roth. - In Heclien, Gebüschen in Kr. n. südl. T. 2. 4. ‘.

\section{Fam. XXYlI. Litiáceae. Litiengeräshse.}

\section{Schluissel der Gattungen.}

1. Zwiebelgewächse.

W zstocligew ächse.

2. Perigon rerwachsenulütrig, Blt, traubig auf aacktem Schaft. 3. Perigon getrenntblätrig od. tief 6 theil $\mathrm{g}$.

3. Perigon krugfürmig od. walzig, 6 zäbrig.

Perigon glockenförmig, 6 spaltig. Muscari (149). Hyacintlius ( 1 i).

4. Blt. zahlreich in einfacher kugliger Dolde od. wenige in flattriger Dolde mit Zwiebelknospen zwischen d. Stielen.

-Allium (152.

Blt. ruders angeordnet. Furche.

5. Perigonbl. am Grunde mit einer honigabsondernden Grube cider

Perigonbl. whe Honiggrube od. Furche.

6. Honigrube od. Farche offeu. Blumen mroß.

Honigfurche durch eine Querfalte legrrenzt. St. 1-2 bltig.

7. Houiggrube rundlich mit Nectartropfen od. eine mlänzende lilelurige Furche.

Fritillaria (160).

Honigabsondernde Längrinne am Nagel d. Perigonbl. 
8. (5). Eine einzige Blt. am Ende d. beblätt. St.

Blt. in endständ. Trugdold., Doldentraube od. Traube.

9. Blt. hängend, Perigonbl. zurückgeschlagen, Stbg. vorstehend.

Erythronium (159).

Blt. aufrecht od. nickend, glockig; Stbg. eingeschlossen.

Tulipa (161).

10. Perigonbl. gelb, auswendig griin gestreift.

Gagea (157).

Perigonbl. weiß, grünweiß gerandet od. blau.

11. Perigonbl. weiß od. grïnweiß, Blt. in Dolde od. Traube.

Ornithogalum (156).

Perigonbl. blau, Blt. in Traube.

Scilla (151).

12. (1). Perigon regelmäßig, getrenntblättrig, sternförmig, weiß.

Anthericum (153).

Perigon gloskig-trichterförmig, fast 2 lippig, tief getheilt.

13.

13. Blume weiß.

Paradisia (154).

Blume gelb od. rothbraun, groß.

Hemerocallis (155).

\section{Múscari Tourn. Traubenhyacinthe (VI, 1).}

Bl. grundständ., rinnig-lineal; Blt. in Traube auf nacktem Schaft.

1. Oberste Blt. geschleclitslos, langgestielt, genähert, einen Schopf bildend, blauviolett, die übrigen wagrecht, grünlich. Schaft $30-70 \mathrm{~cm} \mathrm{h.2.}$

Alle Blt. zwitterlich, gleichgeformt, blau, hängend. Bl. lineal. Schaft 15 bis $30 \mathrm{~cm}$ ll.

2. Fruchtbare Blt. weit geöffnet, Stiele d. Schopfblt. viel länger als d. Blume. - Auf Äckern, Weinbergen, zerstreut. 4. 5. 6.

Schopfhyacinthe, $M$. comosum Mill.

Frchtb. Blt. mit stark eingeschnürter Mündung, Schopfblt. kurz gestielt. - Felsige bebuschte Orte auf Kalk in B., Mh., Noe.; zerstreut. 7. 5. 6 .

M. tenuiflórum Tsch.

3. Blt. eiförmig-kuglig, $3 \mathrm{~mm}$ l., hellblau, geruchlos. - Ảcker, Weinberge, Gebïsche, zerstreut; häufige Zierpfl. 4. 4. ๊. M. botryoides Mill.

Blt. eiförmig od. länglich, $4-5 \mathrm{~mm}$ l., dunkelblau, wohlriechend. Wie vorige, gem. Zierpt., oft verwild. 4. 4. 5. M. racemosum Mill.

\section{Hyacinthus L. Hyacinthe (VI, 1).}

Bl. grundständ., brlineal, rinnig; Schaft bis $30 \mathrm{~cm}$ h., Blt. wohlriechend in dichter Traube, verschiedenfarbig. - Aus d. Orient, gem. Zierpfl. 4. 2-4. H. orientalis $\mathrm{L}$.

\section{Scilla L. Sternhyacinthe (VI, 1).}

Bl. grundständ., lineal; Blt. in lockrer Traube auf nacktem Schaft, Perigonbl sternförmig ausgebreitet, blau.

1. Bl. 2, weit abstehend; Schaft $6-16 \mathrm{~cm}$ h. - Laubwälder, Grasgärten, Auen; zerstreut. 4. 3. 4.

2. Bl. $3-5$, aufrecht, Schaft $7-25 \mathrm{~cm}$ h. - Zierpfl., in Grasgärten hier $u$. da verwildert. 4. 4. 5. 


\section{Sllium L. Lauch (VI, 1).}

St. bllos od. am Grunde od. bis zur Mitte von d. röhrigen Scheiden d. grundst. Bl. umhüllt.

1. Ziviebel ohne Wzst.

Zwiebel an d. Spitze eines schiefen Wzstks; St. $8-45 \mathrm{~cm}$ h. bllos, kantig, Bl. lineal, Blt. rosenroth.

2. St. nur am Grunde von d. Scheiden d. Bl. umschlossen.

St. bis $1 / 3$ od. $1 / 2$ d. Höhe beblättert erscheinend. 18 .

3.

4.

3. Blt. rosa, Dolde vielbltig, halbluglig, mit 2 purpurnen Hiillbl.; Schaft rund $8-20 \mathrm{~cm}$ h., Bl. schmal, rund, hohl. - Steinige od. sandige Flussufer u. als Gemüsepfl. cult. 4. 6. 7.

Seh nittla u ch, A. Schoenóprasum L.

Var. sibiricum (Willd): größer, St. bis $30 \mathrm{~cm}$ lı, Blscheiden fast bis zur Mitte d. St. reichend. In Hocligebirgen, zerstreut.

Blt. weiß, sternförmig, in flacher Dolde; Schaft kantig, bis $30 \mathrm{~cm}$ h., Bl. eilanzettförmig, gestielt. - Schattige Isaubwälder. 4. 4. 5.

B ïrenlauch, $A$. ursinum L.

4. Bl. flach, rinnig od. stielrund, ab. nicht hohl.

Bl. hohl, röhrig, stielrund, halbrund od. rinnig.

5. Dolde vielbltig, ohne Zwiebelchen zwischen d. Bltstielen. 6.

Dolde armbltig, mit Zwiebelchen.

6. Bl. gestieit, elliptisch-lanzettförmig; St. $30 \rightarrow 50 \mathrm{~cm}$ l., Blt. weiß in kugliger Dolde. - Felsige Plätze d. Alpen, Sudeten u. d. Riesengeb; zerstreut. 4. 7. 8. Allermannsharnisch, A. Victoricilis L.

Bl. nicht gestielt.

7. Blt. rosa od. purpurn, St. $30-45 \mathrm{~cm}$ h., Bl. schmallineal 8 .

Blt. weiß, gelblichweiß od. gelb.
8. Bl. flach, Dolde kuglig-flattrig. - Busclige, steinige Hiigel, Äcker, besond. auf Kalk u. Basalt, in B., Mh., Ve.; zerstreut. 4. 7. 8.

A. rotundum $\mathrm{L}$.

Bl. halbrund, rinnig, am Grunde oft hohl; Dolde kugelrund. - Wie vorige, zerstreut. 4. 7. 8 .

A. sphaerocéphalum L.

9. Blt. .weiß, kl., in kugelrunder dichter Dolde; Bl. brlineal, rinnig. St. bis $60 \mathrm{~cm}$ h. - Cult. in Gemüsegärten. 4. 6. 7 .

Porrezwiebel, A. Porrum L.

Blt. gelblichweiß, in halbkugliger dichter Dolde; Bl. schmallineal, flach, St. $15-30 \mathrm{~cm}$ h. - An felsigen Orten in B., K., T.; zerstreut. 4. 7. 8 .

A. ochroleucum W. K.

Blt. gelb, langgestielt, in flattriger Dolde; Bl. schmallineal, rinnig, St. bis $60 \mathrm{~cm}$ h. - Bebuschte Kalkhügel in Mh., Noe., südl. T.; zerstreut. 4. 7. 8 .

A. flavum L.

10. (5). Blt. rosa od. purpurn. chen).

Blt. gelblichweiß, grünlich od. röthlich od. gar keine (bloß Zwiebel11.

11. Stbf. ungetheilt, Bl. lineal, unten rinnig; Blt. langgestielt in flattriger Dolde. St. $30-60 \mathrm{~cm}$ b. - Bebuschte Hügel d. Alpenländer, zerstreut. 21. 7. 8 . A. carinatum $\mathrm{L}$.

Stbf. abwechselnd breiter, 3 theilig. 
12. Bl. brlineal, flach, Stbf. kürzer als d. Perigon; St. $0.45-1 m, \mathrm{~h}$.

- Gras- n. Weingärten, zerstreut. 4. 6. 7.

A. Scorodóprasum I.

Bl. lineal-stielrund, unten hohl, Stbf. länger als d. Perigon, St. 30 bis $45 \mathrm{~cm}$ h. - Sandiger u. bebauter Boden; zerstreut. 4. 6. 7.

A. vineale $\mathrm{L}$.

13. (10). St. an d. Spitze ungebogen, 45-60 cm h.; Bl. brlineal, Blt. grünlich od. blaurothe Zwiebelchen. - Cult. 4. 7. 8.

Schlangenlau ch, $A$. Ophioscórodon Don.

St. aufrecht.

14.

14. Blt, gelblichweiß, Zwiebelchen weißlich; St. $0 \cdot 60-1 \mathrm{~m} \mathrm{h.,} \mathrm{Bl}$. brlineal, flach. - Cultiv, 4. 7. 8.

Knoblauch, $A$. sativum L.

Blt. schmutzigröthlich od. grínlich, in flattriger Dolde; St. $30-60 \mathrm{~cm}$ h, Bl. schmallineal. - Bebaut. Bocen, Grasgärten. 4. 6-S.

A. oleráceum $\mathbf{L}$.

15. (4). Blt. rosa, groß, Bl. schmallineal.

A. sibiricum (s. 3).

Blt. weiß mit grünl. Kiel, St. u. Bl. rölırig.

16.

4. 7.

16. St. $(30 \mathrm{~cm} \mathrm{~h})$ 1. Bl. schlank, dünn, Dolde dicht, kuglig. - Cult.

St. u. Bl. dick, Dolde dicht, kuglig, 45-60 $\mathrm{cm}$ h.

17.

17. St. iib. d. Basis aufgeblasen, d. 3 innern Stbf. mit 2 Seitenzähnen. - Allgemein cult. $\odot$.6. 7. G $\quad$ e meine Zwiebel, $A$. Cepa L.

St. in d. Mitte aufgeblasen, Stbf. ohne Zähne. - Cult. 4, 6-8.

IV in te rzwi eb e l, $A$. fistulosum $\mathbf{L}$.

18. (1). Bl. scharf gekielt, untere 3 kantig. (A. acntángulum Schrd.) - Nasse TViesen, zerstrent. 7. 6-8.

A. angulosum L.

Bl. nicht gekielt, am Grunde abgerundet; Stbf. lang vorragend. (A. fallax Schult.) - Felsige bebuschte Orte; zerstreut. 4. 6. 7.

A. senescens $\mathrm{L}$.

\section{Anthéricum I. Zaunlilie (VI; 1).}

Wzst. bïschelig.fasrig, Bl. grundständig, lineal; nackter Bltschaft $30-60 \mathrm{~cm} \mathrm{~h}$.

1. Blt. in einfacher Traube. - Bebuschte Hügel, Weinberge, auf Kalk. 4. 5. 6. A. Liliago L.

2. Blt. in ästiger Traube. - Ebendaselbst, zerstreut. 4. 6. 7.

A. ramosum L.

\section{Paradísia Mazz. Paradieslilie (VI, 1).}

Wzst. buischelig, Bl. grundständ., lineal; Schaft $30-45 \mathrm{~cm} \mathrm{h.,} \mathrm{mit}$ einfacher Traube, Blt. bis $25 \mathrm{mim}$ l. - Bergwiesen der Kalkalpen in $\mathbf{K}$. und. $\mathbf{\Gamma}$., auch Zierpflanze. 4. 7. 8.

P. Liliastrum Bertol.

\section{Hemerocállis L. Taglilie ( $\left.V^{\top} J, 1\right)$.}

IVzst. knotig, Bl. grundständig, brlineal, gelielt; Schaft oben ästig, $0 \cdot 30-1 \mathrm{~m}$ h.; Blt. 2.5-7.5 $\mathrm{cm} \mathrm{1.} \mathrm{-} \mathrm{Zierp \theta ,} \mathrm{hin} \mathrm{und} \mathrm{wieder} \mathrm{verwildert.}$ 7. 8 .

1. Blumen gelb, wohlriechend. - Verwildert in St., K., Kr. 4. H. flava $\mathrm{L}$. 
2. Blume rothbraun, geruchlos. - Verwildert in Noe., Sz., K. H. fulva L.

\section{Ornithogalum L. Vogelmilch (VI, 1).}

Bl. grundständig, lineal; Schaft einfach.

1. Perigon steruförmig, Stbf. lanzettlich, zahnlos.

Perigon glockig, innen weiß, außen grün, weiß gerandet, bis $25 \mathrm{~mm}$ lang. Stbf. blumenblartig. 3 zähnig, aufrecht; Schaft $25-50 \mathrm{~cm}$ h. Traube nickend. - Grasgärten, Weinberge, Äcker; zerstreut, auch Zierpf. 4. 5. O. nutans L.

2. Perigonbl. grünlich, weiß gerandet; Schaft $30 \mathrm{~cm} \mathrm{h.,} \mathrm{mit} \mathrm{langer}$ Traube, Bl. tiefrinnig. (O. pyrenáticum Jcqn.). - Bergwiesen in Mh., 0e., St., K., T.; zerstreut. 4. 6. 7. O. sphaerocarpum A. Kern.

Perigonbl. weiß mit grünem Rückenstreif.

3. Bl. einfarbig grün, rinnig; Schaft bis $60 \mathrm{~cm}$ h., Bltstd. vielbltig. 4 .

Bl. grün mit weißem Mittelstreif; Blt. in lockerer Doldentraube. 5.

4. Dichte Doldentraube, Deckbl. 1., an d. Spitze d. Bltstds schopfig hervortretend. - Wiesen u. Hügel auf Kalk in Noe., zerstrent. 4. 5. 6. O. comosum $\mathbf{L}$.

Pyramidale Traube, Deckbl. kürzer als d. Bltstiele. - Äcker in Noe,, zerstreut. 7.7.

O. pyramidale $\mathrm{L}$.

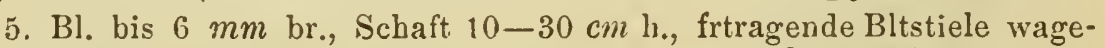
recht. - Wiesen, verbreitet, auch Zierpfl. 4. 4. 5. O. umbellatum L.

Bl. $2-3 m m$ br., Schaft $7-20 \mathrm{~cm}$ h., frtragende Bltstiele aufrechtabstehend. - Wiesen, bebuschte Hügel in B., Mih., 0e. 4. 4. 5.

O. tenuifolium Guss.

\section{Gágea Salisb. Gelbstern (VI, 1).}

Bl. grundständ., lineal, länger als d. Bltschaft. Blt in Trugdolde, selten $1-2$.

1. Je 3 Zwiebeln beisammen, d. größte $1-2$ Bl. und einen $8-15 \mathrm{~cm}$ hohen 1-3 bltigen Schaft treibend. - Äcker, trockene Wiesen. 4. 4. 5. G. pratensis R. Sch.

Bloß 1 od. 2 Zwiebeln (dann beide von gemeinsamer Haut umschlossen, oft mit vielen Brutzwiebelchen).

2. Ein grundständ. Bl. neben dem Schaft.

Zwei grundständ. Bl.

3. Bl. hohl, halbstielrund (bisw. 2); Schaft $8-15 \mathrm{~cm}$ h., Blt. 2-5 langgestielt. - - Alpentriften in K. u. T. 4. 5. 6. G. Liotardi Schult.

Bl. nicht hohl.

4. Bl. bis $5 \mathrm{~mm}$ br., rinnig; Schaft $5-15 \mathrm{~cm}$ h., Blt. $1-8.5$.

Bl. 6-13 $\mathrm{mm}$ br., flach, gekielt; Schaft 10-25 $\mathrm{cm}$ h., Blt. 1-8. - Grasgärten, Gebüsche, Laubwälder. 4. 3. 4.

G. luitea Schult.

5. Untercs Hüilbl. d. Bltstds lanzettlich, bis $13 \mathrm{~mm}$ br., die übrigen Hüllbl. kurz, schmallineal. - Laubhaine, Waldwiesen, sehr zerstreut. 4. 4. 5 .

G. minima Schult.

Deckbl. meist nur 2, fast gegenständ, d. unterste noch einmal so lang, als d. übrigen, oft alle verkümmert. - Buschige Hügel, Grasplätze in B., Mh., Noe.; zerstrent. 4. 3. 4.

G. pusilla Schult. 
6. (2) Bl. $2 \mathrm{~mm}$ br. rinnig, Schaft $S-20 \mathrm{~cm}$ h., Blt. 1 -viele, Perigoubl. spitz, außen rauhhaarig. - Äcker. 4. 3.4. G. arvensis Schult.

Bl. $1 \mathrm{~mm}$ br. fädlig, Schaft $2 \cdot 5-5 \mathrm{~cm}$ h., meist 1 bltig, Perigonbl. stumpf, flaumig oder kahl. - Steinige Triften in P., Mh,; Noe., zerstreut. 4.3 .4 .

G. bohemica Schult.

\section{Lloydia Salisb. (VI, 1).}

Zwiebel 1., schmal, St. beblätt., $8-13 \mathrm{~cm}$ h., Bl. lineal-lanzettlich, Blt. aufrecht, glockig, weiß und roth gestreift. - Steinige Triften und Felsen der Alpen $(1900-2550 \mathrm{~m})$; zerstrent. 4. 6-8.

L. serótina Salisb.

\section{Erythrónium L. Hundszahn (VI, 1).}

Zwiebel 1., schmal; Bl. brlanzettförmig, gestielt, purpurbraun ge. fleckt; St. 1 bltig, bis $20 \mathrm{~cm} \mathrm{I}$; Blt. groß, hellpurpurn. - Bergwälder in B., St., K., Kr., T.; zerstreut. 4. 4.

E. Dens canis L.

\section{Fritillária L. Schachblume, Kaiserkrone (VI, 1).} olättert.

Zwiebel groß, außen beschuppt. Blume groß, glockig, hängend; St. be-

1. Blt. fuchsroth, quirlständig unter einem Blschopf; St. bis $60 \mathrm{~cm} \mathrm{~h}$. - Zierpfl. aus Persien. 4. 4.5. Ka is e r krone, $F$. imperialis L.

Blt. endständig, 1-2, schachbrettartig dunkelroth gefleckt auf fleischrothem od. gelblichem Grunde; St. $15-30 \mathrm{~cm}$ h. - Wiesen in Oe. (un Aurolzmünster). Kr. (Laibach); 'Zierpfl. 4.5. Sch a ch bl u m e, F.Melecígris L.

\section{Túlipa L. Tulpe (VI, 1).}

Zwiebel schalig. St. unten beblättert, einfach, 1 bltig; Blume glockig.

1. Blume goldgelb, anfangs nickend, wohlriechend; St. bis $50 \mathrm{~cm}$ h.

- Bebaut. Boden, Waldwiesen, Grasgärten, Parks ; zerstreut. 4. 4.

Blume bunt, aufrecht; Zierpfl.

Wild e T., T. silvestris L.

2. St. bis $15 \mathrm{~cm}$ h., Blume roth und gelb, meist gefüllt. - Aus Italien. 4. 3 .

Duc van Toll, T. praecox Ten.

St. $30-60 \mathrm{~cm}$ h.

3. Perigonbl. scharlachroth, mit schwarzem gelbumsäumtem Fleck am Grunde. - Südeuropa. 4. 4. 5.

T. Oculus solis St. Amd.

Perigonbl. kurz bespitzt, in allen Farben. - Asien. 4. 5.

Gartentulpe, T. Gesneriana L.

\section{Lílium L. Lilie (VI, 1).}

Zwiebel schuppig, St. beblättert, Blt. endständig.

1. Blumen turbanförmig, hängend, Stbg. weit vorstehend. 2.

Blumen trichter- od. glockenförm, aufrecht, Stbg. eingeschlossen 3.

2. Blumen rosenroth od. lila, purpurn gefleckt, in Traube; St. 0.30 bis 1.20 $m$ h., untere Bl. quirlständig. - Wälder, Waldwiesen. 4. 6. 7. 'T'ürke nbưnd, L. Mártagon L.

Blumen (meist 1) scharlachroth; St. $30-45 \mathrm{~cm}$ h., Bl. alle wechselständig. - Sonnige Hüigel in K. u. Kr r., auch Zierpfl. 2. 6. 7. 
In den Blwinkeln glänzend schwarze Zwiebelchen, St. $30-60 \mathrm{~cm}$ h., Blt 1-2 fuchsroth oder orange. - Wiesen, Getreidefelder, Waldschläge; zerstreut, auch Zierpt. 4. 6. 7.

Blwinkel ohne $\mathrm{Zwiebelchen.}$

4. Blumen feuerroth, innen am Grunde schwärzlich gefleckt. - Gemeine Zierpt. 4. 6. 7.

Z. bulbiferum L.

Bl. schneeweiß, wohlriechend. - Orient, gem. ZierpA. 7. 6. 7.

Weibe L., L. cindidum L.

\section{III.}

Bedecktsamige Pflanzen mit zwei Samenlappen.

(Plantae angiospermae dicotyledoneae.)

\section{A. Apétalae: ohne Blumenkrone.}

Fam. XXVIII. C'eratophýlleae. Hornblattgeuächse.

\section{Ceratophyllum L. Horublatt (XXI, 5).}

Untergetauchte Wasserpflanzen. St. fadenförmig, Bl. gabelspaltig, quirlständig.

1. Blzipfel fädig, weich; Frcht. dornenlos. - Gewässer. 4. 6. 7. C. submersum $\mathrm{L}$.

2. Blzipfel lineal, starr; Frcht. 3 dornig. - Wie vorige, häufger. 4. 6. 7 .

C. denersum L.

\section{Fam. XXIX. Hippurídeae. Tannwedelartige.}

164. Hippúris L. Tannwedel $(I, 1)$ :

St. einfach, aufrecht (bis $30 \mathrm{~cm} \mathrm{h.)} \mathrm{od.} \mathrm{flutend} \mathrm{(bis} 2 m$ l.), röhrig, gegliedert; Bl. zu 8-12 quirlständ., lineal; Blt. achselständ., grünlich. Gewässer, zerstreut. 4. 6-8.

H. vulgaris $\mathrm{L}$.

\section{Fam. XXX. Callitrichineae. Wassersterne.}

165. Callítriche L. Wasserstern (I, 2 od. XXI, 1).

Wassergewächso mit flutendem, fadenförm., an d. Knoten wurzelndem St.; Bl. gegenständ., ganz u. ganzrandig; Blt. achselständ., kl., mit 2 Deckbl.

1. Bl. verkehrteiförmig, spatelf. od. lineal, am Grunde verschmälert, oberste in schwimmender Rosette.

2.

Bl. lineal, am Grunde breiter, an d. Spitze ausgeschnitten, oberste gehäuft. - Gewässer d. Alpenländ., mit Ausn. v. Ooe.; zerstreut. 4. 7. 8.

C. autumnalis $\mathrm{L}$.

2. Deckbl. gebogen, sich nicht kreuzend; Fr. gekielt, untere Bl. lineal. - Gewässer. 4. 4-10. C. verna (L.) Ktzg.

Deckbl. sichelförmig, sich kreuzend Fr. geflügelt. 
3. Bl. alle verkehrt-eifn̈rmig; Fr. kreisrund, br. geflügelt. - Gewåsser. 2. $5-10$.

C. stagnalis Scop.

Untere BI. lineal, obere verkehrt- od. spatelförm.; Fr. schmal gefliigelt.

4. Obere Bl, verkehrt-eiförmig, Spitze d. Deckbl. gerade. - Gewässer, zerstreut. 2. 5-10.

C. platycarpa $\mathrm{Ktzg}$.

Obere Bl. spatelförmig, lang verschmälert; Spitze d. Deckbl. hakig.

- Gewässer, sehr zerstreut. 4. 7-10. C. hamulata Ktzg.

\section{Fam. XXXI. Salicineae. Weidenartige.}

\section{Salix L. Weide (XVII, 2).}

Bäume, Str., Erdhölzer; Bl. stets ganz, Kätzchen aufrecht, gerade od. gekrümmt.

1. Kätzchen seitenständig, sitzend od. auf beblättertem Stiele. 2.

Kätzchen endständig. Erdhölzer: Gletscherweiden. 25.

2. Kätøchenschuppen zweifarbig, Stbg. 2 .

Kätzchensch. einfarbig, gelblichgrün, Stbg. 2-5; Kätzchen auf beblätt. Stiele: Ba u m w id e n.

3. Zweige mit abwischbarem bläulichem Reif, Kätzchen vor dem Laubausbruch blübend, männl. sehr dick, weißzottig; Bl. länglich, kahl. Str. od. B. - Sandige Ufer, zerstreut, auch angepflanzt. Ђ. 3. 4. Reif weide, S. daphnoides Vill.

Zweige nicht bereift.

4. Beutel der verwachsenen Stbg, sammt d. Narben, beim Blühen roth, später schwarz. Kätzchen vor dem Laubausbruch blühend; Str. od. B.: Purpurweiden.

Beutel der freien Stbg. gelb, auch nach d. Verblühen.

5. Bl. lineal bis verliehrt-eilanzettlich, unterseits bläulich bereift; Narben fast sitzend, kopfförmig. - Fluss- u. Bachufer. Ђ. 3. 4.

\section{S. purpuirea L.}

Bl. lanzettförm. od. lineal-lanzettlich, unterseits blässer, seidig behaart; Narben fadenförmig, ausgespreizt (S. purpurea-viminalis). - Ufer: zerstreut. Ђ. 3. 4.

S. rubra Huds.

6. Frkn. und Kapseln sitzend oder kurz gestielt.

Frkn. und Kapseln lang gestielt: Sahlweidenartige.

15.

7. Kätzchen vor dem Laubausbruch blühend, Bl. lineal oder lanzettförmig, spitz.

Kätzchen mit oder nach dem Laubausbruch erscheinend und blühend, Gr. meist lang, mit 2 spaltig. Narben. Kleinsträucher: Alpenwe iden. 9.

8. Bl. lineal-lanzettförmig, lang zugespitzt, plan, unterseits glänzend silbergrau-filzig. Strauch. - Flussufer. †. 3. 4.

Korbweide, S. viminalis $\mathbf{L}$.

Bl. lineal od. lineal-lanzettlich, am Rande umgerollt, unterseits weißfilzig. Großstrauch od. Baum. - Flussufer in den Alpenthälern, auch in Sch. 万. 4. 5 .

9. Bl. ganz kahl (höchstens jung abfällig-seidenhaarig).

Bl. unterseits bleibend weißhaarig, grau- od. weiß-filzig. Kätzchenschuppen lang und glänzend weißzottig. 
10. Bl. unterseits bläulich bereitt; Kätzchenstiel kurz, beblättert. 11 .

Bl. beiderseits grün, gekerbt od. gesägt, selten ganzrandig; Kätzchen (wenigstens männl.) auf beblättertem Stiel, walzig.

12.

11. Bl. elliptisch od. eilanzettförmig, entfernt gekerbt oder ganz. randig, mit gelbem Mittelnerv; Kätzchenschuppen oben braun, Frkn. filzig. Strauch 1-2 $m$ h., sehr variierend. - Gebirgsabhänge d. Kalkalpen, auch im Riesengebirge, häufig als Zierstr. cult. ち.5.6. S. phylicifolia L.

Bl. oval-lanzettlich, scharf gesägt-gekerbt, oberseits spiegelnd; Kätzchenschuppen oben rosenroth, Frkn. kahl, St. $1 \frac{11}{2} m$ h. - Auf Gerölle der Alpen $(950-1560 m)$. Ђ. 5. 6.

S. glabra Scop.

12. Kätzchenschuppen glänzend weißzottig, Frkn. gestielt, kahl; BI. eiförmig bis elliptisch, kleingesägt, kahl. St. $0 \cdot 30-1.50 \mathrm{~m}$ h., aufrecht. Feuchte Triften d. Alpen $(1260-2900 \mathrm{~m})$, auch im Gesenke. ち. 6.

S. hastata L.

Kätzchenschuppen behaart, Frkn. sitzend. Niederliegende oder aufsteigende Kleinstr.

13. Stamm aufsteigend, bis $1 \mathrm{~m}$ h., Bl. lanzettlich oder eiförmig, gekerbt-gesägt, kahl, oberseits glänzendgrün, unterseits bläulich; Frkn. weiß filzig. - Triften u. Felsen d. Alpen $(1260-1900 \mathrm{~m})$. 5. 6. 7,

S. Arbuiscula L.

Varietäten: $\beta$. Waldsteiniana (Willd.). Bl. entfernt gekerbt, Gr. tief gespalten; $-\gamma$. foetida (Schl.). Bl. genähert u. drüsig gekerbt, Gr. nicht gespalten; - j. prunifolia (Sm.), Bl. kl., scharf u. wellig gezähnelt, Gr. kaum gespalten.

Stamm niedergestreckt, Bl. elliptisch-lanzettlich, netzadrig, dicht drüsig gezähnelt; Kätzchenschuppen lila bis schwarzroth, Gr. roth, Stbb. violett. - Gerölle d. Alpen (1260-1900 m). 5.6. 7. S. Myrginites L.

14. (9) Kätzchen sitzend, BI. lanzettlich od. elliptisch, spitz, unterseits weißgraufilzig, oberseits runzlig, graugrün; Nebenbl. halbherzförmig. St. bis $1 m$ h. - Feuchte Plätze der Alpen (1900-2000 m), auch im Riesengeb. u. Gesenke. ђ. 5. 6.

S. Lápponum L.

Var. Daphné ola (Tsch.). Bl. kahl. -- Pantschewiesen i. Riesengeb.

Kätzchen lang gestielt, Bl. elliptisch od. länglich-lanzettf., beiderseits seidigzottig; Nebenbl. eiförmig, spitz. Str. $30-60 \mathrm{~cm} \mathrm{h.} \mathrm{-} \mathrm{Feuchte} \mathrm{Plätzt}$ der Alpen, zerstreut. Ђ. 6. 7.

S. glauca L.

15. (6) a) Aufrechte Str. u. B. mit frühzeitigen sitzenden Kätzchen, deren Schuppen (besond. die d. männl.) glänzendweiß zottig behaart sind; Bl. unterseits bleibend filzig.

16.

b) Aufrechte Mittelstr., deren Kätzchen mit den Bl. erscheinen; Bl. oft unterseits kahl od. flaumig, sammt den Nebenbl. scharf und hakig gezähnt.

19.

c) Klstr. mit meist niederliegenden Stämmchen; Kätzchen frühzeitig, kl., länglich bis kuglig; Bl. kl., mit oft zurückgekrümmter Spitze. 20.

16. Frknstiel so lang od. länger als d. Kätzchenschuppe. 17.

Frknstiel halb so lang als d. Kätzchenschuppe; Bl. verkehrt-eiförm. bis rundlich, kl., wellig gesägt, runzlig, Nebenbl. nierenförm., bleibend; Kätzchen kl, walzig, an den zartea $Z$ weigen dicht gedrängt. Str. 1.25 bis $2.60 \mathrm{~m}$ h. - Moorige Wälder u. Wiesen. Ђ. 4. 5.

Ohrweide, S. aurita $L$. 


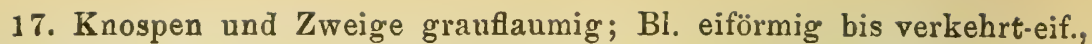
groß, wellig, gekerbt od. ganzrandig; Kätzchen walzig, dick, lang. Str. bis $3 m$ h. - Feuchte Wiesen, Ufer, Waldränder. ந. 4. 5.

Werftweide, S. cinérea $\mathrm{L}$. walzig.

Knospen und Zweige kahl; männl. Kätzchen länglich, dick, weibl. 18.

18. Bl. oval-lanzett- bis eiförmig od. herzeiförmig, wellig, gekerbt od. ganzrandig; Nebenbl. kl. Großstr. od. B. - Wälder, Gebüsche. ち. 3. 4 . Palmweide, Sahlweide, S. Cáprea L.

Bl. verkehrteiförmig-länglich, fiach, undeutlich gekerbt, sehr groß, Nebenbl. groß, herzeiförmig, gezähnt. Aufrechter Mittelstr. - Gebirgswälder d. Voralpen, Böhmerwald. ち. 3. 4.

S. grandifolia Sw.

19. (15 b) Bl. verkehrt-ei- bis eilanzettförmig, ziemlich gleichfarbig; Kätzchen alle walzig, Gr. kurz. - Gebirgswälder in B. u. Mh. ち. 5. 6. S. silesiaca W.

Bl. eiförmig, elliptisch-lanzettförmig bis lanzettlich, unterseits meist blänlichweiß (beim Trocknen sammt d. Kätzchen sich schwärzend); männl. Kätzchen länglich, weibl. walzig; Gr. lang. - Feuchte Laubwälder, Sumpfwiesen; zerstreut. Ђ. 4. 5 .

$S$. nigricans $\mathrm{Sm}$.

20. (15 c) Bl. beiderseits kahl, kl., herzeiförmig, elliptisch od. lanzettlich, ganzrandig. Kätzchen schmächtig, langgestielt. - Torfmoore in B., T. u. K., selten. 5. 5. 6.

S. myrtilloides L.

Bl. unterseits silbergrau od. weiß, dicht filzig, lineal-lanzettförmig bis elliptisch. Kätzchen länglich bis fast kuglig. Sehr variabel. - Sandund Moorboden, sumpfige Wiesen. 5. 4. 5 .

S. repens L.

Varietäten: $\beta$. angustifolia (Wulf). Bl. lineal-lanzettförmig, 5 bis $7.5 \mathrm{~mm} \mathrm{1.;}$ Narben lang; - $\gamma$. rosmarinifolia L. Bl. ebenso, aber 25-37 $\mathrm{mm}$ l.; Narben kurz; - $\delta$. a rg én te a $\mathrm{Sm}$. Bl. oval od. elliptisch, 13-25 mm l.; Narben kurz; - $\varepsilon$ fusca Sm. Bl. oval-lanzettlich, spitz, $25 \mathrm{~mm} \mathrm{l}$; Narben kurz.

21. (2) Stbg. meist 2, selten 4,5 od. mehr; Kätzchenschuppen lange vor dem Abfall d. Kätzchen abfallend. Rinde d. Stämme aufreißend. 22.

Stbg. 3, Kätzchenschuppen bleibend, Rindo schuppig abblätternd Bl. lanzettlich od. länglich, spitz, gekerbt-gesägt. Variiert mit beiderseits ziemlich gleichfarbigen $\mathrm{Bl}$. (concolor) und mit unterseits bläulich bereiften (discolor). - Flussufer. 5. 4. 5. Mandelweide, S. amygdálina L.

22. Stbg. 2, Bl. lanzettförmig od. lineal-lanzettlich, spitz. 23.

Stbg. $5(4-10)$, Bl. eiförmig-elliptisch od. eilanzettförmig, 5-10 cm lang, kahl, oberseits glänzendgrün. - Ufer, zerstreut. ち. 5 .

$$
\text { S. pentandra L. }
$$

10 23. Bl. unterseits weißflzig, oberseits seidenhaarig, feingesägt, 5 bis cm lang; Zweige biegsam, am Grunde nicht brüchig. - Flussauen, häufig cult. ち. 4. 5 . silberweide, $S$. alba L.

Var. vitéllina L. Zweige dottergelb.

Bl. beiderseits kahl. 
24. Zweige aufrecht, am Grunde brüchig; Bl. oberseits glănzend dunkelgrün, unterseits blass, $3 \cdot 7-10 \mathrm{~cm}$ 1., Zähne einwärts gebogeu. Ufer, zerstreut. ந. 4. 5. K K K k-, B u chweide, S. frágilis L.*)

Zweige hängend, dünn, nicht brüchig; Bl. blaugrün, bis $10 \mathrm{~cm} \mathrm{1.} \mathrm{-}$ Nur als Zierb. angeptlanzt. \$. 6. Trauerweide, S. babylonica L. bltig.

25. (1) Bl. beiderseits kahl, grïn; Kätzchen kurz gestielt, wenig-

Bl. unterseits weißfilzig u. netzadrig, elliptisch, ganzrandig. Rätzchen langgestielt, walzig. - Gerölle und Felsen d. Alpen (1580-1900 m). Ђ. 6. 7 .

S. reticulata $\mathrm{L}$.

26. Bl. ganzrandig, verkehrt-eiförmig od. Jänglich-keilig, stumpf oder ausgerandet, selten bespitzt, $12-13 \mathrm{~mm}$. Variert mit kaum $6 \mathrm{~mm}$. Bl. (S. serpyllifolia Scop.) - Kalkalpen, auf Gerölle u. Felsen. Ђ. 6. 7.

S. retusa $\mathrm{L}$.

Bl. fein gesägt, netzadrig, elliptisçh od. rundlich, 4-13 $\mathrm{mm}$ lang; Stämmchen meist unter Moos u. Steinen verborgen. - Alpen (1900 bis $2550 \mathrm{~m})$. Gesenke, Riesengeb. †. 6. 7.

S. herbicea L.

\section{Pópulus I. Pappel (XXII, 7).}

Bäume mit langgestielten, breiten, bisweilen gelappten Bl.; Kätzchen frühzeitig, hängend.

1. Kätzchen dichtblütig, walzig.

Kätzchen locker-, weibl. entferntbltig; Schuppen stets kahl.

2. Kätzchenschuppen grauzottig gewimpert.

2.

Kätzchenschuppen kahl, zerschlitzt. gezähut.

3. Kätzchensch. tief zerschlitzt, Bl. ganz, ausgeschweift oder eckig

Kätzchensch. gezähnt, Bl. handförmig gelappt, oberseits glänzend grün, unterseits schneeweiß-filzig. - Donauauen, häufig cult. u. verwild. Ђ. 3. 4 .

Silberpappel $P$. alba L.

4. Bl. auf sehr 1. Stiel zitternd, rundlich-eiförmig, unterseits blassgrün; Narben 2 theilig. - Wälder, Gebuische. \$. 3. 4.

$$
\text { Zitterp., Aspe, Espe, P. trémula I. }
$$

Bl. kürzer gestielt, nicht zitternd, unterseits grauweiß filzig, alt kahl; Narben 3-4 theilig. - Flussauen, Laubwälder; zerstreut, häufig cult. Ђ. 3. 4 .

$P$. canescens Sm.

5. (2) Krone ausgebreitet, Bl, 3 eckig-eif., gekerbt, kahl; Stbb. rosenroth. - Flussauen, Ufer, häufig cult. Ђ. 4. Schwarzp., P. nigra L.

Krone kegelförmig, Bl. rhombisch od. eif. 3 eckig, gezähnt; Stbb. purpurroth. - Aus dem Orient, überall cult. Ђ. 3. 4.

Pyramiden p., $P$. pyramidalis Roz.

6. (1) Bl. alt nicht klebrig, kahl, 3eckig-eiförmig, gekerbt, sehr lang gestielt; Kätzchenschuppen gelblich, purpurn gewimpert, Frkätzchen sebr lang, perlschnurförmig. - Aus Nordamerika, cult. $\hbar$. 4.

Can adische P. P. monilitera Ait.

*) Viel häufiger als d. echte Bruchweide, findet sich angepflanzt und verwildert. S. $\nabla$ iridis Fr. (fragilis $x$ alba), mit lang zugespitzten, fein gekerbt-gesägten, oberseitz kahlen, unterseits seidenhaarigen $\mathrm{Bl}$. und brüchigen $\mathrm{Z}$ weigen. 
B1. und Kuospen klebrig, balsamisch wohlriechend, nicht sehr 1. ge stielt. - Aus Nordamerika: Bals ampappeln.

7. Bl. länger als br., eif. od. ellipt. - Häufig cult. $\hbar$. 4.

P. balsamifera $\mathrm{L}$.

Bl. so 1. wie br., herzf., groß. - Cult. Ђ.4. P. macrophylla Lindl.

\section{Fam. XXXII. Betuláceae. Birkenartige.}

\section{Alnus Tourn. Erle, Eller (XXI, 4).}

B. u. Str. mit gestielten Knospen. Nüsschen meist ungelügelt, kantig.

1. Beiderlei Kätzchen auf gemeinschaftlichem Stiele traubig, schon im Spätsommer entwickelt, vor d. Laubausbruch blühend; Nüsschen kantig. B. u. Str.

Männl. u. weibl. Kätzchen au verschiedenen $\mathrm{Z}$ weigen, letztere erst im Frühling erscheinend; Nüsschen schmal geflügelt; Bl. eiförmig, spitz, doppelt gesägt. Str. bis $4 \mathrm{~m}$ h. - Gerölleabhänge d. Alpen (900 bis $2000 \mathrm{~m}$ ), auch im südlichen B. ち. 万. Alpenerle, $\boldsymbol{A}$. viridis DC.

2. Bl. kahl, oberseits klebrig, rundlich, stumpf od. ausgerandet. Bl. mit dunkler rissiger Rinde. - Uffer, Sümpfe (Erlenbrüche). Ђ. 3. 4.

Schwarzerle, Rotherle, A. glutinosa Gärtn.

Var. incisa: BI. fiederspaltig. Als Zierb. cult.

Bl. nicht klebrig, unterseits flaumig od. filzig. Rinde glatt.

3.

3. Rinde glänzend silbergrau, Bl. eiförmig spitz, gezackt $u$. doppelt gesägt, unterseits fein grauflzig. B. od. Str. - Alpen, anderwärts cult. 万. 2. 3 .

WeiBerle, $A$. incana DC.

Rinde braun, Bl. rundlich, eiförmig, verkehrt-eiförmig; Großstr. 4.

4. Bl. meist stumpf, doppelt gekerbt-gesägt, unterseits sammt den Zwweigen weichhaarig bis filzig (A. glutinosa $\mathbf{x}$ incana). Auf feuchtem Boden in B. u. Mh.; sehr zerstreut. $\hbar$. 3. 4. A. pubescens Tsch.

Bl. meist spitz, einfach bis doppelt gesägt, unterseits auf d. Rippen und an den Stielen rostfarben weichhaarig. - Aus Nordamerika, verwila. in B. 5 . 3. 4 .

A. servilata W.

\section{Bétula L. Birke (XXI, 6).}

B., Str., Erdhölzer mit sitzenden Knospen u. glatter Rinde. Männl Kätzchen im Spätsommer entwickelt, weibl. mit dem Laubausbruch. Nüsschen breit ge日ligelt.

1. Bl. langgestielt, Kätzch. walzig, Frchtkätzch. hängend. Bäume. 2.

Bl. kurzgestielt, Kätzchen länglich bis kuglig, alle aufrecht. Str. 7.

2. Bl. 3 eckig, rauten-, ei- od. herzförmig. Rinde erwachsener St. weiß, sich quer abrollend.

Bl. ei- od. eilanzettförmig (nordamerikan. Arten).

3. Bl. 3 eckig od. rautenförmig, gezähnt, lang zugespitzt, dünn; Fruchtschuppen langgestielt, Nüsschen sehr br. geflügelt. Rinde glänzend weiß, Stockausschläge mit Wachswarzen bedeckt. - Wälder $u$. Gebüsche auf trockenem Boden. \$. 4. 5. Rauhbirke, We ißb., B. verrucosa Ehrh.

Variet. $\beta$, péndula (Hoffm.) Zweige hängend, Bl. lang-rhombisch: Trauerbirke. - $\gamma$. laciniata (Rchb). Bl. fiederspalt. Cult. 
Bl. ei- od. herzei-, selten rautenförmig, gezähnt, kurz zugespitzt, derb; Frschuppen kurggestielt, Flügel d. Nüsschens wenig breiter als dieses; Rinde mattweib, keine Wachswarzen. - Auf torfigem u. moorig. Boden bis in d. Alpen. 5. 4. 5 .

B. alba L.

Varietäten: $\alpha$. pubescens (Ehrh.). Bl. und Triebe weichhaarig. a. gl a brata (B. carpathica W.). Bl. '1. Triebe kahl, Bl. ei- bis rhombisch-eiförmig. - Gebirge, Hochmoore. "Schwarzbirke

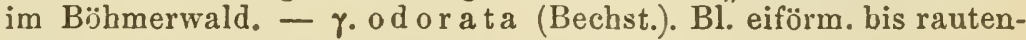
förmig sammt den Trieben feinsammtig od. kahl; Bl. jung klebrig, stark duftend. "Ruchbirke".

4. Rinde weiß, sich abrollend; Bl. eiförm., doppelt gesägt, kahl; B. - Cult. 5. 4. 5 . Papierbirke, B. papyrácea Ait.

Rinde braun, röthlich grau, sich kaum abrollend.

Rinde aufreißend, röthlich od. schwärzlichgrau. Bl. eiförnig. - Cult. 4. 5 . B. nigra L.

Rinde nicht aufreißend. 4. 5 .

6. Rinde silbergrau, Bl. herzeiförmig, zugespitzt, gesägt. - Cult.

Rinde braun. Bl. eilanzettförm., gesägt, gr., glänzend dunkelgrün. Cult. 4. 5 .

B. carpinifolia Ehrh.

7. (1) Zweige mit Wachsdrüsen, junge auch behaart; Bl. eiförmigrundlich, doppelt gesägt; weibl. Kätzch. gestielt. Str. aufrecht, bis $1.30 \mathrm{~m}$ hoch. - Torfwiesen in Mh., Sz., K., selten. 5. 4. 5.

B. húmilis Schrk.

Zweige ohne Wachswarzen, Bl. rund, grobgekerbt, sehr kl., weibl. K. sitzend. Erdholz, bis $30 \mathrm{~cm} \mathrm{l}$. - Hochmoore d. Alpen, sonst sehr selten. Ђ. 5 .

B. nana L.

\section{Fam. XXXIII. Carpineae. Hornbaumartige.}

\section{Carpínus L. Hornbaum (XXI, 5).}

Bl. länglich-eiförmig; sqitz, doppelt gesägt. Kätzchen mit d. Laubausbruch blühend, männl.- walzig, l., hängend, weibl. kl., schmächtig. Frkätzchen gr., hängend, Deckschuppen gr., blartige 3 theilig. Nüsschen gerippt. B. mit glatter grauer Rinde. - Laubwälder, Gebüsche. Ђ. 4. 5. Weif-, Hainbucbe, C. Bétulus L.

\section{1. Óstrya Hich. Hopfenbaum (XXI, 5).}

Bl. eilänglich, doppelt gesägt, Kätzchen wie bei Carpinus, ab. Nüsschen in schlaucheförmigen, häutigen, netzadrigen Deckschuppen, daher die Frkätzchen Hopfenzapfen ähnlich. - Laubgebüsche in K. v. Kr., auch als Zierb. cult. 5. 4. 5. Hopfenbuche, O. carpinifolia Scop.

\section{Córylns L. Hasel (XXI, 5).}

Str. und B., Bl. gestielt, herzeiförmig, zugespitzt, doppelt gesägt, be haart. Männl. Kätzchen im Spätsommer entwickelt, blühen mit den weibl. Blt. vor dem Laubausbruch auf. Nuss von einer blartigen Hülle ungeben. 
1. Rinde dick, kantig, rissig; Frhuille doppelt, ïußere kurz, imnero lïnger als die Nuss, tief zerschlitzt. B. - In Sildostemropa, cult. b. 4. 5. Tiirkise h o H., C. Colurna $\mathbf{l}$.

Rinde nicht korkig, glatt; Frhiille einfach. Str., selten baumart. 2.

2. Frhiille kiurzer als d. Nuss, glockig, zerschlitzt. - Gebuische, Wiilder, 5. 2. 3. Gemeine H., C. arellana L.

Frhiille lïnger als d. Nuss, röhrig-krugförmiç, an d. Miindung zer. schlitzt. - Süidostemopa, cult. 1). 3. I ambertsuss, C. tubulosir L.

\section{Fam. XXXIV. Cupuliferae. Napfträger.}

\section{3. (Guereus L. Eiche (XXI. 5).}

B. mit kurzgestielten, buchtig gelappten od. fiederspaltigen bis fieder. theiligen Bl. Männl. Kätzch. u. weibl. Blt. mit d. Laubausbruch erscheiuend.

1. Blstiele und Kinospen von fädlichen Nebenbl. umgeben; Bl. spitz. lappig-buchtig od. fiederspaltige. Schuppen d. Frbechers fadenföm., sparrig abstehend. - Laubwälder in Noe., St., K.. Kr., siidl. Mh. †) 5. Z $\in$ rreiche, Q. Cerris $\mathbf{L}$,

Keine füdigen Nobenbl., Frbecherschuppen kl., stumpt, angedrückt. 2.

2. Bl. buchtig od. fiederspaltig, mit abgerundeten Lappen. 3.

Bl. ebenso mit spitzen, borstentragondon Lappen, im Herbst roth (nordamerikanische Eichen).

3. Blspreite meist keilig in $d$, ziemlich 1 . Stiel verschmälert; weibl. Blt. in d. Blwinkeln einzeln, geknäuelt od. traubig, meist sitzend. 4.

Blspr. unten meist herzförm.-2lappig, Stiel sehr kur\%; weibl. Blt. u. Fr. an blwinkelständigem; oft 1. Stiele ihronförmig sitzend. 13. bis $40 m \mathrm{m.-}$ Laubwälder. 5).5. St tele ishe, Som mereicho, R. pedunculata Ehrl.

Culturvarietäten: $\beta$. pyramidalis, Krone kegelfïmig-pyramidal; - $\gamma$. péndula: Äste hïngend; - ס. variegata, 13l. weibgescheckt; - - . purpúrea: 13l. roth (Bluteiche). In Girtcu.

4. Bl. beiderseits kalıl. B. his $40 m$ h. - Bergwiiller. b. 5, 6. Tra benejehe, Wintereiche, Q. sessiliflóra Sm.

Bl. unterseits weichfilzig. B. od. Str. - Laubwailder in B., Mh., Noe, K., Kr. Ђ. 5. 6.

Q. pubescens W.

5. (2) Bl. rundlich eiförmig mit sehr flachen Buchten. - Cult. 1). 5 Q. rubra L.

Bl. verlängert-eiförmig, tief buchtig-fiederspaltig. - Cult. $\mathfrak{1}$. 5 .

Q. coccinea $\mathrm{Wgh}$.

\section{Castánea Touru. Edelkastauie (X.II; 5).}

B. mit br. dichtbelaubter Krone; Bl. gr., länglich-lanzettförm., stachel. spitzig-grobgezïhnt; Bltïhren gebiischelt, gelblichweiß, bis $15 \mathrm{~cm}$. Aus Siidemropa, als Walr-, Obst- und Zierbaum cult. †. 6. 7.

C. vesca Giirtu. 
174 b. Fagus I. IBuche (XXI, 5).

B. bis $33 m$ h., mit glatter, silbergrauer Rinde; Bl, oval od, eilänglich, ge.ichweif Ł-gezähnt, gewimpert. Mäunl. Kätzchen länglich, lavggestielt, bängend. - Gebirgswälder. 5.5. Rothbuche, F. silvática L.

Gartenvarietäten: B.sanguinea, Bl.roth (Blutbuehe). - - qu u rcifolia: Bl. eingeschnitten-gelappt; - $\%$ asplenifolia: Bl. lanzottiörnig, zugespitzt, unregelmäifig eingeschnitten-spitzlappig.

\section{Fam. XXXY. Platáneae. Flatancnartige.}

\section{Plátanus L. Platane (XXI, 1).}

Fremdländische, als Ziergelıölze cult. sommergrüne B. mit sich abschülfernder Rinde lind deshalb hellgeflecktem Stamme. Bl. langgestielt.

1. Bl. 5 eckig od. 5 lappig, unterseits flaumig; Stiel braunroth. Aus Nordamerikin. 1 ). 5. 6.

$P$. occidentalis L.

2. Bl. tief 3lappig, alt kahl, Stiel grün. - Aus d. Orient. 5. 5. 6. P. orientalis $\mathrm{I}$.

\section{Fam. XXX'VI. Ulmáceae. Rüsterartige.}

\section{Ulmus L. Ulme, Rüster (V, 2).}

B. mit gestielten, am Grunde ungleicien, zugespitzten und doppeltgesägten Bl.; Blt. in Büscheln, vor dem Laulausbruch. Ḧ̈ufig als Ziergehölze cultiviert.

1. Blt. lang und ungleich gesticlt, in flattrigen Büscheln, Fr. oval, gewimpert; 131. oval, sehr ungleich; Rinde sich abschülfernd. - Anenwälder, zerstreut. \$). 3. 4 .

Flat terrüster, U. effusa W.

Blt. kurz gestielt, in dichten Büscheln, Fr. kahl, Rinde sich nicht abblätternd.

2. Zweige glänzend glatt, BI. verkehrt-eiförmig, derb, unterseits in den Nervenwinkeln behaart; Fr. verkehrt-eiförmig, mit excentrischem Nüsschen (U. campestris Auct.). - Auenwälder. \$). 3. 4.

Rothrüster, U. glabra Mill.

Var. suberosa (I.) Kinde korkig, Äste mit Korkflügeln. ${ }_{n}$ Kork$r$ üs tert.

Zweige horstig behaart, Bl, groß, elliptisch bis verkehrt-eiförmig, beiderseits scharfhaarig; Fr. gr., elliptisch bis verkehrt-eiförmig, mit centralem Nüsschen (U. montana Sm.). - Bergwälder. 5. 3. 4.

Feld-, Pergrüster, $U$. campestris $L$.

\section{F'am. XXXVII. Celtideae. Zürgelbaumartige.}

177. Celtis L. Zürgelbaum (V, 2 od. XXI, 5).

B. und Str., Bl. gestielt, am Grunde schief, zugespitzt; Blt. gelblich, gestielt, blwinkelständig. Beerenförmige schwarze Steinfrucht.

1. Bl. eilanzettfürmig, scharf gesägt; Blt. meist alle zwitterlich. Berggehölze im südl. T. u. St.; liäufig cult. 5. 4. 5. C. australis I, 
2. Bl. eiförmig, Blt. meist 1 geschlechtig. - Aus Nordamerika, cult. C. occidentalis L.

\section{Fam. XXXVIII. Móreae. Maulbeerartige.}

178. Morus L. Maulbeerbaum (XXI od. XXII, 4).

B. mit ei- od. herzeiförmigen, oft handlappigen, gesägten Bl.; Blt. in Kätzchen, weibl. Kätzchen sich in eine Scheinbeere umgestaltend. Ђ. 5 .

1. Bl. am Grunde kaum herzförmig, Beere weiß. - Aus China, cult.

2. Bl. am Grunde tief herzförmig, Beere schwarzroth. - Aus Mittelasien, cult. †. 5 .

M. nigra L.

179. Ficus L. Feigenbaum (XXI, 2).

B. od. Str.; Bl. 5 lappig, oberseits scharfhaarig, unterseits flaumigfilzig. - Verwild. im südl. T. u. Kr.; cult, ち. $5 . \quad F$. Cárica L.

\section{Fam. XXXIX. Camnabineae. Hanfartige.}

180. Cánuabis L. Hanf (XXII, 5).

St. 30-60 cm 1., Bl. gegenständig, gefingert; männl. Blt. in endständigen, beblätterten Trauben, weibl. in achselständigen Ähren. - Cult. ๑. 7. 8 .

C. sativa L.

\section{Húmulus L. Hopfen $\left(\mathrm{XXI}_{2}, 5\right)$.}

Rechtswindende $\mathrm{Pfl}$. mit 2-4 $m$ l. St.; Bl. gegenständ., haudförmig 3-5 lappig, blütenständ. abwechselnd, herzeiförmig. Männl. Blt. in Rispen, weibl. in hängenden Kätzchen, frtragende Kätzchen zapfenförmig. Cult. u. in Hecken u. Gebüschen verwildert. 4. 6-8. H. Lupulus L.

\section{Fam. XL. Urticáceae. Nesselartige.}

\section{Urtíca L. Brennuessel (XXI od. XXII, 5).}

Pfl. mit Brennhaaren bedeckt. St. 4 kantig, Bl. gegenständig, gestielt ; BIt. grünlich, in achselständigen verzweigten (rispigen) Ähren.

1. Einhäusig. St. $15-40 \mathrm{~cm}$ h.; Bl. oval, eingeschnitten-gesägt; Ähren kurz, aufrecht. - Schutt, bebaut. Boden. $\odot .7-9$.

$$
\text { Kle ine B., U. urens L. }
$$

2. Zweihäusig, St. 1-2 $m$ h., Bl. herzeiförmig od. eif. länglich, grobgesägt; Ähren lang, hängend. - An Hecken, Mauern, in Wäldern. \%. $7-9$. Große B., U. diórca L.

\section{Parietária L. Glas-, Wandkraut (IV, 1).}

St. stumpfkantig, bis $1 m$ h.; Bl. wechselständig, eilänglich od. breitlanzettförmig, ganzrandig; Blt. grünlich in achselständig. Knäueln. Auf Schutt, an Mauern, Hecken; zerstreut. 4. 6-7. P. officinalis L. 


\section{Fam. XLI. Chenopodiáceae. Meldengewächse.}

\section{Schlüssel der Gattungen.}

1. St. gegliedert, ästig, bllos; Blt. zu 3 in Höhlungen zu beiden Seiten d. Glieder d. kolbigen Endglieder eingesenkt; Stbg. 1-2, Narben 2.

Salicornia (184).

St. nicht gegliedert, beblättert.

2. Blt, zwitterlich, selten vielehig, Stbg. 5, selten 1, Gr. 2 ; einsamige Schlauchfr.

3.

Blt. 1 - od. 2 häusig, Stbg. 3-5; Gr. 2 od. 4, einsamige Sclılauchfr. 9.

3. Blt. sehr kl., zu 1--5 in Blachseln sitzend, lockere beblätterte Ähren bildend.

Blt mit 3 spaltigem od. 5 theiligem Perigon, in Knäueln, diese trauben-, trugdolden- od. rispenförm. angeordnet.

4. Frtragende Perigonbl. ohne Anhängsel.

Frtragende Perigonbl. mit einem Anhängsel am Rücken.

7.

5.

6.

5. Bl. lineal-stachelspitzig; Perigon fehlend; Fr. zusammengedruickt, ge日lïgelt, nackt.

Corispermum (190).

Bl. halbwalzig stumpf, Perigonbl. 5, verwachsen, Fr. nicht gefligelt, vom Perigon umschlossen.

Suaeda (192).

6. Perigonbl.5, verwachsen, zur Fruchtzeit mit blartigem Anhängsel, Bl. stumpf. Kochia (191].

Perigonbl. 5, frei, zur Fruchtzeit am Rücken knorplig, mit häutiger Spitze; Bl. stechend-dornspitzig.

Salsola (193).

7. (3) Perigon 3 spaltig, zur Frzeit vergrößert, saftig.fleischig, Bltknäuel dann eine himbeerartige rothe Scheinbeere bildend; Stbg. 1. Blitum (185). Stbg. 5.

Perigon 5 theilig, nicht fleischig werdend, sich nicht vergrößernd;

8. Perigon vertrocknend, Stbg. im Grunde des Perigons eingefügt. Chenopodium (186).

Perigon verholzend, Stbg. einem fleischigen Ringe eingefügt. Beta (187).

9. (2) Blt. 1 häusig, männl. mit $3-5$ theiligem Perigon und 3 bis 5 Stbg., weibl. mit 2 Perigonbl., die in an einander liegende, d. Schlauchfr. einschließende Bl. (Frklappen) auswachsen; Gr. 2. Atriplex (189).

Blt. 2 häusig, männl. mit $4-5$ theiligem, weibl. mit $2-3$ spaltig. Perigon; Gr. 4, Fr. im vergrößert. Perigon .ngeschlossen. Spinacia (188).

\section{Salicornia L. Glasschmalz (I od. II, 2).}

St. sehr ästig, fleischig, gras- od. blaugrün, bis $30 \mathrm{~cm}$ h. - Auf Salzboden im südl. Mh., auch in Noe. $\odot .8 .9 . \quad S$. herbcicea I.

\section{Blitum L. Erdbeerspinat (I, 2).} spießförmig.

St. meist niederliegend, ästig, 30-60 cm l.; Bl. gestielt, 3 eckig od.

1. Bitknäuel eine endständige, oft kopfige Ähre bildend. - Cult. u. verwildert; zerstreut. (-) 7. 8 .

$B$. capitatum $\mathrm{L}$.

2. Bltkn. entfernt, achselständig, in langer, beblätterter $\ddot{A} h r e .-$ Ebenso. $\odot$.

$B$. virgatum $\mathrm{L}$. 


\section{S6. Chenopódium L. Gänsefuß, Melde (V, 2).}

Kräuter mit gestielten, breiten Bl. und griinlichen Blten.

1. Ganze Pf. kahl, glatt od. mehlig bestäubt.

Ganze PA. klebrig-faumig, ohne Mehlüberzug, wohlriechend; St. bis $30 \mathrm{~cm}$ h., Bl. buchtig-fiederspaltig; Bltknäuel in verlängerter Trauhe. Uferkies von Flïssen, Schutt; sehr zerstreut. ○. 6-8. Ch. Botrys L.

2. Ganze PA. nach faulem Häring stinkend, mehlig, graugrün; St niederliegend, bis $30 \mathrm{~cm}$ l., Bl. eirautenförm., ganzrandig. - Schutt, an

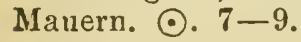

Ch. Vulvária L.

PA. geruchlos.

3. Bl. ganzrandig.

Bl. buchtig od. eingeschnitten-gezähnt od. wie ausgebissen.

4. Bl. 3 eckig-spießförmig, sammt d. $30-60 \mathrm{~cm}$ h. St. mehlig bestäubt; Bltknäuel in endständ. schweifart. Rispe. - In Dörfern an Wegen. 4. 5-8. Wilder Spinat, $\mathrm{H}$ a us melde, Ch. Bonus Henricus. L.

Bl. eiförmig, eilänglich od. lanzettförmig; St. niederliegend od. aufsteigend, bis $30 \mathrm{~cm}$ l., Bltkn. in ästigen end- und achselständigen Trugdolden. Ganze Pfl. glatt. - Auf bebaut. Boden. ๑. 8. 9.

\section{Ch. polyspermum L.}

5. Bl. am Grunde herzförmig, eilänglich, buchtig spitzgezähnt; Bltknäuel in ästigen, dusgespreizten Trugdolden; St. 0.30-1 $m$ h. - Auf Schutt, an Diingerstätten. $\odot .7-9$.

S aumelde, Sautod, Ch. hýbridum L.

Bl. am Grunde nicht herzförmig, gezähnt od. d. obere ganzrandig. 6 .

6. Bl. beiderseits glatt und glänzend.

B1. unter- od. beiderseits mehlig bestäubt, matt.

7. Bltknäuel in ästigen, ausgespreizten bllosen end- u. seitenständig. Trugdolden; Bl. eirautenförmig spitz; St. bis $60 \mathrm{~cm}$ h. - An Mauern, auf Schutt. $\odot .7-9$.

Ch. murale $\mathrm{L}$.

Bltkn. in zusammengesetzten, straff aufrechten Ähren; Bl. fast lederartig-fleischig, 3 eckig-rautenförmig, buchtig gezähnt.

8. St. meist roth überlaufen, aufrecht od. niederliegend, $30-60 \mathrm{~cm}$ lang; Ähren dick. - Schutt, an Wegen. ๑. 7-9. Ch. rubrum L.

St. grün, aufrecht, bis $1 m$ h., Ähren schmächtig, dem St. angedrückt. - Auf Schutt, an Wegen; zerstreut. $\odot .7-9$.

Ch. úrbicum $\mathrm{L}$.

9. (6) Bl. unterseits mehlig-weiß, oberseits dunkelgrün, länglich, buchtig-gezähnt; Bltkn. in zusammengesetzten Ähren; St. 0.30-1 $\mathrm{m} \mathrm{I}$, liegend od. aufrecht. - Schutt, wüste Plätze; zerstreut. ๑. 7-9.

Ch. glaucum L.

Bl. beiderseits fast gleichfarb., mehlig-bestäubt; St. $0 \cdot 15-1 m$ h. 10 .

10. Untere und mittlere $\mathrm{Bl}$. viel länger als breit. 11.

Untere und mittlere Bl. fast so lang wie br., rundlich od. eiförmigrhombisch, 3lappig, bnchtig-gezähnt, obere elliptisch od. lanzettl., ganzrandig; zusammengesetzte, fast bllose Knäuelähren. - Schutt, an Wegen; zerstreut. $\odot .7-9$.

Ch. opulifolium Schrd.

11. Untere $\mathrm{Bl}$. eirautenförmig bis eiförmig-länglich, buchtig od. ausgebissen gezähnt, obere keilig-lanzettförm. od. lineal, ganzrandig. - Unkraut, überall. $\odot .7-9$.

Ch. album $\mathrm{L}$. 
Varietäten: $\alpha$. spicatu m Neilr. (Ch. album L.). Bltknäuel in dich-

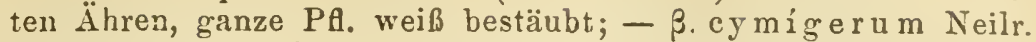
(Ch. viride L.). Bltkn, in ausgesperrten Trugdolden, ganze $\mathrm{Pfl}$. dunkel graugrün.

Untere Bl. rhombisch-lanzettförm., 3 lappig, großbuchtig-gezähnt, obere ganz, länglich od. lineal, oft ganzrandig; alle dunkel- oder bläulichgrün. Knäuelähren zusammengesetzt, dicht, fast bllos. - Auf Schutt, bebautem Boden; zerstreut. $\odot .7-9$.

Ch. ficifolium $\mathrm{Sm}$.

\section{Beta L. Runkelruibe $(V, 2)$.}

Grundständ. Bl. groß, gestielt, herzeiförmig, dickrippig; St. 0.90 bis $1.25 m$ h., ästig; Bltknäuel in rispigen beblättert. Ähren. - Culturpfl. ๑.) 8. 9.

$B$. vulgaris $\mathrm{L}$

Varietäten: $\alpha$ Cicla, Wz. schmächtig, Bl. groß mit dicken, fleischigen Rippen: Mangold; — $\beta$. rapácea, Wz. fleischig, rübenförmig, weiß, gelb od. roth: Runkelrübe, $\mathrm{Zucker-}$ rübe, Rothe od. Salatrübe (Spielarten).

\section{Spinácia L. Spinat (XXII, 5).}

St. 030-1 $\mathrm{m}$ l., Bl. gestielt, spießförmig od. eilänglich, ganzrandig od. gezähnt; Bltknäuel in beblättert. Rispen; Frhülle 2 dornig (S. spinosa Mnch.) od. dornenlos (Sp. inermis Mnch.) - Culturpfl. aus dem Orient. $\odot$. od. ค. 5. 6.

Sp. olerácea L.

\section{9. Átriplex L. Yrelde (XXI, 5).}

Kahle, bald glatte, bald mehlig bestäubte $\mathrm{Kr}$.; St. ästig, Bl. gestielt, Blt. geknäuelt, einhäusig od. polygamisch.

1. Blt. polygamisch, weibl. mit od. ohne Deckbl. durcheinander gemischt, erstere mit senkrechtem, letztere mit wagerechtem Samen; Fruchtklappen ganzrandig, Ähren in Rispen.

Blt. einhäusig, weibl. alle mit Deckbl. u. senkrechtem Samen. 3.

2. Bl. 3 eckig-spießförmig, buchtig gezähnt, oben glänzendgrün, unten silberweiß-schuppig; St. $30-60 \mathrm{~cm}$ h. - Wüste Plätze, Ufer in B., Mh.o. Oe.; zerstreut. $\odot .7 .8$.

A. nitens Rebt.

Blt. herzförmig-3 eckig, glanzlos, fast gleichfarbig, grün od. roth; Frklapp. netzadrig, St. $1-1.6 \mathrm{~m}$ h. - Als Gemüsepfl. cult u. verwild. ๑. 7. 8.

A. hortense L.

3. Frklappen getrennt (höchstens am Grunde verwachsen), gezähnt, krautig; St. $0 \cdot 30-1 m$ h., Bl. glatt od. mehlig, untere und mittlere meist buchtig gezähnt.

Frkl. bis zur Mitte verwachsen, 3 eckig-rautenförmig, gezähnt, knorplig-hart, weißlich; St. $30-60 \mathrm{~cm}$ h., ganze Pf. weißgrau bestäubt. 5 .

4. Untere Bl. oft gegenständig, 3 eckig-spießförmig, obere lanzettlichspießförmig, oberste lanzettlich; Frklappen 3 ekig-ei- od. herzförmig, gezähnt od. ganzrandig. - Sehr variierend (A. latifolium Wahlb.) - Schutt, an Wegen. $\odot .7 .8$.

A. hastatum $\mathrm{L}$.

Varietäten: $\beta$. incanum Neilr. Bl. grauweiß, oft fleischig. Auf Salzboden; - . microspermum (W. u. K.). Bl. grün, nie gegenst., Frkl. u. Samen klein. 
Untere Bl. oft spießförm., d. übrigen eilanzett- od. lanzettförm., keilig od. auch alle lanzettlich bis lineal (A. angustifolium Sm.), ganzrandig; Frkl. spieß-rautenförmig, ganzrandig od. gezähnt; St. ausgebreitet-ästig. - Wie vorige Art. $\odot$. 7. 8.

A. pátulum L.

Varietäten: B. appendiculat a Neilr. Frkl. mit Zähnen auf dem

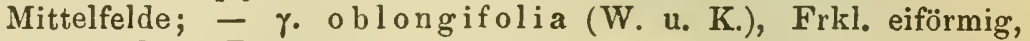
gauzrandig. Zerstreut.

5. Bltknäuel in bllosen, schlaffen, endständigen Ähren, Frklappen eirautenförmig od. 3 lappig, netzadrig, meist gezähnt; Bl. tief buchtiggezähnt. - An Mauern, Wegen in B., Mh., Noe.; zerstreut. ๑. 7. 8. A. tatáricum $\mathrm{L}$.

Bitkn. blwinkelständig, oft Quirle od. Rosetten bildend, mitunter rosenroth, Bl. buchtig-gezähnt. - Auf Schutt, an Wegen in B., Mh., Noe.; zerstreut. $\odot$. 7. 8 .

A. róseum $\mathrm{L}$.

\section{Corispermum I. Wanzensame (I, 2 und V, 2).}

St. niederliegend od. aufstrebend, ausgebreitet-ästig, unten meist roth, 15-30 cm l.; Blt. einzeln in d. Blwinkel, kürzer als d. eilanzettf. Deckbl.

1. Deckbl. breit häutig gerandet, Fr. oval, schmal gefliggelt. Donauinseln $u$. Ufer oberhalb Wien. ๑. 7. 8. $\quad$ C. nitidum Kit.

2. Deckbl. schmal gerandet, Fr. rundlich-eiförmig. -- Donauufer bei Wien. $\odot$. 8.9.

C. hyssopifolium L.

\section{Kóchia Roth. (V, 2).}

Bl. lineal, Blt. zu $1-5$ in d. Winkeln d. Deckbl. Behaarte Kräuter.

1. Bl. sitzend fädlich-pfriemenförmig.

Bl. lineal-lanzettlich, flach; Blt. wollig-zottig bis kahl, Perigonanhängsel sehr kurz, 3 eckig; St. 0.30-1.60 m h., aufrecht. - Auf Schutt, Sand in B., Mh., Noe.; auch cult. (als Besenkraut). ๑. 7-?.

K. scopária Schrd.

2. St. liegend bis aufrecht, fadenförmig, $15-60 \mathrm{~cm} \mathrm{l.;} \mathrm{Perigon-}$ anl,ängsel trockenhäutig, lineal-lanzettlich, sternförmig abstehend. - Auf Sand in den Marchgegenden von Mh. u. Noe. $\odot$. 7-9.

K. arenciria Roth.

St. viele, buschig, aufsteigend, verholzend. bis $60 \mathrm{~cm} \mathrm{l.;} \mathrm{untere} \mathrm{Bl}$. gebüschelt, Perigonanhängsel verkehrt-eiförmig. radförmig. - Auf Schutt, Sand in B. (verwild.) und Mh.; zerstreut. 4. 7-9. K. prostrata Schrd.

\section{Suaeda Forsk. (V, 2).}

St. $15-40 \mathrm{~cm}$ l., liegend bis aufrecht; Bl.sfleischig, blaugrau, länglich, an den Ästen ellipsoidisch, stumpf, Bit. zu 3 in den Blwinkeln. Auf feuchtem salzigem Boden in Mh., Noe. und südl. St.; zerstreut. $\odot$. 8. 9 .

S. maritima Dumort.

\section{Sálsola L. Salzkraut (V, 2).}

St. aufrecht od. liegend, sehr ästig, sammt den lineal-pfriemlichen Bl. mehr od. weniger fleischig, graugrün. - Auf Sand und Schutt in B., Mh., Noe.; zerstreut. ๑. 7-9. 


\section{Fam. XLIL. Amarantáceae. Amarantartige.}

194. Polyenénum L. Knorpelkrant (III, 2).

St. niederliegend od. aufrecht, 5-20 cm l.; Bl. wechselständ., pfriem. lich-stachelspitzig, am Grunde hautrandig; Blt. kl. achselständig, mit 2 eilanzettförmigen begrannten Deckbl., weiß. - Auf Sandäckern in B., Mh., 0e.; zerstreut. $\odot$. 7-9.

$P$. arvense $\mathrm{L}$.

Variiert: $\alpha$. minus: Deckbl. so 1. wie d. Perigon; - B. majus (A. Br.), Deckbl. länger als d. Perigon, ganze PA. größer; $\gamma_{\text {: }}$ verrucosum (Lang), Bl. sehr kurz, Blt. sehr kl., St. und Äste fädig, hin- und hergebogen. In Mh. (um Iglau, Znaim, Brünn).

\section{Amarantus L, Amarant (XXI, 5).}

Polygamische Kr. mit ästigem St.; Bl. gestielt, ganzrandig; Blt. von 3 Deckbl. gestützt, geknäuelt.

1. Schlauchfr. nicht aufspringend, mit d. Kelch abfallend. 2.

Schlauchfr. ringförmig aufspringend.

2. Bltknäuel grün, in dicker beblättert. Rispe; St. liegend, bis $60 \mathrm{~cm}$ lang, Bl. eirautenförm. (Albersia Blitum Kth.). - Auf Schutt, an Wegen; zerstrent. $\odot$. 7. 8 .

Bltkn. hell- bis blutroth (Zierpfl.).

A. viridis $\mathrm{L}$.

3.

3. Rispenähre 1., aufrecht, sammt St. und Blnerven blutroth. - Aus Amerika. Cult. und verwild. $\odot .7-9$.

A. sanguineus $\mathrm{L}$.

Rispenähre schlaff überhängend, hellroth. - Aus Asien, cult. und verwildert. $\odot .7-10$.

$\mathrm{Fuchssch}$ w a z,$A$. caudatus $\mathrm{L}$.

4. Blt. 3 männig; St. 15-45 cm lang, aufrecht oder niedergestreckt, kahl; Knäuel achselständ. (A. silvestris Desf.) od. in Ähren (A. prostratus Fzl.) Bl. eirautenförmig. - Auf bebautem Boden, an WTegen in $\mathbf{B}$, Mh., Noe.: zerstreut. $\odot$. 7. 8.

A. Blitum L.

Blt. 5 männig: Knäuel dichte Sträuße bildend; St. 0·15-1 $m$ hoch, oft zurückgekrümmt, behaart; Bl. eiförmig od.länglich, unterseits höckrig punktiert. - Auf Schutt, bebautem Boden; zerstreut. $\odot$. 7-9.

A. retroflexus $\mathrm{L}$.

\section{Fam. XL1II. Polygóneae. Knöterichgewächse.}

\section{Rheum L. Rhabarber (IX, 3).}

Großblättrige Staude bis $1.6 m \mathrm{~h} ., \mathrm{Bl}$. herzeiförmig, wellig, Blt. weiß in rispig gruppierten Quirlähren. - Aus Sibirien, häufig cult. 4. 5. 6. Rh. undulatum L.

\section{Rumex L. Ampfer (VI, 3 od. XXII, 6).}

Kr. mit abwechselnd beblättert. St., Bl. gestielt, ganzrandig; Nebenblätter trockenhäutig, zerschlitzt; Blt. in Quirltrauben.

1. Blt. zwitterlich, Bl. in d. Stiel verschmälert od. mit abgerundetem od. herzförmigem Grunde, von herbem Geschmack.

Blt. 2 häusig-polygam., Bl.pfeil-od. spießförm, sauer schmeckend. 12.

2. Frklappen (alle 3 od. 1) mit einer Schwiele, oft gezähnt. 3.

Frklappen ohne Schwiele, herzeiförmig, ganzrandig; Blttrauben bllos, gedrungen. 
3. Alle Bl. in d. Stiel verschmälert; St. $0 \cdot 30-1 \mathrm{~m} \mathrm{~h}$.

4.

Untere Bl. am Grunde abgerundet od. herzförmig.

4. Frklappen beiderseits mit 2 borstlichen Zähnen, Bl, lanzett- od. lineal-lanzettlich; Trauben beblättert.

Frkl. ganzrandig, 3 eckig od. rundlich ei- od. herzförmig; Trauben bllos.

5. Schwielen kl.. Blttrauben dicht, zuletzt schön goldgelb. - An Ufern, in Sümpfen; zerstrent. $\odot$. 7. 8.

$R$. maritimus L.

Schwielen groß, Blttraub. zuletzt schmutzig gelbgriin. - Wie voriger, auf Schlammboden. -. . 7. 8.

R. paluster L.

6. Bl. wellig gekräuselt, länglich-lanzett-, obere lanzettförmig; St. 0.45-1 $m$ h. - Auf Wiesen, Schutt, an Wegen. 4. 7. 8. R. crispus L.

Bl. flacl, nntere ellipt. od. länglich-lanzettförm., ohne Stiel, $30-60 \mathrm{~cm}$ lang; Frklappen mit großer Schwiele. St. 1-2 $m$ h. - In Wassergräben, Sümpfen, Teichen. 4.7. S.

S. Hydrolápathum Huds.

7. (3) Frklappen beiderseits 3-5 zïhnig, alle mit Schwiele; Grund blätter am Grunde herz- od. eiförmig, d. ersten stumpf, die späteren spitz sehr gr.; St. $0.50-1 \mathrm{~m}$ h. - Auf Schutt, an Wegen. 4. 7. 8.

Ochsenzunge, $R$. obtusifolius L.

Variiert: $\beta$. silvester (Wallr.), Frlslappen kl,, 3 eckig-länglich,

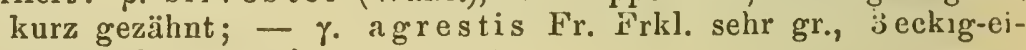
förmig, lang gezähnt, zerstreut.

Frklappen ganzrandig (selten etwas gez:̈hnelt). 8.

8. Bltquirle d. Trauben beblättert, entfernt; Frklappen lineal-länglich, alle mit br. Schwiele; St. $30-60 \mathrm{~cm} \mathrm{~h}$., untere Bl. herzförmig, od. eilänglich, obere lanzettlich. - Ufer, Gräben, Süimpfe. 4. 7. 8.

$R$. conglomeratus Mnch.

Bltquirle der Trauben bllos.

9. Alle Bltquirle d. Trauben getrennt; Frklapp. lineal-länglich, nur 1 mit Schwiele; St. $0 \cdot 60-1 m$ h., Bl. wie bei vorigem. Variiert mit blutlothem St, Blstielen und Schwielen (R. nemorosus Schrl.). - Auenwäller. 7. 7. 8 . $R$. sanguineus $\mathrm{L}$.

Obere Quirle der Trauben an einander gedrängt, St. $1-2 m$ h. 10.

10. Frklapp. rundlich-herzförmig, nur 1 mit Schwiele; Bl. selır lang zugespitzt, untere herz- od. eiförmig-länglich, bis $30 \mathrm{~cm} \mathrm{l}$. - Als Gemüsepflanze cult. $u$, verwild. 4. 7. 8 .

\section{Englischer Spinat, R. Patientia L.}

Frklapp. 3 eckig-herzförmig, alle mit Schwiele; Stiel d. am Grunde schief ei- od. herzförmigen Grundbl. beiderseits durch eine scharfe Rippe berandet. - In Gräben, Teichen; zerstreut. 4. 7. 8.

11. (2) Untere Bl. herzeiförmig, spitz, ohne Stiel, bis $30 \mathrm{~cm} l$. unl bis $20 \mathrm{~cm}$ br., obere lanzettförmig; St. $1-2 m \mathrm{~h}$. - In Gräben, Teichen; zerstreut. $4.7-10$.

$R$. aquáticus $\mathrm{L}$.

Untere Bl. herzförmig-rundlich, stumpf und bespitzt, $7 \cdot 5-20 \mathrm{~cm} 1$. und br., obere lanzettlich; St. 0.3-1 m h. - Alpen, Böhmerwald, Riesengebirge, Sudeten, auf fettem Boden. 4. 7-10. $R$. alpinus $\mathrm{L}$.

12. (1) St. zerbrechlich, liegend od. aufsteigend, sammt den Bl. bläulich beduftet; Bl. 3 ekig-spießförmig, Bltrauben kurz, locker, bllos, Frklapp 
schwielenlos. - Steinige Plätze der Alpen, verwildert in B. u. Mh., zuweil. auch cult. 4. 5-7. Römischer Spinat, R. scutatus L.

St. niclit zerbrechlich, sammt den Bl. grün; männl. Blt. größer als dio weibl.

13.

13. St. meist einfach, $7 \cdot 5-15 \mathrm{~cm}$ h., in eine einzige bllose Traube endigend; Bl. dicklich, fast alle grundständig, die äußeren herzeirundlich, die innere spieß-eifürmig. - Gerölle der Alpen in Sz. u. Kir. (1900 bis $2600 \mathrm{~m})$. 4. 7. 8 .

R. nivális Hegetschw.

St. meist eiufach, sehr saftig, mehrere bllose Trauben in einer Rispe tragend, Frklapp. meist roth.

14.

14. Frklappen herzförmig-rundlich, 3-4 $\mathrm{mm}$ l. u. br., mit kurzer Schwiele am Grunde.

Frkl. eirund, schwielenlos, $1 \mathrm{~mm}$ l.; St. liegend bis aufrecht, 15 bis $30 \mathrm{~cm}$ l., saftlos, Bl. schmallauzettlich, meist mit wagrechten Olırchen, welche bisweilen 2-3 spaltig ( $R$. multifidus DC.). - Auf Sand, Schutt, Gerölle. 4. 5-7. R. Acetosella L.

15. Bl. pfeil- od. spießlanzettförmig, bl॰ß mit Mittelrippe, plan oder wellig, mit ganzen abwäirts gerichteten Öhrchen; Nebenbl. zerschlitzt; St. 30--45 cm h. - Wiesen. 4.5-7. S a u e rampfer, $R$. Acetósa L.

Var. $\beta$. Kochii (Willk.). St. meist mehrere, 0.60-1 $m$ h., Nbl. sitzend, brlineal, wellig gekräuselt, lang zugespitzt, Ölırchen zerschlitzt. - Auf Auenwiesen.

BI. aus pfeilförmigem Grunde eifürmig od. 3eckig-lïnglich, außer d. Mittelrippe mit 5-7 strahligen Nerven, grundständig. bis $5 \mathrm{~cm} \mathrm{br}$; Nebenbl. ganz, tutenförmig; St. $0 \cdot 30-1 m \mathrm{~h}$. - Anf Wiesen und an Bächen d. Hochgebirge. 4. 7. 8. . $R$. arifolius All.

\section{Oxyria Hill. Säuerling (VI, 2).}

BI. grundständig, nierenfürnig mit langem Stiel; St. bllos, 6-12 cm hoch, in eine bllose Quirltraube endigend; Frklapp. roth. - Gerölle der Alpen $(1900-2530 \mathrm{~m})$. $6-8$.

\section{Polýgonum L. Knöterich (V-VIII, 3).}

St. beblättert, Bl. ganzrandig mit röhren. od. trichterförmigen häutigen Nebenbl. (Gelenkscheiden). Zwitterbltige Kr.

1. Bl. kurz u. breit, herzpfeilförmig, zugespitzt.

Bl. viel lïnger als br.

2. St. aufrecht, $30-60 \mathrm{~cm}$ h.; Blt. in Trugdolden od. Ähren; Per'gon das Niisschen nur am Grunde umhüllend.

St. windend, Bl. langgestielt, Blt. grünlichweiß. 3.

3. Blt. weiß oder rosenroth in verzweigten Trugdolden; Nüsschen ganzrandig. - Aus Asien, auf Sandboden cult. ค. 7. 8.

B uc h weizen, Ha idek orn, P. Fagopýrum L.

Blt. grünlich, in schlaffen Ähren; Nüsschenlsanten ausgeschweift. gezähnt. - Aus Asien, Unkraut auf Buchweizenfeldern. ๑. 7. 8.

P. tataricum L.

4. Trauben wenigbltig,, innere Perigonzipfel stumpf gekielt; St. $0 \cdot 15$ bis $1 \mathrm{~m} \mathrm{l}$. - Unkiaut auf bebautem Boden. ๑. 7-9.

P. Convólvulus L. 
Trauben vielbltig, innere Perigonzipf. am Kiel brgeflügelt, St. bis 2 m 1. - In Hecken, Gebüschen. $\odot$. 7-9.

$P$. dumetórum L.

5. (1) Blt. zu 1-4 blwinkelständig, griinlich od. rëthlich; St. liegend, ästig, 10-15 cm l.; Bl. kl. elliptisch bis lineal, Gelenkscheid. glänzend. weil. - Unkraut auf Beeten, PGaster, an Wegen. ๑. 6-10.

Vogelknöterich, $P$. aviculaive L.

Blt. in endständigen bllosen Ähren.

6. Wz. od. Wzst. dünn, St. meist ästig.

7.

Wzst. knollig, wurmförm. gekrümmt; St. einfach mit ein er Ähre. 1巨.

7. Einjährige Arten, Wz. senkrecht fasrig.

S.

Ausdauernde mit kriechendem Wzst. $u_{\text {. }}$ aufsteigendem St.; Bl. ge. stielt, Blt. 5 männig, rosenroth, in walziger Ähre. $4.6-S$.

\section{P. amphíbium L.}

Variet. $\alpha$. aquáticum:. St. untergetaucht, Bl. langgestielt. länglich, schwimmend, Ähren aufgetaucht. In Teichen, Seen; 3. terrestre: St. kriechend od. aufrecht, Bl. lanzettförmig, steifhaarig. Auf Teichschlamm, an Utern.

8. Gelenkscheiden trichter-bis tellerförmig, Blt. 7 männig, purpurroth. in walzigen, hängenden Ähren. St. $1-3 m$ h., Bl. oval. - Zierpt. aus dem Orient. $\odot .6-8$.

$P$. orientale $\mathrm{L}$.

Gelenkscheiden röhrig, angedrückt, Blt. meist 6 männig.

9. Ähren gedrungen, walzig, aufrecht od. nickend.

Ähren locker, fadenförmig, nickend od. hängend; Gelenkscheiden borstig gewimpert.

13.

10. Gelenkscheid. nicht od. kurz gewimpert.

11.

Gelenkscheid. lang borstig gewimpert, steifhaarig; Bl. kahl, lanzettförmig od. länglich, oft schwarz gefleckt; Blt. hellroth, selten weiß; St. 0.30-1 $\mathrm{m} \mathrm{h}$, aufrecht od. liegend. - Unkraut auf fettem Boden. $7-10$.

Flohkrant, P. Persicária L.

11. St. knieförmig aufsteigend, ausgebreitet-ästig. 12.

St. viele, niedergestreckt, sehr ästig, strahlig ausgebreitet; Bl. rundlich-ei .. bis lanzettförmig, unterseits grau od. weißlich wollig od. kahl; Blt. roth, Ähren rispig gruppiert. - Sandige Flussufer in B., Mh., Noe.; zerstreut. $\odot$. 8. 9 .

$P$. danubiale Kern.

12. Blt. und Bltstiele drüsig punktiert, erstere hellgrün od, röthlich, in kurzen, dicken Ähren. St. 30-60 $\mathrm{cm}$ h., Bl. lanzettlich bis lineal, oft schwarz gefleckt, kahl od. unten graufilzig (P. incanum Schm.). - Äcker, Schutt. $\odot .7-9$.

$P$. tomentosum Schrk.

Blt. und Bltstiele drüsenlos, erstere hellroth, grünlich oder weiß. Ähren rispig gruppiert; St. $1-1.5 \mathrm{~m}$ h., Internodien roth gefleckt; $\mathrm{Bl}$. eilänglich, oft mit schwarzem Fleck, untere groß. - Flussufer. (P. nodosum P.) $\odot$. 7-10.

P. lapathifolium $\mathrm{L}$.

13. (9) Brennendscharf schmeckend, Blt. grünlich, röthlich, weiß, drüsig punktiert; St. $30-60 \mathrm{~cm}$ h., Bl. lanzettlich bis lineal, glänzend. - Gräben, feuchte Plätze. ๑. 8. 9. Wasserpfeffer, P. Hydrópiper L.

Geschmacklos od. herb schmeckend.

14.

14. Blt. 5 männig, hellroth; St. $30-60 \mathrm{~cm}$ 1., Bl. $6-21 \mathrm{~mm}$ br.; lanzettlich; Gelenkscheiden borstig behaart. - Feuchte Plätze, Gräben, zerstreut. $\odot .7-9$.

P. mite Schrk. 
13lt. 6 männig, hellroth od. weiß; St. fadenförmig, 15-30 cm l.; Bl. 4-S $m m$ br., lineal-lanzettlich, Gelenksch. angedrückt-behaart. - Ebenso. ○. $6-10$.

P. minus Huds.

15. (6) Ähre schmächtig, ihre ober. Blt. weif od. röthlich, untere in röthliche Zwiebellinospen verwandelt; St. $7 \cdot 5-15 \mathrm{~cm} \mathrm{h.,} \mathrm{Bl.} \mathrm{lanzettlich.}$ - Wiesen und Gerölle d. Alpen (1600--2000 m). 4. 6-8.

P. viviparum L.

Ähre walzig, aus lauter rosenrothen Blt. bestehend; St. $0.30-1 m$ hoch. Bl. länglich-laızettförmig, grundständ. langgestielt, groß. - Wiesen. 4. 7. 8 . Natterwurz, B lutkraut, $P$. Bistorta L.

\section{Fam. XLIV. Santalćceae. Sandelholzartige.}

\section{Thesíum L. Bergfiachs $(V, 1)$.}

Kahle vielstenglige $\mathrm{Kr}$. mit zerstreuten linealen od. lanzettlichen spitzen Bl.; Blt. seitenständig, gestielt, von Deckbl. gestuitzt, weiß.

1. Unter jeder Blt. nur 1 Deckbl.; Fr. kuglig, beerenartig, gelb, halb so 1. als d. röhrige, oben eingerollte Perigon. St. $10-20 \mathrm{~cm}$ h. Auf Kies und trockenen Grasplätzen in B., Sz., K., T.; sehr zerstreut. 4. 6. 7.

Th. rostratum M. K.

Unter jeder Blt. 3 Deckbl.; St. einfach od. rispig-ästig. 2.

2. Eingerolltes Perigon so 1. od. länger als d. kuglige Fr. 3 .

Eingerolltes Perig. viel kürzer als d. längliche Fr.

3. Bl. lineal, 1 nervig; St. aufstrebend od. liegend, $15-30 \mathrm{~cm}$ lang, von der Mitte an einseitswendig-traubig; Perigon meist 4 theilig. - Hochgebirgstriften. 4. 5. 6.

Th. alpinum L.

Variet. tenuifolium (Sauf.), St. von d. Mitte an rispig-ästig, Blt. in allseitswendiger Traube. 00e. (am Steyrbach, in d. Feichtau).

Bl. lineal bis lineallanzettl., 3 nervig; St. $15-45 \mathrm{~cm} \mathrm{h.,} \mathrm{aufreclit,}$ bltentragende Ährchen fast wagerecht abstehend; Perigon 5 theilig. Bergwiesen in 13., Ml., Me., K.; zerstreut. 4. 6. 7. Th. pratense Ehrh. gezähnt.

4. (2) Mittleres Deckbl so 1. od. kürzer als d. Fr.; Perigonzipfel

Mittleres Deckbl. viel länger als d. Fr.; Perigonzipf. ganzrand. 6.

5. Bl. schmallineal, 1 nervig; St. anfstrebend, bis $30 \mathrm{~cm} 1$, oben rispig-ästig, Ästchen ausgespreizt, Fr. walzig-länglich; Wzst. ohne Aus. läufer. - Alpen von K. u. Kr.; zerstreut. 4. 7. 8.

Th. divaricatum Jacqu.

Bl. lineal-lanzettlich bis lanzettförmig., obere $3-5$ nervig; St. aufrecht, $15-30 \mathrm{~cm}$ h., oben pyramidenförmig rispig-ästig, Ästchen trug. doldig verzweigt, Fr. ellipsoidisch. - Berrwiesen u. sonnige Hügel. 4. $6-8$.

Leinblatt, Th. Linophyllum L.

Variiert. $\alpha$. minus Neilr. (Th. intermedium Schrd.), unterirdische Auslänfer treibend. Bl. undeutich 3 nervig; - 3 . majus Neilr. (Th. montanum Ehrh.), ohne Ausl., Bl. deutlich 3-5 nervig.

6. (4) St. einfach, $5-20 \mathrm{~cm}$ h.; Bl. 1 nervig, dunkelgrïn, Blt. längs d. Stengels traubig. - Brachen, Weiden. Raine in Mh. und Noe; zerstreut. $\odot$ od. $\odot .5$.

Th. humile Vahl. 
St. nach oben rispig-ästig, 8-30 $\mathrm{cm} \mathrm{1.;Bl.} 1$ nervig; Blt. längs der Äste tranbig. - Trockene Triften, Brachen im südlichen Mh. u. in Noe. (b. Laxenburg); zerstrent. $\odot, \odot$ od. 4. 5-8. Th. ramosum Hayne.

\section{Fam. XLV. Lorantháceae. Riemenỏlumenartige.}

\section{Loranthus L. Riemenblume (VI, 1).}

Sommergrüner Schmarotzerstrauch mit gabeltheiligen Stämmchen und Ästen. Bl. gegenständig, verkehrt-eiförmig od. länglich; Blt. in schmächtigen Trauben, kl. gelbgrün; Beeren hellgelb. - Auf Eichen, zerstreut. 5. 5. 6 .

Eichen mistel, L. europaeus L.

\section{Viseum 1. Mistel (XXII, 4).}

Immergrüner, gabeltheilig verästelter Schmarotzerstrauch. Bl. elliptisch od. länglich, keilig, dick. Blt. in endständigen Knäueln, gelb, Beeren weiß. - Auf allerhand Laubbäumen, auch Edeltannen. \$. 2-3.

\section{V. album L.}

Var. la xum (Boiss-Reut.), Bl. lineal-länglich, schwach sichelförm.; Beeren gelblich. Auf Kiefern in B., Mh., T.; selten. 2-3.

Fam. XLVI. Daphnoídeae. Seidelbastartige.

\section{Thymelaea Tourn. Sperlingssehnabel (VIII, 1).}

St. aufrecht, schlank, einfach od. ästig, $15-30 \mathrm{~cm}$ h.; Bl. lineallanzettlich, Blt. achselständig, kl., grünlich. (Stellera Passerina L.). Äcker, Brachen, Raine in B., Mh., Sçh., Oe., zerstreut. ๑. 7. 8.

\section{Th. Passerina Coss. Germ.}

\section{Daphne L. Seidelbast (VIII, 1).}

Kleinsträucher mit wechselständigen, ganzen und ganzrandigen $\mathrm{Bl}$.; Beeren giftig.

1. Blt. frïhzeitig, purpurroth, wohlriechend, in gedrängt stehenden Büscheln an den Seiten der $\mathrm{Z}$ weige; Beeren scbarlachroth. Sommergriiner Str. bis $1.25 m$ h.; Bl. lanzettlich. - Gebirgswälder, auch cult. Ђ. 3. 4. Kellerhals, D. Mezeréum L.

Blt. erst mit den Bl, aufblühend.

2. Blt. rosenroth, in endständigen, doldenformigen Büscheln; BI. lineal-keilig. Immergriine Kleinstr. $15-30 \mathrm{~cm} \mathrm{~h}$.

Blt weiß od. gelb.

3. Blt. gestielt, wohlriechend, äußerlich sammt d. St. und obersten B1. Haumhaarig. - Auf trockenen Triften, in Kiefernwäldern in B., Mh., Oe., St., K.; zerstreut. Ђ. 5. 6. Steinrös chen, D. Cneórum L.

Blt. sitzend, geruchlos, sammt St. und Bl. kahl. - Felsige, grasige Plïtze d. Alpen von 00̈., St., K., Kr., T.; zerstrent. b. 7. 8.

Ste inrösl, D. striata Tratt.

4. Sommergrüner Kleinstr. von $0.30-1.30 m \mathrm{H}$; Bl. lanzettlich od. verkehrt-eiförmig, Blt. in endständigen Büscheln, weil. - Felsen d. Kalkalpen. 5. 5-7.

D. alpina $L$.

Immergrüne Klstr., $30-60 \mathrm{~cm} \mathrm{~h}$. 
5. Blt. grüulichgelb, in blwinkelständigen, hängenden Trauben. Beeren schwarz; Bl. keilig-lanzettförmig. - Bergwälder in 0e., T.; zerstreut. 5. 3. 4.

D. Lauréola L.

Blt. gelblichweiß in endständ. Büscheln, Bl länglich-verkehrt-eiförm., stachelspitzig. - Bergwälder von St. und Kr.; selten 5.6 .7$.

D. Blagayana Freyer.

\section{Fam. XLVII. Elaeágneae. Oleasterartige.}

\section{Elaeagnus Id. Oleaster (IV, 1).}

Sommergrüne B. od. Str.; Bl. wechselständig, ganzrandig, beiderseits silberweiß schuppig; Blt. blwiukelständ., innen gelb, außen beschuppt, wohlriechend. Z:ergehölze.

1. Bl. lanzettförnig, spitz. - Aus Siideuropa. 5. 5. 6.

Olwe id e, Bals a mw e ide, $E$, angustifolia L.

2. Bl. elliptisch od. länglich, stumpf. - Aus Nordamerika. 5. 6. $E$. argéntea Prsh.

\section{Hippóphä L. Sanddorn (XXII, 4).}

Sparrig verästelter, sommergrüner Str. mit dornspitzigen, rostroth beschuppten Zweigen; Bl. lineal-lanzettlich, oben grün, unten silberweißbeschuppt; Blt. kl., gelb, zwischen den jungen Bl. sitzend; Beeren goldgelb, braun punktiert. - Auf Kiesbänken der Alpenbäche und in den Donauanen, auch cult. 5. 4. 5.

$H$. rhamnoides $\mathrm{L}$.

\section{Fam. XLVIII. Aristolochiaceae. Osterluzeiartige.}

\section{Aristolóchia L. Osterluzei (XX, 3).}

1. Blt. gelb od. grünlichgelb; Kr, mit einfachen aufrechten St. 2. Blt. grün, einem Tabakspfeifenkopf ähnlich, Kletterstrauch aus Nordamerika mit gr. herznierenförm. Bl. - Häufig cult. †. 7. 8.

\section{Pfeifenstrauch, $A$. Sipho L.}

2. Blt. gelb: gebüschelt in den Winkeln der nierenförmigen Bl.; St. 0.30-1 $\mathrm{m}$ h., hin- und hergebogen. - Weinberge, Ackerränder, Gebüsche; zerstreut. 4. 5. 6.

A. Clematitis L.

Blt. grünlichgelb, roth geadert, einzeln in den Winkeln der 3 eckigeiförmigen Bl.; Wzst. knollig, St. $30-60 \mathrm{~cm} \mathrm{h.} \mathrm{-} \mathrm{Bebuschte} \mathrm{Hügel} \mathrm{in}$ Sz. und Kr.; zerstreut. 4. 5. A. pállida Willd.

\section{8. Ásarum L. Haselwurz (XI, 1).}

Wzst. kriechend, St. verkürzt, anfsteigend, Bl. gegenständig, lang gestielt, nierenförmig; Blt. einzeln endständig, kurz gestielt, gewürzhaft, mit außen grünlichem, innen purpurbraunem Perigon. - Laubwälder, schattige Gebüsche. 7f. 4. 5.

A. europaeum L. 


\section{B. Gamopétalae: mit ganzblättriger Blumenkrone.}

\section{Fam. II. Cucurbitáceae. Kürbisgewächse.}

209. Cucúrbita L. Kiirbis (XXI, 6).

St. liegend oder kletternd, sammt d. weclıselständigen, hındförmig gelappten Bl. scharfhaarig, mit 2-3 theiligen Wickelranken. Blt. einzeln, achselständig, gelb, Fr. kuglig od. länglich. Culturpf.

1. Fr. glatt, sehr verschieden an Größe und Färbung. - Ans Ostindien. $\odot .6-10$.

Gemeiner Kürbis, C. I'cpo L.

Fr. gerippt, höckerig, warzig.

2. Fr. vor d. Scheitel eingeschnürt, sonst der Länge nach gerippt und gefurcht. - Zierkürbis aus Ostindien. $\odot$. 6-9.

Tii rke ubund, C. Melopepo L.

Fr. nicht eingeschnïrt, kuglig, warzig-höckerig. - Wie vorige.

W arzenk ürbis, C. verrucosa $\mathrm{L}$.

210. Cúcumis L. Gurke, Melone (XXI. 6).

Wickelranken einfach, Blt. gebiischelt, sonst wie vorige Gattung. Culturpflanze.

4. Fr. langgestreckt. Bl. spitzlappig, Blt. gelb. - Aus Ostindien. $\odot .6-9$.

Gemeine Gurke, C. sativus L.

Fr. kuglig od. ellipsoidisch.

2.

2. Bl. tief handtheilig, Fr. kürbisförmig, griin, glatt, geruchlos, inwendig mit sehr saftreichem, rothem od. gelbem Fleisch; Samen schwarz. - Aus Ostindien, in St., Kr., siidl. T. gebaut. ๑. 7-9.

Wassermelone, Arbuse, C. Citrullus Ser.

Bl. ungetheilt, abgerundet-eckig, Fr. sehr wohlriechend, glatt, gestreift, genetzt od. gerippt (Cantaluppen). - Aus Asien, cult. $\odot .6-9$. Melone, C. Melo L.

211. Bryonia L. Gichtribe, Zaunribe (XXI u. XXП, 6).

Kletterp H. mit rübenförmigem, fleischigem Wzst. u. einfachen Wickelranken; Bl. gestielt, herzförmig, 5-7lappig; Blt. kl., grünlichweiß, in achselständ. gestielten Trugdolden; Fr. kuglig, erbsengroß.

1. Blt. einhäusig, Narbe kahl, Fr. schwarz. - In Hecken und Gebiischen in B., Hh., Noe. und den sïdlichen Kronländern; zerstreut. 4. 6. 7 .

$B$. alba L.

2. Blt. 2 häusig, Narbe rauhhaarig, Fr. roth. - Ebenso, doch viel seltener und meist nur verwildert. 4. 6.7. B. dióica L.

Anmerk. Beide Arten werden häufig zu Lauben und Wandbekleidungen verwendet.

Fam. L. Campanuláceae. Glockenblüller.

\section{Schlïssel der Gattuugen.}

1. Blkrone radförmig, 5 lappig; Stbf. am Grunde verbreitert; Kapsel prismatisch, 3 fächrig, unter d. Spitze mit 3 Löchern aufspringend.

Specularia (212). 
Blkr. glockig od. röhrig.

2. Blkr. glocken-, trichter- od. rölırenförmig, 5 lappig; Stbf. am Grund. eiförmig verbreitert; Kapsel 3 fächrig, mit seitlich. Löchern aufspring. 3.

Blkr. vor dem Aufblühen röhrig, dann von unten nach oben in 5 lineale Abschnitte sich trennend.

3. Gr. fadenförmig, am Grunde ohne Ring, mit 3-5 Narben.

Campanula (213).

Gr. ebenso, am Grunde von einem napfförmigen, drüsigen Ringe umgeben, mit 3 Narben, weit vorragend.

Adenophora (214).

4. Stbf. am Grunde verbreitert, Stbb. frei; Gr. fadenfürmig, mit 2 bis 3 Narben, Kapsel 2-3 fächrig, mit seitlichen Löchern aufspringend. Phyteuma (215).

Stbf. fadenförmig, Stbb. am Grunde zusammenhängend, Narben 2, Kapsel 2 fächrig, an d. Spitze mit ciı em Loch sich öffnend. Jasione (216).

\section{Speculairia Heist. Venusspiegel $(\mathrm{V}, 1)$.}

Blt. kurz gestielt, blau, in end- und seitenständigen Trugdolden; St. 7-15 cm 1., Bl. schwach gekerbt od. ganzrandig, untere gestielt, läoglich-verkehrt-eiförmig, obere sitzend, lanzettlich.

1. Äste ausgebreitet, Kelchzipfel lineal von der Länge der Blkr., Frkn. ebenso lang od. länger. - Unter Getreide der südlichen Kronländer, in Oe., Mh., B. eingeschleppt; zerstreut. ๑. 6. 7. S. Spéculum DC.

2. Äste aufrecht, Kelchzipfel lanzettförmig, kürzer als die Blkr., Frkn. viel länger als diese. - Unter Getreide in $\mathbf{K r} ., \mathbf{K}$., T.; zerstreut. ๑. 6. 7 .

S. hýorida DC.

\section{Campánula L. Glockenblume (V, 1).} beblättert.

Blt. verschieden angeordnet, Bl. wechselständig, ganz, St. meist ästig,

1. Buchten zwischen den Kelchzipfeln ohne Anhängsel.

2.

Buchten zwischen den Kelchzipfeln mit zurückgeschlagenem Anhängsel.

2. Blt. gestielt, einzeln, end- und achselständig, oft in Trauben oder Rispen.

3.

Blt. sitzend, in Büscheln, welche eine zusammengesetzte Ähre bilden oder in einem endständ, von den obersten Bl. umhüllten Köpfchen. 18.

3. Blkr. aufgeblasen-röhrig, vor der Mündung eingeschnürt mit in. wendig gebarteten Zipfeln, hellblau; St. 5-10 cm l., Bl. kl., ganzrandig, unterste oval, die andere lanzettlich; Blt. einzeln, end- und achselständig. - Gerölle und Felsen d. Kalkalpen von K. und Kr. $(2000-2700 \mathrm{~m}) .4$. 7. 8 .

Blkr. trichter- od. glockenförmig, Zipfel nicht bärtig.

4. Bl. verschieden gestaltet, grundständ. nieren-, herzei- od. verkehrteiförmig, kl., stengelständ. lineal od. lineal-lanzettlich; Kapseln hängd. 5 .

Bl. alle ziemlich gleichgeformt, gesägt, bisweilen lineal und ganzrandig (danı d. Kelchzipfel lanzettförmig).

5. Kelchzipfel schmallineal, fast so lang wie d. glockenförmige blaue Blkr.: St. 15-30 $\mathrm{cm}$ l., einfach, schlaff, meist $1 \mathrm{bltig}$. - Felsspalten der Kalkalpen v. St., K., T., Kr.; zerstreut. 4. 6. 7. C. cárnica Schiede. Kelchzipfel pfriemenförm., lıalb so l. als d Blkr. od. noch kürzer. 6 . 
6. Blkr. glockig-trichterförmig bis walzig.glockig, dunkelblau. 7 .

Blkr. mit aufgetriebenem Schlunde, walzig-glockig bis fast halbkuglig, blassblau, bis $13 \mathrm{~mm}$ l.; Blt. in einseitiger Traube; St. 5-15 cm h., sehr zahlreich, rasenbildend; grundständ. Bl. herzförmig, langgestielt, untere Stbl. gesägt. - In den Alpenländern an Felsen, auf Gerölle, Sand, im Kies der Bäche. 4. 6-8.

C. pusilla Hke.

Var. Hoppeaua (Ruppr.), 1 bltig. Blkr. tiefblau. In $\mathbf{K}$, selten.

7. Blt. end- und achselständig, in einseitiger Traube, St. meist einfach, Wzst. rasig.

Blt. einzelnstehend, in lockerer Rispe, Blkr. 13-18 $\mathrm{mm} \mathrm{1.;} \mathrm{St.} 7$ bis $30 \mathrm{~cm}$ h., nach oben sehr ästig; grundsständige Bl. nierenförmig-rundlich, Äste mit kl. linealen Blättchen. Sehr vielgestaltig, kahl oder behaart. Wiesen, Grasplätze, Raine, Felsen. 4. 6-10.

C. rotundifolia $\mathrm{L}$.

8. Blkr. bis $25 \mathrm{~mm}$ l., St. $5-25 \mathrm{~cm}$ l., einzeln, grundständ. Bl. herzfürmig, lang gestielt, untere Stbl. elliptisch od. lanzettlich. - Hochgebirgstriften. 24. 7. 8.

C. Schéuchzeri Vill.

Blkr. $13 \mathrm{~mm}$ 1., Blt. nickend; St. sehr zahlreich, rasig, $8-30 \mathrm{~cm}$ hoch; grundständ. Bl. oval od. verkehrt-eiförmig, kurz gestielt, Stbl. steif, glänzend. - Felsspalten und Gerölle der Kalkalpen. 24. 7. 8.

C caespitosa Scop.

9. (4) St. einfach, 1- bis vielbltig.

10.

St. traubig- od. rispig-ästig, mehr- bis vielbltig.

10.

10. Niedrige vielstenglige rasenbildende Pfl, St. $2 \cdot 5-10 \mathrm{~cm}$ h., eiublütig; Bl. gekerbt, untere oval od. elliptisch, oberste lanzettlich; Blt. nickend, dunkelviolett. - Alpentriften (1:00-1900 m), besond. auf Kalk. 4. 7. 8 .

C. pulla L.

Nicht rasenbildend; St. $0.30-1.60 \mathrm{~m}$ h., Blt. in endständiger, meist einseitswendiger Traube, selten einzeln am Ende d. St.

11.

11. Unterste Bl. lanzettlich od. länglich-verkehrt-eiförmig, in d. Stiel verschmälert, d. folgenden lanzettlich bis lineal; Kapseln aufiecht. 12.

Unterste Bl. am Grunde herzförmig od. rundlich, langgestielt, die folgenden an Größe allmählich abnehmend; Blt. nickend in lang. Traube, Kapseln hängend.

13.

12. Blkr. halbkuglig-glockig, 25-37 $\mathrm{mm}$ l, blau, selten weiß, Kelchzipfel lanzettlich; St. straft. - Wälder, Gebüsche. 4. 6. 7.

C. persicifolia L.

Blkr. glockig-trichterförmig, $13-25 \mathrm{~mm}$ l, hellviolett, Kelchzipfel pfriemenförmig; Wz. spindelförmig, fleischig. - Grasige Orte, Wegränder, Gebüsche in Mh. und $\mathbf{0 e}$; zerstreut (in 0e. auch cult.). $\odot .5-8$.

Rapunzel, C. Rapúncu?us L.

13. Blkr. $377-5 \mathrm{~cm}$ l., walzig-glockenförmig, dunkelblau od. weiß, Kelchzipfel eilanzettförmig; St. 4 kantig, Bl. grob, doppelt gekerbt-gesägt, untere sehr gr. Kahl od. rauhhaarig. - Bergwälder, feuchte Gebirgsthäler; zerstreut. 4. 7. 8.

C. latifolia $\mathrm{L}$.

Blkr. bis $25 \mathrm{~mm}$ l., glockig-trichterförmig, Kelchzipfel lanzettlich, I3lt. sehr zahlreich in einseitiger Traube.

14.

14. Blkr. 18-25 $\mathrm{mm}$ 1., violett od. lila, Gr. vorstehend, Wzst. kriechende Ausläufer treibend. Kahl od. behaart. - Auf bebautem Boden, Schutt. 4. 6-9. C. rapunculoides $\mathrm{K}$. 
Blkr. $13 \mathrm{~mm} \mathrm{1,} \mathrm{dunkelviolett,} \mathrm{Gr.} \mathrm{eingeschlossen;} \mathrm{Wzst.} \mathrm{ohne} \mathrm{Aus-}$ läufer. - Bebuschte Hügel, trockene Wälder in B. u. Mh.; «erstreut. 7. 8 . C. bononiensis $\mathrm{L}$.

15. (9) Unterste Bl. herzförmig, langgestielt; St. traubig-ästig. 16.

Unterste Bl. ei- od. lanzettförmig, in einen kurzen Stiel verschmälert.

16. Steif borstenbaarig, St. scharfkantig, $0 \cdot 5-1 m$ h., Bl. grob- od. eingeschnitten doppelt-gesägt, Blt. geknäuelt od. traubig in 1. zusammcngesetzter 'Traube, Blkr.walzig-glockig, bis $5 \mathrm{~cm}$ l., violettblau (selten weiß). - Gebiische, Laubhaine, Ufer. 4. 7. 8. H alskraut, C. Trachélium L.

Kahl, St. stumpflkantig, bis $3 \mathrm{~m}$ l., Bl. gesägt; Blt. in zusammengesetzter pyramidaler Traube, Blkr. glockig, bis 25 mm 1., hellblau. Wild in Kr., sonst Zierpfl. ๑. 7. 8.

C. pyramidalis $\mathrm{L}$.

17. St. zerstreut- od. rispig-ästig, dünn, 30-60 $\mathrm{cm}$ h., Bl. schwach gekerbt, Blt. einzeln, endständig, anfrecht, Blkr. brglockenförnig, i 8 bis $25 \mathrm{~mm}$ 1., lila. Kahl oder behaart. - Wiesen, Grasplätze. ๑. 5 6.

\section{C. pátula $\mathrm{L}$.}

St. nur an d. Spitze traubig-ästig, Blt. in zusammengesetzter Traube, ästige Form d. C. Rapunculus (s. 10).

bis $60 \mathrm{~cm} \mathrm{~h}$.

18. (2) Blt. in end- und seitenständigen, kopfigen Büscheln; St. 15

Blt. in eiı. Ähre, Blkr. walzigg-glockenförm.; ganze Pfl. rauhhaarig. 20.

19. Kahl, tlaumig od. kurz scharfhaarig; Bltbiischel von deckblatt. artigen eiförmigen zugespitzten häutigen Bl. umhüllt., Blkr. violett; $\mathrm{Bl}$. lanzett- od. eiförmig. - Trockene Wiesen, bebuschte Hiigel. 4. 6-9.

\section{C. glomerata $\mathrm{I}_{\text {. }}$}

Variet. $\beta$. aggregata (Willd.), achselständ. Bltknäuel entfernt, daher Ähre länger; Blt. größer, Blstiel breit geflïgelt; - $\%$ specios a (Horn.), obere Bltbüschel in ein endständ. Köpfchen zusammengedrängt, mit den übrigen eine Traube bildend; Blt. größer.

Steif borstenhaarig, grau; Hüllbl. d. halbkugligen Köpfchen von den übrigen Stbl. nicht verschieden; Blkr. dunkel- od. hellblau, Bl. länglich od. lanzettförmig, gekerbt. - Laubwälder, Gebiische, Waldwiesen; zerstreut. 4. 6. 7.

C. Cervicaria $\mathrm{L}$.

20. Blkr. violett, Gr. eingeschlossen; Bltähre lang, am Grunde unterbrochen; St. $30-60 \mathrm{~cm}$ 1., reich beblättert, Bl. gekerbt, unterste zungenförm., in Rosette. - Trockene felsige Hänge d. Kalkalpen v. K., T., IIr.; zerstreut. $\odot .6$. 7 .

C. spicata L.

Blt. gelblichweiß, Gr. weit vorstehend, Bltähre länglich, dicht. St. $15-30 \mathrm{~cm}$ h. dichtilättrig, Bl. ganzrandig, länglich-lanzettförm., unterste in Rosette. - Wiesen u. Abhänge d. Alpen v. Noe., St., K., T., Ḱr. ๑. 7. 8 .

C. thyrsuidea $\mathrm{L}$.

21. (1). Narben u. Kapselfächer 3, Blt. nickend bis hängend. 22.

Narben u. Kapselfächer 5; Blt. einzeln am Ende blwinkelständiger Ästchen, Blkr. 3-4 cm l., weitröhrig-glockig, blau od. weiß; St. $15-45 \mathrm{~cm}$ h., Bl. eiförmig.länglich. - Zierptl. aus Südeuropa. 4. 6. 7. 
22. Blt. in zusammengesetzter rispiger Traube, Blkr. $18 \mathrm{~mm} 1$. himmelblau, Kelchanlänge lineal-lanzettlich; St, 15-45 cm h., Bl, länglichkeilförmig. Scharfhaarig. - Trockene Grasplätze, Gebüsche in IIh. u. Noe.; zerstreut. $\odot .5 .6$. C. sibirica L.

Blt. in einfacher Traube, ihre Stiele achselständ., mit kl. Blättchen besetzt, Blkr. walzig-glockenförmig. 23.

23. Kelchanhänge eiförmig, halb so 1. als d. Kelchzipfel; Blkr. 25 bis $37 \mathrm{~mm}$ l., hellblau, bärtig gewimpert; St. $8-30 \mathrm{~cm}$ h., grundständ. Bl. eiläıglich, obere lineal. Raulhaarig. - Wiesen d. Alpen, auch im Gesenke u. Glatzer Geb. 4. 7. 8.

C. barbata L.

Kelchanhänge viel kürzer als d. Kelchzipf., Blkr. 8-25 $\mathrm{mm}$ l., azurblau; St. 2.5-15 cm l., grundständ. Bl. keilförm., in dichter Rosette, d. übrigen lineal-lanzettlich. Zottig behaart. - Triften u. Gerölle d. Alpen, besond. auf Kalk. 4. 7. 8.

C. alpina L.

\section{Adenóphora Fisch. Becherglocke (V, 1).}

St. einfach, rund, $0 \cdot 30-1 m$ h.; Bl. verkehrt-ei- bis lanzettförmig, gesägt; Blt. in endständ. Rispe od. einfacher Traube, nickend, Blkr. bauchigglockig, blassblau. - Bebuschte Bergwiesen und Gebiische in B. u. Kr.; zerstreut. 4. 7-9. A. liliifolia Bess.

\section{Phyteúma L. Rapunzel $(\mathrm{V}, 1)$.}

Blt. in endständigen Körbchen, Köpfchen od. Ähren, selten in eïnfacher Dolde. St. einfach, abwechselnd beblättert.

1. Blt. gestielt, in einfacher Dolde, B!kr. verkehrt-birnförmig, blau mit dunkelvioletter Spitze; St. liegend od. aufsteigend, $5-15 \mathrm{~cm} \mathrm{l}$; grundständige Bl. langgestielt, nierenförmig, Stbl. lanzettlich. - Felsspalten d. Kalkalpen von $\mathbf{K}$., T., Kr.; zerstretit. 4. 6. 7. Ph. comósum L.

Blt. sitzend, in einern von grünen Deckbl. umhüllten Korbchen oder in kopfiger Ähre; Blkr. röhrig, oft gekrümmt.

2.

2. Blt. in ein kugliges Körbchen vereinigt, blau od. violett. 3.

Blt. in eiförmiger (später oft walziger), am Grunde von linealen Deckbl. umringter Ähre; St. $30-60 \mathrm{~cm}$ h.. untere Bl. gestielt, herz- od. herzeiförmig.

3. Bltkörbchen 5-6 bltig, Hüllbl. eiförmig-rundlich; St. 1·3-65 cm hoch, Bl. verkebrt-eilanzettförmig, grundständ. in Rosette. - Hohe Alpenjoche $(1900-2850 \mathrm{~m})$ in St., K., T. 4. 7. 8. Ph. pauciflórum L.

Bltkörbchen mindestens 12 bltig.

4. Hüllbl. lineal, spitz, länger als d. Blt.; St. $30-60 \mathrm{~cm}$ h., straff, untere Bl. langgestielt, herzeiförmig od. herzeilanzettf, obere lineal-lanzettlich, alle gesägt. - Felsige Alpentriften in St., K., T., Jír. 4. 7. 8. Ph. Schéuchzeri All.

Hïllbl. ei- od. eilanzettförmig, halb oder fast eben so lang od. länger wie d. Bltn.; St. 5 bis $15 \mathrm{~cm}$ h., selten lïnger.

5. Bl. lineal od. lineal-lanzettförmig, meist ganzrandig.

Unterste Stbl. wie d. Bl. der unfruchtbaren Büschel langgestielt, herzei- od. lanzettförmig, obere Stbl. sitzend, rautentörmig-lïnglich, alle gesägt od. gezähnt; Hüillbl. schmal, länger als d. Blt., gewimpert, zurückgekrümmt. - Grasige Triften, Wiesen; zerstreut. 4. 5-8. 
Variet. $\alpha$. genui num Rehb., Decklul. eilanzettlich, kaum gesägt; - $\beta$. fis tulos um (Rehb.), ebenso, St. straff, hohl. Alpenländ.; - . S e beri (Spr.). Deckbl. eiförmig zugespitzt, gesägt. Kalkalpen. in $\mathbf{T}$.

6. St. oben nackt, Hiillbl. ei- od. eilanzettförmig, lang zugespitzt, ganzrandig od. gezähnt, gewimpert. - Triften d. Alpen (1580-2200 m). 4. 7. 8 .

Ph. hemisplatericum L.

St. bis zum Körbchen beblättert, Hüllhl. br. eiförmig, ganzrandig, ganzrandig-gewimpert, - Grasplïtze der Urgeb., Alpen von St., K. ı. 'T.; zerstreut. 7. 7. S.

Ph. confusum Kern.

7. (2) Blt. gelblich od. grünlichweiß, ̈̈hre längİich; Bl. doppelt gekerbt-gesägt, untere herzeiförmig, sehr lang gestielt. - Wiesen, Ufer, Laubwälder. 4. 5. 6. Ph. spicatum L.

Blt. hell- bis schwarzviolett.

3. Ähre walzig (bis $5 \mathrm{~cm}$ l.), dicht; Deckbl. kurz, lineal, gauzrand., Blt. hellviolett; Wzst. knollig. - Wiesen, Gebüsche d. suidl. Alpenländer, bis K.; zerstreut. 4. 7. 8.

Ph. Michelii Bertol.

Variet. $\alpha$. bet o n i c a e folium (Vill.), grundständ. Bl. herzförmig odeiförmig-länglich; - $\beta$. scorzonerifolium (Vill.), untere Bl.

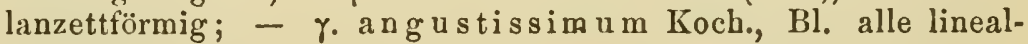
lanzettlich.

Ähre eiförmig, länglich od. verkehrt-eiförmig; Blt. schwarzviolett. 9.

9. Deckbl. lineal, ganzrandig, Bl. einfach gekerbt. - Frische Wiesen, schattige Laubwälder in B. und in den Alpenländern; zerstreut. 4. 5. 6. Ph. nigrum Schm.

Deckbl. lineal-lanzettförmig, gekerbt; Bl. doppelt gekerbt od. einreschnitten-gesägt. - Schluchten und Wiesen in K., Kr., T.; zerstreut. 4. 6. 7 .

Ph. Hálleri All.

\section{Jasióne L. $(\mathrm{V}, 1)$.}

Vielstenglig, St. $15-30 \mathrm{~cm}$ h., meist von unten an ausgebreitet ästig, unten reichlich beblättert, sonst nackt, Bl. lineal-lanzettlich, wellig, behaart; Blt. himmelblau, in abgeplattet-kugligen, von Hüllbl. umringten, endständ. Körbchen. - Sonnige Hügel, Raine. $\odot$. $6-9$.

J. montana L.

\section{Fam. LL. Ambrosiacene, Ambrosiaceen.}

\section{Xánthium L. Spitzklette (XXI, 6).}

St. ästig, aufrecht, robust; Bl. wechselständig, gestielt; Blt. grünlich in end- und achselständigen Trauben.

1. St. und Äste mit 3 theiligen, gelben Dornen, Bl. ganz od. 3 spalt., unterseits schneeweiß, St. $30-60 \mathrm{~cm}$ h. - Aus dem Süden eingeschleppt und stellenweis verwildert. $\odot .7-10 . \quad X$ spinosum L.

St. und Äste unbewehrt, Bl. groß, beiderseits grün, behaart, gezähntgekerbt.

2. Bl. herzförmig-3 lappig, mit gezackten Lappen, Frhüllen 10 bis $13 \mathrm{~mm}$ l., eiförmig, kurz behaart, drüsig, zerstreut bestachelt, Stacheln gerade, an d. Spitze lıakig. St. bis $60 \mathrm{~cm}$ h. - Auf Schutt, an Wegen, Mauern; zerstreut. $\odot . ~ 7-10$.

X. slrumárium L. 
Bl. am Grunde keilig, ganz od. schwach 3-5 lappig; Frhüllen 16 bis $25 \mathrm{~mm}$ l., länglich, dicht bestachelt; St. $0.5-1 m \mathrm{~h}$. - An sandigen Ufern in B. (Elbufer von Raudnitz abwärts, gemein). $\odot .7-10$.

X. italicum Moretti.

\section{Fum. III. Compósitce. Korbblütler.}

A. Liguliflórae s. Cichoriáceae, Zungenblütige: alle Blt. des Körbchens zwitterlich, mit zungenförmiger Blkr.

\section{Schlüssel der Gattungen.}

1. a) Fr. ohne oder mit schuppigem Pappus.

2.

b) Fr. mit einem haarigen Pappus.

6.

c) Fr. mit einem aus tedrig. Haaren od. Borsten gebild. Pappus. 15.

2. Distelartige, von Dornen starrende Staude; Fr. mit gekerbtem Kelchrande. Scolymus (218).

Uornenlose Gewächse. gelb.

3. Fr. mit kronenartigen Kelchsaum oder undeutlich berandet; Blt.

Fr. mit schuppigem Pappus, $3-5$ kantig; Blt. himmelblau.

Cíchorium (222).

4. Fr. 5 kantig, mit kurzem, 5 kantigem, abfälligem Krönchen; Hüllschuppen 1 reilhig, zur Frzeit kuglig zusammenschließd. Arnoseris (220).

Fr. zusaminengedrückt, mit undentlichem Kelchsaum; Hïllschuppen 1 reihig, auch zur. Frzeit aufrecht.

5. St. bllos, einfach. 1 köpfig; Fr. 5 riefig.

5.

St. beblitttert, ästig, vielköpfig; Fr. vielrippig. Lampsana (219)

6. (1, b.) Pappus sitzend.

Pappus gestielt.

Aposeris (221).

7. Fr.stielrund, gerippt od prismatisch-kant., nicht zusammengedrückt, geschnäbelt (darin am Grunde des Schnabels glatt) cd. schnabellos. 8.

Fr. spindelförm., halbrund, stumpfkantig, nicht gerippt, ungeschnäbelt; Pappus schneeweiß, weich, 1 reihig.

Chlorocrepis (241).

Fr. zusammengedrückt, ungeschnäbelt, gerippt.

9.

8. Hüllschuppen 2 reihig, äußere meist kürzer; Fr. gegen die Spitze verdünnt od. kuı geschnäbelt, Pappus rein weiß, weich. Crepis (239).

Hülisch. ziegeldachig, selten 2 reihig, Fr. walzig, gestutzt, Pappus schmutzig bis röthlich- od. bräunlichweiß, spröde, zerbrechlich.

\section{Hieracium (240).}

9. Bltkörbchen meist nur 5 bltig, Blt. purpurn; Korbhiille schmal walzig, 2 reihig.

Prenanthes (235).

Bltkörbchen vielbltig.

10.

10. Korbhülle walzig, fast 2 reihig; Blt. blau, Pappus schmutzigweiB, von einem dichtborstigen Krönchen umgeben.

Mulgedium (238),

Korbhïlle ei- od. fast kegelförmig, ziegelschuppig; Blt. gelb; Pappus schneeweiß, weich, ohne Außenkrönchen.

Sonchus (237).

11. (6) Pappusstiel (fädlicher Schnabel d. Fr.) glatt.

Pappusstiel am Grunde mit Knötchen od. Schüppchen besetzt. 13, 
12. Korbhülle 2 reihig-schuppig, walzig, äußere Reihe sehr kurz. Crepis (z. Th. 239).

Korbhülle walzig, zur Frzeit am Grunde meist bauchig, 2- bis vielreihig-schuppig od. dachzieglig; Blt. gelb, selten blau. Lactuca (236).

13. Bltkörbchen mit nur 7-12 Blt. in 2 Reihen; Korbhülle walzig, 1 reihig-Łlättrig, am Grunde von sehr kleinen Schuppen umringt.

Chondrilla (233).

Bltkörbchen vielbltig.

14.

14. St. ästig, beblättert; Korbhülle 2- bis mehrreihig-schuppig, Fr. prismatisch 5 kantig, Kanten dick, oberwärts knotig querrunzlig.

Willemetia (234).

St. einfach, bllos, hohl, 1 lsöpfig; Korbhülle walzig, 2 reihig, äıßere Reihe viel kiirzer, Frrippen mit schuppigen Weichstacheln bedeckt.

Taraxacum (232).

15. (1, c.) Pappus sitzend, Frboden nackt, Korbhülle dachzieglig. 16.

Pappus gestielt. Büschel.

16. St. bllos, mit od. ohne Schuppen; Grundbl. in Rosette oder

St. beblättert.

17.

18.

17. Nur die Scheibenfr. mit fedrigem Pappus, die Randfr. mit einem gezähnten Krönchen; St. einfach 1 köpfig.

Ihrincia (2:4).

Alle Fr. mit fedrigem Pappus, St. einfach od. ästig, meist beschuppt.

Leontodon (223).

(Fr. einem Stielchen aufsitzend, St. 1 köpfig. Scorzonera aristata, s. 19.)

18. St. rispig-ästig, Bltkörbchen kırz gestielt, traubig-trugdoldig; Fr. kurz geschnäbelt, Haare des Papp. in einen Ring verwachsen, äußere kürzer einfach, innere fedrig.

Picris (225).

St. einfach od. nach oben hin wenig ästig; Bltkörbchen endständig, lang gestielt.

19.

19. Fr. einem später hohlen Stielchen aufsitzend u. mit demselben abfallend; BI. schmal, ganz, meist auch ganzrandig. Scorzonera (228). theilig.

Fr. am Grunde von einer dicken hohlen Schwiele gestützt; Bl. fieder-

20. (15) Bltkörbchen von herzförmigen Deckbl. umhüllt.

$\begin{array}{ll}\text { Bltkörbchen ohne Deckbl. } & 21 . \\ \text { 21. Frboden spreublättrig, Korbhülle ziegeldachig. } & 22 .\end{array}$

Helminthia (226).

Frboden nackt, Hüllbl 1 reihig, Fr. langgeschnäbelt, Bl. lineal.

21. Tragopogon (227).

22. Pappushaare 2 reihig, die der äußeren Reihe kürzer, nicht fedrig. Hypochaeris (230)

Pappushaare 1 reibig, alle fedrig. Achyrophorus (231). 


\section{Scólymus L. Golddistel (XIX, 1).}

St. 0 30-1 $m$ h., sparrig-ästiø̋, wollhaarig und an den Kanten gefligelt; Bl. fiederspaltig sammt den Flügeln dornig; Bltkörbchen achselständig, mit dornspitzigen Hüllschuppen, Blt. goldgelb. - Aus Siideuropa, verwildert in $\mathbf{K} \mathbf{r}$. und um Wien. $\odot .6-\mathrm{S}$.

S. hispanicus $\mathbf{L}$.

\section{Lámpsana L. Rainsalat (XIX, 1).}

St. 0.30-1 $m$ h., rissig-ästig; Bl. ausgeschweift-gezühnt; untere leierfölmmig, gestielt, die anderen länglich, sitzend; Bltkörbchen doldentraubig, Blt. schwefelgelb. - Unkraut auf bebautem Boden und in Gebïschen. $\odot .6-8$.

L. communis $\mathrm{L}$.

\section{Arnóseris Gärtn. Lämmersalat (XIX. 1).}

Bl. grundständig in Rosette, länglich, ausgeschweift od. bucbtig cezälunt; St. meist mehrere, $10-20 \mathrm{~cm} \mathrm{~h}$, einfach od. gabeltheilig, nackt, unter d. endständ. Blłkörbchen keulig aufgeblasen; Blt. schwefelgelb. Auf sandigen Äckern; zerstreut. ○. 6-8.

A. minima Lk.

\section{Apóseris Neck. Hainsaiat (XIX, 1).}

Stinkendes Kraut; Bl. grundständig in Rosette, schrotsägeförmigfiederspaltig; St. einfach, nackt, $1 \mathrm{köpfig,} \mathrm{bis} 24 \mathrm{~cm}$ h.; Blt. schwefelgelb. - Wiesen und feuchte Waldplätze der Alpenlïnder; zerstreut. 4. 7. 8. 4. fóetida Less.

\section{Cichórium L. Cichorie (XIX, 1).}

Grundständige Bl. in Rosette, St. sparrig-ästig, wenig beblättert; Bltkörbchen in end- und achselständigen Knäueln. Stbl. sitzend, buchtig gezähnt.

1. Bltkörbchen zu 2-3, eins sitzend, das andere gestielt; St. 30 bis $60 \mathrm{~cm}$ h.; Wzst. spindelförmig holzig (od. hei d. Culturpt. fleischig). An Wegen, Rainen, auch cnlt. 4. 7. 8.

Cichorie, Wegwarte, Hindläufte, C. Intybus L.

2. Bltkörbchen zu 5, je 4 auf einem gemeinschaftlichen, 1 a uf einem besonderen Stiel; St. $0.6-1.3 m$ h.; grundständ. Bl. länglich, bei den cult. PA. zertheilt, zerschlitzt, kraus, vielgestaltig. - Aus Indien, cult. u. verwild. (.) 7. 8 .

Endivien, C. Endivia L.

\section{Leóntodon L. Lörenzahn (XIX, 1).}

Bl. grundständ., in Rosette, St. einfach $1 \mathrm{köpfig} \mathrm{und} \mathrm{bllos} \mathrm{od.} \mathrm{ästig,}$ mehrköpfig, beschuppt; Korbhülle walzig, ziegelschuppig, Blt. gelb.

1. St. meist ästị, mehrköpfig, $10-60 \mathrm{~cm}$ h., Äste nach oben verdickt und beschuppt, Bltkörbchen aufrecht; Bl. gestielt, lanzettförmig, gezähnt, schrotsägeförm. od. kammförmig-fiedertheilig. - Wiesen. 2. $7-9$.

\section{L. autumnalis L.}

Variet. $\beta$. trichocéphalus Neilr., Korbhülle schmutzigweiß oder schwärzlich-zottig. Hochgebirgswiesen. - \% monocéphalus Neilr. St. 1 köpfig, oberwärts reich beschuppt. Kalkalpen.

St. einfach und $1 \mathrm{köpfig.}$

2. Wzst, abgebissen, kurz walzig, mit dicken Wzfasern.

Wzst. verlängert, senkrecht; Bltkörbch. vor d. Aufblihen nickend. 5. 
3. Bltkörbchen stets aufrecht, Korbhülle und oberer Theil d. 2.5 bis $10 \mathrm{~cm}$ h. St. mit weißen gekräuselten Härchen besetzt u. zugleich schwärzlich lang-zottig; Bl. keilig-lanzet,tich, ganzrandig bis schrotsä,refürmig. Triften der Kalkalpen. 4. 7. 8. L. Taráxaci Lois.

Bltkörbchen vor dem Aufblühen nickesd; St. unter dem Bltkörbchen verdickt.

4. Korbhülle und verdickter Stengeltheil schwärzlich-zottig, St. 7 bis $30 \mathrm{~cm} \mathrm{h.;} \mathrm{Bl.} \mathrm{mit} \mathrm{schmalem} \mathrm{Stiel,} \mathrm{länglich-lanzettförmig,} \mathrm{ganzrandig} \mathrm{oder}$ gezähnt; Blt. gold- bis safrangelb. - Triften und Gerölle d. Kalkalpen. 4. 7. 8 .

L. pyrenáicus Gou.

Korbhülle und verdickter Sttheil ohne schwarze Haare, St. 15 bis $30 \mathrm{~cm}$ h.; Bl. mit geflügeltem Stiel, länglich- od. keilig-lanzettförmig, gezähnt bis fiederspaltig. Sehr vielgestaltig. - Wiesen, Triften. 24 6-10. L. hástilis Koch.

Varietät. $\alpha$. glabratus Neilr. Kahl oder mit Gabelhaaren spärlich bestreut; - B. híspidus Neilr. St. und Bl. oder nur d. Bl. gabelhaarig, Korbhülle flaumig od. borstlich; - - . hyoseroídes Koch, Bl. bis zur Mittelrippe fiedertheilig, Fiedern lineal; kahl oder gabelharig. Kalkalpen; - o. o pímus Koch, St. dick, sammt d. br. dicken fetten Bl. kahl od. gabelhaarig; Bl. gescbweift od. buchtig gezähnt. Kalkalpen; - $\varepsilon$. ps eudocrisp u s C. H. Schultz, Bl. kurzhaarig, fiedertheilig; Zipfel grob gezähnt, wellig-krausig. Auf Kalkgerölle in $\mathbf{K}$.

5. (2) Bl. tief fiedertheilig, nackt d. $10-20 \mathrm{~cm}$ h. St. gabellaarigrauh; Bltkörbch. $25 \mathrm{~mm}$ br. - Sonnige Felsen in Kr. und sïdl. T.; zerstreut. 4. 6. 7.

L. crispus Vill.

Bl. ganzrandig, lïnglieh-lanzettlich, nebst d. $15-30 \mathrm{~cm}$ h. St. und der kreiselförmigen Korbhülle gabelhaarig-graufilzig; Bltkörbchen 25 bis $50 \mathrm{~mm}$ br. - Auf Felsen und Gerölle der Kalkalpen, auch in Mh. (selten!). 4. 5. 6.

$L$. incanus schrk.

\section{Thrincia Roth. Hundslattich (XIX, 1).}

Wzst. schief abgebissen. St. einfach, dünn, nackt, 1 köpfig, $5-20 \mathrm{~cm}$ lang, Bl. grundständig in Rosette, lanzetfförmig, buchtig gezähnt od. ganzrandig, rauhhaarig. - Feuchte sandige Triften in Mh, Oe., K.; zerstreut. 4. 7. 8 .

Th. hirta Roth.

\section{Picris L. Bitterkraut (XIX, 1).}

St. $30-60 \mathrm{~cm}$ h., sammt den länglich-lanzettförmigen, buchtig gezähnten oder ganzrand. Bl. kurz steifhaarig, rauh; Bltkörbchen $25 \mathrm{~mm}$ br., Blt. gelb. - An wüsten Plätzen, Waldrändern, auf Hügeln; zerstreut. (-) od. 4. 7. 8 .

$P$. hieracioides L.

\section{Helminthia Juss. Wurmsalat (XIX, 1).}

Weichstachlig und steifborstig. St. $30-60 \mathrm{~cm}$ h., ästig, Bl. liinglichlanzettförmig, buchțig gezähnt; Bltkörbchen doldentraubig, 25-37 $\mathrm{mm}$ br., Blt. gelb. - Aus Siideuropa eingeschlepptes Ackerunkraut; hier und da. ๑. $6-8$. 


\section{Tragopógon I. Bocksbart (XIX, 1).}

Kahle milchende Kräuter. St. einfach od. ästig, Bl. mit scheidig erweitertem Grunde halbstengelumfassend, lineal od. lineal-lanzettlich, lang zugespitzt, ganzrandig; Bltkörbchen endständig, Blt. gelb.

1. St. $30-60 \mathrm{~cm}$ h.; unter d. (ausgebreitet) $5 \mathrm{~cm}$ br. Bltkörbchen keulenförmig aufgeblasen; Korbhüllbl. meist 12. - Wiesen, Hügel, besond. auf Kalk, in B., Mh., Oe.; zerstreut. -). 5-7. T. major Jacqu.

St. $50-60 \mathrm{~cm}$ h., sammt d. Ästen unter d. Bltkörbchen nicht ver; dickt; Korbhülle 8 blättrig.

2. Bltkörbch. (ausgebreitet) $3.7 \mathrm{~cm}$ br., Blt. hellgelb; Fr. so lang wie d. Pappusstiel. - Wiesen, Grasplätze. $\odot .5-7$.

T. pratensis L.

Eltkörbchen 5-6 cm br., Blt. goldgelb; Fr. viel länger als d. Pappusstiel. - Fette Auenwiesen besonders weiter Flussthäler. ๑. 5-7.

T. orientalis $\mathrm{L}$.

\section{Scorzonérà L. Schwarzwurzel (XIX, 1).}

Milchende Kräuter. St. einfach od. ästig, Bl, meist ganzrand., grundständig, gestielt in Büscheln, Stbl. halbstengelumfassend. Bltkörbchen endständig, mit walziger Hülle.

1. Blt. purpurviolett od, rosenroth, Bltkörbchen bis $4 \mathrm{~cm}$ br.; St. 15 bis $45 \mathrm{~cm}$ h., 1-bis mehrköpfig; Bl. schmallineal, Stbl. wenige, alle sammt d. St. kahl od. spinnwebwollig. - Sonnige Hügel und Bergwiesen in B., Mh., Oe., K., IIr., besonders auf Kalk; zerstreut. 4. 5. 6.

Blt. gelb. S. purpurea L.

2. Kopf d. Wzst. fasrig-schopfig; St. einfach, 1 lsöpfig, nackt od. mit einigen Schuppen, $2.5-25 \mathrm{~cm}$ h., kürzer als d. länglich. bis lineallanzettlichen Bl.; Bltkörbchen 25-37 $\mathrm{mm}$ br., Pappus weiß. - Sonnige Hügel und Bergwiesen in Mh. und Oe.; zerstreut. 2.4.5. S. austriaca Willd. weiß.

Kopf d. Wzst. trockenhäutig-schuppig od. nackt; Pappus schmutzig.

3. Bltkörbchen nur $14-24 \mathrm{~mm}$ br., St. $1-3 \mathrm{köpfig,} 14-45 \mathrm{~cm}$ h., ganz beblättert, Bl. lanzettlich od. lineal-lanzettförmig, rinnig. Kahl. Sumpfige Wiesen in B., Mh., Noe.; zerstreut. 4. 5-7.

S. parviflóra Jacqu.

Bltkörbchen 37-50 $\mathrm{mm}$ br., Pf. kahl od. spinnwebwollig. 4.

4. St. zur Hälfte reich beblättert, nach oben in nackte Äste getheilt, $0.30-1.30 m$ h.; Bl. lineal-lanzettlich bis elliptisch, lang zugespitzt, ganzrandig od. gezähnt. - Grasige Hügel u. Wiesen in Noe., Ml., B.; zerstreut; häufig cult. 4. 6. 7. S $\mathrm{chwarzwurzel,} \mathrm{S.} \mathrm{hispanica} \mathrm{L.}$

St. bllos od. mit $1-3 \mathrm{Bl}$. besetzt, meist einfach, $8-30 \mathrm{~cm}$ h. 5 .

5. St. 1-3 köpfig, 2-3 blättrig, Bl. lineal bis elliptisch, spitz. Feuchte Wiesen in B., Mh., Oe.; verbreitet. 4. 5. 6. S. húmilis L.

St. einfach, 1 köpfig, bllos, Bl. lineal-lanzettförmig; äußere Hüllbl. mit pfriemlicher Spitze. - Alpenwiesen in K., T., Kr. (2200-2850 m); zerstreut. 4. 7.

S. aristata Ramd. 
 \\ 229. Podospérmum EC. Stielsame (XIX, 1).}

Milchende Kr., St. meist ästig, Bl. meist fiedertheilig bis fieder. schnittig; Bltkörbchen endständ., mit walziger ziegelschuppiger Hülle; Blt. schwefelgelb, Pappus bräunlichweiß.

1. St. $8-45 \mathrm{~cm}$ h., sammt d. Ästen stielrund, gerieft; Bltkörbchen $13 \mathrm{~mm}$ br., Randbit. kürzer als d. Korblülle. - An Wegen, auf steinigen

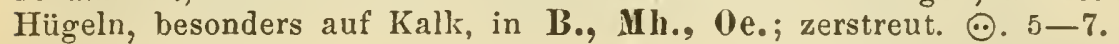

P. laciniatum DC.

2. St. 15-60 cm h., sammt d. Ästen gefurcht; Bltkörbchen $37 \mathrm{~mm}$ br , Randblt. von d. Länge d. Hüllbl. - Wïste Plätze, Raine in B., Mlh., Noe. 4. $7-8$.

P. Jacquinianum Koch.

\section{Hypochíeris L. Ferkelkraut (XIX, 1).}

St. einfach od. ästig, ohne Bl., nur beschuppt; Bl. rosettenständig, ungestielt; Bltkörbchen endständ., mit walziger, ziegelschuppiger Hülle; Blt. gelb.

1. St. einfach od. gabelästig, 2- od. mehrköpfig, wenig heschuppt, $15-30 \mathrm{~cm}$ h.; Bl. keilförmig-länglich, buchtig gezähnt od. schrotsägeförm.; Bltkörbchen 10-13 mm br. - Auf Sand- u. bebaut. Boden', in Wäldern;

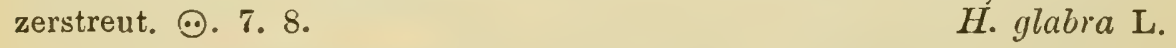

2. St. gabelästig, reichlich beschuppt, $2-5 \mathrm{köpfig}, 30-60 \mathrm{~cm} \mathrm{~h}$; B Bl. länglich-verkehrt-eiförmig, buchtig gezähnt od. schrotsägeförmig mit starker gelbweißer Mittelrippe: Bltkörbchen $25-37 \mathrm{~mm}$ br. - Wiesen, Triften. 4. $7-8$.

$H$. radicata $\mathrm{L}$.

\section{Achyróphorus Koch. Hochelkopf (XIX, 1).}

Wie vorige, ab. St. unten beblättert u. sammt d. Bl. kurz steifhaarig.

1. St. einfach, 1 köpfig, nach oben stark verdickt und röhrig, 8 bis $30 \mathrm{~cm} \mathrm{~h}$; grundständ. Bl. länglich-lanzettförm., gezähnt; Bltkörbch. bis $5 \mathrm{~cm}$ br. - Hochgebirgstriften. 4. 7. 8. A. uniflórus Bl. Fing.

2. St. einfach od. gabeltheilig, $30-60 \mathrm{~cm} \mathrm{~h}$; grundständige Bl. eiförmig-länglich, ganzrandig od. geschweift od. gezähnt, oft purpurn gefleckt; Bltkörbchen 2-3 cm br. - Waldwiesen, Bergtriften, Hügel; zerstreut. 4. 6. 7.

A. maculatus Scop.

\section{Taríxacum Juss. Pfaffenröhrlein (XIX).}

Milchende Kr. mit rosetten- od. büschelständigen Bl. und einfachem bllosem, röhrigem, 1 köpfigem St.

1. St. dick, unter d. Bltkörpbchen und am Grunde od. ganz weißwollflockig, 5-30 cm h.; Bl. dick, oberseits graugrün, die ersten länglickverkehrt-eiförmig, die folgendeu buchtig-gelappt; Blt. hellgelb. - Grasige Hügel, Raine in Mh. u. Oc.; zerstrent. 4. 7-10. T. serótimum Sadl.

St. schlank, kahl od. spinnwebhaarig,

2. Äußere Schuppen d. Korbhülle zurückgeschlagen od. abstehend, Bltkörbchen $25-50 \mathrm{~mm}$ br. St. $25-30 \mathrm{~cm}$ 1., 51 . meist schrotsägeförm. Yielgestaltig. $4.3-5$.

Maiblume, Hunde-, Kuhblume, T. officinale Wigg.

Variet. $\alpha$. g enuinum Koch. (Leontod. Taraxac. L.). Bltkörbchen groß. Slı. goldgelb, äußere Hüllbl. zurückgeschlagen. Wiesen, Willk $\supset \mathrm{mm}$, Schulfora. 
Grasplätze; - 3. corniculatum Neilr. Hiillbl. wie bei voriצem, áber an d. Spitze gehörnt, Bltkörbchen kl., Blt. schwefelgelb.

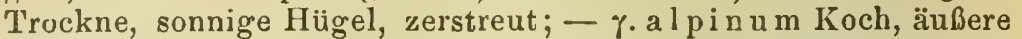
Hiillbl. abstehend, St. niedrig, liegend od. aufsteigend, Bltkörbch. kl., Blt. goldgelb. Grasige Joche d. Kalkalpen; - ó. ta raxacoídes Koclı, Bl. schrotsägeförmig mit zerschlitzten Zipfeln od. ganz, buchtig-gezähnt; Bltkürbchen kl., Blt. goldgelb. Alpen.

Außere Hüllschuppen aufrecht od. angedrückt; St. $2 \cdot 5-60 \mathrm{~cm}$ h., Blt. blassgelb, selten ( $b$ :. T. Pàcheri) orangegelb.

3. Bltkörbchen 25-37 $\mathrm{mm}$ br., Blt. citrongelb, unterseits grünlich; Bl. dicklig, bläulichgrün, schrotsägeförmig, gezähnt od. fast ganzrandig, lineal-lanzettlich bis lineal. - Sumpfige Wiesen; zerstreut. 4. 4. 5.

T. palustre DC.

Bltkörbch. $13 \mathrm{~mm}$ br., Blt. blassgelb, unterseits röthlich; Bl. lineal, ganzrandig bis fiederspaltig. Vielstenglig. - Feuchte salzhaltige Triften in B., Mh., Noe.; zerstreut. 4. 8-10. T. leptocéphalum Rchb.

\section{Chondrilla L. Knorpelsalat (XIX, 1).}

St. ästig, armblättrig od. fast bllos, grundständige Bl. in Rosette, Bltkörbchen kl., Blt. gelb, Pappus schneeweiß.

1. St. vom Grunde an ästig, liegend od. aufstrebend, $0.30-1.25 \mathrm{ml}$., sammt d. ruthenförmigren Ästen mit kl. lineal-lanzettl. Bi.; grundständige BI. schrotsägeförmig; Bltkörbch. geknäuelt-rispig. - Auf sandigen Äckern, Hügeln; zerstreut. $\odot$. od. 4. 7-9.

Ch. jincea L.

2. St. aufrecht, nur oben ästig, $20-35 \mathrm{~cm}$ h., fast nackt; Grundbl. lanzettlich, ganzrandig od. entfernt gezähıt; Bltkörbch. in endständiger Doldentraube. - Im Kies d. Gießbäche d. Kalkalpen; zerstreut. 4. 7. 8. Ch prenanthoides Vill.

\section{Willemétia Neck. (XIX, 1).}

St. 15-30 $\mathrm{cm}$ h., 1-3 köpfig, nebst d. Korbhüllen schwärzlich-raur haarig; Bl. kahl, verkehrt-eilanzettförm., gezähnt bis schrotsägeförmig; Blt. gelb. - Moorige Bergwiesen der Alpenländer, auch im südl. B. 7 . $6-8$.

W. apargioides Less.

\section{Prenanthes L. Hasenkohl (XIX, 1).}

St. $0 \cdot 60-1.30 m$ b., rispig-ästig; Bl. schwach buchtig-gezähnt, unterseits bläulich; Bltkörbch. in ausgebreiteter Rispe. Kahl. - Schattige Bergwälder. 4. 7. 8.

$P$. purpirea L.

\section{Lactúca L. Salat, Lattich (XIX, 1).}

Milchende kahle Kr.; St. meist traubig od. rispig ästig, Grunabl. in Rosette; Bltkörbchen zahlreich, klein.

1. Blt. blau, St. doldentraubig-ästig, 30-60 cm h.; Grundbl. fiedertheilig, eingeschnitten-gesägt, Stbl. kammförmig-fiedertheilig. - Felsiga Orte in B., K., Kr. T.; zerstreut. 4. 6. 7.

Blt. gelb.

2. Bltkörbch. sehr kl, 5 bltig.

2.

Bltkörbch. 8-16 bltig, mit ziegelschuppiger Hülle. 
3. Bltkörbchen mit 1 reihiger Hülle, in eiförmiger lockerer Rispe; St. 0.30-1 $m$ h., Bl, unterseits bläulichgrün, untere leierförmig. - Wälder. 4. 7. 8 .

Hasenlattich, L. muralis Gärtn.

Bltkörbchen mit ziegeldachiger Hülle, zu $1-3$ in den Achseln der schuppenförmigen Stbl. sitzend, Blt. schwefelgelb, unterseits lila; Grundbl. schrotsägeförm. bis kammförmig-fiedertheilig; St. $030-1 \mathrm{~m}$ h. - Felsige Abhänge, steinige Plätze in B., Mh., Noe., St., Kr. ๑. 7. 3.

L. viminea Presl.

4. Stbl. durch Drehung am Grunde senkrecht gestellt.

Stbl. nicht gedreht, horizontal, am Grunde pfeilförmig; St. 0.60 bis $1.6 \mathrm{~m}$ hoch.

5. Bl. dornig geziihnt, unterseits an d. Mittelrippe krautstachelig, unterste und mittlere fiedertheilig od. leierförmig; St. $0.60-1 m \mathrm{~h}$., Bltkörbchen rispig-doldentraubig. - Auf Schutt, an Wegen in B., Mh., Oe., Kr. $\odot$. 7. 8. Wilder Lattich, L. Scariola L

Bl nicht dornig gezähnt, unterste schrotsägeförmig, die übrigen ver. längert lineal, ganzrandig auf pfeilförm. Basis sitzend, St. $0.30-1 \mathrm{~m} \mathrm{~h}$, Äste ruthenförmig, Bltkörbchen in 1. schmaler beblätt. Rispe. - Auf bebautem Buden, wüsten Plätzen in B., Mh., Noe.; zerstreut. ๑. 7. 8.

L. saligna L.

6. Bl. scharf und fein gezälınelt, untere schrotsägeförmig mit großen 3 eckigen Endlappen, mittlere tief fiederspaltig, oberste ungetheilt; Bltkörbch. rispig-doldentraubig, Hüllschuppen schwarzroth geffeckt, Blt. sattgelb, kurz gestielt. - Laubwäld., besond. auf Kalk in B., Mh., Noe.; zerstreut. $\odot$. $6-8$.

L. quércina L.

Var. $\beta$. sagittata (W. Kit.), Stbl. alle ungetheilt, länglich oder elliptisch-lanzettförmig. In Mh. u. Noe.

Bl. ganzrandig, nur die oberen gezähnt, Blt. schwefelgelb, Pappus langgestielt. Sehr vielgestaltig bezüglich d. Bl. - Überall cult. ๑. 6. \%. Gartensalat, L. sativa L.

\section{Sonchus L. Sau-, Gïnsedistel (XIX, 1).}

Milchende Kr., St. aufrecht, meist ästig, beblättert; Bl. unterseits 'bläulichgrün, grundständ. mit geflügeltem Stiel; Bltkörbch. doldentraubig.

1. Einjährige Kr. mit dïnner Wz. und dünnen $\mathrm{Bl}$; St. $15-60 \mathrm{~cm}$ hoch; Bltliörbchen $25 \mathrm{~mm}$ br.

Ausdauernde $\mathrm{Kr}$. mit starkem Wzst. und fast lederartigen Bl.; St. oben drüsig behaart.

2. Bl. schrotsäge-leierförmig od. fiedertheilig, selten ganz, stachelspitzig gezähnt, obere stumfassend herz- od. pfeilförmig mit abstehenden, spitzen gezähnten Ährchen; Fr. querrunzlig. - Auf Schutt, bebautem Boden, $\odot$. $6-9$.

S. oleráceus L.

B]. meist ganz, selten gebuchtet bis fiederspaltig, ungleich dornig-

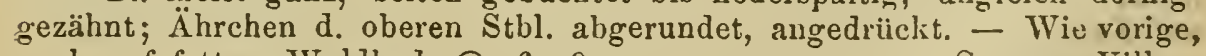
auch auf fettem Waldbod. $\odot$. 6-9.

S. asper Vill.

3. Wzst. kriechend, St. $0.30-1.30 m$ h., Bl. buchtig-fiederspaltig, fast dornig gezälınt; Bltkörbchen $25-50 \mathrm{~mm}$ br. - Unkraut auf Eeldern. 7 . .

S. arvensis $\mathbf{L}$. 
Var. uliginosus (M. Bieb.), Bltkörbchen kleiner, zahlreicher, drüsenlos. Feuchte Wiesen, an Gräben, Teichrändern in B., Mh., Oe.; zerstreut.

Wzst. nicht kriechend, St. 1-2 $m$ h., hohl, unten daumesdick; Bl. stachelspitzig gezähnt, unterste schrotsäge-fiedertheilig, oberste ungetheilt, stengelumfassend-pfeilförmig; Bltkörbchen 25-37 mm br. - An Ufern, in Sümpfen in K., Oe., Mh., B. (angebl.; meist mit S. uliginosis verwechselt). 4. 7-9.

S. paluster L.

\section{Mulgédium Cass. Milchdistel (XIX, 1).}

St. robust, hohl, straff, $060-1.60 \mathrm{~m}$ h, purpurn überlaufen, sammt den Körbchenstielen und Korbhüllen drüsenborstig; Bl. schrotsägeförmigleierförmig, mit sehr gr. spießförm. Endzipfel; Bltkörbchen 25-37 mm. breit. - Hochgebirge an Bächen, quellig. Orten. 4. 6. 8.

\section{M. alpinum Cass.}

\section{Crepis L. Pippau (XIX, 1).}

Kr. mit einfachem od. ästigem St.; Grundbl. meist in Rosette Bltkörbchen einzeln od. doldentraubig.

1. Fr. langgeschnäbelt, Hüllschuppen 2 reihig, äußere Reihe sehr kurz, Blt. geib (Barkhausia Mnch.).

Fr. nicht od. sehr kurz geschnäbelt (Crepis DC.). 2.

2. Bltkörbchen einzeln od. doldentraubig an 1. Ästen, vor d. Blühen nickend, Korbhülle borstighaarig; St. $15-45 \mathrm{~cm}$ h., steifhaarig, Bl. fiedertheilig od. schrotsägeförm.; Wz. stinkend. - An Wegen, Rainen in B., Mh., Noe. ๑. ๑. 6-8.

C. rhoeadifolia M. Bieb.

Bltkörbchen doldenrispig, kl., schon vor dem Blühen aufrecht, Hüllschuppen u. Körbchenstiele steifborstig; St. $30-60 \mathrm{~cm}$ h, Stbl. länglich, am Grunde pfeilförm. u. fiederspaltig, sonst gezähnt. - Vom Süden eingeschleppt, auf Felderu u. Wiesen in B., Mh., Noe.; zerstreut. $\odot$. ค. $6-9$.

C. setosa Hall.

3. St. nackt od. beschuppt, Bl. grundständ., in Rosette.

St. beblättert, wenigstens am Grunde; Blt. gelb.

4. Blt. hellpurpurn, Bltkörbchen 13-25 mm br. in ästiger Doldentraube am Ende d. 14-45 cm h. St.; Bl. verkehrt-eiförmig-länglich, gezähnt. - Bergwiesen d. Kalkalpen. 7. 6.

C. incarnata Tsch.

Blt. gelb bis orangeroth.

5. Bltkörbchen $13-25 \mathrm{~mm}$ br., in einfacher od. zusammengesetzter Traube am Ende d. 15-60 $\mathrm{cm}$ h. St.; Bl. elliptisch-lanzettförmig, geschweift-gezähnt; Wzst. abgebissen. - Waldwiesen, Wälder, besonders auf Kalk, zerstreut. 4. 6. 7.

C. pracmorsa Tsch.

Bltkörbchen $18 \mathrm{~mm}$ br., einzeln endständig, mit schwärzlich-rauhhaariger Hülle, Blt. safrangelb bis orangeroth; St. $1-3 \mathrm{köpfig,} 2.5-30 \mathrm{~cm}$ hoch; Bl. länglich, gezähnt od. schrotsägeförm. - Alpentriften, besonders. auf Kalk. 4. 7. 8.

C. auirea Cass.

6. (3) St. einfach 1 köpfig; Bltkörbchen $25-37 \mathrm{~mm}$ br.

St. ästig, mehr- bis vielköpfig.

7. St. d. ganzen Länge nach beblättert, $2-7 \mathrm{~cm}$ h., oben sammt d.. Korbhülle schwarzzottig-hehaart; Bl. länglich-lanzettförm., leier-od. schrot- 
sägeförmig fiedertheilig. - Steinige Triften d. Kalkalpen (2200-2550 m). 4. 7. 8 .

C. hyoséridifolia Tsch.

St. nur unten mit 1-2 Bl., Bl. buchtig gezähnt od. schrotsägeförm. 8.

8. Stbl. am Grunde herz-, pfeil- od. spießförnig, stengelumfassend, unterste verkehrt-eilanzettlich mit geflügeltem Stiel; St. $20-50 \mathrm{~cm}$ h. nebst d. schwärzlichen Korbhülle steifhaarig. - Triften und Gerölle der Kalkalpen. 4. 7. 8.

C. blattarioides Vill.

Stbl. am Grunde abgerundet od. verschmäl., nicht stengelumiass. 9.

9. St. robust, nach oben auffallend verdickt u. hier sammt d. Korbhülle schwarzzottig, $15-30 \mathrm{~cm}$. h.; Bl. kahl od. zerstreut behaart, grundständige mit kurzem breitgeflügeltem Stiel. - Alpenwiesen in Oe., Sz., K., T.; zerstrent. 4. 7. 8.

C. montana Tsch.

St. schmächtig, nicht verdickt, $8-30 \mathrm{~cm}$ h.; Korbhülle rauhborstig (oft drüsig), Bl. d. Rosette verkehrt-eilanzettförmig. Kahl od. flaumig. Trockene Berg- u. Alpenwiesen in Oe., Sz., K.; zerstreut. 4. 5-7.

C. alpestris Tsch.

10. (6) Ein- od. 2 jährige $\mathrm{Kr}$. mit dünner Wz.; St. $15-60 \mathrm{~cm}$ h., meist sehr ästig, mit sitzenden Bl.. Grundbl. gestielt; Bltkörbch. in Rispen od. Doldentrauben.

11.

Ausdauernde Pfl. mit schwarzem od, braun, vielfasrigem Wzst. 13.

11. Äußere Hüllschuppen angedrückt, St. bis $60 \mathrm{~cm} \mathrm{h.,} \mathrm{meist} \mathrm{viele,}$ aufsteigend od. niedergestreckt, oben glatt. Sehr vielgestaltig. - Wiesen,

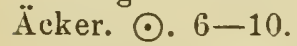

C. virens $\mathrm{L}$.

Äußere Hüllschuppen abstehend.

12.

12. Stbl. am Rande zurückgerollt, lineal, ganzrand., am Grunde pfeil- od. spießförmig, grundständ, buchtig gezähnt od. schrotsäge-fiederspaltig, mit linealen oft sichelförm. Zipfeln. - Auf Mauern, Dächørn, bebautem Boden. $\odot .5 .6$.

C. tectórum L.

Stbl. nicht zurückgerollt, untere und mittlere länglich, vielgestaltig (fast ganzrandig, buchtig-gezähnt, leier-, schrotsäge- bis kammförmig-fiedertheilig od. zerschlitzt); obere am Grunde gerundet, geöhrelt od. spießförm. - Wiesen, an Wegen. -). 5-7.

C. biennis $\mathrm{L}$.

13. (10) Erste grundst. Bl. spatelförmig, ganzrand. od. entfernt gezähnt, spätere sowie d. unteren und mittleren Stbl. fiedertheilig bis fiederschnittig mit lineal-lanzettl., oft sichelförm. Zipfeln, oberste lineal; St. $2 \cdot 5$ bis $30 \mathrm{~cm} \mathrm{~h}$., in $2-3$ einköpfige Äste getheilt; Korbhülle grauflockig od. schwarzzottig. - Gerölle u. Felsen d. Kalkalpen $(1580-2200$ m) . 4. 7. 8 . (C. Jacquini Tsch.)

C. chondrilloides Jacqu.

Bl. alle ungetheilt, meist buchtig.gezähnt.

14.

14. Stbl. sitzend, am Grunde abgerundet, untere kurz gestielt, in Rosette, alle länglich; St. $30-60 \mathrm{~cm}$ h., sammt d. Bl. kahl od. behaart: Körbchenstiele u. Korbhüllen schwärzlich behaart. - Wiesen, Bergtriften, Waldränder in IIh., 00e., T.; zerstreut. 4. 7. 8. C. succisaefolia Tsch.

Stbl. sitzend, am Grunde pfeil- od. spießförmig.

15.

15. Abstehend drüsig-rauhhaarig; St. stark, gefurcht, $15-45 \mathrm{~cm}$ h., wenig ästig; Bl. grob buchtig- bis schrotsägeförmig.gezähnt, grundständ. in Rosette; Bltkörbchen 25-37 $\mathrm{mm}$ br., einzeln. - Gebirgstriften der Alpen, Sudeten und des Riesengeb. 4. 7. $8 \quad$ C. grandiflóra Tsch. 
Kahl; St. schlank, straff, gefurcht, hohl, 0.30-1 $m$ h.; Bl. gezälınt unterseits bläulich, grundständ. länglich-lanzett- od. verkehrt-eiförmig, mit schmalem Stiel, obere Stbl. breitlanzettlich; Bltkörbch. in Doldentraube, 13-18 $\mathrm{mm}$ br. mit schwarzborstlicher Hülle. - Sumpfige Wiesen und Waldstellen. 4. 7. 8 . C. paludosa Mönch.

\section{Hierácium L. Habichtskraut (XIX, 1).}

Vielgestaltige Kräuter, die von den ihnen nahe verwandten Pippauarten am sichersten an dem spröden, schmutzig gefärbten Pappus unterschieden werden können.*)

1. Fr. höchstens $2.5 \mathrm{~mm}$ l., am abgestutzten oberen Ende gekerbtgezähnt, 10rippig, mit 1 reihigen Pappushaaren; Wzst. gewöhnlich mit Ausläufern (Pilosella).

Fr. 2.5-45 mm 1., oben nicht gezähnt, 10-13rippig. Keine Ausl. (A rehbieracium).

17.

2. St. einfach $1 \mathrm{köpfig,} \mathrm{borstig,} 2.5-30 \mathrm{~cm}$ h.; Bl. oberseits grasgrün, unterseits grau- bis weißfilzig, lanzett- od. keilförm.; Blt. ge!b, unterseits roth gestreift.

3.

St. gabeltheilig od. nach oben ästig, 2- bis viellöpfig.

3. Hüllschuppen schmallineal spitz, feinhaarig-filzig, drüsig u. zerstreut langhaarig, Blt. schwefelgelb, Bl. beiderseits borstig u. starrhaarig; Ausl. lang, beblättert. -- Trockene Grasplätze, Raine, Felsen. 4. 8-10.

\section{H. Pilosella $\mathbf{L}$.}

Hüllschuppen eilanzettlich, innerste stumpf, Bl. oberseits grün, fast kahl, unterseits schneeweiß filzig; Ausl. kurz, beblättert. - An gleichen Orten in d. Alpen v. Oe., Sz., K. 4. 7. 8. H. pilosellaeforme Hppe.

4. St. einmal od. wiederholt gabeltheilig, 2-4-7 köpfig, Bl. gelb. 5 .

St. oben doldentraubig-od.trugdold.ästig, meist viel $(10-100)$ köpf. 9.

5. Blt. unterseits rothgestreift.

Blt. beiderseits gelb.

6. Ausl. sehr kurz od. nicht vorhanden, St. aufsteigend, $2-5 \mathrm{köpfig,}$ 8-30 cm 1., sammt d. lanzettförmig. grünen Bl. lalig-borstenhaarig; Korbhülle schwärzlich zottig, nach dem Verblïhen kuglig. - Alpentriften in K. u. T. (bis $2270 \mathrm{~m}$ ). 4. 7. 8. H. sphaerocéphalum Froel.

Ausl. lang. blreich, kriechend, einzelne aufsteigend und Bltkörbchen tragend, sammt d. $8-30 \mathrm{~cm}$ h. St. dicht zottig; Bl. lanzett- bis spatelförm.. grün; Korbhülle halbkuglig, sammt Körbchenstiel schwarz drüsenhaarig ( $H_{\text {. }}$ flagellare W.). - Wiesen, Grasplätze in B. u. Mh.; zerstreut. 4. 5-7. H. stoloniflórum W. Kit.

7. (5) Wzst. lange, blreiche Ausläufer treibend.

Wzst. kriechend, sitzende Blrosetten tragend, Bl. keilig-, spatelig-od. länglich-lanzettförmig, borstenhaarig; St. 5-15 cm h., einfach, 1 blättrigr. oben 3-5 gestielte trugdoldig gruppierte Bltkörbchen tragend. - Alpenwiesen in $\mathbf{K}$. und T. $(1900-2500 \mathrm{~m})$; zerstreat. 4. 7. 8.

H. glaciale Reyn.

*) Ebendeshalb müssen von Hieracien auch fruchttragende Exemplare gesammelt. werden, wie auch mit Wurzeln begabte, um zu sehen, ob die betreffende Pf. Ausläufer besitzt oder nicht. Es können hier weder die zahlreichen Bastarde, noch der Formenkreis der Arten berücksichtigt werden, sondern bloß die verbreiteteren Haupttypen, welche zum Theil als Artengruppen betrachtet werden müssen. 
8. Bl. am Grunde gewimpert, sonst kahl, bläulichgrün, lanzett- bis spatelförmig; St. nackt od. 1 blättrig, $10-13 \mathrm{~cm}$ h., unten n. oben borstig. 1 köpfig od. an Ende 2-5 Bltkörbchen doldentraubig tragend od. gabeltheilig 2-5köpfig; Blt. schwefelgelb. - Wiesen, Grasplätze. 2. 5-10.

H. Aurícula $\mathrm{L}$.

Bl. borstenhaarig, lanzettlich, spitz, bläulichgrün; St. einmal oder doppelt gabeltheilig, 2-4köpfig, bllos, bis $30 \mathrm{~cm}$ h.; Korbhülle eiförmig, schwarz drüsig-borstig. - Trockene Raine, Grasplätze in B., Oe., St., K., T., Kr.; zerstreut. 4. $5-7$.

H. bifurcum M. Bieb.

9. (4) Bl. bläulich- od. graugrün. 10.

Bl. u. St. gras- od. gelblichgrün.

10. Bltkörbchen $8 \mathrm{~mm}$ br, zahlreich, in lockerer gabeltheilig. Trugdolde, Korbhülle walzig, schwärzlich; St. $15-30 \mathrm{~cm}$ h., nebst den Ästen drüsig behaart od. kahl; Bl. lanzettlich. Keine Ausl. - Bergwiesen, Gerülle, Kies der Flüsse in 0oe., T., Kr.; zerstreut. 4. 8. 9.

\section{H. florentinum All.} förmig.

BItkörbchen 10-15 mm br., auf sternfilzigem Stiel, Korbhülle ei-

11. Wzst. kriechend, unterirdische Auslüufer treibend; St. $10-50 \mathrm{~cm}$ lang, 1 blättrig, nach obeu oft roth, zerstreut-schwarzborstig od. kahl; Bltkörbchen in schirmförmiger Trugdolde, mit schwärzlich-drüsenhaar. Stiel, Blt. goldgelb; Bl. lanzettförmig-spatelig, borstig gewimpert. - Wiesen u. Grasplätze in B. u. Mh.; zerstreut. 2. 5. 6.

\section{H. floribundum Wimm. Gr.}

Wzst. kurz, schief, ohne unterird. Ausl.; St. grün, $30 \mathrm{~cm}$ bis $1 \mathrm{~m}$ h., unten $1-3$ blättrig, langborstig; Bltkörbchen in zusammengesetzt. rispiger Trugdolde, bisweilen sehr zahlreich, Korbhülle hell- bis schwarzgrün, mit od. ohne Drüsenhaare; Bl. lineal-lanzettlich bis lanzettförm., borstenhaar. Mit od. ohne oberird, beblätt. Ausl. Sehr vielgestaltig. - Trockene Wiesen, Gebüsche, IVälder. 4. 5-7.

H. praealtum Koch.

12. (9) Blt. orangeroth, Bltkörbchen 13-25 mm br. in schirmförm. Trugdolde; St. $15-45 \mathrm{~cm}$ h., Bl. eiförmig-länglich od. lanzettförm. Rauhhaarig. - Gebirgswiesen d. Alpen, Sudeten und Riesengeb. 2. 6. 7.

H. aurantiacum $\mathrm{L}$.

Blt. gelb.

13.

13. St. bis zum Blütenstand reich beblättert, $30-60 \mathrm{~cm}, \mathrm{Bl}$. lanzettlich, Bltkörbchen 13-15 mm br., in lockerer Trugdolde. Borstig-rauhhaarig, ohne Ausl. - Steinige, felsige Plätze und Abhänge in B., Ilh. u. Noe.; zerstreut. 4. 67 .

H. echioides Lumn.

St. nur unten $1-3$ blättrig, sonst naclst, schaftartig.

14.

14. Wzst. kriechend, mit od. ohne oberird. Ausl.; St. 0.30-1 m $\mathrm{h.,}$ hohl, unten 2-3 blättrig 1 . dicht weißzottig; Bl. länglich-lanzettlich, zerstreut behaart; Bltkörbchen in gedrung. Trugdold., deren Stiele in ungleicher Höhe entspringen, Korbhülle $u$. Stiele schwärzlich drüsen- und borstenhaarig. - Wiesen, grasige Hiigel. 4. 6. 7. H. pratense Tsch

Wzst. kurz, olıne Ausläufer.

15. Bltkörbch. 7-10 $\mathrm{mm}$ br., zahlreich in schirmförmiger regelmäßiger Trugdolde, deren Hauptstiele von einem Punkte entspringen; St. 
0.30-1 $m$ l., unten 1-3 blättrig, Bl, länglieh-lanzettlich, spitz. Rauhhaarig. - Grasige Hiigel, Waldwiesen, Gebüsche, in d. Alpenländ, seltner. 7. 6. 7.

H. cymosum L.

Bltkörbclıen in unregelmäßiger Trugdolde, deren Hauptstielo in ungleicher Höhe entspringen.

16.

16. Bltkürbchen zu $20-30$ dicht zusammengedrïngt, nit zottigen und driisenharigen Hiillen und Stielen; st. $30-50 \mathrm{~cm} \mathrm{~h}$, borstenhaarig, unten mehrblïttrig; Bl. lanzettlich od. verkehrt-eilanzettförmig. - Bergund Alpenwiesen in 0e. u. K.; zerstreut. 4. 6-8.

H. sabinum Seb. Maur.

Bltkörbchen zu 10-16 in thattriger Trugdolde. Korbhülle u. Stiele grau sternfilzig und sehwarz drïsenharig; St. $30-60 \mathrm{~cm}$ h., unten dreiblättrig, mit l. horizontalen Borsten besetzt; Bl. länglieh od. lineal-lanzettlich, borstenhaarig. - Grasige Hügel, steinige Abhänge, Bergwiesen, besonders auf Kalk, in 13. u. Mh.; zerstreut. 4. 6. 7.

\section{H. setigerum Tsch.}

17. (1) Wzst. iiberwinternde Blrosetten entwickelnd, weshalb die Grundbl, zur 'Ceit des Blïhens meist noch vorhanden (Hierace phyl. lópoda).

$1 \mathrm{~S}$.

Wzst. Knospen entwickelnd, die erst im folgenden Frülijahre austreiben, weshalb grundständ. Bl. zur Bltezeit meist fehlen (H. aphyllópoda).

50.

18. Korbhiille regelm. dachziegelschuppig (A a rella T'sch.). 19.

Kiorbhiulle aus 1 Reihe langer Schuppen gebildet, am Grunde von 1-2 Reihen weit kiirzerer Schuppen umringt (Pulmonaria Fr.). 34.

19. Feldchen des Bliitenbodens (der frtragenden Körbchen) weder gerandet, noch gewimpert.

Feldchen des Bltbodens von einem gewimperten od. zerschlitzten Saume umgeben; Zälıne der Blt. gewimpert, Körbchenstiele und Hüllen drïsenhaarig; St. am Grunde haarschopfig (H. amplexicaulia). 33.

20. Haare d. Bl. zum Theil drüsentragend, Zungen d. 13lt. gewimpert; Bltkörbehen $\mathbf{2 5 - 4 0} \mathrm{mm}$ br., Korbhiille selıwazgrün, rauhhaarig od. zottig und drüsenharig (H. alpina).

Haare d. Bl, ohne Drüsen. 21. 26.

21. Bl. ganzrand. od. seicht gezälunt, rauhharig, grundstäind. lanzettförmig od. spatelig, in eineu 1. Stiel verschmälert; St. $15-30 \mathrm{~cm} \mathrm{~h}$, bllos od. 1-6blättrig, einfach 1 köpfig od. ästig 2-vielköpfig; Korbhülle weißrall- bis fuchsroth zottig, zugleich schwarzborstig und drüsig, vor d. Blülıen kuglig. Sehr vielgestaltig. - Moorige Triften d. Alpen, Sudeten und d. Riesengeb. 4. 7. S.

II. alpinum $\mathrm{L}$

Bl. buchtig grobgezähnt, breit, grundstïnd. gestielt, stengelstïndige (meist zahlreich) von den grundständ. wenig verschieden; St. einfach oder gabeltheilig, 1-4köpfig.

22. St. nur unten beblättert, $15-40 \mathrm{~cm}$ h., meist ästig, mehrköpfig, oben wie d. Korbhïllen von sehwärzlichen Börstchen und Drüsenhaaren fast schwarz; grundständ. 13l. elliptisch-lanzettförmig, zerstrent borstig od. kahl. - Wo H. alpinum. 7. 7. 8. H. nigrescens Willd.

St. d. ganzen Länge nach beblättert; Bltkörbchen $20-30 \mathrm{~mm}$ br., Korbhülle und Körbchenstiele mit schwarzen oft drïsigen Borsten bedeckt. außerdem oft grauzottig. 
23. Korbhülle lang, grau- od. rostfarben-zottig und zuglejeh schwarzLorstig, aber wenig drüsig; $\mathrm{St} .15-30 \mathrm{~cm} \mathrm{h.,} 1 \mathrm{k}$ ijpfig od. mit mehreren blwinkelstïnd. I kijpfigen Ästen, langzotigg und obenhin drüsenhaarig; B]. eilänglich, mittlere a. obere Stbl. sitzend, am Grunde abgerundet. Triften and Gerijle d. Riesengeb. 4. 7. 8.

H. sudéticum Strbs.

Korhhülle nicht od. kurz zottig, meist reichlich drüsenhaarig. 24.

21. St. j-30 cm h., oben doldentraubig ästig, 2-vielkijpfig (selten einfach $1 \mathrm{kgpfig}$ ), unten reich-, bis zur dfitte $1-3$ blittrig, weiter hinauf mit kl. Deckbl. besetzt, oberwiarts mit 1. schwarzen Borstenhaaren uud eingestreuten Drïsenhadren; Bl. länglich-eiförmig, langzottig, Korbhiille dicht schwarz borsten- u. drisenlaarig. - Kammtriften s1. Riesengel. und der Sudeten. 4. 7. 8 .

H. nigritum Uechtr.

St. d. ganzen Länge nach gleichmälig beblüttert, roth gefleckt oder uberlaufen. wie oft auch die unteren Pl.; Korbhille a. Stiel schwarzborstig und drüsig.

25.

25. Bl. grasgrün, grundständ. u. untere eilänglish mit breit gefiugaltem Stiel; St. stark, $20-70 \mathrm{~cm}$ h., doldentraubig-istig u. vielk ïpfig. Grasige Lehnen des böhmisch. Riesengeb. 4. 7. 8. H. bohémicum Fr.

Bl. bläulich-dunkelgrün, grundatänd. länglich-lanzettfïrmig, in einen schmalen ungefligelten, meist rothen Stiel verschmälert; St. schlank, 15 bis $30 \mathrm{~cm}$ h., einfach $1 \mathrm{k} \ddot{p} p f i g$ od. gabeltheilig 2-3kijpfig. - Grasige u. steinige Triften d. mähr.-schles. Sudeten. 4. 7. 8. H. siygium Uechtr.

26. (20) Hüllschuppen spitz, meist lang gran- od. weifuottig, St. meist eirufach 1 köpfig, selten gablig 2- od. mehrköpfig (H. villosa). 2i.

Hiillschuppen stumpf, St. meist doldentraubig-ästig, $2-7 \mathrm{köpfig}$, kahl, 20-60 cm h.; Bl. blaugrün, kahl od. behaart (H. glauca). 32.

27. St. nackt od. 1 blättrig, einfach u. 1 kijpfig, selten gabeltheilig2 köpfig. 28.

St. 2- bis mehrblättrig, einfach u. 1 köpfig od. gabeltheilig. aistig. 2. bis mehrköpfig.

29.

28. St. nachi oben grau sternfilzig u. dicht schwarz drüsenhaarig, $1 \mathrm{köpf}$, $8-20 \mathrm{~cm} \mathrm{h.;} \mathrm{Bl.} \mathrm{lanzettlich,} \mathrm{ganzrand.,} \mathrm{beiderseits} \mathrm{langhaarig} \mathrm{bis} \mathrm{wollig}$ lang-zottig, od. oberseits kahl; Bltkörbchen $20 \mathrm{~mm}$ br. - Huchtriften der Alpen von Sz., K., T. $(1900-2300 \mathrm{~m})$. 2. 7. 8.

\section{H. glanduliferum Hoppe.}

St. weifgraufilzig, mit I. weilen, am Grunde schwarzen Haaren bekleidet, driisenlos, $1 \mathrm{köpfig}$ od. gablig getheilt $2-3 \mathrm{k} \ddot{\mathrm{p}} \mathrm{pfg}$ (H. Schraderi Schl.), 5-20 cm h., Bl. lanzettlich, ganzrand. od. gezähnelt, rauhhaarig od. fast kahl; Bltkörbchen bis $30 \mathrm{~mm}$ br. - Hochwiesen der Alpen von Sz., K., T. $(2000-2500 \mathrm{~m})$. 4. 7. 8.

H. piliferum Hoppe.

29. Äußere Hüllschuppen weit abstehend, breiter als d. anderen, blartig, alle lang weibzottig, Bltkörbchen bis $40 \mathrm{~mm}$ br.; St. $10-20 \mathrm{~cm}$ hoch, reich beblättert, $1 \mathrm{köpfig} \mathrm{od.} \mathrm{ebenstränßig-ästig,} \mathrm{mehrköpfig,} \mathrm{zottig.}$ hehaart, selten kahl; Bl. unterseits bläulichgrün, grundständ. lanzettlich, spitz, Stbl. länglich or?. eiform., stumfassend. - Felsige Triften, Gerijlle, Felsen d. Alpen $(1260-2000 \mathrm{~m})$. 4. 6-8.

H. villosum L.

Hïllschuppen locker aufrecht (außere bisweilen etwas abstehend) or. angedrückt.

30. Hüllschuppen angedrückt, alle lineal-lanzettlich. 
Hüllschuppen locker aufrecht od. äußere etwas abstehend, lanzettlich, lang zugespitzt, dicht grauweiß-zottig; Bltkörbchen bis $30 \mathrm{~mm}$ br.; St. 12-30 cm h., 1-melırköpfig, sammt d. Bl. abstehend langhaarig oder (selten) kahl; Bl. steif, blänlichgriin, grundständ, lanzettlich, stengelständ. eilanzettförm. od. länglich, alle lang zugespitzt. - Steinige Lehnen, Felsen der Alpen von 0e., st., K., T.; zerstreut. 4. 7. 8.

H. scorzonérifolium Vill.

31. St. u. Bl. mehr weniger abstehend, zottig behaart, St. außerdem sternflaumig, $10-25 \mathrm{~cm}$ h., 1-2 köpfig, wenig-u. klblättrig od. reichlich mit gr. eiförmigen umfassenden $\mathrm{Bl}$. besetzt; grundst. Bl. lanzettförm., gestielt, ausgeschweift oder kl. gezähnt. - Felsige, sonnige Abhänge der Alpen v. Noe., K. u. T.; zerstreut. 4. 7. 8. H. dentatum Hppe.

Ganze Pf. kahl, blaugrün, außer d. obern Sttheil n. d. lang grauweißzottige Korbhülle; St. 12-25 cm h., 1-3 köpfig; Bl. lineal-lanzettlich, l. zugespitzt, ganzrandig od. seicht buchtig-gezähnt. - Gerölle der Alpen $(1900-2300 \mathrm{~m})$; zerstreut. 4. 7. 8.

H. glabratum Hppe.

32. (26). Korbhiille mehlig-sternflaumig, driisenlos, Schuppen angedrückt; St. zart, unten entferntblättrig, nach oben nackt; Bltkörbcher sehr 1. gestielt, $30-35 \mathrm{~mm}$ br.; Bl. lineal-lanzettlich, gezähnt, am Grunde gewimpert. - Steinige Plätze, Kies d. Alpenbäche in 0oe., K., T.; zersreut. $4.7-8$.

H. glaucum All.

Korbhiille fast nackt, Schuppen abstehend; St. zart, kaum beblättert, ruthenförnig-rispig; Bl. lineal, fein zugespitzt, ganzrandig od. gezähnelt (H. saxátile Jequ.). - Sonnige, sandige Abhänge u. Tobel d. Kalkalpen; zerstreut. 4. $7-9$.

H. porrifolium Vill.

33. (19). Stbl. mit verschmälerter Basis sitzend, eilanzett- od. lanzettförmig, unterste gezähnt, grundständ. länglich-lanzettförm., kurz gestielt, alle zerstreut behaart u. zottig gewimpert; St. $15-45 \mathrm{~cm}$ h., drüsig-klebrig, ästig, vielköpfig; Bltkörbch. 20-30 $\mathrm{mm}$ hr., mit schwärzlich-drüsenhaariger Hülle. - Sonnige Felsen d. Alpen v. K. u. T.; zerstreut. 4. $6-8$.

H. pulmonarioides Vill.

Stbl. mit herzeiförm. Grunde stumfassend-sitzend, unterste elliptisch, obere br.-eiförmig, spitz, grundständ. verkehrt-eilanzettförnig mit geflügeltem Stiel, alle zerstreut kurzhaarig u. drüsig; St. $20-50 \mathrm{~cm}$ h., sonst wie d. vor. - Sonnige Felsen, steinige Plätze d. Alpen v. Sz., K., T. (1260 bis $2300 \mathrm{~m})$. 4. $6-8$.

H. amplexicaule $\mathrm{L}$.

34. (18) Bl. am Rande und unterseits mit federförmigen Haaren bekleidet, außerdem drüsenhaarig, länglich-eiförmig, untere tief buchtig-gezähnt, obere sitzend, halbstengelumfassend, oberste kl. lineal; St. 12 bis $25 \mathrm{~cm}$ h., $1 \mathrm{köpfig} \mathrm{oder} \mathrm{gabeltheilig} \mathrm{2-5} \mathrm{köpfig,} \mathrm{nebst} \mathrm{Körbchenstielen} u$. Korbhüllen abstehend lang-zottig u. kurz drüsenhaarig; Bltkörbchen bis $4 \mathrm{~cm}$ br. - Felsen d. Kalkalpen von 0e., St., K., T.; 4. 6. 7.

H. huimile Jequ.

Bl. mit weißen fast krausen Haaren bekleidet, stets drüsenlos, Stbl. niemals stengelumfassend; Bltkörbchen doldentraubig od. trugdoldig (H. vulgata).

35. Zungen d. Blt. gewimpert; St. $20-40 \mathrm{~cm}$ h., schlank, $1-3$ blättrig, gablig od. doldentraubig-ästig, 1-7 köpfig, feinbehaart; seitl. Körbchenstiele bogenförmig, Körbchen $20-25 \mathrm{~mm}$ br., mit schwärzlicher driisen- 
reicher Hülle; Bl. dünn, hellgrün, gewimpert, gruudständ. elliptisch bis länglich-lanzettförmig, gezähnt, mit zottigem Stiel. — Riesengeb., obere Region; zerstreut. 4. 7. 8.

Zungen d. Blt. kahl.

H. Wimmeri Uechtr.

36. St. bllos od. 1-3 blättrig, Hiillschuppen scharf zugespitzt. 37.

St. beblättert, Bl. 3-viele, obere in Deckbl. übergehend, grundständ.

in d. Stiel verschmälert; Hüllschupp. stumpf od. zugespitzt mit abgeruu-

deter Spitze.

37. Bl. beiderseits blaugrïn.

44.

Bl. beider- od. nur oberseits grasgrin.

38 .

41.

3S. Körbchenstiele u. Korbhüllen drüsenlos.

39.

Körbchenstiele u. Korbhüllen drüsig, St. 20-60 $\mathrm{cm}$ h., gabeltheiligod. doldentraubig-ästig, 2-vielköpfig, Bltkörbchen $20-30 \mathrm{~cm}$ br. mit sciıwärzlicher Hülle.

39. Gr. rauchbraun; St. nackt od. 1-2 blättrig, oben grauflaumig, $15-20$ cm h., 1-3 köpfig; grundständ. Bl. gestielt, eiförmig od. lanzettlich, am Grunde buchtig eingeschnitten, weichzottig; Bltkörbchen 20 bis $25 \mathrm{~mm}$ br., mit graufilziger u. schwarzhaariger Hiille. - Felsen d. Kalkalpen von K. und $\mathbf{T}$.; zerstreut. 4. 7. 8. $H$. Trachselianum Christ.

Gr. gelb; St. meist nackt, selten $1-2$ blättrig, $30-60 \mathrm{~cm} \mathrm{h.,} 1$ bis $4 \mathrm{köpfig,} \mathrm{flaumig;} \mathrm{Bl.} \mathrm{unterseits} \mathrm{sternhaarig} \mathrm{od.} \mathrm{spinnwebig,} \mathrm{grundständige}$ elliptisch bis läinglich-lanzettförmig, buchtig-gezähnt; Bltlörbchen b. 25 mm breit, mit schwärzl. Hülle. - Felsen, steinige Hänge, Triften der Alpen, auch im Riesengeb. u. Gesenke. 4. 6-8.

II. caesium Fr.

40. Grundbl. keilig, in einen langen gefligelten Stiel verschmälert, lanzett- od. länglich-lanzettförmig, seicht buchtig-gezähnt bis ganzrandig, beiderseits lang oft wollig-behaart od. oberseits kahl, mit langzottig. Stiel; St. abstehend behaart, 1-2 blättrig. Vielgestaltig. - Felsen, steinige Abhänge in B., Mh., Oe.; zerstreut. 4. 6. 7. H. Schmidtii Tsch.

Grundbl. am Grunde abgerundet od. fast herzförmig, plötzlich in d. ungefiügelten zottigen Stiel zusammengezogen, elliptisch bis eilanzettförm., ausgeschweift, bis buchtig gezähnt, oben kahl, unten zerstreut behart; St. naclst od. 1 blättrig, sternflzig u. drüsenborstig. - Gebirgstriften u. Waldschläge in B., Mh., T.; zerstreut. 4. 5-9.

H. glaucinum Jord.

Grundbl. aus herzförm. od. geschweiftem Grunde länglich-eiförmig, inners bis brlanzettförmig, bläulichgrün bis hechtblau, kahl, gewimpert, am Grunde tief eingeschnitten-gezähnt mit lineal. Abschnitten; St. bllos od. 1 blättrig, fast kahl, zerbrechlich; Köpfchenstiele u. Hüllen grau sternflaumig. schwarzdrüsig-behaart u. schwarzborstig. - Wälder, Gebüsche im südl. IIl.; zerstreut. 4. 5. 6.

H. frágile Jord.

41. (37) Grundständ. Bl. von ziemlich gleicher Form, gestielt. 42.

Grundständige Bl. verschiedengeformt, die ersten elliptisch or. rundlich, die folgenden eilänglich od. lanzettförmig, spitz keilig od. geschweift in d. Stiel verschmälert, buchtig gezähnt, alle am Rande u. Stiel weichzottig, sonst fast kahl; St. $15-50 \mathrm{~cm} \mathrm{h.,} 1-2$ blättrig, gubeltheilig 2- bis vielköpfig, meist kahl; Hülle d. 2-3 cm br. Körbchen dicht schwarz-borstig und schwarz-driisenhaarig. - Subalpine Triften des Riesen- und Glatzer Geb., auch in Sz., K..'T.; zerstreut. 4. 7. 8. H. atrátum Fr.

42. Grundst. Bl. seicht herzförm. od. abgerundet, am Grunde grob und eingeschnitten-gezähnt. 
Grundständ. Bl. allmählich in d. Stiel verschmälert, lanzettförmig, seicht buchtig gezähnt, oberseits kahl, unterseits zerstreut behaart, am Rande u. Stiel langzottig; St. $20-35 \mathrm{~cm}$ h., meist mit 1 lanzettlichen Bl., gabeltheilig mehrköpfig, fast kahl; Bltkörbchen bis $25 \mathrm{~mm}$ br., langgestielt, Stiel u. Hülle mehlig-flaumig. - Kiesige und felsige Abhänge in B. (Riesengebirge; bei Teplitz); zerstreut. 4. 6-8. H. rupícolum Fr.

43. Korbhüllen u. Körbchenstiele reichlich schwarz-drüsenhaarig und schwarzborstig; St. $25-60 \mathrm{~cm}$ h., 1-2 blättrig od. bllos, gablig-od. trugdoldig-ästig, behaart; grundständ. Bl. oberseits hellgrün, oft purpurn gefleckt, unterseits bläulichgriin od. purpurn, weichhaarig-zottig gewimpert; Bltkörbchen 20-30 $\mathrm{mm}$ br., auf bogigen Stielen in gespreiquter Trugdolde. - Höchst vielgestaltig. - Wälder, Triften, Mauern. 4. 5-7.

H. murórum L.

Korbhüllen schwärzlichgrün, nebst d. Stiel sternfilzig, von weißen, am Grunde schwarzen Haaren zottig, mit einzelnen Drüsenhaaren; St. 20 bis $45 \mathrm{~cm}$ h., bllos, 1-3 köpfig, flaumig od. oberwärts zottig; sonst wie vorige Art. - Felsen u. Gerölle d. Alpen v. Noe., St., T., Kr. (2000 bis $2300 \mathrm{~m}$ ), in B. (Sperlingsstein b. Tetschen). 4. 6-8.

$$
\text { H. subdólum Jord. }
$$
Stiele.

44. (36) Bltkörbchen schon vor dem Aufblühen aufrecht auf langem

BItkörbchen vor dem Aufblühen auf gekrümmtem Stiel nickend, gedrängt stehend; St. $25-50 \mathrm{~cm}$ b., oben trugdoldig.ästig, sammt Ästen, Körbchenstielen und Korbhüllen lang schwarzborstig und kurz drüsenhaarig; B!. keilig-lanzettförmig, am Rande und Stiel lang weißzottig, sonst zerstreut behaart. - In Mh. (Gesenke, an kräuterreichen Stellen). 4. 8. 9 .

H. silesiacum Krause.

45. Subalpine u. alpine $P f$. mit schwach gezähnten od. fast ganzrandigen Bl. u. 1-3köpfigem, $30-50 \mathrm{~cm}$ h. St. 46.

Große Pf. d. Ebenen u. Hügelgelände mit grob buchtig-oder eingeschnitten gezähnten od. gesägten Bl. u. bis $1 \mathrm{~m}$ h. St.; Bltkörbchen zahlreich, in zusammengesetzten Trugdolden od. Rispen.

46. Korbhülle u. Körbchenstiele graufilzig, drüsenlos; St. steif aufrecht, einfach 1 köpfig od. trugdoldig-ästig, mehrköpfig, kahl, oberlıalb graufilzig; Bl. bläulich, steif, lanzettlich, oben kahl, grundständ. seicht gezähnt mit langem zottigem Stiel; Körbchenstiele 1, aufsteigend, graufilzig, beschuppt. - Felsen, Gerölle, sonn. Abhänge d. Alpen v. Noe, St., K., T., Kr.; zerstreut. 4. 7. 8 .

$H$. canescens Schleich.

Korbhüllen u. Körbchenstiele dicht schwarzborstig u. drüsenhaarig; St. purpurn gefleckt od. purpurn überlaufen, bogig; Bltkörbchen 15 bis $25 \mathrm{~mm}$ br.

47. Bl. weich, blaugrün, unterseits weißlich od. purpurn, länglich od. lanzettförm., spitz, zerstreuthaarig, am drïsigen Rande u. am Stiel zottig, Stbl. gerundet- od. herzförmig-stengelumfassend; St. 2-7köpfig. - Steinige Triften u. Gerölle d. Riesengeb. 4. 7. 8.

II. albinum Fr.

BI. steif, beiderseits grün u. borstenhaarig, sich schärflich anfühlend, drüsig gezähnt od. ganzrandig, grundständ. oval od. brlanzettlich mit l. zottigem Stiel, stengelst. lanzettlich, mit geöhrelter Basis stumfassend; St. 2-3-, selten mehrköpfig. - Grasige Lehnen d. westl. Riesengeb. (1200 bis $1400 \mathrm{~m})$. 21. 8. 9 . II. aspérulum Freyn. 
48. (45) Körbchenstiele u. Korbhüllen drüsenlos, sternfilzig, mit grad. am Grunde schwarzen Borstenhaaren, Körbchen 15-20 mm br.; St. 0.60 bis $1 m \mathrm{~h}$., entfernt beblättert, von d. Mitte od. von unten an abstehend ästig, sich in eine vielköpfige zusammengesetzte Trugdolde zertheilend; Bl. grün, länglich od. lanzettf, grob buchtig gezähnt, behaart. - Gebuische, Berglehnen in K. u. Kï.; zerstreut, auch in B. (Mensegeb.) 7. 6. 7 .

H. ramosum W. Kit.

Körbchenstiele u. Korbhüllen drüsenhaarig; St. ästig, im ober en Theil sammt d. Ästen mit kl. schuppenförm. od. linealen Deckbl. besetzt. 49.

49. St. $40-60 \mathrm{~cm} \mathrm{~h}$, meist von unten an aus d. Blwinkeln l. dünne, nackte od. wenigblättrige, gleich d. Hauptachse Trugdolden von Körbchen

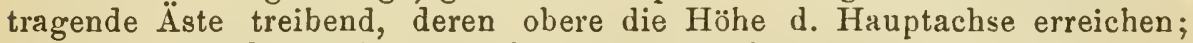
Bl. oval od. brlanzettförm., grob buchtig-gezähnt, zerstreut behaart, fast alle gestielt. - Holzschläge, Waldränder in B. u. Mh.; zerstrent. 4. 8. 9 H. fastigiatum $\mathrm{Fr}$.

St. 0.30-1 $m$ h., meist einfach $u$. oben eine viel verzweigte Trugdolde von Bltkörbchen tragend; Bl. zerstreut behaart od. kahl, am Rande und Stiel zottig, länglich od. lanzettförmig, buchtig gezähnt, untere in de:ı Stiel verschmälert, obere mit schmaler od. abgerundeter Basis sitzend. Sehr vielgestaltig (H. vulgatum $\mathrm{Fr}_{\mathrm{r}}$ ). - Wälder, Gebüsche. 4. 6. 7.

H. silváticum Lamk.

50. (17) Korbhiille 1 reihig, am Grunde mit einer aus Deckbl. bestehenden Außenhülle, sammt Körbchenstielen u. St. mit l. gelblichen klebrigen Drüsenhaaren bekleidet; St. $10-35 \mathrm{~cm}$ h., blreich, $1-4 \mathrm{köpfig,}$ Bltkörbchen 3-4 cm br., Blt. hellgelb. Bl. länglich-lanzettförm., buchtig̨gezähnt, drüsenhaarig. - Felsen u. Gerölle d. Alpen v. T. u. K. 4.6-s. H. intybáceum Wulf.

Korbhülle dachziegelschuppig (H. accipitrína).

51.

51. Zähne d. Bltrungen mit kurzen gegliederten Haaren gewimpert; Korbhülle drüsenhaarig.

52.

Zähne d. Blütenzungen nicht gewimpert.

54.

52. Fr. dunkelroth bis schwarzbraun; St. oberwärts doldentraubig. ästig: Äste fast aufrecht, wenig-köpfig.

53.

Fr. blass gelblich-braun; St. $30-60 \mathrm{~cm}$ h., oben trugdoldig- oder rispig-ästig, vielköpfig; Bltkörbchen bis $25 \mathrm{~mm}$ br., Stiele u. Hüllen stern-

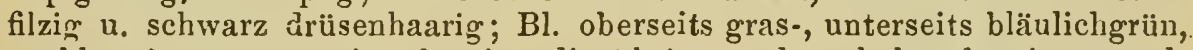
rauhhaarig, untere geigenförmig, die übrigen schwach herzförmig-stengelumfassend. - Bergwiesen u. Wälder d. Alpen, Sudeten u. d. Riesengeb. 4. 7. 8 .

H. prenanthoides vill.

53. St. steif, dicht beblättert, $30-50 \mathrm{~cm}$ h., obeu 2 bis viele doldentraubig gruppierte Bltkörbchen tragend, nach oben sammt den Körbchenstielen u. Hüllen dicht schwarz drüsenborstig; Bl. länglich od. lanzettförm., obere herzförmig-stumfassend. - Triften u. steinige Abhänge d. Riesengeb. und Gesenkes. 4. 7. 8.

H. strictum Fr.

St. entfernt $(4-7)$ blättrig, $28-35 \mathrm{~cm}$ h., $1-4 \mathrm{köpfig,} \mathrm{unterwärts}$ zottig behaart, oberwärts sammt d. Körbchenstielen u. Korbhüllen reichlich-schwarzborstig; Bl. länglich od. eilanzettförm., spitz, mittlere u. obere mit gerundeter Basis sitzend. - Grasige Lehnen d. Riesengeb. (1350 bis $1450 \mathrm{~m})$. 4. 7. 8 .

H. ripháeum Uechtr. 
54. (51) Schuppen d. Korbhülle angedrückt od. äußere locker aufrecht abstehend.

$5 \dot{5}$.

Schuppen d. Korbhülle aufrecht abstehend, äußere mit riickwärts umgebogener Spitze, schwärzlich kahl; Bltkörbch. 20-30 $\mathrm{mm}$ br., in Ebenstrauß an d. Spitze d. meist einfachen, $0.30-1.2 m \mathrm{~h}$. St.; Bl. lanzettförm. bis lineal, gezähnt bis ganzrandig, meist kahl. - Wiesen, Waldränder, bebuschte Hiigel. 4. 7-9.

H. umbellatum L.

55. Bl. oberseits gras- od. trübgrün, unterseits blass- bis bläulichgrün u. melır od. weniger deutlich netzadrig; St. blreich, 25-60 cm b., hohl, steif; Bltkörbchen $20 \mathrm{~mm}$ br.

56.

Bl. fast gleichfarbig; St. oben trugdoldig-rispig, selten traubig-ästig, vielköpfig.

57.

56. St. rund, glänzend kahl; Bl. kahl (nur die untersten unterseits weichhaarig u. gewimpert), länglich bis länglich-lanzettförm., gezähnt, mittlere $u$ - obere mit abgerundetem Grunde halb stumfassend; Bltkörbch. 2-8, trugdolden-rispig, mit schwärzlicher, fast kahler Hülle (H. crocatum Fr.). - Steinige Triften im Riesengeb., Glatzer Geb. u. Gesenke; zerstreut. 7. 7. 8 .

H. inuloides Tsuh

St. gestreift, kahl od. abstehend rauhhaarig-zottig; Bl, unterseits behaart, drüsig-gezähnt, länglich, brlanzett- bis eiförmig, obere mit keiliger Basis sitzend; Bltkörbchen in Doldentrauben od. rispigen Trugdolden, auf sternflockigen, drüsen- $u$. borstenhaarigen Stielen, Hüllschuppen zerstreut borsten- u. oft auch driisenharig (H. striatum T'sch. $u$. H. pachycéphalum Uechtr.). - Bergwiesen im Glatzer Geb. u. Gesenke; zerstreut. 4. 8. 9.

H. corymbosum Fr.

57. Hüllschuppen stumpf, Stbl. meist im unteren Theile od. gegen d. Mitte d. St. zusammengedrängt, selten gleichmäßig vertheilt, obere stengelumfassend od. mit breitem Grunde sitzend; St. schärflich-flaumig od. kahl.

58. vertheilt.

Hüllsch. (wenigstens d. innere) spitz, Stbl, ziemlich gleichförmig

58. Korbhiille schwarzborstig, spärlich sternflarmig, mit locker ahstehenden äußeren Schuppen, Stiele sternfilzig, mit linealen Deckbl.; St. $0.30-1.60 \mathrm{~m} \mathrm{~h}$., blreich, rauhbaarig, nach oben trugdoldig- od. rispig-ästig; Bl. oberseits kahl dunkelgrün, unterseiis zerstreut behaart, blassgrün, ei-, lanzett-, lanzettf. od. länglich buchtig-gez̈̈hnt, spitz. Vielgestaltig. Wälder, Gebüsche. 4. 8-10.

$H$. boreale Fr.

Korbhülle bleich od. schmutziggrün, Bl. ei- od. eilanzettförm., spitz, buchtig gezähnt, beider- od. nur unterseits laugborstig; St. trugdoldigrispig.

59. Hüllschuppen in d. Mittelzone kurz weißhaarig, äußerste locker abstehend, Körbchenstiele unter d. Körbchen mit ebenso behaart. Schuppen besetzt; St. 50-80 $\mathrm{cm}$ h., abstehend rauhzottig, blreich. - Waldränder, Gebiusche in Mh.; zerstreut. 4. 9. 10.

H. barbatum Tsch.

Hüllschuppen, Körbchenstiele u. Äste sternflaumig, letztere fast bilos; St. $0.60-1.25 \mathrm{~m}$ h., der ganzen Länge nach gleichmäßig beblättert, rauhhaarig od. kahl. Sehr vielgestaltig. - Gebüsclıe, Waldblößen in Ooe., St., K.; zerstreut. 4. 8. 9. H. sabaudum L.

60. Äußere Schuppen d. Korbhülle breiter als die übrigen, alle kahl od. sternflaumig, dunkelgrïn (getrockn. schwarz); St. $20-60 \mathrm{~cm}$ h., 1- bis 
2 köpfig od. trugdoldig-mehrköpfig, steif, entfernt beblättert; Bl. länglich bis lineal-lanzettförm., spitz, entfernt-gezähnt, oberseits kahl, unterseits zerstreut-rauhhaarig. - Gerölle, Felsen, steinige Abbänge in Mh. (Gesenke), B. (Hochgebirge), Ooe., K.; zerstreut. 4. 7. 8.

H. gothicum Fr.

Äußere Hüllschuppen lineal, alle stern- $u$. zerstreut-borstenhaarig (getrocknet nicht schwarz); St. $0.6-1 \cdot 2 m$ h., oben trugdoldig- od. rispigästig, vielköpfig, reich u. genähert beblättert; Bl. kahl od, unters. zerstreut behaart, länglich bis lineal-lanzettförm., jederseits am Rande mit wenigen (oft nur 3) Zähnen, untere u. mittlere 1. gestielt, obere mit abgerund. od. verschmälert. Grunde sitzend. Sehr vielgestaltig (H. tridentatum). - Wälder, Gebüsche. 4. 6-8.

H. laevigatum Willd.

\section{Chlorocrépis Griseb. (XIX, 1).}

Kahl, blaugrün; St. $10-25 \mathrm{~cm}$ h., bllos, 1 köpfig od. gabeltheilig $2-5 \mathrm{köpfig;} \mathrm{Bl.} \mathrm{in} \mathrm{Rosette,} \mathrm{lineal-lanzettlich,} \mathrm{gezähnt} \mathrm{od.} \mathrm{ganzrandig,}$ steif; Bltkörbchen $20 \mathrm{~mm}$ br., auf beschuppt. Stiel, Blt. hellgelb (Hieracium static. Vill.) - Gerölle, Kies, steinige Plätze der Alpen von T., K., St., Kr. 4. 6. 7 .

Ch. staticifolia Gris.

\section{B. Radiatae: Strahlblütler.}

Randständ. Blt. des Bltkörbchens zungenförmig (Strahlblüten), die übrigen Blt. (Scheibenblt.) röhrig, seltner alle Blt. röhrig od. fädlig. Gr. mit 2 getrennten Narben.

\section{Schliussel der Gattungen.}

1. Alle Blt. röhrig od. Randbl. fädlig od. (b. Petasites) mit kurz zungenförm. Blkr. (Körbchen ohne wirkliche Strahlblt.).

Körbchen mit einem Strahl zungenförm. Randblt.

2. Fr. ohne od. wenigstens ohne haarigem Pappus.

Fr. mit haarigem Pappus.

3. Korbhülle dachziegelschuppig.

8.

4.

Korbhülle 2 reihig (äußere Schuppen abstehend), Pappus aus 2 bis 4 steifen, rückwärts stachligen Borsten bestehend. Bidens (z. Th. 258).

4. Kein Pappus.

Ein kurzer häutiger Kelchsaum od, ein zangenförm. häutiger Pappus (Tanacetum Balsamita) auf d. Fr.; Blt. gelb.

7.

5. Bltkörbchen kl, halbkuglig od. eiförm., in Ähren, Trauben, Rispen. Artemisia (266).

Bltkörbchen halbkuglig, einzeln, endständ.; Blt. gelb. Blättern.

6. Krautige Pfl. mit wechselständ. gr. Bl. Carpesium (262).

Kl. Halbstrauch mit gedrängten fleischigen linealen 4 reihig-gezähnten

7. Bltboden eben, nicht hohl, Bltkörbchen halbkuglig. Santolina (268).

Tanacetum (267).

Bltboden kegelförm., hohl.

Matricaria (z. Th. 271). Grunde.

8. (2) Korbhülle 1 reihig-schuppig, mit od. ohne kl. Schüppchen am

Korbhülle dachziegelschuppig.

9. Blt. weiß, röthlich, rosenroth, purpurn. 
10. Bltkörbchen einzeln od. zu 2-3 endständig, Blt. röthlich. Homogyne (245).

Bltkörbch. in einem traubigen Strauße, Blt. weiß od. rötblich.

Petasites (244).

Bltkörbchen in zusammengesetzter schirmförmiger gewölbt. Doldentraube; Korbhülle walzig, Blt. rosenroth od. purpurn, Gr. weit vorragend. Adenostyles (243).

11. (8) Korbhülle walzig, wenigbltig, Blt. pfirsichrotl od. weiß, mit weit vorragendem $\mathrm{Gr}$. Eupatorium (242).

Korbhülle vielbltig.

12. Hüllschuppen krautig.

Hüllschuppen alle od. theilweis trockenhäutig.

13. Huillschuppen anliegend.

Äußere Hiillschuppen sparrig zurückgekrümmt, Blt. gelb.

14.

Inula Conyza (257).

14. Blt. sehr kl., weißlich; Bltkörbchen kl., in l. Rispe.

Erigeron canadensis (250).

Blt. goldgelb, Bltkörbchen kl., in dichter Doldentraube.

Linosyris (253).

15. Korbhülle kegelförm. 5 kantig, äußere Schuppen krautig, wollig, innere trockenhäutig; Blikörbch. sehr kl, Blt. weißlich. Filago (263).

Alle Schuppen trockenhäutig, kahl, glänzend, Blt. gelb. 16.

16. Korbhülle halbkuglig od. walzig, bräunlich, braun, weiß, gelblich, rosen- bis purpurroth. Gnaphalium (264).

Korbhülle glänzend goldgelb od. weiß, innere Hüllschuppen größeı als die übrigen, bisweilen strahlförmig verlängert. Helichryson (265).

17. (1) Strahlblt. weibl, fruchtbar, Scheibenblt. verkümmert-zwitterlich, männlich; Fr. ohne Pappus, bogig gekrümmt, äußerste gezähnt.

Calendula (280).

Strahlblt. weibl., selten geschlechtslos (b. Helianthus), Scheibenblt. zwitterlich, beiderlei fruchtbar.

18.

18. Pappns fehlend od. als ein häutiges Krönchen od. aus Schüppchen od. Borsteu gebildet.

Pappus aller od. wenigstens d. Scheibenblt. haarig.

19.

19. Bltboden nackt.

30.

Bltbod. spreublättrig od. haarig.

20. St. nackt, 1 köpfig, Fr. ohne Pappus.

20.

23.

Bellis (248).

St. beblättert

21.

21. Bltboden eben od. convex, nicht hohl, Hüllschuppen trocken. häutig, gerandet.

22.

Bltbod. kegelförm., hohl, Pappus felılend od. kröncheuförmig.

$$
\text { Matricaria (271). }
$$

22. Fr. ohne od. mit ohrförm. Pappus.

Fr. mit kröncheuförm. Pappus.

Leucanthemum (272).

23. (19) Bl wechselständig.

Pyrethrum (273).

Bl. gegenständig.

24. Fr. ohne Pappus.

Fr. mit krönchenförmigem od. spreublättrigem Pappus. 
25. StrahluIt. kurz u br., höchstens 12, Fr. verkehrt eilänglich, zusammengedrückt. Achillea (269).

Strahlblt. länglich od, brlineal, zahlreich, Fr. verkehrt kegrelfürmig od. länglich-rund od. 4 kantig. Anthemis (270).

26. Pappus krönchenförm., Bltkörbch. sehr groß.

Pappus spreublättrig.

27.

27. Bltbodeu weit vorragend, säulenförmig, Strahlblt. nicht zahlreich, Korbhiille 2 reihig.blättrig. Rudbeckia (260).

Bltboden convex, Strahll)lt. sehr zahlreich, Korbhülle ziegelschuppig. Teleckia (254).

28. Strahltit. geschlechtslcs, Pappus leicht abfallend, Fr. zusammengedrückt; Bltkörbchen sehr groß, mit flach. Bltboden. Helianthus (259).

Strahlblt. weibl., Pappus bleibend, Fr. 3 kant. Buphthalmum (255).

29. (23) Pappus aus $2-4$ rückwärts stachligen Borsten gebildet. Bidens (258).

Pappus spreublättrig, mit franzig gezähnten Schuppen; Bltkörbchen paarweis auf gemeinschaftlichem Stiel, meist nur 5 Strahlblt. enthaltend. Galinsoga (261).

30. (18) Bltboden behaart, Korbhülle walzig, 2 reihig, Bl. gegrenständ. Arnica (276).

Bltboden nackt.

31.

31. Haarkrone d. Pappus von einem kronenförm. gezackten Hautrande umgeben; Korbhülle dachziegelschupp.; Blt.gelb. Pulicaria (256).

Haarkione d. Pappus ohne Hautrand.

32. Nur d. Scheibenblt. mit haarigem Pappus begabt, die Strablblt. ohne Pappus; Korbhülle 2-3reihig; Bltkörbch. groß. Doronicum (274).

Alle Blt. mit haarigem Pappus.

33. St. bllos od. schuppenblättrig, einfach, $1 \mathrm{köpfig.}$

St beblättert, meist vielköpfig.

33.

34. St. ganz nackt, Strahlblt. weiß, Scheibenblt. gelb, 1 reihig.

Bellidiastrum (249).

St. beschuppt, alle Blt. goldgelb, Strahlblt. sehr zahlreich, schmal. lineal, mehrreihig.

Tussilago (246).

35. Korbhülle dachziegelschuppig.

36.

Korbhülle aus $1-3$ Reihen gleichlanger Blättchen gebildet od. die äußerste Reihe viel kürzer, als kleinschuppiger Rand erscheinend. 39.

36. Strahlblt. mehreihig, weißlich, röthlich, lila, purpurn, innerste oft fadenförmig.

Strahlblt. 1 reihig.

37. Blt. gelb.

Erigeron ( 250$)$.

Strahlblt. blau, violett od. lila, Scheibenblt. gelb.

38. Strahiblt. schmallineal, zahlreich, Strıb. unten geschwänzt.

Inula (257).

Strahlblt. lineal, wenige $(5-8)$, Stbb. ungeschwänzt. Solidago (252).

39. Korbhülle 1 reihig, Strahl- u. Scheibenblt. gelb bis orange. 40. Korbhülle 2-3reihig.

40. Korbhülle 1 reihig, mit Schüppch. od. Blättch. am Grunde. 41.

Korbhïlle 1 reihig, olıne Schüppchen.

Cineraria (279).

Tillkom m, Schultlora. 
41. Nur 2 gegenständ. längliche Blättchen am Grunde der walzigen Korbhülle; Bltkörbch. in endständiger Traube.

Ligularia (277).

Mehrere bis viele an d. Spitze oft schwärzlich, wie verbrannt aus. sehende Schüppchen am Grunde der Korbhülle.

Senecio (278).

42. Alle Blt. gelb bis orange; Bltkörbch. groß, einzeln, endständig Aronicum (275).

Strahlblt. weiß, schmallincal, 2 reihig, Schcibenblt. gelb; Bltkörbch. klein, doldentraubig.

Stenactis (247).

\section{Eupatórium L. Wasserdost (XIX, 2).}

St. 0.60-1.75 $m$ h., Bl. gegenständig, handförm. 3-5 theilig, Theilstiicke lanzettförm., gesägt; Bltkörbchen kl., in zusammengesetzt. Doldentrauben. - Ufer, Gräben, Waldsümpfe; verbreitet. 4. 7-9.

E. cannábinum L.

\section{Adenostýles cass. Drüsengriffel (XIX, 2).}

Stauden mit großen nierenförm., oberseits stets kahlen Bl.

1. BI. ungleich gezähnt, unterseits weißgrau-filzig, stengelständ. geöhrelt, zugespitzt; St. $0.50-1.25 \mathrm{~m}$ h. - An Bächen, quellig. Plätzen d. Alpen, Sudeten u. d. Riesengeb. 4. 6-8.

A. allitions Rchb.

2. B1. gleichmälig, buchtig gezühnt, unterseits fast kalıl, stengelstänıl. niclıt geöhrelt, stumpf; St. $40-60 \mathrm{~cm}$ l. - Kalkalpen, an älnlichen Orten. 4. 7. 8. A. alpina Bl. Fing.

\section{Petasítes Tourn. Pestwurz (XIX, 2).}

Polygamisch-zweilıäusige Kräuter, deren stets grundständ. herzförm • gestielte Bl. sich nach d. Bîtezeit entwickeln. Bltst. beschuppt, Strauß d. weibl. Pfl. sich in eine Traube verlängernd. Weibl. Blt, fadenförm., männl. u. Z witterblt. langröhrig-glockenförmig.

-. 1. Blt. hellroth, Hüllschupp., Deckbl., Stschuppen purpurn überlauf.; Bl. brherzförm., unterseits graufilzig, sehr groß werdend. - Ufer, sumpfige Wiesen. 4. 3. 4.

P. officinalis Mnch.

Blt. weiß cd. röthlich; Hüll-, Stschuppen u. Deckbl. gelblichgrün od. bräunlich.

2. 131. herzförm, rundlich, ungleich u. spitz gezähnt, unterseits dünn weißgrau-filzig, Korbhülle gelbgriin, Blt. weiß. - An Bächen, feuchten Plätzen in Hochgebirgen. 4. 3. 4.

$P$. albus Gärtn.

BI. herzförm. 3 eckig, unterseits schneeweiß-filzig; Korbhülle braun, Blt, weiß od. röthlich, - An Bächen d. Alpen, besond. auf Kalk. 4. 5. 6. $P$. niveus Baumgt.

\section{Homógyne Cass. Alplattich (XIX, 2).}

Wzst. kriechend, einfache beschuppte St. und langgestielte Bl. mit herz:nierenförm. Spreite gleichzeitig entwickelnd. 
1. Bl. oberseits dunkelgrün, unterseits weißfilzig, seicht gezähnt; St. $7 \cdot 5-10 \mathrm{~cm}$ h., Korbhülle purpurn. - Triften d. Kalkalpen $(1580-2000 \mathrm{~m})$. 4. 6. 7 .

Bl. beiderseits grün, Korbhülle grünlich. H. discolor Cass.

2. Bl. grob u. eckig gezähnt, St. $15-30 \mathrm{~cm}$ h., meist 1 köpfig; sammt d. Blstielen wollig. - Wälder, moorige Triften, Gerölle d. Hochgebirg. 4. 5. 7. H. alpina Cass.

B.. eingeschniten-gezähnt, fast gelappt; St. 1-3 köpfig, behaart, 15 bis $45 \mathrm{~cm}$ h. - Gebirgswälder von St., K., Kr. 4. 5. 6.

H. silvestris Cass.

\section{Tussilágo L. Huflattich (XIX, 2).}

Wzst. vielköpf., zahlreiche beschuppte, weißfilzige, $8-25 \mathrm{~cm} \mathrm{~h}$. Bltst. lange vor d. Bl. entwickelnd; Bltkörbchen mit walziger, 1 reihiger Korb. hïlle; Bl. gestielt, 3 eckig-herzförm., unterseits graufilzig. - Auf feuchtem Thon-, Mergel- u. Sandboden. 4. 3. 4.

T. Fárfara L.

\section{Stenactis Cass. Schmalstrahl (XIX, 2).}

St. $30-60 \mathrm{~cm}$ h., einfach, straff, eine Doldentraube 1. gestielter Bltkörbchen tragend; Bl. gesägt, grundständ. oval, 1. gestielt, Stbl. lanzettlich. - Aus Nordamerika, verwild. in 0e. u. d. Alpenländern an Ufern, in Auenwäldern. $\odot-4.6 .7$. St. bellidiflóra A. Br.

\section{Bellis L. Maßßieb, Gïnseblïmchen (XIX, 2).}

Bl. grundständ., in Rosette, spatelförm., gekerbt, St. $3-15 \mathrm{~cm}$ h., Bltkörbchen mit gelber Scheibe und weißem oder purpurnem Strahl. Wiesen, Grasplätze. 4. 2-12. In Gärten mit lauter Zungen- od. Röhrenblüten: "Taus endschön, Sammetröschen, Mageritchen.".

B. perennis L.

\section{Bellidiastrum Cass. Sternliebe (XIX, 2).}

Bl. grundständ., länglich-verkehrt eiförm., gekerbt; St. $8-25 \mathrm{~cm}$ h., Bltkörbchen 1.5-3 $\mathrm{cm}$ br. - Feuchte Triften u. Gerölle d. Alpen. 4. $5-6$.

B. INichelii Cass.

\section{Erígeron L. Berufkraut (XIX, 2).}

Grundständ. Bl. meist in Rosette, Stbl. abwechselnd; St. einfach einköpfig od. doldentraubig- od. rispig-ästig.

1. Strahlblt. sehr kurz, aufrecht, undeutlich.

Strablblt. lang, zahlreich, horizontal od. zurückgelrümmt. 2.

2. Bltkörbchen sehr kl., zahlreich, in 1. pyramidaler od, schweifart. Rispe, Blt. schmutzig-weiß; St. 0.30-1 $m$ h., Bl. lineal-lanzettlich. - Unkraut auf Sandboden, aus Nordamerika stammend. $\odot$. 7-9.

E. canadensis L.

Bltkörbchen halbkuglig, 6-13 $\mathrm{mm}$ br., in lockerer Traube od. ästiger Doldentraube; Bl. lanzettlich, Scheibenllt. gelblichgrün.

3. Strahlblt. sehr kurz, röthlich, Körbchen kurz gestielt; St. 15 bis $30 \mathrm{~cm}$ h., steif, Bl. u. St. rauhhaarig. - Raine, Hïgel, Felsen. (-) od. 4. 7. 8 . $E$. acer L.

Strahlblt. deutlich, lila, Körbchen 1. gestielt; St. 1-3 köpfig, Bl. kahl, gewimpert. - Gerölle, Flusskies in d. Alpen; zerstreut. $\odot$. 7. 8. E. Droebachensis Mill. 
4. (1) St. 2-vielköpfig.. (dann doldentraubig-ästig), $15-30 \mathrm{~cm} \mathrm{h.;}$ Bl. länglich-lanzettf., nebst Ästen u. Korbhäl. drüsenhaarig; Körbchen 20-30 $\mathrm{mm}$ br. mit purpurnem Strahl u. gelber Scheibe. - Felsen der Alpen von K. u. T.; zerstreut. 4. 7. 8 .

E. Villarsii. Bell.

St. einfach, meist 1 köpfig, sammt d. lanzettl. Bl. behaart od kahl. 5 .

5. Bl. nicht fleischig.

6.

Untere Bl. fleischig, Jänglich-spatelförm., am Rande behaart, sonst kahl; St. straft aufrecht, $10-18 \mathrm{~cm}$ l., stets $1 \mathrm{köpfig;} \mathrm{Korbhülle} \mathrm{dunkel}$ pnrpurbrann, Strahl pfirsichroth, Scheibe gelb. - Centralalp. 4. 6-8.

E. neglectus Kern.

6. Rauhharig. Scheibe grünlich, Strahl lila od. weißlich, Kürbchen 15-25 mm br.; St. $2 \cdot 5-10 \mathrm{~cm}$ h., bogig gekrimmt. - Alpentriften in St., K., T., Kr. $(1900-2530$ m). 4. 7. 8 .

E. uniflórus L.

Flaumig. Scheibe gelb. Strahl hell purpurn; Körbchen 20--30 $\mathrm{mm}$ breit, St. 6-20 cm h., häufig mehrköpfig. - Gerölle u. Triften d. Alpen. 4. 7. 8 .

$E$. alpinus L.

Variet. glabratus (Hoppe), St. kahl, Bl. kahl, kurz gewimpert.

\section{Aster L. Sternblume (XIX, 2).}

St. beblättert, meist doldentraubig-ästig, selten einfach.

1. St. einfach, $1 \mathrm{köpfig,} \mathrm{bis} 15 \mathrm{~cm}$ h., Bltkörbchen $4-5 \mathrm{~cm}$ breit, Hüllschuppen lanzettlich, Strahl violett, Scheibe gelb; Bl. ganzrandig, untere 3 nervig, länglich-lanzettf., gestielt. - Gerölle u. Felsen der Alpen, auch in B. (auf Basalt- u. Phonolithbergen) u. Mh. (Gesenke). 4. 6-8. A. alpinus $\mathrm{L}$.

St. ästig, aufrecht od. aufsteigend.

2. Hüllschuppen groß, blartig, spatelförm., Bltkörchen bis $10 \mathrm{~cm}$ br. (Scheibe gelb, Strahl verschiedenfarbig), oft mit lauter Zungen- od. Röhrenblïten. - Aus China. $\odot$. 7-10. Gartenaster, A. chinensis L.

Hüllsch. kl., eine halbkuglige, eiförmige od. walzige Hülle bild. 3 .

3. Bl. fleischig, lineal-lanzettl., ganzrand.; St. $0 \cdot 15-1 m$ h., Bltkörbchen $37 \mathrm{~mm}$ br. in Doldentraube, Strahl lila od. blau, Scheibe gelb. - Auf salzigem feuchtem Boden in Mh. u. Noe.; stellenweis. 4. 8. 9. A. Tripólium L.

Bl. nicht fleischig; Scheibenblt. gelb. 4.

4. Bl. 3 nervig, Hüllschuppen oval-rundlich, sparrig zurïckgekrümmt, Strahl azurblau, St. $0 \cdot 30-1$ in h., oben doldentraubig-ästig, sammt d. Bl. flaumig-scharfhaarig, Bltlkörbchen $37 \mathrm{~mm}$ br.; Grundbl. elliptisch, Stbl. lanzettlich. - Buschige Hügel, Waldränder; zerstreut, auch cult. 4. 8. 9. Virgilsaster, A. Amellus L.

Bl. 1 nervig, kahl; Bltkörbch. $25 \mathrm{~mm}$ br., Strahl lila, röthlich, hellviolett; St. $1-1.25 \mathrm{~m}$ h., doldentraubig-ästig.

5. Bl. mit verschmälertem Grunde sitzend, lanzett- bis lineal-lanzettf., sehr spitz; Hïllschupp. angedrückt, Strahl erst weiß, dann lila. - Flussufer in Mh., 0e., K.; zerstreut. 4. 7. 8.

A. salicifolius Scholl.

Bl. umfassend sitzend, lanzettlich, spitz; Hüllschupp. locker, unterste abstehend, Strahl hellviolett. - Aus Nordamerika, häufig cult. und verwildert an Ufern in B., Mh. 4. 9. 10.

Herbstaster, A. Novi Belgii L. 
Anmerk. Außer A. Novi Belgii werden verschiedene kleinköpfge im Herbst blïhende Arten aus Nordamerika als "Herbstastern" in Gärten cultiviert und finden sich diese hin und wieder an Flussufern verwildert.

\section{Solidảgo L. Goldruthe (XIX, 2).}

Kr. mit kriechendem Wzst. u. aufrechtem, ruthenförmigem, reich beblättertem, oben traubig- od, rispig-ästigem St.

1. Bltkörbchen $13 \mathrm{~mm}$ br., in allseitswendigen Trauben, Strahlblt. länger als d. Hülle; St. $0 \cdot 30-1 \mathrm{~m}$ h., Bl. kahl, untere elliptisch od. länglich-lanzettlich, in den br. geflïgelten Stiel verschmälert, obere lanzettf., sitzend. - Trockene Wülder u. Hügel. 4. 7-9. S. Virga aúrea L.

Variet. al pestris (W. Kit.), niedriger, gedrungener, ab. Körbchen bis $25 \mathrm{~mm}$ br. Alpen $(1260-2200 \mathrm{~m}) \mathrm{u}$. a. Hochgebirge, auf steinigen Triften.

Bltkörbchen sehr kl., mit abgekürztem Sirahl, in einseitige Trauben gestellt, (nordamerikan. Arten).

2. Trauben zurückgekrümmt, eine pyramidale Rispe bildend, St. 1 bis 1.30 $m$ h., Bl. lanzettförm., zugespitzt. - Gemeine Zierptl., hier und da verwildert. $4.8-10$.

S. canadensis L.

Trauben abstehend, in länglicher Rispe; St. $0.5-1.5 m$ b., Bl, lanzettlich. - An Ufern in Mh. u. B., stellenweis massenhaft. 4. 8-10.

S. serótina Ait.

\section{Linósyris DC. Goldschopf (XIX, 2).}

St. 30-60 cm h., ruthenförm., oben doldentraubig-ästig; Bl.gedrängt lineal, spitz, rauh. - Trockene Hügel $u$. Abhänge in B., Mh., Noe. zerstreut. 4. 7. 8.

L. vulgaris Cass.

\section{Teleckia Baumg. (XIX, 2).}

St. $30 \mathrm{~cm} \mathrm{h.,} 1$ köpfig, Bltkörbchen bis $7 \mathrm{~cm}$ br., Blt. goldgelb; Bl. lederartig, kahl, gezähnt, untere gestielt, länglich-verkehrt-eiförm., obere stengelumfassend, herzeiförm. - Im südl. T. wild, als Zierpt. in Gärten. 4. 7. 8 .

T. speciosissima Lois.

\section{Buphthalmum L. Rindsauge (XIX, 2).}

St. $15-50 \mathrm{~cm}$ h., 1 köpfig od, oben in 1 köpfige Äste getheilt, zottig behaart; Bl. länglich-lanzettförm, gezähnelt od. ganzranđig; Körbcken $3.7-5 \mathrm{~cm}$ br., Blt. goldgelb. - Steinige buschige Abhänge in d. Alperländern. 4. 7. 8.

B. salicifolium L.

\section{Pulicária Gärtu. Flohkrant (XIX, 2).}

St. aufrecht, ästig, $30-80 \mathrm{~cm}$ h., Bl. länglich-lanzettförmig, ganzrandig, spitz.

1. Strahlblt. kaum so 1. od. wenig länger als d. Scheibe, Körbchen 6-9 $\mathrm{mm}$ br., in lockerer Rispe; Bl. wollig od. kahl, obere am Grunde

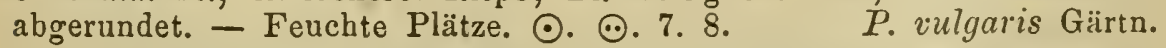

2. Strahlblt. viel länger als d. Scheibe, Körbchen bis $25 \mathrm{~mm}$ br.. in schirmförm. Doldentraube; Bl. unterseits graufilz., obere am Grunde herzförmig. - Ufer; zerstreut. 4. 7. 8.

$P$. dyssentérica Gärtn. 


\section{7. Ínula L. Alant (XIX, 2).}

St. einfach 1 köpfig od. doldentraubig-ästig, vielköpfig; Korbhülllo halbkuglig, Scheibe flach.

1. Innere Hüllschuppen gegen d. Ende spatelförmig und zurückgekrümmt, Bltkörbchen $6-7 \mathrm{~cm}$ br., am Grunde d. Hülle von kl. Bl. umringt; St. $1-1.5 m \mathrm{~h}$., oben in kurze 1 köpfige Äste getheilt; Bl. gezähnt, unterseits graufilzig, grundständ. gestielt, bis $60 \mathrm{~cm} \mathrm{l}$., elliptisch-lanzettförmig, Stbl. am Grunde herzförn. - Als Heil- u. Zierpf. cult., auch verwildert. 4. 7. 8.

1. Helénium L. hoch.

Innere Hüllscb. zugespitzt, Bltkörbch. $13-37 \mathrm{~mm}$ br., St. $30--60 \mathrm{~cm}$

2. Strahlblt. sehr kurz (scheinbar fehlend), Hüllsch. zurückgekrümmt. Körbchen doldentraubig, Bl. oval-lanzettförmig. - Bebuschte Hügel. 4. 7. 8 . I. Conyza DC.

Strahlblt. lang, zahlreich.

3.

3. Stbl. am Grunde verschmälert.

4.

Stbl. am Grunde herzförmig od. abgerundet.

5.

4. Hüllschuppen auswärts gekrümmt; St. $15-30 \mathrm{~cm}$ h., 1-5 köpfig; B1. lineal od. lanzettlich, steif, glänzend. - Steinige, bebuschte Hügel u. Abhänge in Mh., 0e., St., T., Kr.; zerstreut. 4. 7. 8. I. ensifolia L.

Hüllschuppen angedrückt, St. $1-3 \mathrm{köpfig,} 30-45 \mathrm{~cm}$ h.; nebst den länglich-lanzettförm. Bl. rauhhaarig-wollig. - Sonnige Hüigel. 4. 5. 6.

\section{1. hirta L.}

5. (3) Hüllsch, angedrückt, lineal-lanzettlich, innere trockenhäutig; St. 30-45 cm h., 1-3 köpfig, wollig, Bl. länglich od. länglich-lanzettförm.. nebst d. Korbhüllen seidenhaarig-wollig. - Sonnige Hügel in Mh. u. Noe.; zerstreut, auch Zierpfl. 4. 6. 7. Christusauge, 1. Oculus Christi L.

Hüllsch. auswärts od. rückwärts gekrümmt. 6.

6. Äußere Hüllsch. blartig, lineal-lanzettförm., so l. od. länger als d. inneren, wollig; St. $15-45 \mathrm{~cm}$ h., $1-3 \mathrm{köpfig} \mathrm{od.} \mathrm{rispig-vielköpfig;} \mathrm{Bl}$. lineal-lanzettlich od. lanzettförm. - Ufer. 4.6. 7. I. Britannica L.

Äußere Hüllsch. nicht blartig, lanzettlich, kürzer als d. inneren 7.

7. Strahlblt. kaum länger als d. Scheibe, Körbchen in dicht. Doldentraube; St. $30-60 \mathrm{~cm}$ h., wollig, Bl. länglich, elliptisch, lanzetttörmig, unterseits wollig. - Steinige buschige Hügel u. Abhänge in B., Mh., Oe.; zerstreut. 4. 6. 7 .

I. germanica L.

Strahlblt. viel länger als d. Scheibe, St. $30-60 \mathrm{~cm}$ h., Bl. kahl. 8 .

8. Bl. länglich-lanzettförm., steif, glänzend; St. 1-3 köpfig. - Gräben, Ufer, Waldränder; zerstreut. 4. 6. 7. I. salicina $\mathrm{L}$.

Bl. oval od. eilanzettförm., am Grunde abgerundet; Bltkörbchen in dichter Doldentrauhe: Hüllschupp. stark zurückgekrümmt. - Bebuschte Hëgel in Noe. u. Kr.; zerstreut. 4. 7.8.

I. squarrosa L.

\section{Bidens L. Zweizahn (XIX, 3).} Blt. gelb.

St. ästig, Bl. gegenständ., Bltkörbchen gestielt end- u. achselständig,

1. Bl. doppelt fiedertheilig, Bltkörbchen ohne Deckbl., Strahlblt. kanm länger als d. Scheibe, St. $30 \mathrm{~cm}$ h. - Unkraut unter d. Saat in K. und

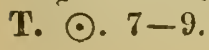
$B$. bipinnatus L. 
Bl. 3-5 theilig od. ganz, Bltkörbchen von Deckbl. umgeben. 2.

2. Bl. 3-5 theilig, gestielt, Theilstiicke lanzettförm., grobgesägt, Bltkörbchen aufrecht, meist ohne Strahl, St. $0 \cdot 15-1 m \mathrm{~h}$. - Ufer, Gräben. ○. 7-9.

B. tripartitus L.

Bl. lanzettförm., grobgesägt; Bltkörbchen nickend, mit oder ohne Strahl; St. $15-60 \mathrm{~cm}$ h. $\odot$. 8.9. B. cérnuus L.

\section{Helianthus L. Somnenrose (XIX, 3).}

Riesige Stauden aus Siidamerika; Bl. gr. scharfhaarig, wechselstä日d. Bltkörbchen einzeln, sehr gr., mit gelbem Strahl und brauner Scheibe.

1. St. bis $2.5 m$ h., Bl. herzförmig, Bltkörbchen nickend, bis $25 \mathrm{~cm}$ noch. - Zier- u. Ölpfl. ๑. 7-9. Gemeine S., H. ánnuus L.

2. St. bis $3 \cdot 3 \mathrm{~m}$ h., Bl. länglich bis lanzettf., Bltkörbe aufrecht, $10 \mathrm{~cm}$ breit; Wzst. Knollen tragend. - Als Gemüsepf. cult. 4. 9. 10.

Topinambur, H. tuberosus L.

\section{Rudbeckia L: (XIX, 3).}

Staude von 1.50-2 $m$ H., mit 1 köpfigen Ästen; Bl. schärflich, untere fiederschnittig, obere 3 theilig; Blıkörbchen bis $15 \mathrm{~cm}$ br., Strahl gelb, Scheibe grünlichbraun. - Zierplanze aus Nordamerika, in B., Mih., Noe, Kr. aucl verwildert. 4. 8-10. R. laciniata L.

\section{Galinsóga Pav. (XIX, 2).}

St. $15-50 \mathrm{~cm}$ h., 3 theilig-ästig; Bl. eiförm. od. länglich, grobgesägt; Bltkörbchen iu 3 theiligen Trugdolden, $6-7 \mathrm{~mm}$ br., mit weißem, (bisweil. fehlendem) Strahl u. gelber Scheibe. - Aus Peru, hier und da verwildert auf Äckern und an Wegen. $\odot .7-9$.

G. parviflóra Cav.

\section{Carpésium L. Kragenblume (XIX, 2).}

St. 30-60 cm h., ästig, weichhaarig; Bl. länglich-lanzettförm., gezähnt; Bltkörbchen hängend, $12-19 \mathrm{~mm}$ br. - An Zäunen, Wegen in

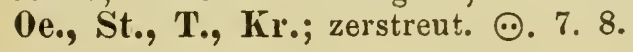
C. cérnuum L.

\section{Filăgo L. Filzkraut, Schimmelkraut (XIX, 2).}

Kl. graue od. weißfilzige Kr.; St. meist ästig, Bl. gedrängt, sitzend; Bltkörbchen geknäuelt od. gebiischelt.

1. Hiillschupp. spitz, zur Frzeit aufrecht; St. gablig-getheilt, 10 bis $30 \mathrm{~cm}$ h., Bl. lineal-lanzettförm., Bltkörbchen geknäuelt in den Gabeltheilungen. Weißwollig. - Sonnige Hüigel, Äcker. ๑. 7. 8.

\section{F. germanica L.}

Variet. $\beta$. canescens (Jord.), dünn graufilzig, St. nur an d. Spitze ästig; - $\gamma$. lutescens (Jord.), dick, gelblich-filzig, oft vom Grunde an ästig. - Zerstreut.

Hüllsch. stumpf, Bl. lanzettlich od. lineal-lanzettförm., spitz. 2.

2. Weißgrau-wollig; St. 15-30 $\mathrm{cm}$ h., traubig-ästig, Körbchenknäuel end- u. seitenständ., Hüllschuppen wollig. - Sandige Acker, Steinbrüche. ๑. 7. 8 . $F$. arvensis $\mathrm{L}$.

Seidenglänzend-graufilzig; St. $10-20 \mathrm{~cm}$ h., gabeltheilig, Knäuel gabel- u. endständ., Hüllschuppen an der Spitze kahl. - Sandige Felder und Hügel; zerstreut. $\odot$. 7. 8 . F. minima Fr. 


\section{Gnaphálium L. Ruhrkraut (XIX, 2).}

Filzige Kr., St. aufrecht od. aufsteigend, einfich od. ästig, Bl. klein, ganzrandig.

1. Bltkörbchen mit fadenförm. weibl. Blt. am Rande und röhrigen Zwitterblt. in der Scheibe.

Bltkörbchen lauter fadenförm. weibl. od. röhrige $Z$ witterbit, enthaltend auf verschiedenen Exemplaren: 2 häusige Arten.

9.

2. Bltkörbchen doldig gehäuft an d. Spitze des $2.5-20 \mathrm{~cm}$ h. St., umringt von sternförmig ausgebreiteten schneeweißwolligen Deckbl. Felsspalten u. Gerölle d. Alpen von Noe., St., K., T, Kr. $(1900$ bis $2550 \mathrm{~m})$. 4. $7-9$.

Edelwei $\beta, G$. Leontopódium L.

Bltkörbchen ohne Deckblkranz, in $\ddot{\Lambda} h r e n$, Doldentraub. od. einz. 3.

3. Hüllschupp. bräunlich od. dunkelbraun.

Hïllsch. strohgelb od. weiß, Bltkörbchen geknäuelt an d. Spitze des St. u. d. Äste.

4. St. vom Grund an ästig, $5-25 \mathrm{~cm}$ h., weißwollig-filzig; Bl. keiliglanzettlich; Bltkörbchen in beblätt. Knäueln am Ende d. Äste. - Feuchte Äcker, Sümpfe. ๑. 7-9.

G. uliginosum L.

St. einfach, sammt d. Unterseite d. Bl. weißfilzig; Bltkörbch. ährenod. traubenförm. längs d. St. (achsel-u. endständ.) od. an dessen Spitze 5 .

5. Bltkörbchen in beblätt. Ähre od. Traube von d. Mitte d. 15 bis $30 \mathrm{~cm}$ h. St. an; Bl. lanzettlich. - Wälder, Holzschläge. 4. 7-10.

G. silváticum L.

Bltkörbch. in eine endständ., oft kopfige Ähre zusammengedrängt. 6 .

6. Bl. 3 nervig, lanzettlich; Älre länglich, am Grunde beblätt., St. 15-30 $\mathrm{cm}$ l. - Alpen, Sudeten, Riesengeb., Böhnerwald; zerstreut. 4. $7-10$.

G. norvegicum Gunn.

Bl. 1 nervig, lineal-lanzettl.; St. 2-10 cm h., Bltkörbchen zu 3-5 (selten $1-2$ ) in kopfiger, endständiger Ähre.

7. Wzst. 1 stenglie, oberste Stbl. kürzer als d. Ähre. - Alpentriften von K. u. T. $(1900-2550 \mathrm{~m})$, auch im Riesengeb., Erzgeb. u. Bühmer. wald; zerstreut. 4. 7. 8.

G. Hoppeanum Koch.

Wrst. vielstenglig, obere Stbl. länger als d. Ähre. - Auf feuchten felsigen Plätzen u. Gerölle d. Alpen, d. Riesengeb. u. Gesenkes. 4. 6-8. G. supinum L.

8. (3) Bltkörbch. kl., glänzend strohgelb, Schuppen anliegend; St. 10-30 cm h., gebüschelt. - Auf Sandboden in B., Mh., Oe.; zerstreut. ๑. $7-9$.

G. lutco album L.

Bltkörbchen erbsengroß, glänzend weiß, Schuppen gr., auseinanderstelıend; St. 30-60 $\mathrm{cm}$ l. - Zierpfl, aus Nordamerika, hier u. da verwildert. 4. 7. 8 .

G. margaritáceum $\mathrm{L}$.

9. (1) Weibl. Körbchen mit weißer, männl. mit rosen- bis purpurrother Hiille; Wzst. Ausläufer treibend, St. $8-30 \mathrm{~cm}$ h. - Trockene Plätr.e. 4. 5. 6.

Katzen pfötchen, $G$. dióicum L.

Alle Körbchen mit brauner Hülle, Wzst. ohne Ausl., St. 5-15 cm hoch. - Nasse felsige Abhänge d. Alpen (1900-2550 m); zerstreut. 4. 7. 8 .

G. carpathicum Wahlenb. 


\section{Helíchryson Gïirtn. Immortelle $(X I X, 2)$.}

1. Bltkürbchen erbsengroß, goldgelb, selten urangeroth, in dichter, zusammengesetzter Doldentraube am Ende d. $15-50 \mathrm{~cm}$ h. weißwolligen St.; Bl. lineal, graufilzig. - Auf Sandboden in B., Mh., Noe. 4. 7-9. H. arenárium DC.

2. Bltkörbchen mit langstrahlenden, glänzend goldgelb. od. weißen Hüllschuppen, einzeln am Ende d. Äste d. $45-60 \mathrm{~cm}$ h. St. - ZierpH. aus Neuholland. $\odot .9$.

H. bracteatum Vent.

\section{Artemísia L. Beifuß (XIX, 2).}

Kr. mit schlankem od, ruthenförm. St. u. Ästen. Weibl. Randbl. fädlich, so l. wie d. Scheibenblt.

1. Bl. ganz, lineal-lanzettlich, St. $0 \cdot 60-1 m$ h., rispig-ästig; Bltkörbch. kuglig, hängend in einseitiger Traube. Kahl. - Küchengewürrptl. aus d. Orient. 4. 8.9. Dragun, Estragon, A. Dracúnculus L.

Bl. fieder-od. handförmig-getheilt (wenigstens d. unteren). 2.

2. St. ruthenförm., traubig- od. rispig-ästig, verholzend. 3.

St. schlank, niedrig, krautig, einfach; $\mathrm{Bl}$. weißgrau-u. seidenglänzendfilzig (rasenbildende Alpenkräuter).

9.

3. Bltkörbch. länglich od. oval, aufrecht od. hängend.

4.

Bltkörbch. halblkuglig od. kuglig, überhängend, in einseitigen Trauben; Blt. gelb.

6.

4. Bl. oberseits kahl grün, unterseits weißfilzig, untere fiedertheilig, oberste lanzettlich; St. $0.60-1.50 \mathrm{~m}$ h., traubig-ästig, kahl; Bltkörbchen eilänglich, aufrecht, Blt. röthlich. - An Hecken, Mauern, auf Schutt. 4. 8. 9 .

Be if u $B, A$. vulgaris $\mathrm{L}$.

Bl. beiderseits kahl, Bltkörbchen eiförmig, aufrecht od. uiberhängend, in einseitswend rispig gruppiert. Trauben; Hiille kahl, Blt. grünlichbraun. 5 .

5. Wz. spindlig, St. (ein einziger) steif aufrecht, $30-60 \mathrm{~cm} \mathrm{~h}$; untere Bl. gestielt, $2-3$ fach fiederschnittig, oberste lineal; Bltkörbch. rundlich-eiförmig. - Auf Sandboden in B., IIh., Oe., St.; zerstreut. $\odot$, $\odot$. 8. 9 .

Wzst. viele, $0.30-1^{\circ} 30 \mathrm{~m} \mathrm{I}$, vom Grunde an traubig.ästige, purpurbraune St. treibend; Bl. 2-3 fach fiederschnittig, kahl od. seidig-grau; Bltkörbchen eiförm. - Auf Sand, Schutt, an Felsen. 4. 7-9.

A. campestris $\mathrm{L}$.

6. (3) $\mathrm{Bl}$. einander sehr genähert. untere u. mittlere $2-3$ fach fiederschnittig, mit linealen Zipfeln; Bltkörbchen nur 2-4 mı br.

Bl. entfernter, breitzipflig, seidenglänzend weißgrau-filzig, grundständ. sehr 1. gestielt, 3 fach-, stengelständ. 2 fach- bis 1 fach fiedertheilig; Bltkörbchen 6-7 mm br.; St. 0.50-1.25 $\mathrm{m}$ h. - Auf Sand, Schutt, an Felsen; zerstreut. 4. 7. 8. Wermuth, A. Absýnthium L.

7. Bl. grauweiß-filzig, seidenglänzend; St. $30-60 \mathrm{~cm}$ h., weißfilzig. Dürre Kalkhügel in B., Mll., Noe.; sehr zerstreut. 4. 8. 9.

A. austríaca Jacqu.

Bl. oberseits kahl, unterseits dünn graufilzig od. flaumig; St. $0 \cdot 30$ bis $1 \mathrm{~m} \mathrm{~h}$. 8.

8. Bl. unterseits grau-, Korbhüllen weißfilzig, St. grünlich, 0.45 bis $1 \mathrm{~m}$ h. - Sonnige felsige Hiigel in B., Mh., 0e., K.; zerstreut. 4. 7-9. A. póntica L. 
Bl. unterseits sowie d. Korbhüllen flaumig, St. kahl, steif, 30-60 cm hoch. - Küchengewürzpfl. aus Südeuropa. 4. 9. 10.

Eberraute, Stabwurz, A. Abrótanum L.

9. (2 Untere B1. gestielt, fingerförm., obere sitzen丸, fiedertheilig od. eingeschnitten; Bltkörbchen in endständ., ährenförm. Traube; St. $8-15 \mathrm{~cm}$ hoch. - Felsen u. Gletschermoränen d. Alpen von K. u. T. $(1900$ bis $2550 \mathrm{~m})$. 4. 7. 8 .

A. spicata Wulf.

Alle Bl. gestielt, untere handschnittig mit fiederspalt. Abschnitten, obere $u$. blütenständ. fingerförm.; Bltkörbchen in kurzer Ähre, St. 3.5 bis $12 \mathrm{~cm}$ h. - Felsen d. Alpen $(1900-2560 \mathrm{~m})$. 4. 7. 8.

Edelraute, $A$. Mutéllina Vill.

\section{Tanacētum L. Rainfarr (XIX, 2).}

1. St. viele, $0.6-2 m \mathrm{~h}$., doldentraubig-ästig; Bl. fiederschnittig, Abschnitte kammförmig-fiederepaltig; Bltkörbch. $10-12 \mathrm{~mm}$ br., in schirmfürmigen Doldentrauben. - Raine, Hecken, Ufer. 4. 7-8. T. vulgare L.

2. St. ebenso, Bl. elliptisch, untere l. gestielt, alle gesägt. - Zierund Heilpfl. aus Südeuropa, auch verwildert. 4. 9.

Glatte Salbei, T. Balsamita L.

\section{Santolina L. (XIX, 2).}

Gránfilzig; St. viele, $15-30 \mathrm{~cm}$ h., in aufrechte, 1 köpfige Äste getheilt; Bltkörbchen 6-9 mm br, Blt. goldgelb. -- Zierpflanze aus Südeuropa, wild (?) in St. u. T. Ђ. 7.

Cypressenkraut, S. Chamaecyparissus L.

\section{Achilléa L. Schafgarbe (XIX, 2).} schuppig.

St. aufrecht, oben doldentraubig-ästig; Korbhiille halbkuglig, ziegel-

1. Bl. ganz, gesägt, lineal-lanzettförm., St. $30-60 \mathrm{~cm}$ h.; Bltkörbch. $13 \mathrm{~mm}$ br., mit 8-12 Strahlblt. Kahl. - Ufer (auch als Zierpflanze mit vollen Körbchen). 4. 7. 8.

A. Ptármica L.

Bl. fiederförmig getheilt.

2. Strallblt. 6-12, br.; Kürbchen 8-25 $\mathrm{mm}$ br. in meist einfacher Doldentraube, selten einzeln, endstaindig.

Strahlblt. 4-5, kư', Körbchen zahlreich, in zusammengesetzter Doldentraube.

3. Bl. grün, sammt d. St. kahl od. behaart. 7. 4.

Bl. u. St. seidenglänzend-graufilzig, Grundbl. fiederspaltig, langgestielt, Stbl. lanzettlich, eingeschnitten; Hüllschuppen br., schwarzgerandet, St. 8 bis $20 \mathrm{~cm} \mathrm{h.} \mathrm{-} \mathrm{Felsen} \mathrm{u.} \mathrm{Gerölle} \mathrm{d} \mathrm{Alpen} \mathrm{v.} \mathrm{Oe.,} \mathrm{Sz.,} \mathrm{K.,} \mathrm{T.,} \mathrm{Ḱr.} 4$. $6-8$. Almwermu th, Weißer Speik, A. Clavennae L.

4. St. $2 \cdot 5-25 \mathrm{~cm}$ h., einköpfig od. mit einfacher Doldentraube. 5 .

St. $0 \cdot 30-1 m$ h., Doldentraube zusammengesetzt; Bl. gr., fiederschnittig, Abschnitte lanzettförm., eingeschnitten-doppeltgesägt. - Wälder der Voralpen von K. u. T.; zerstreut. 4. 7. 8. A. macrophylla L.

5. Bl. kammförm.-fiedertheilig, Zipfel ganzrandig; St. 5-15 cm b. - Alpen von Sz., St., K., T.; an felsigen Plätzen $(1900-2600 \mathrm{~m})$. 4 . 7. 8 .

A. moschata Wulf. 
haart.

Bl. doppelt-fiederschnittig od. fiedertheilig, St. $7 \cdot 5-25 \mathrm{~cm}$ h., be-

6. Bl. fiederschnittig, Fiedern 2-3 spaltig od. fiederspaltig, Zipfel lineal stachelspitzig; Hüllschuppen br., schwarzbraun gerandet. - An nassen Felsen u. Bächen d. Alpen $(1600-2200 \mathrm{~m})$. 4. 7-9.

A. atrata L.

Bl. doppelt fiedertheilig, Zipfel spitz, z. Th. 2 spaltig od. gezähnt. Feuchte Plä̀ze d. Kalkalpen v. Ooe., Sz., St., K., Kr. 4. 7-9.

A. Clusiana Tsch.

7. (2) Bl. einfach fiederschnittig od. fiedertheilig, Abschnitte eilanzettförmig, fiederspaltig, am Grunde zusammenfließend, Zipfel kleingesägt; Grundbl. gestielt, bis $60 \mathrm{~cm} \mathrm{l}$; St. bis $1 \mathrm{~m}$ h. Kahl od. wollig, Strahlblt. weiß od. purpurn, - Bergtriften u. Felsen d. Voralpen v. Ooe., St., K., Kr. 2. $7-10$. A. tanacetifolia All.

Bl. doppelt bis dreifach fiederschnittig od. fiedertbeilig.

8. Strahlblt gelblich, zurückgebogen, viel kürzer als d. Korbhülle, Bl. (u. St.) grauflaumig, grundständ. l. gestielt, 3 fach fieder-, Stbl. sitzend; 2 fach bis 1 fach fiederschnittig; St. $15-30 \mathrm{~cm}$ h., Bltkörbch. sehr kl. (A. nobilis Neilr. nicht L.). - Trockne bebuschte Bergabhänge in B., Mh., Noe., K.; zerstreut. 4. 6. 7.

A. Neilreichii Kern.

Strahlblt. weiB, rosen- od. purpurroth, ausgebreitet, halb so 1. als d. Korblü̈lle.

9.

9. Blspindel schmal, ungezähnt od. von der Mitte gegen die Spitze spärlich gezähnelt.

10.

Blspindel breitgeflügelt, häufg gezähnt, Zipf. br., starr, mit knorplich zugespitzten Zähnen, Doldentraube gr., locker.

13.

10. B1. dunkelgrün, mit ausgebreiteten Abschnitten, daher im Umriss br. lineal; Doldentraube gr., reichköpfig; Hüllschuppen schmal hellbräunlich berandet, Strablblt. weiß, rosa bis purpurroth; St. $30-60 \mathrm{~cm} \mathrm{h.} 11$.

Bl. stark behaart, daher graugrün, mit zusammengezogenen Abschn., daher im Umriss schmallineal, Abschn. sehr gedrängt stehend; Doldentraub. u. Bltkörbchen kleiner, diese selır dicht zusammengedrängt, Hüllschuppen wie bei 10 , Strahlblt. weiß.

12.

11. Kahl od. fast kahl. - Alpen v. T., wahrscheinlich auch anderwärts. 7. 6--9. A. Millefólium $\mathrm{L}$.

Mehr weniger wollig behaart (A. Millefolium Auct. nicht L.). Wiesen, Raine, Hügel bis in d. Gebirge. 4. 6--9.

Gemeine Sch., A. collina Beck.

12. St. $30-60 \mathrm{~cm}$ h., robust, steif. - Sonnige Kalkhügel in B., Ih., Noe. 4. 7-9.

A. pannónica Schle.

St. $10-30 \mathrm{~cm}$ h., zierlich, steif; Stbl. sehr schmal, Blzipf. pfriemenförmig. Ganze Pfl. weißzottig. - Wie vorige. 4.7-9. A. setćcea W. Kit.

13. (9) Korbhüllschuppen hellbraun berandet, Strahlbl. meist pfirsich. roth; St. $20-60 \mathrm{~cm} \mathrm{h.} \mathrm{-} \mathrm{Sumpfige} \mathrm{Wiesen,} \mathrm{salzhaltige} \mathrm{Plätze} \mathrm{in} \mathrm{Mh.} \mathrm{u.}$ 0e.; zerstrent. 4. 7-10. A. asplenifolia Vent.

Hüllschuppen br. schwarzbraun berandet, Strahlblt. weiß, rosen- bis purpurroth; St. 0.6-i $m$ h. - Riesengebirge, stellenweis. 4. 7-9. 


\section{Anthemis L. Afterkamille (XIX, 2).}

St. einfach $1 \mathrm{köpfig} \mathrm{od.} \mathrm{in} 1 \mathrm{köpfige} \mathrm{Äste} \mathrm{getheilt;} \mathrm{Bl.} \mathrm{Rederförmig}$ zertheilt, Korbhülle ziegelschupp., Bltboden spreublättrig, nicht hohl.

1. Strahl- u. Scbeibenblt. goldgelb, Bltkörbchen $37 \mathrm{~mm}$ br.; St. 30 bis $60 \mathrm{~cm}$ h. mit gleichhohen Ästen; Bl. kammförmig-fiedertheilig. Sonnige Hügel, zerstreut, auch Zierpf. () od. 4. 7. 8 .

Färbekamille: A. tinctória L.

Strahl weiß, Scheibe gelb, selten (nur bei A. alpina) alle Blt. neiß. 2.

2. a) Spreublättch. lineal, spitz, nervenlos; Bltboden kegelförmig, Körbchen $13-25 \mathrm{~mm}$ br.; St. 15-45 $\mathrm{cm}$ h., doldentraubig ästig, Bl. 2- bis 3 fach fiederschnittig. Kahl, stinkend. - Schutt, an Wegen. ๑. 6-9.

\section{A. Cótula L.}

b) Spreubl. mit deutlich. Mittelnerv, stachelspitzig; Bi. 2 fach fiedertheilig, spitzzipflig; St. $15-45 \mathrm{~cm} \mathrm{h.;} \mathrm{Pfl.} \mathrm{mit} \mathrm{Wzst.}$

3.

c) Spreubl. mit Mittelnerv, nicht stachelspitzig, stumpf oder zerschlitzt. 5.

3. Bltboden halbkuglig, Fr. kreiselförmig, zusammengedrückt rierkantig; St. sehr ästig, nebst d. Bl. Alaumig-wollig; Bltkörbch. 25-37 mm breit. - Äcker, Wege in B., Mh., 0e.; zerstreut. ๑. 5. 6.

A. austriaca Ję̧u.

Bltbod. kegelförm., Körbchen 18-37 $\mathrm{mm}$ br.

4. St. u. Bl. grün, flaumig-wollig, Spreublättch. ganzrandig, Fr.kreiselförmig, rundlich; St. aufrecht bis niedergestreckt. - Felder, wüste Plätze. ๑. $6-10$.

A. arvensis $\mathrm{L}$.

St. u. Bl. grau- bis schneeweiß-zottig, Spreubl, zerrissen-gezähnelt' St. meist aufrecht. - Auf Sandboden in B., Mh., Noe.; zerstreut. $\odot$. $5-7$. A. ruthénica M. Bieb.

5. (2, c.) Strahl u. Scheibe weiß, Bltköıbchen $25 \mathrm{~mm}$ br., m. sclrwarzbraun gerandeten Hüllschuppen; St. $7 \cdot 5-20 \mathrm{~cm}$ h., meist 1 köpfig, Bl. kammförmig-fiedertheilig, grün. Rasenbildend. - Steinige Lehnen d. Kalkalpen von St., K., T. 4. 7. 8. A. alpina L.

Strahl weiß, Scheibe gelb; Körbchen $25 \mathrm{~mm}$ br. Rasige vielsteng. lige Arten.

6. Angedrückt bebaart; St. aufsteigend $1 \mathrm{köpfig,} \mathrm{7-15} \mathrm{cm}$ h., Bl. fiedertheilig bis fiederschnittig, Abschn. anseinanderstehend, lineal-lanzettl. od. keilförm.-3 theilig. Hüllschuppen schmal bräunlich-gesäumt. - Auf sandigem Bod. in B. (bei Dobrissch und Weltrıc, häuf.) in $0 \ddot{0}, 4.6-8$.

A. montana $\mathrm{L}$.

Flaumig; St. aufrecht, in 1 köpfige Äste zertheilt, $30-60 \mathrm{~cm} \mathrm{h.;}$ Bl. kurz und schmal, untere $2-3$ tach, obere 1 fach fiedertheilig. - Als Arznei-Zierpf. (meist mit vollen Kürbchen) cult. Aus Südeuropa, hin und wieder verwildert. 4. 6. 7. Rümische Kamille, A. nóbilis L.

\section{Matricaria L. Mutterkraut (XIX, 2).}

Kahle aromatische Kr.; St. $15-30 \mathrm{~cm}$ h., meist doldentraubig-ästig; Bl. 2-3fach fiederschnittig mit linealen Zipfeln; Korbhülle halbkuglig ziegeldachig.

1. Bltkörbch. 12-20 $\mathrm{mm}$ br. mit weißem (meist zurückgeschlagenem) Strahl und gelber Scheibe. - Getreidefelder. $\odot .5-9$.

Feldkamille, Hermel, $M$. Chamomilla L.

2. Bltkörbchen 6-9 $\mathrm{mm}$ br. ohne Strahl. - Aus Asien, an Eisenbahndämmen u. Straßen in B. verwildert. ๑. 7. 8. M. discoídea DC. 


\section{Leucánthemum L. Wucherblume (XIX, 2).}

Bltkörbchen gr. mit ziegelschupp. Hülle, convexem Bltboden, gelber Scheibe und weißem Strahıl; St. 1 köpfig od. in wenige 1 köpfige Äste getheilt. Kahle Kr.

1. Fr. ohne Pappus; St. $30-80 \mathrm{~cm} \mathrm{~h}$, oben (wie auch d. Äste) nackt, untere Bl. spatelförmig, gestielt, gesägt, gekerbt od. gezähnt, Stbl. sitzend, länglich od. lanzettförm, eingeschnitten gezähnt; Hüllschuppen grün. Wiesen, Graspliatze. 4. 6-10. (Chrysantliemum Leucanth. L.).

Große Malblieb, Johannis-, Orakelblume, $\boldsymbol{L}$. vulgare Lam.

Fr. mit ohrförmigem Pappus; Hüllschuppen schwarzbraun berandet; St. einfach 1 köpfig; untere $\mathrm{Bl}$. in Rosette, fiederspaltig od. eingeschnittengesägt. Rasenbildend.

2. Alle Bl. gesägt od, eingeschnitten-gezähnt bis fiederspaltig; St. 10 bis $25 \mathrm{~cm} \mathrm{~h}$.

3.

Grundbl. kammförmig-fiederspaltig, gestielt, Stbl. (2-3) lineal-lanzettförmig, ganzraudig. - Kiesige Grasplätze d. Alpen $(1740-2550 \mathrm{~m}) .4$. 7. 8 .

L. alpinum (L.).

3. Bl. gesägt, St. $15-30 \mathrm{~cm}$ h.; Bltkörbch. $30 \mathrm{~mm}$ br., Hüllschupp. schmal berandet. - Alpentriften in K. u. T.; zerstreut. 4. 6. 7.

L. montanum (L.).

Bl. eingeschnitten-gezähnt bis fiederspalt., St. 8-20 cm h.; Bltkörbch. $30-40 \mathrm{~mm}$ br., Hüllschuppen br. berandet. - Gerölle, felsige Plätze, an Bächen d. Kalkalpen $(1580-2220 \mathrm{~m})$. 4. 7. 8. L. coronopifolium (Vill.).

\section{Pyréthrum L. Bertram (XIX, 2).}

St. aufrecht, doldentraubig-ästig, blreich; Bltkörbch. endständ., mit halbkugliger, ziegeldachiger Hülle, weißem Strahl u. gelber Scheibe.

1. Bl. 2-3 fach fiederschnittig mit lineal. od, fadenförm. Zipfeln; St. 15-60 $\mathrm{cm}$ h., Bltkörhch. 18-25 $\mathrm{mm}$ br.. Bltbod. ei- bis kegelfürm., Strahl meist zurückgebogen. Kahl. - Auf Feldern, wüsten Plätzen. ๑. 6-9.

$P$. inodórum Sm.

Bl. 1-2 fach fiedertheilig bis fiederschnittig, Abschn, ei- od. lanzettförmig ; Bltkörbchen 1. gestielt, in schirmförmigen Doldentrauben, 13 bis $25 \mathrm{~mm}$ br.

2. Bl. fiedertheilig, Theilstücke eilänglich, fiederlappig und gesägt; St. $30-60 \mathrm{~cm}$ h., sehr ästig. - Aus Südeuropa, verwildert auf Schutt, an Mauern, Hecken; häufig als Zierpfl. mit gefülltem Körbchen. 4. 6. 7. Mutterkraut, Römische Kamille, P. Parthenium Sm.

Bl. fiederschnittig, Abschn. fiedertheilig u. gesägt: St. 0.6-1 m h., straff, einfach, oben doldentraubig-ästig. - Gebüsche, Waldränder. 4. 6. 7. P. corymbosum Sm.

\section{Dorónicum L. Gamswurz (XIX, 2).}

Bltkörbchen einzeln, endständig, $3.7-7.5 \mathrm{~cm}$ br., mit halblkugliger Hülle, fast ebenem Bltborlen, goldgelben Strahl-u. Scheibenblt. Stauden mit knolligem Wrst. u. ganzen Bl.

1. Wzst. Ausläufer treibend, St. $0 \cdot 30-125 \mathrm{~m}$ h. einfach 1 köpfig od. oben doldentraubig. ästig; Bl. seicht gez̈̈hnt, grundständ. gestielt, herzod. herzeiförmig, obere eiförm. länglich. Weichbehaart. - Feuchte Wälder und Wiesen d. Alpen von K. u. T.; häufig als Zier- u. Heilpfl. cult. 4 5. 6 .

D. Pardalianches $\mathbf{L}$. 
Wzst. abgebissen, ohne Ausl.

2. Wzst. liegend, ohne Grundbl., St. $0.35-1.25 \mathrm{~m}$ h., $1-3 \mathrm{köpfig} \mathrm{od.}$ doldentraubig-ästig; Bl. geschweift-gezähnt, untere herzförm. m. brgeflügeltem Stiel, d. andern sitzend, mittlere herzförm.-länglich. Weichhaarig. An Bächen, quelligen Orten d. Alpen (1260-1900 m), auch in B. (Böhmerwald), Ilh. u. Sch. (Sudeten). 4. 7. 8.

D. austríacum Jeqn.

Wzst. schief, Grundbl. treibend; St. $30 \mathrm{~cm}$ h., einfach od. wenigästig, 1-3 köpfig; Bl. grobgezähnt, grundständ. herz- od. nierenförmig, lang gestielt.

3. Korbhülle viel kürzer als d. Strahl, St. oft nur 1 blättrig (Bl. herz-eiförmig, stengelumfassend). Kahl od. flaumig. - Felsige Plätze der Kalkalpen von K., T., Kr. $(1900-2250 \mathrm{~m})$; zerstreut. 4. 7. 8.

(D. corlifolium Strb.)

D. cordatum Wulf:

Korbhïlle fast so lang wie d. Strahl, Schuppen sehr schmal, l. zugespitzt, gewimpert; Stbl. herzförm.-lïnglich. - Laubwälder im südl. B.; stellenweis. 4. 7. 8.

D. caucásicum M. Bieb.

\section{Arónicum Neck. Krebswurz (XIX, 2).}

Bltkörbchen wie b. Doronicum. Wzst. dick beschuppt, St. meist einköpfig, Bl. ganz.

1. Bl. gr. u. br., buchtig.gezähnt, untere ei- od. herzeiförmig mit brgeflügeltem Stiel, die andern herzförmig-stengelnmfüssend. länglich; St. 15-60 cm b., 1-3 köpfig. - Gerölle u. felsige Pläłze d. Kalkalpen (1580 bis $1900 \mathrm{~m})$. 4. 7. 8 .

A. scorpioides Koch.

Bl. länglich-lanzettförm., ausgeschweift-gezähnt, untere l. u. schmal gestielt, d. andern sitzend; St. $2.5-3.7 \mathrm{~cm}$ b., $1 \mathrm{köpfig.}$

2. Wzst. wagerecht, St. hohl, Bl, dünn u, weich. - Feuchte Gerölle u. Triften d. Kalkalpen $(1580-2200 \mathrm{~m})$; zerstreut. 4. 7. 8.

A. Clusii Koch.

Wzst. schief, St. nicht hohl, Bl. dicklich, steif, zerbrechlich. - An gleichen Orten d. Urgehirgsalpen $(1900-2600 \mathrm{~m})$; zerstreut. 4. 7. 8. A. glaciale Rchb.

\section{Arnica L. Wohlverleih (XIX, 2).}

St. $30-60 \mathrm{~cm}$ h., 1-3 köpfig, fast nackt, drüsig-flaumig; Bl. ganzrandig, grundständ. in Rosette, länglich-verkehrt-eiförmig; Bltkörbchen nickend, $5 \mathrm{~cm}$ br. mit dottergelbes Blt. - Moorige Gebirgswiesen. 4. $6-8$.

A. montana $\mathrm{L}$.

\section{Ligulária Cass. (XIX, 2).}

St. einfach, aufrecht, $0.30-1.30 \mathrm{~m}$ h.; Bl. abwechselnd, grundständ. herzeiförmig, gezähnt, sehr l. gestielt, Stbl. 1-3, kleiner; Bltkörbchen $5 \mathrm{~cm}$ br. in endständ. Traube, Blt. goldgelb. - In B. (Sumpfwiesen bei Habstein u. Weißwasser). 4. 6. 7.

L. sibirica Cass.

\section{Senécio L. Kreuzkraut (XIX, 2).}

Vielgestaltige $\mathrm{Kr}$. mit meist doldentraubig-ästigem, selten einfachem 1 köpfigem St.; Bltboden nackt.

1. Alle Blt. röhrig, gelb; St. $2 \cdot 5-30 \mathrm{~cm}$ h., Bl. fiederspaltig, Zipfel ungleich eckig-gezähnt. Kahl od. spinnwebwollig. - Gemeines Unkraut. ○. 2-12. 
Strahlblt. vorhanden.

2. Strahlblt. kurz, zurückgerollt, St. $15-50 \mathrm{~cm}$ h., Blzipfel buchtig gezähnt.

3.

4.

Strahlblt. I. zurgenförınig, ausgebreitet.

3. Hüllblättch. d. eiförm.-länglichen Korblıülle 3-3 mal länger als d. Schüppchen, PAl drüsig-tlaumig. - Holzschläge, Steinbrüche, auf Sand. ๑. $6-10$. S. viscosus $\mathrm{L}$.

Hüllblättchen d. walzigen Korbhülle viel länger als d. Schüppchen. PA. spinnweb-flaumig. - Wälder, Waldblößen u. Schläge. ๑. 7. 8. S. silváticus L.

4. Bl. verschiedenartig zertheilt; selten ganz (dann am Grunde herzförmig).

Bl. ungetheilt, am Grunde niemals herzförmig.

5. Strahlblt. purpurroth, lila od, weiß; Bl. leierförmig-fiederspaltig. - Zierpfl aus Südafrika. ๑. 7-9.

S. élegans L.

Strahl- u. Scheibenblt. gelb.

6. a) Untere Bl. 2 fach, obere 1 fich fiederschnittig, Zipfel lineal; St. 8-30 cm h., oben doldentraubig-ästig; Bltkörbchen $20 \mathrm{~mm}$ br. - Felsen u. Gerölle d. Kalkalpen $(1200-1600 \mathrm{~m})$. 4. 7-9. S. abrotanifólius L.

b) Alle Bl. fiederspaltig, fiedertheilig od. leierförmig, nur d. untersten bisweilen ganz.

c) Alle od. die unteren Bl. ganz u. gestielt., am Giunde herzf. 15.

7. Ganze Pf. grün, kahl od. verschiedenartig behaart.

Ganze PA. grau- od. weißfilzig; Bl. gestielt.

8. Alle Bl. fiedrig getheilt, untere gestielt, obere sitzend; St. doldentraubig-ästig.

9.

Untere Bl. gauz od. leierförm., gestielt, obere leierförm. od. fiederspaltig, sitzend; Körbchenstiele mit linealen Deckblättch. besetzt. 12.

9. Kriechender, walziger, Ausläufer treibender Wzst.; St. 0.30-1 m hoch, eine br. schirmförm., vielköpfige Doldentraube tragend. Kahl oder spinnweb-flockig.

10.

Dünne spindlige $\mathrm{Wz}_{\text {., St. }} 30-60 \mathrm{~cm}$ h., Bl. buchtig fiedertheilig, Zipfel eckig.gezähnt.

11.

10. St. mehr weniger roth, Bl, dunkelgrün, ungleichmäßig leierförm.fiedertheilig, Abschnitte keilförm., eingeschnitten-gesägt, plan; Hüllblättch. lanzettlich, gewimpert. - Flussauen, Geübscbe, Wiesen; zerstreut. 4. $7-9$.

S. erucifolius Huds.

St. grün, dicht beblättert; Bl. hellgrün, fiederspaltig bis fiedertheilig, Zipfel lineal, zugespitzt, gauzrandig od. eingeschnitten, am Rande meist zurïckgerollt; Hüllblättch. verkehrteiförm. zugespitzt. - Steinige Abhänge, Hügel, auch auf Salzbod. in Mh., 0e.: zerstreut. 4. 7-9.

\section{S. tenuifolius Jcqu.}

11. Ganze Pf. spinnweb-wollflockig, Blzipfel kraus gezähnt. - Äcker und Brachen in Mh. n. Schl.; zerstreut. ๑. 5.6. S. vernalis W. Koch.

Kahl od. jung wollig, Blzipfel nicht kraus gezähnt. - Waldränder, felsige Athänge der Kalkvoralpen; zerstreut. $\odot$. ค. 6-7.

(S. Nebrodensis DC.)

S. rupestris W. Kit.

12. (8) St. oben doldentraub. ästig, straff, reich beblätt., bis $1 m$ h. 13.

St. von d. Mitte an in 1. mit lineal angedrückten Blättch. besetzte mehrköpfige Äste getheilt, $0 \cdot 30-1 \mathrm{~m}$ h ; Bl. leierförm.-fiedertheilig: grund. 
ständlige mit gr. herzeiförmigen Endlappen, - Feuchte Wiesen, Ufergebuische in B., Ml., Sch., Oe.; zerstreut. 4. 6-9.

S. barbareaefólius Krock.

13. Untere Bl. meist leierförmig-fiedertheilig (unterste zuweilen ganz), d. andern 1-2 fach fiedertheilig. Abschnitte länglich, fiederspaltig-gnzähnt. Trockne Wiesen, Hiigel, Raine. $\odot .6-9$.

J a cobskraut, Spinnkraut, S. Jacobiea L.

Grundbl. stets, untere Stbl. meist ganz, eilänglich od. oval, gestielt, ganzrandig od. buchtig- bis eingeschnitten-gezähnt, obere leierförm.-fiederod. fiederspaltig. - Feuchte Wiesen u. Sümpfe, Seeufer in Ooe. u. K ; zerstreut. $\odot .6-9$.

$S$. aquáticus Huds.

14. (7) Schneeweiß-wollfilzig; Bl. fiedertheilig, Theilstücke d. unteren eingeschnitten-gekerbt, d. oberen lineal; Bltkörbchen in Doldentraube, selten St. 1 köpfig. - Steinige Plätze d. Alpen von St., K., T., Kír. (1900-2500 m); zerstreut. 4. 7. 8 .

S. incanus L.

Seidenglänzend-graufilzig; untere Bl. spatel-od. keilig-lanzettförmig, eingeschnitten-gekerbt bis fiederlappig, obere gesägt. - Gerölle a. Triften d. Alpen. 4. 7. 8.

S. carniólicus Willd.

15. $(6$, c.) Alle Bl. ganz u. ungleich gesägt, unterseits sammt dem 30-60 cm h. St. spinnweb-graufilzig, untere herz-eiförm.; Bltkörbchen doldentraubig, 25-37 mm br. - Bäche, feuchte Gerölle (um d. Sennhütten) d. Alpen; zerstreut. 4. 7. 8.

$S$. cordatus Koch.

Untere Bl. herzeiförmig od. spießtörm., grobgezähnt, obere fast leicrförmig, alle sammt d. St. kahl. Sonst wie vorige. Variiert mit orangegelbon Bliiten. - Feuchte Wiesen der Alpen (1260-1600 m), auch in Sch. (Beskiden). 4. 7. 8.

S. subalpinus Koch.

16. (4) Strahlblt. fehlen, Röhrenblt. gelblichweiß, St. 1-2 $m \cdot h$, reichblättrig, oben doldentraubig-ästig; Bl. ellipt. lanzettförm., gezähntgesägt. - Thäler d. Voralpen von Sz., K., T.; zerstreut. 4. 7. 8.

\section{Stracaliaster Lam.}

Strahl vorhanden, sammt d. Sclieibe goldgelb. 17. ästig.

17. Strahlblt. 5-8; St. ruthenförm., oben doldentraubig- od, rispig-

Strahlblt. $10-20$.

18.

20.

18. St. bis an d. körbchentragenden Äste beblättert, diese mit lineal. Deckbl. besetzt.

19.

St. nach oben fast nackt, da d. Bl. allmällich in lineal-lanzettliche Deckbl. übergehen; Bi. lederartig, länglich od. länglich-lanzettförm., untere gezähnt, St. $0 \cdot 45-2 m$ h. - Feluchte Wiesen u. Gebüsche in Mh., Noe., K.; zerstreut. 4. 7. 8.

S. Dória L.

19. Bl. locker gestielt, abstehend, ungleich gezähnt mit abstehenden Zähnen, lanzettlich bis oval, Strahlblt. meist 5 (4-6), St. $0.60-1.30 \mathrm{~m}$ hoch. - Berg- u. Auenwälder, Ufergebüsche. - 4. 7. 8.

\section{S. nemorensis $\mathrm{L}$.}

Variet. $\alpha$. Jacquinianus (Rchb.), mittlere u. obere Bl. vor dem Grunde verschmälert, halbstengelumfassend, sitzend, alle feiu behaart; - $\beta$. Fuchsii (Gmel.), alle Bl. gestielt, kahl.

Bl. zahlreich, dicht gestellt, aufrecht-abstehend, knorplig berandet, ungleich gesägt mit vorwärts geneigten Zähnen, länglich-lanzettförm. od, 
lannzettlich, untere gestielt, obere mit keiliger Basis sitzed. Strahlblt. 7-8, St. $1-1.6 m$ h. - Flussufer, zwischen Weiden. in B., Mlı., Oe., St., K.; sehr zerstreut. 4. 7. 8.

S. fluviatilis Wallr.

20. (17) St. 1-2 $m$ h., hohl, fingerdick, eine brschirmförm. Dolden. traube $25 \mathrm{~mm}$ br. Körbchen tragend; Bl. lineal-lanzettförm., scharf gesägt, unterseits dünn graufilzig, seltner dicht weißfilzig (S. riparius Wallr.) od. kahl (S. bohemicus Tsch.). - Flussufer, sumpf. Auenwälder; sehr zerstreut. 24. 7. 8.

S. paludosus L.

St. $15-45 \mathrm{~cm}$ h., nicht hohl, 1-3 köpfig; Bl. lederartig, meist wollflockig, untere länglich-lanzettförm., gezähnt, obere ganzrandig; Bltkörbch. fast $5 \mathrm{~cm}$ br. - Steinige Triften d. Alpen $(1300-2300 \mathrm{~m})$; zerstreut. 7. 7. 8 .

S. Dorónicum L.

\section{Cinerária L. Aschenkraut (XIX, 2).}

St. aufrecht, meist einfach, eine meist einfache Trugdolde v. Bltkörbch. tragend, deren Stiele am Grunde von sclimalen ganzrandigen Bl. umringt zu sein pflegen, selten 1 liöpfig. Bl. ungetheilt.

1. St. gegen obenhin ästig; $30-60 \mathrm{~cm}$ l., jeder Ast eine Trugdolde tragend; Bl. grob buchtig-gezähnt, lanzettförm., sammt d. St. weichzottig; Strahlblt. schwefelgelb. - Torfsümpfe, Teichränder im südl. B. u. Mh.; sehr zerstreut. $\odot .6 .7$.

C. palustris L.

St. einfach, nebst d. Bl. spinnweb-wollflockig.

2. Blt. safrangelb bis dunkelorangeroth, Strahlblt. bisweilen fehlend; Grundbl. kurz gestielt, fast ganzrandig, Stbl. am Grunde verschmälert; Korbhülle purpurn; St. $15-60 \mathrm{~cm}$ h.

Blt. gold- od. schwefel-, selten safrangelb.

3. Bl. alt fast kahl, grundständ. eiförm., stengelständ. lanzettlich, obere lineal; Blt. orangegelb. - Feuchte Gebirgswiesen d. Alpen, auch in K., Mh. u. B. (selten). 4. 5. 6. C. aurantiaca Hppe.

Bl. u. Korbhülle dicht wollig, Grundbl. u. untere Stbl. längl.-eiförm., obere lanzettlich; St. 1-3 köpfig, Körbchen gr., Blt. dunkel orangeroth. Trockne Alpenwiesen in K. u. T.; sehr zerstreut. 4. 7. 8.

\section{C. capitata Koch.}

4. Bl. grob buchtig-gezähnt, oft wellig-kraus, untere herzeiförm. bis länglich mit brgeflügelt. Stiel, obere lanzettl. sitzend, sammt d. St. schwach spinnweb-wollig. - Feuchte, quellige Stellen, Torfmoore, an Bächen i. d. Alpenländ., B. u. Mh.; zerstreut. 4. 5. 6.

C. crispa Jcqu.

Variet. $\alpha$. genuina, Bl. u. Blstielränder kraus gezïlnt, Korbhülle grün, Blt. dottergelb; St. $8-15 \mathrm{~cm} \mathrm{h.} \mathrm{-} \beta$. rivularis (IV. Kit.,, Bl. u. Blstielränder nicht kraus, ganzrandig od. geziilınt, Korbhülle grün, Blt. goldgelb; St. 0.30-1 $m$ h. - $\gamma_{\text {. sudética }}$ (Koch), Hüllschupp. an d. Spitze purpurn, Blt. dotter-bis safrangelb, St. $30 \mathrm{~cm} \mathrm{h.} \mathrm{-} \mathrm{\delta .} \mathrm{crócea} \mathrm{(Tratt.),} \mathrm{Korbhülle} \mathrm{ganz} \mathrm{pur-}$ purn, Blt. safrangelb, St. $15-30 \mathrm{~cm}$ h.

Bl. ganzrandig od, ausgeschweift-gezähnt, plan, unterseits nebst dem St. weiß spinnweb-flockig, grundständ. u. untere Stbl. mit brgefligeltem Stiel, obere sitzend; Bltkörbchen $25 \mathrm{~mm}$ br.

5. Fr. kahl; St. $30-60 \mathrm{~cm} \mathrm{h.}$

Fr. kurz steifhaarig. 
6. Stiel d. Grund- u. unteren Stbl. so 1. od. länger als d. herz- bis länglich-eiförm. Spreite; Blt. hell- bis goldgelb. - Feuchte Wiesen und Grasplätze d. Alpenländer; zerstreut. 4. 6. 7.

C. alpestris Hppe.

Variet. $\beta$. longifolia (Jequ.). Stbl. verlängert lanzettförm.; \%. pratensis (Hppe.), Bl. länglich, St. obenhin fast nackt, Korbhülle purpurn.

Stiel d. Grundbl. u. untern Stbl. kürzer als d. eiförm, od. längliche Spreite, alle Bl. nebst d. St. dicht wollflockig, weißgrau. - Wiesen der Alpen; sehr zerstreut. 4. 6. 7.

C. Clusiana Host.

7. Stiel d. Grundbl. u. unteren Stbl. länger als d. spatel-od. herzförm. Spreite, obere Bl. sitzend, alle unterseits weif spinnwebwollig; St. 30 bis $4 \overline{\mathrm{cm}}$ h., Blt. goldgelb. - Fenchte Wiesen in 0oe. u. K.; zerstreut. 4. $5-7$.

C. spathulaefolia Gmel.

Stiel d. Grundbl. kiirzer als d. eiförm. od. rundl. Spreite, Stbl. alle sitzend, länglich, oberste lineal, alle nebst d. $7-30 \mathrm{~cm}$ h. St. grau spinnwebllockig; Blt. hellgelb. - Bergwiesen, Hügel in B., Mh., Oe., St., K.; zerstreut. 4.6 .7 .

C. campestris Retz.

\section{Caléndula L. Ringelblume (XIX, 4).}

St. ästig mit $1 \mathrm{köpfigen} \mathrm{Ästen,} \mathrm{bis} 50 \mathrm{~cm}$ h.; Bl. lanzettlich od. läng. lich, geschweift-gezähnt; Bltkörbchen bis $5 \mathrm{~cm}$ br., Korbhiille 1 reihig, Blt. dottergelb bis orange, Strahlbl. oft mehrreihig. - Zier- u. Arzneipe. aus Südeuropa. $\odot .7-10$. C. officinalis $\mathrm{L}$.

\section{Cynarocéphalae: Distelgew ächse.}

Alle Blt. rïhrig od. trichterförm. u.zwitterlich od. Randblt. geschlechtslos strahlend ( $a b$, nie zungenförmig). Narben meist mehr weniger verwachsen, oft eine Keule bildend. Korbhülle ziegelschuppig. Aeist dornige Pflanzen.

\section{Schliissel der Fattungen.}

1. Blt. in Körbchen gestellt.

Blt. in kugelrunde hiillenlose Köpfe gestellt, jede einzelne mit einer besonderen mehrreihiger, Schuppenhülle.

Echinops (295).

2. Randblt. geschlechtslos, trichterförm., viel länger als die röhrigen Zwitterblt, einen Strahl um diese herum bildend. Centaurea (286).

Alle Blt. zwitterlich (selten polygamisch: b. Serratula) und gleiclgeformt.

3. Innere Schuppen d. Korbhälle verlängert, glänzend-rosenroth oder weiß, einen Strahl um d. Blt. herum bildend.

Innere Schuppen nicht strahlend.

4. Strahlende Schupp. rosenroth; wehrlose Kr. Xeranthemum (294).

Strahlende Schuppen weiß od. gelblich, selten roth; dornige Pfl.

5. Hüllschuppen blattartig.

Carlina (293).

Hüllschuppen nicht blattartig.

6. Äußere Hiillschmppen angedriickt, innere in einen starken Dorn auslaufend; Blt. roth, Bl. milchweiß marmoriert.

Silybum (291). 
Hiillschuppen dornspitzig, Blt. safrangelb. Carthamus (285).

7. Hüllschuppen am Grunde fleischig, an der Spitze aurgerandetdornspitzig; Bltkörbe sehr gr, Blt. blal. Cynara \{292).

Hüllschuppen weder fleischig noch ausgerandet-dornspitzig. 8 .

8. Hüllschupp. lineal mit hakig umgebog. Spitze. Lappa (287).

Hiillsch. an d. Spitze nicht hakig.

9. Hüllschuppen wehrlos od. dornspitzig.

10.

Hüllsch. wehrlos ab. mit einem trocknem häutig. rundlichen Anlang.

Rhaponticum (283).

10. Fr. mit haarigem, borstigem od. spreuborstigem Pappus. 11.

Fr. mit federhaarigem Pappus.

14. 4 seitig.

11. Pappus spreuborstig, 2-3 reihig, kurz gestielt; Fr. kreiselförm.

Pappus borstig od. haarig, sitzend; Fr. zusammengedrickt. 12.

12. Bltboden tief bienenzellig-grubig, Fr. zusammengedriickt-4 seitig, Pappus haarig, Haare am Grunde in eiuen Ring verwachsen.

Onopordon (288).

Bltbod. nicht zellig, borstig od. haarig.

13. Pappus borstig, innere Borsten lïnger als $d$. iibrigen; Blt. bisweilen polygamisch, in länglichen Körbchen.

Serratula (284).

Pappus haarig, Haare am Grunde in einen Ring verwachsen.

Carduus (289).

14. (10) Alle Pappushare fedrig, am Grunde in einen Ring verwachsen; Hüllschupp. meist dornspitzig.

Cirsium (290).

Nur die inneren Pappushaare fedrig, iußere Reihe spreuborstig; Hüllschuppen wie die ganze Pflanze unbewehrt.

S'russurea (281).

\section{Sanssúrea DC. (XIX, 1).}

Dornenlose Alpenkräuter. Korbhülle eiförmig-walzig, Schuppen meist angedriickt.

1. St. $1 \mathrm{köpfig,} \mathrm{5-12.5} \mathrm{cm}$ h.; Bl. lineal od. lineal-lanzettlich, unterseits rauhhaarig; Bltkörbch. $37 \mathrm{~mm}$ br., Hüllschupp. eilanzettförm;, Blt. purpur-violett. - Steinige Plätze d Kalkalpen von 0oe., St., K., Kr.; zerstreut. 4. 7. 8.

S. pygmaea Spr.

St. oben doldentraubig ästig, Bl. gezähnt, Bltkörbchen kl., Hüllsch. eiförm., Blt. hellviolett.

2. Bl. unterseits grau od. weiß spinnweb-wollig od. -filzig; St. 8 bis $45 \mathrm{~cm} \mathrm{h.} \mathrm{-} \mathrm{Grasige} \mathrm{Orte} \mathrm{der} \mathrm{höheren} \mathrm{Alpen;} \mathrm{zerstreut.} \mathrm{4.} \mathrm{7.} 8$.

S. alpina DC.

Variet.: $a$. g e nu in a, Bl. ei- bis länglich-Ianzettförm., grundständ. in den langen Stiel herablaufend. In K., T., Kr.; - $\mathbf{K}$. ma. crophyll a (Saut.), Bl. br. eiförmig, buchtig gezähnt, kurz gestielt. In K. u. T.; - $\gamma$. depressa (Gren.), Bl. schmal lanzettlich, St. verkürzt $2-1$ köpf. In $\mathbf{K}$. (selten).

Bl. unterseits schneeweiß-filzig, untere herzeilanzettfïrm., gestielt, obere lanzettl., ganzrand.; St. $8-30 \mathrm{~cm}$ h. - Felsspalten d. Kalkalpen von Noe., K., T., Kr.; zerstreut. 4. $7-9$.

S. discolor $\mathrm{DC}$. 


\section{Jurínea Cass. (XIX, 1).}

St. nur unten beblätt., Bl. am Rande umgerollt, unterseits sammt d. St. grauweiß-filzig, grundständ. gestielt, fiedertheilig. Stbl. fiedertheilig bis ganz, sitzend; Korbhülle halbkuglig, Blt. purpurn. Dornenlose Kr.

1. Grundbl. in dichter Rosette, Zipfel genähert; Bltkörbch. bis $37 \mathrm{~mm}$ breit, Hüllschupp. an d. Spitze umgebrochen, weißwollig; St. 1 köpfig, 15 bis $60 \mathrm{~cm}$ h. - Sonnige, grasige Hügel in Mh., Noe., St., Kr.; zerstreut. 4. 5. 6.

J. mollis Rchb.

2. Grundbl. in lockerem Büschel, Zipfel entfernt; Bltkörbch. kleiner, Hüllsch. abstehend, fast kahl; St. 1-3 köpfig, $15-45 \mathrm{~cm}$ h. - Auf Sandboden (in Kiefernwäld.) in B. (b. Raudnitz, Theresienstadt). 4. 6. 7.

J. cyanoídes Rclib.

\section{Rhapónticum Vaill, Ruibendistel (XIX, 1).}

St. $0.60-1 m$ h., 1 köpfig; Bl. unterseits weißwollig-filzig, untere herzeiförmig, gr., obere lanzettlich; Bïtkörbe bis $5 \mathrm{~cm}$ br., Korbhülle rostbraun, Blt. purpurn. - Kräuterreiche Orte d. Alpen von T., Varlb., Kr.; zerstreut. 4. 7. 8. Rh. scariosum Lam.

\section{Serrátula L. Scharte (XIX, 1).}

Dornenlose Kr. mit beiderseits grünen $\mathrm{Bl}$., aufrechtem St. u. purpurnen Blt.

1. Bltkörbch. mit länglich-walziger Hülle, $13-19 \mathrm{~mm}$ br., theils männl., theils weibl., in doldentraubiger Rispe; St. 0.6-1 $\mathrm{m}$ h., Bl. theils brlanzettförm., theils leierförm.-fiederspaltig. - Waldwiesen, Gebüsche; zerstreut. 4. 7-9.

Färbescharte, S. tinctória L.

Var. V ulpii Fisch. Körbch. größer, zwitterbltig, gedrängt in den Achseln d. obersten Bl. sitzend. Alpenwiesen in $\mathbf{K}$.

2. Bltkörbchen mit eifürmig länglicher Hülle, $25 \mathrm{~mm}$ br.; St. 1 köpf., 0.3-1 $m \mathrm{~h}$., Grundbl. eiförm. bis länglich-gezähnt, Stbl. fiederspaltig bis fiederschnittig. - Bergwiesen, sonnige Hügel in Mh. u. Noe.; sehr zerstreut. 4. 6. 7.

S. heterophylla Desf.

\section{Cărthamus L. Safflor (XIX, 1).}

St. 0.3-1 $m$ h., in 1 köpfige Äste getheilt; Bl. länglich, dorniggezähnt; Bltlörbch. eiförmig., $37 \mathrm{~mm}$ br., von Deckbl. umgeben; Blt. orangeroth. - Aus Aegypten stammende Färbe- u. Zierpfl. ○. 7. 8.

\section{C. tinctórius $\mathrm{L}$}

\section{Centauréa L. Floekenblume (XIX, 3).}

Korbhülle eiförmig b:s kuglig, Schuppen mit trockenhäutigem Anhange, seltener in einen Dorn auslaufend. Fr. mit od. ohne borstig. Pappus. Kr. mit meist ästigem St. u. meist 1 köpfigen Ästen; Bl. dornenlos.

1. a) Hüllschuppe in einen starken, am Grunde handförm. getheilt. Dorn auslaufend.

b) Hülls:h. mit großem trockenhäutigem Anhange an d. Spiłze; Blt. purpurn.

c) Hüllsch. krautig, an d. Spitze trockenhäutig gesäumt (Saum stets gefärbt, oft kammförmig gefranzt). 
2. Blt. purpurn, Bltkörbchen trugdoldig; St. $15-60 \mathrm{~cm}$ h., Bl. fiedertheilig. - Aus Südeuropa eingeschleppt und verwildert an wästen Plätzen in 0 e., Mh., B. Zerstreut u. unbeständig. ค. 7-10. C. Calcítrapa L.

Blt. gelb; St. $15-30 \mathrm{~cm}$ h. mit 1 köpfigen $\ddot{A s t e n, ~ g e f l u ̈ g e l t . ~-~ W i e ~}$ vorige, aber seltener. $\odot .7-10$. $\quad C$. solstitialis L.

3. (1, b.) Anhänge breiter als d. Hüllsch., muschelförm., zerrissen od. am Rande kurz gefranzt; kein Pappus.

4.

Anhänge 1. u. spitz, lang gefranzt (fiedertheilig), die d. oberen Hüllschuppen aufrecht, die d. übrigen rückwärts umgebogen, länger gefranzt; Fr. mit Pappus.

4. Anhänge rundlich, licht- bis rothbraun, die Korbhülle vollständig verdeckend; St. 10-60 cm h., ästig; Bl. länglish.lanzettförm. bis lineal. ganzrandig, gezähnt bis fiederspaltig. - Wiesen, Grasplätze. 4. 6-10.

C. Jacéa L.

Variet. a. vulgaris (Koch), Anhänge ganz- od. zerrissen-randig. Gemein; - $\beta$. decipiens (Koch), Anhänge d. inner. Schuppen kurzkämmig zerrissen, d. äußeren kanmförm. schwarzbraun gefranzt; zerstreut; - - . pratensis (Thuill.), Anhänge schwarzbraun, gefranzt, nur d. obersten zerrissen-randig. Gebirgswiesen; zerstreut.

Anhänge länglich-rund od 3 eckig, kammförm. gezähnt, dunkelbraun, d. grüne eikuglige Hülle nicht vollständig verhüllend; St. $30-60 \mathrm{~cm} \mathrm{h.,}$ ästig, Bl. länglich eiförm, ganzrandig od. gezälınt. Kahl od. filzig. Bergwiesen in B., Mh. und d. Alpenländern; zerstreut. 4. 7. 8.

C. nigrescens $\mathrm{W}$.

Var. vochinensis (Bernh.), Korbhïlle länglich-walzig. In Noe., K. und Kr.

5. (3) St. einfach $1 \mathrm{köpfig,} \mathrm{Bltkörbchen} 37-50 \mathrm{~mm}$ br., Anhänge lichtbraun; Bl. starknervig, lanzettförm. - Bergwiesen in K., T., K:。; zerstreut. 4. 7. 8. (C. nervosa W.) C. plumosa Lam.

St. meist in 1 köpfige Äste getheilt, Bltkörbch. bis $30 \mathrm{~mm}$ br.; St. $15-60 \mathrm{~cm}$ h.

6. Bltkörbchen fast kuglig, $30 \mathrm{~mm}$ br.; Anhänge sehr verlängert, hellbraun, d. Hülle perückenartig einhüllend, Fr. 3 mal so l. wie der Pappus; Bl. länglich bis elliptisch, gezähnt, obere.am Grunde herzförmig (C. phrygia Auct. nicht L.). - Gebirgswiesen, zerstreut. 4. 7-9.

\section{C. pseudophrygia C. A. M.}

Bltkörbch. länglich-eiförmig, bis $20 \mathrm{~mm}$ br.; Anhäıge der unteren und mittleren Hüllsch. schmallineal, pfriemenförm. verlängert, hellbraun, von d. Mitte an zurückgekrümmt, die oberen zerschlitzt, aufrecht; Fr. 8 mal so l. wie d. Pappus; Bl. lanzettlich, gezähmelt, obere am Grunde verschmälert. - Wiesen, Gebüsche in Mh. u. Noe.; zerstreut. 4. 8. 9.

C. stenolépis Kern.

7. (1, c.) Blt. gelb, Hüllschuppen grün, oben dunkelbraun gesäumt und dornspitzig; St. $8-30 \mathrm{~cm}$ h., $1 \mathrm{köpfig} ;$ Bl. 1-2 fach fiedertheilig. An Felsen in K. u. Kr.; stellenweis. 4. 7. 8. $\quad$ C. rupestris L.

b) Blt. blau, roth, weiß; Schupp. braun gesäumt, obere Stbl. ganz. 8 .

c) Blt. purpurn; ob. Stbl. fiedertheilig. 
8. Stbl. lineal-lanzettlich, obere nicht herablaufend; St. $8-30 \mathrm{~cm}$ h., Blt. azurblau, selten rosen- bis dunkelroth od. weib. - Felder. $\odot$. 6-8.

Kornblume. C. Cýanus L.

Stobl. lanzettförm. bis elliptisch, obere herablaufend; Bltliörbch. 37 bis $50 \mathrm{~mm}$ br.

9. St. br. geflügelt, $1 \mathrm{köpfig,} 30-60 \mathrm{~cm}$ h.; Bl. ganzrandig, grasgrün, spinnweb-flaumig, Blt. blau. - Bergwiesen, buschige Hiigel in B., Sch., 0e., Alpenländ. 4. 5-7.

C. montana L.

Variet. hortensis, ästig, brblättrig, Bltkörbch. sehr gr. Zierpfl.

St. schmal geflügelt, 1 -mehrköpfig, $15-30 \mathrm{~cm}$ h., Bl. ganz oder buclstig-fiederlappig, filzig, grau; Blt. blau. - Bergwiesen n. Hügel auf Kalk in B., Mh., 0c. u. s. w.; läufiger als C. moutana. 4. 5-7.

\section{C. axillaris W.}

10. Bltkörbchen kuglig, bis $37 \mathrm{~mm}$ br., am Ende h. nackter Äste; Saum d. Hüllsch. schwarzbraun, gefranzt; St. $30-60 \mathrm{~cm}$ h., Bl. rauhhaarig od. kahl, untere leierförmig, selten ganz. - Trockne Hügel, Brachäcker. 4. 7-9.

Trommelschlägel, C. Scabiosa L.

Variet. coriátea (WV. Kit.), Bl. lederartig, glänzend kahl. In 0oe. stellenweis.

Bltkörbch. eiförm.-länglich, $8-20 \mathrm{~mm}$ br., sehr zahlreich, in endständiger Rispe: Saum त. Schupp. dunkelbraun, kämmig gefranzt; St. 30 bis $60 \mathrm{~cm}$ h. nebst d. Ästen reich beblättert; Bl. 2-1 fach fiedertheilig, grau. - Dürre Abhänge u. Hügel; zerstreut. ๑. 7-10.

C. paniculata Jacqu.

\section{Lappa Tourn. Klette (XIX, 1).}

St. ästig, bis $2 m$ h., Bl. ganz, unbewehrt, unterseits düun, graufilz., untere sehr gr., gestielt; Blt. purpurn, selten weiß; Fr. 4 kantig, mit haarigem Pappus. web-wollig.

1. Hüllschuppen alle pfriemlich-hakenförmig, kahl od. etwas spinn.

Hüllsch. durch graue Spinnwebwolle verbunden, innere stumpf mit aufgesetzter grader Stachelspitze; Bltkörbchen doldentranbig, bis $25 \mathrm{~mm}$ breit. - Schutt, an Wegen. -). 7. 8.

L. tomentosa Lamk.

2. Bltkörbch. in Doldentraube, $25 \mathrm{~mm}$ br., Hüllsch. grün. (I. major Gaertn.) - An gleichen Orten. -). 7. 8. $\quad$. officinalis All.

Bltkörbch. traubig-rispig, $13 \mathrm{~mm}$ br., innere Hüllsch rothspitzig, Akenen 5-7 mm l. - An gleichen Orten, seltner. $\odot$. 7.8. L. minor DC.

\section{2ss. Onopordon L. Krebsdistel (XIX, 1).}

St. bis $2 m \mathrm{~h}$, nebst d. Ästen br. gefügelt; Bl. u. Flügel stark dornig, grau spinnweb-wollig, Bltkörbch. $37 \mathrm{~mm}$ br., endständig, Blt. pur. purn, Hüllschupp. dornspitzig. - Schutt, an Wegen, Mauern. @. 7. 8.

O. Acanthium L.

\section{Cárduus L. Distel (XIX, 1).}

Hüllsch. zugespitzt, dornspitzig od. wehrlos; Blt. purpsırn, selter weiß. Dornige Kr. mit meist gefligelten St. u. Ästen. 
1. Hüllsch. des bis $50 \mathrm{~mm}$ br. nickenden Körbchens über d. Basis eingeschniirt $u$. zurückgebrochen, stark dornspitzig; St. 0.15-1 $m$ h., sammt d. Asten 1 köpfig u. oben nackt u. weißfilzig; Bl. fiederspaltig. - Wüste Plätze, Triften. ค. 7-10.

(!. nutans L.

Var. platylépis (Saut.), Hüllsch. brlanzettförm., St. od. Äste 2 bis 3 köpfig, je 1 Körbchen aufrecht. In Ooe., K., T.; stellenweis.

Hüllsch. vicht eingeschnürt, schwach dornspitzig od. unbewehrt; Bltliörbehen bis $25 \mathrm{~mm}$ br.

2. St. u. Äste nur bis zur Mitte beblättert od. wenigstens unter den endständ. Bltkörbch. stielartig nackt.

St. u. Äste bis an d. Bltkörbch. beblättert u. geflügelt. 3.

3. St. u. Äste nach oben lang lin nackt, 1 köpfig, erstere $0.30-1 \mathrm{~m}$ hoch; Bl. kahl, lanzettlich bis elliptisch, dornig gewimpert.

St. u. Äste nur unter d. Bltkörbch. nackt, St. $30-60 \mathrm{~cm}$ h. 5 .

4. Bl. dïnn, grün, Flügel d. St. kraus gezähnt, Hüllschupp. schmal lineal. unterste abstehend: Bl. ganz od. buchtig-gezälınt od. fiedertheilig (C. alpestris W. Kit.). - Felsige Lehnen, buschige Hügel in Oe., T. u. K.; zerstreut. 4. 7. 8. C. defloratus $\mathrm{L}$.

Bl. dick, blaugriin, ganz; Flïgel d. St. breit, ganz; Hüllsch. lanzertlich, unterste sehr abstehend od. zurrickgebogen. - Felsen, Waldränder, Holzsehläge in Nö., St. u. K.; stellenweis. 4. 7.8. C.glaucus Baumg.

5. Hüllschupp. abstehend u. einwärts gekrümmt; Bl. kahl, fiedertheilig, bloß die unteren etwas herablaufend; Blt. bisweilen gelblich. Felsige Abbänge in K., T., Kr.; stellenweis. 4. 7.8. C. arctioídes W.

Hüllsch. bogig zurückgekrümmt, Bl. unterseits graufilzig, fiedertheilig, alle herablaufend. - An Wegen, wüsten Plätzen in Noe.; zerstreut. - : $5-7$.

C. hamulosus Ehrh.

6. (2) Untere BI. fiederspaltig, obere ganz, alle dornig gewimpert, unterseits dünn grauwollig; Bltkörbch. knaulförmig gehäuft, $25 \mathrm{~mm}$ br.; St. $0.6-1.6 m$ h., kraus geflügelt. - Flussufer, feuchte Wiesen in Gebirgsgegenden. 4. 7. 8.

C. Personata Jequ.

Alle Bl. gleichgeformt, fiederspaltig od. fiedertheilig.

7.

7. Bl. kahl od, unterseits zerstreut-wollig, Zipfel $2-5$ spaltig, stark bedornt und dornig gewimpert; St. $0.30-1 \mathrm{~m}$ h., reich bedornt; Bltkürbch. $25 \mathrm{~mm}$ br., einzeln, endständ. - Wege, wüste Plätze. ๑. 6-10.

C. acanthoides $\mathrm{L}$.

Bl. unterseits wollig-filzig, weißlich, sammt d. Flitgeln d. 0.60-1.30 m h. St. wenig bedornt; Bltkörbchen 6-13 mm br., einzeln od. zu 2-5 geknäuelt. - An gleichen Orten, seltner. 4. 7. 8.

C. crispus $\mathrm{I}$.

\section{Círsium Touru. Kratzdistel (XIX, 1).}

Hüllschupp. weich-, selten dornspitzig; Bl. meist dornig gezähnt, seltner wehrlos.*)

1. Blt. purpurn, seltner weiß.

Blt. gelb od, gelbweiß.

2. Obere Seite d. Bl. stechend-borstig; St. $0.6--1 \cdot 6 m$ h., oben in 1 köpfige Äste getheilt.

*) Die Arten dieser Gattung bilden häufig Bastarde, welche hier nicht berücksichtigt werden können. Auch bei Carfuus kommen Bastarde vur. 
Obere Seite d. Bl. kahl od. behaart.

3. Hülle d. $37 \mathrm{~mm}$ br. Körbchen eiförmig, Schuppen kahl od, etwas spinnwebwollig, mit abstehend. steifem Dorn; St. u. Äste kraus geflügelt; Bl. buchtig fiedertheilig, stark dornig, beiderseits grün od. unterseits weiß spinnwebwollig (C. nemorale Rchb.). - An Wegen, Mauern (C. nem. in Auenwäldern). $\odot$. 7. 8.

C. lanceolatum Scop.

Hülle d. 60-75 $\mathrm{mm}$ br. Körbchen kuglig, Schuppen durch schneeweiße Wolle dicht versponnen, mit dïnnem Dorn; St. ungeflügelt, Bl. tief fiedertheilig, schwach und kurz bedornt, unters. spinnweb-filzig. - An Bächen, Wald- ^. Wegrändern; zerstreut. -.. 7.8. C. erióphorum Scop.

4. Stbl. herablaufend, wenigstens $d$. unteren.

Stbl. nicht herablauf., alle od. wenigst. d. unteren fiedertheilig. 7 .

5. Bltkörbch. $13 \mathrm{~mm}$ br., traubig geknäuelt an d. Spitze d. 0.6 bis $2 m$ h. St. u. d. Äste; Bl. tief fiederspaltig, nebst d. krausen Flügeln dornig gezähnt, zerstreut behaart; Bltkörbchen sehr kurz gestielt. - Süimpfe, nasse Wiesen u. Waldplätze. $\odot .7-10$.

C. palustre Scop.

Bltkörbch, viel größer, einzeln, endständig, Bi. schwach dornig gewimpert; St. einfach od. in $2-3$ Äste getheilt, wie diese nach oben fast nackt, spinnweb-wollig.

6.

6. Hülle des $37 \mathrm{~mm}$ br. Körbchens eikuglig; St. $0.30-1.60 \mathrm{~m}$ h., Bl. länglich-lanzettförmig, ganz bis fiedertheilig, unterseits meist spinuwebwollig. - Feuchte Wiesen in B., Mh., Sch., Oe., St., K.; zerstreut. 4. 7. 8. C. canum M. Bieb.

Hülle d. $25 \mathrm{~mm}$ br. Körbch. ei-walzenförmig; St. $0.35-1 \mathrm{~m}$ h., Bi. ganz, länglich-lanzettförmig, gezähnt od. ganzrandig. - Feuchte Bergwiesen, grasige Abhänge, Gebüsche; sehr zerstreut. 4. 6. 7.

C. pannónicum Gaud.

7. (4) St. fehlend od. sehr verkürzt; Bl. in Rosette, dornig-gezähnt; Bltkörbch. 25-37 $\mathrm{mm}$ br., einzeln od. gehäuft. - Trockne Bergtriften in B., in d. Alpenländ. selten. 4. 7. 8.

C. acaule All.

St. vorhanden, mindestens $30 \mathrm{~cm} \mathrm{I}$.

8. St. ästig, sammt d. Ästen bis an d. doldentraub. od. rispig gruppiert. 8-13 $\mathrm{mm}$ br. Bltkörbch. beblättert, $06-1.6 \mathrm{~m}$ h.; Bl. länglich, stark hedornt, buchtig gezähut bis fiederspaltig, kahl, seltener unterseits weißfilzig (var. discolor Neilr.). - Äcker, an Wegen. 4. 7. 8.

\section{Ackerdistel, C. arvense Scop.}

St. einfach, .. am Ende 1-3köpfig od. in schlanke 1 köpfige Äste getheilt, sammt d. Ästen nach oben weithin nackt.

9. Bl. oberseits grün, unterseits schneeweiß-filzig, länglich-lanzettfürm., ganz od. fiedertheilig, St. $30-70 \mathrm{~cm}$ h., BItkörbch. $37-50 \mathrm{~mm}$ br., nickend. - Feuchte Gebirgswiesen, in B. häufig. 4.6. 7. C. heterophylllum All.

Bl. beiderseits grün, zerstreut behaart, länglich-lanzettförm. bis eilänglich, buchtig gezähnt od. fiedertheilig; St. 0.30-1 $m$ h., Bltliörbchen $25 \mathrm{~mm}$ br., endständige aufrecht. - Nasse Wiesen in Sch., Mh., B. (selten!) u. d. Alpen. 4. 5. 6.

C. rivulare Lk. beblättert.

10. (1) Bltkörbch. von Deckbl. umgeben, 25-37 $\mathrm{mm}$ br., St. ganz 
Bltkörbch. ohne Deckbl., $37 \mathrm{~mm}$ br., hängend, mit rückwärts gekrïmmten klebrigen Schuppen; St. $0.6-1 \cdot 6 m$ h., bis über d. Mitte beblättert; Bl. dornig gewimpert, untere fiedertheilig, obere buchtig gezähnt. - Gebirgswiesen d. Alpenländer. 4. 7. 8.

C. Erisithales Scop.

11. Deckbl. br. eiförmig, häutig, gelblichgrün, buchtig gezähnt; St. $0.3-1 \mathrm{~m}$ h., Bl. meist fiedertheilig, Bltkörbchen meist geknäuelt. Wenig dornig. - Feuchte Wiesen. 4. 7-9.

C. oleráceum Scop.

Deckbl. schmal, stark bedornt; Bltkörbch. $25-37 \mathrm{~mm}$ br. 12 .

12. St. oben nebst Körbchenstielen u. Deckbl. rostroth-filzig, Deckbl. kammförmig, langdornig-gewimpert; St. $0 \cdot 6-1 \cdot 3 \mathrm{~m}$ h., $2-3 \mathrm{köpfig,} \mathrm{Bl.} \mathrm{ganz}$ od. fiederlappig, dornig gewimpert. - Alpentriften; zerstreut. 4. 7. 8.

C. carniólicum Scop.

St. u. Bl. fast kahl, St. 15-60 $\mathrm{cm}$ h., Bl. u. Deckbl. fiederspaltig bis fiedertheilig, Zipfel dornig gewimpert $u$. in einen l. Dorn auslaufend. - Bachufer, nasse Wiesen u. Gerölle d. Alpen (1580-2500 m); zerstreut. 4. 7. 8.

C. spinosissimum Scop.

\section{Silybum Gärtn. Mariendistel (XIX, 1).}

St. 1-1.6 $m$ h., ästig; Bl. glänzend glatt, wollig, sannt d, Hüllsch. starkdornig gewimpert, untere sehr gr., buchtig gezähnt; Bltkörbch. endständig, 37-50 $\mathrm{mm}$ br., Blt. roth. - Zierpfl. aus Südeuropa, auch verwildert. $\odot .6-9$.

S. Marianum Gärtn.

\section{Cýliara L. Artischoke (XIX, 1).}

St. $15-30 \mathrm{~cm} \mathrm{~h}$, meist einfituh, $1 \mathrm{köpfig;} \mathrm{Bl.} \mathrm{dornig} \mathrm{gewimpert,}$ fiedertheilig u. ganz; Hüllsch. d. $63-75 \mathrm{~mm}$ br. Körbch. eiförmig, unbe. wehrt. - Gemüsept. aus Südeuropa, in d. südl. Kronländ. gebaut. 4.8. C. Scólymus L.

\section{Carlína L. Eberwurz (XIX, 1).}

Bltkörbch. einzeln, endständig, Blt. gelblichweiß. Fr. länglich-walzig, mit fedrigem Pappus.

1. St. fehlend od, sehr verkürzt, Bltkörbch, 50-73 $\mathrm{mm}$ br., strahlende Hüllschuppen oben weiß, unten röthlichbraun, Bl. fiedertbeilig in Rosette. - Trockne Triften; zerstreut. 4. 7. 8.

C. acaulis $\mathrm{L}$.

Variet. 3. ca ulescens (Lam.), St. bis $30 \mathrm{~cm}$ h., beblätt. Stellenweis; - \% simplex (W. Kit), wie vorige, Strahlschuppen sehr

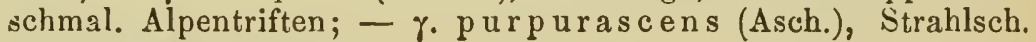
roth. In $\mathrm{Mh}$, vereinzelt.

2. St. $15-45 \mathrm{~cm}$ h., einfach od. ästig; Strahlschupp. gelblich, Körbclien 30-40 mm br., Bl. lanzett- od. eilanzettförm., buchtig gezähnt bis fiedertheilig. - Trockne Hügel. -.. 7. 8. C. vulgaris L.

Variet. $\beta$. nigrescens (Forman.), Spitzen d. oberen BI. schwarz;

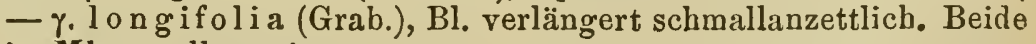
in Mh., stellenweis.

\section{Xeránthemum L. Strohblume (XIX, 1).}

St. 15-60 $\mathrm{cm}$ h., einfach od. ästig, sammt d. linealen Bl. (unterseits) graufilzig; Bltkörbch. einzeln, endständig, Strahlschupp. ausgebreitet, Blt. weißlich. - Dürre Hügel u. Abhänge in B., Mh. u. Noe.; zerstreut. $\odot .6-8$. 


\section{Echínops L. Kugeldistel (XIX, 5).}

St. meist einfach $1 \mathrm{köpfig,} \mathrm{13l.} \mathrm{fiedertheilig,} \mathrm{dornig} \mathrm{gezähnt,} \mathrm{unterseits}$ filzig; Fr. mit häntigem krönchenfơrmigem Pappus.

1. St. $30-60 \mathrm{~cm}$ h., stets 1 köpfig, Bltkörbch. $25-50 \mathrm{~mm}$ br., Blt. azurhlau. -- Dürre Kalkhügel in Noe,; verstreut. 4. 7. 8. E. Ritro L.

2. St. 0.6-1.6 $m$ h., $1-3$ köpfig; Bltkörbch. $50-75 \mathrm{~mm}$ br., Blt. hellblau bis weiß. - Trockne bebuschte Hügel u. Abhänge in B. u. Mh.; zerstreut. Auch Zierpfl. 4. 7. S.

E. sphaerocéphalus L.

\section{Fam. LIII. Dipsáceae. Kardenartige.}

\section{Schliussel der Gattungen.}

1. Blüteriboden mit Spreubl, zwischen d. Blt. 2.

Bltboden ohne Spreubl., behaart; Hüllbl. d. Körbch. sternförm. aus. gebreitet; Hüllchen oben gezähnt, Pappus beckenförm., mit pfriemlichen Borsten; Blkr. 4-5 spaltig.

Knautia (298).

2. Spreubl. gerade, krautig, weich.

3.

Spreubl. nach außen gekrümmt, spitz, weich od. steif u. stechend; Bltboden walzig od. kuglig; Hüllchen 8 furchig, Pappus beckenförmig, ohne Borsten; Blkr. 4 spaltig.

3. Blkr. 4 spaltig.

Dipsacus (296).

Blkr. 5 spaltig, Randblt. strahlend; Hiillchen mit rad- od. glockenförmigem trockenlä̈utigem Saume, Pappus 5-10 borstig. Scabiosa (300).

4. Korbhülle ziegelschuppig, Hüllchen oben gezähnt, Pappus becherförmig, gezähnt.

Cephalaria (297).

Korbhiille 1 reihig, Hüllchen mit 4 lappigem krautigem Saum, Pappus mit 5 borstigen Zähnen.

Succisa (299).

\section{Dípsacus L. Karden (IV, 1).}

Blütenkörbch. endständig, von einer Reihe krautiger Hüllbl. umgeben, diese wie auch d. Kanten d. St. krautstachlig od. borstig.

1. Hüllbl. viel länger als d. Spreubl., krautstachlig; Bltboden walzig, Spreubl. steif u. stechend, Blt. weiß od. lila; St. $1-2 m$ h., Stbl. am Grunde verwachsen.

Hüllbl. so 1. od. wenig länger als d. Spreubl., keilig-lanzettlich, wagerecht abstehend, gleich d. nicht stechenden Spreubl. borstig gewimpert; Bltboden kuglig, Blt. gelblichweiß; Stbl. nicht verwachsen, ei- od. lanzettf., gesägt, St. 0.6-1.3 $m$ h. - Auenwälder, Waldränder in B., Mh., Oe.; zerstreut. $\odot$. 7. 8 .

D. pilosus L.

2. Sprenbl. sehr steif, hakig zurückgekrümmt; Stbl. lanzettlich, ganzrandig od. gekerbt. - Aus d. Orient, stellenweis als technische Pfanze cult. $\odot$. 7.8 . Weberkarden, $D$. fullónum $\mathrm{L}$.

Spreubl. weniger steif, nicht zurückgekrïmmt. 3.

3. Bl. länglich-lanzettförm. od. lanzettlich, gesägt od. ganzrandig. Schutt, Weg- u. Waldränder, Ufer; zerstreut. $\odot$. 7. 8. D. silvester Huds.

Bl. fieder- od. leierspaltig, Zipfel eingeschnitten gekerbt, borstig gewim. pert. - An ähnlichen Orten, seltner. $\odot$. 7. 8.

D. laciniatus L. 


\section{Cephalária Schrad. Kopfblume (IV, 1).}

St. ästig, 30-60 $\mathrm{cm}$ h., Bl. leierförm. fieder theilig, Bltkörbchen endständig, Blt. gelblich-weiß.

1. Bltkörbch. flach, äußere Blt. strahlend. - Äcker, Weinberge um Wien. $\odot$. 7.8.

C. trinssilvanica Sehrd.

2. Bltkörbch. halbkuglig, Randblt. kaurn größer. - In Ḱr.; zerstreut. ๑.) 7. 8 .

C. leucantha Schrd.

\section{Knáutia Coult. Ḱnopflolume (IV, 1).}

St. einfach od. ästig. Untere Bl. in d. Stiel verschmälert, obere sitzend; Bltkörbchen endständig, flachgewölbt; Randblt. strahlend.

1. Bl. ganz u. ganzrand., verlängert lanzettförmig, kahl, glänzend; St. $30-60 \mathrm{~cm}$ h., nach oben sammtig kurzhaarig, oben klebrig-drüsenhaarig; Blt. bläulichroth. - Alpenwiesen in K. u. Ooe.; zerstreut. 4. 7. 8.

K. longifolia Kocl.

Bl, gekerbt od. gezähnt, ganz od. fiederförmig zertheilt.

2. St. mit abwärts gerichteten, am Grunde rothzwiebligeu Borstenhaaren, oben flaumig drüsenlos, $0.30-1.25 \mathrm{~m} \mathrm{~h}$.; Bl. lanzettlich od. eilanzettförmig, grob gesägt od. gekerbt (selten am Grunde eingeschnitten); Blt. bläulichroth bis violett. - Gebirgs- und Auenwälder; zerstreut. 4. 7-9.

$K$. silvática Duby.

Variet. dips a cifolia (Host.), Bl. sehr gr. u. br., Stbl. am Grunde breit gestutzt; Borstenhaare gelblich, Hüllbl, purpurn. Alpen von Noe.

St. nit abwärts gerichteten, am Grunde schwarzzwiebligen Borstenhaaren, oben driisenlos, $30-60 \mathrm{~cm}$ h.; Bl. behaart, bald alle ganz, gesägt od. gekerbt, bald alle fiedertheilig, bald d. unteren ganz, d. iibrigen fiedertheilig; Bl. fleischroth, rosa, lila, weiß. Sehr variabel. - Wiesen, Äcker. 2. $6-9$.

$K$. arvensis Duby.

Variet. $\beta$. glandulífera (Koch), St. oben drüsenhaarig. - In Kr.; - \% eradiata (Neilr.), Randblt. nicht strahlend. In 0e.; zerstreut.

\section{Succísa Mert. Koch, Teufelsabbiss (IV, 1).}

St. einfach od. ästig, $0 \cdot 30-\mathbf{i} m$ h.; Bl. elliptisch-lanzettförmig od. länglich, ganzrandig od. entfernt-gezähnt; Bltkörbchen endständig, hallkuglig bis kuglig, Randblt. nicht strahlend.

1. Wzst. seukrecht, abgebissen; Hüllchen 4 kantig, behaart, Pappus 5 borstig; Blkr. dunkelblau bis violett, selten weiß - Wiesen. 4. 8. 9.

S. pratensis Mnch.

2. Wzst kriechend; Hiillehen stielrund, kahl, Pappus borstenlos, Blkr. hellblau. - Fenchte Wiesen, Sumpfstellen in 0e., St., K.; zerstreut. 4. 8. 9.

S. australis Rehb.

\section{Scabiósa L. Skabióse, Knopfblume (IV, 1).}

St. einfach od. ästig; Bltkörbchen endständig, flach, mit vielblättriger, ausgebreiteter Hülle.

1. Bl. lineal od. lineal-lanzettlich, ganzrandig; St. meist 1 köpfig, 30 bis $45 \mathrm{~cm}$ h., Blt. blau. Silberhaarig od. kahl. - Trockene Hügel in K., Kr., südl. T.; zerstreut. 4. 7. 8. 
Bl. verschieden geformt; Stbl. (wenigstens obere) 1 fach bis 3 fach fiederschnittig.

2. Blkr. dunkel- bis schwarzroth, sammtig; St. 30-60 cm h., ästig. - Zierpfl. aus Ostind. (?). ๑. 7-9.

$S$. atropurpurea $\mathrm{L}$.

Blkr. verschiedengefärbt, nie dunkelroth.

3. Kelchborsten $2-3$ mal so l. als d. Hüllchen; Blt. wohlriechend, azurblau, lila, weiß, selten gelb; St. $30-60 \mathrm{~cm}$ h., Bl. fast lederig, grundständige länglich od. lanzettförm., ganzrandig. Grauflaumig. - Trockene steinige Hügel; zerstreut. 4. 7-9.

S. suaveólens Desf.

Kelchborsten 3-4 mal länger als d. Hüllchen, Blt. geruchlos. 4.

4. Blt. gelblichweiß od. blassgelb; St. $1 \tilde{\jmath}-50 \mathrm{~cm}$ h., Bl. grauflaumig, untero spatel- bis leierförmig, d. übrigen $2-3$ fach fiederschnittig. - Sandboden. 4. 6-9.

S. ochroléuca L.

Blkr. hellpurpurn, lila, blau, weiß.

5.

5. Bl. glänzend, derb, untere ei- od. spatelförm., gekerbt-gesägt, die übrigen leiertörm. bis fiederschnittig; St. $30 \mathrm{~cm} \mathrm{~h}$., Blt. hellroth, violett, weiß. - Bergtriften d. Alpen (1260-1900 m), Sudeten u. d. Riesengeb. (Belten). 4. 6-9.

S. luicida Vill.

Bl. nicht gläuzend, behaart. 6.

6. Grundbl. theils ganz lanzettförm., gekerbt, theils leierförm.-fiedertheilig, Stbl. fiederschnittig mit lanzettl. gesiigt. Abschnitten; St. 30-60 cm hoch, Blt. blau, rosa, weiß. - Trockene Wiesen u. Hügel; zerstreut. 4. $6-8$.

S. columbária L.

Grundbl. länglich, gekerbt, kl., Stbl. 2-3 fach fiederschnittig mit linealen ganzrandigen Zipfeln; Blt. blau. - Sonnige Kalkhügel im südl. K. u. T.; zerstreut. 4. 6-9. S. gramúntia L.

\section{Fam. LIV. Valerianáceae. Baldriangewächse.}

\section{Valerianella Tourn. Rapiinzchen (III, 1).}

St. wiederbolt gabeltheilig, $15-45 \mathrm{~cm}$ h., Bl. gegenständig, spatelod. lanzettförmig; Blt. kl. in endständ. geknäuelten Trugdolden, weiß od. bläulich.*)

1. Kelchsaum d. Fr. undeutlich gezähnt.

Kelchsaum d. Fr. 4-5 zäłınig, d. vordere Zahn beträchtlich größer. 3.

2. Fr. seitlich zusammengedrückt, quer-oval, an d. Rändern gefurcht, auf d. Flächen mit 1 Rippe u. Furche. - Grasige Abbänge, Wege, Äcker, auch cult. $\odot .4$. 5 .

\section{Feldsalat, Rapünzchensalat, V. olitória Mönch.}

Fr. länglich-4 kantig, vorn kahnförmig vertieft, hinten mit 1 Rippe u. Furche. - Wie vorige, weniger verbreitet. $\odot .4 .5$. V. carinata Lois.

3. Fr. eiförmig-kuglig, gedunsen, vorn gefurcht, binten 3 rippig, kahl, seltner behaart (lasiocarpa Koch). - Saaten, Brachen; zerstreut (V. Auricula DC.). $\odot .6-8$.

V. rimosa Bast.

Fr. eikegelförm., vorn gewölbt 3 rippig, hint. mit ein. längl. Eindruck, Kelchsaum krönchenförmig. - Saatfelder, Brachen; zerstreut. ๑. 8. 9. V. dentata Poll.

*) Die Arten sind nur im fruchtenden Zustande bestimmbar! 


\section{Valeriăna L. Baldrian (III, 1).}

St. meist einfach, Bl. gegenständ., Blt. in gabeltheiligen, schirm-od. kopfförmigen Trugdolden. Kr. mit widerlich-aromatisch duftendem Wzst. zwitterlich.

1. Bl. alle fiederschnittig; Blt. röthlich, in schirmförm. Trugdolden;

Bl. alle ganz od. d. Stbl. fiedertheilig od. 3 schnittig; Blt. polygam. 4.

2. Wzst. einen St. sowie Ausläufer treibend.

Wzst. mehrere St. ab keine Ausl. treibend; St. 1-2 $m$ h., gefurcht, Bl. mit 7-10 Paaren lanzettlicher, gesägter Abschnitte. - Feuchte Wälder von St. u. anderwärts. 4. 7. 8.

$V$. exaltata Mik.

3. Bl. br., mit 3-5 Paaren gesägter od. gezähnter Abschnitte, diese b. d. unteren eilanzett-, b. d. oberen lanzettförmig, Bl. d. Ausl. oft 3 sclınitt.; St. $0.6-1.3 m \mathrm{~h}$. - Quellige $u$. kräuterreiche Orte höherer Gebirge in B., Hh., Sch., d. Alpen. 4. 6-8.

V. sambucifolia Mik.

Bl. mit 7-10 Paaren v. Abschnitten, diese eilanzett- bis lanzettförm., gezähnt; St. $0 \cdot 5-1 m$ h. - An Bächen, Felsen, auf feuchten Wiesen. 4 . 5. 6 .

$V$. officinalis $\mathrm{L}$.

Variet. angustifolia (Tsch.), Bl. kammförmig-fiederschnittig, mit linealen ganzrandigen Abschnitten. - Auf feuchtem Gerölle, steinigen Abhängen in Gebirgen.

4. (1) Stbl. fiedertheilig od. leierförmig, grundständ. Bl. ganz, gestielt ; Blt. polygamisch-2 häusig, St. $15-30 \mathrm{~cm} \mathrm{~h}$.

b) Stbl. 3 sclnnittig, Mittelabschnitt gr., eiförm., grob gezähnt, seitliche kl. lanzettlich, ganzrandig; untere Bl. gestielt, herzeiförmig, gezähnt; Blt. röthlich, St. $15-50 \mathrm{~cm}$ h. Keine Ausl. - Feuchte Plätze u. Gerölle i. ¿. Alpen u. in Mh. (Gesenke, Karpathen). 4. 5. 6.

c) Alle Bl. ganz.

$V$. tripteris L.

6.

5. Wrst kriechende Ausl. treibend, Grundbl. u. Bl. d. Ausl. rundlich bis herzförmig, l. gestielt, Stbl. leierförmig-fiedertheilig; Blt. weißlich od. röthlich. - Torfige Wiesen. 4. 5. 6.

$V$. dióica $\mathrm{L}$.

Wzst. ohne Ausl., rübenförm., Grundbl. in d. Stiel verschmälert, Stbl. fiederschnittig, Blt. rosa. - Steinige Hügel u. Bergwiesen in Kr. 4. 6. 7.

V. tuberosa L.

6. Wzst. Ausläufer treibend, kriechend; St. $20-40 \mathrm{~cm}$ h., geflügelt; Grundbl. eiförmig-rundlich, ganzrandig, gestielt, Stbl. länglich, sitzend, oberste bisweilen 3 spaltig; Blt. röthlich. - Waldsümpfe in Ml. u. Sch. (Gesenke), Noe., K.; sehr zerstreut. 4. 5.6. V. polýgama Bess.

Keine Ausläufer. 7.

7. Wrst. kriechend, keine Rasen bildend: var. intermedia Vahl. ৯. V. polyga ma. In Sch. (Gesenke) u. K.; vereinzelt.

Wzst. vielköpfig, nicht kriechend.

8. St. ästig, Trugdolden end- u. seitenständig, traubig, rispig, doldentraubig gruppiert.

9.

St. einfach, mit endständ, kopfiger von d. obersten Bl. umhüllter Trugdolde; St. $2 \cdot 5-37 \mathrm{~cm}$ h., Bl. spatelförm. - Feuchte Stellen der Alpen $(1900-2600 \mathrm{~m})$. 4. 7. 8 .

$V$. supina L.

9. Trugdolden kl., quirlig, in unterbroch. Traube, Blt. gelb; St. 2.5 bis $10 \mathrm{~cm}$ h.; Bl. kahl, grundst. längl.-lanzettf., Stbl. lineal. - In Felsspalten d. Alpen $(2000-2500 \mathrm{~m})$; zerstreut. 4. 7. 8. Speik, V. celtíca L. 
Trugdolden in lockerer Rispe od. in äichtblütiger Doldentraube. 10.

10. BIt. gelb od. fleischroth, BI. br., gezähnt.

Blt. weiß, Bl. lanzettförmig, ganzrandig; St. $7 \cdot 5-25 \mathrm{~cm}$ h. - In Felsspalten u. auf Gerölle d. Kalkalpen (bis $2000 \mathrm{~m}$ ). 4. 6. 7.

$V$. saxátilis L.

11. Blt. gelb, Grundbl. lang gestielt, eiförmig-rundlich, ganzrandig, Stbl. sitzend, eifürnig, grob gezähnt; St. bis $30 \mathrm{~cm}$ h. - Felsspalten u. Gerölle d. Kalkalpen; zerstrent. 7. 8.

V. elongata L.

Blt. rosa; alle BI. eiförm. od. länglich, ganzrand. od. gezähnt; St. 30 bis $45 \mathrm{~cm} \mathrm{~h}$. - Feuchte steinige Plätze u. Felsspalten d. Alpen (1000 bis $3000 \mathrm{~m}$ ), auch in $\mathbf{H h}$. (selten!) 4. 5-8.

V. montana L.

\section{Centranthus DC. Spornblume $(I, 1)$.}

St. $30-60 \mathrm{~cm}$ h., Bl. gegenständig, eiförmig, ganzrandig od. gezähnt; Blt. in dichten gabeltheiligen Trugdolden, purpurroth. - Zierpfl. aus Südeuropa, stellenweis verwildert. 4. 6--9.

C. ruber DC.

\section{Fam. LV. Rubiáceae. Krappartige.}

\section{Schliissel der Gattungen.}

1. Kelchsaum deutlich, gezähnt, Blkr. trichterförm 4 spaltig, Theilfr. trocken, halbkuglig. Sterardia (304).

Kelchsaum undeutlich.

2. Theilfr. nussartig, trocken.

Theilfr. beerenartig;, saftig; Blkr. radförmig, 4-5 spaltig.

Rubia (307).

3. Blkr. trichter- od. glockenförm., mit deutlicher Röhre. 4-(3-5.) spalt. Asperula (305).

Blkr. rad- od. beckenförm., ohne Röhre.4-3 spaltig. Galium (306).

304. Sherardia Dill. (IV, 1).

St. liegend, ausgebreitet-ästig, $15-30 \mathrm{~cm}$ l.; Bl. zu 4-6, lineallanzettlich; Blt. lila, in endstäıdigen, von einer 8 blättrigen Hiille umgeb. Büscheln. - Ackerunkraut. ๑.) 5-10.

S. arvensis $\mathrm{L}$.

\section{Aspérula L. Waldmeister (IV, 1).} od. Trugdolden.

St. ästig, meist 4 kantig, Bl. quirlständig, Blt. in endständ. Büscheln

1. Bltbüschel von einer sternförm. 6-8blättr. Hülle umgeb. 2.

Lockere hüllenlose Truogdolden; Blkr. meist weiß.

2. Blkr. blau, Hïllbl. länger als d. Büschel, lang gewimpert; St. 15 bis $30 \mathrm{~cm} \mathrm{h.} \mathrm{-} \mathrm{Ackerunkraut,} \mathrm{meist} \mathrm{eingeschleppt,} \mathrm{wild} \mathrm{in} \mathrm{K.,} \mathrm{T.,} \mathrm{Kro:}$ zerstreut. $\odot .5-7$.

A. arvensis $\mathrm{L}$.

Blkr. weiß, Hüllbl. kürzer als d. Büschel, nebst d. Stbl. eilanzettförmig, 3 nervig. - Schattige Bergwälder in Va., T., Kr.; zerstreut. 2. 5. 6. 
3. Stkanten, Blränder u. Mittelrippe d. Bl. feinstachlig.rauh; Bl. zu 8, Ianzettförm., Trugdolden rispig, St. $0.6-1 \mathrm{ml}$. - Unter Gebüsch, an Ufern in Sch., $\mathbf{l l h} .$, B.; zerstreut. 4. 7. 8. A. Aparine M. Bieb.

Stgikanten glatt.

4. Bl. am Kande rauh, zu 6-8, verkehrtei- bis lanzettförmig, aromatisch duftend; Trugdolłen schirmförmig; Theilfr. mit hakig. Börstchen besetzt; St. $15-60 \mathrm{~cm}$ h. - Schattige Laub. (besond. Buchen-) u. Mischwälder, namentlich in Gebirg. 4. 4. 5.

Bl. am Rande glatt, Theilfr. kahl od. warzig. Geruchlos.

5. Blkr. rötllich bis purpurn od. violett

Blkr. weiß, Bl. lineal od. lineal-lanzettlich; Theilfr. glatt.

6. Blkr. röthlichweiß bis rosa, Theilfr. warzig; Bl. zu 4, schmallineal, oberste gegenständig; St. $30-60 \mathrm{~cm}$ l., niedergestreckt, zahlreich. - Steinige Triften $u$. Abhänge auf Kalk. 4. 6-9.

A. cyninchica L.

Blkr. trüb purpurn, innen gelblich, Röhre $2-3$ mal länger als der Saum. Sonst wie vorige. - Sonnige felsige Plätze d. Kalkalpen von St., K., T., Kr. 4. 7. 8 .

A. longiflóra W. Kit.

7. St. 4 kantig, 30-60 cm 1., aufrecht; Bl. grün, gleichfarbig, zu 4 bis 6, Blkr. trichterfürmig; Wzst. gelb, roth färbend. - Buschige Kalkhügel in IIh., B., Oe., K.; zerstreut. 4. 6. 7.

A. tinctória L.

St. rund, $0 \cdot 30-1 m$ l.; aufsteigend; Bl. unterseits blaugrün, zu 8 bis 10; Jlkr. glockig. - Bebuschte Orte, besond. auf Kalk; zerstreut. 4. 6. 7. A. galioides M. Bieb.

\section{Gálium L. Labkraut (IV, 1).}

Blt. verschieden angeordnet, meist in Trugdolden.

1. Bl. 1 nervig, meist zu 5-9, selten zu 4 .

BI. 3 nervig, zu 4 ; St. 4 kantig.

22.

2. Blt. in endständigen, rispigen Trugdolden. St. glatt, selten rauhkantig. Ausdauernde Pfl.

BIt. in achselständigen, armbltigen Trugdolden. Stkanten meist feinstachlig-rauh. Einjälırige $\mathrm{Kr}$.

3. Zipfel d. Blkr. stumpf, meist weich stachelspitzig; Theilfr. fein grubig-punktiert, glatt; Wzst holzig.

Zipfel der Blkr. spitz (nicht stachelspitzig); Theilfr. feinwarzig oder körrig; Wzst. spindlig, zahlreiche, rasige zerbrechl. Stäınmch. treib. 12.

4. Blkr. roth; St. 4 kantig, Bl. zu 6, 8-12. 5 .

b) Blkr. gelb.

c) Blkr. weiß.

5. Bl. lineal, spitz, Blt. sehr kl.. purpurroth, in aufrechter pyramidaler Trugdoldenrispe; St. aufrecht, $0 \cdot 30-1 \mathrm{~m} \mathrm{~h}$. - Stcinige trockene Plätze in K., Kr., T. ; zerstrent. 4. 7. 8.

G. purpureum L.

Bl. lineal-lanzettförm., stachelspitzig; Blt. purpurn, später gelblich, in schlaffer flattriger Rispe; St. niederliegend, $15-4 \overline{c m ~ l}$. - Trockene Triften u. Hügel ebendaselbst; zerstreut. 7. 6. 7. G. rubrum L.

6. Blt. goldgelb, in dichten, in eine lange Rispe gruppierten Trugdolden; St. $30-60 \mathrm{~cm}$ h, rund; Bl. zu 6-12. lineal, ungerollt, unterseits grauflaumig. - Trockne Wiesen, Raine. 4. 7-9.

G. verum $\mathrm{L}$.

Variet. Wirtgeni (T. Schultz), Bl. breiter, oberseits feinflaumig, St. unten 4 kantig, straff. In B. u. Mh.; zerstreut.. 
Blt. blassgelb od. gelblichwei $\beta$, in langer schweifartiger Trugdolden rispe; St. $0 \cdot 30-1 m$ h., 4 kantig, Bl. lineal-lanzettförmig, schwach zurïck gerollt. - Wiesen, Raine; zerstreut. 4. 6-8. G. ochroleucum Wolf.

7. (4, c.) St. stielrund, aufrecht od. aufsteigend, $0.30-1.25 m \mathrm{~h}_{\text {, }}$ ästig; Bl. zu S, länglich od. lanzettförm., unterseits bläulich; Blt. vor d. Aufblühen hängend, in rispigen Trugdolden. Kahl. - Wälder. 4. 6. 7.

G. silváticum L.

St. 4 kantig (wenigstens oben), BI. meist abwärts gerichtet. S.

8. St. oben 4 kantig, unten rund, kahl u. glänzend, $0.5-1 m$ h.; Bl. zu 8, lanzettlich, graugrün; Zipfel d. Blkr. lang bespitzt, Theilfr. bläulich bereift, soust wie vorige. - Laubwälder von Mlh., Sch. u. K.; zerstreut. 4. 7. 8.

G. Schultesii Vest.

St. ganz 4 kantig, Bl. zu 8 (seltener zu 5-7).

9.

9. St meist aufsteigend od. niederliegend, vom Grunde an mit abstehenden blttragenden Seitenïsten und reichbltigen Trugdolden. 10.

St. straff aufrecht, starr, mit aufrechten Ästen.

11.

10. St. $30 \rightarrow 60 \mathrm{~cm}$ l., Bl. lineal od. lineal-länglicls an d. verdickten Stkanten; Wzst. verzweigt, rasig, zahlreiche St. u. Blsprossen treibend. Kahl, selten weichhaarig. - In Gebïschen, auf Wiesen. 4. 5-7.

\section{G. Mollrigo I.}

St. 1-1.5 $m$ l., Bl. dünner, länglich od. verkehrt-eiförmig länglich. Sonst wie vorige. - Gebiusche; zerstreut. 4. 5-7. G. elatum Thuill.

11. Wzst. büschelig beisammenstehende, $30-60 \mathrm{~cm}$ h. St. treibend, diese glänzend $\mathrm{kahl}$; Bl. lïnglich od. lineal, am Rande umgerollt, Rückennerv von 2 glänzenden Streifen eingefasst. Trugdolden rispig. - Eelsen, Gerölle auf Kalk, Basalt, Phonolith in B., Mh., 0e.; zerstreut. 4. 5-7. G. erectum Huds.

Wzst. einzelne entfernte, $30-60 \mathrm{~cm} \mathbf{h}$. St $\mathbf{u}$. Ausläufer treibend; Bl. lineal od. länglich-lanzettlich, l. zugespitzt, unterseits bläulich; Trugdolden doldentraubig, Zipfel d. Blkr. mit l. Spitze. - Lichte Berswälder in B., St., K., T.; zerstreut. 4. 7. 8.

G. avistalum L.

12. (3) Bl. am Rande mit verkieselten Hökerchen, słachelspitzig, (G. silvestre Poll.)

Bl. am Rande feinstachlig-rauh.

15.

13. Bl. u. St. mehr weniger behaart, erstere alle mit zahlreichen Höckerchen besetzt, zu 6-8, lineal-lanzettlich, l. stachelspitzig; St. 10 bis $30 \mathrm{~cm}$ l., berippt-4 kantig, aufsteigend od. liegend, lockere Büschel bildend; Trugdolden in flattriger Rispe. V'ielgestaltig! - Trockne Wiesen, steinige Plätze, bis auf d. Alperı. 4. 5-7. G. scabrum Jcqu.

Bl. u. St. glänzend kahl, nur die oberen Bl. mit Höckerchen, St. liegend od. aufsteigend.

14. Bl. lineal, stachelspitzig, mit starkem Rückennerv, zu 5-10; St. $2.5-15 \mathrm{~cm} \mathrm{1,}$, in lockeren Büscheln; Trugdolden lockerbltig rispig. (G. pumilum Lam.) - Trockene Grasplätze, Felsen, Gerölle, besond. auf Kalk, in Mh., Oe., St., K., T.; zerstreut. 4. 5-7. G. austriacum Jequ.

Bl. lanzettlich, stachelspitzig, dünn, ungleichlang, zu 6-8; St. 10 bis $20 \mathrm{~cm} \mathrm{l}$.; Trugdolden armbltig, doldentraubig, dunkelgrün, b. Trocknen schwarz werdend. - Wälder, Felsen, Gerölle d. Voralpen, auch in Mll. (selten). 4. $7-9$. G. anisophýllum Vill. 
Variet. sudeticum (Tsch.), St. 6-10 $\mathrm{cm}$ h., dichte Rasen bild., aufsteigend, sparrig-ästig; Trugdolden end- u. achselständig. Kämme d. Riesengeb., auch im Gesenke.

15. (12) Bl. stachelspitzig.

16.

Bl. stumpf, am Grunde verschmälert, zu 4-5.

19.

16. St. aufsteigend od. liegend, $15-60 \mathrm{~cm} \mathrm{l.,} \mathrm{dünn,} \mathrm{schlaff,} \mathrm{ästig,}$ berippt-4kantig, an d. Kanten feinstachlig.rauh; Bl. zu 7-8 (meist 6), an Rande stachlig-rauh, lineal-lanzettlich bis verkehrt-eiförmig; Trugdolden $\mathrm{kl}$., end- u. achselständ. - Torfige Wiesen, Sümpfe; zerstreut. 5-7. G. uliginosum L.

St. liegend, sehr zahlreich, mit Bltrieben dichte niedrige Rasen od. Polster bildend; Trugdolden endständig, armbltig. 17.

17. Bl. wirklich stachelspitzig, am Rande feinstachlig-gezähnt, glanzlos, meist zu 6 . 18.

Bl. mit einem Knorpelpitzchen, am Rande glatt, glïnzend, meist zu 8, lineal bis eilanzettlich; Blt. gelblichweib. - Höchste Kuppen der Kalkalpen von Noe., St., T. 4. 7. 8.

G. baldense Spr.

18. Blkr. gelblich- od. grünlichweiß, Frstiele abwärts gekrümınt; Bl. dicklich, am Rande rückwärts-stachelzähnig, untere spatel-, obere lanzettförmig. - Gerölle u. Sand d. Kalkalpen (1900-2500 m); zerstreut. 4. 7. 8 .

G. helveticum Weig.

Blkr. milchweiß, Fr. aufrecht; Bl. am Rande vorwärts stachelzähnig, verkehrt eilanzetfförm. Beim Trocknen sich schwärzend. - Steinige und moorige Plätze auf d. Erz., Iser- u. Riesengeb. 4. 7. 8. G. saxátile L.

19. (15) St. liegend od. aufsteigend, schlaff, zart, $20-50 \mathrm{~cm}$ l., zahlreich; Rispenäste weit abstehend od. zurückgebogen; Bl. lineal-länglich. - Sümpfe, Sumpfwiesen. 4. 5-7.

G. palustre $\mathrm{L}$.

St. aufrecht, steif, an d. Kanten schmal geflügelt, $30-60 \mathrm{~cm} \mathrm{~h}$; Rispenäste aufrecht-abstehend; BI. länglich-lanzetṫörm. bis elliptisch, zart. - Sumpfwiesen, Moore in Ml. ; zerstreut. 4.6-8. G. elongatum Presl.

20. (2) Trugdolden 2-vielbltig, ausgespreizt gabeltheilig, Stiele nach dem Verblühen gerade, aufrecht; Blt. weiß.

21.

Trugdolden 2-3 bltig, Stiele nach d. Verblühen zurückgekrümmt, Blt. gelblichwei $\beta$, Fr. feinwarzig; St. $15-30 \mathrm{~cm} \mathrm{l.,} \mathrm{Bl.} \mathrm{zu} \mathrm{6-8,} \mathrm{lineal-}$ lanzettlich. - Ackerunkraut in B., Ih., 0e.; zerstreut. ๑. 6-9.

G. tricorne With.

21. St. kletternd, sehr ästig, üb. $1 m$ l., sammt d. zu 6-8 stehenden Bl. überaus feinstachlig-rauh; Bl. verkehrt-eiförmig.länglich, stachelspitzig; Theilfr. gr., hakig stachelborstig. - Hecken, Gebüsche, bebaut. Boden. $\odot$. $5-10$.

Klebkrau ${ }^{\dagger}, G$. Aparine L.

St. aufrecht od. kletternd, $15-45 \mathrm{~cm}$ l., sammt d. BI. weniger rauh; Fr. gekörnelt, kahl od. borstig behaart (G. infestum W. Kit.). - Ackerunkraut in B., Wh., Oe.; zerstreut. $\odot .6-9$. G. spurizim L.

22. (1) Blkr. gelb; Blt. polygamisch, in achselständigen Trugdolden, deren Stiele nach dem Verbliuhen sich abwärts unter d. Bl. zurückbiegen; Fr. glatt.

Blkr. weiß; Blt, zwitterlich, in end-u, achselständigen, eine Pyramide bildenden Trugdolden. Stiele nach dem Verblühen aufrecht.

24.

W i $11 \mathrm{komm}$, Schulfora. 
23. Stiele d. reichbltigen Trugdolden mit $2 \mathrm{kl}$. lanzettl. Vorbl.; St. $15-45 \mathrm{~cm}$ h., Bl. eiförmig-elliptisch, zurückgeschlagen. Zottig-rauhhaarig. - Gebüsche, Wiesen. 4. 5. 6.

G. Cruciata L.

Stiele der armbltigen Trugdolden nackt; St. $8-30 \mathrm{~cm} \mathrm{h,} \mathrm{Bl.} \mathrm{auf-}$ recht, elliptisch-lanzettförm., gewimpert. Kahl oder fein kurzhaarig. Wälder, Gerölle, Waldwiesen; zerstreut. 4. 4-6. G. vernum Scop.

24. St. schwach, aufsteigend od. liegend, $15-30 \mathrm{~cm} \mathrm{l}$; Bl. elliptisch od. oval, kurz stachelspitzig, fein gewimpert; Trugdolden armbltig, Fr. lakenborstig. - Schattige Wälder. 4. 6. 7. G. rotundifolium L.

St. steif, aufrecht, 39-60 $\mathrm{cm}$ h.; Bl. lanzettförmi reich-u. dichtbltig, Fr. glatt, kahl od. sammtartig. - Waldwiesen, grasige Hügel u. Abhänge; zerstreut. 24. 6. 7.

G. boreále L.

\section{Rúbia L. Krapp (IV, 1).}

Wzst. kriechend, holzig, roth; St. 0.60-1.30 $\mathrm{m}$ l., ästig, 4 kantig; Bi. zu 4-6, elliptisch od. lanzettförm.; Blt. grünlichgelb, Beeren schwarz. Stkanten, Blränder u. Rückennerv stachlig. - Culturpfl. aus d. Orient. 4. $6-8$. Färberröthe, $R$. tinctórum L.

\section{Fan. LVI. Lonicírece. Geisblattgewächse.}

\section{Ad6xa I. Moschuskraut (VIII, 4).}

Wzst. kriechend, gezähnt, weiß; St. einfach, 2 blättrig, 7-15 $\mathrm{cm}$ h., ein fast würfliges, meist 5 blt. Köpfchen grünlicher Blt. tragend; Grundbl. 1. gestielt, 3 zählig zerschnitten. Kahl, nach Moschus duftend. - Schattige Laubwälder und Gebüsche. 4. 3. 4.

A. Moschatéllina L.

\section{Sambúcus L. Hollunder ( $\mathrm{V}, 3)$.}

Bl. gegenstäıd., unpaarig gefiedert, Blättchen gesägt; Blt. in 1. gestielten endständ. quirlästigen Trugdolden.

1, B. od. Str.

Stande mit anfrechtem einfachem $0.6-1.6 \mathrm{~m} \mathrm{~h}$. St. ; Blt. röthlich-weiss, in schirnförm. Trugdolde, Beeren schwarz. -- Waldblößen, Gebüsche, besond. auf Kalk; zerstreut. 4. 6-8.

Attich, S. Ébulus L.

2. BIt. griinlichgelb, in kngligen Trugdolden vor d. Laubausbruch; Beeren scharlachroth. Str. - Waldränder, Ufer, Thalhänge, Gebiische; zerstreut. Ђ. 4. 5 .

S. racemosa L.

Blt. weiß in schirmförmigen Trugdolden, nach der Lauhentfaltung; Beeren schwarz. B. od. Str. - Hecken, Wälder, ïberall cult. ち. 6. 7. Gemeiner Hollunder, Flieder, S. nigra L.

\section{Vibúrnum L. Schneeball $(V, 3)$.}

Bl. gegenständig, einfach; Blt. weiß, in enlständigen quirlästigen schirmförmigen Trugdolden.

1. Bl. ganz, eitörmig, gekerbt, unterseits sammt d. Knospen u. Trieben mehlig-grauweiß filzig; Blt. alle zwitterlich, Beeren schwarz. Str. - Feld. bölzer, Gebüsche, auf Kalk; zerstreut, auch gewöhnl. Ziergelölz. †. 5. 6. Schling baum, V. Lantana L. 
2. B1. 3-5 lappig, kahl; äußere Blt. gesch'echtslos, groß, innere zwitterlich, kl.; Beeren länglich, glänzend roth. Str. od. kl. B. - Auenwälder, Waldränder, Gebüsche. Ђ.6. G e m. Schneeb., V. Ópulus L.

Variet. hortensis, alle Blt. geschlechtslos, daher Trugdold. kug-

lig. Gartenzierstr.

\section{Lonicéra L. Heckenkirsche, Geisblatt (V, I).}

Bl. gegenständig, ganz und ganzrandig. Sträucher.

1. Aufrechte Str.; Bl. kurz gestielt, Blt. paarweise auf einem achselständigen Stiel mit kurzröhriger Blkr. (Heckenkirsche).

2.

Schlingende Str.; Blt. in endständ. Quirlen, mit langröhriger Blkr.; Beeren roth. (Geisblatt).

2. Frkn. d. beiden Blt. sowie deren Beeren getrennt.

3.

Frkn. u. Beeren verwachsen.

5.

3. Bl., Bltstiele u. Blkr. flaumig; Bl. ei-od. herzeiförmig, Blkr. gelb. lich- od. röthlichweiß, Beeren roth. - Hecken, Gebüsche in Berggegenden, besond. auf Kalk. Ђ. 5. 6.

Beiuholz, L. Xylósteum L.

Bl., Bltstiele u. Blkr. kahl, erstere mit herzförm. Grunde. 4.

4. Bl. länglich, spitz, Blumen röthlichweiß, Beeren blauschwarz. rebirgswälder. Ђ. 5. 6 .

L. nigra $\mathrm{I}$.

Bl. eiförmig, stumpf; Blumen weiß, gelb, roth; Beeren purpurroth. - Aus Asien stammender Zierstr., in Hecken oft verwildert. Ђ. 5. 6.

L. tatárica L.

5. (2) Bl. länglich-elliptisch, Blt. kurz gestielt mit röthlichweißer Blkr., Beere dunkelblau. - Bergwälder d. Alpenländer. Ђ. 4. 5.

L. coeritea L.

Bl. gr., eilanzettförm., spitz; Blt. selır l. gestielt, mit purpurn. Blkr.; Beeren dunkelroth. - Waldränder, Bachufer, Gebüsche in d. Alpen. 4. 5. 6 .

L. alpigena L.

6. (1) Bl. getrennt, kurz gestielt, eiförmig od. elliptisch; Blkr. gelblichweiß od. röthlich, drüsenflaumig. - Aus Norddeutschland stammende Zierpfl. 5. 6-8.

L. Periclýmenum L.

Obere $\mathrm{Bl}$. zusaminengewachsen.

7. Blkr. röthlich- od. gelblichweiß, Bl. kahl, wenig glänzend; Blt. sehr wohlriechend. - Südeurop. Zierpfl, in Hecken u. Gebilschen oft verwildert. 5. 5. 6.

Garten-Geisblatt, Jelängerjelieber, L. Caprifolium L.

Blkr. scharlachroth, Bl. glänzend, Blt. geruchlos. - Zierstr. aus Nordamerika. Ђ. 6. 7 .

L. sempervirens L.

\section{Symphoricárpus Adans. Schneebeere $(V, 1)$.}

Bl. gegenständig, kurz gestielt, eiförmig od. elliptisch, ganzrandig, kahl; Blt. kl., röthlichweiß, in achselständ. geknäuelten Träubchen; Beere kuglig, schneeweiß. - Zierstr. aus Nordamer. Ђ. 6. 7. S. racemosus Michx.

\section{2 b. Linnáea L. (XIV, 2).}

Immergrünes Erdholz mit kriechendem fadenförmigem Stämmchen. Bl. gegenständig, kurz gestielt, verkehrt-eiförmig od, elliptisch, kahl; Blt. pararweise auf l. nacktem Stiel, nickend, Blkr. glockenförm., weiß. - Moospolster d. Alpenwälder in T. u. K.; zerstreut. 5. 6. I. boreális L. 


\section{F'am. LVII. Oleaiceae. Ölbaumartige.}

\section{Ligustrum $\mathbf{L}$. Liguster $(\Pi, 1)$.}

Bl. gegenständig, elliptisch bis eilanzettlich, ganzrandig; Blt. weiß, wohlriechend, in endständigen, dichten Sträußen. Beeren schwarz. Sommergrüner Str. - Gebüsche, besond. auf Kalk; zerstreut, auch häufig cult. h. 6.7 .

Ra inweide, span. Weide, L. vulgare $L$.

\section{Syringa L. Flieder ( $\Pi, 1)$.}

Bl. gegenständig, gestielt, ganz u. ganzrandig; Blt. in endständigen dichten pyramidalen Sträußen. Sommergrüne Str. u. B., als Ziergehölze cult.

1. Bl. herzeiförmig, zugespitzt, Blkr. hellblau od. weiß. - In Südosteuropa, in Hecken, an Waldrändern stellenweis verwildert. Ђ. 5. 6 .

Türkischer Hollunder, S. vulgaris L.

2. Bl. eiförmig, zugespitzt, Blkr. gzößer, pfirsichroth od. lila. - Verbreiteter Zierstr. Ђ. 5. 6 .

$S$. chinensis Willd.

3. Bl. eilanzett- bis lanzettförmig, Blkr. blasslila od. weiß, kl. Seltener cult. Ђ. 5. 6.

S. persica L.

\section{Fráxinus L. Esche (II, 1 u. XXI, 1).}

Sommergriiner B., bis $20 m$ h.; Bl. gegenständ.. unpaarig gefiedert; Blt. vor d. Laubausbruch, polygamisch, in seitenständigen Biischeln oder Trugdolden, schwärzlich. - Auen- u. Gebirgsswälder, Ufer. Hecken, überall angepflanzt, in Gärten vielfach variierend. Ђ. 4. 5. F. excelsior. I.

\section{Ornus Pers. Orme. (II, 1).}

Sommergrüner B. von $3-7 m \mathrm{H}$.; Bl. wie bei d. Esche, Blt. nach dem Laubausbruch in endständ. dichten pyramidalen Sträußen, wohlriechend, weiß. - Gebirgswälder v. K., südl. T. u. Kr. auf Kalk, auch Ziergehölz. Ђ. 5. 6. Blumen-, Mannaesche, O. europaea P.

\section{Fam. LVIII. Apocinneae. Hundstodartige.}

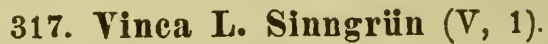

Bl. gegenständ., ganz u. ganzrandig, alt lederartig; Blt. langgestielt, einzeln blwinkelständig, Blkr. lichtviolett. Immergrüne $\mathrm{Kr}$. m. liegend. St.

1. St. holzig, wurzelnd, Bl. kahl, elliptisch od. eilanzettlich, Blkr. $25 \mathrm{~mm}$ br. - Steinige schattige Plätze in Laubwäldern. Gebüschen, häufig cult. 2. 4. 5. Im mergrü n, Wintergrün, $V$. minor L.

2. St. krautig, nicht wurzelnd; Bl. länglich-lanzettförmig, gewimpert, Blkr. $18 \mathrm{~mm}$ br. - Bisamberg u. a. O. b. Wien. 4. 4. 5.

$V$. herbácea W. Kit.

A nmerk. Zu den Apocyneen gehört auch der im Mittelmeergebiet heimische Ol e and er, Nerium Oleander L. 
Fam. LIX. Asclepiádeae. Seidenpflanzenartige.

318. Vincetóxicum Mnch. Schwalbenwurz (V, 2).

Wzst. vielköpfig, St. aufrecht, $15-45 \mathrm{~cm}$ h., einfach; Bl. geg $\in$ nständ., herzei- od. eilanzettförm., zugespitzt; Blt. kl. weiß, in achselständ. l. gestielten Trugdolden. (Cynanchum Vincetoxicum L.) - Steinige, bebuschte Hügel, besond. auf Kalk; zerstreut. 4. 5-7. $\quad V$. officinale Mnch.

Variet. $\beta$. lax u m (Bertl.), St. verlängert, schlaff, windend. Stellenweis; $-\gamma$. punctatum (Pach.), St. violett, schwarz punktiert, nach oben sammt Blrippen, Bltstielen $u$. Kelchen blutroth. In K.

\section{Asclépias L. Seidenpflanze $(V, 2)$.}

St. einfach, reihblättrig, $0.8-1.5 \mathrm{~m}$ h.; BI. gegenständig, länglich,

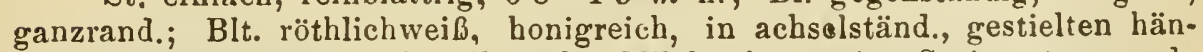
genden Dolden. Ganze PA. voll weiBen Milchsafts. - Aus Syrien stammendo Zierpt. 4. 7. 8.

A. syríaca L.

\section{Fam. LX. Gentianáceae. Enziangewächse.}

\section{Schlïssel der Gattungen.}

1. Blkrzipfel in d. Knospenlage klappig gefaltet. Sumpf- u. Wassergewächse; Kapsel 1 fächrig, 2 klappig.

Blkrzipfel in d. Knospenlage zusainmengedreht. Vorwieg. Landp甘, 3.

2. Bl. rundlich, schwimmend; Blkr. radförmig, 5 theilig, im Schlundo bärtig; Stbg. 5, Frkn. von 5 Drüsen umgeben. Limnanthemum (320).

Bl. 3 theilig; Blkr. trichterförmig, 5 theilig mit bärtigen Zipfeln; Stbg. 5, Frkn. auf drïsiger gewimperter Scheibe. Menyanthes (321).

3. Stbb. nach d. Verstäuben gerade, Kapsel 1 fächrig.

Stbb. nach d. Verstäuben schraubenförmig gedreht, Blkr. trichterig E spaltig, Stbg. 5; Kapsel unvollkommen 2 fächrig.. Erythraea (326).

4. Stbg. 5-4, Blkr. mit 5-4 lappigem Saum.

5.

Stbg. 8, Blkr. mit 8 theiligem Saum; Gr. mit 2 Narb. Chlora (322).

5. Blkr. radförmig, Zipfel am Schlunde mit 2 Schuppen od. Honiรgrübchen, Gr. fehlend, Kapsel 1 fäch rig, 2 klappig.

6.

Blkr. trichter-, glocken-, keulen- od. präsentiertellerförmig, selten radförmig, ohne Schuppen od. Honiggrübchen im Schlunde; Narben 2, sitzend, Kapsel 1 fächrig, 2 klappig.

Gentiana (325).

6. Blkrzipfel mit 2 Schuppen, Narbe auf beiden Seiten d. Frkn. herablaufend; Blt. einzeln, l. gestielt. Lomatogonium (324).

Blkrzipfel mit 2 Grübchen; Narben 2 getrennt, nicht herablaufend; Blt. in end- u. achselständ. Trugdolden. Swertia (323).

\section{Limnánthemum Gmel. Sumpfblame, Seekrone (V, 1).}

St. im Schlamme kriechend u. aufsteigend; Bl. gegenständig, l. gestielt, herzförmig rundlich; Blt. lang gestielt, doldenförm. in d. Blwinkeln, schwimmend, gelb, gr. - In stehenden u. langsam fießender. Wässern in Б, Mh., Sch. u. 0̈̈.; zerstreut. 4. 7. 8.

L. nymphoides Lk. 


\section{Menyanthes L. Fieberklee $(V, 1)$.}

Wzst. gegliedert, kriechend; Bl. grundständ., l. gestielt ; St. nackt, $8-15 \mathrm{~cm}$ h.; Blt. in endständig. Traube, weiß od. blassröth̀lich. - In Sümpfen, Gräben; zerstreut. 4. 8.9.

Fieberklee, Bitterklee, $M$ trifoliáta L.

\section{Chlora L. Bitterling (VIII, 1).}

Bl. ganzrandig, grundständige in Rosette, Stbl. gegenständig, am Grunde verwachsen, eilanzettförm., blaugrün; Blt. in end- u. achselständ. Trugdolden, gelb; St. $15-30 \mathrm{~cm}$ h. - Uebcrschwemmte Plätze, Ufer in

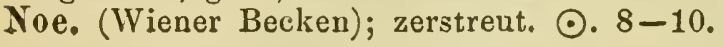

Ch. serótina Koch.

\section{Swertia L. (V, 2).}

St. aufrecht, einfach, 4 kantig, $15-45 \mathrm{~cm}$ h.; Bl. gegenständig, elliptisch, 5-7 nervig, ganzrand.; Blkr. grauviolett, dunkel gestrichelt. Sumpfige, torfige Plätze d. Alpen, Sudeten, d. Riesen- u. Erzgeb. 4. 7. 8.

S. perennis L.

\section{Lomatogónium A. Br. $(\mathrm{V}, 2)$.}

St. aufrecht, $2 \cdot j-10 \mathrm{~cm}$ h., meist ästig; Bl. gegenständig, eiförmig, spitz, grundständige in Rosette, verkehrt-eiförmig; Blt. meist 3, Blkr. hellblau, $13 \mathrm{~mm}$ br. - Sonuiges Gerölie d. Alpen von K. u. T. (1580 bis $2250 \mathrm{~m}$ ); zerstreut. $\odot .7-9$. L. carinthiacum A. Br.

\section{Gentiána L. Enzian (V, 2).}

Kahle Kräuter, Bl. gegenständig, ganz u. ganzrandig, grundständige meist in Rosette.

1. Blkr. mit grünlicher od. gelblicher Röhre u. blauem, violettern od. lilafarbenem (selten weißem) Saume.

Blkr. ganz gelb od. mit purpurroth. od. purpurviolett. Saume. 21.

2. Blkr. am Schlunde kahl.

Blkr. am Schlunde bärtig gefranzt; einjührige Pfl. m. dünner Wz. 16.

3. Blkrzipfel (4, selten 5) an den Rändern gefranzt, azurblau; Blt. einzeln, endständig, bis $5 \mathrm{~cm}$ l.; St. $8-30 \mathrm{~cm}$ h., Bl. lanzettlich od lineal. - Gebüsche, Triften, besond. auf Kalk; zerstrent, 4. 8. 9. G. ciliata L.

Blkrzipfel (meist 5) nicht gefranzt.

4. Blt. in Scheinquirlen in d. Winkeln d. kreuzweis gegeuständigen Stbl., kenlig-glockenförmig, $18 \mathrm{~mm}$ l, außen grünlich, innen blau; St. 10 bis $40 \mathrm{~cm}$ h., Bl. länglich-lanzettförmig, 3 nervig. - Waldwiesen, Gebiische, Triften; zerstreut. 4. 7-9. G. cruciata L.

Blt. einzeln od. gegenständig, oder wechselständig-traubig.

5. Röhre d. Blkr. keulig, Saum ausogebreitet, kurz.

Röhre d. trichter-od. tellerförm. Blkr. walzig.

6. St. 15-45 $\mathrm{cm}$ h., einfach, reichbeblättert u. reichbltig.

St. $2 \cdot 5-10 \mathrm{~cm}$ h., 1 bltig od. stengellose Kr. mit grundständ. Bltn.; Grundbl. uud die der unfruchtbaren Blsprossen in Rosette.

7. Bl. 1 nervig, lineal-lanzettförmig; Blt. gestielt, einzeln od. gegenständig in lockerer Traube; Blkr. 3-4 cm l., innen azurblau. - Nasse und sumpfige Wiesen; zerstreut. 4. 7-9. G. Pneumonanthe L. 
B1. 5nervig, eilanzettförm., zugespitzt; Blt. gegenständig, in langen beblätterten Trauben, Blkr. 3-5 cm l, azurblau, selten weiß. - Bachufer, Waldschluchten d. Voralpen, Sudeten, d. Iser- u. Riesengeb. 4. 8. 9.

8. Blkr. blau.

G. asclepiadéa L.

Blkr. gelblichwciß, innen mit 5 bläulichen Streifen, 25-38 $\mathrm{mm}$ 1.; St. kurz, 1 bltig, Bl. lineal-lanzettförm., 1 nervig. - Höchste Granitalpen von St. 4. $7-9$.

G. firígida Hke.

9. Blkr. bis $5 \mathrm{~cm}$ l., keulig-glockig, innen azurblau, außen grünlich, Kelchzipfel angedrückt; St. $1.3-3.8 \mathrm{~cm}$ l. od. felılend; Bl. eiförm., elliptisch od. eilanzettförmig, 1-3 nervig. - Fenchte Wiesen d. Alpen. 4 $5-7$.

G. acaulis $\mathrm{L}$.

Variet. $\beta$. excis a (Presl.), Kelchzipfel abstehend, mit br. Bucliten dazwischen.

Blkr. $25 \mathrm{~mm}$ l., blassblau, am Grunde gelblich; St. $13-25 \mathrm{~mm}$ h., $1 \mathrm{bltig} ;$ Bl. gehäuft, lanzettlich od. lineal.lanzettförmig, 1 nervig. - Triften d. Kalkalpen von K. (Karawanken) u. Kr.; zerstreut. 4. 8.9.

\section{G. Hroelichii Jan.}

10. (5) Niedrige ausdauernde rasenbildende Kr. mit 1 bltigem, 1.3 bio $20 \mathrm{~cm}$ h. St.; Blkr. innen azurblau.

11.

Einjährige Pf. mit dünner Wz.; St. aufrecht od. liegend, 2.5 bis $20 \mathrm{~cm}$ lang.

11. Alle Bl. gleichgeformt u. gleichgroß.

Untere (rosettenständige) größer. 14. 12. 13.

12. Bl. stumpf, verkehrt-eiförmig, untere sehr genälıert, obere entfernt; Blkr. $25 \mathrm{~mm}$ l., St. bis $20 \mathrm{~cm} \mathrm{l}$. - Bachufer, feuchte Gerölle d. Alpen. 7. 7.8 .

G. bavarica L.

Var. rotundifolia (Hppe.), Bl. kl. rundlich, sämmtl. dicht gedrängt.

Bl. spitz, elliptisch-lanzettförmig, alle dachig gedrängt; St. 13-25 mm hoch, Blt. 14-16 $\mathrm{mm}$ l., zwischen den obersten Bl. sitzend. - Sonnige Felsen d. Kalkalpen von T., K., Kr. $(1900-2530$ m). 4. 7. 8.

G. imbricata Froel.

13. Bl. lineal od. lineal-lanzettl., spitz, untere gedrungen; St. 13 bis 25, Blkr. 20-24 mm 1. - Auf Sand u. Triften d. Kalkalpen. 4. 7-9.

G. primila Jacqu.

Bl. elliptisch od. lanzettförm., untere stumpf, Stbl. entfernt, St. 6 bis $10 \mathrm{~cm}$, Blkr. $25 \mathrm{~mm}$ l., Kelch flügelkantig. - Wiesen, Triften, quellige Orte d. Alpen, auch im Gesenke (selten!). 4. 6-8.

$G$. verna $\mathrm{L}$.

Variet. $\beta$. a estiva (R. Sch.), Kelclıkanten breit geflügelt, Bl. lineallanzettlich, St. bis $5 \mathrm{~cm}$, Blkr. über $25 \mathrm{~mm}$ l. Voralpen; $\gamma$. b r a chy phyll a (Vill.), St. verkürzt, Bl. kl., fleischig, rundlicheiförmig; Blkr. länger als d. St. Triften d. höchsten Alpen (1900 bis $2600 \mathrm{~m}$ ).

14. (10) Kelch aufgeblasen, häutig, Blkr. bis $16 \mathrm{~mm} \mathrm{l.,} \mathrm{mit} \mathrm{azurblauem}$ Saum; St. 7.5-20 cm 1., Grundbl. eiförmig, Stbl. länglich. - Feuchte Wiesen d. Alpen. $\odot$. 6-8.

G. utriculosa L.

Kelch nicht aufgeblas., walzig, kantig, Blkr. kl., 6-12 $\mathrm{mm}$ br. 15 .

15. Saum d. Bl.rr. azurblau; St. bis $15 \mathrm{~cm}$ l., meist pyramidalästigvielbltig; Grundbl. eiförmig in Rosette, Stbl. länglich. - Alpentriften (bis $2550 m)$. $\odot .7-9$. 
Saum d. Blkr. blassblau; St. bis $5 \mathrm{~cm}$ 1., liegend od. aufsteigend, am Grunde ästig, Bl. verkehrt-eiförmig od. länglich, kl., untere nicht in Rosette. - Auf Kies u. Gerölle d. Centralalpen von St., K., T. (2000 bis $2700 \mathrm{~m})$; zerstreut. $\odot$. 7. 8 .

G. prostrata Hke. 1 bltig.

16. (2) St. nur am Grunde ästig u. beblättert, Äste nach oben nackt

St. straff, aufrecht, d. ganzen Länge nach traubig-od. rispig-ästig, Schlund $d$. Blkr. mit aufrechtem weißlichem Wimperkranz.

18.

17. Kelch 4 spaltig, Blkrsaum 4 lappig, violett od. weiß, Blt. 6-12 mm lang; St. (meist viele) 5-8 $\mathrm{cm}$ l., Bl. elliptisch-länglich. - Hohe Alpentriften in K. u. T. $(1900-2850 \mathrm{~m})$. $\odot$. 8. 9. G. tenella Rottb.

Kelch 5 spaltig, Blkrsanm 5 lappig, lila od. weißlich, Blt. $6 \mathrm{~mm} \mathrm{l.;}$ St. 13-38 mm h., Bl. kl, verkehrt-eiförmig-rundlich. - Gletscherkies in K. u. T. $(2200-2900 \mathrm{~m})$. $\odot 8.9$.

G. nana Wulf.

18. Kelch 4 spaltig, äußere Zipfel blartig, oval, innere viel kleiner, lineal; Blkr. mit 4 lappigem Saum, 14-20 $\mathrm{mm}$ l., außen grünlich, innen hellviolett; St. bis $25 \mathrm{~cm}$ h., Bl. verkehrt-ei- bis eilanzettförm. - Trockene Bergtriften. $\odot$. 7. 8 .

G. campestris L.

Kelch 5 spaltig, Zipfel gleich; Blkrsaum 5 lappig; St. 15-50 $\mathrm{cm}$ h. Bl. 3 nervig.

19.

19. Blkr. 16-20 mm 1., mit walziger Röhre, röthlich-lila; Frkn. und Kapsel sitzend; Grundbl. spatelförm., gestielt, Stbl. eilanzettlich sitzend. -

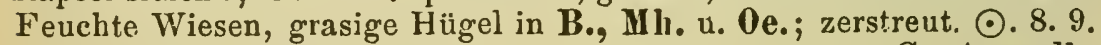

\section{G. Amarella L.}

Blkx. 18-45 mm l., röhrig-glockenförm.; Frkn. u. Kapsel gestielt. 20. umgerollt.

20. Kelchzipfel durch spitzwinklige $Z$ wischenräume getrennt, am Rande

Kelchzipfel durch stumpfe buchtige Zwischenräume getrennt, lineallanzettlich, flach; Blkr. 25-45 $\mathrm{mm} \mathrm{l.,} \mathrm{m.} \mathrm{hellviolettem} \mathrm{Saume;} \mathrm{mittlere} \mathrm{Stbl.}$ eiförmig-lineal od. eilanzettförmig. - Grasige Abliänge, sumpfige Moorwiesen auf Kalk in Oe., K., Kr. 4. 8.9. G. austriaca Kern.

21. Blkr. dunkel- od. blassblau, Grundbl. verkehrt-ei- od. spatelförm., Stbl. aufrecht-abstehend, länglich bis lanzettförmig, die obersten spitz. Moorige Wiesen u. Triften d. Alpen (bis $1600 \mathrm{~m}$ ), auch in B. u. Mh. (Karpathen). $\odot .6-9$.

G. obtusifolia Willd.

Blkr. lila, $18-27 \mathrm{~mm}$ l., Grundbl. spatelförm., Stbl. weit abstehend, ei- od. herzlanzettförmig, zugespitzt, kürzer als d. Internedien. Pfl. von breitpyramidalem Wuchs. - Trockene Wiesen u. Triften, von B. u. Mh. bis in d. Alpen bis $(2000 m)$. ๑. 8. 9 .

G. germanica W.

Blkr. mit dunkelviolettem Saum, 30-46 mm l., mittlere Stbl. herzförmig-3 eckig, von der Länge $d$. Internedien. - Grasige Hügel in Ooe., Noe. u. K. 4. 9. 10.

G. Sturmiana Kern.

21. (1) Blkr. purpurn, keulig-glockenförmig, gr.

Blkr. gelb; Blt. in achselständigen Quirlen.

22.

23.

22. Blkr. purpurroth, mit gelber, $25 \mathrm{~mm}$ l. Röhre; Blt. in endständ., von d. obersten Bl. umhüllten Büscheln; St. $30-60 \mathrm{~cm} \mathrm{h.,} \mathrm{Bl.} \mathrm{br.} 5$ nervig. - Kräuterreiche Stellen d. Alpen von Va. u. T.; zerstreut. 4. 6-8. 
Blkr. purpurviolett, schwarz punktiert, bis $38 \mathrm{~mm}$ 1.; St. bis $45 \mathrm{~cm}$ hoch, 5l. br., 5-7 nervig. - Kräuterreiche Stellen d. Alpen, auch im Böhmerwald; zerstreut. 4. 7-9.

G. pannonica Scop.

23. Blkr. keulig-glockenförmig, gelb, schwarzviolett punktiert, $25 \mathrm{~mm}$ lang; St. bis $45 \mathrm{~cm}$ h., Bl. oval, 5-7 nervig. - Grasige Triften d. Alpen, auch im Gesenke; zerstreut. 4. 7-9.

G. punctata L.

Blkr. radförmig, gelb, spitzzipflig, $18 \mathrm{~mm}$ br.; St. 0.45-1 $m \mathrm{~h}$., Bl. 5-7 nervig, Grundbl. sehr gr., elliptisch, gestielt, Stbl. herzeiförmig. Krreiche Stellen u. Wiesen d. Kalkalpen; zerstreut. 4. 7.8. G. lútea L.

\section{Erythráea L. Tausendgiildenkraut $(V, 1)$.}

St. 4 kantig, ästig; Bl. kreuzweis gegenständ.; Blt. kl., in gabeltheil , schirmförm. Trugdolden; Blkr. trichterig, hellroth (selten weiß) mit gelber Röhre.

1. Untere Bl. in Rosette, St. oben ästig, Trugdolden tragend; Blkr. $10-13 \mathrm{~mm} 1$.

Alle Bl. gegenständig, untere eiförmig, obere lanzettlich; St. 5 bis $15 \mathrm{~cm} \mathrm{h.,} \mathrm{meist} \mathrm{vom} \mathrm{Grunde} \mathrm{an} \mathrm{gabeltheilig-ästig;} \mathrm{Blkr.} 8 \mathrm{~mm}$ 1. Feuchte Äcker u. Wiesen; zerstreut. ๑. 7. 8. E. ramosissima P.

2. Rosettenbl. verkehrt-eiförmig, Stbl. länglich-lanzettförmig; St. 15 bis $40 \mathrm{~cm}$ h. - Waldwiesez, bebuschte Hügel. ๑. 7-9.

E. Centáurium L.

Alle Bl. länglich-lineal od. untere keilig, Stbl. lineal; St. 8-25 cm hoch. - Auf feuchtem, salzhaltigem Boden in B., Mh., Noe.; sehr zerstreut. $\odot$. 7. 8. E. linearifolia P.

\section{Fam. LXI. Labiatae. Lippenblïtler.}

\section{Schliissel der Gattungen.}

1. a) Blkr. fast regelmäßig 4 spaltig, trichterig.

b) Blkr. deutlich 2 lippig.

c) Blkr. scheinbar 1 lippig, Kelch röhrig, 5 zähnig.

2. Stbg. 4, zweimächtig; Blt. kl. in dichten Quirlen, Köpfchen, Quirlähren.

Mentha (328).

Stbg. 2, Blt. in entfernten, blwinkelständigen dichtbltigen Quirlen. Lycopus (329).

3. Stbg. 2, Mittelband querbalkenförmig, mit d. Träger durch Gelenk verbunden, an dem einen Ende ein volles, am andern ein verkümmertes Stbbfach tragend.

Stbg. 4, zweimächtig. Salvia (330).

4. Frtragender Kelch offen.

Frtragender Kelch geschlossen.

5. Stbg. eingeschlossen.

26.

Stbg. aus d. Blumen hervorstehend.

6.

6. Blkr. weiß, mit Alacher ganzer od. 2 spalt. Oberlippe, Kelch röhrig, 5-10 zähnig. Marrubium (352).

Blkr. gelb, zuletzt braun; Oberlippe flach, ganz oder ausgerandet, Kelch glockig, mit 2 lippig-fünftheiligem Saum. Sidericis (353). 
7. Stbg. oberwärts auseinander spreizend, unter d. Oberlippe beiderseits hervorragend.

b) Stbg. unter d. Oberlippe bogig zusammenneigend.

c) Stbg. unter d. Oberlippe parallel od. untere auswärts gedreht. 14.

8. Kelch gleichmäßig 5 zähnig.

9.

Kelch 2 lippig, Bltquirle ohne Deckbl., entfernt od. in Köpfchen.

Thymus (332).

9. Bltquirle nach einer Seite gerichtet, eine einseitswendige Ähre bildend.

Hyssopus (338).

Bltquirie (meist nur einzelne Blt.) in d. Winkel dicht dachig gestellter eiförmiger Deckbl., mit diesen zusammen zu dichten Ähr:n vereinigt.

Origanum (331).

10. $(7$, b.) Blt. in dichten, am Grunde von schmalen Deckblättchen umhülltën Quirlen; Kelch 2 lippig, mit gekrümmter Röhre.

Clinopodium (335).

Blt. in deckbllosen Quirlen od. blwinkelständ. od. in Trugdolden. 11.

11. Kelch 2 lippig.

12.

Kelch 5 zähnig, 10 streifig; Blt. blwinkelständig od. in Trugdolden. Satureja (333).

12. Kelchröhre gekrümmt, am Schiunde eingeschnürt; Blt. in gॄbeltheiligen Trugdold. od. Quirlen, deren Blt. gestielt sind. Calamintha (334).

Kelchröhre gerade, nicht eingeschnürt, Blt. in Quirlen, sitzend. 13.

13. Quirle entfernt, armbltig; Kelchschlund behaart. Melissa (336).

Quirle in unterbrochener Traube, Kelch tief 2 lippig-gespalten, nicht behaart; Blkr. glockig-2 lippig.

Horminum (337).

14. (7, c.) Stbg. unt. d. Oberlippe stets parallel, d. 2 oberen läng. 15.

Stbg. parallel, später d. unteren oft nach außen gedreht, die 2 un. teren länger.

17.

15. Oberlippe gewölbt, helmförmig, Röhre aufoeblasen, Kelch 2 lippig, Blt. in Quirlen. Dracocephalum (341).

Oberlippe flach, Kelch fast gleichmäßig 5 zähnig.

16.

16. Blt. in Quirlen, Stbb. 2 Kreuze bildend. Glechoma (340).

Blt. in gabeltheiligen Trugdolden od. Quirlen, Stbb. geradlinig. Nepeta (339).

17. (14) Oberlippe d. Blkr. rund, flach, Stbb. Kreuze bildend; Kelch 2 lippig, weitglockig.

Melittis (342).

Oberlippe gewölbt, oft helınförmig, Kelch ziemlich gleichmäßig 5 zähnig.

18.

18. Unterlippe mit kl. od. zahnartigen Seitenläppchen.

Unterlippe br. 3 lsppig.

Lamium (343).

19.

19. Lappen d. Unterlippe gleichbreit u. von gleicher Form, spitz. Galeobdolon (344).

Lappen d. Unterlippe stumpf, ungleich, d. mittleren ausoerandet. 20.

20. Am Grunde der Unterlippe beiderseits 1 hohler Zahn, Stbfächer quer mit 1 Klappe aufspringend.

Galeopsis (345).

Am Grunde der Unterlippe keine hohlen Zähne, Stbfächer mit Längsspalten aufspringend.

21.

21. Blkrröhre inwendig mit Haarring. Kelche 5 zähnig.

22.

Blkrröhre ohne Haarring.

25. 
22. BI handförmig gelappt, untere Stbg. nach d. Verstäuben nach auswärts gedreht.

Leonurus (350).

Bl. nicht gelappt, meist; gekerbt od. gesägt

23.

23. Untere Stbg. nach d. Verstäuben nach auswärts gedreht.

Stachys (346).

Untere Stbg. nach d. Verstäuben nicht auswärts gedreht. 24.

24. Blt. mit pfriemenförm., steifhaarig bewimperten Deckbl. in đicnten Quirlen.

Phlomis (348). den.

Blt. mit kl. linealen Deckbl,, in kurzgestielten vielbltigen TrugdolBallota (349).

25. (21). Kelch 5 nervig; Bltquirle fast alle in eine walzige Ähre zusammengedrängt.

Betonica (347).

Kelch 10 nervig, mit dornspitzigen Zähnen; Bltquirle entfernt.

Chaiturus (351).

26. (4). Oberlippe d. Blkr. helmförmig, Stbg. sicbtbar; Kelch 2 lippig. 27.

Oberlippe d. Blkr. Aach 2 spaltig, Stbg. u. Gr. in d. Röhre eingeعsłlossen; Blkelch durch d. zusammenneigenden Zähne geschlossen.

Lavandula (327).

27. Lippen d. Kelches ganz, obere am Rücken mit einem aufrechten concaven Querkamm; Unterlippe d. Blkr. ungetheilt. Scutellaría (354).

Oberlippe d. Kelches 3 zïhnig, Unterlippe 2 spaltig, beide zur Fruchtzeit an einander geschmiegt; Unterlippe d. Blkr. 3 lappig. Prunella (355).

28. (1, c). Oberlippe sehr verkürzt, ein ausgerandeter Saum, Unterlippe 3 lappig.

Ajuga (356).

Oberlippe tief 2 spaltig, ihre Zipfel herabgebogen, daher scheinbar bloß eine 5 lappige Unterlippe vorhauden.

Teucrium (35i).

\section{Lavándula L. Larendel (XIV, 1).}

Aufrecht. ästiger, $15-30 \mathrm{~cm}$ h. Halbstr.; Bl. lineal-lanzettlich. zurückgerollt, Quirle in 1. gestielten Ähren, Blkr. blau. - Küichengewürzp日. aus Südeuropa. Ђ. 7. 8.

L. vera DC.*).

\section{Hentha L. Minze (XIV, 1).}

Vielgestaltige, zur Bastarderzeugung geneigte, stark aromatische, meist behaarte $\mathrm{Kr}$.; Kelch röhrig, Blkr. kurzröhrig, mit 4 ungleich großen Saumlappen, (Die zahlreichen Varietäten, Unterarten u. Bastarde können hier nicht beriicksichtigt werden.)

1. Kelch 2 lippig, Blkr. hellpurpurn od. lila, ziemlich 2 lippig; Blt. in entfernten Quirlen: St. 15-30 cm l, Bl. gestielt, elliptisch. - Aus Südeuropa, cult. an sandigen Ufern hie und da verwildert. $\odot$. 7-9. Poleiminze, M. Pulegium L.

Kelch 5 zähnig.

*) In d. Nähe von Lavandula gehört auch das aus Ostindien stammende, vorziiglich als 'Topfpel. cult. Basilienk ra ut, Osymum Basilicum L。: Bl. breit, Blkr. weiB, umgekehrt. $\odot$. 7. 8 . 
2. Quirle zahlreich, in endständigen, dichten od. unterbrochenen, spitzen Ähren (spicatae)

b) Quirle in d. Achseln gewöhnl. Stbl. entfernt (verticillatae). 5.

c) Quirle in endständige halbkuglige Köpfchen od. kurzwalzige Ähren zusammengedrängt, wohl auch gestielte Quirlköpfchen in den Blwinkeln; Blkr. lila, Blt. gestielt, eiförmig od. eiläuglich, gesägt, bisweilen krausrandig (M. crispa L. "Kra useminze." ${ }^{*}$ ); St. $18-60 \mathrm{~cm}$ h. Ufer, Gräben, Sümpfe. 4. 7. 8.

M. aquática L.

3. Stbl. sitzend od. undeutlich gestielt

Stbl. deutlich gestielt, lanzett- od. länglich-lanzettförm., spitz, gesägt ; St. 30-60 cm h.; Ahren schlank, meist unterbrochen, Blt. weiß. - Cult. 4. 7. 8.

Pfefferminze, M. pipérita L.

4. Bl. elliptisch, eiförmig-rundlich bis herzeiförmig, runzlig, gekerbt unterseits grau-bis weißfilzig; Quirlähren rispig, Blkr. weiß; St. 30-60 cm h. zottig. - Aus Südeuropa, verwild. an Ufern hier und da besond. in T., Kr., K. 4. 7. 8 .

M. rotundifolia $\mathbf{L}$.

Bl. länglich-lanzettförm. od. lanzettlich, spitz, gesägt od. gezähnt, sammt d. $0 \cdot 30-1 \mathrm{~m}$ h. St. verschieden behaart, selten kahl (M. viridis L.); Quirlähren rispig, Blkr. lila, selten weiß. - Ufer, Gräben, gemein, M. viridis auch cult. und verwildert. 4. 7-9. M. silvestris $L$.

5. (2. b.) QuirJe bis ans Ende d. St. u. d. Äste reichend, diese durch einen kl. länglichen Quirl, oder durch einen Bltbüschel geschlossen; Kelch röhrig-glockig, gerippt, Zähne 3 eckig-pfriemenförmig, Blkr. innen dicht behaart.

Quirle sämmtlich blwinkelständig, St. u. Äste durch Blbüschel geschlossen, Blkr. innen kahl.

6. Kelchzähne kurz-pfriemenförmig, obere Quirle meist genähert 7.

Kelchzähne lang-pfriemenförmig, Quirle alle getrennt, sitzend oder d. untersten gestielt; St. $15-45 \mathrm{~cm}$ h., sammt d. Bl. dicht behaart, Bl. oval od. br. elliptisch, gezähnt, kurz gestielt. - Cult., stellenweis verwildert. 4. 7. 8. M. sativa L.

7. Bl. br. eiförmig bis rhombisch, grob gesägt-gezähnt, obere sitzend; Quirle reichbltig, groß, oberste oft so gr., wie ihre Stützbl.; St. $0.5-1 \mathrm{~m}$ h., unten kahl, sonst wie ג. Bl. mehr weniger behaart. - Ufer, Gräben in B. u. Mlh,; zerstreut. 4. 7-9.

IM. palustris Mnch.

Bl. länglich-eiförmig, spitz, gesägt (ob. nicht grob), alle gestielt, Quirle kl., oberste genähert, stets kürzer als d. Stützbl.; St. $50-80 \mathrm{~cm}$ h., oben sammt d. Bl. nicht zottig; Blkr. lila. - Ufer in Mh. u. Oe.; zerstreut. 4. 7-9. M. paiudosa Schreb.

8. Kelch glockenförmig, Zähne kurz 3 eckig. 9.

Kelch röhrig-glockig, Zähne lanzettförm. od. pfriemlich. 12.

9. Blstiele länger als die Quirle. 10.

Blstiele kürzer als die Quirle. 11.

10. Bl. br. eilarizettl. bis rhombisch-lanzettförm., stumpf, von d. Mitte an gezähnt, l. gestielt; Quirle armbltig, Blt. lila; St. $50-75 \mathrm{~cm}$ h., kahl od. fast kahl. - Ufer, Gräber in Mh. u. Noe.; zerstreut. 4. 8. 9. M. parietúriaefólia Beck.

*) Krausblättrige Formen kommen auch b. M. silvestris, viridis, sativa und arrensis vor, vorzüglich cult, als "Krauseminzen". 
Bl. elliptisch bis lanzettförm. von unter d. Mitte an gezähnt, gestielt; St. 25-75 $\mathrm{cm}$ h., nebst d. Bl. kahl od. behaart, Kelche u. Bltstiele meist zottig, Blkr. röthlich-lila. - Ufer, Gräben, Sümpfe in Mh. u. Oe.; zerstreut. 4. 8. 9.

M. verticillata $\mathrm{L}$.

11. Bl. kl., schmal ei-lanzettlich, scharf gezähnt, gelblichgrün, zart, behaart od. kahl; St. aufrech! einfach od. ästig, 20-35 $\mathrm{cm}$ h., behaart; Quirle sehr zahlreich, Blkr. kl., purpurn, Kelch abstehend-behaart. Ufer in Mh. u. 0e.; zerstreut. 4. 8.

M. austriaca Jequ.

Bl. kl. eiförmig od. länglich, gesägt, grün, derb; St, aufrecht oder liegend, meist vom Grunde an ästig, $15-40 \mathrm{~cm}$ l.; Blkr. lila. Dicht behaart bis zottig. - Feuchte Äcker, Ufer, Gräben. 4. 7-9. M. arvensis L.

12. (8). Bl. oval, gesägt, kurz gestielt od. sitzend; Quirle zahlreich, vielbltig, alle entfernt, Stützbl. lanzettförm., Blkr. blass lila; St. 40 bis $60 \mathrm{~cm}$ h., purpurbraun, sammt d. Bl. kahl od. zerstreut-behaart. Nach Citronen riecheud. - Ufer, Gräben in Mh. u. B.; zerstrèut. 4. 7-9. M. rubra Sm.

Bl. eilanzettförmig u. tief gesägt, runzlig, Stützbl. d. Quirle almählich kleiner; St. 30-60 $\mathrm{cm}$ h. Kahl od. zerstreut-behaart. Nach Basilicum duftend. - Cult., hier und da verwild. 4. 7. 8.

M. gentílis Sm.

Anmerkung: Die hier angeführten Arten (?) der Menthae verticillatae, welche nach $\mathrm{O}$ borny bearbeitet wurden, dürften in allen Kronländern vorkommen.

\section{Lýcopus L. Wolfsfuß (II, 1).}

St. straff; Bl. ei- od. länglich-lanzettförmig; Blt. kl. weiß.

1. Untere Bl. fiederspaltig, obere grob-od. eiugeschnitten-gesägt; St. $0.6-1 m$ h. - Ufer. 4. 7-9.

L. europaeus L.

2. Alle Bl. fiedertheilig, St. 1-1.6 $m$ h. - Ufer in B., Mh., Noe.; sehr zerstreut. 4. 7. 8.

L. exaltatus L.

\section{Salvia L. Salbei (II, 1).}

Bltquirle von Deckbl. gestützt, welche von d. Stbl. sehr verschieden sind, in unterbrochenen Ähren od. Trauben. Blkr. rachenförmig2 lippig, Oberlippe helmförmig.

1. Quirle 20- u. melırblütig, entfernt, lange Trauben bildend; Blt. kl., hell-violett bis weiß; Deckbl. Kl. eiförm., ganzrandig; St. $30-60 \mathrm{~cm} \mathrm{~h}$. Bl. 3 eckig-herzförm, doppelt gesägt, gestielt. - Trockene Wiesen, Hügel, Raine, besonders auf Kalk. 4. 6-8.

S. verticillata $\mathrm{L}$.

\section{Quirle 4-6 (höchstens 10) bltig.}

2. Halbstrauch. Bl. elliptisch bis lanzettförm., gekerbt, runzlig, dünn graufilzig; Deckbl. eilanzettförm., ganzrandig; Blt. gr., dunkelblau, lila, weiß. - Aus Südeuropa, häufig cult. ち. 6. 7. S. officinalis L.

Kräuter.

3. Deckbl. gr., herzförmig-rundlich, bespitzt, häıtig, weißlich, Blkr. weiß; St. $0 \cdot 30-1 m$ h., Bl. gr., tiförmig od. länglich, lappig gebuchtet. Weißwollig. - Wüste Plätze, Felsen, Ackerränder, in Mh. u. Noe.; auch Zierpfl. (-) 6.7.

S. Aethiopis L.

Deckbl. kl., eiförm. od. oval zugespitzt, ganzrandig. 
$60 \mathrm{~cm} \mathrm{~h}$.

4. Blkr. violett, blau, rosa, weiß, obere Bl. sitzend; St. 30 bis

Blkr. gelb, alle Bl. gestielt

6.

5. Quirle entfernt, Deckbl. kürzer als d. Kelche, grün, Blkr. bis $25 \mathrm{~mm}$ l. azurblau od. violett (selten rosa od weiß); Bl. herzei- bis eilanzettförm., doppelt gesägt. - Wiesen, Hügel, Raine. 4. 5-7.

S. pratensis $\mathrm{L}$.

Quirle genähert, Deckbl. länger als d. Kelche, purpurviolett. Blkr. nur $3 \mathrm{~mm}$ 1. azurblau; Bl. ei- bis eilanzettförm., spitz, doppelt gekerbt. - Hügel, Raine, besond. anf Kalk. 4. 6-8.

S. nemorosa L.

6. St. $30-60 \mathrm{~cm}$ h., fast bllos, nebst Kelchen u. Blkr. zottig; Bl. eiförm. od. länglich, seicht gelappt u. gekerbt, Blkr. $13 \mathrm{~mm}$ l. - Wiesen, Feldränder in Mh. u. Noe.; zerstreut. 4. 5. 6. S. austriaca Jequ.

St. $0.6-1 \cdot 6 m \mathrm{l}$., beblättert, nebst Blstielen, Kelchen u. Blkr. klebrig u. zottig; Bl. herzeiförm., zugespitzt, grob gesägt. - Waldränder, Gebüsche, Holzschläge, besond. auf Kalk; zerstreut. 4. 7-9.

\section{S. glutinosa L.}

Anmerk. Nahe verwandt mit Salvia sind Rosmarinus u. Monarda, deren Blt. auch nur 2 Stbg. enthalten. In Gärten der südl. Kronländer häufig cult.: der gemeine Rosmarin, R. officinalis L., immergrüner Str. aus Südeuropa und M on arda di d yma L., Zierpfl. aus Nordamerika mit gr. purpurrothen Blumen und rothen Deckbl. (in K. in Gemüsegärten verwildert).

\section{Oríganum L. Dost (XIV, 1).}

St. aufrecht, rispig ästig; Bl. gestielt, ganzrandig, Bltähren oder Köpfchen mit 4 zeiligen Deckbl., rispig.

1. Blkr. rosenroth, selten weiß, Deckbl. purpurn; St. $30-60 \mathrm{~cm}$ h., Bl. eifürmig od. eilänglich, grün, behaart. - Sonnige bebuschte Hügrel. 4. $6-8$.

O. vulgare L.

2. Blkr. weiß, Deckbl. grün, Bl. elliptisch. Graufilzig, höchst aromatisch. - Gewürzpf. a. d. Orient. $\odot$ 6. 7. M ajor a n, O. majorana L.

\section{Thymus L. Thymian (XIV, 1).}

Bl. kl., ganzrandig, drüsig punktiert, wie auch Kelch u. Blkr.; Bltquirle meist kopf- od, ährenförmig gehäuft. Aromatische, meist rasenbildende, dünnstenglige Halbsträucher.

1. St. anfrecht, selır ästig, bis $30 \mathrm{~cm}$ h.; Bl. am Rande umgerollt, lineal od. länglich; Blkr. weiß. Grauflaumig. - Küchengewürzp日. aus Südeuropa. $5.5-7$

Th. vulgaris $\mathrm{L}$.

St. liegend, mit bis $30 \mathrm{~cm}$ l., aufsteigenden $\ddot{\text { Asten }}$; Bl. Hach, Blkr. purpurn, selten weiß. (Th. Serpyllum L.) h.

2. St. u. Äste rundlich, ringsum gleichmäßig behaart, (flaumig, filzig, zottig).

St. u. Äste, 4 kantig (wenigstens obenhin) 3.

3. Bl. sehr schmal u. kl., lineal-keilig, kahl oder gewimpert; Blkr. kl, hellroth. Dicht rasig. - Sandfuren, zerstr. 6. 7. Th. angustifolius $\mathrm{P}$.

Bl. lineal-lanzettlich bis kreisrund, mehr weniger deutl. gestielt. 4.

4. Bl. lineal-lanzettlich bis br. lanzettförm., stumpf, wie die ganze Pf. dicht grauzottig, seltener fast kahl; Blkr. gr., lila, rosa, selten weiß. - Sonnige grasige Hügel, besond. auf Kalk. zerstreut. 5-7. Th. Marschallianus W. 
Bl. eiförmig bis kreisrund, deutlich gestielt, gewimpert, sonst kahl; Blkr. gr., rosenioth. St. umherkriechend, kaum rasig. - Wie vorige. $5-7$. Th. humifúsus Brhd.

5. (2). Bl. eifürmig, gestielt am Grunde gervimpert; St. an 2 seltener allen Kanten behaart, sonst kahl ; Blkr. kl. purpurn (selten roth od. weislich.) Trockene Wiesen, Hügel, Raine. 8-10.

Th. Chamáedrys Fries.

Bl. eitörmig bis rundlich, kahl, St. purpurn an allen Kanten behaart, sonst kahl; Blkr. gr. dunkel-purpurn. - Gerölle der Alpen. in den Sıdeten u. d Riesengebirge. 7. 8.

Th. alpestris Tseb.

\section{Saturéja L. Pfefferkrant (XIV, 1).}

St. $15-30 \mathrm{~cm}$ h., aufrecht, sehr ästig, Bl. schmal lanzettlich, Blkr. lila od. weiß. - Küchengewürzpt, aus Südeuropa. ๑. 7-10.

S. hortensis L.

\section{Calamintha Tourn. Bergthymian (XIV, 1).}

Bl. gestielt, lebhaft grün; Blkr. langröhrig mit aufgeblasenem Schlunde. Behaarte Kr.

1. Bltquirle aus 6 gestielten Blt. bestehend; St. $7-15 \mathrm{~cm} .1 .2$.

Gestielte gabeltheilige, vielbltige Trugdolden, St. $15-45 \mathrm{~cm} \mathrm{~h}$. ästig; Bl. eiförmig, am Grunde ganzrandig, soust grob gesägt oder gekerbt.

2. St. aufrecht od. aufsteigend, meist einfach; BI. länglich-lanzettförm., Blkr. 6-S $\mathrm{mm}$ l., hellviolett. - Stcinbriiche, Felsen, Sandäcker. $\odot 6-8$. C. Ácinos Clairv.

St. liegend, ïstig; Bl. elliptisch bis lanzettförm., Blkr. 12-20 $\mathrm{mm}$ 1., hell- bis purpurviolett. - Gerölle u. Felsen der Alpen. 4. 5-9.

C. alpina Lamk.

3. Blkr. 10-18 mm 1, rosenroth od. lilapurpurn; Bl. stumpf. Waldränder, buschige Abhänge in 0e., St., K.; zerstreut. 4. 7-9. C. officinalis Mnch.

Blkr. 25-30 $m m$ h., rosenroth; Bl. spitz. - Felsige, bebuschte Ablänge in St., K., Kr., T.; zerstreut. 4. 7. 8. C. grandiflóra Mnch.

\section{Clinopódium L. Wirbelborste (XIV. 1).}

St. einfach od. ästig. $30-45 \mathrm{~cm}$ h., Bl. eiförmig od. länglich, stumpf, gekerbt; Blkr. hellroth oder weiß. Weichzottig. - Gebüsche. 4. 6-8. C. vulgare $\mathrm{L}$.

\section{Melissa L. Melisse (XIV, 1).}

St. 30-60 $\mathrm{cm}$ h., ästig; Bl. eiförmig od. oval-länglich, grob gesägt; Blt. weiß, einseitswendig. Citronenduftend. - Gewürzpll. aus Südeuropa. 4. 7. 8 . $M$. officinalis $\mathrm{L}$.

\section{Hórmiunm L. Dracheumaul (XIV, 1).}

St. einfach, 8-12 cm h., Bl. eiförmig-rundlich, grob gezähnt, in d. Deckbl. übergehend; Blkr. his $15 \mathrm{~mm} \mathrm{l}$, violett. Kahl. - Kallgeb. in K., Kr., südl. T.; zerstreut. 4. 7. 8 .

H. pyreníicum L. 
338. Hyssópus L. Ysop (XIV, 1).

Hlbstr. mit ruthenförm, bis $30 \mathrm{~cm}$ 1. Zweigen; Bl. lineal, spitr, ganzrand.; Blkr. azurblau oder violett, selt. weiß. - Gewürz- u. Zierp̧?. aus Süleuropa, in den sïdl. Alpenländ. verwildert. Ђ. 7. S.

H. officinalis $\mathrm{L}$.

\section{Yépeta L. Katzenmiuze (XIV, 1).}

St. aufrecht, ästig, $0.45-1 m$ h.; Blt. gestielt, grob gesägt od. gekerbt; Blkr. langröhrig.

1. Blt. in dicbten, eine unterbrochene Traube bildenden Quirlen, Blkr. gelblichweiß; Bl. herzeiförmig. Citronenduftend. - Wüste Plätze, an Mauern; zerstreut. 4. 7. 8.

N. Catária L.

Blt. in Trugdolden, Blkr. lila od. weiß: Bl. herzförnig-länglicb. Stinkend. - Waldränder, Raine in B., Mh., Noe., St., K., T.; zezstreut. 4. 7. 8.

N. nuda L.

Variet. pannonica (Jequ.), St. u. Kelche amethystblau, Blkr. violett. Hier und da.

\section{Glechóma L. Gundermann (XIV, 1).}

St. kriechend, wurzelnd, ästig'; Bl. gestielt herz- oder nierenförmig, grob gekerbt; Blkr. hellblau od. lila. Ausläufer treibend. - Unter Hecken u. Gebüschen, auch Unkraut. 7. 4-6.

G. hederácea L.

\section{Dracocéphalum L. Drachenkopf (XIV, 1).}

St. aufrecht od. aufsteigend, $30-60 \mathrm{~cm}$ h., Bl. u. Deckbl. fiederschnittig, Blkr. bis $38 \mathrm{~mm}$ l., dunkelblau; Bltquirle in unterbrochener Traube. - An Kalkfelsen in B. u. Noe.; stellenweis, auch Zierp9. 4. 6. 7 .

D. austriacum L.

\section{Melittis L. Immenblatt (XIV, 1).}

St. einfach $30-45 \mathrm{~cm}$ h., Bl. gestielt, herz- od. eiförm.-]änglich, grobgesägt; Blt. zu 1-3 blwinkelständ., Blkr. 25-37 mm l., weiß od. rosenroth, purpurn gefleckt. Rauhhaarig. - Gebüsche, Laubwïlder auf Kalk; zerstreut. 4. 5. 6. M. Melissophýllum L.

\section{Lámium L. Taubuessel (XIV, 1).}

St. aufrecht od. aufsteigend, Bl. gestielt; armbltige Quirle blwinkelständig. Rauhhaarige $\mathrm{Kr}$. genähert.

1. Wrzst. kriechend, Ausl. treibend; St. $30-60 \mathrm{~cm}$ h., obere Quirle

Einjährige Arten; Blkrröhre stets gerade.

2. Blkr. bis $37 \mathrm{~mm}$ l., purpurroth mit gerader Röhre; Bl. gr., breit ei- od. herzeiförm., grob gesägt. - Gebüsche, Waldränder in St., K., Kr., T.; zerstreut. 7. 5. 6.

Blkr. bis $25 \mathrm{~mm}$ l., mit gekrünmter, höckriger Röhre. L. Órvala L.

3. Blkr. hellpurpurn, mit weißl., dunkelroth gefleckter Unterlippe, selten blassrosa; Bl. herzeiförm., eingesthnitten gesägt, bisweil. weiss gefleckt. - Hecken, Gebüsche, Ufer. 4. 4-9.

L. maculatum L.

Blkr. weiß, zottig; Bl. herzeiförm. od. länglich, spitz, grobgesägt. - Grasplätze, Heckeı, Mauern. 4. 4-7.

L. album $\mathrm{L}$. 
4. (1). Bl. grob gekerth, berzeit. alle gestiels; Si. uap untec tri

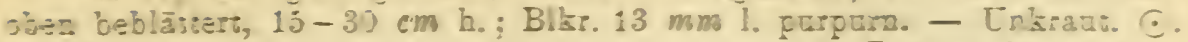
$1-12$.

L. purcureum L.

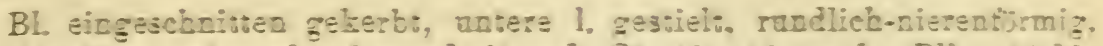

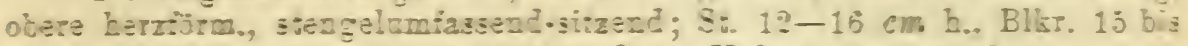

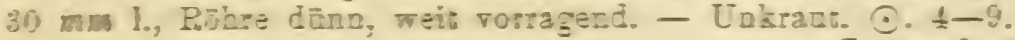

L. amplexicaule L.

Tariet. clandestincm |Rebb. Blkr. terkummert, küzer als d. Releh.

\section{4\%. Galeóbdolon Hads. Goldnessel IIT, 1).}

Wrzs: kniachend, 1tsl. treibesd: S: eicfach, $15-30 \mathrm{~cm} \mathrm{l.;} \mathrm{Bl.} \mathrm{ge-}$

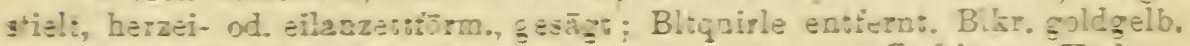

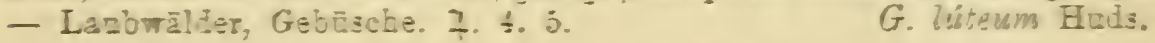

\section{$3 \div$. Galeópsis L. Hohlzaho $\mid \mathrm{I} T, i$.}

Si. mais āstig, Bl. gestielt, Quirle od. za 1-2 suetredde Bl. blwin. kelatäzdiz. Behaarte Kr.

1. S. tater dem Knoten nicht rerdiek:

S. ruter dem Kroten rerdickt, meisi steiftuarig. $0 \cdot 15-1 \mathrm{mb}$. 3.

2. Blkr. gelblichweib, $25-33 m$ 1. coi: 1 decrer Rühre: St. 15 bis $30 \mathrm{~cm}$ b., Bl. laczertlich od. länglich-lanzetturm, cekerbi-gesägt. Sei-

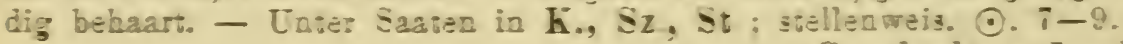

G. ochrclencer Lamk.

Blat purpure, selien weid, $12-20 \mathrm{~mm}$ l. mit kurzer od. I. R-hre; S: $10-50 \mathrm{~cm}$ h., Vielgestaltig, behaar oc, kabl. - daf Saatfelderc, Sacdboden. (. :-10.

G. Lálanum L.

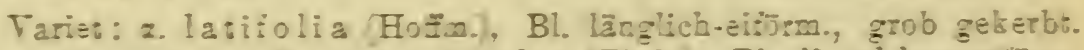
Gencein: - G. angesuifolia Etrh. Bl. lineal-lanzettitm. oł. lineal, extern: gezdus: od. ganzrandig. def Kalkbodea.

3. Blkr. hellpurparn mit gelber Pajhre a. goldgelbem Fleck ath d. Unterlippe, 18-oj mm l.; Bl. eitormig, zugespitzt, weichbarig. -

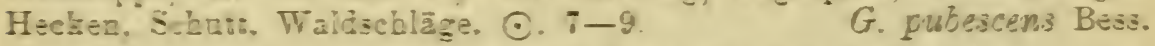

Blkr. weib ojer gelb, ben:yescheckt, od. einfäbig gelb. 4.

4. Bl's?. 25-3.5 $m=1$., hellgelb mit gollgelben Lippec a. riolettem Mittellappen d. Unterlippe; Bl. eifurmig-läglich bis lanzetturm.. gesazt; Quirle genāhert (G. versicolor Curt). - Felsige Plātze, Gerolle. Bachufer in Gebirgsgegend, ๑. T-10.

$G$. speciosa Mill.

Bikr. $3-20$ mm 1., gelblichweib, weiß od. blasslila. Unterlippe gol\}.

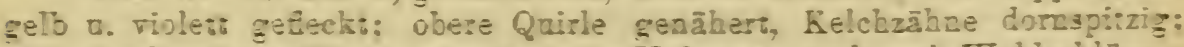

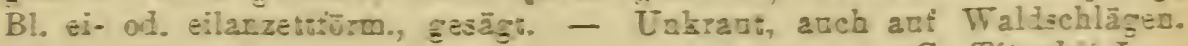
C. $\mathrm{i}-10$.

G. Tétrahit L.

Variet: bifida (Bijongh.), Bls. kl., Mittallappen d. Linterlippe 2 apaliz. Anf Saaten in $\mathbf{M h . ,}$ Oe., K., T.; stellenwe:

\section{4ว. Staehrs L. Ziest $\mid \mathrm{XIT}, 1)$.}

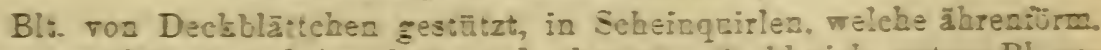
zusammengedräng: sind (wenigrtens d. oberen. Si. bl:eich, nntere B!. gsstills. Bebarte $\mathrm{K}$. 
1. Blkr. gelblichweiß.

Blkr. purpurn.

2. Ähren lang, Quirle 6-12 blt., unterste von d. Ähre weit entfernt; St. $30-60 \mathrm{~cm}$ h., straff, ästig; Bl. länglich-lanzettförm., gekerbt. - Bebuschte folsige Hügel $u$. Lehnen. 4. 6-8.

St. recta L.

Ähre kurz, Quirle $2-5$ bltig.; St. $15-30 \mathrm{~cm}$ h., Bl. lanzettlich, ge. sägt-gekertt. - Äcker, Brıchen, Triften; zerstreut:○.5-9. St. ánnua L.

3. Quirle 30-40bltig, Deckblättchen d. Blt. lineal-lanzettlich, von d. Länge d. Kelche.

Quirle 5-12 bltig, Deckbl. fädlich, viel kürzer als d. Kelche; St. 0.30-1 $m$ h.; Unterlippe d. Bllir. mit weißer Zeichnung.

4. Ganze Pfl. seidenglünzend, zottig-behaart, silbergrau; St. 0.30 bis $1 m$ h., Bl. elliptisch od. länglich, gekerbt. - Steinige Plätze, Gebüsche; zerstreut. 4. 7. 8.

St. germanica L.

Oberer Th. des bis $1 \mathrm{~m}$ h. St. sammt d. Kelchen klebrig-drüsenhaarig; Bl. herzeifürm., gekerbt-gesägt. Rauhhaarig. - Waldränder, Holzschlaige in Gebirgen; zerstreut. 4. 7. 8.

St. alpina L.

5. Quinläluren gegen die Spitze sehr gedrungen, Blkr. hellroth; St. drüsenlos, BI. cifürmig od. länglich, gesägt. - Feuclıte Äcker, Ufer. 4. 7. 8 .

Quirlïbren unterbrochen, Blkr. dunkelroth, St. nach oben sammt den Kelchen drüsig-klebrig; $\mathrm{Bl}$. br. herzeiförmig, gesägt. - Wïlder, Hecken, Gräben. 4. 6-8.

St. silvática L.

\section{Betónica L. (XIV, 1).}

Blt. von kl. Deckblättchen gestuitzt, Röhre d. Blkr. weit vorragend; St. 15-60 $\mathrm{cm}$ h., einfach, mit wenigen Blpaaren; Grundbl. 1. gestielt, alle Bl. grob gekerbt. Rauhhaarig.

1. Blkr. gelblichweiß, Quirle eine kopfige Ähre bildend, St. mit nur $1 \mathrm{Blpaare,} \mathrm{Bl}$. Lerzeiförmig. - Gerölle u. Triften d. Kalkalpen, bis $1600 \mathrm{~m}$. 4. 7. 8. (B. Alopecúrus Jaequ., Neilr. u. A., nicht L.) B. Jacquini Gren. Godr.

Blt. purpurn, Bl. herzförmig-länglich.

2. Kelch netzadrig, $10-12 \mathrm{~mm}$ l., Quirle in dichter walziger Ähre; St. nur unter d. Ähre mit 1-2 Blpaaren, sonst nackt. Sehr rauhhaarig. Bergwiesen in K., Ǩr., T. 4. 7. 8.

B. hirsula $\mathbf{L}$.

Kelch nicht netzadrig, 4-6 $\mathrm{mm}$ I., Quirle in dichter od. unterbroch. Ähre, St. mit 2-3 Blpaaren. Behaart, selten kahl. - Waldwiesen, buschige Hüigel. 2. 7. 8.

$B$. officinalis $\mathrm{L}$.

\section{Ballóta L. (XIV, 1).}

St. $0.6-1.3 \mathrm{~m}$ h., ästig; Bl. gestielt, herzeifürmig, grob gekerbt; Bl. in gestielten blwinkelständigen dichten Trugdolden, Kelchzipfel abstehend, begrannt, netzadrig, Blkr. purpurn. Behaart, stinkend. - Hecken, Mauern, Schitt. 2. 6-9. B. nigra $\mathrm{L}$.

\section{Phlomis L. Filzblume (XIV, 1).}

St. $0.6-1.6 m$ h., ästig; Bl. gestielt, untere 3 eckig.herzförmig, grob gekurbt, obere herzformig-länglich, tief gesägt; Blt. gr. purpurn, in dichten entfernten Quirlen. Behaart. - Steinige, buschige Plätze in Mh.u. Noe.; zerstreut. 2. 6. 7. 


\section{Leonúrus L. Löwenschwanz (XIV, 1).}

St. $0 \cdot 6-1.6 m$ h., straff, ästig; Bl. gestielt, untere handförm. 5 theil., grobgesägt, obere 3 theilig, ganzrandig; Blt. kl. in dichten entfernten Quirlen; Rlkr. hellroth, zottig. - Schutt, an Mauern, Zäunen. 4. 6-8. Herzgespann, L. Cardiaca L.

\section{Chaitúrus Willd. Katzenschwanz (XIV, 1).}

St. 0.6-1 $m$ b., straff, ästig; Bi. gestielt, grob gesägt, unterseits druisig-filzig, untere rundlich-eiförmig, obere lanzettförmigr; Blt. kl. weiß od röthlich. - Schntt; sehr zerstreut. ๑. 7. 8. Ch. Marrubiastrum Rchb.

\section{Marrúbium L. Andorn (XIV, 1).}

St. 30-60 cm h, ästig: Bl. gestielt, gelierbt, Blt. in dichten achsel. ständigen entfernten Quirlen. Grau- od. weiffilzige Kr.

1. Kelchzähne 5, gerade, Bl. länglich-ei- bis lanzettförmig. - Wüste Plätze, an Wegen in u. um Dörfern im östl. B., Mll., Noe.; zerstreut. 4. 7. 8 .

M. peregrinum L.

2. Kelchzähne 10, abwechselnd kleiner, hakig; Bl, herzförm.-rundlich. - Wie vorige, ab. im ganzen Gebiet; hänfig. 4.7-9. M. vulgare L.

\section{Siderítis L. Gliedkraut (XIV, 1).}

St. 15-30 cm h., meist einfach; Bl. länglich-lanzettförm., gesägt od. ganzrandig, Quirle 6 bltig, blwinkelständig: Blkr. kürzer als d. aufgeblas. Kelch. Wollharig, stinkend. - Hügel, Weinberge, auf Kalk in B. (selten!), Mh., 0e. $\odot .7 .8$.

S. montana L.

\section{Scutellảria L. Helmkraut (XIV, 1).}

St. ästig, Bl. kurz gestielt, Blt. einzeln blwinkelständig, einseitswend., hellviolett od. blau. Kahle Kr. mit kriechendem Wzst.

1. Bl. aus herzförmigem Grunde lanzettlich od. länglich, entfernt gekerbt; Keleh flaumig od. kahl, drüsenlos; St. $25-75 \mathrm{~cm} \mathrm{~h}$. Ufer, Sümpfe. 4. 7. 8.

Sc. galericuláta $\mathbf{L}$.

2. Bl. am Grunde gestützt, fast spießförmig, ganzrandig; Kelch drüsig, weichharig; St. 10-30 cm h. - An gleichen Orten, selten. 4. 7. 8 .

Sc. hastifolia L.

\section{Prunella L. Braunelle (XIV, 1).}

Quirle von br. eiförmigen zugespitzten ganzrandigen Deckbl. gestützt, in eine endständige Ähre zusammengedrängt; St. einfach od. ästig, Bl. gestielt, Wrst. kriecliend.

1. Blkr. gelblichweiß, Stbl. fiedertheilig, Grundbl. ganz; St. 15 bis $30 \mathrm{~cm} \mathrm{h.} \mathrm{-} \mathrm{Steinige} \mathrm{Triften,} \mathrm{Hügel,} \mathrm{besonders} \mathrm{auf} \mathrm{Kalk:} \mathrm{zerstreut.} 2$. 7-9. (P. alba Pall.) P. laciniata $\mathrm{L}$.

Blkr. violett, selten weiß, Bl. ganz (länglich-eiförmig), sehr selten fiederspaltig.

2. Blkr. 6-12 $\mathrm{mm}$ 1., St. bis dicht ax d. Ähre beblättert, $15-45 \mathrm{~cm}$ hoch, - Wiesen, Grasplätze, Raine. 4. 7-9.

$P$. vulgaris $\mathrm{L}$.

Blkr. 18-25 mm 1., St. unter d. Ähre nackt, 10-35 cm h. - Wie rorige, aber nur auf Kalk. 4. 7-9.

$P$. grandiflóra Jequ. 


\section{6. Ájuga L. Günsel (XIV, 1).}

St. einfach, aufrecht. Kräuter.

1. Blt. einzeln, blwinkelständig, Blkr. gelb; St. 5-15 cm 1., reichblättrig, Bl. 3 theilig. Zottig behaart. - Äcker, Hügel mit Kalk- od. Thonboden in B., Mh., Oe.; zerstreut. $\odot$. A. Chamaépitys Schreb.

Blt. zu 6-12 in Quirlen, diese von ganzrandigen grünen od. blauer Deckbl. gestïtzt. in endständ. Ähre; Blkr. blau, selten rosa, roth, weiß; Bl. ganzrandiø od. gekerbt, untere gestielt, die übrigen sitzend. 2.

2. Wzst. kriechende beblätterte Ausl. treibend; St. 7-30 cm h., Bl. verkehrt-ei- bis lanzettförmig. Kahl. - Wiesen, Grasplätze. 4. 4-6. $A$. reptans $\mathrm{L}$.

Wzst. ohne Ausl., obere Bl. in d. Deckbl. übergehend. Zottig behaart.

3. Obere Deckbl. ganz, kürzer od. so l. wie d. Blt., untere 3 spaltig; Stbl. lanzettförmig od. länglich, grob gezähnt, St. $15-30 \mathrm{~cm}$ h. - Sonnige, steinige Hügel. 4. 5. 6.

A. genevensis L.

Alle Deckbl. ganz, länger als d. Blt, eine 4 seitige Pyramide bildend; Stbl. oval od. elliptisch: St. 5-25 $\mathrm{cm}$ h. - Triften d. Voralpen v. Oe., Sz., St., K., auch in B. (Erzgeb., Böhmerwald). 4. 5. 6.

\section{A. pyramidalis $\mathbf{L}$.}

\section{Téucrium L. Gamander (XIV, 1).}

St. ästig. Kräuter od. Halbsträucher.

1. Bl. einzeln in d. Achseln kl. ovaler Deckbl., in langen einseitswendigen Ähren, gelblich od. grïnlichweiß, Kelch 2 lippig; St. 30-60 cm hoch, Bl. gestielt, herzeiförmig od. länglich. Weichhaarig. - Waldränder, steinige Plätze in Ooe.; zerstreut. 4. 7. 8.

T. Scorodónia L.

Blt. zu 2-6 in Quirlen, Kelch 5 zähnig.

2. Bl. ganzrandig, umgerollt, lineal-lanzettförm., oberseits glänzend. grün: Quirle in endständ. Köpfchen, Blkr. gelblíchweiß; St. 5-25 cm l., liegend od. aufsteigend. - Gerölle, Felsen, auf Kalk in d. Alpenländern, auch in IIh. Ђ. $6-8$.

T. montanum $\mathrm{L}$.

Bl. zertheilt od. tief gekerbt od. gesägt; Blkr. purpurn, selten weiß. 3 .

3. Stbl. handförmig fiedertheilig, st. $7-30 \mathrm{~cm}$ h., drüsig-flaumhaarig, klebrig. - Ärker, steinige Plätze, besonders auf Kalk; zerstreut. $\odot$. 7. 8. T. Botrys L.

Alle Bl. länglich, gekerbt od. gesägt. 4.

4. St. liegend od. aufsteigend, rauhhaarig, $7-15 \mathrm{~cm} \mathrm{l}$; $\mathrm{Bl}$. kahl oder zerstreut behaart, kurz gestielt; Blt. mit meist purpurnem, seltener griinem Kelch, traubig gelı̈̈uft. - Steinige Hügel und Abhänge, besonders auf Kalk und Lehm. 万. 7-9. T. Chamaedrys L.

St. aufrecht, 15-4う $\mathrm{cm}$ h., zottig; Bl. kahl, sitzend, Blt. zu 1-2, blwinkelständig, kl., Kelch grïn. Wzst. Ausl. treibend. - Sümpfe, nasse Wiesen, Gräben in B., Ml.., Noe., St., K.; zerstreut. 4. 7. 8. 
Fain. LXII. Verbenáceae. Eisenkrautartige.

358. Verbéna L. Eisenkraut (XIV, 2).

St. 4 kantig, ästig, $30-60 \mathrm{~cm} \mathrm{h.;} \mathrm{Bl.} \mathrm{kreuzweis} \mathrm{gegenständ.,} 3$ theil. od. fiederlappig; Blt. kl., lila, in dünnen l. gestielten rispigen Ähren. Schutt, an Wegen. ๑. 6-9.

V. officinalis $\mathbf{L}$.

\section{Fam. LXIII. Globulaviéae. Kugelblumenartige.}

\section{Globulária L. Kugelblume (IV, 1).}

Immergrïne $\mathbf{K r}$., deren Wzst. Blbüschel od. Blrosetten und einfache St. treibt, die ein kugliges, von einer IIülle umgebenes Köpfchen kl. blauer Blt. tragen.

1. St. bis ans Köpfchen reichlich beblättert, $15-30 \mathrm{~cm} \mathrm{~h} ; \mathrm{BI}$. der Büschel gestielt, spatelförmig, ausgerandet od. 3 zähnig, Stbl. sitzend, lanzettförmig, viel kleiner (G. vulgaris Lamk., nicht L.). - Steinige Hügel u. Lehnen mit Kalkbod, ; sehr zerstreut. 4. 5. 6. G. Willknmmii Nym.

St. mit wenigen kl. Schuppen, Bl. grundstäindig.

2. Wzst. vielköpfig, Blbüschel rasig, Bl. verkehrt-eilanzettförmig od. länglich-keilig, gestielt, 5-15 cm 1., St. kaum länger, Köpfchen $18 \mathrm{~mm}$ breit. - Felsige Plätze d. Kalkalpen (1260-1600 m). 4. 6. 7.

\section{G. nudicaulis L.}

Wzst. kriechende Stämmchen treibend, Bl. kl., spatelförınig, alt tief ausgerandet, gestielt, $12-18 \mathrm{~mm} \mathrm{l}$; St. $5-10 \mathrm{~cm} \mathrm{~h}$, Köpfuhen $8-10 \mathrm{~mm}$ breit. - Ebendaselbst (bis $23(0 \mathrm{~m}$ ). 4. 5.6. G. cordifolia L.

\section{Fam. LXIV. Asperifólice. Scharflirüuter.}

\section{Schliissel der Gattungen.}

1. Blkrschlund offen, inwendig nackt.

2.

Blkrschlund durch dichte Hohlschuppen, Falten, Leisten u. a. mehr weniger verengt od. ganz geschlossen.

2 Nüsschen (Theilfrüchtchen) 2, zweisamig, mit halbkreisförmiger Grundfäche; Stbb. pfeilförmig, am Grunde zusammenhängend

Nüsschen 4, einsamig.

Cerinthe (369).

3. Blkr. glockig- od. trichterig-2 lippig, Stbg. vorstehd. Echium (367).

Blkr. regelmäßig, Stbg. eingeschlossen; Kelı:h röhrig.

4. Blkr. trichterförm., im Schlunde behaart, Kelch 5 eckig.

Pulmonaria (370).

Blkr. walzig-glockig, im Schlunde kahl, Kelch rund. Onosma (368).

5. (1) Gr. sehr kurz, Blkrschlund mit 5 Längsfalten, Fr. steinfruchtartig, zuletzt in $2-4$ Stücke spaltend.

Heliotropium (37ỏ).

Gr. lang, Nüsschen vom Anfange an getrennt, 4 (selten durch Fehlschlagen weniger).

6. Nüsschen mit dem Rücken an d. bleibenden Gr. angewachsen. 7.

Nüsschen an d. flachen Frboden angewachsen, Gr, frei; Blkrschlund durch 5 gewölbte Schuppen geschlossen, 
7. Kelch nach dem Blühen sich sehr vergrößernd, dann zusammengedrückt u. aus 2 buchtig gezähnten Klappen bestehend. Asperugo (360).

Kelch nach dem Blühen sich nicht anders gestaltend. 8 .

8. Nüsschen weichstachlig.

Nüsschen rundlich, glatt, mit einwärts gebogenem Rande (genabelt). Omphalodes (363).

9. Nüsschen platt, eiförmig od. oval, über und über weichstachlig.

Nüsschen pyramidal-3kantig, am Rande weichstachlig. Cynoglossum (361). Echinospermum (362).

10. (6) Nüsschen am Grunde nicht ausgehöhlt u. ohne Ringwulst. 11. Nüsschen am Grunde ausgelıöhlt und hier von einem Ringwulst um gelien.

13.

11. Schlund der kurzröhrigen tellerförmigen Blkr. durch kl. gelbe, einen erhabenen Ring bildende Schüppchen verengt.

12.

Schlund der trichterförmigen Blkr. durch 5 behaarte Leisten verengt. Lithosper'mum (366).

12. Nüsschen glatt, an d. Seitenrändern gekielt, ohne Hautsaum. Myosotis (364).

Nüsschen glatt, mit vorspringendem Hautsaum am Grunde. Eritrichium (365).

13. Blkr. langröhrig, Schlund durch 5 Schuppen geschlossen oder verengt. 14.

Blkr. radförmig, Stbfäden mit einem länglichen steifen Anhängsel versehen und kegelförmig zusammengeneigten Beuteln, mit d. 5 aufrechten Schlundschuppen eirien schnabel bildend.

Borago (375).

14. Schlundschuppen rundlich, behaart, Blkr. trichterförmig. 15.

Schlundschuppen lanzettlich, spitz, drüsig gezähnt, Blkr. walzigglockenförmig.

Symphytum (37t).

15. Kelch nach d. Blïhen sehr vergrößert, blasig, Schlundschupp. kl. Nomnea (371).

Kelch nach d. Blühen nicht od. wenig vergröß., nie blasig; Schlundschuppen gr., einen 5 lappigen, d. Schlund schließend. Stern bildend. 16.

16. Blkrröhre gerade.

Blkrröhre gekrümmt, unter d. Mitte eingeschnürt. Lycopsis (373).

Anchusa (372).

\section{Asperigo L. Scharfkraut $(\mathrm{V}, 1)$.}

St. liegend, ästig, 15-60 cm l.; Bl. länglich-keilförmig, ganzrandig od: gezähnt; Blt. kl., blwinkelständig, blau; Stgkanten u. Binerven von rückwärts gerichteteten Stacbelchen raub. - Schutt, an Wegen, Mauern; zerstreut. $\odot .4-6$.

A. procumbens $\mathrm{L}$.

\section{Cynoglóssum L. Hundszunge $(V, 1)$.}

Blt. in rispig gruppierten bllosen einseitswendigen Wickeltrauben, Blkr. trichterförmig; Bl. länglich od. lanzettförm., ganzrandig, spitz, untere gestielt; St. aufrecht, $0 \cdot 30-1 \mathrm{~m}$ h.

1. Frkelch aufrecht, Blkr. schmutzig-blutroth. Weich-graufilzig, widerlich riech, - Schutt, steinige Triften. $\odot$. 5-7. $\quad C$. officinale L. 
2. Frkelch sternförmig ausgebreitet, Blkr, schmutzig-purpurviolett. Zerstreut behaart, grün, Bloberseite glänzend. - Holzschläge d. Voralpen von Noe.; zerstreut. $\odot$. 6. 7. C. germanicum Jequ.

\section{Echinospérmum Sw. Igelsame $(V, 1)$.}

Blt. in rispigen deckblättrigen Wickeltrauben, Blkr. trichterförmig, kl., himmelblau; Bl. lanzettlich od. lineal-lanzettförm., ganzrandig; St. 15 bis $30 \mathrm{~cm} \mathrm{~h}$.

1. Frstiele aufrecht. Steifhaarig. - Auf Sandboden, Schutt, trockenen Hügeln; zerstreut. $\odot .5-8$. E. Iáppula Lehm.

2. Frstiele herabgebogen. Weichhaarig. - Steinige Plätze, Holzschläge in Bergwäldern in B., Mh., $\mathbf{0}$., $\mathbf{K}$.; sehr zerstreut. ค. 5. 6. E. deflexum Lehm.

\section{Omphalodes Tonrn. Nabelnuss $(V, 1)$.}

Blt. in Wickeltrauben, Blkr. rad-trichterförmig, azurblau; Bl. ganzrandig, untere gestielt, St. gabeltheilig-ästig. Spärlich behaart, grün.

1. Wickeltrauben beblättert, sehr locker, Blkr. 4-6 $\mathrm{mm}$ breit mit gelben Schlundschuppen; St. liegend od. anfsteigend, $8-30 \mathrm{~cm}$ l., untere Bl. spatel-, Stbl. lanzettförmig. - Laubwälder, Gebüsche anf feuchtem Boden; zerstreut. $\odot$. 4. 5 .

O. scorpioides Lehm.

2. Wickeltraub. nackt, Blt. genähert, Blkr. 12-16 $\mathrm{mm}$ br., mit weiß. Schlundschuppen; St. aufrecht, 15-.20 cm h., untere Bl. ei- od. herz-, obere lanzettförmig. - Schattige Bergwälder in Kr., südl. St. und T.; sonst ZierpA. 4. 4. 5.

Gedenkemein, O. verna Mnch.

\section{Myos 6 tis L. Vergissmeinnicht $(\mathrm{V}, 1)$.}

Blt. in einfachen od. gabeltheiligen, meist nackten Wickeltrauben, Blkr. trichter-tellerförmig, Saum blau mit gelbem Schlund; Bl. ganzrand., unterste gestielt, St. ästig. Behaarte Kr.

1. Blt. kl., himmelblau, selır entfernt, d. unteren gabelständig, die oheren $(2-4)$ am Ende d. St. u. d. Äste in bllosen Wickeln; St. 8-30 cm hoch, untere Bl. spatel-, obere lanzettförmig. - Feuchte Laubwälder und Gebüsche; zerstreut. $\odot$. 5. 6 .

M. sparsiflóra Mik.

Blt. in reichbltigen nackten od. nur am Grunde beblättert. Wickeltrauben, die sich in l., meist : reihige Frtrauben ausdehnen. 2.

2. Kelch 5 zähnig, angedrückt behaart; Wzst. kriechend. 3.

Kelch 5 theilig, abstehd. behaart (untere Haare hakig gekuümmt). 4.

3. St. kantig, $15-45 \mathrm{~cm}$ h.; Bl. länglich bis lintal; Wickel nackt, Kelchzähne eiförmig, Blkr. 4-7 $\mathrm{mm}$ br., himmelblau (anfangs meist rosenroth). Spärlich und absteliend behaart. - Nasse Wiesen, Ufer, Gräben. 4. $5-9$.

Gemeines V., $M$. palustris $\mathrm{L}$.

St. rund, Kelchzähne länglich, Wickel unten meist beblättert., Blkr. kleiner, sonst wie vor. - Gräben, Ufer, Sumpfwiesen; zerstreut. 4. 5-9. M. caespitosa F. Schultz.

4. Wickeltrauben nackt, PA. abstehend behaart.

5.

Wickeltraub. unten beblätt., üb. d. Stengelgrunde beginnend; Blt. sehr zahlreich, Kelch kegelförm., später geschlossen, Blkr. kl., himmelblau; St. 8-30 cm 1., sammt d. Bl. zerstreut behaart. - Auf Sandboden (̈̈cker, Hügel). $\odot .4-6$. M. stricta Lk. 
5. Blkrsaum flach, 6-10 $\mathrm{mm}$ br., anfangs röthlich, dann himmel- bis azurblau; Grundbl. spatel-, Stbl. länglich-lanzettförm. od. lineal. $\quad 6$.

Blkrsaum concav, $3-4 \mathrm{~mm}$ br. 7.

6. Dicht weichhaarig, St. $15-50 \mathrm{~cm}$ h., Trauben schlaff, Blt. geruchlos, bisweileu weiß. - Waldwiesen u. Holzschläge, auch Zierpf. 4. 5. 6. W ald - V., $M$. silvática Hoffm.

Steif- u. grauharig, St. steif aufrecht, $5-15 \mathrm{~cm}$ h., Stbl. schmal li-neal; Trauben lockerbltg., Blt. schwach wohlriechend. - Triften u. Gerölle d. südl. Alpen $(1260$ bis $2000 \mathrm{~m})$, auch in B. 4. 6-9.

M. suavéolens W. Kit.

7. Blkröhre länger als d. Kelch, Saum erst gelb, dann himmelblau, Frkelch geschlossen, Blt.- u. Frstiele aufrecht-abstehend; St. $8-25 \mathrm{~cm}$ h., Bl. länglich. - Auf Sandboden; zerstreut. ○. 5. 6. M. versícolor Pers.

Blkröhre kürzer als d. Kelch, Saum voın Anfange an himmelblau, Frstiele wagerecht.

8. Frkelch geschlossen, Frstiele doppelt so 1. als a. Kelch; St. 15 bis $45 \mathrm{~cm}$ h., Bl. länglich-lanzettförmig. - Sandige Äcker. ค. 6-8. (M. intermedia Lk.)

MI. arvensis $\mathrm{L}$.

Frkelch offen, Frstiele so 1. als d. Kelch od. wenig länger; St. 8 bis $25 \mathrm{~cm}$ h., Bl. länglich. - Sandige Äcker u. Hügel. ๑. 4. 5..

M. hispida Schtdl.

\section{Eritríchium Schrad. Himmelsherold $(V, 1)$.}

St. zahlreich, $1.3-5 \mathrm{~cm}$ h., Blt. in büschelförmigen Wickelähren, Blkr. $6 \mathrm{~mm}$ br., himmelblau; Bl. länglich-lanzettförm. Seidenglänzend-weißzottig, dicht rasig. - Gerölle u. Felsen d. Alpen von St., Ḱ., 'T., Kr. $(2200-2500 \mathrm{~m}$.$) 4. 7. 8$.

E. nanum Schrad.

\section{Lithospermum L. Steinsame $(V, 1)$.}

Blt, einzeln in d. Winkeln d. oberen $\mathrm{Bl}$., l. beblätt. einseitswendige Trauben bildend; St. aufrecht, ästig, Bl. ganzrandig. Scharfhaarige Kr.

1. Blkr. $13 \mathrm{~mm}$ l., erst hellroth, dann azurblau; Nüsschen glatt, wei ; St. $25-45 \mathrm{~cm}$ h., Bl. lanzettförm. - Laubwälder, steinige Hügel auf Kalk in B., Mh., 0e., St.; zerstreut. 4. 5.6. L. purpúreo-coerilleum L.

Blkr. 4-7 mm l.

2. Blkr. gelblichweiß. Nüsschen glatt, glänzend weiß; St. $40-80 \mathrm{~cm}$ hoch, traubig-ästig, reichblättrig; Bl. lanzettförm. - Steinige buschige Orte, besonders auf Kalk; zerstreut. 4. 5-7.

L. officinale $\mathrm{L}$.

Blkr. weiß, selten bläulich, Nüsschen runzlig, bräunlich; St. 15 bis $45 \mathrm{~cm} \mathrm{~h}$, oben ästig. Bl. länglich-verkehrt-eiförmig bis lanzettlich, Wzl. roth, abfärbend. - Äcker. $\odot .4-6$.

$L$. arvense $\mathrm{L}$.

\section{7. Échium L. Natterkopf $(\mathrm{V}, 1)$.}

Blt. in traubig angeordneten einseitswendigen Wickelähren. Stechendborstige $\mathrm{Kr}$.

1. Wickelähren 1., dichtbltig, Blkr. erst rosa, dann blau (selten) oder weiß; St. $0 \cdot 60-1 m$ h. - Brachen, Mauern, steinige Plätze. $\odot .6-9$. E. vulgare $\mathrm{L}$.

Wickelähren kuirz, armbltig, Blkr. blutroth, selten weiß; St. 30 bis $60 \mathrm{~cm}$ h. - Trockene Waldplätze u. Waldwiesen in Hh. u. Noe.; zerstreut. $\odot$. 6. 7 . 


\section{Onósma L. Lotwurz $(\mathbf{V}, \mathbf{1})$.}

Blt. in überhängenden beblätterteu Wickeltrauben; St. aufrecht, Bl. schmutzig-grïn, untere lineal-lanzettlich, gestielt, obere lanzettförmig. Stechendborstige $\mathrm{Kr}$.

1. Neben dem St. ausdauernde Blbüschel, St. $25-50 \mathrm{~cm}$ h., oben buschig-ästig, Blkr. blassgelb; Nüsschen 3 seitig, spitz, am Grunde verschmälert, grünlichgrau. - Auf Sandboden in Ilh. u. Noe.; hier u. da. 4. $5-8$.

O. arenárium W. Kit.

2. Keine Blbüschel neben d. bis $45 \mathrm{~cm}$ h. St., dieser von der Mitte an ästig, purpurbraun; Blkr. erst weiß, dann gelb: Nüsschen geschnäbelt, grau. - Grasige, steinige Orte in $\mathbf{M h . ,}$ Noe., Kr., T.; sehr zerstreut. ๑.) 5. 6 .

O. calycinum Ster.

\section{Cerinthe $\mathbf{L}$. Wachsblume (V, 1).}

Blt. in überhängenden beblätterten Wickeltrauben, Blkr. röhrigglockenförmig. Kahle blaugrüne $\mathrm{Kr}$. mit $30-60 \mathrm{~cm}$ h. oben ästigem St.

1. Blkr. citrongelb, tief a spaltig mit zusammengeneigten Zipfeln; Bl. länglich, alt weiß gefleckt, obere mit herz- od. pfeilförmig. Basis stengelumfassend. - Acker- u. Wegränder, Triften auf Kalk; zerstreut. $\odot .5-7$.

C. minor L.

2. Blkr. blassgelb mit goldgelbem u. 5 zähnigem Saume u. meist purpurn gefleckt am Grunde d. Einschnitte. - Gerölle d. Alpen von T.; zerstreut. 4. 6.

C. alpina Kit.

\section{Pulmonária Tourn. Lungenkraut $(\mathrm{V}, 1)$.}

Blt. in endständigen beblätterten büschligen Wickeltrauben; Blkr. erst roth, dann violett, zuletzt blau. Wzst. $15-30 \mathrm{~cm}$ h., reichblättrige Bltst. und (später) Büschel 1. gestielter Bl. (Sommerbl) treibend. Behaarte $\mathrm{Kr}$.

1. Sommerbl. herz- od. eilanzettfürm., plötzlich in d. Stiel zusammengezogen, oberseits sammt d. St. u. Bltstand borstig rauh.

Sommerbl. ei- od. lanzettförm., allmählich in d. Stiel verschmäl. 3.

2. Sommerbl. herzeiförmig, spitz, weißlich gefleckt, $1 \frac{1}{2}$ mal länger als br.; St. $15-30 \mathrm{~cm}$ h. - Laubwälder, Gobüsche. 4. 3-5.

\section{P. officinalis $\mathrm{L}$.}

Sommerbl. herzförm.-länglich od. herz-eilanzetttörmig, zugespitzt, 2 mal länger als br., sehr l. gestielt, ungefleckt, sonst wie vor. - Ebendaselbst, zerstreut (od. übersehen\%. 4. 3-5. P. obscúra Dumort.

3. Bl. dunkelgrün, ungefleckt.

Bl. mit gr. silberweißen Flecken gezeichnet, lanzettförmig, sammt d. 20-30 cm 1. St. borstig-rauhhaarig. - Gebüsche in St.; auch Zierpfl. 4. 4. 5 .

P. saccharáta Mill.

4. Oberer Sttheil u. Bltenstand rauhborstig, Bl. unterseits striegelhaarig, Sommerbl. länglich-od. lineal-lanzettförmig, 8 mal länger als br.; St. $30 \mathrm{~cm} \mathrm{h.,} \mathrm{Blkr.} \mathrm{azurblau.} \mathrm{-} \mathrm{Laubwälder,} \mathrm{Gebüsche;} \mathrm{zerstreut.} 4$. 4. 5 .

P. angustifolia L.

Oberer Sttheil u. Bltstand drüsenhaarig, klebrig; Bl. oberseits sammtaı tig. weichlıarig, mit Drüsenhaaren vermischt. 
5. Bl. grün, Sommerbl. br. elliptisch-lanzettförm., St. $15-50 \mathrm{~cm}$ h., Blkr. violett, Stbb. schwarzviolett. - Felsige bebuschte Orte in Oe., Sz.; zerstreut. 4. 4. 5 .

P. montana L.

BI. graugrün, Sommerbl., fein zugespitzt, Blkr. kleiner, Stbb. gelblich, sonst wie vor. - An gleichen Orten in Mh., Oe., St., T.; zerstreut. 4. 4.

P. mollissima Kern.

371. Nonnea Med. $(V, 1)$.

St. 15-45 cm h., Bl. länglich, wollig, Blt. in beblätterten Wickeltrauben, Blkr. purpurbraun. Borsten- u. zugleich weich drïsenhaarig. Triften, Hügel, an Wegen auf Kalk in B., Mh., Oe. (-). 5-7.

$$
\text { N. pulla DC. }
$$

\section{Anchúsa L. Ochsenzunge $(V, 1)$.}

St. $0 \cdot 30-1 m$ h., ästig, Bl. lanzettlich, untere gestielt; Blt. in traubig gruppierten deckblättrigen Wickeltrauben, Blkr. azurblau od. violett, selten weiß, Schlundschuppen weiß. Dicht rauhbaarig. - Wiesen, Äcker, Schutt, besond, auf Kalk u. Sand. (-). 5-9.

A. officinalis L.

Variet. leptophylla (R. Sch.), BI. scbmal lanzettlich, schwach gezähnt, Blt. kleiner. In T.

\section{Lycopsis L. Krummhals $(V, 1)$.}

St. 8-60 $\mathrm{cm}$ h., meist ästig, Bl. länglich od. lanzettförmig, Blt. in beblätterten Wickeltrauben, Blkr. kl., himmelblau. Steifborstig. - Äcker. ค.) 6. 7 .

L. arvensis $\mathrm{L}$.

374. Sýmphytum L. Beillwell $(V, 1)$.

Blt. in nackten überhängenden gabeltheiligen Wickeltrauben; St. anfrecht, Bl. ganzrandig, untere in den Stiel verschmälert. Steifhaarige oder borstige $\mathrm{Kr}$.

1. St. ästig, 0.30-1 $m$ h., àn den Ästen geflügelt, Bl. eilanzett-od. lanzettförmig, Stbl. herablaufend; Blkr. purpurn od, gelblichweiß. Wzst. dick, schwarzbraun. - Frische Wiesen an Ufern. 4.5-7. S. officinale L.

2. St. einfach od, oben gabeltheilig, $15-30 \mathrm{~cm} \mathrm{~h}$., ungeflügelt; Bl. eiförm. od. elliptisch, Blkr. blassgelb; Wzst. wagerecht, knotig verdickt, gelblichweiß. -- Laubwälder, Gebüsche, Ufer; zerstreut. 4. 4-6.

\section{S. tuberosum L.}

\section{Borrágo L. Boretsch ( $V, 1)$.}

St 30-60 cm h., ästig, Bl. gr., eiförmig od, elliptisch, wellig; Blt. lang gestielt, nickend, in deckblättrigen, oft trugdoldig gruppiert. Wickeltrauben, Blkr. himmelblau. Stechend-borstig. - Zier- u. Gemüsept. aus Südeuropa, hier und da verwildert. $\odot .6-8$.

Gurkenkraut, $B$. officinalis $\mathrm{L}$.

\section{Heliotrópium L. Sonnenwende $(V, 1)$.}

St. aufrecht od. liegend, $8-30 \mathrm{~cm} \mathrm{l,} \mathrm{Bl.} \mathrm{gestielt,} \mathrm{eiförmig.} \mathrm{Blt.} \mathrm{in}$ nackten Wickelähren, Blkr. kl., weiß od. bläulich. Dünnfilzig. - Äcker, Wegränder, wüste Plätze in Mh., Noe., St., Kr.; zerstreut. $\odot$. 7. 8. H. europaeum L.

A nmerk. Beliebte Zierpt. d. Gärten ist das halbstranchige $H$. peruvianum L. mit vanilleduftenden blauen Blt. ("Vanillestrauch"). 


\section{Fam. LXV. Polemoniáceae. Sperrkrautartige.}

377. Polemónium L. Sperrkraut $(V, 1)$

St. $15-30 \mathrm{~cm}$ h., oben ästig; Bl. unpaarig gefiedert, mit lanzettlich. Blättchen; Blt. in end- $u$. achselständigen rispigen Wickeltrauben; Blkr. blau, selten weiß. Kahl, Bltstände drüsig. - Gem. Zierph., im südlichen $\mathbf{B}$, in K. u. T. anscheinend wild (Laubwälder, Ufer). 4. 6. 7. Jak obsleiter, $P$. coeríleum L.

\section{Collómia Nutt. Leimsame $(V, 1)$.}

St. $30-60 \mathrm{~cm}$ h., oben oft ästig und sammt d. Bl. und Kelchen drüsenhaarig, Bl. länglich-lanzettförmig, ganzrandig od. gezähnt; Blt. in achselständigen Büscheln, am Ende d. St. u. d. Äste kopfig gehäuft; Blkr. langröhrig-trichterförmig, gelbröthlich. - Aus Nordamerika eingeschleppt, in $\mathbf{B}$. hier $u$. da verwildert. $\odot$. 6. 7 .

C. grandiflóra Dougl.

Anmerk. Zu dieser Familie gehören auch die beliebten Zierpt. der Gattung $P h^{7} O x$ aus Nordamerrka.

\section{Fam. LXVI. Convolvuláceae. Windengewächse.}

\section{Conrólrulus L. Winde $(V, 1)$.}

Schlingpfl, mit wechselständigen, ganzrandigen Bl. und einzeln blattwinkelständigen gestielten Blt.

3. Kelch von $2 \mathrm{gr}$. Deckbl. eingeschlossen. Kapsel einfächrig; St. hochsteigend, Bl. herzeiförmig, Blkr. bis $5 \mathrm{~cm} \mathrm{l}$. (Calystegia R. Br.). 2.

Entfernt vom Kelch $2 \mathrm{kl}$. Deckbl. am Stiel, Kapsel 2 fächrig. 3.

2. Blkr. weiß, Lappen d. Blgrundes spitz. Kahl. - Hecken, Gebiische. 4. 7. 8 .

C. sépium $\mathrm{L}$.

Blkr. rosenroth, Lappen d. Blgrundes abgerundet. - Zierpflanze aus Asien. 4. 7-9.

C. dahurica L.

3. St. windend od. kriechend, bis $1 \mathrm{~m}$ h., Bl. pfeiltörmig, Blkr. 12 bis $20 \mathrm{~mm} \mathrm{l.,} \mathrm{weiß} \mathrm{od.} \mathrm{blassrosa.} \mathrm{-} \mathrm{Salatäcker,} \mathrm{an} \mathrm{Wegen,} \mathrm{Rainen.} 4$. $5-9$. A ckerwinde, C. arcensis L.

St. a ufsteigend od. aufrecht, kaum windend, Bl. verkehrt-eiförmig, Blkr. bis $38 \mathrm{~mm}$ l., 3 farbig (Röhre weiß, Schlund gelb, Saum blau). Zierpf. aus Südeuropa. $\odot .6-9$. C. tricolor L.

Anmerk. Die hochschlingenden Winden mit sehr großen purpurrothen Blumen, welche in Gärten an Stangen, Wänden, Pyraıniden gezogen werden, gehören der amerikanischen Gattung der Trichterwinden (Ipomaea) an.

\section{Fam. LXVII. Cuscriteae. Flachsseidengewächse.}

\section{Cuscúta L. Flachsseide (V, 2).}

Bllose Schmarotzerpfl. mit schlingenden fadenförmigen St. u. Ästeu, die mittelst reihenweis gestellter Saugwarzen an anderen Pf. haften. Blt, $\mathrm{kl}$. in seitenständ. Knäueln od. Träubchen.

1. Blt. gestielt in Träubchen, Gr. 1 mit 2 lappiger Narbe; Blkr. länglich-krugförmig, gelblichweiß od. (gleich dem St.) röthlich. - Aul Weiden- u. Pappelgebiisch in Mh. u. Noe.; zerstrent. ๑. 4. 6. 7.

Blt. sitzend in Knäueln, Gr. 2 getrennt. 
2. Blkröhre kuglig, doppelt so iang als d. Saum, sammt dem St. grüulichgelb (C. europaea $\beta$. L). - Flachsfelder $\odot$. 4. 6.7.

Flachsseide. C. Epilinum Weihe. röthlich.

-Blkröhre zur Zeit d. Blühens walzig, später kuglig; Bl. weiß oder

3. Knäuel reichbltig, Schlundschuppen angedrückt, St. röthlich hochsteigend (C. europaea $\alpha$. L.) Auf Hopfen, Weiden, Nesseln, Hanf und a. Pf. $\odot$. 4. 7. 8.

C. major DC.

Knäuel armbltig, Schlundschuppen zusammengeneigt. St. mehr horizontal sich ausbreitend, purpurroth. - Auf allerhand Kräutern in Halb. sträuchern; zerstreut. $\odot$. 4. 6. 7.

C. Epithymum L.

Variet.: Trifolii (Bab.) Blt. größer, in reichblt. Knäueln. Auf Kleefeldern $\left({ }_{n} \mathrm{Kl}\right.$ e e seid $\left.\mathrm{e}^{u}\right)$.

\section{Fam. LXVIII. Solanáceae. Nachtschattenartige.}

\section{Schliissel der Gattungen.}

1. Blkr. radförmig. Fr. eine Beere. od. Kapsel.

b) Blkr. glockenförm. od. röhrig-glockig. Fr. eine kuglige Beere

c) Blkr. trichterförmig.

4.

2. Stbbt. an einander liegend, einen Kegel bildend; Blt. in seitenständ., gabeltheiligen Trugdolden, Beeren kuglich od. länglich. Solanum (381).

Stbbt, von einander entfernt; Blt. einzeln.

3. Kelch nach dem Verblühen sehr vergrößert, blasig, Beere kuglig, eingeschlossen.

Physalis (383).

Kelch nach dem Blühen nicht vergrößert, Beeren nackt, länglich, sehr groß, oft monströs.

Capsicum (382).

4. (1, b.) Blkr. glockig, Kelch nach dem Verblühen bauchig aufgetrieben, kantig geflügelt; kuglige Beere.

Nicandra (384).

Blkr. röhrig-glockig, Kelch nach d. Verblühen wenig verändert. 5 .

5. Fr. eine saftige Beere.

Airopa (386).

Fr. eine trockene, ringsum aufspringende Kapsel. Scopolia (387).

6. $(1$, c). Sträucher, Blt. zu 1-3 blwinkelständig.; kuglige Beere.

Kräıter, Fr. eine Kapsel. Lycium? (385).

7. Blt. einzeln, end- und astwinkelständig, Kapsel ellipsoidisch, krautstachlig, 4 fächrig, 4 klappig.

Datura (389).

Blt. in endständigen beblätterten Wickeltrauben; Kapsel im vergröBerten Kelch eingeschlossen, mit abspringendem Deckel, 2 fächrig.

Hyoscyamus (388).

Blt. in endständigen Trauben od. Rispen, Kapsel länglich, an der Spitze 4 klappig.

Nicotiana (390).

\section{Solánum L. Nachtschatten, Tollkraut (V, 1).}

St. ästig, beblättert, Trugdolden gestielt, Beeren saftig, meist giftig.

1. Bl. ganz od. am Grunde geöhrelt.

Bl. unterbrochen fiedertheilig od. fiederschnittig, Trugdolden scheinbar cndständig. 
2. Blkr. violett, Beeren länglich, glänzend scharlachroth. Klettarnder Halbstr. mit holzigen Stamm und krautigen Ästen; Bl. gauzrandig, eiförmig od. herzeiförmig, oft geöhrelt. Hulz widerlich riechend. - Ufergebüsche, hohle Weiden, Ђ. 6-8. Bittersü B, Mäuseholz.

S. Dulcamára L.

Blkr. weiß, Kräuter mit eiförm., geschweift od. buchtig gezälınten Bl.; St. 30-60 $\mathrm{cm} \mathrm{h}$.

3. Flaumnaarig, grün; Stkanten höckerig, oft krautig geflügelt. Beeren kuglig, schwarz. - Schutt, bebauter Boden. ๑. 7-10.

Tollkraut, S. nigrum L.

Variirt mit grïnen Beeren (S. chlorocarpum Spenn.), gelblichen (S. húmile Brhd.) u. mennigrotheu (S. miniatum Brhd.).

Zottig bis filzig-zottig, Beeren gelb, kuglig. - An gleichen Orten in B. u. 0e.; zerstreut. $\odot .7-10$.

S. villosum Lamk.

4. (1) St. aufrecht, Blabschnitte eiförmig, Blumen weiß od. lila, Beeren, kuglig, grün; Wzst. knollentragend. - Culturpfl. aus Südamerika. 4. 7. 8 .

Kart offel, S. tuberosum L.

St. liegend od. aufsteigend, Blabschnitte gelappt, Blumen kl. weiß, Beeren sehr gr. oft monströs, gefurcht, mennigroth, essbar. Culturpf. a. Südaner. $\odot .7-10$. Li e bes a $\mathrm{p}$ f e $1, \mathrm{P}$ ar a d e is a $\mathrm{p}$ fel, S. Lycopérsicum L.

\section{Cápsicum L. Beißbeere $(V, 1)$.}

St. aufrecht, ästig, Bl. ei-od. eilanzettförmig, spitz; Blt. achselständig, nickend, Blkr. weiß, Beeren gr. kegelförm. od. monströs, reif scharlachroth und trocken. - Culturpflanze aus Südamerika ๑. 6-8.

Paprika, Spanischer Pfeffer, C. ánnuum L.

\section{Plissalis L. Schlutte $(V, 1)$.}

Wzst. kriechend, St. aufsteigend bis aufrecht, $30-60 \mathrm{~cm} \mathrm{h.;} \mathrm{Bl.}$ eiförm., gezähnt; Blt. achselständ. hängend, Blkr. weiß, Frkelch außen roth, die eingeschlossene kuglige, essbare Brere scharlachroth. - Wuiste Plätze, Weinberge, bebuschte Hïgel; zerstreut, auch Zierpfl. 4, 5. 6. Judenkirsche, Ph. Alkekengi L.

\section{Nicandra Adaus. Giftbeere $(\mathrm{V}, 1)$.}

St. sehr åstig, 0.6-2 on h., Bl. gr., eiförm. od. länglich, buchtig gezähnt; Blt. einzeln, achselständig, nickend; Blkrsaum hellblau, Röhre weiß; Beere grün. - Zierpllanze aus Peru, stellenweis verwildert. $\odot$. $7-9$.

N. physaloides Gärtn.

\section{Lýcium L. Bocksdorn $(V, 1)$.}

Zweige hängend, rutheufürmig, oft dornig; Bl. gestielt, länglich od. lanzettförm., ganzrandig, Blkr. hellroth od. lila, Beeren länglich, scharlachroth. - Zierstrauch aus südeuropa, in Hecken häufig verwildert. $\downarrow$. $7-9$. Teufelszwirn, L. bárbarum L.

\section{Atropa L. Tollkirsche $(\mathrm{V}, 1)$.}

St. gabeltheilig,-ästig, verholzend, $1-1 \cdot 6 m \mathrm{~h}$; Bl. gestielt, eirörm. od. oval, Blt. einzeln nebenblständig, hängend; Blkr. schmutzig violettbraun, Beere glänzend schwarz. - Schattige Bergwälder, besonders auf Kalk und Basalt. 4. 6. 7.

A. Belladonna L. 
387. Seopólia Jacqu. $(\nabla, 1)$.

St. bis $20 \mathrm{~cm}$ h., oben ästig, Bl. oval od. länglich, Blt. achselständ,, lang gestielt, hängend, Blkr. außen braun, innen grün. Kahl. - Gebirgswälder in St., K. u. Kr.; zerstreut. 4. 4. 5. Sc. atropoides Schult.

\section{Hyoscýamus L. Bilsenkraut $(\nabla, 1)$.}

St. $30-60 \mathrm{~cm} \mathrm{~h}$, erst einfach, dann gabelästig; Bl. im 1. Jahre grundständig, fiederspaltig, Stbl. eiförmig-länglich, buchtig gezähnt; Blkr. gelblichweiß, violett, netzadrig, mit violettem Schlunde. Klebrig-rauhhaarig -- Schutt, bebauter Boden. -). 6. 7.

H. niger L.

\section{Datúra L. Stechapfel $(V, 1)$.}

St. 0.30-1 $m$ h., erst einfach, dann gabelästig; Bl. gestielt, eiförm. od. längliclı, buchtig gezähnt; Blkr. weiß, bis $10 \mathrm{~cm}$ l., Kelch prismatischröhrig, am Grunde ringförmig abspringend. - Schutt, bebauter Boden. ๑. 7. 8 .

D. Stramónium L.

\section{Nicotiana L. Tabak $(\mathrm{V}, 1)$.}

St. aufrecht, ästig, Bl. ganzrandig. Ganze Ptanze druisig-flaumig. Amerikarische Culturpflanze.

1. Blkr. langröhrig, hellroth; Bl. länglich-lanzett- oder eiförmig, spitz; Rispe pyramidal. - ๑. 7-9. Gemeiner T., N. Tabácum L.

2. Blkr. kurzröhrig, grüinlichgelb; Bl. eiförmig, Rispe traubig. $\odot$. N. rustica L.

Fam. LXIX. Scrophulariciceae. Braunwurzartige.

\section{Schliissel der Gattungen.}

1. Stbg. 5, die 3 kürzeren od. alle wollbaarig, Blkr. radförmig, ungleich 5 lappig, Kapsel 2 fächrig, wandspaltig 2 klappig.

Stbg. 4 (zweimächtig), selten 2; Kapsel 2 fächrig. Verbascum (391).

2. Stbb. dem oben verbreiterten Stbf. quer aufsitzend, mit zusammenfließenden, mittelst einer gemeinsamen Ritze aufspringenden Fächern; Stbg. 2 mächtig.

Stbb. mit 2 getrennten Fächern, jedes mit einer Ritze (selten Klappe) aufspringend.

4.

3. Kelch 5 theilig, Blkrröhre fast kuglig, Saum kurz 2 lippig; zwischen d. oberen Stbg. cin stcriles schuppenförm. Stbg., Kapsel wandspaltig2 lklappig.

Scrophularia (392).

Kelch 5 zähnig, Blkr. kurz glockig, fast regelmäßig. 5 spaltig, Kapsel unvollständig- 2 fächrig, 2 klappig.

Limosella (393).

4. Stbg. 2 (wenigstens nur 2 mit Beuteln begabt).

Stbg. 4, zweimächtig.

8.

5. Blkr. radförmig-4 lappig, Lappen flach, obere breiter, Kapsel zusammengedrückt, ausgerandet, fachspaltig 2 klappig. Veronica (403).

Blkr. 2 lippig.

6. Kelch am Grunde mit 2 linealen Deckblättchen; 5 theilig, Blkr. röhrig, fast 4 seitig, mit 4 spaltig 2 lippigem Saume. Neben den 2 fruchtbaren Stbg. 2 sterile; Narbe 2 lappig, Kapsel wandspaltig 2 klappig. 
Kelch ohne Deckbl., Blkrröhre stielrund, Narbe ungetheilt, Kapsel 2 klappig.

7.

7. Kelch 5 spaltig, Stbb. herzeiförmig mit 2 Längsritzen aufspringend, Stbg. im Grunde der Blkrröhre eingefügt.

Paederota (398).

Kelch 5 theilig, St̂bb. nierenförmig, mit einer Klappe aufspringend, Stbg. zwischen den die Lippe trennenden Buchten eingefügt.

Wulfenia (397).

8. (4). Blkrsaum, ungleich 5 lappig, tellerförmig, Röhre schlank, rund, Kelch tief 5 theilig.

Erinus (399),

Blkr. 2 lippig.

9.

9. Blkr. maskirt (Schlund durch eine emporgewölbte Falte d. Unterlippe - Gaumen - geschlossen).

10.

Blkr. nicht maskirt (Schlund weit geöffnet).

11.

10. Blkrröhre am Grunde höckerig, Kapselfächer mit Löchern aufspringend.

Antirrhinum (401).

Blkrröhre am Grunde gespornt, Kapsel mit mehreren Klappen od. am Scheitel durch ein abspringendes Deckelchen aufspringd. Linaria (400).

11. Blkr. röhrig-glocirig, mit schiefem, schwach 2 lippigem Saum. Kapsel fachspaltig; 2 klappig.

Digitalis (402).

B!kr. deutlich 2 lippig, Narbe 2 lappig.

12.

12. Oberlippe ausgerandet, Unterlippe 3 lappig, Blkr. kürzer als d. 5 theilige Kelch, Kapsel wandtheilig-2 klappig.

Lindernia (394).

Oberlippe 2-, Unterlippe 3 lappig, Kelch 5 zähnig, viel kürzer als d. Blkr.; Kapsel fachspaltig-2 klappig.

Mimulus (396).

\section{Verbascum L. Wollkraut, Königskerze (V, 1).}

St. aufrecht, einfach od. rispig-ästig, Stbl, sitzend od, herablaufend. Blt. in endständ. Trauben od. Röhren. Wollfilzige, seltener flaumige oder kahle $\left.\mathrm{Kr} *^{*}\right)$.

1. Blt. einzeln, lang gestielt, von Deckblättchen gestützt, einfache od. ästige lockere Trauben bildend; alle Stbf. violett-wollig.

Blt. kurz gestielt in Büscheln, welche eine dichte od. lockere walzige Traube od. eine pyramidale Rispe bilden.

3. Blkr. violett, Blt. in einfacher drüsigflaumiger Tranbe; St. 14 bis $45 \mathrm{~cm}$ h., Bl. eiförmig od. länglich, gekerbt, untere in Rosette. - Sandboden, trockene Hügel; zerstreut. $\odot$. . 5-7.

V. phoeniceum L.

Blkr. gelb, selten weiß, St. $30-45 \mathrm{~cm}$ h., einfach oder oben ästig, oben nebst Bltstielen und Kelchen drüsig; Bl. kahl, untere buchtig-fiederspaltig, gestielt, Stbl. länglich, gezähnt, sitzend. - Raine, Ackerränder, Triften, Ufer; zerstreut. $\odot$. 6. 7. Mottenkraut, V. Blattária L.

4. Alle 5 Stbf. wollig, St. $0.45-1.30 m$ h., untere Bl. gestielt. 5 .

Nur die 3 kürzeren Stbf. weißwollig mit kleinen nierenförmigen Beuteln, die 2 längeren kahl mit großem herablaufendem Beutel. Weiß wollfilzig, Stbl, herablaufend, Traube einfach.

8.

5. Wolle der Stbf. weiß; Bltbüschel in pyramidalen Rispen. 6.

Wolle der Stbf. purpurn; Bl. oberseits grün, ungleich gekerbt, Blkr. $18 \mathrm{~mm}$ br. gelb.

*) Die Arten dieser Gattung bilden zahlreiche Bastarde, welche hier nicht berücksichtigt werden können. 
6. Bl. gekerbt, oberseits fast kahl, unterseits sammt d. St. staubigweißfilzig, untere länglich-verkehrt-eiförmig, obere eilanzettförmig; Blkr. 8 - 20 mm br., gelb, selten weiß. - Trockene Hügel, Gebüsche, Raine. ๑. 6.7 .

V. Lychnitis L.

Bl. ganzrandig, unterste in Rosette, länglich oder länglich-lanzettförm., obere herzeiförmig; Blkr. $13-25 \mathrm{~mm}$ hr., gelb. Ganze PA. dicht weißgrau-filzig. - Steinige Orte, buschige Hiigel, Ufer in Mh. u. Noe.; stellenweis. $\odot$. 7. 8 .

V. speciosum Schrad.

7. Untere Blt. herzförmig, obere sitzend, eilanzettförmig, unterseits mehr weniger filzig; Bltbüschel in eiufacher, selten am Grunde ästiger Traube, - Wegränder, Hiigel, steinige Orte. ๑. 6. 7. V. nigrum L.

Variet.: lanatum (Schrad.), Blstiele schneeweiß langwollig. Bl. unterseits wollig-filzig. Bergwälder in $\mathbf{K}$., T., $\mathbf{K} \mathbf{r}$., auch in $\mathbf{B}$. (selten).

Untere Bl. am Grunde abgerundet od. herzförmig, eiförmig, länglich, obere eilanzettförm., sitzend; Bltbüschel in rispig gruppirten Trauben. Bebuschte sonnige Hiigel in B., Mh., Oe., Sz., St., K., T.; zerstreut. ๑. 6. 7.

$V$. austriacum Schrd.

8. (4). Bl. an den Stkanten von Bl. zu B. herablaufend.

Bl. kurz od. halb hinablaufend, ungleich gekerbt, untere länglich bis br. lanzettförm., obere eiförmig; St. 0.30-1.30 $m$ h., Traube bis $60 \mathrm{~cm}$ l., Blkr. $3.8-5 \mathrm{~cm}$ br. - Steinige Hügel, sandige Felder und Ufer. $\odot$. 7. 8.

$V$. phlomoides L.

9. Blkr. 25-38 $m$ br., Traube bis $60 \mathrm{~cm} \mathrm{1.,} \mathrm{St.} \mathrm{bis} 1 m \mathrm{~h}$., Bl. ungleich gekerbt, länglich od. oval. - An gleichen Orten, gemein. $\odot$. 7. 8 .

$V$. thapsiforme Schrd.

Blkr. 13-18 $\mathrm{mm}$ br., trichterig-radförmig, Traube bis $30 \mathrm{~cm}$., St. bis $1 m 1, \mathrm{Bl}$. gezähnelt, untere verkehrt-eiförmig-länglich, obere oval. Waldränder, Gebüsche, Ufer; sehr zerstreut. ๑. 7. 8. V. Thapsus L..

\section{Serophulária L. Braunwurz (XIV, 2).}

St. meist 4 kantig, Bl. kreuzweis gegenständig, Blt. in gabeltheilig. Trugdolden, kl.

1. Trugdolde dichtbltig, von kl. gesägten Bl. umliüllt, l. gestielt, Blt. winkelständ; Blkr. fast krugförmig, grünlichoelb, Stbg. vorstehend; St. 30-60 $\mathrm{cm}$ h., nebst Bltstielen und Kelclien drisig-weiclihaarig, Bl. herzeiförmig, doppelt gesügt, kahl. - Schattige, f̈euchte Orte, Gebüsche in B., Mll., Scl.,, Noe., St., K., Kr.; zerstreut. ๑. 5. 6.

\section{Sc. vernalis $\mathrm{L}$}

Trugdolde 3 bis viclbltig, mit kl. Deckblättchen, Blt. end- u. seitcuständ., in schmaler Rispe.

2. Bl. ganz, St. 4 kantig, Blkr. grünlich od. grünlich-rothbran. 3 .

Bl. einfach- bis doppelt fiedertheilig od. fiederschnittig, Blkr. purpurviolett, St. $30-60 \mathrm{~cm}$ h. nebst den Bl. kahl.

3. St. und Blstiele weichzottig, Bl. flaumig, eingeschnitten doppeltgekerbt, ei-od. herzeilïinglich; St. $0 \cdot 30-1 \mathrm{~m}$ h. - Gebirgswälder, auf Kalk in Sch., $\mathbf{M h}$., St., K., Kr., T.; 4. 7. 8. Sc. Scopólii Hppe.

Kahl, nur d. Bltstiele drüsig-flaumig; St. $0.6-1.3 \mathrm{~m} \mathrm{~h}$.

4. Stkanten nicht gefliigelt, Bl, eiförmig bis eilanzettförmig, mit gestutztem od. herzförmigem Grunde, doppelt gesägt; Wz. knotig. - Gräben, Ufer, Schutt. 4. 6-8.

Sc. nodósa L. 
Stkanten br. geflügelt, Bl. eiförmig lä̉nglich od. herzeiförmig, scharf gesägt (Sc. aquatica Auct. nicht L.) - Ufer, Gräben, quellige Orte; zer. streut. $4.6-8$.

Sc. aláta Gilib.

5. St. stumpf 4 kantig, Rispe drüsig punktiert, Frstiele kürzer als der Kelch. - Kies der Bäche in den Kalkalpen von St., K., Kr.; zerstreut. 4. 6. 7.

Sc. canina L.

St. rund, Rispe drüsig-flaumig, Frstiele doppelt so lang als d. Kelch. - An gleichen Orten in St., K., Kr., T.; zerstreut. 4. 6. 7.

Sc. Hóppei Koch.

\section{Limosella L. Schlammkraut (XIV, 2).}

Kl., kahles, stengelloses Kräutlein, kriechende Ausläuf. treibend; B1. l. gestielt, oval bis lanzettlich, Blt. kurz gestielt, kl., weißlich oder lila. - Überschwemmte Ufer, Schlamm in B., Mh., Oe.; zerstreut. $\odot$. 8. 9.

L. aquática $\mathrm{L}$.

\section{Lindernia L. (XIV, 2).}

St. 3-15 cm l., 4 kantig, niedergestreckt; Bl. gegenständ., sitzend, länglich od. eiförmig, 3 nervig, l. gestielt ; Blt. kl. achselständ., röthlichweiß. Vielstenglig, kahl. - Überschwemmte Plätze. feuchter Sandboden in B., Mh., Noe., St., K.; zerstreut. ๑. 8. 9. L. pyxidåria L.

\section{Gratíola L. Gnadenkraut (I, 1).}

Wzst. kriechend, gegliedert, in den aufsteigenden, meist einfachen, bis $30 \mathrm{~cm} \mathrm{~h}$. St. übergehend; Bl. kreuzweis gegenständig, länglich oder eilanzettförmig, gesägt; Blt. gestielt, blwinkelständiy, Blkr. weiß oder röthlich. Kahl. giftig. - Wassergräben, Ufer, Sumpfwiesen; zerstreut. 4. 6. 7 . G. officinalis L

\section{IÍmulus L. Gauklerblume (IV. oder XIV, 2).}

St. 4 kantig, 20-50 $\mathrm{cm}$ h.; Bl. kreuzweis gegenständ., rundlich bis länglich, gezähnt, untere gestielt; Blt. einzeln, achselständig, gr., Blkr. goldgelb, im Schlunde braun gefleckt. Kahl. - Aus Nordamerika, verwildert auf Sumpfwiesen, au Gräben, Ufern hier und da. 4. 6-10.

\section{Wulfénia Jequ. (II, 1).}

Wzst. kriechend, St. $14-45 \mathrm{~cm}$ h., nackt, nach oben hin beschuppt; Bl. grundständig, verkehrt-eiförmig-länglich, gekerbt; Blt in endständiger 2 reihiger Traube, Blkr. dunkelviolett. Kahl. - Felsen, Triften, lichte Waldplätze in K. $(1500-1900 \mathrm{~m}$.); zerstreut. 4. 7 .

$$
\text { W. carinthiaca Jcou. }
$$

\section{Pacderóta L. (II, 1).}

St. $10-20 \mathrm{~cm} \mathrm{h.,} \mathrm{kl.} \mathrm{gegenständig;} \mathrm{Blt.} \mathrm{in} \mathrm{endständigen,} \mathrm{ährigen}$ Trauben. Behaarte Kr.

1. Blkr. blau, mit ganzer Oberlippe, Kelch und Deckbl. purpurn, Bl. eiförmig, spitz, gekerbt. - Felsspalten der Kalkalpen in St., K., Kr., T.; 4. 6. 7. M äi d e rle, P. Bonaróta L.

2. Blkr. gelb mit gespaltener Oberlippe, Kelch u. Deckbl. grün, Bleilanzettförmig, eingeschnitten-gesägt. - Kalkalpen in St., K., Kr.; 4. 6. 7 . P. Agéria I. 


\section{9. Érinus L. Leberbalsam (XIV, 2).}

St. mehrere aufsteigend, 5-13 cm h.; Bl. verkehrt-eiförm., gezähnt, Grundbl. in Rosette, Stbl. wechselständig; Blt. in beblätterter Traube, purpurn. - Steinige Plätze der Alpen v. T. 4. 5-7. E. alpinus L.

\section{Linália Mill. Leiukraut (XIV, 2).}

Bl. meist schmal, ganz u. ganzrandig, gewöhnlich wechselständ.; Blt. gestielt.

1. St. und Äste fadenförm., liegend oder hängend; BI. br., gestielt; Blt. l. gestielt, $\mathrm{kl}$. sitzend.

St. aufrecht od. aufsteigeud, einfach oder ästig; 1jlt. meist schmal,

2. Bl. lang gestielt, herzförm•rundlich, 5 lappig, Blt. lang gestielt, Blkr. hellviolett mit weißem gelb geflecktem Gaumen; St. sehr ästig, bis $1 \mathrm{~m}$ l. - Alte Mauern, zerstreut, auch Zierpł. 4. 6-9.

\section{Cymbalária L.}

Bl. kurz gestielt, ganzrandig oder eckig gezähnt; Bltstiele länger als d. Bl., Blkr. gelb, St. kriechend, $7-30 \mathrm{~cm}$ 1. Zottige Pf.

3. Bl. länglich-rund oder rundlich-eiförmig, Bltstiele behaart, Oberlippe inwendig schwarzroth. Sporn gekrümmt. - Äcker, Brachen in B., Mh., 0e.; zerstreut. $\odot .7-10$.

L. spuria Mill.

Obere Bl. spieß- bis pfeil-, untere eiförmig: Bltstiele kabl, Oberlippe inwendig violett, Sporn gerade. - An gleichen Orten ebendaselbst; zerstreut. ๑. $7-10$.

L. Elatine Mill.

4. Blt. einzeln, blwinkelständig, lila, kl.; St. $7-15 \mathrm{~cm} \mathrm{h.,} \mathrm{sehr} \mathrm{ästig;}$ Bl. lanzettlich od. lineal. Drüsig-flaumig. - Sandfelder, Schutt; zerstreut. ๑. 6-10.

L. minor Desf.

Blt. in endständ. Trauben.

5.

5. Ganz kahl; St. liegend od, aufsteigend, zahlreicb, strahlenförmig ausgebreitet, zerbrechlich; Bl. lineal od. länglich, dick; Trauben kurzwalzig, Blkr. 16-20 $\mathrm{mm}$ 1, blauviolett mit orangerothem Gaumen. - Kies. und Sandplätze d. Alpen $(1500-2400 \mathrm{~m})$. 4. 7-9.

L. alpina DC.

Bltstiele u. Kelche meist drüsig-flaumig; St. aufrecht, meist ästig. 6.

6. Untere Bl. gegenständig od. in Wirteln; St. $15-30 \mathrm{~cm}$ h., Bl. lineal, spitz; Trauben ährenförm., Blkr. 4-6 $\mathrm{mm}$ l., blasslila mit weißem Gaumen. - Sandäcker in B., Mh., Noe.; zerstreut. ๑. 7. 8.

\section{L. arvensis Desf.}

Alle Bl. wechselständig, St. einfach od. ästig, Blkr. gelb. 7.

7. Bläulich beduftet, St. $0.45-1.30 m$ b., rispig-ästig, Bl. länglich bis eilanzettförmig, 3-5 nervig, Blkr. 12-16 $\mathrm{mm} \mathrm{l.,} \mathrm{gelb} \mathrm{mit} \mathrm{goldgelbem}$ Gaumen. - Sonnige Hügel u. Abhänge, besonders auf Kalk in B., Mh., Noe.; zerstreut. 4. 7. 8. L. genistifolia Mill.

Grün, St. $30-60 \mathrm{~cm}$ h., Blkr. schwefelgelb mit orang. Gaumen. 8.

8. Traubenspindel $u$. Bltstiele drüsig-haarig, Blkr. $18-25 \mathrm{~mm}$ l., Bl. lineal bis lanzettlich, 3 nervig. - Hügel, Mauern, Steinbrüche. 4. 6-10. Frauen flachs, $I$. vulgaris Mill.

'Traubenspindel $u$. Bltstiele kahl, Blkr. 10-12 $\mathrm{mm}$ l., sonst wie vor. - Steinige Plätze im südl. St. u. T.; zerstreut. 4. 6-10. 


\section{Antirrhílum L. Löwenmaul (XIV, 2).}

St. aufrecht, ästig, oben nebst d. Bltstiel.u. Kelchen drïsig-Alaumig; Bl. wechselständig, lanzett- od. lineal-lanzettförmig, ganzrandig.

1. Blt. blwinkelständig, Blkr. 8-12 $m m$ l., kürzer als d. Kelch, blassrosa; St. $15-45 \mathrm{~cm}$ h., nebst d. Bl. behaart. - Auf Sandboden; zerstreut. $\odot$. 7. 8 .

A. Orontium L.

2. Blt. in endständigen dichten 'Trauben, Blkr. 38 mm l., viel länger als d. Kelch, purpurroth, rosa, gelb, weiß mit gelbem Gaumen; St. 30 bis $60 \mathrm{~cm}$ b., kahl. - Zierpe. aus Südeuropa, an Mauern oft verwildert. 4. $6-9$. A. majus L.

\section{Digitális L. Fingerlat (XIV, 2).}

St. aufrecht, einfach, reichblättrig; Bl. wechselstäudig, untere gestielt; hlt. in endständiger deckblättriger Traube, lıängend od. nickend. Giftige $\mathrm{Kr}$. kurz.

1. Traube einseitswendig, Blkr. röhrig, Mittellappen d. Unterlipps

Traube einseits- od. allseitswendjg, Blkr. glockig, Mittellappen der Unterlippe wenig kürzer als d. Röhre.

3.

2. Blkr. gelblichweib, inwendig braun gestreift od. gefleckt, 30 bis $38 \mathrm{~mm} \mathrm{l.;} \mathrm{St.} 0 \cdot 30-1 \mathrm{~m}$ h., Bl. länglich.lanzettförmig, gesägt. - Be• buschte Hügel, Steinbrüche. 4. 6. 7 .

D. ambigua Murr.

Blkr. purpurroth (selten weif), inwendig behaart, init dunkelrotlien Augenflecken, bis $5 \mathrm{~cm}$ l.; St. $0 \cdot 30-1 \mathrm{~m}$ h., Bl. ei- od. eilanzettförmig, gekerbt. - Zierpfl., auch verwildert. ๑. 6. 7.

D. purpirea L.

3. Traube einseitswend., Blkr. 18-2j $\mathrm{mm}$ l., ockergelb, braun geadert, Unterlippe weiß behaart; St. $0.30-1 \mathrm{~m}$ h, Bl. lanzettförmig. Kahl. - Steinige Hügel im südl. St. u. Kr. -.) 7. 8. D. laevigata W. Kit.

Traube allseitswend., Blkr. $25 \mathrm{~mm}$ 1., rostgelb, innen dunkler genetzt, Unterlippe violett, weiB behaart; St. $0.6-1.6 m \mathrm{~h}, \mathrm{Bl}$. länglich-lanzettod. lanzettförmig. - Steinige Plätze b. Wien und in $\mathbf{K r}$.; zerstreut. 4. 7. 8 .

D. ferruginea L.

\section{Ferónica L. Ehrenpreis (II, 1).}

Vielgestaltige Kr., Blkr. kl, meist blau.

1. a) Blt. in gestielten blwinkelständigen Trauben, Hauptachse nux (gegenständ.) Laubbl. entwickelnd; Blkr. sehr kurzröhrig.

b) Blt. in endständig. Traube (oft noch seitenständig. Nebentrauben), diese mit kl. Deckbl., rom iaubbltragenden Sttheil scharf abgegrenzt, Blkr. mit kurzwalziger Röhre.

c) Blt. einzeln blwinkelständig od. in lockerer beblätterter Traube, welche rom laubbltragenden Sttheil nicht abregrenzt erscheint (Bl. in die Deckbl. allmählich übergehend); Blkr. sehr kurzröhrig.

2. Kelch 4 theilig.

Kelch 5 theilig, die hinteren Zipfel kleiner.

3. St. u. Bl. kab]; Sumpf- u. Wassergewächse.

St. u. Bl. behaart; Bewohner trockenen Landes.

4. Trauben meist entgegengesetzt-blwinkelständig; Frstiele aufrechtabstehend, Kapseln rundlich, gedunsen, schwach ausgerandet. 
Trauben nicht gegenständig, Frstiele wagerecht od. zurückgeschlagen, Kapsel zusammengedrüickt, tief ausgerandet (brillenförmig); 5 t. bis $30 \mathrm{~cm}$ hoch, Bl. lineal-lanzettförmig, Blkr. bläulich od. weißlich, roth geadert. Ufer, Sümpfe. 4 6-10.

V. scutellata L.

5. St ru ıdlich, $10-50 \mathrm{~cm}$ h., Bl. kurz gestiele, br. oval bis länglich, fleischig; Trauben weit abstehend, Blkr. azurblau, selten rosa - Wassergräben, Bachufer. 4. $5-8$.

B a chbunge, V. Beccabunga L.

St. 4 kantig, mittlere u. obere Bl. am Grunde herzförm., sitzend. 6 .

6. St. fest, $10-60 \mathrm{~cm}$ h.; Bl. lanzettlich bis lineal-lanzettförmig, gesägt; Trauben drüsenhaarig, Blkr. weiß, bläulich geadert, Frstiele fast wagerecht, Kapsel länglich-elliptisch. - Sümpfe, Gräben in IIh. u. Noe.; sehr zerstreut. 4. 7. 8 .

$V$. anagalloides Guss.

St. hohl, 0 10-1 $m$ l. 7.

7. Bl. br. ei- bis eilanzettförmig, Trauben aufrecht-abstehend, Blkr. $4 \mathrm{~mm}$ br., lila, purpurviolett geadert, Frstiele spitzwinklig abstehend, Kapsel eiförmig-rundlich. - Wassergräben, Bäche. 4. 6-10.

\section{Anagallis L.}

Bl. eiförm.- länglich bis lanzettförmig, Traub. weit abstehend, Blkr. kleiner, blassroth; Frstiele fast wagerecht, Kapsel rundlich-elliptisch. Gräben; auf Schlamm in B., Mh. u. Noe.; sehr zerstreut. 4. 6-10.

V. aquática Brhd.

8. (3) Trauben kurz, locker, höchstens 4 bltig; Kapsel flach gedrückt, quer breiter.

9. schmälert.

Trauben vielbltig, Kapsel 3 eckig-verkehrt-eiförmig, am Grunde ver-

9. Trauben- u. Bltstiele drüsig-flaumig, Blkr. licht azurblau, dunkleı gestreift; Bl. kurz gestielt, ei-od. verkehrt-eiförmig, Stämmehen fadenförm., kriechend, Äste höchstens $25 \mathrm{~mm}$ l., dicht beblättert. - Kalkalpen, auf Gerölle u. Triften. 4. 6-8.

$V$. aphylla $\mathrm{L}$.

Trauben- u. Bltstiele rauhhaarig, Blkr. blïulichweiß, dunkler gestreift; Bl. lang gestielt, eiförmig od. rundlich, grob gekerbt; $\ddot{\text { stste auf- }}$ steigend, bis $25 \mathrm{~cm} \mathrm{l}$. - Schattige Gebirgslaubwälder; zerstreut. 4. 5. 6. V. montána L.

10. St. 2 reihig behaart, $15-30 \mathrm{~cm} \mathrm{l}$; Bl. ei- od. herzeiförmig, grob gekerbt; Traub. kurz gestielt, Blkr. $8 \mathrm{~mm}$ br., azurblau. - Wiesen, Gebüsche. 4. 5. 6.

V. Chamaedrys L.

St. rundum behaart, Blkr. $6 \mathrm{~mm}$ br.

11.

11. Traub. gedrungen-bltig, Bltstiele aufrecht, Blkr. lila; St. kriechend, aufsteigend-ästig. $30 \mathrm{~cm}$ l.; Bl. eiförmig, elliptisch, läcglich, ge• kerbt. - Nadelwälder. 4. 6. 7.

$V$. officinalis $\mathrm{L}$.

Traub. l., lockerbltig, Bltstiele abstehend, Blkr. rosa; St. aufreclit od. aufsteigend; bis $70 \mathrm{~cm} 1$.; Bl, eiförm., gesägt, obere l. zugespitzt (V. urticifolia Jcqu.). - Gebüsche u. Wälder d. Voralpen. 4. 6. 7.

V. latifolia L.

12. (2) St. niederliegend od. aufsteigend, bis $20 \mathrm{~cm} \mathrm{l.;} \mathrm{Bl.} \mathrm{sitzend,}$ eilanzett- bis lineal-lanzettförmig, gekerbt- od. eingeschnitten-gesägt; Traub, gedrungen, Blkr. 6-8 $\mathrm{mm}$ br., azurblau (selten rosa od. weiß). Triften, besond. auf Kalk; zerstreut. 24. 4. 5.

$V$. prostráta L. 
St. aufrecht od. aufsteigend, Traub, locker, Blkr. 10-12 mm breit, szurblau.

13. Bl. lineal od. lineal-lanzettlich, gekerbt-gesägt od. eingeschnitt.gezähnt, St. bis $45 \mathrm{~cm}$ l. (V. dentata Schm.), - Bebuschte Hügel, besond, auf Kalk; zerstreut. 4. 5. 6.

$V$. austiaca L.

Bl. eiförmig od. eilänglich, grob n. ungleich gekerbt, am Grunde oft herzförmig; St. $0 \cdot 30-1 m$ h. - Bebuschte Hiigel u. Abhänge. Waldränder. 2. 5. 6.

V. Téucrium L.

14. (1, b.) Bl. gegenständig, an den Rändern gekerbt, gegen d. Spitze ganzrandig, untere gestielt, eiförmig bis länglich, die andern lanzettförm.; St. 10-40 cm h., einfach od. doldentraubig-ästig; Traub. älı̈enförmig, spitz, dicht. Sebr variierend. - Grasige Hügel u. Triften. 4. 7-9.

V. spicáta L.

Variet. $\beta$. nitens (Host), glänzend kahl, Bl. u. Kelche gewimpert.

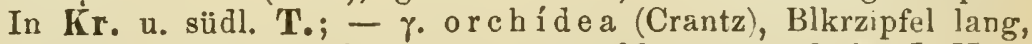
zugespitzt, die seitlichen abwärts geschlagen u. gedreht. In Noe.

Bl. zu 3-4 quirlständig, bis zur Spitze scharf-od. eingeschnittengesägt, länglich-lanzettförmig; St. $0.6-1 \cdot 6 m \mathrm{~h}$., einfach od. oben rispigästig; Traub. ähı enförmig, meist viele. - Flussufer in B., Mlı., Noe.; zerstreut, auch Zierpfl. 4. 7. 8.

$V$. longifolia L.

15. (1, c.) Blt. in endständigen lockeren beblätterten Trauben; Laubbl. gegenständig.

16.

Blt. einzeln, blwinkelständig, gestielt; Stiele nach dem Verblühen zurückgebogen. 24.

16. Bl. ungetheilt, ganzrandig od. gekerbt.

17.

Bl. handtheilig od. fiederspaltig, gegenständig, Deckbl. wechselständ.; drüsig-flaumige $\mathrm{Kr}$.

23.

17. Traube armbltig, Blkr. 6-10 $\mathrm{mm}$ br., Kapsel wenig oder nicht ausgerandet. Rasenbildende Alpenkr. mit Wzst.

Traube reichbltig.

18.

21.

18. Blrosetten bildend, Bl, verkehrt-eiförm., sammt d. $5-15 \mathrm{~cm}$ h. St. rauhhaarig; Blt. kurz gestielt, anfangs kopfig, azurblau. - Gerölle der Alpen (1580-2600 m), Sudeten u. d. Riesengeb. (Schneekoppe). 4. 7. 8. $V$. belludioides L.

Keine Blrosetten, untere Bl. kleiner als d. oberen, zur Bltezeit verwelkt.

19. Blkr. dunkelblau.

19.

20.

Blkr. rosenroth; St. aufsteigend, bolzig, bis $15 \mathrm{~cm}$ l., Bl. länglich, kreuzweis gegenständig; kahl. - Steinige grasige Plätze u Gerölle der Alpen. 4. 7.8.

$V \cdot$ truticulosa L.

20. Blkr. azurblau mit purpurrothem Schlundring, Traube drüsenhaarig; St. aufsteigend, unten holzig, bis $20 \mathrm{~cm} \mathrm{l.;} \mathrm{Bl.} \mathrm{länglich,} \mathrm{kahl.} \mathrm{-}$ Felsspalten, Gerölle, Grasplätze der Alpen $(950-1600 \mathrm{~m})$. 4. 7. 8 .

$V$. saxátilis Scop.

Blkr. einfarbig azurblau, St. aufsteigend od, aufrecht, bis $10 \mathrm{~cm}$ h., oben sammt d. Kelchen rauhhaarig; Bl. oval bis eilanzettförmig, kahl. Grasplätze d. Alpen (1216-2500 m) u. d. Riesengeb. (selten!). 4. 6-8. 
21. (17) Ausdauernd St. aufrecht, $10-30 \mathrm{~cm} \mathrm{h.,} \mathrm{Bl.} \mathrm{elliptisch,} \mathrm{ei-}$ förmig od. länglich, kahl; Blkr. $3-4 \mathrm{~mm}$ br., blasslila od, weiß, Kapsel verkehrt-herzförmig. - Feuchte Triften und Äcker. 4. 4-7.

V. serpýllifólia $\mathrm{L}$.

Einjährige PA. mit dünner Wz.; Bl. herz- od. eiförmig, gekerbt. 22.

22. Abstehend-drüsenhaarig, St. aufrecht, $5-15 \mathrm{~cm} \mathrm{h.,} \mathrm{Bltstiele} \mathrm{läng.}$ als d. Deckbl. n. Kapseln, Blkr. azurblau. - Bebaut. Boden, gras. Hügel; zerstreut. ๑. 4. 5 .

V. praecox All.

Abstehend behaart, drüsenlos (nur d. Kapselränd. drüsig gewimpert); St. 5-25 cm h., Bltstiele kürzer als d. Decklbl, u. Kapseln, Blkr. himmelblau. - Bebaut. Boden. $\odot$. 4. 5.

V. arvensis $\mathrm{L}$.

23. (16) BI. handtheilig, Zipfel verkehrt-eiförm. länglich, mittelster d. größte, Deckbl. 3 theilig, St. 5-20 cm h., Blkr. azurblau. - Äcker, Raine. $\odot .4-6$.

V. triphýllos L.

Bl. fiederspaltig, Deckbl. ganz u. ganzrandig; St. 5-15 $\mathrm{cm}$ h., Blkr. sahr kl., himmelblau, - Felder, Triften, wüste Plätze; zerstreut. $\odot$. 4.5.

V. verna L.

24. (15) Bl. gekerbt od. gekerbt-gesägt. 25.

Bl. 5-9lappig, alle abwechselnd, gestielt, herzförm. rundlich; St. aufrecht od. liegend, ästig, $2.5-30 \mathrm{~cm}$ l.; Kelchzipfel herzförm., Blkr. kl. bläulich od. lila. - Bebaut. Boden, Schutt. $\odot .3-6$. V. hederífólia L.

Variet. tríloba (Opiz), Bl. 3 lappig, Blkr. größer, azurblau. In B., Mh. u. Noe.; zerstreut.

25. Bl. alle wechselständig, ei- od. herzeiförm., grob gekerbt; St. liegend od. aufsteigend, ästig, bis $30 \mathrm{~cm} \mathrm{l.,} \mathrm{zottig;} \mathrm{Kelchzipfel} \mathrm{eilanzett-}$ lich, unterer Lappen d. Blkr. weiß, die anderen blau (V. persica Poir.). Bebaut. Boden. ๑. 4-9.

V. Tournefortii Gm.

Untere BI. gegen-, die andern wechselständig, alle gestielt. 26.

26. Blkr. bläulichwei $\beta$, dunklerblan gestrichelt. Kapselfächer doppelt so hoch als br., weich driisenhaarig, Kelchzipfel eiförmig; St. liegend od.

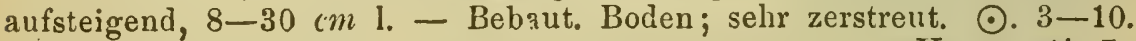

$$
V \text {. agrestis } \mathrm{L} \text {. }
$$

Blkr. blau, St. liegend od. aufsteigend, ästig, bis $30 \mathrm{~cm} \mathrm{l.} 27$.

27. Kelchzipfel länglich od. eilänglich, am Grunde dicht abstehendbehaart, Fächer d. rechtwinklig ausgerand. Kaps. am Rücken gekielt, drüsenhaarig; Bl. weich und grau behaart, länglich od. eiförm. rundlich. - Äcker, zerstreut. $\odot .3-5$.

V. opáca Fr.

Kelchzipfel br. eiförmig, angedrückt behaart, Fäçher d. spitzwinklig ausgerandet. Kaps. nicht gekielt, kurz drüsenhaarig; Bl. dicklich, fast kahl, eiförmig-rundlich. - Bebaut. Boden, verbreitet. ๑. 3-10.

V. polita Fr.

\section{Fam. LXX. Rhinantháceae. Klappertopfartige.}

\section{Schlïssel der Gattungen.}

1. Grüne beblätterte $\mathrm{Pfl}$., Kapsel 2 fächrig.

Bllose, beschuppte, bleiche od, röthliche Pf.; Kapsel 1 fächrig. 
2. Kelch röhrig od. glockig, 5 zähnig od, 5 spaltig; Blkr. 2 lippig. 3.

Kelch 4 zähnig od. 4 spaltig, Blkr. 2 lippig.

3. Kelch 5 zähnig, glockig, Oberlippe der Blkr. flach 2 lappig, Unterlippe 3 lappig; Kaps. durch Fehlschlagen 1 fächrig, wenigsamig.

Tozzia (409).

Kelch 5zähnig od. 5 spaltig, aruch 2 lippig, mit blartigen Zähnen; Oberlippe d. Blkr. helmförmig, 2 spaltig, Unterlippe 3 spaltig; Kaps. zweifächrig, vielsamig.

Pedicularis (406).

4. Kelch aufgeblasen-zusammengedriickt, netzadrig; Oberlippe der Blkr. zusammengedrückt-helmförmig, 2 spaltig, Unterlippe 3 spaltig.

Rhinanthus (407). glockig.

Kelch weder zusammengedrïckt noch aufgeblasen, röhrig oder

5. Kelch 4spaltig, glockenförmig; Blkr, mit ganzer Oberlippe und 3 spaltiger Unterlippe.

Kelch 4 zählmig.

Bartschia (405).

6. Kelch röhrig od. glockig, Blkr, rachenförmig-2lippig, Oberlippe helmförmig, Unterlippe 3spaltig bis 3 theilig; Samen längsrippig.

Euphrasia (404).

Kelch röhrig, Oberlippe d. Blkr. zusammengedrückt mit umgeschlag. Rändern, Unterlippe mit 2 Höckern im Schlunde, 3spaltig; Samen glatt. Melampyrum (408.

\section{Euphrásia L. Augentrost (XIV, 2).}

Bl. sitzend, untere (od. alle) Stbl. gegenständ., obere und Deckbl. wechselständ.; Blt. in endständ., deckblättriger Ähre.

1. Oberlippe 2 lappig, gezähnt, an d. Rändern zurïckgeschlagen, Zipfel d. Unterlippe ausgerandet; Blt. in allseitswendigen Ähren. 2.

Oberlippe seicht ausgerandet od. ungetheilt, gewölbt, Ränder nicht zurïckgeschlagen; Zipfel d. Unterlippe stumpf, Blt. in l. einseitswendigen Ähren (Odontítes Duby).

8.

2. Blkrröhre während $d$. Blühens sich verlängernd, zuletzt weit aus d. Kelch vorragend, Gr. nach dem Verblühen gerade, Blkr. gr.; St. meist von unten ästig, weichhaarig.

3.

Blkrröhre sich nicht verlängernd, im Kelch eingeschlossen bleibend, Gr. zuletzt halbkreisförmig gebogen; Blkr. kl. (E. officinalis L.) 4.

3. St. oberwärts sammt Deckbl. u. Kelchen drüsenhaarig, 5 bis $25 \mathrm{~cm} \mathrm{h.,} \mathrm{Bl.} \mathrm{br.} \mathrm{eifürmig,} \mathrm{grobgesägt,} \mathrm{untere} \mathrm{stumpfzähnig,} \mathrm{weichbehaart,}$ obere stachelzähnig, druisenhaarig; Blkr. 8-12 mm l., weib, violett gestreift, mit citronengelb. Fleck auf d. Unterlippe (E. pratensis Rchb.). Wiesen. $\odot .7-9$.

E. Rostioviana Hayne.

St. oberwärts sammt Deckbl. u. Kelchen nicht drüsig, Bl. drüsenlos, untere aus keiligem Grunde länglich, gekerbt-gesügt, stumpfzähnig, obere und Deckbl. br. eiförmig. eingeschnitten-gez:̈hnt; Kelch schwarz geadert, Blkr. oft violett iiberlaufen, sonst wie vor. (E. picta Wimm.). - Wiesen, Grasplätze d. Alpen, Sudeten u. d. Kiesengeb., in T., Sz. ๑. 7-9. jederseits).

4. Bl. eiförmig od. länglich, ringsherum gezälnt (wenigstens 3 Zähne 
Bl. schmal, fast lineal, am Grunde keilig, mit 1-2 (entfernt.) Zähnen jederseits.

5. Blkr. sehr kl., höchstens $6 \mathrm{~mm} \mathrm{l.,} \mathrm{mit} \mathrm{ganz} \mathrm{gelb.} \mathrm{od.} \mathrm{weiß.} \mathrm{Unter-}$ lippe; St. einfach, $2-6 \mathrm{~cm} \mathrm{~h}$., untere Bl. rundlich-verkehrt-eiförmig, stumpf-, obere länglich, stachelspitzig gezähnt. - Triften u. Gerölle d. Alpen (1260 bis $2500 \mathrm{~m}$ ). ๑. 7. 8 .

E. minima Schleich.

Blkr. größer, $8 m m$ u. mehr l.; St. auffallend steif, $5-25 \mathrm{~cm}$ h., meist einfach; $\mathrm{Bl}$. kl., entfernt von einander.

6. Bl. dicklich, starr, eiförmig, am Rande etwas umgerollt, mit 5 vortretenden Nerven und $3-5$ haarspitzigen Zähnen beiderseits; Blkr. blassblau od. lila, violett gestreift, mit gelb. Schlundfleck. - Bergwiesen, Waldplätze in Gebirgsgegenden, bis in d. Alpen. $\odot .7-9 . ~ E$. stricta Host.

Bl. weich, flach, mit 3 wenig vortretenden Nerven, eiförm.-länglich; Blkr. fast ganz blau, selten weiß, Unterlippe violett gestreift. - Auf Bergwiesen in B.; sehr zerstreut. $\odot$. 7-9.

$E$. coerílea Tausch.

7. Bl. jederseits 2 zähnig, St. $7 \cdot 5-10 \mathrm{~cm}$ h., einfach oder ästig; Blkr. 6-8 $\mathrm{mm}$ l., Unterlippe weiß oder lila, violett gestreift und gelb gefleckt. Variiert mit großen ganz violetten Blumen (E. cúprea Jord.). Alpentriften (bis $1900 \mathrm{~m}$ ). $\odot .7-9$.

E. Salisburgensis Funk.

Bl. spitz, jederseits mit 1 kurzen, spitzen Zähnchen od. zahnlos; St. bis $15 \mathrm{~cm} \mathrm{h.,} \mathrm{Blkr.} 8-10 \mathrm{~mm} \mathrm{l}$; s sonst wie vorige. - Alpentriften in K., Kr., T.; zerstrent. $\odot .7-9$.

E. tricuspidata L.

8. (1) Blkr. schmutzig-hellroth (selten weiß), Deckbl, u. Bl. (lineallanzettlich), entfernt grob gesägt; St. $14-45 \mathrm{~cm}$ h., Deckbl. länger als die Blkr. - Feuchte Äcker, Ufer. ๑. 6-10.

$E$. Odontites L.

Blkr. gelb, Deckbl. kürzer als die Blkı.; St. steif, sehr ästig, $15-45 \mathrm{~cm}$ h., Bl. lineal-lanzettlich. - Bebuschte Hïgel, Waldplätze; zerstreut. $\odot .6-10$.

E. lútea L.

\section{Bartschia L. (XIV, 2).}

St. einfach, bis $20 \mathrm{~cm}$ h., Bl. sitzend, kreuzweis gegenständig, eioder herzeiförmig, grob gekerbt; Blt. achselständig in dichter Ähre, Blkr. und Deckbl. dunkelviolett. - Quellige Orte, torfige Wiesen und Triften der Alpen, des Gesenkes und Riesengebirges. 4. 6-8. B. alpina L.

\section{Pediculáris L. Läusekraut (XIV, 2).}

Bl. einfach-oder doppeltfiedertheilig, Blt. meist in deckblättriger endständiger allseitswendiger Ähre. Saftvolle $\mathbf{K r}$.

1. Stengellos, Bl. und Blt. grundständig, Bl. gestielt, fiedertheilig, Blt. kurz gestielt, Blkr. röthlich-weiß. - Feuchte bebuschte Abhänge iu Kr. u. T.; zerstreut. 4. 4. 5 . $P$. acaulis Scop.

Stengeltreibende Kr., St. beblättert, selten nackt (bloß b. P. rosea).

2. Oberlippe in einen linealen Schnabel ausgezogen (rostrata), Stbl. wechselständig.

Oberlippe nicht geschnäbelt, Blkr. rosenroth oder purpurn.

3. Blkr. rosen- bis purpurroth.

Blkr. gelb. 
4. St. $15-45 \mathrm{~cm}$ h., viel länger als die grundständigen Bl., beblättert, alle Bl. tief kammförmig-fiedertheilig, mit fiederspaltigen oder eingeschnittenen Theilstücken; Blt. in langen Ähren, ̈̈hrenspindel, Deckbl.u. Kelche weißwollig. - Steinige Alpenwiesen i. 00e., St., K., T.; (1260 bis $2000 \mathrm{~m})$. 4. 7. 8.

$P$. incarnáta $\mathbf{L}$.

St. höchstens $10 \mathrm{~cm}$ h., kaum länger als die Grundblätter; Blt. in länglichen od. halbkugligen, am Grunde beblätt. Doldentrauben.

5. Bl. kammförmig, 2 fach fiedertheilig, Blt. gr. hellpurpurn. Kahl. - Steinige Triften. Felsspalten der Alpen von 00e., K., T. (1260 bis $2000 \mathrm{~m})$. 4. 7. 8.

$P$. Jacquinii Koch.

Bl. kammförmig 1 fach fiedertheilig, Zipfel ungleich gesägt, Blkr. gr., hellroth.

6. Oberlippe sehr schmal, halbkieisförm. gekrümmt, Unterlippe sehr breitlappig, Röhre 1. u. schmal, weit vorragend; St. zart, 1-3 bltig, Blt. 1. gestielt. - Fecichte Grasplätze der Granitalpen v. K., St., T. (2000 bis 2550 m.); zerstreut. 4. 6. 7.

P. Portenschlagii Saut. geschlossen.

Oberlippe breiter, sichelförmig, Unterlippe schmallappig, Röhre ein-

7. St. aufrecht, obenhin sammt den Kelchen von 1. gegliederten Haaren zottig. - Feuchte kiesige Plätze der höchsten Centralalpen in Sz., St., K., T. (2000-2600 m.); zerstreut. 4. 7. 8. P. asplenifolia Flörke.

St. áufsteigend, 1-2 reihig behaart, Kelche zottig. - Feuchte Wiesen und Triften der Kalkalpen von Noe., St, K., Kr., T. (1580-2500 m). 4. 7. 8 .

$P$. rostráta $\mathrm{L}$.

8. (3). Ähre kopfig, dicht, Kelchzipfel kahl; St. 10-15 $\mathrm{cm}$ h., unten nebst den Bltstielen weichzottig; Bl. fiederschnittig mit fiederspaltigen Zipfeln; Wzst. knollig. - Feuchte Wiesen und Triften der Alpen von K., Kr., 'T. 4. 7. 8.

P. tuberosa L.

Ähre 1., locker, Kelchzipfel gewimpert; St. $15-35 \mathrm{~cm}$ h., 2 zeilig behaart, Wzst. walzig lznotig, sonst wie vorige. - Bergwiesen der Kalkund Dolomitalpen vou K. u. T. 4. 7.

$P$. elongáta A. Kern.

9. (2). Oberlippe der Blkr. abgestutzt und in 2 Spitzen vorgezogen (bidentatae).

10.

Oberlippe stumpf, weder geschnäbelt, noch 2 spitzig (erostratae) 11.

10. St. nur am Grunde åstig, $2 \cdot 5-15 \mathrm{~cm}$ h., Äste liegend od. aufsteigend; Bl. fiedertheilig, Tueilstuicke oval fiederspaltig; Blt. in kurzen dichten Ähren. - Moosige sumpfige Waldwiesen. 4. 5. 6.

\section{P. silvática L.}

St. bis zur Mitte ästig, 15-30 cm h., Äste aufrecht-abstehend; Bl. kammförm. fiedertheilig, Theilstück länglich, gezähnt; Blt. achselständig, in 1. beblätterten Ähren. - Sümpfe, Ufer. 4. 5-7. P. palustris L.

11. Stbl. zu 3-5 quirlständ., alle Bl. kammförmig-fiedertlıeilig, Theilst. länglich, gezähnt; St. $5-20 \mathrm{~cm}$ h., Ähren quirlbltig, kopfig. Feuchte, steinige Triften der Kalkalpen (1260-2000 m). 4.6-8.

$P$. verticilláta $\mathrm{L}$.

Stbl. wechselständig oder fehlend.

12. Blkr. gelb, gelblichweiß oder gelb mit rothen Flecken.

Blkr. purpurn oder rosa 
13. Blkr. gelb mit einem rothen Fleck unter der Spitze der Oberlippe; St. $2 \cdot 5-10 \mathrm{~cm}$ h., Bl. kammfürm. 1 fach fiedertheilig, Tbeilstücke eilänglich, gekerbt. - Felsspalten und Gerölle der Alpen von St., K., T.; zerstreut. 4. 6. 7. $\quad$. versícolor Wahlenb.

Blkr, einfarbig gelb oder gelblichweiß; St. $0.15-1.30 m$ h.; reich beblättert; BI. 1-2 fach fiederschnittig, Abschnitte fiederspaltig; Ähre beblättert.

14.

14. Ähre $5 \mathrm{~cm} \mathrm{l.,} \mathrm{Oberlippe} \mathrm{zottig,} \mathrm{Blstiele} \mathrm{und} \mathrm{Bi.} \mathrm{zerstreut} \mathrm{be-}$ haart. - Gerö!le und Triften der Alpen. 4. 6. 7. P. fuliosa L.

Ähre 10-25 cm l., Oberlippe, St. u. Bl. kahl. - Gerölle d. Kalkalpen von K., Kir., siidl. T.; zerstreut. 4. 7. 8. P. Hacquetii Graf.

15. (12). St. 1 blättrig oder bllos, $0 \cdot 30-1 m$ h., obenhin sammt Deckbl. u. Kelchen weißwollig; Bl. fiederschnittig, Abschn. lineal-lanzettlich, eingeschnitten gesägt; Ähre kurz, kopfig. - Kiesige Triften der Kalkalpen. 4. 7. 8.

P. rósea L.

St. 15-60 $\mathrm{cm}$ h., wenig beblättert, nebst d. Bl. kahl; Bl. kammförmig fiedertheilig, Theilstücke br. lineal oder länglich, gekerbt bis fiederspaltig.

16.

16. Kelch, Deckbl. und Ährenspindel zottig, Ähre länglich. -- Torfige Kammtriften des Riesengebirges. 4. 6. 7. P. sudética Hänke.

Ganze Pfl. kahl, Ähre walzig. - Feuchte Plätze der Alpen. (1260 bis $1900 \mathrm{~m}) .7 .6 .7$.

P. recutita $\mathrm{L}$.

\section{Rhinanthus L. Klappertopf (XIX, 2).}

St. 4 kantig, einfach od. ästig; Bl. sitzend, kreuzweis gegenständ.; Blt. in endständ. beblätt. Ähren; Deckbl. eilanzettförm, eingeschnitten. gesägt; Blkr. gelb.

1. Deckbl. grün, Blkr. kl., ihre Röhre gerade, kürzer als der Kelch; St. 15-30 cm h., bisweil. braun gestrichelt (var. fallax Wimm. Grab.) Bl. lineal-lanzettförm., gesägt. Kahl. - Wiesen, Saaten. ๑.5. 6.

Deckbl. bleich. Rh. minor Ehrh.

2. Blkr. gr., Röhre aufwärts gelsrümmt, d. Kelch ïberragend. 3.

Blkrröhre kurz, plötzlich in d. stark gekrümmte Oberlippe übergehend, Unterlippe bläu gefleckt, nach abwärts gerichtet, Zähne d. Oberlippe blau; St. 5-30 cm l., blauschwarz gestrichelt, Bl. aus herzeiförm. Grunde länglich-lanzettförm., grobgesägt. Kahl. - Hochgebirgswiesen u. steinige Triften, bis in d. Alpen. $\odot$. 7. 8. Rh. alpinus Baumg.

3. St. Äste, Bltstiele u. Kelche weichzottig; Blkr. bis $20 \mathrm{~mm}$ l., goldgelb m. blauen Zähnen d. Oberlippe; St. $0 \cdot 30-1 \cdot 30 m \mathrm{~h}$., Bl. bleichgrïn, länglich-lanzettförmig. - Unter Getreide in Gebirgsgegenden $\odot$. $5-7$.

Rh. hirsútus All.

Ganze Pfl. fast kahl, Zähne d. Oberlippe blau, St. $25-60 \mathrm{~cm}$ h. 4 .

4. Bl. aus herzförm. Grunde länglich bis länglich-lanzettförm., grobgesägt; Deckbl. am Grunde mit 3 eckig-lanzettl. Zähnen; St. oft braun

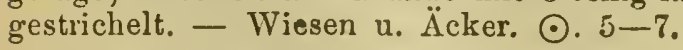
Rh. major Ehrh.

Bl. aus gerundetem Grunde lineal od. lineal-lanzettlich, scharf gesägt, Deckbl. am Grunde mit schmalen langen grannigen Zähnen; St. schwarz gestrichelt (Rh. angustifuliae Gmel.?) - Raine, Hügel, Trifien; zerstrзut. $\odot .7-9$. Rh. serótinus Schönh. 


\section{Melampýrum L. Wachtel-, Kübreizen (XIV, 2).}

St. aufrecht, 15-60 $\mathrm{cm}$ h., Bl. sitzend, kreuzweis gegenständ.; Blt, von Deckbl. gestützt, ährig oder traubig.

1. Ähren allseitswendig, dicht, 4 kantig oder kegelförmig.

Ähren einseitswendig, lockerbltig.

2. Ähren 4 kantig mit dachigen herzförm. kammartig gezähnten, meist purpurn überlaufenen Deckbl.; Blkr. $12 \mathrm{~mm}$ l., purpurn, mit dottergelb. Unterlippe; Bl. lineal-lanzettförm. - Waldwiesen, Gebüsche. $\odot$. 6. 7.

Ähre walzig. M. cristatum $\mathrm{L}$.

3. Deckbl. grün, am Rande kammförmig zerschlitzt, Blkr. $25 \mathrm{~mm}$ 1., citrongelb; untere Stbl, lineal, ganzrand, obere eilanzettförm., beiderseits mit 2-3 l. Zähnen. - Unter den Saaten in Noe., K.; zerstreut. ๑. 6. 7. M. barbátum W. Kit.

Deckbl. purpurroth, am Rande kammförm. zerschlitzt; Blkr. 16 bis $20 \mathrm{~mm}$ 1., purpurn mit gelbem Schlunde; Stbl. lanzett- od. eilanzettfürm. - Saaten, Gebüsche. $\odot$.6. 7.

$M$. arvense $\mathrm{L}$.

4. (1) Deckbl. br., am Grunde herz-oder spießförm., sonst ei- odel eilanzettförm., $d$. mittleren und oberen violettbiau, selten wei $\beta$, $d$. obersten schopfig; Blkr. bis $20 \mathrm{~mm}$ l., goldgelb, Stbf. eilanzettförm. - Laubwälder, Gebiische. $\odot$. 7. 8 . M. nemorósum L.

Deckbl. länglich am Grunde augerundet od. verschmälert, grün. 5 .

5. Deckbl, anders geformt ais die Stbl.

Deckbl. mit d. Stbl. gleichgeformt, nur kleiner, alle Bl. lanzett- od. lineal-lanzettförm., spitz; Blkr. 6-8 $\mathrm{mm}$ l., goldgelb. - Gebirgswälder. $\odot .6-8$.

M. silváticum L.

6. Deckbl. lanzettlich, am Grunde abgestutzt und beiderseits mit 1-3 l., lanzettlich-pfriemlichen Zähnen; Blkr. 12-18 $\mathrm{mm}$ l., weißlich od. citrongelb mit geschlossenem Schlunde; Stbl. eilanzett- bis lineal-lanzettförm. - Waldwiesen, Wälder. $\odot .6-8$.

MI. pratense L.

Deckbl. lineal-lanzettlich, am Grunde jederscits kurz 2 zähnig; Blkr. kl. trichterig.2 lippig, mit offenem Schlunde und in 3 stumpfe Zähne gespaltenør Unterlippe: Stbl. lineal-lanzettlich. - Laub- und Nadelwälder im nordöstl. B. u. in Mh.; zerstr. ๑. 7-9. MI. bohémicum. A. Kern.

\section{T6zzia L. (XIV, 2).}

St. ästig, 4 kantig, $15-30 \mathrm{~cm}$ h., rückwärts behart'; Bl. kreuzweis gegenständ., eiförm., grobgesägt; Blt. einzeln blwinkelständ., Blkr. 6 mm l., goldgelb, roth punktiert. Feuchte Felsen- und Geröllplätze der Alpen von 0e., K., T., auch in Sch. (selten). 4. 6. 7.

T. alpina $\mathrm{L}$.

\section{Lathraéa L. Schuppenwurz (XIV, 2).}

Fleischig, weiß, blassrosa od. purpurn überlaufen. Wzst. ästig, viele $15-30 \mathrm{~cm}$ h. St. treibend; Blt. in einseitswend. deckblättr., drüsigtaumig. Ähre, Blkr. 2 lippig, purpurn. - Feuchte Laubwälder, auf Baumwurzeln; zerstreut. 4. 4. 5 .

L. Squamária L. 


\section{Fam. LXXI. Orobaincheae. Sommerwurzartige.}

\section{Orobarche $\mathbf{L}$. Sommerwurz $(X I V, 2)$.}

Bllose, nicht grüne, bleich-oder buntfarbige Schmarotzerpfl, deren meist zwieblig angeschwollene Stbasis mit $d$. Wurzeln lebender Planzen verbunden ist. Stbasis stets dicht beschuppt, St. genähert od. entfernt beschnppt, meist einfach; Blt. in endständ. allseitswendiger Traube oder Ähre, von Deckbl. gestützt; Blkr. 2 lippig, Fr. eine 2 klappige vielsamige Kapsel. Zerstreut vorkommende Pfanzen.

1. Blt. kurz gestielt, außer d. Deckbl. ron 2 kleinern, am Stiel eingefügten gegenständigen Schuppen gestützt; Kelch röhrig, 4-5 spaltig. (Gatt. Phelipaea C. A. Mey.)

Blt. sitzend, nur von dem Deckbl. gestiitzt; Kelch am Rücken gespalten, aus 2 vorn verwachsenen oder ebenfalls getrennten ganzen oder 2 spaltigen Bl. bestehend (Orobanche Auct.)

2. St. ästig, 5-10 $\mathrm{cm}$ h., Blkr. 1-12 $\mathrm{mm}$ l., am bauchigen Grunde gelblichweiß, mit bleicblila bis amethystblauem Saum; Ähre l., schmächtig, locker. - Auf Hanf, Tabak, Mais und anderen Pfanzen in Mh., Oe., K. $4 \cdot 6-9$.

O. ramosa $\mathrm{L}$.

St. einfach, Ähre meist gedrängtbltig.

3. Kelchzähne länger als die bauchige Kelchröhre, Blkr. 26 bis $35 \mathrm{~mm}$ lang, röhrig, wenig gekrümmt, trichterig erweitert, außen hell-, inwendig tiefblau; St. $20-45 \mathrm{~cm}$ h., sammt Deckbl. und Kelchen bleichgelb. - Auf Artemisia campestris in B., Mh., Noe., K. 4.7.

O. arenária Borkh.

Kelchzähne kürzer als d. Röhre, Blkr. röhrig gekrümmt. 4.

4. Kelchzähne lanzettlicb, ganzrandig, durch stumpfe Buchten getrennt; Blkr. $18-25 \mathrm{~mm}$ l., außen bleichviolett, dunkler geadert, Sairn azurblau oder violett; St., Deckbl., Kelche und Blkrröhre bleichgelblich, mehr oder weniger stahlblau od. braunviolett überlaufen; St. 20-25 cm b. - Auf Achillea Millefol. u. a. Arten. 4.6. 7. O. purpuirea Jcqu.

Kelchzähne lanzettlich, pfriemlich, gezähnelt, durch spitze Buchten getrennt; Blkr. aufgerichtet, in d. Rückenmitte nach auswärts gekrümmt, dunkel violett; St. $15-36 \mathrm{~cm}$ h., nebst Deckbl. u. Kelchen drüsenhaarig und schmutzig-violett. - Auf Artemisia campestr, in B., hie und da. 4. 7. O. bohémica Čelak.

5. (1). Blkr. unter d. Einfügangsstelle d. Sthg. bauchig aufgetrieben, bogig gekrümmt, 12-16 $\mathrm{mm}$ l, blau od. amethystfarben; St. 15-25 cm h. nach oben weiß-spinnwebwollig. - Auf Artemis. campestr. in B., Mh., 0. 4. 6. 7 .

$O$. coerulescens Steph.

Blkr. röhrig, unter d. Einfügungsstelle der Stbg. verengt.

6. Ruickenlinie der Blkr. winklig gebrochen, auf d. Oberlippe abschüssig; Narbenlappen halbluglig.

7.

Riickenlinie vom Grunde aus bogig, Narbenlappen verschieden geformt, meist gelb oder orange.

9.

7. Narbenlappen gelb, Blkr. 20-30 $\mathrm{mm}$ l.. bleichbraun oder hellviolett, am Grunde gelb (selten citrongelb oder fleischfarben: O. lutea Baumg.); St. $20-70 \mathrm{~cm}$ h., braunroth bis schmutzig-violett. - Auf Medicago- und Trifoliumarten; zerstreut. 4. 5. 6. O. rubens Wallr. 
Narben karminroth od. kastanienbrau (selten, bei gleicher Färbung der ganzen PA. gelblich oder weißlich.)

8. Blkr. 20-30 $\mathrm{mm}$ l, gelblich nelkenbraun od. röthlichviolett, Narben braunpurpurn; St. $15-40 \mathrm{~cm}$ b., reichlich beschuppt, sammt den Kelchen hellgelb (trucken rothbraun). - Auf Teucrium montanum u. Chamaedrys in 0e., St., K. 4. 6. 7.

O. Téucrii F. Schultz.

Blkr. 18-25 $\mathrm{mm} \mathrm{l.,} \mathrm{braungelb} \mathrm{od.} \mathrm{röthlich} \mathrm{(vertrocknet} \mathrm{schwärzlich-}$ braun), Narben dunkel karminroth ; St. $20-55 \mathrm{~cm}$ b., weißlich bis röthlichbraun, nach oben spärlich beschuppt. - Auf Galium Mollugo, verum, silvat. u. Asperula galioides; verbreitet. 4. 6. 7. O. caryophyilácєa $\mathrm{Sm}$. fiigt.

9. (6). Stbg. im ersten Drittheil oder Viertheil der Blkrröhre einge-

Stbgef. nahe d. Grunde d. Blkrröhre eingefügt; Blkr. weit glockig, bis $25 \mathrm{~mm}$ l., gelb, gegen d. Oberlippe rothpurpnrn, innen trüb blutroth, glänzend (selten ganz gelb); Narben kuglig, schmal zusammenfließend, gelb, oft braunpurpurn berandet; St. $20-50 \mathrm{~cm}$ b., gelb, am Grunde röthlich überlaufen; Blt. wohlriechend (O. cruenta Bertol.). - - Auf verschiedenen Schmetterlingsblïtlern in 0e., St., T., K., Kr. 4. 6-8.

O. grácilis Sm.

10. Oberlippe d. gr. weitglockigen Blkr. mit dunklen, oft auf einem Knötchen sitzenden Drüsenbaaren bestreut (wie punktiert); Narbenlappen kuglig, br. verbunden.

Oberlippe mit hellen Drüsenhaaren bedeckt.

11.

12.

11. Kelchbl. deutlich nervig, trocken braun; Bikr. $20 \mathrm{~mm} \mathrm{l.,} \mathrm{weiß}$ od. gelblich, gegen die Oberlippe mehr weniger roth, selten purpurn überlaufen; Narben dunkelroth, selten orange; St. $7 \cdot 5-60 \mathrm{~cm} \mathrm{h.,} \mathrm{mehr} \mathrm{weni-}$ ger rothbraun, am Grunde kaum verdickt (O. Epithýmum DC.). - Auf Thymus Serpyllum u. a Labiaten. 4. 5. 6.

O. alba Steph.

Kelchbl. verwischt nervig, getrocknet schwärzlich; Blkr. 18-23 $\mathrm{mm}$ 1., Narben schwarzviolett, St. am Grunde verdickt. 4. 6.

O. pallidiflóra Wimm. Grab.

Variet.: $\alpha$. pallidiflor a (O. Cirsii Fr.), Blkr. bleichgelb, Oberlippe bleich violett. mit violett, Drüsenhaaren; St. bräunlichgelb, unten violett iiberlanfen. Auf Cirsium arvense u. a. Disteln, in B., Mh., Oe.; - $\beta$. platystigma (Rchb.), Blkr. gelblichweiß, gegen d. Oberlippe violett bis schwärzlich, St, hellgelb, violett überlaufen. Auf Skabiosen, Carduus deflorat., Cirsien in 0e., St., K., 'T.

12. (10) Blkr. 20-25 mm. l., Stlug. im ersten Drittheil der Röhre eingefiigt, Narben bisquitförmig, mit tiefer Querfurche, gelb 13.

Blkr. 8-20 $\mathrm{mm}$ l., Stbg. im 1. Viertheil eingefügt, Narben br. verbunden, mit br. Querfurche, violett

16.

13. St. am mittleren Theile reichlich beschuppt, Zwischenräume der Schuppen kiurzer als diese; Blkr. rosenruth, später gelblich (vertrockuet nicht dunkler); St. $15-60 \mathrm{~cm}$ h. roth überlaufen. - Auf Centaurea Scabiosa u. a., sehr zerstreut. 4. 6. 7.

O. elátior Sutt.

St. im mittleren Theile spärlich beschuppt, Schuppenzwischenräume größer als d. Schuppen; Blkr. gelblich od. hollviolettbraun (vertrocknet meist dunkler) 
14. Oberlippe tief 2 lappig, Zipfel d. braunvioletten Blkr. fast kahl; St. $12-55 \mathrm{~cm}$ h., gelblich, l. drüsig-behaart, getrocknet schwarz. - Auf Salvia glutinosa in d. Kalkalp. v.0e., Sz., St., K. 4.7. 8. O. Salviae F. Schz.

Oberlippe ganzrandig, Zipfel d. Unterlippe reichlich d̉rüsenhaarig 15.

15. Kelchbl. 1 nervig, Blkr. gelb, mit gleichfarbigen Adern, sehr rasch vertrocknend, Lappen d. Oberlippe anfangs kappenförmig vorgezogen später zurückgeschlagen; St. 20-65 $\mathrm{cm}$ h., auch oben reich beschuppt, hellgelb. - Auf Petasit. niveus, alb. u. officin. in d. Kalkalp. v. Oe. 4. 7.

O. flava Mart.

Kelchbl. mehrnervig, Blkr. bräunlichviolctt, dunkler geadert, Oberlippenlappen abstehend, St. bleich 4.

O. alsática Kirschl.

Variet. $\alpha$ Laserpitii Sileris (Reut.) St. $40-80 \mathrm{~cm} \mathrm{~h}$, am Grunde keulig, Blkr. $25 \mathrm{~mm}$ l. u. länger, in gr. dichter Ähre. Auf Laserpit. Siler. in d. Alpen v. Noe. 7. S.; - $\beta$. Cervariae (Suard.) St. $20-55 \mathrm{~cm}$ h., am Grunde wenig verdickt; Blkr. u. Ähre kleiner. Auf Peuced. Cervaria u. Libanot. mont. in M. u. Noe. (selten!)

16. (12) Blkr. 8-15 $\mathrm{mm}$ l., gelblichweiß lila geadert od, gegen vorn violett überlaufen, Schlund geschlossen, Zipfel d. Oberlippe vorgestreckt; St. 10-15 cm h. - Auf Kleefeldern in B., Mh., Oe., St., K. 4. 6.

O. minor Sin.

Bikr. 15-20 $\mathrm{mm}$ 1. gelblichweiß, röthlich od. lila geadert, Schlund weit geöffnet, Zipf. d. Oberlippe umgeschlagen. -) 6. 7. O. loricata Rchb.

Variet. $\alpha$. Picrid is (F'. Schz.), Deckbl. so l. wie d. Unterlippe, Stbg. kahl, St. 18-54 $\mathrm{cm}$ h., gelblich od. (wio d. Kelchzähne) roth iiberlaufen, 1. driisenhaarig. Auf Picris hieracioid. in B., Oe., St., Kr.; $-\beta$ loricata, Deckbl. länger als die Unterlippe, Stbg. drüsenhaarig, St. $14-38 \mathrm{~cm}$ h. Auf Artemis. campestr. in B., Oe., K., T.

\section{Fam. LXXII. Plantagineae. Wegerichartige.}

\section{Plantágo L. Wegerich, Wegebreit. (IV, 1).}

Blt. kl. unscheinbar, sitzend, in Ähren od. Köpfchen, von Deckschuppen gestützt; Blkr. glänzend strohgelb od. bräunlich, Stbg. vorstehend. Kräuter.

1. Bl. grundständig, gebiischelt od. in Rosette; entständ. Ähre auf blosem einfachem Schaft. Ausdauernd mit Wrzst.

Bl. gegenständ., lineal, an einem meistästigen, $15-30 \mathrm{~cm}$ h. St.; achselständ. 1. gestielte Köpfchen. Kurz steifhaarig. - Auf Sandbod. in B., Mh., Oe.; zerstreut. $\odot$ 7. 8 .

$P$. arenária W. Kit.

2. Blkrröhre kahl.

Blkrröhre behaart.

3. Bl. eiförmig, oval, elliptisch, krummnervig; Deckschuppen krautig, nur am Rande trockenhäntig.

Bl. lanzettförmig parallelnervig; Deckbl. ganz trockenhäntig. $\mathbf{5}$.

4. Bl. locker gebuischelt, aufrecht abstehend, l. gestielt, kahl; Schaft kantig gefurcht, mit d. Ähre $15-30 \mathrm{~cm}$ h., länger als d. Bl, Ähre walzig, frtragende sehr verlängert; Wrzst. kurz. - Schutt, bebauter Boden. 4. $5-9$. 
Variet. leptostáchys Wallr. (P. asiatica Decne), niedrig, Bl. dünn, Schäfte dünn, aufsteigend, Ähre armbltig, diinn, locker. Auf sterilem Sandboden, stellenweis.

B1. in einer dem Boden angedrückten Rosette, elliptisch, spitz, kurz gestielt, knrzhaarig; Schaft $8-50 \mathrm{~cm}$ h., Ähre länglich, Stbf. 1., violett, Stbb. weißlich. - Wiesen, Raine. 4. 5-9.

P. media L.

5. Schaft kantig, gefurcht, bis $30 \mathrm{~cm}$ h., Bl. $3-7$ nervig aufrecht Ähre eiförnig bis walzig, Stbf. l., nebst den Beuteln gृelblichweiß. Wiesen. 4. 5-9.

P. lanceolata L.

Variet. $\beta$. altissima (L.), Schaft bis $1 m \mathrm{~h}$., Bl. bis $30 \mathrm{~cm}$, Ähre $5-7.5 \mathrm{~cm}$ l. Sumpfwiesen in Ve., Kr., T.; $\gamma$. púmil a Maly. Sck. 7-15 $\mathrm{cm} \mathrm{h}$, Ahre kuglig, Bl. bis $5 \mathrm{~cm}$ l. (P. sphacrostáchya M. et K.). Auf diurrem Loden.

Sch. rund, Bl. 3-5 nervig, Ähre eiförmig.

6. Bl. ang edrückt wollig, weiß, seidenglänzend; Sch. sammt Äbre 10-15 $\mathrm{cm} \mathrm{h.,} \mathrm{Deckschuppen} \mathrm{kastanienbraun.} \mathrm{-} \mathrm{Steinige} \mathrm{Orte} \mathrm{in} \mathrm{T.} \mathrm{und}$ Kr. 4. 5. 6. (P. argéntea Vis.) P. capitata Hpp. Hornsch.

B1. grür, nebst d. $2 \cdot 5-15 \mathrm{~cm}$ h. Sch. zerstreut wollhaarig; Deckbl. schwarzbraun. - Triften d. Kalkalpen $(1260-1900 \mathrm{~m})$, auch im Mährischen Gesenke. 4. 7. 8.

$P$. montana Lamk.

7. (2) Bl. schmallineal, 3-kantig, kurz, steif; Sch. $25-10 \mathrm{~cm} \mathrm{h.;}$ Ähre länglich ol. kopfig. - Steinige sonnige Plätze ir K., Kr., T. zerstreut. 2. 7-9.

$P$. serpentina Lam.

Bl. lineal od. lineal-lanzettlich, 3-5 nerrig, fleischig, kahl, Sch. $5-30 \mathrm{~cm} \mathrm{~h}$, ̈̈hre $2.5-10 \mathrm{~cm} \mathrm{1.} \mathrm{-} \mathrm{Salzige} \mathrm{Wiesen,} \mathrm{Triften,} \mathrm{Ufer} \mathrm{in} \mathrm{B,}$ Uh., Noe.; zerstreut. 4. 6-9.

P. maritima L.

\section{Litorella L. Strandling. (XXI, 4).}

Wrzst. faserig, Bl. lineal-pfriemlich, querfächrig; männl. Blt. einzeln, gestielt, weibl. zu 2-4 beisammen. - Teiche u. Seeufer in B. uná IIh. (?) 4. 6. 7.

I. lacustris L.

\section{Fam. LXXIII. Utriculariécie. Wasserschlanchartige.}

\section{Pinguícula L. Fettkraut (II, 1).}

Bl. in Rosette, länglich bis verkehrt-eiförm., ganzrand., am Rande sich einrollend, gelbgrün; BIt. l. gestielt; nickend. Stengellose, klebrig. drüsige, insectenfangende $\mathrm{Kr}$.

1. Blkr. hellviolett, $12-25 \mathrm{~mm}$ l., Sporn walzig-pfriemlich, $2 \mathrm{mal}$ kürzer als die Blume; Bltstiele bis $20 \mathrm{~cm}$ h. - In Torfmoospolstern auf Sumpfwiesen. 4. 5. 6.

$P$. vulgaris $\mathrm{L}$.

2. Blkr. weiß mit 2 gelb. Flecken auf d. Unterlippe, $8-16 \mathrm{~mm}$ 1., Sporn kegelförm., viel kürzer als d. Blume. - An gleichen Orten in d. Alpen. 4. 4. 5.

$P$. alpina $\mathrm{L}$.

\section{Utriculária I. Wasserschlauch (II, 1).}

Untergetauchte Wassergewächse mit fadenförm., ästigem St.; Bl. vieltheilig mit linealen Zipfeln und zum Insectenfang bestimmten Blasen; Blt. in 1. gestielten über d. Wasserspiegel emportauchenden Trauben. Sehr zerstreut vo:kommende Pfl. 
1. Bl. 2 zeilig, wiederloolt gabeltheilig; Trauben $2-3$ bltig; Stiel bis $15 \mathrm{~cm} \mathrm{h.;} \mathrm{Blkr}$. lichtgelb, Oberlippe blutroth, Gaumen rothgestreift. Stehende Gewässer, hier u. da 4. 7. 8. U. intermedia Hayne.

Bl. allseitig abstehend.

2. Bl. wiederholt gabeltheilig mit glatten Zipfeln, Trauben 2- bis 4 bltig, Oberlippe ausgerandet, so l. wie d.Gaumen. Kleinblütig. 3. 8 bltig.

Bl. fiederspaltig-vieltheilig, mit dornig gewimp. Zipf.; Traub. 4- bis

3. Unterlippe eiförm., am Rande umgerollt. Blkr. blassgelb, Gaumen rothbraun gestrichelt. - Sümpfe, Torfgräben; ïberall selten. 4. 6-8.

U. minor L.

Unterlippe kreisrund, flach; Blkr. schwefelgelb einfarbig. - Ebenso in $\mathbf{K}$. $\mathbf{T}$. 4.8.

U. Bremii Heer.

4. Oberlippe d. dottergelb. Blkr. rundlich-eiförm., mit d. orange gestreiften Gaumen gleichlang, Stbb. verwachsen. - Stehende u. langsam fließende Wässer. 4. 6-8.

$U$. vulgaris $\mathbf{L}$.

Oberlippe eiförm, länglich, 2-3-mal länger als d. Gaumen, Stbb. frei; sonst wie vor. - An gleichen Orten in B. (viel häufiger als U. vulg.), anderwärts wohl übersehen. 4. 7. 8 .

M. neglecta Lehm.

\section{Fam. LXXIV. Primulaceae. Primelartige.}

\section{Schliissel der Gattungen.}

1. Untergetauchte Wasserpf. mit aufgetauchten Blttrauben; Blkr. mit radförm. Saume. Kapsel mit 5 unten u. oben verbundenen Klappeñ aufspringend.

Land-, selten Sumpfgewächse.

Hottonia (421). 2.

2. Frknot. halb unterständ, mit d. Kelch verwachsen; Kelch u. Blkr. glockig, 5 spaltig; Stbg. 5, außerdem 5 pfriemenförmig ohne Beutel; Kaps. nit 3 Zähnen aufspringend.

Samolus (427).

Frkn. oberständ., frei, Kelch u. Blkr. in d. Regel 5 theilig, Stbg. meist 5 .

3. 5 klappig

3. Blkr. fehlend, Kelch blumenartig glockig, 5 spaltig; Kapsel

Keİch u. Blkrone. Glaux (4:2).

4. Stengellose Kr. mit rosetten- od, büschelförm. Bl, u. nackten grundständ. Bltschäften.

Kr. mit beblättertem St. u. achsel- od. endständ. Blt.

5. Blkr. trichter- od. stieltellerförmig.

Blkr. glockig.

6. Blkrröhre walzig, ohne Schlundschuppen.

10.

6.

9.

Blkrröhre eiförm., im Schlunde vereng t u, beschuppt, Kapsel5klapp. S. 5 klappig.

7. Blkr. langröhrig. Stbg nicht durch einen Ring verbunden, Kaps.

Blkr. kurzröhrig, Stbg. durch einen Ring verbunden, Kaps. 2 klappig. Cortusa (418).

8. HIt, in elnfacher Dolde, Blkr. kl, weiß, Bl. in dichten Rosetten. Androsace (416).

Blt. einzeln am Ende d. Schaftes, sonst wie vor. Aretia (416). 
9. (5) Blkr. kurzglockig, Zipfel zurückgeschlagen, ganz; Kaps. mit 5 sich zurückrollenden Klappen aufspringend Cyclamen (420).

Blkr. glockenförmig mit gefranzten Zipfeln; Kaps. kegeJförmig mit 5 Zähnen aufspringend Soldanella (419).

10. (4) Blkr. meist 7 theilig, sternförmig, weiß, Stbg. meist 7, Kaps. $5-7$ klappig Trientalis (422).

Blkr. 5 theilig, Stbg. 5

11. Kaps. 5, selten 2 klappig; Blkr. rad- od. trichterförmig, kurzröhrig, gelb; Stbf. am Grunde verwachsen

Lysimachia (423).

Kaps. ringförmig mit Deckel aufspringend

12. Blt. 5 zählig, Blkr. radförmig, leicht abfallend Anagallis (425).

BIt. 4 zählig, Blkr. (sehr kl.) mit krugförmiger, unten kuglig aufgetriebener, oben verengter Röhre, lange bleibend Centunculus (426).

\section{Andrósace Tourn. Mannsschild. $(\nabla, 1)$.}

Bl. in dichten Rosetten od. Polstern, ganz, meist auch ganzrand. Blt. kl., meist weiß, mit gelbem Schlund.

1. Wrzst. sehr ästig, Stämmchen dichte, polster- bis walzenförm. Rosetten $\mathrm{kl}$. ganzrand. Bl., von denen d. unteren abgestorben sind, tragend; Blt. einzeln hüllenlos (Aretia L)

Ausdauernde od. einjähr. Kr.; Blt. stets in einfacher Dolde, von einer vielblättr. Hölle umgeben (Androsace L.)

2. Stämmchen säulenförmige Blättermassen bildend, die in einem dichten Rasen zusammengedrängt sind

3.

Stämmchen locker beblättert, zertheilte oder kriechende Räschen bildend; Bl. an d. Spitzen d. Äste in dichter Rosette, gestielt, länglich, sternhaarig; Blkr. weiß bis rosenroth. - Felsspalten, Gletschermoränen in 0oe., St., K., T. $(2000-2700 \mathrm{~m})$ 4. 7. 8 A. glacialis Hppe.

3. Blkr. weiß, Bl. sehr kl. lanzettlich stumpf, kurzhaarig dicht dachig; Blt. sehr kurz gestielt, fast sitzend. - Felsspalten, Gerölle d. Alp. v. Sz. u. T. selten 24.7. 8 . $A$ helvética Gaud.

Blkr. röthlich, rosa bis purpurn 4.

4. Blkrsaum flach, $4-5 \mathrm{~mm}$ br., Zipfel ausgerandet; Blt. kurz gestielt, Bl. kl. länglich od. lanzettf., behaart. - Dolomitfelsen in St., K., T. $(2300-2900 \mathrm{~m}$.); selten 4. 5. 6. A Hausmanni Leyb.

Blkr. trichterig, $8-9 \mathrm{~mm}$ br., Blt. I. gestielt, Bl. lanzettl., spitz, mit Gabelhaaren. - Schieferfelsen d. Alp. v. Sz, St., K. 2. 7. 8. (A. Pácheri Leyb.)

A. Wulfeniana Sieb.

5. (1) Alpenkr. mit vielköpf. Wzst. u. zahlreichen Blrosetten tragenden Stämmchen, welche Rasen bilden

6.

Ein- od. 2-jährige Pf. mit dünner Wrz.; Bl, meist gezähnt in einer dem Boden angedrïckten Rosette

9.

6. Kahl, nur d. grasgrüne lineal-lanzettl. Bl. spärlich gewimpert; Blkr. weiß, 8-10 $\mathrm{mm}$ br. Schaft 5-15 $\mathrm{cm}$ h. - Felsspalt. d. Kalkalp. (1250 bis $1900 \mathrm{~m}$ ). 4. 6 . 7

A. läctea L.

Schaft, Hülle, Bltstiele u. Kelche (oft auch Bl.) zottig od. flaumig, Schaft $2 \cdot 5-10 \mathrm{~cm} \mathrm{~h}$. 
7. Bl. grün fast kahl, lanzettlich, in offener Rosette; Schaft, Bltstiele u. Kelche flaumig; Blkr. weiß od. röthlich, $6-8 \mathrm{~mm}$ br. - Felsen, Gerölle d. Alp. (bis $2500 \mathrm{~m}$ ) 4.6. 7

A. obtusifulia All.

Variet. na na Pach. Bl. sehr $\mathrm{kl}$. abgerundet sternhaarig. In $\mathbf{K}$.

Ganze PA. mehr weniger weißzottig, Blkr. 6-8 $\mathrm{mm}$ br:

8.

8. Bl. in offener Rosette, nur am Rande langzottig, länglich-lanzettförm.; Blkr. weiß. - Felsen u. Gerölle d. Alp. (1500-2500 m) 4. 6-8 A. Chamaejásme Host.

Bl. in halbkugligen Rosetten, ganz weißzottig, Blkr. röthlich. Felsen d. Kalkalp. 4. 6-S

A. villósa. $\mathrm{L}$.

9. (5) Blkr. länger als d. Kelch, weiß; Hüllhlättchen viel kürzer als d. Bltstiele, St. 8-15 $\mathrm{cm}$ l., Dolde vielbltig. - Sonnige Hügel, Äcker, besond. auf Sand in B., Mh., Noe., T.; zerstreut. $\odot, \odot 5.6$

\section{A. septentrionalis $\mathrm{L}$.}

Blkr. kürzer als d. Kelch

10.

10. Frkelch nicht wesentlich vergrößert, Blkr. weiß, Bltsticle zur Frzeit nicht so l. wie d. $3-10 \mathrm{~cm}$ l. St.; Bl. lanzettförm. - Auf Sandbod. in B., Mh., Noe. $\odot$. ๑. 4. 5.

A. elongáta L.

Frkelch sehr gr., mit blartigen Zipf., Blkr. röthlich, Bltstiele kurz, kaum länger als d. verkehrteiförm. Hüllbl.; St. 5-15 cm l., klebrig-flaumig. - Auf Sand. u. Kalkbod. in Ml. u. Noe.; zerstreut. ๑. 4. 5.

A. máxima L.

\section{Primula L. Primel $(V, 1)$.}

Bl. grundständ., eine Rosette od. einen offenen Büschel bildend; Blt. in einfacher, von Hüllschuppen umgebener Dolde auf nacktem grundständ. Schaft, selten einzeln, grundständ., l. gestielt.*)

1. Bl. in d. Jugend zurückgerollt, Kelch 5 kantig

Bl. jung einwärts gerollt, Kelch ohne Kanten (Auricula)

2. Blt. einzeln auf 1. grundständ. Stiel, geruchlos; Blkrsaum flach, $25 \mathrm{~mm}$ l., schwefelgelb; Bl. länglich, gestielt, wellig gekerbt, runzlig. Wiesen, Gebüsche in den Alpenländern. Auch Zierpflanze mit roth. Blume. 4. $3-5$.

Blt. doldenförmig auf nacktem Schaft.

$P$. acaulis $\mathrm{L}$.

3. Bl. runzlig, eiförmig bis länglich, mit geflügeltem Stiel, behaart od. filzig; Blt. gelb, wohlriechend (Himmelschlüssel).

4.

Bl. glatt, unterseits nebst St., Bltstiel. u. Kelchen weiß, mehlig- uestäubt; Blkr. rosenroth mit gelbem Schlunde.

5.

4. Blkr. flach, 16-25 $\mathrm{mm}$ br., schwefelyelb mit dottergelb. Schlunde; Schaft 15-30 cm h. - Wiesen, Wälder. 4. 4. 5. P. elátior Ehrh.

Variet. hortensis, Blkr. bunt, oft gedoppelt: "Gartenprimel".

Blkr. concav, 8-10 mm br., dottergelb mit orangefarb. Schlunde; Bl. unterseits weißlich dünnfilzigr, sonst wie vor. - Wiesen, Wälder, Bachufer. 4. 4. 5 .

P. officinalis Scop.

5. Blkrsaum 5-6 mm br., Röhre $1 \frac{1}{2}$ mal so l, wie d. Kelch, Schaft $5-25 \mathrm{~cm} \mathrm{~h}$. - Feuchte, torfige Wiesen u. Triften in Oe., St., K., Kír. 4. 5. 6 .

P. farinosa L.

*) Die Arten dieser Gattung neigen ebenfalls sehr zum Bastardieren, doch kön. nen hier ihre Bastarde nicht berücksichtigt werden. 
Blkrsaum 12-16 $\mathrm{mm}$ br., Köhre 3 mal länger als d. Kelch. - Nasse Alpentriften in St., K., T. $(1600-2000 \mathrm{~m})$. 4. 6. 7. P. longiflóra L.

6. (1) Blkr. gelb (b. d. wilden Pfl.), 16-20 mm br.; Bl. fett, beiderseits mehlig-bestäubt, verkehrt-eiförmig, keilig; Schaft $3-15 \mathrm{~cm}$ h., nebst Bltstiel. u. Kelchen weiß mehlstaubig. - Felsen und Gerölle d. Alpen. 4. 4. 5 .

A urikel, $P$. Auricula L.

Var. hortensis, Blumen in allen Farben: "Garten-Aurikel“.*)

Blkr. purpurn od. violett, selten weiß.

7. Bl. kahl, bisweilen klebrig.

Bl. flaumhaarig, am Rande drisig gewimpert. Kleine Arten mit rundlich-verkehrt-eiförm. Bl.

8. Blrand nicht knorplig verdickt.

Blrand weißknorplig verdickt; Bl. ganzrandig.

9. Bl., Schaft, Btstiel u. Kelch mehr weniger mehlstaabig, Blkrzipf. verkehrt-eiförmig.

10. 2 spaltig.

Ganze Pf. ohne Mehlstaub, Bl. gezähnt od. gesägt, Blkrzipfel tief

10. Bl. gezähnt-gesägt, mit weißem (nicht knorpligem) Rande, verkehrt-eiförmig-keilig; Blkr. $16-20 \mathrm{~mm}$ br., Schaft bis $15 \mathrm{~cm}$ h. - Alpen von T. u. Kr.; selten. 4. 4. 5.

$P$. venusta Host.

Bl. ganzrandig od. seicht gezähnt, ohne weißem Rand, verkehrt-eiförmig, in den br. Stiel zusammengezogen; Blkr. 12-18 $\mathrm{mm}$ br., Scliaft bis $15 \mathrm{~cm} \mathrm{h.} \mathrm{-} \mathrm{Alpen} \mathrm{von} \mathrm{Kr.} \mathrm{4.} \mathrm{5.} 6$.

P. carniólica, Jequ.

11. Bl. klebrig, von d. Mitte an gesägt, länglich-lanzettlich, Blt. zٌ bis 5 , fast sitzend, Blkr. 12-14 mm br., Schaft 5-10 $\mathrm{cm}$ h. - Feuchte Alpentriften in St., K., T., Kr. $(1900-2000 \mathrm{~m})$. 4. $8-8$.

\section{P. glutinosa Wulf.}

B1. nicht klebrig, am vorderen Rande gesägt od. gezähnt. 12.

12. Bl. verkehrt-eiförmig-keilig, Schaft 1.3-5 $\mathrm{cm} \mathrm{h.,} \mathrm{armbltig;} \mathrm{Blkr.}$ $18 \mathrm{~mm}$ br. - Höchste Alpen von St., K., T.; zerstreut. 4. 7. 8.

P. Floerkeána Schrad.

Bl. keilig, vorn abgestutzt u. eingeschnitten-gesägt; Schaft 1 bltig, 13-25 mm h., Blkr. 16-20 mm br. - Gerölle, Felsspiaten der Alpen $(1300-2550 \mathrm{~m})$ u. im Riesengeb. 4. 7. 8.

P. minima L.

13. (8) Zipfel d. 16-25 $\mathrm{mm}$ br. Blkr. 2 spaltig mit zusammengeneigt. Lappen; Schaft 1-2-5 bltig, $5-7.5 \mathrm{~cm}$ h.; Bl. läuglich-lanzettförm., an Rande druisig-flaumig. - Gerölle u. Felsen d. Kialkalpen von Ooe., Noe. u. St.; zerstreut. 24. 5. 6. P. Clusiána Tsch.

Zipfel d. Blkr. ausgebreitet, verkehrt herzförmig. 14.

14. Bl. länglich-lanzettförmig, kahl od. zerstreut behaart, Schaft $2 \cdot 5$ bis $3.8 \mathrm{~cm}$ h., $1-3 \mathrm{bltig}$, Blkr. $25 \mathrm{~mm}$ br. - Kalkalpen v. K., T., Kr.: selten. 4. $6-8$.

P. Wulfeniána Schott.

Bl. länglich-rhombisch, oberseits punktiert; Schaft $5-8 \mathrm{~cm}$ h., 1- bis 5 bltig; Blkr. 14-18 mm br. - Alpen von St., Kr., T. 4. 5.6.

$P$. spectábilis Tratt.

*) Die Gartenaurikel sind Bastarde von P. Auricula und rothblühenden Arten der Aurikclgrupne. 
15. (7) Bl. fett, klebrig-drüsig, mit knorplig verdickten Zähnen; Schaft 13-25 mm h., 1-2 bltig, Blkr. 13-18 $\mathrm{mm}$ br., sehr langröhrig. - Dolomitfelsen d. siidl. 'T. 4. 5. 6.

$P$. tirolensis Schott.

B1. dïnn, von der Mitte an gezähnt-gesägt, klebrig-flaumig; Schaft and Bltstiele drüsig.zottig, $1-3 \mathrm{~cm}$ h., 1-5 bltig; Blkr. 8-12 $\mathrm{mm}$ breit, bisweilen weiß. - Grasige Felsabhänge d. Alpen von St., K. u. T.; zerstreut. 4. 5. 6.

P. villosa Jequ.

\section{Cortúsa L. $(\mathrm{V}, 1)$.}

Bl. grundständig, l. gestielt, herzförm. rundlich, eingeschnitten-gelappt; Schaft 15-30 $\mathrm{cm}$ h., eine 3-vielbltige Dolde tragend; Blkr. $10 \mathrm{~mm} \mathrm{br}$., purpurviolett. - Quellige steinige Plätze, feuchte Felsen der Alpen von Ooe., Sz. (Schafberg, kahle Form), St., K. 4. 5. 6. C. Mathínli L.

\section{Soldanélla Tourn. Alpenglöckchen $(\mathrm{V}, 1)$.}

Wzst. kriechend, B]. grundständig, 1. gestielt, in Rosette, herz- oder nierenförmig rundlich; Blt. 1-10, gestielt, hängend auf nacktem Schaft, violett od. lila; Frstiele steif aufrecht. Kahl.

1. Gr. lang, weit vorragend, Bl. unterseits punktiert.

Gr. eingeschlossen, Bl. nicht punktiert, Schaft 1-3 bltig.

2. Bl. seicht gekerht, Schaft 3-10 bltig, blühend bis 15, fruchtend bis $30 \mathrm{~cm}$ h. - Auf Moosboden schattiger Gebirgsnadelwälder i. d. Alpen, im Böhmerwalde und in Mh. 4. 5. 6.

$S$. montaina Willd.

Bl. ganzrandig, Schaft $1-3 \mathrm{bltig}$, blühend $5-10$, fruchtend bis $20 \mathrm{~cm}$ hoch. - Wälder u. Wiesen d. Alpen $(1200-2000 \mathrm{~m})$. 4. 5-8.

$$
\text { S. alpina } \mathrm{L} \text {. }
$$

3. Blkr. glockig-trichterförmig, bis zur Hälfte »erschlitzt; Schaft bis $10 \mathrm{~cm} \mathrm{~h}$, Blkr. $16 \mathrm{~mm}$ br. - Hochalpentriften am schmelzenden Schnee. 4. 6. 7 .

S. pusilla Baumg.

Blkr. walzig.glockig, bis $1 / 3$ zerschlitzt; Schaft bis $5 \mathrm{~cm}$ h., Blkr. 4-6 $\mathrm{mm}$ br. - An gleichen Orten in St., K., T., Kr. 4. 6. 7.

S. minima Hoppe.

\section{Cyclámen L. Erdscheibe $(V, 1)$.}

Bl. u. Blt. 1. gestielt, grundständig, Bltstiele zur Frzeit schraubig zusammengezogen, Blt. wohlriechend, Blkr. purpurroth; Blscheibe herzförm. rundlich, mit weißlicher Zeichnung. Kuchenförm, tiefliegender Knollen. - Nadelwälder d. Alpenländer, auch in Mh. u. B. (?). 4. 8. 9.

$$
\text { Alpenveilchen, C. europaeum L. }
$$

\section{Hottónia L. Wasserfeder ( $V, 1)$.}

St. im Schlamme wurzelnd, schief aufsteigend; Bl. quirlständ., kammförmig fiederschnittig; Trauben endständig, l. gestielt, quirlbltig; Blkrone rötblichweiß, im Schlunde gelb, bis $16 \mathrm{~mm}$ br. -- Wassergräben, stehende Wässer in B., Mh., 0e., Kr. 4. 5. 6. H. palustris $\mathbf{L}$.

\section{Trientális L. Dreifaltigkeitsblümchen (VII, 1).}

Wzst. kriechend, St. einfach, $8-20 \mathrm{~cm}$ h., eine Rosette länglich. lanzettförmiger bis ellipt. Bl. und 1-2 l. gestielte Blt. tragend; Blkr. weiß od. rosa, bis $16 \mathrm{~mm}$ br. - Moosige Nadelwälder, moorige Triften in B., Mh., 0e. 4. 6. 7 .

Siebenstern, T. europaea L. 


\subsection{Lysimáchia $\mathrm{L}$. $(\mathrm{V}, 1)$.}

Bl. ganz u. ganzrandig, gegen- od. quirlständig; Blt, einzeln od, in Trauben od. Rispen.

1. St. aufrecht, 0.30-1 $m$ h., Bltstiele stets aufrecht, Wzst. kriech. 2.

St. kriechend, fadenförmig, Bl. 2 zeilig.gegenständig; Blt. einzeln blwinkelständig, Stiele zur Frzeit abwärts gebogen.

2. Blt. sehr $\mathrm{kl}$, in achselständigen gestielten kopfigen Träubchen; 131. kreuzweis gegenständig, lineal-lanzettförmig. - Teichränder, Moorgräben in B., Mh., 0e.; zerstreut. 4. 6. 7. I. thyrsiflóra L.

Blt. ansehnlich, nicht in Trauben; Bl. alle oder die unteren zu 3-5 quirlständig.

3. Blt. in end- und achselständigen, eine pyramidale Rispe bildenden Trugdolden; Blkr. kahl, Bl, eilanzettförmig, unterseits Alaumig. - Ufer, feuchte Gebüsche. 4. 6. 7.

L. vulgaris L.

Blt. einzeln, gestielt, quirlständig; Bllkrzipfel drüsig gewimpert, BI. eiförmig-länglich, unter'seits oft schwarz punktiert. Flaumig weichhaarig. Ufer, feuchte Gebüsche in B. u. Mh., stellenweis; auch Zierpt. 4. 6. 7.

L. punctata L.

4. (1) Bl. rundlich, Kelchzipfel herzeiförmig; Blkr. $16-20 \mathrm{~mm}$ br. Grasplätze, Hecken. 4. 6-9. Pfennigkraut, L. Nummulária L.

Bl. ei- od. herzeiförmig, Kelchzipfel lineal-pfriemlich, Blkr. 8-12 $\mathrm{mm}$ breit. - Schattige Bergwälder. 4. 6-9.

L. némorum L.

\section{Glaux L. Milchkraut $(\mathrm{V}, 1)$.}

St. 5-10 cm h., niederliegend, Bl. gegenständig, dicht stehend, länglich, fleischig; Blt. kl., achselständ., weiß od. röthlich. - Feuchte, salzige Sand- u. Uferplätze in B., Mh.; zerstreut. 4. 5. 6.

G. maritima L.

\section{Anagallis L. Gauchheil $(V, 1)$.}

Bl. gegenständ., eiförmig od. länglich, ganzrandig, unterseits punktiert; Blt. einzeln, blwinkelständ., l. gestielt; Frstiele abwärts gebogen. Kahle Kr.

1. Blkr. mennigroth, selten weiß, im Schlunde purpurn, Kelchzipfel so lang wie d. Blkr. - Äcker, Brachen. $\odot .6-10$. A. arvensis L.

2. BIkr. azurblau, im Schlunde purpurn, Kelchzipfel kürzer als die Blkr. - An gleichen Orten, weniger häufig. $\odot$. 6-9.

$$
\text { A. coeriilea Schreb. }
$$

\section{Centúnculus L. Kleinling $(I V, 1)$.}

Zwergpt. mit liegendem od. aufsteigendem, bis $10 \mathrm{~cm} \mathrm{l}$. St.; Bl. wechselständig, eiförm., ganzrandig, kl.; Blt. in d. Blwinkeln sitzend, kl., weiß od. röthlich. - Feuchter Sandboden, an Ufern; zerstreut. $\odot .5-8$. C. minimus L.

\section{Sámolus $L$. Pungen $(V, 1)$.}

St. aufrecht, $15-45 \mathrm{~cm}$ h.. Bl. wechselständig, unterste in Rosette, verkehrt-eiförmig-länglich; Blt. kl., weiß, in rispigen Trauben. - Gräben, Moorwiesen, besond. auf salzhaltigem Boden, in B., Mh., Noe.; zerstreut. 4. 6.7 .

S. Valerándi L. 


\section{Fam. LXXV. Plumbagineae. Bleiwurartige.}

\section{Arméria W. Grasuelke $(V, 5)$.}

Bl. schmal, grundständ. dichte Rasen bildend; blloser Schaft, ein Bltkörbchen tragend, dessen äußere Hülle eine abwärts sich erstreckende, d. Spitze d. Schafts umfassende Röhre bildet.

1. Bl. lineal, 1 nervig, spitz, feingewimpert; St. $30-45 \mathrm{~cm}$ h., Bltkörbchen 18-20 $\mathrm{mm}$ br.; Hüllschuppen stumpf, stachelspitzig, hellbraun, Blkr. rosenroth. - Trockene Grasplätze, Sandboden in B., Mh., Noe, 4. $6-9$.

A. vulgaris Willd.

2. Bl. lineal, 3 nervig, am Rande rauh, sonst kahl wie d. g. Pfl.; St. 7.5-25 $\mathrm{cm}$ h., Bltkörbchen bis $20 \mathrm{~mm}$ br., Blume liellpurpurn. Alpentriften $(1580-2300 \mathrm{~m})$. $4.6-8$.

A. alpina W.

\section{Fam. LXXVI. Ericáceae. Haideartige.}

\section{Schliissel der Gattungen.} 5 klappig.

1. Blkr. 5 blättrig, Kelch ganz, 5 zähnig, Stbg. 10; Kapsel 5 fäclırig, Ledum (434).

Blkr. ganzblättrig.

2. Kelch u. Blkr. 4 theilig, Stbg. 8, Kapsel 4 fächrig, 4 klappig. 3.

Kelch n. Blkr. 5 spaltig od. 5 theilig, Stbg. 10 od. 5.

3. Kelch blumenartig, länger als d. Blkr.; Klappen d. Kapsel sich von den an d. Mittelsäule angewachsenen Scheidewänden abtrennend.

Calluna (429).

Kelch krautig, viel kürzer als d. Blkr.; Klappen je eine Scheidewand in d. Mittellinie tragend. Erica (430).

4. Stbg. 5, Blkr. glockig, abfallend, Kapsel 2-3 fächrig: mit 2-3 Klappen wandspaltig aufspringend. Azalea (432).

Stbg. 10.

5. Blkr. trichter- od. radförmig, Kapsel 5 fächrig, mit 5 Klappen wandspaltig aufspringend.

Rhododendron (433).

Blkr. glockig, eiförmig od. fast kuglig, mit 5 zähnig. Saume. 6.

6. Blkr. eiförmig-glockig, Fr. eine 5 fächrige, mit 5 Klappen fachspaltig aufspringende Kapsel. Andromeda (431).

Blkr. krugförmig, Fr. eine 5 kernige Steinbeere.

7. Kleinsträucher. Beere glatt.

7.

Grstrauch od. B.; Beere spitzhöckerig.

Arctostaphylos (435).

Arbutus (436).

\section{Callúna Salisb. Besenhaide (VIII, 1).}

Immergrüner Klstrauch; Stämmchen $0.15-1 \mathrm{~m}$ l, liegend od, aufsteigend; Bl. kl. nadelförm, dachziegelig 4 reihig; Blt. in dichten rispig gruppierten Trauben; Blkr. rosenroth, selten weiß. - Haide- und Moorboden. 5. 7-9. Haidekraut, C. vulgaris Salisb. 


\section{Eríca L. Haide (VIII, 1).}

1. Niederliegend. od. aufsteigend., immergrüner Klstrauch; Stämm. chen bis $30 \mathrm{~cm}$ l., Bl. zu 4 quirlständig, lineal; Blt. in einseitswendigen Trauben, fleischroth, selten weiß. - Wälder d. Kalkalpen, auch in Noe. und südl. B. (b. Hohenfurt). Ђ. 2-5.

E. cárnea L.

2. Aufrecht. Grstrauch; Bl. zu 3, lineal, Blt. kl. weiß, in rispig gruppierten Trauben. - Im südl. T. (Giudicarien), an steinigen Plätzen. Ђ. 5. 6.

\section{Andrómeda I. Polei (X, I).}

$E$. arbórca $\mathrm{L}$.

Immergrün; Stämmchen im Moos kriechend, BI, weclıselständig, lanzett- od. lineal-lanzettförmig, umgerollt, unterseits bläulichweiß; Blt. lang gestielt, zu 2-4 endständig; Blkr. röthlichweiß. - Torfmoore. Ђ. 5. 6.

\section{Azálea L. (V, 1).}

A. polifólia L.

Immergrün; Stämmchen kriechend, Rasen bildend, Zweige aufsteig., dicht beblättert; Bl. gegenständig, oval od. länglich, umgerollt; Blt. zu 2 bis 4 endstïndig, kurz gestielt; Kelch purpurn, Blkr. rosenroth. - Alpen, auf Gerölle $(1580-2550 \mathrm{~m})$. Ђ. 5. 6.

A. procimbens L.

A nmerk. Die als Zierplanzen beliebten "Azaleen" stammen von A. indica L., chinensis Sweet. u. a. asiat. Arten ab. Als Zierstrauch wird in Gärten nicht selten A. pontica L. mit gr. gelben u. A. moll is Lindl. mit gr. braunrothen Trichterblumen cult. Beide sind sommergrün. Erstere stammt aus d. Krim, letztere aus Japan.

\section{Rhododéndron L. Alprose $(X, 1)$.}

Immergrüne Str. mit wechselständigen glänzenden Bl.; Blt. in endständigen Doldentrauben, selten einzeln, ansehnlich; Blkr. heli- bis purpurroth.

1. Blkr. radförmig, Blt. 1. gestielt, zu 2-3, Stiel u. Kelch drüsig behaart; Bl. länglich od. lanzettförmig, gewimpert; Stämmch. $15 \mathrm{~cm} \mathrm{h.} \mathrm{-}$ Gerölle der Kalkalpen (bis $1900 \mathrm{~m}$ ). Ђ. 5-7. Rh. Chamaecistus L.

Blkr. trichterförmig, fast 2 lippig, auswendig sammt d. Stiel drüsig punktiert; Blt. in Doldentrauben, Stämme bis $1 \mathrm{ml}$.

2.

2. Bl. am Rande gewimpert, flach, unterseits drüsig punktiert, lanzettlich bis verkehrt-eiförmig. - Kalkalpen, auf Gerölle (bis $2000 \mathrm{~m}$ ). ち. $6-9$. Alm ra us ch, Rh. hirsutum L.

Variet. latifolium (Hoppe), Bl. rundlich od. elliptisch, fast kahl, Blt. größer.

BJ. kahl, umgerollt, unterseits rosttarben, lanzettlich. - Granitalp. an Bächen $(1260-2000 \mathrm{~m})$. Ђ. 7-9. A $1 \mathrm{mrausch,} \mathrm{Rh.} \mathrm{ferrugíneum} \mathrm{L.}$

Anmerk. In Gärten werden cult. Rh. ponticum L. u. Rh. maxin um L., breit- u. großblïttr. Grsträucher mit Doldentraub, u. gr. purpurnen Trichterblumen aus Kleinasien und Nordamerika.

\section{Ledum I. Porst $(\mathrm{X}, 1)$.}

Immergrüner Str. von 0.60-1.30 m H.; Bl, wechselständ., lineallanzettlich, umgerollt, oben glänzendgrün, unten rostroth-filzig; Blt. l. gestielt in endständigen Doldentrauben, weiß. Giftig. - . Torfmoore in B., Hh. u. Toe.; zerstreut. 5. 6. 7. Wilder Rosmarin, L. palustre L 


\section{Arctoståphylos Adans. Bärentraube $(X, 1)$.}

Kriechende Klstr. mit zimmetbraunen Stämmchen und aufsteigenden reichblättrigen Ästen; Bl. wechselständig, netzadrig; Blt. in endständigen Trauben, röthlichweiß. Beeren ungenießbar.

1. Immergrün; Bl. lederart., länglich-verkehrt-eiförmig, ganzrandig, kahl; Traaben 6-10 bltig, überhängend, Beeren erbsengroß, scharlachroth. - Bebuschte felsige Waldplätze der Kalkalpen, auch in B. u. Wh. in Nadelwäldern (sehr zerstreut). ち. 5-7.

A. Uva ursi Spr.

2. Sommergrün; Bl. dünn, länglich-verkehrt-eiförmig od. keilig, gekerbt u. gewimpert; Trauben 2-6 bltig, mit d. Bl. erscheinend; Beeren reif blauschwarz. - Gerölle u. Felsen d. Alpen; zerstreut. Ђ. 5. 6.

A. alpina Spr.

\section{Arbútus L. Erdbeerbảum (X, 1).}

Immergrün; Bl. elliptisch-lanzett- od. verkehrt-eiförmig, gekerbt, bis $7.5 \mathrm{~cm}$ l.; Blt. in endständ. nickenden zusammengesetzten Trauben, röthlich- od. grünlichweiß; Beeren kirschengroß, scharlachroth, essbar. Felsige bebuschte Orte im südl. T. u. Kr.; dort auch Zierstr. †. 10-2. A. Únedo $\mathrm{L}$.

\section{Fam. LXXVII. Vacciniéae. Heidelbeerartige.}

\section{Vaccínium L. Heidelbeere (VIII, 1).}

Klstr. mit wechselständigen karz gestielten Bl.; Blt. blwinkelständ. od. in endständigen Trauben; Beeren kuglig, mit gerandetem Scheitelfeld (Kelchrudiment).

1. Immergrün; Bl. elliptisch od. lanzettförmig, oberseits glänzend dunkel-, unterseits blassgrün und punktiert; Blt. in überhängend. Traub., Blkr. glockig, röthlichweiß, Beeren roth. - Heide- u. Moorboden, lichte Nadelwälder. 5. 5-7.

Preiselbeere, $V$. vitis idaea L.

Sommergrün; Blkr. krugförmig, Beeren schwarz, blau bereift. 2.

2. Stämmchen und Äste kantig, grün; Bl. feingesägt, lanzettlich od. elliptisch, grün; Blt. achselständig, Blkr. rötblich- od. grünlichweiß; Beeren kugelrund, wenig bereift, bisweilen weiß (var. leucocarpum Wender.) Wälder, Heiden. 5. 4. Ge m. Heid el-, Schw ar z be e re, V. Myrti?!us L.

Stämmchen und Äste rund, zimmtbraun; Bl. ganzrandig, verkehrteiförmig, unterseits netzadrig, bläulichweiß; Blt. zu $1-4$ an kurz. Seitentrieben, Blkr. weiß od, rosa; Beeren größer, oft länglich, stark beretft. Torfmoore. Ђ. 5. 6.

$\mathrm{R}$ aus ch be ere, $\boldsymbol{V}$. uliginósum L.

\section{Oxyécecos Pers. Moosbeere (VIII, 1).}

St. fadenförm., im Moos kriechend, ästig; Bl. wechselständ., eiförm. od. länglich, umgerollt, lederartig, unterseits bläulichiveiß; Blt. zu 1 bis mehreren, auf 1. rothem Stiel, Blkr. rosenroth, Beere gr., kuglig, purpurroth, sauer. - Gebirgstorfmoore. 5. 6. 7.

O. palustris Pers. 


\section{Fam. LXXVIII. Piroláceae. Birnkrautartige.}

\section{Pírola L. Birnkraut (X, 1).}

Inmergrüne kallle $\mathrm{Kr}$. mit holzigem Wzst.; Bl, wechsel-, rosettenod. quirlständig, gestielt; Blt. in endständig. Traube, selten Trugdolde od. eiuzelne endständ. Blïte.

1. Eine endständ. nickende Blte; Blkr. radförmig-glockig, weiß, 12 bis $18 \mathrm{~mm}$ br., St. $2.5-10 \mathrm{~cm}$ h., Bl. spatel- od. verkehrt-eiförmig bis rund, fein gekerbt. - Schattige Nadelwälder auf Moosbodes; zerstreut. 4. 6. 7 .

P. uniflóra L.

Blt. mehrere in Trugdulde, Blkr. radförmig, weiß od. hellrosa, St. $8-15 \mathrm{~cm} \mathrm{~h}$, oben nackt, Bl. verkehrt-eilanzettförm., gesägt, quirlständig. - Schattige Nadelwälder, zerstreut u. selten. 4. 6. 7. P. umbelláta L.

Blt. viele, in endständ. Traube.

2. Traube einseits'wendig, Blkr. eiförmig, grünlichweiß; St. $8-15 \mathrm{~cm}$ lang, zur Hälfte beblättert; Bl. eiförmig od. länglich, spitz, gekerbt. Schattige Bergwälder und Gebiusche. 4. 6. 7.

P. secrinda L.

Traube allseitswendig, Blt. nickend, St. nur unten beblättert, Bl. l. gestielt.

3 . locker.

3. Stbf. einseitig aufwärts, Gr. sclief abwärts gekrümmt; Traube

Stbf. nicht einseitig, gleichmäßig um den Stempel gestellt, Gr. gerade; Traube dicht, Blkr. kuglig, weiß, oft rosa überlaufen.

4. Blkr. gelblichgrïn, halbkuglig, 6-8 $\mathrm{mm}$ br.; St. $10-25 \mathrm{~cm} \mathrm{h.,}$ Bl. rund od. verkehrt-eiförmig, seicht gelkerbt. - Schattige Nadelwälder; zerstreut. 4. 6. 7 .

P. chlorantha Sw.

Blkr. weiß, radförmig glockig, bis $18 \mathrm{~mm}$ br.; Trauben reichbltig; St. 15-40 $\mathrm{cm}$ h., Bl. rund bis verkelırt-eiförmig, seicht gekerbt. - Nadelwälder, Gebüsche. 4. 6. 7.

$P$. rotundifólia $\mathrm{L}$.

5. Blkr. 8-10 $\mathrm{mm}$ br., Gr. vorragend, Kelchzipfel eilanzettförm., spitz, Traube 3-12 bltig; St. $15-30 \mathrm{~cm}$ h., Bl. eiförmig od. rundlich, schwach gekerbt. - Schattige Wälder, zerstreut u. selten. 4. 6. 7. P. média Sw.

Blkr. 4-5 mm br., Gr. eingeschlossen, Kelchzipfel eiförmig-3 eckig, Traube 8-20 bltig; St. 10-22 cm k., Bl. wie b. vor. - Schattige Wälder. 4. 6. 7 .

P. minor L.

\section{Monótropa L. Ohnblatt (X, 1).}

Bllose fleischige bleich gelblichgrüne Moderpt.; St. $1 \mathrm{C}-25 \mathrm{~cm}$ h., locker beschuppt, einfach; Blt. in endständiger, anf angs umgebogener, lockerer einseitiger Traube. Fein weichhaarig, seltener kahl (M. hypo. phégea Wallr.). - Schattige moosige Fichten- u. Kiefernwälder (M. hypopheg. in Buchenwäld.). 4. 7.8. $\quad \mathrm{F}$ i chtensparge 1, M. Hypópitys L. 


\section{Dialypétalae: mit getrenntblättriger Blumenkrone.}

\section{Fam. LXXIX. Córneae. Hartriegelartige.}

\section{Cornus L. Hornstrauch (IV, 1).}

B1. gegenständ,, krummnervig, ganzrand.; Blt. in endständ., einfachen Dolden od. schirmförm. zusammengesetzten Trugdolden. Sommergrüne B. u. Str.

1. Blt. vor d. Laubausbruch, in kugligen, von 4 gelßlichen Hüllbl. umgebenen Dolden, gelb; Steinfr. länglich, roth, essbar; Bl. oval, zugespitzt. - Laubwälder, bebuschte Hügel; zerstreut, häufig verwildert, weil überall cultiviert. $\hbar$. 3. 4.

Cornelkirsche, C. mas L.

Blt. nach der Entfaltung der Bl. sich entwickelnd, in hüllenlosen schirmförm. Trugdolden, weiß: Fr. kuglig, beerenartig; Zweige u. Stämme im Winter blutroth.

2.

2. Bl. eiförmig, zugespitzt, beiderseits grün, Fr. schwarz; Zweige dufrecht. - Gebüsche, Waldränder, im Nieder- u. Mittelwalde. 4. 6. 7

Hartriegel, C. sanguinea L.

Bl. br. eiförmig, spitz, unterseits dünn, weißfilzig, Fr. weiß; Zweige zurückgekrümmt. - Zierstr. aus Nordamerika. Ђ. 6. 7. C. alba Auct.

Anmerk.: Außer C. alba werden verschiedeue andere nordamerikanische Hornsträucher als Ziergehölze cult., z. B. C. flórida L., dessen grünliche Blütendöldchen von $4 \mathrm{gr}$. weißen Hüllbl. umringt sind.

Fam. LXXX. Araliciceae. Aralienartige.

\section{Hédera I. Epheu $(V, 2)$.}

Immergrüner Kletterstrauch mit Luftwurzeln; Bl. alt lederartig, wechselständig, handförm. 5 lappig od. 5 eckig, die der bltentwickelnden Äste eiförmig; Blt. grünlichgelb in halbkugligen liüllenlosen Dolden; Beeren schwarz. - Felsen, Mauern, Wälder u. cult. in Gärten. $\hbar, 10$. 11, Frreife 4. H. Helix L.

\section{Fam. LXXXI. Umbelliferae. Doldenbliitler.}

\section{Schliissel der Gattungen*).}

1. Blt. in dichten trugdoldig gruppierten, selten einzeln stehenden Köpfchen, von dornigen Hüllbl. umringt; Kelchzähne blartig, dornspitzig. Dornige $\mathrm{Kr}$.

b) Blt. in einfachen, von Hüllschupp. umringten Dolden od. Köpfchen od. in Quirltrauben. Wehrlose $\mathrm{Kr}$.

c) Blt. in zusammengesetzten Dolden.

2. Bl. kreisrund, schildstielig; a.mbltige Quirlträubchen

Bl. niemals schildstielig, hand- od. nngerförmig getheilt.

*) Zum sichern Bestimmen unbekannter volaengewacnse 1st es durchaus nöthig, möglichst ausgebildete Früchte zu haben. 
3. Eine einzige, von sehr gr. Hüllbl. umringte kopfige Dolde ars Ende d. bllosen St.

5. Hacquetia (446).

Dolden einzeln, endständ. od. trugdoldig gruppiert, Bit. zwitterlich und männlich.

4.

4. Dolden von einer vielblättrigen, sternförmig. weißen Hülle umge• ben; Jit. sitzend, Theilfrüchtchen mit dicken gezähnten Rippen.

Astrantia (447).

Dolden kopfig, mit sehr kurzer Ḧ̈ile, männl. Bl. 1. gestielt, Theilfr. dicht hakig-borstig. Sanicula (445).

5. (1, c.) Theilfr. mit 5 Hauptrippen, selten rippenlos (C. Chaerophyllum, Authriscus, Scandix). Nebenrippen fehlend (Haplozygiae). 6.

Theilfr. mit 5 Haupt- und 4 Nebenrippen (Diplozygiae) oder (b. Coriandrum und Bifora) alle Rippen undeutlich u. dann d. Theilfr. innen hohl; äußere Bltbl. viel größer als die 2 innern.

6. Blt. 2 häusig, die d. männl. Dolden gelblichweiß, die der weibl. weiß; Theilfr. eiförm., seitlich zusammengedrïickt (A mmín ea e).

\section{Trinia (448).}

Blt. meist zwitterlich, selten auch männl. (in ein u. derselb. Dolde); Blbl. aller Blt. von e in er Farbe.

7. Bl. ganz und ganzrandig, Haupt- und Nebenhiillen vielblättrig, lang; Blbl. gelb, Theilfr. seitlich zusammengedrückt. eiförmig (B u ple ureae)

Bupleuvum (459.)

Bl. gesägt gekerbt, gelappt od. 1-3 fach fieder-theilig oder fiederschnittig.

8. a) Fr. seitlich zusammengedrückt, mit verschiedenartigen Rippen, selten ohne deutliche Rippen, glatt.

b) Fr. auf d. Querschnitt halbrund (weder von d. Seiten noch vom Rücken her zusammengedrückt), mit faden- oder kielförmigen Rippen (Orbiséctiles.)

26.

c) Fr. vom Rücken her zusammengedrückt; Randrippen verdickt od. geflügelt (Len ticula res)

9. Fr. nicht geschnäbelt.

37.

10.

Fr. deutlich geschnäbelt; ohne Rippen, ab. mit geripptem Schnabel; Thälchen ohne Ölstriemen; Hüllchen vielschuppig, Hülle fehlend oder blättrig (Scandicíneae).

10. Rippen dick oder dünn, niemals hohl.

25.

11.

Rippen sebr vorragend, hohl; Blbl. weiß (Scandicineae). 24.

11. Rippen leistenförmig, dick, wellig gekerbt; Fr. eiförmig-kuglig. Conium (488.)

Rippen verschieden, niemals gekerbt.

12. $\mathrm{Fr}$. rippenlos, glatt, länglich oder lineal; Gr. lang. Chaerophyllum (483).

Fr. mit deutlichen Rippen (A m minea e). 13. 13. Hüllchen vorhanden.

Hüllchen (meist auch Haupthüllen) fehlend.

14. Haupthülle fehlend od. 1-2 blättrig; Hüllchen vielblättrig. 15.

Haupthülle mehr- bis vielblättrig, Blbl. weiß.

15. Blbl. weiß, Kelchzähne deutlich, Dolden vielstrahlig, Rippen dick, stumpf; Blstiele rund, röhrig. 
Blbl. grünlichgelb, Kelchrand undeutlich, Dolden wenigstrahlig, Rippen fädlich.

Petroselinum (454).

16. Rippen d. fast 2 knopfigen Fr. flach, breit. Cicuta (419).

Rippen d. eiförmig. Fr. erhaben, abgerundet, korkig. Sium (450).

17. Dolden den BI. gegenüberstehend, niemals endständ., l. gestielt, wenigstrahlig; Fr. eiförmig od. länglich, Rippen füdlich.

Helosciadium (452).

Dolden end- und seitenständig.

18.

18. Rippen stark entwickelt, Hüllen u. Hüllcben vielblättrig, keulig.

19.

Rippen fädlich, stumpf, jede Theilfr. 5 kantig.

20.

19. Fr. länglich, Rippen 3 eckig, gekielt, Thälchen mit 3 Ölstriemen, Blbl. oval ansgerandet.

Malabaila (490).

Fr. eirund, Rippen dick stumpf, die 3 rückenständ. flügelförmig, Thälchen m. 1 Ölstriemen, Blbl. lanzettförm., spitz. Molopospermum (487).

20. Fr. eiförmig, ein Ring verbundener Ölstriemen in jeder Theilfr.; Haupthülle viel- und langblättrig, krautig.

Berula (451).

Fr. lanzettförm., Thälchen mit 1 Ölstriemen, Hüll- u. Hüllchenblättchen pfriemenförmig, $3-5$.

Falcaria (458).

Fr. länglich-lanzettförm. Thälchen mit 1 Ölstriemen, Hüll- u. Hüllchenbl. lanzettlich. Knollengewächs. Carum Bulbocastanum (456).

21. (13). Blbl. sehr kl., grünlichweiß, eirund m. eingebogener Spitze; Dolden kl., wenigstrahlig, die meisten achselständig, traubig; Fr. rundlich, 2 knotig, Rippen fädlich.

Apium (453).

Blbl. weif, verkehrt-herzförmig, mit einwärts geschlagenem Zipfel; Dolden end- und achselständig, l. gestielt, meist vielstrahlig.

22.

22. Fr. br. eiförmig, Rippen dünn, fädlich, Thälchen mit $2-4 \mathrm{kl}$. Ölstriemen, Theilfr. mit breiter Fläche aneinanderliegend.

\section{Pimpinella (455).} gend.

Fr. länglich-eiförmig, Theilfr. mit schmalen Streifen aneinanderlie-

23. Rippen dick, stumpf, Thälchen mit 1 br. Ölstriemen; Theilst. d. Bl. kl. und schmal.

Carum (456).

Rippen dünn, fädlich, Thälchen ohne Ölstriemen, Theilstücke der Bl. gr. und br. Aegopodium (457).

24. (10). Fr. lanzettförm.,..gr., Rippen sehr vorragend, scharf gekielt, ganzrandig; Thälchen ohne Ölstriemen, Hüllchen mehrblättrig, Hülle fehlend.

Myırhis (486).

Fr. eiförmig, Rippen sehr vorragend, stumpf, gekerbt, im Querschnitt 3 eckig, jede in ihrer Höhlung 1 kleinere Rippe einschließend; Thälchen mit 1 Ölstriemen; Hülle und Hüllchen vielblättrig.

Pleurospermum (489).

25. (9). Fr. kurz geschnäbelt, eiförm, bis lineallänglich, glatt oder kurz stachelig. Anthriscus (484).

Fr. sehr 1. geschnäbelt, lineal, glatt; Dolde 1-3 strahlig.

26. $(8$ b) Blbl. weiß, selten röthlich bis rosa. Scandix (485).

Blbl, gelb oder gelblich. 
27. Haupt- und Nebenhüllen vielblättrig; Kelch deutlich.

Haupthülle fehlend oder 1-2 blättrig, Hüllchen stets vorhanden, 3 -vielblättrig.

28. Fr. eiförmig, Rippen flügelförmig, dick, Bl. der Hanptlıülle so 1 . wie d. Strahlen; St. einfach, nur 1 Dolde tragend. Pachypleurum (466).

Fr. eilänglich, Rippen kantig, nicht geflügelt, Bl. der Haupthülle kuirzer als die Strahlen; St. meist ästig, zah̉lreiche Dolden tragend.

\section{Libanotis (462).}

29. Je 3 lineale hängende Hüllchenblättchen an der Seite der Döld. chen, Haupthülle fehlend; Fr. kuglig-eirund, mit scharf gekielten Rippen.

Hüllchenblättchen rings um die Döldchen. Aethusa (463).

30. Kelchsaum deutlich 5 zähnig.

Kelchsaum undeutlich gezähnt oder ganz verwischt.

32.

31. Kelchzähne meist groß, Blbl, verkehrt-herzförm. mit eingeschlagenem Endzipfel, die 3 äußeren größer; Fr. länglich-walzig bis kreiselförnig, stumpfrippig, Gr. l.

Oenanthe (460).

Kelchzähne kl., Blbl. verkehrt-eiförmig, wegen d. eingeschlag. Endzipfels scheinbar ausgerandet, gleichgroß; Fr. oval oder länglich, Rippen dick, stark vortretend.

Seseli (461).

32. Rippen häutig geflügelt, scharfkantig; Fr. eilänglich.

Rippen nicht geflügelt. men.

33. Randflügel breiter als d. Rückenflügel; Thälehen mit 3 Ölstrie-

33.

35.

34.

Alle 5 Flügel gleichbreit, schmal; Fr. eiförm., mit 1. zurückgeschlag. Gr., Thälchen 1 striemig; Blbl. gleichgroß, verkehrt-herzförmig mit eingeschlagenem Zipfel.

Cnidium (464).

34. Blbl. ungleich, äußere größer, alle verkehrt-herzförmig, mit eingeschlagenem Zipfel.

Conioselinum (465).

Blbl. gleichgroß, rundlich mit eingeschlag. Zipf. Ligusticum (468).

35. Rippen scharfkantig, stark vortretend; Fr. länglich, kahl, Thälchen mit vielen Ölstriemen, Gr. sehr kurz, Blbl. weiß oder rosa.

Meum (470).

Rippen fädlich, stumpf, Fr. lanzettförmig, dicht kurzborstig, Thälchen mit 1 Ölstriemen; Gr. lang, Blbl. weiß. Athamanta (467).

36. (26). Hüllchen mehrschuppig, Haupthülle fehlend od. 1 schuppig; Blbl. hellgelb, eiförmig mit eingeschlagenem Zipfel ; Fr. eilänglich, scharfrippig.

Silaus (469).

Weder Hüllen noch Hüllchen, Blbl. goldgelb, rundlich, ausgerandet, zusammengekrümmt, Fr. länglich, stumpfrippig, oft gekrümmt.

\section{Foeniculum (471).}

37. (8, c). Randrippen der beiden Theilfr. gr. häutig geflügelt, Flïgel auseinander stehend (klaffend), nicht verwachsen (Angelíc e a e). 38.

Randrippen dicht aneinander geschmiegt, entweder geflügelt, (dann die ganze Fr. von einem einfachen Flügelsanm umgeben) oder verdickt (dann die ganze Fr. von einem knorpligen Saum umringt); Rückenrippen fein, oft kaum bemerkbar ( $\mathrm{P}$ e ucedán eae).

38. Blbl, weiß oder grünlich.

Blbl. hellgelb, rundlich, eingerollt; Fr. eirund, Rippen alle geflügelt, randständig." doppelt breiter; Haupt- und Nebenhiillen. Levisticum (475). 
39. Blbl. verkehrt-herzförm. mit eingebogenem Zipfel, weiß; Fr. eirund, Rippen alle geflügelt, randständig. doppelt so br.; Hüllchen viel-, Haupthülle $1-2$ blättrig.

Selinum (472).

Blbl. elliptisch oder lanzettlich, spitz; Haupthülle fehlend. 40.

40. Blbl. lanzettlich, weiß; Fr. eilänglich, Randrippen br. geflügelt, Rückenrippen fädlich.

Angelica (473).

Blbl. elliptisch, grünlich; Fr. eiförmig, Randrippen schmal geflügelt, Rückenrippen gekielt. Archangelica (474).

41. (37). Fr. von einem abgeflachten Flügelsaum umgeben.

42.

Fr. von einem br. verdickten knorpligen gekerbten Rand umringt, borstlich-rauh; Blbl. weiß, äußere viel größer.

Tordylium (482).

42. Blbl. goldgelb, hell- oder grünlichgelb, gleichgroß.

43.

Blbl. weiß, selten röthlich.

46.

43. Blbl. rundlich, abgestutzt oder ausgerandet, einwärts zusammen. gekrümmt.

44.

BIbl. länglich convex, in einen linealen abgestutzten einwärts geschlagenen Zipfel verlängert; Dolden rispig oder trugdoldig.

\section{Peucedanum z. Th. (477).}

44. Weder Haupt-, noch Nebenhüllen (selten beiderlei 1-2 blättrig, hinfällig).

Beiderlei Hüllen vorhanden, vielblättrig, Dolden vielstrahlig; Fr. verkehrt-eiförmig-länglich, oft gekrümmt, Rückenrippen fädlich.

Ferula (476).

45. Fr. linsenförmig, br. flügelrandig, Rückenrippen fädlich, schwach; Bl. sehr fein zertheilt.

Anethum (479).

Fr. elliptisch, schmal flügelrandig, Rückenrippen stark vorragend; Blabschnitte gr. und br.

Pastinaca (480).

46. (42). Blbl. gleichgroß, durch das einwärts geschlagene Endläppchen verkehrt-herzförmig.

47.

Blbl. sehr urgleich, äußere viel größer, tief 2 spaltig; Fr. verkehrteiförmig, oben ausgerandet, mit schmalem Flügelsaum; Rückenflächen mit 3 fädlichen Rippen und $2-4$ br. durchschimmernden Ölstriemen von $1 / 3$ oder $1 / 2$ Länge der Fr.

Heracleum (481).

47. Kelchrand deutlich 5 zähnig; Fr. linsenförmig oder länglich, mit, br. od. schmalem Flügelsaum, Rückenrippen fädlich, wenig vortretend; beiderlei Hüllen vielblättrig.

Peucedanum (477).

Kelchzahne undeutlich; Fr. linsenförmig. mit sehr br. Flügelsaum, Rückenrippen vortretend; Hülle fehlend, Hüllchen borstlig.

Imperatoria (478).

48. (5). Fr. vom Rücken her schwach zusammengedrückt, länglich; Hauptrippen dick, wulstig, Nebenrippen dünn, kantig; Dolden gr., vielstrahlig, mit Hüllchen; Blbl. weiß.

Siler (491).

b) Theilfr. vom Rücken her zusammengedrüickt, mit $4 \mathrm{br}$. häutigen Flügeln (d. Nebenrippen), Fr. länglich; Dolden vielstrahlig, meist mit beiderlei Hüllen; Blbl. weiß, gelb, roth.

Laserpitium (492).

c) Alle Rippen oder wenigstens die Nebenrippen mit Reihen von Weichstacheln besetzt oder die ganze Fr. über und über kurzstachlig, Blbl. weiß (A rmatae). 
d) Fr. aufgeblasen-kuglig od. 2 knöpfig, fast glatt; Rippen sehr fein, oft kaum wahrnehmbar; Theilfr. im Innern mit einem Hohlraum; Blbl. weiß, äußere viel größer als die 2 innern (Coriándreae).

49. Blättchen d. Haupthülle 1., fiedertheilig, d. Nebenhüllen ganz oder 3 theilig; Fr. vom Rücken her zusammengedrückt, jede Hälfte mit 4 Reihen l. gerader pfeilspitziger Stacheln.

Daucus (494).

Alle Hüllblättchen ganz, äußere Blbl. meist größer.

50.

50. Nebenrippen mit 1-2 Reihen spitzer gerader oder hakiger Stacheln besetzt, Hauptrippen kurz borstig.

51 .

Alle Rippen mit kurzen verschieden langen Stuchelborsten besetzf, daher d. ganze Oberfäche der seitlich etwas zusammengedrückten Fr. dicht stachlig.

51. Stacheln schlank, in 1-2 Reihen auf jeder Nebenrippe, Fr. länglich, vom Rïcken her zusammengedrückt; Dolde $2-5$ strahlig, armbltig, mit beiderlei Hüllen.

Orlaya (493).

Stacheln aus kegelförm. Basis 1. zugespitzt, nur 1 reihig; Fr. länglich, von d. Seite etwas zusammengedrückt; Dolde 2-vielstrahlig, Haupthülle fehlend oder 1 blättrig.

Caucalis (495).

52. Dolden 2-3 strahlig, mit Haupt- und Nebenhüllen; Strahlen dick, Döldchen armbltig, Hüllbl. br., weißhäutig gerandet; Fr. gr., Stacbeln purpurn.

Turgenia (496).

Dolden 3-vielstrahlig, meist nur mit Hüllchen; Strahlen dünn, Döldchen mehrbltig, Hüllbl. pfriemenförmig, Stacheln grün, oft pfeilspitzig. Torilis (497).

53. (48 d.). Fr. aufgeblasen-kuglig, mit geschlängelten feinfädigen Rippen; Blt. nach Wanzen riechend, oft röthlich. Coriandrum (498).

Fr. aufgeblasen-3 knopfig, mit undeutlichen Rippen; Blt. geruchlos. Bifora (499).

\section{Hydrocotyle L. Wassernabel $(\mathrm{V}, 2)$.}

St. fadenförm., kriechend u. wurzelnd; Bl. l. gestielt mit schildförm. runder Spreite; Bltträubchen gestielt, blwinkelständig, Blt. sehr kl., röthlich. - Moorwiesen, Ufer, Erlenbrüche in B., Sch., Sz., Kr.; zerstreut u. selten. 4 7. 8.

$H$. vulgaris $\mathrm{L}$.

\section{Erỷngium L. Mannstreu $(V, 2)$.}

St. aufrecht, $15-60 \mathrm{~cm}$ h.; B1. lederartig, grundständ. gestielt; Hüllbl. länger als d. Köpfchen, Fr. dicht beschuppt, von d. 1. Kelchzipf. u. d. Gr. gekrönt. Dornige kahle Kr.

1. Grundständ. BI. ganz dolden

Grundständ. Bl. fiedertheilig; Köpfchen in zusammengesetzten Trug-

2. Hüllbl. vieltheilig, stechend borstig-gezähnt, blau od. weiß, Blt. weiß; St. 1-3 köpfig, Grundbl. herzförm., eingeschnitten-gesägt, Stbl. 3 lappig. - Alpentriften in K. u. Kr. 4. 7. 8.

E. alpinum L.

Hüllbl. ganz, lineal-lanzettförm., dornspitzig, Köpfch. in Trugdold., Kelche und Blbl. amethystblau; Grundbl. u. untere Stbl. herzeiförmig, gekerbt, obere Stbl. 3-5 spaltig, dornig gezähnt. - Auf Sandbod. in Mh. u. Noe.; zerstreut. 4. 7-10. E. planum L. 
3. Grundbl. u. untere Stbl. 3 zählig zerschnitten mit doppelt-fiederspalt.-Abschnitten, Blt. weiß. Graugrün, sehr ästig, von Dornen starrend. Trockene Plätze, Hügel, Triften. 4. 7-10.

E. campestre L.

Grundbl. u. untere Stbl. doppelt fiederspaltig, dornig gezähnt: Köpfchen, Köpfchenstiele u. Hüllbl. amethystblau. - Dürre Plätze im südl. T. u. Kr. 4. 7. 8 .

E. amethystinum. L.

\section{Sanicula Tourn. Sanikel $(V, 2)$.}

St. 25-50 cm h., einfach od. gabeltheilig, nackt od. wenigblättrig; Grundbl. 1. gestielt, herzförmig-handtheilig, stachelspitzig-gesägt, Stbl. kl. 3 spaltig; Dolde in endständ. Trugdold., Blt. weiß od. röthlich. - Moosige Nadelwäld. 4. 4. 5.

S. europaea L.

\section{Hacquétia Neck $(\mathrm{V}, 2)$.}

St. 8-18 cm l., nackt, mit endständ., von gr. grobgesägten gelben Hüllbl. blumenartig umringter Dolde; Blt. goldgelb, sitzend; Bl. grundständ., 1. gestielt, handtheilig, doppelt-gesägt. - Schattige Laub- u. Auen. wälr. in sclı., Mh., Noe., St., K., Kr.; zerstreut. 4. 4. 5.

\section{H. Epipactis DC.}

\section{Astrántia L. Sterndolde (V, 2).}

St. aufrecht, wenigblättrig; Grundbl. lang, Stbl. kurz gestielt; Dolden in endständ., unregelmäßigen Trugdolden, Blt. weiß. Kahle Kr.

1. Grundbl. fingerförmig in 7-9 lanzettförm. eingeschnitten-gesägte Stücke zertheilt; St. $15-30 \mathrm{~cm}$ h. mit $2-4$ strahliger Trugdolde. - Alpen v. T. u. 00e. 4. 7. 8.

A. minor L.

Grundbl. handförm. 5-7 theilig, Theilstücke länglich-verkehrt-eifürmig, ungleich gesiigt

2.

2. Hüllbl. länger als d. Blt.; St. $15-30 \mathrm{~cm}$ h., einfach mit $2-4$ strahliger Trugdolde; Grundbl. kl., Theilstücke keilig-lanzettförm., unterseits bleich u. netzadrig. - Gerölle und Gebüsche d. Kalkalp. v. St, , K., Kir., 'T. 4. 7. 8.

A. gricilis Bartl.

Hüllbl. so 1, wie d. Blt. 3.

3. HüllbI. 6-8 mm 1., Kelchzähne eiförmig, stachelspitzig; sonst wie vor. Art. - An ähnlichen Orten in St., K., Krr. 4. 7. 8.

\section{A. carniólica Wulf.}

Hüllbl. $13 \mathrm{~mm}$ l., Kelchzähne eilanzettförm., stachelspitzig; St. 30-60 cm . h., oft ästig; Trugdolde vielstralllig, Grundbl. gr. - Waldschluchten, Bachufer, Waldwieseu. 4. 6-9.

A. major L.

\section{Trinia Hoffm. Fasersehirm ( $\mathrm{V}, 2)$.}

St. zahlreich $7 \cdot 5-15 \mathrm{~cm}$ 1., ästig mit 1. gestielten Grundbl. und dickem Wrzst., einen lokeren Busch bildend; Grundbl. 3-fach-fiederschnittig mit lineal. Zipf.; Dold. kl. rispig.

1. Hüllchen 3-6 blättrig, Bl. grün. - Buschige Orte, trockene Grasplätze mit Kalkbod. in Mlı u. Noe.; zerstreut u. selten ค. 4. 7. 6. (Pimpinella glauca W. K)

T. Kitaibélii $M$. Bieb.

2. Hüllchen fehlend ou. 1-3 blättr., hinfällig, Bl. grangrün. Trockene sonnige Bergwiesen u. Hïgel mit Kalkbod. in Sch., Mh., Noe., Kr., südl. T. zerstreut. (-) 4. 5. (T. vulgaris DC) T'. gluuca Dumort. 


\section{Cicúta L. Wasserschierling (V, 2).}

Wrzst. rübenartig, fleischig, weiß, geringelt, innen hohl u. quergefächert; St. 0.60-1.30 $m$ h., röhrig, ausgebreitet ästig; Bl. $2-3$ fach fiederschnittig, untere sehr gr., Zipfel lineal-lanzettförm., gesägt; Dolden vielstrahlig, Blt. weiß. Kahl, giftig. - In Wassergräben, an Teichufern. 4. 7. 8 .

\section{Sium L. Merk (V, 2).}

C. virosa $\mathrm{L}$.

Wrzst. fasrig, St. kantig gefurcht, $0.6-1.6 \mathrm{~m}$ h., ästig; Bl. fiederschnittig, d. unteren gefurchten mit kammförmig zerschlitzten, borstlich. zipfligen Abschnitten; die oberen mit lanzettl. gesägten Abschnitten; Dold. vielstrahlig, Blt. weiß. Kahl, giftig. - An Ufern im Wasser; zerstreut. 4. 7. 8 .

S. latifolium L.

\section{Bérula Koch. Berle (V, 2).}

Wrz. t. büschlig, St. 0:30-1 $m$ h., ästig, röhrig, rund; Bl. gleichgeformt, 1 fach fieảerschnittig, mit lanzettl. ungleich gesägten Abschnitten, Dolden vielstrahl. mit vielblättr. Hülle $u$. Hüllchen, Blt. weif. - Wassergräben, Sümpfe, Ufer. 4. 7. 8. $B$. angustifolia Mert. Koch.

\section{Helosciádium Koch. Sumpfschirm $(V, 2)$.}

St. kriechend u. wurzelnd, $15-50 \mathrm{~cm}$ l., ästig; Bl. l. gestielt, fiederschnittig, mit 7-9 rundlich-eiförm., ungleich gelappten u. eingeschnittenen Abschnitten; Dold. wenigstrahlig mit 2-3 blättr. Hauptthülle; Blt. weiß. - Sumpfige Stellen in 0e. u. St.; zerstreut. 4. 7-9. H. repens Koch.

\section{3. Ápium L. Sellerie (V, 2).}

St. $30-60 \mathrm{~cm}$ h. sammt d. Ästen kaitig-gefurclit; Grundbl. gestielt, fiederschnittig, mit 3 theiligen Abschnitten u. ungleich eingeschnitten gesägten Lappen; Dold. zahlreich, kì., sitzend u. gestielt; Wrz. d. wild. Pf. dünn. - An Gräben, auf fenchtem salzhalt. Bod., hie u. da wohl verwild., weil überall cult. $\odot \cdot 6-8$. A. graveólens L.

\section{Petroselínum Hoffm. Petersilie $(V, 2)$.}

St. $0 \cdot 30-1 m$ h. feingerillt, ästig; Bl. hellgrün, aromatisch duftend, untere 2-3 fach federschnittig mit keilig-eiförm., obere 1-2-fach fiederschnittig mit lineal-lanzettl. Abschnitten. - Aus Südeuropa, allgem. cult. $\odot$. 7. 8 .

P. sativum Hoffm.

\section{Pimpinella L. Biebernell (V, 2).} spindlig.

St. aufrecht, ästig, wenigblättrig; Grund- u. Stbl. verchieden; Wrz.

1. Grundbl. herzförm. rundlich, gesägt, $d$. folgenden 3 -theilig mit rundlichen gekerbt. Abschnitten, d. obere 2 fach fiedertheilig mit kl. lanzettl. Zipf.; St. $60 \mathrm{~cm}$ h. - Küchengewürz aus d. Orient. ๑. 7. 8.

B1. alle fiederschnittig. Kr. mit Wrzst. Anis, $P$. Anisum L.

2. St. rund, fein gestreift., $15-60 \mathrm{~cm}$ h, nach oben nur mit Blscheiden; Abschnitte der Grundbl. rundlich bis länglicl, gekerbt, eingeschnitten-gezälunt od. fiederspaltig. - Trockene Wiesen u. Hiigel. 4. 7-10. P. Saxifraga L. 
Variet. $\beta$. alpestris Neilr. Abschnitte d. Grundbl. fast handthei-

lig. Alpentriften in 0oe. u. St.; $\gamma$ d is secta (Retz.) Abschnitte 1-2 fach fiederschnittig; - $\delta$. p u bescens (P. nigra W.) Ganze Pfl. feinflaumig, Wrz. abgerissen schwarz werdend. In 0oe.

St. kantig gefurcht, $0{ }^{\circ}-1 m$ h ; Grundbl. u. untere Stbl. gestielt, mit herzeiförm. bis länglichen spitzen gesägten Abschnitten, obere Stbl. sitzend mit 3 theiligem Blsaum. - Wiesen, Gebüsche, Waldränd. in Gebirgsgegend.; zerstreut. 4. 7-10.

P. magna $\mathrm{L}$.

Variet. laciniáta Wallr. Blabschnitte handförm. fiederspaltig, eingeschnitten-gesägt.

\section{Carum L. Küimmel $(\mathrm{V}, 2)$.}

St. aufrecht, einfach od. ästig, wenigblättrig; Dolden vielstrahlig, hüllenlos. Kahle $\mathrm{Kr}$.

1. Wrz. spindelförmig, weißlich; St. 0.3--1 $m$ h., kantig, BI. 2-3fach fiederschnittig mit lineal. Zipf.: Blbl. bisweil, röthlich. - Wiesen. ๑. 5. 6.

Gem. K, C. Carvi L.

2. Knolliger brauner Wrzst.; St. $30-60 \mathrm{~cm}$ h., Bl. 2-3 fach fiederschnitt. mit lineal. Zipf. Blt. weiß. - Kalkige Äcker in Kr. u. Noc., eingeschleppt in $\mathbf{M h}$. 4. 6. 7.

C. Bulbocástanum Koch.

\section{Aegopódium L. Geißfuß $(\mathrm{V}, 2)$.}

Wzst. krichend, verzweigt; St. 48-80 $\mathrm{cm}$ h., gefurcht; Bl. doppelt 3-zählig zerschnitten, Abschnitte herz- od. schiefeiförmig-länglich, gesägt; Dold. vielstrahlig, Bit. weiß. Kahl. - Auenwäld., Baumgärten, Gebüsche. 2. 5-7.

Giersch, A. Podagrária L.

\section{Falcária Host. Sicheldolde (V. 2).}

St. $0.30-1 m$ h., ausgebreitet ästig; Bl. 3 zählig zerschnitten, Abschn. br. lineal od. lineal-lanzettförm., stachelspitzig gesägt, etwas gekrümmt; Dold. zahlreich, Blt. weiß. Kahl. - Getreideäicker, Raine, auf Kalkbod. ๑. od. 4. 7. 8. F. Rivini Host.

\section{Bupléurum L. Hasenohr $(\nabla, 2)$.}

St. aufrecht od. aufsteigend, ästig; Bl. hell- od. gelblichgrün, parallelnervig; Dold. wenigstrahlig, Blt. fast sitzend, meist kürzer als d. Hüllchen, Blbl. einwärts geschlagen. Kahle kalkliebende $\mathrm{Kr}$.

1. Alle Bl. u. Hüllbl. br., letztere länger als d. Blt. lineal.

Alle Bl. (od. wenigstens d. grundständ.) schmal, lanzettförm. bis

2. Bl. oval od. rundlich, obere vom St. od. d. Ästen durchwachsen; St. $30-60 \mathrm{~cm}$ h., ausgebreitet ästig, Hüllbl. eilanzettförm., gelbgrün. Unter d. Saat; zerstreut. $\odot$. 6. 7.

$B$. rotundifolium. L.

Bl. oval od. länglich-elliptisch, grundst. mit geflügelt. Stiele. Stbl. mit herzförm. Grunde umfassend sitzend; St. 0:30-1 $\mathrm{m}$ h., einfach od, oben ästig, Hüllbl. br. oval, gelbgrün. - Laubwäld. in B., Mh., in d. Alpenländ. selten. 2. 7. 8. B. longifolium L.

3. Grundbl. lineal-lanzettförm., l., ungestielt od. in einen br. Stiel verschmälert, Stbl. anders geformt od. fehlend.

4.

Alle Bl. gleich od. ziemlich gleich, St, reichlich beblättert 6. oval, spitz.

4. Stbl. (1-3) eilanzettförm., umfassend sitzend, Bl. d. Haupthülle 
St. nackt od. mit 1 länglichen Bl., einfach, 7-22 $\mathrm{cm}$ h., Grundbl. lineal-lanzettlich, zugespitzt; Dolle $3-7$ strallig, Hüllbl. lanzettförm., Hüllchenbl. oval, alle griin. - Felsspalten d. Alp. . St., K., T., Kr., zerstreut. 4. 7. 8.

B. petraeum L.

5. Hüllclıenbl. in eine napffürm., brgekerbte Hüll, verwachsen, St. 15-30 cm h., meist einfach. - Felsige Plätze d. Alp. v. T. u. Kr.: selten. 4. 7. 8.

B. stellatum L.

Hüllchenbl. getrennt, oval; Strahlen d. Dolde wenig länger als d. 2-4 blättr. Haupthiille; wr. gerippt, St. $15-30 \mathrm{~cm} \mathrm{~h}$, einfach od. ästig. Steinige Alpentriften in Sz., T., Kx.; zerstreut. 4. 7. 8. B. ranuculoides L.

6. Hüllchenblättchen länger als d. Blten 7 .

Hüllchenbl. kürzer als d. Blt., lanzettlich; Bl. lanzettförm., spitz, grundst. in einen geflügelten Stiel verschmälert, Stbl. sitzend, schwach gebogen; St. 0·30-1 $m$ h., ästig. - Bebuschte Hiigel, Waldränder. 4. 7-9. B. falcatum $\mathrm{L}$.

7. Blättchen aller Hüllen 1., lauzettförm. grün, die d. Hüllchen kurz begrannt, doppelt so l. als d. Blt.; St. $3-30 \mathrm{~cm} \mathrm{h.,} \mathrm{meist} \mathrm{abstehend} \mathrm{ästig;}$ Bl. lineal-lanzettlich. - Steinige, sonnige Hügel in St., Kr., T.; zerstreut. $\odot$. 7. 8.

$B$. aristátum Bartl.

Hüllchenbl. nicht begrannt, lanzettlich-lineal, spitz, wenig länger als die Blt.

8.

8. St. aufrecht, ausgesperrt rispig-ästig, $20-45 \mathrm{~cm}$ h.; Bl. schmal lineal-lanzettlich, 1. zugespitzt; endständ. Dold. 5-7-, seitenständ. 1-3strahlig; Fr. glatt. - Trockene buschige Orte, Weingärten in Mh. u. Noe.; zerstreut. $\odot$. 7. 8.

$B$. Gerardi Jacqu.

St. meist aufsteigend, von unten an abstelsend-ästig $10-30 \mathrm{~cm}$ h.; Bl. lineal-lanzettförm., kurz zugespitzt; Dold. 1-5 strahlig, Fr. warzig. Salzhalt. Triften u. Gräben in Mh., Noe., B. (nur um Saidschütz) $\odot .7-9$.

$B$. tenuissimum $\mathrm{L}$.

\section{Oenanthe L. Rebendolde $(V, 2)$.}

St. aufrecht, åstig, Bl. feinzertheilt, Döldchen vielbltig, nach d. Blü. hen meist stark zusammeugezogen; Blbl. verkehrt herzförm. mit eingeschlagenem Zipf. Kahle Sumpfkr.

1. Wzst. spindelförm. mit Quirlen von Wzfasern, St. $0.6-1.5 \mathrm{~m}$ h. sammt d. Blstielen röhrig; Bl. gr., 2-3 fach fiederschnittig, Dold. gr., vielstrahlig, Blt. alle zwitterlich; Fr. länglich-lanzettförm. - Teiche, Lachen. 4. 6. 7 .

W as serfenchel, Oe. Phellandrium L.

Wzst. als ein Büschel knolliger Fasern ausgebildet, St. $30-60 \mathrm{~cm}$ h.; endständ. Dolden mit Zwitterblt., seitenständ. meist nur mit männl. Blt.

2.

2. Stiel u. Mittelrippe d. Stbl, rund u, gleich d. St. röhrig.hohl; Bl. 2-3 fach fiedersclınittig, mit keilig-lineal. Zipf.; Dolden wenigstrahlig, Strahl. sehr dick. - Sumpfwiesen, Wassergräben in $\mathbf{B}$, , $\mathbf{M}$., Oe. u. a. zerstrent $u$. selten. 4. 6. 7. Oe. fistulosa L.

Stiel d. Stbl. nicht röhrig, Dold. 5-10 strahlig, Fr. walzig 3.

3. Wzstknollen gestreckt-länglich od. verkehrt eiförm., untere Bl. 3-fach, obere 2-1-fach fiederschnittig, mit lanzettl. bis liueal. Zipfeln. Sumpfwiesen in Mh., (Marchwiesen), Noe., Kr., T.; sehr zerstreut. 4. 6. 7.

Oé. silaifólia M. Bieb. 
Wrastknollen fadenfërm. 1., am Ende angeschwollen; Bl. 2-fach fiederschnittig, Abschn. d. unteren br., fiederspaltig, d. oberen liveal-lanzettl., ganz. - Sumpfige Wiesen in Noe.; zerstreut. 4.6. 7.

Oe. pimpinelloides $\mathrm{L}$.

\section{Séseli I. Sesel (V, 2).}

St. aufrecht, sammt d. Ästen rund, gestreift; Bl. fein zertheilt, Blt. weif od. röthlich. Kahle od. flaumige $\mathrm{Kr}$. mit schopfigem Wzst.

1. Hüllchenblättch. in eine beckenförm. gezähnte Haut verwachser. St. 15-50 $\mathrm{cm}$ h., fast bllos, steif; Grundbl. 2-3 fach fiederschnitt. mit lineal. Zipf. - Sonnige Kalkhügel u. Kalkfelsen in B. u. Mlı. 4. 7. 8. S. Hippomárathrum L.

Hüllchenblättch, nicht verwachsen 2.

2. Hüllch. so l. od. länger als d. Döldchen. Dold. 10-15 strahlig; St. $15-60 \mathrm{~cm}$ h., einfach od. ästig, beblättert; Bl. 2-3 fach fiederschnittig mit lineal. Zipfeln. - Buschige Hiigel, Waldränd,, Triften in B., Mh., Sch., Oe.; zerstreut. $\odot$ bis 4. 7. 8.

S. ánnuum $\mathrm{L}$.

Húllch. kürzer als d. Döldchen, St. 0:30- $1 \cdot 20 m$ h., ausgebreitetästig, nur unten beblättert; Äste fast nackt (mit Blscheiden) 3.

3. Blstiele oberseits rinnig, Hüllchenblättch. lanzettlich; Bl. 2-3. fach fiederschnitt. mit lineal., bis $25 \mathrm{~mm}$ 1. Zipfeln; Doldenstrahl, sehr ungleich lang. Grün. - Trockene Grasplätze, sand. Triften in Mh., Noe., T.; selten. $\odot$.$) 7. 8$.

S. varium Trev.

Blstiele nicht rinnig, rund, Hüllchenblättch. pfriemlich, Doldenstrah len gleichlang

4. Dold. 10-15 strahlig, Bl. 33 zählig 3 fach-fiederschnitt. mit 1. lineal. Zipfeln. Bläulich bereift. - Auf Kalkhügeln, verbreit. 4. ๑. 7. 8.

S. glaucum L.

Dold. 2 - 6 strahlig, Bl. einfach od. 3-zählig fiederschnitt. mit lineal. spitzen, fast 3 kantigen Abschnitten. Grün. - Kalkberge im südl. T. u. Kr.; $\odot$. 7. 8 .

S. Gouáni Koch.

\section{Libanótis Crtz. Heilwurz (V, 2).}

St. aufrecht, $0 \cdot 15-1.30 m$ h., sammt d. Ästen (wenn vorhanden) kantig gefurcht; Bl. fiederförmig zerschnitten, Dold. groß, vielstrahlig, reichllitig.

1. Untere Bl. gr., im Umriss 3 eckig-länglich, 2-3 fach-, obere einfach fiederschnittig; Abschnitte eiförm. od. länglich fiederspaltig, unterste Paare an d. Mittelrippe sich kreuzend. - Bebuschte Hügel u. Berge, auf Kalk 11. Basalt; zerstreut. $\odot$. 7. 8.

L. montana Crtz.

2. Bl. 3 fach fiederschnitt., Abschnitte schmäler, 2-3 spaltig, Zipf. lineal, stachelspitzig. - An gleichen Orten in $\mathbf{K} 1$.; zerstreut. $\odot$. . 7. 8. I. athamantoides D. C.

\section{Aethúsa L. Gleiße $(V, 2)$.}

St. aufrecht, ästig, fein gestreift; Bl. 2-3 fach fiederschnitt. mit lanzettl. bis lineal. Zipf., glänzend dunkelgriin (beim Zerreiben knoblauchart. riechend), Dold. vielstrahlig, Blt. weifo. Giftig. - $\odot$. 6-9

Gartenschierling, Hundspetersilie, Ae. Cynápium L. 
Variet. $\boldsymbol{x}$. aglestis Wall. St. $5-60 \mathrm{~cm}$ h., von unten an ä3tig. Unkraut auf bebaut. Boden; - $\beta$. elatior Döll. St. $1-1 \cdot 6$ $m \mathrm{~h}$., nach oben ästig, blaubereift. (Ae. cynapioídes M. Bieb.) In Wäldern zerstreut und seltener, in B., Mh., Noe.

\section{Cuídium Cress. Bremdolde ( $T, 2)$.}

St. aufiecht, 30-60 cm h., beblättert; Bl, 2-3 fach flederschnitt. mit lineal. od. lineal-lanzettl. Zipf.; Dolden vielstrall. u. reichbltig, dicht. Hüllclienbl. borstlich od. pfriemlich. Fr. eiförmig.

1. Scheiden d. oberen Bl. 1. cylindrisch, dicht anliegend, St. oben ästig. - Sumpfwiesen, lichte Wälder an feuchten Stellen in B., Mll., Noe.; zerstreut. 4. 7. 8.

Blscheiden vom St. absteliend.

C. venosum Koch.

2. Hüllchen kahl, von d. Länge d. Bltstiele; B!zipfel durchscheinend geadert. - Felsige Orte in Kr.; zerstreut. 4. 7. 8. C. apioides Spr.

Hüllchen borstig-rauh, so l. od. länger als d. Döldchen; Bladern nicht durchscheinend. - Unter Hecken u. Gebischen in Kr.; zerstreut. ๑. 7. 8 .

C. Monniéri Cuss.

\section{Coníoselinum Fisch. Schierlingssilge (V, 2).}

St. $0 \cdot 5-1 m$ h., bläulich bereift, nach oben gefurcht; Blscheiden aufgeblasen, Bl. 2-3 fach fiederschnittig, mit lanzetilichen, weiß stachel. spitzigen, etwas umgerollten Zipf.; Dold. flach, vielstrahlig, Blbl. griinlichweiß; Fr. eirund. - Buschige, kräuturreiche Abhänge u. Triften im Gesenke; zerstreut. 4. 8.9.

C. tatáricum Fisch.

\section{Pachypléurum Mey. Dickrippe $(Y, 2)$.}

St. 3-10 cm h., einfach, nac'st od. 1-2 blättrig; Grundbl. lang ge.stielt, 2-3 frch fieảerschnittig mit lineal-länglichen Zipf.; Hiillbl. 3 spalt. - Feuchte Triften d. Alpen $(1690-2550 \mathrm{~m})$. 2. 7. 8. P. simplex Rehb.

\section{Athamánta Koch. Augenwurz (V, 2).}

St. aufrecht, rund, einfach od. ästig, Bl. fein zertheilt, Döllchen reichbltig; Hüllchenbl. lanzettlich, weißhäutig mit grünem Rückenstreif.

1. BI. 2-3 fach fiederschnitt., Zipfel kurz lineal od. länglich, spreizend; St. 8-60 $\mathrm{cm}$ h., oben wie d. Äste nackt, Dold. 5-15 strahlig; Fr. abstehend dicht weißfilzig. Weichflaumig. - Gerölle d. Alpen, besonders auf Kalk (1260-1900 m). 4. 6-8.

A. cretensis $\mathrm{L}$.

2. Bl. 3-t fach fiederschnittig, mit 1. fadenförmigen Zipfeln; St. 30 bis $60 \mathrm{~cm}$ h., Dold. 15-25 strahlig, Fr. grausammtig. - Felsspalten, felsige Plätze d. Kalkalpen von St., K., T. $\odot$. 6. 7. A. Matthioli Wulf.

\section{Ligústicum L. (V, 2).}

St. $0.50-1.30 m$ h., ästig, gestreift; Bl. 3 fach fiederschnittig mit lineal-stachelspitzigen Zipf.; Dold. 20-40strablig. Kahl. - Auf Bergen in $\mathrm{Kr}$. u. südl. T., selten. 4. 7. 8 .

L. Seguiéri Koch.

\section{Sílaus Bess. Silau ( $\mathrm{V}, 2)$.}

St. $0 \cdot 30-1 m$ h., sammt d. Ästen kantig; Bl. $2-3$ fach fiederschnitt., Abschnitte fieder- od. 3-4 spaltig, mit lineal-lanzettl. Zipfeln; Dolden ungleichstrablig. - Wiesen. 4.6-9. (S pratensis Bess.) S. selinoídes Jacqu. 


\section{Meum L. Bairwurzel $(V, 2)$.}

St. aufrecht, bis $30 \mathrm{~cm}$ h., rund, gestreift, einfach u. bllos od. ästiq, 1-2 blättrig; Grundbl. gestielt, 2-3 fach fiederschnittig, fein zertheilt; Dolden mehrstrahlig. Kahle $\mathrm{Kr}$.

1. Bl. 3 fach fiederschnittig mit haarfeinen Zipfeln, Doldenstrahlen ungleich lang, Hüllchenbl. pfriemlich; Blt. weiß. - Gebirgswiesen in B. (Erzgeb., Isergeb.) u. auf Gerölle in d. Kalkalpen $(960-1600 \mathrm{~m})$. 4. 6. 7. M. athamánticum $\mathrm{L}$.

2. Bl. 2 fach fiederschnittig mit lanzettförm. Zipf., Doldenstrahlen gleichlang, Hïllchenbl. lanzettlich, Blt. röthlich bis rosa. - Bergwiesen, felsige Hänge d. Alp. (1260-2300 m), d. Gesenkes u. Böhmerwald. 4. 7. 8.

M. Mutéllina Gärtn.

\section{Foenículum Tourn. Fenchel $(\mathrm{V}, 2)$,}

St. $1-1.6 m$ h., ästig, rund, fein gestreift; Bl. $3-4$ fach fiederschn. mit lineal-borstlichen Zipfeln. Kahles, aromatisch süß duftendes Kr. Gewürzp日. aus Südeuropa, cult. u. verwild. $\odot .7-10$.

$F$. officinale All.

\section{Selínum $\mathrm{L}$. Silge $(\mathrm{V}, 2)$.}

St. $0.30-1 m$ h., kantig gefurcht, ästig; Bl. $2-3$ fach fiedersclinitt. mit lanzettförmigen od. linealen Zipfeln; Dolden vielstrahlig, gewölbt; Wzst. mit fleischigen walzigen Zasern. - Feuchte Wiesen, Gebüsche, Auenwälder. 4. 7-8.

S. Carvifolia L.

\section{Angélica L. Engelwurz (V, 2).}

St. aufrecht, rund, glatt, bläulich bereift, $0 \cdot 30-1 \cdot 30 m \mathrm{~h}$. , oben ästig; Bl. kahl, $2-3$ fach fiederschnittig mit bauchiger Scheide u. ei- od. eiförmig-länglichen Abschnitten; Dolden gr., vielstrahlig, gewölbt; Hüllsh. vielblättr. - An Bächen, auf sumpfigen Wiesen. 4. 7-9. A. silvestris L.

Variet. montana (Schleich.), Blabschnitte lanzettförmig. Waldwiesen subalpiner Gebirgsregionen.

\section{Archangélica Hoffm. Erzengelwurz ( $V, 2)$.}

St. $0 \cdot 6-2 m$ h., gefurcht, obenhin ästig; Bl. doppelt fiederschnittig mit gr. bauchigen Scheiden u. gr. ei- od. lanzettförmig gesägten Abschn., unterste sehr gr.; Dolden vielstrahl. mit vielblättrig. Hüllchen. Kahl. Kräuterreiche Schluchten d. Riesengeb. u. d. Alpen von St. und $\mathbf{K}$.; in Gebirgsdörfern cult. 4. 7. 8.

A. officinalis Hoffm.

\section{Levísticum Koch. Liebstöckel (V, 2).}

St. 1-2 $m$ h, rund, glatt, ästig; Bl. hellgrün, untere fiederschnittig mit gr. keilig rautenförm. gelappten u. eingeschnitten-gesägten Abschnitt.; Dold. vielstrahlig mit vielblättr. Hüllen u. Hüllchen. Kahl, süßlich duftend. - Aus Südeuropa, in Bauerngärten d. Alpen u. a. Hochgeb. cult. u. verwildert. 4. 7. 8 .

L. officinale Koch.

\section{Férula I. Birkwurz (V, 2).}

St. $0.6-1.3 \mathrm{~m}$ h., rund, gestreift, obenhin quirlästig; Bl. vielfach fiederig zerschnitten mit schmal linealen Zipf., untere l. gestielt, bis $60 \mathrm{~cm}$ lang, oberste bloße Scheiden; Dold. in pyramidaler Rispe. Kahl. - Wüste Plätze im südl. T. u. Kr. 4. 6. 7. 


\section{Peucédanum L. Haarstrang (V, 2).}

St. aufrecht, meist ästig, Bl. 1- bis mehrfach fiederig zerschnitten; Dolden vielstrahlig. Kahle $\mathrm{Kr}$.

1. Obere (doldentragende) Äste quirl-, untere wechselständig, St. 1.3 bis $2.6 m$ h., rund; Bl. 3 fach fiederschnittig, Abschn. eiförmig od. länglich, grob gesägt; Dolden vielstrahlig, ganz hüllenlos, trugdoldig; Blbl. grünlichgelb, Fr. mit br. Flügelsaum. - Steinige Plätze in Noe., St. u. Kr., selten... 4. 6. 7.

Äste alle wechselständig. P. verticillare M. Koch.

2. Hülle u. Hüllchen vielblättrig.

Hülle fehlend od. 1-3 blättrig.

3. St. röhrig, gefurcht, $1-1.6 m$ h., beblättert; Bl. $2-3$ fach fiederschnittig, Abschnitte fiedertheilig mit länglichen od. lineal.lanzettlichen Zipfeln; Dold. gr., flach; Blt. weiß. (Thysss linum palustre Hoffm.) - Wassergräben, Sümpfe, Teiche. 4. 7. 8.

$P$. palustre Mönch.

St. niclit hohl, innen markig.

4. Flügelsaum durchscheinend, von d. Breite d. ganzen Fr.; St. gefurcht, einfach od. ästig, $0.6-1.3 \mathrm{~m}$ h., glänzendweiß gestreift; Bl. 2. bis 3 fach fiederschnittig, Abschnitte 1-2 fach fiederspaltig mit länglichen od. lanzettlichen Zipfeln; Dold. vielstrahl., Blt. weiß. Steinige Plätze in 0e., St., K., K'r.; zerstreut. 4. 7. 8.

$P$. austriacum Koch.

Variet. Raiblense (Koch), St. niedrig, oft einfach $u$. bllos; Blzipfel schmal lineal. In K. (Raiblthal), Kr. (Wochein), südl. T.

Flügelsaum nicht durchscheinend, so br. wie d. halbe Fr. oder noch schmäler; St. obenhin nur mit Blscheiden.

5. Verzweigungen d. Blstiele von d. Mittelrippe recht- od. stumpfwinklig abstehend, Abschnitte d. 2-3 fach fiederschnitt. Bl. fiederspaltig mit lanzettlichen Zipfeln; St. $0.3-1 m \mathrm{~h}$, feingestreift, Blt. weiß. Trockene Wiesen, Bergwälder, Gebüsche, besond. auf Kalk. 4. 7. 8.

\section{P. Óreoselinum Mönch.}

Verzweigung. d. Blstiele spitzwinklig von d. Mittelrippe abstehend; St. $0 \cdot 3-1 \cdot 6 m$ h., Bl. 3 fach fiederschnittig.

6. St. rund, gestreift, nach oben hin ästig; Blabschnitte eiförmig od. länglich, stachelspitzig, $1-2$ fach gesägt, unterseits blaugrün, fast lederartig; Dold. vielstrahl., Blt. weiß. - Trockene Wiesen, bebuschte Hügel, besond. auf Kalk. 4. 7. 8.

Hirschwurz, $\boldsymbol{P}$. Cervária Cuss.

St. kantig.gefurcht, rispig-ästig; Blabschnitte 1-2 fach fiederspaltig, mit lanzettl. od. länglich-lanzettförm. Zipfeln.

7.

7. Blbl. weiß, Doldenstrahlen innenseits flaumig. - Trockene steinige Berge in Kr. u. südl. T.; serstreut. 4. 7. 8. P. vénetum Koch.

Blbl. hellgelb, Doldensirahlen kahl. - Trockene bebuschte Htugel, besonders auf Kalk, in B., Mh., Noe., St.; zerstreut. 4. 7. 8.

\section{$P$. alsáticum $\mathrm{L}$.}

8. (2) Grundbl. 3-mehrfach fiederschnittig, mit schmallinealen linng. Zipfeln; St. $0.6-1.6 m$ h., steif, stielrund, glatt; Blbl. blassgelb. - Waldwiesen, Flussauen in 0oe. u. St.; zerstreut. 4. 7. 8. P. officinale L.

Grundbl, 1 fach fiederschnittig mit 1-2 fach fiedertheilig. Abschnitt. u. länglichen oder lanzettl. Zipfeln, Stbl. fiederschnittig mit ganzen lineallanzettlichen Abschnitten; St. $0 \cdot 30-1 m$ h., gefurcht, Blt. gelblich. Wiesen, Waldränder in Noe. u. St.; selten. 4. 7. 8. P. Chabraci Rchb. 


\section{Imperatória L. Meisterwurz (V, 2).}

St. $0 \cdot 30-1 m$ h., Bl. 1 fach bis 2 fach 3 zählig zerschnitten, mit eiförmig gezïhnten Abschn. u. bauchigen Scheiden; Dolden vielstrahlig, Blt. weiß od. röthlich. Kah!. Wzst. mehrköpfig, fleischig. - Kräuterreiche Orte, steinige Triften d. Alp. $(1260-1900 \mathrm{~m})$, auch in Mh. u. B. (in Bauerngärt. d. Grenzgeb. cult. u. stellenweis verwildert). 4.6-8. I. Ostrithium L.

\section{Anéthum L. Dill (V,2).}

St. ästig, rund, glatt, $0 \cdot 30-1 \mathrm{~m}$ h.; Bl. vielfach fiederig in lineale, borstliche Zipfel zerschnitten, Dolden vielstrahlig, hülienlos. Kahl, aromatisch duftend. - Gewïrzpf. aus Südeuropa, uiberall cult. ๑. 7-9.

\section{A. gravéolens $\mathrm{L}$.}

\section{Pastináca L. Pastinak (V, 2).}

St. kantig-geiurcht, $0 \cdot 30-1 \mathrm{~m}$ h., ästig; Bl. einfach fiederschnittig mit br. eilänglichen od. herzeiförmig. grob gekerbten Abschn.; Dold. vielstrahlig, hüllenlos od. mit 1-2 blättr. hinfälligen Hüllen u. Hiillchen.

1. St. fast geflügelt-kantig, Blabschnitte oberseits glänzend, unters. scharf kurzhaarig; Blt. goldgelb. - Wiesen, Raine, Hügel mit Sand-und Kalkboden, auch als Gemüsept. cult. $\odot$. 7-9.

$P$. sativa $\mathrm{L}$.

2. St. schwach-kantig od. fast stielrund, Blabschnitte oberseits matt, beiderseits (wie d. g. PA.) dicht kurzhaarig, Blt. grünlichgelb. - Wälder, Gebüsche in B.; zerstreut. $\odot .7-9$.

P. opáca Brìd.

\section{Herácleum L. Bärenklau (V, 2).}

St. gefurcht, hohl; Bl. breitlappig, mit meist bauchigen Scheiden; Dold. vielstrahl., trugdoldig, Enddolden d. St. sehr gr., alle mit vielblättr. Hüllchen. Scharfhaarige Kr.

1. Bl. herzförmig-rundlich, gelappt; Lappen abgerundet, ungleich gesägt; St. $30-60 \mathrm{~cm}$ h.; Ölstriemen undeutlich. - Gebirgswälder v. Sz. 4. 7. 8 .

Bl. 3 zählig- od. fiederförmig-zerschnitten; Ölstriemen sichtbar. 2.

2. Bl. 3 zählig-zerschnitten, 7 -3 lappig, grundständ. bis $30 \mathrm{~cm} \mathrm{l.,}$ Lappen zugespitzt, ungleich gesägt; St. $1-2 m \mathrm{~h}$. - Voralpenwälder in De., Sz., St., T. ค. 7. 8.

H. pyrenáicum Lam.

Bl. fiederschnittig mit gr., meist 3 lappig. Endabschnitt. 3.

3. Scheiden nicht bauchig, Abschnitte d. grundständ. Bl. eiförm. od. eilänglich, d. oberen lanzettförm., zugespitzt, alle ungleich gekerbt.gesägt; St. 20-60 $\mathrm{cm}$ h. - Triften, Gerölle d. Alpen v. Oe., St., K., T., Sz. 4. 7. 8 .

H. austriacum $\mathrm{L}$.

Variet. si ifolium (Rchb.), Kleiner, Blt. rosen- bis purpurroth. In Ooe. u. Kr.

Scheiden gr., bauchig, Abschnitte aller Bl. gelappt bis fiederspaltig, ungleich gekerbt od. gesägt; St. $0.6-1.6 \mathrm{~m}$ h., steifhaarig. - - $.7-10$ H. Sphondýlium L.

Formen: $\alpha$. la til o bátum (Neilr.), Blabschnitte kurzlappig, eiförm. od. verkehrt-eiförmig, stumpf, gekerbt; Blbl. weiß bis rosenroth. Überall auf Wiesen; - $\beta$. arig u stilobát um (Neilr.), Blabschn. fiederspaltig, Zipfel lanzettförmig bis lineal, spitz. Auenwäldes und Bergwiesen in den Kalkroralpen; zerstreut. 


\section{Tordýlium L. Zirmet (V, 2).}

St. 落tig, 0.30-1 $m$ h., gefurcht; Bl. fiederschn, Abschn. d. unteren Bl. eilänglich, d. oberen länglich-lanzettförmig, alle eingeschnitten-gekerbt; Dolden wenig strahlig, flach, mit wenigen linealen Hüll- und Hüllchenbl. - Sonnige buschige Abhänge in Mh. u. B.; zerstrent. ๑. 7. 8.

\section{T. máximum L.}

\section{Chaerophýllum L. Kälberkropf (V, 2).}

St. aufrecht, ästig; Bl. 2-mehrfach od. 3 zählig-fiederschnittig, Dold. vielstrahlig, mit vielblättr. Hüllchen, ab. olıne od. mit $1-2$ blättr. Hülle; Blbl. meist weiß, verkehrt-herzförmig mit einwärts geschlagenem Zipfel. haarig.

1. Blbl. gewimpert, weiß od, rosenroth, Fr. lineal; St. u. Bl. steif-

Blbl. kahl, weiß; Fr. länglich.

2.

2. Bl. 2 fach 3 zählig- od. 3 zählig fiederschnittig, Bl. eiförmig oder Jänglich, spitz, eingeschnitten od. fiederspaltig, gesägt; St. $30-60 \mathrm{~cm} \mathrm{h.,}$ stielrund, markig. - Gebirgsgegend. an Bächen. 2!. 6-8.

\section{Ch. hivsútum L.}

Bl. 2 fach fiederschnittig, Abschn. länglich od. lanzettförm., fiederspaltig od. eingeschnitten gesägt, St. $0.6-1.3 \mathrm{~m}$ h., stielrund, holl. Wiesen d. Knieholzregion d, Alpen von 0e., Sz., St., T., Kr. 4. 6. 7. Ch. Villarsii Koch.

3. St. an d. Knoten kaum angeschwollen, $0 \cdot 6-1 \cdot 3 \cdot \mathrm{m}$ h., kantig gerieft; B1. 2-3 fach fiederschnittig, Abschnitte eilanzettförmig, fiederspaltig bis fiedertheilig, Zipfel gesägt; Fr. reif gelbbraun. - Waldränder, Gebüsche, Hecken in B., Mh. (?), Oe., St., Sz. 4. 6. 7. Ch. aureum L.

St. an d. Knoten angeschwollen.

4. St. rund, glatt, bläulich bereift u. blutrotl gefleckt od. überlaufen; Bl. vielfach fiederschnittig mit $\mathrm{kl}$. linealen Zipf.; St. $1-2 m \mathrm{~h}$., Wz. riibenförnig. - Hecken, Waldränder, Gebüsche. ๑. 6. 7. Ch. builbosum L.

St. nicht bereift, stielrund, fein gerillt.

5. St. bläulichgriin, dunkelroth gefleckt, schmächtig, $30-60 \mathrm{~cm} \mathrm{~h}$; Bl. 2 fach fiederschnitt. mit eiförmigen fiederlappigen Abschn. u. gekerbten Zipfeln; Dolden kl. Giftig. - An Mauern, Hecken, in Gebiischen. $\odot$. 6. 7.

Ch. témulum L.

St. grün, stark, 0.60-1 $m$ h.; Bl. 2-3 fach 3 zählig-zerschnitten od. 3 zählig- 2 fach-fiederschnittig, Abschn. gr., eiförmig od. eilänglich, ganz od. gelappt, gesägt; Fr. aromatisch. Behaart. - Ufergebüsche, Waldränd., «1 Bächen in B., Hh., Sch., Oe. 2. 6-8.

Ch. aromáticum $\mathrm{L}$.

\section{Anthriscus L. Kerbel $(V, 2)$.}

St. aufrecht, ästig; Bl. 2-3 fach-od. 3 zählig-fiederschnittig; Dolden ohne Hülle, obere mit mehrblättr. Hiullchen; Blbl. weiß.

1. Fr. sehr kurz geschnäbelt, mit zusammengedrückter 5 riefiger Spitze; Dolden vielstrahlig, gestielt, Hüllchen 5-8blättrig, Blabschnitte fiederspaltig.

2.

Fr. deutlich geschnäbelt, Dold. wenigstrahlig, th. endständig, th. den Bl. gegenüber, gestielt od. sitzend; St. rund, fein gestreift, Blabschnitte fiederspaltig.

2. Fr. länglich-lanzettförmig, glatt, glänzend; St. $0.60-1.50 m$ h. 3 . 
Fr. lineal-lanzottförmig, kantig-weichstachlig, Llz pfel schmallänglich, St. $30-60 \mathrm{~cm}$ h. Kurz u. dicht flaumig. - Voralpen von Kr. 4. 5. 6. A. fumarioides Spr.

3. Blt. fast alle zwitterlich, fruchtbar, gleichgroß, Blbl. lange stehen bleibend; Bl. derb, 2-3 fach fiederschn., die beiden untersten Hauptabschn. kleiner als d. übrigen, Zipfel länglich-lanzettlich, spitz, matt. - - Wiesen, Grasgärten, Hecken. 4. 5. 6. P ferdek ü m mel, A. silvestris Hoffm.

Randblt. d. Döldchen zwitterlich und viel größer als d. übrig. meist männlichen, Blbl. hinfällig; Bl. zart, 3 zählig-fiederschnittig, die 3 Hauptabschnitte gleichgroß, abnehmend fiederschnittig mit eiförm od. länglichen stumpfen glänzenden Zipfeln. - Schattige Wälder, feuchte Waldschluchten d. Hochgeb. von B., Mh. u. d. Voralpen. 4. 6-8. A. nítida Wahlb.

4. (2) Fr. lineal, glatt; Doldenstrahlen u. Bltstiele feinbebaart, Hüllchen halb ausgebildet, $2-3$ blättrig, Blscheiden ganz, St. $15-30 \mathrm{~cm}$ h., hellgrünes, süßlich-aromatisches Kr. - Cult. u. verwildert. $\odot .5,6$.

Suppenkerbel, A. Cerefólium Hoffm.

Variet. $t r i c h$ os perma (R. Sch.), Fr. steifhaarig. - Wild auf bebuschten Auhöhen, Ãckern, an Waldränd.; zerstreut.

Fr. eilänglich, dicht gekrümmt-stachlig; Doldenstrahlen u. Bltstiele kahl; Hüllchen vollständig, Blscheiden gefranzt, St. $15-50 \mathrm{~cm}$ h., -

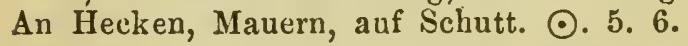

A. vulgaris $\mathrm{P}$.

\section{Scandix L. Nadelkerbel (V, 2).}

St. 8-30 $\mathrm{cm}$ h., rund; Bl. 2-3 fach fiederschnittig mit linealen Zipfeln; Dolden 1. gestielt, den $\mathrm{Bl}$. gegenüber, hüllenlos mit vielblättrigen Hüllchen, Blt. kl., weiß. - Saatfelder, aus Südeuropa eingeschleppt; zerstreut. $\odot .6-10$.

S. pecten Véneris L.

\section{Myrrhis Scop. Suißdolde (V, 2).}

St. rund, gestreift, $0.5-1 m$ h.; Bl. im Umriss 3 eckig, $2-3$ fach fiederschnittig, mit eilanzettförm., gesägten bis fiederspalt. Abschn.; Dold. vielstrahlig; Blt. weiß, Fr. sehr gr., glänzendbraun. - Waldwiesen, Waldränder der Voralpen, verwildert (weil in Bauerngärten cult.) in Gebirgen von Seh., Wh., B. 4. 6. 7. M. odorata Scop.

\section{Molopospérmum Koch. Striemensame ( $\mathrm{V}, 2)$.}

St. rund, hohl, $1-2 m$ h. ästig; Bl. 3 fach fiederschnittig mit eilanzettförm, 1. zugespitzten, eingeschnitten-gesägten Abschn.; Dolden vielstrablig, oberste mit Zwitterblt., untere zu 3-4 quirlständig mit männl. Blt.; Blbl. weiß. Steinige Berge im südl. T. u. Kr. 4. 7. 8.

\section{M. cicutárium DC.}

\section{Coníum L. Schierling $(V, 2)$.}

St. aufrecht, 1-2 $m$ h., rund, bläulich bereift und unten roth gefleckt, sehr ästig; Bl. 2-3fach fiederschnittig mit lanzettlich. ganzen od. eingeschnitten-gesägten Zipf.; Dold. vielstrahlig, Hülle vielblättr., zurückgeschlagen, Hüllchen balbiert, 3-6 blättr.; Blt. weiß. Giftig. - Hecken, Wald-und Feldränder; zerstreut (nicht häufig). $\odot$. 7. 8. 


\section{Pleurospérmum Hoffm. Rippensame (V, 2).}

St. $06-1.6 m \mathrm{~h}$., dick, gefurcht, röhrig, oben ästig; untere $\mathrm{Bl}$. 2-3fach-, obere 2 fach fiederschnittig mit lanzettförmigen Abschn.; Dolden zahlreich, vielstrahlig, Hülle und Hüllchen zurückgeschlagen, Blt. weiß. - Felsige, buschige, kräuterreiche Plätze im Riesengebirge, Gesenke u. den Kalkalpen; zerstreut. 4. 6-8.

$P$. austriacum Hoffm.

\section{Malabảila Hofín. ( $V, 2)$.}

St. 0.6-1 $m$ h. rund, voll, obenhin ästig; Bl. im Umriss 3 eckig, 3 zählig zerschnitt., Abschn. doppelt fiedertheilig, Zipf. eingeschnitten gezähnt; Dolden vielstrahlig, Blt. weiß. Kahl. (Ligusticum carniolicum Host.) Berge im südlichen T. u. Kr.; zerstreut. 4. 6. 7.

\section{Gólaka (Hacq.) Kern.}

\section{Siler Seop., Rosskiimmel (V, 2).}

St. $0 \cdot 6-2 m$ h., rund, obenhin ästig; Bl. 2-3fach 3 zählig geschnitten, Abschn. gr., rundlich, oft gelappt, ungleich grobgekerbt, unterseits, wie auch d. St. bläulich bereift. Kahl. - Gebüsche, Waldränder in Noe. u. St.; selten. 4. 5. 6. S. trílobum Crtz.

\section{Laserpítium L. Laserkrant (V, 2).}

St. aufrecht, ästig; Bl. 3 zählig oder fiederförmig zerschnitten. Dolden gewölbt, Wzst. schopfig.

1. Blbl. weiß, Hülle und Hüllchen vielblättrig.

Blbl. gelb, gelb mit rothem Rande oder rosenroth; Hülle fehlend od. wenigblättrig, Hüllchbl. pfriemlich; St. $0 \cdot 6-1 m$ h., rund, gestreift; Bl. 3 zählig -fiederschnittig, Abschnitte ei- oder herzförm., gekerbt oder gezähnt. - Wälder, Gebüsche auf Kalk in $\mathbf{I} \mathbf{r}$. u. südl. T.; zerstreut. 4. 7. 8 .

L. marginatum W. Kit.

2. Blabschnitte ganz und ganzrandig, lineal oder lanzettförmig; St. $0.3-1 \mathrm{~m} \mathrm{~h}$. rund.

Blabschn. fiederspaltig od. gezähnt.

3. Bl. 3 fach-fiederschnittig; Fr. länglich, $6 \mathrm{~mm}$ l., Gr. zurückgekrümmt. - Zwischen Gebüsch in den Alpen; zerstreut. 4. 7. 8.

L. Siler L.

BI. 3 zählig, 2- bis 3 fach fiederschnittig; Fr. oval, $4 \mathrm{~mm} \mathrm{l.,} \mathrm{Gr.}$ ausgespreizt. - Alpenwiesen in St., K., T., Kr.; zerstreut. 4. 6. 7, L. peucedanoídes $\mathrm{L}$.

4. St. rund, gestreift.

St. gefurcht, mehr weniger rückwärts rauhhaarig.

5. Blabschnitte gr., herzförmig-elliptisch od. herzeiförmig, nach vorn stachelspitzig-gezähnt, spitz, St. $0^{\circ} 6-1^{\circ} 6 \mathrm{~m}$ h., Bl. gr., 3 zählig 2 fachfiederschnittig. Kahl. - Gebüsche, Waldränder, Auenwiesen, auf Kalk; zerstreut. 4. 7. 8.

L. latifolium L.

Variet. ásperum (Crtz). Bltstiele und untere Fläche der Blabschnitte kurz rauhhaarig.

Blabschn. kl., fiedersraltig.

6. Bl. 2 fach-fiederschnitt., Abschnitt im Umriss länglich, scharfgesägt, oberseits kahl und glänzend; St. $30-60 \mathrm{~cm}$ n., steifhaarig; Hüllblättch. 2-3 spaltig. - Felsen im südl. T. 4. 7. 8. L. nitidum Zante. 
Bl. vielf ach zerschnitten, Zipfel d. eiförm. Abschn. lineal, beiderseits kurzhaarig; St. 15-60 $\mathrm{cm}$ h., kahl, Hüllbl. ganz. - Alpentriften des central. u. südl. 'T. auf Schieferboden. 4. 7. 8.

L. hĩrsutum Lam.

7. (4). Blscheiden sehr gr., bauchig; Bl. 3 zählig 3 fach-fiederschnitt., unterseits rauhhaarig, Abschn. gr. eitörm., ungleich gesägt; St. 1-2.3 cm h. - Kräuterreiche bebuschte Orte im Hochgesenke und in Kr. 4. 7. S.

L. Archangélica Wulf.

Blscheiden nicht bauchig, Bl. 2 fach-fiederschnitt., kahl oder unters. rauhhaarig; Zipf. d. Abschn. lanzettförm., spitz; St. $45-60 \mathrm{~cm}$ b. Wiesen, Gebüsche; zerstreut. 4. 7. 8.

L. pruthénicum L.

\section{Orláya IIoffm. Strahldolde (V, 2).}

St. gefurcht, $15-60 \mathrm{~cm}$ h., Bl. 2-3fach fiederschnitt. mit kì. lineallänglichen Zipf.; Hüll- und Hüllchenbl. gr., weißhäutig gerandet; äußere 13lbl. sehr gr. - Saatfelder, steinige buschige Orte; besond. auf Kalk, in Nih. u. Noe.; zerstreut. $\odot$. 6. 7 .

O. grandiflóra Hoffm.

\section{Daucus L. Möre, Mohrrube $(V, 2)$.}

St. gefurcht, ästig, $30-60 \mathrm{~cm}$ h.; Bl. 2-3fach fiederschnittig mit lineal-lanzettl. oder lineal. Zipf.; Dold. vielstrahlig, oft mit centraler geschlechtsloser purpurrother Blt., im Frzustande nestartig zusammengezogen. Scharfhaarig. - Wild (mit dünner Wz.) an Rainen, auf Feldern n. Wiesen, überall cult. $\odot .6-10$.

D. Caróta L.

\section{Cáucalis L. Haftdolde (V, 2).}

St. gefurcht, ausgebreitet-ästig; Bl. 2-3fach fiederschnitt. mit lineal od. lanzettl. Abschn.

1. Dolden endständ., gr., vielstrahlig; äußere Blbl. sehr gr., schnerweiß; Fr. bis $13 \mathrm{~mm}$ l., Stacheln dicht stehend, pfeilspitzig; St. 45 bis $60 \mathrm{~cm}$ h., rund. - Aus dem Oriente; in B. (b. Kuchelbad) verwildert u. gemein. -) 7. 8.

C. orientalis $\mathrm{L}$.

Dolden den $\mathrm{Bl}$. gegenüber, $2-3$ strahlig, Blbl. kl. weiß oder rötllich, Fr. mit entfernt stehenden gebogenen Stacheln; St. $15-30 \mathrm{~cm}$ h.

2. Stacheln so 1. wie der Querdurchmesser der 8 mm 1. Fr., an der Spitze hakig. - Saatfelder, Gebüsche, anf Kalk. ๑. 6-8.

C. daucoides L.

Stacheln viel kürzer als d. Querdurchmesser d. 12-13 $m m$ I. Fr. aufwärts gebogen. - Saatfelder in B. u. Noe.; zerstreut und selten. $\odot$. $6-10$.

C. muricáta Bisch.

496. Turgénia Hoffm. (V, 2).

St. 30-4j $\mathrm{cm}$ h., meist ästig; Bl. einfach fiederschnitt., Abschn. fiederspalt. oder eingeschnitten-grobgesägt; Blbl. weiß oder purpurn. Saaten in Мh. U. Yoe, zerstreut u. selten (aus Südeuropa eingeschleppt). ๑. 7. 8 . T. latifólia Hoffm.

497. Tórilis Adans, Bastdolde $(V, 2)$.

St. ästig, rund; $15-60 \mathrm{~cm}$ h.; untere Bl. 2fach-, obere 1 fach-fiederschnittig, Abschn. grobgesägt bis fiederspaltig. Angedrückt-steifhaarige, rauhe $\mathrm{Kr}$. 
1. Stachelborsten der Fr. aufwärts gekrümmt, stumpf, raub; Blbl. weiß od. rosa, Haupthülle vielblättr. - An Hecken, Mauern, auf Sclıutt. ค.) $7-9$.

T. Anthriscus L.

Stachelborsten gerade, pfeilspitzig; Blbl, weiß, äußere größer; Haupthülle meist fehlend.

2. Blbl. von d. Länge des Frkn. Gr. wenig länger als d. Stempelpolster. - Sonnige steinige Abhäıge, Weinberge, Brachen in B. u. Mi t.; zerstreut. $\odot$. 7. 8 .

T. infesta Koch.

Blbl. noch einmal so l. als d. Frlkn., Gr. viel länger als d. Stempelpolster. - Äcker, Waldräuder in Noe.; stellenweis. $\odot$. 7. 8.

T. neglecta $\mathrm{R}$. Sch.

\section{Coriándrum L. Wanzensame (V,2).}

St. ästig, rund, $30-60 \mathrm{~cm}$ h.; untere Bl. 1-2fach fiederschnitt. mit eingeschnitten-gesägten bis fiederspaltigen Abschnitt., obere 2-3fach fiederschnitt. mit lineal. Zipfeln; Dolden $\breve{5}-8$ stranhlig, mit halbirten $3 \mathrm{bl}$. Hüllchen. Kahl. - Gewürz- und Arzneipfl. aus Südeuropa, hie und da cultiviert und verwildert. $\odot .6 .7$.

C. sativum $\mathrm{L}$.

\section{Bífora Hoffm. Hohlsame $(V, 2)$.}

St. ästig, kantig gefurcht, $15-45 \mathrm{~cm}$ h.; Bl. 2-3 fach fiederschnitt, mit lineal. Zipf.; Dold. 5-8 strahlig, mit halbierten $2-3$ blättr. Hüllchen; Blbl. weiß, äußere viel größer. - Aus Südeuropa cingeschleppt: auf Äckern in B., Noe., T.; stellenweis. ๑. 6. 7. B. rádians M. Bieb.

\section{Fan. LXXXII. Saxifragáceae. Steinbrechartige.}

\section{Saxífraga L. Steinbrech $(X, 2)$.}

Bl. einfacb, ganz od. handförm. zertheilt, meist wechsel-, unterste oft rosettenständig; St. einfach oder ästig, 1-vielbltig, bisweilen fehlend.

1. Bl. am Rande oder an d. Spitze mit kalkabsondernden Grübchen (deshalb jung von weißen Krusten umsäumt, alt nackt), stets ganz. 2.

Bl. ohne kalkabsondernde Grübchen.

16.

2. Bl. gegenständig, mit 1-3 Grübchen am stumpfen verdickten Eude; St. liegend, dicht beblättert, rasig, blttragende kurz aufrecht. Alpenkräuter.

Bl. wechselständig, längs d. Ränder mit Grübchen, am Grunde gewimpert.

3. Bl. gekielt 3 seitig mit 3 Grübchen, länglich-lanzettförm., 4 reihig dachziegelig, sammt d. Kelchzipf. kahl; St. bis $5 \mathrm{~cm}$ h., 1-4 bltig, Bibl. hellroth. - Felsspalten d. Alpen v. St., Sz., K. $(1000-2600 \mathrm{~m})$; zer. streut. 4. 7. 8 .

$S$. retuisa Wahlenb.

Bl. mit 1 Grübchen, alle oder nur d. oberen sammt d. Kelchzipf. gewimpert.

4. Bl. verkehrt-ei- oder spatelförm., flach, ziemlich entfernt, sammt d. Kelchzipf. drüsig gewimpert; Blt. zu 2-3, kopfig, endständ., Blbl. so l. wie d. Stbf., 3 nervig, rosenroth od. weiß. - Felsen u. Gerölle d. Alpen v. St., K., T. $(1900-2800 \mathrm{~m})$. 4. 7. 8.

S. biftóra All.

Variet. macropétala (Kern.) Blbl. 2-3mal länger als d. Stbf., 5nervig, lila. Alpen von Sz., K., T. 
Bl. länglich, gekielt-3 kantig, an d. sterilen Triebeu 4 reihig-dachziegelig; Blt. einzeln.

5. St. kriechend, ästig, lockere Rasen bildend; obere Bl. u. Kelchzipfel l. gewimpert, ohne Drüsen; Blbl. erst rosa, dann violett. - Nasse Felsen und Gerölle der Alpen $(1900-2600 \mathrm{~m})$ u. im Riesengeb. (selten). 4. 6. 7 .

S. oppósitifólia $\mathrm{L}$.

St. aufrecht, kurz, dichte rundliche Rasen bildend; obere Bl. und Kelchzinfel. drüsig gewimpert; Blt. sitzend, violett. - Gerölle und Gletschermoränen der Alpen von Sz., K., T. $(1900-2900 \mathrm{~m})$; zerstreut. 4. 7. 8. L. Rudolphiána Hornsch.

6. (2). Bl. gesägt od. gezähnt mit Grübchen an jedem Zahn, grundständige in dichten Rosetten, mindestens $13 \mathrm{~mm} \mathrm{l}$; St. $15-60 \mathrm{~cm}$ h., beblättert.

7.

Bl. ganzrandig, starr, 3 kantig, oberseits mit mehreren Grübchen, 2-8 $\mathrm{mm}$ 1, dachziegelig gehäuft; Stämmchen dichte Räschen bildend, Bltst. höchstens $12.5 \mathrm{~cm}$ l. 12.

7. Blbl. orangegelb, lineal-lanzettlich; Blt. traubig-rispig, St. 15 bis $45 \mathrm{~cm}$ h. sammt d. Bltstand klebrig-behaart; Rosettenbl, zungenförmig mit knorpligem Rande, bis $25 \mathrm{~mm} \mathrm{l}$. - Gerölle und Felsen d. Alpen, in d. Thäler hinabsteigend. 4. 7. 8.

S. mutáta L. behaart.

Blbl. weiß, verkehrt-eirund oder keilförm., St. und BItstand drüsig

8. Rosettenbl. lineal bis lineal-lanzettl., mit dicken weißen Krusten am Rande, bis $25 \mathrm{~mm}$ l.; St. $15-30 \mathrm{~cm}$ h., Blt. traubig-rispig. Höchste Kalkalpen von St., K., T., Kr. 4. 7. 8. S. crustáta Vest.

Rosettenbl br. lineal, zungen- oder spatelförm., mit weißkalkigen Zähnen (ohne Krusten).

9.

9. St. von uriten an ästign, $30-60 \mathrm{~cm}$ h.; Blt. sehr zahlreich in pyramidaler Rispe, Blbl. keilförm., Rosettenbl kuorplig gesägt. - Felsen d. Alpen von St. (b. Eisenerz); häufige ZierpA., in d. Alpenländern vers wildert. 4. 7. 8.

S. Cotylédon L.

St. von d. Mitte an, oder oben ästig, Blt. in lockerer Traube oder Rispe, Blbl. verkehrt-eiförmig.

10.

10. Äste d. schmalen Rišpe 1-4 bltig, Blbl. am Grunde meist roth punktiert; St. 15-30 $\mathrm{cm}$ h., Rosettenbl. verkehrt-eiförmig-länglich, knorplig scharfgesägt, spitzzähnig, bis $25 \mathrm{~mm} \mathrm{l}$. - Kalkfelsen in B., Mh, Sch. und in den Alpen $(1260-2200 \mathrm{~m})$. 4. 5-8. S. Aizóon L.

Variet. $\beta$. brevifolia Stob. Bl. verkehrt-eiförm., Blbl. nicht punktiert. In B: (b. St. Ivan mit dem Hauptform).

Äste d. br. länglich-pyramidalen Rispe 1., vielbltig, nackt, drüsenborstig; Bibl. roth punktiert; Rosettenbl. mit abgestutzten Zähnen.

11. Rosettenbl br. lineal, $5-6 \mathrm{~cm}$ l. und $5-7 \mathrm{~mm}$ br.; St. 30 bis ₹0 $\mathrm{cm}$ h., von der Mitte an traubig-ästig, Äste 6-12 bltig. (S. elatior M. K.) - Felsen u. steinige Plätze der Kalkalpen von T., K., Kr. und in B. (b. St. Prokop verwildert). 4. 6-8.

S. Hóstii Tausch.

Rosettenbl, zungenförmig, bis $7 \mathrm{~cm}$ l. und bis $10 \mathrm{~mm}$ br.; St. 30 bis $60 \mathrm{~cm} \mathrm{h.,} \mathrm{sammt} \mathrm{d.} \mathrm{7-10} \mathrm{blt.} \mathrm{Ästen} \mathrm{abstehend} \mathrm{drüsenborstig;} \mathrm{Blbl.}$ fis $7 \mathrm{~mm} \mathrm{l}$. und bis $5 \mathrm{~mm}$ br. - Kalkvoralpen von St. 4. 6. 7 .

S. altissima Kern. 
12. (6). St. einfach, 1 bltig, $1-3 \mathrm{~cm}$ h., Blt. gr., schneeweiß; Kelch a. St. druisig behaart, roth; BI. lineal-lanzettlicl, spitz, graugruin. - Felsen u. Gerölle der Kalkalpen (1260-2200 m). 4. 5. 6.

S. Burseriảna L.

St. oben doldentraubig-ästig, mehrbltig. 13.

13. Bl. gerade, aufrecht mit 5 Grübchen, eilanzettförm., stachelspitzig; St. 3-9 bltig, drüsig-zottig; Blt. gr. schneeweiß. - Felsen der Alpen v. T.; zerstreut. $4.6-8$.

S. Vandellii Strb.

Bl. bogig gekrümmt, mit 7 Grübchen, grau; St. $2 \cdot 5-12.5 \mathrm{~cm} \mathrm{~h}$, 2-6 bltig; Blt. kl, weiß oder gelblichweiß.

14. Bl. von unten an bogig zurückgekïümmt, bis zur Mitte gefranzt, länglich, $4 \mathrm{~mm}$ !.; St. 8-10 cm h,, zart. - Felsen u. Gerölle d. Alpen $(1260-2500 \mathrm{~m})$. 4. 6. 7 .

S. caésia L.

Bl. nur an d. Spitze zurückgekrümınt, dachziegelig, St. drïsenhaarig. 15.

15. Bl. lineal-lanzettförm, stumpf und schwach stachelspitzig, am Grunde gefranzt; Blbl. 5 nervig. - Felsen hoher Alpen in St., K., T., Kr.; zerstreut. 4. 7. 8.

S. squarrósa Sieb.

Bl. lineal-länglich, bespitzt, bis zur Mitte gefranzt; Blbl. 3 nervig. - Felsen d. Alpen von T.; selten 4. 7.

S. patens Gaud.

16. (1). Haare und Wimpern d. Bi. nicht gegliedert.

Haare und Wimpern kurz gegliedert.

17.

17. Alle St. abwechselnd beblättert.

21.

18.

Blttragende St. bllos $(2 \cdot 5-15 \mathrm{~cm}$ 1.), unfruchtbare mit Blrosetten oder zerstreut beblättert; Blt. in Doldentrauben, Kelch zurückgeschlagen.

20.

18. Blbl. goldgelb oder orange, selten dunkelroth, Kelchzipfel aufrecht, Frkn. unterständig; St. aufsteigrend, bis $20 \mathrm{~cm} \mathrm{l.,} \mathrm{Bl.} \mathrm{lineal} \mathrm{oder}$ lanzettlich, stachelspitzig. - Feuchte Gerölle und Felsen, quellige Orte der Alpen $(1-2000 \mathrm{~m})$. 4. 7-10.

Blbl. gelblichweiß; kahle Kr.

S. aizoides $\mathbf{L}$.

19.

19. Kelchzipf. stachelspitzig, Blt. $12 \mathrm{~mm}$ br., Bl. lanzettlich, scharfspitzig- und dornig gewimpert, abstehend; Blwinkel nuit knospenförmigen Blbüschein, St. mehrbltig. - Feuchte steinige Orte der Urgebirgsalpen $(1260-2300 \mathrm{~m})$. 4. 7. 8 .

S. áspera L.

Variet. bryoídes (L), Stbl. angedrïckt, St. 1 bltig. Kleiner, gedrungen. Hochalpenzone (bis $2600 \mathrm{~m}$ ); zerstreut.

Kelchzipfel begrannt, Blt. 4-6 $m m$ br., Bl. lineal-pfriemenförmig, begrannt und kurz gewimpert; Blwinkel olne Knospenbüschel. - Felsige Orte der Alpen v. St., K., Kír. 4. 7. 8.

S. tenella Wulf.

20. (17). Bl. verkehrt-keilig, an d. Spitze gezähnt, St. drüsenhaarig, Blkl. lanzettförmig, weiß mit 2 gelben Fleckchen am Grunde. - An Bächen und quelligen Orten der Alpen (bis $2300 \mathrm{~m}$ ). 4. 7-9.

S. stelláris L.

Bl. länglich-keilförm., von d. Mitt. an gesägt, St. zottig, Blbl. weiß, ungefleckt, 3 eilanzettlich, 2 lanzettförm. - Alpenthäler v. T. 4. 7-9.

S. Clusii Gou.

21. (16) Wrist. ausdauernde (meist Blrosetten od, Blbüschel tragende). Triebe entwickelnd. 
Wrzst. ohne ausdauernde Sprossen od. 1jährige Wz.; Kelch balboberständig.

22. Stbf. nach oben verbreitert; Kelch unterständ, zurückgeschla. gen; Blt. l. gestielt, in Rispen am Ende nackter St., weiß; Bl. in Rosett., mit Knorpelsaum.

23.

Stbf. nach oben verschmälert (pfriemenförm.), Kelch halb. od. ganz oberständ., aufrecht od. abstehend.

23. Bl. spatelförmig.keilig, gestielt, dicklich, kahl, gezähnt-gesägt; St. bis $15 \mathrm{~cm}$ h., Rispe klebrig behaart, Blbl. mit 1 gelbem Fleckchen. Schattige Felsen d. Alp. v. K., T., Ǩr. $(1-2000$ m) 2. 6. 7.

S. cuneifólia L.

B]. oval, ellipt. od. rundlich mit zottig gewimpertem Stiel. 24.

24. Bl. oval-keilig, kurz gestielt, gezähnt-gesägt; Blbl. weiß, roth punktiert. - Aus d. Pyrenäen stammende ZierpA. 4. 6. 7.

Porzella nblü m chen, J ehovablümerl, S. umbrósa L.

Bl. herz- od. nierenförmig-rundlich od. elliptisch, gekerbt, l. gestielt; Blbl. gelb. u. roth punktirt. - Wie vorige Art, Zierpfl. (b. Steyer in Ooe., verwild.) $4.5-7$.

S. hirsuita L.

25. (22) Blbl. lineal, viel schmäler als d. Kelchzipf, citrongelb; St. bis $5 \mathrm{~cm}$ b., nackt, 1 bltig, sammt d. Rispe drïsenharig; Bl. d. Triebe th. ellipt. od. lanzettl., ganzrandig, th. keilig, vorn 2-3 spaltig. - An Kalk- u. Dolomitfelsen d. Alp. v. Oe., St. u. T. $(2000-2900 \mathrm{~m}) \cdot$ 4. 7. 8. (S. stenopétala Gaud.)

S. aphylla Sternb.

Blbl. oval, verkehrt-eiförm. od. länglich, so br. od̄. wenig schmäler als d. Kelchzipf.

26. Bl. ganz od. an d. Spitze 3·zähnig. Kleine Alpenkr.

B. fingerförmig in 3-9 $\mathrm{Zipf}$. zertheilt od. zerspaiten. 26.

27. Bl. stachelspitzig, lanzettförm., 3 nervig; St. 1-3 bltig, nebst d. Bltstielen u. Kelchen drüsenhaarig; Blt. kl., gelb.

Bl. stumpf

28.

29.

28. Bltst. nackt, stielförmig; Blbl. schmäler u. kürzer als d. Kelchzipf., einfarbig. - Felsen d. Alp. v. St., Sz., K., T., Kr. 4. 7. 8.

S. sedoides L.

Bltst. beblättert, Blbl, von d. Breite d. Kelchzipf., an d. Spitze schwarzpurpurn. - Felsen d. Alp. v. St., K., Kr.; zerstreut. 4. 7. 8. S. Hohenwártii Strbg.

29. Bltst. bllos od. 1-2 blättrig. 30.

Bltst. mit 3-6 Bl,; Bl. ganzrandig, grundständ. dachziegelig; Blt. 4-6 $\mathrm{mm}$ br.; Blbl, verkekrt-eiförm. Ganze PQ. drüsig-flaumig.

30. Bl. lineal od. schmal länglich, Blbl. blassgelb (s. Nr.)

\section{S. muscoides Wulf.}

Bl. verkehrt-ei- od. spatelförm., in d. Stiel verschmälert. 31.

31. Blbl. gelb, schmallänglich, so br. u. 1. wie d. Kelclızipf.; St. liis $5 \mathrm{~cm}$ 1., meist 1 bltig. Flanmig. - Am ewigen Schnee in T. und K. $(2200-2900 \mathrm{~m})$. 4. 7. 8.

S. Seguiérii Spr.

Blbl. weiß, verkehrt-eiförm., doppelt so 1. u. br. als d. Kelchzipf.; St. bis $7.5 \mathrm{~cm} \mathrm{1,} 1-3$ bitig. Zottig belıart. - Feuchte Felsen u. Gerölle d. Kalkalp. $(1580-2550 \mathrm{~m})$. 4. 6. 7 .

S. androsácea $\mathrm{L}$. 
32. (29) Blbl. weif, 2 mal länger $u$. breiter als d. Kelchzipf.; St. 1-5 bltig, Bl. länglich od. lanzettl., in kl. dichten Polstern. - Alp. v. Sz. u. T.; zerstreut $(1900-2600 \mathrm{~m})$ 7. 8. S. planifolia Lap.

Blbl. roth bis gelblich, wenig länger als d. Kelchzipf; St. 1-3 bltig., Bl. lineal od. länglich. - Alp. des südl. T. $(2200-2550 \mathrm{~m}$ ); selten. 4. 7. 8.

S. Facchinii Koch.

33. (26) Blzipfel abgerundet-stumpf, Bl. frisch dicklich, balsamisch duftend u. klebrig (getrocknet lederartig).

Blzipf. stachelspitzig bis begrannt; Bl. dünn, rosettenständ. 3-7, Stbl. 3 spaltig, obere ganz, alle kahl od. zottig; St. bis $25 \mathrm{~cm} 1 ., 1-3$ blättrig, doldentraubig-ästig, 3-10 bltig, nebst d. Bltstielen $\mathfrak{u}$. Kelchen kahl od. drüsig behaart; Blbl. weiß, 2 mal so l. als d. Kelch. Sehr vielgestaltig, große lockere Rasen bildend. - Felsspalten in B. (verbreit.), Iil.., Noe. (selten) 24. 5. 6.

S. decipiens Ehr.

34. B1. frisch glatt, getrocknet mit wenig erhabenen Nerven, th. lineal, ganz, th. keilig-lineal u. 3 spaltig; St. bis $15 \mathrm{~cm}$ l., nackt od. 1 blätttrig, 1-mehrblütig, sammt Bltstielen u. Kelchen kalll od. drüsig behaart; Blbl, weiB, selten schwarzroh (S. aturpurpúrea Stbg.), wenig länger als d. Kelchzipf. Vielgestaltig, lockere Polster bildend. - Steinige Plätze d. Alpen $(1200-3500 \mathrm{~m})$. 4. 6. 7 .

S. muscoides Wulf.

Bl. frisch oberseits mit 3 facher Furche, trocken erhaben nervig 3-5 spaltig; St. $1-3$ blättrig, $3-5$ bltig; Blbl. weiß, 2 mal so l. als d. Kelch. - Felsen d. Alpen. 4. 6. 7.

S. exaráta Vill.

35. (21) St. beblättert.

36.

St. nackt, steif, zottig behaart, $15-30 \mathrm{~cm}$ h.; Bl. in grundständ. Rosette, eiförm. länglich, gezähnt; Blt, in unterbrochener Traube, kl., Blbl. grünlich, rothgesäumt. - Alpen $\checkmark$. St. auf nassem Torfbod., zerstreut. 4. 7. 8. S. hieracifólia W. Kit.

36. Wzst. kl, zwiebelartige Brutknöllchen entwickelnd; St. aufrecht, Blt. weiß.

Wzst. ohne Brutknöllchen.

37. Obere Stbl. lineal oder lanzettlich, in d. Winkeln kl. schwarze Brutknöllchen tragend. Klebrig-flaumhaarige $\mathbf{K r}$.

38.

Obere Stbl. handförm. 2-6 spaltig, ohne Brutknöllchen, untere $u$. Grundbl. gestielt, rundlich od. nierenförm., grob gelserbt; St. 15-45 cm h., rispig-ästig, drüsig-flaumig; Blt. gr. - Wiesen, grasige Hügel u. $\mathrm{Ab}$ hänge. 4. 5. 6.

S. granuláta L.

38. St. oben trugdoldig-ästig, $3-7$ bltig., bis $30 \mathrm{~cm} \mathrm{h.;} \mathrm{unterste} \mathrm{Bl}$. nieren- bis eiförm., lappig gekerbt, l. gestielt; Blt. kl. - Wiesen, Grasplätze, Hügel in Mh., Noc., T., B.; zerstreut. 4. 5. 6. S. bultifera L.

St. meist einfach $1 \mathrm{bltig}$, bis $20 \mathrm{~cm}$ h.; untere Bl. nierenförm, 5-7lappig. Sonst wie $\mathbf{v}$ - Nasse Felsen d. Alp. v. St., Sz, K., 'T.; zerstreut. 4. 7. 8 .

S. cérnua L.

39. (36) Bl. rundlich-herz. oder nierenförm., grob zackig-gezähnt untere l. gestielt, obere mit keiligem Grunde sitzend; St. $15-60 \mathrm{~cm} \mathrm{h.}$ oben rispig-ästig, abstehend behaart; Blbl. weiß, gelb u. roth punktiert. Schattige feuchte Stellen d. Alp.; auch Zierph. 4. 6-9.

S. rotundifólia $\mathrm{L}$.

Bl. am Grunde keilig, oft handförm. getheilt; Blbl. einfärbig - 40. Willkomm, Schulflora. 
40. Ganze PA. spinnwebwollig von l, weißen, drüsigen Haaren; St. bis $10 \mathrm{~cm} \mathrm{l.,} \mathrm{Bl.} \mathrm{nierenförm.} \mathrm{5-7-lappig,} \mathrm{Blbl.} \mathrm{blassgelb,} \mathrm{kl.} \mathrm{-} \mathrm{Schattige}$ Felsen im südl. T. 24 7. 8. S. arachnoidea Strbg.

Ganze PA. klebrig-flaumig, Blbl. weiß. Kleine Arten. 41.

41. Bl. keilförm. in d. Stiel verschmälert, untere in Rosette, die zu erst entwickelten ganz, die späteren 3-5 spaltig; St. aufrecht od. aufsteigend, traubig-ästig, klebrig-flaumig.

42.

Bl. (untere), herzförm.-rundlich, $3-5$ spalt. mit zerschlitzt gezähnten Zipfeln, oberste ganz od. 3-spaltig; St. 10-20 cm l., liegend od. aufsteigend, ausgespreizt rispig-ästig, vielbltig. - Steinige feuchte Orte in Kr. u. südl. T.; zerstreut. ๑. 5. $6 . \quad$ S. petraéa L.

42. Blt. $4 \mathrm{~mm}$ br., ihr Stiel viel länger als d. frtragende Kelch; St. 2.5-15 cm 1. - Felsen, Mauern, Sand. ๑. 4. 5. S. Tridactýlites L.

Blt. $8 \mathrm{~mm}$ br., ihr Stiel so 1. als d. frtragende Kelch; St. 7·5-20 $\mathrm{cm}$ l., am Grunde meist knieförm. aufwärts gekrümmt, reich beblättert. Steinige Plätze u. Fels. d. Alp. $(1900-2600 \mathrm{~m}) \odot$, ๑. 6-8. S. adscendens Jequ.

\section{Zahlbrúcknera Rchb. $(\mathrm{X}, 2)$.}

St. niederliegend, fadenförm., ästig, bis $15 \mathrm{~cm} \mathrm{l.;} \mathrm{Bl.} \mathrm{1.} \mathrm{gestielt,}$ herznierenförmig, 5-7-lappig; Blt. endständ., l. gestielt, $6 m m$ br, grün. (Saxifr. parádoxa Strb.) - Feuchte Felsen, an Bächen d. Alp. v. St., K., T.; selten. :-). 7. 8 .

$Z$. austriaca Maly.

\section{Chrysosplénium L. Milzkraut (VIII, 2).}

St. saftvoll, zerbrechlich; Bl. gestielt, rundlich, grob gelzerbt; Blt. in flachen deckblättrigen Trugdolden.

1. Stbl. wechselständ, St. aufrecht $3 \mathrm{kantig}$, bis $15 \mathrm{~cm} \mathrm{~h}$; oberste Deckbl. u. Kelche goldgelb. - An Bächen, quelligen Orten. 4. 3. 4. Ch. alternifólium $\mathrm{L}$.

Stbl. gegenständ., St. aufsteigend, wurzelnd, 4 kantig; Deckbl. u. Kelche grünlichgelb. - An gleichen Orten, seltener. 4. 4-6.

\section{Ch. oppositifólium L.}

\section{Parnássia L. Einblatt $(V, 4)$.}

St. einfach, 1 blättrig, mit 1 endständ, weißen, sïßduftenden Bìume $\nabla$. 12-13 mm Br.; Grundbl. l. gestielt, herzförm. Kahl. - Sumpfwiesen, Moore. 4. 7-9.

S tudentenröschen, $\boldsymbol{P}$. palustris L.

A n merkung. Zu den Steinbrechgewächsen gehört auch die bekannte Hortensia (Hydrangea Hortensia DC.) Zierpfl. aus China und Japan, bei welcher sämmtliche Blt. geschlechtslos und mit 5 llumenblartigen Kelchzipf. begabt (rosa od. blau gefärbt) sind. Einige nordamerikanische Arten von Hydrangea (X, 2) mit flachen Trugdold., deren äußerste 131t. geschlechtslos $u$. weiß sind, werden hie $u$, da als Zierpf. cult. (besonders $H$. arborescens L.)

\section{Fam. LXXXIII. Ribesiáceae. Johannisbeerartige.}

504. Ribes L. Johannis- u. Stachelbeere $(V, 1)$.

Str. mit wechselständ., gestielten, handlappigen Bl.; Blt. seitenständ. 1. Zweige mit einfachen od. 2-3theiligen Stacheln bewehrt, Bl. 
rundlich, 3-5 lappig, kahl od. behaart; Blt. zu 1-3, bängend, Kelch röthlich, Blbl. weiß; Beeren gr., grün, gelb, roth. - Überall cult., in Hecken u. an Waldränd. verwild. ち. 4. 5.

\section{Stachelbeere, $R$. Grossulúria L.}

Formen: $\alpha$. villos u m Neilr. Frkn. zottig, Beeren zuletzt kahl (R. uva crispa L.\}; - $\beta$. glandulósum Neilr., Frkn. u. Beeren drüsig-borstig.

Zweige wehrlos, Blt. in Trauben.

2. Kelch glockig od. beckenförmig, Blt. kl.

2.

Kelch rölırig, Blt. gr. (nordamerilsan. Zierstr.).

3.

7.

3. Blt. 2 häusig, gelblich- od, rötllich-grïn, in aufrechten schmächtigen Träubcheu; B1. 3-5 lappig, Beeren erbsengroß, roth, fad. - Bergwälder, auch Zierstr. Ђ. 4. 5.

B. alpinum L. doppelt gesägt.

Blt. zwitterlich, Trauben hängend od. überhängend, Bl. 3-5 lappig

4. Bl. unterseits harzig punktiert; Traub. schlaff, zottig; Blt. röthlichgrün, glockig, Beeren schwarz, drïsig, süß, aromatisch. Nach Wanzen riechend. - Wild in d. Donauamen v. Ooe, u. an Ufern in Uh. u. B. (selten!), sonst stellenweis verwild., weil oft cult. 5. 4. 5.

Bl. ohne Harzpunkt, ganze Pf. geruchlos. Ahlbeere, $R$. nigram L.

5. Traub. kahl, Blt. gelbgrün, Kelch beckenförmig, Beeren roth, gelblich, weiß. - Überall cult., häufig verwild. Ђ. 4. 5 . Joh annisbeere, Ribis, Ribisel, R. rubrum L.

Traub. zottig od. flaumig, Blt. röthlich.

6. Tranben kurz, dick, vielblütig; Kelch glockig, mit gewimperten Zipf.; Beere blutroth, sauer. - Felsige feuchte Plätze d. Alp., auch im Riesengeb. (Elbgrund) u. Gesenke. 5. 5. 6. $R$. petraéum Wulf.

Traub. l., sehr reichbltig; Kelch beckenförm. glockig, wimperlos, röthlich od. grüngelb; Beeren roth, sauer. - Zierstr. aus Croatien. $\hbar$. 4. 5 .

7. (2) Kelch langröhrig, goldgelb, Blbl. kl., weiß, Beeren länglich, zuletzt schwarz, süßsauer; Bl. 3lappig, schwach gezöhnt, kahl. †.5.6. Goldtraube, $R$. aureum Pursh.

Kelch kürzer röhrig, blut- od. rosenroth, Blbl. roth; Beeren blauschwarz, bereift, sauer; Bl. 3 lappig, gesägt, unterseits grauweißffilzig. $\hbar$. 5. 6 .

$R$. sanguineum Prsh.

\section{Fam. LXXXIV. Crassuláceae. Dickblättrige.}

505. Bulliárdia DC. $(I \nabla, 4)$.

St. fadenförm., liegend, $2 \cdot \xi-3 \mathrm{~cm}$ 1.; Bl. gegenständ, lineal, 2-6 $m m$ 1.; Blt. end- u, achselständ., kl., weiß od, röthlich. Kahle Zwergpf. Überschwemmte Plätze, Ufer in B. u. Mh.; stellenweis. $\odot$. 8. 9.

B. aquática DC.

\section{Rhodíola L. Rosenwurz. (XXII, 7).}

Wzst. walzig, knotig, fleischig; St. aufrecht, bis $15 \mathrm{~cm}$ h., Bl. gedrängt-wechselständ., länglich-keilförm., gesägt, dick; Blt. kl. in gewölbter Trugdolde, gelblich od. röthlich. Kabl. - Steinige Orte d. Alp. (1260 bis $1900 \mathrm{~m})$, auch im Riesengeb. u. Gesenke. 4. 7. 8.

Rh. rósea L. 


\section{Sedum I. Fet thenne, Manerpfeffer $(X, 5)$.}

St., Bl., Blt. fleischig-saftig, meist kahl; Blt. meist in trugdoldig od. rispig gruppierten Wickelähren, Blkr. sternförm. ausgebreitet, Stbf. weit vorstehend.

1. Bl. br., flach; Blbl. lanzettlich (F etthennen)

Bl.im Querschn. rund, walz., ellipsoidisch, kugl. (M a u e r p fe ffer) 6 .

2. Blt. in 1. traubiger Rispe, hellrosenroth; St. $18-30 \mathrm{~cm}$ l., sehr ästig, sammt Bltstielen u. Kelchen drüsig-faumig; Bl. ganzrand., untere verkehrt-eiförm., obere lineal-keilig. - Steinige, schattige Orte in T. ค. 7. 8.

S. Cepaéa L.

Blt. in schirmförm., äus Wickeln zusammengesetzten Trugdold,; St. $15-60 \mathrm{~cm}$ h., kahl.

3. Blbl. gelhlichweiß, Bl. länglich bis eiförm., schwach gezähnt. Felsige Orte, Mauern, Felder. 4. 8.9.

Gemeine Fetthenne, S. máximum Sut.

Blbl. purpurn- od. rosenroth, St. stets einfach.

4. St. niederliegend, Bl. ganzrand., verkehrt-eiförm. bis rundlich. Felsige Orte d. Alp. des südl. 'T.; auch Zierpfl. 4. 7.

S. Anacámpseros L.

St. aufrecht, Bl. gezähnt.

5. Bl. verkehrt-eiförmig-länglich od. lanzettförm, obere am Grunde abgerundet, untere oft gegen- od. quirlständ.; Blbl. zurückgekrümmt. Felsen, Mauern, Ackerränder in B., Mh., Oe.; zerstreut. 4. 7. 8.

\section{S. purpúreum Lk.}

Bl. länglich-Ianzettförm., alle wechselständ. u. am Grunde keilig verschmälert; Blbl. gerade abstehend. - Felsspalten, Gerölle in Sch. und Mh.; zerstreut. 4. 6. 7.

S. Fabária Koch. *)

6. (1) Wzst. viele kriechende reichblättrige ausdauernde unfrucht. bare, einen Rasen bildende Stämmchen treibend; Bltst. nach d. Fruchtentwicklung absterbend.

7.

Keine ausdauernden Stäınmchen; Wz. spindelig, Bltst. einfach od. unten "̈stig; Bl. sitzend.

7. Blbl. weiß od. röthlich, 3 mal so l. wie d. Kelch; Bl. sitzend 8 . Kahl

Blbl. gelb, Bl. d. sterilen Stämmchen dachziegelig, d. Bltst. zerstreut.

8. Bl. walzig, blaugrün, $10-12 \mathrm{~mm}$ 1.; Bltst. aufsteigend, bis $15 \mathrm{~cm}$ 1., Stbb. purpurn. Kahl. - Felsen, Mauern, Dächer. 4. 5-9.

$$
\text { S. album L. }
$$

B1. ellipsoidisch, bucklig, 4 mm 1., bestäubt; Bltst. im oberen Theil drüsig-flaumig. - Feuchte Felsen d. Alpenthäler v. Sz., K., T., Kr. 4. $6-9$. S. dasyphýllum L.

9. Bl. mit abgestumpftem Grunde sitzend, stumpf. 10.

Bl. am Grunde gelöst, gekriimmt-walzig od. lineal-pfriemlich, an beiden Enden spitz; Blbl. lebhaft gelb, spitz, 2-3inal länger als d. Kelch; St. $15-30, \mathrm{~cm}$ h. $4.6-8$.

S. reflexum L.

*) Ziemlich häufig als Zierph. cult, u. stellenweis verwild. findet sich das kaukasische S. s púri u m M. Bieb.: St, liegend, Bl. gegenständig, keilig-verkehrt-eiförmig, gewimpert, BIt. rosaroth oder weis. 
Variet. $\alpha$ víride Koch. Bl. grün. Als Küchenkraut cult, u. auf Mauern verwild. (Tripmadum); - $\beta$. rupestre (L.) Bl. bläulichgrün, hechtblau od, röthlich. An Felsen, Mauern, in Nadelwäld.; verbreitet.

10. Stämmchen liegend od, aufsteigend, sehr lockere kriechende Räschen bildend; Bl. regellos angeordnet, verkehrt-eiförm.-länglich, am Grunde gestutzt; Trugdolde armbltig, Blbl. $1 \frac{1}{2} \mathrm{mal}$ lïnger als d. Kelch, eilänglich (S. repens Schl.) - Felsige Lehnen, an Bächen in d. Alp. $(1900-2300 \mathrm{~m})$, Sudeten u. im Riesengeb. 4. 7. 8. S. alpestre Vili.

Stämmclıen zeilig beblättert.

11.

11. Bl. kurz eiförmig, od. abgerundet 3 kantig, bucklig, brennend scharf schmeckend; Wickel 3-6 bltig, Blbl. lanzettförmig, 2 mal so 1 , als d. Kelch. - Mauern, Felsen, Raine. 4. 6. 7.

Gemein. Mauerpfeffer, S. acre L.

Variet. sexangulare (L.) Bl. der Stämmchen dachzigelig-6•zeilig, geschmacklos. Raine, Ack rränder.

Bl. lineal, stielrund, mit kurz $: m$ stumpfem Sporn am Grunde, Blbl. lineal-lanzettlich. - Sandfeld. Felsabhänge, Raine in B., Ml.., Oe. 4. 6. 7 .

S. boloniense Lois.

12. (6) St., Bltstand u. Kelche driisig-flaumig, St. $8-20 \mathrm{~cm} \mathrm{l.,} \mathrm{Bl.}$ lineal, halbrund, Blbl. rosenroth. - Sumpfige, moosige Wiesen; zerstreut. ๑. 6. 7.

Ganze Pfl. kahl. S. villósum Is.

13. Blbl. u. Stpl. 5, Stbg. 10, Blbl, wenig länger als d. Kelch. 14.

Blbl. u. Stpl. 6, Stbg. 12, Blbl, viel länger als d. Kelch, weiß; St. 8-15 cm h., Bl. lineal, ruud. - Felsen d. Alpenthäler v. St., K., Kír., T.; zerstreut. $\odot$. 7 .

S. hispanicum L.

14. Bl. keulenförmig, 2-6 $\mathrm{mm} \mathrm{l}$.; St. 1.3-7.5 $\mathrm{cm}$ h., Blbl eilanzettförmig, bespitzt, weiß, grünlichgelb od. röthlich. Ganze Pfl. oft röthlichbraun. - Felsige Piätze der Kalkalpen $(1260-2300 \mathrm{~m})$. ๑. 7. 8.

S. atrátum L.

Bl. lineal, 2-4 $\mathrm{mm}$ l.; St. 5-10 $\mathrm{cm}$ h., meist sehr ästig; Blbl. lanzettförmig. spitz, gelb. - Felsen, Mauern der Alpenthäler v. K. u. T., auch in Ml. u. B.; selten. ๑. 6-8.

S. ánnuนm L.

\section{Sempervivum L. Hauswurz (XI, 4).}

Wzst. Blrosetten tragende Stämmchen treibend, Bl. fleischig, ganzrandig, Blt. in trugdoldig gruppierten Wickeltrauben; Bltst. aus einer Blrosette hervorwachsend, beblättert.

1. Blbl. sternförmig ausgebreitet, Stbg. 12-24, Frkn. 7-20. 2.

Blbl. aufgerichtet, lineal-lanzettförmig, gefranzt, gelb; Stbg. 12, Frkn. 6.

2. Rosettenbl. gewimpert, sonst kahl; Stbl. gänzlich flaumhaarig, mit od. ohne Drüsen.

Rosettenbl. gewimpert u. gleichseitig beider- od. blob unterseits drüsig-flaumig.

3. Blbl. schwefelgelb, lineal-pfriemlich, 3 mal länger als d. Kelch; St. 10-25 cm h., sammt Bltstiel, u. Kelchen drüsenhaarig; Rosetten gr., mit länglich-verkehrt-eiförm., stachelspitzigen Bl. - Felsen d. Alpen von St., Sz., K.g T. $(2000-2600$ m). 4. 7-8. 
Blbl. rosenroth.

4. Bl. nur mit drüsenlosen Wimpern am Rande; Rosetten gr., mit umgekehrt-eiförmigen stachelspitzigen Bl.; St. $30-45 \mathrm{~cm}$ h., sammt Bltstielen u. Kelchen drüsenhaarig; Blbl. lanzettförmig, 2 mal länger als der Kelch. - Felsen d. Kalkalpen; cult. u. verwildert auf Mauern u. Dächern. 4. 7. 8.

S. tectórum L.*)

Bl. am Rande zwischen 1. gegliederten Wimpern kurz drüsenharig; Rosettenbl. verkehrt-eilanzettförmig; St. $10-16 \mathrm{~cm} \mathrm{~h}$, oft purpurn überlaufen; Wickeltrauben gedrängt doldentraubig, Blbl. schmal lineal, 2 mal länger als d. Kelch. - Gerölle und Felsspalten in K. u. T. (1900 bis $2000 \mathrm{~m}$ ); zerstreut. 4. 7. 8.

S. fimbriátum Lehm.

5. (2) Bl. d. fast kugligen Rosette durch weife Haare verwebt, verkehrt-eilanzettförmig od. länglich; St. $10-15 \mathrm{~cm}$ h., Blbl. 3 mal so l. als der Kelch. - Felsen in St., Sz., K., T. (bis 2000 m). 4. 7. 8.

\section{S. arachnoideum L.}

Var. Doelliánum (Lehm.), Bl. nur an d. Spitze spinnwebwollig, Blbl, kürzer. Alpen von Sz., K., T. $(2200-2550 \mathrm{~m})$.

Bl. ohne Spinnwebhaare.

6. Blbl. roth od. lila, lanzettförmig, zugespitzt.

Blbl. gelblichweiß mit grün. Mittelstreif, schmal, l. zugespitzt, 3 mal so 1. als d. Kelch; Rosetten kl., offen, Bl. verkehrt-eiförmig, länglich. Auf Serpentinlüigeln in St. (an d. Mur b. Krobel). 4. 7. S. Pittónii Schott.

7. Blbl. lila mit violettem Mittelstreif, fast 3 mal länger als der Kelch; Rosetten kl., Bl. länglich-keilförmig, kurz bewimpert; St. 2-12 cm hoch. - Gerölle d. Alpen (1580-2000 m); zerstreut. 24. 7. 8.

\section{S. montanum L.}

Blbl. rosenroth mit purpurnem Mittelstreif, kaum 2 mal länger als der Kelch; Rosette fast kugelrund, Bl. l. bewimpert. - Gerölle d. Alpen von Sz., T., K. 4. 7. 8.

S. Funkii Braun.

8. (1) Rosettenbl. kahl, länglich od. länglich-lanzettförmig, Stbl. kurz behaart, verschieden geformt, alle hell purpurn; St. $3-25 \mathrm{~cm} \mathrm{~h}$. - Felsige Abhänge der Alpen von 0e., St., Sz., K., T. 4. 7-9. S. hirtum L.

Alle Bl. kahl, gewimpert, St. $15-45 \mathrm{~cm}$ h., Rosetten fadenförmige, kl. Rosetten tragende Sprossen entwickelnd. 9.

9. Rosetterıbl. eiförmig, kurz zugespitzt, Stbl. länglich, zugespitzt; Stbf. druisig gewimpert. - Felsen, steinige Abhänge, Mauern in B., Mh., Noe. 4. 7. 8.

S. soboliferum Sims.

Rosettenbl. länglich-lanzettförmig mit verlängerter Spitze, Stbl. länglich, 1. zugespitzt, Stf, unten fein behaart. - Auf Sandboden und an Felsen in T., K., Sz.; zerstreut. 4. 7. 8.

$S$. arenárium Koch.

\section{Fam. LXXXV. Ranunculáceae. Hahnenfußartige.}

\section{Schliissel der Gattungen.}

1. Stpl. meist viele, sich in einsamige Nüsschen umgestaltend. 2.

b) Stpl. meist wenig zahlreich, selten 1 (s. Delphinium), zu mehrsamigen Balgkapseln werdend.

*) Eine je nach d. Standortsbeschaffenheit sehr variierende Art! - Die neuerdings unterschiedenen rothblühenden Arten (S. acuminatum Schott., S. dolomiticum Facch, S. Metteuianum Lehm. Schnittsp. u. a.) dürften nur Standortsformen seiu. Diese sehr zerstreut od. selten vorkommenden Arten, sowie ebenso seltene gelbblühende von zweifelhaftem Wert können hier nicht berücksichtigt worden. 
weiß.

c) Stpl. 1, in eine Beere sich verwandelnd; Kelch- und Blbl. 4, Actaea (531).

2. BIoß ein blumenartiger, gefärbter Kelch, keine Blumenkrone. 3.

Kelch u. Blumenkrone vorhanden, Nüsschen nngeschwänzt. 7 .

3. Unter der Blïte keine Blhülle. 4.

Unter d. Blüte eine aus 3 quirlståndigen $\mathrm{Bl}$. bestehende Hülle. 5 .

4. Bl. gegenständig, Kelch 4-6 blättr., bleibend; Nüsschen weiß mit Federschwanz.

Clematis (509). schwänzt.

Bl. wechselständig, Kelch 4-6 blättr., hinfällig; Nüsschen ungeentfernt.

5. Hüllbl. gr., den Grundbl. ähnlich, stets zertheilt, von den Bltn.

Hüllbl. kl., ganz, grün, dicht unter d. Bltn, einen Scheinkelch bildend; Kelch 6-9 blättr., Nüsschen ungeschwänzt.

Hepatica (514).

6. Hüllbl. 3 zählig od. handförmig zerschnitten; Kelch $5-20$ blättr., Nüsschen ungeschwänzt; St. 1-, selten mehrbltig. Anemone (512).

Hüllbl. meist gefingert-vieltheilig; Kelch 6-8 blättrig; Nüsschen mit Federschwanz.

Pulsatilla (513).

7. (2) Blbl. 5 bis viele, ohne Nagel und Honiggrube am Grunde, Kelch 4-5 blättrig.

8.

Blbl. mit einem Honiggrübchen am Grunde d. inneren Fläche. 10.

8. Kelchbl. 4, gr., blumenartig; Blbl. viele, sehr kl., lineal-spatelförmig, Nüsschen geschwänzt, Bl. gegenständig.

Atragene (510).

Kelchbl. 5, viel kleiner als d. 5--20 Blbl., Nüsschen ungeschwänzt, Bl. wechsel- od. grundständig.

9.

9. Blbl. gelb od, roth, Nüsschen ährenförm. gruppiert. Adonis (515).

Blbl. weiß, Nüsschen in kuglig. Köpfchen. Callianthemum (516).

10. (7) Kelch 3-, Blkr. 5-10blättr., Honiggrube m. Schuppe.

Kelch 5 blättrig.

Ficaria (519).

11. Kelchbl. ohne Anhängsel, Blbl. nichtod. sehr kurz genagelt. 12.

Kelchbl. am Grunde kurz gespornt, Blbl, mit linealem Nagel, Honiggrube mit Schuppe, Nüsschen auf l. walzigem Träger. Myosurus (521).

12. Kelchbl. lange bleibend.

13.

Kelchbl. abfallend, Nüsschen 1 fächrig, zahlreich, auf halbkugligem, kugligem od. kurz walzigem Träger.

14.

13. Blbl. 5, bleibend, zuletzt trockenhäutig, Nüsschen zusammengedrückt, am Rücken häutig berandet; Bl. vieltheilig. Oxygraphis (516 b.).

Blbl. 5, kl., abfallend; Nüsschen mit 2 leeren Fächern neben dem samentragenden, 1. geschnäbelt; BI. vieltheilig. Ceratocephalus (520).

14. Blbl. 5, meist gelb, seltener weiß od. bunt, Honiggr. mit Schuppe, Nüsschen verschieden.

Ranunculus (518).

Blbl. 5-12, weiß, mit gelbem Nagel, Honiggr. ohne Schuppe, Nüsschen zusammengedrückt, querrunzlig. Wasserptl.

Batrachium (517).

15. (1, b.) Blt. regelmäßig.

15.

Blt. unregelmäßig, mit blumenartigem 5 blättrigem Kelch. 23. $5-10$.

16. Bloß ein blumenartiger 5 blättriger Kelch, keine Blbl.; Balgkaps.

Caltha (522). 
Kelch u. Blkr. vorhanden, Kelchbl. flach od. concàv.

17.

17. Kechbl. krautig, grün, derb, bleibend, 5 ; Blbl. 5 od. mehr, viel größer als d. Kelchbl.; Bltboden concav, Stpl. 2-5 mit sitzender zungenförmiger Narbe.

Paeonia (533).

Kelchbl. zart, oft blumenartig, meist größer als d. Blbl.

18.

18. Kelch- u. Blbl. 4, ziemlich gleichgroh, hinfällig; Stpl. 2, Blt. kl. in dichten rispig-gruppierten Trauben.

Cimicifuga (532).

Kelchbl. 5 od. mehr, Blbl. meist viel kleiner, als hohle Honigbehälter entwickelt; Blt. einzeln od. in lockeren Trugdolden.

19.

19. Kelchbl. sehr zablreich, eine kuglige Blume bildend; Blbl. schmal, lineal, röhrig; Balgkaps. zahlreich, kl., gescbnäbelt. Trollius (523).

Kelchbl. 6, Blbl. viele, kl., kurz, röbrig; Balgkaps. gestielt; unter d. Blt. eine sternförmige kelchartige Blhülle.

Kelchbl. 5, blumenblattartig.

Eranthis (524).

20. Blbl. 5, senkrecht zu d. flach ausgebreiteten Kelchbl. gestellt, größer als diese, abwärts in einen unten hakig gekrümmten Sporn verlängert; Stpl. 5 .

Aquilegia (528).

Blbl. 5-viele, viel kleiner als d. Kelchbl., röhrig, nicht gespornt. 21.

21. Blbl. knieförmig gebogen, mit 2 lippiger Mündung, 8; Balgkaps. $5-10$, der Länge nach verwachsen.

Nigella (527).

Blbl. gerade, röhrig; Balgkapseln getrennt.

22.

22. Kelchbl. abfallend, Blbl. 5-6, kurzröhrig, 1 lippig, Kaps. 1-5. Isopyrum (526).

Kelchbl. bleibend, Blbl. viele, keulenförmig; Kaps. 2-10, gr., lang geschnäbelt.

Helleborus (525).

23. (15) Bltn. gespernt (das obere größere Kelchbl.); Blbl. 4, frei od. verwachsen, die 2 oberen mit im Kelchsporn verborgenem spornartigem Honigbehälter; Stpl. 1-3.

Delphinium (529).

Bltn. helm- od. sackmützenförmig (das obere Kelchbl.); Blbl. 2, als gestielte honigabsondernde Kapuzen im oberen Kelchbl. eingeschlossen; Stpl. 3-5.

Aconitum (530).

\section{Clemátis L. Waldrebe (XIII, 3).}

Blt. ansehnlich, gestielt, einzeln end- u. achselständig od. in Trugdolden. Kl-tternde $u$. schlingende Str, od, aufrechte Kr.

1. Bl. ganz u. ganzrandig, ei- od. eilanzettförmig, krummnervig, sitzend; St. meist einfach, 1 bltig, $30-45 \mathrm{~cm} \mathrm{h.;} \mathrm{Blt.} \mathrm{nickend,} \mathrm{Kelch}$ 4 blättr., gr., dunkelviolett. - Sumpfwiesen in Mh. u. Noe., selten; gemeine Zierph, 4. 6. 7.

C. integrifólia L.

Bl. 1-2 fach gefiedert.

2. Krautartig; St. $0.6-1.3 m$ h., oft fast schlingend, oben ästig; $\mathrm{Bl}$. unpaarig gefiedert, Blättch. gestielt, gr., ei- od. herzeiförmig; Blt. in rispigen Trugdolden, Kelch 5-6 blättr., weiß. - Bebuschte Hügel, besond. auf Kalk. 4. 6. 7. C. recta L.

Str, mit 1-4 m 1. Ästen. 
3. Blt. 1. gestielt, zu 1-3 endständig, gr.; Kelchbl. 4, verkehrt-eiförmig, violett od. purpurn, Nüsschen ungeschwänzt; Bl. 1-2 fach gefied., Blättch. eiförmig, ganz od. 3 lappig. - Zierstr. aus Südeuropa. 5. 5-8.

C. Viticella $\mathrm{L}$.

Blt. gestielt, in rispigen gabeltheiligen Trugdolden; Kelchbl. 6, weiß, Nüsschen mit Federschwanz.

4. Bl. 1 fach gefiedert, Blättch. gr., gestielt, herzeiförm., spiłz, ganzrandig od. gesägt od. gelappt; Kelchbl. beiderseits filzig. - Hecken, Gebüsche, in d. Kalkalpenthälern gemein, häufig cult. und verwild. 5. 7-9.

C. Vitalba L.

Bl. 2 fach gefied., Blättch. kl., eiförmig bis lineal, ganz od. 2-3 spalt.; Kelchbl. oberseits kahl, - Im südl. Kr., im südl. Gebiet oft cult. 5.6. 7. C. Flámmula L.

\section{Atrágene L. Alprebe (XIII, 3).}

Kletterstrauch; Stämme u. Äste bis $3 m$ l., BI. l. gestielt, doppeit 3 zählig zerschnitten, Abschnitte ei- od. eilanzeftförmig, gesägt; Blt. achselständig, 1. gestielt; Kelch violett, Blbl. weißlich. - Gebiische d..Alpen (bis $1270 \mathrm{~m}$ ). $5.5-7$.

A. alpina $\mathrm{L}$.

\section{Thalictrum L. Wiesenrante (XIII, 3).}

St. aufrecht, meist ästig u. beblättert; Bl. 2-4 fach gefiedert, Blt. meist in rispig gruppierten lockeren flattrigen Trugdolden; Kelchbl. hinfällig. Sehr variable formenreiche Kräuter und Stauden.

1. Stbf. lila od. purpurviolett, aufrecht, mit gelbem Beutel; Nüsschen geflügelt-3 kantig, gestielt, hängend; Rispen pyramidal od. doldentraubig; St. $0 \cdot 3-1 m$ h., Bl. $2-3$ fach gefiedert, Blättchen gr., verkehrtei- od. keilförm., grob gekerbt od. gelappt. - Feuchte Gebüsche. 4.5-7.

$T h$. aquilegifólium $\mathrm{L}$.

Stbf. u. Beutel gelb, Nüsschen gerippt, aufrecht, sitzend oder kurz gestielt.

2. Blt. in schlaffer Traube am Ende des einfachen, meist nackten, $5-15 \mathrm{~cm}$ h. St., nickend; Bl, grundständig, 1-2 fach gefiedert, Blättchen kl., rundlich, tief gekerbt. - Feuchte Plätze d. Alpen von St., Sz., K., T. $(2200-2600 \mathrm{~m})$; zerstreut. 4. 6. 7.

Th. alpinum L.

Blt. in ausgebreiteter flattriger Rispe od. traubigen, rispig gruppiert. Trugdolden.

3. Stbg. bängend mit bespitztem Beutel. 3.

Stbg. aufrechi mit meist stumpfem Beutel, St. der Länge nach beblättert.

4. St. $(15-30 \mathrm{~cm}$ h., unten nackt u. beschuppt) u. Bl. graufaumig und drüsig-klebrig; Bl. um d. Mitte zusammengedrängt, 3 eckig, 3-4fach gefiedert; Blättch. herzeiförmig, 3lappig; Blt. l. gestielt in pyramidaler schlaffer Rispe. - Felsspalten, Gerölle auf Kalk in B. u. T.; zerstreut. 4. 7.8 . Th. foétidum L.

St. u. Bl. kahl. 5.

5. Wzst. kriechend, gegliedert, oft beschuppte Ausläuf. treibend; St. bis $1 m$ h., zwischen d. Knoten oft schlangenförmig gebogen; Bl. 3- bis 4 fach gefiedert, Blättchen rundlich, 3-5zähnig od. gespalten, unterseits blaugrün; Rispenäste abstehend. - Laubwälder in K. u. T.; zerstreut. 4. 6. 7 . Th. silváticum Koch. 
Wzst. schief od. senkrecht, grobfasrig, St. $0.3-1.3 \mathrm{~m}$ h., Bl. 2- bis 4 fach gefied., Blättchen rundlich, oval, verkelırt-eiförmig od, keilig, 3 zähnig bis 3 lappig, gezähnt.

6. St. am Grunde nackt u. beschuppt, weiter oben od. in d. Mitte reichlich beblättert, obenhin wenig- u. kleinblättrig, sammt d. Bl. bläulich beduftet; frtragende Rispenäste weit abstehend, Nüsschen 8 rippig. - Bebuschte steinige Hügel, Felsen; zerstreut. 4. 5. 6.

Th. minus L.

Var. elátum (Gaud. - Th. majus Crtz.), St. bis 1.6 $m$ h., Blättch. unterseits fast grasgrün. Zerstreut in B. u. 0e.

St. von unten an beblättert, $\mathrm{Bl}$. beiderseits grün, frtragende Rispenäste aufrecht-abstehend, Nüsschen 10 rippig. -- Bebuschte Hïgel, trocken Wiesen; sehr rerstreut. 4. 7. 8.

Th. Jacquiniánum Koch.

Var. $\alpha$. stipellatum (Koch', mit kl. Nebenbl. in den unteren Verzweigungen d. Bl. (in B., Oe., Sz., Kr.); - $\beta$. exstipellatum Koch (Th. flexuosum Brhd., Th. collinum Wallr.), ohne Nebenbl., St. meist hin $\mathbf{u}$. her gebogen (in Mh., Noe.).

7. (3) Wzst. kriechend.

8.

Wzst. nicht kriechend, büschelfasrig, ohne Ausl.; St. 0.6-1.3 $\mathrm{m}$ h., einfach od, ästig. Bl. 2-3 fach gefiedert, Blättch. lineal-lanzettlich bis schmal lineal, stumpf; Rispe pyramidal od. länglich, reichbltig. - Feuchte Wiesen. 4. 6. 7.

Th. angustifólium Jequ.

8. Wzst. gegliedert, ohne Ausl,; St. steif, 0:30-1 $m \mathrm{~h}$., einfach bis zur endständigen schmalen traubig-ästigen Rispe, 5 kantig; Blättchen d. $2-3$ fach gefiedert. Bl. sammt d. St. glänzendgrün. - Wiesen, kräuterreiche Hügel. 4. 6. 7. Th. simplex L.

Formen: a. latis ectu m Neilr. Blättchen keilförmig-länglich, 2-bis 3 spaltig. In B. (b. Saatz angebl.). - $\beta$. angusti sectum Neilr. (Th. galioides Nestl.), Blättchen fadenförmig, Rispe reichbltig. In Oe., St., K., Krr.; zerstreut.

Wzst. nicht gegliedert, mit vielen Zasern; St. 0.6-1 $m$ h., kantig gefurcht; Bl. 1-2 fach gefiedert, Blättch. th. keilförmig 3 spaltig, tb. lineallänglich, nicht glänzend, beim Trocknen sich schwärzend; Rispe pyramidaldoldentraubig, reichbltig. - Feuchte Wiesen in B. n. Oe.; zerstrent. 4. 6. 7. Th. nígricans Jequ.

Wzst. lang gegliedert, Ausl. treibend; St. 0.6-1.3 $m$ h., stark, gefurcht; Blättch. keilig-verkehrt-eiförmig, vorherrschend 3 spaltig; Rispe gr., pyramidal, reichbltig (Th. medium Jequ.), - Feuchte Wiesen in B. und Ve.; selten; auch Zierpfl. 4. 6. 7.

Th. flavum $\mathrm{I}$.

\section{Anémone L. Windblame (XII, 3)}

St. einfach, nur die Hïllbl, am Grunde d. Bltstiele traggend; eigentliche Bl. grundständ, l. gestielt, hand-oder fiederförmig zerschnitten.

1. Kelchbl. himmelblau, 9 ; St. $15 \mathrm{~cm}$ h. 1 bltig, Grundbl. 3 fach, Hüllbl. 1 fach 3 zählig zerschnitten, Wzst. knollig. - Verwildert in Gärten von Noe. 4. 4. 5 .

Kelchbl. gelb, weiß, lila, rosen- bis purpurroth. A. appenina $\mathrm{L}$. 2. Wzst. wagerecht kriechend, walzig; Kelch 20-30 $\mathrm{mm}$ br. 3.

Wzst. nicht kriechend, mehrköpfig oder knollig.

3. Kelch weiß oder purpurn überlaufen, 6 blättrig, Hüllbl. gestielt, St. 1 bltig. 
Kelch goldgelb, 5 blättrig; St, 10-25 $\mathrm{cm}$ b., 1-2 bltig; Grund-u. Hällbl. 3 zählig zerschnitten, Abschnitte lanzettförmig, grob gekerbt bis fiederlappig. - Laubwälder, Waldwiesen. 4. 5.

Gelbes Waldhähncben, $A$. ranunculoides $L$.

4. Abschnitte d. 3-zählig zerschnittenen Grund- u. Hüllbl, ungleich eingaschnitten-gesägt bis fiederspaltig; St. bis $30 \mathrm{~cm} \mathrm{~h}$. - Wiesen, Wälder. 4. 4. 5. Weißes Waldhähnchen, $A$. nemorósa L.

Blabschnitte ganz, rhombisch-eiförmig, zugespitzt, gesägt; St. bis $25 \mathrm{~cm}$ h. - Alpenländer, in Gebüschen. 4. 4. 5. A. trifólia L.

5. (2). Mehrere Blt. $(3-20)$ an d. Spitze des bis $45 \mathrm{~cm}$ l. St. in einfacher Dolde; Kelch $6-7$ blättr., weiß, bis $25 \mathrm{~mm}$ br.; Bl. hand. schnittig, mit linealen Zipfeln. Weichzottig. - Triften der Alpen, auch im Riesengebirge u. Gesenke. 4. 5-7.

A. narcissiflóra $\mathrm{L}$.

Eine einzige Blte auf d. St.; Kelchbl. 5-6; äußere behaart; Nüsschen wollig.

6.

6. Abschnitte der 2 fach 3 zählig-zerschnittenen Bl., kl., keilförmig, 3-5 spaittig; St. 5-10 $\mathrm{cm}$ h., Kelch außen lila, innen weiß, bis $38 \mathrm{~mm}$ br. - Triften und Gerölle der Alpen von Sz., K.g T. $(1900-2300 \mathrm{~m})$. 4. 7. 8 . A. baldensis $\mathrm{L}$.

Abschnitte $d$. handschnittigen $\mathrm{Bl}$. gr., rautenförm., 3 theilig $u$. tief gesäot; St. bis $45 \mathrm{~cm}$ h., Kelch beiderseits weiß bis $5 \mathrm{~cm}$ br. Weichzottig. - Bebuschte Kalkhügel, auch Zierpt. 4. 5.6. A. silvestris L.

Zierpflanzen: A. pavonina Lam. St. 1 bltig, Blume bis $5 \mathrm{~cm}$ br., purpurroth; - A. coronária L., St. 1 bltig, Blume weiß mit purpurrothem Kranze im Grunde, $5 \mathrm{~cm}$ br.; - A.hortensis L., St. 1 bltig, Blumen lila (8-14 blättr.), bis $35 \mathrm{~mm}$ br., Stbbt. dunkelblau. Alle aus Südeuropa.

\section{Pulsatilla Tourn. Kiichenschelle (XIII, 3).}

Hïllbl. am Grunde in eine Scheide verwachsen; St. 1 bltig, Kelch äuferlich seidenglänzend-zottig; Nüssch. einen Federbusch bildend. Zottig behaarte $\mathrm{Kr} . *$ ).

1. Hüll- und Grundbl. gleichgeformt, 3 theilig-fiederschnittig, Abschn. fiedertheilig, mit länglichen od. lanzettl. Zipf.; St. 15-30 cm h., Blumen weiß, 3-5 $\mathrm{cm}$ br. Gr. bis zur Spitze fedrig. - Triften und Gerölle im Riesengebirge. 4. 5. 6.

Teufelsbart, $P$. alba Rchb.

Var. sulphúrea (L.) Blume schwefelgelb. Selten. theilig.

Grundbl, and Hüllbl, verschieden geformt, letztere fingerförmig-viel-

2. Grundbl. 3 zählig-handschnittig, Abschn. keilförm., tief 3 theilig; St. $8-15 \mathrm{~cm}$ h., Blume $6-8 \mathrm{~cm}$ br., sternförm., hellviolett. Weichzottig. - Steinige Hügel, Feldlehnen, Kiefornwälder in B.; zerstreut. 4. 4. 5 . P. patens Mill.

Variet. grandis (Wender.). Blabschn. sehr schmal, lineal, Blume größer, Kalkhügel in Noe. (Wiener Becken).

Grundbl. 1-3 fach fiederschnittig oder fiedertheilig.

*) Auch in dieser Gattung kommen Bastarde vor. 
3. Grundbl. 1 fach fiederschnittig, Abschn. verkehrt-eiförmig, 2-3spaltig, fast kahl; St. $5-30 \mathrm{~cm}$ h., nebst d. Hüllbl. l. weißzottig; Blume bis $5 \mathrm{~cm}$ br., sternförmig, schmutzigweiß-violett. - Wiesen, trockene Hügel in B. u. Noe.; zerstreut. 4. 4. 5.

$P$. vernális Mill.

Grundbl. 2-3 fach fiederschnittig, mit lineal- od. lanzettlich spitzen Zipfeln; Blume ganz violett oder purpurn-braunviolett, St. $15-30 \mathrm{~cm} \mathrm{~h}$.

4. Blume aufrecht, fast glocken- bis sternförmig, bis $5 \mathrm{~cm}$ br.; Grundbl. 3 fach fiederschnittig, mit linealen $1-3 \mathrm{~mm}$ br. Zipfeln. (Anemone Pulsatilla L.) - Sandige Hïgel und Heiden im südl. B. und in Oe.; zerstreut. 4. 3. 4.

$P$. vulgaris Mill.

Variet. latise cta Neilr. (Anem. Halleri All.) Blzipfel lanzettlich, 6-8 $\mathrm{mm}$ br. Alpen von 0e. und St.

Blumen nickend bis hängend, glockenförm., bis $20 \mathrm{~mm}$ br.; Bl, wic b. voriger Art. - (P. nigricans Störk.) Trockenc Hï ¿ el und Abhänge besonders auf Kalk, in B., Mlh., Noe., Kr.; zerstreut. 4. 4. 5. P. pratensis (L.)

Variet. pátula Pritz. Blume größer, Kelchbl. an d. Spitze krumm zurickgebogen. In B., Noe.

\section{Hepática Dill. Leberkraut (XIII, 3).}

Stengellos. Bl. und Bltstiele grundständ., äußere l. gestielt, herzförm. 3 lappig, ganzrandig; Kelch himmel- bis violettblall, selten rosen- bis purpurroth oder weiß, sternförmig, bis $30 \mathrm{~mm}$ br. (Anem. Hepatica L.). - Laubwälder, Gebüsche; auch Zierplanze mit gefüllten Blumen. 2. 3. Leberbl ü mchen, H. tríloba Choix.

\section{Adonis L. (XIII, 3).}

St. beblättert, Bl. 3-4 fach fieder:chnittig mit linealen Zipfeln; Blt. einzeln, endständig.

1. Blumen vielblättrig bis $7.5 \mathrm{~cm}$ br., glänzend hellgelb; Nüsschen kuglig mit hakigem Schnabel in länglichen Köpfchen; St. $15-20 \mathrm{~cm} \mathrm{~h}$. - Steinige Kalk- und Sandhügel in B., Mh.; zerstreut. 4. 4. 5

$$
\text { A. vernalis } \mathrm{I} \text {. }
$$

Blume 6-8 blättrig, $16-25 \mathrm{~mm}$ br., Nüsschen schief eiförmig in walziger Ähre; St. $15-45 \mathrm{~cm}$ h.

2.

2. Blbl. blutroth mit schwarzem Fleck, aufwärts gebogen; Nüsschen

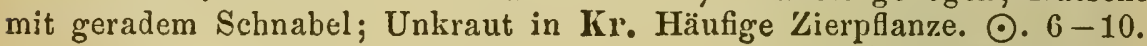

Blbl. mennig. bis scharlachroth, seltener citrongelb, ausgebreitet, Nüsschensehnabel etwas gekrümmt.

3. Kelch kahl, Blbl. mennigroth, selten citrongelb (A. citrina Hoffm) Nüsschen grün gezähnt. - Unter d. Saat, besonders auf Kalk: zerstreut. $\odot$. 5-7. A. aestivalis $\mathrm{L}$.

Kelch behaart, Blbl. scharlachroth (od, citrongelb: A. citrina DC.); Nüsschen zahnlos, grün mit schwarzblauem Schnabel. - An gleichen Orten. ๑. 6. 7.

A. Aámmea Jcqu.

\section{Callianthemum C. A. M. Schmuckblume (XIII, 3).}

St. meist einfach, 1-2 blättrig; Bl. 2 fach fiederschnittig, grundständ. 1. gestielt, Zipfel länglich, stumpf, stachelspitzig; Blt. einzeln endständig. Kable Alpenkr. 
1. Blbl. verkehrt-eiförmig, Blume 5-12 blättr., $18 \mathrm{~mm}$ br., St. bis $15 \mathrm{~cm}$ h. (Ranunculus L.) - Gerölle und Bachufer der Centralalpen (1900 bis $2600 \mathrm{~m})$. 24. 7. 8 .

C. rutaefólium (L.).

2. Blbl. lineal-keilig, Blume $9-20$ blättr., bis $25 \mathrm{~mm}$ br.; St. bis $25 \mathrm{~cm}$ h. (Ranunculus Zahlbr.) - Gerölle hoher Alpen in Oe., St., T. 4. 3. 4 .

C. anemonoides (Zahlbr.)

\section{6b. Oxygraphis Bunge (XIII, 3).}

St. aufsteigend, 1-4 bltig, $2.5-25 \mathrm{~cm}$ l.; Bl. 3 zählig-zerschnitten, mit eilanzettlichen Zipfeln; Kelchbl, rauhhaarig, sammt den weißen, lilafarbenen od. purpurn überlanfenen Blbl. bleibend. Meist kahl. - Gletschermoränen, an schmelzendem Schnee $(2200-2800 \mathrm{~m})$. 4. 7. 8. (Ranunc. glacialis L.).

O. vulgaris Freyn.

\section{Batrảchium E. Mey. Froschkraut, Wasserranunkel (XIII, 3).}

St. fadenförmig, gabeltheilig, an d. Knoten Wz. treibend, schwimmend od. flutend; Bl. mit häutigen Stielscheiden, untergetauchte gabligvieltheilig, mit linealen Zipfeln; Blt. l. gestielt, seitenständig, frtragende Bltstiele bogig zurückgekrümmt. Kahle Kr.

1. Obere Bl. schwimmend, gelappt, d. andern untergetaucht, mit borstenförm. Zipfeln; (vgl. auch B. paucistamineum). Petiveri).

Alle Bl. in der Regel untergetaucht und fein zertheilt (vgl. auch $R$.

2. Bltstiele von d. Länge d. Bl. od. wenig länger, Frträger kuglig, behaart; Blbl. br. verkehrt-eiförmig; 6-10 mm l.; Stbg. sehr zahlreich, länger als das Frknköpfchen; Schwimmbl. nierenförmig, 3-5 lappig, Wasserbl, mit schlaffen, außerhalb des Wassers pinselförmig zusammenfallenden Zipfeln. Sehr variabel. - Stehende Wässer. 4. 5-9.

\section{$B$. aquátile (L.).}

Variet. 3. s u b mers u m God. Ganz untergetancht, ohne Schwimmbl.; $\beta$. terrestre. God. außerhalb des Wassers auf Schlanm, rasenbildend.

Bltsticle viel länger als d. Bl, Frträger eikëgelfürm., fast kahl; Blbl. verkehrt-eiförmig-lreilig, $6 \mathrm{~mm}$ l.; Schwimmbl. kl., nierenförm., tief 3 theilig, Wasserbl. mit allseits starr abstehenden Zipf. (oft untergetaucht flutend, ohne Schwimmbl.). - Stehende und langsam fließende Gewässer in B. u. Noe.; zerstreut. 4. 6-8. $B$. Petiveri (Koch).

3. Stbg. kürzer als d. Frknköpfchen, Frträger kahl, Blbl. 5-10, bis $20 \mathrm{~mm}$ l., Bltstiele so 1. wie d. Bl.; St. sehr 1., flutend; Blzipfel außerhalb des Wassers zusammenfallend. - Fließende Wässer. 4. 6-9.

$B$. fluitans (L.)

Stbg. längè als d. Frknköpfehen, Blbl. 5, Frträger dicht rauhhaarig; Blzipfel starr, außerhalb d. Wassers nicht zusammenfallend. 4.

4. Bltstiele wenig länger als d. Bl., Blbl. schmal verkehrt-eiförm., Stbg. 10-15; Frträger kuglig, Bl. sehr zerbrechlich, untere 1. gestielt. Stehende und langsam fliekende Wässer in B., Oe., T.. V. 4. 5-9.

\section{B. paucistamineum (Tausch).}

Variet. $\beta$. heterophýllu m Čelak. mit rundlich-nierenförmig., $3-5$ spalt. Schwimmbl; $\gamma$. terrestre Čelak. Auf Teichschlamm, mit dicken Blzipfeln. Zerstreut. 
Bltstiele viel länger als die Bl., Blbl. br. verkehrt-eiförmig, Stbg. 15-20; Frträger kuglig, Bl. kl., viel kürzer als d. Stglieder, mit sehr starren, kreisförmig ausgebreiteten Zipfeln. - Stehende Wässer; zerstreut. 4. $6-8$.

B. circinnátum (Sibth.)

\section{Ranúnculus L. Hahnenfuß (XIII, 3).}

St. beblättert, Bl. mit scheidigem Stiel, Blt. meist 1. gestielt, endund seitenständig, einzeln od. in sehr lockern gabeltheiligen Trugdolden. Vorberrschend Landpflanze.

1. Blbl. weiß, bisweilen lila oder purpurn uiberlaufen.

Blbl. glänzend goldgelb.

2.

Blbl. roth, violett, blau, bunt gestreift; Blume einfach, halb oder ganz gefüllt, gr. - Zierpllanze aus Asien. 4. 5. 6.

Gartenranunkel, $R$. asiáticus $\mathrm{K}$.

2. Bl. ganz und ganzrandig, parallelnervig, Blume wei $\beta$, St. 5 bis $22 \mathrm{~cm} \mathrm{~h}$.

Bl. zertheilt, winkeinervig.

3. Grundbl. herzeiförm., Stbl. eilanzettförm., alle krummnerv., unterseits und am Rande zottig; St. $7 \cdot 5-20 \mathrm{~cm}$ h., einfach oder trugdoldigästig. - Gerölle u. Triften hoher Alpen in 'T. u. K.; zerstreut. 4. 6. 7. R. parnassifólius L.

Bl. lanzett- od. lineal-lanzettförm., geradnervig, kahl; St. $7 \cdot 5$ bis $20 \mathrm{~cm}$ h., 1-3 bltig. - Ebendaselbst. 4. 7. 8.

R. pyrenaéus L. nackt.

4. St. $2 \cdot 5-25 \mathrm{~cm}$ b., meist $1 \mathrm{bltig}$, mit 1-2 Bl. od. Schuppen od.

St. $0 \cdot 30-1 m$ b., ästig; Bl. gr., tief handtheilig, Theilstücke verkehrt ei- od. lanzettförm., eingeschnitten-gesägt, untere 1. gestielt, oberste sitzend; Blt. trugdoldig, Blkr. weiß. Kahl. - Gebirgsbäche u. Bergwäld.; 4. 5-9.

$R$. aconitifólius L.

Variet. platanifólius (L.) Blstücke länger zugespitzt, St. sehr reichbltig. Verbreiteter als d. Hauptform, besonders in $\mathbf{B}$.

5. Kelch rauhhaarig, bleibend, Blbl. meist lila oder purpurn überlaufen, l., bleibend; St. aufsteigend, 1-4. bltig; Bl. 3 zählig zerschnitten mit lanzettl. Zipfeln. Meist kahl. - Gletschermoränen, (siehe Gatt. Oxygraphis).

R. glacialis $\mathrm{L}$.

Kelch kahl.

6. St. aufsteigend, 1-3 bltig, sammt d. Bl. zottig; Bl. tief handtheilig, Theilstücke fiederspalt., Zipf. lanzettl., spitz; Blbl. weiß. Höchste Alpen von K. u. T.; selten. 4. 7. 8.

St. aufrecht, sammt Bl. kahl.

R. Seguiérii Vill.

7. Grundbl. l. gestielt, nierenförmig. rundlich, gekerbt; St. 1-8 bltig, Blbl. weiß. - Hobe Granitalpen im südlichen St. u. T.; selten. 4. 7. 8. R. crenátus W. Kit. randet.

Grundbl. handtheilig, rundlich, kl.; Blbl. weiß, br. eiförmig, ausge-

8. Grundbl. 3-5 lappig, Lappen verkehrt-eiförmig, vorn gekerbt; Nüsschenschnabel hakig. - Feuchte Gerölle der Alpen und Voralpen; zerstreut. 4 . $6-8$.

$R$. alpestris $\mathrm{L}$. 
Grundbl, tief 3 theilig, Theilstücke in lineale oder lanzettliche Zipfel gespalten; Nüsschenschnabel nervig gekrümmt, fast gerade. - Steinige Plätze der Alpen $(2200-2600 \mathrm{~m})$; zerstreut. 4. 6. 7 .

\section{R. Traunféllneri Hoppe.}

9. (1). Wzst. ein kugliger Knollen mit vielen Zasern am Grunde; St. $15-45 \mathrm{~cm}$ h., einfach oder ästig, sammt Bltstiel. und Kelchen abstehend-zottig; Grundbl. 1. gestielt, 1-2 fach 3 zählig zertheilt, eingeschnitten-gezähnt. - Trockene Hügel und Triften. 4. 5-7.

R. buloosus L.

b) Wzst. aus keulen- bis spindelfürm. Knollen bestehend mit eingemengten Zasern.

c) Wzst. zaserig oder fasrige 1 jälırige Wz.

10. Seidenglänzend grauzottig; Grundbl. l. gestielt, d. ersten lanzettförm., ganzrand., d. folgenden $3-5$ zählig zerschnitten, Zipf. lineal-lanzettlich; St. $30-45 \mathrm{~cm}$ h., ästig, vielbltig; Nüsschen in Älıre. - Sandige Plätze in B., Mh., Noe., Kr.; zerstreut. 4. 5. 6.

$B$. iliyricus $\mathrm{L}$.

Ganze Pflanze kahl.

11.

11. Grundbl. und unterste Stbl. br., fast nierenförmig, voru abgestutzt und eingeschnitten.gekerbt od. gespalten, erstere 1. gestielt; St. bis $15 \mathrm{~cm}$ h., 1-3 bltig; Bllir. $13 \mathrm{~mm}$ br. (R. hybridus Biria). - Gerölle d. Kalkalpen (1580-2200 m); zerstreut. 4. 6. 7.

R. Pthora Crtz.

Grundbl. fehlend; unterstes Stbl. sitzend, gr., br. herzförmig-rundlich, vorn abgestutzt u. grob gekerbt; St. $45-60 \mathrm{~cm} \mathrm{~h}$, 1-2 bltig; Blkr. bis $20 \mathrm{~mm}$ br. Giftig! - Gebirgstriften in St., T., Kr.; selten. 4. 5. 6.

R. Thora L. nervig.

12. $(9$, c). Bl. ganz, lang, ganzrandig oder seicht gezähnt, parallelspalten.

BI. (wenigstens die Stbl.) zerschnitten, zertheilt, gelappt oder ge14 .

13. St. dick, hohl, in d. hohlen gegliederten, an d. Kanten Wz7.asern treibenden Wzst. übergehend, $0.60-1.30 \mathrm{~m}$ l.; Bl. l. lanzettförmig, geschweift-gezähnt; Blume bis $3 \mathrm{~cm}$ br. - Teiche, Gräben, Sümpfe; selten. 4. 7. 8 .

$R$. Lingua L.

St. dünn, aufsteigend oder liegend und an den Knoten wurzelnd, $15-50 \mathrm{~cm} \mathrm{l.,} \mathrm{Wzst.} \mathrm{büschelzasrig;} 51$. lanzettförm. bis lineal, unterste l. gestielt; Blume kl. - Gräben, Sumpfwiesen; gemein. 24. 6-10.

R. Flámmula L.

14. Blkr. $4-8 \mathrm{~mm}$ br.

Blkr. 12-25 $\mathrm{mm}$ br., selten noch breiter.

15.

15. Niusschen glatt; kahle Kräuter.

18.

16.

Nüsschen krautstachlig oder erhaben netzrunzlig, geschnäbelt; Blbl. schwefelgelb.

16. St. aufrecht, hohl, ästig, $15-45 \mathrm{~cm}$ h.; Blt. in schirmförmiger Trugdolde, schwefelgelb; Nüsschen viele, in länglichen Köpfchen; unterste BI. l. gestielt, handfürmig gelappt, obere 3 theilig. Giftig! - Wassergräben, Ufer, 4. 6. 7.

$\mathrm{G}$ if $\mathrm{t}-\mathrm{H}$ a hne $\mathrm{nfu} B, R$. scelerátus $\mathrm{L}$.

St. 1 bltig, höchstens $25 \mathrm{~mm}$ h., Nüsschen in kugligem Köpfehen, Grundbl. l. gestielt, handtheilig, dem St. gleichlang. - Hohe Alpen in Sz. и. T.; selten, 4. 6. 7 .

R. pygmaéus Wablenb. 
17. Grundbl, 3 theilig, Stbl. doppelt 3 zählig zerschnitten, Abschn. keilig-lanzettförm., eingeschnitten; St. aufrecht, $15-30 \mathrm{~cm}$ h., meist vielbltig; Nüsschen wenige, gr.:, l. kruutstachlig (selten bloß erhaben-netz-

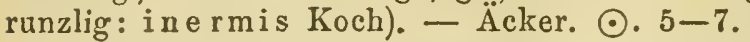

$R$. arvensis $\mathrm{L}$.

Alle Bl. herzförm. rundlich, untere 1. gestielt, grobgekerbt, obere sitzend, 3-5 lappig; St. liegend bis $30 \mathrm{~cm}$ l.; Nüsschen kurz krautstachlig. Behaart. - Feuchte Äcker in Kr. $\odot$. 6. 7. R. muricátus L.

18. (14). Bltstiele gefurcht, Nüsschen kahl glatt, geschnäbelt, in Köpfchen; Frträger behaart; Kelchbl. zurückgeschlagen.

Bltstiele rund, Kelchbl. abstehend.

22.

19. Wzst. mit liegenden, oft wurzelnden, beblätterten Ausläuf.; St. aufsteigend 15-60 $\mathrm{cm}$ h.; Grundbl. und untere Stbl. 1-2 fach 3 zählig. zerschnitten; Blt. l. gestielt, Kelch zurückgeschlagen. - Unkraut auf feuchtem Boden, auch Zierpflanze mit gefüllter Blume. 4. 6-10.

\section{$R$. repens L.}

Keine Ausl., St. aufrecht, Grundbl. 1. gestielt, handtheilig. 20.

20. Kelch zurückgeschlagen; St. 7-30 $\mathrm{cm}$ h., sammt Bltstielen abstehend-zottig. (R. Philonotis Ehrh.). - Feuchte Äcker, Wiesen, Gräben; zerstreut. $\odot .5-10$.

R. sárdous Crantz.

Kelch abstehend; St. $30-60 \mathrm{~cm}$ h., ästig. 21 .

21. Anliegend behaart; Abschnitte der handtheiligen Grundbl. br., fast rhombisch, 3 spaltig; Stbl. 3 theilig, oberste mit ganzen linealen Stücken; Blumen 15-20 $\mathrm{mm}$ br., Nüsschen mit hakigem Schnabel. Bergwiesen, Gebirgswälder; zerstreut. 4. 5. 6. $R$. nemorósus DC.

Unterwärts abstehend behaart; Abschn. d. handtheil. Grundbl. rhom. bisch-verkehrt-eiförm., fiedertheilig; Blume 25-30 mim br., Nüsschenschnabel wenig gebogen. - Grasige Hügel, Waldwiesen, Laubwälder; zerstreut. 2. 5-7.

$R$. polyänthemus L. fehlend.

22. (18) Grund- $u$. Stbl, von verschiedener Form od. (selten) Stbl.

Alle Bl. ziemlich gleichgeformt, handförmig $3-5$ theilig od. lappig; St. anfrecht, ästig, $0.3-1 \mathrm{~m}$ h., stets beblättert; Blume 16-25 $\mathrm{mm}$ br., goldgelb.

23. Grundbl. herz- od. nierenförmig, gekerbt od. gelappt, l. gestielt; Stbl. fingerförmig, in lineale od. lanzettliche Stïcke getheilt, sitzend; St. $15-45 \mathrm{~cm} \mathrm{~h}$., meist ästig.

Grundbl. im Umriss rundlich, handförmig 5 theilig; Theilstiicke verkehrt-eiförmig-rhombisch, 2-3 spaltig u. eingeschnitten; Stbl. wie b. 23, mit ganzrandigen Stücken; Schnabel kurz, hakig.

25.

24. Grundbl. sehr gr., nierenförmig, gekerbt; Abschn. d. Stbl. lanzcttförmig, tief gesägt; Blume 16-20 mm br., Nüsschenschnabel l., an d. Spitze hakig. - Schattige Laubwälder in B. u. Mh.; zerstreut. 4. 5. $R$. cassúbicus L.

Grundbl. herzförmig-rundlich, grob gekerbt od. 3-5lappig; Abschn. d. Stbl. lineal, ganzrandig od. an d. Spitze 2-3 spaltig; Blume 12-28 mm breit, Niisschenschnabel kurz, umgerollt. Sthr verïnderlich. - Feuchto Wiesen, Laubhaine. 4. 4-6.

$R$. auricomus $\mathrm{L}$.

25. Frträger nur oben behart, unten kahl; St. $15-30 \mathrm{~cm} \mathrm{~h}, 2-3$ blïttrig, $1-5$ bltig, Blume $25 \mathrm{~mm}$ breit. Zottig behart. - Steinige Triftew u. Gerölle d. Kalkalpen. 4. 5-8.

$R$. montanus Willd. 


\section{- $241-$}

Frträger ebenso; St. $3.8-15 \mathrm{~cm}$ h., $1-2$ blättr. od. nackt, Blkr. 12 bis $18 \mathrm{~mm}$ br. oder noch kleiner. Fast kahl. - Hochalpen von K., St., Noe.; zerstreut. 4. 7.8. $R$. carinthiacus Hoppe.

26. (22) Abstelend langzottig; St. röhrig, Theilstücke d. Grundbl. br. verkehrt-eiförmig; Nüsschenschnabel lang, umgerollt. - Auenwälder. 4. $5-7$.

$R$. lanuginosus $\mathrm{L}$.

Behaart od. kahl; Schnabel kurz, gekrümmt. 27.

27. Wzst. abgebissen, fasrig, Abschnitte d. Grundbl. rhombisch, 1bis 2 fach 3 spaltig $u$. eingeschnitten, oft schwarz gefleckt. Brennend-scharfsaftig. Mfeist kahl. - Wiesen. 4. 5-10. R. acer $\mathrm{L}$.

Wzst. kriechend, Abschn. d. Grundbl. br. rerkehrt-ei- od. rautenfürm., grob gezähnnt. Abstehend borstig od. angedrückt behaart. - Aus Südeuropa eingeschleppt, hier und da. (Noe., um Wien). 4.6-8. R. Steréni Andrz.

\section{Ficária Dill. Scharbocliskraut (XIII, 3).}

Wrst. aus länglichen Knollen, biischelig; St. liegend, ästig, wurze!nd, in den Blwinkein Knöllıhen entwickelnd, bis $15 \mathrm{~cm} \mathrm{I.;} \mathrm{Bl.} \mathrm{lang} \mathrm{gestielt,}$ herzförmig, rundlich, eskig-grobgezähnt; Blt. 1. gestielt, glänzend gelb, Kahl. - Unkraut in Gärten, Auen. 4. 3-5. F. ranunculoídes Rtl.

\section{Ceratocéphalus Mönch. Hornköpfehen (XIII, 2).}

Stengellos; Bl. u. Bltstiele grundständig; erstere 3-handförm. vieltheilig mit linealen Zipfeln; Blt. kl., scbwefelgelt; Nüsschen zahlreich, in Äbren. Wollig behaart.

1. Schnabel d. Nüsschen gerade, wollig. - Trockener Sandbod. in B., Ih., Yoe., T.; sehr zerstreut. ๑. 3. 4. C. orthóceras DG.

2. Schnabel sichelförm. gekrümmt, kahl od. wollig. - Bebaut. und sandiger Boden in Noe.; zerstreut. $\odot$. 4. 5. C. falcátus DC.

\section{Myosúrus L. Jiiuseschwanz (XIII, 3).}

Stengellos; Bl. lineal, sammt d. $2 \cdot 5-10 \mathrm{~cm}$ h. Bltstielen grundständ.; Blt. kl., schwefelgelb, Nüsschen eckig, 2 spaltig, in bis $3 \mathrm{~cm}$ 1. Ähre. Kahl. - Feuchte Äcker; zerstreut. ๑. 4. 5.

II. minimus L.

\section{Caltha L. Dotterblume (XIII, 3).}

St. liegend od. aufsteigend, ästig, bis $60 \mathrm{~cm} \mathrm{1.;} \mathrm{Bl.} \mathrm{gestielt,} \mathrm{herz-} \mathrm{od.}$ nierenförmig, Blt. in lockeren Trugdold., Kelch 18-33 mm br., goldgell. Vollsaltig, fettglänzend, - Sümpfe, Bachufer, Quellen. 4. 4. 5. Butter-, Schmalzbluine, C. palustris L.

\section{Tróllius L. Trollblume (XIII, 3).}

St. $15-60 \mathrm{~cm} \quad \mathrm{l}_{\text {r. }}$, meist einfach u. $1 \mathrm{bltig} ; \mathrm{Bl}$. handschnittig mit 3 . od. fiederspaltigen, tiefgesägten Alschnitten, grundständig, l. gestielt; Blt. gr., Kelchbl. citron-, Blbl, orangegelb. Kahl. - Feuchte Waldwiesen und Gebirgstriften; zerstreut. 4. 5-7.

T. europaeus L.

Var. napellifolius (Röp.), Bl. vielfach zertheilt. Feuchte Felsterrassen der Alpen von Sz. und $\mathbf{K}$; ; selten. $5 \mathrm{~cm}$ br.

Anmerk. Als Zierpt, cult.: T. asiáticus L. Blume goldgelb, bis 


\section{Eránthis Salisb. Winterblume (XIII, 3).}

Wzst. knollig, wagerecht; St. 5-10 $\mathrm{cm}$ h., nackt, 1 bltig; Grandbl. 1. gestielt, handschnittig, in lineale Zipf. zertheilt; Blume bis $38 \mathrm{~mm}$ br., goldgelb. Kahl. - Wälder im südlichen Kr., verwildert in Grasgärten in Noe.; auch Zierpfl. 4. 3.

$E$. hiemális Salisb.

\section{Helléborus L. Nießwurz (XIII, 3).}

Wzst. mehrköpfig, reichzasrig; St. aufrecht, einfach od. ästig; Grundbl. lang gestielt, fußförmig, 7-11 theilig; Blt. gr., nickend. Kahle scharfsaftige $\mathrm{Kr}$.

1. Immergriin; St. bllos mit 1-3 Schuppen od. nackt, 1-2 bltig, 7-15 cm h.; Grundbl. lederartig, 7-9 theilig, Abschnitte verkelırt-eilanzet tod. keilförmig, vorn gesägt.

Sommergrün; St. $15-50 \mathrm{~cm}$ h., ästig, an d. Verzweigungen beblätt., 1-3 bltig; Bl. dünn, mit unterseits erhaben vortretenden Nerven, Grundbl. mit 7-12 lanzettförm. gesägten Abschnitten, Stbl. sitzend 3 theilig; Kelch meist hellgrün, 5-6.3 $\mathrm{cm}$ br. - Bergwälder, bebuschte Hügel, Weinberge in Mh. u. 0e.; zerstreut. 4. 3-5

H. viridis L.

Varietät. $\beta$. Boccónei (Ten.), Blabschnitte fingerförm, zertheilt, Blt. kleiner. In Kr.; - $\gamma$. dumetórum (W. Kit.), St. 3- und mehrbltig, Blnerven eingesenkt. In Oe., St., Kr.; - o. od órus (W. Kit.), St. melirb!tig, Nerven vortretend, Kelch bleichgrün. In $\mathbf{S z}, \mathbf{K} ., \mathbf{K} \mathbf{r} . ;-\varepsilon$. atrorúbens (IV. Kit.), Kelch purpur-violett. In Kr.

2. Kelch 5-6 cm br., beckenförmig, weiß od. röthlichweiß; 'Blstiel wenig länger als die Spreite. - Thïler d. Kalkalpen, in Wäldern. 4. $2-5$ (oft schon 12, 1). Schwarze N, Christwurz, Schneerose, Winterblume, $H$. niger $\mathrm{L}$.

Kelch 6-8 cm br., ausgebreitet, schneeweiß; Blstiel viel lïnger als d. Spreite, sammt d. St. roth punktiert. (H. macranthus Freyn) - Ebendaselbst. Auch Zierpfl. 4. 12, 1, 2-5.

H. altifolius Hayne.

\section{Isopýrum L. Muschelblïmchen (XIII, 3).}

Wzst. kriechend, St. aufrecht, $15-30 \mathrm{~cm}$ h., ästig, beblättert; Bl. doppelt 3 zählig zerschnitten, Abschn. br. verkehrt-eiförnig, 2-3lappig, gekerbt, d. unteren Bl. gestielt; Blt. achselstïnd., 1. gestielt. Kelch weiß, 12-18 mm br. Kahl. - Wälder in B., IIh., Oe., St., K., Kr.; zerstreut. 4.4.

I. thalictroides $\mathrm{L}$.

\section{Niggella L. Schwarzkiimmel (XIII, 2).}

St. aufrecht, beblättert, einfach od. armästig, 1-mehrbltig; Bl. 2-3 fach fiederschnittig mit linealen Zipfeln; Blt. endständ, aufrecht. Kalıle $\mathrm{Kr}$.

1. Blt. von feinzertheilten Hüllbl. umgeben; Kelch hellblau, bis $38 \mathrm{~mm}$ br. - Zierpfl. aus Südeuropa. ๑. 7-9.

Braut in $\mathrm{Ha}$ aren, Gretchen im Busch, N. damascéna $\mathrm{L}$.

2. Blt. ohne Hülle, 18-25 $\mathrm{mm}$ br., Kelchbl. weißlich od. bläulich. grün geadert. - Äcker, Hügel, besonders auf Kalk; zerstreut. ○. 7-10. 


\section{Aquilégia L. Akelei (XIII, 2).}

St. aufrecht, meist ästig, mit wenigen kl. sitzenden Bl.; Grundbl. 1. gestielt, 1-2 fach 3 zäblig zerschnitten; Blt. gr., gestielt, nickend, meist blau od. violett.

1. Sporn d. Blumenbl. umgerollt, Saum küurzer als d. Stbg.; Grundblätter doppelt 3 zählig, Abschn. gr., eiförmig-rundlich, grob gekerbt, unterseits bläulichgrün und flaumig; St. bis $60 \mathrm{~cm}$ h., ästig. - Wälder, Gebüsche, Waldwiesen; zerstreut. 4. 5-7.

A. vulgaris $\mathrm{L}$.

Variet. $\beta$. vá ri a Maly. Blumen blau, violett, rosa-bis dunkelroth od. weiß, oft gefüllt. Zierpfl.; - $\gamma$. Haenkeana (Koch), Blt. bis $6.5 \mathrm{~cm}$ br., Blabschn. kleiner, 3 theilig, Theilstücke abgestutzt, eingeschnitten-gekerbt. Alpen von K. u. Kr.; - $\delta$. atráta (Koch), Blt. schwarzviolett od. purpurbraun, kleiner. Voralpenwiesen auf Kalk in $0 \mathrm{e}$.

Sporn d. Blbl, nicht umgerollt, hakig gebogen; Blumen 25-30 $\mathrm{mm}$ breit. Saum d. Blbl. von der Länge der Stbg.; St. zart, $15-30 \mathrm{~cm}$ h., $1-3$ bltig; Bl. kl.

2. Bllappen ei- od. verkehrt-eiförmig, kahl; St. oben klebrig-flaumig (A. Einseleana F. Schultz). - Felsige Orte d. Voralpen v. Sz., T., K., Kr. 4. 6. 7. A. Bauhini Schott.

Bllappen lineal-länglich, Bl. u. St. klebrig-faumig (A. viscosa Rchb.). - Alpenthäler d. südl. 'T. 4. 6. 7.

A. thalictrifolia Schott.

\section{Delphínium L. Rittersporn (XIII, 1. 2).}

St. ästig, beblättert; Bl. hand- od. fingerförmig zertheilt; Blt. in endständigen Trauben. hoch.

1. Im Kelchsporn nur 1 gesporntes Blbl., 1 Frkn.; St. $15-45 \mathrm{~cm}$

Im Kelchsporn 2 gespornte Flbl., Frkn. 3-4; Blt. in l. Trauben, gr., hellblau bis dunkelviolett; St. 1-2 $m$ h., Bl. hand theilig, bilappig. - An kräuterreichen Orten in den Alpen, im Riesengebirge u. Gesenke; auch Zierpfl. 2. 7. 8.

D. elátum L.

2. Trauben kurz, lockerbltig, Blt. azurblau bis violett, selten weiß; St. breitästig; aufrecht od. aufsteigend, Blabschn. lineal. - Felder; auch Zierpf. mit gefüllt. Blumen. ○. 6-8. F eld-R., D. Consólida L.

Trauben l., walzig, dicht; Blt. violett, lila, rosenroth, weiß, oft gefüllt; Blzipfel fast haarförm, St. steif aufrecht. - Zierpfl. aus Südeuropa. $\odot . \odot .6-7$.

D. Ajácis L.

\section{Aconitum L. Sturmhut (XIII, 2).}

St. aufrecht, reich beblättert; Bl. hand- od. fingertheilig; Blt. in endständigen Trauben. Giftpflanzen.

1. Blt. gelb od. weifgelb, in einfachen od. ästigen Trauben. 2.

Blt. dunkelblau bis violett, selien gescheckt od. wei $\beta$, oberes Kelchblatt helmförm.; Blabschnitte rautenförm., 3 theilig od. fiederspalt., Theilstücke eingeschnitten.

3.

2. Oberes Kelchbl. helmförm., abgerundet; Blt. sammt Stielen u. d. $0.30-1 \mathrm{~m}$ h. St. flaumig; Blabschnitte fiederförm. vieltheilig mit linealen Zipfeln. - Kalkalpen von Noe, Kr. und siidl. 'T., an telsigen Orten. 4. 8. 9.

A. Anthóra L. 
Obere Kelchbl. verlängert, sackmützenförm., walzig od. kuglig, spitz od. stumpf, gerade; St. $0: 30-1 \mathrm{~m}$ h., sammt Bl. rauhhaarig, flaumig od. kahl; Blabschnitte rhombisch-keilförm., gespalten, mit lanzettlichen Zipfeln. Sehr variierend. (R. Vulpária Rehb.). - Gebüsche, Wälder, Bachufer in den Alpenländern, in B. u. Mh.; zerstreut. 4. 7. 8. A. Lycóctonum L.

3. St. $(0 \cdot 30-1 m$ h. $)$ nach oben sammt Blt. klebrig-flaumig; Blt. in ästigen 'Trauben od. ausgebreiteten Rispen, dunkelviolett, mit länglichrundem od. halbkreisförmigem Helm. - Feuchte bebuschte Stellen der Alpenläuder; zerstreut. 4. 8.9.

A. paniculatum Lain. hoch.

Ganz kahl od. oben flaumig, aber nicht klebrig; St. 0.30-1.30 m

4. Helm d. Quere nach am breitesten, halbkreisfïrm.; Trauben dichtbltig, meist einfach, Kelch blau od. violett. Höchst variabel! - Gebirgswälder, an Bächen. 4. 6-8.

A. Napellus L.

Hauptformen: $\alpha$. angustisectum Čelak, Blabschnitte länglich. rautenförm. mit schmal-linealen spitzen Zipfeln; - $\beta$. latis ectum Celak., Blabschn. br. eiförm.-rhombisch, mit länglich-lan. zettförmigen Zipfeln.

Helm länger als br., gerade od. einwärts gebogen; Trauben locker. bltig, ästig: Kelch hellviolett, blau, weiß od. gescheckt; St. br. ästig, Bl abschnitte rautenförm., mit linealen od. lanzettl. Zipf. - Waldthäler $u$. Bergwälder d. Alpenländ, und in B. 4. 7-9. A. rostratum Brhd.

Helm so 1. als br., Kelch violett od. weißgescheckt, Balgkaps. einwärts gekrümmt, sonst wie vor. - Gartenzierpfl. 4. 7. 8.

\section{A. Stoerkeånum Rehb.}

\section{Actaéa L. Christophskraut (XIII, 1).}

St. $30-60 \mathrm{~cm}$ h., ästig; Bl. gestielt, doppelt 3 zälllig gefiedert, Blättch. ei- od. herzförm.-länglich, eingeschnitten-gesägt; Blt. kl. weiß, in endständigen Trauben; Beere länglich, schwarz (giftig!). - Bergwälder. 4. 5. 6 .

A. spicáta L.

\section{Cimicífuga L. Wanzenkraut (XIII, 2).}

St. $0.5-1.5 m$ h.; Bl. gr., 3 zählig doppelt gefiedert, Blättchen eiförmig od. länglich, doppelt gesägt; Blt. kl. gelblichweiß, stinlkend; Balgkapseln gedoppelt. Kahl. - Laubwälder in Mh. u. Noe. (Markersdorf.Reviere b. Hardegg); auch Zierpfl. 4. 7. 8.

C. foétida $\mathrm{L}$.

\section{Paeónia L. Gicht-, Pfundrose (XIII, 2).}

Bl. gr., gestielt, doppelt 3 zählig zerschnitten, unterseits graugrün; Blt. endständig.

1. Strauch 0.6-1.3 $m$ h.g kahl; Blabschnitte eiförmig-länglich; Blt. 5-10 cm br., Blbl. weiß, röthlich bis rosenroth, meist gefüllt. - Zierstr. aus China. 5. 5. 6.

P. Moutan Sims. breit.

Kahle Kr. mit knolligem Wrst.; St. 30-60 cm h.; Blkr. 5-8 cm

2. Frkn. meist 5, Balgkaps. wagerecht, Blkr. blutroth, Blabschnitte elliptisch-lanzettförm. Ganz kuhl (P. officinalis L. z. Th.). - Gebirgswälder in Noe., St. u. Kr., selten; gemeine Zierpfl. (mit getüllten Blumen). 4. 5. R. corállina Rchb. 
Frkn. 2-3, Kapseln aufrecht-abstehend, filzig.

3. Bl. 3-4 fach fiederschnittig mit schmallinealen Zipf.; Blbl, blutroth. - Zierpfl. aus Asien u. Osteuropa. 4. 5. 6. P. tenuifolia L.

Bl. 3 zählig zerschnitten, Blbl. hellpurpurn od. rosenroth.

4. Blabschnitte elliptisch- od. länglich-lanzettförmig, unters. flaumig, Wzknollen dick, länglich (P. officinalis L. z. Th.). - Bergwälder d. südl. T. u. Kr.; an Felsen im nördl. B. (b. Brïix). 24.5. 6. P. peregrina Mill.

Blabschn. lanzettförmig, oft purpurn gesäumt, unterseits nebst den Stielen fein behaart; Wzkn. walzig, dünn. - Ebendas., selten 4. 5. P. pubens Sims.

\section{Fam. LXXXVI. Magnoliciceae. Magnolienartige.}

\section{Nagnólia L. Bieberbaum (XIII, 3).}

Fremdländische Ziergehölze; B1. gr., ganz u. ganzrand., Blt. gr., endständig. Blumen lilienfïmunig, wei $\beta$ mit purpurn. Anflug, $6-8 \mathrm{~cm}$ l., duftend, vor d. Blentfaltung blühend; Bl. verkehrt-eilänglich, spitz. - Aus China und Japan. 5. 4.5.

M. Yulan Desf.

Anmerk. Weniger häufig werden M. glauca L. (Blbl. graublav, Bl. elliptisch, stumpf) u. M. acuminata L. (Blbl. grünlichweib, Bl. oval zugespitzt) u. a. nordamerikanische Arten in Gärten angetroffen.

\section{Liriodéndron L. Tulpenban in (XIII, 3).}

Baum (bis $20 \mathrm{mh}$.); B1. 1. gestielt, gr., herzförmig. 3 lappig mit br. abgestutzt. u. ausgeschweift. Mittellappen; Blt. gr, endständ, grünlichgelb, bis $7.5 \mathrm{~cm}$ br. - Aus Nordamerika. 5.6 . L. tulipifera L.

\section{Fam. LXXXVII. Berberideae. Sauerdornartige.}

\section{Bérberis L. Sauerdorn, Berberize (VI, 1).}

Str. mit ruthenförm. dornigen Zweigen; Dornen einfach od. 3 theilig am Grnnde d. Blbiischel; Bl. länglich-verkehrt-eiförmig, dornig gezähnt; Blt. goldgelb in hängenden Trauben; Beeren länglich, purpurroth, scharfsauer. - Gebüsche, Hecken auf Kalk; gemeiner Zierstr. und oft verwild. 5. 5. 6.

B. vulgaris $\mathrm{L}$.

\section{Epimédium L. Sockenblume (IV, 1).}

Wzst. kriechend; St. $15-60 \mathrm{~cm}$ h., 1 blättrig; Grundbl. gr., 1. ge. stielt, doppelt 3 zählig; Blättch. herzeiförmig, gezähnt; Blt. in seitenständ. zusammengesetzt. Trauben, Kelchbl. braunroth, scheibenförm., Blbl. gelb. Gebüsche in Kr. u. südl. T•; auch Zierpf. 24. 4. 5. Z. alpinum L.

\section{Fam. LXXXVIII. Nymphaéceae. Seerosenartige.}

\section{Nymphaéa L. Seerose, Wasserlilie (XIII, 1).}

WasserpH. mit dickem, im Schlamme kriechendem Wzst., nntergetauchten zarten Wasser-u. l. gestielten lederartigen 2 lappig-rundlichen Schwimmbl.; Blt. grundständig, l. gestielt, auf dẹm Wasser schwimmend, gr.; Blbl. wei $\emptyset$, 
1. Blume aufgeblüht ausgebreitet, $10-15 \mathrm{~cm}$ br, Narbenstrahlen gelb, Lappen d. Schwimmbl. auseinanderstehend, stumpfeckig. - Seen, Teiche, Flüsse. 4. 6-9.

N. alba L.

2. Blume aufgeblüht halb od. ganz geöffnet, kleiner, Narbenstrablen roth, Bllappen eiförmig, spitz, auseinanderstelrend. - An gleichen Orten, seltener. 24. 6-9.

$N$. cándida Presl.

Formen: $\alpha$. a perta Čelak. Blumen ganz geöffnet; $-\beta$. semi . a perta (Klinggr), Blumen halb geöfinet (N. biradiata Somm.). In B., Ml.., St., T.; zerstreut.

\section{Nuphar Sm. Nixblume (XIII, 1).}

Bltstiel über d. Wasserspiegel emportretend, Kelch- u. Blbl. gelb.

1. Blt. bis $38 \mathrm{~mm}$ br., Blbl. 3 mal kitrzer als d. weitglockige Kelch, Narbe flach, ganzrandig, 10-20 strahlig; Lappen d. elliptisch rundlichen Schwimmbl. abgerundet, unterseits grün, Blstiel oben 3 kantig. - Stehende und langsam fließende Wässer. 4. 6-8. N. liteum Sm.

Blt. bis $25 \mathrm{~cm}$ br., Blbl. länger, Narbe convex, 10 strahlig, am Rande gezähnt, griinlich; Schwimmbl. kl., eiförmig-rundlich, Lapp. stumpf, auseinander stehend. - Stehende Wüisser im südl. B., Mh. u. Ooe.; zerstreut. 4 . $6-8$. N. pümilum Sm.

\section{Iiam. LXXXIX. Papaveráceae. Mohnartige.}

\section{Schlïssel der Gattungen.}

1. Narbe sitzend, mit 4-20 Strahlen; Kapsel durch unvollständige Scheidewände (Samenträger) 4-20 fächrig, unter dem Narbenrande mit Löchern aufspringend.

Papaver (540)

Narbe stumpf od. 2 lappig, Kapsel 1., schotenförmig, 2 fächrig. 2.

2. B!t. einzeln, endständig, Schote mit ganzer Scheidewand.

Glaucium (541) wand.

BIt. in gestielten Trugdolder, Schote mit durchıöcherter ScheideChelidonium (542)

\section{Papáver L. Mohn (XIII, 1).}

Blt. ansehnlich, sehr l. gestielt, end- oder grundstïndig; Bl. fiederspaltig bis fiederschnittig.

1. Stengellos, Wzst. kriechend, beschuppt; Bl. und Bltstiele grundständio, Blbl, 20-30 nım l., Kapsel steifborstig.

St. einfach oder ästig, beblättert; Blt. endständig.

2. B1. einfach fiederschnittig; \& Ĺbschn. lanzettlich, Bltstiele 3 bis $12 \mathrm{~cm}$ l., Blbl. weiß, gelb oder mennigroth, Kapsel verkehrt-eiförmig. Borstig behaart. - Gerölle der Alpen, zerstreut. 4. 6. 7.

P. pyrenáicum DC.

B1. 2-3 fach fiederschnittig mit lineal. Zipf., Bltstiele bis $20 \mathrm{~cm} 1$, Blbl. weiß, gelb, rosen- oder orangeroth, Kapsel verkelırt-kegelförmig. Kahl oder zerstreut behaart. - Gerölis, Tobel, Holzriesen in Oe., St., IK., $\mathrm{Kr}$. (bis $2850 \mathrm{~m}$ ). 4. 6. 7. $\quad$ P. alpinum L. 
3. Kapsel aufrecht borstig, verlängert keulenförmig, mit 4-5 strahliger Narbe; Blkr. 25-38 $\mathrm{mm}$ br., scharlaclıroth mit schwarzem Fleck am Grunde d. Blbl.; St. 15-30 $\mathrm{cm}$ h., Bl. 2-3 fach fiedertheilig. Steifhaarig. - Saaten, Schutt. $\odot .5-7$.

P. Argemóne L.

Kapsel kahl.

4. St. und Bl. abstehend-steifhaarig, Bl. grün, Stbf. pfriemenförmig. 5.

Ganze Pfl. kahl (bisweilen d. Bltstiele steifhaarig), bläulich beduftet; St. $0 \cdot 3-1 m$ h., ästig, Bl. grob und ungleich gezälnt, untere länglich, buchtig, obere herzförmig-stengelumfassend; Blkr. 5-10 cm br., Stbf. n ich oben verbreitert.

7.

5. Blkr. $10-13 \mathrm{~cm}$ br., Blbl. scharlachroth mit schwarzem Fleck, St. $60 \mathrm{~cm} \mathrm{h.} \mathrm{-} \mathrm{Zierpflanze} \mathrm{aus} \mathrm{Asien.} \mathrm{4.} \mathrm{7.} \mathrm{8.} \quad P$. orientale L.

Blbl. $3 \cdot 8-7 \cdot 5 \mathrm{~cm}$ br., Blbl. scharlachroth ungefleckt.

6. Blkr. $5-7.5 \mathrm{~cm}$ br., Kapsel verkehrt-eiförmig, Narbe genàbelt, 7-14 strahlig; St. 30-60 cm h., untere BI. 1-2 fach fiederspaltig oder theilig, Theilstücke länglich, eingeschnitten. - Getreidesaaten, auch Zierpflanze mit voller Blume. $\odot$. 6. 7.

$\mathrm{K}$ latschrose, $P$. Rhoeas L.

Blkr. 3.8-5 cm br., Kapsel keulenförmig, Narbe flach 5-10 strahlig; St. $5-15 \mathrm{~cm} \mathrm{~h}$, untere Bl. 1-2 fach fiederlappig, Lappen eiförmig bis lanzettlich, grobgezähnt oder ganzrandig. - Wie voriger. $\odot .5 .6$.

$$
\text { P. dubium } \mathrm{L} \text {. }
$$

7. (4). Kapseln (Mohnköpfe) kuglig, bis $25 \mathrm{~cm}$ l., unter der vielstrahligen horizontalen Narbe mit Löchern aufspringend; Blbl. lila oder hellroth, selten weiß, Samen hechtblau. - Öl- und Zierpfl. (diese mit vollen Blumen in allen Farben, oft zerschlitzten Blbl.), aus d. Orient. $\odot$. $6-8$.

Gartenmohn, $P$. somniferum L.

Kapsel länglich-eiförmig, bis $38 \mathrm{~mm}$ l., geschlossen bleibend, Narbe concav, Blbl. meist weiß mit lilafarbenem Fleck, Samen weiß. - Culturpeanze aus d. Orient. $\odot .6-8$.

$P$. officinale Gmel.

\section{Glaúcium Tourn. Hornmohn (XIII, 1). .}

St. àufrecht, ästig, beblättert; $\mathrm{Bl}$. dick, Schoten $15-23 \mathrm{~cm} \mathrm{l}$.

1. Blkr. $5-7.5 \mathrm{~cm}$ br., gelb, Schote rauh; St. bis $1 m \mathrm{~h}$., Bl. 1 bis 2 fach fiederlappig. Weißlich blaugrün. - Sandplätze, dürre Hügel in St. und Noe.; wohl eingeschleppt. $\odot-6-8 . \quad G$. flavum Crantz.

2. Blkr. 25-38 $\mathrm{mm}$ br., Blbl. orangegelb oder scharlachroth oder roth mit schwarzem Fleck; Schote steifhaarig; St. $15-45 \mathrm{~cm}$ h., Bl. fiedertheilig. Grasgrün. - Auf Kalk- und Sandboden in B., Mh., Noe.; sehr zerstreut. $\odot .6-8 . \quad$ G. phoeníceum Crtz.

\section{Chelidónium L. Schöllkraut (XIII, 1).}

St. ästig, 30-60 $\mathrm{cm}$ h., von dottergelb., ätzendscharfem Saft strotzend; Bl. fiederschnittig, Abschn. gr., eiförmig-rundlicb u. eingeschnitten-gelappt, Blt. kl., gelb, Schoten $2 \cdot 5-5 \mathrm{~cm}$ ।. - Unkraut u. Schuttpflanze. 4. 5-8.

Ch. majus L.

Anmerk. Gemeine Zierpt.: Eschscholtzia californica Cham, Bl. fein zertheilt, blaugrün, kahl; Blt. l. gestielt, endständ., gr., goldgelb. 


\section{Fam. XC. Fumariáceae. Erdrauchartige.}

\section{Corýdalis CC. Lerchensporn (XVII, 2).}

Bl. doppelt-3 zählig od. 2-3 fach fiederförmig zersclnitten, Blt. in gestielten deckblättrigen Trauben. Kahle $\mathrm{Kr}$.

1. Blkr. gelblich- od. grünlich weiß od, gelb, Wzst. zaserig. 2.

Blkr. purpurn, l. gespornt, Trauben endständ.; Wzst. ein Knollen. 6.

2. Stengellos od. kurzstenglig; Bl. u. Blttrauben grundständig, l. gestielt, Blkr. 12-14 $\mathrm{mm}$ l., weißlich-grüngelb. - Fels- und Manerspalten im südl. Kr. n. T. 4. 5. 6.

C. acaulis Pers.

Arten mit 15-30 $\mathrm{cm}$ h., beblättertem St.; Trauben seitenständ. 3 .

3. Sporn walzig, von d. Länge d. gelblichweißen Blkr.; Schötchen länger als $d$. Bltstielchen. - Sonnige Bergablänge im südl. Kir. u. T.; zerstreut. $\odot$. 6. 7 .

C. capnoides Pers.

Sporn kurz, sackförmig, Blkr. 13-14 mm l, Schötchen so l. oder länger als die Bltstielchen.

4. Blkr. goldgelb, Schötchen sehr l., gekrüimmt, perlschnurförmig. Zierpfl. aus Nordamerika. 24. 5. 6.

C. arirea Willd.

Blkr. gelblichweiß od. citrongelb, an d. Spitze dunkelgelb; Schötchen kurz, gerade.

5.

5. Blkr. gelbweiß, Stiele schmal häutig gerandet; Samen glanzlos mit ganzrandigem angedrücktem Anlang. - Felsspalten im südl. T. 4. 7. 8 .

C. ochroleuca Koch.

Rlkr. citrongelb, Stiele nicht gerandet, Samen glänzend mit abstebendem gezähnten Anhange. - Ebendaselbst, auch Zierpt. gleich voriger $\mathbf{a}$. hier und da verwildert. 4. 7. 8.

C. lútea DC.

6. (1). Deckul. d. Tranbe ganz und ganzrandig.

Deckbl. fingerfïrmix zertheilt, Knollen dicht.

7. Knolle gr. hohl; St. bis $30 \mathrm{~cm}$ h., einfach, unten nackt, 2 blätt. rig; Traube vielbltig, Blt. balsamisch duftend, $18 \mathrm{~mm}$ l., purpurn oder weiß. - Laubwälder, Gebüsche, Hecken. 2. 3. 4.

\section{Hohlwurz, C. cava Schweigg.}

Knollen voll, kl., St. bis $18 \mathrm{~cm}$ h., einfach, 2 blättrig, unten mit einer häutigen Schuppe; Traube armbltig. - Laubgebüsche in B. u. Mh.; zerstreut. 4. 3. 4.

C. fabácca P.

8. Trauben reichbltig, aufrecht; Sporn der 16-18 mm l. Blkr. abwärts gekrümmt; Schötchen lanzettförm. hängend; St. 7-30 cm h. Wie vorige; zerstreut. 4. 3. 4.

C. digitata $\mathrm{P}$.

Variet. a ustralis (Hausm.), Blt. größer, weiß, rosig überlaufen. Südl. T., Oe.

Trauben armbltig, im Frstande überhängend; Sporn der $12 \mathrm{~mm} \mathrm{l}$. Blkr. gerade, spitz; Schötchen elliptisch. - Wie vorige, in B., $\mathbf{M l h . ,}$ Noe.; zerstreut. 3. 4.

C. primila Host.

\section{Fumária L. Erdıauch (XVII, 2).}

St. ästig, beblättert; Bl. gestielt, doppelt fiedertheilig bis fiederschnittig, Blt. in end- und seitenständ. Trauben, an der Spitze schwarzroth. Kahle, zarte zerbrechliche, blaugrüne $\mathrm{Kr}$. 
1. Blkr. 10-12 mm l., bunt; Nüsschen kuglig, glatt; St. rankend und kletternd, bis $1 \mathrm{ml}$. - Südeuropa, in Kr., T., St.; an Hecken verwildert. $\odot .6-8$.

F. capreoláta $\mathrm{L}$.

Blkr. 4-10 mm l., rosen- oder purpurroth, Nïsschen runzlig; St. aufrecht od. aufsteigend, $15-30 \mathrm{~cm}$ h.

2.

2. Kelchbl. deutlich gezähnt, 2-3 mal kürzer als die 7-8 $\mathrm{mm} 1$. Blkr. (ohne Sporn).

3.

Kelchbl. 5-10 mal kürzer als d. Blkr., schmäler als d. Bltstiel od. fehlend; Nüsschen kuglig, St. $15-30 \mathrm{~cm}$ h.

3. Kelchbl. eilanzettförmig, schmäler als d. Blkrröhre, aber breiter als d. Bltstiel, äußere Blbl. stumpf; Nïsschen abgeplattet-kuglig, ausgerandet. - Unkraut auf Feldern. ๑. 5-10.

$F$. officinalis $\mathbf{L}$.

Kelchbl. rundlich-eiförmig, halb so 1. als die Blkr. und breiter als deren Röhre; äu@ere Blbl. vorn kurz geschnäbelt, Nüsschen kuglig, kurz bespitzt, nit 2 Grübchen. - Wie vorige, nur in B., Mh., Noe.; zerstreut. ๑. 6. 7 .

F. rostellata Knaf.

4. Äußere Blbl. eine kurze Röhre bildend, oberes Blbl. 2 lappig, Blkr. 3-5 $\mathrm{mm}$ l., blassrosa; Nuisschen auf dickem kurzen Stiel, Bl. graugrün. - Äcker, Schutt, besonders auf Kalk, in B., Mh., Oe., St.; zerstreut. $\odot .6-9$.

F. Vaillantii Lois.

Äußere Blbl. eine lange Röhre bildend, oberes Bl. ganz, Blkr. 5 bis $10 \mathrm{~mm}$ l., lebhaft purpurroth, Trauben dicht, Nüsschen dünn a. l. gestielt. Hellgrün. - Äcker, Weinberge auf Kalk in 13. u. Mh.; zerstrent. $\odot$. $7-9$. F. Schleicheri Soy. IVill.

Anmerk. Verbreitete Zierpfl.: Diclytra spectábilis DC. (Getheiltes Herz, Jungfernherz) aus Nordchina: Blt. groß, purpurn, in überhängenden Trauben, doppelt gespornt.

\section{Fam XCI. Capparideae. Kaperngewächse.}

\section{Cápparis L. Kapernstrauch (XIII, 1).}

Zweige gekrümmt-dornig, Bl. gestielt, eiförmig, blaıgrün; Blt. gr., achselständig, l. gestielt, Blkr. $5 \mathrm{~cm}$ br., weiß oder blassiosa. Kahler Kletterstr. - An Mauern im südl. T. †. 6. 7.

\section{Fam. XCII. Ciruciferae. Kreuzblütler.}

\section{Schliissel der Gattungen.}

1. Fr. eine aufspringende Schote oder ein Schötchen, mit Längsscheidewand.

2.

Fr. nicht aufspringend, schoten- oder schötchenförmig, ohne Längsscheidewand.

44.

2. Scheidewand schmäler als die seitlich zusammengedrückte Fr., (Klappen derselben sehr concar (Angustiseptae).

3.

Scheidewand so breit wie die vom Rücken her zusammengedrückte Fr., Klappen derselben flach oder wenig concav (Latiseptae).

11.

3. Fr, eine lineale schmächtige vielsamige Schote. 
Fir. ein Schötchen.

4. Schötchenfächer 1 samig.

Schötchenfächer 2-bis vielsamig.

5. Blbl. von ungleicher Größe (äußere viel größer); Schötchen nach vorn zu an d. Rändern geflügelt, Flügel vorn tief ausgeschnitten, spitzlappig.

Blbl. gleichgroß.

Iberis (548).

6. Schötchen brillenförmig. Biscutella (549).

Schötchen rundlich, ei- oder herzförmig, am Rande bisweilen ge. flïgelt.

Lepidium (550).

Schötchen verkehrt-eiförmig-länglich. - Zwergpt, der Alpen. Hutchinsia brevicaulis (551).

7. Blbl. ungleich, Stbf. mit blblartigem Anhang; wchötchen verkehrteiförmig, planconvex, 4 samig.

Teesdalia (547).

Blbl. gleichgroß, Stbf. ohne Anhang.

8. Schötchen 4 samig.

Schötchen vielsamig.

9. Blbl, weiß, Schötchen verkehrt-eiförmig-länglich, gleichseitig. rande.

Blbl. rosa, Schötchen rundlich, planconvex, mit gezähntem Flïgel-

Schötchen oval oder verkehrt-eiförmig, oben tief ausgerardet, an den Rändern geflügelt.

Thlasp (546).

10. Schötchen 3 eckig oder länglich, oben stumpf ausgerandet, nicht geflügelt.

11. (2). Fr. ein Schötchen (b. Lunaria sehr gr.).

Capsella (552).

Fr. eine Schote (mindestens 4 mal länger als br.)

12.

12. Blbl. blasslila, rosa oder violett.

23.

Blbl. weiß oder gelb (blass- bis goldgelb).

13.

13. Schötchen sehr gr., elliptisch oder länglich, papierartig dünn, mehrsamig. Große Stauden.

Lunaria (563). kräutlein.

Schötchen kl. lünglich, doppelt convex, 4 sarnig. Kleines AlpenPetrocallis (562).

14. S̉chötchen 2- oder 4 samig, stark zusammengedrückt, rundlich oval oder verkehrt-eiförnig; Blt. weiß oder gelb. Alyssum (566).

Schötchen vielsamig.

15.

15. Schötchen stark zusammengedrückt, dicht sternfilzig; Samen gefliigelt.

16.

Schötchen beiderseits gewölbt oder blasig aufgetrieben, kahl oder flaumig.

17.

16. Blbl. weiß, tief 2 spaltig, Schötchen elliptisch, mit 1. Griffel.

Berteroa (565).

Blbl. gelb, ganz; Schötchen br. länglich, mit kurzem Gr.

17. Schötchen netzadrig (meist!), kahl.

Farsetia (564).

Schötchen nicht netzadrig.

18.

18. Blbl. weiß, Schötch. kuglig od. verkehrt eiförmig, vielsamig. 19.

Blbl. hellgelb, Schötchen verkehrt-eiförmig, aufgeblasen, vielsamig. 
19. Schötchen kuglig, aufgeblasen, Stbf. gerade. Große Staude. Armoracia (556).

Schötchen verkehrt-eiförmig-kuglig, längere Stbf, einwärts gekriimmt. Kl. Alpenkraut. Kernera (557).

20. (17). Blbl. 2 lappig (verkehrt-herzförmig), weiß; Sclıötch. lanzelt förmig oder länglich, kall. Kl. Kräutlein.

Blbl. gauz oder ausrerandet.

Eroplula (560).

21. Blbl. weiß, ausgerandet; Schötchen länglich bis lanzettfürn ió, meist sternflaumig und griffellos, selten mit l. Griff:ln, vielsanig.

$$
\text { Draba (z. Th. } 561) \text {. }
$$

Blbl. gelb.

22.

22. Blbl. ausgerandet, Schötchen lanzettlich, mit 1. Gr., oft stern. flaumig; kl. Alpenkr. mit Blrosetten. Draba (z. Th. 561).

Blbl. ganz, Schötchen kuglig, ellipsoidisch, kurzwalzig, mit meist 1. Gr., kahl, vielsamig. Ansehnliclie Kr. ohne Blrosett. Ruripa (z. Th. 558). 23. (11). Samen in jedem Fach 1 reihig.

Samen 2 reihig.

24.

24. Klappen der Schote nervenlos.

25 und 40.

Klappen d. Schote mit 1, 3, 5 Längsnerven, oft noch geschlängelt adrig.

25. Samen in jedem Fach 1 reihig, Blbl, weiß, lila, rosa, violett. 26.

Samen 2 reihig. 27.

26. Wzst. fleischig, kriechend, beschuppt oder gezähnt, Blume sehr gr.; Schote lineal, gesclinäbelt, Klapp. nicht elastisch. Dentaria (572).

Wzst. faserig, Blume kleiner oder sehr kl.; Schote lineal, nicht od. kurz geschnäb., mit elastisch sich umbiegenden Klapp. Cardamine (571).

27. Blbl. weiß, Schoten länglich, gebogen, dick. Nasturtium (559).

Blbl gelb, Schote lineal oder länglich (oft Schötchen, siehe 22). Roripa (558).

28. (24). Klappen i nervig (selten noch mit 2 geschlängelten Neben. nerven oder adrig, siehe Brassica).

Klappen 3 oder 5 nervig.

29. Blbl. weiß, lila, violett oder schmutzigroth geadert.

29.

38.

Blbl. gelb oder gelblichweiß.

30.

32.

30. Narbe d. Schote spitz, aus 2 an einanderliegenden Plättchen gebildet, Schote l., lineal, rund, Blume gr.

Narbe anders geformt.

Hesperis (573).

31. Narbe 2 hürnig (Spitze der 1. linealen rundlichen Schote verdickt-2 lappig), Blume groß.

Matthiola (567).

Narbe stumpf oder ausgerandet, Schote schmal lineal, zusammell. gedrückt, Blume kl., meist weiß. Blt. gr.

32. (29) Narbe tief 2 lappig, zurückgebogen; Schote lineal, 4 kantig

Narbe stumpf od. schwach ausgerandet.

Cheirantus (568). Arabis (569).

33. Schote nicht geschnäbelt, höclıstens kurz bespitzt, 1. lineal. 34 .

Schote deutlich oft 1 . geschnäbelt.

33.

34. Schote 4 kantig, selten 8 kantig. 36.

35 .

Schote zusammengedrückt, Samen mit br. Hautrand, Blbl. blassgelb, Stbl. stengelumfassend, gezähnt. Arabis Turrita (569). 
35. Klappen aderlos, Blbl. lebhaft gelb, Stbl. nicht stengelumfassend, meist schmal und gezähnt.

Erysimum (578).

Klappen neben d. Mittelnerv adrig, Blbl. bleichgelb, Stbl. herzförmigumfassend, br., ganzrandig.

Convingia (577).

36. (33) Schuabel kurz walzig, lineal; Blt. kl.

37.

Schnabel spitz zulaufend, 1., rundlich od. zusammengedrückt; Blt. gr., Samen kuglig.

Brassica (581).

37. Schote abgerundet-4kantig, Samen 3 kantig-kuglig, selten länglich.

Barbarea (580).

Schote zusammengedrückt-4 kantig, Samen oval od. länglich.

Erucastrum (583).

38. (28) Blbl. weiß, Schote 4 kantig, ungeschnäbelt; Samen gerippt. Alliaria (575).

Blbl. gelb. 39.

39. Schote schmal lineal, stielrund, fein 3 nervig, schnabellos od. kurz geschnäbelt, Samen länglich.

Sisymbrium (574).

Schote br. lineal, zusammengedrückt, 3-5nervig, mit l. schwertfürmigem, 3-5 nervigem Schnabel; Samen kuglig.

Sinapis (582).

\section{0. (23) Schote ungeschnäbelt, Klappen 1 nervig.}

Schote mit zusainmenged:ücktem Schnabel.

41. Blt. kl., Blbl. weiß, ausgerandet; Schote kurz, länglich, mit 1 nervigen Klappen.

Blt. mittelgr. Blbl. gelblichweiß, ganz; Schote schmal lineal.

Turritis (570).

42. Blt. gr., Blbl. schmutzigweiß, violett geadert; Schote dick, lïnglich, mit br. 3 nervigem spitzem Schnabel.

Eruca (585).

Blt. mittelgr. gelb, Klappen 1 nervig, Schnabel lineal, nervenlos. 43. lineal.

43. Schote lineal, flach, zusammengedrückt, kahl; Schnabel br.

Schote länglich, kurz, zusammengedrückt 4 kantig, sternflaumig; Schnabel l., dünn mit 2 lappiger Narbe.

Syrenia (579).

44. (1) Fr. schotenfürmig, l. geschnäbelt, markig, mehrsamig; Blt. gr. Raphanus (586).

Fr. schötchenförmig.

45.

45. Blbl. weiß.

46.

Blbl. gelb.

48.

46. Fr. netzadrig, nicht gegliedert, zusammengedrückt.

47.

Fr. glatt, aderlos, verkehrt-eiförmig-kuglig, am verschmälerten Grunde quer gegliedert.

Crambe (588).

47. Fr. verkehrt-eiförmig, flach zusammengedrückt, ganzrandig, 1-2 samig, hängend.

Peltaria (591).

Fr. 2 knöpfig, erhaben netzadrig, am Rande gezähnt, 2 samig.

48. (45) Fr. nicht gegliedert. Senebiera (590). 49.

Fr. in d. Mitte eingeschnürt-gegliedert, kenlenfürmig, gerippt, geschnäbelt, 1 samig.

Rapistrum (587).

49. Fr. glatt, länglich, geflügelt, hängend, 1 samig, reif schwarz. 
Fr. nicht glatt, aufrecht- od. abstehend-gestielt.

50. Fr. kl. kugelrund, netzadrig 1 samig. 4 samig.

Fr. schief-eilänglich, geschnäbelt mit gezackten Flügeln, 4 fä̀lhrig,

\section{Thlaspi L. Täschelkraut ( $X V, 2)$.}

in Doldentrauben.

1. Blbl. wei $\beta$, selten lila, Schötchen in verlängerter Traube.

Blbl. lila bis violett, Schötchen in gewölbter Doldentraube, schmal geflügelt; St. einfach, liegend od. aufsteigend, 2.5-10 cm l. Wzst. Blbüschel treibend, rasenbildend.

2. Schötchen br. gefliigelt mit abgerundeten Flügellappen.

Schötchen fast ungefliugelt.

9.

3.

8

3. Stbb. purpurroth; Blt. weiß od. lila in kopfigen Doldentraub.; Schötch. verkehrt-herzförm. länglich, bis $8 \mathrm{~mm}$ l. Frstiele wagerecht; St. 7-25 cm h., Grundbl. in Rosetten; verkehrt-eilänglich. Kahl. - Wiesen, begraste Hiigel, Felsspalten bergiger Gegend. 4. 4. 5.

Th. alpestre $\mathrm{L}$.

Stbb. gelb.

4. Schötchen ohne od. mit kurzem Gr.; einjährige Arten

Schötchen langgriffelig; ausdauernde Arten mit meist einfachem St. 6.

5. Schötchen ringsherum sehr br. geflügelt, bis $13 \mathrm{~mm}$ l. auf weit abstehendem Stiel; St. $15-45 \mathrm{~cm}$ h., Bl. lïnglich ganzrand. od. buchtig gezähnt. Stbl. mit schmal pfeilförm. Grunde. - Ackerunkraut. ๑. 5-9. $T h$. arvense $\mathrm{L}$.

Schötch. nur vorn br. gefügelt, verkehrt-herzförm., 4-6 $\mathrm{mm} \mathrm{l}$; St. 15-30 cm h., Bl. ganzrand., ellipt. od, oval, Stbl. mit br. herzförm. Basis sitzeud. - Unkraut auf Kalkbod. in B. u. Oe.; zerstrent ๑. 4. 5.

Th. perfoliatum L.

6. Wrst. unfruchtbare Blrosetten treibend; Schötch. verkehrt-herzförmig, wenigsamig.

Keine Blrosetten, St. meist viele, $25-50 \mathrm{~cm}$ h.; Bl. ganzrandig, Blt. gr., Schötch. $8 \mathrm{~mm}$ l., in l. Trauben auf wagerechtem Stiel länglich-verkehrt-eiförmig, buchtig ausgeschnitten, mit l. Gr. - Felsen, lichte Nadelwäld. auf Kalk u. Serpentin, in Noe. u. St.; zerstreut 4. 4. 5.

Th. Goesingense Hal.

7. Schötch. 4-5 $\mathrm{mm}$ l., am Grunde abgerundet, Blbl. 2 mal länger als d. stets grüne Kelch; St. $7 \cdot 5-15 \mathrm{~cm}$ l. Grasgrün. - Hügel, Wälder, Felsen auf Kalk; zerstreut. 4. 4. 5.

Th. montanum L.

8. (2) Wzst. mit rasenbildenden Blrosetten, St. $2 \cdot 5-10 \mathrm{~cm} \mathrm{h.,} \mathrm{Bl.}$ ganzrand., grundständ. gestielt, rundlich od. spatelförm.; Schötchen länglich, $5 \mathrm{~mm}$ l., mit 1. Gr. - Triften d. Kalkalp. in 00e., St., K. 4. 4. 5. Th. alpinum $\mathrm{L}$.

Keine Blrosetten, Wz. schmächtig, St. $15-45 \mathrm{~cm}$ h. Bl. gezähnt, grundständ. verkehrt-eiförm. länglich; Schötchen verkehrt-eiförm., $6 \mathrm{~mm}$ 1., kurzgriffelig. - Acker in Sz. (Geisberg u. a. O.) @. 5-7. 
Schötch. bis $6 \mathrm{~mm}$ 1., am Grunde verschmälert; Blbl. 2-3 mal långer als d. meist purpurne Kelch; St. $3-10 \mathrm{~cm} \mathrm{~h}$. Blaugrün. - Kalkhügel im südl. St., Kr., T.; zerstreut. 4. 3. 4. Th. praecox Wulf.

9. (1) Bl. rundlich od. spatelförm., ganzrand., Grund d. Stbl. geöhrelt, Schötch. vorn abgerundet. - Gerölle u. Felsen d. Kalkalp. (1900 bis $2550 \mathrm{~m})$ 4. $7-9$.

Th. rotundifólium Gaud.

Bl. länglich, grundständ. gezähnt, Stbl. am Grunde nicht geöhrelt, Schötch. vorn ausgerandet. - Kalkgerölle der Alpen von K.; stellenweis 4. 7. 8.

Th. cepaeaefólium Koch.

\section{Teesdália R. Br. (XV, 2).}

St. 5-12 cm h., einfach, nackt; Bl. in Rosette, buchtig-gezähnt bis leierförmig fiedertheilig, selten ganz; Blt. kl., wei $\beta$, in Doldentraub. Auf Sandboden in B. u. Mh.; zerstreut $\odot .4-6$. T. nudicaulis R. B3r.

\section{Ibéris L. Schleifenblume (XV, 2).}

St. einfach od. ästig, beblättert; Blt. in einfachen od. zusammengesetzten Doldentrauben.

1. Bl. keilförmig, nach d. Spitze zu eingeschnitten gezähnt; Blbl. weiß, selten lila, Schötch. $6 \mathrm{~mm}$ l., mit zusammengeneigten Lappen; St.

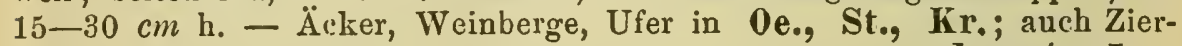
pfl. $\odot$. 7. 8.

1. amára $\mathrm{L}$.

2. Bl. lanzettlich, untere schwach gezähnt; Blbl. rosen- bis purpurroth, Schötchen o $\mathrm{mm}$ l., Lappen gerade; St. $15-30 \mathrm{~cm}$ h. - Zierpt. aus Südeuropa. $\odot$. 6-8.

I. umbelláta $\mathrm{L}$.

\section{Biscutella L. Brillenschote (XV, 2).}

St. ästig, bis $45 \mathrm{~cm}$ h., armblättrig; Bl. ganzrand. od. gezähnt, un . tere länglich-verkehrt-eiförm., gestielt, rasig, obere lanzettlich bis lineal; Blt. hellgelb, Schötch. in 1. Trauben. Behaart od. kahl, sehr variierend. Kalkhügel, zerstreut; in d. Kalkalp. bis $2600 \mathrm{~m} \mathrm{4.5-8.}$

\section{B. laevigáta L.}

\section{Lepídium $\mathrm{L}$. Kresse $(X V, 2)$.} trauben.

St. meist ästig, aufrecht, beblättert; Blt. kl., in aufrechten Dolden-

1. Schötch. nach vorn zu br. geflügelt;Blbl. weiß, Schötch. länglich. 2. 3.

Schötch. nicht geflïgelt.

2. Schötch. $3 \mathrm{~mm}$ l., in schmächtigen Trauben; St. $15-30 \mathrm{~cm}$ h., oberste Bl. lineal, d. übrigen 1-2 fach fiedertbeilig. Kabl. - Küchengewürzpf. aus Südeuropa. $\odot$. ‥ 7. Gartenkresse, L. sativum L.

Schötch. $4 \mathrm{~mm}$ l.; St. $15-30 \mathrm{~cm}$ h., Grundbl. leierförmig-fiedertlıeilig, Stbl. länglich od. lanzettförm., mit pfeilförm. Basis. Blaugrün, behaart.Schutt, bebauter Boden, besond. auf Kalk. -.. 5-7. L. campestre L.

3. Untere od. alle BI. 1-3 fach fiedertheilig, obere ganz. Kable Pf. 4.

Bl. alle ganz, Blbl. weiß.

4. Obere Bl. lineal, d. übrigen 1-2 fach fiedertheilig, mit lineal. Zipfl.; St. $8 .-30 \mathrm{~cm}$ h. mit vielen gleichhohen Ästen; Blt. ohne Blbl., Schötch. $4 \mathrm{~mm} \mathrm{l}$. in 1. Trauben. Stinkend, - Schutt, an Mauern. -.. 5-7. 
Obere Bl. rundlich-oval, herzförmig-stengelumfassend, untere 2-3 fach fiedertheilig, mit lineal. Zipf. Blbl. gelb, Schötch. rhombisch-eiförmig. Eisenbahndämme, Acker- u. Wegränder in B. (eingeschleppt), Noe.; zerstrent $\odot$. 5. 6 .

L. perfoliátum L.

5. Bl. grauflaumig, länglich, gezähnt, obere pfeilförmig-stengelumfassend; St. 15-60 cm h., doldentraubig-ästig; Schötch. herzförmig-3 eckig, netzadrig, $3 \mathrm{~mm}$ br. (Cardaria Draba P.) - Wege, Dämme, Acker, besond. auf Kalk, in B., Mlı., Oe., St.; 4. 5. 6. L Draba L.

Bl. kahl, grün, fleischig, ganzrandig, unterste verlzehrt-ei- od. spatelförmig; St. 15-25 $\mathrm{cm}$ h., Schötch. eiförmig, $3 \mathrm{~mm}$ 1. - Salzhaltige Triften in Noe., stellenweis 4. 5. 6.

L. crassifólium L.

\section{Hutchínsia R. Br. (XV, 2).}

St. aufsteigend od. aufrecht, Bl. fiederschnittig mit ganzrand., elliptischen od. lanzettl. Abschnitten; Blt. kl., in Doldentrauben, Schötchenstiele wagerecht. Kl. kahle Kräutlein.

1. St. ästig, beblättert, $3-10 \mathrm{~cm}$ h., Schötchen elliptisch. - Felsige Plätze, steinige Hügel, auf Kalk, in d. Alpenländern; zerstreut. $\odot$. 4. 5. H. petraea R. Br.

St. nackt. Rasenbildende Alpenkräuter.

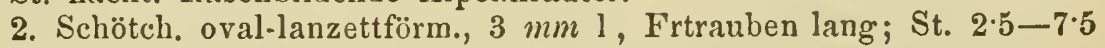
$c m$ h. - Feuchte Gerölle d. Kalkalp. $(1580-2530 \mathrm{~m})$ 4. 6 -9.

H. alpina R. Br.

Schötch. verkehrt-eiförmig-länglich, Frtraub. gedrungen; St. 13 bis $25 \mathrm{~m} n$ h. - Bachufer u. feuchte Gerölle d. Alp. $(1900-2850$ m). 4. 7. 8. H. brevicaulis Hppe.

\section{5๊. Capsella Vent. Hirtentåschel (XV, 2).}

St. beblättert, Blt. kl., weiß; Schötch. l. gestielt, in schlaffer Traube.

1. Schötch. 3eckig, vorn seicht ausgeschnitten, bis über $6 \mathrm{~mm} \mathrm{l.;}$ St. aufrecht, bis $30 \mathrm{~cm}$ h., meist ästig; Grundbl. in Rosette, fiederspaltig. seltener gezäbnt od. ganzrand, Stbl. mit pfeilförm. Grund. - Unkraut. $\odot$ ○-12.

C. Bursa pastóris (L.)

Variet. apétala, ohne Blbl., Stbg. 10. Stellenweis, auf fettem Buden.

2. Schötch. oval, $3 \mathrm{~mm}$ l., Traub. reichbltig; St. bis $10 \mathrm{~cm}$ h., Bl. fiedertheilig od. -spaltig, od. obere ganz. - Feuchte salzige 'Triften in T., selten. $\odot .5-8$.

C. procumbens Fr.

3. Schötch̀. rundlich, $3 \mathrm{~mm}$ br., Traub. $3-4$ bltig; St. $5-7 \mathrm{~cm}$ l., liegend; Grundbl. 3 lappig-fiederspaltig, Stbl. länglich, ganz. - Südl. T., (Fassathal.) $\odot .5-8$.

C. pauciflóra Koch.

\section{Aethionéma R. Br. Steinkresse $(X V, 2)$.}

St. (meist viele) $7 \cdot 5-20 \mathrm{~cm}$ h., aufsteigend, Bl. lineal-länglich, ganzrandig, Blt. kl., in Doldentrauben; Schötchen $6 \mathrm{~mm}$ l. - Felsen u. Gerölle d. Alpen. 4. 5. 6.

Ae. saxátile R. Br.

\section{Stenophrágma Čelak. $(\mathrm{XV}, 1)$.}

St. diunn, zart, $8-30 \mathrm{~cm}$ h., fast bllos; Grundbl. in Rosette, länglich-lanzettförmig, gezähnt, gewimpert, oberseits gabelhaarig; Blt. kl., weiß, traubig; Schuten 10-17 $\mathrm{mm}$ 1. Bläulich beduftet (Arabis Thal. L.). Sandboden. $\odot$. 4. 5 .

St. Thaliánum Ćelak. 


\section{Camelína Crtz. Leindotter (XV, 2).}

St. 30-60 cm h., Bl. länglich od. lanzettförm., Grundbl. gestielt, Stbl. mit pfeilförm. Basis sitzend; Blt. kl., Schötch. in 1. Trauben.

1. Schötch. verkehrt-eiförmig, oben abgestutzt od. ausgeranґet, $4 \mathrm{~b}$. $5 \mathrm{~mm}$ l., dünnwandig, mit sehr kurzem Gr.; Bl. ganzrandig od. d. unteren buchtig gezälınt bis fiederspaltig. Kahl od. behaart. - Auf Feldern (besond. Flachsfeld.) in B., Mh., Oe., ๑. 6. 7.

C. dentáta P.

Scliötch. oben abgerundet od. in d. Gr. verschmälert, hartschalig, langgriffelig.

2. Schötch. birnförmig mit schmalem Rande, $5-7 \mathrm{~mm}$ l., Samen 3 kantig-walzig, BI. zerstreut sternhaarig. - Hier u. da als ölfr. gebaut u. verwildert. $\odot .5-7$.

C. sativa Crtz.

Schötch birnförm., mit scharfem br. Rande, $5-6 \mathrm{~mm}$ l. in 1. Trauben, Samen eiförm. 3 eckig; St. u. Bl. ranhhaarig. - Wiiste Plätze, Hügel, Wegränder; zerstrent, besond. auf Kalk. ๑ . 5-7.

C. microcarpa Andrz.

\section{Armoricia Th. Wett. Meerrettig. (XV, 2).}

St. 0.45-1.30 m h., rispig-ästig; Grundbl. sehr gr., l. gestielt, herz. eiförmig-länglich, gekerlt, untere Stbl. kammförmig-fiederspalt., obere länglich od. lanzettlich; Blt. doldentraubig, weiß; Wzst. senkrecht, l. (Cochlearia Armorac. L.) - Allg. cult., an Flussufern verwild. 4. 7. 8. Kren, $A$. rusticána Th. Wett.

\section{Kéruera Med. (XV, 2).}

St. 15-30 cm. h., Grundbl. in Rosette, gestielt, verkehrt-eilanzettförm., ganzrandig od. gezähnt bis leierförm., Stbl. lineal-länglich; Blt. kl., weiß, l. gestielt, in Doldentraub.; Schötch. scharf gerandet, $2 \mathrm{~mm}$ br. Felsen u. Gerölle d. Kalkalp.; zerstreut. 4. 5. 6. K. saxátilis Rchb.

\section{Roripa Bess. Sumpfkresse (XV, 2).}

St. aufrecht od. anfsteigend-bogig, ästig, beblättert; Blt. kl., gelb, in Doldentraub.; Schötch. od. kurze Schoten, 1. gestielt, in 1. Trauben. Kahle Kr. *).

1. Blbl. nur so 1. als d. Kelch od. wenig länger.

Blbl. 1-2 mal länger als d. Kelch.

2.

4.

2. Blbl. nicht länger als d. Kelch, Schötchen länglich-walzig, $6 \mathrm{~mm}$ 1., etwas gekrümmt, so 1 . wie d. fast wagrechte Stiel; St. $15-60 \mathrm{~cm}$ h., untere Bl. leierförmig fiedertheilig gestielt, obere fiederspalt. bis fiedertheilig. Theilstücke gezähnt. - Sümpfe, Ufer, feuclıte Plätze. ๑. 6. 7. R. palustris Bess.

Blbl. länger als d. Kelch, goldgelb; Schote od. Scliötchen kürzer als d. rechtwinklig abstehende Stiel; St. 0:30-1 $m$ h.

3. Sclı̈̈ichen kıglig, sehr kl, Bl. länglich od. lanzettförm., gesägt, obere mit lierzförm. Grunde stengelumfassend, - Flussufer in B., Mll., 0e., St. 4. 6. 7.

R. austriaca Bess. sichtigt bleiben.

*) Es kommen in dieser Gattung Bastardformen ror, welche hier unberück- 
Schötch. länglich od. ellipsoidisch, 3-6 $\mathrm{mm}$ l., Stiele wagrecht, untere oft herabgebogen; St. hohl, aufsteigend od. liegend, unten wurzelnd. Sehr variierend. - Gräben, stehende Wässer, Ufer. 4. 5-7.

\section{R. amphíbia Bess.}

Variet. $\alpha$. indivisa DC. Bl. ganz, gezäbnt, grundständ. mit br. geflïgeltem Stiel. Landform; - $\beta$. $\nabla$ ariifolia DC. untere Bl. od. alle kammförmig fiederspaltig, St. bis fingerdick. Wasserform; - $\gamma$. auriculata (Maly), mittlere Bl. mit geöhreltem Grunde sitzend, untere leierförmig.

4. (1) Erste Grundbl. ganz, 1. gestielt, d. folgenden leierförmig, Stbl. tief fiedertheilig mit linealen Theilstücken; Fr. eine schmallineale 5-8 $\mathrm{mm}$ l. Schote von d. Länge d. Stieles; St. $15-60 \mathrm{~cm}$ h., dünn. Steinige sounige Plätze in Kr. 4. 5. 6.

Alle Bl. zertheilt, St. $15-60 \mathrm{~cm}$ h. R. lippicensis (DC).

5. Fr. eine lineal-walzige, oft schwach gekrümmte, 6-16 $\mathrm{mm}$. Schote mit abstehendem gleichlang. Stiele; Bl. fiedertheilig bis fiederschnittig; Abschn. länglich od. lanzettl., tief gezähnt od. fiederspaltig. Ufer, feuchte Wiesen, Wegränder. 4. 6-10.

R. silvestris Bess.

Fr. ein längliches, $4 \mathrm{~mm}$ l. Schötchen, kürzer als d. alstehende Stiel; untere Bl. leierförm. fiedertheilig od. fiederspaltig, obere keilförmig. länglich, nach unten fiederspaltig. - Flussufer, feuchte Plätze in B. 4. 6. 7.

$R$. barbaraeoides (Tausch).

\section{Nasturtium Rehb. Brunnenkresse (XV, 1).}

St. aufsteigend, am Grunde kriechend u. wurzelnd, hohl, gefurcht, bis $1 m$ l.; Bl. unparig gefiedert, Blättch. eiförm. od. länglich, geschweift. gekerbt od. ganzrand., Endblättch. herzeiförmig; Stbb. gelb, Schotenstiel wagerecht od. abwärts gebogen. - Quellige Orte, Bäche. 4. 5-7.

\section{N. officinale $\mathrm{R}$. Br.}

\section{Eróphila DC. Hungerbliimchen ( $X V, 2)$.}

St. (oft mehrere) 3-10 $\mathrm{cm} \mathrm{h.,} \mathrm{nackt;} \mathrm{Bl.} \mathrm{in} \mathrm{Rosette,} \mathrm{lanzettförm.}$ od. länglich, ganzrand. od. gezähnt, behaart; Blt. kl. in lockerer Traube; Schötch. länglich od. Ianzettförm. 3-9 $\mathrm{mm}$ l. Sehr variierend. - Aut Sand, Mauern, Felsen. ๑. 3-5.

E. verna (L.) E. Mey.

\section{Draba L. Hungerblume (XV, 2).}

St. meist einfach, Grundbl. in Rosetten, Blt. in dichten Doldentraub, Schötch, in lockeren Trauben. Meist stern- od. ästighaarige kl. Kr.

1. Blbl. weiß.

Blbl. gelb.

2. Keine ausdauernden Blrosetten, sondern nur d. Grundbl, in einer lockeren, bald verwelkenden Rosette; St. beblättert, sammt d. Bl. sternhaarig.

Ausdauernde rasenbildende Blrosetten; St. armblättrì od. nackt, 2.5-10 cm h.; Frtrauben kurz, locker. Alpenpflanzen.

3. Schötchenstiel länger als d. Fr., wagerecht abstehend, Frtrauben sehr 1. u. schlaff; frtragender St. fadenförm. bis $30 \mathrm{~cm} \mathrm{l.;} \mathrm{Grundbl.} \mathrm{ver-}$ kehrt-, Stbl. herzeiförmig, alle grob gezähnt. - Maneın, steinige Hügel, Felsen in B. u. Mh.; zerstreut. $\odot$. 5. 6. 
Schötchenstiel kürzer als d. Fr., mit dieser aufrecht; Frtraub. 1. u. schmal, Schötchen gedreht, bis $10 \mathrm{~mm} \mathrm{l}$; St. bis $25 \mathrm{~cm} \mathrm{h.,} \mathrm{diclıt} \mathrm{beblät-}$ tert, sammt d. lanzettförm. Bl. weiß-graufilzig. - Steinige Orte im südl. T. u. Kr.; zerstreut. 4. 5. 6 .

D. incána $\mathrm{L}$.

4. Bl. graugrün, sternhaarig-flaumig bis filzig. 5.

Bl. glänzend grün, kahl, l. gewimpert, Rosettenbl, verkehrt-eiförm., Stbl. länglich, St. 3-8 cm h., Schötch. lineal. - Alp. v. Kr., zerstreut. 4. 5. 6 .

D. ciliata Scop. ralidet.

5. St. u. Blstiele sternflaumig, Stbl. 1-3 (meist 2), Blbl, ausge-

Oberer Theil d. St. nebst Blstielen u. Schötchen kahl.

6.

7.

6. Schötch. oval od. länglich, am Rande gewimpert, St. $3-5 \mathrm{~cm}$ h., Stbl. br. herzeifürm., grob gezähnt, Grundbl. schmäler, elliptisch. - Felsen d. Kalkalp. v. Sz., T., Kr. (1900-2800 m.) 4. 7.

D. tomentosa Wahlenb.

Var. púmila (Mielichh.) St. bllos, kaum länger als d. Rosette, Schötch, kahl. (Rauriser Goldberg).

Schötch. Ianzettförm., kahl; St. 3-10 cm h., 1-2 blättr. od. nackt; Grundbl. lanzettförm., Stbl. eiförmig. - Felsspalten d. Alp. v. Sz., St., K., T. $(1580-2200 \mathrm{~m})$. 4. 7.

7. Blbl. 3-6 $\mathrm{mm}$ 1., 2-3 mal länger als d. Kelch. D. frígida Sant.

Blbl. $2 \mathrm{~mm}$ l., 1-2 mal länger als $\mathrm{d}$. Kelch, ausgerandet. 8. 9.

8. Blbl. 1. genagelt, verkehrt-eiförm. od. oval; S̈chötch. elliptisch bis oval, kurzgriffelig; St. 3-6 cm h., gebogen, steif, kahl; Rosettenbl. verkehrt-eiförm. od. länglich, Stbl. oval od. br. eiförm. - Felsspalten d. Alp. v. T. u. K.; selten. 2. 7.

D. nivea Sant.

Blbl. kurz genagelt, verkehrt-eiförm., ausgerandet; Schötch. ovallanzettlich, 1. griffelig, Bl. ganzrand. od. gezähnt, Grundbl. lanzettlich od. elliptisch. - Felsspalten d. Kalkalp. v. Noe. u. St. $(1900-2600$ m). 4. 6. 7 .

J. stellata Jequ.

9. Schötch. mit deutlichem Gr., lanzettförm, St. 3-10 cm 1., einfach od. gabeltheilig, Rosettenbl. länglich-lanzettförm, ganzrandig, Stbl. br. eiförm. od, länglich, gezähnt. - Felsspalten hoher Alp. in Sz. s. T.; zerstreut. 4. 6. 7.

D. Traunsteineri Hppe.

Schötch. griffellos od. mit undeutlicher Gr., Bl. lanzettlich. 10.

10. St. oft ästig, 2-3 blättrig, unten sternhaarig bis $15 \mathrm{~cm}$ h.; Stbl. am Grunde steifhaarig gewimpert. - Felsen hoher Alp. in Sz., Ki., T.; zerstreut. 4. 7. 8 .

D. Johannis Host.

Var. glabrata Koch. Ganz kahl. Höchste Alp. v. Sz.; selten.

St. einfach, kahl, oft bllos, $3-5 \mathrm{~cm}$ h., Bl. gewimpert, außerdem zerstreut-behaart, sternflaumig od. kahl, - Am ewigen Schnee in Sz., K.; T.; zerstreut. 4. 7. 8 . D. Wahlentergii Hartm.

11. (1). Keine ausdauernden Blrosetten, Wz. diinn; St. $8-20 \mathrm{~cm}$ h., Bl. eiförmig-länglich od. elliptisch, gezähnt, belıart; Blbl. ausgerandet, Schötch. länglich, griffellos, flaumig od. liahl, l. gestielt. - Auf Sandbod. u. Bahndämmen in Mh. u. Noe., stellenweis. $\odot .5 .6 . \quad D$. nemorósa L.

Wzst. mit starren, ein dichtes Polster bildenden Blrosetten, Rl. l. gewimpert; St. 3-12 cm h., nackt; Blbl. 4--8 $\mathrm{mm}$ l., ausgerandet, Schötch. mit Gr. 
12. Bl. oberseits kahl, unters. steifhaarig, lineal-lanzettförm., Schötch. lanzettförmig, struegelhaarı od. kahl mit 1. Gr. - Felsen d. Kalkalpen. $(1260-2000 \mathrm{~m}) \cdot 25-7$.

D. aizoides $\mathrm{L}$.

Bl beiderseits kahl, Schötchen kahl od. zerstreut u. kurz striegrelhaa. rig, kurz od. langgrifflich. Zwerghafte Alpenkr.

13. Bl. schmailineal. spitz; Stbg. so l we d. Blbl. Graugrün. Höchste Granitalp. v Sz., St., K., T.; (2200-2850 m); stellenweis 7. 6. 7. (D. Zahlbrúcknerı Host.).

D Hoppeána Kchb

Bl. lanzettförmig, stumpf; Stbg. halb so lang wie d Blbl. Grün. Höchste Kalkalp v. Sz. u, St. 467.

D. Sauteri Hppe

\section{Petrocallis R. Br. Steinschmiickel (XV, 2).}

St. nackt, 13-25 cm h.; Bl. in Rosetten, keilförm., 3-5 spaltig, gewimpert: Blt, rosa od. lila in dichter Doldentraube. - Gerille u. Felsspalt. d. Alp. v. Sz, T., Kr. $(2200-2900 \mathrm{~m})$; zerstreut. 4. 5. 6.

\section{P. pyrenáica $\mathrm{R}$. Br.}

\section{Lunária L. Mondreil ( $\mathrm{XV}, 2)$.}

St. aufrecht, ästig, beblättert, $0.45-1 \mathrm{~m}$ h.; Bl. gestielt, herzförm., gezähnt, zugespitzt; Blt. gr., wohlriechend. Weichhaarig.

1. Blbl. blass lila, Schötch. elliptisch-lanzettförm., bis $5 \mathrm{~cm} \mathrm{l.} \mathrm{u.}$ $16 \mathrm{~mm}$ br. - Schattige Bergwälder; zerstreut. 4. 5. 6. L. rediviva L.

2. Blbl. violett od. weiß, Schötch. br. oval, abgerundet, bis $38 \mathrm{~mm}$ 1. u. 24-30 mm br. - Zierpt., auch verwild. ๑. 5. L. biennis L.

\section{Farsétia R. Br. (XV, 2).}

St. $30 \mathrm{~cm} \mathrm{h.,} \mathrm{dicht} \mathrm{beblättert;} \mathrm{Bl.} \mathrm{lanzettförm.,} \mathrm{ganzrandig;} \mathrm{Blt.} \mathrm{in}$ Doldentraube, Schötch. $20 \mathrm{~mm}$ l., in schmalen Trauben. Sternfilzig, graugrün. - Steinige Hügel im südl. T. ๑. 4. 5.

F. clypeáta R. Br.

\section{Bertéroa DC. (XV, 2).}

St. 30-60 cm h., Bl. lanzettlich, ganzrandig od. gezähut; Blt. in kopfigen Doldentrauben. Schütch. in 1. schmalen Trauben. Sternhaarig-

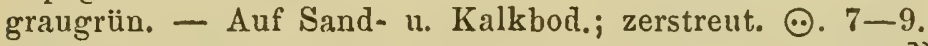

B. incána DC.

\section{Alýssum L. Steinkraut (XV, 2).}

St. einfach od. ästig, beblättert; Bl. ganzrandig, Blt. kl., in einfachen od. zusammengesetzten Doldentrauben. Sternhaarige, oft filzige $\mathrm{Kr}$.

1. Blbl. wenig länger als $d$. Kelch, gelblichweiß, Blt. kl., in einfachen Doldentrauben, Schötchen 2 samig.

Blbl. noch einmal so groß als d. Kelch, 2 lappig, goldgelb; Schötch. meist 4 samig.

2. Kelchbl. stehenbleibend, das kreisrunde, $3 \mathrm{~mm}$ br. Schötch. einhüllend; Blbl. ausgerandet; Schötch. sternbaarig, in 1. Trauben; St. 7-30 $\mathrm{cm}^{\circ}$ h., Bl. keil- od. lanzettförmig. - Mauern; Felsen, sand. Äcker. $\odot$. $4-9$.

A. calýcinum $\mathrm{L}$.

Kelchbl. abfallend, das Schötchen entblößend, Blbl. ganz, Schötch. kreisrund, ausgerandet, kahl, dicht gedräigt; St. $3-20 \mathrm{~cm}$ h., Bl. lineal. - Sandplätze, trockene Hügel in Mll. u. Noe.; stellenweis. ○. 4. 5. 
3. Wzst. mit unfruchtbaren rasenbildenden Blbüscheln; Bltstengel aufsteigend, zahlreich; die 4 längeren Stbf. geflügelt, Schötch. sternfaumig, grau.

Holziger üb. d. Boden tretender Wzst., dessen Aeste Blbüscheln u. Bltstengel tragen; Blbl. tief ausgerandet. Halbstrauchige Büsche bildende Arten.

4. B1. sternfilzig, grau, lineal od. d. unteren verkehrt-eilanzettförm.; St. $10-25 \mathrm{~cm}$ h. Schötrh. länglich-rund, gerandet, sternfilzig, 2-3 $\mathrm{mm}$ br. - Sand-, Kalk- u. Basaltboden, auf Hügeln; zerstreut. 4. 5. 6.

\section{A. montánum $\mathrm{L}$.}

Bl. sternhaarig, grün, untere verkehrt-eiförmig, obere länglich od. lanzettförmig; St. $30-30 \mathrm{~cm}$ h., Blt. in dichten gewölbten Doldentraub.; Schötch. elliptisch od. verkehrt-eiförm., 5-6 $\mathrm{mm} \mathrm{l}$. - Gerölle d. Alp. v. St., K., Kr.; zerstreut. 4. 7. 8. A. Wulfenicinum Brlid.

5. Schötch. mit Flügelrand, oval od. rundlich, $5-6 \mathrm{~mm} \mathrm{1.,} 8-12$ samig; Büschelbl. lanzettförm., St. bis $15 \mathrm{~cm} \mathrm{l.} \mathrm{-} \mathrm{Kalkfels,} \mathrm{in} \mathrm{K.} \mathrm{u.}$ Kr. ; zerstreut. 4. 5. 6. A. médium Host.

Schötch. ohne Flïgelrand, br. oval od. verkehrt-eiförm., $3 \mathrm{~mm}$ br., 4 samig; Büschelbl. länglich-lanzettförm., ganzrand. od. gezähnt; St. 15 bis $30 \mathrm{~cm} \mathrm{l.} \mathrm{-} \mathrm{Felsspalten} \mathrm{(bes.} \mathrm{an} \mathrm{Kalkfels.)} \mathrm{in} \mathrm{B.} \mathrm{(Moldauthal} \mathrm{u.} \mathrm{a.),} \mathrm{Mh.,}$ Oe.; zerstreut. 4. 4. 5 .

A. saxátile L.

\section{Matthíola $\mathbf{R}$. Br. Levkoy $(\mathrm{XV}, 1)$.}

St. aufrecht, einfach od. ästig; Bl. ganzrand., gestielt, Blt. gr., in endständ. Trauben.

1. Halbstrauchig, St. $45-60 \mathrm{~cm}$ h., sammt d. lanzettförm. Bl. weißgrau-filzig; Blbl. violett, lila, weiß. - Zierpfl. aus Südeuropa. 4. Ђ. $4-6$.

Winter-L., M. incána $\mathrm{R}$. Br.

2. Krautig, St. 15-30 $\mathrm{cm}$ h., nebst d. länglichen Bl. graugriin; Blbl. w. b. v. A. - Zierpt. aus Südeuropa. $\odot$. 6-9.

Som mer-L., M. ánnua R. Br.

\section{Cheirauthus L. Lack. $(\mathrm{XV}, 1)$.}

St. ästig, beblättert, $15-60 \mathrm{~cm}$ h.; Bl. lanzettl., ganzrand., angedriickt behaart, grün; Blt. gr., in dichten Trauben, wohlriechend; Blbl. goldgelb od. goldbraun. - Zierpfl. aus Südeuropa u. verwild. an Mauern, Steinew. 4. 5, 6.

Goldlack, Ch. Cheiri L.

\section{9. Árabis L. Gänsekohl (XV, 1).} Trauben.

St. einfach od. ästig, beblättert; Blt. in einfachen Doldentraub. od.

1. Stbl. mit herz- od. pfeilförm. Basis sitzend.

Stbl. mit abgerund. od. verschmälerter Basis sitzend, selten gestielt.

2. Kahl, blaugrün; St. $0.3-1 \mathrm{~m}$ h., Bl. ganzrandig, untere 1. gestielt, oval od. länglich, d. andern sitzend, länglich-lanzettförm.; Blbl. weiß. Schot. 5-7.5 cm 1. steif, aufrecht. - Laubwäld. bergiger Gegend. in B., Mh., Oe., St., T.; zerstreut. 4. 5.6. A. brassicaeformes Wallr.

St. u. Bl, mehr weniger behaart. 
3. Blbl. blassgrelb od. gelblichgrin; Schot. $7 \cdot 5-12.5 \mathrm{~cm} 1 .$, bogig, meist einseitswendig; St. $30-60 \mathrm{~cm}$ h., Bl. geschweift-gezähnt, wellig, untere elliptisch, d. and. länglich-lanzettförmig. Graugrün-filzig. - Steinige Orte, Felsen in 0e., St., T., Kr. 4. 5. 6.

A. Turrita L. stielt.

Blbl. weiß, Schote $2.5-5 \mathrm{~cm}$ 1., aufrecht; Grundbl. in Rosette, ge-

4. Kriechende Wzst., rosettentragende Stämmchen u, beblätterte Auslänfer treibend; St. $7-30 \mathrm{~cm}$ h., sammt d. grobgezähnten Bl, gabelhaarig-filzig, Rosettenbl. verkehrt-eiförm., Stbl. länglich; Blbl. abstehend mit 2-5 $\mathrm{mm}$ br. Platte.

๖. breit.

Wzst. ohne Ausl. od. 1-2 jähr. Wz.; Blbl. aufrecht, Platte $1 \mathrm{~mm}$ 6.

5. Bl. vielzähnig, Aste u. Schoten abstehend. - Gerölle a. Felsspalt. d. Alp. $(1250-2550$ m.). 4. 5-9. A. alpina $\mathrm{L}$.

Bl. wenig- u. grobzähnig, Äste u. Schoten aufrecht. Weißgrauflzig. - Zierpfl. aus Asien. 4. 4-6.

A. álbida Stev.

6. Schoten abstehend, in sehr lockerer Traube, deren Spindel zickzackförm. gebogen, Blbl. $4 \mathrm{~mm}$ l.; St. $8-30 \mathrm{~cm}$ h., diinn; Bl. entfernt, nval od. länglich, gezälınt, gabelhaarig, graugrün. - Kalkhügel in B.,

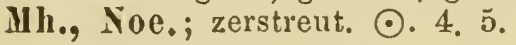

A. auriculáta Lam.

Schot. dem St. angedriickt, gedrängt stehend, in 1. schmalen Trauben; St. meist behaart, Bl. ei- bis lanzettförm., gezähnt od. fast ganzrand.

7. Stbl. vom Grunde bis zur Mitte d. St. diesem angedrückt, obere abstehend, alle am Grunde tief herz-pfeilförm; St. $30 \mathrm{~cm}$ h., steif. Auenwäld., Wiesen in B., Noe.; zerstreut. ๑. 5.6. A. Gerardi Bess.

Stbl, alle aufrecht-abstehend.

8. St. meist einfach, straffi, $30-45 \mathrm{~cm}$ h., Stbl. am Grunde abgestutzt od. herzförm.; Schoten bis $25 \mathrm{~mm}$ 1. mit deutlichem vortretend. Längsnerv. - Wiesen, Äcker, Hügel. ๑. 4. 5-7.

A. hivsita Scop.

Var. glaberrima Wallr. (A. sudetica Tsch.) Kahl. Riesengeb.

St. traubig-ästig, 0.6-1 m. h., Äste ruthenförmig; Stbl. am Grunde tief herz-pfeilförm.; Schoten bis $5 \mathrm{~cm} \mathrm{1.,} \mathrm{mit} \mathrm{undeutlichem} \mathrm{Längsnerv.}$ - Steinige Hügel, Waldränder, besond. auf Kalk in B., Mh., Noe., St.; zerstreut. $\odot$. 4. 5-7.

A. sagittáta DC.

9. (1) Bl. ganz od, nur gezähnt; Schoten aufrecht, br. lineal, Samen br. geflügelt.

10.

Bl. (untere) buchtig-gezähnt bis fiedertheilig od. leierförmig-fiedertheilig, selten ganz u. ganzrandig; Schot. sammt d. Stiel meist abstehend, schmallineal, Samen nicht od. schmal getiugelt.

12.

10. Blbl. violett-blau. Schot. gedrängt, $13-25 \mathrm{~mm}$., St. $2 \cdot 5-7 \cdot 5 \mathrm{~cm}$ h. ; Bl. verkehrt-eiförmig-keilig, gezähnt, gewimpert. - Gerölle d. Alp. v. Sz., K., T. $(1900-2550$ m.). 4. 7. 8 .

A. coerílea Wulf.

Blbl. weiß, Grundbl. ganzrand. od. schwacl gezähnt, in d. geflügelt. Stiel verschmälert od, ungestielt (vrgl, auch A. ciliata $\mathrm{Nr}, 15$ ). 11.

11. Behaart, Wzst. ohne Ausläuf., St. $5-15 \mathrm{~cm} \mathrm{b.;} \mathrm{Schot.} \mathrm{gedrängt,}$ 1f $-32 \mathrm{~mm}$ 1. - Felsen u. Gerölle d. Kalkalp. (1580-2200 m.). 4. 6. 7. 
Kahl, Wzst. rosettentragende Ausl. treibend; St. $15-45 \mathrm{~cm}$ b., reic' beblätt., Stbl elliptisch; Schot. auf 1. abstehendem Stiel aufrecht, bis $40 \mathrm{~mm}$ 1. - Steinige feuchte Plätze d. Alp. (1580-1900 m.); zerstrent. 4. 4. 5 .

A. béllidifólia Jequ. Traube.

12. (9). Wzst. Ausläufer treibend, Schoten abstehend, in lockerer

Wzst. olıne Ausl. od, ein- bis zweijährige dünne Wzl. 13.

13. Ausl. eine Blrosette tragend, aus welcher ein Bltst. u. andere Ausl. entspringen, St. unten beblättert u. angedrückt behaart, $8-15 \mathrm{~cm}$ 1., Bl. länglich, ganzrandig, kahl; Blbl. weiß, Schoten bis $25 \mathrm{~mm}$ l. Schattige Felsen in Kr. 4. 4. 5 .

A. procurrens Wallr.

Var. voch in en sis (Spr.), Bl. stachelspitzig, Schot. kürzer. Kalkalp. v. St., K. Kr.

Ausl. beblättert od. lockere Blbüschel, aber nicht Rosetten tragend. 14.

14. Blbl. weiß; St. aufrecht od. aufsteigend, $8-30 \mathrm{~cm}$ l., rispig. ästig; Grundbl. herzförm., rundlich od. eiförm. mit l. dünnem Stiel, selten leierförmig.fiedertheilig; Schot. 16-2t $\mathrm{mm}$ l. Kahl. - Flussauen, feuchte Wiesen u. Brachen auf Kalk in B., Oe., St.; zerstreut. 4. 5. 6.

A. Hálleri $\mathrm{L}$. Nr. 17).

Blbl. rosa od. lila: Var. stolonífera Host. von A. ovirensis (s.

15. (12). Blbl. weiß, Bl. gezähnelt od. ganzrand, von ästigen Haaren gewimpert, Grundl. in Rosette, verkehrt-eif rmig-länglich, Stbl. länglich; St. 8-15 cm h, straff, Schoten gedrängt, aufrecht, $20 \mathrm{~mm} \mathrm{l}$. - Gerölle, Felsspalt. u. Triften d. Alp. $(1500-2000 \mathrm{~m}$.) ; zerstreut. ๑. 5. 6 .

A. ciliáta $\mathrm{R}$. Br.

Blbl. weif, Grundbl. buchtig gezähnt, fiederspalt. od. leierförmigfedertheilig; weißblühende Formen v. A. arenosa u. stricta $(\mathrm{Nr} .16,17)$ Blbl. lila od. rosenroth.

16.

16. Grundbl. in dem Boden aufliegender Rosette, leierförmig-fiedertheilig mit buchtig-gezähutem Fndlappen, selten ganz, nur gezähnt (var. integrifolia Čelak.); St. aufsteigend od, aufrecht $7-30 \mathrm{~cm} \mathrm{l.,} \mathrm{wenig}$ blättrig, selten nackt (var. scapiformis Čel.); Schot. abstehend, 25 bis 38 mm l. Abstehend rauhhaarig bis kahl. - Sandbod., felsige Plätze; zerstreut. $\odot$ bis 4 . 4. 5 .

$A$. arenósa $\mathrm{L}$. förmig.

Grundbl. in aufrechter lockerer Rosette od, gebüschelt, nicht leier-

17. Grundbl. lanzettförm. od. länglich, buchtig gezähnt bis fiederspaltig, Stbl. wenige, länglich bis lineal, ganzrandig; St. $8-15 \mathrm{~cm} \mathrm{~h}$. bläulich beduftet; Blbl. $6-8 \mathrm{~mm}$ l., lila od. weiß, Schot. aufrecht-abstehend, bis $38 \mathrm{~mm}$ l. - Gerölle u. Felsen von Kalk u. Gyps in B., Mh., 0e., St., Kr. 4. 4. 5.

A. petraéa Koch.

Grundbl. herzförm. rundlich od. verkehrt-eiförm., mit l. schmalem Stiel, Stbl. läıglich od. elliptisch, alle gezälnnt od. ganzrand.; St. 8 bis $30 \mathrm{~cm}$ h., Blbl. $6 \mathrm{~mm}$ l., rosa od. weiß, Schot. abstehend, $13 \mathrm{~mm}$ l. Alpentriften in K., K $\bullet$., St. 4. 5-8.

A. ovirensis Wulf. 


\section{Turrítis L. Thurmkraut $(X V, 1)$.}

St. $0.6-1.3$ on h., straff, reichblättrig; Grundbl. rosettenständ., gestielt, buchtig gezähnt, Stbl. länglich-lanzettförmig, herzförmig-stengelumfassend, ganzrandig; Blt. u. d. $7 \cdot 5 \mathrm{~cm}$ 1. aufrechten Schot. in jl. schmaler Traube. Kahl, blaugrün. - Waldränder. ๑. 5-7. T. glabra L.

\section{Cardámine L. Schamkraut (XV, 1).}

St. einfach od. ästig, beblättert; Blt. in einfachen Doldentrauben, Schoten aufrecht. Meist kahl.

1. Bl. 3 zählig zerschnitten, Grundbl. 1. gestielt, unterseits purpurn, Stbl. kl., sitzend od. fehlend; St. aufsteigend, $15-30 \mathrm{~cm}$ 1., Blbl. weiß. Kahl. - Schattige Bergwälder der Alpenländer, auch im Böhmerwalde. 4. 5. 6 .

C. trifólia L.

Bl. verkehrt-ei- od. rautenförm., ganzrandig, geschweift od. schwach gelappt, Grundbl. 1. gestielt; St. aufsteigend, $2 \cdot 5-7 \cdot 5 \mathrm{~cm} \mathrm{~h}$; Blbl. weiß. - Quellige $u$. steinige Plätze d. Central-Schieferalp. $(1900-2600 \mathrm{~m}) .4$. 7. 8 .

C. alpina Willd.

Alle Bl. od. wenigstens d. Stbl. fiedertheilig bis fiederschnittig. 2.

2. Erste Grundbl. eirund od. herzförmig-rundlich, spätere 3 spaltig, 3 theilig bis $2-3$ paarig fiedertheilig, Stbl. fiederschnittig; St. $3-15 \mathrm{~cm}$ b., Blbl. weiß. - Quellige Orte d. Alpen (1580-1900 m), d. Riesengeb. v. Gesenkes (selten!). 4. 6-8.

Alle Bl. fiederschnittig.

C. resédifólia L.

3. Blt. sehr kl., Blbl. schmal, weiß, Schot, auf abstehendem Stiel aufrecht, $\mathrm{Bl}$. vielpaarig-fiederschnittig.

Blt. ansehnlich, Blbl. mit br. verkehrt-eiförmiger Platte; St. 15 bis $45 \mathrm{~cm} \mathrm{~h}$.

4. Stbl. am Grunde pfeilförmig-geöhrelt, Abschnitte d. oberen Bl. lanzettförmig, ganzrandig, d. unteren 2-3lappig od. grob gezähnt; St. 15 bis $45 \mathrm{~cm}$ h., vielblättrig. - Laubwälder. ๑. 5. 6. C. Impátiens L،

Stbl. am Grunde nicht geöhrelt.

5. Abschn. aller Bl. schmal länglich bis lineal, ganzrandig; St. 10 bis $20 \mathrm{~cm}$ h. - Schattige sumpfige Grasplätze, Teichränd. in $\mathbf{M h}$.; stellenweis. $\odot$. 6. 7 .

C. parviflóra L.

Abschnitte d. grundständ. od. unteren Bl. rundlich, eckig gezähnt, endständig. größer als d. seitenständig.; St. kantig gefurcht. Sehr variierend. - Feuchte, schattige Waldstellen; zerstreut. $\odot$ bis 4.4 .5 (:m Hochgebirge 6). C. hirsuita L.

Variet. $\alpha$. ca mpestris Fr. St. $5-20 \mathrm{~cm}$ h., einfach, $2-4$ blättrig: Grundbl. zahlreich, in Rosette, Abschn. d. Stbl. lanzettlich, gezähnt. Spärlich behaart; - $\beta$. silvática (Lk.). St. $15-30 \mathrm{~cm}$ hoch, reichbeblättert, Grundbl. wenige, nicht in Rosette, $\mathbf{A b}$. schnitte d. Stbl. von denen d. Grundbl. wenig rerschieden, länglich. Stärker behaart.

6. (3) Blbl. weiB, Stbl. purpurroth od. violett; St. kantig gefurcht, aufsteigend, Abschnitte d. unteren Bl. rundlich od. eiförmig, d. oberen länglich, alle buchtig od. eckig gez:̈hnt. Kahl. - Bachufer, quellige Orte. 4. $4-6$.

C. amára L.

Var. O pízii Presl. Niedrig, dickstenglig; Bl. gedrängt stehend, glänzend. Kahl od. rauhhaarig. Riesengeb. u. Gesenke. 
Blbl. lila od. weiß, lila geadert, Stbb. gelb; Grundbl. in Rosette, leierförmig-fiederschnittig. mit rundlichen eckig.gezähnten Abschn., Stbl. mit längliehen bis linealen Abschn. Sehr vielgestaltig. - Wiesen, Bachufer. 4. $4-6$.

Wiesenkresse, C. pratensis L

Variet. $\beta$. Hayneána Welw Niedrıg, vielstenglig, St. sehs ästig, Abschn. d Stbl. kl., lineal, Blt. kleiner, weiß. Noe. u Mh.; Y..acaulis (Berg) Stengellos m. l. gestielten grundständ. Blt. (abnorme Form!). In B., selten.

\section{Dentária Tourn. Zahnwurz $(\mathrm{XV}, 1)$.}

St. aufrecht, einfach, beblättert, unten nackt; Blt. in schirmförmiger Doldentraube, Blabschnitte gr., eilanzett- od. lanzettförm, zugespitzt, gesägt. Kahl.

1. Bl. fingerförmig zerschnitten; St. $15-40 \mathrm{~cm} \mathrm{~h}$

Bl. fiederschnittig.

2. Bl. 3 zählig zerschnitten, zu 3 quirlständig.

Bl. $3-5$ zählig zerschnitten, wechselständig.

3.

3. Blbl. gelblichweiß. -- Schattige Gebirgsbuclıenwäld. in B., Mh., 0e., Sz., St.; zerstreut. 4. 4. 5.

D. enneaphillos $\mathrm{L}$

Blbl. purpurn; zwischen jeder Bltheilung 1 Drüse. - Schattige Gebirgswälder in Mh. u. Schl.: stellenweis. 4. 4. 5.

D. glandulósa W. Kit.

4. Bl. 3 zählig zerschnitten, Blbl. weiß. - Schattige Thäler in Sz. St. und Unter-Kr.; selten. 4. 4. 5D. trifólia W. Kit

Untere Bl. 5-, obere 3 zählig; Blbl. rosenroth. - Alpenthäler von Sz., T., K., St., in Wäldern; zerstreut. $4.45 . \quad$ D. digitáta Lam.

5. (2). In d. Blachseln schwarze Zwiebelknospen, St. $30-60 \mathrm{~cm}$ h., Blbl. lila. - Schattige Laubwälder. 4. 5. 6.

D. bulbifera L.

| Keine Zwiebelknospen, St. 30-60 cm h., Blbl, weiß oder blasslila. - Schattige Gebirgswäld. in Unter-St.; selten. 4. 4. 5. D. pinnata Lam.

\section{Hésperis L. Nachtviole (XV, 1).}

St. aufrecht, einfach od. ästig, beblättert; Bl. eilanzett- od, lanzettförmig, Blt. in einfachen od. zusammengesetzten Doldentrauben. Behaart.

1. Blbl. schmutzig gelbgrün, violett geadert, schmal, hängend; Schoten $12-13 \mathrm{~mm}$ l, kürzer als der sehr 1. Stiel; St. $15-45 \mathrm{~cm} \mathrm{h.,} \mathrm{Bl.} \mathrm{ganz-}$ randig. - Wald- und Ackerränder in ML. und Noe.; zerstreut. Auch Zierpflanze. $\odot .5$.

H. tristis L.

2. Blbl. lila oder weiß, breit, abstehend; Schote knotig, bis $10 \mathrm{~cm}$ l, viel länger als ihr Stiel; St. $030-1 \mathrm{~m}$ h. - Gemeine Zierpflanze, auch wild und verwildert. $\odot$. 5-7.

H. matronális L.

Variet. $\alpha$. integrifólia Maly. Bl. nur gezähnt, nach oben hin ganzrandig. Waldränder, Hecken, Gebiische; zerstreut. Häufige Zierpf. mit wohlriechenden einfachen (Nachtschatten) und vollen Blumen (Nachtviole). - $\beta$. runcináta (W. Kit.) Unterste $\mathrm{Bl}$ schrotsäge- oder leierförmig, St. drüsig-klebrig. Wälder bei Wien. 
574. Sisỷmbrium L. Rauke $(X V, 1)$.

St. einfach od. ästig, beblättert; Blt. kl., in einfachen, seltener zusammengesetzten Doldentrauben. Meist behaarte unangenehm riechende $\mathrm{Kr}$.

1. Bl. ei- oder länglich-lanzettförmig, gezähnt; St. $0.6-1.3 \mathrm{~m}$ h., oben ästig; Doldentraub. zahlreich, in pyramidaler Rispe, Schoten aufrecht, $5-7.5 \mathrm{~cm} \mathrm{l.} \mathrm{-} \mathrm{Waldränder,} \mathrm{Hecken,} \mathrm{Ufer} \mathrm{in} \mathrm{B.,} \mathrm{Mh.,} \mathrm{Oe.,} \mathrm{St.,} \mathrm{K.,}$ T. 4. 6.7 .

S. strictissinum L.

Bl. zertheilt, wenigstens die meisten.

2.

2. Bl. 2-3 fach fiederschnittig mit schmallineal. od. schmallänglichen Zipfeln; St 0.30-1 $m$ h., Blt. sehr kl., Schoten in 1. Trauben. - Bebauter Boden, Schutt, an Wegen, Mamern. $\odot .5-9 . \quad$ S. Sópkia L.

Bl. schrotsägeförm., leierförmig-fiedertheilig od. fiederschnitt. 3.

3. Unterste Bl. schrotsägeförm., mittlere fiedertheilig, oberste fiederschnittig mit schmallinealen Abschn.; St. 0.3-1 m h., unten steifhaarig; Doldentraub. armbltig, Schoten weit abstehend, entfernt, bis $7 \cdot 5 \mathrm{~cm} \mathrm{l}$. Steinige Hügel, auf Sand in $\mathbf{M h}$. und Noe.; zerstreut. $\odot .5 .6$.

\section{S. Sinapistrum Crtz.}

Alle Bl. schrotsägeförmig-fiederspaltig oder die obersten ganz. 4.

4. Schoten dem St. angedrückt, kegelförmig, $13 \mathrm{~mm} \mathrm{l}$, rauhhaarig in 1. ruthenförmigen Trauben; Blt. sehr kl., St. $30-60 \mathrm{~cm}$ h., ausgespreiztästig. Stinkend. - Schutt, an Mauern, Wegen. $\odot .6-8$.

\section{S. officinale Scop.}

Schoten abstehend, lineal.

5.

5. Schotenstiele ebenso dick, wie d. steifen bis $7.5 \mathrm{~cm} \mathrm{l}$. Schoten, Kelchbl. aufrecht, Blbl. 8-12 $\mathrm{mm}$ l.; St. 0.3-1 $\mathrm{m}$ h. Kurz grauhaarig. - Trockene Hügel, Mauern, Schutt in Mh., Oe., St., K.; zerstreut. -.. 6. 7.

S. Columnae L. $6 \mathrm{~mm} \mathrm{l}$.

Schotenstiele dünner als die Schote, Kelchbl. abstehend, Blbl. 2 bis

6. Blbl. $2 \mathrm{~mm}$, Schote $5 \mathrm{~cm}$ 1., diese fast $8 \mathrm{mal} \mathrm{länger} \mathrm{als} \mathrm{ihr} \mathrm{Stiel,}$ die jungen die Blt. überragend; St. $5-30 \mathrm{~cm} \mathrm{h.;} \mathrm{Blabschnitte} \mathrm{sehr}$ verläugert, spitz, buchtig gezähnt. - Schutt, an Mauern in $\mathbf{S z}$., Noe.; zerstreut. $\odot .5-7$.

S. Irio L.

Blbl. $4 \mathrm{~mm}$ l., Schoten 3-4 mal länger als ihr Stiel, in l. Trauben, die jungen kürzer als d. Blt.; St. $30-60 \mathrm{~cm}$ h.

7. St. und Bltstiele rückwärts steifhaarig, Schoten sammt dem Stiel wagerecht abstehend. - Schutt, Mauern, steinige Hügel in B., Mh., Oe. $\odot$. 6. 7 .

S. Loesélii L.

Kahl; Schoten kurz gestielt, fast aufrecht; Grundbl. 1. gestielt in aufrechtem lockerem Büschel, schrotsägeförmig, obere buchtig gezähnt, länglich-lanzettförmig. - Felsige bebuschte Plätze, Mauern in Mlı., 0e., Kr.; zerstreut. $\odot .5 .6 . \quad S$ austriacum Jequ.

\section{Alliária DC. Knoblauchskraut $(\mathrm{XV}, 1)$.}

St. 030-1 $m$ h., ästig; Bl, einierenförmig, buchtig gezähnt, gerieben nach Knoblauch duftend, untere 1. gestielt. - Schutt, Hecken. Gebüsche $\odot$. 4. 5 . A. officinalis Andrz. 


\section{Bráa Strb. Hppe (X, 1).}

St. einfach, $2 \cdot 5-7 \cdot 5 \mathrm{~cm}$ h., beblättert; Bl. lineal-lanzettlich, ganzrand.; Blt. in Doldentraub., Schot. gerade, aufrecht, 8-10 mm 1. Beharart. Gerölle, Gletschermoränen in K. u. T.; stellenweis. 4. 7.

B. alpina Stb. Hppe.

\section{Conríngia DC. (XV, 1).}

St. 5-50 cm h., beblättert; Bl. elliptisch od. verkehrt-eiförmig, armbltige Doldentraube, Schoten straff, bis $10 \mathrm{~cm}$ 1. Kahle blaugrüne $\mathrm{Kr}$.

1. Schoten 4 kantig mit 1 vervigen Klappen u. kurzein Gr., weit abstehend. - Kalk- u. Thonäcker, zerstreut. ○.5-9. C. orientális P.

2. Schot. 8 kantig mit 3 nervigen Klapp.u. 1. Gr., aufrecht. - Äcker in Noe. (Lechfeld). ○. 5. 6.

C. austriaca P.

\section{Erýsimum L. Hederich $(X V, 1)$.}

St. aufrecht, einfach od. ästig, beblättert, sammt d. spitzen, am Grunde verschmälerten Bl. strieglich behaart; Blt. in einfachen Doldentraub, Schot. lineal, steif, in 1. Trauben.

1. Bltstiele 2-3 mal länger als d. Kelch $u$. halb so 1. als d. weit abstehende Schote; St. $30-60 \mathrm{~cm}$ h., Bl. länglich-lanzettförm. meist geschweift-gezähnt. - Bebaut. Boden, an Wegen, Ufern. ๑. 7-9

\section{E. cheiranthoides L.}

Bltstiele etwa so l., wie d. Kelch, viel kürzer als d. Schote. 2.

2. Blbl. 6-10 $\mathrm{mm}$ l. u. 1-3 $\mathrm{mm}$ br.

Blbl. 12-25 mm l, mit br. verkehrt-eiförm. Platte; Schoten dicker als ihr Stiel.

3. Schot. abstehend, die jüngeren d. Doldentraube überragend. Graugrüne PA.

Schot. aufrecht, Bl. lanzettförm. ; St. 0.3-1 m h., straff, oben ästig. 5 .

4. Bl. lanzettförm., geschweift- od. buchtig gezähnt; St. $15-30 \mathrm{~cm}$ h., abstehend-ästig, Schoten weit abstehend, so dick wie ihr Stiel; Blt. sehr kl. - Wegränder, Ackerraine, Sandbod. in B., Mh., Oe. St.; zerstreut. $\odot .4-6$.

E. repandum L.

Bl. lineal od. lineal-lanzettförm., meist ganzrand., mit zurückgebogener Spitze; St. bis $1 m$ h., Asthl. sehr kl., Schote dünn, bogig, etwas dicker als ihr Stiel. - Ufer, Mauern, trockene Hiigel in Mih. u. Oe.; zerstreut. $\odot$. 6. 7 .

E. canescens Roth.

5. Bl. lanzettförmig, geschweift-gezähnt, grasgrün; Blbl. $10 \mathrm{~mm} \mathrm{1.} \mathrm{-}$ Ufer, Auenwälder in B., Mh., 0e., St.; zerstreut. ๑. 6-7.

E. hieracifólium L.

Bl. lineal-lanzettlicb, ganzrand, od. d. unteren gezähnt, graugrün; Blbl. $6 \mathrm{~mm} \mathrm{1.} \mathrm{-} \mathrm{Dürrer} \mathrm{Sand-} \mathrm{u.} \mathrm{Kallsbod.} \mathrm{in} \mathrm{B.,} \mathrm{Mh.,} \mathrm{Noe.;} \mathrm{zer-}$ streut. $\odot$. 6. 7 . E. virgátum Rth.

6. (2) Blbl. 12-16 $\mathrm{mm}$ l. mit $3-4 \mathrm{~mm}$ br. Platte; Bl. (wenigstens d. unteren) buchtig gezähnt od. fiederspaltig; St. bis $1 m$ h., scharfkantig.

7.

Blbl. 16-25 $\mathrm{mm}$ 1. mit $6-8 \mathrm{~mm}$ br. Platte; St. $5-60 \mathrm{~cm}$ h., Bl. lineal od. lineal-lanzettl., meist ganzrandig; Blt. in dichten gewölbten Doldentrauben. - Gerölle und Felsspalt. d. Alp. (bis 2700 m) 4. 5. 6. (E. Cheiranthus Pers.) E. silvestre Crtz. 
7. Bl. an d. Spitze zurïckgebogen, grundständ. im 1. Jahre in dichtem Büschel, 1. gestielt; Äste, wenn vorhanden, gleich hoch, Schoten weit abstehend. - Steinige Abbänge, Schutt, Wegränd, auf Kalk in B. Noe., St.: zerstreut. ๑. 5. 6.

$E$. crépidifólium Rchb.

Bl. nicht zurückgebogen, St. pyramidalästig, Blt. schwach wohlriechend, Schote bis $7.5 \mathrm{~cm}$ 1. aufrecht-abstehend. - Laubgebuisclie, auf

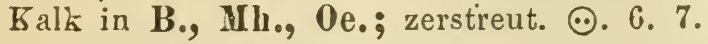

E. pannónicum Crtz.

Variet. carniólic nm (Doll.), Grundbl. buchtig-fiederspalt., Stbl. kamaförmig gezähnt. In Unter-St. u. Kr.

\section{Syrénia Audrz. Fadengriffel $(X \nabla, 1)$.}

Angedrückt behaart, graugrün; St. $30-60 \mathrm{~cm}$ h., oben ästig; Bl. lineal, ganzrandig, Schoten aufrecht, in 1. schmächtigen Trauben. - Auf Sandboden in Noe., stellenweis. $\odot .6-8 . \quad S$. angustifólia Rchb.

\section{Barbaréa R. Br. Barbenkraut (XV, 1).}

St. 30-60 cm h., einfach od. ästig, beblättert; untere Bl. stets leierförmig-fiedertheilig; Doldentraub. vielbltig; Blbl. gelb, Schot. lineal, lang, kurz gestielt, in 1. Trauben. Kahle Kr.

1. Schoten gerade, aufrecht, zahlreich, gedrängt stehend, in schmal. straffen Trauben; Blbl. keilförm., $4 \mathrm{~mm}$ l.; St. $0.6-1 \mathrm{~m} \mathrm{~h}$., straff-ästig; obere Bl. buchtig gezäbnt u. eingeschnitten. - Flussufer, Weidengebüsche in B., Mh., Oe.; zerstreut. ๑. 4-6. B. stricta Andrz.

2. Schot. abstehend, Trauben kurz, rispig gruppiert, Blt. süß duftend, Blbl. $6 \mathrm{~mm}$ l.; oberste Stbl. ausgeschweift u. winklig gezähnt und eingeschnitten. - Feuchte Plätze, Ufer, Äcker, Gräben. ๑. 4-6.

Wilder $\mathrm{R}$ übsen, B. vulgaris R. Br.

Var. arcuáta (R. Br.). Schoten bogig aufwärts gekrümmt, weit ab. stehend. Zerstreut $u$. seltener.

\section{Brássica L. Kohl $(\mathrm{XV}, \mathbf{1})$.}

St. aufrecht, meist ästig, bis $1 m$ h., Grundbl. gr., leierförmig, Blt. gr., Schoten holprig, in 1. lockeren Trauben.

1. Schoten sitzend.

Schoten kurz gestielt; Stbl. fiederspaltig, unregelmäßig stumpf gezähnt, steifhaarig gevimpert, oberste länglich-lineal, ganzrandig, alle unterseits blaugrün; Trauben verlängert, Schot. auf halb so l. Stiel aufrechtrbstehend, kurz geschräbelt. - Auf Äckern in B. (um Leitmeritz und Prag). $\odot$ bis $4.6-9$. $B$. elongáta Ehrh.

2. Schoten der Spindel angedrückt, $13-25 \mathrm{~mm}$ l., kurz geschnäbelt; Blkr. 8-10 $\mathrm{mm}$ br., hellgelb; Grundbl. grasgrün, zerstreut behaart oder kahl, obere länglich bis lineal-lanzettlich, bläulich beduftet, kahl. - Wild im südl. T., an Flussufern, sonst cult. u. verwildert, $\odot$. 6. 7 .

Schwarzer Senf, B. nigra Koch.

Schot. abstehend, $5-7.5 \mathrm{~cm}$ 1., 1. geschnäbelt, Culturpfl.

3. Blt. anfangs in ebener od. concaver Doldentraube, Blkr. 8-12 mm breit, unterste $\mathrm{Bl}$. zerstreut steifhaarig, obere kahl und blauduftig, oberste am Grunde herzförmig.

Blt. vom Anfang an traubig, Blkr. $18 \mathrm{~mm}$ br.; Bl. alle blauduftig. 5 . 
4. Unterste Stbl. u. d. Bl. d. 1. Jahres grasgrün, obere Stbl. blanduftig, Blkr. sattgelb. Schot. mit dünnem pfriemenförm. Schnabel. $\odot$ und ๑. 4. 5 .

B. Rapa L.

Var. $\alpha$. ol eífera. Ölffucht: Rübenraps, Rübsame, R ï bsen; - . rapácea. Wz. fleischig, rübenförmig: Weiße $R$ übe, Wasser-, Stoppel-, Steckrübe, Turnips.

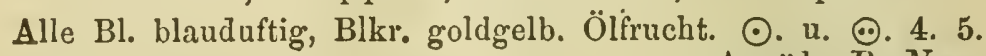
A wöl, B. Napus L. $4-6$.

5. Unterste Bl. anfangs zerstreut behaart; Blkr. gollgelb. ○. u. ๑. $B$. campestris $L$.

Variet. $\alpha$. oleifera. Ölfrucht: Raps, Reps; $-\beta$. Napobrássica. Rübenpfl. Ko hlrübe.

Alle Bl. vom Anfang an kahl, Blkr. schwefelgelb. In zahllosen Varietäten gebaut. $\odot$ u. $\odot .4$. 5 .

Kohl, B. olerácea L.

\section{Sinảpis L. Senf $(X V, 1)$.}

St. aufrecht, ästig, 30-60 $\mathrm{cm}$ h., behlättert, unterwärts steifhaarig; Schot. abstehend.

1. Bl. eiförmig-länglich od. verkehrt-eiförmig, ungleich buchtig gezähnt, unterste geöhrelt od. leierförmig; Schot. stielrund, anfangs perlschnurförmig eingeschnürt, kahl od. kurz behaart, 25-38 $\mathrm{mm}$ l., Klappen 3 nervig. Sehr variierend. - Unkraut auf Äckern, auch auf Wiesen. $\odot$. $6-8$. Ackersenf, Hederich, S. arvensis L.

2. Bl. fiedertheilig od. leierförm., Theilstücke eiförmig od. länglich, gelappt od. gezähnt; Schnabel schwertförmig, länger als d. Fr., sammt d. Klappen 5 nervig, Schot. steifhaarig. - Cult. u. verwildert. ๑. 6. 7. WeiBer Senf, S. alba L.

\section{Erucástrum Presl. Rampe $(\mathrm{XV}, 1)$.}

St. aufrecht, 15-60 $\mathrm{cm}$ h., beblättert; Blt. in einfach. Doldentraube.

1. Bl. kammförmig-fiedertheilig, mit länglichen stumpf gezähnten Stücken; Traube deckbllos, Schot. wagerecht abstehend. - Sand, Äcker, Mauern in Noe., Sz., Kr.; zerstreut, 4. 6. 7. E. oblusángulum Rchb.

2. Bl. buchtig-fiederspaltig mit geschweift-gezähnten bis fiederspalt. Stücken; Trauben mit Deckbl., Schoten ahstehend. - Wie vorige, in

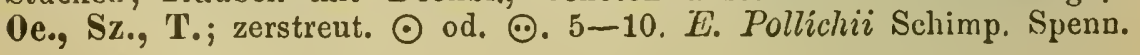

\section{Diplotúxis DC. Doppelsame (XV, 1).}

St. niederliegend od. aufsteigend, Doldentraub. armbltig, Blbl. schwefelgelb, Schoten in 1. schlaffen Trauben, 25-35 $\mathrm{mm}$ 1. Kable od, zerstreut behaarte $\mathrm{Kr}$.

1. St. reich beblättert, ästig, $45-60 \mathrm{~cm} \mathrm{1.;} \mathrm{Bl.} \mathrm{fett,} \mathrm{fiederspalt.} \mathrm{bis}$ fiedertheilig, Theilstücke lineal oder länglich, ganzrand. bis fiederspaltig. Stinkend. - Schutt, an Wegen, Dämmen; zerstreut, 4. 6-9.

\section{D. tenuifólia DC.}

2. St. nackt od. am Grunde mit 1-2 Bl., oft mehrere aus einer Wz., $15-30 \mathrm{~cm}$ h.; Grundbl. rosettenständig, gebuchtet bis buchtig-fiedertheilig. - An Wegen, Mauern in B., Mh., 0e.; stellenweis. $\odot$ od. $\odot$ 5-9. 


\section{Erúca DC. Runke $(X V, 1)$.}

St. $30-60 \mathrm{~cm}$ h., beblättert; Bl. leierförmig-fiedertheilig mit gezăhnten Theilstücken; Doldentrauben armbltig., Schot. aufrecht, angedrückt, $25 \mathrm{~mm}$ l., in schmalen Trauben. Behaart od. kahl, stinkend. - Unkraut in Süd.T. anderwärts verwild. $\odot .5 .6$.

E. sativa DC.

\section{Rảphanus L. Rettich $(X \nabla, 1)$.}

St. ästig, Grundbl. leierförmig, gestielt, obere Stbl. länglich, gezähnt; Schoten l. gestielt, abstebend, in l. Trauben. Zerstreut-haarige od. kahle $\mathrm{Kr}$.

1. Blbl. schmutzig-hellgelb od. weiß, violett geadert, seltener schwefelgelb u. dunkelgelb geadert; Schot. perlschnurförmig eingeschnürt, gefurcht; St. $30-45 \mathrm{~cm}$ h. - Ackerunkraut, häufig auf Haferfeld. ๑. 5-9. Hederich, $R$. Raphanistrum L.

2. Blbl. lila od. hellviolett, dunkler geadert; Schot. länglich, glatt; Wz. knollig, fleischig. - Culturpfl. in vielen Variet. (schwarzer, weißer Rettich, Radieschen u. s. w.) gebaut. $\odot$ und $\odot$. 6-9. R. sativus L.

\section{Rapistrum Boerh. Rapsdotter ( $X V, 2)$.}

St. 30-60 $\mathrm{cm}$ h., ästig; Grundbl. fiedertheilig, mit länglichen eckiggezähnten Theilstücken; IIIt. kl., dottergelb; Schötchen $6 \mathrm{~mm}$ l. in 1 .

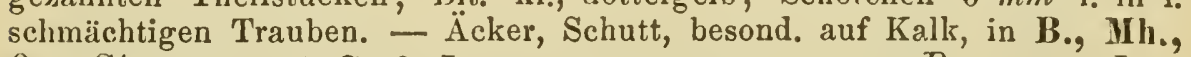
Oe., St.; zerstreut. 4. 6. 7.

R. perenne L.

\section{Crambe L. Meerkohl $(\mathrm{XV}, 2)$.}

St. bis über $1 m$ h., ausgebreitet-ästig; Grundbl. gr., doppelt-fiedertheilig mit gezähnten od. eingeschnittenen Theilstücken. Grün, jung (an d. Bl.) behaart, alt kahl. - Wüste Plätze, Ackerränder in Mh. u. Noe. (eingeschleppt, stellenweis). 4. 4.5.

C. tatária Jcqu.

\section{Búnias L. Zackenschote $(\mathrm{XV}, 2)$.}

St. 15-30 cm h., ästig; Grundbl. l. gestielt, schrotsägeförmig-fiederspaltig, obere Stbl. lanzettlich, buchtig-gezähnt; Schötch. mit rothen Drüsen bestreut, in 1. schlaffen Traub. - Ackerunkraut in Noe., St., T.; eingeschleppt. $\odot$. 5. 6 . B. Erucágo L.

\section{Senebíera Pers. (XV, 2).}

St. niederliegend, ästig, 7-15 cm 1., meist viele, beblättert; Bl. fiedertheilig mit schmallänglichen Theilstïcken; Blt. sehr $\mathrm{kl}$, in end- $u$. achselständ., fast sitzenden Doldenträubchen, Schötchen geknäuelt. - An

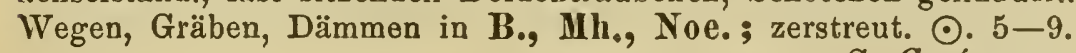

\section{S. Corónopus Poir.}

\section{Peltária L. Scheibenkraut $(X V, 2)$.}

St. $15-60 \mathrm{~cm}$ h., rispig. ästig; Bl. ganzrand. od. ausgeschweift, untere verkehrt-eiförmig-länglich, obere herz-eilanzettlich, sitzend, Kahl, blauduftig. - Bachufer u. Felsspalten in d. Voralp. v. Noe. u. St.; zerstreut. 5. 6 .

$P$. alliácea Is.

\section{2. Ísatis L. Waid (XV, 2).}

St. $0.45-1.30 \mathrm{~m}$ h., doldentraubig-ästig; Bl. ganzrandig, untere länglich, gestielt, obere lanzettl., pfeilförmig-sitzend; Blt. kl, goldgelb 
in schirmförm., zusammengesetzten Doldentraub. Kahl, blauduftig. Sonnige Hügel, Felsen, Mauern auf Kalk in B., Mh., Noe., St., Kr.; auch cult. 2. 5. 6.

I. tinctória L.

\section{Néslia Dest. Ackernïsschen (XV, 2).}

St. 15-60 cm h., ästig; Bl. länglich od. lanzettförm., ganzrand. od. gezälnnt, Grundbl. gestielt, stbl. pfeilförmig-sitzend; Blt. kl., Schötch. l. gestielt, in 1. Traub. Behaart, grün. - Ackerunkraut. ๑. 6. 7.

N. paniculáta Desv.

\section{Fam. XCIII. Resedáceae. Resedacutige.}

\section{Reséda L. Reseda (XII, 3. 6.).}

St. aufieclıt, einfach od. ästig, beblättert; Bl. wechselständig, Blt. lil., in endständ. dichten ährenförm. Trauben.

1. Kelch- u. Blbl. 4, Kapseln aufrecht; Blbl. weiß, fingerig zertheilt, Kaps. verkehrt-eiförmig, kurz, in 1. schmalen 'Trauben; Bl. länglich-lanzettförmig, ganzrandig; St. $0 \cdot 3-1 \cdot 3 \mathrm{~m}$ h. Kahl. Schutt, wüste Plätze. ๑. 7. 8. Wa u, R. Lutéola L.

Kelch- u. Blbl. 6.

2. Blt. wohlriecliend; Blbl. gelblichweiß, 6 fingerig-zerschlitzt, Kaps. verkehrt-eiförmig-länglich, abgestutzt; St. $15-30 \mathrm{~cm}$ h., ästig; Bl. lanzettförm. u. 3 theilig. Kahl. - Zierpf. aus Sỉdeuropa. $\odot$ u. 4. 6-10. G a re $\mathbf{n} \cdot \mathbf{R}$., $R$. odoráta $\mathrm{L}$.

Bit geruchlos. 3.

3. Untere Bl. länglich, ganz od. 2-3 lappig, obere $1-2$ fach fiederschnittig mit länglichen od. lineal, Zipf.; Blt. kl., grünlichgelb, Kaps. länglich-walzig, abgestutzt; St. $15-30 \mathrm{~cm}$ h. - Schutt, Wege, Ufer. ○. 5-10.

R. lítea $\mathrm{L}$.

Bl. ganz od. d. mittlere u. oberen 3 theilig; Blt. wie b. R. odorata, Iíaps. länglich, abgestutzt, Kelch $n$. d. Verblühen sehır vergrößert. Ackerränder, Weinberge in Noe., eingeschleppt. $\odot$. 6-8.

R. Phytéuma L.

\section{Fam. XCIV. Cistineae. Cistusartige.}

\section{Heliánthemum Tourn. Sonnenröschen (XIII, 1).}

Bl. ganz u. ganzrandig, meist gegenständig; Blt. in endständ. einseitswendigen Wickeltrauben. KI. Halbstr. mit liegenden oder aufsteigenden Bltstengeln.

1. Bl. mit Nebenbl., gegenstänđig.

Bl. ohne Nebenbl., Blbl. gelb.

2.

3.

2. Dlbl. gelb, Nebenbl. lineal-lanzettförmig, die oberen fast blartig; Bl. flach, oval bis lineal, bald beiderseits grün, bald unterseits weißfilzig, menr weniger behaart; Blkr. 6-12 $\mathrm{mm}$ br.; Bltst. 10-30 $\mathrm{cm}$ l. Sehr variierend (H. vulgare Gärtn.) - Sonnige Hügel u. Triften, lichte Wälder; zerstreut. Ђ. 6. 7 .

H. Chamaecistus Mill.

Blbl. weiß, Nebenbl. kl., lineal od. pfriemenförm., Bl. lanzettlich, zurückgerollt, sammtartig, weißfilzig, Blkr. bis $25 \mathrm{~mm}$ br. - In Süd-T. Ђ. $6-8$. I. pulverulentum DC var. velútinum (Jord.). 
3. Bl. gegenständ., kl. lineal-längl. od. eiförm., flach; Trauben kurz, Blkr. 8-16 $\mathrm{mm}$ br., blühende St. 7.5-15 $\mathrm{cm} \mathrm{l}$. Rasenbildendes Zwergsträuchlein. - Sonnige steinige Hügel u. Abhänge, besond. auf Kalk. 5. $6-8$.

H. montánum Vis.

Variet $\alpha$. viride Wk. (H alpestre Rchb.) Bl. beiderseits grün, kahl oder gewimpert oder beiderseıts striegelhaarig. Kalkalpen (1260-2600 m.), - $\beta$. incánu m Wk. (H. vineále P.) Bl. unterseits grün- bis weißflzig. Im Hügellande auf Kalk in B.; zerstreut.

Bl. wechselständig, gedrängt, lineal, stachelspitzig; Blt. zu 1-3, sinseitig gestielt, mit Deckbl., Blkr. 14-20 $\mathrm{mm}$ br., Frrstiele zurückgekrümmt. Immergrün - Sonnige Kalkfelsen und Kalkhügel in B., Noe., Kr., T.; zerstreut. h $6-8$. H Fumána Mill.

\section{Fam. XCV Drosericece. Somnenthanartige.}

\section{Drósera L. Sonnenthau $(V, 5)$.}

Bl. grundständ., in Rosette, 1. gestielt, Spreite am Rande und oberscits mit l. gestielten purpurnen klebrigen Drüsen; Bltst. nackt, grundständig mit endständiger einseitiger Wickelähre; Blt. kl., weiß. Zarte in Sumpfmoospolstern wurzelnde, insectenfangende Kräutlein.

1. Blspreite fast kreisrund, Bltschäfte $6-20 \mathrm{~cm} \mathrm{~h}$. - Torfmoore, torfige Wiesen. 4. 6-8.

Blspreite 1. und schmal.

D. rotundifólia L.

2. Bltschaft gerade, aufrecht, $10-20 \mathrm{~cm} \mathrm{l.,} \mathrm{doppelt} \mathrm{so} 1$. als die lineal-keiligen Bl. - Wie vorige; zerstreut, bis in d. Alpen. 4. 6-8.

\section{D. ánglica Huds.}

Bltschaft bogenfïrmig aufsteigend, wenig länger als die verkehrteiförmig-keiligen Bl. - In 0oe., K. (versumptte Seeuter be Villach), selten. $4.6-8$.

D. intermédia Hayne.

\section{Aldrovándia L. $(\mathrm{V}, 5)$.}

Untergctauchte, schwimmende Wasserpfl.; St. fadenförmig, 10 bis $25 \mathrm{~cm}$ l., mit gedrängten Blquirlen; $\mathrm{Bl}$. mit l. gewimp. Stiele und blasiger (als Thierfalle ausgebildeter) Spreite; Blt. achselständig, l. gestielt, weiß. Thierfangende Pf. - In T. (Etschthal). ๑. 7-9. A. vesiculósa L.

\section{Fam. XCVI. Violáceae. Veilchenartige.}

\section{Víola L. Veilchen $(V, 1)$.}

Bl. ganz, seltener zertheilt, grund- od. wechselständ., mit Nebenbl.; Blt. 1. gestielt, grund-, end- oder achselständig. Stengellose oder stengeltreibende $\mathrm{Kr}$., oft mit Ausläufern*).

1. Stengellose Arten mit grundständigen, 1. gestielten Bl. und Blt.; Bltstiel mit 2 linealen Deckblättch.; Wzst. kriechend, oft Ausläufer (bisweilen nur unterirdische) treibend.

*) Etwaiger unterirdischer Ausläufer wegen müssen die perennierenden Veilchen mit d. Wzst. ausgegraben werden. Auch in dieser Gattung kommen zahlreiche Bastardo vor. 
Stengeltreibende Arten, St. beblättert, Blt. achselständig. 12.

2. Bl. handtheilig, Theilstücke fiederspaltig; Blkr. kl., blassviolett. Kahl. - Alpentriften in K., T., Kr.; zerstreut. 4. 6. 7.

V. pinnáta L.

Bl. ganz, gekerbt.

3. Narbe in ein schiefes vertieftes Scheibchen ausgebreitet, Kapsel 3 seitig, Frstiele aufrecht, hakig.

Narbe in ein herabgebogenes Schnäbelchen verschmälert, Kapsel kuglig, Frstiele liegend, gerade.

Narbe kopfförmig, hohl.

$V$. alpina Jcqu. (siehe Nr. 22).

4. Blkr. gr., bis $25 \mathrm{~mm}$ br., lila; Bl. herzeiförmig, mit geflügeltem Stiel. - Sumptivesen in K. u. Kr. (b. Lasbach). 4. 4. 5. V.uliginósa L.

Blkr. kl., 8-12 mm br., hellviolett; Bl. nierenförmig, Stiel ungeAiigelt. - In Torfmoospolstern d. Ebenen und Gebirge; zerstrent. 4. 5. 6. $V$. palustr is $\mathrm{L}$.

5. Grundachse ohne Ausläufer. 6.

Grundachse beblätterte Auslänfer treibend; Blt. wohlriechend. 9.

6. Bltstiele kahl, nach oben 3 kantig, Blt. dunkelviolett, sehr wohlriechend; Bl. eiförmig-länglich, gestutzt oder geschweift in d. Stiel verlaufend, fast kahl, zur Bltezeit röhrig zusammengerollt. - Grasplätze, Waldrander in Noe., auch in B. u. Mh.; zerstrent. 4. 3. 4.

$$
\text { V. ambigua W. Kit. }
$$

Bltstiele rauhhaarig, Bl. behaart.

7. Kapseln kahlı, länglich-eiförmig; Blt. violett mit weißem Schlunde od. blau, wohlriechend; Bl. br. herzeiförmig, zuletzt fast kahl. - Schattige Gebüsche und Laubwälder in 0oe., Sz., T.; zerstreut. 4. 4. 5.

$$
\text { V. sciáphila Koch. }
$$

Kaps. behaart, kuglig; Bl. tief herz-eiförm.; Nebenbl. gefranzt. 8.

8. Nebenbl. spärlich gewimpert, untere ei-, obere lanzettförmig, Franzen kürzer als d. Breite der Nebenbl., kahl; Bl. grasgrün, abstehend kurzhaarig; Blt. geruchlos, $16-24 \mathrm{~mm}$ br., violett, bläulich, weiß. Sehr variabel. - Gebiische, Hecken, Raine. 4. 3-5.

V. hirta L.

Nebenbl. lanzettlich, in eine Haarspitze verschmälert, nebst d. Franzen gewimpert, diese so 1 . wie d. Breite d. Nebenbl.; Bl. graugrün, fein gekerbt, fast kahl; Blt. schwach duftend, kleiner, hellviolett od. lila. Laubgebüsche, Hiigel, auf Kalk in B., IIh., Oe., T.; 4. 3. 4.

$$
\text { V. collina Bers. }
$$

9. (5) Ausläuf. nicht wurzelnd, schon im 1. Jahre mit d. Mutterpt. bliiliend. 10.

Ausl. langgegliedert, wurzelnd, erst im 2. Jahre blühend; Nebenbl. ıanzettlich. 11.

10. Blkr. weiß mit grünlichem Ŝporn, od, das gespornte Blbl. violett gestreift u. d. Sporn violett (V. scotophylla Jord.); Bl. fast 3 eckig-herzförmig mit br. Ausschnitt. Nebenbl. schmal lineal, drüsig gefranzt, Franzen so 1. wie d. Breite d. Nebenbl. - Hecken, Gebüsche, Raine in Noe.g 0oe., St., T., Sw., V., auf Sandstein u. Kalk. 4. 3-5. V. alba Bess.

Blikr. violett, d. gespornte Blbl. ausgerandet; Bl. br. eiförmig, tief herzförm. init br. Ausschnitt, Ausläuferbl. fast nierenförm.; Nebenbl. schmallanzettl., Franzen drüsig, halb so l, wie d. Nebenbl. - Grasplätze in Oe., Sz., K., T.; zerstreut. 4. 4. 5. $V$. austriaca Kern. 
11. Blkr. dunkelviolett, selten lila, rosa od. weiß; Kelchanhängsel br., weit abstehend; Deckblättch. in d. Mitte d. Bltstiels; Bl. rundlich nierenförm. bis herzeiförm. - Grasplätze, Hecken, Wälder; allg. cult. 4. 3-5. März-V., V. odoráta L.

Blkr. himmel- bis kornblumenblau, im Schlunde weiß; Kelchanhängs. kurz, dem Stiel anliegend, dessen Decỉblättch. tief unter dessen Mitte; Bl. rundlich, d. oberen br. herzförm., zur Bltezeit kahl, fettglänzend. Grasgärten, Wiesen, Hecken in B. u. Mh.; zerstreut. 4. 3. 4.

V. cyánea Čelak.

12. (1) Die 2 seitlichen Blbl. wagerecht abstehend od. abwärts ge. richtet, Narbe ein herabgebogenes Schnäbelchen.

13.

Die 2 seitlichen Blbl. zu den oberen emporgekrimmt, Gr. gekniet aufsteigend mit gestutzter od. kopfförmiger Narbe. 20.

13. St. erst nach d. Verblühen d. grundständ. unfruchtbaren Frühlingsblt. hervorbrechend, sammt $d$. Bitstielen 1 reilig behaart, $15-30 \mathrm{~cm}$ h., einfach od. ästig; Bl. br. herzeiförmig, fast ganzrand.; Frühlingsblt. 1. gestielt, wohlriechend, mit gr. blassvioletter Blkr., spätere Blt. achselstänc., kurz gestielt, meist ohne Blkr. - Laubwäld.; zerstreut. 4. 4. 5.

D. mirábilis L.

Blt. end- u. achselständ, einerlei, erst am entwickelten St. erscheinend; dieser sammt d. Bltstielen kahl od. rundum flaumig.

14.

14. Nebenbl. kl, länglich od. lanzettlich, nebst d. Kelchbl. spitz. 15.

Nebenbl. gr., blartig, länglich od. lanzettförm., die d. mittleren Stbl. mindestens länger als d. halbe Blstiel; Bltstiele sehr l., mit 2 Deckblättch. unterhalb d. Blt.; St. aufrecht, aus d. Wzstästen entstehend.

18.

15. Blspreite länger als br., herzeiförmig od. eilänglich mit herzförm. Basis, Nebenbl. d. mittleren Stbl. gezähnt od. gefranzt, Wzstäste in d. St. sich verlängernd; Blt. geruchlos, Blkr. hellazurblau bis lila, selten weiß, Sporn br., zusammengedrückt; Kopf länglich, bespitzt. Kahl od. behaart. - Gebüsche, Wälder. 4. 4. 5.

Hundsveilchen $V$. canina $L$.

Variet. $\alpha$. longifolia Neilr. St. aufrecht, $15-30 \mathrm{~cm}$ h., Bl. gr., viel länger als br., Sporn weißlich (var. lucórum Rchb., V. montana F. Dan.); - $\beta$. brevifoli a. Neilr. Bl. kleiner, oft wenig länger als br., Sporn gelblich, St. liegend (V. ericetórum Schrd., V. flavicornis Sm.)

Blspreite fast so 1. wie br., herzförm.; St. aufsteigend od. aufrecht, sertlich aus einem centralen Blbüschel entspringend.

16.

16. Frkn. u. Kaps. stumpf, filzig; St. zahlreich, bis $7.5 \mathrm{~cm} \mathrm{l.,} \mathrm{Bl.}$ herförmig, rundlich, kl.; Blkr. lila mit weißem Sporn od. ganz weiß, 8-16 $\mathrm{mm}$ br. Kleine vielblütige Rasen bildend. - Auf Sand- u. Kalkboden; zerstreut. 4. 4. 5 .

V. arenária DC.

Frkn. u. Kaps. spitz, kall ; Sporn gefurcht u. am Ende ausgerandet; Nebenbl. pfriemlich-bespitzt, kammförmig gefranzt.

17.

17. Anhängsel d. Kelchbl. kl., verkümmert, Blbl. blauviolett, das unpaarige ausgerandet, die seitlichen am Grunde kurzbärtig, Sporn dunkelviolett, Bl. nieren- bis herzeiförm., fein gekerbt, kabl; St. $15-30 \mathrm{~cm} \mathrm{h.} \mathrm{-}$ Wälder, Gebïsche, Waldwiesen. 4. 4. 5.

V. silvestris Lam.

Willkom m, Schulflora. 
Anhängs. d. Kelchbl. gr., ausgeschnitten, gefurcht; Blbl. hellblau bis weiß, das unpaarige abgerundet, die seitlichen lang-bärtig, Sporn gelblichweiß; Bl. br. herzförm., kurz zugespitzt. - Schattige Laubwälder; zerstrent. 4. 4. 5.

V. Riviniána Rchb.

18. (14) Nebenbl. d. mittleren Stbl. so l. od. länger als der halbe Blstiel; Bl. länglich-lanzettförmig mit gerundeter od. schwach herzförmig. Basis, derb, glänzend; St. aufrecht, $5-25 \mathrm{~cm}$ h., Blkr. milchweiß od. bellblau, 12-18 mm br. - Sumplige Wiesen, Gräben, Teichufer; zerstrent. 4. 5. 6 .

V. stagnina Kit. Blstiel.

Nebenbl. d. mittleren St.bl. so l. od. länger als d. ganze br. geflügelte

19. Bl. lanzettförm. mit keiliger od. abgerundeter Basis, seicht gekerbt, glänzend, $25-38 \mathrm{~mm}$ l., Nebenul. seicht gezäbnt; Blkr. bläilichweiß bis lila, selten weib; St. 7-15 cm h. - Feuchte Wiesen in B., 0e.; zerstreut. 4. 5. 6.

V. primila Chaix.

Bl. lanzettförm., mit meist abgerundeter Basis, gekerbt, $25-75 \mathbf{~ m m}$ lang; Nebenbl. sehr gr., am Grunde eingeschnitten grobgezähnt; Blkr. hellblau, $18-20 \mathrm{~mm}$ br.; St. $15-45 \mathrm{~cm}$ h. (V. persicifolia Schr.). AuenwäJder in B., Blh., 0e.; zerstreut. 4. 5. 6. V. elátior Fr.

20. (12) Narbe verdickt, abgestutzt, vertieft, fast 2 lappig; Blkr. gelb, 12-14 $\mathrm{mm}$ br.; St. zart, aufsteigend, $5-15 \mathrm{~cm}$ 1., einfach od. gabeltheil.; Bl. nierenförm., Nebenbl. kl. - Nasse moosige Plätze, an quellig. Stellen nnd Bächen d. Alpen (1260-2000 m), Sudeten, d. Riesen- u. Isergebirg., d. bühm. Schweiz. 4. 5-8. V. biflóra L.

Narbe kopfförm., hohl, m. seitlich. Öffnung (S t i e f $\mathrm{m}$ ü t t e r ch en). 21.

21. B1. gekerbt.

Bl. ganzrandig, kl., untere eiförmig-rundlich, obere länglich bis lanzettförmig; Nebenbl. gr., spatelförm., ganz od. 2-4 theilig; Blkr. blau, violett od. lila, gr. Kahl, lockere Rasen bildend. - Gerölle u. F $\epsilon$ lsspalten d. Alpen von Süd-T.; zerstreut. 4. 7. 8.

$V$. cenisia $\mathrm{L}$.

22. Stengellos, BI. u. Blt. grundständ., 1. gestielt; Bl. rundlich-eiförmig, gekerbt, kl.; Blt. gr., blau, selten gelb, bis $30 \mathrm{~mm}$ br. - Triften d. Kalkalpen von 0e., St., Kr.; zerstreut. 4. 7. 8. V. alpina Jequ.

Beblätterter St. u. grundständige Bl., Nebenbl. gr., fiederspaltig bis fiedertheilig; Bltstiele 1., blwinkelständig, meist mit $2 \mathrm{kl}$. Deckblättchen unter d. Bltn.

23.

23. Nebenbl. leierfürm., fiederspaltig, mit gr., lanıettförmig. gekerbt. Endstück; Bl. flach gekerbt, untere ei- od. herzförm., obere länglich bis lanzettförm.; Blkr. 4-25 mm br., dreifarbig (violett, gelb u. gelblichweiß) od. 2 farbig (violett n. gelb od. gelb u. weiß) od. einfarbig gelb; St. aufsteigend, 8-30 cm 1. Höchst variabel. - Äcker, Wald wiesen, Schutt. $\odot$ bis 4. 3-10. Gemeines Stiefmü.tt., V. trícolor L.*)

Hauptformen: $\alpha$. arvensis (Murr.). Blkr. sehr kl., gelblichweiß, kiirzer als d. Kelch. Sandäcker; - $\beta$. vulga ris Kocb. Blkr. größer als d. Kelch, violett od. 2-3 farbig. Besond. häufig auf Kleefeld. u. Brachen.

*) Die Gartenstiefmuitterchen od. Pensees sind theils Varietät. von $\nabla$. tricolor a. lutea, theils Bastarde von beiden. 
Nebenbl. fast gleichmäßig fiederspalt. od. fingerförm. vịeltheilig, mit linealen od. länglichen Zipfeln. Ausdauernde Arten mit kriechenden beschuppten Siämmehen.

24. Untere $\mathrm{Bl}$. herzförmig-rundlich od. elliptisch, die anderen länglich bis lanzettförm., alle gekerbt; Blkr. bis $35 \mathrm{~mm}$ br., gelb (selten d. beiden oberen od. alle Blbl. violett); St. aufsteigend, ästig, 4 kantig. -- Wiesen d. Alpen, Sudeten u. d. Riesengeb. 2. 5-7.

V. luitea Sm.

Untere Bl. eiförmig od. länglich, obere lineal-lanzettförmig, alle ausgeschweift-gekerbt; Blkr. 18-25 $\mathrm{mm}$ br., Blbl. blau, mit dunkelviolettem weiß oder gelb punktiertem Fleck am Grunde; St fadenförm., bis $10 \mathrm{~cm}$ lang, meist 1 bltig. - Gerölle u. Felsspalten d. Alpen von Süd•T.; zerstreut. 4. 7. 8.

$V$. heterophýlla Bertol.

\section{Fam. XCVII. Portulacaceae. Portulaliartige.}

\section{Portuláea I. Portulak (XI, 1).}

St. liegend, 8-20 cm 1., ästig; Bl. länglich-keilförmig, dick, wechselständig; Blt. kI. zu $1-3$ in d. Astgabeln u. endständig, gelb, nur bei Sonnenschein offen. - Auf Sandboden hier und da, häuffig cult. (P. sativa Haw.) u. verwildert. $\odot .6-9$.

P. olerácea $\mathrm{I}$.

\section{II 6 tia L. (III, 1).}

St. dicht beblättert; B1. gegenständig, sitzend, verkehrt-eilänglich od. lanzettlich, fleischig, 4-12 $\mathrm{mm} \mathrm{l}$; Blt. kl. weiß, zu $3-5$ blwinkelständig. Saftvolle, dichte kahle Rasen bildende Kr. (M. fontana L.).

1. St. aufrecht, Samen knotig-rauh, glänzend. - Auf feucht. Äckern und Sandplätzen; zerstreut. $\odot .5$.

M. minor Gmel.

2. St. anfsteigend od. flutend; Samen fein punktiert glänzend. In Bächen, Quellen, an quelligen Wiesenstellen; zerstreut. $\odot .5-9$.

\section{M. rivuláris Gmel.}

\section{Fam. XCVIII. Scleraintheae. Fin̈richartige.}

\section{Scleranthus L. Knörich (X, 2).}

St. (meist viele) :istig, $3-20 \mathrm{~cm}$ l.; Bl. gegenständig, sitzend, halbrund-pfriemlich, dicklich, kahl; Blt. kl., grünlich, in lockeren zusammen gesetzten Trugdolden. Vielgestaltige kl. Kräuter.

1. Kelchzipfel abgerundet od. stumpf, br. weißhäutig gerandet, beim Blühen.sternförmig ausgebreitet; Stbg. fast so l. wie d. Kelch. Vielstenglig, kl. dichte Rasen bildend; St. liegend. - Sand- u. Kiesboden, felsige Plätze. 4. 5-9.

S. perennis $\mathrm{L}$.

Kelchzipf. während d. Blühens aufrecht od. schief absteliend; Stbg. kürzer als d. Kelch.

2. Kelchzipfel spitz, an d. Spitze eingerollt, sclımal weißhäutig gerandet; Stbg. viel kiürzer als d. Kelchi: St. aufrecht od. aufsteigend, lockere Rasen bildend. - Äcker, bebaut. Boden. ๑. 5-10. S. ánnuus I.

Kelchzipfel ejlanzettförm., zugespitzt, ab. stumpf, milchweiß gerandet; Stbg. halb so l. als d. Kelch. - Feldränder, trockene Hügel in $\mathbf{B}$. u. anderwärts; zerstreut. $\odot$ bis $4 . \quad S$. intermédius Kitt 


\section{Fam. XCIX. Paronychiáceae. Paronychiaartige.}

\section{Herniária L. Bruchkrant $(\nabla, 1)$.}

St. niedergestreckt, ausgebreitet-ästig, zahlreich, reichlich beblättert, flache Rasen bildend; Bl. kl., ganzrandig, untere gegen-, obere wechselständig, alle mit eiförmig. häutigen Nebenbl.; Blt. kl., in ährenförmig gehäuften Knäueln.

1. St. u. Bl. kahl, letztere lanzettförmig, länglich od. elliptisch; Kelchzipfel kahl, kürzer als d. reife Kapsel. St. $7-30 \mathrm{~cm}$ l. - Sandbod. $\odot$ и. 4. 6-9.

H. glabra L.

2. St. u. Bl. abstehend behaart, Bl. lanzettförmig od. länglich; Kelchzipfel steifhaarig, mit endständ. Borste. Graugrün. - Sandboden in B., Mh., Oe.; zerstreut. $\odot$. od. 4. 7-10.

H. hirsuta L.

\section{Illécebrum L. Knorpelkraut $(\nabla, 1)$.}

Vielstenglig, kahl, rasig; St. niedergestreckt, ästig, wurzelnd, 7.5 bis $15 \mathrm{~cm} \mathrm{l.;} \mathrm{Bl.} \mathrm{gegenständig,} \mathrm{verkehrt-eiförmig,} \mathrm{mit} \mathrm{kl.} \mathrm{weißhäutig.} \mathrm{Nebenbl.;}$ Blt. sehr kl., weiß, in kl., achselständige Quirle bildenden Knäueln. Auf feuchtem Sandboden in Suid-B. u. Noe.; stellenweis. $\odot$. od. ๑. 7. 8.

\section{I. verticillátum L.}

\section{Corrigiola L. Uferkraut $(\mathrm{V}, 3)$.}

St. zahlreich, niederliegend, ästig, 7-30 $\mathrm{cm}$ l., strahlig ausgebreitet; Bl. wechselständig, sitzend, lanzettförmig od. lineal-keilig, mit halbpfeilförmigen häutigen Nebenbl.; Blt. sehr kl., weiß, in kl. Trugdolden. Auf feuchtem sand am Elb- u. Moldauuter in B., Noe., b. Wien an d. Donau, stellenweis. ๑. 7. 8 . C. litorális L.

\section{Spérgula L. Spark (X od. V, 5).}

St. einfach od. ästig, klebrig-flaumig; Bl, gegenständig (wegen der blwinkelständ. jungen Bl. scheinbar quirlständig), pfriemlich, fleischig, mit br. eiförm. häutigen Nebenbl.; Blt. kl., weiß, in endständigen gabeltheil. Trugdolden; Bltstiele lang, nach d. Blühen zuriickgeschlagen.

1. Stbg. meist 10, Samen kuglig-linsenförm., mit schmalem weißem Saum od ohne solchem, schwarz. St. aufrecht od. aufsteigend, $15-45 \mathrm{~cm}$ h., Bl. 13-25 $\mathrm{mm} \mathrm{l}$, unterseits gefurcht. - Sandige Äcker, auch als Futterpflanze gebaut. $\odot$. 6-10.

S. arvensis $\mathrm{L}$.

2. Stbg. meist 5, Samen linsenförm., mit br. weißem Hautsaum; St. $8-25 \mathrm{~cm}$ h., Bl. nicht gefurcht. - Sand́boden; zerstreut. $\odot$. 4. 5 .

S. pentandra $\mathrm{L}$.

Var. Morisónii (Boreau.). Hautsaum braun. In B.; zerstreut.

\section{Spergulária Pers. Salzmiere (X, 3).}

Wie vorige Gattung, aber Nebenbl. weißhäutig, Blt. einzeln oder trugdoldig, Stiele d. Blt. u. Trugdolden nach d. Verblïhen wagerecht abstehend od. zurückgeschlagen. St. liegend od. aufsteigend, Bl. lineal-fädlig.

1. Bl. beiderseits flach, stachelspitzig; Nebenbl. oft zerschlitzt, silberglänzend, BIbl. roth, Samen ohne Hautrand, 3 eckig-birnförm., St. bis $15 \mathrm{~cm}$ lang. - Sandboden, Steinbrïche; Ufer, Wege; zerstreut. $\odot .5-10$.

Sp. rubra P. 
2. Bl. unterseits gewölbt, stumpf; Nebenbl. kaum glänzend, Blbl. weiß, Samen gerundet 3 eckig, feinstachlig-warzig u. ungeflügelt (Sp. marina Beck.) od. am Rande glatt $u$. br. geflügelt (Sp. marginata Kitt., Sp. media Gris.); St. bis $30 \mathrm{~cm}$ l. - Auf salzigen Triften u. Wiesen in B., Hh., Noe.; stellenweis. ๑. u. 4. 5-9.

Sp. salina Presl.

\section{Fam. C. Alsineae. Mierenartige.}

\section{Schliissel der Gattungen.}

1. Kelch u. Blkr. 4 blättrig (b. Saginá apetala d. Blbl. fehlend). 2.

Kelch u. Blkr. 5 blättrig (selten d. Blbl. fehlend), Stbg. 10, selten 5 oder noch weniger.

\%. Stbg. u. Gr. 4, Kaps. 4 klappig (S a gi n a z. Th., 607) od. 8 zähn. Moenchia erecta (615).

Stbg. 8.

3. Gr. 2, Kapsel 4 klappig.

3.

Gr. 3, Kapsel $3 \mathrm{klappig,} \mathrm{Blbl.} \mathrm{bisweilen} \mathrm{fehlend.} \mathrm{Siebera} \mathrm{(610).}$

4. Gr. 3.

Gr. 5.

5.

5. Blbl, ganz, höchst schwach ausgerandet, selten ganz fehlend.

Blbl. gezähıt od. 2 spaltig.

6. Blbl. meist fehlend, selten an ihrer Stelle 5 borstliche Blättclien von der Länge d. Kelches; Kapsel 2 mal länger als der Kelch, bis zur Mitte 3 klappig.

Cherleria (609).

Blbl. stets vorhanden.

7. Kapsel in 3 ganze Klappen zerspaltend, Samen nierenförm.; Stbf. am Grunde mit 2 Drüsen. Alsine (608).

Kapsel mit 3 an d. Spitze 2 spaltigen od. m. 6 Klapp. aufspringd. 8.

8. Kansel sich mit 6 Zähnen öffnend $u$. dann sich in 3 zweispaltig Klappen theilend; Samen ohne Anhang. Arenaria (612).

Kapsel sich bis zur Hälfte od. bis zum Grunde in 6 ganze, sich zurückbiegende Klappen theilend; Samen mit einem Anhängsel.

\section{Moehringia (611).}

9. (5) Blbl, vorn gezähnt, Stbg. meist nur 3-5, Kapsel sich mit 6 Zähnen öffnend und dann im oberen Theil 6 klappig, Samen schildförmig. Holosteum (613).

Blbl. 2 lappig bis 2 theilig, Stbg. 3, 5, 8, 10; Kap. 6 klappig, Samen nierenförmig.

10. (4) Blbl. ganz.

Stellaria (614).

Blbl. 2 lappig od. 2 theilig.

11. Kapseln 5 klappig, B1. kl., grün.

12.

Kaps. röhrig, 5 zähnig, Bl. weißhäutig gerandet. Moenchia (615).

12. Kaps. bis zur Hälfte in 5 zweizähnige Klappen spaltend.

Malachium (615).

Kaps. röhrig, mit 10 auswärts gebogenen Zähnen sich öffnend. 


\section{Sagína L. Mastkraut (IV, 4 und V, X, 5).}

Vielstenglige, lockere Polster od. moosartige Rasen bildende Kräutleiu; Bl. schmallineal od. fadenförmig, Blt. kl., gestielt, achsel- u. endständig, bisweilen trugdoldig.

1. Kelchbl., Bibl., Stbg. u. Gr. 4, Kaps. 4 klappig; St. 3-10 cm. 2.

Kelchbl. u. Blbl. 5, Stbg. 5-10, Gr. 5, Kapsel 5 klappig. 5.

2. Bl. wie d. ganze Pf. kahl; St. liegend od. aufsteigend, Bltstiele 1., verblüht hakig umgebogen, frtragend aufrecht; Blbl. u. Kelchbl. kreuzweis, erstere sehr kl., oft fehlend. - Feuchter Sandboden. 4. 5-10.

S. procumbens L.

Var. tenuifolia Fzl. St. gestreckt, schlaff; in d. Blachseln gr. Büschel langer Bl. In Griiben von Moorwiesen $u$. nassen Sandgräben in $\mathbf{0 e}$.

B1. gewimpert.

3.

3. Bl. bis zur Spitze fein gewimpert, Kelchbl, zur Frzeit kreuzweis ausgebreitet.

4.

Bl. nur am Grunde gewimpert und begrannt, Bl. des Frkelchs aufrecht abstehend, d. beiden äußeren zugespitzt, Blbl. sehr kl.; St. $4 \mathrm{~cm} \mathrm{~h}$. - Brachen und Äcker in Mh. und Noe.; zerstreut. $\odot .6-9$.

S. ciliata Fr.

4. St. aufrecht mit aufsteigenden Ästen, Bltstiele stets aufrecht, Blbl. meist fehlend; Äste kahl oder drüsig-flaumig. - Feuchte Äcker; zerstrent. $\odot$. 5. 6 .

S. apétala L.

St. niedergestreckt od. aufsteigend, Bltstiele nach d. Blühen hakig, später wieder anfrecht; Blbl. viel kürzer als d. Kelch. Moosartige Polster bildend. - Auf feuchtem Boden in 0oe., K., T.; zerstreut. ○. 6. 7.

S. bryoides Froel.

5. (1). Blbl. so 1. oder kürzer als d. Kelch; St. aufsteigend, 2.5 bis $7 \cdot 5 \mathrm{~cm} 1$.

6.

Blbl. doppelt so 1. als d. Kelch; Stbl. viel kürzer als d. grundständ. Bl., mit Buischeln kl. Bl. in d. Achseln; St. 5-15 cm 1., Blt. trugdoldig. Kahl oder drüsig-flamig. - Moorwiesen, sandige Ufer; zerstrent. 4.7. 8.

S. nodósa E. Mey.

6. Bl. begrannt, Bltstiele 1., meist nickend, dann aufrecht, Blbl. so 1. wie d. Kelch; Bltstand und oberer Sttheil drüsig-kurzhaarig. - Sandfelder in B. (um Weißwasser und Niemes gemein). 4. 7. 8 .

\section{S. subuláta Wimm.}

Bl. stachelspitzig, Kelchbl. stumpf, weiß gerandet; Bltstiele nach d. Blühen hakig, später wieder aufrecht, Kapsel eikegelförmig, vorstehend. - Quellige, moosige, steinige Plätze der Alpen, Sudeten, d. Riesen- und Isergebirges u. d. Eöhmerwalds. 4. 7. 8.

S. Linnaei Presl.

Variet. $\alpha$. micrantha Fzl. Blbl. halb so 1. als d. Kelch; Stbg. weniger als $10 ;-\beta$. decandra Fzl. (Spergella macrocarpa Rchb.), Blbl. so 1. wie d. Kelch, Stbg. 10, Kapsel fast 2 mal länger als d. Kelch.

\section{Alsíne L. Miere $(\mathbf{X}, 3)$.}

Grüne, meist vielstenglige Kr. mit lineal. oder lanzettförm. Bl.; Blt. meist in endständ. gabeltheiligen T'rugdolden, selten einzeln, unansehnlich. 
1. St. niedergestreckt mit aufsteigend., dachig beblätterten Astclen, moosartige Rasen bildend; Bl. lanzettlich, spitz, Blt. sehr kurz gestielt, Kelchbl. 5 nervig. - Felsspalten d. Alpen v. Sz.n K., T., Kr。(1900 bis $2530 \mathrm{~m}) .4$. 6. 7.

A. lanceoláta M. Koch.

Exemplare einzeln wachsend od. in lockern Rasen, St. aufrecht od. aufsteigend, Blt. meist in Trugdolden oder Büscheln, selten einzeln; Kelchbl. meist 3 nervig. Arten.

2. Blbl. viel kürzer als d. Kelchbl, diese fein zugespitzt. Einjähr.

Blbl. so lang od. länger als d. Kelch; Wzst. viele Stämmchen trei. bend, rasenbildend.

4.

3. Blt. in lockern gabeltheiligen Trugdolden, 1. gestielt, Kelchbl. gleichlang, 3 nervig; St. 5-15 $\mathrm{cm}$ h., gabelästig; Bl. lineal borstlich. Drüsig-flaumig (A. tenuifolia Crtz. nicht Wahlenb.) - Sandäcker in B., Mh.. Noe.; zerstreut. $\odot .6-8$.

A. viscósa Schreb.

Blt. in endständ. Biischeln, Kelchbl. ungleichlang, weiß mit doppeltem grünem Rückenstreif; St. ästig, 7-30 $\mathrm{cm}$ h.; Bl. pfriemlich-borstlich, 3 nervig, am Grunde gewimpert. Kahl. - Trockener Sand- u. Kalkboden an Eisenbahndämmen in Mh., 0e., St., K.; zerstreut ๑. 7. 8.

A. fasciculáta M. Koch.

4. (2). Blbl. so lang oder etwas länger als d. Kelch.

Blbl. 2-3 mal so l. als d. Kelch; St. $7 \cdot 5-25 \mathrm{~cm} \mathrm{~h}$, Bl, linealpfriemlich.

5. Kelchbl. 1 nervig, weiß mit 2 grünen Rückenstreifen, eilanzettförmig; Blt. in endständ. lockeren Trugdold., 1. gestielt; St. viele, $20 \mathrm{~cm}$ h., Bl. horstlich-pfriemlich, halbrund. - An Kalkfelsen, auf Kalkgerölle in B., Mh., Oe.; zerstreut. 4. 6-8.

A. setácea M. Koch.

Kelchbl. 3-mehrnervig, grün mit weißem Hautrande.

6. Oberer Theil d. PA. drüsenhaarig, Bl. lineal-pfriemlich, halbstielrund, 3 nervig.

Kahl. Bl. nervenlos; Blt. zu 1-2 endständ.; St. aufsteigend, 2.5 bis $5 \mathrm{~cm} \mathrm{l.,} \mathrm{Bl.} \mathrm{schmallineal,} \mathrm{Kelchbl.} \mathrm{lineal,} \mathrm{stumpf.} \mathrm{-} \mathrm{Am} \mathrm{ewigen} \mathrm{Schnee}$ d. Alp. จ. T. 4. 7. 8.

A. biflóra Wahlenb.

7. Bl. d. unfruchtbaren Stämm心hen spaarig zurückgekrümmt u. einseitswendig; Blt. zu 2-3 od. trugdoldig, äußere Kelchbl. $5-7$ nervig, St. $2.5-7.5 \mathrm{~cm} \mathrm{l}$. - Auf Gerölle d. Alp. v. Sz., K., T.; zerstreut. 4 . 7. 8 . A. recurva Wahlenb.

Bl. nicht zurückgekrümmt, Kelchbl. 3 nervig, eilanzettfürmig; Blt. in lockerer Trugdold.; St. 5-20 cm l. hellgrün, drüsig-flaumig, in lockeren Rasen. - Auf Sand- u. Kailkbod. in B.; Hh., Noe., T.; zcrstreut. 4. 6-8.

A. verna Bartl.

Var. Gerárdi (Wahlenb.), St. $5-8 \mathrm{~cm}$ h., $2-3$ bltig: Bl. dach ziegelig, dem St. angedrückt. Dichte dunkelgrüne Polster bildend. Gerölle d. Alp. (bis $2000 \mathrm{~m}$.), auch im Riesengeb. u. Gesenke (selten!).

8. (4). Blbl. verkehrt-eiförmig-keilig, Kelchbl. länglich, stumpf, Blt. zu 1-3 endständ., od. in gabligen Trugdold., Bl. halbstielrund, meist aufwärts gekrümmt. Klebrig-flaumig. - Alpentriften in Oe., St., Kr.,; auch in IIh. (selten!) 4. 7.8. A. láricifólia Wahlenb. 
Blbl. länglich·keilförmıg, ausgeiandet, Kelchbl. spitz. Blte. zu 1-3, endständ., sehr l. gestielt; Bl. Alach. Drïsig-flaumig. - Gerölle, Schutt, Felsen d. Kalkalp. 4. 7. 8.

A. austríaca M. Koch.

\section{Cherléria $\mathbf{L}$. Zwergmiele (X, 3).}

Bl. dicht dachig, länglich, stumpf, $3 \mathrm{~mm} \mathrm{l}$; Blt. einzeln en'ständig, sitzend, kl.; zwischen d. Stbg. ein weißlicher Schuppenkranz. Hellgrüne dichte moosartige Polster bildende PA. - Gerölle u. Felsspalt. d. Alp. $(1900-2550$ m.). 4. 6. 7.

Ch. sedoides $\mathbf{L}$.

\section{Síebera Hoppe. (VIII, 3).}

Bl. länglich-lanzettförm., stachelspitzig, tief rinnig; Blt. einzeln, endständ., sitzend. Kahl, dichte hellgrüne Polster bildend. - Felsspalten u. Gerölle d. Alp. $(1900-2600$ m.). 4. 6. 7. J. cherleioides Hppe.

611. Moehringia L. (VIII, 2 u. X, 3).

St. meist viele, liegend od. aufsteigend, ästig, meist fadenförm.; Bl. 1. gestielt, endständ., zu $1-3$ od. in Trugdolden.

1. Kelch- u. Blbl. 4, Stbg. 8, Gr. 2, Kaps. 4 klappig; St. 5-15 cm 1., Bl. fadenförmig, Blt. l. gestielt, Blbl. kürzer als d. Kelch. Lockere lsahle Rasen bildend. - Fels- u. Mauerspalten, Gerölle in d. Alpenländ., auch in B. u. Mh. (sehr selten!). 4. 6-9.

Kelch- u. Blbl. 5, Stbg. 10, Gr. 3, Kaps. 6 klappig.

M. muscósa L.

2. Bl. (wenigstens d. unteren) ei-od. eilanzettförm., Blt. in lockeren Trugdold., selten zu $1-3$; St. $15-30 \mathrm{~cm} \mathrm{l}$.

Alle Bl. lineal, selten lineal-lanzettlich.

3. Bl. alle ei- od. eilanzettförm., 3 nervig, Blbl. kürzer als d. Kelch. - Feuchter Sand- u. Kiesboden. $\odot$ od. ๑. 5. 6. M. trinervia Choix.

Bl. 1 nervig, untere eiförm., zugespitzt, 1. gestielt, d. übrigen lineallanzetttörm.; Blbl. fast so 1. wie d. Kelch. - Schattige Kalkfels. in Ooe., I.., St., Kr.; zerstreut. -.. 5. 6. MI. diversifolia Doll.

4. St. $25-5 \mathrm{~cm}$ l., in dichten Polstern, Bl. dachig, stumpf; Blt. zu 1-2, endständ., fast sitzend, Blbl. länger als d. Kelch. - Alp. v. T.; zerstreut. 4. 7. 8 .

M. sphagnoides Fröl.

St. 5-15 cm 1. in lockeren Rasen, Blt. zu 1-3 endständ., 1. gestielt. 5.

5. Blbl. kürzer als d. Kelch, Bl. halbstielrund, stachelspitzig, blaugrün. - In T. (Dolomitwände d. Ampezzothales). 4. 7. M. glauca Leyb.

Blbl. länger als d. Kelch.

6. Bl. lineal-lanzettl., spitz, flach; Blkr. 6-8 $\mathrm{mm}$ br., Samen mit becherförm. Hülle. Flaumig. - Alp. v. Ober-Kr.; an Felsen; zerstreut. 2. 7. 8. M. villósa Fzl.

Bi. lineal, Kelchbl. eilanzettförm., stumpf, weißrandig. Kahl 7.

7. Bl. stielrund, stachelspitzig, blaugrün, entfernt; Blkr. $8 \mathrm{~mm}$ br. Samen mit gefranzter Hülle. - Kalkwände in St. u. T.: zerstreut 2. 6. 7. (M. Ponae Fzl.) IM. bavárica L.

Bl. flach, stumpf, grün, gedrängt; Blkr. $6 \mathrm{~mm}$ br., Samen nackt. Triften u. Gerölle d. Alpen. $(1580-2200 \mathrm{~m})$. 4. 7. 8. 


\section{Arenaria $L$. Sandkraut $(X, 3)$.}

St. ästig, Blt. einzeln endständ., od. in endständ. Trugdold. u. Trau. ben, Kelchbl. eilanzettförmig.

1. Blbl. kürzer als d. Kelch. Ein- u. 2-jährige PA. mit dünner Wz. 2.

Blbl. länger als d. Kelch. Ausdauernde unfruchtbare Stämmchen treibende, rasenbildende Pfl.

2. Bl. eiförmig, zugespitzt, sitzend, 4-6 mm 1.; St. gabeltheilig-ästig aufsteigend od. aufrecht, $5-20 \mathrm{~cm}$ 1., Frstiele länger als d. Kelch, Kaps. eiförmig, derbwandig, am Grund bauchig. $\odot$. 5-8. A. serpyllifolia L.

Bl. eiförmig od. länglich, untere kurz gestielt, $2 \mathrm{~mm}$ l.; St. aufrecht, dicht beblättert, $13-25 \mathrm{~cm}$ h.; Frstiele so 1 . od. kürzer als d. Kelch. Dicht kurzhaarig. - Höchste Alp. v. Sz., K.. T.; zerstreut. $\odot$. 7. 8. (A. Marschlinsii Koch.)

A. alpina Gaud.

3. Bl. pfriemlich-lineal, fast stechend, am Rande verdickt, am Grunde gewimpert, mit Blbüscheln in d. Achseln; St. aufsteigend, 5-10 cm h., nebst d. Bltstiel. u. Kelchen drüsig-flaumig; Blt. zu 1-3, l. gestielt. Felsige Plätze in Mh., Noe, u. Krr.; zerstreut. 4. 7. 8:

\section{A. grandiflóra All.}

B1. br., unterseits meist mehrnervig, àm Grunde gewimpert. 4.

4. Bl. ei- od. eilanzettförm. spitz. sitzend: St. liegend od. aufsteigend, bis $10 \mathrm{~cm}$ l., nebst d. Bltstielen flaumig; Blt. einzeln (A. pauciflóra Maly) od. zu 3-9 in Trugdold., Blkr. 8-12 $\mathrm{mm}$ br. - Steinige Triften u. Gerölle der Alpen, besond. auf Kalk $(1900-2550 \mathrm{~m})$. 4.7-9. A. ciliata L.

Bl. länglich, stumpf, kurz gestielt, gedrängt, oft 4 reihig; St. liegend bis $20 \mathrm{~cm} \mathrm{l.,} \mathrm{Blt.} \mathrm{zu} \mathrm{1-2,} \mathrm{kurz} \mathrm{gestielt,} \mathrm{Blkr.} 6 \mathrm{~mm}$ or. - Feuchte, quellige u. felsige Plätze, an Bächen d. Alp. (1900-2550 m). 4. 7. 8. A. biflóra $\mathrm{L}$.

\section{Holósteum L. Spurre (X, 3).}

St. aufrecht, einfach, $5-20 \mathrm{~cm}$ h., oben nackt; Bl. sitzend, ellip. tisch od. lanzettförm., bläulichgrün; Blt. in einfacher Dolde, kI., Bltstiele nach d. Blühen zurückgeschlagen. Klebrig-flaumig. - Bebaut. Bod., Sand, Grasplätze. ๑. 3. 4.

H. umbellátum L.

\section{Stellária 1. Sternmiere $(X, 3)$.}

St. meist ästig, Blt. meist 1. gestielt, einzeln zu $1-2$ od. in endständ. lockeren gabeltheiligen Trugdolden.

1. Wzst. fadenförm., mit zwiebligen Knollen besetzt; St. rund, aufrecht, 8-15 cm h.; Bl. ei- od. elliptisch-lanzettförm, spitz; Blt.l. gestielt zu 1-3, Blkr. $10 \mathrm{~mm}$ br. - In schattigen Eichenwäld. in St., K. u. Kr.; zerstreut. 4. 4. 5 . St. bulbosa Wulf.

Wzst. ohne Knollen, dünn, fasrig od. 1 jährige $\mathrm{Wz}$.

2. St. 4 kantig, Bl. sitzend.

St. rund, untere Bl. gestielt.

3. Blbl. 2 lappig, 1-3 mal länger als d. Kelch; St. aufsteigend, 30 bis $60 \mathrm{~cm}$ h., Bl. lanzett- od. lineal-lanzettförm., l. zugespitzt; Blt. I. gestielt, in lockerer Trugdold., Stiele nach d. Blühen hakig. - Laubgebüsche, Waldränder. 4.5. 6. St. Holóstea L.

Blbl. tief 2 theilig, meist kürzer als d. Kelch 
4. Stengelkanten u. Blränder feinzackig-rauh. Deckbl. kahl, trockenhäutig; Bl. lineal-lanzettförm, spitz; St. liegend, ausgebreitet-ästig, bis $30 \mathrm{~cm}$ 1., Blt. in schlaffer, langzweimimer Trugdolde; Blkr. $6 \mathrm{~mm}$ br. Torfige Waldstellen im siidl. B., 0oe., T.; zcrstreut. 4. 7 .

St. Frieseána Sw.

St. u. Bl. glatt.

5.

5. Deckbl. am Rande gewimpert, trockenhäutig, concav, kl.; Blt. l. gestielt, in rispigen od. traubigen Trugdold., Blkr. $6 \mathrm{~mm}$ br.; St. faden. förm., liegend od. aufsteigend, gespreitzt-ästig, $30-45 \mathrm{~cm}$ l., Bl. lanzettod. lineal-lanzettförm. Kahl. - Wiesen, Hecken. 4. 5-7.

Deckbl. kahl.

St. graminea L.

6. Blbl. kürzer als d. Kelch; Blt. l. gestielt, in lockeren traubigen Trugdold., Bltstiele nach $d$. Verblühen wagerecht od. schief nach unten gerichtet; St. liegend, aufsteigend od. fluthend, bis $30 \mathrm{~cm} \mathrm{l.;} \mathrm{Bl.} \mathrm{elliptisch,}$ lanzettförm. od. länglich, spitz, dicklich. Kahl, blaugrün. - In u. an Bächen, quelligen Waldstellen, auf Sumpfwiesen. 4. 6. 7.

St. uliginósa Moor.

Blbl. 2 mal länger als d. Kelch; St. fadenförm., aufrecht od. aufsteigend, 30-60 cm l.; Bl. lineal od. lineal lanzettlich, spitz; Blt. 1. gestielt, in rispigen lokeren Trugdold., Bltstiele nach d. Blühen weit abstehend. Kahl, blaugrün. (St. glauca With.). - Nasse Wiesen, Ufer. 4. 6. 7.

St. palustris Ehrh.

7. (2) Blbl. 2 lappig.

Blbl. tief 2 theilig.

8.

9.

8. Drüsig u. klebrig-flaumig; St. bis $30 \mathrm{~cm} \mathrm{l}$, untere Bl. keilförmį̧, gestielt, obere lineal-lanzettl., sitzend; Blt. zu 1-2 od. in lockerer Trugdolde, Blkr. 8-10 $\mathrm{mm}$ br. - Auf Sand- u. Thonboden in B., Mh., Noe.; zerstreut. $\odot$. 5. 6.

St. viscida M. Bieb.

Kahl od. d. liegende St. oben 1 reihig bebaart; Äste aufrecht, 5 bis $15 \mathrm{~cm} \mathrm{l.;} \mathrm{Bl.} \mathrm{lineal-lanzettförm.} \mathrm{od.} \mathrm{llänglich;} \mathrm{Blt.} \mathrm{zu} \mathrm{1-2,} \mathrm{Stiele} \mathrm{nach}$ d. Verblühen abwärts gerichtet, Blkr. 12-16 mm br. - An Bächen u. feuchten felsigen Plätzen d. Alp. $(1580-2200 \mathrm{~m})$. 4. 7. 8 .

St. cerastioides L.

9. Blbl. so 1. od. kürzer als d. Kelch, bisweilen fehlend (var. ap ét a la) Stbg. 3, 5 od. 10; Blt. end- u. achselständ,, 1. gestielt, Stiele nach d. Blülıen abwärts gerichtet; St. 1 reihig behaart, liegend od. aufsteigend bis $30 \mathrm{~cm}$ l., Bl. elliptisch od. eiförmig, spitz, kahl. - Gemeines Unkraut ○. $1-12$. Vogelmiere, Hühnerdarm, St. media Vill.

Blbl. 2 mal länger als d. Kelch, Blt. 1. gestielt in lockeren Trug dold., Stiele nach d. Bluilhen wagerecht, Blkr. $18 \mathrm{~mm}$ br.; St. liegend od. aufsteigend, $0.3-1 \mathrm{~m}$ 1.; Bl. ei- od. herzförmig, gewimpert. Fein behaart. Auenwällder, feuchte Waldplätze. 4. 6. 7.

St. némórum L.

\section{Moenchia Ehrh. (IV, 4 u. X, 5).}

St. aufrecht, Bl. u. Kelchbl. weißhäutig gesäumt, Blt. 1. gestielt, end- $\mathrm{u}$. seitenständig. Kahle, blauduftige $\mathrm{Kr}$.

1. Kelch- u. Blbl. 4, Stbg. u. Gr. 4, Kaps. 8 zähnig; St. 3-10 cm l., 1-2 bltig, Bl. lineal-lanzettförm. - Sandbod. in B., Mh., Noe.; zerstreut. $\odot$. 4. 5 . 
2. Kelch- u. Blbl. 5, Stbg. 10, Gr. 5, Kaps. 5zähnig; St. 15-30 $\mathrm{cm}$ h., gabeltheilig, melıbltig; Bl, lanzettlich. - Kräuterreiche Stellen in K.., Kr., 'T.; zerstreut. ๑. 5. 6. II. mántica Bartl.

\section{Maláchium. Tr. Weichkraut $(\mathrm{X}, 5)$.}

St. liegend od. aufsteigend, $0 \cdot 30-1 \mathrm{~m}$ 1.; Bl. ei- od. eilanzettförm., zugespitzt; Blt. gestielt, in lockeren Trugdold.; Blkr. $13 \mathrm{~mm}$ br., länger als d. Kelch. Oberer Theil d. Pfl. drisig- u. klebrig-flaumig. - An Gräben, Sümpfen, in Flussauen. 4. 6-9.

M. aquaticum $\mathrm{Tr}$.

\section{Cerástium L. Horukraut $(X, 5)$.}

St. einfach od, gabeltheilig-ästig, Blt. endståndig, einzeln zu $1-3$ od. in Trugdolden; Kaps. länger als d. Kelch. Behaarte Kr.

1. Blbl. kürzer od. so l. wie d. Kelch.

Blbl. 2 mal länger als d. Kelch.

2. Deck- u. Kelchbl. ganz krautig, dicht, an d. Spitze bärtig-behaart 3.

Deck- $u$. Kelchbl. nur in $d$. Mitte krautig $u$. behaart, fast durchscheinend weißhäutig u. kahl.

3. Dicht $u$. weich behaart, graugrün, Kaps. wenig länger als $d$. Kelch; St. bis $30 \mathrm{~cm} \mathrm{h.,} \mathrm{Bl.} \mathrm{oval} \mathrm{od.} \mathrm{länglich,} \mathrm{Trugdold.} \mathrm{erst} \mathrm{gedrungen,}$ dann ausgebreitet, schlaff. - Grasige, sonnige Hügel, Raine, Waldplätze. $\odot$. 4. 5 .

C. Brachypétalum Desp.

Drüsig.klebrig (C. viscosum L.) od. drüsenlos kurzhaarig, gelbgrün; Kaps. 1-2 mal länger als d. Kelch; St. $3-30 \mathrm{~cm}$ h., Bl, oval od, rundlich, lang gewimpert; Trugdolden knaulförmig, zuletzt schlaff. - Schattige Grasplätze, Ufer, Gräben. $\odot .5-8$.

C. glomerátum Thull.

4. Einjährige Arten ohne unfruchtbare Sprossen; St. $3-15 \mathrm{~cm}$ l., aufsteigend od, aufrecht, nebst d. länglichen od. ovalen Bl. u. d. Bltstielen kurzharig u. meist drüsig-klebrig; Trugdold. gedrungen.

5.

Zweijährige od. ausdauernde Arten mit sterilen Blsprossen; St. aufsteigend, $10-40 \mathrm{~cm}$ l. Ganze Pfl. rauhharig, meist driisenlos.

6.

5. Deck- u. Kelchbl. fast zur Hälfte trockenhäutig, Stbg. meist 5, Frstiele abwärts gebogen. - Auf Sandboden. ๑. $3-5$

\section{C. semidecándrum L.}

Untere Deckbl. krautig, obere sammt d. Kelchbl. schmal häutig.gerandet; Stbg. 10, Frstiele an d. Spitze nickend. Dunkelgrün. - Trockne sandige Triften in Noe. $\odot .4 .5$.

C. obscurum Chaub.

6. BI. länglich-elliptisch, od. lanzettlich,.. Kaps. fast doppelt so 1., wie d. Kelch. Vielgestaltig, rasenbildend. (C. triviále Lk.) - Äcker, IViesen, Raine, Ufer. $\odot$ od. 2!. 5-9.

C. vulgatum L.

Variet. $\beta$. glaudulósum Koch. Bltstiele u. Kelchbl. drüsig·behaart; \% holosteoídes Koch. Bl. u. Kelch fast kahl, St. kahl od. mit 1-2 Reihen von Haaren. Stellenweis; - ס. nemorále Üchtr. Groß, Bl. zart, fast durchscheinend. Auenwälder in B. (Elb- u. Moldauthal.)

Bl. länglich, Kaps. fast 3 nal länger als d. Kelch. - Grasige Gebirgslehnen in Mh. (Gesenke) u. Noe.; zerstreut. 4. 7. 8.

\section{C. macrocarpum Schur.}

7. (1) Weißfilzige od. langwollhaarige Pfl. 8.

Kurzhaarige od. flaumige (selten kahle) gras- od. graugrüne PA 9. 
8. Weißwollig, rasenbildend, St. 5-10 $\mathrm{cm}$ h., 2-3 bltig, Blkr. 18 $m m$ br., Kaps. $1 \mathrm{mal}$ so 1 . als d. Kelch; Bl. länglich-lanzettförm. - Alpentriften in St., K., T. $(2000-2300 \mathrm{~m})$; zerstreut. $4.6-8$.

C. lanátum Lam.

Dicht weißfilzig, St. $3-30 \mathrm{~cm}$ h., Blt. in endständ. Trugdolden, Blkr. $25 \mathrm{~mm}$ br.; Bl. lanzett- od lineal-lanzettförmig. - Zierpfl. aus Südeuropa. 4. 5. 6.

C. tomentósum $\mathrm{L}$.

9. Blt. 1. gestielt, einzeln, end- u. seitenständig; St. kriechend mit aufsteigend. Ästen. Rasenbildende Arten.

10.

Blt. gestielt in gabeltheiligen vielbltigen Trugdolden.

13.

10. Deckbl. fehlend od. den Stbl. ähnlich, nicht häutig-gerandet, Bltstiele 2-vielmal länger als $d$. weißhäutig gerandeten Kelchbl. Blkr. weit beckenförmig, $14-20 \mathrm{~mm}$ br.; St. $3-7.5 \mathrm{~cm}$ h., behaart, drüsig-klebrig; Büschel od. Polster bildend.

Deckbl. den Stbl. unälınlich, weißhäutig gerandet, Bltstiele 1-2 mal länger als $d$. Kelch, nach d. Blühen abstehend-nickend; Kaps. 1 mal länger als d. Kelch.

12.

11. Bl. eiförm.od.eiförm.-ellipt., starr, brüchig, graugrün; Kaps. mehr als doppelt so l. wie d. Kelch, in einen br. Cylinder ausgezogen. - Steinige Triften u. Gerölle d. Alp. v. 00e. u. T. $(1900-2600$ m). 4. 5-7.

C. latifólium $\mathrm{L}$.

B1. eilanzettförmig, biegsam, grün; Kaps. in einen schmalen Cylinder ausgezogen. - Gerölle u. Gletschermoränen in 00e., St., K., T. 4. 5-8. C. uniflórum Mur.

12. Blkr. Alach, radförmig, $14-20 \mathrm{~mm}$ br.; St. $5-15 \mathrm{~cm}$ h., Bl. elliptisch od. lanzettförm., ohne Blbüschel in d. Achseln. - Triften u. steinige Plätze d. Kalkalp. 4. 5-8.

C. alpinum $\mathbf{L}$. irend. 4. 4-9.

Blkr. glockenförmig, Bl. mit Blbüscheln in d. Aclıseln. Sehr vari-

Variet. $\alpha$. hirtum Maly. St. $15-20 \mathrm{~cm}$ h., Bl. lineal od. lanzettlich.

Blkr. 12-16 mm br. Kurzhaarig, graugrïn. Ackerränder, Mauern, Felsen; gemein; - $\beta$. glabrescens Maly (C. suffruticosum L.) St. $3-8 \mathrm{~cm}$ h., Bl. lineal bis ellipt.-lanzettförm., Blkr. bis $25 \mathrm{~mm}$ br. Kahl od. kurzhaarig. Alpen.

13. (9). St. aufsteigend, unten wurzelnd, oben gabeltheilig, 30 bis $60 \mathrm{~cm} \mathrm{l}$, am Grunde kleinblättrige Sprossen treibend, nicht rasenbildend; Sprossen- u. unterste Stbl. gestielt, eiförm. bis ellipt.-lanzettförm., d. übrigen sitzend; Blkr. $13 \mathrm{~mm}$ br. Kurzhaarig, oben meist drüsig. - Feuchte schattige Wäld. in Noe.; zerstreut. 4 od. $\odot .6-8$.

\section{C. silváticum W. Kit.}

St. zahlreich, aufrecht od. aufsteigend, $2-30 \mathrm{~cm} \mathrm{~h}$. Bl. alle sitzend, eiförm., elliptisch bis lanzettförm.; Deck- u. Kelchbl. br. häutig-gerandet, Blkr. 12-20 $\mathrm{mm}$ br.; Bltstiele nach d. Blühen wagrecht od. schief nach unten abstehend. Rasenbildend. - Gerölle, Alpenbäche in $\mathbf{0 e . ,}$ Ii., Kr. 4. 7. 8.

C. carinthíacum Vest. 


\section{Fam. CI. Siléneae. Leimkrautartige.}

1. Gr. 2.

\section{Schlüssel der Gattungen.}

b. Gr. 3.

2.

c. Gr. 5, bisweilen (b. Melandryum) auch 6-8; Blbl. 1. genagelt.

9.

2. Kelch am Grunde mit einem 2- bis vielschuppigem Außenkelch; Kaps. 4 klappig.

Kelch am Grunde ohne Schuppen.

3. Kelch walzig rund, Blbl. 1. genagelt.

4.

Kelcb glockig, 5 kantig, zwischen d. Kanten trockenhäutig; Blbl. nach unten keilig verschmälert.

Tunica (620).

4. Kelch glockig oder pyramidenförmig, 5 spaltig od. 5 zähnig. 5.

Kelch walzig, etwas bauchig, rund, 5 zähnig; Blbl. 1. genagelt, meist mit einem Krönchen am Grunde d. Platte; Kapsel 4 zähnig.

Saponoria (622).

5. Kelch pyramidal, 5 kantig, zuletzt 5 Aliglig; Blbl. 1. genagelt, ohne Krönchen; Kaps. 4 zähnig.

Vaccaria (623).

Kelch glockig, nicht kantig, zwisçhen den Zipfeln weiß-häutig; Blbl. gegen d. Grund allmählich keilig verschmälert, Kaps, tief 4 klappig.

Gypsophila (619).

6. $(1, b)$. Bl. in einen Dorn auslaufend, lineal; Kelch röhrig, Blbl. 1. genagelt, Platte tief 2 theilig, mit Krönchen; Stbg. 5, Kap». mit einem Deckel aufspringend.

Drypis (618).

Bl. unbewehrt, Stbg. 10 .

7.

7. Fr. eine vielsanige Beere, Kelch glockig, 5 spaltig, Blbl. mit 2 spaltiger, allmählich in d. Nagel verschmälerter Platte, ohne Krönchen.

Cucubalus (624).

Fr. eine mit 6 Zähnen aufspringende Kapsel, Blbl. l. genagelt. 8.

8. Platte d. Blbl. ganz od. 2 spaltig, mit od. ohne Krönchen; Kapз. am Grunde unvollständig-3 fächrig; Samen ohne Anhängsel. Silene (625).

b. Ebenso, ab. Kaps. 1 fächrig. Melandryum noctiflorum (627).

c. Platte d. Blbl. getheilt od. 4-5 zïhnig, mit Krönchen, Kapsel 1 fächrig, Samen mit einem strahlenden 4 reihigen Kamme kl. linealer Spreubliittch. umgeben.

Heliosperma (626).

9. $(1, \mathrm{c})$. Blt. 1 geschlechtig ou. zwitterlich, Zwitter- und weibliche Blt., mit bauchigem, männl. mit röhrigem Kelch; Platte d. Blbl, 2 spaltig mit Krönchen; Kaps. 2 fächrig, mit 10 Zähnen aufspringend.

\section{Melandryum (627).}

Blt. alle zwitterlich, Kelch röhrig, 10 rippig, Kaps. mit 5 Zähnen aufspringend.

10.

10. Kelchzipf. blartig, Platte d. Blbl. ausgerandet, mit od. oline Krönchen, Kaps. 1 fächrig.

Agrostemma (629).

Kelchzipf. nicht blartig, Platte der Blbl. ganz od. 2 theilig od. zerschlitzt, mit Krönchen; Kaps. 1 fächrig od. am Grunde unvollständig 5 fächrig.

Lychnis (628). 


\section{Drypis L. Kronenkraut $(\mathrm{X}, 3)$.}

St. viele, aufsteigend, $6-15 \mathrm{~cm}$ h.; Bl. lanzettförmig-pfriemlich, steif; Blt. in gabeltheiliger schirmförm. Trugdolde, kl.; Blbl lila, Stbb. blau. Kahl, rasenbildend. - Steinige Plätze in Süd-Kr. 4. 6. 7.

D. spinosa L.

\section{Gypsóphila L. Gypskraut $(\mathrm{X}, 2)$.}

St. ästig, Bl. schmal, am Grunde verwachsen; Blt. kl., in endständigen gabeltheiligen Trugdolden, selten einzeln, end- und achselständig.

1. Blt. einzeln, l. gestielt, sehr $k 1$., rosenroth; St. $5-15 \mathrm{~cm}$ h., vom Grunde an gabeltheilig-ästig; Bl. lineal. Kahıl. - Feuchte Äcker, Mauern, zerstreut. $\odot .7-9$.

G. murális L.

Blt. in reichbltig. Trugdold., St. oben ästig. Ausdauernde Aren. 2.

2. Wzst. unfruchtbare rasenbildende Stämmchen treibend; Bl. lineal. 3.

Wzst. ohne solche Stämmchen, St. ausgebreitet-ästig, 0.3-1.3 $\mathrm{m}$ h.; Äste und Bltstiele drüsig-flaumig; Blt. weiß.

3. St. 7-15 cm h., Trugdolde locker, Blbl. weiß od, rosenroth, ausgurandet. - Steinige Triften u. Gerölle der Kalkalpen $(1260-1900 \mathrm{~m})$. 4. 7. 8 .

G. repens L.

St. $30-60 \mathrm{~cm}$ h., oberwärts sammt d. Bltstand schmierig-flaumig; Trugdolden biischelig, Blbl. weiß, abgerundet. - Sandfluren, Gypshügel in B., Hl. ; zerstreut. $4.6-8$.

G. fastigiáta L.

4. Kelch becherförmig, mit abgerundeten Zipfeln, Blbl. abgerundet, $13 \mathrm{~mm}$ l.; Bl. lineal lanzettförmig, kahl. - Steinige, sandige Hügel in Ml. u. Noe.; zerstreut. Auch Zierpfl. 4. 6. 7. G. paniculáta L.

Kelch glockig mit spitzen Zipfeln; Blbl. ausgerandet, 6-8 $\mathrm{mm}$ l.; Bl. lanzettlich, kahl. - Anf Sandfeldern in Mh. u. Noe.; stellenweis. 4. 7. 8 .

$G$. acutifulia Fisch.

\section{Túnica Scop. Felsnelke (X, 2).}

St. $10-30 \mathrm{~cm}$ h., rispig-ästig; Bl. lineal-pfriemlich, Blt. l. gestielt, end- und seitenständig, kl.; Blbl. ausgerandet, rosenroth oder lila. Kahl, bläulich grün, rasenbildend. - Trockene Hügel, Uferkies, Felsen in den Alpenländern. 4 . 6-9.

T. Saxifraga Scop.

\section{Dianthus L. Nelke (X, 2).}

St. knotig, Bl. am Grunde in eine Scheide verwachsen, Blt. meist ansehnlicb. Meist kahl.

1. Blt. sehr kurz gestielt in Büscheln oder gedrängtbltigen Trugdolden, von einer Deckblhülle umgeben.

Blt. länger gestielt, einzeln stehend, endständig, seltener zu 2-3 beisammen in lockerer Trugdolde.

2. Bltbüschel 2-3 bltig, von trockenläutigen baucligen Hüllbl. umschlossen; Blkr. kl., lila nder rosa, ausgerandet; St. $15-45 \mathrm{~cm}$ h., Bl.

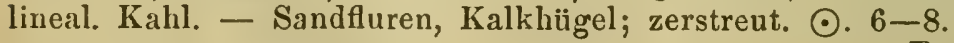

$$
\text { D. prólifer L. }
$$

Hüllbl. u. Anßenkelchschuppen am Rande häutig, sonst krautig od. lederartig, erstere kürzer als die Bltbüschel; Blt. ansehnlich. 
3. Ganze Pfl. flaumig, Bltbüschel 2-10 bltig, end- und seitenständ., Hüllbl. u. Außenkelchschuppen pfriemlich-lanzettförmig, Blbl. hellkarminroth, am Schlunde dunkel punktiert, gezähnelt; St. $30-60 \mathrm{~cm}$ h., Bl. lineal-lanzettlich. - Gebüsche, Waldrïnder; zerstreut. ค. 7. 8.

\section{Arméria L.}

Ganze Pfl, kahl.

4. Bl. lanzett- oder länglich-lanzettförmig, gestielt; Büschel oder Trugdolden vielbltig. gezähnt.

Bl. lineal oder lineal-lanzettlich, ungestielt; Blbl. purpurroth, Platte

5. Bl. lanzettfürmig, spitz, 5-7.5 cm 1. u. 6-12 mm br.; Hüllbl. zurückgebogen, lineal-lanzettlich, Kelchschuppen eiförmig, begrannt, Blkr. rosenroth, 6-8 $\mathrm{mm}$ br., Platte gezähnt, am Schlunde gezeichnet; St. 15 bis $45 \mathrm{~cm}$ h. - Gebirgswälder u. Bergwiesen in Noe., St., K., T., Kr. ; häufige Zierpt. 4. 7. 8. Bartnelke, Karthäusernelke, D. barbatus L.

Bl. länglich-lanzettförmig, stumpf, bis $10 \mathrm{~cm} \mathrm{l}$. u. bis $25 \mathrm{~mm}$ br.; Blt. größer, rosen-, purpurroth oder weiß, oft gefiillt, in convexen Trugdolden. Zierpflanze. 4. 6-8. Karthäusernelke, D. latifolius W.

6. Bltbüschel 2-10 bltig, Platte d. Blbl. so 1. wie d. Nagel; St. 5-15 cm h.; Blkr. 6-20 mm br., dunkel- od. hellroth, selten weiß. Sandboden. 4. 6-8. Wild e Karthäusern., D. Carthusianórum L.

Variet. alpestris Neilr. St. $1-2.5 \mathrm{~cm}$ h., Blkr. 20-24 $\mathrm{mm}$ br. Kalkalpen.

Bltbïschel $12-30$ bltig, Blbl. dunkelroth, Platte halb so l. als der Nagel; St. $15-30 \mathrm{~cm}$ h. (D. atrorubens Kern.) - Grastriften der Alpen von T. 4. 6. 7 .

7. (1). Platte đer Blbl. gezïhnt.

Platte der Blbl. tief gefranzt oder zerschlitzt.

$D$. vaginatus Chaix.

8. Wzst. mit verlängerten, entfernt beblätterten Sprossen; St. 15 bis $30 \mathrm{~cm}$ h., gabeltheilig-vielästig; Bl, dünn, flach, lineal-lanzettlich; Blt. einzeln, Blkr. 13-14 $\mathrm{mm}$ br., Blbl. roth, am Grunde weiß und purpurn gefleckt. - Trockene Wiesen, Raine, Hügel. 4. 6. 7. D. deltoides L.

Wzst. nur Blbiischel treibend.

9. Blt. zu 2-3 gebiischelt, seltener einzeln; St. $15-60 \mathrm{~cm}$ h., einfach oder ästig; Bl. lineal-lanzettlich, rauhgesägt; Blkr. $20-40 \mathrm{~mm}$ br., purpurroth, Platte am Grunde roth punktiert. Kahl. - Bebuschte Hügel, Waldrïnder in B., Mh., Noe., St., T.; zerstr. 4. 6. 7. D. Seguiérii Vill.

Variet. cóllinus (IV. Kit.). St. und Bl. kurz rauhhaarig, Blt. mehr gebüschelt. In Noe.

Blt. einzeln, länger gestielt; B!. lineal, spitz, meist rinnig, dicklich. 10.

10. Außenkelchschuppen so 1. od. länger als d. Kelchröhre, eilanzettförmig, l. zugespitzt; St. einfach, 1 bltig.

Aufenkelchschuppen (meist 4) vielmal kürzer als d. Kelchröhre. 12.

11. Blkr. $38 \mathrm{~mm}$ br., hellpurpurn mit weißgeflecktem Schlundringe; St. 5-10 cm h. - Triften der Kalkalpen von 0e., St., K. 4. 7. 8. D. alpinus $\mathrm{L}$.

Blkr. $16 \mathrm{~mm}$ br., rosenroth, unterseits grünlich; St. $2 \cdot 5-5 \mathrm{~cm}$ h. oder fehlend. - Triften und Gerölle der Granitalpen von St., K., T. $(1900-2600 \mathrm{~m})$. 4. 7. 8.

D. glacialis Hke. 
12. Blbl. rosenroth, am Schlunde mit purpurnem Bart, Blkr. 13 bis $25 \mathrm{~mm}$ br.; St. 7-30 $\mathrm{cm}$ h. viele. Blaugrün, in dichten Rasen. - Felsspalten in B.; zerstreut. 4. 7. 8 .

D. caesius $\mathrm{L}$.

Blbl. olne Bart, St. einfach oder gabeltheilig. 13.

13. Außenkelchschuppen br. eiförmig, begrannt, Blt. geruchlos, Blkr. rosen- od. purpurroth, $25 \mathrm{~mm}$ br.; St. $2 \div-30 \mathrm{~cm}$ h., Bl. hellgrün, rauhrandig. - Steinige Plïtze der südlichen Alpen; zerstrent. 4. 7. 8.

D. inodórus L.

Außenkelchschuppen ei- bis rautenförmig, bespitzt; Blt. wohlriechend่, Blkr. 35-38 $\mathrm{mm}$ br., hellpurpurn; St. 30-60 cm b., Bl. blaugrün (die Stammart der Gartennelken). - Sïdeuropa, auf Manern verwildert. 4. 7. 8 .

D. Caryophýllus L.

14. (7). Platte d. Blbl. fast ganz fingerig zerschlitzt, rosenroth bis weiß; Außenkelchschuppen 4, kurz begrannt; St. $30-45 \mathrm{~cm}$ h., Bl. grasgrün, lineal-lanzettlich. Wollriechend. - Bergwiesen, Gebüsche; zerstreut. 4. oder $\odot$. 7. 8 .

Platte d. Blbl. bis zur Mitte zerschlitzt, Bl. lineal.

D. superbus L.

15. Außenkelchschuppen 4, eiförmig, in eine 1. krautige Spitze verschmälert, halb so 1., wie d. Kelchröhre; Blkr. $18-32 \mathrm{~mm}$ br, hellrosa bis weiß.

16.

Außenkelchschuppen 4, selten 2, kurz zugespitzt, kürzer als die Hälfte der Kelchröhre.

17.

16. St. $30-60 \mathrm{~cm}$ h., ästig, mehrbltig, sammt den schmallinealen, 1. zugespitzten Bl. grasgrün; Blt. zu 2-3 gebüschelt, selten eiuzeln. - Bebuschte Hügel im südlichen St., K., Kr., T.; zerstreut. 4. 6. 7.

\section{D. monspessulánus L.}

St. niedrig, einfach, 1 bltig, sammt d. Bl. blaugrün. - Auf Dolomitsand und Felsen im südl. İ, T. u. Kr. 4. 6. 7. D. Sternbergii Sieb.

17. Außenkelchschuppen $1 / 3$ d. Kelchröhre gleichlang, ziemlich lang zugespitzt; Blt. sehr gr., Blkr. bis $4 \mathrm{~cm}$ br., purpurroth; St. bis $60 \mathrm{~cm}$ h., Bl. lineal-lanzettförmig. Grün. - Bergtriften des Riesengebirges und Gesenkes, auch in Sz., St. u. Kír. 4. 7. 8.

Außenkelchschuppen viel kürzer als d. Kelchröhre, kurz bespitzt. Dichte Polster bildende Pf.

18.

18. Platte d. weißen Blbl. halb so 1. als d. Kelchröhre; St. aufsteigend, bis $25 \mathrm{~cm}$ h., sammt den Bl. grasgrün. - Sandhügel in Noe. u. Kr. 4. $7-11$.

D. serótinus W. Kit.

Platłe der Blbl. so 1. wie d. Kelchröhre; St. aufsteigend. 19.

19. Blt. wohlriechend, $25-38 \mathrm{~mm}$ br., weiß; St. $7-80 \mathrm{~cm}$ h. sammt d. Bl. blaugrün. - Felsige Orte anf Kalk in Ill., Oe., St.; gemeine Zierpflanze. 4. 5. 6. Federnelke, D. plumárius L.

Blbl. geruchlos, $25 \mathrm{~mm}$ br., weiß od. hellpurpurn; St. $10-25 \mathrm{~cm}$ l., sammt d. Bl. grasgrün. - Sandige Kiefernwälder im nördlichen Mh. $\breve{4}$. $7-9$.

$D$. arenárius $\mathrm{L}$.

\section{Saponária $\mathrm{L}$. Seifenkraut (X, 2).} breit.

Blt. in end- u. achselständigen rispig gruppirten Trugdolden; Bl.

1. Kahl, St. $30-60 \mathrm{~cm} \mathrm{h.,} \mathrm{Bl.} \mathrm{elliptisch} \mathrm{bis} \mathrm{länglich-lanzettförm.,}$ Kelch bis $25 \mathrm{~mm}$ l., bleichgrün, Blbl. weiß od. fleischroth. - Flussufer, Wiesen, felsige Abhänge; zerstreut. Auch Zierpt. mit vollen Blumen. 4. 7. 8 . 
2. Kurzhaarig, St. liegend mit aufsteigend. Ästen; Bl. spatel- od. verkehrt-eiförm. bis lanzettlich; Kelch 8-10 $\mathrm{mm}$ l., purpur-, Blbl. hellroth. - Sandhügel in K. u. T. 4. 5-8. S. ocymoides L.

\section{Vaccária Med. Kuhkraut $(\mathrm{X}, 2)$.}

Kabl, blaugrün; St. gabeltheilig, 30-60 cm h., Bl. lanzettförmig; Blt. 1. gestielt in lockerer Trugdolde, Blkr. rosenroth, $12-16 \mathrm{~mm}$ br. Auf Sandfeldern in B., Mh., Oe.; zerstreut. ๑. 7. 8.

\section{V. parviflóra Mnch.}

\section{Cucúbalus L. Taabenkropf $(\mathrm{X}, 3)$.}

Flaumig grasgrün; St. liegend od. kletternd, 1.3-1.6 $m$ h., ausgespreizt-ästig, Bl. länglich-lanzettförm.; Blt. in gabeltheil. Trugdold., Bltbl. hellgrün, Beeren schwarz. - Feuchte Hecken u. Gebuische; sehr zerstreut. 4. 7. 8.

C. báccifer L.

\section{Siléne L. Leimkraut (X, 3).}

Stengeltreibende, selten stengellose Pf. mit am Grunde verwachsene Stbl.

1. a. Blt. einzeln, (selten zu 2-3) endständig.

b. Blt. in einseitswendigen Trauben. Südeuropäische Pfl.

c. Blt. in 3 bltigen od. gabeltheilig-mehrbliatigen Trugdold., welche oft traubig od. rispig gruppiert sind.

2. Stengellose rasenbildende Alpenkräuter; Blt. einzeln in d. Mitte der Blrosetten stehend.

3. $2-3$.

Mit beblättertem einfachem St. begabte Arten; Blt. bisweilen zu

3. Kelch walzig-glockig, 10 nervig, $6 \mathrm{~mm} \mathrm{l.;} \mathrm{Blbl.} \mathrm{rosenroth} \mathrm{(selten}$ weiß), Bl. lineal-p friemlich. Kahl. - Gerölle, Sand, Felsspalten d. Alp. $(1260-2600 \mathrm{~m}$.). 4.6. 7.

S. acaulis $\mathbf{L}$.

Kelch lïnglich-glockig, aufgeblasen $18-20 \mathrm{~mm}$ l., undeutlich 30 nervig; Blbl. gr., Josenroth; Bl. br. lineal. Kahl. - Felsige Plätze d. Granitalp. v. St., K., T.; zerstreut. 4. 6. 7.

S. Pumálio L.

4. Kelch keulenförmig, 9-10 $\mathrm{mm}$ l.; Blbl. 2 lappig, oberseits rosenroth od. weiß, unterseits grünlich, Blt. sehr l. gestielt; St. zahlreich, rasig, 10-15 cm h., Bl. lineal. Kahl. - Steinige Plätze d. Alp. v. St., K., T., Kr. 4. 6. 7.

S. Saxifraga L.

Kelch blasig, netzartig, Blbl. weiß (s. S. inflata Sm. Nö. 7).

5. $(1, b$.$) . Blt. kurz gestielt, in geparrten Trauben, Blbl. weiß mit$ tief 2 theiliger Platte; St. $30-60 \mathrm{~cm}$ h.; Bl. lanzettförmig. Kurz rauhhaarig. - Verwild. auf Äckern in Noe. ๑. 5. 6. S. dichótoma Ehrh.

Blt. in einfachen endständ. Trauben.

6. Blt. kl., Blbl. mit ganzer, gezähnelter od. ausgerandeter Platte, weiB, röthlich, purpurroth; Kelch raulhaarig, drüsig.klebrig; St. 15 bis $45 \mathrm{~cm}$ h., Stbl. lanzettförmig. - Verwild. auf Äckern in Noe., 00e. u* anderwärts. ๑. 6-8.

S. gállzca L.

Blt. gr., purpurroth, zuletzt hängend; St. aufsteigend., bis $30 \mathrm{~cm} \mathrm{l.;}$ Stbl. lanzettförm. bis lineal. - Zierpfl. aus Südeuropa. $\odot ., 5-7$.

S. péndula Desf. 
7. (1, c). Kelch aufgeblasen, häutig, 20 nervig $\mathfrak{u}$. netzadrig, Blbl. weiß mit 2 theiliger Platte; St. meist ästig, $30-60 \mathrm{~cm} \mathrm{l.;} \mathrm{Blt.} \mathrm{elliptisch-}$ lanzettförm. bis lanzettförm., spitz, bläulich bereift. - Wiesen, Raine, Hügel, bis in d. Hochgeb. 4. 5-10.

S. infláta Sm.

Variet. alpina Koch, St. meist einfach, 1 bltig, niedrig; Bl. fast alle grundständ. Alp. in $\mathbf{0 e . , ~ K . , ~ T . ~}$

b. Kelch kegelförmig, aufgeblasen, 20 nervig, nicht netzadrig, hellgrünn; Blbl. rosenroth, "2 lappig; St. $15-30 \mathrm{~cm}$ h., Blt. lauzettlich.

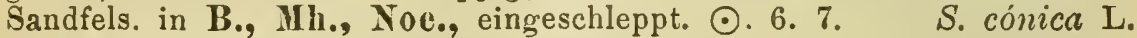

c. Kelch 10 nervig, nicht aufgeblasen.

8. St. gabeltheilig-ästig; Blt. in gabeltheiligen Trugdolảen.

St. nicht gabeltheilig, doch meist ästig; Blt. kurz gestielt, in endu. achselständ., traubig od. rispig gruppierten Trugdolden.

11.

9. Trugdolden arm- (oft nur 3-) bltig, gabelständ. Blte. 1. gestielt; Kelch keulenförm., 10--12 $\mathrm{mm}$ l., Blkr. rosenroth, $8 \mathrm{~mm}$ br.; $\mathrm{St}$. 15 bis $45 \mathrm{~cm}$ h., Bl. lineal-lanzettlich. - Auf Flachsfeldern in Oe.,, eingeschleppt. $\odot$. 6. 7 .

S. linicola Ginel.

Trugdold. reichbltig, convex; Kelch röhrig-keulenförm. Kahle Pf. 10.

10. Blkr. 6 mm br., rosenroth oder milchweiß, Platte d. Blbl. mehr weniger ausgerandet; Trugdold. locker, St. $5-15 \mathrm{~cm}$ h., Bl. lanzettförmig. - Steinige Plätze d. Alp. 4. 7. 8.

S. rupestris L.

Blkr. 8-12 mm br., purpurroth, rosa od. weiß, Platte verkehrt-eiförmig; Trugdold. dicht, schirmförmig; St. 30-60 cm h., oben klebrig, Bl. verkehrt-ei- bis lanzettförmig. - Bebuschte Orte in L., Kr., T.; häufige Zierptl. $\odot$. 7. 8 .

S. Arméria L.

11. (8). Trugdolden traubig und einseitswendig gruppiert, sammt $d$. Spitze des 30-60 cm h. St. nickend; Kelch walzig-keulenförm., Blbl. weiß, unterseits grünlich, 2 theilig; Bl. spatel- bis lanzettförm. Rispe klebrig. drüsig. - Hügel, Raine, Gebüsche. 4. 6. 7.

S. nutans $\mathrm{L}$.

Trugdold. nach allen Seiten gewendet, in schmaler od. ausgebreiteter Rispe; Blbl. weiß, tief 2 theilig, Kelch keulenförmig; St. $30-60 \mathrm{~cm} \mathrm{~h}$.

12. Trugdold. kurz gestielt, Rispe schmal, traubig, Kelch $13 \mathrm{~mm}$ l.; St. meist einfach; Grundbl. verkehrt-ei-lanzettförm., ‡gestielt, Stbl. vieì kleiner, lineal-lanzettlich. - Wiesen u. Gehölze in östlich Noe. ○. 6. 7. S. multiflóra Pers.

Trugdold. 1. gestielt, Rispe ausgebreitet; Kelch 18-20 mm 1.; St. meist ästig, behaart; Grundbl. spatelförm., gestielt, Stbl. länglich od. lanzettförmig. - Gebüsche, besond. auf Kalk in B., Mh., St., Kr.. T. . zerstreut. 4. 6. 7.

S. nemorális W. Kit.

13. $(1, d)$. Blt. ansehnlich, in lockeren genäherten Quirlen; Kelch $13 \mathrm{~mm}$ l., keulenförm., Blbl. weiß, 2 theilig; St. $30-60 \mathrm{~cm}$ h., einfach, stark; Bl. länglich-lanzettförmig. Drüsig-klebrig. - Auf Sand, in Hecke1 in B., Mh., Noe.; stellenweis. $\odot .5$. 6 .

S. viscósa Pers.

Blt. kl., in dichten Quirlen; (untere entfernt); Kelch glockig, 2 bis $4 \mathrm{~mm}$ l., Blbl. grünlichgelb, ganz; St. 30-60 $\mathrm{cm}$ h., Grundbl. in Rosette, spatelförm., Stbl. sehr kl. - Sandbod., Kalkhügel in B., Mh., 0e. 4 . $5-7$. 


\section{Heliospérma Rehb. Strahlensame (X, 3).}

St. zart, gabeltheilig; Grundbl. gestielt, verkehrt-eilanzettförm., Stbl. lineal-lanzettlich; Blt. in endständ. lockerer Trugdolde, l. gestielt, Blbl. weiß. Rasenbildend.

1. Graugrün, klebrig-zottig; Sí. 7-15 $\mathrm{cm}$ h., oft gekniet; Blt. sehr 1. gestielt, Blbl. tief getheilt. (Silene glutinosa Rchb.) - Fels. Orte im südl. St. u. Kr., stellenweis. 4. 7.

H. Vesélskyi Janka.

Kahle Arten, Platte d. Blbl. 4 zähnig od. 4 lappig.

Blkr. 10-12 mm br. (bisweil, röthlich), Kaps. 2 mal länger als d. drïsigflaumige Kelch; St. $15-30 \mathrm{~cm} \mathrm{h.} \mathrm{--} \mathrm{Alpenländer} \mathrm{an} \mathrm{feuchten}$ felsig. Orten. 4. 6-8. $H$. alpestre A. Br.

Blkr. 6-10 mm br., Kaps. so 1. wie d. kahle Kelch; St. $7-15 \mathrm{~cm} \mathrm{~h}$. - Gerölle, Felsen d. Kalkalp. (950-1900 m.). 4. 6-9.

H. quadrifidum A. Br.

Var. pudi búndum (Hoffm.), St. schlaff, hin u. her gebogen, Bl. 1., Blkr. größer. Kalkalp. v. Ooe., selten.

\section{Melándryum Röhl. Nachtnelke (X, 3 u. 5).}

St. einfach od. gabeltheilig, sammt d. Bl. kurzhaarig-zottig; Blt. in gabeltheiligen Trugdolden.

1. Blt. zwitterlich, Kelch 16-20 mm l., zuletzt aufgeblasen, 10 nervig; Blkr. hellrosa od. weiß, Gr. 3 ; St. $10-30 \mathrm{~cm}$ h. Grundbl. spatelig, Stbl. lineal-lanzettlich. Grauzottig u. drüsig-klebrig. Blt. nur bei Nacht geöffnet. - Aus Südeurop. eingeschleppt, auf Äckern in Oe., stellenweis u. unbeständig. $\odot$. 7-10.

M. noctiflórum Fr.

2. Blkr. bis $25 \mathrm{~mm}$ br., weilb, gegen Abend geöffnet; Grundbl. oval bis länglich, Stbl. lanzettförmig. - Bebaut. Boden, Schutt, Hügel. () od. 4. 5-9.

M. pratense Röhl.

Blkr. bis $14 \mathrm{~mm}$ br., hellpurpurn, am Tage geöffnet; Grundbl. spatelig, Stbl. eiförmig od. elliptisch. Zottig behaart. - Ufer, Waldränder, Gebirgswiesen. 4. 5-7.

M. silvestre Röhl.

Var. glabérrimum Maly (Lychnis Preslii Sek.). Kahl, glänzend. In B. (b. Münchengräz).

\section{Lychnis L. Lichtnelke $(X, 5)$.}

St. aufrecht, meist einfach, Blt. in Trugdolden, zwitterlich.

1. Trugdolden wenigbltig, in lockerer pyramidaler Rispe, Blbl. tief zerschlitzt, rosenroth od. purpurn; St. $30-60 \mathrm{~cm}$ h., oft ästig, Bl. lanzettförmig. -- Wiesen. 4. 5-7.

Feuernelke, Kuckucksnelke, L. Flos cúculi L.

Trugdold. vielbltig, in unterbroch. Traube od. endständ. Büschel. 2.

2. Platte d. purpurroth. Blbl. ganz, Trugdold. in unterbrochener Quirltraube; St. einfach, $0 \cdot 30-1 \mathrm{~m}$ h., unter d. oberen Knoten schwarzroth u. klebrig, Bl. lineal-lanzettförm. - Wiesen, Gebüsche, Hügel. 4. $5-7$. Pechnelke, L. Viscáría L.

Platte d. Blbl. 2 lappig; Blt. in einem dicht. endständ. Büschel. 3.

3. St. einfach, 5-10 $\mathrm{cm}$ h., Grundbl. dicht gebüschelt, Stbl. wenige, alle lanzettlich; Blbl. hellpurpurn. Kahl. - Granitalpen von K. und T. $(2000-2850 \mathrm{~m})$. 4. 7. 8 .

L. alpina $\mathrm{L}$. 
St. meist einfach, 30-60 $\mathrm{cm}$ h., sammt d. Bl, behaart. Zierpt. 4.

4. Blkr. hellpurpurn bis karminıoth, Bl. lanzettförmig. Grau, wollfilzig. - Wild in Süd-T. 4. 7. 8. L. Flos Jovis L.

Blkr. feuerroth, Bl. eilanzettförmig. Kurzharig, grün. - Aus den Orient. 4. 7-9. Brennende Liebe, L. chalcedónica L.

\section{Agrostemma L. Rade $(X, 5)$.}

St. aufrecht, oben gabeltheilig, Blt. gr., purpurroth. Behaart.

1. Blbl. ohne Krönchen, Kelchzipfel länger als d. Blkr., Blt. sehr 1. gestielt, einzeln; St. $0.3-1 \mathrm{~m}$ h., Bl. lineal-lanzettförm. - Saaten. $\odot$. 6-9.

A ckerrade, A. Githágo L.

2. Blbl. mit steifem, fast stechendem Krönchen, Kelchzipfel viel kïrzer als d. Blkr.; St. $15-45 \mathrm{~cm}$ h., Blt. einzeln od. in Trugdold., Bl. verkehrteiförmig-länglich bis lanzettförmig. Wolligfilzig. - Zierptl. aus Siideuropa. 4. $6-9$.

Vexiernelke, $A$. coronária L.

\section{F'am. CII. Malváceae. Malrenartige.}

\section{Schliissel der Gattungen.}

1. Viele Stempel in jeder Blte; Spaltfrucht, in einsamige Karpellen zerfallend.

Ein einziger 5 fächriger Frkn. mit 5 unten verwachsenen Gr., Fr. eine 5 fächrige mehrsamige Kaps.; Außenkelch vieltheilig. Hibiscus (634).

2. Stempel und Karpellen kopfförmig zusammengehäuft, Außenkelch 3 blättrig, den Kelch verhüllend. Malope (633).

Stemp. u. Karpellen wirtelförm. um eine Mittelsätule angeordnet. 3. stehend.

3. Außenkelch aus $3 \mathrm{kl}$, dem Kelch angewachsenen Blättchen be-

Außenkelch verwachsenblättrig, 3 spaltig.

Außenkelch verwachsenblättrig, 6-9 spaltig. Malva (632).

Lavatera (630). Althaea (631).

\section{Lavatéra $\mathrm{L}$. (XVI, 4).}

Sternhaarig. Bl. gestielt, handnervig; Blt. l. gestielt, achselständig, in schliften Trauben.

1. Untere Bl. 5-, obere 3 lappig, alle ungleich gekerbt; Bltstiele länger als d. Bl., Außenkelch filzig, Blkr. $5-7 \cdot 5 \mathrm{~cm}$ br., rosenroth; St. 0.6 bis $1 m$ h. - Hügel, Weingärten, Holzschläge in B., Ml., Oe.; zerstreut. 4. 7. 8 .

L. thuringiaca $\mathrm{L}$.

2. Untere Bl. herzförmig-rundlich, obere herzeiförmig, fast 3 lappig, alle gekerbt; Bltstiele kürzer als d. Bl., Außenkelch kahl, netzadrig, Blkr. gr., purpurroth; St. $30-60 \mathrm{~cm} \mathrm{l.} \mathrm{-} \mathrm{Zierpfl.} \mathrm{aus} \mathrm{Südeuropa.} \mathrm{\odot .} \mathrm{6-9.}$ Garten.Lavatere, L. trimestris $L$.

\section{Aithaéa L. Eibisch (XVI, 4).}

Behaart od. filzig. Bl. gestielt-handnervig, Blt. end- u. achselständig. 1. Blt. in achselständigen Biischeln, kurz gestielt, eine gelnäuelte und beblïtterte Traube bildend; St. $0.6-1 m$ b., Bl. 5-3lappig, gekerbt. Sammtartig-graufilzig. 
Blt. einzeln, selten zu 2 an einem Stiele.

2. Bl. u. Blbl. länger als br., Blkr. blassrosa bis weib, 30-40 $\mathrm{mm}$ breit. - Feuchte, besonders salzhaltige Wiesen in B., Mh., Noe.; selten; häufig als Arzneipfl. cult. 4. 7. 8.

A. officinalis $\mathrm{L}$.

Bl. u. Blbl. breiter als lang, Blkr. röther, $25 \mathrm{~mm}$ br., Überzug rauher; Bl. kleiner, tiefer getheilt. - In Noe.; zerstreut. 4. 7. 8.

A. micrantha Wiesb.

3. Außenkelch 8 spaltig, mit lanzettl. spitzen Zipfein, Blkr. 25-38 mm br., Blt. l. gestielt.

Außenkelch 6 spaltig mit eiförm. Zipf.; Blkr. $50 \sim 75 \mathrm{~mm}$ br., Blt. kurz gestielt.

4. Rauhhaarig, untere Bl. schwach 5 lappig, obere handförm. 5 theil., alle gekerbt; Blkr. lila ort. hellrosa, Stbb. gelb; St. 15-45 $\mathrm{cm}$ h. - Auf Kalkboden in Noe.; zerstreut. ๑. 7-9.

A. hivsrita L.

Feinflaumig od. filzig; untere Bl. 5 spaltig, mittlere 5-, obere 3 theil., alle grob gesägt; Blkr. rosenroth, Stbb. purpurn, St. $0.6-1.6 m \mathrm{~h}$. Gräben, Hecken in Noe., stellenweis. 4. 7. 8.

A. cannábina $\mathrm{L}$.

5. St. $0.3-1.3 m$ h., Bl. seicht 5-7 lappig, Blbl. blassrosa oder lila. - An Wegen, Bahndämmen in Noe.; zerstreut. $\odot$ od. $\odot .7-9$.

A. pállida W. Kit.

St. $0.60-2.50 m$ h., Bl. 5-7 eckig, Blbl. rosen- bis purpurroth (in Gärten, meist gefüllt in allen Farben). - Zierpfl, aus Südeuropa, (;) oder 4. $7-10$. Käsepappel, Stockrose, $A$. rósea Cuv.

\section{Malva L. Malve, Pappel (XVI, 4).}

Sternhaarig., Bl. gestielt, handnervig, herzförm. rundlich od. herzeiförmig, Blt. achselständig, Blbl. verkehrt-herzförmig od. ausgerandet.

1. Blt. zu 2-5 gebüschelt, verschieden 1. gestielt; St. liegend bis aufrecht, ästig, $0.3-1 \mathrm{ml}$.

Blt. einzeln, Trauben bildend, St. aufrecht, $0.6-1.3 \mathrm{~m}$ h. 5 .

2. Blkr. $38-50 \mathrm{~mm}$ br, rosa od. hellpurpurn mit dunklen, rothen Streifen; untere Bl. kurz 5lappig, obere handförm. 5 theilig. - Wege,

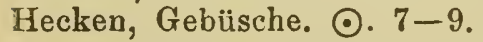
$M$. silvestris L.

Blkr. bis $25 \mathrm{~mm} \mathrm{1.,} \mathrm{lila,} \mathrm{röthlich,} \mathrm{weiß;} \mathrm{Bl.} \mathrm{seicht} \mathrm{gelappt.}$ 3.

3. Bl. wellig gekräuselt, Bltstiele nach d. Blühen aufrecht, Blbl. weiß, noch einmal so l. als d. Kelch. - Aus Südeuropa, hier u. da verwildert. $\odot$. 7. 8.

Krausemalve, M. crispa L.

Bl. eben, ungleich gekerbt; Bltstiele nach d. Blühen wagerecht oder abwärts gerichtet (M. rotundifolia L.).

4.

4. Blbl. 2-3 mal länger als d. Kelch, lila; Karpell. glatt. - Schutt, an Wegen, Hecken. ๑. 7. 8.

M. vulgaris Tr.

Blbl. kaum länger als d. Kelch, weiß od. röthlich, Karpellen netzgrubig. - An ähnlichen Orten, zerstreut u. selten. -.). 7. 8.

II. borealis Wallm.

5. (1) Stbl. herzeiförm., kurz 3-5 lappig, ungleich gekerbt; Blt. lang gestielt, Blkr. $50 \mathrm{~mm}$ br., lila. - Steinige Orte in Kr. u. Süd-T.; zerstreut. 4. 7. 8. IM. Bismalva Brihd.

Stbl. tief handförmig zertheilt. 
6. Blt. moschusduftend, Blkr. $38-50$ mm br., rosa bis weiß, Karpell. glatt, behaart; Abschnitte d. Stbl. 1-2 fach fiederspaltig. Steif rauhhaarig. - Bebuschte Hügel, Hecken in B., Noe., St., K., Kir.; zerstreut, auch cult. u. verwild. 4. 7. 8.

M. moscháta L.

Blt. geruchlos, Blkr. 50-63 mm br., rosenroth, Karz. querrunzlig, kahl; Theilstücke d. Bl. grob gesägt bis fiederspaltig. Filzig-rauhhaarig. - Bebuschte Hügel, Waldränder; zerstreut. 4. 7. 8. M. Álcea L.

\section{Málope L. (XVI, 4).}

St. liegend od. aufsteigend, ästig, 30-60 cm 1., Bl. herzförm.-rundlich, gekerbt, untere seicht gelappt, obere 3 spaltig, Blt. l. gestielt, achsel. ständig, Blkr. $50 \mathrm{~mm}$ br., purpurroth. - Zierpf. aus Südeuropa. ๑. 6-10.

M. trifida Cav.

\section{Hibiscus L. Ibisch (XVI, 4).}

St. liegend od. aufsteigend, $30-60 \mathrm{~cm}$ l., Bl. eingeschnitten gelappt u. gezähnt; Blt. achselständ., Kelch aufgeblasen, Blkr. $38 \mathrm{~mm}$ br., scbwefelgelb, im Grunde purpurbraun. - Bebaut. Boden in Mh., Oe., St., Kr.; zerstreut. $\odot$. 7. 8 .

H. Trionum L.

2. Aufrechter Str. bis $2 m \mathrm{~h} . ; \mathrm{Bl}$. eiförmig-rhombisch, eingeschnitten gekerbt, kahl; Blt. achselständ., Blkr. $7.5 \mathrm{~cm}$ br., weiß od. rosa, am Grunde purpurn gefleckt. - Zierstr. aus d. Orient, in Süd-T. verwildert. ち. 7. 8. H. syriacus L.

\section{Fain. CIII. Tiliciceae. Lindenartige.}

\section{Tília L. Linde (XII, 1 od. XVIII, 1).}

B. mit wechselständigen gestielten $\mathrm{Bl}$., Spreite schief herzförmigrundlich, zugespitzt, gesägt; Blt. in achselständ. Trugdolden, an deren Stiel ein zungenförm. Deckbl. angewachsen ist.

1. Bl. beiderseits grün od. unters. bläulich; Stbg. alle vollkomm. 2.

Bl. unterseits weißfilzig, innere Stbg. blumenblattartig (Staminodien), Trugdold. vielbltig.

2. Bl. unterseits kahl, bläulich, in d. Nervenwinkeln rostbraun-bärtig; Trugdold. vielbltig, Fr. dicht filzig, kaum gerippt, schief verkehrt-eiförmig. (J. parvifolia Ehrh.) - Wälder. Ђ.6. 7.

Winterlinde, T. ulmifolia Scop.

Bl. unterseits (wenigstens an d. Rippen) weichfaumig; Trugdold. 2 bis 5 bltig; Fr. 5 kantig.

3. Bl. scharf u. stachelspitzig gesägt, Fr. kuglig-länglich, dickfilzig (T. grandifolia Ehrh.). - Angepflanzt (d. meisten „Dorflinden“) u. verwild. Ђ. 6. 7 .

Sommerlinde, T. platyphýllos Scop.

Bl. gezähnelt, unterseits meist dicht flaumig bis fast filzig, Fr. kuglig. - Aus Nordamer., cult. Ђ. 6. 7.

T. pubescens Ait.

4. Bl. in d. Nervenwinkeln rostfarben bärtig, am Grunde herzförm. od. abgestutzt; Fr. kuglig, 5 kantig. - Aus Nordam., cult. \$) 7.

T. heterophýlla Vent.

Bl. in 丸. Nervenwink. nicht bärtig, am Grunde herzförmig; Fr. ciförm., stumpflkantig. - Aus Ungarn, cult. Ђ. 7. (T. alba Waldst. Kit.) Silberlinde, T. tomentosa Mönch. 


\section{Fam. CIV. Hypericineae. Hartheuartige.}

\section{Hypéricum L. Harthen (XVIII, 1).}

Bl. gegen-, selten quirlständig, sitzend, ganz u. ganzrandig; Blt. in end-, oft auch achselständ. Trugdolden, Blbl. gelb.

1. Kräuter; Fr. eine 3-5 fächrige u. klappige Kapsel. 2.

Halbstr. mit aufrechten od. aufsteigend. St.; Bl. gr., eiförmig od. läuglich, durchscheinend punktiert; Trugdold. armbltig, Blkr. $18 \mathrm{~mm}$ br.; Fr. eine schwarze Beere. - Gebüsche in Süd-T. 5. 6. 7.

Grundheil, H. Androsaémum L.

2. Kelchzipfel ganzrandig, drüsenlos; Bl. stets gegenständ. Kable Kr.

3.

Kelchzipf. gefranzt od. drüsig gewimpert.

3. St. 4 kantig, stets aufrecht, ästig, $30-60 \mathrm{~cm} \mathrm{~h}$.

4.

St. rund mit 2 gegenüberliegenden herablaufenden Kanten; B1. durchscheinend punktiert.

d. Stkanten geflügelt, Bl. oval, Kelchzipf. lanzettförm., Blkr. 10 bis $20 \mathrm{~mm}$ br. - Ufer, Sümpte, an Gräben; zerstreut. 4. 7. 8.

\section{H. tetrapterum Fr.}

Stkanten nicht geflügelt, Bl. eiförmig bis länglich, am Rande schwarz punktiert; Kelchzipf. lanzettlich, sammt d. 16-24 $\mathrm{mm}$ br., Blkr. schwarz punktiert u. gestrichelt. - Waldwiesen, Gebüsche, Ufer in Gebirgsgegend. 4. 7. 8.

H. quadrángulum $\mathrm{L}$.

5. St. aufrecht, traubig- od. rispig-ästig $15-45 \mathrm{~cm}$ h.; Bl. elliptisch bis lineal, (H. veronense Schrk.), Trugdold. zahlreich in oft pyramidaler Rispe, Blkr. 12-24 $\mathrm{mm}$ br., schwarz punktiert. Sehr variierend. - Hügel, Raine, Triften, die schmalblättr. Form im Süden. 2. 7. 8.

\section{Johanniskraut, $H$. perforátum L.}

St. niedergestreckt, 5-15 cm l., fadenförmig; Bl. oval od. länglich, sammt d. Kelchzipf. am Rande schwarz punktiert; Trugdolden armbltig, Blkr. 10-12 $\mathrm{mm}$ br. - Feuchte Äcker, zerstreut. $\odot$ od. $\odot$. 7. 8.

\section{H. humifúsum $\mathrm{L}$.}

6. (2) St. u. Bl. weichhaarig, Kelchzipf. drüsig gewimpert 7 .

St. (stets aufrecht) u. Bl. kahl 8 .

7. St. aufrecht, $30-60 \mathrm{~cm} \mathrm{h.;} \mathrm{Bl.} \mathrm{elliptisch} \mathrm{bis} \mathrm{lanzettförm.;} \mathrm{Trug.}$ dold. reichbltig, traubig, Blkr. 14-18 $\mathrm{mm}$ br. - Gebüsche, Wälder. 4. $6-8$.

H. hivsiitum L.

St. liegend od. aufsteigend, $10-30 \mathrm{~cm}$ 1.; Bl. genähert, oft sich deckend, eiförmig, rundlich ; 'Trugdold. armbltig, Blkr. 6-8 $m m$ br. Sumpfwiesen u. Torfstiche in 0oe.; zerstreut u. selten. 4. 7. 8.

H. elódes $\mathrm{L}$.

8. Bl. zu 3-4 quirlständig, lineal, umgerollt; Blkr. 14-18 mm br., St. $15-60 \mathrm{~cm} \mathrm{h.} \mathrm{-} \mathrm{Felsige} \mathrm{Orte} \mathrm{in} \mathrm{Siud-T.} \mathrm{4.} \mathrm{7.} \mathrm{8.} \mathrm{H.} \mathrm{Coris} \mathrm{L.}$

Bl. gegenständig, ei- od. lanzettförmig; St. $30-60 \mathrm{~cm}$ h. 9 .

9. Kelchzipfel drüsig gewimpert, lanzettlich, Blkr. 12-13 $\mathrm{mm}$ br., Trugdold. endständig; Bl. am Rande schwarz punktiert, St. oben nackt.Wälder, Gebüsche in Berggegenden. 4. 6. 8. H. montánum L.

Kelchzipf. gefranzt, drïsenlos; Bl. durchscheinend punlstiert, unterseits bläulichgrün, Trugdold. end- u. achselständig. 
10. Kelchzipfl. u. Deckbl. 1. gefranzt, erstere schwarz gefleckt, Franzen weiß, Blkr. $18 \mathrm{~mm}$ br., schwarz punktiert. - Waldwiesen in Noe. u. St.; zerstreut. 4. 5. 6.

H. barbátum L.

Kelchzipf. u. Deckbl. kurz gefranzt mit weißen schwarzspitzigen Franzen; Blkr. ebenso br.; Deckbl., Kelchzipf. u. Blbl. schwarz punktiert. Sonnige Hügel u. Abhänge auf Kalk in B., Mh., Noe.; stellenweis. 4. 6. 7 .

H. élegans Steph.

\section{Fan. CV. Elatineae. Tännelartige.}

637. Elátine L. Tånnel (VIII, 4 od. VI. 3).

St. reich beblättert, Bl. gegen. od. quirlständ., ganzrandig; Blt. kl, einzeln, achselständig. Kahle kl., meist büschelförmig wachsende Sumpf- u. Wasserkr.

1. Bl. quirlständig, untergetauchte zu $8-10$, schmallineal, aufgetauchte zu 3-5, ei- od. eilanzettförmig; Blbl. 4 weiß, Stbg. 8; St. 5 bis $15 \mathrm{~cm} \mathrm{1.} \mathrm{-} \mathrm{Teichränder} \mathrm{in} \mathrm{seichtem} \mathrm{Wasser} \mathrm{in} \mathrm{B.} \mathrm{u.} \mathrm{Noe.;} \mathrm{zerstreut.}$ 7. 7. 8 .

E. Alsinástrum L. fadenförmig.

Bl. gegenständ., St. liegend, an d. Knoten wurzelnd, 1-10 cm I.,

2. Blbl. 4, Stbg. 8, Kaps. 4 spaltig; Bl. elliptisch od. länglich, gestielt. - Teichufer in B., b. Wien; zerstreut. ๑. 6-8. E. Hydrópiper L.

Blbl. 3, Stbg. 6-3, Kaps. 2-3 spaltig; Bl. spatelförmig od. länglich, $2-4 m m l$.

3. Blt. gestielt, Stbg. 6, Kaps. 3 spaltig. -- Teichränd. in B., Noe.

Blt. sitzeud, Stbg. 3, Kaps. 2spaltig. - Wie vorige. ๑. 7. 8.

E. triandra Schk.

\section{Fam. CVI. Tamariscíneae. Tamariskenartige.}

\section{Myricária Desv. (XVI, 3).}

Aufrechter Str. จ. 1-2 $m$ Höhe; Zweige ruthenförmig, Bl. dachziegelig stehend, kl. lineal-lanzettlich. Blaugrün; Blt. kl. hellrosenroth, in oft rispigen Ähren. - Uferkies d. Alpenflüsse bis in d. Ebene hinab. 5. 7.8 .

Deutsche Tamariske, $M$. germánica Desv.

Fam. CVII. Acerineae. Ahomartige.

\section{Acer L. Ahorn (VIII, 1).}

Bl. gegenständ., 1. gestielt, meist handlappir od. theilig; Blt. in endständigen zusammengesetzten Trugdold. od. Trauben. B. u. Str.

1. Blt. in schirmförmigen Trugdolden.

Blt. in Trauben, stets erst nach d. Laubentfaltung erscheinend. 4.

2. Bl. kl. 3 lappig, Lappen ganzrandig; Trugdolden mit d. Lanbausbruch blühend, Flügel d. kl. Fr. aufrecht-abstehend. B. 7-10 $\mathrm{m} \mathrm{h}$. Gebüsche in Süd-T., auch ZiergehöIz. ち. 4. 5. A. monspessulänum L. Bl. handförmig, 5 lappig. 
3. Bl. gr., Lappen durch gerundete Buchten getreunt, spitz u. buchtig spitzgezähnt, Blstiele und junge Sprossen milchend; Trugdolden vor d. Laubausbruch erscheinend; Frflügel gr., ausgebreitet. B. 20-27 $m$ h. Berg- u. Auenwäld., vereinz. 5. 4.5. Spitzahorn, A. platanoides L.

Bl. kl., Lappen durch spitze Winkel getrennt, ganz od. d. 3 mittlern stumpf grobgezähnt; Trugdold. mit d. Bl. erscheinend, Fr sammtig behaart, Flügel gr., wagrecht abstehend, kahl. B. oder Str., Äste (auf dürrem Boden oft mit Korkflügeln). - Gebuische, Laubwälder, Hecken, auch als Ziergehölz cult. Ђ. 5. Feld a horn, Ma Bholder, A. campestre L.

Variet. a ustrícum (Tratt.) Fr. kahl, Bllappen zugespitzt, am Ende abgerundet.

4. (1). Bl. gr., handtheilig, Lappen stumpf, ungleich- und eingeschnitten-gesägt; Tranben reichbltig, hängend, erst nach d. Laubentfaltung blühend; Frelligel aufrecht. B. bis $25 m$ h. - Bergwälder, auch cult. $\hbar$. 5.

Bergahorn, W e i Ber A., A. Pseudoplátanus L.

Bl. kl., herzeiförmig, spitz, am Rande seicht gelappt und ungleich gekerbt-gesägt; Trauben aufrecht, Blbl. weißlich, Frilugel aufrecht, meist roth. B. oder Str. - Ziergehölz aus Suidrussland, in $\mathbf{K} \mathbf{r}_{\text {., }}$ verwildert. $ђ$. 5. 6 .

A. tatáricum $\mathrm{L}$.

\section{Negúndo Much. Eschenahorn (XXII, 4, 5).}

Bl. gegenständig, 1. gestielt, unpaarig gefiedert, Blättch. (3-5) grobgezähnt, Blt. mit d. Laubentfaltung erscheinend, grïnlich oder röthlich, männl. in schlaffen hängenden Trauben, weibl. in Büscheln. Zweihäusiger B. oder Str., in Gärten oft mit weißgescheckten Bl. (Acer Negundo L.). - Ziergehölz aus Nordamerika. Ђ. 4.

$N$. fraxinifólium Nutt.

\section{Fam. CVIII. Hippocastúneae. Rosskastanienartige.}

\section{Aésculus L. Rosskastanie (VII, 1).}

Bl. gr., gegenständ., 1. gestielt, gefingert; Blättchen (7) bis $20 \mathrm{~cm} \mathrm{l}$, gesägt; Blt. in aufrechten, aus Wickeln zusammengesetrten Sträußen, Blbl. weiß mit gelbem oder rothem Fleck. - Zierbaum aus dem Orient. 5. 5 .

G emeine R., A. Hippocástanum $\mathbf{L}$.

Anmerk. Die rothe $\mathrm{Rosskastanie,} A$. rubicunda Lodd. ist ein Bastard von A. Hippocastanum und Pavia rubra Lam. (Aesc. Pavia L.). Die Pavien, nordamerikanische B. haben einen röhrigen $\mathrm{Kelch}$, aufrechte Blbl., gerade Stbg., stachellose Kapsel und 5 zählige kahle Bl. Als Ziergehölze werden cult. P. rubra mit rothen, P. flava DC. mit bleichgelben und P. macrostáchya Mchk. mit weißen Blbl. Letztere blüut erst im 7. und 8 .

\section{Fam. CIX. Polygaláceae. Krenzblümchenartige.}

\section{Polýgala L. Kreuzbiümchen (XVII, 3).}

Bl. meist wechselständig, ganz und ganzrandig; Blt. in endständigen Trauben, seltener achselständig. Seitliche Deckblättchen häutig, gefärbt, bald abfallend. 
1. Kl. immergrüner Halbstrauch; Äste liegend oder aufsteigenă, bis $16 \mathrm{~cm}$ 1.; Bl. länglich-lanzettförmig oder elliptisch; Blt. gr., zu 1-3 achselständig; Flügel gelblichweiß, Blkr. gelb. - Bergwiesen, Heiden, TVälder in B., Mh., 0e., 'T.; zerstreut. 5. 4-6. P. Chamaebrixus L

Var. purpúrea Neilr., Flügel und Blkrröhre purpurn. In Ooe.

Vielstenglige kahle Kräuter; Blt. blau, weiß oder rosenroth. 2.

2. Blt. 12-16 mm l, rosenroth, selten blau oder weiß, in l. Trauben; Blkr. 1., aufwärts gebogen, St. 15-30 $\mathrm{cm}$ h. - Auf Kalkboden in Mh. und Noe. 4. 5. 6.

P. major Jcqu.

Blt. 2-10 mm l., Blkr. gerade oder wenig gebogen.

3. Trauben kurz, $3-8$ bltig, lockør, die endständigen von bltentragenden Seitenzweigen übergipfelt; Blkr. 4-5 $\mathrm{mm}$ l, meist hornblumenblau; untere Bl. gegenständig. - Sumpfwiesen in B.; zerstreut. 4. 5. 6.

$P$. depressa Wender.

Trauben vielbltig, meist 1, endständ.; Bl. abwechselnd od. Grundbl. in Rosette.

4. Untere Bl. nicht größer, höchstens breiter und stets kürzer als d. übrigen, gewölnlich nicht in Rosetten.

Untere Bl. viel größer als d. übrigen, verkehrt-eiförmig, in Rosetten. Kraut bitter.

9.

5. Blt. kl. (ausgewachsene Kelchflügel $4-5 \mathrm{~mm}$ 1.), azurblau in kurzen dichten Trauben; St. 5-10 cm h., Bl. elliptisch. - Triften der Alpen, auf Kalk (bis $1800 \mathrm{~m}$ ). 4. 6.

P. alpestris Rchb.

Blt. ansehnlich (Kelchflügel 5-8 $\mathrm{mm}$ l., elliptisch), zahlreich, in Trauben; Bl. von unten nach oben an Größe zunehmend, unterste verkehrt-eiförmig, oberste lineal-lanzettlich.

6.

6. Deckbl. an d. Spitze d. Traube kürz. als d. Bltknosp.; Blkr. meist blau, selten rosa od. weiß; St. $10-25 \mathrm{~cm}$ h. aufrecht bis nieder-gestreckt. 7 .

Deckbl. länger als d. Bltknospen, daher die meist sehr l. Traube an d. Spitze schopfig; Blkr. purpurn oder rosa, selten blau oder weiß; St. $15-30 \mathrm{~cm}$ 1., meist niedergestreckt und strahlig ausgebreitet. - Grasige bebuschte Hügel, besond. auf Kalk; zerstreut. 4. 5. 6. P. comósa L.

7. Trauben locker, jung spitz; seitliche Deckblättchen der aufgeblüten Blt. kürzer als d. Bltstielchen, Kelchflügel $6 \mathrm{~mm}$ 1, elliptisch-lanzettförmig ; Blumen meist blau, seltener rosa od. weiß. Vielgestaltig, lockere Rasen bildend. - Trockene Wiesen und Grasplätze. 4. 5. 6.

Tausendschönchen, $P$. vulgaris L.

Var. oxýptera (Rchb.). Wzst. dünne unfruchtbare Ausläufer treibend. Flügel länger als dic Kapsel. Zerstreut.

Trauben dichtbltig, vom Anfang an stumpf, abgerundet, br.; Kelchflügel elliptisch, $7-8 \mathrm{~mm}$ l. und bis $6 \mathrm{~mm}$ br. In dichten Rasen wachsend; St. aufrecht oder aufsteigend, gleichhoch.

8. Seitliche Deckbl. $2 \mathrm{~mm}$ l., noch einmal so 1. als d. Bltstielchen; Blume schön azurblau, selten violett, sehr selten weißlich; Blkr. länger als d. Flügel, Kapsel deutlich geflügelt. - Steinige Triften der julischen Alpen in Kr. $(800-1030 \mathrm{~m})$. 4. 6. 7.

$P$. carniólica Kern.

Seitl. Deckbl. so 1. wie d. (sehr kurzen) Bltstielchen; Blume schön rosenroth, seltner blass, Blkr. so 1. wie d. Flügel; Kapsel sehr schmal häutig gerandet. - Auf Kalk- und Dolomitgerölle der Alpen von K., Kr., Süd-T. $(600-1700 \mathrm{~m})$. 6. 7 .

$P$. forojulénsis Kern. 
9. (4). Blt. 5-6 min., l., dunkel- od. blassblau, selten weiblich od. rosenroth, in ährenförmigen spitzen Trauben; St. aufsteigend oder aufrecht, 5-15 cm l. (P. amarella Crtz). - Feuchte moosige Wiesen und Grasplätze auf Kalkuntergrund; zerstreut. 4. 4-8. P. amára L.

Var. rubriflóra Wiesb. Blt. purpurroth, in l. Trauben. In Noe.

Blt. 2-3 $\mathrm{mm}$ 1., weiß oder bläulich, seltener violettblau; St. zarter, bis $8 \mathrm{~cm}$ l. (P. uliginósa Rchb.) - Torfige Sumpfwiesen in B., Mh., 0e.; zerstreut. 4 . 6 .

$P$. austriaca Crtz.

Fam. CX. Staphyleáceae. Pimpermussartige.

643. Staphyléa L. Pimpernuss (V, 2, 3).

Bl. gegenständig, unpaarig gefiedert, Blättchen eiförm. od. elliptisch, fein gesägt; Blt. in hängenden achselständ. Trauben, Kelch-u. Blbl. wei röthlich; Kapsel dünnhäutig, blassgrün. Str. od. kl. B. - Bergwälder in 0e., T., Kr., auch Ziergehölz. Ђ. 5. 6.

St. pinnáta L.

\section{Fam. CXI. Celastrineae. Celasterälnnliche.}

\section{Evónymus L. Spindelbaum (IV, 1).}

Str. mit gegenständigen ganzen zugespitzten feingesägten Bl.; Blt. in gabeltheiligen achselständigen Trugdolden; Kapsel rosen- bis karninroth („Pfaffenhütchen ${ }^{4}$ ).

1. Äste und Zweige mit schwärzlichen Warzen bestreut; Bl. elliptisch bis lanzettlich, Trugdold. 3 bltig, Blbl. grünlich, Kapsel 4 knopfig. - Laubwälder in B. (selten!), Mh., Noe., St., Kr. ந. 5. 6.

Äste und Zweige glatt, Trugdolden vielbltig.

$E$. verrucósa L.

2. Junge Äste 4 kantig, Bl. länglich-lanzettförmig oder elliptisch; Blbl. 4, grünlichweiß, Kaps. 4 knopfig. - Gebüsche, Laubwälder. \$.5.6. E. europaéa L.

Junge Äste zusammengedrückt, Bl. gr., eilanzettförmig; Blbl. 5, grünlichbraun, Kapsel 5 knopfig. - Bergwälder in Oe., St., Kr., T.; zerstreut. Ђ. 5. 6.

E. latifólia Scop.

\section{Fam. CXII. Ilicineae. Hülsenartige.}

645. Ilex L. Huilsen (IV, 4).

Immergrüner Str. oder B. mit lederartigen, eiförm. od. elliptischen, dornig gezähnten, wechselständ. Bl.; Blt. achselständig, kl., weiß in kurz gestielten Doldenträubchen; Beeren erbsengroß, scharlachroth. - Wälder der nördl. Alpenthäler, auch in Kr.; Ziergehölz. 5. 5. 6.

Stechpalme, Stecheiche, I. Aquifólium L.

Fam. CXIII. Ampelídeae. Rebengewüchse.

646. Vitis L. Weinrebe $(V, 1)$.

Bl. handförmig-3-5 lappig, Bltensträuße traubig, seitenständig, Blt. grünlich, Beeren essbar. Kletterst. mit gabeltheiligen Wickelranken. Cult. 5. 7. 8.

We instock, V. viniffera $\mathrm{L}$. 
647. Ampelópsis Mchx. Zaunrebe $(\mathrm{V}, 1)$.

Bl. gefingert-3 zählig, sich im Herbst blutroth färbend; Blt. grünlich, in gabeltheiligen Trugdold.; Beeren kl. blauschwarz, sauer. - Kletterstr. aus Nordamerika, überall cult. Ђ. 7. 8.

Wilder We in, A. quinquefólia Rchb.

Fam. CXIV. Rhámneae. Kreuzdornartige.

Schlüssel der Gattungen.

1. Blt. zwitterlich od. unvollständig-2 häusig od. vielehig, mit 1 Gr. 1-5 Narben, 4-5 spaltigem Kelch, 4--5 (bisweilen fehlenden) Blbl.; beerenförmige Steinfr. mit 1-5 kl. Steinkernen. Rhamnus (648).

2. Blt. zwitterlich mit $2 \mathrm{Gr}$, 5 spaltigem Kelch u. $5 \mathrm{Blbl}$; s saftige pflaumenförmige 2 kernige Steinfr.

Zizyphus (649).

3. Bl. zwitterlich mit $3 \mathrm{Gr}$., scheibenförmige holzige hä口tig gerandete Schließfr., sonst wie vorige.

Paluurus (650).

\section{Rhamuus L. Kreuzdorn, Wegdorn $(\mathrm{V}, 1)$.}

Bl. ganz, gestielt, mit 2 abfallenden Nebenbl.; Blt. kl. in achsel-od. seitenständ. Büscheln od. Trugdolden. Sommergrüne Holzgewächse.

1. Slt. meist 2 häusig, grünlichgelb; Kelchzipf., Blbl. u. Stbg. 4, Gr. mit 2-5 Narben.; Bl. feingesägt.

Blt. zwitterlich, Kelchzipf., Blbl. u. Stbg. 5, Gr. ungetheilt mit kopfiger Narbe; Bl. stets wechselständ., Zweige unbewehrt.

2. Bl. u. Zweige gegenständ., letztere oft dornspitzig.

Bl. u. Zweige wechselständ., letztere stets unbewehrt.

3. Rinne d. Steinkerne (Samen) geschlossen; Bl. eiförmig bis ellipt., $3.8-7.5 \mathrm{~cm}$ l., mit 8-12 $\mathrm{mm}$ l. Stiel; Str. od. kl. B. - Waldränder, trockene Hiigel, Hecken. Ђ. 5. 6. Gem. Kreuzdorn, Rh. cathártica L.

Rinne d. Steinkerne klaffend, Bl. lanzettlich bis ellipt., 13-25 $\mathrm{mm}$ 1., mit 2-4 $\mathrm{mm}$ 1. Stiel; Str. - Sonnige steinige Plätze d. Alpenländ. 万. 5. 6.

Rh. saxátilis Jeqn.

Variet. $\alpha$. erecta Maly (Rh. tinctoria T.) Aufrechter Str. von 1 bis $1.3 m$ Höle, mit schlanken Ästen. In Noe.; $-\beta$. húmilis Maly. Stämmchen 5-80 $\mathrm{cm} \mathrm{l.} \mathrm{mit} \mathrm{niederliegend.} \mathrm{od.} \mathrm{aufsteigend.}$ knorrigen Ästen. In Oe., St., T', Kir.

4. Stämme $1.3-3 \cdot 5 m$ h., aufrecht.

Stämmchen niederliegend, an Felswände fest angeschmiegt, 15-60 $\mathrm{cm}$ l.; Bl. kl., rundlich od. ellipt., jederseits mit 4-6 parallelen Seitennerven. - In Kalkfelsenspalten d. südl. Alpenländ.; zerstrent. Ђ. 5. 6. Rh. puimila L.

5. Bl. ellipt. od. oval, zugespitzt; jederseits mit 10-14 Seitennerven. - Gebüsche d. Al penländ. $\hbar$. 5. 6. Rh. alpina L.

Bl. lanzettförm. mit 16-20 Seitennerven. - Tannenwälder im südl. St., K., Kr. an felsigen Hängen. Ђ. 5. 6. Rh. carniólica Kern.

6. (1) Bl. ganzrandig, oval od. ellipt., spitz; Blt. weißlich, Fr. erst grün, dann roth, reif schwarz. Aufrechter Str. 1'6-3 $m$ h. - Wälder, Gebüsche auf feucbtem Moosboden. 5. 5-9.

Pulverholz, Schiebbeere, Faulbaum, R. Frángula L. 
B1. gekerbt-gesägt, oval od. rundlich, stumpf; Fr. erst roth, dana schwarz. Aufrechter Str. $0.6-2 m$ h. - Steinige Orte in K. u. Kr. 5. 6. 7 . Rh. rupestris Scop.

\section{Zízyphus Tourn. Judendorn (V, 2).}

Zweige ruthenförm., mit paarweisen Dornen (umgewandelten Nebenbl.) j Bl. abwechselnd-2 reihig, gestielt, eilänglich, gekerbt; Blt. sitzend, in achselständ. Knäueln, gelb; Fr. hellroth (Brustbeeren). Str. 1.3-3 $m$ h. Aús Syrien, im südl. Kr. u. T. cult. u. verwild. ち. 6. 7.

\section{Z. vulgaris Lam.}

\section{6õo. Paliúrus Touru. Stechdorn $(V, 3)$.}

Zweige ruthenförmig, hin und hergebogen, mit paarweisen Dornen; Bl. abwechselnd-2 zeilig, gestielt, eifürmig, gekerbt; Blt. grünlichgelb, in achselständigeu Doldentrauben; Fr. kreisrund, braun. - Steinige Plätze im südl. T. u. Kr. b. 6. 7 .

$P$. australis Gärtn.

\section{Fam. CXV. Empétreae Nutt. Krähenbeerartige.}

651. Émpetrum L. Kråhenbeere (XXII, 3).

Immergrünes, niedergestrecktes Sträuchlein mit dicht stehenden linealen 4-6 $\mathrm{mm}$ l., am Rande umgerollten $\mathrm{Bl}$.; Blt. einzeln, blwinkelstïndig, kl., röthlich; Beeren schwarz. - Gebirgs-Torfmoore, bis in die Alpen; zerstreut. Ђ. 5-7.

E. nigruin L.

\section{Fam. CXVI. Buixeae. Buchsbanmartige.}

652. Buxus L. Buchsbaum (XXI, 4).

Immergrüner Str. mit wechselständigen eiförmig-länglichen, oberseits glänzend dunkelgrïnen Bl.; Blt. achselständig, geknäuelt, grünlich-gelb. Aufrechter Str. 1-3 $m$ h. (B. arborescens Lam.) oder aufsteigend. Kleinstrauch von 0.6-1 $m$ Höhe (B. suffruticosa Lam.). - Wild od. verwild. auf Kalkhügeln in Ooe., Kr., T., stellenweis; Zwergform allgem, cult. Ђ. 3. 4 .

$B$. sempervirens $\mathrm{L}$.

\section{Fam. CXVII. Euphorbiáceae. Wolfsmilchartige.}

\section{Euphorbia L. Wolfsmilch (XXI, 1).}

Blt. in meist quirlstïndigen, von einem Kreise von Deckbl. umringten Trugdolden, deren Strahlen gewölnnlich wiederholt gabeltheilig und an den Gabeltheilungen mit gegenständigen Deckbl. besetzt sind. $\mathrm{Kr}$. mit weißem scharfem Milchsaft; Bl. ganz, meist wechselständig.

1. Blthïlldrüsen queroval od. 3 eckig (nur selten einzelne halbmondförmige darunter gemischt.)

Blthülldrüsen halbmondförmig oder 2 hörnig.

2. Ein oder 2 jährige Arten mit dünner Wz.

Ausdauernde Arten mit Wzst. 2.

3. Kapseln glatt, Samen bienenzellig; St. $5-30 \mathrm{~cm}$ h., Bl. spatelförmig, vorn fein gesägt; Trugdold. $4-5$ strahlig, Äste wiederholt 3 gabliğ oder erst 3-, dann 2 gablig; Hüllchenbl. gelb. - Unkraut u. Schuttpflanze. $\odot .4-9$. Hundsmilch, E. Helioscópia L. 
Kapsel warzig, Trugdold. $3-5$ strahlig, Strahlen 2 gablig; Hüllchenbl. eirautenförmig sammt den $\mathrm{Bl}$. feingesägt; Bl. kahl od. unterseits behaart, untere gestielt, verkehrt-eiförmig-länglich, die übrigen sitzend, lanzettlich.

4. Stbl. am Grunde verschmälert, St. $15-30 \mathrm{~cm}$ h., Warzen halbkuglig. - An Wegen, Gräben, auf bebautem Boden; zerstreut. $\odot$ oder ค.) 6. 7.

E. plathyphýlla L.

Var. literáta (Jacqu.) Bl. unterseits dicht zottig, die zuerst entwickelten oft mit einem purpurnen Eleck. In 0oe.

Stbl. am Grunde schmal herzförmig; St. straff, $30-45 \mathrm{~cm}$ h.; Warzen kurz walzig. - Bebuschte Ufer, waldige Orte in Mh. u. 0e.; zerstreut. $\odot$ oder $\odot$. 6. 7 . E. stricta L.

5. (2). Wzst. wagerecht kriechend; Trugdold. 5 strahlig, Strahlen 2. gablig, Kapsel warzig.

Wzst. senkrecht, mehrköpfig.

6.

6. Hüllchenbl. elliptisch, im Mittelpunkte d. Trugdolde 11. gestielte Blthülle (auch d. übrigen Blt. 1. gestielt); St. bis $45 \mathrm{~cm} \mathrm{~h}$., Bl. länglichlanzettförmig und Hüllbl. ganzrandig. Kahl. - Sonnige Hügel in St. u. Kr.; zerstreut. 4. 5. 6. E. carniólica Jequ.

Hüllchenbl, am Grunde abgestutzt oder fast herzförmig; Bl. ganzrandig oder vorn fein gezähnelt.

7.

7. St. rund, $30-60 \mathrm{~cm}$ h.; Bl. länglich oder länglich-lanzettförmig, unterseits weichhaarig; Hüllchenbl. 3 eckig-länglich, grün, Blthülldrüsen zuletzt dunkelroth. - Laubwälder; zerstreut. 4. 5. 6. E. dulcis L.

Variet. a lpígen a (Kern.) Schmächtiger, Hüllchenbl. rhombisch3 eckig. Buchenwälder in T. (Salzberg bei Hall).

St. kantig, $30-45 \mathrm{~cm}$ h., Bl. oval oder länglich, Hüllchenbl. 3eckig-rundlich, gelblich; Drüsen zuletzt rothgelb. - Bergwälder in B., Mh., Oe., St. 4. 6. 7.

$E$. anguláta Jequ.

8. Kapseln glatt, Blthülldrüsen wachsgelb.

Kapsel warzig, Hüllchenbl. elliptisch oder eiförmig.

9. Bl. behaart, lanzett- od. länglich-lanzettförm., St. kahl, einfach od. oben ästig, $0 \cdot 3-1 \mathrm{~m}$ h.; Trugdold, 5- od. mehrstrahlig, Strahl. erst 3-, dann 2 gablig: Hüllchenbl. oval, Kaps. kahl (E. procera M. Bieb.). Fcuchte Waldplätze, Bachufer; zerstreut (in B. u. Noe., selten!). 4. 5. 6. E. villósa W. Kit.

Var. $\beta$. trichocarpa Neilr. Kaps. abstehend behaart.

Bl. u. St. kahl, erstere ganzrand. u. stachelspitzig, letzterer einfach; Hiillchen gelblich.

10.

10. Bl. lineal bis lineal-lanzettförm., gedrängt; Trugdold. 5- u. mehrstrahlig mit 2 gabligen Strahlen; Hüllchenbl. rauten- od. 3 eckig-herzförm. - Sandboden in B., Mh., Oe., St., T.; zerstreut. 4. 5-7.

E. Gerardiána Jequ.

Bl. länglich, lederartig, steif; St. $30-60 \mathrm{~cm}$ h., steif; Trugdolden vielstrahlig, Strahlen 2 gablig, Hüllchenbl. 3 eckig-herzförm. Blaugrün. (E. pannónica Host.) - Äcker, Wiesen in Noe.; zerstreut. 4. 5-7. 
11. (8) St. 0.6-1.6 $m$ h., einfach od. oben ästig, dick; Bl. lanzett. förmig: glänzendgrün, nebst allen Hüllbl. ganzrandig; Trugdolden 5- bis vielstrahlig, Strahlen meist 2-, dann 3 gablig. Kahl. - Flussufer, Auenwiesen; stellenweis. 4. 5. 6. E. palustris L.

St. 15-45 cm h., sammt d. Bl. (od. nur letztere) behaart; Trugdold. 5 strahlig, Strahl. 2-3 gablig, mit 2 gabligen Ästchen.

12.

12. Warzen d. gelblichen od. grünlichen Kaps. kurzwalzig; Hüllchenbl. verkehrt-eiförmig od. elliptisch; St. unten halbstrauchig u. in viele liegende od. aufsteigende kahle Äste zertheilt; Bl. länglich od. eiförmig, fein gesägt, Hüllchen zuletzt orange. - Wüste Plätze, Heiden in 0e. u. K.; zerstreut. 4. 5. 6.

E. verrucósa L.

Warzen d. zuletzt orange- bis purpurrothen Kaps. fadenförm.; Hüllchen eiförmig-rundlich od. elliptisch.

13.

13. Kaps. länglich, alle Hüllen gelb, zuletzt orsnge; Bl. 12-20 mm breit. - Steinige bebuschte Hügel in Mh., Noe., St., Kr. 4. 4. 5.

E. polychróma Kern.

Kaps. kuglig, Hiillen kleiner, Bl. $6-8 \mathrm{~mm}$ br. - Steinige Berge in St. n. Kr. 4. 4. 5.

$E$. fragifera Jan.

14. (1) PA. mit Wzst.; Samen glatt.

Ein-od. zweijährige PA. mit dünner Wzl.

15.

22.

15. Hüllchen paarweise in ein kreisrundes 2 lappiges gelbliches $\mathrm{BI}$. verwachsen; St. $30-60 \mathrm{~cm}$ h., aufsteigend, blttragende unten nackt, in d. Mitte rosettenförmig beblättert; Trugdolden 5-vielstrahlig, Kaps. kahl. - Gebirgslaubwälder in B., Mh., Noe.; zerstrent. 4. 4. 5.

\section{E. amygdaloides L.}

Hüllchen nicht verwachsen.

16.

16. Trugdolden 5 strahlig mit 2 gabligen Strahlen; St. bis $15 \mathrm{~cm}$ h., einfach, frbare unten nackt, in d. Mitte rosettenförmig beblättert. Kahl. — Steinige Berge in Noe., St., Kr., T.; zerstreut. 4. 5. 6.

\section{E. saxátilis Jacqu.}

Trugdolden vielstrahlig, St. reich beblättert, unten nicht nackt. 17 .

17. Kaps. glatt, Trugdold. schirmförmig; St. $15-45 \mathrm{~cm}$ h., steif; Bl. lineal-lanzettförmig, 3 nervig, blaugrün; Hüllchenbl. br. eiförmig-rundlich, gelblich. Kahl. - Wüste Plätze in Süd-T. u. Krr.; zerstreut. 4. 7. 8.

E. nicaeensis All.

Kaps. am Rücken d. Knöpfe feinwarzig; Hüllchen rauten- od. herzförmig-3 eckig, Bl. ganzrandig, 2 nervig; St. unterhalb d. Enddolde doldentragende $Z$ weige treibend.

18. Dichtflaumig; St. $0 \cdot 5-1 m$ h., B!. lineal-lanzettlich, Trugdolde schirmförmig. - Äcker u. Wiesen in Ml. u. Noe.; zerstreut. 4. 5. 6. E. salicifólia Host.

Kahle $\mathrm{Kr}$. 19.

19. Bl. sehr gedrängt, lineal, die d. unfruchtb. Seitenzweige fast nadelförmig; St. $15-30 \mathrm{~cm}$ h., Trugdold. dicht, halbkuglig; Hüllchen goldgelb, zuletzt roth. - Dürre Abhänge, Hügel, Sandfluren. 4. 4-9. E. Cyparissias L. kleiner.

Bl. lanzett-, länglich-lanzett- od. keilförmig, die d. unfrbaren Ȧst€ 20. 
20. Bl. gegen d. Grund hin allmählich verschmälert, lanzett- oder lineal-lanzettförmig; St. 15-60 cm h.. Trugdold. gr., schirmförmig, Hüllch. gelblichgrün. - Flussauen, feuchte Wiesen; zerstreut. 4. 5-8.

\section{E. Ésula L.}

Bl. gegen d. Spitze hin allmählich verschmälert.

21. St. 30-60 cm h., schlank; Bl. lanzett- od. lineal-lanzettförm., Hüllchen hellgrün oder gelblich, Blthülldrüsen wachsgelb. - Raine, Ufer in B., Mh., 0e., Kr.; zerstreut. 4. 5-8. E. virgáta W. Kit.

St. $0 \cdot 6-1.3 \mathrm{~m}$ h., Bl. lanzett- od. länglich-lanzettförm., steif, glänzend; Hüllchen gelb bis dottergelb, Drüsen orange. - Sumpfwiesen, Weidenheger in B., Ml., Noe.; zerstreut. 4. 6. 7. E. luicida W. Kit.

22. (14). Bl. kreuzweis gegenständig, lineal-lanzettförm., im 1. Jahre sehr dicht u. abwärts gerichtet; St. $0 \cdot 6-1 m$ h., Trugdolde sehr gr., ausgebreitet mit 2 gabligen Strahlen; Kaps. gr., kahl. - Wild in SüdT.; als Arzneipfl. cult. u. verwild. $\odot$. 6. 7.

E. Láthyris L.

Bl. wechselständig. entfernt.

23. Bl. verkehrt- ei - od. länglich.lanzettförm., kurz gestielt, etwas

Bl. lineal od. lineal-lanzettlich, sitzend, gedrängt.

24.

25.

24. Bl. verkehrt-eiförmig, sehr stumpf, Hüllbl. eiförmig, Knöpfe d. Kapseln doppelt geflügelt; Samen gefurcht u. grubig punktiert; Trugdolde 3 strahlig, Strahlen wiederholt 2 gablig; St. $15-30 \mathrm{~cm}$ h. - Unkraut. $\odot .7-9$.

E. Peplus L.

Bl. lanzettlich, spitz od. zugespitzt; Hüllbl. eiförmig od. elliptisch, stachelspitzig, Kaps. glatt. Samen 4 reihig quergefurcht; St. $5-20 \mathrm{~cm} \mathrm{h.}$

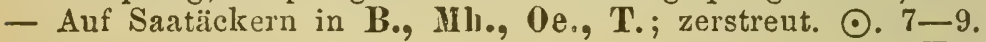

E. falcaita L.

25. Blthülldrüsen kurz 2 hörnig, Kaps. rauh punktiert, Samen netzgrubig; Trugdold. 5 strahlig mit gabeltheil. Strahlen; Hüllchen gelblich, St. bis $30 \mathrm{~cm}$ h. Saatfelder in 0e., St., Kr.; zerstreut. ๑. 6. 7.

E. segetális L.

Blthülldrüsen halbmondförm., Kaps. glatt, Samen warzig.runzlig; Trugdold. 3-5 strahlig, Strahl gabeltheilig; Hïllch. grün, St. $0.2-20 \mathrm{~cm} \mathrm{~h}$. - Unkr. auf Kalkbod.; zerstreut. ๑. 7-9. Exigua L.

\section{Mercuriális L. Bingelkraut (XXII, 8).}

St. aufrecht, $15-30 \mathrm{~cm}$ h.; Bl. gegenständ., Blt. grünlich, männl. in 1. achselständ. Trauben, weibl. einzeln od. gekrıäuelt in Blachseln.

1. St. von unten an ästig u. beblättert, Bl. ei- od. eilanzettförmig,

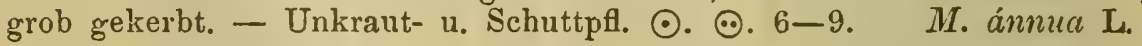
Wist.

St. einfach, unten nackt, oben beblättert, Bl. spitz, grobgekerbt;

2. Bl. alle gestielt, eiförmig-länglich, eilanzett- od. lanzettförmig. Beim Trocknen stahlblan werdend. - Laub-, besond. Buchenwälder. 4. 4. 5 .

$M$. perennis $\mathrm{L}$.

Bl. sitzend (höchstens d. unteren kurz gestielt), elliptisch od. eiförm. -- Gebüsche in Mh., Oe., K., St., Kr., T.; 4. 4. 5. 


\section{Fam. CXVIII. Terebintháceae. Pistazienartige.}

\section{5̃5. Pistácia L. Pistazie (XXII, 5).}

Immergrüner Str. mit unpaarig gefiederten Bl., grünlichen kl. Blt. in seitenständ. Trauben u. erbsengroßen blauen Steinfr. - Sonnige Orte im südl. Kr. u. T. ち. 4.5 .

$P$. Therebinthus L.

\section{Rhus L. Sumach (V, 3 od. XXII, 3).}

Holzgewächse mit wechselständ. gestielten $\mathrm{Bl}$., kl. grünlichen Blt. u. kl. trockenen Steinfrüchten.

1. Bl. einfach, verkehrt-eiförm., ganzrand., kahl; Blt. zwitterlich in endständ. lockeren Rispen, welche infolge der Verlängerung d. Stiele der abfallenden Blt., die sich mit Haaren bedecken, federbuschartig werden. Str. bis $4 m$ h. - Wild in T. u. Kr., häuf. Ziergehölz. 5. 5.

Bl. zusammengesetzt. Perrückenbaum, Rh. Cótinus L.

2. Bl. 3 zählig, l. gestielt; Blättıh. ei- od. herzeiförm., zugespitzt, ganzrand;。Blt. 2 häusig, in achselständ. Trauben; Fr. weißlich, kahl, giftig. - Kleinstr. mit niederliegenden Stämmchen aus Nordamerikı, verwild. in B., stellenw. 5. 6. 7. Giftsumach, Rh. Tóxicodéndron L.

Bl. unparig gefiedert.

3 . Bl. bis $45 \mathrm{~cm} \mathrm{l}$. mit 8-10 Paaren lanzettförm. gesägter unters. weichhaariger Blättchen; Blt. polygamisch, in dichten endständ. Sträußen, Fr. mit purpurrother, sauer schmeckender Wolle bedeckt. $B$ mit wolligen Zweigen. - ZierpA. aus Südamer. 5.6. Essigba um, Rh. týphinum L.

Bl. bis $20 \mathrm{~cm}$ l. mit 5-15 Paaren elliptischer gesägt., unters. zottiger Blättchen; Blt. zwitterlich, in kurzen Trauben, Fr. kahl. Str. mit gelbwolligen Zweigen. - Aus Südeuropa, cult. als Gerbpf. in Süd-T.; b. 7.8 .

Gerbersumach, Schmack, Rh. Coriária L.

Fam. CXIX. Xanthoxílecue. Gelbholzartige.

65̆7. Ailánthus L. Götterbaum (X, 2-5).

Sommergrüner B. mit wechselständ. unpaarig gefiederten gr. Bl.; Blättch. vielpaarig, gr., eilanzettförm., am Grunde drüsig grobgezühnt, kahl; Blt. in endständ. Sträußen, grünlich, Flügelfr. länglich. - Zierb. aus China. Ђ. 6. 7.

A. glandulósa Dest.

658. Ptélea I. Lederblume (IV, 1).

Sommergrüner Str. mit wechselstäud. gestielten 3 zähligen Bl.; Blättchen oval, seitliche unten schief; Blt. in endständ. straußförmig gruppierten Trugdold., gelblich-purpurn; Fltigelfr. elliptisch, netzadrig. Zierstr. aus Nordamerika. Ђ. 6. 7.

Pt. trifoliáta L.

\section{Fam. CXX. Juglandineae. Wallnussartioe}

\section{Juglaus L. Wallnussbaum (XXI, 5).}

Sommergrüne B. mit wechselständ, unpaarig gefiederten Bl.; Blt. mit d. Bl. erscheinend.

1. Blättchen elliptisch, ganzrand., glänzend, sammt d. kugligen grünen Fr. kahl. - Aus d. Orient, überall cult. ந. 4. 5.

Ge meiner W., J. régia L.

Willk o m m, Schulfiora. 
Blättch. gesägt, unterseits flaumig bis filzig, sehr vielpaarig. Zierb. aus Nordamerika.

2. Blättch. länglich-lanzettförmig, Blstiele klebrig, Fr. eilänglich, filzig, braun. Ђ. 5 .

$J$. cinérea L.

Blättch. lanzettförmig, Blstiele flaumig, Fr. kuglig, rauh punktiert. $\hbar .5$. J. nigra L.

\section{Fam. CXXI. Rutáceae. Rautenartige.}

660. Ruta L. Raute (VIII, 1).

St. (meist viele) $30-60 \mathrm{~cm}$ h. ästig; Bl. wechselständ., 3-3 fach fiederschnittig, durchsichtig drüsig-punktiert; Blt in endständ. schirmförm. Trugdolde, Blbl. concav, gefranzt, gelb. - 4. bis 5. 6. 7 .

\section{R. gravéolens L.}

Variet. $\alpha$. vulgaris: Centralblt, mit 5 Blbl. u. 10 Stbg., d uibrigen mit 4 Blbl. u. 8 Stbr; Blabschnitte länglich. Wild an sonnigen felsigen Plätzen in Süd-T., häufig cult.; - $\beta$. divaricáta (Ten.); alle Blt. 8 männig, Blabschn. lineal, ausgespreizt. In südl. St.

\section{Dictamnus L. Diptam (X, 1).}

St. 30-60 cm h., einfach; Bl. wechselständ., unpaarig gefiedert, Blättchen (7-9), gesägt, eiförmig ellipt. bis lanzettlich; Blt. gr, in endständ. Traube, Bltstiele, Kelche u. Kaps. mit gestielten schwarzrothen Drüsen, Blbl. weiß od. rosenroth. - Sonnige Kalkhügel; zerstreut (D. Fraxinella L.). 4. 5. 6.

D. albus L.

\section{Fam. CXXII. Gerániaceae. Storchschnabelartige.}

\section{Gattungen.}

1. Stbg. alle mit Beutel, Gr. beim Aufspringen d. Fr. sich bogenförmig od. uhrfederartig nach außen umrollend; Blt. meist paarweis.

Geranium (662).

2. Je 5 Stbg. mit u. (mit diesen abwechselnd)je 5 ohne Beutel; Gr. sich schraubenförmig zusammenrollend; Blt. in Dolden. Erodium (663).

\section{Geránium L. Storchschnabel (X, 2).}

St. ästig, Bl. handförmig getheilt, gestielt, mit persistenten häutigen Nebenbl. am Grunde d. Stiels, obere wechsel-, d. übrigen gegenständig; Blt. meist paarweis, selten einzeln, gestielt, von kl. Deckblättch. umringt, auf blwinkelständigem Stiel. Behaarte, selten kable Kr.

1. Arten mit walzigem langfasrigem Wzst.

Einjährige Arten mit dünner senkrechter $\mathrm{W} \mathrm{z}$.

10.

2. Theilfiri chte querrunzlig, Blkr. 12-18 $\mathrm{mm}$ br., Bl. herzförmigrundlich, $5-7$ theilig; St. einfach od. oben gabeltheilig.

Theilfr. glatt; Blttragstiele meist 2 bltig.

3.

3. Blbl. blut- od. dunkelrosenroth, 1. genagelt; Theilfr. kahl, Blttragstiele 2 od. $1 \frac{1 / 2}{1}$ od. $2 \frac{1}{2}$ Paare kurz gestielter Blt. tragend; St. 15 bis $30 \mathrm{~cm}$ h., Wzst. dick. Steinige Plätze d. Alp. v. K., Krr., Süd-T., auch Zierpt. 4. 5. 6. G. macrorrhizum L. 
Blbl. schwarzviolett, Theilfr. behaart, Blttragstiele 2 bltig; St. 30 bis $60 \mathrm{~cm}$ h. - Wiesen, Wälder, Gebüsche in B., Ml., Noe.; zerstreut, auch Zierpf. 4. 5. 6.

G. phaeum L.

Var. lívidum (L.) Blbl. schmutzig lila, alt mit violettem Fleck. In $\mathbf{T}$.

4. Ganze Pflanze angedrückt seidenhaarig, silberweiß, mit $5-20$ $\mathrm{cm}$ h., einfachem od. ohne St.; Bl. tief handtheilig, mit 3-4 spaltigen Theilstücken; Blbl. hellrosa. - Alpen v. Kr. u. T.; zerstreut. 4. 7. 8. G. argénteum L.

Ganze Pfl. grün, kahl od. behaart.

5. Bl. nierenförmig-rund, in 5-9 Stïcke zertheilt; St. u. Blstiele rauhhaarig od. zottig.

Bl. herzförmig, 3-7 spaltig od. theilig; Bittragstiele 2 bltig, Kelchbl. begrannt.

6. Blttragstiele 1 bltig, 1., Blbl. blutroth, $13 \mathrm{~mm} \mathrm{1.,} \mathrm{Kelchbl.} \mathrm{be-}$ grannt; St. $30-60 \mathrm{~cm}$ h., ausgebreitet ästig, Blabschnitte fiedertheilig. Abstehend rauhhaarig. - Bebuschte somnige Kalkhügel; zerstreut. 4. $5-7$.

G. sanguineum L.

Blttragstiele 2 bltig, kurz, Blbl. lila, $6 \mathrm{~mm}$ l., Kelchbl. stachelspitzig; St. 30-60 cm 1., liegend od. aufsteigend, ästig; Bltheilstücke eingeschnitten stumpt-gekerbt. Weihhaarig. - Verwild. auf Grasplätzen n. an Hecken; zerstreut. (-) und 4. 5-9.

G. pyrenáicum L.

7. Ganze PA. rauhhaarig, St. liegrend od. aufsteigend, $30-60 \mathrm{~cm} \mathrm{l.,}$ Theilstücke d. BI. 3 spaltig, grob eingeschnitten-gesägt; Blbl. purpurroth, $13 \mathrm{~mm}$ l.; Fr. abstehend behaart. - Gräben, Sümpfe, feuchte Grasplätze. 4. 7. 8 .

Ganze Pfl. feinflaumig od. kahl.

G. palustre L.

8. Blbl. verkehrt-herzförm., rosa, $13 \mathrm{~mm}$ 1., Fr. flaumig; St. aufrecht, 30-60 cm h., Grundbl. 5-, Stbl. 3 theilig, Theilstücke eiförm., eingeschnit. ten-gesägt. - Wälder in Kr. 4.6.7.

G. nodósum L.

Blbl. verkehrt-eiförm., Fr. abstehend-drüsenhaarig; St. $30-60 \mathrm{~cm}$ h., oben drüsig-flaumig; untere Bl. 5-7 theilig, obere 5 schnittig; Theilstücke fiederspaltig od. eingeschnitten.

9.

9. Bltstiele nach d. Bliihen abwärts gerichtet, frtragend wieder aufrecht; Blkr. azurblau. 14-18 $\mathrm{mm}$ br. - Frische Wiesen, Ufer. 4. 7. 8.

G. pratense I.

Bltstiele immer aufrecht, Blkr. purpurblau, $13 \mathrm{~mm}$ br. - Sumpfige Wald- u. Bergwiesen, bis in d. Alpen. 4. 7. 8. G. silváticum L.

Variet. $\beta$. parviflórum Knaf. Blbl. wenig länger als d. Kelch. In B., vereinzelt; - $\gamma$. de $\mathrm{n} u d$ dat $\mathrm{u} \mathrm{m}$ Č̉elak. Theilfr. beinahe kahl. B. (Riesengeb.)

10. (1). Bl. 3-5 schnittig mit gestielten 1-2 fach fiederspaltigen gekerbten Abschnitten; St. $30-60 \mathrm{~cm}$ h., gablig-ästig; Blbl. hellroth. $13 \mathrm{~mm} \mathrm{l}$, Theilfr. netzartig-runzlig. Driisig-rauhhaarig, stinkend. - Schutt, Gerölle, bis in d. Alp. ๑. 6-9.

G. Robertiánum L.

Bl. kreisrund od. nierenförm., handtheilig.

11.

11. Bl. 5-7 theilig, Stücke $1-2$ fach fiederspaltig, Blbl. verkehrtherzförm., begrannt; Theilfr. glatt.

12.

Bl. 5-9 theilig, Stücke br. verkehrt-eiförm. od. kuglig.

13. 
12. Blttragstiele kurz, Blbl, karminroth, den Kelchbl. gleichlang (4-6 $\mathrm{mm}$ 1.), Fr. abstehend drüsenharig; St. liegend od. aufsteigend, 15-30 cm 1. Kurzhaarig. - Unkraut, an Hecken. ๑. 5-9.

$$
\text { G. dissectum } \mathrm{L} \text {. }
$$

Blttragstiele 1., Bltstiele 1., zuletzt einwärts gebogen; Blbl. lichtpurpurn, länger als d. Kelch $(8 \mathrm{~mm}$ l.), Fr. kahl; St. aufsteigend, bis $50 \mathrm{~cm}$ l., ausgespreizt-ästig, behaart od. kahl. - Felsige Orte, Schutt. ๑. 5-9. G. columbinum L.

13. Blbl. verkehrt-herzförmig.

Blbl. keilig-länglich od. verkehrt.eilänglich; Kelchbl. bespitzt. 17.

14. Theilfr. glatt, angedrückt behaart; St. bis $30 \mathrm{~cm} \mathrm{l.} 15$.

Theilfr. runzlig, Bltst. nach dem Blühen abwärts gerichtet. Zottige Kr.

15. Dicht u. kurz flaumig; St. aufsteigend, Bl. kl., Theilstücke keilförm., kurz 3 lappig; Blttragstiele kürzer als d. Bl., Blbl. rosa, $4 \mathrm{~mm} \mathrm{l.,}$

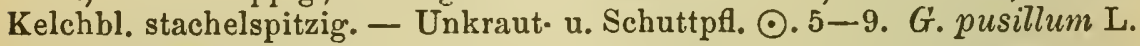

Langzottig u. drüsenhaarig; St. aufrecht, Bl. gr., Theilstücke verkehrt.eiförm., 2-3 lappig u. eingeschnitt. grob gekerbt; Blttragstiele dem Bl. gleichlang, Blbl. blau od. violett, $8 \mathrm{~mm}$ 1., Kelchbl. begrannt. - In B., sehr zerstreut. $\odot$. 6. 7 .

G. bohémicum L.

16. Blbl. hellpurpurn, $6 \mathrm{~mm}$ l., länger als d. stachelspitzigen Kelchbl., Theilfr. kahl; St. aufrecht od. liegend, dünn; Blttragstiele locker traubig, in d. Achseln kl. 3-5 lappiger ganzrand. Bl.; Stbl. größer, mit 3lappigen Theilstücken. Zerstreut kurzhaarig od. kahl. - Grasplätze, Acker- u. Wegränder; zerstreut. $\odot$. $5-9$.

G. molle $\mathrm{L}$.

Blbl. hellrosa, $4 \mathrm{~mm}$ l., den begrannten Kelchbl. gleichlang; Theilfr. kurzhaarig; St. aufrecht, Bl. gleichgestaltet, l. gestielt, mit 3 spaltigen u. eingeschnitt. gekerbten Theilstücken. Abstehend langzottig. - Hügel Weinberge in B. u. Mh.; zerstreut. $\odot$. 7. 8. G. divaricátum Ehrh.

17. (13) Blttragstiele kürzer als d. Bl., Kelchbl. glatt, während d. Blühens abstehend, Blbl. 6-8 $\mathrm{mm}$ l., keilig-länglich, rosenroth; Theilfr. glatt, drüsig behaart; St. liegend od. aufrecht, abstehend behaart u. klebrig-drüsig. - Unkr. in B., Ilh., 0e. $\odot .6-9 . \quad G$. rotundifólium L.

13lttragstiele länger als d. Bl., Kelchbl. querrunzlig, während d. Blühens zusammenschließend; Blbl. 8-10 $\mathrm{mm}$ l., verkehrt-eiförm., rosa; Theilfr. netzrunzlig, kahl; St. aufsteigend, 30-60 $\mathrm{mm}$ 1., sammt d. glänzenden Bl. kahl. - Felsen, Gerölle in Noe., St., Kr. $\odot .6-8$. G. lúcidum L.

\section{Eródium 1'Hér. Reiherschnabel (X, 2).}

St. (viele) sammt d. grundständ. Bl. strahlig ausgebreitet, liegend od. später aufrecht, bis $30 \mathrm{~cm} \mathrm{1.;} \mathrm{Bl.} \mathrm{fiederschnittig,} \mathrm{Blttragstiele} \mathrm{achsel-}$ ständ., Blbl. ungleich, länglich. Behaarte Kr.

1. Bl. 1 fach fiederschnittig, Abschnitte eiförm., gelappt u. gesägt; Blbl. purpurn. Klebrig-flaumig u. zottig, moschusduftend. - Unkr. u. Schuttpfl. in Mll., 0e., St.; zerstreut. $\odot$. 5-7. E. moschátum l'Hér.

2. Bl. doppelt fiederschnittig, Zipfel kl., lineal od. lanzettlich, Blbl. lila od, blassroth. Klebrig-flaumig u. zottig. - Unkr. u. Schuttpfl. $\odot .4-10$ $E$. cicutárium l'Hér. 
Anmerkuug. Zu den Geraniaceen gehören auch die als Topf- u. Teppichbeetptl. so beliebten Kranichschnäbel od. Pelargonien (Pelargonium), oft auch Geranien genannt, Str. vom Cap d.g. Hoffinung. Verwandt mit d. Geraniaceen sind ferner die in Südamerika heimischen Tropaeoleen (VIII, 3) mit zygomorphen gespornten Blumen und 2-3 knöpfigen Spaltfriichten, zu denen die $K a p u z i n e r-o d$. spanische Kresse (Tropaéolum majus L.) gehört, eine beliebte Schling-Zierpfl. mit schildförm. Bl. u. gr. goldgelben bis dunkelrothen wohlriechenden Blumen.

Fam. CXXIII. Lineae. Leinartige.

\section{Radíola L. Zwergflachs (IV, 4).}

St. $2 \cdot 5-5 \mathrm{~cm}$ h., vom Grunde an wiederholt gabeltheilig, zart; Bl. gegenständ., rundlich eiförmig, kaum $2 \mathrm{~mm}$ l.; Blt. kl. weiß, endstïind. - Fenchter Sandbod, in B.; zerstreut. ๑. 7. S.

R. linoides $\mathrm{Gm}$.

665. Linum L. Flachs, Lein (V, 5 od. XVI, 5). dolden.

St. reichblättrig, Bl. sitzend, ganzrand.; Blt. in Traub. od. Trug-

1. Bl. gegensliind., untere verkehrt-eilänglich, oberste lanzettförm.; St. $16-25 \mathrm{~cm}$ h. fadenförm., 3 fach gabeltheilig; Blt. kl. weiß. Kabl. Feuchte Wiesen; zerstreut. $\odot$. 6-8.

L. cathárticum L.

Bl. wechselständig, Blkr. $25-50 \mathrm{~mm}$ br.

2. Blbl. gelb, Kelchbl. lanzettförm.; St. 15-45 cm. h. Bl. 3 nervig eilanzett- lis lanzettförm.; Trugdold. traubig. Kahl. - Kalkhügel in B., Wh., Oe., St., Kr.; zerstreut. 4. 6. 7.

Blbl. blau, rosenroth, lila, weiß.

3. Kelchbl. drüsig gewimpert.

L. flavum L.

3.

Kelchbl. wimper- u. drüsenlos, Blbl. stets blau, kahle Pfl.

4.

6.

4. Blbl. wei 6 , röthlich geadert; St. $15-30 \mathrm{~cm}$ h., Bl. 1 nervig lineal: Blt. in end- u. achselständ., zu einer Rispe vereinigten Trugdold. Kahl, graugrün. Kalkhügel in B., Ml., Oe., St., Kr.; zerstreut. 4. 6. 7. L. tenuifótium L.

Blbl. nicht wei 6 , Bl. lanzettförm., 3-5 nervig, St. $30-60 \mathrm{~cm}$ h., nebst d. Bl, zottig; Blt. in rispigen Trauben.

5. Blbl. rosa, dunkel geadert, Kelch-, Deck- u. obere Stbl. drüsig gewimpert. Klebrig. - Bergwiesen, Heiden auf Kalk in 0oe., K., T., Kir.; zerstreut. 4. 6. 7.

L. viscósum $\mathrm{L}$.

Blbl. lila, am Grunde weißlich; Kelchbl. zottig u. nebst d. Deckbl. drüsig gewimpert. Nicht klebrig. - Sonnige Wiesen, Hügel in Mh., Noe., St. 4. 6. 7 .

L. hirsútum L. Narbe keulig.

6. (3) Kelchbl. จ. gleicher Größe, ei- od. lanzettförm., zugespitzt.

Kelchbl. ungleich, eiförm., die 2 äußeren schmäler, spitz, d. inneren stumpf; Narbe kopfig.

7. Blkr. mindestens $25 \mathrm{~mm}$ br., Blt. in endständ. Trugdold. St. 30 bis $60 \mathrm{~cm}$ h., Bl. 3 nervig, lineal-lanzettförmig. - Gebirgswiesen in $\mathbf{K r}$. u. Unter-St. 4. 7. 8.

$L$. nartonnense $\mathrm{L}$.

Blkr. 12-16 mm br.; Blt. in schlaffen Trauben. 
8. Bl. 3 nervig, schmal lanzettförm., Kelchbl. kurz gewimpert. -St. 0.3-1 $m$ h. - Culturpf. $\odot .5-9$.

Gemeiner Fla chs, $L$. usitatissimum L.

Bl. 1 nervig, schmal lineal-lanzettlich; St. 15-30 $\mathrm{cm}$ h. - Steinige Triften in Süd-Kr. 4. 7. 8.

L. angustifólium Hads.

9. (6) Blt. in endständ. Trugdold., Blbl. sich mit d. Rändern nicht deckend, Kaps. oval; St. $10-40 \mathrm{~cm}$ h., Bl. lineal. - Wiesen u. Triften d. Alpen. 4. 6. 7.

L. alpinum L.

Blt. in zuletzt 1. Trauben, Blbl. sich mit d. Rändern deckend, Blkr. 20-25 $\mathrm{mm}$ br.; Bl. lineal-lanzettförm., St. $0 \cdot 3-1 \mathrm{~m} \mathrm{~h}$.

10.

10. Traube allseitswendig, frtragende Bltstiele steif aufrecht, Kaps. eikuglig. - Wiesen des Donauthales in Ooe.; zerstreut. 4. 6. 7.

\section{I. perenne $\mathrm{L}$.}

Traube einseitswendig, frtragende Bltstiele rechtwinklig od. abwärts abstehend, Kaps. kuglig. - Wiesen, Heiden in B., Mh., Noe., Kr. 4. 6. 7. L. austriacum L.

\section{Fam. CXXIV. Oxalideae. Sanerkleeartige.}

\section{Oxalis L. Squerklee (X, 5 od. XVI, 5).}

Bl. 1. gestielt, 3-4 zählig; Blättch. verkehrt-herzförm., Bltstiele grund- od. achselständig. Scharf sauer schmeckende Kr.

1. Stengellose ausdauernde Arten mit grundständ. Bl. u. Blt. 2.

Stengeltreibende 1jährige Arten; St. beblättert, $15-30 \mathrm{~cm}$ h., Blt. zu 1-5 auf achselständ. Stiele, Blbl. gelb.

2. Bl. 3 zählig, Blbl. weiß od. lila, roth geadert, selı" zart, Bltstiele 1 bltig; Wzst. kriechend. - Wälder, unter Hecken, Gebüschen. 4. 4. 5. Gem ei ner S., O. Acetosella L.

Bl. 4 zählig, Blbl. purpurroth, Bltstiele $3-7$ bltig, Wzst. zwieblig. Zierpfl. aus Mexico. 4. 6-8.

O. tetraphýlla Cav.

3. St. straff aufwärts (ein einziger), keine Nebenbl,, frtragende Blt-

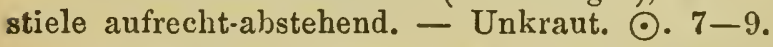
O. stricta $\mathrm{L}$.

St. (mehrere) aufrecht od. niedergestreckt, Blstiele mit öhrchenförm. Nebenbl, frtragende Bltstiele abwärts gerichtet mit aufrechter Kapsel. Unkraut. $\odot .6-9$.

O. corniculcita $\mathrm{L}$.

\section{Fam. CXXV. Balsamineae. Balsaminenartige.}

667. Impátiens L. Springkraut $(V, 5)$.

St. aufrecht, ästig : Bl. wechselständ., gesägt, spitz, Blt. acbselständ. Kahle zarte saftstrotzende $\mathrm{Kr}$.

1. Bltstiele kurz, 1 bltig, zu $2-3$ gebüschelt; Blume meist roth (übrigens in allen Farben), gewöhnlich gefüllt; Bl. lanzettförm., St. 15 bis $45 \mathrm{~cm}$ h. - Zierpfl. aus Ostindien. ๑. 7-10.

$$
\text { Garte } n \text { balsamine, I. Balsamina L. }
$$

Bltstiele 1., 1-4 bltig, bogig abwärts gekrümmt, Blt. daher hängend; St. $30-60 \mathrm{~cm}$ h., Bl. ei- od. eilanzettförmig. 
2. Blkr. gr., goldgelb, inwendig roth punktiert. - Laub-, namentlich Buchenwälder auf feuchtem Bod., an Bächen. $\odot$. 7. 8.

Rührmichnichtan, I. Nolitángere L.

Blkr. kl., hellgelb, unscheinbar. - Aus Sibirien, verwild. in Städten wo botan. Gärten sind (z. B. Prag). ๑. 7. 8. I. parviflóra L.

\section{Fam. CXXVI. Philadélpheae. Pfeifenstranchartige.}

\section{Philadelphus L. Pfeifenstrauch (XII, 1).}

Bl. gegenständ, elliptisch od. eiförmig, zugespitzt, kurzhaarig; Blt. gr., weiß, in endständ., aus 3 bltigen Trugdold. zusammengesetzten Sträußen. Sträucher.

1. Blkr. $25 \mathrm{~mm}$ br., gelblichweiß; Blt. zu 3-5, stark sïß duftend; Bl. gesägt-gezähnt, 5 zählig-nervig. - Wild in Gebiischen in K. u. T., anderwärts verwild., weil überall als Zierstr. cult. 5 . 5. 6 .

Unechter Jasmin, Ph. coronárius L.

2. Blkr. 38-40 $\mathrm{mm}$ br., Blt. schwach duftend, Bl. gezähnelt, 3 zählignervig. - Zierstr. aus Nordamer. Ђ. 5. 6.

Ph. inodórus L.

Anmerkung. Außerdem werden noch andere nordamerik. Arten als Zierstr. cultiviert.

\section{Fam. CXXVII. Myrtaceae. Myrtenartige. 669. Myrtus L. Myrte (XII, 1).}

Immergrüner Str. v. 1-2 $m$ Höhe; Bl. gegenständ., ei- od. eilanzettförm., ganzrandig, punktiert; Blt. einzeln, achselständ., gestielt, weiß, gewürzhaft duftend; Beeren schwarzbraun. - - Wild u. verwild. in Süd-T. und Kr.; uberáll (die klblïttrige Form als "Brautmyrte" ) in Töpfen cult. h. 6 .

M. communis $\mathrm{L}$.

\section{Fam. CXXVIII. Oenothéreae. Nachtkerzenartige.}

670. 0enothéra L. Yachtkerze (VIII, 1).

St. 30-60 cm h., reich beblättert; Bl. eilanzett- od. lanzettförm., unterste gestielt $u$. rosettenständ.; Blt. einzeln, aohselständ., sitzend, in beblätterten Äbren; Blkr. 25-38 mm br., gelb. - Nordamerikan. eingeschleppte, an Flussufern auf Sand verwilderte P甘. $\odot: 6--8$. Oe. bienniṣ L. *).

\section{Epilóbium L. Weidenröslein (VIII, 1).}

Bl. ganz, Blt. in endständ., meist beblätterten Ähren od. Trauben Blbl. lila, rosa, purpurn, selten weiß. Vielgestaltige stengelbegabte, zur Bastardbildung sehr geneigte $\mathrm{Kr}$.**).

1. Bl. wechselständ., Blbl. flach ansgebreitet, Stbg. u. Gr. abwärts gebogen.

Untere Bl. gegen- od. quirlständ, obere abwechselnd; Blbl. 2 lappig, trichterig zusammenschließend, Stbg. u. Gr. aufrecht.

*) Verschiedene exotische Arten mit rothen, weißen, gelben od, bunten Blumen sind ziemlich häufig cult. Zierpfanzen.

$\left.{ }^{* *}\right)$ Auch hier können die Bastarde nicht berücksichtigt werden. 
2. Blt. 1. allseitswendige nackte dichte Trauben bildend, Blbl. kurz genagelt, purpurroth, selten weiß; St. $0.6-1.3 \mathrm{~m}$ h., Bl. lanzett- od. eilanzettförm. - Waldschläge, Steinbrüche. 4.6-8. E. angustifólium $\mathrm{L}$.

Blt. in kurzen lockeren beblättert. Trauben, Blbl. sitzend; St. unten kahl, oben sammt d. Bltstielen, Kelchen u. Kaps. flaumig.

3.

3. St. (meist viele), straff aufrecht, $0.3-1 \mathrm{~m} \mathrm{~h}$., meist buschig-ästig; Bl. lineal, mit Bltbüscheln in den Achseln, Blkr. $25 \mathrm{~mm}$ br., rosen- bis purpurroth. - Alpenthäler auf Kies und Gerölle, an Eisenbahndämmen, auch in Mh. und Sch. 4. 7. 8.

E. Dodonaéi Vill.

St. niederliegend-aufsteigend, $30-45 \mathrm{~cm}$ l., von unten an ästig; $\mathrm{Bl}$. lineal-lanzettlich, gezähnelt, ohne Achselbüschel, sonst wie v. - Gletschermoränen und Gerölle in T.; zerstreut. 4. 7. 8. E. Fleischeri Hochst.

4. (1). Narben frei, kreuzweis ausgebreitet, St. rund. 5.

Narben in eine Keule verwachsen, Blkr. 6-13 $\mathrm{mm}$ br. 10.

5. St. 1. weichzottig und kurz drüsenharig, $0.6-1.3 \mathrm{~m}$ h., ästig; Bl. länglich od. lanzettförmig, gezähnt, zottig od. kahl; Blkr. $25 \mathrm{~mm}$ br. purpurn. - Ufer, Flussauen, Sümpfe; zerstreut. 4. 6-8.

E. hirsuitum L.

St. Alaumig oder kahl, Blkr. 6-12 $\mathrm{mm}$ br., selten größer. 6 .

6. Wzst. unterirdische aufrechte gelbliche oder röthliche, fleischigschuppige Sprossen treibend.

7.

Wzst. nach d. Blühen oberirdische, mit entfernt stehenden Paaren kl. Bl. besetzte Ausläufer treibend.

7. Bl. ganzrandig, eilanzettförmig, zugespitzt, untere gegenständig $\mathfrak{u}$. gestielt; Blbl. erst weißlich, dann rosenroth. - Auf Gerölle freier Berg. kuppen in B. (Milleschauer, Schneeberg bei Tetschen). 4. 6. 7.

\section{$E$. hypéricifólium Tausch.} purpurroth.

Bl. ungleich geschweift-gezähnt; St. $15-60 \mathrm{~cm} \mathrm{h.,} \mathrm{fiaumig;} \mathrm{Blkr.}$

8. BI. bis unter dem Bltstand gegenständig, ei- od. länglich-eiförm., kurz gestielt (mittlere bisweilen sitzend), am Grunde abgerundet, spitz; Blkr. erst weißlich, dann rosa-purpurn, St. meist einfach. - Wälder, Holzschläge, Hecken. 4. 6. 7.

E. montánum L.

Bl. nur unten gegenständig, alle klo, steiflich, deutlich gestielt, untere eilänglich, obere eiförmig elliptisch, oberste lanzettlich, alle in den Stiel verschmälert, spitz; Blkr. blassrosa, St. meist vom Grunde an ästig - Wie vorige. $4.6-8$.

$E$. cóllinum Gmel.

9. (6). Bl. 1. gestielt, am Grunde keilig und ganzrandig, sonst gezähnt, länglich-lanzettförmig; Blbl. erst weiß, dann rosenroth; St. 15 bis $45 \mathrm{~cm}$ h., flaumig. - Buschige Berghänge, Wälder in Mh.; zerstreut. 4. 6. 7 . E. lanceolátum Seb. Maur.

BI. am Grunde abgerundet, lanzettförmig, abwechselnd oder gegen-, seltner zu 3 quirlständ.; Blbl. bleich purpurn; St. $0.3-1 \mathrm{~m}$ h., abstehend zottig oder flaumig, selten kahl. - Gräben, Ufer. 4. 6. 7.

$$
\text { E. parviflórum schreb. }
$$

10. (4). Wzst. oder Stbasis schon vor oder während des Blühens unterirdische beschuppte oder über den Boden hervortretende beblätterte Ausläufer treibend. 11.

b) Wrst. zur Bltezeit oberirdische fast sitzende Blrosetten tragend, welche überwintern; St. $30-60 \mathrm{~cm}$ h., meist ästig; Bl. gezälınt. 15 . 
c) Wzst. zur Bltezeit ohne Ausläufer und Blrosetten, erst im Herbst Ausläufer treibend; $\mathrm{Bl}$, gezähnt.

11. St. mit 2-4 herablaufenden erhabenen Linien (Blspuren). 12.

St. mit 2 gegenständigen Haarleisten, rund, $15-50 \mathrm{~cm} \mathrm{h.;} \mathrm{Ausläufer}$ fadenförm., oberirdisch, mit sehr kl. Bl.; Bl. mit keiligem Grunde sitzend, lineal-lanzettlich, meist ganzrand., etwas umgerollt; Blkr. blassrosa, selten weiß. - Gräben, Sumpfwiesen, quellige Orte. 4. 6-8. E. palustre L.

Variet. $\beta$. montícolum Hausskn. St. einfach, mit sehr verlängerten Gliedern. Gebirsssumpfwiesen in B. und Mh.; $\gamma$. s caturíg in u m (Wimm.). Bl. schwach glänzend, Blt, nickend. Riesengebirge und Gesenke an quelligen Orten; - o. adenóphorum Hausskn. St. steif aufrecht, behaart, oben drüsig, oft auch d. Deckbl. und Kapsel. Wälder in Mh.

12. Ausläufer unterirdisch, fleischig, gelblich, mit entfernt stehenden Schuppenpaaren; St. schmächtig, $7-25 \mathrm{~cm}$ b., zuerst nickend; Bl. eioder lanzettförmig, gezähnelt, Blkr. licht purpurn. -- Quellige Plätze der Alpen, Sudeten, Beskiden, d. Riesengebirges. 4. 7. 8.

$E$. alsinefólium Vill.

Ausl. oberirdisch, fadenförmig, mit entfernt stehenden Blättchenpaaren.

13. Obere Stbl. mit abgerundeter Basis sitzend, alle länglich-lanzettförmig, gezähnelt; St. $30-80 \mathrm{~cm}$ h., ästig, oben weichhaarig; Blt. erst nickend, rosa, Kapsel weichhaarig. - Quellige und sumpfige Orte, Ufer in Gebirg. von B., Mh., 0e. 4. 7. 8. E. obscúrum Rchb.

Obere Stbl. mit verschmälertem Grunde sitzend od. kurz gestielt, St. anfangs nickend.

14.

14. Wzst. verzweigt, fruchtbare $u$. unfruchtbare, aufsteigende St. treibend; Bltsteng. 3-10 cm l., zart; Bl. verkehrt- od. länglich-verkehrteiförmig, Blt. hellroth, Kaps. kahl. - Gerölle, Felsspalten, quellige Orte der Alpen, auch im Riesengeb. u. Gesenke. 24. 7. 8.

\section{E. anagállidifólium Lam.}

Wzst. einfach, kriechend, St. aufsteigend, $5-20 \mathrm{~cm}$ h., obenhin nebst d. Bltstielen u. Kelchen weichhaarig; Bl. länglich, Blt. lila, Kaps. weichhaarig. - Quellige Orte, Bachufer in d. Alpen, Sudeten, Riesengeb. 4. 7. 8 .

E. nutans Schmidt.

15. (10, b.) St. stumpf 4 kantig, sehr ästig, fast kahl; mittlere Bl. angewachsen od. etwas herablaufend, mit abgerundeter Basis, lanzettlich od. lineal-lanzettlich; Blbl. rosa, Kaps. feinflaumig. Hellgrün. - Gräben, Ufer. 4. 6-8.

E. adnátım Griseb.

St. rundlich, mit 4 erhabenen Linien, einfach od. ruthen-ästig; Bl. gestielt, nicht herablaufend, kl., lineal-länglich, gezähnelt; Blbl. rosa, purpurn geadert, Kaps. feinflaumig. - Waldschläge, Gebüsche, Hügel in B., Ih., Oe., Sz. 4. 6. 7.

E. Lámyi F. Schtz.

16. $(10$, c.) Untere Bl. gegenständig, obere abwechselnd, alle gestielt, mit keiligem Grunde, lanzettförmig; St. $30-60 \mathrm{~cm} \mathrm{~h}$., mit 2-4 erhabenen Linien; Blbl. blassrosa od. weiß. - Ufer, Sümpfe, Gräben. 4. 7-8.

E. róseum L.

Untere Bl. zu 3-4 quirlständig, mittlere u. obere am Grunde abgerundet; St. $15-60 \mathrm{~cm}$ h., mit 2-4 Linien, oft fast 3 kantig; Blt. hellpurpurn, 12-16 $\mathrm{mm}$ br. - Feuchte Triften, quellige Orte d. Alpen und Gebirge von Sch., Ih., B. 4. 7. 8.

E. trigonum Schrk. 
672. Isnárdia $\mathrm{L} \cdot(\mathrm{IV}, 1)$.

St. am Grunde wurzelnd $u$. im Schlamme kriechend od. im Wasser flutend, 4 kantig, $15-45 \mathrm{~cm}$ l.; Bl. gegenständig, gestielt, lanzettlich; Blt. kl., blwinkelständig, sitzend, gelblich. - Stehende Wässer in Noe., St., Kr.; zerstreut. 4. 7. 8 .

I. palustris L.

\section{Circaéa L. Hexenkraut (II, 1).}

St. aufrecht, Äste u. Bl. gegenständig, letztere gestielt, fiedernervig; 3lt. kl. weiß od. röthlich, in end- $u$. achselständigen l. gestielten lockeren Trauben. Zarte Kr. mit kriechendem Wzst.

1. Trauben ohne Deckbl.; Fr. verkehrt-eiförmig, 2 fächrig, mit hakig gekrümmten Härchen besetzt; $\mathrm{Bl}$. ei- od. herzeiförmig, zugespitzt, gezähnt, St. 15-60 $\mathrm{cm}$ h. Kabl od. flaumig od. abstehend-weichhaarig. Schattige Wälder, Flussauen, Bachufer; zerstreut. 4. 7. 8.

\section{C. lutetiana L.}

Kleine pfriemenförmige Deckblättchen am Grunde d. Bltstiele. 2.

2. Deckbl. selır undeutlich. Fr. fast birnförmig, 2 fächrig, mit gebog. weichen Härchen; Bl. wie b. vor, geschweift-gezähnt, St. $15-40 \mathrm{~cm} \mathrm{~h}$. - Schattige Gebirgslaubwälder; zerstreut. 7. 8. C. intermédia Ehrh.

Deckbl. deutlich, Fr. ungleichseitig.keulenförmig, 1 fäcbrig, locker weißstachlig; Bl. herzeiförmig, geschweift-gezähnt, St. 5-20 cm h. sammt Blstielen u. Blrippen meist roth. - Gemein in Gebirgslaubwäldern. 4. $6-8$.

C. alpina $\mathrm{L}$.

\section{Fam. CXXIX. Halorágeae. Halorageen.}

\section{Myriophýllum L. Tausendblatt (XXI, 5).}

Untergetauchte Wasserpfl, deren Bltäste sich über d. Wasserspiegel erheben. St. fadenförmig, gablig-ästig, Bl. quirlständig, haarfein fiederschnittig; Blt. sitzend, in endständ. Quirlähren, untere weibl., obere männl.; Blbl. kl. weiß od. röthlich, nach dem Aufblühen abfallend.

1. Deckbl. der Quirlïhren meist kürzer als d. Bltquirle, untere gezähnt, obere ganzrand. - Stehende Gewässer. 4. 6-8. M. spicátum L.

2. Deckbl. länger als d. Quirle, fiedertheilig, Quirlähren daher beblättert erscheinend. - Wie vorige Art. 4. 6-8. M. verticillátum L.

\section{Trapa L. Wassernuss (IV, 1).}

St. schnurförmig, im Schlamme wurzelnd od. flutend, mit federförm.fiederschnittigen Bl. besetzt, am Ende eine schwimmende Rosette gestielt. Bl. mit blasig aufgetriebenem Stiel und rhombischer, an den Vorderräud. buchtig gezahnter Spreite tragend; Blt. kl. weiß, achselständig. - Teiche, Seen im südl. B., in Mh., Oe.; zerstreut. 4. 6. 7. T. natans L.

\section{Fam. CXXX. Lythrariéae. Weiderichartige.}

676. Lythrum L. Weiderich (XI od. VI, 1).

St. Ineist ästig, Bl. ganz u. ganzrandig, Blt. blwinkelständig, Blbl. purpurroth, lila od. violett. 
1. Bl. w€chselständig, länglich od. lanzettförm., cbere lineal; Blt. 6 männig, einzeln, kl., dunkellila; St. $3-30 \mathrm{~cm} \mathrm{l.,} \mathrm{liegend} \mathrm{od.} \mathrm{aufsteigend.}$ Kahl. - Überschwemmte Plätze in Noe.; zesstreut. ๑. 7. 8.

L. Hyssopifólia L.

Bl. gegen- od. quirlständig, Blt. 12 männig, endständige, gedrungene od. unterbrochene Quirlähren bildend, purpurroth; St. aufrecht, $0.3-1 \mathrm{~m}$ hoch.

2. Kelchzähne gleichlang, die 6 äußeren 3 eckig, die 6 inneren pfriemlich: Äste ruthenförm., Bl. lanzettförmig. Kahl. - Gräben, feuchte Orte in B. (selten), Ml:., Oe., St., Kr.; zerstreut. 7. 7. 8. L. virgátum L.

Kelchzähne ungleich, die 6 äußeren 3 eckig, viel kürzer als die 6 inneren 1. pfriemenförmigen; St. robust, Bl. länglich-lanzett- od. lanzettförmig, mit abgerundet. ol. herzförm. Grunde. Kahl od. flaumig bis filzig. Sehr variierend. - Ufer, Hecken, nasse Wiesen. 4. 7-9.

L. Salicária L.

\section{Peplis L. Portulkraut (VI, 1).}

St. fadenförmig, 3-30 cm l., kriechend od. flutend; Bl. gegenständ., kl., spatelförm. od. länglich; Blt. kl. blassröthlich, einzeln, achselständig. Kahles Zwergkraut. — Überschwemmte Plätze, Lachen, Teichränder; sehr zerstreut. $\odot .7-9$.

P. Pórtula L.

\section{Fam. CXXII. Calycantheae. Gewï̈:strïuchor.}

\section{Calycanthus L. Gewiirzstrauch (XII, 3).}

Zweige ruthenförmig, Bl. gegenständig, eiförm., gauzrandig, fiedernervig; Blt. einzeln, endständ,, gr., gewürzhaft duftend, rothbraun. Zierstr. aus Nordamerika. \$. $6-8$.

C. flóridus $\mathrm{L}$.

\section{Fam. CXIXII. Pomáceae. Apfelfrïchtige.}

\section{Schliussel der Gattungen.}

1. Fr. ein meist beerenförm. Steinapfel mit verknöcherten harten 1 samigen Fächern.

2.

Fr. ein Kernapfel mit papierartig-knorpligen, 1- bis vielsamigen, vom Frfleisch gänzlich umschlossenen Fächern.

4.

2. Kelchzipfel gr., blartig; Scheinfrucht gr., kuglig, mit ein. breiten Scheibe am Scheitel, die Steinkerne vollständig einschließend.

Kelchzipfel kl., 3 eckig od. lanzettlich, nicht blartig. Mespilus (679).

3. Kelchröhre (hohle Bltachse) becher- od. krugförmig, offen, nur am Grunde mit den Frknoten verwachsen, Steinkerne (3-5) daher nach oben frei, aus dem geringen Frleische hervorstehend; Kelchzipfel über denselb. einwärts zusammengeschlagen; Blbl. kl.

Cotoneaster. (681).

Kelchröhre becher-, krug- od. kreiselförmig, mit d. Frknoten bis an deren Scheitel innig verwachsen; Scheinfrucht am Scheitel mit ein. Scheibe, die schmäler als d. Durchmesser d. Fr. ist; Steinkerne 1-5, vom Frlleisch umschlossen.

Crataegus (680).

4. (1) a. Blt. in aufrechten Trauben, Blbl. schmal, sternförm. ausgebreitet; Scheinfr. beerenförm., Kernhaus 3-5 fächrig mit getheilt. Fächern. Amelanchier (682). 
b) Blt. in einfachen od. zusammengesetzten Trugdolden, Kelchzipfel kl., vertrocknend.

c) Blt. einzeln, endständig, gr.; Kelchzipfel blartig; Kernhaus 5 fächrig, Fächer vielsamig, Samen mit außen verschleimender Haut.

Cydonia (685).

5. Blt. gr., in einfachen lockern büschligen (nur bei P. Pollveria in zusammengesetzten schirmförmigen) Trugdolden, Kernhaus 5 fächrig, Fä. clier 2 samig.

Pirus (684).

Blt. kl., in zusammengesetzten schirmförmig. Trugdolden, Kernhaus 2-5 fächrig, Fächer 1-2 samig.

Sorbus (683).

\section{Méspilus L. Mispel (XI, 2).}

B1. länglich-Janzettförmig, ganzrandig oder seicht gezähnt, unterseits granfilzig; Blt. einzeln, endständig, gr., weiß; Fr. 25-38 mm br., braun, essbar. B. oder Str., Zweige oft dornspitzig. - Obst- und Ziergehölz, verwildert an Waldrändern in Mh. u. Oe. ち. 5.

M. germánica L.

\section{Crataegus L. Hagedorn (XII, 2 selten 1).}

Bl. meist hand- oder fiederförmig zertheilt, am Grunde gewöhnlich keilig, gestielt; Nebenbl. halbherzförm., eingeschnitten gezäbnt, bleibend; Blt. kl., in endständ. meist zusammengesetzten Doldentrauben oder Trugdolden. Str. oder B. mit bedornten Zweigen.

1. Junge Zweige dünnfilzig, Bl. bleibend behaart, 3 lappig mit ganzen od. gezähnten Lappen, Blt. weiß in armbltigen zottigen Doldentrauben; Fr. gr., glänzendroth oder gelb; ossbar. - Südeuropa, cult. und verwildert in Kr. und Süd-T. 5. 5. 6. A zaroldorn, C. Azarólus L.

Junge Zweige kahl, Dornen schwach, kurz, Blt. in schirmförmigen Trugdolden, Fr. länglichrund, beerenförmig, roth.

2. Bl. im Umriss rundlich oder rerkehrt-eiförmig, vorn 3 lappig, ungleich eingeschnitten-gesägt, sammt Bltstiel u. Kelchen kahl; Blbl. weiß, Gr. 2. Meist Str. - Gebuische, Wälder, auch als Zierpflanze cult. (oft mit gefüllten Blumen oder gescheckten Bl.) 5.5 .

Gemeiner Mehl-, Weißdorn, C. Oxyacántha L.

Bl. im Umriss verkehrt-eiförmig, fiederspaltig bis fiedertheilig; Zipfel spitz, ungleich gesägt; Blbl. weiß oder (in Gärten) rosen- bis purpurroth, Gr. 1. Str. oder B. - $\hbar$. Wie vorige Art, in Gärten oft mit gefül!ten Blumen. \$. 5. 6.

C. monógyna Jcqu.

Anmerk. Als Ziergelıölze werden mehrere nordamerikanische, orientalische $u$. sibirische Arten cult., z. b. der Fe uerd orn, C. Pyracantha P. (immergrün, mit scharlachrothen kugligen Fr.), der $\mathrm{H}$ ah nendorn, C. Crus galli Ait. (Bl. verkehrt-eiförmig, lederartig, Dornen bis $7.5 \mathrm{~cm}$ l., Fr. kuglig, ziegelroth), der Scharla chdorn, C. coccínea L. (Bl. herzeiförmig, gesägt, Fr. gr. scharlachroth, essbar) u. a. m.

\section{Cotoneáster Med. Bergmispel (XII, 2).}

Bl. ganzrandig, unterseits weißgraufilzig, kurz gestielt; Blt. kl. in armbltigen lockern Trugdolden, glockig; Blbl. aufrecht, weiß oder rosa, Fr. kuglig, erbsengroB, scharlachroth. Dornenlose, oft niederliegende Kleinstr. 
1. Kelchrölre und Fr. kahl, Kelchzähne wollig gewimpert; Bl. oval, spitz oder stumpf, oberseits kahl. - Bebuschte Kalkhiigel; zerstreut. ち. 4. 5 .

C. vulgaris Lind!.

2. Kelchröhre filzig, Fr. flaumig, Bl. oberseits behaart, unterseits dickfilzig; sonst wie vorige. - Kalkalpen von Oe., St., T.; auch Zierplanze. 5. 5. 6.

C. tomentósa Lindl.

Anmerk. In Gärten häufig: C. nigra L. aus Nordamerika mit reichbltigen Trugdolden $u$. schwarzen Fr.

\section{Amelánchier Med. Felsenbirue (XII, 2).}

Bl. gesägt, oval oder elliptisch-rundlich, kurz gestielt, jung unterseits flaumig bis filzig. Dornenlose aufrechte Str. mit weißen Blumen und schwarzen Fr.

1. Bl. stumpf, abgerundet, Kelchzipfel kahl, Blbl. länglich-lanzettförmig. Str. 1-2 $m$ h. - Felsige Orte der Kalkalpen, häufig als Zierstr. cult. 万. 4. 5 .

A. vulgaris Mönch.

2. BI. spitz, Kelchzipf. behaart, Blbl. verkehrt-eiförm., gewimpert. Str. od. B. 2-5 $m$ h. - Ziergehölz aus Nordamer. 5. 5. A. ovális DC.

\section{Sorbus L. Vogelbeere (XII, 2).}

Wehrlose B.

Bl. ejnfach od. unpaarig gefiedert, Blt. weiß, Fr. beerenförmig.

1. Bl. einfach, ganz od. zackig-gelappt.

Bl. unpaarig gefiedert, mit gesägten Blättchen; B. bis $20 m$ h. 6 .

2. Blbl. aufrecht, rosenroth; Bl. länglich od. elliptisch, doppelt gesägt, kahl; Fr. kuglig-eiförmig, scharlachroth. Aufsteigender KIstr. bis $2 m$ h. - Felsige Orte, Gerölle d. Kalkalp. $(950-2000$ m.). 5. 6. 7 .

\section{Zwergmispel, S. Chamaeméspilus Crtz.}

Variet. $\beta$. lanuginósa Duftschm. (Aria Hostii Jcqu.), Bl. unterseits dünn wollig. Kalkalpen; - - tomentósa Willk. (Pirus sudética Tsch.) Bl. unterseits nebst Kelchen u. Bltstieleia griinbis weißfilzig. Riesengeb.

Blbl. ansgebreitet, weiß.

3. Bl. dnppelt gesägt, eiförm., elliptisch od. rundlich, unters. schnee. weiß-filzig; Fr. länglichrund, scharlachroth od.'gelblich. Str. od. B. Laubwäld., Gebüsche auf Kalk; gemein in d. Kalkalp., anç Ziergehölz. 5. 5 .

Mehlbirne, S. Ária Crantz.

Bl. ringsherum gezackt od. eingeschnitten gelappt od. fiedertheilig. 4.

4. Bl. eiförm.-länglich, spitz, seicht gelappt, unterseits grauweißfilzig, im Herbst roth; Lappen abgerundet, gesägt; Fr. kuglig, scharlachroth. Str. od. kl. B. - Ziergehölz aus Schweden, wild (?) im Riesengrund d. Riesengeb. Ђ. 5. 6 .

S. scándica Fr.

Bl. br. eiförmig, am Grunde oft herzförm., spitz, ringsherum mit 3 eckigen Lappen.

5. Bl. unterseits bleibend granflzig, Lappen gesägt, gegen d. Blbasiss größer werdend u. abstehend; Fr. kuglig, scharlachroth. Str. - Bergwälda. in 0e.; zerstreut, in d. subalpinen Regionen häufig. Ђ. 5. 6. 
Bl. beiderseitż kahl, mit gr. 3 eckig-eiförm., zugespitzten, ungleich gesägten Lappen (die untersten abstehend); Fr. länglichrund, lederbraun, gelb punktiert, essbar. B. od. Str. - Gebirgslaubwäld., zerstreut; auch Zierb. 5. 5. Els bee r-, Elz ebeerbaum, S. torminális Crtz.

6. (1). Trugdold. reichbltig, Fr. länglichrund, $8-10 \mathrm{~mm}$ l., scharlachroth, herbsauer. - Wälder, Gebüsche bis in d. Alpenregion, wo strauchig; überall cult. 5.5 .

Eberesche, Ebschbeerbaum, Vogelbeerb., S. Aucupária L.*).

Trugdolde armbltig, Blt. größer, Fr. birnförm., bis $25 \mathrm{~mm}$ l., gelbgriin u. röthlich, essbar. - Bergwäld. in Lr., hin u, wieder als Obstb. cuit. 5.5 .

Speierling, S. doméstica L.

\section{Pirus L. Apfel-, Birnbaum (XII, 2).}

B. (selten strauchig) mit unbewehrten od. bisweilen dornspitzigen Zweigen $\mathrm{u}$. gestielten einfachen $\mathrm{u}$. ganzen $\mathrm{Bl}$.; Fr. gr. (mindestens $25 \mathrm{~mm}$ br.).

1. Fr. kuglig, am Grunde genabelt; Stammrinde abblätternd, Krone unregelmäßig, breit: A p felbäume.

Fr. länglich od. kuglig, in d. Stiel verschmälert; Stammrinde längsrissig, nicht abblätternả; Krone pyramidal: Birnbäume.

2. Fr. kirschengroß, l. gestielt, roth, gelb, od. roth- u. gelbbackig, säuerlich-süß od. herb; Blt. I. gestielt, weiß; Bl. l. gestielt, oval-länglich od. eiförm., feingesägt, kahl. - Zierb. aus China (?). Ђ. 5. 6.

Kirschen apfel, Paradiesapfel, P. prunifólia W.

Fr. größer, sammt d. BIt. kurz gestielt.

3. Blkr. sehr gr. (bis $5 \mathrm{~cm}$ br.), meist halb gefüllt, vor d. Blühen purpurroth, dann außen rosenroth; Bl. eiförmig-länglich, gesägt, kahl. Zierb. aus China. 5. 5. 6.

Prachtapfel, $P$. spectábilis Ait.

Blkr. $25 \mathrm{~mm}$ breit od. größer, weiß od. außen purpurn od. rosenroth; Bl. eiförmig, spitz, gekerbt. Ђ. 5.6. Gemein. A p felb. P. Malus L.

Variet. $\alpha$. silvestris Mill. Zweige meist dornspitzig, Bl., Bltstiele und Kelche kahl, Fr. grünlich, herbsauer. - Laubwälder, Gebüsche, oft strauchig: Holzapfel; - $\beta$. tomentósa Koch, Zweige oft dornspitzig, Bl. unterseits wie auch $d$. Bltstiele und Kelclie filzig. Wie vorige, selten; $-\gamma$. hortensis Willk. Unbewehrt, sonst wie vorige Var., Fr, süß: Z a hm er A pfelb.

4. (1) Bl. (wenigstens d. entwickelten) kahl, ei- oder herzeiförmig, spitz, fein gesägt; Blt. lang gestielt, weiß, 25--38 $\mathrm{mm}$ br., Bitstiele ohne Deckbl., Fr. länglich (birnförmig). †. 4. 5.

\section{Gemeiner Birnb., P. commúnis L.}

Variet. $\alpha$. Pyraster Wallr. Zweige dornspitzig, Fr. am Grunde abgerundet, sehr herb, sammt d. Frknoten u. jungen Bl. kahl. B. od. Str. Wälder: Holzbirne; $-\beta$. A chras Wallr. Zweige dornspitzig, Fr. in den Stiel verschmälert, herb; junge Bl. und Frkn. wollig. Waldränder, um Ortschaften: Holzbirne; \%. hortensis Willk. Zweige wehrlos, sonst wie vorige Var., Fr. süß: zahmer Birnbaum.

*) Als Zierb. häufig angepflanzt: S. hýbrida L. (= S. Aucuparia, Aria). B1, am Grunde fiedertheilig bis fiederschnittig, sonst ganz od, eingeschnitten gelappt, unterseits weilgrau-filzig mit gesägten Lappen; Fr. kugelrund, scharlachroth. 
Bl. unterseits sammt Bltstielen u. Kelchen bleibend filzig, Bltstiele mit kl. Deckblättchen, Zweige unbewelrut.

5.

5. Bl. ganzrandig, länglich-lanzettförm., elliptisch od, verkehrt-eiförmig, unterseits weiffilzig; Blt. in lockeren Doldentrauben, $25 \mathrm{~mm} \mathrm{br}$., Stbb. rosenroth; Fr. kuglig, $25-38 m m$ br., grün u. herb od. gelb- und rothbackig und (nach $d$, ersten Frösten) essbar (P. nivális Jcqu.). Wild (?) in Noe, (grünfrüchtig), sonst als Zierb. cult. ち. 5.

Schneebirne, $P$. amýgdalifórmis Vill.

Bl. grob- und eingeschnitten-gesägt, eiförmig, unterseits graufilzig; Blt. in dichten zusammengesetzten Trugdolden; Blks. 18 mm br.. Stbb. purpurn; Fr. kreiselförmig, 3-5 cm l., roth- u. gelbbackig, sïß. - Zierund Obstbaum aus d. Elsass. 5. 4. 5.

\section{Hag ebuttenbirne, P. Pollvéria L.}

\section{Cydónia Tourn, Quitte (XII, 2).}

1. Bl. eiförmig od. oval, ganzrandig, oberseits (alt) grün, unterseits graufilzig; Blt. nach d. Laubentfultung sich öffıend, gr, weiß od. außen blassrosa; Fr. gr., apfel-od. birnförmig, hart, citrongelb, wollig, sehr wohlriechend. - Obstgehölz aus Asien, verwild. an Waldränd. in 0e. Ђ. 5.

C. vulgáris $\mathrm{L}$.

2. Bl. oval, gekerbt-gesägt, kahl; Blt. vor dem Laubausbruch erscheinend, Blkr. scharlachroth, seltener blassrosa, $25 \mathrm{~mm}$ br.; Fr. kl., kahl, grün, geruchlos. - Zierstr. ans Japan. 5. 4. 5. C. japónica P.

\section{Fam. CXXXIII. Rosáceae. Rosenartige.}

\section{Schliissel der Gattungen.}

1. Bltachse (Bltboden) als ein hohles, oben offenes Organ $\nabla$. Krug od. Kugelgestalt entwickelt, welches zahlreiche Einzelstempel (Karpellen) einschließt, deren Gr. aus der oberen Öffnung hervorragen; Stbg. viele, Kelch- u. BlbI. 5, erstere mit dem oberen Rande der einen unterständig. Scheinfrkn. bildenden Bltachse verwachsen, welche durch Verdickung und Fleischigwerden zur Hagebutte (Rosenfr.) wird; eigentliche Fr. niisschenartig, 1 samig. Rosa (686).

Bltachse scheibenförmig, oft mit centraler convexer bis kegelförmig. Erhöhung, welche die zahlreichen Karpellen trägt; Kelchbl. mit d. Scheibe verwachsen. zipfel.

2. Zwischen den Kelchzipfeln keine einen Außenkelch bild. Neben-

Zwischen den Kelchzipf. meist kleinere, einen Außenkelch bildende Nebenzinfel; Karpell. zu 1 samigen trockenen Nisscben werdend. 4.

3. Kelchzipfel und Blbl. 8-9, Stbg. und Karpell. viele, letztere auf halbkugliger Erhöhung, in trockene, von 1. fedrigen Gr. gekıönte Nüsschen sich umgestaltend.

Dryas (691).

Stbg. und Karpell. viele, letztere auf einer centralen kugel-oder walzenförmigen Erhöhung d. Bltbodens sitzend, zu 1 samigen Steinfrüchtchen werdend, welche gegenseitig verwachseud eine zusammengesetzte Beere (Him-, Brombeere) bilden Rubus (687).

4. Kelch- und Außenkelchzipf. 4.

Kelch- u. Außenkelchzipf., wie auch Blbl. 5. 
5. Blkr. fehlend, Kelch- u. Außenkelchzipfel (diese sehr kl.) 4, Stbg. 4 (selten 1-2), Karpell. 1-2. Alchemilla (695).

Blkr. vorhanden, Stbg. und Karpell. viele.

6. Staubg. und Karpellen 5 od. 10; Blt. sehr klein (besonders dio Blbl.), zu $3-6$ in endständ. Doldentriiubchen.

Staubgefüße und Karpellen viele.

7. Blbl. abfallend.

Sibbaldia (692).

Blbl. stehenbleibend, lanzettförm., zugespiłzt; Centrum d. Bltbodens nach d. Blühen anschwellend, schwammig-fleischig werdend.

Comarum (688).

8. Bltboden nach dem Blühen zu einer fleischig-saftigen Scheinbeere werdend, welche d. Nüsschen in Grübchen d. Oberfäche trägt (Erdbeere). Fragaria (689).

Bltboden nicht anschwellend und trocken bleibend.

9. Centrum des Bltbodens convex, Gr. nicht gegliedert u. sich nach dem Blühen nicht verlängernd, Nüsschen deshalb ungeschwänzt.

Potentilla (693).

Centrum des Bltbodens einen walzenförmig. Karpellenträger bildend; Gr. oft gegliedert, nach dem Verblühen sich verlängernd, Nüsschen deshalb geschwänzt.

Geum (690).

\section{Rosa L. Rose (XII, 3).}

Bl. unpaarig gefiedert mit an d. Stiel angewachsenen Nebenbl. und gesägten oder gezähnten Blättchen; Blt. einzeln oder doldentraubig am Ende junger Seitensprossen. Stachlige, alljährlich sterile Blsprossen (Schößlinge) treibende, sehr variierende, zur Bastardbildung geneigte Sträucher*).

1. Blbl. gelb oder innen scharlachroth, Kelchzipf. meist fiederspaltig; Blkr. bis $5 \mathrm{~cm}$ br., nach Wanzen duftend. Bis $2 \mathrm{~m}$ h. - Zierstrauch aus Südeuropa, hier und da in Hecken verwildert. 5. 6. R. lútea Mill.

Blbl. rosa, purpurn oder wei 6 , gleichfarbig.

2. Nebenbl. der sterilen Zweige röhrig-rinnig, d. blttragenden flach; Blättchen (5-7) kl., ellipt. od. länglich, einfach gesägt, ohne Drüsen; Blt. ainzeln, Blkr. 25-50 $\mathrm{mm}$ br., rosa (in Gärten meist halbgefüllt); Scheinfr. kl., kuglig, roth. Str. bis $2 m$ h. mit zimmtbraunen Ästen. - Sonnige Hügel auf Kalk in den Alpenländern und in B.; häufig in Gärten. \$. 5 6.

Pfingstrose, Zimm trose, $R$. cinnamómea $L$.

Alle Nebenbl. flach, Stacheln meist zerstreut, selten gegenständ, 3.

3. Stacheln sehr ungleich (größere und kleinere borstenförmige, oft drüsentragende vermengt), an d. Bltzweigen bisweilen fehlend. 4. Stacheln ziemlich gleichförmig, Blättchen meist 5-7, selten 9. 9. ganz.

4. Stacheln d. Schößlinge gerade, Kelchzipf. auf d. Fr. aufgerichtet,

Größere Stacheln gekrümmt, Kelchzipfel meist fiederspaltig.

*) Es kann hier weder auf die Bastarde, noch auf die zahlreichen Formen, welche neuerdings von $H$. Braun und A. als eigene Arten in der österreichischen Flora unterschieden worden sind, Rücksicht genommen werden, da es einestheils unrnöglich ist, diese sogenannten Arten mit wenigen Worten kurz u. verständlich nach der allalytischen Methode za unterscheiden, anderntheils die meisten derselben nur ein sehr be. schränktes locales Vorkommen besitzen. Wer dieselben kennen lernen will, studiere die "Nachträge zur Flora Niederösterreichs" von Halacsy und H. Braun (Wien, 1882) und Oborny's Flora von Mähren und Schlesien, 4. Th. (Brünn, 1887). 
5. Blbl. weiß, nit gelbem Grunde, Blkr. 25-38 mm br., Bltstiel stets gerade, Fr. kuglig, dunkelbraun bis schwarzblau. Str. $1-1 \cdot 3 \mathrm{~m} \mathrm{~h}$, Blättch. 6-13, kl. Sehr variierend. - Buschige Kalkhügel, sehr zerstreut, auch Zierstrauch. Ђ. 5. 6.

R. pimpinellifólia $\mathrm{DC}$. roth.

Blbl. hellpurpurn, Bltstiele nach d. Verblühen zurückgekrümmt, Fr.

6. Bltzweige wehrlos, Schösslinge gedrängt stachlig; Blïttch. $7-11$, unterseits blass, kahl, einfach bis doppelt drüsig-gesägt, Blkr. 38-50 $\mathrm{mm}$ br., Fr. in einen Hals verschmälert. Aufrecht od. aufsteigend, $0 \cdot 30-1 \mathrm{~m} 1 .-$ Alpen, Hochgeb. v. B. u. Mh. an feuchten steinigen Plätzen. 5. 6. 7.

R. alpina $\mathrm{L}$.

Bltzweige stachlig, Blättchen 5-7, unters, weißlich-grün u. zerstreutdrüsig; Fr, nicht in einen Hals verengt, sonst wie vor. - In Unter-St. Ђ. 5 .

$R$. reversa W. Kit.

7. (4) Nebenbl. d. Bltzweige größer u. oreiter als die d. sterilen, Blättcì. 5-7, gr., eiförm. od. oval, unterseits flaumig; Kelchzipf. ganz od. oben fiederspaltig, Blkr. purpurroth, $3 \cdot 8-7.5 \mathrm{~cm}$ br,; Fr. kreiselförmig, roth mit abstehenden od. aufiechten Kelchzipf.; Str. 1.3-2 m h. - An Iecken in Noe., Sz.; auch Zierstr. mit halbvollen Blumen. \$. 6.

\section{$R$. turbináta Ait.}

Nebenbl. aller Zweige gleich, schmal, Kelchzipf. fiederspaltig, Blume purpurrotb, gr.; Fr. kuglig, orange bis bräunlicl.

8.

8. Aufrechter Str. bis $1 m$ h., wenig stachlig, Blättch. länglich, gr.s drüsig-zähnig; Blume meist halb gefiillt. - Zierpf. aus Südeuropa \$.6.7, Essigrose, $R$. gállica L.

Halbstr., kriechende unterirdische Stämmchen treibend, oberirdische aufsteigend, $30-50 \mathrm{~cm}$ 1.; größere Stacheln schmal, schwach gekrümmt, Bltzweige dicht drüsenborstig; Blättch. rundlich-elliptisch, unters. bläulichgrün, drüsig-gesägt. - Bebuschte Hügel, besond, auf Kalk, in B., Mh., Ooe, Sz.; 5 . 6 .

R. austriaca Crantz.

9. (3) Gr. in eine vorragende Säule verwachsen, Nebenbl. gleichgeformt, $\ddot{A} s t e$ 1. rankenartig.

10.

Gr. nicht verwachsen, ab. bisweilen dicht zusammengedrängt, äußere Kelchzipf. meist fiederspaltig.

11.

10. Blättch. (5-7) diinn, eirund od. elliptisch, unters. blassgrün, einfach gesägt; Endzipf. d. Nebenbl. eiförmig, gerade; Blt. kl. zu 1-10 doldig, Blbl. weiß, Grsäule kahl; Stämmehen niedergestreckt, Äste liegend od. aufsteigend. - Holzschläge, Hecken, Waldränd. in Mh. u. Oe. ந. 6. $R$. arvensis Huds.

Blättch. (5-7) lederartig, glänzend grün, von mehrjähr. Dauer, eiförm. bis rundlich; Endzipf. d. Nebenbl. lanzettl. mit abwärts gebogener Spitze; Blt. zu 2-3, weiß od. blassrosa, Grsäule zottig. Zierstr. aus Südeuropa, in d. südl. Alpenländ. 5. 6 .

$R$. sempervirens $\mathrm{L}$.

11. Blättch. unterseits drüsig (wenigstens auf $d$. stärkeren Seitennerven), doppelt-drüsig-gesägt.

12.

Blättch, unterseits drüsenlos (höchstens am Mittelnerv drüsig), einfach od. doppelt gesägt; Sägezähne drüsenlos.

19.

12. Blättch. meist kl., unters. sehr drüsenreich; Stacheln íwenigstens größere) sichelförm.

13.

Willk om m, Schulfora. 
Blättch. (5-7) kl., unters. armdrüsig, od. gr., drüsenreich (dann d. Stacheln fast od. ganz gerade.)

13. Stiele der einzeln od. zu 2-5 stehenden Blt. sammt d. Kelchzipf. u. Scheinfrkn. kahl; Blättch. entfernt, länglich od. schmal elliptisch, keilig, spreizend grobgezähnt, Zähne drüsig, gezähnelt; Blkr. kl., weißlich selten rosa; Fr. eilänglich, orangeroth; Aste ruthenförm. mit starken hakigen Stacbeln. Str. bis $2 m$ h.; sehr variierend. - Gebüsche, Hecken, auf Kalk in B., Mlı., Oe.; 5.6.

R. sépium Thuill.

Bltstiele u. Kelchzipf. stieldrüsig, Fr. kahl.

14.

14. Blkr. 25-50 mm br, rosenroth, nach Wein duftend, Blt. meist einzeln; Blättch. oval, abstehend grobgezähnt, unters. klebrig-drüsig; Fr. kuglig, blutroth. Stämmchen $0.6-1 \cdot 3 \mathrm{~m} \mathrm{~h}$, mit starken sichelförmigen u. feinen geraden Stacheln. Sehr variierend. - Gebüsche, Hecken, Waldränd. zerstreut. Ђ. 6 .

R. rubiginósa L.

Blkr. d. einzelnen od. zu 2-S doldigen Blt. kl., blass fleischfarben; Blättch. br. oval, hellgriin, behaart, doppelt bis mehrfach gesägt; Fr. ei- bis fast flaschenförm., scharlachroth; Stämmchen bis $2 m \mathrm{~h}$., Äste bogig mit gleichförm. hakigen Stacheln. Sehr variierend. - Gebisclie in Ml.. u. Noe.; zerstreut Ђ. 6 .

R. micrantha Sm.

15. (12) Kelchzipf. an d. Fr. zurückgeschlagen; Fr. roth.

16.

Kelchzipf, an d. Fr. aufgerichtet od. abstehend, Fr. roth; Stacheln gerade od. schwach gekrümmt, 1. u. dünn, Bltstiele stieldrüsig; Blättchen 2 fach gesägt, unterseits fast graufilzig.

18.

16. Stacheln br., halkig, gelbbraun; Blt. einzeln od. zu $2-4, \mathrm{kl}$., mit kahlem Stiel; Blbl. weiß, rosa gesäumt, Kelchzipfel fiedertheilig, drüisiggesägt; Blättchen (5-7), kl., dicklich, rundlich, oberseits glänzend dunkelgrün, unterseits feinfilzig; Fr. eiförmig, gr.; Str. 1.5 $m$ l. - Gebüsche in Wh., Noe., Sz., T.; zerstreut. †. 6 .

R. tomentella Lém.

Stacheln fast gerade, Blkr.gr., intensiv rosenroth, äußere Kelchzipfel fiederspaltig, alle mit 1. schmalem Anhängsel; Blättchen doppelt bis mehrfach gezähnt; Bltstiele u. Kelchzipfel stark stieldrüsig.

17.

17. Blättchen beiders. kahl, steif, elliptisch; Bit. zu 1-4, von br. Deckbl. gestützt; Blkr. bis $5 \mathrm{~cm}$ br., Fr. gr., eiförmig. Str. bis $1 \mathrm{~m} \mathrm{~h}$., Äste blau bereift, alle mit derben, etwas gebogenen Stàcheln. - Sonnige bebuschte Hügel, auf Kalk in B., Mh., Noe.; zerstreut. $\hbar .6$.

R. trachyphýlla Rau.

Blättch. gr., starr, br. oval, obers. kahl, bläulichgrün, unters. zerstreut behaart, weißlich; Blt. zu 1-3, kleiner; Fr. lang gestielt, gr., kuglig od. eiförmig. Untere Äste u. Stämmchen mit 1. dünnen gerad. Stach., obere wehrlos. - Gebüsclie in Mh. u. Noe.; zerstreut. Ђ. 6 .

R. Jundzilliána Bess.

18. (15) Blättch. oval bis länglich-lanzettförmig, sammtig-weichhaar., graulich oder oberseits mattgrün; Bltstiele zu $1-3$, frtragende übergebog.; Blkr. 25-50 mm 1., hell- bis dunkelrosa, mit drïig gewimperten Bl.; Fr. sehr gr., kuglig od. birnförmig, bläulich bereift. Str. $0.6-1: 3 m \mathrm{~h}$., sehr variierend. - Waldränder, Hecken, Gebüsche; zerstreut. Ђ. 6.

$R$. pomífera Herrm.

Blättch. eiförm. od, elliptisch, stumpf od. spitz, weichhaarig od. fast kabl, unters. stets graugrü; Bltstiele einzeln bis doldentraubig, frtragende aufrecht, gerade; Blkr. wie bei vor., bleichrosa, Blbl. nicht gewimpert; 
Fr. ellipsoidisch bis kuglig, nicht bereift, Kelchzipfel abfallend. Str. 0.5 bis $1.5 \mathrm{~m}$ h. - Wie vorige, noch mehr variierend. $\hbar .6$.

R. tomentósa Sm.

19. (11) Blättch. beiderseits od. nur unterseits (auf d. Nerven) nebsi d. Blstiel behaart. 20.

Blättchen kahl, 5-7.

23.

20. Gr. in eine dicke Säule zusammengedrängt, welche kürzer als d. Stbg. ist, kahl; Blkr. hellrosa od. weiß, länger als d. fiederspait. Kelch. zipfel; Bltstiele zu 1-12 (doldentraubig), kahl od. stieldrüsig, Fr. eiförm., scharlachroth; Blättchen länglich-elliptisch, 1 fach gesägt. Großstr. - Gebüsche in Noe. u. St.; zerstreut. 5. 5. 6.

B. systyla Bast.

$\mathrm{Gr}$. frei od. in ein vorragendes Köpfch. zusammengedrängt. 21.

21. Kelchzipfel an d. Fr. ausgebreitet od. aufgerichtet, bleibend, Grköpfchen wollig; Blättchen (5-7) lederig, elliptisch-verkehrt-eifürmig, einfach gesägt, unters. rauh, alt dicht graufilzig; Bltstiele zu 1-3, Blkr. lebhaft rosenroth; Fr. kuglig bis birnförmig, orange- od. scharlachroth. Grstr. mit derben sicheltörmigen Stacheln. - Gebüsche in B., Mh., Oe., Sz.; zerstreut. Ђ. 6. 7.

R. coriifólia Fr. $5-7$.

Kelchzipfel zurückgeschlagen, abfällig; Bltstiele zu 1-3, Blättchen

22. Bltstiele dick, filzig, zerstreut, stieldrüsig, Blkr. hellrosa oder Heischfarben, Fr. eiförmig, orangeroth; Blättchen genähert, breit-eirund bis rund, einfach u. stachelspitzig gezähnt, oberseits kahl, unterseits flaumig; Str. 1-2 $m$ h. - Gebüsche in B., Mh., Noe.; zerstreut. \$. 6.

R. cóllina Jequ.

Var. alba (L.). Blättchen gr., Blkr. weiß od. rosig angehaucht, meist halbgefüllt. Zierstr. u. in Hecken verwildert: "W e i Be Rose".

Bltstiele schlank, l., kahl, Blkr. bleichrosa bis weiß, Fr. kuglig, scharlachroth; Blättchen elliptisch od. oval, einfach gesägt, gewimpert, oberseits angedrückt dünnbehaart, unterseits dicht weichflaumig; Str. 1 bis $2 m$ h. - Waldränder, sonnige Hügel; zerstreut. $\hbar$. 6.

\section{$R$. dumetórum Thuill.}

23. (19) Kelchzipfel an d. Fr. zurückgeschlagen, abfällig, Fr. ei- bis Alaschenförmig, scharlachroth, Blkr. bis $5 \mathrm{~cm}$ br., gr., hellrosa od. fleischfarben, äußere Kelchzipfel reich fiederspaltig; Blättchen oval od. elliptisch, einfach gesägt, Blstiel stachlig, Stacheln (alle) derb, breit, hakig. Str. 2 bis $3 \mathrm{~m}$ h. Höchst vięlgestaltig. - Hecken, Gebüsche. ந. 5-7.

Hundsrose, Heckenrose, $R$. canina $\mathrm{L}$.

Kelchzipf. an d. Fr. abstehend od. aufgerichtet, bis zur Reife bleibend; Zweige bläulich bereift.

24.

24. Stacheln sichelförm., zahlreich, Blt. zu 3-7 auf kurzen in d. bltragenden br. Deckbl. verborgenen Stielen, Blkr. $3 \mathrm{~cm}$ br., lebhaft rosa; Blättch. gr., br. eirund, einfach gesägt, unters. bläulichgrün; Str. 1.5 bis $2 m$ h. - Raine, Hügel in 0e., Sz., T.; zerstreut. h. 6. R. glauca Vill.

Stacheln gerade od. fast gerade, schlank, Fr. kuglig, scharlachroth. 25.

25. Kelchzipf. meist ganz, mit lanzettl. Anhängsel, kahl, länger als d. $13-38 \mathrm{~mm}$ br. rosenrothe Blkr.; Bltstiele $\mathrm{zu} 2-15$, doldentraubig, Blättch. elliptisch od. länglich, einfach gesägt, meist sammt d. Nebenbl. 
u. jungen Zweigen roth überlaufen; Str. 1-1.5 $m$ h. - Waldränd., Gebiische der Alpenthäler, auch Zierstr. (R. rubifolia Vill.). †. 6. 7.

R. ferruginea Vill.

Kelchzipf. (d. 3 äußeren) fiederspalt, am Ricken dicht stieldriisig, kürzer als d. kl. blass rosenrothe Blkr., Blt. zu 1-4; Blättch. kl., rundlich-oval, fast einfach gesägt, sammt d. Zweigen blutroth überlaufen. Str. 1-2 $m$ h. - Gebuische d. Voralpen in Noe. u. St.; zerstreut. 5.6 .

$R$. montána Chaix.

\section{Rubus L. Him •, Brombeere (XII, 3).}

Bl. meist haudförmig zusammengesetzt, selten einfach; Blt. meist in endständ., aus Trugdolden gebildeten Sträußen.

1. Wehrlose Kr., Bl. beiderseits grün.

Sträucher mit aufrechtem Bltstäinmchen u. aufsteigenden od. niederliegenden sterilen, meist reich beblätterten Schösslingen.

2. Bl. herz-nierenförm., 5 lappig, ungleich gesägt; St. $5-15 \mathrm{~cm}$ h., 1 bltig, Blkr. gr., weiß; Beere gelb, säuerlich-süß. - Torfwiesen des Riesen- u. Isergebirgs; selten. 4.5. 6.

R. Chamaemórus L.

Bl. 3 zählig, gestielt, Blättch. ei- od. verkehrt-eiförm. bis rautenförm., doppelt-gesägt; Bltst. aufrecht, $10-30 \mathrm{~cm} \mathrm{h.,} \mathrm{sterile} \mathrm{St.} \mathrm{liegend,} 0.3$ bis $1 \mathrm{~m}$ l.; Blt. einzeln achselständ. od. in endstäud. Trugdold., kl., weiß; Beeren aus wenigen gr. Einzelbeeren bestehend, roth, sauer. - Bergwälder, zerstreut. 4. 5. 6.

R. saxatilis $\mathrm{L}$.

3. Bl. handförmig 5 lappig, gr., doppeltgesägt, behaart; Blt. in rispigen Sträußen, Blkr. bis $5 \mathrm{~cm}$ br., pfirsichroth; Str. $1-1^{\circ} 6 \mathrm{~m}$ h. Zierstr: aus Nordamer., in Hecken oft verwild. $5.5-9 . \quad R$. odorátus L.

Bl. gefingert zusammengesetzt, $3-5-7$ zählig. Stachlige Str. 4.

4. Bltstämmchen u. Schösslinge rund, bläulich bereift. 5 .

Bltstämmchen $u$. besonders $d$. Schösslinge meist kantig, nicht bereift, sammt d. Bl.- u. Bltstielen stachlig, anßerdem mit od. ohne Stieldrüsen, kahl od. behaart; Bl. 3-5 zählig, kahl od. behaart bis filzig mit. verschieden gesägten Blättch.; Blt. in aufrechten Sträußchen od. Rispen, Blkı: weiß, selten blassrosa; Beeren schwarz od. schwarzbraun, nicht bereift von dem kegelförm. Bltboden sich nicht ablösend, aromatisch-süß. Höchst veränderlich. - Wälder, Gebüsche, Hecken. 5. 6-8.

Brom beere. $R$. fruticósus $\mathrm{L} *$ ).

5. Untere Bl. 5-7 zählig, obere 3 zählig, Blättch, unterseits schneeweiß-filzig, gesägt; Blbl. weiß, anfangs aufrecht. Beere roth (in Gärten auch gelb od. weiß), sich von dem walzigen Bltboden ablösend, sïß; Stämme u. Schössl. feinstachlig. - Wälder, Waldränder, Waldschläge u. cult. Ђ. 6. 7 .

Hi m beere, $R$. idaéus L.

Bl. 3-, selten 5 zählig, Blättch. beiders. grün, unters. zerstreuthaarig bis filzig, ungleich doppelt gesägt; Blbl. weiß, ausgebreitet; Beere schwarz, blaubereift, sauer; Stämmchen u. Schössl. fein- bis grobstachlig, erstere 0.3-1 $m$ h. - Äcker, Wälder, Gebüsche. ђ. 6-9. R. caésius L.

*) Wis oben von den Rosen gesagt worden ist, gilt in noch höherem Grade von den Brombeeren. Die zahllosen Formen des $R$. fruticosus $L$, welche neuerdings als Arten unterschieden worden sind, von denen viele wieder überaus variieren und unter einander bastardieren, lassen sich in analytischer Weise kurz und bündig gar nicht un. terscheiden und würde ein Versuch dieser Art den Anfänger nur verwirren. Wer sich eingehend mit dem Studium der Brombeerformen beschäftigen will, den verweisen wir auf: Focke:- Synopsis ruborum Germaniae. Die deutschen Brombeerarten. Bremen, 1877. 8. and Willkom m, Fithrer in's Reich d. Pflanzen Deutschlands, Österreichs u. d. Schweiz. 2. Auflage. Leipzig 1881. 8. S. $656-682$. 
688. Cómarum L. Blutauge (XII, 3).

Wzst. kriechend, walzig, holzig; St. aufsteigend, $30-60 \mathrm{~cm} \mathrm{~h}$, oben äistig; Bl. unpaarig gefiedert mit scheidigem Stiel, Blättch, lanzettförm. orl. länglich, grob gesägt, Blt. endständ., bis $25 m m$ br., purpurbraun. Kalıl. - Sümpfe, an Gräben. 4.6..

C. palustre L.

\section{Fragária L. Erdbeere (XII, 3).}

Wzst. schief od. abgebissen, fadenförmige, liegende u. wurzelnde, entfernt- u. klblättrige Ausläufer treibend. Bl. grundständ., 1. gestielt, .3 zählig, mit verkehrt-eiförm., grobgesägten Blättch.; Bltst. aufrecht, 1 bis 2 blättrig, einfach, gabeltheilig od. trugdoldig-ästig; Blt. trugdollig, gestielt, Blbl. weiß.

1. Kelchzipf, an der Scheinbeere wagrecht abstelend od. zurückgeschlagen.

Kelchzipf. der Scheinbeere angedrückt od. aufrecht od. schiefabstehend.

2. Blstiele wagrecht-abstehend-, Bltstiele angedrückt-behaart; Blkr. 12-16 $\mathrm{mm}$ br., Scheinbeere kuglig od. kegelförm., scharlachroth, kl.; St. 8-15 cm h., Ausl. sehr 1. - Wälder, Gebuische; auch cult. 4. 4-10.

IV a ld erd be e re, $F$. vesca $\mathrm{L}$.

Bl.- u. Bltstiele sammt St. wagrecht-abstehend rauhhaarig; Blkr. $25 \mathrm{~mm}$ br., Scheinbeere gr., eiförm. od. unregelmäßig, röthlich v. grünlichweiß; St. 8-30 cm h., reichbltig. - Bebuschte steinige Hiigel (Stammform der meisten Gartenerdbeeren). 4. 5. 6.

F. elcítior Ehrh.

3. Kelchzipf. der Beere angedriickt. beeren.

Kelchzipf. aufrecht od. schief abstehend. Auslïndische Gartenerd-

4. Blstiele wagerecht-abstehend-, Bltstiele angedrückt-behaart; Blkr. bis $25 \mathrm{~mm}$ br., Scheinbeere kuglig, roth. Der Walderdbeere sehr ähnlich. — Bebuschte Hügel, steinige Abhänge, Holzschläge. 4. 5. 6.

\section{F. cóllina Ehrh.}

Beiderlei Stiele mit aufrechter Behaarung, Blättch. obers. glänzendwrün, Blkr. gr., Beeren sehr gr., verschieden geformt, scharlachroth. Aus Südamerika, cult. 4. 5. 6.

Ananaserdbeere, $F$. grandiflóra Ehrh.

5. Kelchzipf. aufrecht, Blättch. beiders. zottig, Beeren gr., roth. Aus Chile, cult. 4. 5. 6.

Chilierdbeer, $F$. chiloënsis Ehrb.

Kelchzipf. schief abstehend, Blättch. obers. kahl, Beere gr., scharAachroth. - Aus Nordamer., cult. 4. 5. 6.

Him be ere-Erdb., $F$. virginiana Ehrh.

\section{Geum L. Nelkenwurz (XII, 3).}

St. aufrecht od. aufsteigend, meist ästig; Bl. leierförmig- od. untertrochen fiedertheilig bis fiederschnittig; Blt. enảständ., einzeln od. trugdoldig. Behaarte $\mathrm{Kr}$.

1. Gr. gegliedert, oberes Glied abfallend; untere Bl. leierförmig u. razterbrochen fiederschnittig, obere 3 zählig zertheilt; St. 2 -mehrbltig. Abstekend beharate $\mathrm{Kr}$.

Gr. nicht gegliedert, in ein. Federschwanz auswachseild; St. einfach, 1 blig; n'kr grlh, $2538 \mathrm{~mm}$ l. Zottig behaarte Kr. (Sieversia Spr.) 3. 
2. Blt. nickend mit zusammengeneigten Kelchzipf. u. Blbl., Kelchzipf. purpurbraun, drüsig-zottig, Blbl. gelblich-rosenroth, purpurn geadert; St. 15-45 $\mathrm{cm} \mathrm{h.,} \mathrm{meist} \mathrm{einfach} \mathrm{mit} \mathrm{endständ.} \mathrm{Trugdolden.} \mathrm{-} \mathrm{Sumpf-}$ wiesen, Ufer, Gräben. 4. 5-7.

G. rivále L.

Blt. aufrecht, Kelchzipf. nach d. Blühen zurückgeschlagen, Blbl. ausgebreitet, gelb, 8-13 $\mathrm{mm}$ br.; St. $30-60 \mathrm{~cm}$ h., gabeltheilig. - An schattigen Plätzen, Hecken, in Wäldern. 4. 7-9. G. urbánum I.

3. Wzst. ohne Ausläufer, St. $2 \cdot 5-30 \mathrm{~cm}$ h., Stbl. kl. 3 spaltig, Grundbl. leierförmig-fiederschrittig. - Steinige Trieften d. Alp. u. d. Riesengeb. 4. 5. 6.

G. montánum L.

Wzst. liegende beblätterte Ausl. treibend. St. 5-15 cm h., Stbl. kl. fiedertheilig, Grundbl. unterbrochen-fiederschnittig. - Felsen und Gerölleder Alp. von St., Sz., K., T.g (1900-2600); zerstreut. 4. 6. 7.

G. reptans $\mathbf{L}$.

\section{Dryas I. Silberwurz.}

Bl. gestielt, länglich, spitz, grob gekerbt-gesägt und am Rande umgerollt, oberseits glänzendgrün, unterseits schneeweiß-filzig; Blt. 1. gestielt, Blkr. $25 \mathrm{~mm}$ br., weiß; Stämmchen holzig, niedergestreckt, flache Rasen bildend. - Gerölle, steinige Triften und Felsen d. Alpen, mit d. Bächen bis in d. Thäler hinabsteigend. 4. ち. 6-9.

D. octopétala L.

\section{Sibbáldia $\mathbf{L}$. (V, 5 od. $X, 5)$.}

Wzst. vielköpfig, St. liegend od. aufsteigend, $2 \cdot 5-5 \mathrm{~cm} \mathrm{l}$.; Bl. gestielt, 3 zählig, mit keiligen, vorn abgestutzten und grobgezähnten Blättch.; Blt. kl. in endständig. Doldentraub., Blbl. grünlichgelb. Rasenbildend. Gerölle d. Alpen $(1580-2250 \mathrm{~m})$; zerstreut. 4. 7. 8. S. procumbens L.

\section{Potentilla L. Fingerkraut (XII, 3).}

Bl. meist fingerförmig $3-7$ zählig od. unpaarig gefiedert, untere stets gestielt. Ausdauernde, selten einjährige $\mathrm{Kr}$., manche Arten auch strauchig.*)

1. Kleinstrauch bis $1 \mathrm{~m}$ b., Bl. unpaarig gefiedert od. fiederschnitt., Blättchen oval, ganzrandig, unterseits seidig behaart; Blt. in endständigen Rispen, selten einzeln, gr., gelb. - Zierstr. aus Sibirien. $\hbar .7$.

Kräuter. P. fruticósa $\mathrm{L}$.

2. Blbl. rosen- od. dunkelroth.

b) Blbl. weiß.

c) Blbl. gelb.

3. Blkr. schwarzpurpurn, $25 \mathrm{~mm}$ br.; St. liegend oder aufsteigend, ästig, 30-60 cm l.; Bl. 3 lappig, unterseits schneeweiß. - Zierpfl. aus Nepal. 4. 7-9.

$P$. atrosanguinea Lodd.

Blkr. rosenroth, $18-25 \mathrm{~mm}$ br., St. aufrecht, meist $1 \mathrm{bltig}$, bis $7.5 \mathrm{~cm}$ hoch; Bl. 3 zählig, seidenglänzend graufilzig. Dichte Polster bildend. Felsen d. Kalkalpen $(2000-2500 \mathrm{~m})$. 4. 7 .

P. nótida L.

*) Auch diese Gattung zeichnet sich durch Vielgestaltigkeit und Bastardierungsneigung der Arten aus und sind neuerdings, besonders von $Z$ i m meter viele Arten von sehr zweifelhaftem Wert und meist nur beschränkter Verbreitung unterschieden worden, welche hier nicht berücksichtigt werden können. 
4. Untere Bl. unpaarig gefiedert, obere 3 zählig, Blättchen eiförmigrundlich, eingeschnitten-gesägt; St. $30-45 \mathrm{~cm}$ h., gabelästig, oft roth. Abstehend behaart. - Felsen, steinige Plätze. Gebüsche; zerstreut. 4. 5. 6.

Alle Bl. gefingert 3-5 zählig. $P$. rupestris $\mathrm{L}$.

5. Grundbl. 5zählig, Blättch, vorn gezähnt, sonst ganzrandig. 6. gesägt.

Grundbl. 3 zählig, Blättchen von der Mitte od. vom Grunde an

6. St. der ganzen Länge nach beblättert, aufsteigend, $7 \cdot 5-25 \mathrm{~cm}$ lang; Blt. in endständiger zusammengesetzter schirmförmiger Trugdolde, Blkr. 12-16 $\mathrm{mm}$ br. Zottig behaart, dichte Büschel bildend. - Felsen d. Kalkalpen. 4. 7. 8.

$P$. caulescens $\mathrm{L}$.

St. fadenförmig, wenig beblättert, mit 1-5 Blt. am Ende.

7.

7. Grundbl. kurz gestielt, Blättchen vorn 3 zähnig, länglich-lanzettod. keilfürmig, kahl od, unterseits seidig, beiderseits şrün; St. aufsteigend, 2.5-7.5 cm l., länger als d. Grundbl., nebst d. Blstielen abstehend.behaart. - Felsspalten d. Alpen $(1600-2200 \mathrm{~m})$. 4. 7. 8.

\section{P. Clusiana Jcqu.}

Grundbl. 1. gestielt, meist länger als d. $8-30 \mathrm{~cm}$ l. aufsteigende St.; Blättch. nach vorn zu gesägt, länglich-lanzettförm., obers. kahl, unterseits seidenhaarig, silberweif od. grau; Blkr. 16-20 mm br. - Trockene Berg. wiesen, Waldränder; zerstreut. 4. 4. 5. $P$. alba $\mathrm{L}$.

8. (5) Wzst. Ausläufer treibend, St. $3-15 \mathrm{~cm} \mathrm{l.,} \mathrm{so} \mathrm{1.} \mathrm{als} \mathrm{d.} \mathrm{Grundbl.,}$ Blättchen rundlich- od. verkehrt-eiförmig, Blbl. verkehrt-herzförmig; St. v. Bltstiele abstehend zottig (Fragaria sterilis L.). - Bebuschte Hügel, Waldränder, Raine; zerstreut. 4. 4. 5

P. Fragariástrum Ehrh.

Wzst. obne Ausl., St. $2.5-7.5 \mathrm{~cm}$ l., kürzer als d. Grundbl., Blättehen verkehrt-eiförmig od. oval, Blbl. verkehrt-eiförmig, St. u. Bltstiele zottig. Niedrige dichte Rasen bildend. - Steinige Plätzo in Oe., St., T., Kr. ; zerstreut. 4. 4. 5.

$P$. micrantha Ramd.

9. $(2, c) \mathrm{Bl}$. (wenigstens d. unteren) unpaarig gefiedert. 10.

Bl. gefingert $3-7$ zählig.

12.

10. Bl. unterbrochen gefiedert, vielpaarig, Blättch. länglich kammförmig eingeschnitten, unters. seidenglänzend-silberweiß; St. fadenförm., wurzelnd, 15-60 cm l., Blt. l. gestielt, einzeln an d. Stknoten, Blkr. bis $25 \mathrm{~mm}$ br. - Grasplätze, Schutt, Ufer. 4. 5-9.

\section{Gänsekraut, $P$. anserina $\mathrm{L}$.}

Bl. nicht unterbrochen-gefiedert, $2-5$ paarig, Stbl. (wenigstens d. oberen) 3 zählig. St. gabeltheillg.

11.

11. St. niederliegend od. aufsteigend, $15-30 \mathrm{~cm}$ 1., Blättch, länglich od. verkehrt-eiförm., tief gesägt; Blt. einzeln, Blkr. 6-8 $\mathrm{mm}$ br.; Stiele der frtragend. Kelche zurückgekrümmt. - Bebaut. Boden, an Wegen, Dungstätten

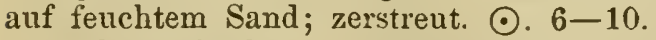

$P$. supina L.

St. aufrecht, $15-30 \mathrm{~cm}$ h., gabeltheilig; Blättch. länglich od. lanzettlich, tief gesägt, Blt. in Trugdolden, stets aufrecht, Blkr. $8 \mathrm{~mm}$ br., kürzer als d. Kelch. Rauhhaarig. - Auf feuchtem Sand an Teich- u. Seeufern in B. u. Mh.; zerstreut. $\odot$ od. $\odot$. 6. 7.

$P$. norvégica $\mathrm{L}$.

12. (9) St. fadenförm., liegend, wurzelnd, $15-60 \mathrm{~cm} \mathrm{1.;} \mathrm{Bl.} \mathrm{l.} \mathrm{ge-}$ stielt, 5- selten 3-zählig, Blättch. länglich od. verkehrt eilanzettlich, tiefgesägt; Blt. 1. gestielt, einzeln an d. Stknoten, Blkr. bis $25 \mathrm{~mm}$ br. Sandige Ufer, Schutt, an Hecken. 4. 6-9.

$P$. reptans $\mathrm{L}$. 
St. aufrecht od, aufsteigend, nie wurzelnd.

13. Bl. 3 zählig

14.

Bl. (wenigstens d. unteren) 5-7 zählig

17.

14. Blättch. unters, schneeweiß-filzig, keilig-eiförm, tief gesägt; St. 2.5-10 cm 1., 1-2 blättrig, 1-4 bltig; Blkr. $13 \mathrm{~mm}$ br. - Grasplätze d. Granitalp. v. T. $(2800 \mathrm{~m})$; stellenweis. 4. 6. 7.

P. nivea L.

Blättch. unters. graufilzig od. kahl u. grün, St. 1-3 blättrig. 15 .

15. Blkr. 16-25 $\mathrm{mm}$ br., Blt. zu $3-10$ in endständ. Trugdolde, St. 13-30 cm h., Blättch. verkehrt-eiförm., tief gesägt. Zottig. - Alpentriften in St., Sz., T.; zerstreut. 4. 7. 8. P. grandiflóra L.

Blkr. 4-8 $\mathrm{mm}$ br., St. 1-2 bltig, 1.3-2.5 $\mathrm{cm}$ l., Blättch. kl., verkehrt-eiförmig. Rasenbildende kl. Alpenkr.

16. Abstehend-zottig, graugrün; Blättchen meist roth mit $5 \mathrm{gr}$. Zähnen. - Gerölle d. höchsten Alp. v. St., K., T. (2200-2800 m), stellenweis. 4. 7. 8 .

$P$. frigida Vill.

Wenig behaart, lebhaft grün, Blättch. spitzgezähnt. - Triften, felsige Plätze d. Alp. $(1260-2500 \mathrm{~m})$ 4. 7. 8.

P. minima Hall.

17. (13) Ein centrale ausdauernde Blrosette, aus deren Achseln d. blttragenden St. alljährlich hervorwachsen.

18.

Keine ausdauernde Blrosette; Bltst. aus d. Köpfen d. Wzst. entspringend, aufrecht, oben trugdoldig-ästig, vielbltig.

23.

18. Blättch. unters. mit silberglänzenden Haarstreifen, sonst kahl u. netzadrig, länglich od, verkehrt-eiförm., vorn grob gesägt; St. $2 \cdot 5-30 \mathrm{~cm}$ h. 1- bis mehrbltig, Blkr. 12-16 mm br., goldgelb. - Triften d. Alp.; d. Riesengeb. u. Gesenkes. 4. 5. 6.

Blättch, unters. ohne silberglänzende Haarstreifen. P. arirea $\mathrm{L}$.

19. St. niederliegend, $15-45 \mathrm{~cm}$ l., oft strahlig ausgebreitet, sehr ästig, reichblättrig u. reichbltig, fadenförm., dünn graufilzig u. abstehend behaart; Blättch. keilig-lanzettförm. bis lineal-keilig, vorn ungleich eingeschnitten; Blkr. 8-12 mm br. - Grasige Hügel in B., Mh., Noe.; zerstreut. 4. 5. 6. P. Gúentheri Pohl.

St. aufrecht aufsteigend od. liegend, armblättrig, mehrbltig. 20.

20. Blättch. vom Grunde an bis zur Spitze gesägt (6-14 Zähne jederseits), grün, unters. rauhhaarig, eiförmig, die d. Grundbl. meist 7; St. 15-30 cm l., Blkr. $13 \mathrm{~mm}$ br. - In Nadelwäldern, an waldigen Orten; zerstreut. 4. 5. 6.

$P$. heptaphýlla Mill.

Variet. $\alpha$. in ter m é di a (Nestl.) Grundbl. 7-od. 5-zählig, Blättch. hellgruin, Bltstiele u. Kelche drüsenlos. In B.; - $\beta$. B o u qu o yán a (Knaf). Grundbl. 7-9 zählig, Blättch. dunkelgrün, Bltstiele und Kelche zerstreut drüsenliaarig. Nord-B.

Blättchen am Grunde ganzrandig, nach vorn zu tief gekerbt oder gesägt; St. $7 \cdot 5-15 \mathrm{~cm}$ l., Blkr. 8-16 $\mathrm{mm}$ br. Sehr nahe verwandte vielgestaltige Arten.

21.

21. Sternhaarig-graufilzig, kriechende niedirige Rasen bildend; $\mathbf{B l}$. 3-5 zählig, Blättchen verkehrt-eiförmig oder eilänglich. - Auf Sand, an sonnigen felsigen Abhängen; zerstreut. 4. 3-5. P P. arenária Borkh.

131. grün, grundständige $5-7$ zählig. 22.

22. St. fadenförm., liegend, schlaff, am Grunde meist purpurn, sammt den Bl. abstehend-lang- und weichhaarig; Blättchen länglich-lreilförmig; Bltstiele 1., mit d. Fr. herabgekriimmt. - Bebuschte Hügel, Waldränder, ılsige Orte; zerstreut. 4 . $4-\dot{0}$.

$P$. opíca $\mathrm{L}$. 
St. liegend oder aufsteigend, grün, nebst den Bl.- u. Bltstielen angedrïckt- oder aufrecht, abstehend kurzharrig; Blättch. verkehrt-eilänglich, untere Nebenbl. lineal, obere lanzett- bis eiförmig. Dichte, schön grüne Rasen bildend. - Steinige sonnige Hügel, Feldraine. 4. 3-5.

$$
P \text {. verna } \mathbf{L} \text {. }
$$

Variet. $\beta$. s a lisburgensis (Hänke). Blättch. breiter, sich gegenseitig mit den Rändern deckend, Nebenbl. d. Grundbl. eilanzettförmig. Der P. aurea ähnlich. Alpentriften $(1900-2500 \mathrm{~m})$; ү. pusilla (Host). Blättch. verkehrt-eiförmig, mit nur 2 Sägezähnen. Kleinblättrig, kurzstenglig aber großblumig. Alpen.

23. (17). Bl. beiders. grün, sammt d. reich beblättert. trugdold.-ästigen vielbltig. St. rauhhaarig, 5-7 zällig; Blättch. grob eingeschn.•gesägt. 24 .

Blättchen oberseits grün, unterseits grau- oder schneeweißfilzig; St. aufsteigend, trugdoldig-ästig, vielbltig.

24. Blättchen an beiden Rändern mit 2-3 eiförmigen Zähnen, die der unteren $\mathrm{Bl}$. (5-7) verkehrt-eiförmig-keilig, die d. obern lineal-keilig; St. meist roth, $15-30 \mathrm{~cm}$ h., Blkr. 18-25 $\mathrm{mm}$ br. - Trockene Grasplätze im südlichen Iír. 4. 7. 8 .

$P$. hirta L.

Blättchen an beiden Räudern mit 6-12 Zähnen, länglich-keilig od. lanzettförmig-keilig, beiderseits od. unten langhaarig; St. aufrecht, 30 bis $80 \mathrm{~cm}$ h., grüin; Blkr. $25 \mathrm{~mm}$ br., schwefelgelb. - Gebüsche, Waldränd., sonnige Hügel; zerstreut. 2. 6. 7.

$P$. recta L.

Variet. $\beta$. obscúra (Willd.), St. meist purpurn überlaufen; zarter; zottiger, Blkr. nur $13 \mathrm{~mm}$ br. - Hier und da.

25. Blättchen unterseits schneeweiß od. silbergrau, am Rande umge. rollt, länglich-keilig oder verkehrt-eiförmig, tief eingeschnitten oder fiederspaltig; St. $15-30 \mathrm{~cm}$ h., Blt. ebensträußig, Blkr. $8-12 \mathrm{~mm}$ br. Raine, Hiigel, Felsen. 4. 6. 7.

$P$. argéntea $\mathrm{L}$.

Blättchen unterseits graufilzig, nicht umgerollt, länglich-lanzettlich, mit 6-10 dreieckigen Zähnen an jedem Rande; St. $15-60 \mathrm{~cm} \mathrm{h.,} \mathrm{weich-}$ zottig und filzig; Blkr. 12-16 mm br. - Trockene grasige Hügel und Abhänge; zerstreut. 4. 5-7.

$P$. canescens Bess.

\section{Tormentilla L. Blutwurz (XII, 3).}

Bl. gefingert $3-5$ zählig, Blkr. kreuzförmig, gelb.

1. St. aufrecht oder aufsteigend, nicht wurzelnd, $8-30 \mathrm{~cm}$ h., gabeltheilig, vielbltig; Grundbl. 3-5-, Stbl. 3 zählig, letztere sitzend; Blättch. länglich-keilförmig, nach vorn zu gesägt. Wzst. knollig, innen blutroth. - Wälder. 2. 6-9.

$T$. erecta $\mathrm{L}$.

St. liegend, fadenförmig, wurzelnd, oft strahlig ausgebreitet. 2.

2. Untere Bl. 5-, obere 3 zählig, Blättch. verkehrt-eiförmig, eingeschnitten-gesägt; Blt. einzeln, blwinkelständig, 1. gestielt, großblumig; St. 15-30 cm 1. Angedrückt-behaart. - Wälder, moosige Triften in den Gebirgen von B. 4. 6. 7.

$T$. reptans $\mathrm{L}$.

Bl. 5- und 3 zählig, unter einander gemengt, 1. gestielt, sonst wie vorige. In B., zerstreut. 4. $6-8$.

T. mixta (Nolte).

\section{Alchemilla L. Frauenmantel (IV, 1, 2).}

St., meist viele, niederliegend oder aufsteigend, meist gabeltheilig; Blt. kl. hellgrỉn, in trugdoldig gruppierten, selten achselständig. Knäueln. 
1. St. dicht beblättert, $3-10 \mathrm{~cm} \mathrm{1.;} \mathrm{Bl.} \mathrm{sitzend,} 3$ theilig, Zipfel keilförmig; 3-5 zähnig, Nebenbl.gr., verwachsen; Bltknäuel kl. seitenständig. - Stoppelfelder, Brachen, Äcker; hier und da. ๑. 5-9.

$\mathrm{S}$ in a $\mathrm{u}, A$. arvensis Scop.

St. armblättrig, ästig; Stbl. kurz gestielt, mit gr. blartigen Nebenbl., Grundbl. l. gestielt; Bltknäuel in endständ. gabeltheiligen Trugdold. 2.

2. Spreite d. Grundbl. rundlich-nierenförnig, ringsherum kurz 7- bis. 9 lappig.

Spreite d. Grundbl. fingerförm., 5-7 theilig od. -schnittig. 5.

3. Bllappen halbkreisförmig, ringsherum gesägt, Stbl. deutlich gestielt, St. $15-30 \mathrm{~cm}$ l. Mehr oder weniger weichhaarig. - Wiesen, Grasplätze. 4. 5-7.

A. vulgaris $\mathrm{L}$.

Variet. $\beta$. subsericea Koch (A. montana W.), Bl. auf beiden od. nur der unteren Seite scidenglänzend behaart. Gebirgstriften der Alpen, Sudeten, d. Riesengeb.

Bllappen nur am Grunde ganzrandig, sonst ringsherum gesägt, obero Stbl: fast sitzenu.

4. Spreite d. Grundbl. bis $1 / 3$ ihrer Länge in $7-9$ verkehrt-eiförmige, fast abgestutzte Lappen getheilt; St. $5-15 \mathrm{~cm}$ h. Weichbehaart. - Triften d. Alpen von Sz., K., T. $(1900-2500 \mathrm{~m})$. 4. 6. 7 .

$$
\text { A. pubescens M. Bieb. }
$$

Spreite d. Grundbl. bis fast zur Mitte in 7-9 verkehrt-eiförmige Stücke getheilt; St. $15-30 \mathrm{~cm}$ l. Ganze Pf. kahl, - Feuchte Triften u. Gerölle, Bachufer d. Alpen und d. Riesengeb. 4. 7. 8. A. fissa Schum.

5. (2) Abschnitte d. Grundbl. 5, verlkehrt-eiförmig-keilig, am Grunde. ganzrandig, sonst eingeschnitten-gesïgt, oberseits kahl, unterseits schwa:h seidenharig; St. $7 \cdot 5-15 \mathrm{~cm}$ h., nelst Bl.- u. Bltstielen abstehend-weichhaarig. - Nasse Plätze, Gletscherränder d. Alpen von T.; zerstreut. 4. 7. 8 .

A. pentaphýlla L.

Abschn. d. Grundbl. 5-9, lanzettlich, nach vorn angedrückt-gesägt, oberseits kahl, unterseits silberweiß-seidenfilzig; St. 7-20 cm 1., nebst Bl. - u. Bltstielen seidenhaarig. - Felsen u. Gerölle d. Alpen (1200 bis $1600 \mathrm{~m})$. 4. 7. 8 .

A. alpina $\mathrm{L}$.

\section{Fam. CXXXIV. Sanguisórbeae. Wiesenknopfartige.}

\section{Aremónia Neck. (XI, 2).}

St. aufsteigend, $2-3$ blättrig, eine $3-6$ blütige Doldentraube tragend; Bl. gestielt, Grundbl. unterbrochen gefiedert, Stbl. 3 zählig; Blt. kl. gelb. - An steinigen waldigen Plätzen in St., Ḱr., 'T. 4. 5. 6.

$$
\text { A. agrimonioídes Neck. }
$$

\section{Agrimónia L. Odermennig (XI, 2).}

St. aufrecht, $0.30-1.25 \mathrm{~m}$ h., meist einfach; Bl. unterbrochen gefiedert, Blättchen grob gesägt, oberseits behaart, unterseits gran-wollfilizig; Blt. kl., gelb, in l. endständ. Ähre. - Raine, Hügel, Grasplätze. 4.6-8. A. Eupatória L.

\section{Potérium L. Becherblume (XXI, 5).}

St. (meist viele) aufsteigend, $30--50 \mathrm{~cm}$ h., einfach $1 \mathrm{köpfig} \mathrm{od,} \mathrm{in}$ 1 köpfige Äste getheilt; BI. fast alle grundständig, unpaarig gefiedert, 
Blättchen eiförmig-rundlich bis länglich, tiefgesägt; Bltköpfchen grünlich od. röthlich; Frkelch 4 kantig, netzrunzlig. Kahl od. behaart. — Sonnige Hügel, Eisenbahndämme, Wegränder. 4. 5-9.

$P$. Sanguisorba L.

Variet. a látu m Willk. (P. polýgamum Waldst. Kit.). Frlkelch an d. Kanten geflügelt, mit erhabenen gezähnten Runzeln. In St., K., Kr.

\section{Sanguisorba L. Wiesenknopf (IV, 1).}

St. aufrecht, $0.30-1 \mathrm{~m}$ h., in bllose $1 \mathrm{köpfige,} \mathrm{doldentraub.} \mathrm{gestellte}$ Äste getheilt; Bl. meist grundständig, unpaarig gefiedert, Blättchen herzförmig-rundlich bis länglich-lanzettförm., scharf gesägt; Bltköpfch. schwarzroth. Kahl. - Frische u. feuchte Wiesen. 4. 8. 9. S. officinalis $\mathrm{L}$.

\section{Fam. CXXXV. Spiraeáceae. Spierstandenartige.}

\section{Spiraéa L. Spierstaude, Spierstrauch (XII, 2).}

Blt. kl., in zusammengesetzten endständ. Doldentrauben, Trugdold., Rispen, Sträußen; Bl. sehr verschieden. Kr. u. Str.

1. Kräuter

Sträucher.

2. Blt. 2 häusig, weiß, sehr kl, in l. schmalen, zu einer federbuschart. Rispe gruppirten Ähren; Kaps. hängend, kahl; St. $1-2 m$ h., ästig, Bl. 2-4 fach fiedrig zusammengesetzt, gr. Blättch. herzeiförm. bis lanzettlich, doppelt-gesägt, ohne Nebenbl. Kahl. - Bachufer, feuchte Gebüsche in Gebirgsthälern, auch Zierpfl. 4.6. 7.

\section{Geisbart, S. Arincus L.}

Blt. zwitterlich, in zusammengesetzten rispigen Trugdold., Kaps. aufrecht; Bl. unpaarig-fiederschnittig mit halbherzförm. gesägten Nebenblättern.

3. Wzst. mit länglichen Knollen, St. $30-60 \mathrm{~cm}$ h. mit $2-3 \mathrm{kl}$. Bl., fast nackt; Grundbl. zahlreich, bis $30 \mathrm{~cm}$ 1., kammförm. fiederschnittig mit kl. fiederspalt. Abschnitten; Blt. weiß. Kahl. - Trockene Wiesen, Triften, Raine. 4. 5-7.

S. Filipéndula L.

Wzst. ohne Knollen, St. beblättert, $0.60-1.50 m$ b., Blabschnitte gr., nicht fiederspaltig.

4.

4. Blt. weiß, Kaps. schraubenförm. gedreht; Bl. unterbrochen-fiederschnittig, Abschnitte ei- od. eilanzettförm., endständige handförmig 3 bis 5 theilig, alle doppelt-gesägt. - Sümpfe, Ufer, auch Zierpt. mit vollen Blt. 4. 6. 7 .

S. Ulmária L.

Blt. rosenroth, Kaps. nicht gewunden; Bl. handförmig-fiederschnittig, gesägt, kahl. - Zierpfl. aus Nordamerika. 4. 7-9 S. lobáta Murr.

5. (1) Bl. unpaarig-fiederschnittig, schmal doppelt-gesägt; Blt. in länglichen od. kugligen Sträußen, weiß. - Zierstr. aus Sibirien. 5. 6. 7. S. sorbifólia $\mathrm{L}$.

Bl. ganz od. gelappt. 6.

6. Blt. in dickeu walzigen, büschelig gruppierten Trauben, weiß; Bl. länglich, ganzrandig, gebïschel.t. Kahl. - Zierstr. aus Sibirien. \$. 5. 6.

Blt. anders angeordnet. 
7. Blt. in pyramidalen Sträußen.

$b$. Blt. in gewölbten od. halbkugligen Doldentrauben, weiß. trauben.

c. Blt. in flachen zusammenges. Trugdold. od. wenigblt. Dolden-

8. Bl. kahl, grün, länglich-lanzettförm., doppelt-gesägt; Blt. hellrosa od. fleischfarben, Äste ruthenförmig. - Laubgebüsche, Waldränder, Ufer in B., Oe., K., St., auch Zierstr. u. in Hecken verwildert. \$. 6-8.

S. salicifólia L.

Bl. unters. weißfilzig, länglich, gekerbt; Blt. rosenroth. - Zierstr. aus Nordamerika. 5.6 . 7 .

S. tomentósa $\mathbf{L}$.

9. (7, b.) Bl. 3 lappig, eingeschnitten-gekerbt, l. gestielt, Kaps. anfgeblasen, oft purpurn, beim Zerdrücken knisternd aufplatzend. - Zierstr, aus Nordamerika, in Hecken verwild. Ђ. 6. 7.

Bl. ganz, Kaps, nicht aufgeblasen.

S. opulifólia L.

10. Bl. eiförm, am Grunde abgerundet $u$. ganzrand., an d. Rändern eingeschnitten-ungleich-gesägt, spitz, kahl; Doldentraub. einfach vielbltig. Str. $0 \cdot 6-1 \cdot 6 m$ h. - An felsigen Plätzen in St. u. Kr.; überall cult., auch verwild, Ђ. 5. 6.

S. ulmifólia Scop.

Bl. verkehrt-eiförmig od. länglich, stumpf, flaumig gewimpert, untere ganzrand., obere gegen d. Spitze gekerbt; Doldentraub. einfach. Str. $0 \cdot 6$ bis $13 \mathrm{~m}$ h. - Gebüsche in St. u. Kr., auch Zierstr. ち. 5. 6.

S. chamaedryfólia L.

11. $(7$, c) Blt. roth, in zusammenges. Trugdold.; Bl. elliptisch eiod. eilanzettförm., l. zugespitzt, am Grunde ganz, sonst doppelt-gesägt, unters. graugrün-filzig. Str. $1 m \mathrm{~h}$. - Zierstr, auz China u. Japan. Ђ. $7--9$.

S. callósa Thb.

Blt. weiß in Doldentraub.

12.

12. Aufrechte Str. von $0.6-2 m$ Höhe.

13.

Zwergstr. mit niederliegenden, $15-60 \mathrm{~cm} \mathrm{l}$. Stämmchen 14.

13. Doldentraub. sitzend, von kl. Bl. umringt, längs d. ruthenförm. $\mathrm{Zweige} \mathrm{auf} \mathrm{Kurztrieb.,} \mathrm{gedrängt} \mathrm{stehend,} \mathrm{einseitswendig;} \mathrm{Bl.} \mathrm{lanzettförm.,}$ 3 nervig, kl., ganzrand. od. an d. Spitze gezähnt. Kahl. - Zierstr. aus Sibirien. 5. 5. 6.

S. hypéricifólia $\mathrm{L}$.

Variet. o bováta (W. Kit.), Bl. keilig-verkehrt-eiförmig. Sonnige Hügel in $\mathbf{K}$. $u$. $\mathbf{K} r$.

Doldentraub. mit beblättertem Stiel, Bl. länglich-lanzettförm., spitz, untere ganzrand., obere an d. Sp. eingeschnitten-gesägt. Kahl. - Bebuschte Hügel in St. u. Kr.; zerstrent. $\hbar .6$.

S. oblongifólia W. Kit.

14. Bl. kahl, länglich spitz, am Grunde ganzrand., sonst ungleich feingesägt, kl; Doldentraub zusammengesetzt. - Felsige Plätze d. Alp. von K., lír. u. Siid-T. Ђ. 5. 6. S. decumbens Koch.

Bl. unters. graufilzig, läuglich-eirund, ganzrand. od. an d. Spitze gezähnelt; Doldentraub. meist einfach. - Ebendaselbst, zerstreut. $\hbar$. 5. S. Hacquétii Fzl. u. C. Koch.

\section{Kérria DC: Goldamsel. (XII, 2).}

Bl. eiląnzettförm., grob- u. ungleich-gesägt, unters. scharfhaarig; Blt. einzeln, endständ., gold-gelb, meist gefiillt. - Zierstr. $1-2 m \mathrm{~h}$. aus Nordamerika. 5. $7-9$. K. japónica DC. 


\section{Fam. CXYYTI. Amygdalúceae. Mandelartige. \\ 702. Amýgdalus L. Mandel. (XII, 1).}

Bl. sehmal, gesägt, spitz; Blt. vor d. Laubausbruch, zu 1-2 seit. lich an d. Zweigen; Steinfr. mit filziger od. sammtiger, selten kahler Schale. B. u. Str.

1. Fr. kuglig gr., schön gefärbt mit sammtig-filziger, selten kahler Schale u. dicker süßer Fleischschicht; Steinkern dickschalig mit kl. Samen, Blt. rosenroth. - Obstb. aus Asien. 5. 4. 5.

Pfirsich bau m, A. Pérsica L.

Fr. zusammengedrückt, mit zottig-filziger Schale, züher ungenießbarer Fleischschicht u. gr. Samen: Mandel.

2. Blt. vor d. Laubausbruch weiß od. blassrosa mit purpurnem Kelch; Fr. länglich od. eiförm, Steinkern mit tiefen Löchelchen, Same süß od. bitter. - Aus Asien. in Kr. u. Süd-T. cult. 5. 3. 4.

Mandelbaum, A. communis $\mathrm{L}$.

Blt. mit d. Laubausbruch, lebhaft rosa mit purpurnem Kelch; Fr. kuglig, Steinkern ohne Löchelchen, Same ungenießbar. - Zierstr. aus Osteuropa, in Noe. u. Mh, verwild. Ђ. 4. 5. Zwergmandel, A. nana L.

\section{Prunus L. Pflaume, Zwetsche, Kirsche (XII, 1).}

Bl. gestielt, gesägt; Blt. weiß, Steinfr. mit dünner Schale und stets saftiger Fleischschicht. B. u. Str.

1. Fr. kuglig, sammtig-filzig, orangegelb, wolllriechend; Blt. zu 1 bis 2 seitenständ., vor d. Laubausbruch; Bl. herzei- od. eiförmig, kahl. Obstb. aus Asien. 5. 3. 4. Aprikose, Marille, P. Armeniaca L.

Fr. kuglig od. länglich, mit kahler glatter Schale.

2. Blt. zu 1-2 seitenst. kurz gestielt, Fr. bereift: Pfla umen. 3.

b) Blt. zu 2-mehrere, l. gestielt in Doldentrauben, mit d. Laubausbruch sich öffnend. Fr. kuglig, unbereift, am Grunde genabelt: Kirschen.

c) Blt. kl., viele, mässig l. od. kurz gestielt, in l. Trauben od. gewölbten Doldentrauben, nach d. Laubentfaltung sich öffnend. Fr. kl. knglig, beerenförmig: Traubenkirschen.

3. Schwarzrindiger, $1-3 m$ h. Str. mit dornspitzigen $Z_{\text {weigen, Blt. }}$ vor d. Laubausbruch, die Zweige dicht bedeckend; Bl. elliptisch-lanzettl., Fr. aufrecht, kuglig, schwarzblau, herb. - Gebüsche, Hecken. Ђ. 4. 5.

Schleh-, Schwarzdorn, P. spinósa L.

Wehrlose Str. u. B., Blt. mit d. Laubausbruch sich öffnend, Fr. meist hängend, Bl. elliptisch od. verkehrt-eiförmig-länglich.

4.

4. Junge Zweige kahl, Blbl. gelblich-od. grünlichweiß, Fr. eiförmiglänglich, dunkel-blau, selten röthlich od. gelb. - Obstb., in vielen Sorten cult. 5. 4. 5 .

$\mathrm{Z}$ wets che, $P$. doméstica $\mathrm{L}$.

Junge Zweige flaumig, Blbl. reinweiß, Fr. kuglig, schwarzblau, violett, roth, gelb, grün; Str. oder B. Wild (Str.) in Hecken, Gebüschen, an Waldrändern, cult. als Obstbaum in vielen Sorten. 5. 4.5. S pilling, Haferschlehe, Kriechenpflaume, Pflaumenb., P. insitítia L.

5. $(2$, b.). Blstiel unter der Spreite mit 2 Drüsen, Bl. gr., schlaff, elliptisch oder verkehrt-eiförmig, unterseits weichhaarig; Fr. schwarz, roth, gelb, süß. B. bis $20 \mathrm{~m}$ h. Wild in Wäldern, cult. in vielen Sorten. 5. 4. 5. Wild: Vogelkirsche, cult.: Siißkirsche, P. ávium L. 
Blstiele ohne Drüsen, Spreite kl., steif, kahl, obers. glänzend. 6.

6. Bl. elliptisch oder verkehrt-eiförmig-länglich, $5-7^{\circ} 5 \mathrm{~cm}$ l., Blkr. 18-25 $\mathrm{mm}$ br., Fr. bis $25 \mathrm{~mm}$ dick, schwarz oder roth. B. oder Str. Ubstb., in vielen Sorten cult., auch verwildert. ち. 4. 5.

Sauerkirsche, Weichsel, P. Cérasus L.

Bl. lanzettförmig oder elliptisch, 13-25 $\mathrm{mm}$ l. seitenständige gebüschelt; Blkr. kaum, $13 \mathrm{~mm}$ br.; Fr. kl., dunkelroth, scharf-sauer. Zwergstrauch $0.15-1 \mathrm{~m}$ h. - Bebuschte Hügel, Bergabhänge in B., Mh., Noe. 5. 4. 5 .

$\mathrm{Z}$ wergkirsche, $P$. Chamaecérasus Jequ.

7. (2, c.) Aufrechte kurze 4-12 bltige Doldentrauben, Blt. l. gestielt; Bl. ei- od. herzeiförmig, od. rundlich, kahl; Fr. erbsengroß, schwarzroth, süßlich; Str. oder B., 1-7 $m$ h. - Waldränder, buschige felsige Plätze auf Kalk in Oe., selten: um Wiener-Neustadt und andern Orten in Noe. im Großen cult., auch Ziergehölz. Ђ. 5. 6.

Steinweichsel, Felsenkirsche, P. Máhaleb L.

Überhängende, vielbltige l. Trauben, Blt. kurz gestielt; Fr. erbsen. groß, bittersüß.

8.

8. Blstiel ohne Drüsen, Spreite oval, zugespitzt, steif, oberseits glänzend grün; Trauben schmächtig, Fr. schwarz. - Ziergehölz aus Nordamerika. 5.6 . 7 .

Blstiel mit Drüsen, Spreite zugespitzt, fast doppelt gesägt, nicht steif noch glänzend.

9.

9. Bl. eiförmig oder länglich, Stiel mit 2 Driisen, Fr. schwarz. Str. oder B. - Waldränder, Gebüsche, Bachufer, auch Ziergehölz. †. 5. 6. Ahl-, Traubenkirsche, P. Padus L.

Var. petraéa (Tausch). Kleinstr. mit fast aufrechten Trauben und grobgesägten $\mathrm{Bl}$. Im Riesengebirge.

Bl. oval, Stiel mit 3-4 Drüsen, Fr. roth. - Ziergehölz aus Nordamerika. †. 4. 5 . $P$. virginiána $\mathrm{L}$.

\section{Fam. CXXXVII. Caesalpiniáceae.}

\section{Cercis L. Judenbaum ( $X, 1)$.}

Blt. vor dem Laubausbruch sich öffnend, in seitenständig. Büscheln, rosenroth, selten weiß; Bl. gestielt, herzförmig-rundlich, ganzrandig, kahl; Hülsen flach zusammengedrückt, bis $8 \mathrm{~cm}$ l., an den Rändern geflügelt, hängend. - Zierbaum aus Südeuropa. Ђ. 4. 5. C. Siliquastrum L.

705. Gledítschia L. (VIII oder IX, 1).

Bl. gr., 1-2 fach paarig-gefiedert, Blättchen verkehrt-eiförmig-länglich; Blt. nach d. Laubentfaltung sich öffnend, grünlich, in walzigen ährenförmigen Trauben; Hülsen hängend, br., flach, gedreht. B. mit starken l., einfachen und 3 theiligen Dornen. - Zierbaum aus Nordamerika. Ђ. 7. Christusakazie, G. triacanthos L.

Fam. CXXXVIII. Papilionáceae. Schmetterlingsblïtige.

\section{Schliussel der Gattungen.}

1. Blos die Fahne entwickelt (diese die vorstehenden Stbg. umhüllend), Flïgel u. Schiffchen fehlend; Hülsen sichelförm. Amorpha (717). 
Vollständige Schmetterlingsblume.

2. Stbf. 2 brüderig ( 9 in eine röhrige Rinne verwachsen, der 10. obere, frei).

b) Stbf. 1 brüderig (alle in eine geschlossene Röhre verwachs.) 26.

c) Stbf. 1 brüderig, aber der 10. (obere) nur zur Hälfte seiner Länge mit den übrigen verwachsen; Hülse gestreckt, vielsamig, Bl. unpaariggefiedert.

Galega (713).

3. Bl. gefiedert, bisweilen ihr Stiel in eine Ranke auslaufend. 4.

Bl. 3·, selten (Dorycuium) 5 zählig.

4. Bl. unpaarig gefiedert, mit gegenständ. Seitenblättchen

18.

Bl. Endblättchen, mit od. ohne endständige Ranke, bisweilen an ihrer Stelle bloß ein rankentragender Stiel (Viciéae).

5. Frucht gestreckt, quer gegliedert, in einzelne Stücke zerspringend (Gliederhülse), selten nussartig, kl., nicht aufspringend (H e dy sár ea e) 6 .

Fr. eine der Länge nach aufspringende mehrsamige Hülse.

8.

6. Fr. nussartig, kl., nicht aufspringend, verkehrt-eiförmig, glatt od. kammförm. gezähnt, grubig-netzadrig, an d. unteren Nath flügelartig-bekielt, 1 samig.

Onobrychis (709).

Gliederhülse.

7.

7. Glieder hufeisenförmig, Gliederhülse gekrümmt.

Hippocrepis (707).

Glieder scheibenförmig, krautstachlig, Gliederhülse perlschnurförmig. Hedysarum (708).

Glieder walzig od, vierkantig, oft geflügelt, Gliederhülse gerade od. gekrümmt.

Coronilla (706).

8. (5) Hülse durch Einbiegung der Näthe 2 fächrig, oft blasig auf. getrieben (Astragáleae)

Hülse 1 fächrig ( $G$ a lég e a e)

9. Schiffchen stumpf, Hülse an d. unteren Nath eingedrückt.

10.

Astragalus (710).

Schifichen !in eine gerade grannenartige Spitze auslaufend, Hülse an d. oberen Nath eingedrückt, oft gestielt.

10. Hülse gestielt aufgeblasen, mehrsamig.

Hülse nicht gestielt, lineal; B. u. Str.

Oxytropis (711).

11. Hülse kurz, kl., behaart; Stiel länger als d. Kelch; Gr. kahl, mit endständ. Narbe. Alpenkräuter.

Phaca (712).

Hülse gr., vielsamig; Gr. hakenförmig, gèwimpert, in d. Biegung d. Narbe tragend. Sträucher.

Colutea (714).

12. Kelch becherförmig, 5 zähnig, Fahne mit zurückgeschlagenen Seiten, Hülse (reif) fast stielrund.

Caragana (716).

Kelch fast 2 lippig, Fahne gr., aufrecht, Hülse zusammengedrückt.

13. (4) Blstiel in eine Wickelranke auslaufend. Robinia (715).

Bl. rankenlos.

14. Nebenbl. gr., den Blättchen ähnlich; Blt. gr., Gr. 3 kantig-flachgedrückt, oberseits gegen d. Narbe hin bärtig.

Pisum (718).

Nebenbl. meist klein, selten blartig; Gr. nicht 3 kantig.

15. St. nie gefligelt, rund od. kantig, Gr. fadenförmig. 

beharart.

St. geflügelt od. kantig, Gr. breitgedrückt Alach, an d. Außenseito

16. Blkr. länger als d, Kelchzipfel, Gr. unter d. Narbe bärtig od. ringsherum behaart.

Vicia (719).

Blkr. kürzer als d. Kelchzipfel, Gr. gegen d. Narbe rundum behart. Ervum (720).

17. Bl. paarig gefiedert, Stiel in ein krautiges Spitzchen auslaufend, St. kantig od. geflügelt; Gr. wie b. Lathyrus. Orobus (722).

Bl. unpaarig gefiedert ohne Endblättch., St. rund od. kantig.

Vicia Faba u. oroboides (719).

18. (3) Gr. unterhalb. d. Spitze außen bärtig, sammt d. Stbg. u. d. Schiffchen schraubig gedreht; Hülse fleischig, innen markig-gefächert.

Gr. kahl, gerade, wie auch Stbg. u. Schiffchen. Phaseolus (723).

19. Schiffchen geschnäbelt, Nebenbl. groß. (Ló te a e)

Schiffchen nicht ceschäbelt spitz od stumpf (Trifoliéa $)$ 20. B1. 3 zählig.

Bl. 5 zählig, Flügel in d. Mitte nach außen backig aufgetrieben, Hülse kuglig 1-2 samig, zuletzt die Kelchröhre zersprengend.

Dorycnium (724).

21. Kelch glockig, ungleich 5 spaltig; Hülse länglich, gerade, inwendig gefächert.

Bonjeania (725).

Kelch trichterförm., 5 zählig, Hülse gerade, nicht gefächert. 22.

22. Hülse stielrund od. zusammengedrückt, Klappen beim Aufspringen sich spiralig drehend.

Lotus (726).

Hülse fleischig, lineal, m. geflügelt. Kanten. Tetragonolobus (727).

23. (19). Stbfbündel mit d. Schiffch. u. d. Flügeln, oft auch sämmtliche Blbl. unter einander in eine Röhre verwachsen; Hülse kl., 1-2 samig, oft nicht aufspringend, von d. verwelkten Blkr. bedeckt.

Trifolium (730).

Stbfbündel mit d. Blbl, nicht verwachsen, diese ebenfalls frei. 24 .

24. Hülse sichel- od. schneckenhausförmig gewunden, mehrsamig, aufspringend.

Hülse nicht gewunden.

Medicago (731).

25. Hülse oval od. lineal, gerade, od. gekriimmt, vielsamig, aufspringend.

Trigonella (728).

Hülse kurz, 1-3 samig, nicht aufspringend, eiförmig, netzgrubig od. runzlig.

Melilotus (729).

26. (2, b.). Flügel nicht gefaltet, Kelch 5 zähnig od. undeutlich 2 lippig (Anthyllídeae).

27.

Flügel über d. Grunde runzlig-gefaltet, Kelch 2 lippig (Genísteae). 28.

27. Untere Bl. 3 zählig, obere einfach; frtragender Kelch offen, Schiffchen geschnäbelt, Hülse kurz, aufgeblasen.

Ononis (733).

Blt. paarig gefiedert mit Endblïttch., Grundbl. bisweilen einfach; frtragender Kelch geschlossen, Hülse kl., 1 samig, im Kelch gestielt, nicht aufspringend.

Anthyllis (732).

28. B1. fingerförmig 5-vielzählig, Schiffch. geschnäbelt, Hülsø ineal, vielsamig; $\mathrm{Kr}$.

Lupinus (734). 
Bl. 3 zählig od. einfach od. beiderlei Formen an esuer Pfl, Nebenbl. fehlend, Schiffch. stumpf; Str. n. B.

29.

29. Kelch 2 blättrig, fast so 1. wie d. Blkr.; Hülse kurz, aufgetrieben, aus d. Kelch wenig vorragend; Bl. einfach, kl. Ulex (735).

Kelch viel kürzer als d. Blume.

30.

30. Bl. alle einfach, ganz 1 . ganzrandig.

Bl. alle 3 zählig od. d. oberen einfach.

31.

31. Äste u. Zweige stielrund, grü, markig, binsenförm., Bl. alle einfach, entfernt; Hülsen 1., lineal, zusammengedrückt, kahl.

Spartium (736).

Äste u. Zweige holzig, nicht binsenartig, bisweilen bedornt od. gefligelt; Hülsen verschieden, meist behaart.

Genista (738).

32. Untere Bl. 3 zählig, obere einfach; Blt. gr'., Schiffchen herabhängend, d. Stbg. entblößend; Gr. 1. kreisförmig zusammengerollt; Hülse lineal, flach zusammengedrückt.

Sarothamnus (737).

Alle Bl. 3 zählig; Schiffchen nicht hängend, d. Stbg. einschließend, Gr. lineal aufwärts gebogen; Hülsen lineal.

Cytisus (739).

\section{Coronilla L. Kronenwicke (XVII, 3).}

Blt. in blwinkelstïndigen gestielten einfachen Dolden.

1. Aufrechter Str. 1-1.6 m h.; Blättch. 2-4 paarig, verkehrt-eiförm. od. länglich-keilig; Dolden 2-3 bltig, kurz gestielt, Blbl. gelb, l. gønagelt; Gliederhülse hin $u$. her gebogen, 3-8 gliedrig. - Auf Kalkboden in d. Voralpen von 0e., St., K.., Kr., T., auch Zierstr.; ち. 4. 5.

\section{C. Émerus L.}

Kräuter mit liegenden od. aufsteigenden, selten aufrechten St. 2.

2. Blkr. bunt, weiß u. rosenroth od. lila, selten ganz weiß, Dold. 12- 20 bltig, 1. gestielt; Huilsen lineal, 4 kantig, 3-12 gliedrig; Blättch. meist 10 paarig, oval od. länglich. - Trockene Wiesen, Raine, auf Kalk u. Sand, 4. 6. 7 .

C. vária L.

Blkr. gelb, St. u. Bl. blaugriin.

3. St. aufrecht od. aufsteigend, $30-45 \mathrm{~cm}$ h., ganz krautig; Blättch. 3-4 paarig, verkehrt-eiförm. od. oval, Nebenbl. verwachsen, kl.; Dold. 15-20 bltig, Gliederhülse 4 kantig, 2-3 gliedr., rosenkranzförmig. Auf Kalkbod. in Oe., St., Kr.; 4.6. 8.

C. montina scop.

St. liegend, am Grunde holzig, ästig 10-20 cm 1.; Blättch. 4-6 parrig gedrängt, verkehrt-eiförmig, oft ausgerandet; Nebenbl. in eine br. häutige Scheide verwachsen; Dold. $4-10$ bltig, Gliederh. 4 Aügelig, 3-8 gliedrig. - Auf trockenem Kalkbod. in B., Oe., St., Kr., T.; zerstreut. 4. 5. 6 .

C. vaginális $\mathrm{L}$.

\section{Hippocrépis L. Hufeisenklee (XVII, 3).}

St. zahlreich, liegend od. aufsteigend, strahlig ausgebreitet, am Grundo holzig; Blättch. 4-7 paarig, grasgrün, die d. unteren Bl. verkehrt eiförmig, die oberen länglich; Blt zu 6-12 in achselständ., l. gestielten Dolden; Gliederhüls. geschlängelt, 1-6 gliedrig. - Auf sonnigem Kalkbod. in Oe., St., K.; zerstreut. $4.5-7$.

H. comósa L. 


\section{S. Heởsarum L. Hahnenkopî (XVII, 3).}

Eläitch. vielpaarig, Blt. in l. gestielten, scheinbar endstãud., dichten kopfigen Trauben.

1. St. einfach, aufrecht od. aufsteigend, mit $d$. Traube $7 \cdot 5-25$ cin 1.; Biättch. eiförm. od. länglich, Blt. purpurblau; Gliederh. hängend, mit 14 rundlichen Gliedern. - An quelligen Plätzen u. Bächen d. Alp. (15S0 bis $22.20 \mathrm{~m}$ ), auch im Riesengeb. (nur im Teufelsgärtchen). 4. 7. 8.

H. obscrirum $\mathrm{L}$.

2. St. ästig, liegend od. aufsteigend, 30-60 $\mathrm{cm} \mathrm{l.,} \mathrm{hohl;} \mathrm{Blättch.}$ verkehrt-eiförmig-länglich, Endbl. größer; Trauben vielbltig, Blkr. glän. zend blutroth. - Zierpfl. aus Südeuropa. 4. 5. 6. H. coronárium L.

\section{Onobrýchis L. Esparsette (XVII, 3).}

St. aufrecht oł. aufsteigend, ästig; Blättch. vielpaarig, elliptisch, länglich od. brlineal; Blt. in blwinkelstäind., l. gestielten, dichten Tratıben, Blkr. rosenroth, purpurn gestreift. - Trockene Kalkhügel, außerdem cult. u. an Eisenbahndämmen u. a. O. verwild. 4. 5. 6. O. sativa L.

\section{Astrágalus L. Traganth (XVII, 3).}

Blättch. meist vielpaarig, Blt. in blwinkelständ. gestielten Trauben, Ahren, Köpfchen.

1. Blkr. purpurulau, violett, lila.

Blkr. weißlich, gelblichweiß, gelb.

2. Nebenbl. frei, am Grunde d. Blstiels.

Nebenbl. verwachsen, d. Blatte gegenüberstehend, Hüls. aufrecht. $\mathbf{5}$.

3. Flügel 2 spaltig, Blt. $6 \mathrm{~mm}$ 1, Hüls. hängend, länglich, stumpf 3 kantig; St. viele, liegend od. aufsteigend, $15-30 \mathrm{~cm}$ l.; Blättch. 7-10 paarig, lineal. - Trockene Hügel, Hänge, Triften auf Kalk in B., MH., Noe., Kr.; zerstreut. 4. 5-7.

Flügel ganz, Hüls. aufrecht.

A. austriacus Jequ.

4. BIt. in lockerbltigen schmächtigen Trauben, 6-S $\mathrm{mm} \mathrm{1.;} \mathrm{Hiilse}$ länglich, stumpf $3 \mathrm{kantig}$; St. aufrecht, $15-60 \mathrm{~cm}$ h., nach oben gefurcht; Blättch. 7-10 parig, lanzettlich od. lineal. - Kictuterreiche Stellen in Noe. zerstreut. 4. 5. 6.

A. sulcátus I.

Blt. in dichtbltigen kopfigen Ähren, 6-12 mm l., Hüls. länglich aufgeblasen, zottig; St. liegend od. aufsteigend, $8-20 \mathrm{~cm} \mathrm{1.;} \mathrm{Blättch.} \mathrm{5-7}$ paarig, länglich od. ellipt. - Trokene Kalkberge in Noe., Kr., T.; zerstreut. 4. 5. 6.

A. vesiccirius $\mathrm{L}$.

5. (2) Fahne lineal-länglich, $3 \mathrm{mal}$ länger als d. Flügel; Blt. $25 \mathrm{~mm}$ 1. in dichten schmalen 1. gestielten Trauben, Hüls. länglich stumpf $3 \mathrm{kan}$ tig, zottig; St. aufrecht, $30-60 \mathrm{~cm}$ h., Blättch. 8-14 paarig, lineal od. lanzettlich. - Trockene Hügel u. Triften in B., Mli., Oe., T., Kr.; zerstreut. 4. 6. 7.

Fahne eiförmig $1 \frac{1}{2}$ mal so l. als d. Flügel. $A$. Onobrychis L.

6. Blättch. 3-4 parig, entfernt, lineal, stumpf; Trauben liaum länger als d. Bl., 4-8 bltig, Hüls. lineal-länglich, grauhaarig; St. liegend od. aufsteigend, 7-30 $\mathrm{cm}$ l. Grauhaarig, seidenglänzeud. - Sandbod., Kiefernhaiden in B. u. Mh.; zerstreut. 24.6.7. $A$. arencirius $\mathrm{L}$.

Blättchen 6-12 paarig, Trauben 1. gestielt, dicht, kopf- od. eiförmig; Hülse rundlich-eiförm., rauhhaarig; St. aufsteigend. Argedrückt behaarte $\mathrm{Kr}$. 
7. Kelch langröhrig, abstehend-sclıwarzhaarig, Blkr. purpurblau, 10-12 $\mathrm{mm}$ l., Hülse angedrückt-schwarzhaarig und grauweiß.wollhaarig; St. 2.5-15 cm l., Blättchen eilanzettlich oder elliptisch, ausgerandet Gerölle und Felsen der Alpen von Süd-T. 4. 7. 8. A. purpuireus L.

Kelch kurzröhrig, angedrückt-schwarzhaarig.

S. Ähre kuglig, sich nicht verlängernd, $10-20$ bltig, Kelch schwarz haarig und oft noch abstehend weiß-wollig, Blkr. violett, Hülse 1. weißhaarig; St. $8-30 \mathrm{~cm}$ l., Blättchen lanzettförmig. - Trockene Triften $u$. Raine in B. und Mh.; zerstreut. 4. 5. 6.

A. dánicus Retz.

Ähre eiförmig, sich später verlängernd, 10-15 bltig, Blkr. blassblau, Hülse kurz-flaumig; St. $2 \cdot 5-7 \cdot 5 \mathrm{~cm}$ l., Blättchen länglich-eiförmig, Haare d. St. u. Bl. in d. Mitte angeheftet. - Felsige Plätze der Alpen von T., K., St., Kr.; zerstreut. 4. 7. 8.

9. (1). Arten mit beblättertem St. A. leontinus Wulf.

St. verkürzt oder fehlend, Bl. alle grundständig, bis $15 \mathrm{~cm} 1 .$, Blättchen 10-15 paarig, eiförmig bis elliptisch, abstehend behaart; Blt. 20 bis $24 \mathrm{~mm}$ l., hellgelb, in 1. gestielten grundständigen Trauben. - Grasige Hügel u. Berge auf Kalk od. Basalt in B., Mh., T.; zerstreut. 4. 5. 6. A. exscápus L.

10. St, aufrecht, gestreift oder gefurcht, hohl.

11.

St. liezend oder aufsteigend, Ähren eiförmig oder länglich, Blt. $13 \mathrm{~mm} 1$. 12.

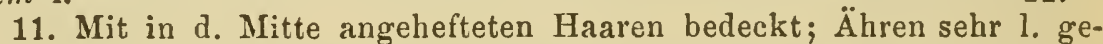
stielt, Blt. hellgelb, 16-20 $\mathrm{mm}$ l., samm` d. länglichen Hülsen aufrecht; St. 30-60 cm h., Blättchen 10-15 paarig, lineal od. lineallanzettlich. Wiesen, kräuterreiche Orte in Mh. und Noe.; zerstreut. 4. 5. 6.

\section{A. asper Jacqu.}

Kahl; Trauben 1. gestielt, rispig, Blt. weißlich, $12 \mathrm{~mm}$ l., sammt d. halbovalen gestielten Hülsen hängend; St. $1-1.6 \mathrm{~cm}$ h., Blättchen 10 bis 15 paarig, länglich. - Zierpt. aus Asien. 4. 6. 7. A. galégifórmis L.

12. Blättchen 5-7 paarig, gr., elliptisch oder eiförmig; St. 0.6 bis $2 m$ 1., ästig, süßlich schmeckend; Blt. gelblich weiß oder bläulich überlaufen, Änren länger als d. Bl.; Hülsen lineal, stumpf 3 kantig, 1. geschnäbelt, gekriimmt. Kahl. - Wälder, Gebïsche. 24. 5-7.

\section{A. glycyphýllus L.}

Blättchen 8-13 paarig, kl., länglich oder oval; St. $30-60 \mathrm{~cm} \mathrm{l.,}$ Blt. hellgelb, Ährenstiel nur so 1. wie die Bl.; Hiilsen aufgeblasen kugligeiförmig, schwarzhaarig. - Trockene Wiesen, Raine, besonders auf Kalk; zerstreut. 4. 6. 7.

A. Cicer L.

\section{Oxýtropis DC. Spitzkiel (XVII, 3).}

Blättch. vielpaarig, Blt. in 1. gestielten meist grund-, selten achselständigen Trauben.

1. St. reich beblättert, $15-40 \mathrm{~cm}$ h., sammt d. Bl. rauhhaarig; Blättchen länglich oder lineal; Trauben achselständig, 1. gestielt; Blt. gelblich, Hülsen lineal-länglich. - Trockene felsige Hiigel und Hänge auf Kalk in B., Mh., T.; zerstreut. 4. 6. 7.

O. pilósa $\mathrm{DC}$.

St. bllos, selten $1-2$ blättrig, Bl. fast alle grundständig. 
2. Hülsen in Kelch siłzend, eiförmig, aufgeblasen, 2 fächrig; $\mathrm{Bl}$. alle grundständig, eilanzettförmig; St. bllos, $7-15 \mathrm{~cm}$ h., Blt. violett. Zottig-rauhhaarig. - Gerölle der Alpen von K. und T. $(1900-2530 \mathrm{~m})$. 4. 6. 7.

Hülsen halb 2 fächrig.

o. Hálleri Bge.

3. Hülsen im Kelche sitzend, eiförmig, aufgeblasen, behaart; Blt. gelblich grün und violett gescheckt (var. sórdida Gaud.) oder blau mit grünlichgelbem Fleck auf d. Fahne (var. coerúlea Koch); Bl. alle grundständig, Blättchen lanzettförmig, St. bllos, $5-20 \mathrm{~cm} \mathrm{~h}$. - Gerölle und Tritten der Aipen von sz., st., K., T. $(1260-2200 \mathrm{~m})$. 4. 7. 8.

Hülsen im Kelch gestielt; St. kurz, mit 1-2 Bl.

0 . campestris DC.

4. Hülsen hängend, walzig, fast kahl, Blkr. hellviolett; St. 2-8 cm h., Blättchen lanzettförmig. - Gerölle d. Alpen v. T., Sz., K. (1900 bis. $2530 \mathrm{~m})$; zerstreut. 4.7 .8 .

O. lappónica Whlb.

Hülsen aufrecht, oval-länglich. 5.

5. Hülsenstiel so l. wie d. Kelchröhre, Blt. rosa; St. bis $7.5 \mathrm{~cm} \mathrm{h.,}$ Blättchen eiförmig bis eilanzettförmig. Seidenhaarig. - Triften der Alpen $(1580-2220 \mathrm{~m})$. 4. 7. 8 .

O. montána DC.

Hülsensticl halb so l. als d. Kelchröhre, Blt. blau (O. cyánea Gaud). oder rosa ( $O$. triflóra Hppe), Blättchen eiförmig-länglich. Grauhaarig. Gerölle der Alpen von K., Sz., T. $(1900-2400 \mathrm{~m})$. 7. 7. 8.

O. Gaudini Reut.

\section{Phaca L. Berglinse (XVII, 3).}

Blättchen vielpaarig, Blt. in gestielten achselständ. Trauben, BltstieleKelche und Hülsen schwarzhaarig. Belaarte Alpenkr.

1. Hülsen durch eine von der Bauchnaht nach innen vorspringendeMembran unvollständ. 2 fächrig; St. liegend od, aufsteigend, $6-15 \mathrm{~cm} 1$.

Hülse 1 fächrig, l. gestielt; St. aufrecht oder aufsteigend. 2.

2. Flïgel kürzer als d. Schiffchen, dieses mit violetter Spitze, fast: so l. als die blaue Fahne; Blättchen 8-12 paarig, oval oder länglichlanzettförmig; Hülsen hängend. - Triften der Alpen von Sz., K., T. $(1580-2500 \mathrm{~m})$. 4. 7. 8 .

Ph. astragalina DC.

Flügel länger als $d$. Schiffchen, welches nur halb so 1 . ist, wie die Fahne; Blättchen 5 paarig.

3. Blkr. weiß, Flügel ansgerandet, Stiel d. länglich-elliptisch. Hülse. länger als der Kelch; Blättchen oval-länglich oder lanzettlich. - Gerölle und Triften der Alpen von Sz, K., T. 4. 7. 8. Ph. austrális L.

Blkr. violett, Hülsenstiel kürzer als d. Kelch, Blättchen oval oder länglich. - Grasige Abhänge der Alpen in St., K., T.; selten. 4. 7. 8. $P h$. oroboides DC.

4. (1). Blättchen 3-4 paarig, oval oder eiförmig-länglich, NebenbI. gr., eiförmig; St. $5-15 \mathrm{~cm}$ h., Blt. gelblichweiß. - Triften höherer Alp.; stellenweis. 4.7. $P h$. frigida $\mathrm{L}$.

Blättchen 9-12 paarig, lineal oder länglich, Nebenbl. lineal-lanzettlich; St. $15-45 \mathrm{~cm}$ h., Blt. gelb. - Triften, steinige Plätze der Alpen. von $\mathbf{S z}, \mathbf{K}$. . T. $(1560-1900 \mathrm{~m})$. 7. 7. 8 . 
713. Galéga L. Gaisraute (XVII, 3).

St. aufrecht, $0.6-1.3 m$ h., Blättchen $6-10$ paarig, lanzettlich oder Jänglich; Blt. in achselständigen gestielten 1. Trauben, weiß oder lila. Kahl. - Sumpfwiesen u. wüste Plätze in B., Mh., Oe., St., Krr., T., auch Zierpf. 4. 6.7.

$G$. officinalis $\mathbf{L}$.

\section{Colútea L. Blasenstrauch (XVII, 3).}

Blättchen S-10 paarig, verkehrt-eiförmig; Blt. zu 2-6 in achselständigen Trauben, Hülsen hängend, beim Zerdrücken mit lautem Knall zerplatzend. Kahle Str.

1. Blkr. hellgelb, Hülse geschlossen. - Wild auf bebuschten Hügeln in Süd-T.; Zierstrauch. ち. 5. 6. C. arborescens $\mathbf{L}$.

2. Blkr. orange bis rothgelb oder roth gefleckt; Hülse an d. Spitze klaffend. - Zierstranch aus dem Orient; stellenweis verwildert. ち. 6. 7.

C. cruenta Ait.

\section{Robinia L. Falsche Akazie (XVII, 3).}

Blättchen vielpaarig, gr.; Blt. in endständigen reichbltigen Trauben. Zierbäume aus Nordamerika.

1. Zweige kahl mit paarweis gestellten Stacheln, Blt, weiß, wohlriechend. Bis $17 \mathrm{~m}$ h. - Als Zier- und Waldbaum cult. ち. 5. 6 .

Gemeine Akazie, $R$. Pseudacícia L.

Zweige unbewehrt, borstig oder klebrig.

2. Blkr. sehr gr. rosenroth, Zweige borstig. Kl. B, $3-7 m \mathrm{~h}$. Rothe Akazie, $R$. hispida L.

Blkr. röthlich-weiß, Zweige drüsig-klebrig; B. 7-10 $m \mathrm{~h}$. R. glutinósa L.

\section{Caragána L. Erbsenbaum (XVII, 3).}

Blättchen 4-6 paarig, oval-länglich; Blt. 1. gestielt, in seitenständ. Büscheln, Blkr. schwefelgelb. Str. oder B., 3-4 $m$ h. - Ziergehölz aus Westasien. 5. 6. 7 .

C. arborescens Lam.

717. Amorpha L. (XVII, 3).

Blätter unpaarig gefiedert, Blättchen 5-10 paarig, länglich oder lauzettförmig, Blt. in dichten, ährenförmigen, straufförmig gruppierten Trauben, Fahne schwarzroth, Stbb. goldgelb. - Zierstrauch aus Nordamerika. †. 6. 7. A. fruticósa L.

\section{Pisum L. Erbse (XVI, 1).}

Blstiel in eine $2-3$ gablige Wiclselranlie auslaufend, Blättch. nicht gregenständig, Blt. zu $1-2$ auf achselständ. Stiele. Kahle, bläulich bereifte $\mathrm{Kr}$.

1. Nebenbl. unten abgerundet u. gekerbt-gezähnt, halbherzförm.; Hülsen reif walzig, mit gedrängt stehenden Samen. driickt.

Nebenbl. schief-eirund $u$. ausgeschweift; Hülsen zusammenge-

2. Bltstiele 1 bltig, Fahne lila od. roth, Flügel roth, Schiffch. weiß; Blättch. 2-3. - Unter Erbsen- u. Wickensaat, stellenweis. $\odot 5-7 . \cdot$ 
Bltstiel 2 bltig, Blkr. weiß, blassroth, violett; Samen kugelrund. Überall cult. $\odot$. 5. 6 . Ge meine E., $P$. sativum $\mathbf{L}$.

3. Huilsen br. schwertförmig, zwischen d. entfernt stehenden Samen. eingebogen; Blkr. weiß od. bunt, Samen beiderseits eingedruickt. - Cult. ๑. $6-9$.

Z uckererbse, $P$. saccharátum Host.

Hülsen schwertförm, zwischen d. Samen nicht eingedrückt diese gedrängt kuglig-4 eckig, Blkr. weiß od. bunt. - Cult. ๑. 6-8.

Markerbse, $P$. quadrátum Mill.

719. Vícia L. Wicke (XVII, 3).

Bltstiel meist in eine Ranke auslaufend, selten abgebrochen endigend, Blättch. gegenständ. in Praren od. wechselständig; Blt. achselständ.

1. Blt. einzeln od. parweis od. in kurz gestielten $2-6$ bltigen Trauben.

Blt. in 1. gestielten meist vielbltigen Trauben, Blättch. ganzrand., Hiils. kahl, hängend; Bl. mit Wickelranke.

13.

2. Blstiel in eine Stachelspitze od. (nur an d. oberen Bl.) in eine kurze einfache Ranke endigend.

Blstiel (wenigstens d. oberen Bl.) mit 1. einfacher od. gabliger Wickelraike.

3. Blt. gr., gebiischelt $(2-5$ in kurzer Traube), weiß, mit schwarzem Fahnenfleck, wohlriechend, Hiils. fleischig, dick bis $10 \mathrm{~cm}$ l., kahl, reif schwarz, Samen gr., zusammengedruickt; St. 0.6-1 m h., Blättch. gr., 1-3 paarig, elliptisch, fleischig, rankenlos. - Culturpf. ๑. 7. 8.

Blt. kl., gelb od. lila. Puff-, Sa ubohne, V. Faba I.

4. Blt. zu 2-6 in ungestielten Trauben, bleichgelb, $16 \mathrm{~mm} \mathrm{1.,} \mathrm{Hül-}$ sen aufrecht, lineal-länglich; St. $30 \mathrm{~cm}$ h., Blättch. 1-3 paarig, eiförmig od. länglich. - Gebirgswälder v. Ooc., Noe., St., K., Kr. 4. 5. 6.

V. oroboides Wulf.

Blt. einzeln, lila, 4-6 mm l., Hülsen aufrecht-abstehend, lineal, reif glänzend schwarz; St. (meist viele) liegend bis aufrecht, $8-30 \mathrm{~cm} \mathrm{l.;}$ obere Bl. mit lkurzer einfacher Ranke, Blättch. 2-3 paarig, ausgerandetstachelspitzig. - Sandige Triften u. Felder, zerstreut. ○. 5. 6. gedrüickt.

$V$. lathyroides L.
Hülsen zusammen

Blt. zu 2-6 in kurz gestielten Trauben.

6.

6. Blkr, roth od. violett od. bunt, obere Bl. mit mehrgabliger RankeBlättch. 4-6 paarig.

Blkr. gelb.

10.

7. Die 4 oberen Kelchzälıne emporgerichtet, alle lanzettlich; $131 \mathrm{kr}$. violett, $12 \mathrm{~mm}$ l., Hülse zurïckgeschlagen, braun, flaumig; St. $30 \mathrm{~cm} \mathrm{h.,}$ Blättch. 4-7 paarig, entfernt, lineal-keilig, ausgerandet-stachelspitzig. Saaten v. Unter-St. u. Süd-'T. ○. 5. 6.

$V$. peregrina L.

Alle 5 Kelchzähne gerade vorgestreckt, pfriemlich-lanzettförm.; Hüls. aufrecht-abstehend.

8.

8. Blkr. bis 24 mm 1., Fahne violett, Flügel purpurn, Schiffchen weiß od. schwarzroth gefleckt, Hülsen flaumig, hellbraun; St. $30-60 \mathrm{~cm}$ hoch, Blättch. 7 paarig, verkehıt-eiförm.-länglich, ausgerandet-stachelspitzig. Weichflaumig. - Cult. u. verwild. $\odot .5-7$.

$$
\text { Futterwicke, } V \text {. sativa } \mathbf{L} \text {. }
$$


Blkr. purpurroth, 12-16 mm 1 .

9. Blättch. meist 7 parig, die d. unteren Bl. verkehrt-herzförmig, die d. oberen lineal-keilig, tief ausgerandet; St. $30-60 \mathrm{~cm} \mathrm{h.,} \mathrm{Blt.} \mathrm{meist}$ zu 2, Hïls. lineal. - Auf Saaten in Kr. -. 5-7. V. cordáta Wulf.

Blättch. meist 5 paarig, die d. unteren Bl. verkehrt-herzförm., oft d. oberen lineal lanzettförm. od. länglich, spitz bis ausgerandet; $\mathbf{S t .} 15$ bis $30 \mathrm{~cm}$ b., Blt meist einzeln. Hülse schmal. - Auf Saaten. ○. 5. 6.

$V$. angustifólia Rth.

10. (6). Blkr. bleichgelb od. mit rauchgraner Fahne, $25 \mathrm{~mm}$ 1., Hülse aufrecht-absteliend, kahl; St. $30-60 \mathrm{~cm} \mathrm{h.,} \mathrm{Blättch.} \mathrm{3-7} \mathrm{paarig,}$ verkehrt-herzförmig bis lineal-länglich. - Grasplätze in Noe. u. Kr.; zerstreut. - 5. 6 .

V. grandiflóra Scop.

Variet. sórdida (Waldst. Kit.) Blt. 20-22 $m m$ 1., Blättchen fast alle länglich-keilförmig. In Noe. u. Mh., zerstreut.

Blkr. citrongelb, kahl, 16-20 mm 1., Hüls. zurückgeschlagen, rauhhaarig; St. $15-45 \mathrm{~cm}$ h., Blättch. nicht gegenständ., $12-14$, die d. unteren Bl. oval od. länglich, d. oberen lineal. Kahl od. behaart. - Saaten, Wiesen in Noe., stellenweis, aus d. Sïden eingeschleppt. ○. 6. 7.

\section{$V$. litea $\mathrm{L}$.}

11. (5). Fahne zottig, braun liniert, sonst d. Blkr. weißlich od. blass gelblich-grün, 14-18 $\mathrm{mm}$ 1., Hülse zuriłckgeschlagen, länglich, angedrücktbehaart; St. aufsteigend, 0.6-1 m 1., Blättch. 5-10 paarig, länglich od. oval, oft ausgerandet-stachelspitzig, behaart. - Äcker in Mh., Noe., Ooe., St.; stellenweis. $\odot .5-7$.

Fahne kahl, Hüls. aufrecht-abstehend.

V. pannónica Jcqu.

12. Blkr. 16-20 $\mathrm{mm}$ l., Fahne u. Schiffch. schmutzigroth, Flügel purpurn, Hülse längl., gewimpert; St. 30-60 cm h., Blättch. 1-3 paarig, eiförm. od. oval, gr., ganzrandig od. gesägt (V. serratifolia Jcqu.). — Auf

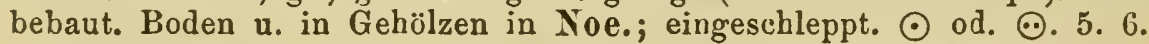

\section{V. narbonnensis $\mathrm{L}$.}

Blkr. $12 \mathrm{~mm}$ l., blass- od. schmutzig-violett, Hüls. kahl, meist glänzend-schwarz; St. aufsteigend, 30-60 cm 1., Blättch. 4-8 paarig, eiförmig bis länglich, stumpf od. ausgerandet-stachelspitzig. Kahl. - Gebuische, Hecken. 4. 5. 6.

$V$. sépium L.

13. (1). Blkr. blassgelb od. gelblichweiß, Trauben gedrungen, Hüls. länglich, kahl; St. liegend od. kletternd, bis $2 m$ l., Blättch. 3-5 paarig, sehr gr., eiförmig. Kahl, hellgrün. - Wälder, Gebüsche auf Kalk und Basalt. 4. 6. 7.

Blkr. weiß, lila, violett, blau od. bunt. V. pisiformis $\mathrm{L}$.

14. Blbl. weiß, lila od. violett gestreift, Trauben vielbltig, einseitswendig, St. bis $2 m$ l., liegend od. kletternd, Blättch. 6-9 paarig, kl., eiförmig-länglich. Kahl. - Gebirgslaubwäld. 4. 6. 7. V. silvática L.

Blkr. blau, violett, purpurn, bunt. ternden St.

15. Trauben 6-10 bltig, locker; kahle Pf. mit liegenden od. klet-

Trauben vielbltig, gedrungen, einseitswendig zurückgekriimmt; St. liegend, aufsteigend od. kletternd.

17.

16. Nebenbl. halbmondförm., buchtig gezähnt; Blättch. 3-5 paarig, eiförmig od. eilänglich, stachelspitzig, entfernt-wechselständ.; Blkr. purpurviolett, St. 1-1.3 $m$ 1. - Gebüsche, Waldränder in Gebirgsgegenden, besond. auf Kalk, 4. $6-8$. 
Nebenbl. halbspießförmig, nicht gezähnt; Blättch. 10-12 paarig, länglich bis oval, genähert; Fahne violett, Flügel u. Schiffch. weiß; St. $30-60 \mathrm{~cm}$ 1. - Gebirgswälder, zerstreut. 4. 6. 7. V. cassribica I.

17. Traubenstiele zur Bltezeit viel länger als d. Bl., gefurcht; Trauben reichbltig, Blkr. hellviolett mit weißen Flügeln, 15 m l., Hüls. hängend; St. 0.3-1 $m$ 1., Blättch. vielpaarig, lineal. - Felsen, Gebüsche, Bergabhänge; zerstreut. 4. 6. 7.

$V$. ¿enuifólia Rth.

Traubenstiele zur Bltezeit so 1. od. kiurzer als d. Bl., nicht gefurcht; Huilsen fast wagrecht od. etwas nach unten gerichtet, sehr br., gestielt. 18 .

18. Hülsenstiel kürzer als d. Kelchzähne, Blkr. hellviolett bis dunkelblau, 8-10 mm 1., Fahnenplatte so 1. als d. Nagel; St. 0.3-1 m l, Blättch. 10-12 paarig, länglich od. lineal. Angedriickt behaart. - Hecken, Gebüsche, Wiesen. 4. 6. 7. Vogelwicke, V. Cracca L.

Hülsenstiel länger als d. Kelchzähne, Blkr. dunkelviolett, 12-14 mm 1. Fahuenplatte 2 mal kürzer als d. röhrige Nagel; St. $30-60 \mathrm{~cm} \mathrm{l.,}$ Blättch. 6-8 paarig, lanzettl. od. länglich. Abstehend grauzottig. Saaten in 13., Mlı., Oe., Sz.; \%crstreut. $\odot$ od. ค. 6-8. V. villósa Rith.

Variet. glabrescens Koch. Wenig behaart od. fast kahl. Ebendas., selten.

\section{Ervum L. Linse (XVII, 3).}

St. dünn, niederliegend od. kletternd; Bl. paarig gefiedert, mit oder ohne Ranke ı. kl. Blättchen; Blt. kl., blwinkelständig.

1. Bl. rankenlos.

2.

Bl. (wenigstens obere) mit Wickelranke, Blättch. 3-7 paarig. 3 .

2. Blättch. 10-12 parig. Blt. zu 1-3 auf kurzem Stiele, Blkr. weißlich, Fahne violett gestreift; Hülse perlschnurförmig; St. $30 \mathrm{~cm} \mathrm{h.} \mathrm{-} \mathrm{Aus}$ Südeuropa, verwild. in B., stellenweis. ๑. 6. 7.

\section{Saaterve, Linsen wi cke, E. Ervilia L.}

Blättch. 2-3 paarig, Bltstiele 1-2 bltig, länger als d. Bl., Blkr. bläulichweiß, Hülse rhombisch-länglich, 2 samig, Samen schwarz. - Unkraut in Süd- $\mathbf{L} \mathbf{r} . \odot$. 5. 6 E. nigricans M. Bieb.

3. Kl. u. gr. Nebenbl., letztere tief fingerförmig zerschlitzt; Blättch. meist 7 parig, Bltstiele 1 bltig von der Länge des Bl.; Blkr. meist mit lilafarbener Fahne, Hüls. länglich, 3 samig; St. $30 \mathrm{~cm}$ b. - Unkraut in B., Mh., Oe., auch cult. u. verwild. ๑. 6. 7.

Nebenbl. von gleicher Form, halbspießförmig.

E. monanthos $\mathbf{L}$.

4. Gemeinsamer Bltstiel in eine Granne auslaufend, Hüls. fast rauten. förmig, zusammengedrückt, kahl, 2 samig; Samen zusammengedrückt. 5

Bltstiel nicht begrannt.

5. Blkr. kürzer als d. Kelchzähne, weiß, lila geadert, Samen gr., rund, scharfrandig; St. $30 \mathrm{~cm}$ l., Blättchen 6 parig, Bltstiele $1-3 \mathrm{bltig}$, - Cult. ○.6. 7. Saatlinse, E. Lens L.

Blkı. viel kürzer als d. fedrigen Kelchzähne, weißlich, Hüls. und d. stumpfrandig. Samen kleiner als b. voriger Art, sonst ibr gleich. - Cult. in $\mathbf{K}$. $\odot .6 .7$.

E. dispérmum Rchb.

6. (4) Hülsen 4 samig, S-12 $\mathrm{mm} \mathrm{l.,} \mathrm{kahl;} \mathrm{Bltstiele} \mathrm{1-2} \mathrm{bltig,} \mathrm{von}$ der Länge des Bl., Blkr. bläulichweiß, 3-4 mm 1.; St. 30-45 cm lang, Blättch. 3-5 paarig. Kahl. - Bebaut. Boden, Gebiische. ๑. 5-7. 
Hüls. 2 samig, 6-S $\mathrm{mm}$ l.

7. Hüls. rauh, zuletzt schwarz, Bltstiele $2-6$ bltig, kürzer als d. BI.; Blki. weißlich, 2-4 mm l.; St. 30-60 cm l., Blättch. 3-10 paarig. Gebüsche, Unkraut auf Saaten. $\odot, 5-7$. E. hirsútum L.

Hüls. feinflaumig, nicht schwarz werdend; Bltstiele 1 bltig, länger als d. Bl.; Blkr. lila, $4 \mathrm{~mm}$ l.; St. aufrecht, $8-16 \mathrm{~cm}$ h., Blättcli. 2-3 paar. - Äcker in K. 1 . Kr. $\odot .5 .6$. E. Lenticula L.

\section{Láthyrus L. Platterbse (XVI, 3).}

Blättch. 1-6 paarig, spitz, selten ganz fehlend; Blt. zu 1-2 an achselständigen Stielen od. in gestielten achselständigen Trauben: Hülsen gerade, br. zusammengedrückt.

1. Blstiel ohne Blättchen, in eine Wickelranke auslaufend, Nebenbl. sehr gr., blartig, am Grunde pfeilförm.; St. kantig. aufrecht, $15-45 \mathrm{~cm}$ hoch, Bltstiele 1 bltig, Blkr. gelb. - Auf Saaten hier und da, aus dem Süden eingeschleppt. $\odot$. 6. 7 . L. Aphaca L.

Blstiel mit Blättchenpaaren, rankentragend.

2. St. u. Blstiele geflügelt.

2.

St. kantig, nicht geflügelt.

3.

3. Bltstiele 1-2 bltig, Blstiel nie geflügelt, 1 Blättchenpaar tragend; Plkr. gr.

Bit. in 1. gestielten 3 -vielbltigen Trauben.

8.

4. Hiilsen am oberen Rande doppelt gefliigelt, br. rhombisch, kahl; Blkr. bis $18 \mathrm{~mm} \mathrm{l}$., weiß, bläulich, lila, rosenroth; St. $30-60 \mathrm{~cm} \mathrm{h.,}$ Blättch. lineal-lanzettförmig; kahl. - Aus Südeuropa, cult. in Oe. $\odot$. $5-8$. Kicherling, $L$. sativus $L$.

Hülsen nicht geflügelt.

5. Hiilsen u. ganze Pf. kahl, St. $0.60-1 m l$.

Hiils, behaart.

6. Blättchen länglich-lineal, Blkr. rosenroth, Falıne braun geadert.

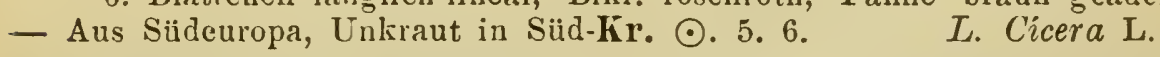

Blättch. eiförmig, stachelspitzig, Blkr. purpurroth, $25 \mathrm{~mm}$ l. - Zierpflanze aus Nordafrika. ๑. 7. S.

L. tingitánus $\mathrm{L}$.

7. Blättchen oval od. eiförmig, stachelspitzig, Blt. sehr gr., wohlriechend, Fahne pfirsich- od. rosenroth. Flügel dunkelviolett od. weiß; St. bis $1.3 \mathrm{~m}$ h. - Zierpfl. $\odot$. 6. 7.

Gartenwicke, spanische Wicke, L. odorátus L.

Blättch. lineal-lanzettförm., Blkr. blaı, Hüls. l. rauhhaarig; St. 0.3 bis $1 \mathrm{ml}$. - S:atunkraut im südlichen Gebiete, hier und da. $\odot$. 6. 7.

L. hirsietus L.

8. (3) Blättch. 1 paarig. Kahle Pf. mit liegend, od. kletternd., 0.6 bis $2 m$ l. St. u. $4-8$ bltigen gedrungenen Trauben.

Blättch. 2-vielpaarig.

9. Blstiel br. geflïgelt, Blättch. oval-lanzettförn., 5 nervig, bis $7.5 \mathrm{~cm}$ lang, Blkr. rosenroth. - Waldwiesen, bebuschte Hügel in Mh., Noe., T., auch Zierpt. 4. 7. 8.

L. latifólizes $\mathrm{L}$.

Blstiel schmal geflïgelt, Blättch. lanzettförm., 3 nervig, bis $10 \mathrm{~cm} \mathrm{1.;}$ Blkr. gelbgrün, rosig überlaufen, verwelkend bläulich od. violett. - Laubwälder, Gebüsche. 7. 6. 7.

L. silvester L. 
10. St. u. Blstiele br. gefïgelt, Blättch. lanzett- od. lineal-lanzettfïrmig, 5-7.5 cm l.; Trauben vielbltig, Blkr. purpurroth, St. $0.6-1.3 \mathrm{~m}$ lang. - Gebüsche, Laubgehölze in B., sehr zerstreut. 4. 6-8.

\section{L. heterophýllus $\mathrm{L}$.}

Blstiele nicht geflügelt, Blättch. Iänglich od. lineal-lanzettlich, Trauben 3-5 bltig, Blkr. blassviolett; St. bis üluer $1 \mathrm{~m}$ l. - Sumpfwiesen in B., Min., Ooe., Noe.; zerstreut. 14 . C. 7.

I. paluster L.

11. (2) Bltstiele 1 bltig, an d. Spitze begrannt, länger als d. Blatt; Blkr. purpurviolett, Hülse lineal, mit weiblichen Samen; St. liegend oder aufsteigend, $30 \mathrm{~cm}$ l., Blättchen lineal. Kahl. - Saaten, Weinberge in Kr. und Süd-T. $\odot$. 5. 6.

L. angulátus L.

Vielbltige 1. gestielte Trauben, St. liegend od. kletternd, 0.3-1 m lang.

12. Blkr. gelb, geruchlos, Blättchen lanzettförmig, Wzst. kriechend. - Wiesen, Gebüsche. 4. 6. 7. L. pratensis L.

Blkr. rosenroth, woblriechend, Blättch. oval od, verkehrt-eiförmiglänglich; Wzst. mit hängenden (essbaren) Knollen. - Saatfelder, besond. auf Kalk. 4. 6-8.

L. tuberósus L.

\section{Orobus L. Walderbse (XVII. 3).}

Blättchen 2-8 paarig, Blt. in achselständ, gestielten einseitswendig. Trauben, Hülsen zusammengedrïckt. Kahle $\mathrm{Kr}$.

1. St. geflügelt, $15-30 \mathrm{~cm}$ h., Blättchen $2-3$ paarig, länglich oder lineal-lanzettï̈rm., unterseits blaugrün; Trauben $3-5$ bltig, Blkr. hellpurpurn; Wzst. kriechend; mit hängenden Knollen. (Lath. montanus Brhd) - Bebuschte Hiigel, Waldwiesen; zerstreut. 4. 5. 6. O. tuberósus L.

St. kantig.

2. Blättchen $2-3$ parig.

Blättchen 4-8 paarig.

3. Wzst. mit gebüschelten, länglichen, $8-20 \mathrm{~cm} \mathrm{l.} \mathrm{Knollen,} \mathrm{St.} 15$ bis $45 \mathrm{~cm} \mathrm{~h}$., Blättchen lineal-lanzettförmig, Trauben 4-7 bltig, länger als d. Bl.; Blkr. weiß. - Bergwiesen, bebuschte Abhänge auf Kalk in B.. Mh., Not.; zerstreut. 4. 5. 6. (O. albus Koch Syn.) O. versicolor Gmel.

Var. pannónicus (Jequ.). Wzstknollen nur 20-25 $\mathrm{mm}$ l. Sumpfwiesen in Noe.

Wzst. kriechend, fasrig, Blättch. ei- bis eilanzettförm., gewimpert. 4.

4. Trauben locker, 3-8 bltig, Blkr. $13 \mathrm{~mm}$ l., erst purpurroth, dann blau; St. $30-45 \mathrm{~cm}$ h. - Lichte Laubwälder. 4. 4. 5. O. vernus L.

Traube dicht- u. vielbltig, Blkr. kleiner, mit purpursother Fahne u. rosenrothen Fliigeln u. Schiffchen. - Bergwïlder in Kr. u. T. 7. 5. 6. o. variegátus Ten.

5. (2) Blkr. purpurroth, Traube 5-10 bltig; St. liegend od. aufsteig., 0.3-1 $m$ l., Blättchen 6-8 paarig, länglich, stachelspitzig. Beim Trockuen schwarz werdend. - Steinige, sonnige Waldorte, besonders auf Kalk. 4. 6.7 .

0 . niger $\mathrm{L}$.

Blkr. gelblich, Trauben 5-10bltig: St. aufrecht, $15-45 \mathrm{~cm}$ h., Blättchen meist 4 paarig, oval od. eilanzettförm. - Gebirgswälder in $\mathbf{0 e .}$., St., T., Kr. 4. 5. 6.

O. luiteus L. 


\section{Phaséolus L. Bohne (XVII, 3).}

St. kantig, scharfhaarig; meist windend; Blättch. ganzrand., mittles stets größer als die seitlichen; Blt. in achselständ. 1. gestielten Trauben, Hülsen fleischig, hängend.

1. Trauben vielbltig, Blkr. feuerroth od, roth $u$. weiß, od. weiß, Hüls. rauh;' St. windend, hoch gehend. - Culturpfl. aus Südamerika. $\odot, 7-10$. Feuer-, Prunkbobne, Pl. multiflórus L.

2. Traub. 2-3 bltig, Blkr. kleiner, weiß, lila, röthlich, Hüls. glatt; St. windend od. (bei d. "Busch- od. Zwergbohnen") aufrecht. - Aus Asien. $\odot$ ๑. 8. Gemeine B., Schminkbohne, Ph. vulgaris L.

\section{Dorýcnium Tourn. Backenklee (XVII, 3).}

St. aufrecht od, aufsteigend, Bl. sitzend, scheinbar 5 zählig (3 zählig mit 2 gr. Nebenbl.), Blättch. länglich od. lineal, stachelspitzig; Blt. in end. u. achselständ. gestielten Köpfchen.

1. Angedrückt-seidenhaarig, Köpfch. meist 12 bltig, Fahne weib od. röthlich. Schiffchen bläulich mit violettschwarzer Spitze; St. $15-60 \mathrm{~cm} \mathrm{l.,}$ : $\mathrm{m}$ Grunde holzig. - Auf Kalkboden in 0oe.. T. u. Kr.; zerstreut. 2. 5-7. D. decumbens Iorr.

2. Abstehend-kurzhaarig, Köpfch. bis 20 bltig, Blkr. wie b. vor. Art; St. 30-60 cm l., ganz krautig. - Sonnige Triften in Mh., Noe., T. 4. $5-7$.

D. herbáceum Vill.

\section{Bonjeñnia Rchb. (XVII, 3).}

St. aufrecht od. aufsteigend, $15-45 \mathrm{~cm}$ l.; Bl. kurz gestielt, mit gr. Nebenbl., Blättchen länglich-verlsehrt-eiförm.; Blt. in end- u. achselstïnd. gestielten doldigen Köpfch., Blkr. rosenroth, Schiffch. mit dunkelvioletter Spitze. - Wiiste Plätze in Süd-T. 4. 5. 6.

B. hirsúta Rchb.

\section{Lotus L. Hornklee (XVII, 3).}

St. liegend od. aufsteigend, Bl. kurz gestielt, Blättch. d. Bl. u. Nebenbl. gleichgroß; Blt. in l. gestielten a chselständ. Dolden, Blkr. goldgelb, Hülse gerade, walzig, meist sternförmig auseinander stehend.

1. St. diunn, nicht hohl, liegend, $15-45 \mathrm{~cm}$ l., Dolde $3-6$ bltig, höchst vielgestaltig. - Wiesen, Grasplätze, Raine, felsige Plätze. 7. $5-9$. L. corniculátus L.

Variet. $\alpha$. vulgaris Koch. Blättch. u. Nebenbl. br. lanzettförm. od. verkehrt-eiförm., kahl od. zerstreut behaart; $-\beta$. hirsútus (Thnill.), wie vorige ab. ganze Pf. rauhhaarig; $-\gamma$. teuuifólius (Rchb.), Blättch. u. Nebenbl. lineal od. lineal-lanzettförmig. Kahl od. behaart. Sumpfige Wiesen, besond. salzhaltige in B., Mh., Oe.

2. St. stark, hohl, aufsteigend, $30-60 \mathrm{~cm}$ l.; Dold. $6-12$ bltig, Blättchen eiförmig, dicklich. Kahl. - Feuchte Wiesen, Gräben; zerstreut. 4. 5-9.

L. uliginósus Schk.

727. Tetrảgonólobus Scop. Schotenklee. (XVII, 3).

Bl. 3 zählig, kurz gestielt, Nebenbl. gr., an d. St. angewachsen, Blt. gr., einzeln od. parweis. 
1. Blkr. gelb, Blt. auf l. achselständ. Stiele, Hüls. schmal geflügelt, $5 \mathrm{~cm}$ l.; St. liegend od, aufsteigend, bis $30 \mathrm{~cm}$ l. Kahl. - Frische Wiesen; zerstreut. 4. 5. 6.

T. siliquósus Roth.

2. Blkr. purpurroth, Blt. endständ. fast sitzend; Hülse br. geflügelt, dick, 5-7.5 cm l.; St. aufrecht. Rauhhaarig. - Aus Sïdeuropa, cult. ๑. 7. 8 .

Spargelerbse, T. purpureus Rth.

\section{Trigonella L. Bocksklee (XVII, 3).}

Bl. 3 zählig, gestielt; B:t. kl., achselständig.

1. Blkr. gelb.

Blkr. blau, Blt. in rundlich̀-eiförınigen 1. gestielten Köpfchen; Hüls. kurz, eiförm., geschnäbelt; St. $30-60 \mathrm{~cm}$ h., Blättch. oval bis lineallänglich, scharf gesägt. Stark aromatisch. - Aus Südeuropa, hie u. da verwild. $\odot .6-8$.

T. coerúlea Ser.

2. Blt. zu 5-6, gebüschelt, gelb; Hülse lineal, gekrümmt, 8 bis $10 \mathrm{~mm}$ l.; St. liegend od. aufsteigend, $4-30 \mathrm{~cm} \mathrm{l}$, Bläitch. verkehrteiförm., gezähnelt. - Sonnige Berge in B., Mh., Noe., Sz.; selten. $\odot$. 6. 7 .

T. monspeliaca L.

Blt. zu 1-2, weißlich, Hülse lineal, schwach gebogen, l. geschn:̈belt, $6-8 \mathrm{~cm} \mathrm{l.;} \mathrm{St.} \mathrm{aufrecht,} 15-30 \mathrm{~cm}$ h., Blättch. länglich.keilförm., vorn gezïhnelt. - Aus Sïdeuropa, eingeschleppt in Mh. unter d. Saat, stellenweis. $\odot$. 6. 7 .

T. Foenum graecum L.

\section{Melilótus L. IIonig-, Steinklee (XVII, 3).}

St. aufrecht od. aufsteigend, ästig; Bl. 3 zählig, gestielt, Blättchen gesägt od. gezähnt, mittleres gestielt; Blt. in achselständ. ährigen Trauben. Kahle Kr.

1. Blkr. weiß, Hülsen kahl, reif schwärzlich; St. $0 \cdot 6-2 m$ h., Blättchen ei- bis lanzettförmig. - Hecken, Ufer, auf Schutt. $\odot$. 7-9.

Blkr. gelb. Pferde-, Riesenklee, M. albus Desr.

2. Blkr. höchstens über $2 \mathrm{~mm}$ l., Flügel und Schiffchen kürzer als d. Fahne, Hülsen kahl.

Blkr. 4-6 $m m$ l., Blättchen d. untern $\mathrm{Bl}$. verkehrt-eiförmig oder elliptisch. 4.

3. Alle Blättchen länglich oder länglich-lanzettförmig, Hülsen am Rücken zusammengedrückt oder gekielt, St. $30-60 \mathrm{~cm} \mathrm{l}$. - Wiesen, Wegränder, auf Salzboden in B., Mh., Noe., T. ค. 7-9.

M. dentátus $\mathrm{P}$.

Blättchen d. unteren Bl. verkehrt-eiförm., fast ganzraudig, d. obern länglich-rautenförmig, stark gezälınt; Hülsen kuglig, St. 10-30 cm 1. Aus Siideuropa eingeschleppt in Siid-T., stellenweis. ๑. 5. 6.

M. parviflórus Desf.

4. Blbl. gleichlang, Hülsen an Rücken flügelartig gekielt, flaumig, reif schwarz; Blättchen der obern Bl. länglich oder länglich-lineal, St. $0.6-1.6 m$ h., Wz. sehr 1. - Wiesen, Gräben, Ufer; zerstreut. $\odot$. 4. $7-9$.

M. altissimus Thuill.

Fahne und Flügel gleichlang, länger als d. Schiffchen, Hülsen am Rücken abgerundet und stumpf gekielt, querrunzlig, kahl, reif gelbbraun; Blättchen d. oberen $\mathrm{Bl}$. länglich oder länglich lanzettförmig; St. 0.3 bis $1.3 \mathrm{~m} \mathrm{~h}$. - Schutt, Raine, Felder, Ufer. -.. 6. 7. M. officinalis Desr. 


\section{Trifólium L. Kopfklee (XVII, 3).}

BI. 3 zählig, mit sitzenden gezähnten od. gesägten, selten ganzrand. Blättchen; Nebenbl. an d. Bltstiel angewachsen; Blt. in end-, selten achselständigen Köpfchen oder Ähren; Blkr. verwelkend, nicht abfallend.

1. Blkr. purparn oder rosenroth.

b) Blkr. weiß oder gelblichweiß oder bei d. innern Blt. weiß, bei $d$. ¿iuBeren rosenroth. bend.

c) Blkr. gelb, nach dem Verblühen sich hell- bis dunkelbraun fär-

17.

2. Stengellos, Bl. und Köpfchenstiele grundständ.; Köpfchen lockerbltig, aus 2-8 bltigen Quirlen bestehend, Blkr. bis $18 \mathrm{~mm}$ l. - Gerölle und Triften der Alpen von K. und T. $(1900-2850 \mathrm{~m})$. 4. 7. 8 .

Stengeltreibende Arten, St. beblättert. T. alpinum L.

3. Frkelch vergrößert und aufgeblasen.

Frkelch weder vergrößert noch aufgeblasen.

4.

5.

4. Frkelch roth gefärbt, daher d. kuglige Köpfchen dann einer Erdbeere gleichend, Oberlippe d. Frkelchs kuglig-aufgeblasen, netzadrig, Blkr. kl., rosa; St. liegend oder kriechend, bis $30 \mathrm{~cm}$ 1., Köpfchen achselständ., Blättchen oval. - Frische Wiesen und Triften; zerstreut. 4. 6-9.

Erdbeerklee, T. fragiferum I.

Frkelch weißlich, zottigfilzig, bauchig, mit 20 erhabenen kahlen Nerven, Blkr. kl., rosa oder weißlich; Köpfchen end- und achselständig, fast sitzend; St. bis $25 \mathrm{~cm}$ l., Blättchen verkehrt-eiförmig or. keilig. Behaart. - Trockene Grasplätze, steinige Hügel, zerstreut. ๑. 6. 7.

\section{T. striátum L.}

5. Blt. in walzigen Ähren, vor d. Aufblühen 1. behaart (wegen d. l. behaarten Kelche).

Blt. in endständigen kugligen od. eiförmigen Köpfchen, Kelche kurz behaart oder kahl.

8.

6. Ähre kurz-walzig, stumpf, noch zur Frzeit dicht und l. weißgrauzottig, gestielt, achselständig; Blkr. kl., hellrosa, kürzer als die fedrigen Kelchzähne; St. 7-30 cm h., sehr ästig; Blättch. lineal-länglich. Weichzottig. - Äcker, Triften. $\odot .7-9$.

$\mathrm{K}$ atzenklee, $T$. arvense $\mathrm{L}$.

Ähren 1., nur vor d. Aufblühen zottig, später kahl erscheinend, blühend $5-7.5 \mathrm{~cm}$ 1., endständig; Blkr. gr. und 1., purpurroth.

7.

7. Ähre zugespitzt; Blkr. glänzend biutroth; St. $15-60 \mathrm{~cm} \mathrm{h.,} \mathrm{meist}$ einfach; Blättchen verkehrt-eiförmig, vorn gezähnelt. Weichhaarig. - Aus Südeuropa, cult. und verwildert. $\odot$. 6. 7 .

Blutklee, Incarnatklee, T. incarnátum L.

Ähre walzig, stumpf, dick, Blkr purpurroth; St. $30-60 \mathrm{~cm}$ h., steif, meist einfach; Blättchen lineal-länglich, scharf gezähnt. - Gebüsche, auf Kalk; zerstreut. 4. 6. 7. Fuchsklee, T. rubens L.

8. (5) Kelch 20 nervig, weichzottig, mit gevimpert. Zähnen, Köpfch. häufig paarweis auf einem Stiel, Blkr. purpurrotb; St. $15--30 \mathrm{~cm}$ h., einfach; Blättch. lineal-lanzettlich, ganzrandig, obers. kahl. - Bebuschte Hügel,, W Waldwiesen. 4. 6. 7.

T. alpestre $\mathrm{L}$.

Kelch 10 nervig, feinbehaart od. kahl, Köpfch. meist einzeln; St. aufsteigend od. liegend, sammt d. Bl. kahl od. angedrückt-behaart. 9. 
9. St. hin $\mathrm{u}$. her gepogen, $15-30 \mathrm{~cm} \mathrm{l.,} \mathrm{Köpfch.} \mathrm{kurz} \mathrm{gestielt,} \mathrm{Blkr.}$ glänzend purpurroth; 13lättch. elliptisch od. länglich, meist ganzrand., hellgrün, Nebenbl. lanzettl., zugespitzt. - Wälder, Gebüsche. 4. 6. 7. T. médium L.

St. gerade, $15-45 \mathrm{~cm}$ l., Köpfch sitzend, vom obersten Stbl. umhüllt (bei der wilden Pfl.) od. kurz gestielt, von obersten Bl. entfernt (b. d. cultiv.); Blkr. hellpurpurn, Blättch. rundlich bis elliptisch, gezähınt, oft weiß gefleckt, Nebenbl. in eine Granne verschmälert. - Wiesen, Grasplătze u. allgemein auf Feld. cult. 4. 5. 6.

\section{Geme iner K., T. pratense L.}

Variet. pedicellátum Knaf. Blt. gestielt, hellrosa. In Nord-B., hie und da.

10. $(1, b)$ Blkr. gelblichweiß, Schiffch. zuletzt oft roth.

b) Blkr. erst weiß, dann rosenroth (äußere ältere Blt. rosa, innere jüngere weiß).

c) Blkr. weiß, beim Verwelken sich braun färbend.

11.

12.

13.

11. Köpfchen achselständ., 1. gestielt, kuglig; St. aufsteigend, 5-10 $\mathrm{cm}$ l., Blättch. verkehrt-eiförmig, schief gezähnelt. Rasenbildend, kahl. Alpentriften in Sz., K., T., Kr. $(1900-2550$ m) 4. 6. 7.

\section{T. pallescens Schreb.}

Köpfch. endständ., gestielt, kuglig, zuletat oval; St. aufrecht od. aufsteigend, bis $45 \mathrm{cmb}$ l.; Blättch. d. unteren Bl. verkehrt-eiförmig, d. oberen ellipt. od. lïnglich, alle ganzrandig. Scharfhaarig. - Hügel, trockene Wiesen auf Kalk; zerstreut. 4. 6. 7.

T. ochroléucum L.

12. Köpfch. achselständ., l. gestielt, Blt. nach d. Verblühen aufrecht bleibend; St. 5-10 cm l., Blättch. verkehrt-eiförm., fein gesägt. Rasenbildend, kahl. - Gerölle u. Triften d. Alp. v. St., K., T. 4. 6. 7.

\section{T. caespitósum Reyn.}

Köpfch. end- u. achselständ., 1. gestielt, Blt. nach d. Verblühen abwärts gebogen; St. viele, hohl, aufsteigend, $15-45 \mathrm{~cm}$ h., Blättch. verkehrt-eiförm. od. ellipt., stachelspitzig gesägt. Kahl. - Frische Wiesen, auch cult. 2. 5-9. S chwedischer Kle e, T. hýbridum L.

13. (10 c) Köpfch. end- od. end- u. seitenständ., fast sitzend od. kurz gestielt. 14.

Köpfch. acbselständ,, l. gestielt, verblülıte Blt. abwärts gebogen, Blättch. verkehrt-eiförmig, scharf fein-gesägt. Kahle Kr.

16.

14. Köpfch. sitzend, nur endständ., Blt. ohne Deckbl,, Kelch im Schlunde mit einem Haarringe, Gr. haktg; St. aufrecht od. aufsteigend, $7 \cdot 5-20 \mathrm{~cm}$ 1., Blättch. länglich-lanzettförm. od. verkehrt-eiförmig. Zottig. Gerölle u. Triften d. Alp. v. St., K., T., Kr., stellenweis. 4. 7.

\section{T. nóricum Wulf.}

Köpfch. gestielt od. sitzend, Blt. mit kl. Deckbl. am Grunde d. Stielehen, Kelchschlund kahl, Gr. nicht hakig.

15.

15. Köpfch. gestielt, end- u. seitenständ., Blkr. viel kürzer als d. Kelchzähne; St. $7 \cdot 5-20 \mathrm{~cm}$ h., Blättch. verkehrt-eiförm., scharf gesägt. Sonnige Hügel in B., Mh., Noe.; zerstreut. $\odot .6$.

$$
\text { T. parviflórum Ehrh. }
$$

Köpfch. zu 1-2 sitzend, nur endständ, von d. obersten Bl. umhüllt; Blkr. viel länger als d. Kelchzähne; St. $15-30 \mathrm{~cm} \mathrm{h.:} \mathrm{Blättch.}$ elliptisch od. länglich, stachelspitzig gezåhnt. - Trockene Bergwiesen, Triften, Hügel. 4. 5-7. T. montánum L. 
16. (13) St. kriechend u. wurzelnd, Bl. u. Köpfch. sehr I. gestielt, IÏ̈pfuh. kuglig, Blt. süßduftend. Lockerrasig. - Wiesen, Grasplätze, bebaut. Bod. $4.5-9$.

T. repens L.

St. aufsteigend, nicht wurzelnd, sehr ä3tig, bis $13 \mathrm{~cm}$ l.; Köpfchenstiele dick gefurcht, Blt. kl., Kelch halb so l. wie d. Blkr. - Grasplätze, Wegränder in Süd-T. $\odot .5,6$.

T. nigrescens Viv. färbend.

17. (1, c) Köptch. endständ., kurz gestielt, 1-2, Blt. sich rasch braun

Köpfch. achselständ., 1. gestielt, Blt. erst beim Verwelken sich bräunend.

18. Köpfch, erst länglich, dann walzig, 13-25 $\mathrm{mm}$ l., glänzend kastanienbraun; St.) aufrecht, $15-49 \mathrm{~cm}$ h., Blättch. länglich od. verkehrteilanzettförmig. - Moorige Waldplätze, torfige Wiesen. ๑. 7. 8.

Hopfenklee, T. spadiceum L.

Köpfch. erst kuglig, dann eiförm., bis $20 \mathrm{~mm} \mathrm{l}$, glänzend hellbraun; St. aufsteigend, $10-15 \mathrm{~cm} \mathrm{1.,} \mathrm{Blättch.} \mathrm{eiförm.} \mathrm{od.} \mathrm{oval.} \mathrm{-} \mathrm{Feuchte} \mathrm{Trif-}$ ten d. Kalkalp.; zerstreut. $\odot$ od. 4. 7. 8.

1. bádium Schreb.

19. Fahne zusammengefaltet, Flügel vorgestreckt, Blt. kl. hellgelb, zuletzt gelbbräunlich, Köpfch. halbkuglig, 6-8 $\mathrm{mm}$ br.; St. liegend bis aufrecht, 10-20 cm l., fadenförm., Blättch. kl., verkehrt-eiförmig., abgestutzt, vorn gezähnt. -- Wiesen, Grasplätze, Felder. $\odot$. 5-9.

Kleiner Goldklee, T. minus Sm.

Fahne nach rückwärts tusammengedrückt, nach vorn löffelartig erweitert, Flügel auseinander stehend; Blkr. goldgelb, hellbraun werdend. 20.

20. Köpfch. halbkuģlig, lockerbltig, 8-10 $\mathrm{mm}$ br., auf fadenförm. Stiele; St. aufrecht, $15-30 \mathrm{~cm}$ h., Blättch. alle sitzend, verkehrt-eiförmiglänglich, vorn gezähnt. - Grasplätze in Sz., St., Kr.; zerstreut. ๑. 6. 7. T. patens Schreb.

Köpfch. kuglig od. eiförmig, gedrungen-bltig. 21.

21. Alle 3 Blättch. sitzend, länglich od. oval, fein gezähnt; St. aufrecht, ästig, 15-45 $\mathrm{cm}$ h.; Köpfch. kuglig, $13 \mathrm{~mm}$ br., schön goldgelb.Berg- u. Waldwiesen, bebuschte Hügel, 4. 6. 7. (T. aúreum Poll.)

\section{Großer Goldklee, T. agrárium L.}

Mittleres Blättch. deutlich gestielt, alle Blättch. verkehrt-eiförm., ausgerandet, gezähnelt; St. liegend bis aufrecht, bis $30 \mathrm{~cm}$ l., Köpfch. zahlreich, goldgelb, 6--12 $\mathrm{mm}$ l. Sehr variierend. - Wiesen, Felder, Hügel, Schutt. $\odot .5-9$. T. procumbens L.

\section{Medicágo L. Schneckenklee (XVII, 3).}

St. meist ästig, Bl. gestielt, Blättch. gezähnelt od. fein gesägt, Köpfch. zu 1-3 auf 1. achselständ. Stiele.

1. Blt. dunkelblau od. violett in länglichen dichten Traub., Hülsen schneckenförm. mit 2-3 Windungen; St. liegend bis aufrecht $30-60 \mathrm{~cm}$ hoch, Blättch. verkehrt-eiförm. bis keilig-lineal. - Cult. u. verwild. 4. 6-9.

Luzerne, $M$. sativa $L$.

b) Blt. gelblich-blau od. grünlich-violett: Bastard zw. M. sativa u. falcata. gemein auf Wiesen mit d. Stammältern. M. média $\mathrm{P}$.

c) Blt. hell- bis dunkelgelb. 
2. Hülsen sichelförm, od. schneckenhansfürmiğ, ảoch daun in d. Mitte ofren.

Hülsen schneckenhausförm., geschlossen.

3. Hüls. sichelförm. od. fast kreisförmig, Traub. åicht, kopfig; St. liegrnd od. aufsteigend, $30-60 \mathrm{~cm}$ l., Blästch. verkehrt-eiförmig bis linealkeilig. - Trockene Wiesen, sandige Ufer, Schutt. 4. 6-9.

Sichelklee, schwedische Luzerne, M. falcáta L.

Hïls. schneckenhausförm., mit 2-3 Windungen, Blt. kl., in lockeren Doldentrauben, verbïht zurückgeschlagen; St. liegend, $15-30 \mathrm{~cm} \mathrm{l}$; Blättch, verkehrt-eiförmig bis lineal-keilig. - Sonnige Hügel in \$ll., Noe., tr. ; zerstreut. 4. 6-9. M. prostráta Jacqu.

4. Hülsen unbewehrt, kl., nierenförm., reif schwarz; Köpfch. kug. lig, kl.; St. liegend od. autsteigend, bis $30 \mathrm{~cm}$ l., sammt d. Blt. flaumig bis grauzottig, Blättch. verkehrt-eiförm. od. rundlich, vorn gestutzt. Viel-

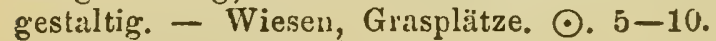

Hüls. krautstachlig.

M. lupulina L.

5. Windungen d. Hiilse aderlos, dünn u. locker, 4-5, mit pfriemenfürm. geraden an d. Spitze hakigen Stacheln, Hülsen kuglig, $4 \mathrm{~mm} \mathrm{br}$; St. liegend od. aufsteigend, 7-30 $\mathrm{cm}$ l., Blättch. verkehrt- eiförmig. Weicl:haarig. - Trockene Grasplätze, Triften auf Sand u. Kalk; zerstreut. ๑. 5. 6. II. minima L.

Windungen d. Huilse erhaben geadert.

6. Blättch. einfärbig, verkehrt-eiförmig; St. aufrecht, $30-60 \mathrm{~cm}$ h.; Hüls. eiförmig-walzig, Windungen.netzadrig, mit seichtrinnigem Rande, u. geraden pfriementörm. Stacheln. - Steinige Waldorte in KY. u. UnterSt. 4. 5. 6. M. carstiensis Jacqu.

Blättchen mit braunem Fleck, verkehrt-ei- oder herzförmig; St. liegend, 15-45 $\mathrm{cm} \mathrm{l}$.; Hülse plattkuglig, Windungen am br. Außenrand $\theta$ 4 kielig mit nach oben und unten bogig zurückgekrümmten Stacheln (M. maculáta W.). - Aus Südeuropa eingeschleppt auf Feldern hie und da; unbeständig. $\odot$. 5. 6.

M. arcibica All.

\section{Anthýllis L. Wundklee (XVII, 3).}

St. liegend od. aufsteigend, Bl. unpaarig gefiedert mit ganzrandigen Blättchen, Bltköpfchen endständig.

1. Grundständ. Bl. von zweierlei Form, d. ersten einfach lanzettförmig, die spätern leierförmig-gefiedert, alle l. gestielt; St. $10-45 \mathrm{~cm} \mathrm{l.,}$ Stbl. unpaarig gefiedert mit stets größerem Endblättchen; Köpfchen meist pararweis, von fingerig zertheilten Deckbl, gestützt. Selir variierend. Trockene Wiesen, Hügel, felsige Plätze, besonders auf Kalk. 4. 5. 6.

\section{Vulnerária L.}

Variet. $\alpha$. a úrea Neilr. Blkr. goldgelb, sich röthlich färbend. Gemein; - $\beta$. alpestris (Hegetschw.), Blkr. gr., schwefelgelb;

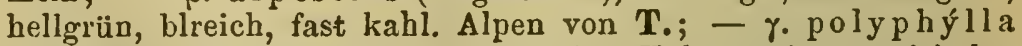
(Kit.) Blkr. gelblichweiß mit blutrother Fahnenspitze; reich beblättert, im untern Theil rauhhaarig-zottig. Voralpen von 0e.;

- $\delta$. rubriflóra Koch. Fahne und Schiffchen blutroth, Flügel gelb, rothgerandet. Alpen.

2. Grundbl. gleichgestaltet, sammt d. Stbl. vielpaarig, mit gleichgroßen Blättchen; Blkr. blassrosa oder röthlichweiß; St. 10-15 cm h. rasig. Seidenhaarig-grangrün. - Alpen von Noe., St., K.,, T. 4. 5. 6. 


\section{Onónis L. Hauhechel (XVII, 3).}

Bl. gestielt, 3 zählig oder einfach (richtiger mit 1 Blättchen); Blt. achselständig, oft traubig oder ährig gruppiert. Flaumige oder zottige, oft zngleich driisige und klebrige $\mathrm{Kr}$.

1. Blt. sitzend od. kurz gestielt, beblätterte Ähren od. Trauben bildend; Hülsen aufrecht, eiförmig.

2.

Blt. 1. gestielt, mit an d. Spitze begranntem Stiele, welcher länger als d. Bl. ist; Hülsen hängend, länglich-lineal. Drüsig-flaumige u. zottige klebrige Pfl.

5.

2. Blkr. gelb, kl.; Blt. sitzend in kurzen Ähren; St. $7-20 \mathrm{~cm}$ h., Blättch. verkehrt-eiförm. bis rundlicn-gezähnt. Klebrig-flaumig. - Sonnige Bergabhänge in Noe., Süd-T.; stellenweis. 4. 6-8. O. Columnae All.

Blkr. rosa oder hellviolett-roth, doppelt so l. als der Kelch; Blt. kurz gestielt, Blättchen feingesägt, drüsig behaart bis fast kahl. 3.

3. St. wehrlos, rundherum 1. zottig (Haare drüsig, schmierig), aufrecht oder aufsteigend, $0.3-1 \mathrm{~m}$ 1.; Blättchen länglich oder oval, Blt. paarweis in dichten ährigen Trauben. Stinkend. - Föhrenwälder in Noe. und Mh., Moorwiesen in Sz. - 4.6. 7.

O. hircina Jequ.

Seitenzweige in Dornen anslaufend, St. u. Kelche drüsenhaarig. 4.

4. St. aufrecht od. aufsteigend, ruthenförmig, 30-60 cm l., d. ganzen Länge nach mit dornigen (oft paarweisen) Ästchen besetzt; Blättchen lanzettförmig oder oval. - Weg- und Ackerränder, Flussufer, wüste Plätze. 4. 6-8.

O. spinósa L.

St. liegend oder aufsteigend, bis $60 \mathrm{~cm}$ 1, nur unten mit einigen

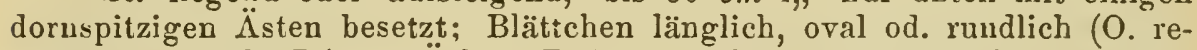
pens Auct. nicht L.). - Äcker, Triften, trockene Wiesen, Ufer. 2. 6-8.

0 . procurrens Wallr.

5. (1). Blkr. rosenroth, Bltstiele 2-3 bltig, länger als d. Bl.; Bl. alle 3 zählig, Blättch. kreisrund, gezähnelt; St. 30-f:0 $\mathrm{cm}$ h. - Steinige Plätze in T. u. Kr.; zerstreut. 4. 6. 7.

O. rotundifólia $\mathrm{L}$.

Blkr. gelb, blutroth gestreift, Bltstiele $1 \mathrm{bltig}$, kürzer als d. Bl.; untere Bl. 3-, obere 1 zählig, Blättchen länglich, gezähnelt; St. (meist viele) $30-60 \mathrm{~cm} \mathrm{l}$. - Sonnige steinige Plätze in Kr. und Süd-T. 4. 6. 7 .

O. Natrix L.

\section{Lupínus L. Wolfsbohne (XVII, 3).}

Blt. in zu endständigen Trauben vereinigten Quirlen; St. aufrecht.

1. Blkr. goldgelb, wohlriechend; Bl. 9 zählig, St. $30-60 \mathrm{~cm} \mathrm{~h}$. Weichbehaart. - Aus Südeuropa, als Grünfutter-, Dünger- und Zierpfl. cult. $\odot .7-9$.

L. liteus L.

2. Blkr. weiß. geruchlos, Bl. 7 zählig; St. $0 \cdot 3-1 m$ h. Weichzottig. -Wie vorige. $\odot .7 .8$.

L. albus L.

3. Blkr. blassblau, geruchlos, Trauben sehr 1., Bl. 12 zählig; St. bis $1 m$ h. Flaumig. - Zierp母. aus Nordamerika. 4. 6. 7. L. perennis L.

\section{Ulex L. Hecksame (XVII, 3).}

Dorniger Str., $0.6-1.30 m$ h.; Zweige u. Dornen grün, gefurcht, jung zottig, Bl. kl. pfriemlich; Blt. zu $1-2$ in d. Blwinkeln, $13 \mathrm{~mm} \mathrm{l}$,, gelb; Hüls. 8-12 $\mathrm{mm}$ l., rauhhaarig. - Dürre, steinige od. sandige Plätze in T., stellenweis. ち. 5. 6 .

$U$. europaeus L.

Will kom m, Schulflora. 


\section{Spártium L. Pfriemen (XVII, 3)。}

Kahler, wehrloser, $0.6-2 m$ h. Str.; Stämmchen u. Äste binsenförm., griin, rund; Bl. sehr entfernt, länglich od. lanzettförmig; Blt. gr., goldgelb, in endständigen Trauben, Hüls. lineal, flach. - Sonnige Hügè in Kr. u. Süd-T. 5. 5. 6. Spanischer Ginster, S. jünceum L.

\section{Sarothámnus Wimm. Besenginster (XVII,3).}

Wehrloser Str. mit aufsteigenden 0.6-2 $m$ l. Stämmen und ruthenförmigen kantigen grünen Zweigen; untere Bl. 3 zählig, obere einfach, Blättch. verkehrt-ei- od. länglich-lanzettförmig; Blt. einzeln, ab. gedrängt, seitenständ., kurz gestielt, Blkr. sehr gr., goldgelb; Hüls. an den Rändern weißzottig, reif kahl. - Sonnige, felsige Plätze und auf Sandboden. Ђ. 5. 6. Besenstrauch, Hasen-, Rehhaide, S. scopárius Koch.

\section{Genísta L. Ginster (XVII, 3).}

Niedrige Str. u. Halbstr.; Bl. ganz u. ganzrandig, Blkr. gelb.

1. St. u. Äste gegliedert u. br. geflügelt, BI. lanzettlich, sitzend; Blt. in endständig., kurzen Trauben; Hülser lineal, seidenhaarig. Rasenbildend, rauhhaarig, St. aufsteigend. - Trockene Hügel und Wälder in ve., K. u. Kr., stellenweis. 4. Ђ. 5. 6.

St. u. Äste weder gegliedert noch geflügelt.

2. St. bedornt, aufrecht od, aufsteigend. G. sagittális $\mathbf{L}$.

St. dornenlos.

3. St. von unten an beblättert, einfach, bis $30 \mathrm{~cm} \mathrm{~h}$., mit biegsamen, kaum stechenden, zusammengesetzten Dornen; Bl. lanzettförmig od. lineallanzettlich; Traube endständig. Rasenbildend. - Felsige Plätze in Siid-St. und Kr. 5. 5. 6.

G. silvestris Scop.

St. unten nackt, mit steifen stechenden, einfachen bis fiedertheiligen grünen Dornen, $15-45 \mathrm{~cm}$ h.; BI. lanzett- od. länglich-lanzettfürmig.; Trauben locker, Hüls, zottig. Rauhhaarig, buschbildend. - Laubwälder, Hügel, Triften. 5. 5. 5.

G. germánica L.

4. Fahne, Schiffchen, Unterseite d. Bl. u. Hülsen seidig behaart. 5 .

Blbl. kahi.

5. Blt. gegen das Ende d. Äste hin seitenständig, kurze beblätterte Trauben bildend; Kelch u. Bltstiele àngedrückt-seidenhaarig; 131. kl., gebüschelt, verkehrt-eilanzettförmig od, länglich, rinnig, St. $30 \mathrm{~cm} \mathrm{h.} \mathrm{-}$ Sandige Kiefernivälder in B. (selten), 0oe., Kr. 5. 4. 5. G. pilósa $\mathrm{I}$.

Blt. $\mathrm{zu} 2-4$ in endständigen Trauben, Kelche u. Bltstiele zottig; Bl. lanzettförmig, flach, St. liegend, $7 \cdot 5-15 \mathrm{~cm}$ 1. - Felsspalten in Süd: Kr. u. Süd-T. †. 6. 7.

6. Äste $3 \mathrm{kantig}$, in eine Blttraube endigend, St liegend, bis $30 \mathrm{~cm}$ lang; Bl. lanzettförm., mit durchscheinendem Saume. - Steinige Berge in Siid-St. u. Kr.; zerstreut. 5. 6. 7.

Äste rund, Bl. ohne durchseheinendem Rand.

G. triquetra W. Kit.

7. Blt. in einfachen endständigen Trauben, Bl. lanzettlich, elliptisch od. eiförmig.

Blt. zu 1-5 auf kurzen beblätterten Seitentrieben, znsammengesetzte Trauben bildend.

9.

8. St. aufsteigend, behaart, selten kahl, $30-45 \mathrm{~cm} \mathrm{l.;} \mathrm{Bl.} \mathrm{kahl} \mathrm{od.}$ angedrückt-behaart, Hülsen kahl. Büsche bildend. - Wald- u Bergwiesen, Triften, Gebüsche. 5. 6. 7.

$\mathrm{F}$ ärbeginster, $G$. tinctória L. 
Var. elátior (Koch), St. aufrecht, bis $1.6 m$ h., fast kahl. Alpen von Siid-T.

St., Bl. u. Hülsen rauhhaarig, sonst wie vorige. - Trockene Hügel in Unter-St., Kr., Süd-T. ち. 6. 7.

G. ovcita W. Kit.

9. Angedrückt-behaart, seidenglänzend; St. liegend-aufsteigend, Äste bis $30 \mathrm{~cm}$ l. - Waldränder, Gebüsche in Mh., Noe., Kr.; zerstreut. $\hbar$. 5. 6 .

G. procumbens W. Kit.

Kahl; St. liegend, mit $15-30 \mathrm{~cm}$ l. strahlig ausgebreiteten Ästen. - Trockene Wiesen, grasige Abhänge in Unter-St. und Kr. Ђ. 5. 6. G. diffrisa Willd.

\section{Cýtisus L. Gaisklee (XVII, 3).}

Blt. in Köpfchen od. Trauben, selten zu $1-3$ seitenständig; Blättchen ganzrandig. Sträucher, Halbstr, selten Bäume.

1. Bl. gegenständig, Blättchen lineal, angedrückt behaart; Blt. zu 3 bis 5 in gestielten Köpfchen am Ende d. gegen- od. quirlständigen Äste, gelb; Hüls. rautenförmig, 1-2 samig.

Bl. wechselständig, Blättchen ei- od. lanzettförmig, Hülsen länglich od. lineal, mehrsamig.

2. Schiffch. seidenhaarig, übrige Blbl. kahl, Fahne tief ausgerandet, Flügel kürzer als d. Schiffchen; Str. $15-45 \mathrm{~cm}$ h., Bl. kl., seidig-grau. Alpen von Unter-St., Kr., K., Siid-T.; zerstreut. Ђ. 5. 6.

\section{C. radicitus DC.}

Schiffchen u. Fahne seidenharig, Fahne abgerundet, Flügel kahl, so lang als d. Schiffchen; sonst wie vorige. - Berge in Kr., stellenwcis. $\hbar$. 5. 6 .

3. Blt. in Tráuben, gelb.

C. holopétalus Fleischm.

b) Bit. in Köpfchen.

c) Blt. zu 1-3 in seitenständigen Büscheln längs d. Zweige. 9 .

4. Trauben vielbltig, 1. und schlaff, herabhäugend, Bl. l. gestielt; Großstr. od. kl. B.

Traub. aufrecht; Str. von 0.3-2 $m$ Höhe.

5. Blättch. stumpf, stachelspitzig, unterseits sammt Bl.- u.'Bltstielen, Kelchen u. Hülsen angedrückt-seidenhaarig; Blkr. goldgelb. Samen sehr giftig! - Gebirgswälder in Kr. und Süd-St., überall cult. Ђ. 5. 6.

Goldregen, Kle e-, Bohnenbaum, C. Laburnum L.

Blättchen spitz, beiderseits sammt d. Bl.- u. Bltstielen, Kelchen und Hülsen kahl; Blkr. blässer gelb, Trauben sehr lang. - Wie vorige Art, minder häufig cult. $\hbar$. 6 . 7 . C. alpinus $\mathrm{L}$.

6. Traub. vielbltig, bis $15 \mathrm{~cm} \mathrm{l.,} \mathrm{spitz,} \mathrm{Blkr.} \mathrm{goldgelb;} \mathrm{Bl.} \mathrm{gestielt,}$ Blättch. lanzettförmig od. länglich. Angedrückt-kurzhaarig, beim Trocknen schwarz werdend. Stämmchen aufsteigend, bis $80 \mathrm{~cm} \mathrm{l}$. - Waldränder, bebuschte Hügel. 5. 5-7.

C. nigricans $\mathrm{L}$.

Traube kurz, 6-10 bltig, Blkr. gelb; Bl. fast sitzend, Blättch. verkehrt-eiförmig od. fast rautenförmig. Kahl. Str. 1-2 $m$ b. - Zierpfl., wild in Sïd-T. 5. 5. 6.

C. séssilifólius $\mathrm{L}$.

7. $(3$, b.) Halbstr. mit krautigem aufsteigendem, $7 \cdot 5-15 \mathrm{~cm} \mathrm{l}$. St., rasenbildend; Köpfchen $2-4$ bltig, gestielt, Blt. gelb; Blättchen elliptisch od. lanzettlich, unterseits sammt Hülsen seidenhaarig-silberglänzend. Steinige Hügel in Süd-T. und Kr. ち. 5. 6.

C. argénteus $\mathrm{I}$. 
Str. mit aufrechtem od. anfsteigendem, bis über $1 m 1$. Stämmchen, $\mathrm{Z}$ weige ruthenförmig.

8. Blättchen lanzett- od. keilförmig, beiderseits angedrückt-seidenhaarig; Bltenzweige nebst Bltstielen u. Kelchen abstehend-behaart, Blt. gold- od. blassgelb. - Bebuschte Hügel in B. (selten!), Mh., Oe., St. 5. 7. 8 .

C. austriacus $\mathrm{L}$.

Var. I e can thus (W. Kit.). Blättchen oberseits kahl, Blt. gelblichweiß bis weiß. Zierpfl. aus Ungarn u. Siebenbürgen.

Blättchen verkehrt-eiförmig od. eiliptisch, Blt. gr., goldgelb, nur an den heurigen Ästen sich entwickelnd; abstehend-rauhbaarig. - Sonnige Hügel u. Haiden in B., Mh., Oe.; zerstreut. 5. 6.7. C. supinus L.

Var. bisflórens (Host.). Blt. an vorjährigen $\mathrm{Z}_{\text {weigen, nur zu } 2}$ seitenständig. Niederliegend, heurige Äste aufsteigend. In $\mathbf{B}$. (selten!), T., Kr.; zerstreut.

9. (3, c.) Blt. purpurroth, gr., meist zu 2 ; Blättch. spitz, lanzettlich od. länglich-lanżettförm.; Stämmchen aufsteigend, $15-30 \mathrm{~cm}$ l. Fast kə.bl. - Bebuschte Hügel und Berge in St., K., Kr., Süd-T.; zerstrent, auch Zierstr. 5. 4. 5.

Blt. gelb.

C. purpureus Wulf.

10. Blättch. beiderseits abstehend-rauhhaarig, verkehrteiförmig oder elliptisch; Blt. zu 1-3, 'seitenständig, d. späteren oft gebiischelt-endständ.; Stämme und Äste liegend od. aufsteigend, $30-60 \mathrm{~cm} \mathrm{l.,} \mathrm{sammt} \mathrm{d.} \mathrm{Bltstielen}$ und Kelchen rauhharig. - Steinige und bergige Orte in Noe., St., Kr., Süd-T.; zerstreut. ち. 4. 5-7.

C. hirsutus L.

Blättchen oberseits kahl, unters. angedrückt-seidenhaarig od. zottig, verkehrt eiförmig-länglich od. lanzettförmig; Blt. zu 1-3 stehend, goldgelb.

11. Blt. am Ende der Zweige zu 2-4, doldig, od. seitenständig zu 1-2, (C. bifórus l'Hèr.); Stämmchen liegend od. aufsteigend, $15-30 \mathrm{~cm}$ lang. - Trockene Bergwiesen, steinige Hügel, Triften, besonders auf Kalk, in B., Mh., Oe. ந. 4.5. C. Ratisbonensis Schaeff.

Blt. längs der ruthenförnrigen Zweige an seitenständ. Kurztrieben, 1. einseitswendige beblätterte Trauben bildend; Str. mit aufrechten oder aufsteigenden Ästen, 1-2 $m$ h. - Zierstr, aus Ungarn. Ђ. 4. 5.

C. elongátus W. Kit. 


\section{Nachträge.}

S. 5. Gattung A splen ium. In Num. 5 nach A. Ruta muraria schiebe ein: Bl. im Umriss länglich od. eiförmig, Fiederchen keilförmig, 3theilig mit sehr schmalen 2-3zähnigen Zipfeln. - An Kalkfelsen in 0oe. (Windischgarten), Kr. (Wochein), Sïd-T., selten. 7. 7. 8.

A. fissum Kit.

S. 12. Gattung Potamogeton. In Num, 13 nach P. natans schiebe ein: Schwimmbl. nicht lederartig, br. eiförmig bis rundlich, bis $6.5 \mathrm{~cm}$ ]., untergetauchte länger und schmäler (bis $10 \mathrm{~cm}$ 1.) Ährenstiel viel länger als d. Bl., schmächtig. Ganze Pfl. grün od. rothbraun. (P. coloratus Hornem.) - In stehenden Wässern von Ebenen in Noe., B. zerstreut. 7. $6-8$.

$P$. plantagineus Ducr.

S. 21. Gattung Bromus. In Num. 3 nach B. secalinus schiebe ein:

Unterste Blscheiden behaart; Bl., Ährchen, Rispenspindel und Stiele fein flaumig; frtragende Rispe aufrecht. - Acker, Saaten in T. ○. 6. 7. (B. hordeaceus Gmel.) B. Billotii F. Schultz.

S. 24. Gattung Festuca. Nach F. spectabilis schiebe ein:

Blscheiden nicht knorplig verdickt. Bl. fein zugespitzt, schmal lineal ( $1-3 \mathrm{~mm}$ br.); Rispe flattrig, nickend; Ährchen grün und violett gescheckt, $3-5$ bltig, $5-8 \mathrm{~mm}$ l.; Halme his $60 \mathrm{~cm}$ hoch. - An felsigen und steinigen Plätzen d. Kalkalpen in Noe. (1580 2000 m.). 4. 6-9.

F. pulchella Schrad.

S. 30. Nach Arrhenatherum schiebe ein:

\section{6 b. Danthonia DC. (III, 2).}

Ährchen lanzettförmig, 3-5bltig; Kelchspelzen gleich lang, spitz, länger als d. Blt.; untere Bltspelze in 2 lange Borsten auslaufend u. mit einer dazwischen entspringenden, geknieten Granne.

Halme 30-45 cm h., Rispe traubenförmig, 5-10 cm l., Ähchen grün od. bunt mit zusammengeneigten Grannen. - Auf Bergwiesen in $\mathbf{K r}$., verbreitet. 2. 6-7.

D. provincialis DC.

S. 30. Gattung Stipa. Nach Num. 1 ist zu lesen:

Grannen fedrig behaart, sehr lang

2.

2. Bl. flach od. im Trocknen züsammengerollt. $1-2.5 \mathrm{~mm}$ br.: Blhäutchen schmal, verlängert. - Dürre Kalk- und Gypshügel in B., Noe. 4. 6. 7. Frauenhar, St. Ivansbart, Federgras, Ste inflachs, St. pennata L.

a) Jo ann is Celak. Bltspelzen $15-16$, selten bis $20 \mathrm{~mm} 1$, Grannen bis ans Knie über $6 \mathrm{~cm}$.

B) Grafiana Stev.. Bltspelzeu 21-24 $\mathrm{mm}$ l., Grannen bis ans Knie bis $9 \mathrm{~cm} \mathrm{l}$. 
Bl. borstlich, rinnig $0.5 \mathrm{~mm}$ br., in eine haarförmige Spitze auslaufend; Blhäutchen sehr kurz, verkümmert; sonst wie St. Joannis. - Auf dürren Basalt- und Phonolitbergen in B., zerstreut. 7. 6. 7. St. Tirsa Stev.

S 30. Nach der Gattung Milium schiebe ein:

\section{1 b. Piptátherum Pal. B. Grannenhirse (III, 2).}

Àhrchen 1 bltig, untere Kelchspelze $3-5$, obere 3 nervig, eiförmig, kahl oder etwas rauh; untere Bltenspelze nach oben zusammengerollt, unter der knorpligen Spitze begrannt.

Halme dichtrasig, iiber $1 m \mathrm{~h} .$, Blscheiden kahl, Bl. flach, br.

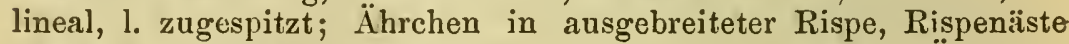
haardünn, geschlängelt aufrecht, länger als d. grüne Ährchen; Granne 3-5 mal länger als d. Spelze. - In Vorhölzern und auf Holzschlägen in Noe. (um Heiligenkreuz, im Leithageb.) 4. 5. 6.

$P$. parádoxum Koch.

S. 30. Gattung Agrostis. In Num. 1 nach A. spica venti schiebe ein: Untere Kelchspelze kleiner als d. obere. Blt mit 10-15 $\mathrm{mm}$ l. Granne, Rispe 4-20 cm l., Rispenäste aufrecht, vom Grunde an verästelt und Ährchen tragend. Halme bis $60 \mathrm{~cm}$ h. - Auf sonnigem Sandboden im östlichen Noe., zerstrent. $\odot$. 6. 7.

S. 32. Nach der Gattung Sorghum schiebe ein:

\section{A. interrupta $\mathrm{L}$.}

\section{5 b. Chrysopógon Mert. Koch. Goldbart. (III, 2).}

Rispe mit quirlständigen einfachen Ästen, welche am Ende 3 einblütige, am Grunde von goldgelber Wolle umgebene Ährchen tragen, von denen das mittlere (zwitterblütige) sitzend, die beiden seitlichen (†) 1. gestielt sind. Untere Blütenspelze der Zwitterblte mit l. grundständiger, starker, gewundener Granne.

Halme rasig, $0 \cdot 6-1 m \mathrm{~h} . ; \mathrm{Bl}$. lineal, langhaarig; Rispe bis $15 \mathrm{~cm}$ l., ausgebreitet; Ährchen violett od. gelblich. - An sonnigen Grasplätzen im östl. Noe. (südl. der Donau) und in Siid-T. 4. 6. 7. (Pollinia Gryllus Spr.)

Ch. Gryllus Trin.

\section{5 c. Heteropogou Pers. Schopfgras (III, 2).}

Ähre mit 1bltigen und 1geschlechtigen Ährchen; diese zu 2-3 an der Spindel; untere Ährchen (†) sitzend, obere theils sitzend (९), theils gestielt $(\delta), ~ ᄋ$ mit einer langbegrannten Spelze. Sämmtliche Grannen vereinigt und seilförmig zusammengedreht.

Halme rasig, $60 \mathrm{~cm}$ h., Blscheiden bärtig, Bl. lineal; Grannen gelblichbraun, kurz behaart, $5 \mathrm{~cm}$ 1., Narben roth. - An felsigen Orten in Süd-T. 4.8. H. Alliónii R. et Sch.

S. 33. Gattung Ses sleria. Unter S. coerulea Ard. stecken 2 verschiedene Arten, nämlich :

1. S. coerulea Host. (Cynosurus coerul. L.): Bl. oberseits weiß od. blaugrün, flach, trocken zusammengefaltet; Ähre kuglig oder 
eiförmig, 10-20 $\mathrm{mm}$ l. Centrifugal wachsend, ringförmige Rasen bildend. - Auf sumpfigen Bergwiesen in B., Oe., St. 4. 4.

2. S. vária Wettst. (S. coerulea Scop.) BI. beiderseits freudig od. bläulichgrün, flach od. rinnig, trocken zusammengerollt; Ähre eiförmig, $20-30 \mathrm{~mm}$ l. Dichte Rasen bildend. - An Kalkfelsen, auf trockenem Kalkboien, verbreitet. 7. Blüht 8-10 Tage früher.

S. 36. Gattung Carex. In Num. 4 nach C. rupestris schiebe ein:

Halme rundlich, 5-10 cm h., Ähre meist 4-bltig, Spelzen und. Fr. pfriemlich-lanzettförmig, stielrund, strohgelb, zurückgeschlagen. Dicht rasig. - Torfmoore des Iser- und Riesengeb. 4. 6. 7.

S. 38. In Num. 21 nach C. mucronata schiebe ein:

C. pauciflora Light.

Fr. elliptisch, schnabellos, länger als die eiförmigen, schwarzbraunen, grüngestreiften Spelzen, deshalb d. Ähren (bis $13 \mathrm{~mm}$ l.) schwarzbraun und grün gescheckt. Halme $5-15 \mathrm{~cm}$ h., Ähren kurz gestielt, doldentraubig. - Höchste Granitalpen von Sz., T., K. 4. 7. 8.

S. 39. In Num. 25 nach C. acuta schiebe ein:

C. bicolor Bell.

Wie vorige, aber Spelzen rothbraun. B. entfernt nervig. - An Gewässern und in Sümpfen in Noe., häufig. 4. 4. 5.

\section{C. $r u f a \mathrm{~L}$.}

S. 40. In Num. 38 nach C. panicea schiebe cin:

Scheiden d. Hüllbl. bis $13 \mathrm{~mm}$ l., Ähren glänzend schwarzbraun, weibliche länglich, 7-9 $\mathrm{mm}$ l, dichtblütig, nickend od. hängend; Fr. 3 kantig, nervenlos. Halme $10-23 \mathrm{~cm}$ h. - An sumpfigen Stellen d. höchsten Aljen v. 0e., St., K., Kr. $(1900-2550 \mathrm{~m})$. 4. 8.

C. ustulata Wahlenb.

Scheiden d. Hüllbl. ebenso, weibl. Ähren aufrecht, genähert, dichtbltig, Spelzen hellrostbraun mit grünem Rückennerv; Fr. längsnervig. Halme $15-30 \mathrm{~cm} \mathrm{~h}, \mathrm{Bl}$. steif, flach, glänzend. - Auf sonnigen Hügeln, in Haiden in Noe., St., Kr., Süd-T. 7. 4. 5.

S. 40. In Num. 39 nach C. pilosa schiebe ein: C. nítida Host.

Halme $10-25 \mathrm{~cm}$ h., Bl. kahl, Scheiden etwas aufgeblasen; weibl. Ähren entfernt stehend, lockerbltig, unterste sehr l. gestielt; Spelzen blassbraun mit grünem Rückennerv; Fr. kuglig-eiförmig, 3kantig, glatt. - An quelligen Bergabhängen im Riesengeb., Gesenke $(1350 \mathrm{~m})$. 4. 6. 7 .

C. sparsiflóra Steud.

S. 40. In Num. 40 nach C. alba schiebe ein:

Hüllbl. häutige, braune, weißgerandete Scheiden bildend; Ähren kl., kopfig zusammengedrängt; Spelzen rothbraun, spitz; Fr. kugligeiförmig, schwarz. Halme zart, umgebogen, $10-15 \mathrm{~cm}$ h. - An felsigen Orten d. Alpen v. T., Ooe., Noe. (Raxalpe); selten. 7. 5. 6. C. ornithopodioides Hausm.

S. 40. In Num. 44 nach C. ericetorum schiebe ein:

Var. membranácea (Hoppe). Spelzen größer, häutig, breit hell gerandet, kahl. (C. approximata All.). - Auf d. höchsten Alpen von Sz., K., T. $(1850-2000 \mathrm{~m})$.

S. 41. In Num. 53 nach C. riparia schiebe ein:

Fr. ebenso, aber der Länge nach vertieft-gerieft; männl. Ähren 1-2 genäliert, weibl. 1-4, entfernt, aufrecht, alle walzig; Spelzen 
glänzend dunkel- oder rothbraun. Halme $30-60 \mathrm{~cm}$ b., an d. Spitze nickend, stumpf dreikantig. - An feuchten Waldstellen und Gewäs. sern ebener Gegenden in B., Noe. (z. B. Marchfeld) St. 4. 5. 6. C. nutans Host.

S. 43. Gattung Heleocharis. In Num. 1 nach H. acicularis schiebe ein:

Narben und Ähre ebenso; Nüsschen glatt, Halme fadenförmig, 5-15 cm h. - Auf überschwemmten Grasplätzen, an schattigen Waldstellen in Kr. (um Adelsberg), St. (b. Cilli). ๑. 7. 8.

\section{H. carniólica, Koch.}

S. 48. Gattung Iris. In Num. 9 nach I. sibirica füge hinzu:

St. rund, $30-60 \mathrm{~cm}$ h., länger als d. Bl., Bltenscheiden groß, krautig, aufgeblasen (bei I. graminea und sibirica klaffend); äußere Perigonbl. mit azur-violetter Platte und weißlichem purpurn geadertem und gelbstreifigem Nagel, innere blauviolett. - In Noe. auf Sumpfwieseu südlich d. Donau und im Marchfelde, zerstreut. 4. 5. 6.

\section{I. spuria L.}

S. 48. Gattung Alisma. In Num. 1 nach A. Plantago schiebe ein:

Bl. langgestielt, schmal elliptisch od. lanzettlich; Schaft aus bogigem Grunde aufsteigend. - In Sümpfen, an Gewässern in Yoe. (Donauauen, bei W.-Neustadt, Hernals). 4. 6-9.

\section{A. arcuátum Mich.}

Var. angustifolium Beck. Bl. lineal, untergetaucht.

S. 49. Nach Gattung 116. Triglochin schiebe ein:

\section{6 b. Elódea Rich.}

Blt. polygamisch-2 läusig, kl., einzeln, langgestielt, achselständig. Flutende untergetauchte Wasserpfl. mit zu $3-4$ quirlständigen, lanzettlichen gesägten Bl. In Europa nur die weibl. PA. (Blt. mit 3 blättrigem Kelch $u$. 2 gr. bürstenförmigen Narben. - Aus Nordamerika eingeschleppt, in Wassergräben, Bächen, Bassins, diese rasch gänzlich ausfüllend. In B. u. Oe. 4. 5-8.

Wasserpest, $E$. canadensis Rich. Mchx.

S. 52. Gattung O $\mathrm{r}$ chis. In Num. 12 nach O. incarnata schiebe ein:

Var. Traunsteíneri (Saut.). Schmächtiger, Bl. kurz, lineallanzettlich; Ähre armbltig. Auf sumpfigen Wiesen in Sz. (bei Zell am See), $\mathbf{T}$.

S. 53. Gattung Nigritella. In Num. 1 nach N. nigra schiebe ein:

Blt. rosenroth, in elliptischer od. verlängerter zugespitzter Ähre, mit kurzem stumpfen Sporn. (N. angustifolia Koch.). - Auf Alpentriften in 0e., St., K., Kr. 4. 6-9. N. rubra Wettst.

S. 53. Gattung Ophrys. In Num. 1 nach O. fuciflora schiebe ein:

Lippe mit abwärts zurückgeschlagenem Anhängsel, 5 lappig, stark gewölbt, purpurbraun-filzig, gelblich gefleckt; äuß. Perigonbl. rosenroth. - An steinigen grasigen Stellen in Noe., K., Süd-T.; zerstreut. 4. 6. 7 .

O. apífera Huds.

Var. a u stríac a Wiesb. Mittelfeck d. Lippe gelblich, mit blauer, 2 braune Fleckchen einschließender Einfassung. In Noe.

S. 53. Nach der Gattung Herminium schiebe ein:

128b. Epipógon Gmel. Bananenorche (XX, 1).

Äußere Perigonbl. schmal, nach abwärts geschlagen, Lippe rückund aufwärts gewandt, ungleich 3lappig, ihr unterer Theil mit 
weit sackförmigem aufwärts gerichtetem Sporn, der vordere Theil (d. Mittellappen) größer, spitz, mit gekräuselter Oberfläche.

Wzst. geweilıähnlich verzweigt ohne Wurzel. Stengel üb. d. Grunde angeschwollen, bllos, mit Scheiden besetzt, weif, nach oben röthlich, 10-25 cm l.; Blt. 1-8 hängend, Perigonbl. weißlich, gelblich od. lila, Lippe weißlich, violett gefleckt. - In feuchten, schattigen Wäldern zw. faulendem Laub, auf faulen Baumstämmen in B., Nge., Süd-T.; selten. 7. 7. 8. E. aphyllus Sw.

\section{8 c. Limodórum Tourn. Dingel ( $\mathrm{XX}, 1)$.}

Äußere Perigonbl. aufrecht abstebend; Lippe vorgestreckt, länglich, gekerbt, in der Mitte eingeschnürt, nach rückwärts mit langem, walzigem, stumpfen, abwärts geneigtem Sporn.

Wzst. walzig, mit fleischigen, verflochtenen Fasern besetzt, St. $30-75 \mathrm{~cm}$ 1., reichlich bescheidet (untere Scheide geschlossen, obere aufgeschlitzt), weib und violett gefleckt od. stahlblau od. d. ganze PG. purpurn; Blt. aufrecht, in beblätterter Traube; Perigonbl. $20 \mathrm{~mm}$ 1. violett, Lippe ohne Sporn bis $17 \mathrm{~mm}$ l., weif u. violett gefleckt. - An Waldrändern, zwischen Gebüsch in Noe, zerstreut (Wiener Wald, Leithageb.) 4.6. 7.

L. abortivum Sw.

S. 54. Gattung Epipactis. In Num. 2 nach E. latifolia schiebe ein:

Wrzt. gebüschelt-fasrig, St. $15-60 \mathrm{~cm} \mathrm{h.,} \mathrm{Bl.} \mathrm{kürzer} \mathrm{als} \mathrm{die}$ Stengelglieder, klein, eilanzettlich; Blt. kl., in lockerer Traube, grünlich-purpurn. - In Vorhölzern, lichten Wäldern in Noe., selten. 4. 6. 7 .

E. microphýlla Sw.

S. 54. nach der Gattung Corrallorrhiza schiebe ein:

\section{5 b. Microstýlis Nutt. (XXIL, 3).}

Äußere Perigonbl. zuriickgeschlagen, innere abstehend, Lippe rückwärts stehend, aufwärts gerichtet, spornlos, aus herzeiförmigem Grunde plötzlich lang bespitzt, mit 3-5 erhabenen Leisten auf der Fläche.

St. $10-30 \mathrm{~cm}$ h., meist mit nur 1 querständigen, elliptischen Bl.; Blt. aufrecht, zahlreich, in beschuppter Traube, gelblichgrün. - An moosigen, nassen Stellen d. Voralpen in Noe., Alpen von St., T.; selten. 4. 7. 8 .

M. monophýllos Sw.

S. 55. Gattung $\mathrm{Luzula}$. In Num. 2 nach $\mathrm{L}$. vernalis schiebe ein:

Perigonbl. ebenso, Spicre wenigbltig., Bl. bloß $1-3 \mathrm{~mm}$ br. In Vorhölzern und Wäldern in Noe. (IVienerwald) und T.; zerstreut. 7. 4. 5 .

L. Fórsteri DC.

S. 56. Gattung Juncus. In Num. 8 nach J. compressus schiebe ein:

Wie vorhergehende Art, aber Perigonbl. gläinzend kastanienbraun, so lang wie d. länglich-ovale glänzend rothbraune Kapsel (bei J. compressus Kapsel fast kuglig, glänzend kastanienbraun, länger als d. Perigonbl.). - In Sümpfen, besonders salzhaltigen in Noe. zerstreut. 4. 7. 8.

J. Gerardi Lois.

In Num. 9 nach J. bufonius schiebe ein:

Perigonbl. lanzettförnig, stachelspitzig, griin, breit weißgerandet, länger als d. fast kuglige Kapsel; St. $6-25 \mathrm{~cm}$ h. - An feuchten 
Orten ebener Gegenden in B. (bei Prag), Noe. (Marchfeld u. siidl. der Donau); zerstreut. $\odot$. 7-9. J. sphaerocarpus N. v. E.

S. 59. Gattung Polygónatum. In Num. 2 nach P. multiflorum füge hinzu:

St. rund, sammt d. Bltstielen und Blnerven zerstreut kurzhaarig; Bl. breit elliptisch, Bltstiele 1-5 bltig. - In Noe., in Anen, Gebiischen d. Donatebene. 4. 5. 6. P. latifolium Desf.

S. 59. Nach Gattung 147. Aspáragus füge bei:

\section{7 b. Ruseus L. Miiusedorn.}

Blt. polygamisch-2häusig, buischelig auf der Oberseite blähnlicher verbreiteter Stengeln (Cladodien). Perigon 6blättrig, Stg. 3; Beere $1-2$ samig.

Immergrüner, bis $40 \mathrm{~cm}$ h. Halbstrauch; Cladodien lederartig, elliptisch, zugespitzt, $4-9 \mathrm{~cm}$ 1.; Blt. gestielt, von $\mathrm{kl}$. Blättchen gestiitzt, griinlichweif; Beeren scharlachroth. - In Wäldern von Noe., St., Kr., zerstreut u. selten †. 4. 5.

R. Hypoglossum L.

S. 60. Gattung $M$ úscari. In Num. 3 nach M. racemosum füge hinzu:

Blt. eifürmig.walzig, $4-7 \mathrm{~mm} \mathrm{l}$, in lockerer (b. M. racemosum dichter) Traube; Bl. 3--5 $\mathrm{mm}$ br., lïnger als d. St. (b. M. racemostum 1-2 $\mathrm{mm}$ br., meist kürzer als der St.). - In Noe. (Wienerwald, um Wien). 4. 4. 5.

M. neglectum Guss.

S. 61. Gattung Alli um. In Num. 8 nach A. sphaeroceplralum schiebe ein:

Bl. sclımal lineal, rinnig; Dolde flach gewölbt, Stf. am Grunde mit 2 kurzen Seitenzähnchen, länger als d. Perigon; St. $30-45 \mathrm{~cm}$ h. straff, Zwiebel schmal kenlenförmig. - Auf Felsen in B., zerstreut und selten. 4. 7 .

A. strictum Schrad.

Bl. sehr schmal, Dolde rundlich, dichtbltig, Stf. ohne Zähne und länger als d. Perigon. - Auf Sumpfwiesen siddlich $d$. Donau in Noe., im siidl. T. 4. 8. 9.

S.67. Gattung Salix. In Num. 13 nach S. Myrsinites füge hinzu:

B1. elliptisch bis verkehrt eiförmig od. flach lanzettlich, spitz, ganzrandig, drüsenlos, anfangs reichlich, später spärlicher behaart. Sonst wie vorhergehende. - Alpenregion der Kalkalpen in Noe. 5. 6.7 .

S. Jacquiniána Willd.

S. 78. Gattung Atriplex. In Num. 5 nach A. tataricum schiebe ein:

Weibl. Blt. in endständiger gedrungener Ähre, männl einzeln od. zu wenigen in den Blwinkeln; Fruchtklappen rhombisch-spießförmig, gezähnt; Bl. eispießförmig, stumpf oder buschig gezähnt. - An wüsten Plätzen im östl. Yue., verbreitet. $\odot$. 7-9.

\section{A. lacinátum $\mathrm{L}$.}

S. 80. Gattung $R u m e x$. In Num. 7 nach $R$. obtusifolitus schiebe ein :

Frklappen beiderseits $3-9$ zïhnig, alle od. nur 1 Schwielen tragend; Grundbl. herzförmig länglich oder länglich, etwas wellig, obere lanzettförmig; St. $0.5-1 m$ h. - Auf feuchten Wiesen in Noe. (besonders im siudl. Wiener Becken.) 4. 7. 8.

$R$. pratensis Mert Koch.

S. 90. Gattung Phyteúma. In Nr. 5 nach Ph. orbiculare füge bei:

Unterste Stbl. und die der unfruchtbaren Büschel gestielt, eiförmig-elliptisch, obere länglich-lanzettförmig, aun Grunde zusammen- 
gezogen, sitzend, alle gekerbt; Hüllbl. fast so lang wie d. Blt., br. eiförmig, aufrecht. - Auf WViesen d. nördl. Kalkalpen in 0e. u. St. $(1200-2500 \mathrm{~m})$; verbreitet. $4.6-8$.

Pl. austriacum Beck.

S. 98. Gattung Ta raxacum. In T. officinale fiige folgende Abarten bei: ع. glaucescens (M. Bieb.) Bl. bläulichgriin, schrotsägeförmig oder fiedertheilig mit sehr schmalen oft gezähnten Zipfeln. St. niedrig, dünn, aufrecht od. zurïckgebogen; Bltkörbchen klein, Blt. schwefelgelb, Blkr. blassgrau. - An felsigen, steinigen, dürren Plätzen, in Kiefernwäldern; zerstreut.

$\zeta$. e rythrospermum (Andrz.) Wie voriges, ab. Blkrone rothbraun. Auf feuchtem Boden an Wegen und Wiesen unter $\alpha$, hier und da.

In Nr. 5 nach T. leptocephalum füge bei:

Bl. schrotsägeförmig od. buchtig gezähnt od. fast ganz, länglich. St. sehr kurz, umgebogen; Bltkörbchen kl., Blt. orangegelb. Auf den höchsten Alpen von K. u. T. $(2500-2700 \mathrm{~m})$, an Gletschern, stellenweis häufig. 4.7.8. T. Pácheri C. N. Schultz.

S. 114. In Gattung Adenostýles füge bei:

3. Bl. ziemlich gleichmäßig fein gezähnt, unterseits flockig dünfilzig, weifgrau, fast lederartig, dick; oberste Stbl. nicht geöhrelt. Sonst wie A. alpina. - An schattigen Felsen der Kalkalpen von T. $(1400 \mathrm{~m})$; selten. 7. 7. 8. A. crassifolia Kern.

S. 119. Anmerkung zu Helianthus u. Rudbeckia.

In die Nälse dieser Gattungen gehören folgende bekannte (im Text vergessene) Zierpflanzen: Die Georgine od. Dahlie (Dahlia variábilis Desf.), gewöhnlich mit ganz od. halb gefüllten Bltkörbchen, selten mit "einfacher", d. h. mit rothem Strahl u. gelber Scheibe; - das Mädchenauge (Coreopsis trípteris L.) mit gegenständigen tief 3 theiligen $\mathrm{Bl}$. u. sehr l-gestielten Bltkörbchen (Strahl goldgelb, Scheibe purpurbraun); - das Sch ö na $\mathrm{ge}$ (Calliopsis bícolor Rchb.) mit zu 3 in Quirlen stehenden, 3 zählig-fiederschnittigen Bl. u. l.-gestielten Bltkörbchen (Strahlblt. goldgelb mit schwarzpurpurnem Fleck am Grunde, Scheibe dunkel blauroth); - die Zinnie (Zinnia élegans Jacqu.) mit gegenständ. st.-umfassenden herzeirunden Bl. u. gr. endständ. Hltkörbchen (Strahl oberseits meist purpur- od. scharlachroth, Scheibe dunkel), und die Studenten-od. Sammt-Blumen (Tagetes pátula u. erecta L.), stinkende Pfl. mit gegenständigen fiederschnittigen Bl. u. endständ. Bltkörbchen (Strahl goldgelb, Scheibe dunkel), Äste bei T. pátula abstehend, bei T. erecta aufrecht. Alle diese Pf. stammen aus Nordamerika und sind einjährig.

S. 122. Gattung Achilléa. In Nr. 4 vor A. macrophylla schiebe ein:

St. $10-15 \mathrm{~cm}$ h., aufsteigend, einfach, einköpfig, behaart; $\mathrm{Bl}$. kahl, kammförmig, fiedertheilig mit ganzrandigen spitzen Zipfeln; Bltkörbchen 20-25 $\mathrm{mm}$ br., Hülschuppen mil sehr br. schwarzbraunem Saume. - In den Kalkalpen von T. auf Kalk u. Dolomit. (Bis $2000 \mathrm{~m}$ ); stellenweis. 7. 7. 8. A. oxýloba Dc.

In $\mathrm{Nr}$. 11 füge nach A. collina bei:

Wie vorige, ab. St. straff aufrecht, an schattigen Orten bis $1 \mathrm{~m}$ h., an trockenen sammt d. Bl. mehr oder weniger wollig behaart 
(hier St. oft nur $30-40 \mathrm{~cm}$ h.) an schattigen verkahlend; Doldentrauben groß, sehr dichtköpfig, Grundbl. oft 20-30 $\mathrm{cm} \mathrm{1.} \mathrm{-} \mathrm{Auf}$ Holzschlägen in Nadelwäldern, an bebuschten felsigen Orten in Noe., verbreitet. 7. 7-9. A. stricta Schl.

Var. alpícola Beck. In der Voralpen- u. Krummholzregion (häufig am Wiener Schneeberg).

S. 124. Gattung Ánthemis. In Nr. 6 nach A. montana schiebe ein:

Ganz kahl, grün; Bltkörbchen bis $37 \mathrm{~mm}$ br., Hüllschuppen breit, schwarz gesäumt. (A. stiríaca Vest). - Alpen v. St., (auf Granitgerölle des Zinken 1800-2100 m häufig). 8. 7.

A. carpáthica Waldst. Kit.

S. 134. Gattung Lappa. In Nr. 2 nach L. officinalis schiebe ein:

Bltkörbchen traubenförmig, 20-25 $m m$ br., die oberen gedrängt übereinander stehend; Akenen 8-11 mm 1., Äste des bis $1.5 \mathrm{~m}$ l., St. abstehend, bogenförmig überhängend. (L. macrosperma Wallr.) - An feuchten Waldstellen im nördl. B. $u$. in Ooe. ox. 7. 8. $\quad L$. nemorósa Körnike.

S. 135. Gattung Cárduus. In Nr. 1 nach C. nutans schiebe ein:

Bltkörbchen kleiner, eiförmig-kuglig, anfangs aufrecht, dann nickend oder hängend, frtragend aufrecht; äußere u. mittlere Hüllsch. eingeschnürt, mit hin und her gebogener, abstehender, weichdorniger Spitze; St. einfach, 1 köpfig od. ästig, mit 1 köpfigen nach oben nackten flockig-wolligen Ästen; BI. fett, beiderseits grün, gezähnt, gelappt od. fiederspaltig. - An felsigen grasigen Plätzen in Ooe. (um Ischl gemein) u. in T. auf Kalk, 1200 bis $2200 \mathrm{~m}$. $\odot$. 7.t $\mathrm{S}$.

C. viridis A. Kern.

In $\mathrm{Nr} .7$ nach C. crispus füge bei:

Bl. beiderseits lebhaft grün, etwas zottig, lang u. dicht dornig gewimpert, Lappen 3 eckig mit starkem Dorn; Bltkörbchen gehäuft, größer. - Gemeines Unkraut auf Äckern u. Wiesen in T. auf Schieferboden (z. B. b. Trient, $1000-1500 \mathrm{~m}$ ) ๑. 7. 8 .

C. agrestis A. Kern.

S. 136. Gattung Cirsium. In Nr. 5 nach C. palustre schiebe ein:

Bltkörbchen flach doldentraubig, langgestielt; Bl. kahl, hellgrün, grundständige lanzettförmig, dornig gezähnelt, l.-gestielt, stengelständ. buchtig bis fiederspaltig, stärker dornig. - Auf sumpfigen Wiesen in Noe., verbreitet. $\odot$. 7. 8. C. brachycéphalum Jur.

S. 140. Gattung Scabiósa. In Nr. 5 nach $\mathrm{S}$. lucida schiebe ein:

Bl. glänzend, grundständige ganz, Stbl. leierförmig mit sehr großem Endzipfel, Blkr. blau. - Auf Kalk- u. Dolomitbergen in Kr. (Gegend von Laibach). 4. 6-9. S. Hladnickiana Host.

S. 143. Gattung Aspérula. In Nr. 6 nach A. cynanchica schiebe ein:

Blkr. hellviolett od. pfirsichroth, Theilfi. glatt; Bl. zu 2 gegenständig, untere lkreisrund bis eiförmig, lederartig, zurückgebogen, obere lineal-aufrecht abstehend; St. steif aufrecht, $6-15 \mathrm{~cm}$ h., unten sehr verästelt, oben trugdoldig-ästig. - An steinigen Plätzen der subalpinen Region der Kalkalpen von Noe. u. OberSt. 2. 6-8. A. Neilreichii Beck.

S. 152. Gattung Gentiána. In Nr. 6 nach A. Sturmiana schiebe ein:

Blkr. mit dunkel-violettem Saum, 25-35 mm l.; mittlere Stbl. länglich-lanzettlich, länger als d. Internodien. - Auf Wiesen der 
Centralalpen v. T. $(1200-1600 \mathrm{~m})$ stellenweis massenhaft. \%. 8. 9. G. rháetica Kern.

S. 156. Gattung Mentha. In Nr. 4 nach M. silvestris füge hinzu:

Bl. länglich, zugespitzt, ungleich gesägt, unterseits graufilzig. Sonst wie vorhergehende. In Noe. an sumpfigen Ackern (Wiener Becken). 4. 7. 8 .

M. cándicans Crtz.

S. 158. Gattung Sálvia. Anmerkung zu S. nemorosa:

$\mathrm{S}$. silvestris L. ist nach $\mathrm{K}$ erner ein Bastard von S. nemorosa L. (S. silvestris Jacqu. u. a. Autoren) und S. pratensis, welcher bisher nur auf Auenwiesen der Leitha u. Fischa (b. Wien) gefunden worden ist.

S. 159. Gattung Thymus. In $\mathrm{Nr} .5$ nach Th. alpestris füge bei:

BI. eiförmig, stumpf, groß, deutlich gestielt, kahl od. am Grunde gewimpert, zuletzt herabgeschlagen; St. an den Kanten behart, sonst kahl, Blkr. klein, graufaumig, purpurviolett. - An Waldrändern n. in Holzschlägen der Hügelregion in Sz. (häufig), Ooe., T. 4. 8-10. Th. montánus W. Kit.

S. 159. Gattung Saturéja. Nach S. hortensis füge bei:

St. zu mehreren aus d. vielköpfigen Wrzlst entspringend, holzig; $7 \cdot 5-20 \mathrm{~cm}$ h.; Bl. lanzett- od. lineal-lanzettförmig, zugespitzt; Blkr. röthlich od. weiß. - An dürren steinigen Plätzen in K r r. (in d. Wochein u. im Karst, wo häufig) u. T. 7. 7. 8.

S. montána L.

S. 161. Gattung Galeópsis. In Nr. 2 bei G. Ladanum füge bei:

$\gamma$. canescens (Schult.) Wie $\beta$., ab. St. u. Bl. grau behaart, Blkr. sehr gr., purpurn., selten gelblichweif. - Auf Kalkboden in Noe. u. Kr.

S. 157. Gattung Myosótis. In Nr. 3 bei M. palustris füge bei:

Var. strigulósa (Rchb) St. u. Bl. angedriickt behaart. - Auf Wiesen in 00e., T. u. anderwärts; seltener.

S. 168. In $\mathrm{Nr}$. 6 nach M. silvática schiebe ein:

Rauhhaarig, mehrstenglig, dichte Rasen bildend; St. aufsteigend, Bl. lanzett-förmig, grün; Trauben dichtbltg., Blt. geruchlos. - Auf Gerölle u. Triften der Kalkalpen (1260-2000 m); verbreitet, anch in B. (Riesen- u. Mittelgeb. u. a. O.) 4. 6-9.

\section{II. alpestris Schmidt.}

Nach Mr. suavéolens füge bei:

Spärlich u. abstehend behaart, St. aufrecht, $15-20 \mathrm{~cm}$ l., nicht rasig, Stbl. elliptisch bis eilanzettfürmig, grün; Trauben entferntbltg., schlaff; Blkr. geruchlos, mit weit vorstehender gelber Röhre 11. himmelblauem Saum. - In subalpinen Wäldern r. Ooe., St. u. T. $4.7-9$.

M. variábilis Ang.

S. 169. Gattung $\mathrm{Pulmonária.} \mathrm{In} \mathrm{Nr.} 3$ nach $\mathrm{P}$. saccharáta fïge bei:

Bl. freudig grün, weißlich gefleckt, Stbl. fast wagerecht abstehend. mittlere am Grunde gestutzt, oberste schwach herzförmig; St. $8-30 \mathrm{~cm} \mathrm{h.,} \mathrm{borstig} \mathrm{u.} \mathrm{oben} \mathrm{sammt} \mathrm{d.} \mathrm{Bltstand} \mathrm{mit} \mathrm{langen}$ Drïsenhaaren bedeckt; Blkr. violett bis azurblau. - In Gebüschen an steinigen feucliten Orten in St. u. Kr. 7. 3-5. 
S. 179. Gattung Dignitális. In Nr. 2 nach D. ambígua schiebe ein:

Blkr. hellgelb, $20 \mathrm{~mm}$ l., schmalröhrig; St. $0 \cdot 6-1 \mathrm{~m}$ h., Bl. länglich oder eilanzettförmig, kabl. - Auf steinigen Hügeln in V. 11. Süd-T., stellenweis. $\odot$. 6-8. D. lútea L.

S. 184. Gattung Euphrásia. Verwandt mit E. mínima sind:

E. púmila A. Kern.: Blkr. sehr kl. (Unterlippe 3-4 mm l.), hellviolett, dunkler geadert, ohne gelbem Fleck; St. einfach od. mit wenigen aufrechten Ästen, straff; Bl. scharf gesägt, untere länglich. - Auf Alpentriften in Mittel-T. (Steinacherjoch b. Trient u. a. O., $1800 \mathrm{~m}$ ).

E. pulchella A. Kern. Blkr. kl. (Unterlippe $5 \mathrm{~mm}$ l.), Oberlippe blauviolett, dunkelviolett gestreift, Unterlippe wei $\beta$, am Grunde mit einem kl. Fleck, im Mittelfelde mit 7 violetten Linien; St. einfach, schwach, untere Bl. verkehrt-eiförmig, am Grunde keilig, stumpf gezähnt. - Alpentriften von Central-T., 2000 bis $2200 \mathrm{~m}$ (am Steinacherjoch sehr häufig).

E. micrantha Rchb. Blkr. sehr kl., gelb mit weißem Schlunde; St. zart, Bl. eiförmig, stumpf gezähnt. - Auf Heideboden, stellenweis (z. B. in B. b. Zawist unweit Prag).

E. variábilis Freyn. Blkr. $5.5 \mathrm{~mm}$ l., goldgelb, lila-goldig od. weißlich-violett und schwarz-violett gestreift; St. $4-5 \mathrm{~cm}$ h. (selten lıöher), BI. länglich, gekerbt-gezähnt. - Auf fruchtbaren Bergweiden der Centralalpen von T., auf Schieferboden (2000 bis $2400 \mathrm{~m})$.

In Nr. 7 nach E. tricuspidata füge bei:

Bl. steif, kabl, lineal, untere jederseits mit 1 gr. dreieckigen Zahne; Blkr. ansehnlich, weiß, mit gelben Flecken u. violetíen Streifen, Unterlippe $6 \mathrm{~mm} \mathrm{l}$. Sonst wio vorige. - An felsigen u. steinigen Orten in Kr. (durch die ganzen Julischen Alpen verbreitet) u. in K. (Wischbachalpe). $\odot .7-9$.

E. carniólica A. Kern.

S. 184. In Nr. 6 nach E. coerúlea füge bei:

BI. weich, wollig, rings herum scharf gesägt, untere länglich, obere eiförmig; Blkr. $8 \mathrm{~mm}$ l., Röhre u. Schlund weiß, Oberlippe purpurviolett, Unterlippe bellpurpurn mit einem gelben Fleck auf weißem Grunde. St. 2-5 $\mathrm{cm}$ h. - Auf steinigen Plätzen am Rande v. Sclineefeldern in Noe. (Wiener Schneeberg, 1800 bis $2050 \mathrm{~m}$; häufig). $\odot$. 7. 8.

E. nivâlis Beck.

S. 187. Gattung Melampýrum. In Nr. 4 bei M. neroorósum füge bei:

Var. grandiflórum (Kern). Blkr. 20-25 mm l, goldgelb; oberes Deckbl. rhombisch od. deltaförmig, azurblau. - Gemein auf Wiesen am Semmering.

Zwischen M. nemorósum u. silváticum kommen folgende Mittelformen vor:

1. Mittlere Stbl. ei- bis lanzettförmig, lang zugespitzt, 5 bis $18 \mathrm{~mm}$ br.; obere Deckbl. grün, kahl; Blkr. $15-17 \mathrm{~mm}$ l. mit geöffnetem Schlunde.

M. commutatum Tsch. In B.

2. Mittlere Stbl. lanzettlich, bis $12 \mathrm{~mm}$ br.; obere Deckbl. blau, behaart; oft ganzrandig; Blkr. 17-18 $\mathrm{mm}$ l. mit halb offenem Schlunde. M. subalpinum Jur. In Noe. 
3. Mittlere Stbl. lineal, bis $5 \mathrm{~mm}$ br.; obere Deckbl. blau, lang 11. schmal zugespitzt, am Grunde belıaart; Blkr. $11-14 \mathrm{~mm}$ 1. mit gesperrtem Schlunde. $M$. angustissimum Beck. In Noe.

S. 190. Gattung Orobanclie. In Nr. 14 nach O. Salviae schiebe ein :

Oberlippe der 16-20 $\mathrm{mm}$ 1. rötlilichgelben Blkr, ausgerandet bis 2 lappig; Zipfel am Rande reichlich driisenhario; St. 18 bis $50 \mathrm{~cm} \mathrm{h.,} \mathrm{trocken} \mathrm{roth-} \mathrm{u.} \mathrm{violettbraun,} \mathrm{drüsig} \mathrm{behrart.} \mathrm{-} \mathrm{Auf}$ Wurzeln v. Berberis vulg., Rubus fruticosus u. caesius in $\mathbf{T}$. (verbreitet) u. Sz. 7. 7. 8 .

s. 191. Gattung Plantágo. Nach P. media füge hinzu:

Bl. elliptisch-lanzettförmig, spitz, am Grunde mit langer weißer Wolle, in einer Rosette; Schäfte aufsteigend, $10-30 \mathrm{~cm}$. h., Ähre erst liegelförmig, dann walzig. - Auf Kalkgerölle im Centrum v. T. (gemein auf den Bergen b. 'l'rins). 4. 6-9.

\section{7. glareósa Kern.}

S. 211. Gattung Bupléurum. In Nr. 5 nach B. ranuculoídes füge bei:

Hüllchenbl. getrennt, oval; Doldenstrahlen haardünn, 3-4 mal so lang als d. meist 1 blättrige Haupthülle; Blt. kleiner, blassgelb, Fr. fast rippenlos. - An rauhen steinigen Plätzen im südl. $\mathbf{K}$. (im Canalthale selr verbreitet). 7. 7. S. B. canalense IVulf.

S. 215. Gattung P eucédanum. In Nr. 8 nach P. officinale schiebe ein:

Grundbl. wie bei vorhergeliender Art, aber Blzipfel lineal-lanzettlich, bis $7.5 \mathrm{~cm}$ l. u. $4 \mathrm{~mm}$ br.; Blbl. weib. - Auf Wiesen in siidl. Kr. 7. 7. 8.

S. 216. Vor Gattg. 478. Im peratória schiebe ein:

P. parisiense DC.

\section{8 b. Tommasínia Bertol.}

Blt. polygamisch, die der Centraldolde fruchtbar, die d. Seitendolden meist unfruchtbar; Blbl. eingerollt. Sonst wie Peucédanum,

Dolden vielstralılig, lï̈llenlos, centrale (endständige) sehr groß. darunter 3-4 langgestielte kleinere Seitendolden quirlständig; St. bis mannshoch, rund, bereift; Bl. 3 fach fiedertheilig mit br. Abschnitten; Blbl. grünlichweiß oder gelblichgriun. - An Alpenhängen in Suid-T., Kr., St. 7. 7. 8.

$T$. verticilláris Beck.

S. 222. Gattung Saxifraga. Zu Gruple Nr. 10 gehört auch die S. rhá etica Kern. Diese 3 sehr älnlichen Arten lassen sich, wie folgt, unterscheiden:

1. Rosettenbl. von sehr ungleicher Länge, die äußersten 5-7 $\mathrm{cm}$ 1. u. 8-10 $\mathrm{mm}$ br., alle zungenförmig, spitzlich; Rispe eiförmig, sehr reichbltg., Blbl. $5-7 \mathrm{~mm}$ 1. 11. $3-5 \mathrm{~mm}$ br.

\section{S. altissima Kern.}

Rosettenbl. weniger ungleich u. schmäler, br. lineal, St. weniger robust u. sammt d. Rispenästen weniger u. kiurzer drüsenhaarig; Blt. kleiner.

2. Rosettenbl. 5-6 cm l. u. 5-7 mm. br., stumpf; Rispe länglich, oben ebensträußig, mit $6-12$ bltg. Ästen.

S. Hostii Tsch.

Rosettenbl. $4-5 \mathrm{~cm}$ l. u. $4-5 \mathrm{~mm}$ br., spitz; St. 15-40 cm h., nur an d. Spitze ästig; Rispe kl., oval, mit $3-5$ bltg. Ästen. - Alpen des westl. u. siidl. T., 1400-1700 m (im Ortlerstocke am häufigsten). 7. 6. 7.

S. rhaetica Kern. 
S. 235. Gattung Pulsatilla. In Nr. 1 nach $\mathrm{P}$. alba schiebe ein:

Hiill- u. Grundbl. 3 theilig fiederschnittig, Abschn. fiederspaltigmit 3 eckigen Zipfeln; Blumen weiß, Griffel an der Spitze kahl. (P. Burseriana Rchb.) - Triften u. Gerölle d. Alpen (2000 bis $2300 \mathrm{~m}) .2$. $6-8$.

P. alpina (L.) Delarb.

Anmerkung. Nach A. Kerner unterscheiden sich P. alba u. alpina beziiglich der Blätter dadurch, dass bei $P$. alha die Zipfel durch schmale tiefe Einschnitte bis stark zum Mittelnerv des Blabschnittes, bei P. alpina durch weite offene, nicht so tief reichende Einschnitte getrennt sind. Die Hüllbl. v. P. alba sind zur Bltezeit gerade und eben ausgebreitet, die v. P. alpina bogig nach auswärts gekrümmt.

S. 238. Gattung Batráchium. Nach B. circinnátum füge bei:

Bltstiele länger als d. Bl.; Blbl, verkehrt-eiförmig, sich berührend; Stbg. 15-18, abstehend, deshalb d. Bltköpfchen nicht iiberragend; Frträger ei- bis kugelförmig, Nüsschen verkehrt-eiförmig, rundum gekielt; Bl. anfangs länger als d. Stglieder, d. St. bedeckend. In schnell fließenden Bächen in B. (im Goldbach b. Opočno. häufig) u. Noe. (im Wiener-Neustadter Canal häufig). 4. 6-8.

$B$. carinátum Schur.

S. 240. Gattung R anúnculus. In Nr. 25 nach R. carinthiacus schiebe ein:

Frträger gänzlich dicht bebaart, Blkr. 20-25 $\mathrm{mm}$ br.; St. u. Blstiele abstehend behaart. - Steinige Triften d. Kalkalpen v. Noe. (z. B. Raxalpe, häufig) u. auf Glimmschiefer in Central-1'. (Berg Padaster b. Trins, $2500 \mathrm{~m}$ ). 4. 6-8.

\section{R. Hornschucli ii Hoppe.}

S. 241. Gattunģ Ficária. Nach F. ranunculoídes füge bei:

Wie vorhergehende, ab. Blscheibe im Umriss br. länglich, seicht geschweift, fast ganzrandig, mit abgerundeten übereinander greifenden. Lappen am Grunde. - An gleichen Orten in B. u. Noe., hie u. da (im Wiener Becken häufig). 4. 4. 5. F. calthaefolia Rchb.

S. 241. Gattung Caltha. Von C. palustris sind neuerdings 2 Formen als Arten abgetrennt worden, welche sich nur nach den Früchten siclier unterscheiden lassen:

1. Reife Balgkapseln allmählich in einen $2 \mathrm{~mm}$ l. Schnabel verschmälert, S-förmig gekrümmt, mit fast hakiger Spitze, abstehend od. nach abwärts gekrïmmt. - In Sümpfen des Tieflandes in Noe.

Reife Balgkapseln, kurz geschnäbelt, aufrecht. C. cornuita Schott.

2. Balgkapseln am Rücken gerade, an der Bauchnaht gekrümmt, halbkreisförmig od. länglich, 9-12, selten nur $6-9 \mathrm{~mm}$ l. - An quelligen Orten d. Alpen v. Noe., Sz., St.; auch im Waldviertel.

C. laeta Schott.

Balgkaps. auf d. Rücken u. d. Bauchnaht bogig gekriimmt, daher schief elliptisch, $7-10 \mathrm{~mm}$ l.

S. 244. Gattung A cónitum. Nach A. Lycóctonum schiebe ein:

Wie voriges, ab. d. miitzenförmige obere Kelchbl. vorwärts gebogen u. d. Grundbl. viel mehr u. tief zertheilt in lineale Zipfel. - Auf nassen Wiesen u. an kräuterreichen Stellen in d. Voralp. v. Noe. 4. 6. 7. A. ranunculifólium Rchb. 
S. 253. Gattung Thlaspi. In Nr. 8 nach Th. alpinum schiebe ein:

Wzst. mit wenig beblätterten, am Ende lockere Blrosetten tragenden Ausläufern; Bl. dicklig, blaugrün, eiförmig-rundlich, l. gestielt; Blt. weif, Schötchen länglich-verkehrt-eiförmig, abgestutzt od. schwach ausgerandet, mit 2 samigen Fächern. - Auf Kalkgerölle in d. Alpen v. Kr. (Isonzothal, $2000 \mathrm{~m}$ ) u. Süd-T. $(1800 \mathrm{~m}$ ). 7. $6-8$. Th. Kérneri Hut.

S. 256. nach Gatt. 556 schiebe ein:

\section{6 b. Cochlearia L. (XV, 2). Löffelkraut.}

Schötchen kuglig od. ellipsoidisch, vielsamig, Samen in jedem Fache 2 reihig. Kahle Kräuter mit lgestielten Grund- u. sitzenden oder kurzgestielten Stbl.; Blbl. weiß.

1. Grundbl. nierenförmig mit tief herzförm. Ausschnitt, Stbl. ausgeschweift od. eckig gezähnt; Schötchen netzadrig, wagerecht abstehend in lg. schlaffen Trauben. St. 8-30 cm h. - Auf Wiesen in Ooe. u. st., zerstreut. $\odot .6 . \quad$ C. pyrenáica DC.

2. Bl. kl., länglich, lang gewimpert, St. $3-5 \mathrm{~cm}$ h., büschlig, beblättert, Blt. lgestielt in kurzen Doldentrauben, Schötchen aderlos. - Auf Gerölle d. höchsten Kalkalp. des südl. u. östl. T. (2000 bis $2300 \mathrm{~m})$; selten. 7. 7. 8 .

C. brevicaulis Facch.

S. 259. Gattung Draba. In Nr. 13 nach D. Sauteri füge bei:

Bl. lineal, spitz, stark gekielt; Stbg. so lang wie d. Blt.; Schötchen lanzettförmig, $10-13 \mathrm{~mm}$ l., zerstreut striegelhaarig, langgriffelig. Blumen gr., goldgelb. - Auf mit Schwarzkiefern bestandenen Kalkbergen in Noe. $(300-1300 \mathrm{~m})$. 7. 6. 7.

D. Béckeri A. Kern.

S. 261. Gattung Árabis. In Nr. 5 nach Arabis alpina schiebe ein:

Var. crispata (Willd.) Bl. gr., Stbl. eiförmig; alle stark und vielfach wollig gezühnt. - Alpen $\mathrm{v}$. $\mathbf{K r}$.

S. 266. Gattung Erýsimum. In Nr. 6 nach E. silvestre Crtz. füge bei:

Blbl. ebenso groß, St. verlü̈rzt, $5-10 \mathrm{~cm} \mathrm{~h}$, dicht beblättert, Bl. lineal-lanzettförmig, buchtig gezïhnt, d. Blt. erreichend; Frtraube verkürzt. - An grasigen Plätzen auf Glimmerschıefer der Pasterzengegend in K. $(2500-2600 \mathrm{~m})$. 7. 5. 6. E. puímilum Gaud.

S. 270. Gattung Heliánthemum. In $\mathrm{Nr} .2$ nach $\mathrm{H}$. Chamaesistus schiebe ein:

Var. glabrum Koch. Bl. ganz kahl, höchstens am Rande und an d. Mittelrippe gewimpert, freudiggrün (N. serpyllifolium Crtz.). - An grasigen Plätzen d. Kalkalpen v. Noe. (Wiener Schneeberg, 1500-1700 $\mathrm{m}$, häufig).

S. 274. Gattung Víola. In Nr. 23 nach V. trícolor fige bei:

Bl. sehr lang gestielt, groß, prächtig, wohlriechend; Blbl. breit verkehrt-eiförmig, anderthalbmal länger als d. Kelch, verschiedenu. vielfarbig; Sporn dünn. Sonst wie vorige. - Auf subalpinen torfigen Wiesen in Sz. u. Nord-T. gemein $(1000-1200 \mathrm{~m})$. 7 . 5-9. $\quad V$. polychróma A. Kern.

S. 281. Gattung A renária. In Nr. 2 nach A. serpyllifolia schiebe ein:

In allen Theilen kleiner u. zarter; Bltstiele haarfein, Kaps. walzig-kegelförmig, dïnnwandig, am Grunde wenig elweitert. - 
Auf Sandboden, mageren Feldern in B. (b. Mariaschein u. a. O. im Erzgeb. häufig) u. Noe. (b. Kalksburg u. a. O.) (.) 6-8.

A. leptocládos Guss.

S. 283. Gattung Cerástium. In Nr. 3 nach C. brachypétalum schiebe ein:

Var. glandulósum Koch (C. trauricum Spr.) Zarter; Behaarung d. oberen Sttheils, d. Blïtenstiele, Deckbl. u. Kelche mit Stieldrüsen untermischt. - In Mh. u. Noe. stellenweis.

S. 289. Gattung Siléne. In Nr. 4 nach S. Saxífraga L. schiebe ein:

Kelch keulig-länglich, aufgeblasen, 10 nervig, $18 \mathrm{~mm}$ l., Blbl. sehr groß, 2 lappig, gesägt, hellpurpurn; St. aufsteigend, einfach, $5-15 \mathrm{~cm}$ 1.; Bl. lanzettförm., zungespitzt. Großblumigste aller Silenen. - Auf Kalkbergen in Süd-T. (Giudicarien), selten. 7. 8.

S. Elisabethae Jan.

S. 295. Gattung Hypéricum. In Nr. 9 nach $\mathrm{H}$. montánum schiebe ein:

Kelchzipfel verkehrt-eiförmig, drüsig gewimpert; Trugdolden traubig, Bl. herzeiförmig, am Rande nicht schwarz punktiert, St. oben beblättert. - In Bergwäldern u. Haiden in B. u. Ooe.: selten. 4. 7-9. $\quad$ H. pulchrum L.

S. 302. Gattung Euphórbia. In Nr. 9 nach E. villúsa W. Kit. schiebe ein:

Bl. am Rande 1 . unterseits kurz weich-zottig, oberseits kahl, länglich-spatelförmig, St. dick, fast hohl, zusammendrückbar, abstehend behaart; Trugdold. wenig-strahlig, mit 2-3-gablichen Strahlen; Kaps. kuglig, kahl, mit erhabenen Punkten u. langen dïnnen Haaren. - In feuchten Thalschluchten u. an Gießobächen der Waldregion in Ooe., Noe. u. St., verbreitet. 4. 5. 6.

\section{E. austriaca A. Kern.}

S. 330. Gattung A I chemil la. In Nr. 3 naeh $A$. vulgaris $L$. $\beta$ schiebe ein:

Var. $\gamma$. glabrata Wimm. Ganz kahl, St. verlängert, niedergestreckt, mit gr. Bl. besetzt, mit traubig angeordneten Trugdold.: Bl. derb. - An grasigen $u$. steinigen Plätzen an Bäclıen und Quellen d. Alpen, d. Riesengeb., Böhmerwald u. a. Geb. (1300 bis $2500 \mathrm{~m}$ ).

\section{Verzeichnis}

von seltenen, nur an einem oder an wenigen Standorten beobachteten oder an den Grenzen Cisleithaniens vorkommenden, den Nachbarfloren angehörigen Pflanzenarten.

Botrychium simplex Hitchk.-Torfwiesen am Fuß d. Zü̈nig bei Windisch-Matrei in $\mathbf{T}$.

Pteris crética L. An felsigen Waldstellen an Gardasee.

Molinia serótina (L.) Mert.-Koch. An Porphyrfelsen d. Berges Guntschna b. Bozen in $\mathbf{T}$.

Scleropóa rígida (L.) Griseb. Auf Grasplätzen b. Riva am Gardasee. Bromus stenophyllus Lk. In d. Wochein in Kr. 
Festuca laxa Host. An grasigen Abliäng. d. Berg. Selenitza im Loiblthale in $\mathbf{K} .(1700 \mathrm{~m})$.

Festuca picta Kit. (F. rubra var. picta Hack.) Alpenmatten des Hochwechsels in Noe.

Carex alpina Sw. Auf feuchtem Schiefergerölle b. Innervillgraten in Ost-'T. $(1600-2300 \mathrm{~m})$.

Carex baldensis L. An feuchten felsigen Abhäng. d. Mt. Baldo in Süd-T. Carex heleonástes Ehrh. Auf d. Hechtenseemoor b. Mariazell in Noe. Carex subnivalis Arv. Thon. Auf d. Cima Paganello bei Trient in Siid-T.

Scirpus Michelianus L. In Noe. auf fenchtem Sand längs d. March zw. Stillfried u. Marchegg.

Vallisneria spiralis L. Im Gardasee b. Torbole in Süd.-T.

Ophrys Bertoloníi Morett. An sonnigen Plätzen am Gardasee.

Orchis commutata Tod. Wiesen u. Weidetriften in Val di Ledro in Süd-T.

Orchis Simia Lam. Sonnige Hiigel am Gardasee iiber Dos Brione.

Serapias longipétala Ten. Sumpfwiesen am Gardasee. Maláxis paludósa Sw. Torfmoore b. Schrems in Noe.

Juncus capitátus Weig. Auf feuchtem Sand b. Gratzen (an der Grenze v. Noe.)

Ruscus aculeátus L. Gebüsche im südlichsten T., zerstreut.

Allium ericetórum Thore. Wiesen u. Triften des Val Vestino in Süd-T. Ornithógalum cóllinum Guss. Renne b. Niederrana in Noe. Ornithóg. Boucheánum Ascl. Verwildert in und um Wien.

Fritillaria delphinensis Gr. Godr. Alpentriften des Val Vestino $(1800-2000 \mathrm{~m})$.

Urtica kioviensis Rogov. In Noe. (Marchsümpfe zw. Baumgarten $и$. Marchegg).

Daphne petraea Leyb. Val Vestino, in Felsspalten.

Campanula cenisia L. Auf Gerölle unter d. Jamthaler Ferner in V. Campanula solstitialis A. Kern. Am Jauerling in Noe.

Campanula Morettiana Rchb. Bei Campiglio in Siid-T.

Crepis jubata Koch. Bei Hühnerspiel bei Gossensass in Central-T. $(2650-2730 \mathrm{~m})$.

Hieracium Grisebachii A. Kern. Oezthal zw. Pillberg, Gurgl u. sonst in Central-T.

Aster canus W. Kit. An der March b. Baumgarten in Noe.

Micrópus erectus L. Auf unbebant. Boden in Noe. (einschleppt).

Centauréa dichroantha A. Kern. Auf Kalkgerölle an Gießbächen an der italienischen Grenze v. T. (Val Zellina, Canale di Ferro),

Centaurea Badensis Tratt. In Noe. (an Kalkfelsen b. Baden).

Centaurea alpestris Hegetschw. Auf subalpinen Wiesen b. Trier in Central-T.

Centaurea cirerhata Rchb. Auf Alpentriften d. Val Vestino in Süd-T. Cardus rhaeticus DC. Auf Steingerölle an einem Bache b. Sterzing in Central-T.

Cirsium montanum W. Kit. An schattigen Stellen des Val Vestino. Scabiosa agrestis W. Kit. Auf Wiesen b. Neuwaldegg b. Wien. Scabiosa bannática W. Kit. Gurzhofgraben b. Aggsbach in Noe. Scabiosa gram nntia L. Auf Sand zw. Ellbögen n. Matrei in Central-T. 
Aspérula glauca Bess. Bei Roveredo in Siid-T.

Asperula Eugeniae C. Richt. Am Kranichberg u. Preiner Gscheid in Noe.

Galium margaritácenm A. Kern. Auf Dolomitgerölle am Höllenstein b. Landro in Südost-'T'

Gentiana praecox A. Kerm. Auf d. Janerling u. Ostrong in Noe. Lycopus moll is A. Kern. Sümpfe b. Patesch (Innsbruck) in T. Thymus caruiólicus Borb. Auf d. Sowitzberg b. Adelsberg in Kr. Calamintha nepetoides Jord., Grenzgraben bei Pontafel in K. Népeta violácea Vill. Im Grenzgraben b. Pontafel in K. Betónica dánica Mill. Waldwiesen zu St. Martin b. Klagenfurt in K. Onosma tridentinum Wettst. Auf sonnigen Hïgeln am Gardasee. Pulmonária Kérneri Wettst. Zw. Groß-Reifling u. Palsau in St. Verbascum stiriacum Fritsch. Um Eggenberg bei Graz. Pedicularis comosa L. Bergwiesen d. Monte Baldo in Siid-T. Pedicularis gyroflexa Vill. Süd-T, Alpenweiden des Berges Roen. Melampýrum morávicum H. Braun. Bergwiesen b. Wsetin in Ul.. Plantágo a lpina L. Hinterälpeln b. Feldkirch in V., auf Weidetriften. Plantágo Cynops L. An bebuschten Abhängen b. Baden in Noe. Piguicula longifolia Ran. - Campiglio in Süd.-T.

Androsáce cárnea L. u. Aretia Vitaliana L. ebendaselbst. Primula Oenensis Thom. Triften d. .Val di Breguzzo in Süd-T. $(2200-2500 \mathrm{~m})$.

Primula intricata Gr. Godr. Triften d. Val. Cadino in Süd-T. (1700 $2000 \mathrm{~m}$ ).

Primula integrifolia L. Saminathal in V. (1900 m).

Primula ciliata Moris. Val di Ledro in Süd-T. $(1400-2000 \mathrm{~m})$.

Primula biflora Hut. Bei Sterzing in Central-r. am Weißspitz u.

Finsterstern.

Primula danubialis C. Richt. Donauauen b. Stockerau.

Libanótis praecox A. Kern. Göller b. St. Egid in Noe.

A thamanta vestina A. Kern. Val Vestino u. Val di Ledro in Süd-T.

Peucédanum Schottíi Bess. Am Veldeser See in Kr.

Laserpitium Gaudini Moris. Val Vestino, an grasigen Felsplätzen.

Saxifraga carniólica Hut. Wischberg b. Raibl in K. (2500-2600 m). Calliánthenum Kernerianum Freyn. Triften d. MIt. Baldo (1700 bis $2100 \mathrm{~m}$ ).

Batráchium confervoides Fr. Alpenseeu b. Gossensass u. Obernberg in Central-'T. (2200-2500 m).

Ranunculus Kérneri Freyn. Wiesen b. Trins in Central-T.

Ranunculus bilobus Bertol. Val Vestino auf Kalkgerölle (1500 bis $1800 \mathrm{~m}$ ).

Ranunculus Aléae Wk. In Süd-T.

Helléborns foetidus L. Nangerberg in Ooe.

Nymphaea minor DC. Bei Leopoldskron in Sz. in Lachen. Alyssum ovirense A. Kern. Berg Obir in K. $(2150 \mathrm{~m})$. Mathiola valesíaca J. Gay. Am Flusse Fella in Süd-K. Arabis saxátilis All. Nordöstl. Pusterthal in T. (Virgenthal). Arabis anachoretica Porta. Val di Ledro in Süd-T. Cardámine rivularis Schur. Stnbalpe in St. an quelligen Orten $(1580 \mathrm{~m})$. 
Dentária polyphylla W. Kit. Schattige Wälder b. Nasselthal in Kr. Dentária intermedia Sond. Schattige Wälder des Val Vestino in Süd-T.

Draba lapponica DC. Riedberg. b. Sterzing in $\mathbf{T}$.

Scleranthus hirsutus Presl. Auf Sand b. Trins in Central-T.

Möhringia glaucovirens Bertol. In Kalkfelsspalten d. Val Vestino. Arenaria Húteri A. Kern. Siid-T. im Canale di Cimolais an der ital. Grenze.

Cerastium macrocarpum Schur. Berg Blaser b. Trins $(2000 \mathrm{~m})$.

Dianthus atrorúbens All. Wiesen d. Val di Ledro in Süd-T.

Dianthus e rubescens Trev. Unter Gesträuch b. Bozen in Sud-T.

Dianthus Lumnítzeri Wiesb. Hainburger Berge in Noe.

Euphorbia Kérneri Hut. Auf Kalkgerölle am Flusse Boita bei Campo im Ampezzothale in Süd-T.

Euphorbia variábilis Ces. In Hainen, auf Wiesen des Val Vestino. Cotoneaster integerrima Med. Geisberg b. Wien.

Rosa farinosa Bechst. In Gebuischen b. Trins in Central-T.

Potentilla carniólica A. Kern. Laurenziberg h. Billichgraz in Kr. Potentilla cinérea Choix. Auf d. Berge Serva an d. tiroler-venetian.

Grenze.

Potentilla Gaudini Gremli. Auf Sandhügeln b. Innsbruck.

Potentilla baldensis A. Kern. Val di Ledro in Süd-T.

Potentilla serótina Vill. Auf Grasplätzen um Hodkowička b. Prag. Potentilla porphyrácea Saut. Auf Porphygerölle b. Bozen in Süd-T. Waldsteinia ternata Fritsch. Am Fuße d. Koralpe b. Wolfsberg in K. Spirae a Ha cquetíi Fzl. In Felsspalten d. Canale di Cimolais in Süd-T. Oxytropis carinthiaca Fisch. Oost. Wischberg in $\mathbf{K}$.

Oxytropis triflóra Hoppe. Auf Gerölle im Tauschnitzthal am Großglockner in K. $(2600-2700 \mathrm{~m})$.

Ononis mitis I. Auf Feldern b. Chudenic in B.

Genista trianguláris Kit. Auf Gerölle des gr. Kahlenberg bei Laibach in Kr.

Genista mántica Poll. An d. tirolisch-venetian. Grenze.

Cýtisus falcatus W. Kit. Val di Ledro in Sïd-T. 


\section{Verzeichnis}

\section{der lateinischen Gattungs- und Familiennamen.}

(Die Ziffer neben dem Namen ist die Seitenzahl.)

Abies DC. 7 .

Acer L. 296.

Acerineae 296.

Achillea L. $122,363$.

Achyrophorus Koch. 97.

Aconitum L. 243, 368.

Acorus L. 12 .

Actaea L. 244.

Adenophora Fisch. 90.

Adenostyles Cass. 114, 363.

Adiantum L. 6 .

Adoris L. 236.

Adoxa L. 146.

Aegopodium L. 210.

Aesculus L. 297.

Aethionema R. Br. 255.

Aethusa I. 212.

Agrimonia L. 330.

Agropyrum P. B. 19.

Agrostemma L. 292.

Agrostis L. 30, 359.

Ailanthus L. 305.

Aira L. 30.

Ajuga L. 164.

Alchemilla L. 329, 370 .

Aldrovandia L. 271.

Alisma L. 48, 360.

Alismaceae 48.

Alliaria DC. 265.

Allium L. 61, 362, 371.

Allosorus Brhd. 6.

Alnus Tourn. 70.

Alopecurus L. 33.

Alsine L. 278.

Alsineae 277.

Althaea L. 292.

Alyssum L. 259, 372.

Amarantaceae 79.

Ainarantus L. 79 .

Amaryllideae 48.

Ambrosiaceae 91.

Amelanchier Med. 317.

Amorpha L. 341.

Ampelideae 299.

Ampelopsis Mchx. 300.
Amygdalaceae 333.

Amygdalus L. 333.

Anacamptis Rich. 52.

Anagallis L. 197.

Anchusa L. 170.

Audropogon L. 32.

Andromeda L. 199, 372.

Androsace L. 193.

Anemone L. 234.

Anethum L. 216.

Angelica L. 214.

Anthemis L. 124, 364.

Anthericum L. 62.

Anthoxanthum L. 34 .

Anthriscus L. 217.

Anthyllis L. 352.

Antirrhinum L. 179.

Apium L. 209.

Apocyneae 148.

Aposeris Neck. 94.

Aquilegia L. 243.

Araliaceae 202.

Arabis L. 260, 369, 372.

Arbutus L. 200.

Archangelica Hoffm. 214.

Aremonia J. 330.

Arenaria L. 281, 369, 373.

Arctostaphylos Adans. 200.

Aristolochia 1. 85.

Aristolochiaceae 85.

Armeria Wilid. 198.

Armoracia Fl. Wett. 256.

Arnica L. 126.

Arnoseris Gaertn. 94.

Aroideae 12.

Aronicum Neck. 126.

Arrhenatherum P. B. 30.

Artemisia L. 121.

Arum L. 12.

Asarum L. 85.

Asclepiadeae 149.

Asclepias L. 149.

Asparageae 58.

Asparagus L. 59.

Asperifoliae 165.
Asperugo L. 166.

Asperula L. 142, 364, 372.

Aspidium R. Br. 4.

Asplenium L. 5, 357.

Aster L. 116, 371.

Astragalus L. 338 .

Antrantia L. 208.

Athamanta Koch. 213 , 372.

Athyrium Döll. 5 .

Atragene L. 233.

Atriplex L. 77, 362.

Atropa L. 173.

Avena L. 28.

Azalea L. 199.

Baldingera Fl. Wett. 34 .

Balsamineae 310 .

Ballota L. 162.

Barbarea R. Br. 267.

Bartschia L. 184.

Batrachium E. Mey. 237, 368.

Bellidiastrum Cass. 115.

Bellis L. 115.

Berberideae 245 .

Berberis L. 245.

Berteroa DC. 259.

Berula Koch. 209.

Beta L. 77.

Betonica L. 162, 372.

Betula L. 70.

Betulaceae 70.

Bidens L. 118.

Bifora Hoffm. 221.

Biscutella L. 254.

Blitum L. 75 .

Bonjeania Rchb. 347 .

Borrago L. 170.

Botrychium Sw. 6, 370.

Brachypodium P. B. 19.

Brassica I. 267.

Braya Strb. Hppe. 266.

Briza L. 25.

Bryonia L. 86.

Bromus L. 21, 357, 370. 
Bulliardia DC. 227.

Bunias L. 269.

Buphthalmum L. 117.

Bupleurum L. 210, 367.

Butomus L. 49.

Buxus L. 301.

Calamagrostis Rth. 31.

Calamintha Tourn. 159, 372.

Calendula L. 130.

Calla L. 12.

Callianthemum C. A. M. 236, 37\%.

Calliopsis Rohb. 363.

Callitriche L. 65.

Calluna Salisb. 198

Caltha L. 241, 368.

Calycanthus L. 315.

Cameline Crtz 256.

Campanula L. 87, 371.

Campanulacae 86.

Cannabineae 74 .

Cannabis L. 74.

Capparideae 249.

Capparis L. 249.

Capsella Vent. 255.

Capsicum L. 173.

Caragana L. 341.

Cardamine L. 263, 372.

Carduus L. 134, 364, 371.

Carex L. 36, 359, 371.

Carlina L. 137.

Carpesium L. 119.

Carpineae 71.

Carpinus L. 71.

Carthamus L. 132.

Carum L. 210.

Castanea Tourn. 72.

Catabrosa P. B. 27.

Cancalis L. 220.

Calastrineae 299.

Celris L. 73.

Centaurea L. 132, 371.

Centranthus DC. 142.

Centuncules L. 197.

Cephalanthera Rich. 53.

Cephalaria Schrad. 139.

Cerastium L. 283, 370, 373.

Ceratocephalus Mönch. 241.
Cerathophyllum L. 65.

Cercis L. 334.

Cerinthe L. 169.

Ceterach Brhd. 3.

Caerophyllum L. 217.

Chaiturus Willd. 163.

Cheiranthus L. 260.

Chelidonium L. 247.

Chenopodiaceae 75 .

Chenopodium L. 86.

Cherleria L. 280.

Chlora L. 150.

Chlorocrepis Gris. 111.

Chondrilla L. 98.

Chrysopogon M. K. 358.

Chrysosplenium L. 226.

Cichoriaceae 92.

Cichorium L. 94.

Cicuta L. 209.

Cimicifuga L. 244.

Cineraria L. 129.

Circaea L. 314.

Cirsium Tourn. 135, 364, 371.

Cistineae 270.

Cladium R. Br. 45.

Clematis L. 232.

Clinopodium L. 159.

Cnidium Cass. 213.

Cochlearia L, 369.

Coeloglossum Hartm. 52.

Colchicaceae 57.

Colchicum I. 58.

Coleanthus Seid. 35.

Collomia Nutt. 171.

Colutea L. 341.

Comarum L. 325.

Compositae 92.

Coniferne 7.

Conioselinum Fisch. 213.

Conium L. 218.

Conringia DC. 266.

Convallaria L. 58.

Convolvulaceae 171.

Convolvulus Is. 171.

Corallorrhiza Hall. 54.

Coreopsis L. 363.

Coriandrum L. 221.

Corispermum L. 78.

Cornus I. 202.

Caronilla L. 337.
Corrigiola L. 276.

Cortusa L. 196.

Coridalis DC. 248.

Corylns L. 71.

Corynephorus P. B. 30 .

CotoneasterMed 360,373.

Crambe L. 269.

Crassulaceae 227.

Crataegus L. 316.

Crepis L. 100, 371.

Crocus L. 46.

Cruciferae 249.

Crypsis Ait. 34.

Cucubalus L. 289.

Cucumis L. 85.

Cucurbita L. 85.

Crocurbitaceae 85.

Cupressus L. 9.

Cupuliferae 72.

Cuscuta L. 171.

Cyclamen L. 196.

Cydonia L. 31 .

Cynara L. 137.

Cynodon L. 32.

Cynoglussum L. 166.

Cynosurus L. 24.

Cyperaceae 35 .

Cyperus L. 46.

Cypripedium L. 54.

Cystopteris Brhd. 4.

Cytisus L. 355, 373.

Dactylis L. 25.

Dahlia 363.

Danthonia DC. 357.

Daphne L. 84, 371.

Daphnoideae 84.

Datura L. 174.

Daucus L. 220.

Delphinium L. 243.

Dentaria L. 264, 372.

Dianthus L. 286, 373.

Dictamnus L. 306 .

Digitalis L. 179, 366 .

Digitaria Scop. 32.

Dioscoreae 59.

Diplotaxis DC. 268.

Dipsaceae 138.

Dipsacus L. 138.

Doronicum L. 125.

Doryenium L. 347.

Draba L. 257, 369, 373 . 
Dracocephalım L. 160. Ficaria Ditt. 241, 368.

Drosera L. 271.

Droseraceae 271.

Dryas L. 326.

Drypis L. 286.

Echinochloa P. B. 32.

Echinops L. 138.

Echium L. 168.

Echinospermum Sw. 167.

Elaeagneae 85.

Elaeagnus 85.

Elatine L. 296.

Elodea Rich. Mchx. 360.

Elymus L. 20.

Elyna Schrad. 43.

Empetreae 301.

Empetrum L. 301.

Epilobium L. 311.

Epimedium L. 245.

Epipactis Rich. 54, 361.

Epipogon Gmel. 360.

Equisetaceae 1.

Equisetum L. 1.

Eragrostis P. B. 25.

Eranthis Salisb. 242.

Erica L. 199.

Ericaceae L. 199.

Erigeron L. 115.

Erinus L. 178.

Eriophorum L. 45.

Eritrichium Schrad. 168.

Erodiun l'Her. 308.

Erophila DC. 257.

Eruca L. 269.

Erucastrum Presl. 268.

Ervum L. 344.

Eryngium L. 207.

Erysimum L. 266, 369.

Erythraea L. 153.

Erithronium L. 64 .

Eupatorium L. 114.

Euphorbia L. 301, 370, 372.

Euphorbiaceae 301.

Euphrasia L. 183, 366.

Evonymus L. 299.

Fagus L. 73.

Falcaria Host. 210.

Farsetia B. Br. 259.

Ferula L. 214.

Festuca L. 22, 357, 371.
Ficus L. 74.

Filago L. 119.

Foeniculum Tourn. 214.

Fragaria L. 325.

Fraxinus L. 148.

Fritillaria L. 64, 371.

Fumaria L. 248.

Fumariaceae 248.

Gagea 63.

Galanthus L. 48.

Galega L. 341.

Galeobdolon Huds 161.

Galeopsis L. 161, 365 .

Galinsoga Pav. 119.

Galium L. 143, 372 .

Genista L. 354, 373.

Gentiana L. 150, 364, 372.

Gentianaceae 149.

Georgina W. 357.

Geraniaceae 306.

Geranium L. 306.

Geum L. 325.

Gladiolus L. 47.

Glaucium Tourn. 247.

Glaux L. 197.

Glechoma L. 160.

Gleditschia L. 334.

Globularia L. 165.

Globulariaceae 165.

Glyceria R. Br. 27.

Gnaphalium L. 120.

Gordyera R. Br. 54.

Gramineae 13.

Gratiola L. 177.

Gymnadenia R. Br. 52.

Gymnogramme Desv. 3.

Gypsophila L. 286.

Hacquetia Neck. 208.

Halorageae 314.

Hedera L. 202.

Hedysarum L. 338.

Heleocharis R. Br. 43, 360 .

Helianthemum Tourn. $270,369$.

Helianthus L. 119, 363.

Helichryson Gaertn. 121.

Heliosperma Rchb. 291.

Heliotropium L. 170.
Helleborus L. 242, 372 .

Helminthia L. 95.

Helosciadium Koch. 209.

Hemerocallis L. 62.

Hepatica D ill. 236.

Heracleum L. 216.

Herminium R. Br. 53.

Herniaria L. 275.

Hesperis L. 264.

Heteropogon Pers. 358.

Hibiscus L. 294.

IIieraciunı L. 102, 371.

Hierochloa Gm. 34.

Himantoglossum Spr. 52.

Hippocastaneae 297.

Hippocrepis L. 337.

Hippophaё L. 85.

Hippuris L. 65.

Holcus L. 29.

Holosteum L. 281.

Homogyne Cass. 114.

Hordeum L. 20.

Horminum L. 159.

Hottonia L. 196.

Humulus L. 74.

Hutchinsia R. Br. 255.

Hyacinthus L. 60.

Hydrocharis L. 49.

Hydrocotyle L. 207.

Hyoscyamus L. 171.

Hypericum L. 295, 370.

Hypochaeris L. 97.

Hyssopus L. 160.

Iberis L. 254.

Ilex L. 299.

Ilicineae 299.

Illecebrum L. 276.

Impatiens L. 310.

Imperatoria L. 216.

Inula L. 118.

Irideae 46.

Iris L. 47,360 .

Isatis L. 269 .

Isnardia L. 314.

Isopyrum L. 242.

Jasione L. 91.

Juglandineae 305.

Juglans L. 305.

Juncaceae 55.

Juncagineae 49.

Juncus L. 56, 361, 371. 
Juniperus L. 9.

Jurinea Cass. 132.

Kernera Med. 256.

Kerria L. 332.

Knautia Goult. 139.

Kobresia Willd. 43.

Kochia Roth. 78.

Koeleria L. 27.

Labiatae 153 .

Lactuca L. 98.

Lamium L. 160.

Lampsana L. 94.

Lappa Tourn. 134, 364.

Larix DC. 8.

Laserpitium L. 219, 372.

Lasiagrostis Lk. 30 .

Lathraea L. 187.

Lathyrus L. 345

Lavandula L. 155.

Lavatera L. 292.

Ledum L. 199.

Leersia Sw. 35.

Lemna L. 10.

Leontodon L. 94.

Leonurus L. 163.

Lepidium L. 254.

Leueanthemum L. 125.

Lencojum L. 48.

Leristicum Koch. 214.

Libanotis Crtz. 212, 372.

Ligularia Cass. 126.

Ligusticum L. 213.

Iigustrum L. 59.

Liliaceae 59.

Lilium L. 64.

Limnanthemum Gm.149.

Limodorum Tourn. 361.

Limosella L. 177.

Linaria Mill. 178.

Linনernia L. 177.

Linnaea L. 147.

Linum L. 309.

Linnsyris DC. 117.

Liriodendron L. 245.

Listera R. Br. 54.

Lithospermum L. 168.

Litorella L. 191.

Lloydia Salisb. 64 .

Lolium I. 18.

Lomatogonium 150.
Lonicera L. 147.

Lonicereae 146.

Loranthaceae 84 .

Loranthus L. 84.

Lotus L. 347.

Lunaria L. 259.

Lupinus L. 353.

Luzula DC. 55, 361.

Lychnis L. 291.

Lycium L. 173.

Lycopodiaceae 2.

Lycopodium L. 2.

Lycopsis L. 170.

Lycopus L. 157, 372.

Lysimachia L. 197.

Lythrarieae 314.

Lythrum L. 314.

Vajanthemum Wigg. 59. Malabaila Hoffm. 219.

Malachium Fr. 283.

Malaxis Sw. 371.

Malope L. 294.

Malva L. 293.

Malvaceae 292.

Marrubium L. 163.

Marsilea L. 7.

Matricaria L. 124.

Matthiolia R. Br. 260, 372.

Medicago L. 351.

Melampyrum L. 187, 366 .

Melandryuın Röhl. 291, 372.

Melica L. 25.

Melilotus L. 348.

Melissa L. 159.

Melittis L. 160 .

Menyanthes L. 150.

Mentha L. 155, 365.

Mercurialis L. 304.

Mespilus L. 316.

Meum L. 2114.

Melium L. 30.

Micropus L. 371.

Microstylis Nutt. 361.

Mimulus L. 177.

Moehringia L. 280, 373.

Moenchia Ehr. 282.

Molinia Schr. 24, 370 .

A. Br. Molopospermum Koch.
Monarda L. 158.

Monotropa L. 201.

Montia L. 275.

Moreae 74.

Morus L. 74.

Mulgedium Cass. 100.

Muscari Tourn. 60, 362.

Myosotis L. 167, 365 .

Myosurus L. 241.

Myricaria Desv. 296.

Myriophyllnm L. 314.

Myrrhis Scop. 218.

Myrtaceae 311.

Myrtus L. 311.

Najadeae 10.

Najas L. 10.

Narcissus L. 48.

Nardus L. 18.

Nasturtium R. Br. 257.

Negundo Moench. 297.

Neottia Rich. 54.

Nepeta L. 160, 372.

Nerium L. 14 S.

Neslia L. 270.

Nicandra Adans. 173.

Nicotiana L. 174.

Nigella L. 242.

Nigritella Rich. 53, 360.

Nonnea Med. 170.

Nuphar Sm. 246.

Nymphaea L. 245, 372.

Oenanthe I. 211.

Oenothera L. 311.

()enothereae 311.

Oleaceae 148.

Omphalodes Tourn 167.

Onobrychis L. 338.

Ononis L. 353, 373.

Onopordon L. 134.

Onosma L. 169, 372.

Ophioglossum L. 7.

Ophrys L. 53, 360, 371 .

Orchideae 49.

Orchis L. 50, 360, 371.

Oreochloa Lk. 33.

Origanum L. 158.

Orlaya Hoffn. 220.

Ornithogalum L. 63, 371.

Ornus P. 148.

218.
Orobanche L. 185, 367.

Orobus L. 346 . 
Osmunda L. 6 .

Oxalideae 310.

Oxalis L. 310 .

Oxycoccos Pers. 200.

Oxygraphis Bge. 237.

Oxyria Hill. 81.

Oxytropis DC. 339, 373.

Pachypleurum Mey. 213.

Paederota L. 177.

Paeonia L. 244.

Paliurus Tourn. 301.

Panicum L. 32.

Papaver L. 246.

Papaveraceae 246.

Papilionaceae 334.

Paradisea Mazz. 62.

Parietaria L. 74.

Paris L. 58.

Parnassia L. 226.

Paronychiaceat 276.

Pastinaca L. 216.

Pedicularis L. 184, 372 .

Peltaria L. 269.

Peplis L. 315.

Petasites Tourn 114.

Petrocallis R. Br. 259.

PetroselinumHoffm. 209.

Peucedanum L. 21 5, 367, 372.

Phaca L. 340 .

Phalaris L. 34.

Phaseolus L. 347.

Philadelpheae 311.

Philadelphus L. 311.

Phleum L. 34.

Phlomis L. 162.

Phragmites L. 32.

Physalis L. 173.

Phyteuma L. 90, 362.

Picris M. 95.

Pilularia Vaill. 7.

Pimpinella L. 20\%.

Pinguicula L. 191, 372.

Pinus L. 8.

Piptatherum Pal. B. 358.

Pirola L. 201.

Pirolaceae 201.

Pirus L. 318.

Pistacia L. 305.

Pisum L. 341.

Plantago L.190, 367,370.
Platanthera Rich. 52.

Platanus L. 73.

Pleurospermum Hoffm 219.

Plumbagineae 198.

Poa L. 25.

Podospermum DC. 97.

Polemonium L. 171.

Polycnernum L. 79.

Polygala L. 297.

Polygalaceae 297.

Polygoneae 79.

Polygonum L. 81.

Polygonatum Tourn. 58. 362.

Polypodiaceae 3.

Polypodium L. 3.

Polystichum Rth. 4.

Pomaceae 315.

Populus L. 69.

Portulaca L. 275.

Portulacaceae 275.

Potamogeton L. 11, 357.

Potentilla L. 326, 373.

Prenanthes L. 98.

Primula L. 194, 372.

Primulaceae 192.

Prunella L. 163.

Prunus L. 333.

Ptelea L. 305.

Pteris L. 6, 370.

Pulicaria Gaertn. 117.

Pulmonaria L. 169, 365.

Pulsatilla Tourn. 235, 368.

Pyrethrum L. 125.

Quercus L. 72.

Radiola L. 309.

Ranunculaceae 230.

Ranunculus L. 238, 368, 372.

Raphanus L. 269.

Rapistrum Boerh. 260.

Reseda L. 270.

Rhamneae 300.

Rhamnus L. 300.

Rhaponticum Vaill. 13:.

Rheum L. 79.

Rhinanthaceae 182 .

Rhinanthus L. 186 .

Rhizocarpeae 7 .
Rhodiola L. 227.

Rhododendron L. 199.

Rhus L. 305.

Rhynchospora Vahl. 45.

Ribes L. 226.

Ribesiaceae 226 .

Robinia L. 341.

Roripa Bess. 256.

Rosa L. 320, 373.

Rosaceae 319.

Rosmarinus L. 158.

Rubia L. 146.

Rubiaceae 142.

Rubus L. 324.

Rumex L. 79.

Ruscus L. 362, 371.

Ruta L. 306.

Rutaceace 306.

Sagina L. 278.

Sagittaria L. 49.

Salicineae 66.

Salicornia L. 75 .

Salix L. 66, 362 .

Salsola L. 78 .

Salvia L. 157, 365 .

Salvinia Mich. 7 .

Sambucus L. 146.

Samolus L. 197.

Sanguisorba L. 331.

Sanguisorbeae 330 .

Sanicula L. 208.

Santalaceae 83.

Santolina L. 122.

Saponaria L. 288.

Sarothamnus Wimm. 354.

Satureja L. 159, 365.

Saussurea DC. 131.

Saxifraga L. 221, 367, 372.

Scabiosa L. 139, 364, 371.

Scandix L. 218.

Schenchzeria L. 49.

Schoenus L. 45.

Scilla L. 60 .

Scirpus L. 44, 371.

Scleranthus L. $275,373$.

Sclerochloa P. B. 27.

Scleropoa Gris. 370.

Scolopendrium L. 5.

Scolymus L. 94. 
Scopolia Jequ. 174.

Scorzonera L. 96. Scrophularia L. 176.

Scrophulariaceae 174.

Scutellaria L. 163.

Secale L. 20.

Sedum L. 228.

Selaginella śpring. 3.

Selinum I. 214.

Sempervivum L. 229.

Senebiera P. 269.

Senecio L. 126.

Serapias L. 371.

Serratula L. 132.

Seseli L. 212.

Sessleria Ard. 33, 358.

Setaria P. B. 32.

Sherardia Dill. 142.

Sibbaldia L. 326.

Sideritis L. 163 .

Silaus L. 213.

Silene L. 289, 370.

Sileneae L. 285.

Siler Scop. 219.

Silybum Gaertn. 137.

Sinapis L. 268.

Sisymbrium L. 265.

Sium L. 209.

Solanaceae 172.

Solanum L. 172.

Soldanella Tourn. 196.

Solidago L. 117.

Sonchus L. 99.

Sorbus L. 317.

Sorghum P. 32.

Sparganium I. 13.

Spartium L. 354.

Specularia Heist. 87.

Spergula L. 276.

Spergularia P. 276.

Spinaria L. 77.

Spiraea L. 331, 373.

Spiraeaceae 331.

Spiranthes Rich. 54.

Stachys L. 161.

Staphylea L. 299.

Stellaria L. 281.

Stenactis Cass. 115.

Stenophragma Celak.|Trollius L. 241.

255.

Stipa L. 30, 358.

Stratiotes L. 49.

Streptopus Mich. 58.

Struthiopteris W. 6.

Suaeda Forsk. 78.

Succisa Mert. K. 139.

Swertia L. 150.

Symphoricarpus Ad. 147.

Symphytum L. 170.

Syrenia Andrz. 276.

Syringa L. 148.

Tagetes L. 357.

Tamariscineae 296.

Tamus L. 59.

Tanacetum L. 122.

Taraxacum Juss. 97, 363.

Taxus L. 10.

Teesdalia R. Br. 255.

Teleckia Baumg. 117.

Terebinthaceae 305.

Tetragonolobus Scop. 347.

Teucrium L. 164.

Thalictrum L. 233.

Thesium L. 83.

Thlaspi L. 253, 369.

Thrincia Rth. 95.

Thuja L. 9.

Thymus L. 158, 365, 372.

Tilia L. 294.

Tofieldia Huds. 57.

Tommasinia Bert. 367.

Tordylium L. 216.

Torilis Ad. 220.

Tormentilla L. 329.

Tozzia L. 187.

Tragopogon L. 96.

Tragus Hall. 33.

Trapa L. 314.

Trientalis L. 196.

Trifolium L. 349.

Triglochin L. 49.

Trigonella L. 348 .

Trinia Hoffm. 208.

Triodia R. Br. 24.

Triticum L. 19.
Tropaeolpum L. 309.

Tulipa L. 64.

Tunica Scop. 286.

Turgenia Hoffm. 220.

Turritis L. 263.

Tussilago L. 115.

Typha L. 13.

Ulex L. 353.

Ulmaceae 73.

Ulmus L. 73 .

Umbelliferae 202.

Urtica L. 74, 371.

Urticaceae 74 .

Urticularia L. 191.

Vaccaria Med. 289.

Vaccinicae 200.

Vaccinium 200.

Valeriana L. 141.

Vallisneria L. 371.

Valerianaceae 140.

Valerianella Tourn. 141.

Veratrum L. 58.

Verbascum L. 175, 372.

Verbena L. $16 j$.

Verbenaceae $16 \overline{0}$.

Veronica L. 179.

Viburnum L. 146.

Vicia L. 342.

Vinca L. 148.

Vincetoxicum Mnch. 149.

Viola L. 271, 369.

Viscum L. 84.

Vitis L. 299.

Vulpia Gm. 24.

Waldsteinia Willd. 373.

Willemetia Neck. 98.

Woodsia R. Br. 3.

Wulfenia Jequ. 177.

Xanthium L. 91.

Xanthoxyleae 305 .

Xerathemum L. 137.

Tahlbrucknera Rchb. 225.

Zanichellia L. 10.

Zea L. 35.

Zinnia L. 363.

Zizyphus Tourn. 301. 


\section{Verzeichnis}

\section{der deutschen Gattungs- und Volksnamen.}

Abmanerwuth 122.

Ackerdistel 136.

Ackernïsschen 270.

Ackerrade 292.

Ackersalat 238.

Adlerfarn 6.

Ahorn 296.

Ährenfarn 6 .

Afterkamille 124.

Ahlbeere 227.

Ahlkirsche 3:34.

Akazie, falsche 341.

Akelei 243.

Alant 118.

Allermannsharnisch 61 .

Almrausch 199.

Alpenerle 70 .

Alpenglöckchen 196.

Alpenrose 199.

Alpenveilchen 196.

Alplattich 114.

Alprebe 233.

Amaranth 79 .

Ampfer 79.

Ananaserdbeere 225.

Andorn 163.

Anis 209.

Apfelbaum 318.

Aprikose 333.

Arbuse 86.

Aronsstab 12.

Artischoke 137.

Aschenkraut 129.

Aspe 69.
Lugentrost 183.

Augenwurz 213.

Aurikel 195.

Awöl 268.

A zaroldorn 316.

Bachbunge 180 .

Backenklee 347.

Bärenlauch 61 .

Bärenklau 216.

Bärentraube 200 .

Bärlapp 2.

Bärwurzel 214.

Baldrian 141.

Balsamine 310 .

Balsampappel 70 .

Balsamtanne 8 .

Balsamweide 85 .

Bananenorche 360 .

Barbenkraut 267.

Bartgras 32.

Bartnelke 287.

Bastdolde 220.

Becherblume 330.

Bechergloćke 90.

Beifuß 121.

Beinholz 147.

Beinwell 170.

Beißbeere 173.

Belladonna 173.

Berberize 245.

Bergahorn 297.

Bergflachs 83.

Berggras 33.

Berglinse 340 .
Bergruister 73.

Bergthymian 159.

Berle 209.

Bertram 125.

Berufkraut 115 .

Besenginster 354 .

Besenheide 198.

Besenstrauch 354 .

Bieberbaum 245.

Biebernell 209.

Bilsenkraut 174 .

Bingelkraut 304 .

Binse 44.

Birke 70.

Birkwurz 214.

Birnbaum 318.

Birnkraut 201.

Bitterklee 150.

Bitterkraut 96.

Bitterling 150.

Bittersüß 173.

Blasenfarn 4.

Blasenschote 341 .

Blumenbinse 49 .

Blumenesche 148 .

Blutauge 325 .

Blutklee 349 .

Blutkraut 83.

Blutwurz 329.

Bocksbart 96.

Bocksdorn 173.

Bocksklee 348.

Bohne 347.

Bohnenbaum 355 . 
Boretsch 170 .

Borstengras 18. 32 .

Braunelle 163.

Braunwurz 176.

Brenndolde 213.

Brennende Liebe 292.

Brennessel 74 .

Brillenschote 254 .

Brombeere 324.

Bruchkraut 276.

Bruchweide 69.

Brunnenkresse 257.

Buche 73.

Buchenfarn 3.

Buchsbaum 301.

Buchweizen 81.

Butterblume 241 .

Canariengras 34.

Cantaluppen 86 .

Chilierdbeere 325 .

Christuskraut 244.

Christusakazie 334.

Christusauge 118.

Ceder, virginische, 9.

Cichorie 94.

Cyperngras 46.

Cypresse 9.

Cypressenkraut 122.

Darrgras 34.

Dickrippe 213.

Dill 216.

Dingel 361.

Dinkel 20.

Diptam 306.

Distel 134.

Doldenolütler 202.

Doppelsame 268.

Dorngras 34 .

Dost 158.

Dotterblume 241.

Drachenkopf 160 .

Drachenmaul 159.

Dragun 121.

Drehorche 54.

Dreifaltigkeitsblümchen 196.

Dreizack 49.

Dreizabn 24.

Drüsengriffel 114.

Duc van Toll 64.

Eberesche 318.
Eberraute 122.

Eberwurz 137.

Ebschbeerbaum 318.

Edelkastanie 72.

Edeltanne 8.

Edelweiß 120.

Eibe, Eibenbaum 10.

Eibisch 292.

Eiche 7\%.

Eichenfarn 3.

Eichenmistel 84.

Einbeere 58.

Einblatt 226.

Einkorn 20.

Eisenkraut 165.

Ehrenpreis 179.

Eller 70.

Elsbeere, Elzebeere 318.

Engelsüß 3.

Engelwurz 214.

Enzian 150.

Epheu 202.

Erbse 341.

Erbsenbaum 341.

Erdbeerbaum 200.

Erdbeere 325.

Erdbeerklee 349.

Erdbeerspinat 75 .

Erdrauch 247.

Erdscheibe 196.

Erle 70.

Erzengelwurz 214.

Esche 148.

Eschenahorn 297.

Esparsette 338.

Espe 69.

Essigbaum 305.

Essigrose 321.

Estragon 121.

Fadengriffel 267.

Färbeginster 354 .

Färbekamille 124.

Färber'scbarte 132.

Faserschirm 208.

Faulbaum 300.

Federnelke 288.

Federgras 357.

Federschwingel 24.

Feigenbaum 74 .

Feldahorn 297.

Feldkamille 124.
Feldrüster 73 .

Feldsalat 140.

Felsenbirne 317.

Felsenkirsche 33 .

Felsnelke 286.

Fenchel 214.

Ferkelkraut 97.

Fetthenne 228.

Fettkraut 191.

Feuerbohne 347.

Feuerdorn 316.

Feuerlilie 65.

Feuernelke 291.

Fichte 7.

Fichtenspargel 201.

Fieberklee 150.

Filzblume 162.

Filzkraut 119.

Fingergras 32.

Fingerhut 179.

Fingerkrant 326 .

Flachs 309.

Flachsseide 171.

Flatterrüster 73 .

Flieder 148.

Flockenblume 132.

Flohkraut 82, 117.

Föhre 8.

Frauenflachs 178.

Frauenhaar 5, 357.

Frauenmantel 329.

Frauenschuh 54.

Frauenthräne 53.

Froschbiss 49 .

Froschkraut 237 .

Froschlöffel 48.

Fuchskiee 349.

Fuchsschwanz 79.

Fuchsschanzgras 33.

Futterwicke 342 .

Gänseblümchen 115 .

Gänsedistel 99.

Gänsefıß 76 .

Gänsekohl 260.

Gaisblatt 147.

Gaisfuß 210.

Gaisklee 355.

Gaisraute 341.

Gamander 164.

Gartenranunkel 238.

Gartenschierling 212. 
Gartenwicke 345.

Gauchheil 197.

Gauklerblume 177.

Gelbstern 63.

Gemswurz 125.

Georgine 368.

Gerbersumach 305 .

Germer 58.

Gerste 20.

Gewürzstrauch 315.

Gichtrose 244.

Gichtrïbe 86 .

Giftbeere 173.

Gifthahnenfu[0 239.

Giftsumach 305.

Ginster 354 .

-, spanischer 354 .

Glanzgras 34.

Glasschmelz 34 .

Glattliafer 30.

Gleipe 212.

Gliedkraut 163.

Glockenblume 86 .

Gnadenkraut 177.

Götterbaum 305.

Goldbart 358.

Golddistel 94.

Goldklee 351.

Goldnessel 161. 332.

Goldregen 355 .

Goldruthe 117.

Goldschopf 117.

Goldtraube 227.

Grannenhirse 353.

Grasnelke 198.

Gräser 13.

Grundheil 295.

Günsel 164.

Gundermann 160.

Gurlke 86.

Gypskraut 286.

Haargras 20.

Haarstrang 215.

Habichtskraut 102.

Hafer 28.

Haferschlehe 333.

Haftdolde 220.

Hagebuttenbirne 318.

Hagedorn 316 .

Hahnendorn 316.

Hahnenfu? 238.
Haide 198.

Haidekraut 199.

Haidekorn 81.

Hainbuche 71 .

Hainsalat 94.

Hainsimse 55.

Halskraut 89.

Hanf 74.

Hartgras 27.

Hartheu 295.

Hartriegel 202.

Hasel 71.

Haselwurz 85.

Hasenheide 354.

Hasenkohl 98.

Hasenkopf 338 .

Hasenohr 210.

Hauhechel 353.

Hausmelde 76 .

Hauswurz 229.

Heckenkirsche 147 .

Heckenrose 323.

Hecksame 353.

Hederich 266. 269.

Heidelbeere 200.

Heilwurz 212.

Helmkraut 163.

Herbstzeitlose 58 .

Hermel 124.

Hexenkrant 314.

Himbeere 324 .

Himbeererảbeere 325 .

Himrnelsherold 167.

Himmelschlüssel 194.

Hindläufte 94 .

Hirschzunge 5 .

Hirschwurz 215.

Hirse 32.

Hirsegras 30 .

Hirtentäschel 255 .

Hochelkopf 97.

Hohlsame 221.

Hohlwurz 248.

Hohlzàhn 161.

Hohlzunge 52.

Hollunder 146.

- türkischer 148.

Holzapfel 318.

Holzbirne 318 .

Honiggras 28.

Honigklee 348.
Hopfen 74.

Hopfenbaum, Hopfenbuche 71 .

Hopfenklee 351.

Hornbaum 71 .

Hornblatt 65 .

Hornklee 347.

Hornköpfchen 241 .

Hornkraut 283.

Hornmohn 247.

Hornstrauch 202.

Hülsen 299.

Hufeisenklee 337.

Huflattich 115.

Hundeblume 97.

Hundslattich 95.

Hundsmilch 301.

Hundspetersilie 212.

Hundsrose 323.

Hundszahn 64.

Hundszehe 32.

Hundszunge 166.

Hungerblümchen 257 .

Hyazin the 60 .

Ibisch 294.

Igelkolben 13.

Igelsame 167.

Immerblatt 160 .

Immergrün 148.

Imortelle 121.

Incarnatklee 349 .

Jacobsleiter 171.

Jasmin, unechter 311 .

Jehovablümchen 224.

Jelängerjelieber 147 .

Johannisbeere 227.

Johannisblume 125.

Johanniskraut 295.

Judenbaum 334.

Judendorn 301.

Judenkirsche 173.

Kälberkropf 217.

Käsepappel 293.

Kaiserlrone 64.

Kalmus 12.

Kamille 124.

- römische 125 .

Kammgras 24. 33 .

Kammorche 52 .

Kapernstrauch 249.

Kapuzinerkresse 309 . 
Karden 138.

Karthäusernelke 287.

Kartoffel 173.

Katzenklee 349.

Katzenpfötchen 120.

Katzenminze 160.

Katzenschwanz 163.

Katzenzahl 1.

Kellerbals 84 .

Kerbel 217.

Keulengras 30.

Kicherling 345 .

Kiefer 8.

Kirschbaum 333.

Kirschenapfel 318 .

Klappertopf 186 .

Klebkraut 145.

Klee 350.

Kleebaum 355.

Kleefarn 7.

Kleeseide 172.

Kleinling 197.

Klette 134.

Klettengras 33 .

Knabenkraut 50 .

Knaulgras 25.

Knieholz 9.

Knoblauch 62 .

Knoblauchskraut 265 .

Knotenblume 48 .

Knörich 275.

Knöterich 81 .

Knopfblume 139.

Knopfgras 45 .

Knorpelizraut 79. 276.

Knorpelsalat 98.

Knotenfuß 58.

Königsfarn 6.

Königslserze 175 .

Kohl 267.

Kohlröschen 53.

Kohlrübe 268.

Kopfblume 139.

Kopflklee 349 .

Korallenwurz 54.

Korbweide 66.

Korkrüster 73.

Kornblume 134.

Kornelkirsche 202.

Krähenbeere 301 .

Kragenblume 119.
Kranichschnabel 309 .

Krapp 146.

Kratzdistel 135.

Krausemalve 293.

Krauseminze 156.

Krebsdistel 134.

Krebswirzel 126.

Kren 256.

Kresse 254.

-, spanische 309 .

Kreuzblütler 249.

Kreuzblümchen 297.

Kreuzdorn 300.

Kriechenpflaume 333.

Kronawett 9.

Kronenkraut 286.

Kronenwicke 337.

Krummhals 170 .

Krummholz 9.

Küichenschelle 235.

Kümmel 210.

Kürbis 86 .

Kugelblume $\mathbf{1 6 5}$.

Kugeldistel 136 .

Kuhblume 97.

Kuhkraut 289.

Kuhweizen 187.

Kuckucksblume 50 .

-, weiße. 52.

Kuckucksnelke 291.

Kukuruz 35.

Labkraut 143.

Lack 260.

Lämmersalat 94 .

Lärche 8 .

Lärchensporn 248.

Läusekraut 184.

Laichkraut 11.

Lambertsnuss 72 .

Lappenfarn 6 .

Laserkraut 219 .

Latsche 8.

Lattich 98.

Laubfarne 3.

Lauch 61.

Lavatere 292.

Lavendel 155.

Lebensbaum 9.

Leberbalsam 178.

Leberblümchen 236.

Leberkraut 236.
Lederblume 305.

Leinkraut 289.

Leinsame 171.

Lein 309.

Leinblatt 83 .

Leindotter 256.

Leimkraut 178.

Levkoy 260.

Lichtnelke 291.

Liebesapfel 173.

Liebesgras 25 .

Liebstïckel 214.

Lieschgras 34 .

Liguster 148 .

Lilie 64.

Linde 294.

Linse 344.

Linsenwicke 344.

Löffelkraut 369.

Löwenmaul 179.

Löwenschwanz 163.

Löwenzahn 94.

Lolch 18.

Lotwurz 168.

Lungenkraut 169.

Luzerne 351.

—, schwedische 352.

Iaßlieb 115.

-, große 125 .

Mädchenauge 363.

Märzbecher 48 .

Maiblume 97.

Maiglöckchen 58 .

Malve 293.

Mandelbaum 333.

Mandelweide 68 .

Mangold 77.

Mannaesche 148.

Mannsschild 193.

Mannstreu 207.

Margaritchen 115.

Mariendistel 137.

Marille 333.

Markerbse 342 .

Maßholder 297.

Maßkraut 278 .

Mauerpfeffer 228 .

Mauerraute 5.

Maulbeerbaum 74 .

Mäusedorn 362.

Mäuseholz $17: 3$ 
Mäuseschwanz 241.

Meerkohl 269.

Meerrettig 256.

Mehlbirne 317.

Mehldorn 316.

Meisterwurz 216.

Melde 76. 77.

Melisse 159.

Melone 86.

Merk 209.

Miere 278.

Milchdistel 100 .

Milebkraut 197.

Milzkraut 226.

Minze 155.

Mispel 316.

Mistel 84.

Möhre 220.

Molın 246.

Mohrriibe 220 .

Mondraute 6.

Mondveil 259.

Moorhirse 32.

Moosbeere 200 .

Moosfarn 3.

Moschuskraut 146.

Mottenkraut 175.

Mückenblume 53 .

Muscbelblümchen 242.

Mutterkraut 124. 125.

Myrte 311.

Nabelnuss 167.

Nachtkerze 311.

Nachtnelke 291.

Nachtscbatten 172.

Nachtviole 264.

Nacktdrüse 52.

Nacktfarn 3.

Nadelhölzer 7 .

Nadelkerbel 218.

Narzisse 48.

Natterkopf 168.

Natterwurz 83.

Natterzunge 7 .

Nelke 286.

Nelkenwurz 325.

Nestwurz 54.

Nießwurz 242.

一, weiße 58.

Nixblume 247.

Nixkraut 10.
() cbsenzunge 80. 170 . Odermennig 330.

Oelweide 85.

Ohnblatt 201.

Ohrweide 67.

Oleander 148.

Oleaster 85.

Orakelblume 125.

Orme 148.

Palmweide 68.

Papierbirke 71.

Pappel 69. 293.

Paprika 173.

Paradeisapfel 173.

Paradiesapfel 318.

Paradieslilie 62.

Pastinak 216.

Pechnelke 291.

Porlgras 25.

Perrickenbaum 305.

Pestwurz 114.

Petersilie 209.

Pfaffenhütchen 299 .

Pfaffenröhrlein 97.

Pfeffer, spanischer 173.

Pfefferkraut 159.

Pfefterminze 156.

Pfeifengras 24.

Pfeifenstrauch 311.

Pfeilkraut 49.

Pfennigkraut 197.

Pferdeklee 348.

Pferdekümmel 218.

Pfingstrose 320 .

Pfirsichbaum 333.

Pflaumenbaum 333.

Pfriemen 354.

Pfriemengras 30 .

Pfundrose 244.

Pillenkraut 7.

Pimperauss 299.

Pinie 8.

Pippau 100.

Pistazie 305.

Platane 73.

Platterbse 345 .

Polei 199.

Poleiminze 155.

Polierschachtelhalm 2.

Porrezwiebel 61.

Porst 199.
Portulak 315.

Portulkraut 275 .

Porzellanblümclien 224.

Prachtapfel 318.

Preiselbeere 200.

Primel 193.

Puffbohne 342.

Pulverholz 300.

Pungen 197.

Punktfarn 4.

Quecke 19.

Quellgras 2i.

Quelriet 95.

Quitte 319.

Rade 292.

Ragwurz 53.

Rainfarn 122.

Rainsalat 94 .

Rainweide 148.

Rampe 268.

Raps 268.

Rapsdotter 269.

Rapunzel 88. 90.

Rapiinzclien 140.

Rauhbirke 70.

Rauhgras 30.

Rauke 265.

Rauschbeere 200

Raute 306.

Rebendolde 211.

Rehhaide 354.

Reifweide 66.

Reiherschnabel 308.

Reisquecke 35.

Reitgras 31.

Reps 268.

Reseda 270.

Rettig 269.

Rharbarber 79.

Ribis, Ribisel 227.

Riemenblume 84 .

Riemenzunge 52.

Riesenklee 348 .

Rietgras 36.

Rindsauge 117.

Ringelblume 130 .

Rippensame 219.

Rispengras 25.

Rittersporn 243.

Roggen 20.

Rohrgras 31 . 
Rohrkolben 13.

Rollfarn 6 .

Rose 320.

Rosenwurz 227.

Rosmarin 158.

—, wilder 199 .

Rosskastanie 297.

Rosskümmel 219.

Rothbuche 73.

Rotehrle 70.

Rothrüster 73 .

Rothtanne 8.

Ruchbirke 71.

Ruchgras 34.

Rübe, rothe 77 .

- , weiße 268.

Rübendistel 132 .

Rübsame, Rübsen 268 .

Rührmichnichtan 311.

Rüster 73.

Ruhrkraut 120.

Runke 269.

Runkelribe 77.

Saaterve 344.

Saatlinse 344.

Sadebaum 9.

Safflor 132.

Sahlweide 68.

Salat 98.

Salatrübe 77 .

Salbei 157.

Salomonssiegel 59.

Salzkraut 78.

Salzmiere 276.

Sammtblume 363.

Sammtröschen 115.

Sanddorn 85.

Sandkraut 281.

Sanikel 208.

Saubohne 342.

Saudistel 99.

Sauerampfer 81.

Sauerdorn 245.

Sauerkirsche 334.

Sauerkleo $\mathbf{2 1 0 .}$

Saumelde 76.

Saumfarn 6.

Sautod 76 .

Säuerling 81.

Schachblume 64 .

Schachtelhalm 1.
Schafgarbe 122.

Schalotte 62 .

Scharbockskraut 241 .

Scharfkraut 166.

Scharlachdorn 319.

Scharte 132.

Schattenblümchen 59 .

Schaumkraut 263.

Scheibenkraut 269.

Scheidengras 35 .

Scheingräser 35.

Scheuerkraut 1.

Schierling 218.

Schierlingssilge 213.

Schießbeere 300 .

Schildfarn 4.

Schilf 32 .

Schimmelkraut 119.

Schlammbinse 43.

Schlammkraut 177.

Schlangenkraut 12.

Schlangentuch 62 .

Schlehdorn 333.

Schleifenblume 254.

Schlingbaum 146.

Schlutte 173.

Schmack 305.

Schmalstrahl 115.

Schmeerwurz 59.

Schmiele 30.

Schminkbohne 347 .

Schmuckblume 236.

Schnabelbinse 45 .

Schneckenklee 351 .

Schneeball 146.

Schneebeere 147.

Schneebirne 319.

Schneeglöckchen 48 .

Schneidegras 45 .

Schnittlauch 61 .

Schöllkraut 247.

Schönauge 363 .

Schopfgras 358 .

Schopfhyacinthe 60 .

Schotenklee 347.

Schuppenfarn 3.

Schuppenwurz 187.

Schwalbenwurz 149.

Schwarzbeere 200.

Schwarzbirke 71 .

Schwarzdorn 333.
Schwarzerle 70 .

Schwarzkiefer 9.

Schwarzkümmel 242 .

Schwarzorche 53.

Schwarzpappel 69.

Schwarzwurzel 96.

Schwertel 47.

Schwertlilie 47.

Schwimmblatt 7 .

Schwingel 22.

Seekrone 149.

Segge 36.

Seidelbast 84 .

Seidenpflanze 149.

Seifenkraut 288.

Sellerie 209.

Senft, schwarzer 267.

一, weißer 268.

Seerose 245.

Sesel 212.

Sichelholde 210.

Sichelklee 352.

Siebenstern 196.

Siegwurz 47.

Silau 213.

Silberpappel 69.

Silberweide 68 .

Silberwurz 326.

Silge 214.

Simse 56.

Sinau 330.

Sinngrün 148.

Sockenblume 245.

Sommereiche 72.

Sommerwurz 188.

Sonnenrose 119.

Sonnenröschen 270.

Sonnenthau 271.

Sonnenwende 170.

Spargel 59.

Spargelerbse 348.

Spark 276.

Speierling 318.

Speik 122.

Spelt, Spelz 20.

Sperlingsschnabel 84 .

Sperrkraut 171.

Spilling 333.

Spinat 77.

-, englischer 80.

—, römischer 80 
Spindelbaum 299 .

Spinnenblume 53.

Spierstaude, Spier-

strauch 331.

Spitzahorn 297.

Spitzkiel 339.

Spitzklette 91.

Spornblume 142.

Springkraut 310.

Spurre 281.

Stabwurz 122.

Stachelbeere 2:7.

Stachelhirse 32.

Stechapfel 174.

Stechdorn 301.

Stecheiche 299.

Stechpalme 299.

Steckrübe 268.

Steinbrech 221.

Steinflachs 357.

Steinklee 348.

Steinkraut 259.

Steinkresse 255.

Steinröschen 84 .

Steinsame 168:

Steinschmückel 259 .

Steinweichsel 334.

Stendelwurz 52.

Sternblume 116.

Sterndolde 208.

Sternhyacinthe 60 .

Sternliebe 115.

St. Ivansbart 357.

Sternmiere 281.

Stiefmütterchen 274 .

Stieleiche 72.

Stielsame 97.

Stockrose 293.

Stoppelrübe 268.

Storchschnabel 306.

Strahldolde 220.

Strahlensame 291.

Strandling 191.

Straußfarn 6.

Straußgras 30.

Streifenfarn 9.

Striemensame 218.

Strobblume-137.

Studentenbiume 363 .

Studentenröschen 226 .

Sturmhut 243.
Süßdolde 218.

Süßgras 27.

Süßkirsche 383 .

Sumach 305.

Sumpfblume 149.

Sumpfkiefer 9.

Sumptkresse 256 .

Sumpfschirm 209.

Sumpfwurz 54.

Suppenkerbel 218.

Tabak 174.

Tamariske, deutsche 296 .

Tännel 296.

Täschelkraut 253.

Taglilie 62.

Tanne 7.

Tannwedel 65 .

Taubenkropf 289.

Taubnessel 160.

Taumelkorn 18.

Tausendblatt 314 .

Tausendgüldenkraut 153.

Tausendschön 115.

Tausendschönchen 298.

Teichkolben 13.

Teufelsabbiss 139 .

Teufelsbart 253.

Teufelshand 2.

Timotheegras 34 .

Thurmkraut 263.

Thymian 158.

Tollkirsche 173.

Tollkraut 172 .

Traganth 338 .

Traubeneiche 72 .

Traubenfarn 6.

Traubenhyacinthe 60 .

Traubenkirsche 334 .

Trauerbirke 70 .

Trauerweide 69.

Trespe 21.

Trollblume 241.

Trommelschlägel 134 .

Tüpfelfarn 3.

Türkenbund 64 .

Türkenbundkürbis 86 .

Tulpe 64.

Tulpenbaum 245.

Turnips 268.

Uferkraut 276 .
Ulme 73.

Vanillestrauch 170 .

Veilchen 271.

Venushaar 6.

Venusspiegel 87.

Vergissmeinnicht 167.

Vexiernelke 292.

Virgilsaster 116.

Vogelbeerbaum 318.

Vogelkirsche 333 .

Vogelknöterich 82.

Vogelmilch 63.

Vogelwicke 344.

Wachholder 9.

Wachsblume 169.

Wachtelweizen 187.

Waid 269.

Walderbse 346.

Walderảbeere 325 .

Waldfarn 5.

Waldhähnchen 235 .

Waldmeister 142.

Waldrebe 232.

Waldvöglein 53.

Wallnussbaum 305 .

Wandkraut 74 .

Wanzenkraut 244 .

Vanzensame 78. 221.

Warzenkürbis 86 .

Wasserdost 114.

Wasserfeder 196.

Wasserfenchel 211.

Wasserlilie 245.

IVasserlinse 10.

Wassernuss 314.

Wassermelone 86 .

Wassernabel 207.

Wasserpest 360 .

Wasserpfeffer 82.

Wasserranunkel 237.

Wasserrübe 49 .

Wasserscheere 268.

Wasserschierling 209.

W asserschlauch 191.

Wasserstern 65 .

Wasserviole 49.

Weberkarde 138.

Wegebreit 190.

Wegedorn 300.

Wegerich 190.

Wegwarte 94. 
Weichkraut 283.

Weichsel 334.

Weide 66.

Weidenröslein 311.

Weiderich 314.

Wein, wilder 300.

Weinrebe, Weinstock 299.

Weißbuche 71.

Weißdorn 316.

Weißerle 70.

Weißföhre 8 .

Weißtanne 8.

Weißwurz 58.

Weizen 19.

Werftreide 68.

Wermuth 121.

Weymouthskiefer 9 .

Wicke 342.

-, spanische 345 .

Widertod 5 .

Wiesenknopf 331.

Wiesenkresse 264.

Wiesenraute 233.
Wimperfarn 3.

Windblume 234.

Winde 171.

Winterblume 242.

Wintereiche 72.

Wintergrün 148.

Winterzwiebel 62.

Wirbelborste 159 .

Wohlverleih 126.

Wolfsbohne 352 .

Wolfsfuß 157.

Wolfsmilch 301 .

Wollgras 45 .

Wollkraut 175.

Wucherblume 125 .

Wnndklee 353.

Wurmfarn 4.

Wurmsalat 95.

Wurzelfrüchtler 7 .

I sop 160.

Zackenschote 269.

Zahnwurz 264.

Zaunlilie 62.

Zaunrübe 86 .
Zeitlose 58.

Zerreiche 72.

Ziest 161.

Zimmtrose 320.

Zinnie 363.

Zirbe 9.

Zirbelkiefer 9.

Zirmet 217.

Zittergras 25.

Zitterpappel 69 .

Zuckererbse 342 .

Zuckerrübe 77 .

Zürgelbaurn 73.

Zweiblatt 54.

Zweizahn 118.

Zwenke 19.

Zwergflachs 309 .

Zwergmandel 333.

Zwergmiere 280.

Zwergmispel 317 .

Zwetsche 333 .

Zwiebel 62. 



\section{Geräthe für Insecten-Sammler.}

Einlage für Insectenkästen: Flussdeckel, Größe 26-43 cm $20 \mathrm{kr}$. ; $43-52 \mathrm{~cm} 40 \mathrm{kr}$; ; Korkplatte, $14-30 \mathrm{~cm}, 20 \mathrm{kr}$; Torfplatte, 8 bis $25 \mathrm{~cm} \quad 3 \mathrm{kr}$.; $14-27 \mathrm{~cm} 6 \mathrm{kr}$.

Etiketten, leere, 1 Bogen, enthaltend 312 Etiketten $10 \mathrm{kr}$.

Eulenscheere, aus Stahl m. feiner Messingdrahtgaze überzogen $3 \mathrm{fl}$. Fangglas (für Raucher geeignet) $30 \mathrm{kr}$.

Fangschachtel, aus Mappe mit schwarzer Leinwand überzogen, $\mathrm{Cy}_{y}$ linder-Form. Der Deckel ist mit einem Drahtsieb versehen $40 \mathrm{kr}$. Flussdeckel, siehe Einlage für Insectenkästen.

Fumigator, Apparat zum Ausräuchern der Thiere aus ihren Schlupfwinkeln $2 \mathrm{fl}$.

Gebläse aus Kautschuk zum Präparieren der Raupen fl. 1.80, größer fl. 2.75 .

Insectenkästen, aus Pappe und Holz mit schwarzer Leinwand überzogen, mit Glasdeckel, Größe $25-30 \mathrm{~cm}$ fl. $1.20 ; 28-40 \mathrm{~cm}$ fl. 1.60 ; $33-51 \mathrm{~cm}$ fl. 2.20 .

Insectenkasten, ganz aus Holz, schwarz poliert, mit Glasdeckel, Charnier und Doppelfalz, Größe 33-51 cm, fl. 3.70; 50-75 cm $8 \mathrm{H}$.

- - doppelt (beiderseitig $\mathrm{zu}$ bestecken), mit schwarzer Leinwand ïberzogen, ohne Glas, Größe 24-31 cm mit Handhabe t. 1.65; $27-40 \mathrm{~cm} 2 \mathrm{fl}$.

Unsere sämmtlichen Insectenkästen sind mit Flussdeckel ausgelegt, innen mit glattem weißeu Papier überzogen und schließen vollkommen luftdicht.

- - einfach, Holzrahmen mit Mappe, innen mit Flussdeckel ausgelegt (nur für Transport von Insecten geeignet, Größe $10-15 \mathrm{~cm}$ $18 \mathrm{kr}$; $15-20 \mathrm{~cm} \quad 25 \mathrm{kr}$.; $20-25 \mathrm{~cm} \quad 35 \mathrm{kr}$; $30-35 \mathrm{~cm} 50 \mathrm{kr}$. Insectennadeln, wei $\beta$, in 11 verschiedenen Nummern (Nr. 0-10). Nr. 0, 1, 2, 100 Stück von einer Nr. 12 kr.; Nr. 3, 4, 5, 6, 7, 100 Stiick von einer Nr. $13 \mathrm{kr}$; Nr. 8, 9, 10. 100 Stiick von einer Nr. $14 \mathrm{kr}$; 1000 Stück in verschiedenen Nr. sortiert fl. 1.30.

Insectenmappe, siehe Einlage für Insectenkästen.

Insecten.Tödtungsglas $30 \mathrm{kx}$.

Insecten-Laterne, sammt Stock-Stativ mit Eisenspitze fl. 8.50.

Käfer-Etiketten. Von Professor Dr. K. Rothe $70 \mathrm{kr}$.

Käferflasche, mit am Hals befestigtem Korkstöpsel, $9 \mathrm{~cm}$ hoch $10 \mathrm{kr}$.; $10 \mathrm{~cm}$ hoch $12 \mathrm{kr}$; $12 \mathrm{~cm}$ hoch $15 \mathrm{kr}$.

Käfergläschen (in Eprouvettenform) mit Korkstöpsel, $45 \mathrm{~mm}$ lang う kr.; $90 \mathrm{~mm}$ lang $8 \mathrm{kr}$.

- - mit Metallverschraubung und Kork-Einlage (schließt luftdicht). Größe 25-65 mm, Inhalt $18 \mathrm{~g} 18 \mathrm{kr}$. ; 25-90 mm, $24 \mathrm{~g} 20 \mathrm{kr}$.

Käfersieb, zwei ineinander passende Säcke aus festem, weißen Zeuge mit Drahtreifen und Drahtsieb H. 1.60.

Klopfkeule zum Abklopfen der Bäume $3 \mathrm{fl}$.

Korkplatten, siehe Einlage für Insectenkästen.

Lupen, siehe Botanik.

Minutiendrähte, (Silber). 100 Stück $50 \mathrm{kr}$.

Naphtalin, pulverisiert, bestes Schutzmittel gegen Motten und andere Raubinsecten, in Päckchen zu 10 und $20 \mathrm{kr}$. 
Puppensucher, auch zugleich Raupenharken, zum Graben, Hacken und Harken eingerichtet fl 1.20 .

Pincette aus Messing mit geraden Spitzen $25 \mathrm{kr}$.

- - mit gebogenen Spitzen $25 \mathrm{kr}$.

- - aus Stahl $25 \mathrm{kr}$.

- - aus Stahl, fein $60 \mathrm{kr}$.

- - aus Stahl, doppelt, innen selbsttbätig haltend fl. 1.10.

Raupenhaus, aus Holz, gestrichen, mit Drahtgaze, Fenster und Glasthür fl. 1.60 .

- - größer, zerlegbar fl. 2.80 .

Sammelschachtel für Raupen, aus Pappe, oval, mit DrahtgazeFenster und Blechthüre, Größ̉ 7-14 cm $30 \mathrm{kr}$.; $9-17 \mathrm{~cm} 35 \mathrm{kr}$.

- - aus Pappe, mit schwarzer Leinwand überzogen, cylindrische Form, mit Hals, Größe 7-12 cm $50 \mathrm{kr}$.

- - aus Blech mit Drahtgaze-Fenster, Thüre und Tragband, Größe $12-20 \mathrm{~cm} 70 \mathrm{kr}$.

Sammelschachtel für Schmetterlinge, aus Pappe, oval, FlussdeckelEinlage, Größe 7-14 cm $25 \mathrm{kr}$; $9-17 \mathrm{~cm} 30 \mathrm{kr}$.

- - Deckel mit Charnier und mit grünem Tragband, Größe 10 bis $22 \mathrm{~cm} 60 \mathrm{kr}$.

- - aus Blech mit Flussdeckel-Einlage und grünem Tragband, Größe $12-20 \mathrm{~cm} 60 \mathrm{kr}$.

Sammeltasche (Käfer-Cartouche) mit schwarzer Leinwand ïberzogen (um den Körper geschnallt zu tragen), mit Käfergläschen versehen $4 \mathrm{ff}$.

Schmetterlings-Schere, aus Stahl mit grüner Gaze überzogen fl. 2.20.

Schmetterlings-Etiketten, zusammengestellt von Professor Dr. Karl Kothe. In Umschlag $40 \mathrm{kr}$.

Schmetterlings-Netz, starker Eisenreif mit Spitze und grïnem GazeSack (ohne Stock) $45 \mathrm{kr}$.

- - an einem Stock mit Metallawinge $65 \mathrm{kr}$.

- - aus Draht mit Charnier zum Zusammenlegen und mit Zwinge zum Befestigen eines Stockes, Sack aus gruiner Gaze, ohne Stock $90 \mathrm{kr}$; mit Stock fl. 1.15 .

Schmetterlings-Netz aus englischem Stahl, sehr elastisch, mit Zwinge und Schraube zum Befestigen eines Stockes, Sack aus grüuer Gaze (lässt sich zusammenlegen und in der Tasche tragen), ohne Stock 6. 1.75 ; mit Stock $2 \mathrm{fl}$.

Schöpfnetz, starker Eisenring mit Stabhülse, Sack aus festem JavaCallevas H. 1.20 .

Spannbrett aus Lindenholz mit Flussdeckelunterlage, $5 \mathrm{~cm}$ breit $25 \mathrm{kr}$.; $9 \mathrm{~cm}$ breit $40 \mathrm{kr}$.

- - veıstellbar, zum Erweitern und Verengern der Spannrinne $55 \mathrm{kr}$.

- - verstellbar, für Mikro-Lepidopteren $55 \mathrm{kr}$.

- - für Käfer $45 \mathrm{kr}$.

Spannadeln, 500 Stück $25 \mathrm{kr}$.

Steckzange mit krummen Enden zum Unterfassen, ganz aus Stahl, mit geripptem Griff fl. 1.30.

Streifsack, starker Eisenring mit Charnier, zum Zusammenlegen; mit Zwinge und Schraube zum Befestigen an einem Sack, aus festem Rohleinen-Zeuge $85 \mathrm{kr}$. 
Stock zu den Schmetterlings-Netzen und zum Streifsack $25 \mathrm{kr}$. Torfplatten, siehe Einlage für Insectenkästen.

Der Insectensammler, eine Sammlung von zum Fangen; Aufziehen und Präparieren der Insecten nothwendigen Geräthen und Utensilien, in elegantem, schwarzen Kasten $25 \mathrm{kr}$.

1 Raupenhaus, zerlegbar, 1 Raupen-Sammelschachtel. Schmetterlingsnetz, zusammenlegbar, 1 Käfer-Streifsack, 4 Käfergläschen mit Korkstöpsel, 2 Käfergläschen mit blechernem Schraubendeckel, 1 Käferflasche, 1 Spannbrett, verstellbar, 1 Lupe, 3fach, 1 Schere mit geraden Spitzen, 1 Steckzange, .l Pincette, 1 Präpariernadel, 1 Kissen mit Insertennadeln verschiedener Nummern, 1 Schächtelchen mit spannadeln, leere Etiketten und ein elegauter Insectenkasten mit abnehmbarem Glasdeckel mit Doppelfalz.

\section{Geräthe für Botaniker.}

Botanisierbüchse, aus starkem Weißblech, solid gearbeitet, grün lackiert und mit Tragband versehen. Länge $24 \mathrm{~cm} 75 \mathrm{kr} ; 32 \mathrm{~cm}$ $90 \mathrm{kr}$.; Länge $36 \mathrm{~cm} 1 \mathrm{fl}$.

Botanisierbüchse, mit Fach f. Käfer $u$. Raupen, $45 \mathrm{~cm}$ lang fl. 2.40 . - - für größere Excursionen mit getheiltem Fach- und Ventilationsgitter für Raupen fl. 3.30.

Botanisiermappe, aus Pappe, mit Wachstuch überzogen, mit durchgezogenen, starken Schnüı en zum Umhängen, Größe $28-33 \mathrm{~cm} 90 \mathrm{kr}$.

Botanisiermappe, mit schwarzem Wachstuch ïberzogen, elegant ausgestattet, mit Metallecken, Schutzdecke und Riemen; Größe 30 bis $40 \mathrm{~cm} 4 \mathrm{fl}$.

Botanisches Besteck, enthält eine Lupe in Messing auf Stativ, Messer, Nadel, Pincette, Schere in elegantem Kästchen $6 \mathrm{fl}$.

Drahtmappe, Eisenrahmen mit Drahtgittern und Messingketten (zum Pressen der Pflanzen). Größe 26-40 cm fl. 1.50.

Filtrierpapier, zum Pflanzenpressen, weiß, 10 Bogen $10 \mathrm{kr}$.

- - grau, 10 Bogen $10 \mathrm{kr}$.

Hammer, aus Stahl m. Holzstiel, einer Schneide u. einer Fläche. fl.1.20.

- - leicht, wie zwei zu einander senkrechten Schneiden $90 \mathrm{kr}$. und fl. 1.50 .

Meißel und Hammer sind nothwendige Geräthe für den Sammler von Algen und Moosen.

Lupe, einfach in Hornfassung (Käferlupe). Durchmesser $20 \mathrm{~mm} 35 \mathrm{kr}$; $26 \mathrm{~mm} 45 \mathrm{kr}$.

- - mit 2 Gläsern in Messingfassung mit Dreifuß $1 \mathrm{fl}$.

- - botanische, in Horneinfassung, einfach, Durchm. $20 \mathrm{~mm} 35 \mathrm{kr}$.; $26 \mathrm{~mm} 50 \mathrm{kr}$; $40 \mathrm{~mm} 90 \mathrm{kr}$; ; zweifach, Durchm. $20 \mathrm{~mm} 55 \mathrm{kr}$.; $26 \mathrm{~mm} 75 \mathrm{kr}$; $40 \mathrm{~mm}$ fl. 1.30; dreifach, Durchm. $20 \mathrm{~mm} 75 \mathrm{kr}$.; $26 \mathrm{~mm} 1 \mathrm{fl}$; $40 \mathrm{~mm}$ fl. 1.70 .

Mikroskop (in der Hand gegen das Licht zu halten) in Pappkästchen fl. 1.80 .

- - mit 1 Präparat und 6 Objectivgläsern, in schwarzem Holzkästchen fl. 2.50.

- - mit 6 Präparaten und 6 Objectivgläsern, in schwarzem Holzkästchen $\mathrm{fl}$. 3.50 . 
Mikroskop mit Pincette, 1 Präparat u. 2 Objectivgläsern, Vergrößerung lin. 30 , in politiertem Kästchen fl. 4.50.

- - mit 2 Linsen, Pincette, 1 Präparat und 2 Objectivgläsern, Vergrößerung lin. 60 ; in politiertem Kästchen f. 7.50 .

- Bessere Mikroskope zu 15, 30, 40, 45 und $65 \mathrm{fl}$.

Pflanzen-Etiketten. Zusammengestellt von Prof. Mik $40 \mathrm{kr}$.

Pflanzenträger, 2 Holzplatten mit Tragriemen, Handgriff und Saugpapier-Einlage. Größe 21-30 cm fl. 1.20 ; mit Spaten fl. 1.80 .

Pflanzenpresse (Schraubenpresse) aus weichem Holz, braun gebeizt, mit starken Schrauben, Größe $25-45 \mathrm{~cm}$ fl. 2.30 .

- - aus hartem Holz, poliert fl. 3.30.

Pflanzenstecher (Botanisierspaten), mit Handgriff, Form 1. $25 \mathrm{kr}$. Form $230 \mathrm{kr}$.; Form $335 \mathrm{kr}$.; Form $460 \mathrm{kr}$.

Pincette, aus Messing, mit geraden Spitzen $25 \mathrm{kr}$; mit gebogenen Spitzen $25 \mathrm{kr}$.

- - aus Stahl $25 \mathrm{kr}$.; fein $60 \mathrm{kr}$.

- - aus Stahl, doppelt, eine selbstthätig haltend fl. 1.10 .

Präpariernadeln, einfach, mit Holzgriff $5 \mathrm{kr}$.

- - aus Stabl, vierkantig, gerade, mit poliertem Heft $20 \mathrm{kr}$.

- - aus Stahl, mit lanzettförmiger Spitze und poliertem Heft $20 \mathrm{kr}$.

Präpariermesser $70 \mathrm{kr}$.

Präparierstäbchen, aus Holz $4 \mathrm{kr}$.

Schere, gerade $70 \mathrm{kr}$; größer und besser fl. 1.10 .

Schnürmappe, zwei durchlöcherte Blechtafeln auf Holzrahmen mit starken Riemen (zum Pressen der Pflanzen). Größe $27-40 \mathrm{~cm}$ fl. 2.30.

Der Pflanzensammler. Eine Collection vou zum Sammeln, Präparieren und Aufbewahren der Pflanzen nothwendigen Geräthen und Utensilien, in elegantem schwarzen Kasten 17 f.

1 Pflanzenträger (zugleich Presse), 1 Spaten, 1 Botanisirbüchse, 1 Pincette aus Messing, 1 botanische 3 fache Lupe, 2 Präpariernadeln, 1 Präparierstäbchen, 1 Herbariummappe von Prof. Mik und Tabellen zur Bestimmung einheimischer Samenpflanzen.

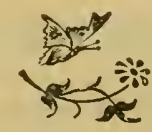




\section{Das Buch der Pilze.}

Beschreibung der wichtigsten Bassidien- und Schlauchpilze mit besonderer Berïcksichtigung der essbaren und giftigen Arten.

\section{Von Karl Sehwalb.}

15 Bogen. Mit 18 fein colorierten Tafeln. Preis geb. $3 \mathrm{fl}=5 \mathrm{M}$.

Das vorliegende Buch bezweckt das Ermöglichen eines leichteren Bestimmens der Yilzarten, einer sicheren Unterscheidung schädlicher und giftiger Pilze von essbaren; es soll die Ergänzungen in jene fühlbaren Lücken bieten, welche die Kenntnis der Pilze noch so sehr erschweren und welche durch die oft zu allgemein gehaltenen Beschreibungen der Arten in den meisten Pilzwerken geboten werden. Die Beschreibung einer Art soll stets eine solche sein, dass man sie nicht gleichzeitig auch für eine andere oder gar für mehrere Arten passend finde, was bei der Undeutlichkeit nnd Allgemeinheit mancher Merkmale, wenn dieselben zur Beschreibung der Art herangezogen und wohl gar gegenüber wichtigeren charakteristischen hervorgehoben werden, leicht eintreten kann.

\section{Die naturgemäße Conservierung der Pilze}

mit einer einleitenden Excursion behufs Einleitung in die Pilzkunde. Von Karl Schwalb.

7 Bogen, geheftet $80 \mathrm{kr}$. = M. 1.60 .

Der Verfasser war also vollkommen berechtigt und befähigt, eine Schilderung seines Verfahrens, durch das er so vorzügliche Resultate erzielt, zu verüfentlichen. Das ganze Büchlein ist so gemeinverständlich und so klar geschrieben, dass Jeder dasselbe benutzen und die darin angegebenen Methoden der Pilzconservieruug erlernen und sich zu Eigen machen kann. Um die dazu erforderliche Kenntnis der Pilze Jedermann zu vermitteln, ist der Verfasser auf der. eben so originellen als praktischen Gedanken gekommen, das Aufsuchen, Sammeln, Unterscheiden und Bestimmen der Pilze durch die Schilderung einer Excursion zu lehren.

(Prof. Dr. M. Willkomm.)

\section{Naturgeschichte der Lurche.}

Eine umfassendere Darlegung unserer Kenntnisse von dem anatomischen Bau, der Entwicklung und systematischen Eintheilung der Amphibien, sowie eine eingehende Schilderung des Lebens dieser Thiere

von Dr. Friedrich K. Knauer.

22 Bogen. Mit 120 Illustrationen, 4 Karten und 2 Tabellen.

Zweite Ausgabe. Ermäligter Preis geh. 2 A. $=4$ M.

\section{Europa's Kriechthiere und Lurche.}

Für den Naturfreund beschrieben und nach ihrem Leben geschildert von Dr. Friedrich K. Knauer.

Zweite Ausgabe, mit 20 Abbildungen auf 8 Bildertafeln vermehrt.

Gebunden $1 \mathrm{Hl} .=2 \mathrm{M}$. 


\title{
HERBARIUM.
}

\section{Mappe zur Anlegung von Schüler-Herbarien.}

\author{
1.-3. Auflage.
}

Inhalt: Anweisung zur Anleitung des Herbariums: 28 Bogen mit Etiketten der wichtigsten Familien, circa 480 Pflanzen-Etiketten, gummierte Befestigungs-Streifen, 100 Blatt starkes Papier zum Einlegen der PAanzen.

Zusammengestellt von Josef Mik,

Professor am k. k. Akademischen Gymnasium in Wien.

Format der eleg. ausgestatteten Mappe $24-35 \mathrm{~cm}$. Preis fl. $1.80=3 \mathrm{M}$.

Das Herbarinm kann Realschulen und Gymnasien zur Anschaffung mit gutem Gewissen empfoblen werdtn.

Prof. Dr. Mallier, Jena.

. . . Ich freue mich umsomelir, mich dieses Auftrages entledigen zu können, da jch mit der Einrichtung des Herbars ganz und gar einverstandeu bin. Es entspricht vollstundig, bis in die kleinsten Einzelheiten den Auforderungen, die ich an meine Schüler bei Einrichtung ihres Herbars zu stellen pflege, und ist offenbar aus gediegener, praktischer Frfahrung hervorgegangen. Vortrefeich gefällt mir die Anwendung verschiedenfärbiger Zettel auf den Umschlägen. Es ist dies ein ganz ausgezeichueter Gedanke.

Dr. F. Iroehme.

Obeılehrer am Falk-Realgymnasium zu Berlin.

Mein Urtheil ïber diese Mappe geht dahin, dass dieselbe von den Schülern un. serer löheren Unterrichts-Anstalten bei: der'Anlage eines Herbars sehr zweckmilig verwendet werden kann.

Dr. Irress,

Sem-Dir. in Münster i/W.

Ebenso erschienen:

Ausgabe in böhmischer Sprache. Herausgegeben von Prof. Dr. Wilh. Kurz in Prag. Preis $2 \mathrm{fl}$. - Ausgabe in polnischer Sprache. Herausgegeben vom Gymnasial-Professor D r. Łomniki in Lemberg. Preis $2 \mathrm{fl}$. - Ausgabe in ungarischer Sprache. Herausgegeben von Gymnasial-Professor D r. Bela rou Des eő in Budapest. Preis fl. 1.80.

Separat erschienen:

\section{Pflanzen-Etiketten.}

Enthaltend: Anleitung, 28 Etiketten der Pflanzen - Familien, 480 Pflanzen-Etiketten, 80 Blanco-Etiketten, sowic 2 Blatt Befestigungsstreifen.

In Umschlag $40 \mathrm{kr}$. $=80 \mathrm{Pf}$. 


\section{Schulflora}

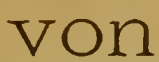

Herausgegeben von Dr. M. Willkomm,

Professor der Botauik an der k. k. deufschen Universität in Prag.

2. Aufl. 1892. $30 \mathrm{Bog}$. in Leinwandband $2 \mathrm{f} .=4 \mathrm{M}$.

Das dem Werkchen zu Grunde gelegte System ist das von Endlicher und Unger mit einigen Modificationen. Eine Erklärung der gebrauchten Kunstausdrücke wurde vermieden, da das theils Sache des Lehrers ist, theils auch in jedem neueren Lehrbuche der Botanik gefunden wird. Dem Leser ist beim Gebrauche zu empfehlen, zuerst die Einleitung zu lesen, welche über das Sammelr und Bestimmen, sowie die Anlage eines Herbariums belehrt. Ein Schlüssel zum Bestimmen der Gattungen nach dem Linné'schen System wird in vielen Fällen rasch zum Ziele tühren. Er verweist auf die natürlichen Familien, wo der Schlüssel zum Bestimmen der Arten sich findet; bei den größeren ist auch anf die Bestimmung der Gattungen Rücksicht genommen worden.

Die Vorzüge der Schulflora erscheinen dem Ref. so groß, dass er glaubt, sie werde in Österreich alle übrigen Bestimmungsbücher verdrängen und auch im angrenzenden Deutschland vielfach Velwendung finden, besonders wegen der Aufnahme der Culturpflanzen, deren Bestimmung nach den meisten Werken dieser Art ausgeschlossen ist. Auch die Ausstattung ist vorzuiglich. Der. Druck klar und übersichtlich, der kleine Band ist zur Benutzung auf Ausflügen geeignet.

Pädagog. Jahresbericht.

\section{DAS HERBAR.}

Anleitung zum Einsammeln, Zubereiten und Trocknen der Herbarpflanzen u. zur Einrichtung u. Erhaltung wissenschaftlicher Pflanzensammlungen

Professor Dr. Noritz Willkomm.

Mit 48 Holzschnitten ca. 10 Bogen eleg. geb. ca. fl. $1.20=$ M. 2.40 .

Wohl das Vollständigste, was jemals über Einrichtung und Conservierung von Herbarien u. s. w. veröffentlicht geworden ist! Mit aneskennenswertem Fleiße hat der berühmte Verfasser alle auf genannte Dinge bezüglichen Angaben gesammelt, alle im Laufe der Zeit empfohlenen Methoden, Instrumente und Gerïthschaften geschildert und kritisch beleuchtet, und dadurch den Leser in den Stand gesetzt, sich ein möglichst praktisch eingerichtetes und wissenschaftlich wertvolles Herbar anlegen zu können. Wir können daher dieses Buichlein allen angehenden Botanikern und botanischen Reisenden und überhaupt Allen, welche sich für Pfanzenkunde interessieren, bestens empfehlen.

\section{TABELLEN}

zur

\section{Bestimmung einheimischer Samenpflanzen.}

Zum Gebrauch beim Unterricht zusammengestellt von Dr. Anton Schwaighofer.

Vierte Auflage. In $8^{0}, 8$ Bogen, geh. $60 \mathrm{kr} .=\mathrm{M} .1 .20$, geb. $80 \mathrm{kr} .=$ M. 1.60 . Von demselben Verfasser erscheint im März 1892:

\section{Tabellen zur Bestimmung von Sporenpflanzen.}


